\begin{tabular}{|c|c|c|c|c|c|c|}
\hline \multirow{3}{*}{\multicolumn{2}{|c|}{$\begin{array}{l}\text { 2. ECN Category } \\
\text { (mark one) } \\
\text { Supplemental } \\
\text { Direct Revision }\end{array}$}} & \multicolumn{2}{|c|}{$\begin{array}{l}\text { 3. Or iginator's Name, Organization, MSIN, } \\
\text { and Telephone No. } \\
\text { T. M. Brown, R2-12, 373-4437 }\end{array}$} & 4. USO $\mathrm{R}$ & & $\begin{array}{l}\text { 5. Date } \\
\qquad 02 / 13 / 97\end{array}$ \\
\hline & & \multicolumn{2}{|c|}{$\begin{array}{l}\text { 6. Project Titte/No./Work Order No. } \\
\text { Supporting Document for the } \\
\text { Historical Tank Content } \\
\text { Estimate for U-Tank Farm }\end{array}$} & \multicolumn{2}{|c|}{$\begin{array}{l}\text { 7. Bldg./Sys./Fac. No. } \\
2750 / 200 \mathrm{E}\end{array}$} & 8. Approval De \\
\hline & & \multicolumn{2}{|c|}{$\begin{array}{l}\text { 9. Document Numbers Changed by this ECN } \\
\text { (includes sheet no. and rev.) } \\
\text { WHC-SD-WM-ER-325, Rev. } 0\end{array}$} & \multicolumn{2}{|c|}{$\begin{array}{l}\text { 10. Related ECN No(s). } \\
N / A\end{array}$} & \\
\hline \multirow{2}{*}{\multicolumn{2}{|c|}{$\begin{array}{l}\text { 12a. Modification Work } \\
\text { [] Yes (fill out Blk. } \\
\text { 12b) } \\
\text { [X] No (NA Blks. 12b, } \\
12 c, 12 d \text { ) }\end{array}$}} & \multirow[t]{2}{*}{$\begin{array}{l}\text { 12b. Work Package } \\
\text { No. } \\
\text { N } / A\end{array}$} & \multicolumn{2}{|c|}{$\begin{array}{l}\text { 12c. Modification Work Complete } \\
\text { N/A }\end{array}$} & \multicolumn{2}{|c|}{$\begin{array}{l}\text { 12d. Restored to Original Con } \\
\text { tion (Temp. or Standby ECN on } \\
\text { N/A }\end{array}$} \\
\hline & & & \multicolumn{2}{|l|}{$\begin{array}{r}\text { Design Authority/Cos } \\
\text { Signature \& } \\
\end{array}$} & \multicolumn{2}{|c|}{$\begin{array}{c}\text { Design Authority/Cog. Engi } \\
\text { Signature \& Date }\end{array}$} \\
\hline \multicolumn{7}{|c|}{$\begin{array}{l}\text { 13a. Description of change } \\
\text { 1. Complete rewrite and update of } \\
\text { 2. Added HTCE and Supporting Docur } \\
\text { 3. Added SW quadrant tank farms t } \\
\text { 4. Updated and restructured waste } \\
\text { 5. Removed temperature data table } \\
\text { 6. Removed drywell data, plots anc } \\
\text { 7. Removed chemical and radionucl } \\
\text { 8. Removed unknown tank transfer } \\
\text { 9. Added the Hanford Tank Chemica } \\
\text { inventory estimate tables. }\end{array}$} \\
\hline
\end{tabular}

\begin{tabular}{|c|c|c|c|c|c|}
\hline $\begin{array}{l}\text { 14a. Justification (m) } \\
\text { Criteria Change [] }\end{array}$ & Design Improvement & {$[X]$} & Environmental & [] & Facility Deactivation \\
\hline AS-Found & Facilitate const & {$[1]$} & Const. Error/Omission & {$[1$} & Design Error/Omission \\
\hline
\end{tabular}

15. Distribution (include name, MSIN, and no. of copies)

See attached distribution sheet. 
THS WOE IRTONONALY LET BL \&XK 


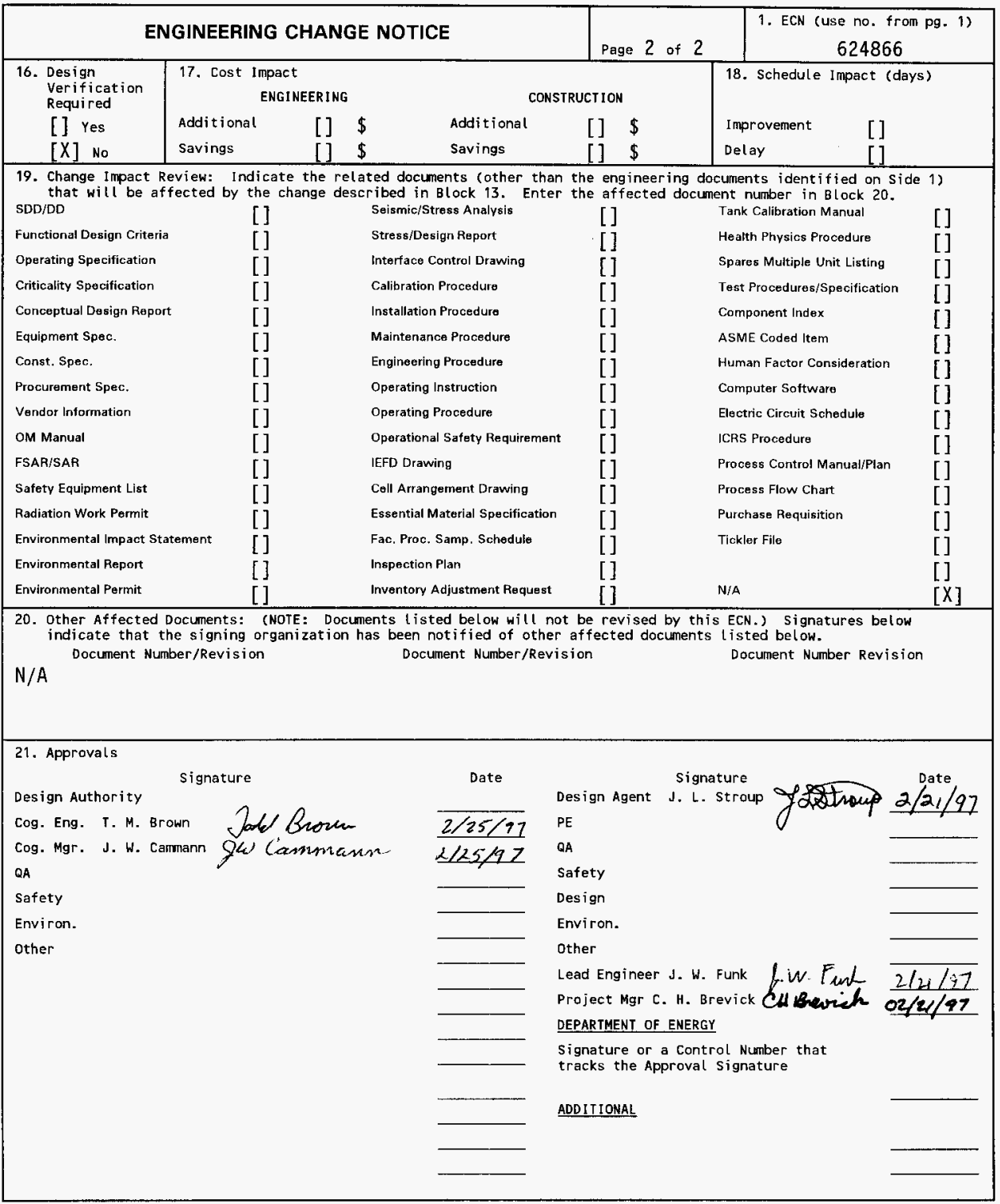


TMS न० Mrenomply LET B.ABK 


\title{
Supporting Document for the Historical Tank Content Estimate for U-Tank Farm
}

\author{
C. H. Brevick, J. L. Stroup, J. W. Funk \\ Fluor Daniel Northwest Inc., Richland, WA 99352 \\ U.S. Department of Energy Contract DE-AC06-96RL13200 \\ EDT/ECN: 624866 \\ Org Code: 408 \\ UC: 2070 \\ Charge Code: E18675 \\ Total Pages: $5 / 6$
}

Key Words: Southwest quadrant, Historical Tank Content Estimate, tank farms, tank level, tank temperture, aerial photos, in-tank montages, TLM, SMM, waste temperature plots, inventory estimates, riser locations

Abstract: This Supporting Document provides historical in-depth characterization information on U-Tank Farm, such as historical waste transfer and level data, tank physical information, temperature plots, 1 iquid observation well plots, chemical analyte and radionuclide inventories for the Historical Tank Content Estimate Report for the Southwest Quadrant of the Hanford 200 West Area

TRADEMARK DISCLAIMER. Reference herein to any specific comercial product, process, or service by trade name, trademark, manufacturer, or otherwise, does not necessarily constitute or imply its endorsement, recommendation, or favoring by the United States Government or any agency thereof or its contractors or subcontractors.

Printed in the United States of America. To obtain copies of this document, contact: Document Control Services, P.0. Box 950, Mailstop H6-08, Richland WA 99352, Phone (509) 372-2420; Fax (509) 376-4989.
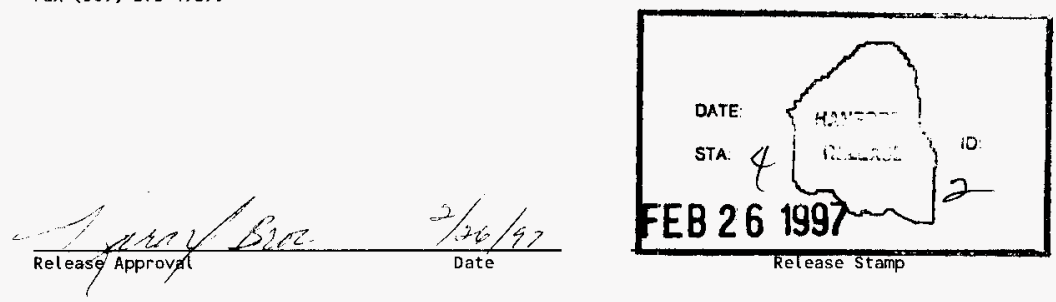

\section{Approved for Public Release}


THS MGE MTWWMOKALY

EFroth 
(2) Title

Supporting Document for the Historical Tank Content Estimate for U-Tank Farm CHANGE CONTROL RECORD

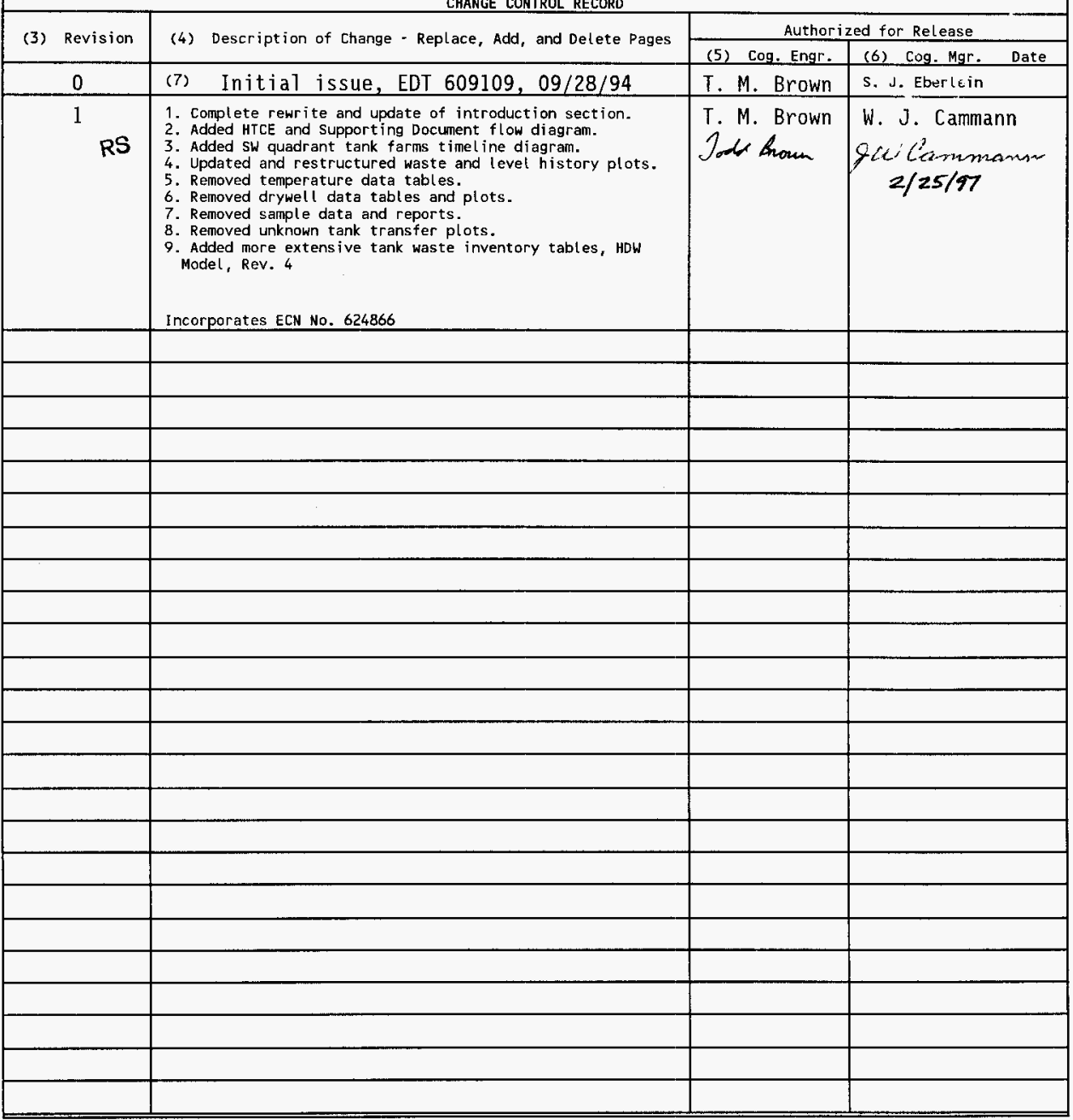


TH hat menTowaly ERT GLAk 


\title{
SUPPORTING DOCUMENT FOR THE HISTORICAL TANK CONTENT ESTIMATE FOR
}

\section{U TANK FARM}

\author{
Prepared for \\ Lockheed Martin Hanford Corporation
}

January 1997

Prepared by

K. L. Ewer

J. W. Funk

R. G. Hale

G. A. Lisle

C. V. Salois

M. R. Umphrey

Fluor Daniel Northwest, Inc.

Richland, Washington 


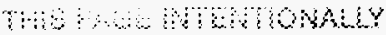
AFT GLMK 


\section{SUPPORTING DOCUMENT FOR THE HISTORICAL TANK CONTENT ESTIMATE FOR}

\section{U TANK FARM}

WORK ORDER E18675

APPROVED:

Fluor Daniel Northwest, Inc.

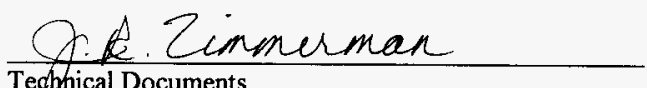

Technical Documents
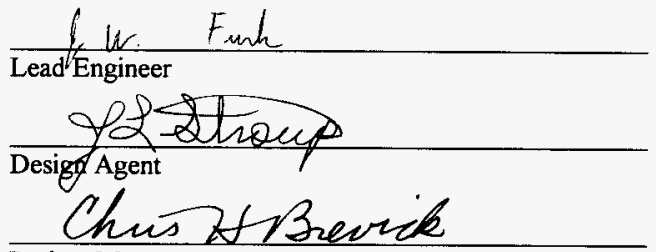

Project Manager

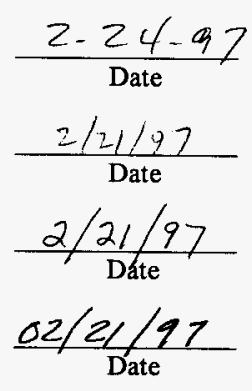

$\frac{2 / 25 / 97}{\text { Date }}$

\section{Lockheed Martin Hanford Corporation}

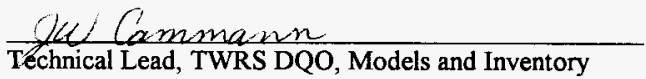




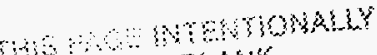
Ger busk 


\section{ACKNOWLEDGMENTS}

A project of the this magnitude would not be possible without the help of a significant number of persons and organizations. Fluor Daniel Northwest, Inc., would like to acknowledge the contributions made by our Los Alamos National Laboratory counterparts: Stephen F. Agnew, Kenneth A. Jurgensen, Robert A. Corbin, Tomasita B. Duran, Bonnie L. Young, Theodore P. Ortiz, John FitzPatrick, and James Boyer. Also, Todd Brown, Brett Simpson and Jerry Cammann of Lockheed Martin Hanford Corporation are recognized for their contributions. 


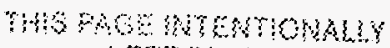
SAt besto 


\section{INFORMATION FEEDBACK CARD}

\section{SUPPORTING DOCUMENT FOR THE HISTORICAL TANK CONTENT ESTIMATE FOR U TANK FARM}

\section{COMMENTS AND CONTRIBUTIONS}

The reader is requested to use this card to comment on this document, report any discrepancies, or contribute new information to improve the accuracy and content of the document. Please use the space provided, add additional pages if necessary, and return the comments to the person noted at the address listed below.

Send Comments to: Mr. Jerry W. Cammann

Lockheed Martin Hanford Corporation

TWRS DQO, Models and Inventory

P.O. Box 1970, MSIN R2-12

Richland, WA 99352

- iii - 
THS PAC WTENTONALY LEF BGAKK 


\section{TABLE OF CONTENTS}

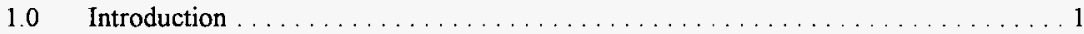

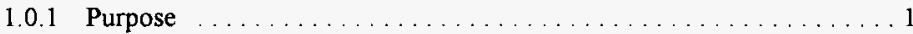

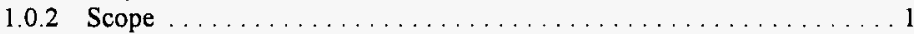

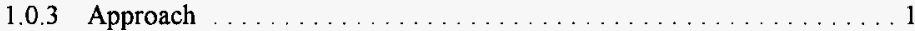

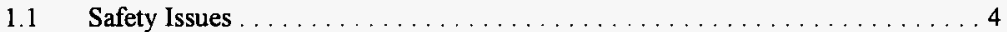

1.1 .1 Watch List Safety Issues $\ldots \ldots \ldots \ldots \ldots \ldots \ldots \ldots \ldots$

1.1 .2 Non-Watch List Safety Issues $\ldots \ldots \ldots \ldots \ldots \ldots \ldots \ldots$

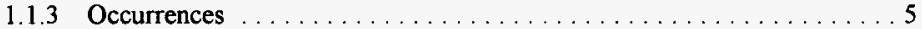

1.2 Waste Generating Plants and Processes $\ldots \ldots \ldots \ldots \ldots \ldots \ldots \ldots$

1.2.1 Plants Processes . . . . . . . . . . . . . . . . . . . . . 5

1.2 .2 Waste Management Operations . . . . . . . . . . . . . . . 9

1.2 .3 Miscellaneous Waste Sources and Equipment $\ldots \ldots \ldots \ldots \ldots \ldots$

1.2 .4 Time Lines . . . . . . . . . . . . . . . . . . . . . . . . 11

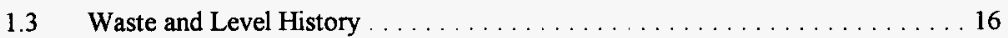

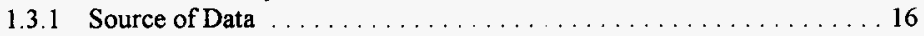

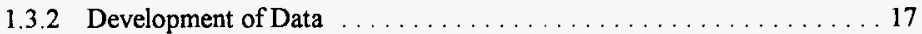

1.3 .3 Assumptions . . . . . . . . . . . . . . . . . . . . . . . 19

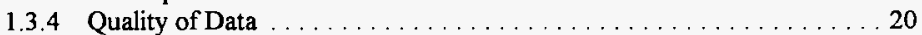

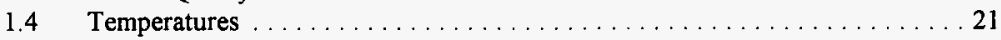

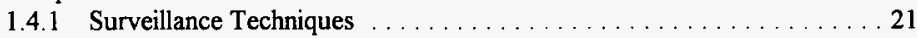

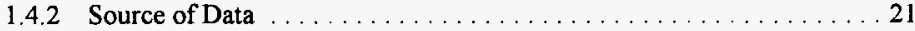

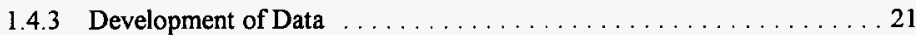

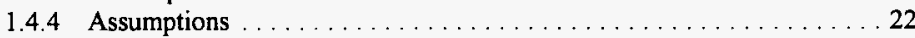

1.4 .5 Quality of Data . . . . . . . . . . . . . . . . . 22

$1.5 \quad$ Waste Surface Level . . . . . . . . . . . . . . . . . . . . . . . . . . 23

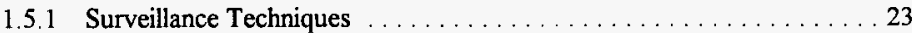

1.5 .2 Source of Data . . . . . . . . . . . . . . . . . . . 24

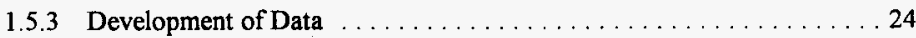

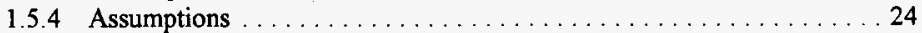

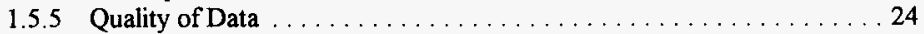

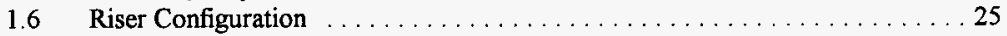

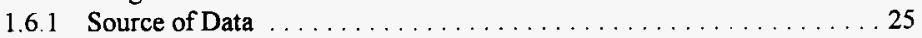

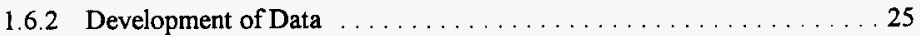

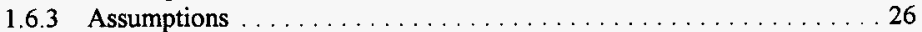

1.6 .4 Quality of Data . . . . . . . . . . . . . . . . . . 26

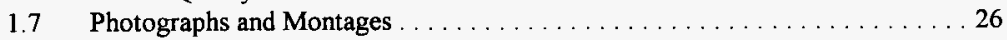

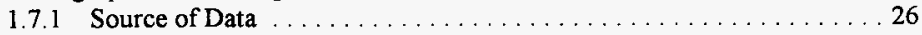

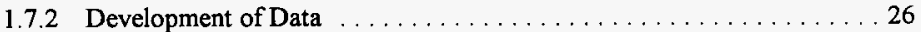

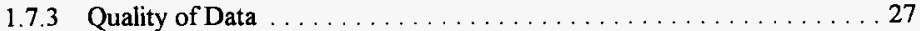

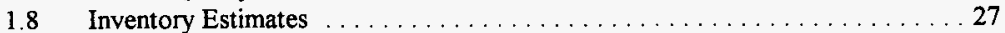

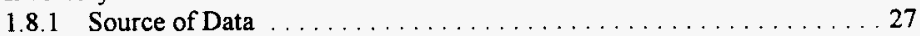

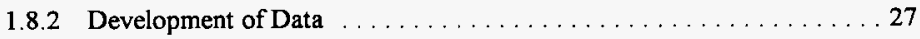




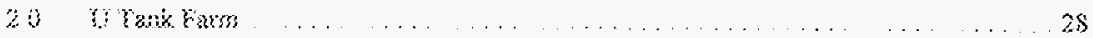

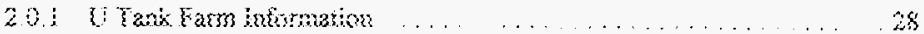

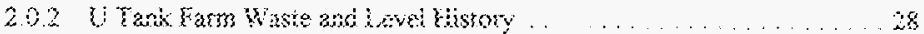

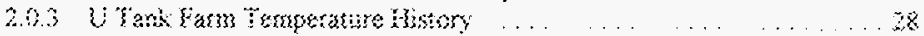

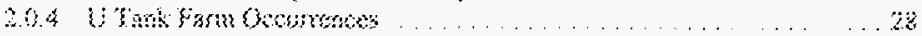

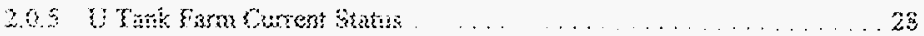

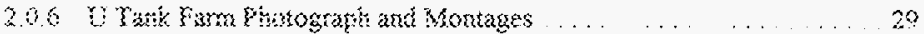

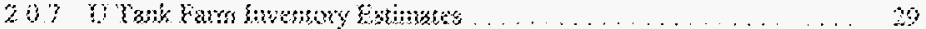

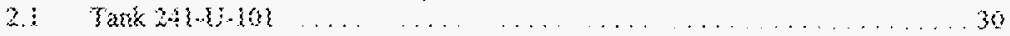

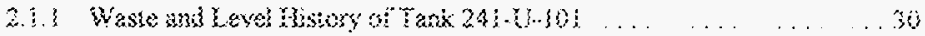

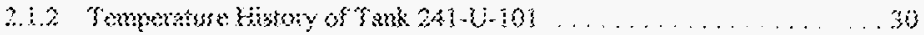

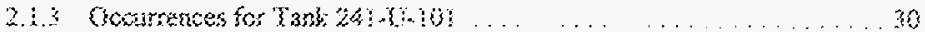

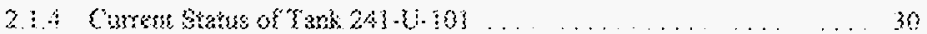

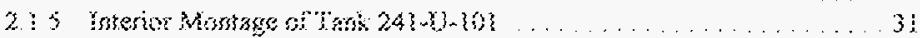

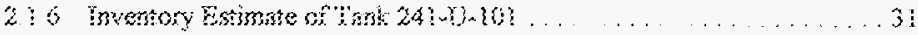

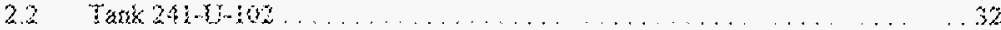

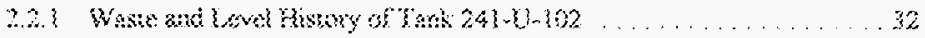

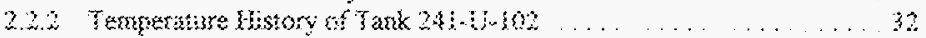

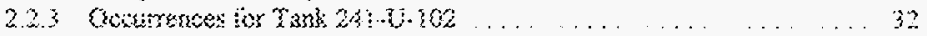

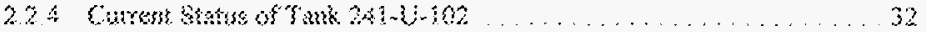

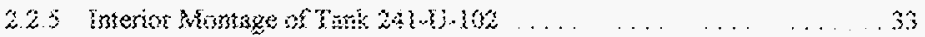

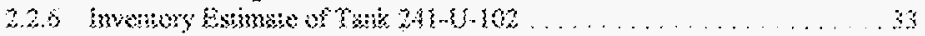

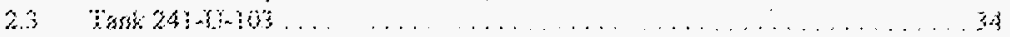

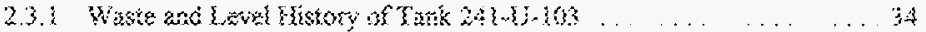

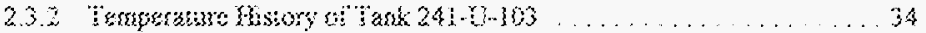

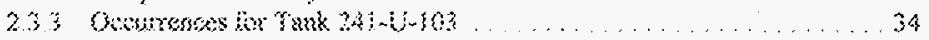

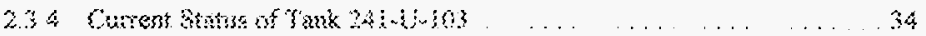

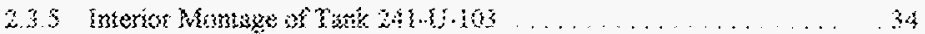

23.5 fnvower Exwme of

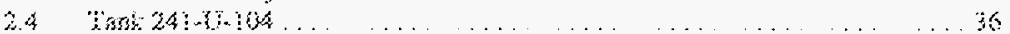

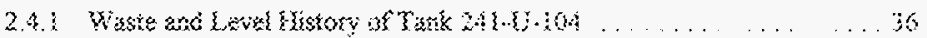

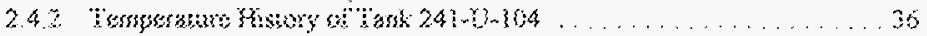

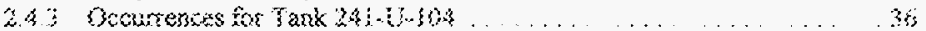

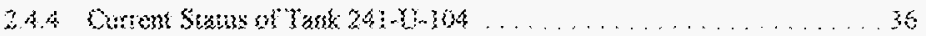

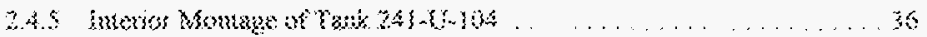

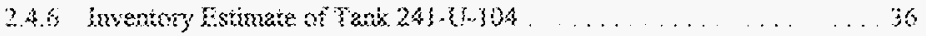

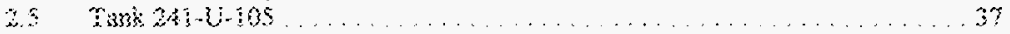

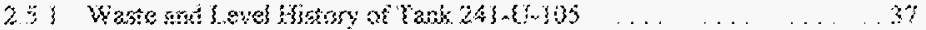

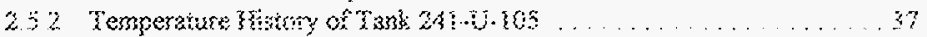

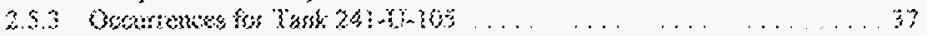

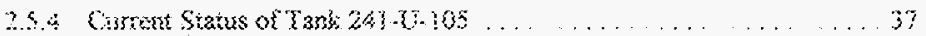

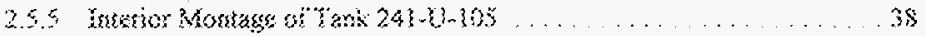

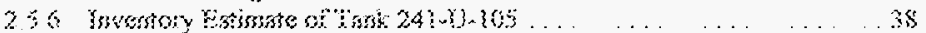

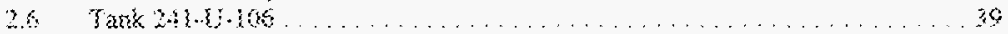

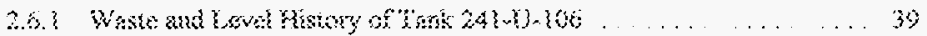

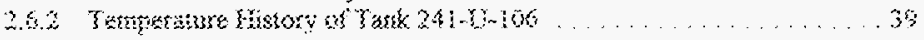

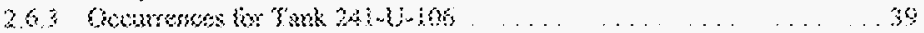




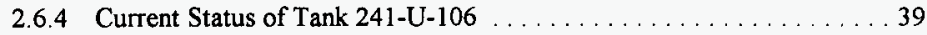

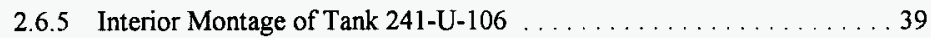

2.6.6 Inventory Estimate of Tank $241-\mathrm{U}-106 \ldots \ldots \ldots \ldots \ldots \ldots \ldots$

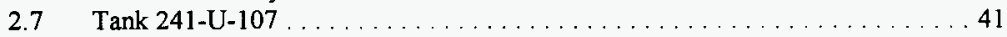

2.7.1 Waste and Level History of Tank $241-\mathrm{U}-107 \ldots \ldots \ldots \ldots \ldots$

2.7 .2 Temperature History of Tank $241-\mathrm{U}-107 \ldots \ldots \ldots \ldots \ldots \ldots$

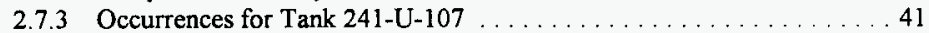

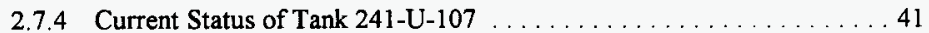

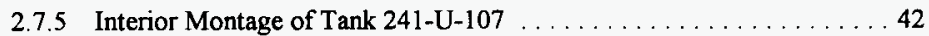

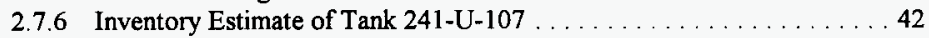

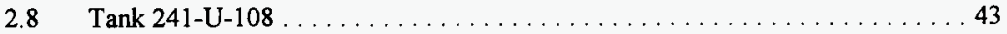

2.8.1 Waste and Level History of Tank $241-\mathrm{U}-108 \ldots \ldots \ldots \ldots \ldots$

2.8.2 Temperature History of Tank $241-\mathrm{U}-108 \ldots \ldots \ldots \ldots \ldots \ldots$

2.8.3 Occurrences for Tank $241-\mathrm{U}-108 \ldots \ldots \ldots \ldots \ldots \ldots \ldots \ldots$

2.8.4 Current Status of Tank $241-U-108 \ldots \ldots \ldots \ldots \ldots \ldots \ldots \ldots \ldots$

2.8.5 Interior Montage of Tank $241-U-108 \ldots \ldots \ldots \ldots \ldots \ldots \ldots$

2.8.6 Inventory Estimate of Tank $241-\mathrm{U}-108 \ldots \ldots \ldots \ldots \ldots \ldots$

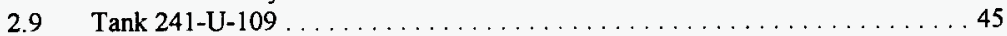

2.9.1 Waste and Level History of Tank $241-\mathrm{U}-109 \ldots \ldots \ldots$

2.9.2 Temperature History of Tank $241-U-109 \ldots \ldots \ldots \ldots \ldots \ldots$

2.9 .3 Occurrences for Tank $241-\mathrm{U}-109 \ldots \ldots \ldots \ldots \ldots \ldots$

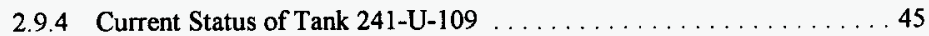

2.9.5 Interior Montage of Tank $241-U-109 \ldots \ldots \ldots \ldots \ldots \ldots \ldots$

2.9 .6 Inventory Estimate of Tank $241-\mathrm{U}-109 \ldots \ldots \ldots \ldots \ldots$

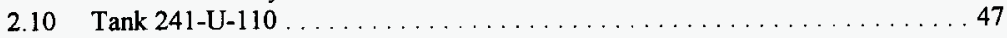

2.10.1 Waste and Level History of Tank $241-U-110 \ldots \ldots \ldots \ldots$. . . . . 47

2.10.2 Temperature History of Tank $241-U-110 \ldots \ldots \ldots \ldots 47$

2.10 .3 Occurrences for Tank $241-\mathrm{U}-110 \ldots \ldots \ldots \ldots \ldots \ldots \ldots$

2.10 .4 Current Status of Tank $241-U-110 \ldots \ldots \ldots \ldots \ldots \ldots \ldots$

2.10.5 Interior Montage of Tank $241-U-110 \ldots \ldots \ldots \ldots \ldots \ldots$

2.10.6 Inventory Estimate of Tank $241-U-110 \ldots \ldots \ldots \ldots . \ldots 48$

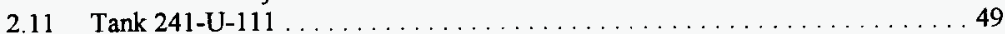

2.11.1 Waste and Level History of Tank $241-U-111 \ldots \ldots . \ldots . \ldots . . . . .49$

2.11.2 Temperature History of Tank $241-\mathrm{U}-111 \ldots \ldots \ldots \ldots \ldots . \ldots \ldots$

2.11.3 Occurrences for Tank $241-U-111 \ldots \ldots \ldots \ldots \ldots \ldots . \ldots \ldots$

2.11.4 Current Status of Tank $241-\mathrm{U}-111 \ldots \ldots \ldots \ldots$. . . . . . . . . . . . . . . . . . . . . . . . . . . . . . .

2.11 .5 Interior Montage of Tank $241-\mathrm{U}-111 \ldots \ldots \ldots \ldots \ldots$

2.11.6 Inventory Estimate of Tank $241-\mathrm{U}-111 \ldots \ldots \ldots \ldots \ldots \ldots \ldots$

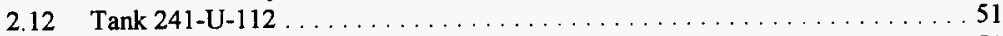

2.12.1 Waste and Level History of Tank $241-\mathrm{U}-112 \ldots \ldots \ldots \ldots$. . . . . 51

2.12.2 Temperature History of Tank $241-U-112 \ldots \ldots \ldots \ldots \ldots \ldots$. . . . . . . 51

2.12 .3 Occurrences for Tank $241-U-112 \ldots \ldots \ldots \ldots \ldots \ldots \ldots \ldots$

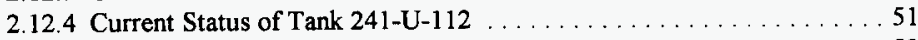

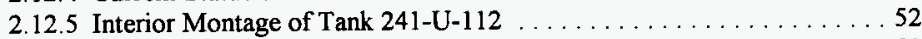

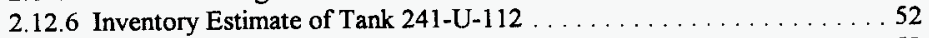

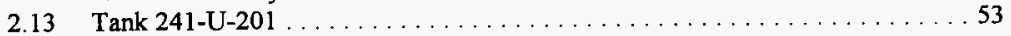

2.13.1 Waste and Level History of Tank $241-U-201 \ldots \ldots \ldots$ 


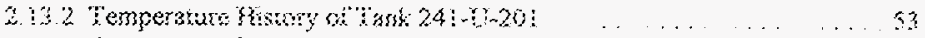

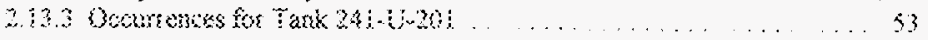

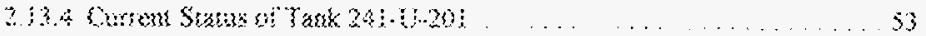

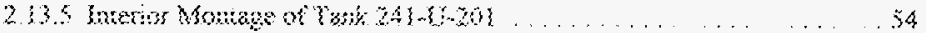

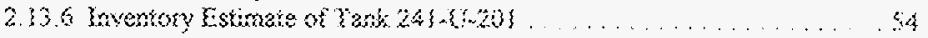

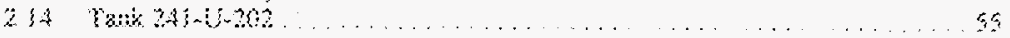

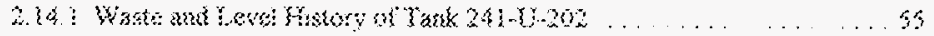

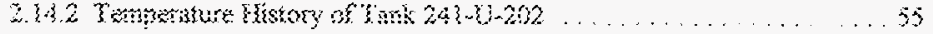

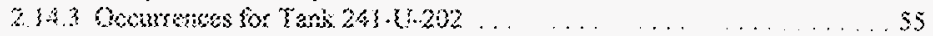

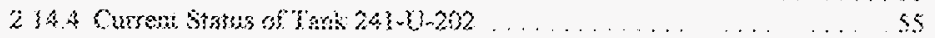

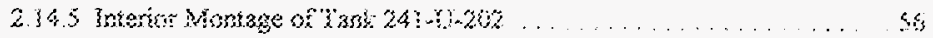

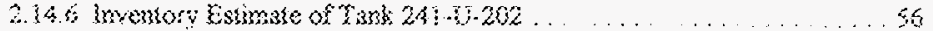

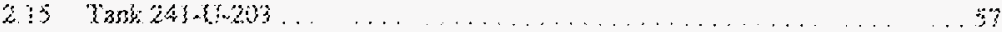

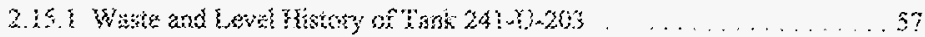

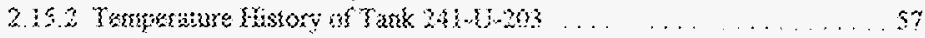

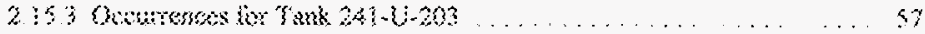

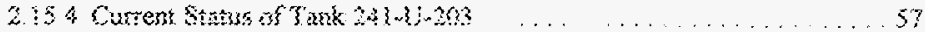

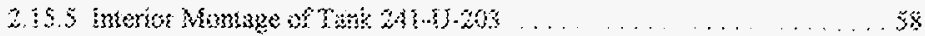

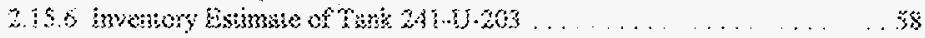

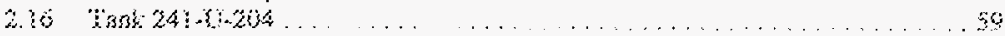

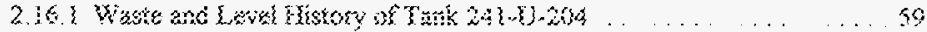

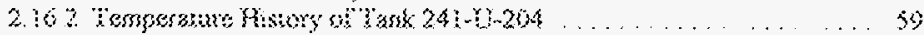

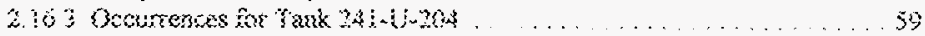

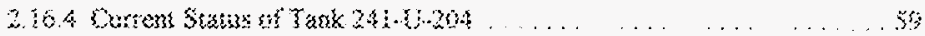

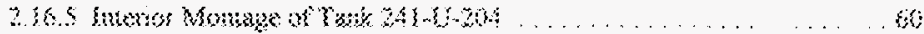

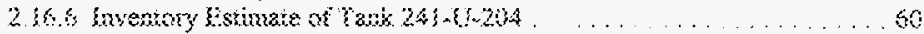

\section{Aerexusyeds}

Appendix $A$ Appendix 8 Sppondx 0 Aprentx 3 Aptondte $\xi$ Apponsix 5 Apensix 6 Appendix
Giossary

Eeference::

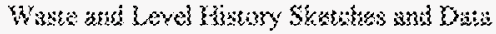

Tamperatere Graphs

Waste Sutace Level Graphs

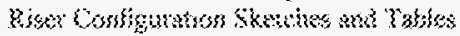

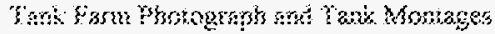

Grvotury Extimmat 


\section{TRADEMARKS}

Microsoft Excel is a registered trademark of Microsoft Corporation.

ENRAF is a registered trademark of Delft Instruments.

AutoCAD is a registered trademark of Autodesk, Inc. 
MHO NE MTENTOMALSY I.) Bunk 


\subsection{Introduction}

\subsubsection{Purpose}

The purpose of this historical characterization document is to present the synthesized summaries of the historical records concerning the physical characteristics, and radiological, and chemical composition of mixed wastes stored in underground single-shell tanks and the physical conditions of these tanks. The single-shell tanks are located on the United States Department of Energy's Hanford Site, approximately 25 miles northwest of Richland, Washington. The document will be used to assist in characterizing the waste in the tanks in conjunction with the current program of sampling and analyzing the tank wastes. Los Alamos National Laboratory (LANL) developed computer models that used the historical data to attempt to characterize the wastes and to generate estimates of each tank's inventory. A historical review of the tanks may reveal anomalies or unusual contents that could be critical to characterization and post characterization activities.

This document was developed by reviewing the operating plant process histories, waste transfer data, and available physical and chemical data from numerous resources. These resources were generated by numerous contractors from 1945 to the present.

Waste characterization, the process of describing the character or quality of a waste, is required by Federal law (Resource Conservation and Recovery Act [RCRA]) and state law (Washington Administrative Code [WAC] 173-303, Dangerous Waste Regulations). Characterizing the waste is necessary to determine methods to safely retrieve, transport, and/or treat the wastes.

This document is not intended for use as a total design basis document. Further investigations of the information may be required before using this data for design purposes or safety analysis.

\subsubsection{Scope}

The scope of this document covers available information about the wastes contained in the single-shell tanks in the U Tank Farm. Waste transfer and level data, tank physical information, and surveillance data of tanks and wastes have been compiled for this document. The inventory estimates of waste types and volumes generated by the computer modeling programs developed by LANL are included also. A summary of this information is contained in the Historical Tank Content Estimate (HTCE) for the Southwest Quadrant of the Hanford 200 West Area (Brevick et al., 1997c). The Southwest Quadrant (SW Quadrant) document covers three single-shell tank farms. These three tank farms, S, SX, and U, are located in the 200 West Area and are shown on the map in Figure 1. A flow diagram showing the relationships between the sources of data, the HTCE, and the supporting documents is in Figure 2.

This document also includes information on the safety issues affecting the tanks and the plants and processes that produced the waste in the underground waste storage tanks.

\subsubsection{Approach}

This document was compiled from work performed by Fluor Daniel Northwest, Inc. (FDNW), LANL, and Lockheed Martin Hanford Corporation (LHMC), as well as work performed by 


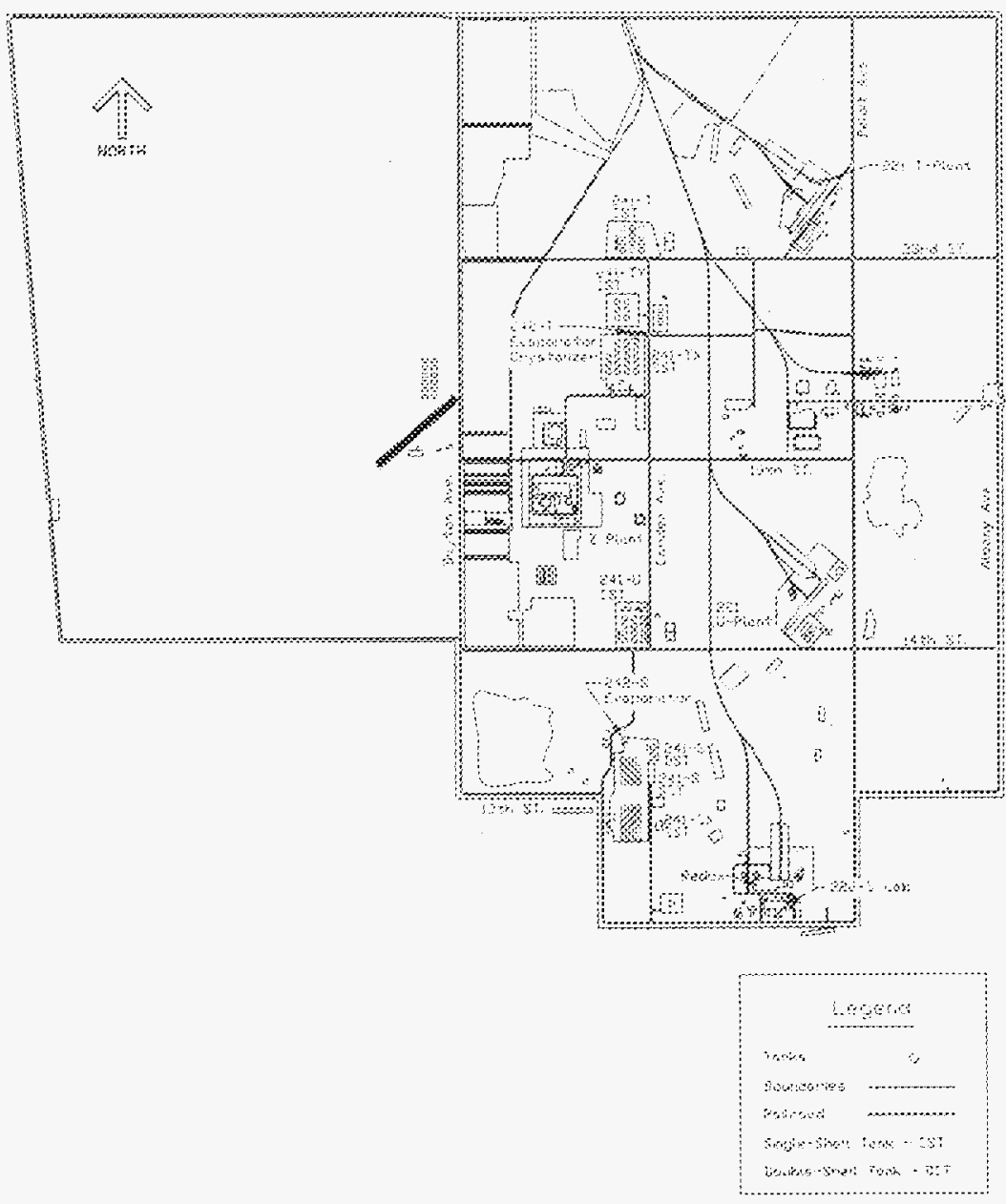

Pure 200 Wost Area. 


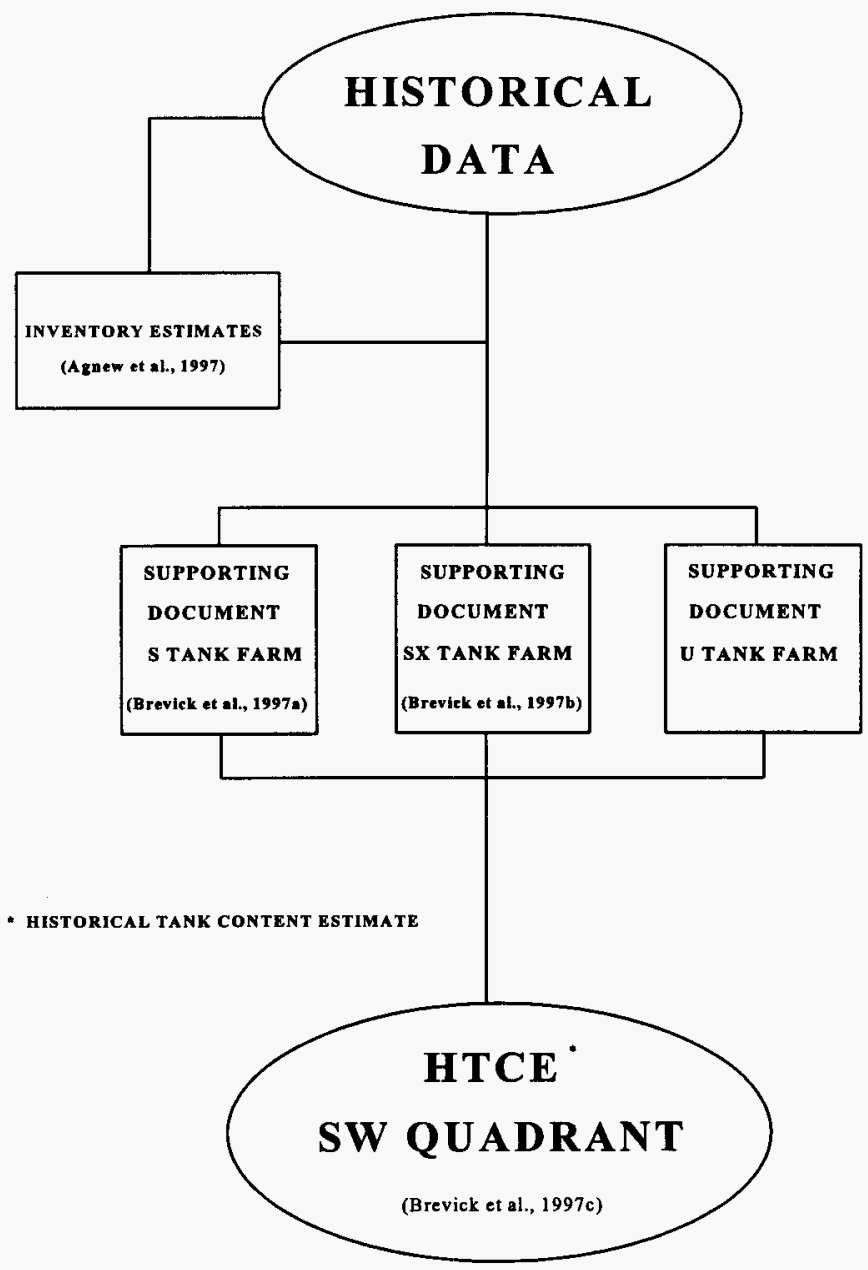

Figure 2. HTCE and Supporting Document Flow Diagram. 


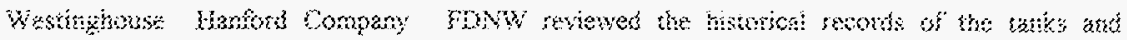

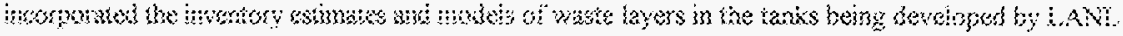
inte this torment

\section{: Safery lsous;}

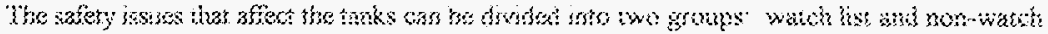

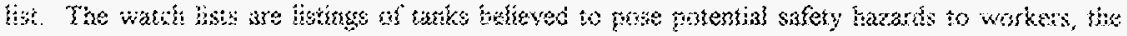

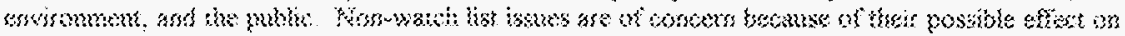

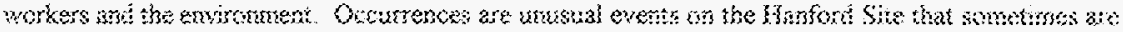
related to satery issues:

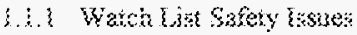

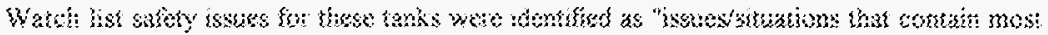

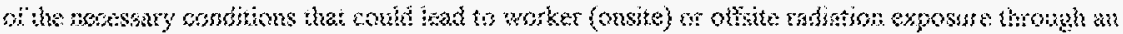

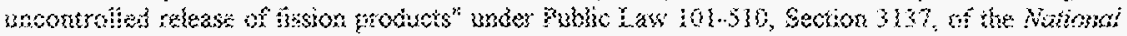

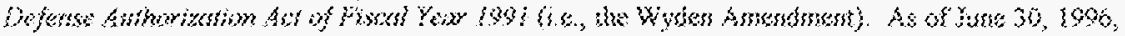

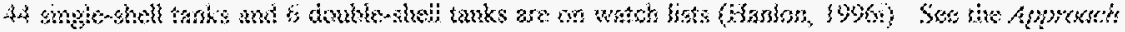

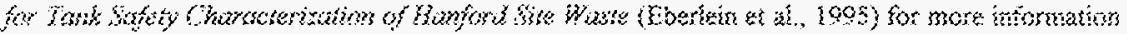

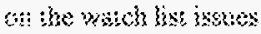

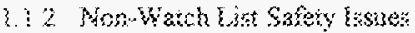

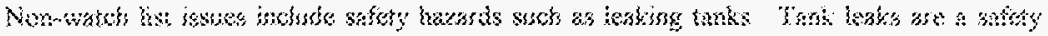

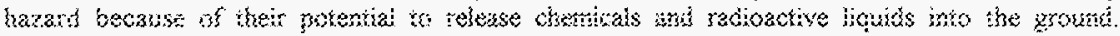

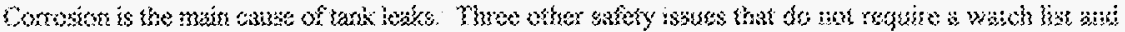

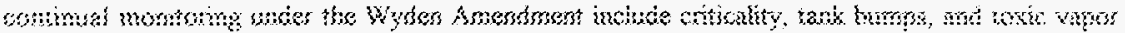

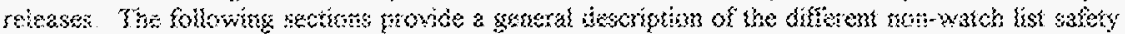

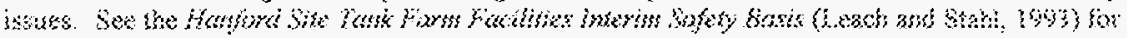
wore istimstion.

\section{* Corsosion}

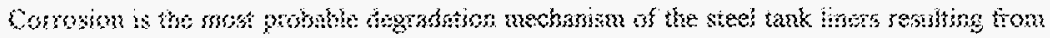

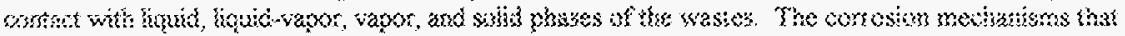

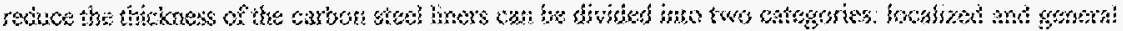

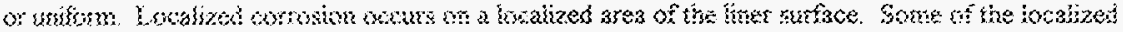

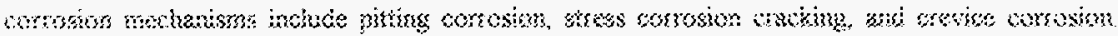

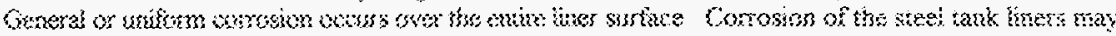

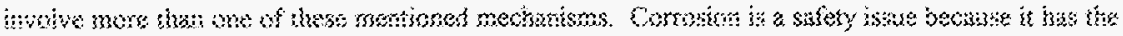

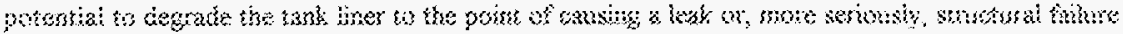

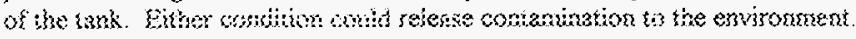

\section{\& Criticalisy}

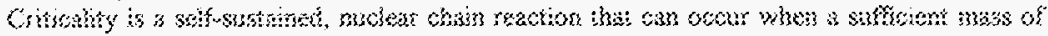

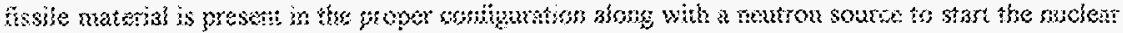

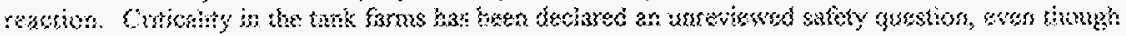


the Hanford Site Tank Farm Facilities Interim Safety Basis (Leach and Stahl, 1993) indicates that a "nuclear criticality accident in the tank farms is probably not an imminent risk." The unreviewed safety question on criticality in the tank farms remains because the inventory of fissile material and its distribution within the tanks cannot be confirmed as being within the approved safety envelope defined in the current safety analysis reports. Criticality is a safety issue because of the potential to release contamination to the environment.

\section{- Tank Bumps}

A tank bump is the sudden pressurization of the tank. This phenomenon occurs when solids overheat in the lower portion of the tank followed by uncontrolled mixing of these solids. The stirred hot solids rapidly transfer heat to the liquid in the tank, some of which quickly vaporizes. The rapid vapor generation causes a sudden internal tank pressurization that causes a bump. Uncontrolled mixing of heated solids can occur when an airlift circulator fails allowing the solids to heat up followed by rapid startup of the airlift circulator which causes rapid mixing. Uncontrolled mixing can also occur when a natural "rollover" of waste occurs in the tank. Tank bumps are a safety issue because of their potential to release contamination to the environment.

\section{Toxic Vapor Releases}

Toxic vapor releases are a recently analyzed safety concern at the Hanford Site. The entire issue of toxic gas releases at the tank farms is being investigated (Leach and Stahl, 1993).

\subsubsection{Occurrences}

Over the years, unusual events (occurrences) have occurred at the U Tank Farm. An occurrence is an event that falls outside the normal operating, maintenance and/or construction procedures of the tank farm. Occurrences have been documented by various reporting methods including unusual occurrences reports, off-normal reports, event fact sheets, and occurrence reports. Before it was included in this document, the occurrence documentation that could be located was evaluated for its significance in determining the waste content of the tanks. The types of significant occurrences included are those involving surface level changes, temperature changes, and radioactivity changes (activity in the drywells). This document does not contain complete information from the reports, only summaries of the events. For more information on occurrences, refer to the Occurrences Section for the specific tank.

\subsection{Waste Generating Plants and Processes}

\subsubsection{Plants Processes}

Brief descriptions and histories of the plants and processes that generated waste now contained in the single-shell and double-shell tanks are presented in alphabetical order. Typically, the name of the plant and the process are synonymous. The dates and events described in the following brief histories are presented on time lines in Figures 3 and 4 . Although not all of the processes listed below contributed waste directly to tanks in the Southwest Quadrant, the waste they generated could have been transferred indirectly from tank to tank. 


\section{* A Wass (ZSRES)}

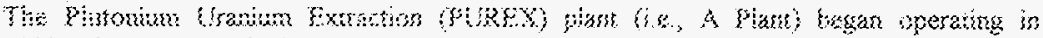

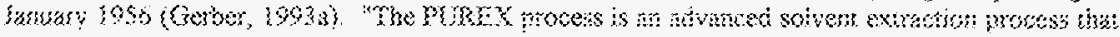

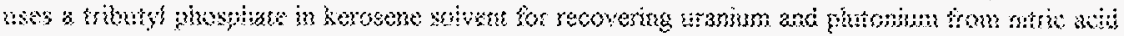

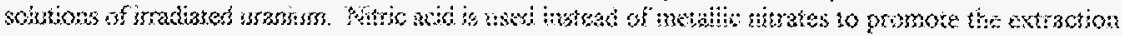

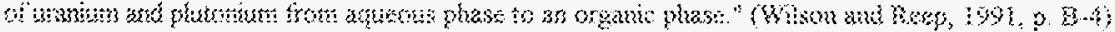

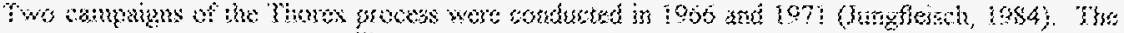

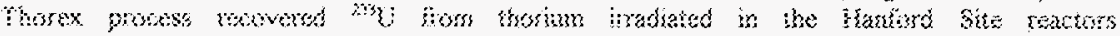

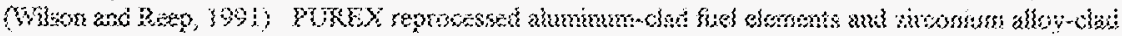

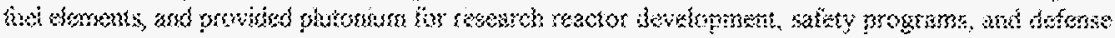

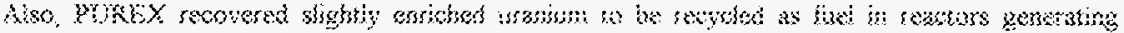

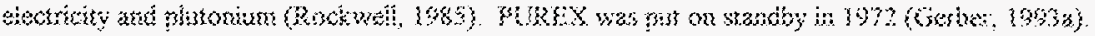

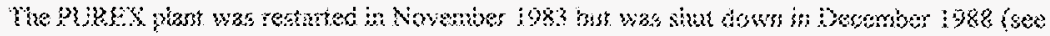

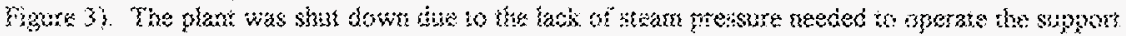

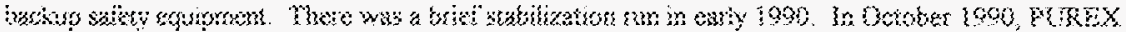

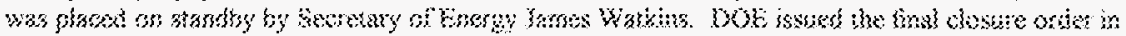

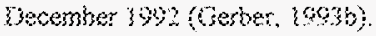

\section{\& Ysist}

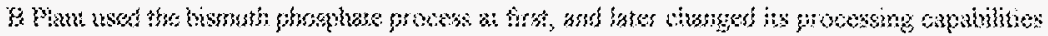

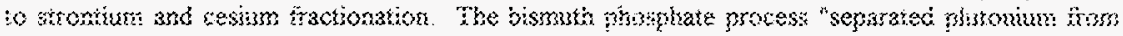

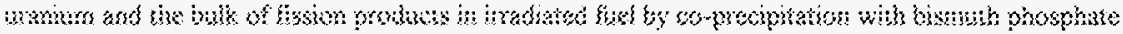

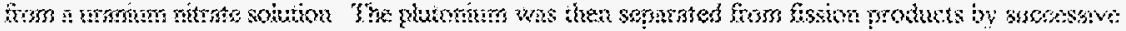

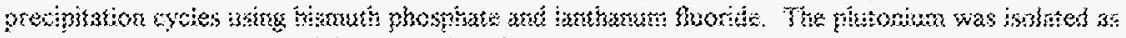

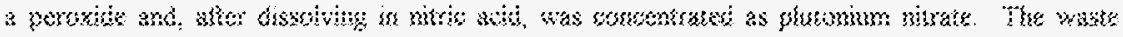

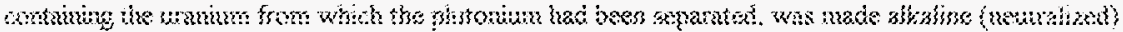

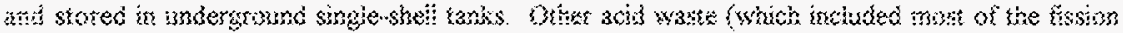

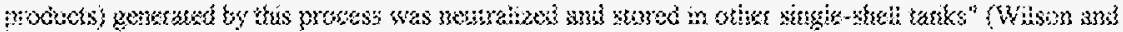

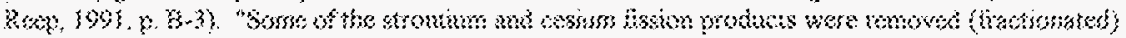

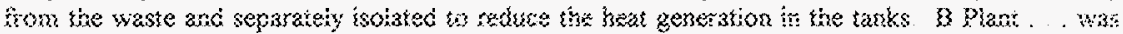

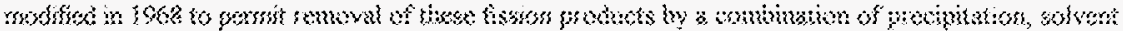

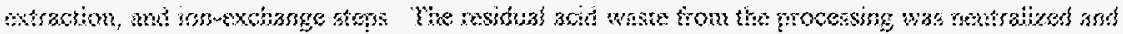

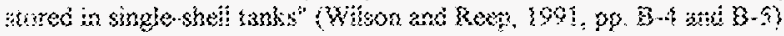

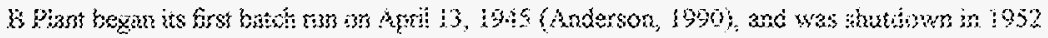

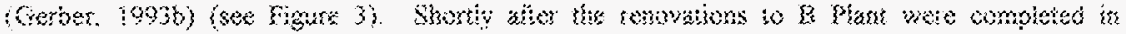

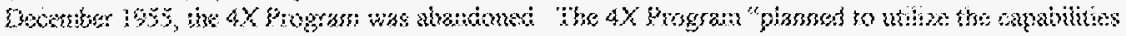

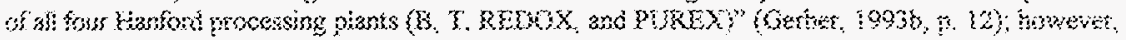

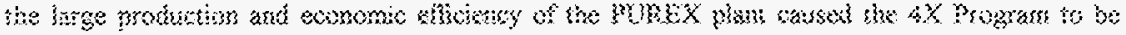

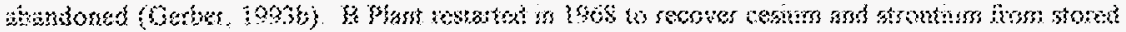

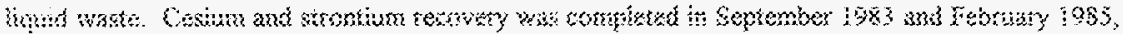

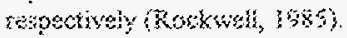

\section{$225-33(3 \mathrm{ESS})$}

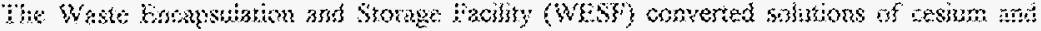

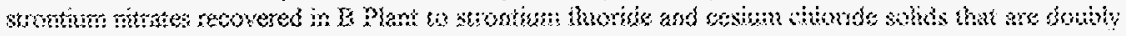


encapsulated in metal (Ballinger and Hall, 1991). "Strontium and cesium capsules have been used in applications of fission byproducts for gamma and heat sources" (Wilson and Reep, 1991, p. B-5).

WESF was constructed in 1974 (see Figure 3). The process optimization for cesium and strontium was completed in 1978 and 1981, respectively (Rockwell, 1985). The cesium processing ended in 1983 and strontium encapsulation in 1985. The capsule return program started in 1988 and ended in 1995 (Gerber, 1996).

\section{- C Plant (Strontium Semiworks)}

The Strontium or Hot Semiworks Facility (i.e., C Plant) began operating in 1952 as a hot pilot plant for the REDOX process (see Figure 3). In 1954, the plant was converted to a pilot plant for the PUREX process and continued operating until 1956 (Ballinger and Hall, 1991). "The process building (201-C) contains three hot cells equipped only for contact maintenance and is supported by an aqueous makeup and control building (271-C) and a solvent handling building (276-C). The facility also includes a fiberglass exhaust filter and a 200-ft stack." (PNL, 1991, Vol. 1, p. 3.6). In 1960, the plant was reactivated as a pilot plant used to recover ${ }^{90} \mathrm{Sr},{ }^{147} \mathrm{Pm}$, and ${ }^{144} \mathrm{Cs}$ from PUREX waste. The plant was shut down in 1967 and the building and the site have been decontaminated and decommissioned (PNL, 1991).

\section{S Plant (REDOX)}

The Reduction and Oxidation extraction (REDOX) plant (i.e., S Plant) began processing on January 9, 1952 (Anderson, 1990) (see Figure 3). "The REDOX extraction process was a secondgeneration recovery process and the first process to recover both plutonium and uranium. It used a continuous solvent extraction process to extract plutonium and uranium from dissolved fuel into a methyl isobutyl ketone (hexone) solvent. The slightly acidic wastestream contained the fission products and large quantities of aluminum nitrate that were used to promote the extraction of plutonium and uranium. This waste was neutralized and stored in single-shell tanks. The volume of high-level waste from this process was much smaller than that from the bismuth phosphate process, but larger than that from the PUREX process" (Wilson and Reep, 1991, pp. B-3 and B-4). REDOX operated until 1967 (Rockwell, 1985).

\section{- T Plant}

T Plant was the first full-scale separations plant at the Hanford Site. T Plant used the bismuth phosphate process to separate plutonium from uranium and the bulk of fission products in irradiated fuel (B Plant used the same process). "The waste containing the uranium from which the plutonium had been separated was made alkaline (neutralized) and stored in underground single-shell tanks. Other acid waste (which included most of the fission products) generated by this process was neutralized and stored in other single-shell tanks" (Wilson and Reep, 1991, p. B-3).

T Plant began operating in 1944 (Rockwell, 1985) as a separations plant and continued until March 1956 (Gerber, 1994) (see Figure 4). T Plant's mission was changed in 1957 to the repair and high-level decontamination of equipment (Rockwell, 1985). T Plant was converted to a "central decontamination facility for the site. As such, failed and contaminated equipment was assessed and either repaired or discarded there for over three decades" (Gerber, 1994, p. 1). Early decontamination operations used steam, sand, chemicals, and detergents. "Smaller equipment pieces were immersed in decontamination solutions in 'thimble tanks,' and larger pieces were flushed with water, chemical solutions, sand-blasted, steam-blasted, high-pressure sprayed (using pressures up to 10,000 pounds per 


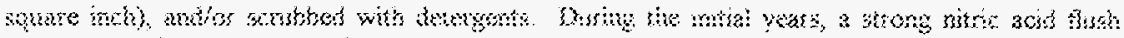

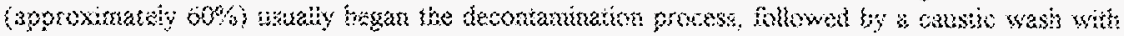

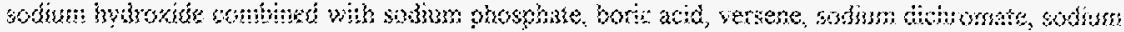

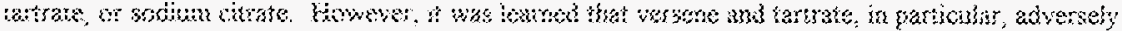

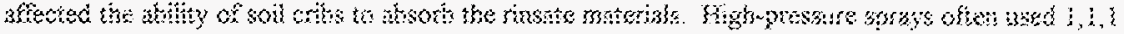

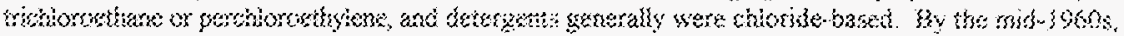

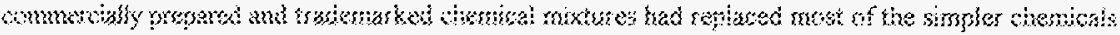

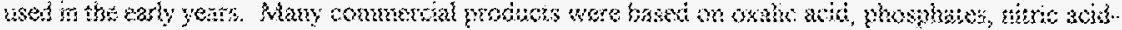

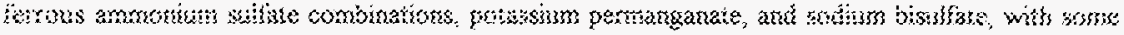

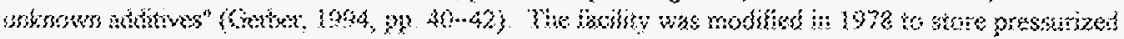
water retor (G)

\section{*}

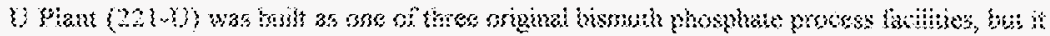

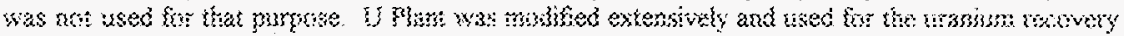

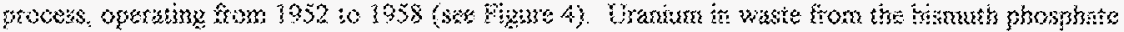

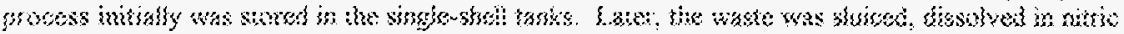

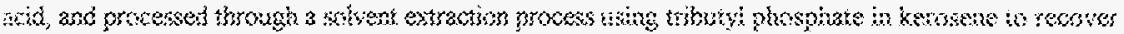

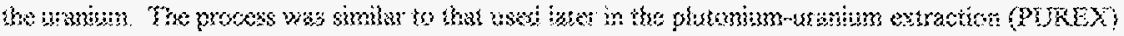

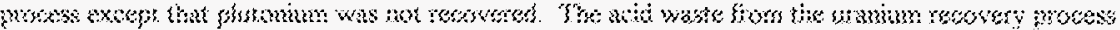

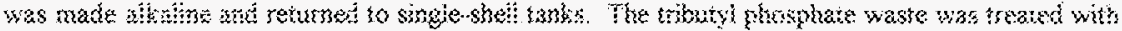

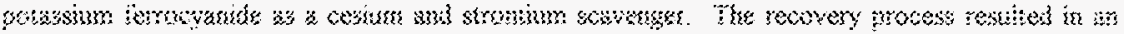

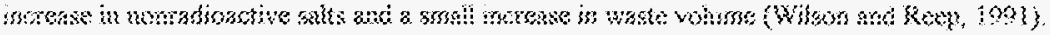

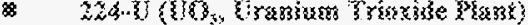

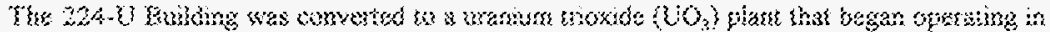

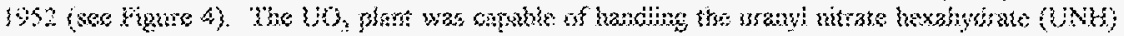

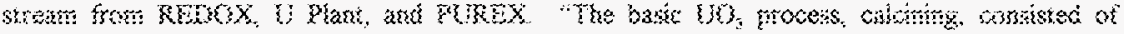

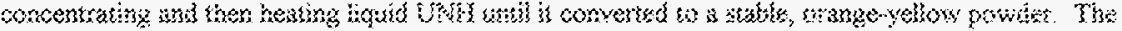

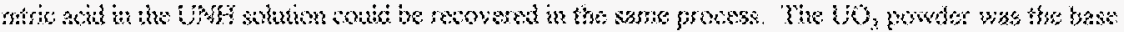

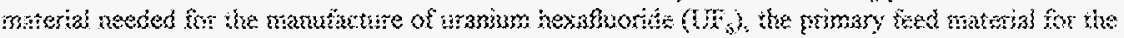

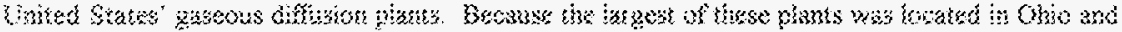

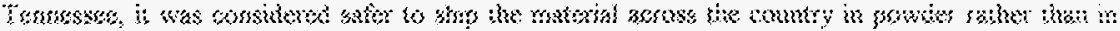

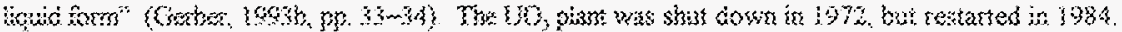

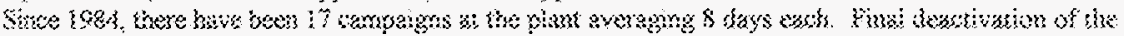

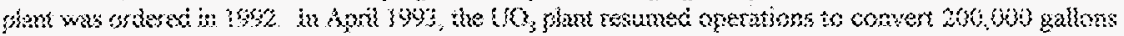

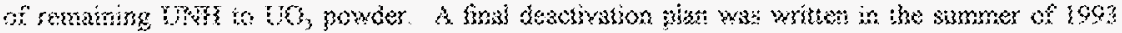
(Gertuk, iogsb)

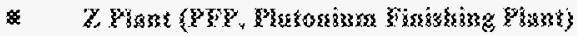

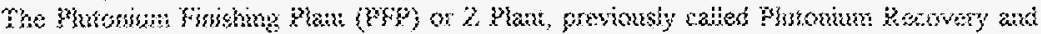

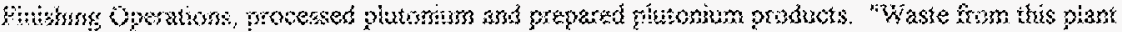

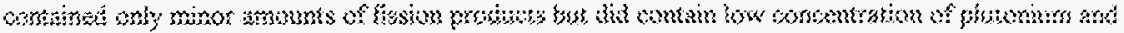

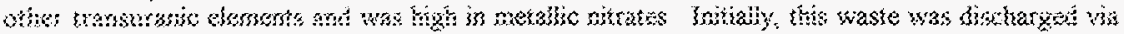

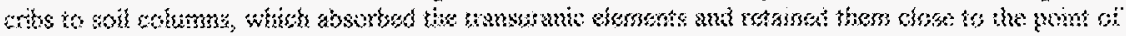

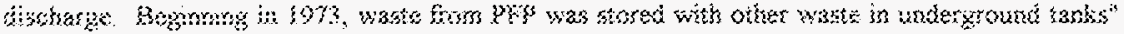

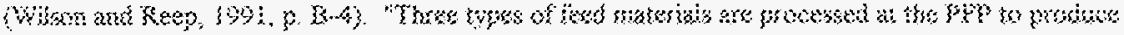


plutonium metal. Feed material types are handled differently in different process lines Historically, the main feed for the PFP was purified plutonium nitrate solution that was produced elsewhere in a fuel reprocessing plant. This feed was charged directly to one of the main process lines, which was initially a glovebox line. The glovebox line was replaced by remote mechanical lines, which were upgraded over the years. In time, processes were added to handle rework and scrap plutonium. These processes were used to convert the rework and scrap materials into a purified plutonium nitrate solution that could be handled by the main process" (Duncan and Mayancsik, 1993, pp. 2-1-2-2).

In July 1949, PFP began operations with a glovebox line (see Figure 4). The remote mechanical A line replaced the glovebox line in May 1953. Installment of the Recuplex Facility at PFP was completed in April 1955. The remote mechanical C line was installed in July 1960. In September 1961, the 232-Z Building had an incinerator and leaching equipment installed. In June 1964, the Plutonium Reclamation Facility (PRF) replaced the functions of the Recuplex Facility. Fabrication of plutonium metal nuclear weapon components ceased at the PFP in December 1965. In April 1973, the 232-Z Incinerator was shut down and the remote mechanical $C$ line was placed on standby. The PRF was placed on standby in February 1979, and the remote mechanical A line was shutdown in December 1979. In January 1984, the PRF was restarted for a series of campaigns. The remote mechanical C line was restarted in June 1985 for a series of campaigns. In September 1986, operations at PFP were halted for nine months. This partial listing of the process history in the PFP is from Duncan et al. (1993).

\subsubsection{Waste Management Operations}

This section describes the different methods used to concentrate waste in the 200 Areas. Evaporating, and in-tank solidification are methods used to reduce the volumes of supernate. Brief descriptions and histories of the operations are presented in alphabetical order. The events and dates described in the brief histories are presented on a time line (Figure 5).

\section{2-A Evaporator-Crystallizer}

"The program objective was to reduce the volume of tanked waste liquors through the boiloff of water. This was accomplished by boiling the liquor in an enclosed vessel at reduced pressure. The evaporation was carried out until a slurry containing about $30 \mathrm{wt} \%$ solids was formed. The slurry was returned to underground waste tanks for cooling, crystallization, and settling. The principal products of waste solidification have been large volumes of sodium nitrate salt cakes and waste liquors that are rich in sodium hydroxide and sodium aluminate" (Wilson and Reep, 1991, p. B-5).

The 242-A Evaporator-Crystallizer began operating on March 18, 1977 (Anderson, 1990) (see Figure 5). In 1981, the evaporator was shut down for ten months to tie AW Tank Farm into the process (Rockwell, 1985). The evaporator was shut down in 1989 because of regulatory issues, but was restarted in 1994 after extensive modifications (Gerber, 1996).

\section{2-B Evaporator}

"The first type of waste solidification facility, the 242-B and 242-T Concentrators, was originally used for concentration of bismuth phosphate process waste. In 1951, they began to concentrate cladding/first cycle waste. These concentrators were steam-heated pot evaporators operated outside the waste tanks and at atmospheric pressure. The liquors were partially boiled down 


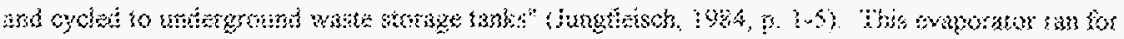

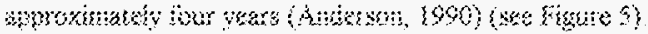

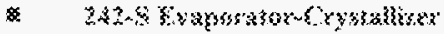

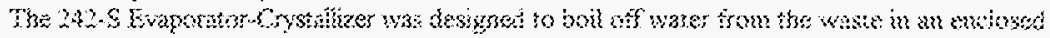

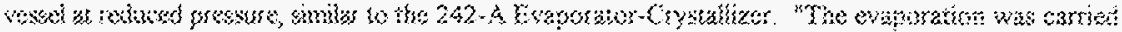

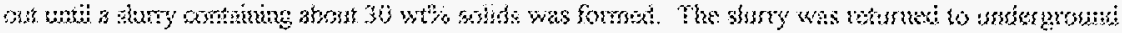

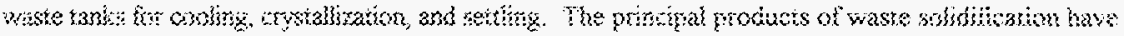

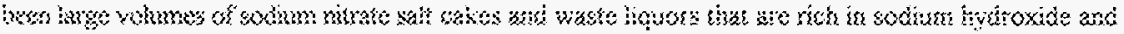

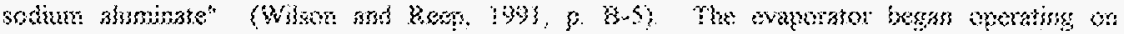

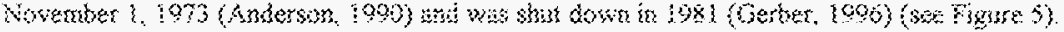

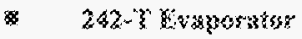

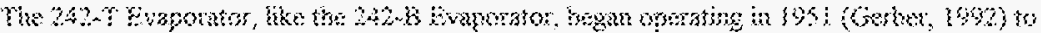

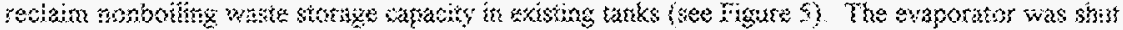

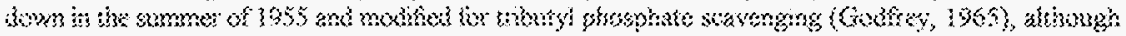

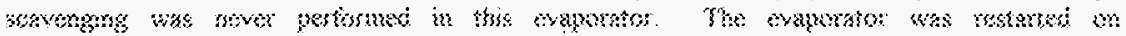

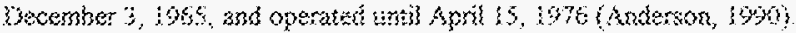

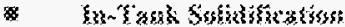

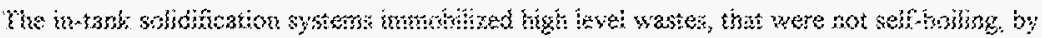

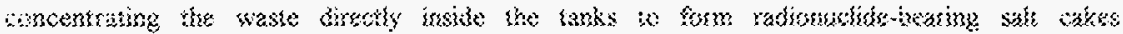

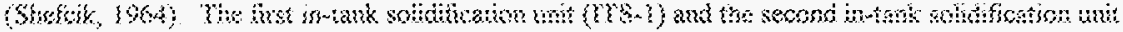

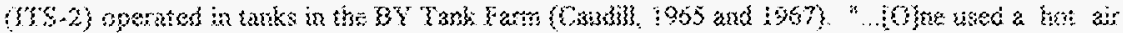

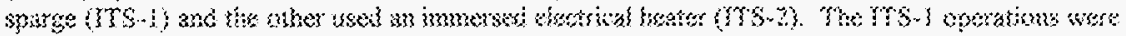

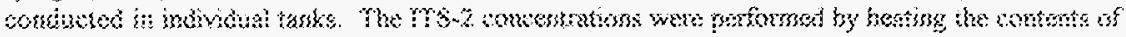

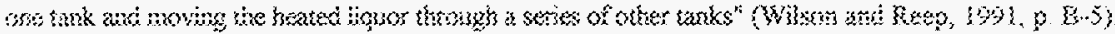

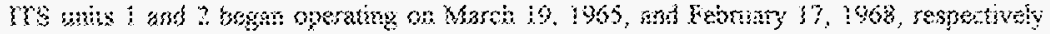

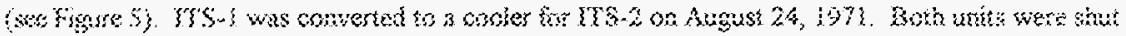

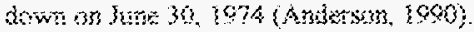

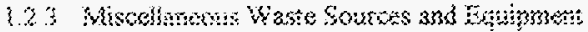

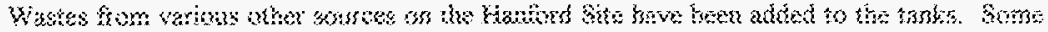

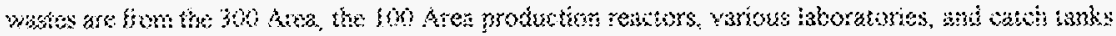

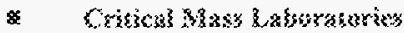

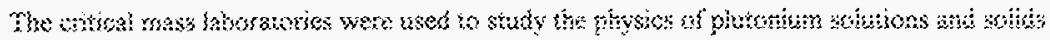

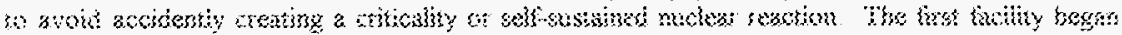

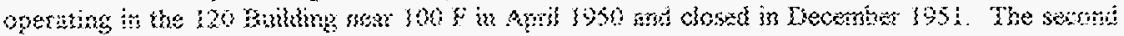

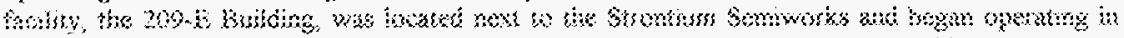

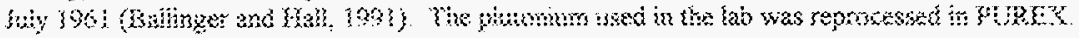

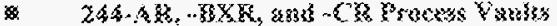

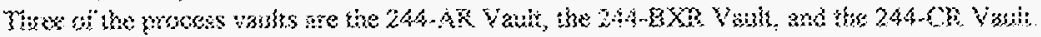

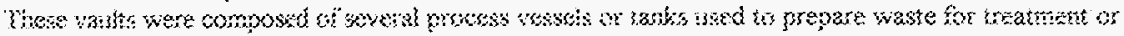


storage. Specific wastes from tanks can be pumped temporarily to the vaults and later sent directly to desired tanks or processing facilities.

The AR Vault, located north and west of the A Tank Farm, was constructed in 1966. The vault facilities include a canyon building with process cells containing tanks. The AR Vault has been on standby since 1978 (Leach and Stahl, 1993).

The 244-BXR Vault, located south of the BX Tank Farm began, operating in 1952 (Rodenhizer, 1987) and became inactive in 1956. The waste in the vault was difficult to handle so the vault was jetted with high-pressure steam in 1976. The 244-BXR Vault was used to process sludge in the recovery of uranium from bismuth phosphate metal waste in the tanks (Rodenhizer, 1987).

The 244-CR Vault, constructed in 1952, is located south of the C Tank Farm (Leach and Stahl, 1993). Salt-well waste from the C Tank Farm is interimly stored in the CR Vault. The 244-CR Vault was used to process sludge in the recovery of uranium from bismuth phosphate metal waste in the tanks (Rodenhizer, 1987)

\section{4-AR and 204-S Railroad Car Facilities}

The 204-AR rail car unloading facility built in 1981 (Leach and Stahl, 1993), replaced the 204-S rail car unloading facility. The facilities were built for pumping liquid radioactive waste from tank cars and sending the waste to 200 East Area tank farms (Leach and Stahl, 1993).

\subsubsection{Time Lines}

Time lines presented on the following pages represent many of the events that occurred during the history of the major plants and waste management operations on the Hanford Site. These are the same events as those described in the description of each facility. The plants, associated processes, and methods for managing waste are the main sources of the wastes stored in the tanks. Abbreviations are defined in the preceding text and in the glossary in Appendix A.

One time line represents the history of each of the tank farms in the Southwest Quadrant of the 200 West Area (Figure 6). The events represented include the dates of construction, the individual tank's entry into service and removal from service, and the deactivation of each tank farm. 


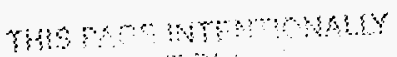

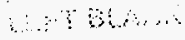




\section{PLANTS / PROCESS - TIME LINE}

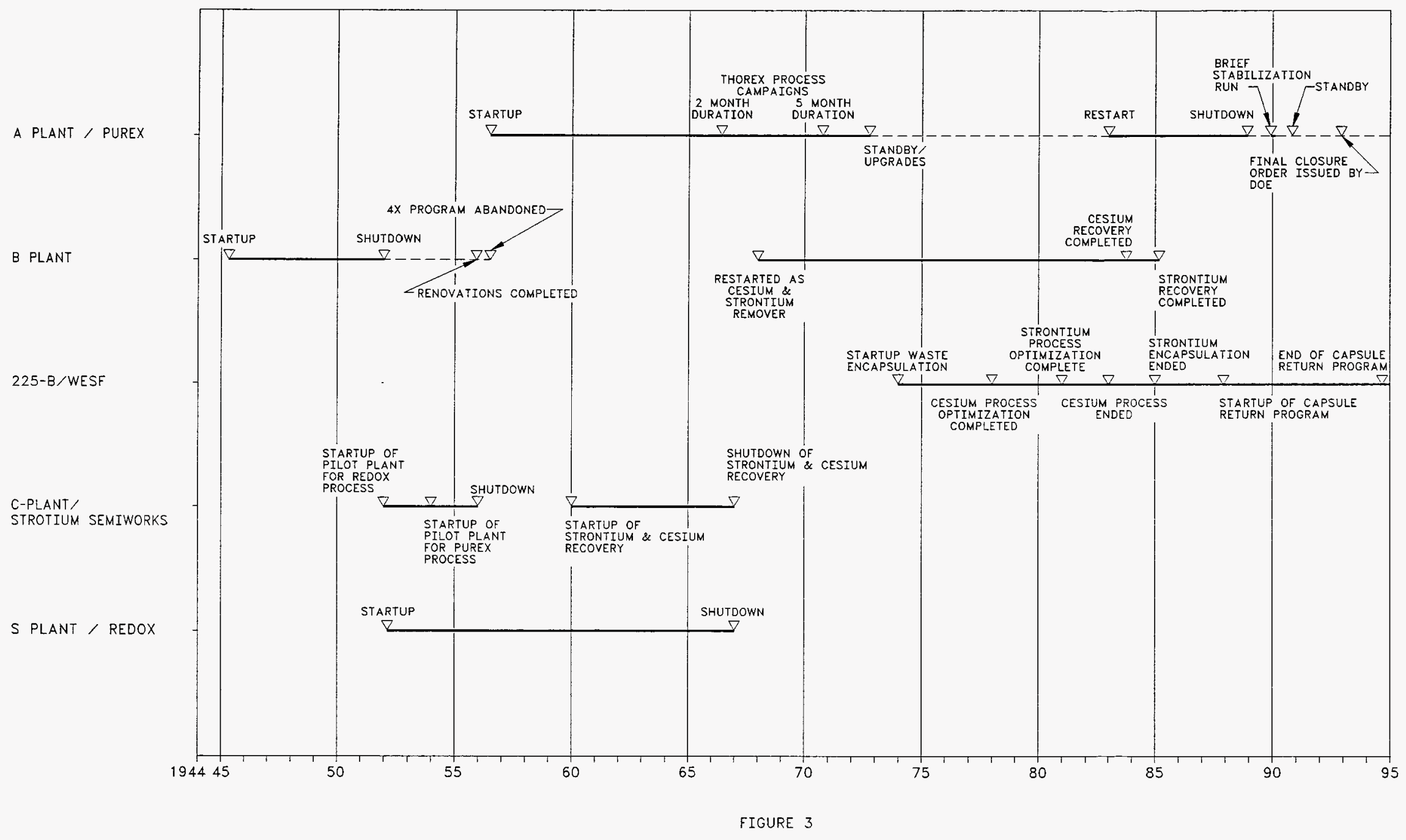




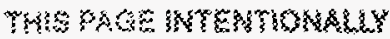

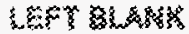




\section{PLANTS / PROCESS - TIME LINE}

T PLANT

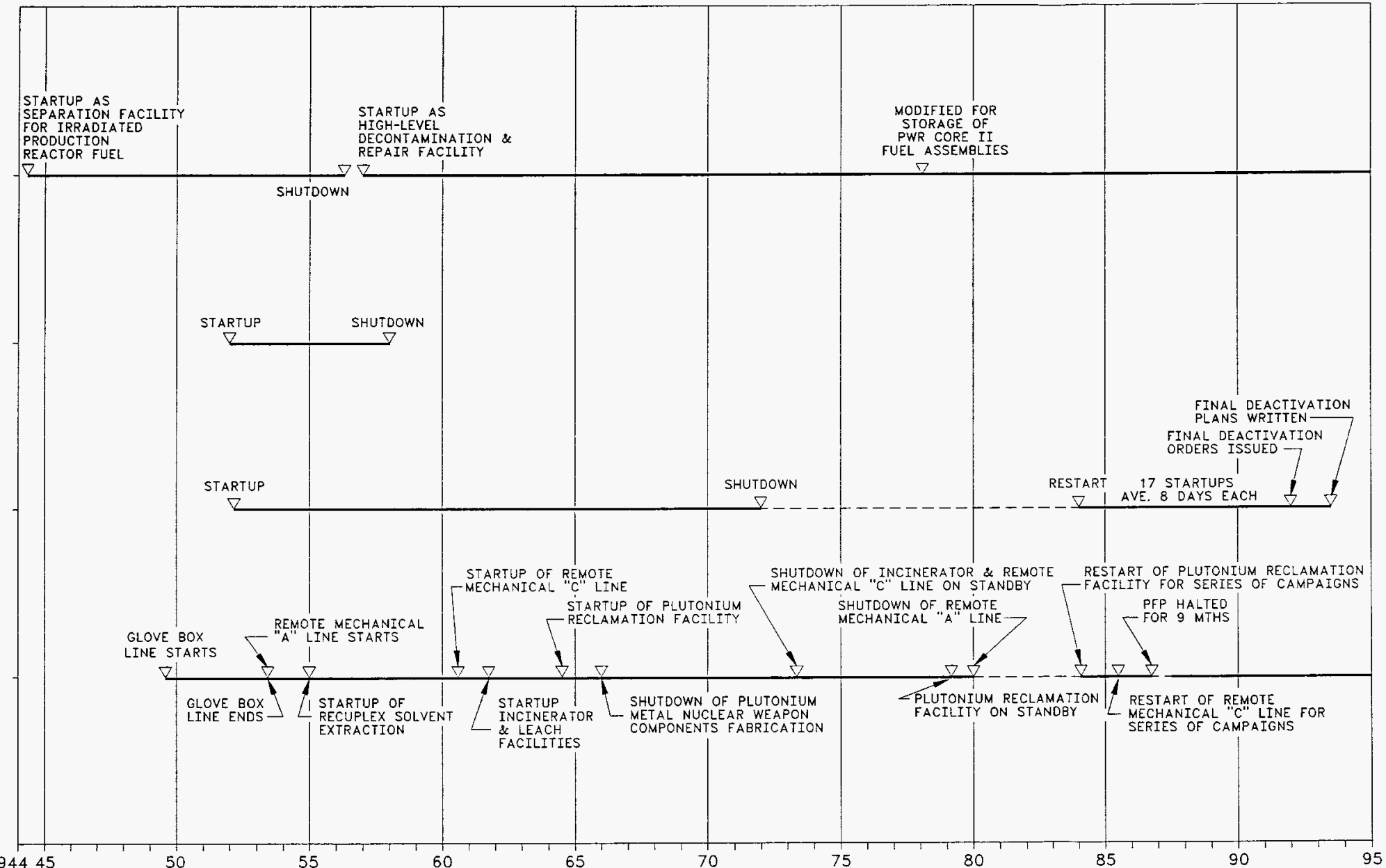

Z PLANT/

(PFP PLUTONIUM

FINISHING PLANT)

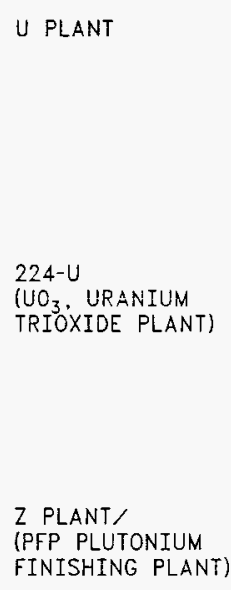

FIGURE 4 


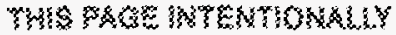

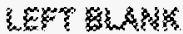




\section{WASTE MANAGEMENT - TIME LINE}

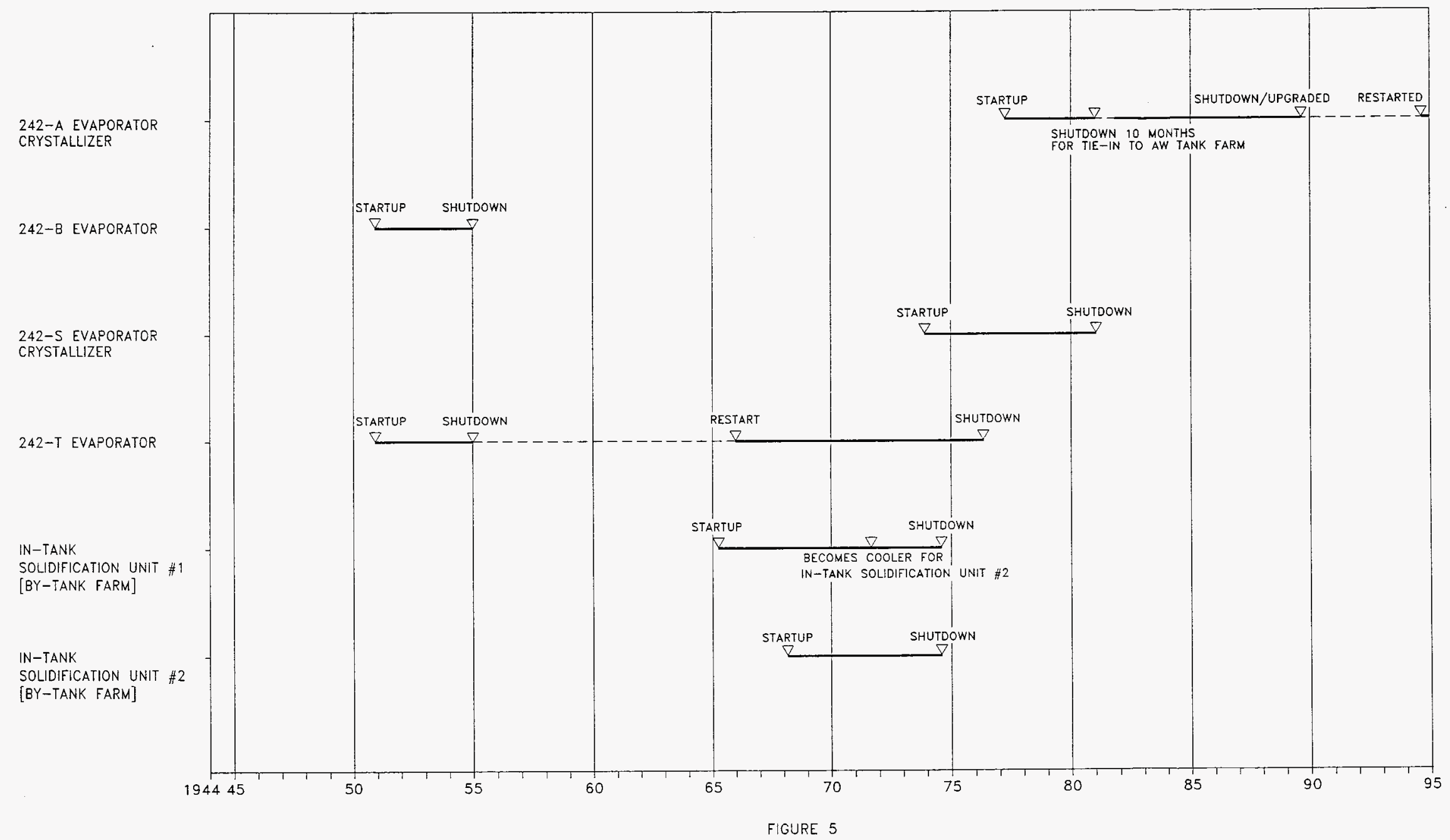




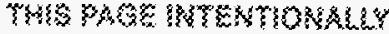

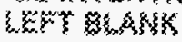




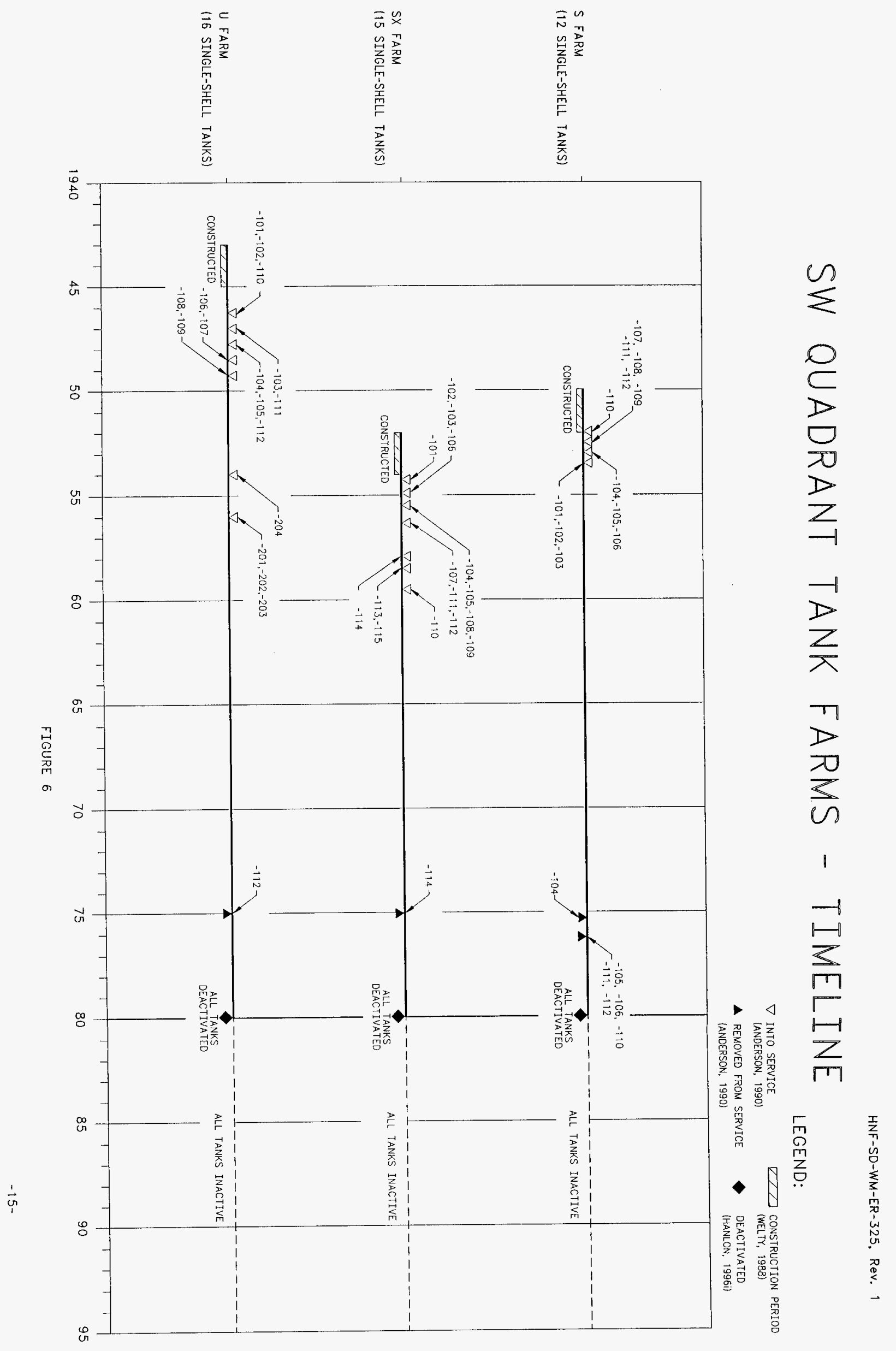


THS PASE KEMTOSALYY SEF MANK 


\subsection{Waste and Level History}

The Waste and Level History section is presented by a combination of two methods and is represented by sketches shown in Appendix C. The first method presents a graph of waste levels versus time for each tank. The waste levels graphed include the total waste level, solid waste level and, when available, the interstitial liquid level. The waste level graphs also include information on transfers, stabilization, intrusion prevention (isolation), salt-well and jet-pumping activities, level adjustments, $\mathrm{pH}$, photographs, and a few other miscellaneous items. The second method presents a time line that is made up of two parts. One part of the time line shows how the classification of the waste has changed for each tank and the other part of the time line shows the different waste types that were added to each tank. The time line and the waste level graphs for a given tank have been arranged so that the time axis for each method correlates with one another.

\subsubsection{Source of Data}

The references used to create the total waste level graph and the solid waste level graph for each level history graph are listed below in chronological order beginning with the oldest documents. Anderson (1990) was the source used for level information from when the tanks entered service until the end of 1980. Level information from 1981 to the present was taken from a series of documents that basically contain the same type of information. These documents have been given various titles over the years but they all reflect the monthly waste status (i.e., waste volumes) for all the tanks. Beginning in 1981, these "monthly waste status reports" have been authored by the following people: O. C. Mudd; O. C. Mudd and D. C. McCann; D. C. McCann; D. C. McCann and T. S. Vail; T. S. Vail; T. S. Vail and G. D. Murry; T. S. Vail and G. J. Carter; G. J. Carter; G. A. Escobar; J. M. Thurman; and B. M. Hanlon. The last "monthly waste status report" reviewed was for June 30, 1996 (Hanlon, 1996i). See Appendix B for more complete reference information. All monthly waste status reports after January 1981 were included in the references.

The reference for the interstitial liquid level (ILL) graph for the applicable level history graphs is from Lockheed Martin Hanford Corporation's Surveillance Analysis Computer System (SACS), formerly maintained by Westinghouse Hanford Company. SACS is a database that stores $\Pi L L$ data along with other types of surveillance data. PCSACS software on a personal computer is the user interface to the SACS database via the Hanford Local Area Network (HLAN). The SACS database was queried back to 1950 for ILL data.

The only reference for the transfer information is Anderson (1990). Anderson contains information for all the tanks through 1980. Transfers that may have occurred after 1980 have not been identified on the Waste and Level History sketches. For more transfer information not included in this document, see Waste Status and Transaction Record Summary for the Southwest Quadrant (Agnew et al., 1995).

The reference for stabilization information is Hanlon (1996i).

For tanks that were intrusion prevented before June 1988, the reference is Welty (1988). For tanks that were intrusion prevented after June 1988, the references are various monthly waste status reports. For more complete reference information on intrusion prevention after June 1988, refer to 


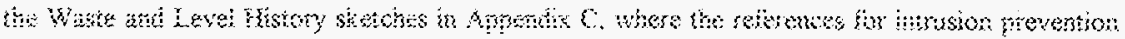
have besm jumbersod.

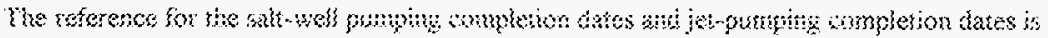

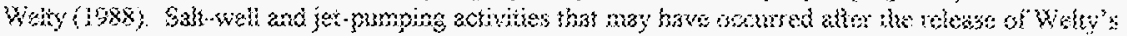

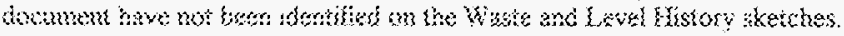

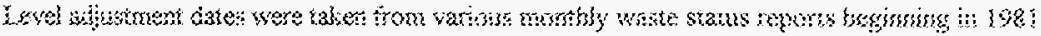

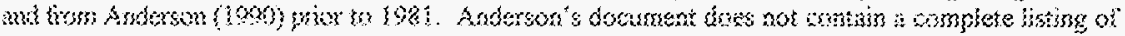

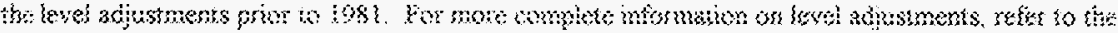

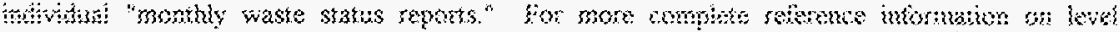

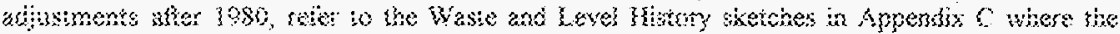

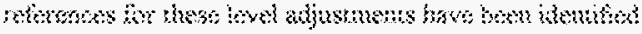

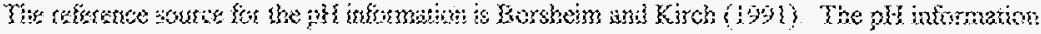

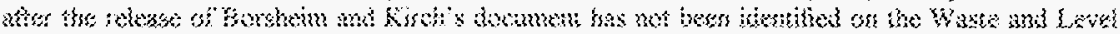
browery stophs

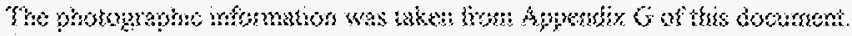

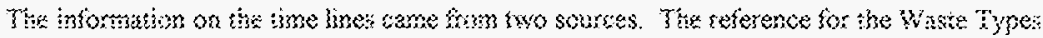

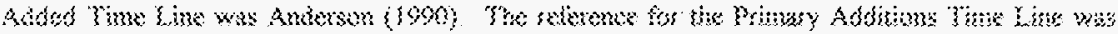

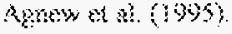

\subsection{Dexaloprent of Mata}

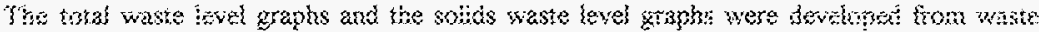

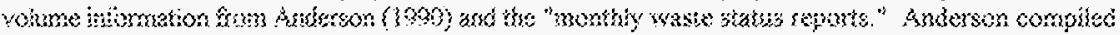

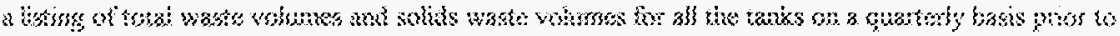

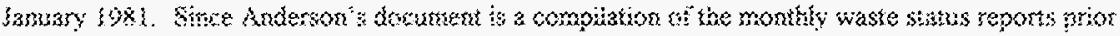

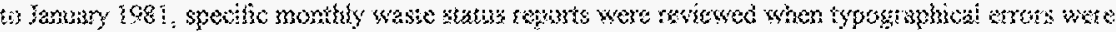

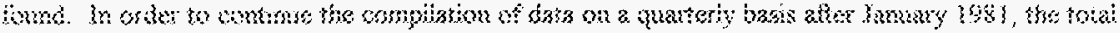

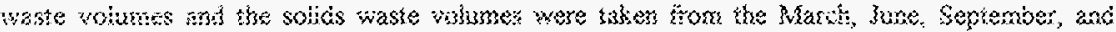

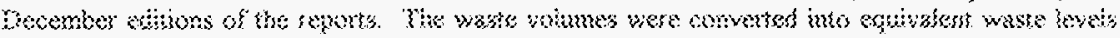

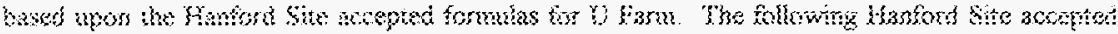

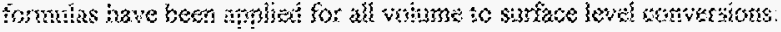

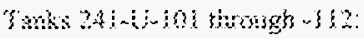

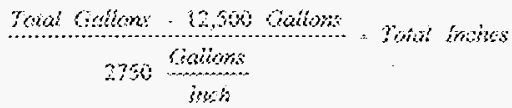


Tanks 241-U-201 through -204:

$$
\frac{\text { Total Gallons }-590 \text { Gallons }}{196 \frac{\text { Gallons }}{\text { Inch }}}+6 \text { inches }=\text { Total Inches }
$$

The " 0 " reference point for the total waste levels and the solids waste levels for tanks 241-U-101 through -112 is at the bottom of the knuckle, inside of the tank. This places the " 0 " reference point 12 inches above the bottom of the tank. The " 0 " reference point for the total waste levels and the solids waste levels for tanks 241-U-201 through -204 is at the bottom inside of the tank. The waste levels have been rounded to the nearest thousand gallons (Kgal). In the event that the total waste level and the solids waste level were the same, the reported volumes were reviewed to determine whether the reported volumes were the same. If the volumes were the same, only the solids level was graphed. If the volumes were not the same, then both the total waste level and the solids waste level were graphed. The quarterly waste volumes and associated waste levels have been arranged in tables and are titled the "Level History" tables. These tables were developed within Microsoft Excel ${ }^{\star}$ and are presented in Appendix C.

The interstitial liquid within the tanks is the liquid that fills the interstitial spaces of the solid waste. The supernatant liquid within the tanks is located above the solid waste. Once the supernatant liquid has been removed from the tanks, the liquid that remains is the interstitial liquid. The interstitial liquid level (ILL) in most tanks is unknown unless a liquid observation well (LOW) was installed. The LOW allows access for instrumentation to record ILL. The ILL graphs were developed from ILL data retrieved from SACS, that were imported into Microsoft Excel ${ }^{\circ}$ spreadsheets. The SACS database custodians labeled the IL data either as good or suspect. Only the data labeled as good were used for the ILL graphs. The SACS data that were labeled as good were reviewed on a quarterly basis. The quarters were set to match the quarterly system set up for the monthly waste status reports (i.e., the last month for each quarter was March, June, September, and December). The last data reading available from each quarter was the data reading used for the ILL graphs. The data from SACS have been rounded off to the nearest whole number. The "0" reference point for the SACS LL data is the bottom inside of the tank. The reviewed quarterly $I L L$ data were added to the appropriate quarter in the Level History tables presented in Appendix C.

The total waste level graphs, the solids waste level graphs, and the interstitial liquid level graphs were all created within AutoCAD ${ }^{3}$. In order to expedite the creation of these graphs, script files were generated from the information contained within the Level History tables. The script files were generated by arranging the waste level information and the corresponding dates from the Level History tables into a Cartesian coordinate system (i.e., $x, y$ coordinates). The script files allowed AutoCAD to automatically generate the graphs on the Waste and Level History sketches.

Transfer information was taken from the "Remarks" column of the Waste Status Summary tables in Anderson (1990). Transfer information was available on a quarterly basis. However, due to the scale of the time axis on the Waste and Level History sketch, the transfer information was placed near the total waste level graph corresponding to the appropriate year. Because of space limitations on the 


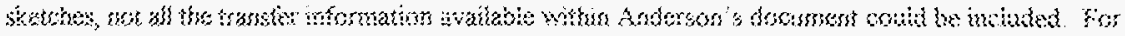

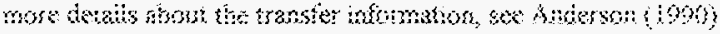

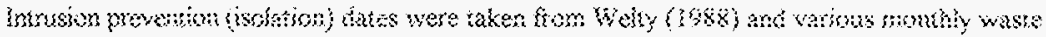

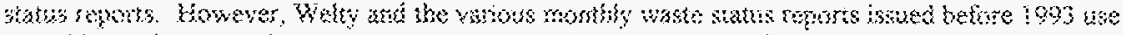

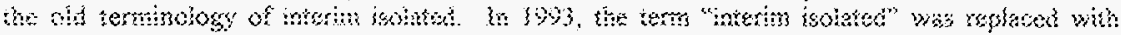

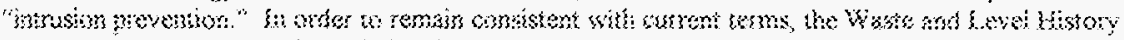

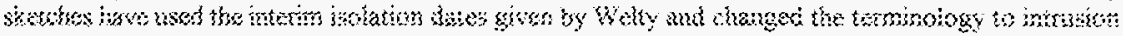
prevention

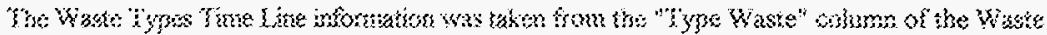

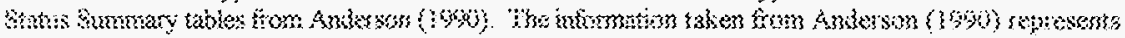

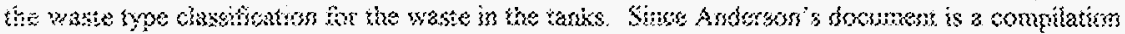

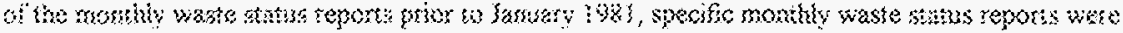

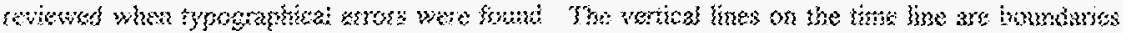

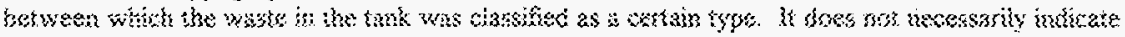

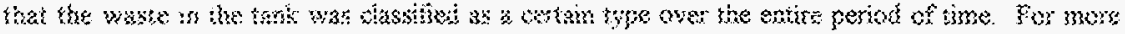

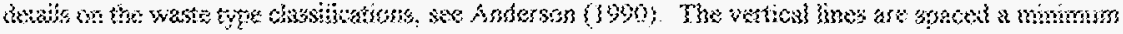
th niwe yesrs spart.

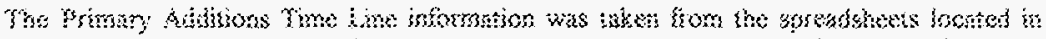

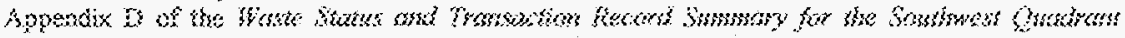

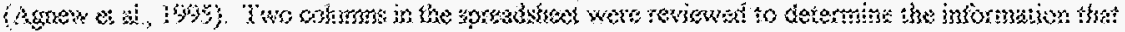

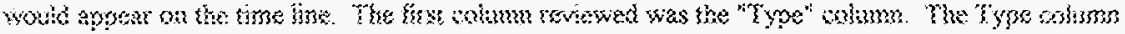

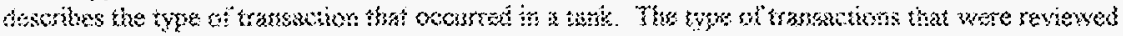

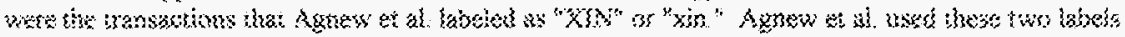

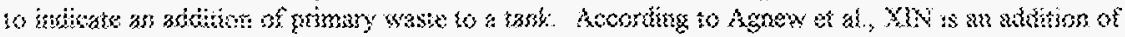

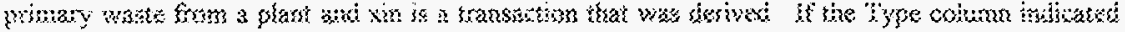

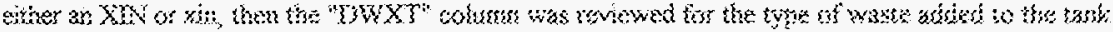

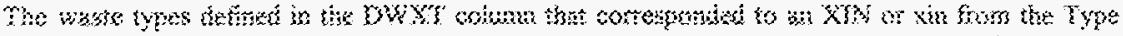

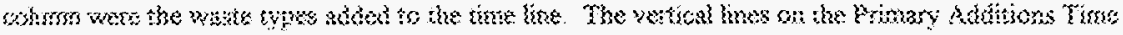

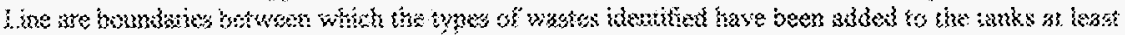

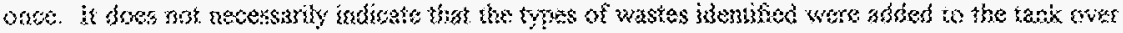

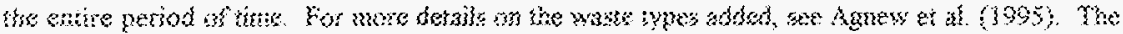

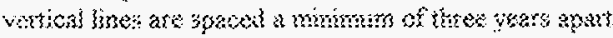

\subsection{S.sinuptions}

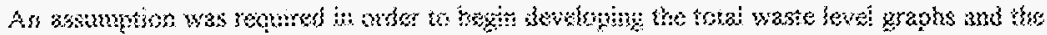

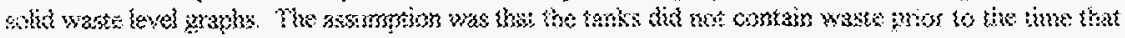

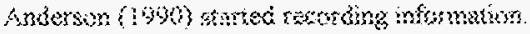

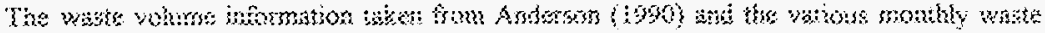

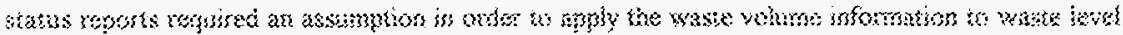

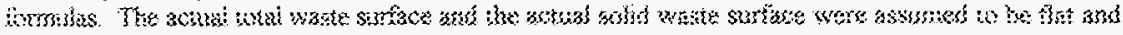
istoit 
The total waste level graphs and the solid waste level graphs required an assumption in order to make complete graphs. There were many cases within the Waste Status Summary tables (Anderson, 1990) where the tables lacked waste volume information for one or more consecutive quarters. When these omissions occurred, it was assumed that the waste volume followed an increasing, decreasing, or horizontal linear trend across these quarters for which Anderson lacked the volume information. Because of the linear nature of the waste-volume-to-waste-level formulas used to convert waste volumes into waste levels, a linear trend in the volumes resuits in a linear trend in waste levels on the Waste and Level History sketches.

The solid waste level graphs required an assumption about the time period when the tanks began receiving waste. Information on the solids volume was not recorded in the Waste Status Summary tables (Anderson, 1990) until well after the tanks started receiving waste. The first accumulation of solids within the tanks was not apparent from information by Anderson. An assumption was made that the first accumulation of solids within each tank followed an increasing linear trend. The first accumulation of solids was also assumed to begin accumulating when the tank first started receiving waste.

\subsubsection{Quality of Data}

The total waste level graphs and the solids waste level graphs on the Waste and Level History sketches were developed by using the Hanford Site accepted waste-volume-to-waste-level formulas. However, there are some limitations with the formulas that affect the waste level results. The formulas do not yield realistic results when the waste volume is less than the volume that can be held below the top of the tank knuckle. The formulas do not account for construction tolerances on the tanks, the knuckle geometry on the tanks, the true geometric configuration of the tanks, and the irregularities in the surface of the solid wastes.

The total waste level graphs were developed from the volume data from Anderson (1990) and from the "monthly waste status reports." The frequency with which these references have their volume information updated is not consistent with the frequency with which the waste surface level readings of the SACS database are updated. Therefore, a discrepancy may be noticed between the total waste level graphs of the Waste and Level History sketches in Appendix C and the waste surface level graphs in Appendix $\mathrm{E}$.

The interstitial liquid level (ILL) graphs were developed from data contained within the SACS database. The SACS custodians have qualified the data as either good or suspect. Only the data labeled as good have been plotted. However, for some tanks, the ILL data plotted showed that the ILL exceeded the total amount of waste as plotted from the total waste level data. This situation is a contradiction to the definition of interstitial liquid. Even though the SACS custodians have labeled the data as good, the data quality seems questionable. The questionable data were graphed anyway. It was not the function of this document to judge or qualify the ILL data nor to discuss in detail this situation. 


\section{i.: Temperatuet}

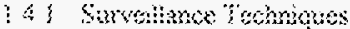

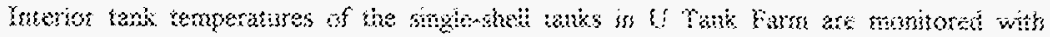

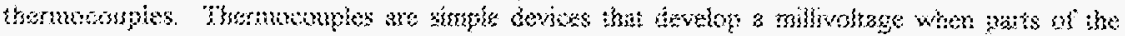

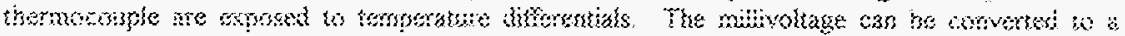

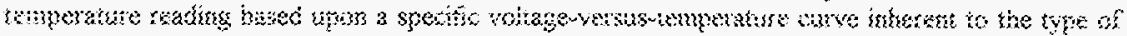

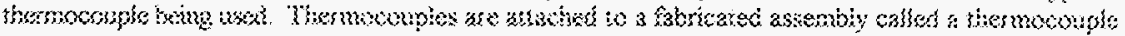

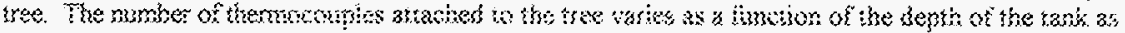

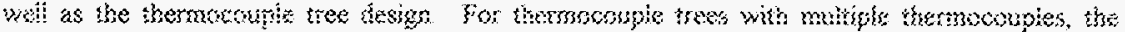

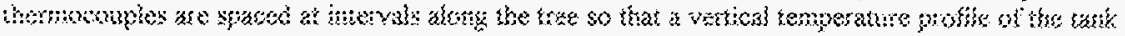

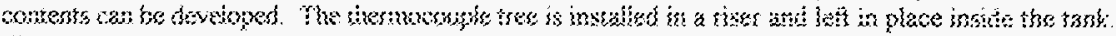

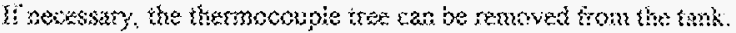

\section{i.4. Srawe of abs}

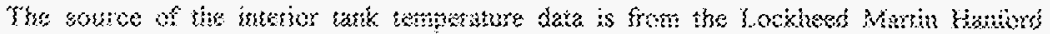

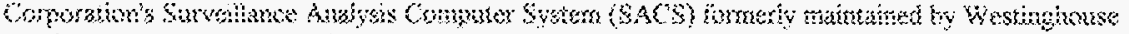

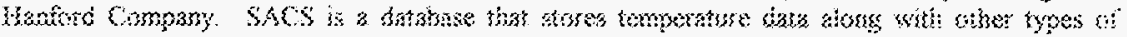

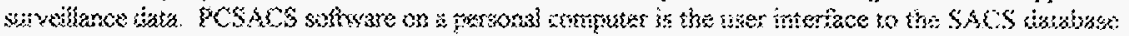

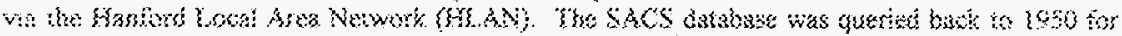

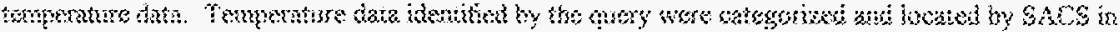

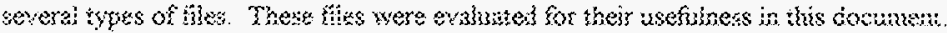

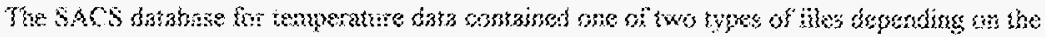

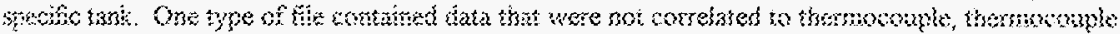

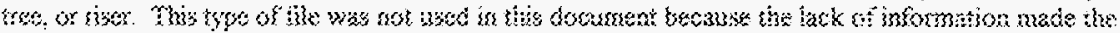

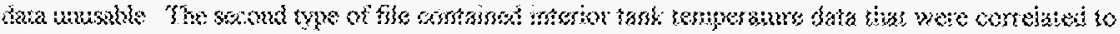

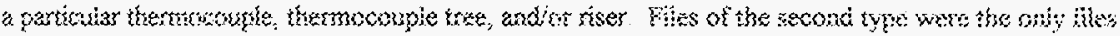

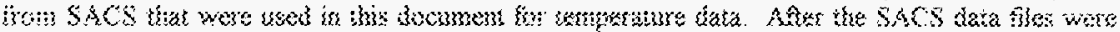

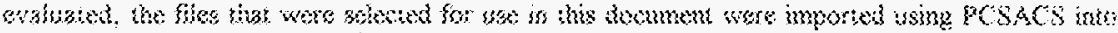
streabheors in Microsor Exce ${ }^{3}$ nothwase

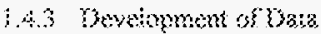

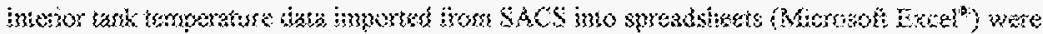

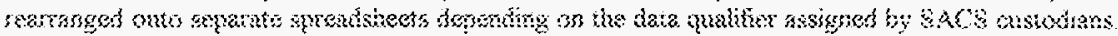

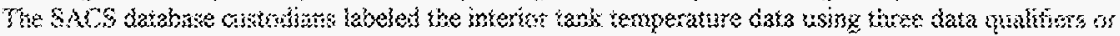

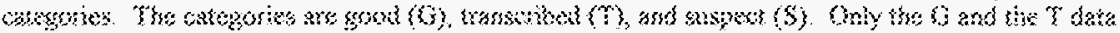

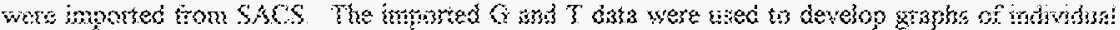

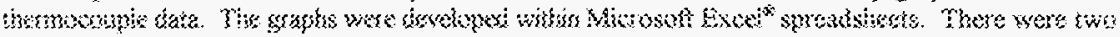

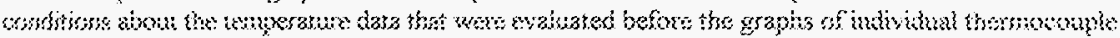

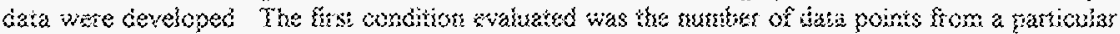

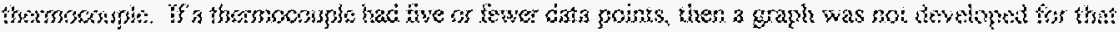

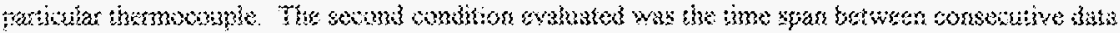


points. If the time span between consecutive data points was greater than 36 months, then the graph was shown as discontinuous across the span (see Appendix D).

The thermocouple elevations identified on the individual thermocouple graphs were determined from design drawings listed in the narratives and from the Thermocouple Status Single Shell and Double Shell Tanks (Tran, 1993). Tran's document contains design drawing references along with thermocouple elevations. If the design drawings listed in Tran's document could be verified for the individual tanks, then the thermocouple elevations listed by Tran were used. If the design drawings listed in Tran's document could not be verified for an individual tank or if design drawings could not be located, then the thermocouple elevations were labeled as unknown. If Tran's document lacked information about thermocouple elevations for a particular tank and design drawings were located, then the thermocouple elevations were labeled as approximate.

Undocumented, as well as some documented, changes and/or modifications to the thermocouple tree designs may have occurred at some tanks. Consideration of these changes and/or modifications, however, depended on whether proper documentation on the change and/or modification was located. Proper documentation of a change and/or modification is documentation that has been recorded and filed with the appropriate Hanford Site document control stations. If proper documentation of a change and/or modification could not be located, then the changes and/or modifications were not considered.

\subsubsection{Assumptions}

The transcribed data points are data points that have not been verified or validated by Lockheed Martin Hanford Corporation (or by Westinghouse Hanford Company). Transcribed data were assumed to be good data and were included on the graphs of individual thermocouple data and in the statistics. Individual judgements were not made on particular transcribed data points even though they had a high probability of being suspect. Verification and/or validation of data is not the function of this document.

The design drawings listed in each of the tank temperature narratives are assumed to be the design drawings that reflect the thermocouple tree design considered in this document.

\subsubsection{Quality of Data}

The quality of the interior tank temperature data is noted by the three category labels assigned by the custodians of the SACS database. The good and suspect data points have been verified and/or validated by Lockheed Martin Hanford Corporation (or by Westinghouse Hanford Company, the previous contractor). The transcribed data points have not been reviewed by Lockheed Martin Hanford Corporation (or by Westinghouse Hanford Company). The transcribed data could be classified as either good or suspect at a later date.

This document has treated the transcribed data as good data. However, an area where the transcribed data points have a high probability of being suspect is when the temperature data values are below 45 to $50^{\circ} \mathrm{F}$. The approximate temperature of the soil surrounding the tanks is 45 to $50^{\circ} \mathrm{F}$ and the soil will prevent the temperature of the tank from dropping below this point. Some of the tanks have many data points below the 45 to $50^{\circ} \mathrm{F}$ range, and these data points should be evaluated carefully as to whether or not they should be considered as good data points. 


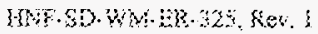

\section{Whate Sustace Level}

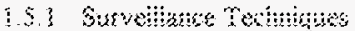

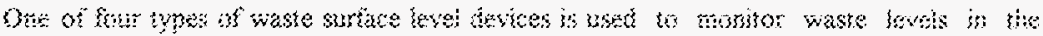

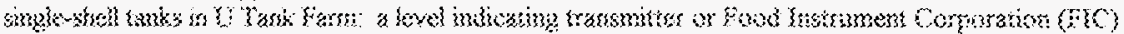

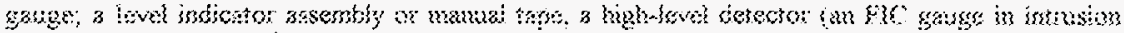

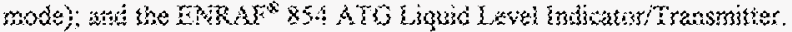

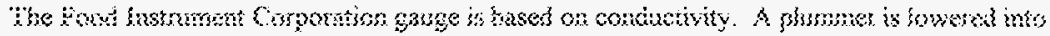

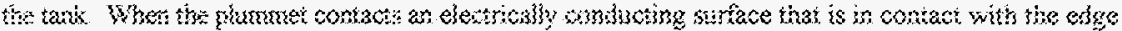

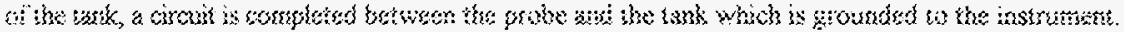

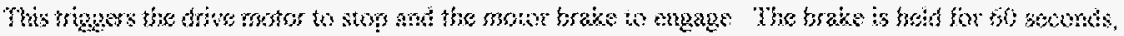

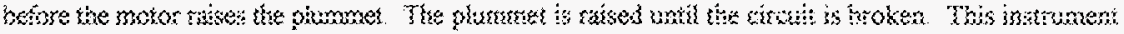

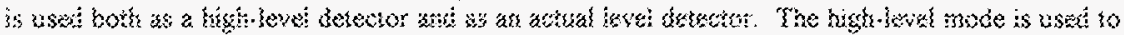

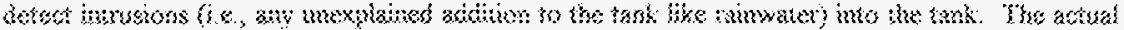

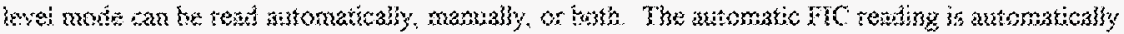

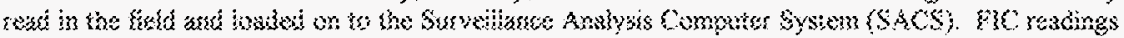

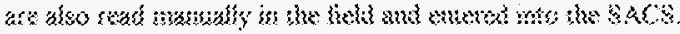

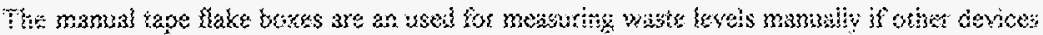

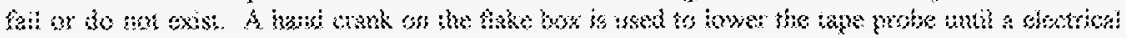

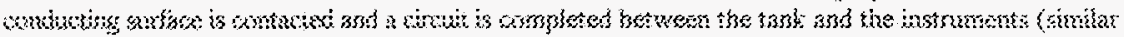

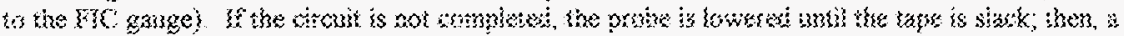

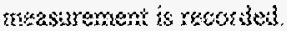

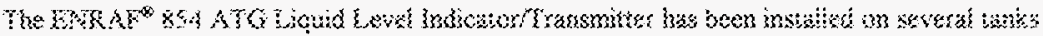

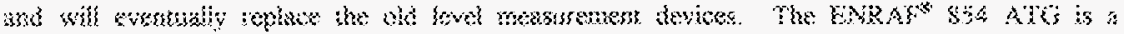

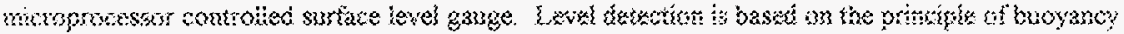

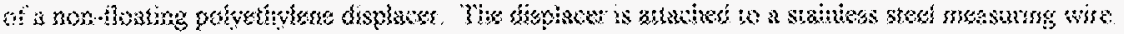

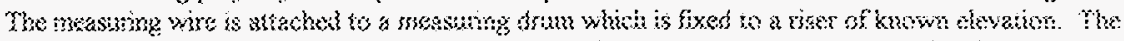

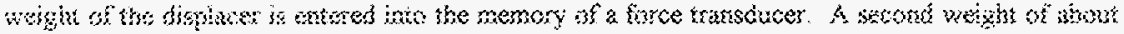

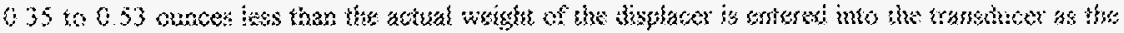

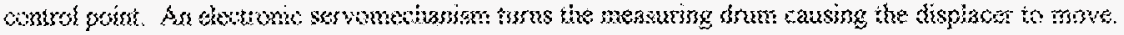

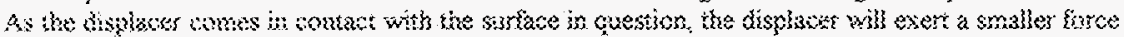

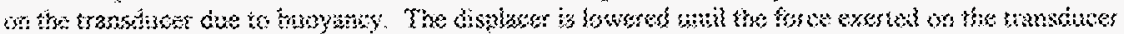

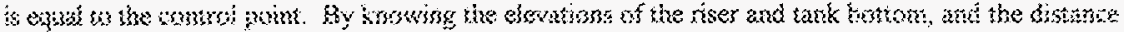

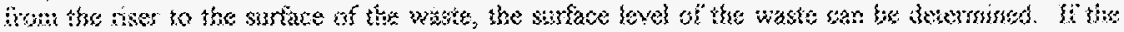

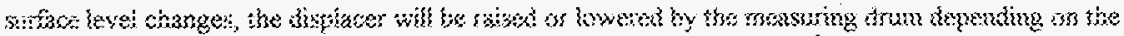

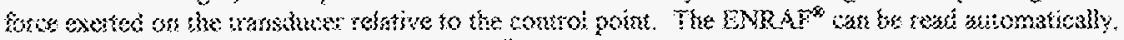

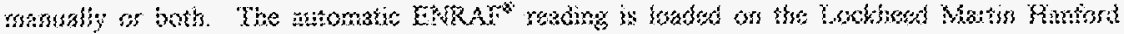

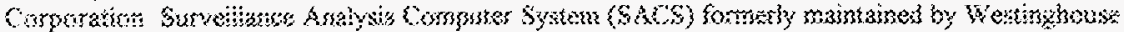

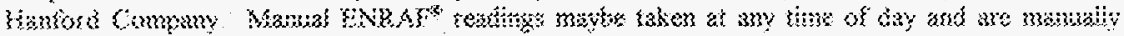
sweres mothe $\$$ ACS. 


\subsubsection{Source of Data}

The data recorded from January 1, 1991, to October 14, 1996, for the waste surface levels were obtained from the SACS database. PCSACS software on a personal computer is the user interface to the SACS database. The information was parsed in a spreadsheet in Microsoft Excel ${ }^{\bowtie}$ software and displayed on graphs. Since the intrusion FIC is fixed at a certain elevation, it only records that elevation unless there is an unexplained addition. The device does not truly measure the waste surface level so the data were not displayed.

\subsubsection{Development of Data}

Waste surface level data imported from the SACS database into spreadsheets (Microsoft Excel ${ }^{\infty}$ ) were rearranged onto separate spreadsheets depending on the data qualifier assigned by SACS database custodians. The SACS database custodians label the waste surface level data using three data qualifiers or categories. The categories are good $(\mathrm{G})$, transcribed $(\mathrm{T})$, and suspect $(\mathrm{S})$. The waste surface level data were then filtered to remove all the $S$ data, leaving only the $G$ and $T$ data. All devices with good or transcribed data, were graphed on one graph to show the possible measurement differences between devices. If the tank has more than one device to measure the waste surface level, an individual graph was made to display the data from each device. The graphs show waste level versus time. The data are displayed using the best representative scale on the y axis. The safety limit maximum waste level is placed in the title of each graph (Dougherty, 1995). The current information on the waste surface levels is in Appendix E. The maximum and minimum waste surface levels, along with the respective dates, are summarized in each tanks Current Status Section.

\subsubsection{Assumptions}

The data obtained from PCSACS are the best available data. The data quality designation, instrument type, and level measurement are accurate. The devices are in good condition and give accurate readings if the following assumptions are made: internal tank temperature changes do not cause the tape, wire, or probe to change length; the tape, wire, and probe are straight; the surface profile of the waste is flat; and changes in atmospheric temperature do not affect the portions of the measuring device exposed to the atmosphere.

\subsubsection{Quality of Data}

Waste surface level readings may be affected by plummet (i.e., manual tape) error, flushing water accumulation, waste surface irregularities, or gas generation. Crystalline wastes (i.e., salt cake) can build up gradually on the end of the plummet and contact the waste which indicates a false surface level increase. Significant level discrepancies occur when the encrusting waste breaks off or when the measuring instrument plummet is flushed to remove the encrusting salt cake. Flushing the FIC gauge, manual tapes, or any other equipment may cause accumulated wash water to collect under the plummet which can also indicate a false increase in the overall volume of waste within the tank. Waste surface level readings are often difficult to obtain from tanks with a relatively dry waste surface of salt cake. Some tanks have crystalline waste built up on internal tank equipment (e.g., pumps, thermocouples, and other protruding equipment). As the supernatant liquid is pumped from the tanks, the crystalline structure may remain attached to the equipment and be suspended above the liquid. Therefore, an accurate waste surface level measurement would be difficult if the breakup of the crystalline structure 


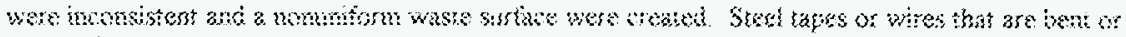

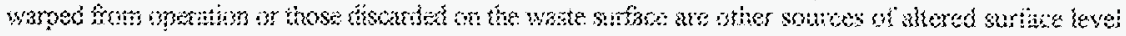
radirress

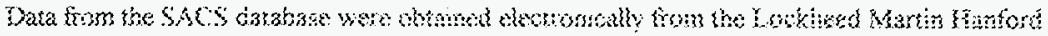

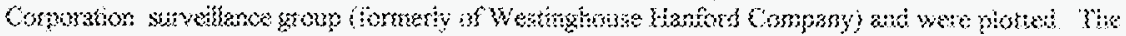

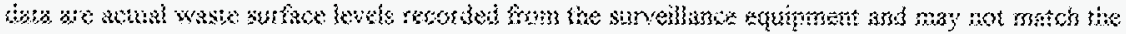

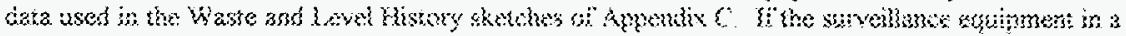

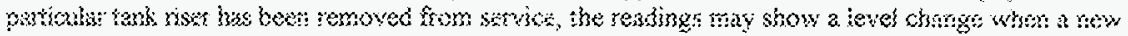

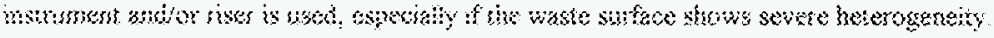

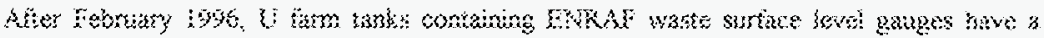

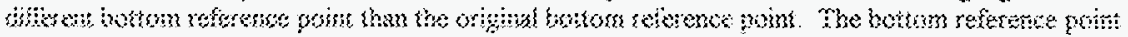

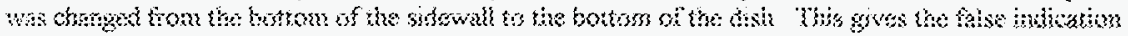
of a 12 inctim incense in waste.

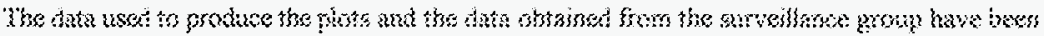

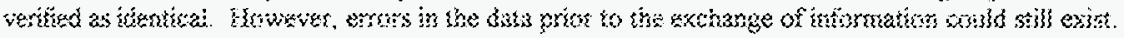

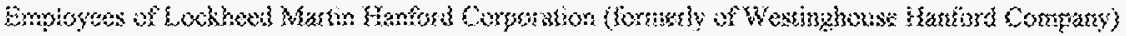

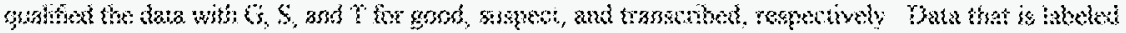

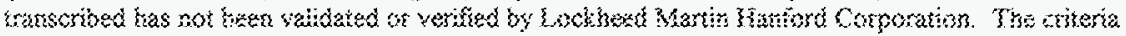

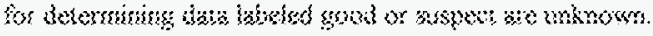

\section{I6 Wiser Configuration}

\section{(6) Sumos of}

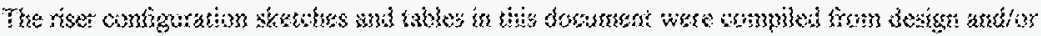

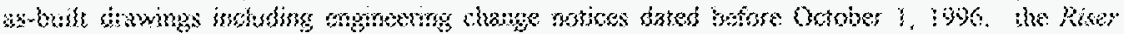

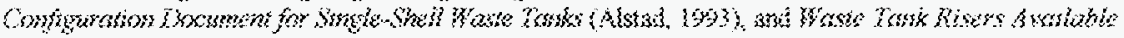

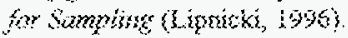

\section{in Deweigment ot $\mathrm{ghn}$}

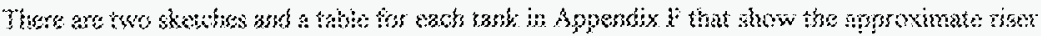

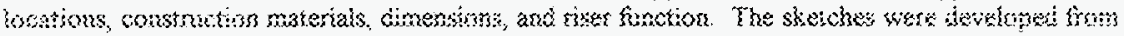

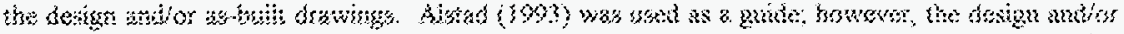

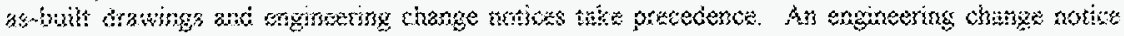

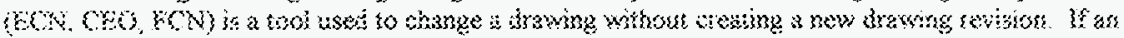

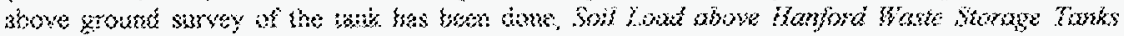

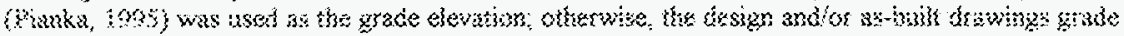

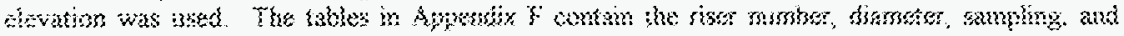

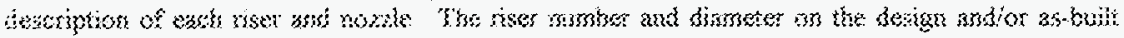

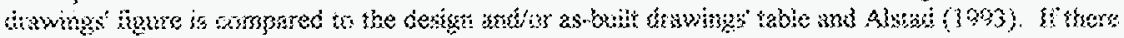

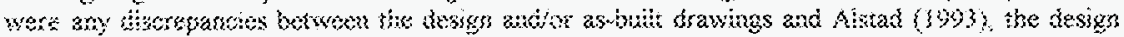

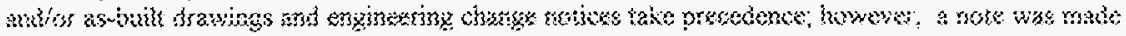

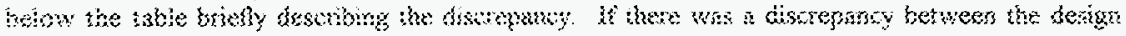


and/or as-built drawings' figure and the design and/or as-built drawings' table, a note was made below the table briefly describing the discrepancy. The sampling column lists risers that are tentatively available for sampling (Lipnicki, 1996). The description and comment column describes the riser's intended use and, if applicable, gives in parentheses the date, number and a brief explanation of the pertaining engineering change notices. The intent of the description and comment column was to provide a historical use of the riser along with providing the current use of the riser.

\subsubsection{Assumptions}

The design and/or as-built drawings are the best available data. All the engineering change notices written against the referenced drawings are released and accurate. Since figures or sources were not listed in Lipnicki (1996), the riser numbers labeled tentatively available for sampling are assumed to be the same as the riser numbers listed in Alstad (1993).

\subsubsection{Quality of Data}

The riser configuration section of this document is a mixture of data from three main sources: design and/or as-built drawings, Riser Configuration Document for Single-Shell Waste Tanks (Alstad, 1993), and Waste Tank Risers Available for Sampling (Lipnicki, 1996). The three sources do not always agree. Alstad (1993) and Lipnicki (1996) reference the design and as-built drawings in their respective documents. The design and/or as-built drawings contain a plan view of the tank dome and a table explaining the function of each riser. Sometimes the plan view and the table do not match. If there was a discrepancy, a comment was made below the table for that tank. Other design and/or as-built drawings show a cross-sectional view of the tank. Changes made to the structure of a tank may not have been documented by an engineering change notice. The sketches and tables are intended to give the reader information as to: approximate location of risers and equipment; approximate dimensions; construction material; diameter of risers; number of risers; and what equipment each riser might contain. The sketches are not to scale

\subsection{Photographs and Montages}

\subsubsection{Source of Data}

The photographs include an aerial photograph of the tank farm and a photographic montage of each tank interior, if available (see Appendix G). All of the photographs were obtained from Boeing Computer Services Richland-Photography (now Lockheed Martin Services, Inc.-Photography). The aerial photographs were reviewed in January 1996 to determine the clearest and most recent representation of the $U$ Tank Farm to be used in this document. The montages were created from sets of interior tank photographs. These sets were also reviewed in January 1996 to determine which ones were the clearest and most recent photographs available. Only interior tank photographs representing the waste surface were used. In some cases, existing montages were the clearest and most recent; therefore, a new montage was not created.

\subsubsection{Development of Data}

The tank farm aerial photograph was labeled to show tank orientation, identifiable equipment, and structures. Arrows were placed on the tank farm aerial photograph to indicate the cascade 


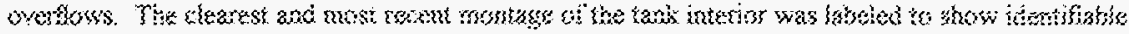

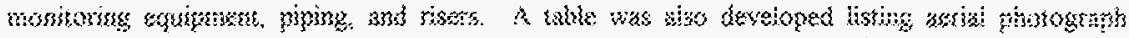

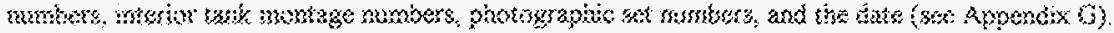

\section{7 .3 Quality stoma}

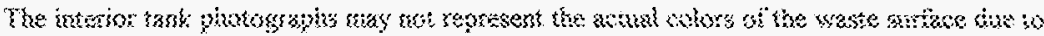

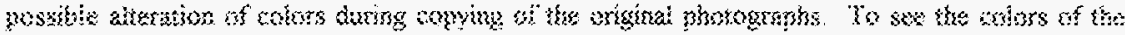

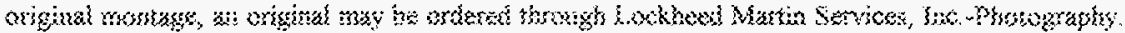

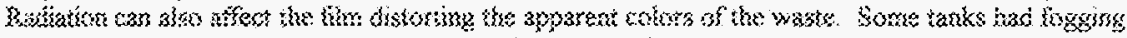

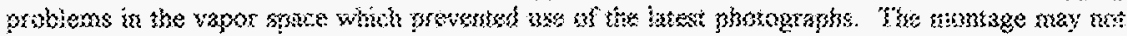

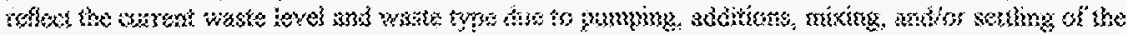

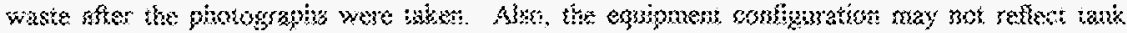
warades ation tatintance.

\section{I艹 Exventory Esimute:}

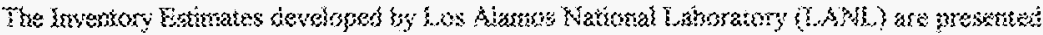

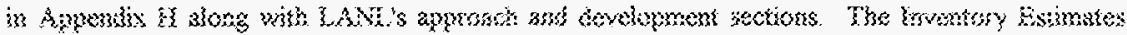

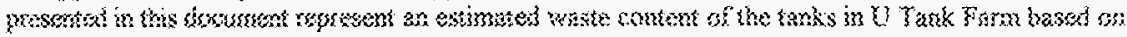

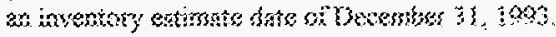

\section{S: Srubce of Datis}

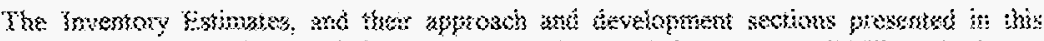

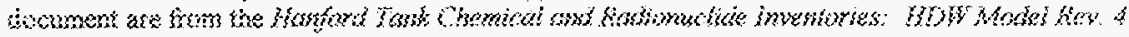

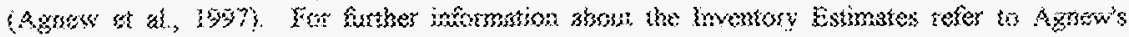
coounert.

\section{L.S.2 Gewelopment oi $\mathrm{O}$ ais}

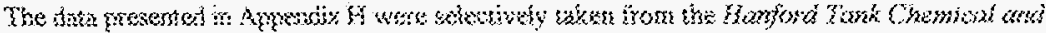

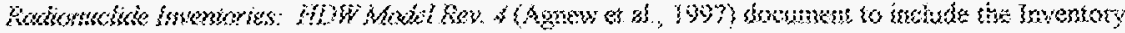

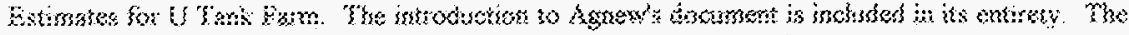

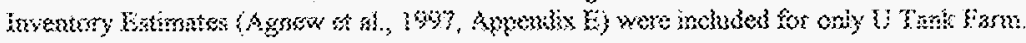




\subsection{U Tank Farm}

\subsubsection{U Tank Farm Information}

The U Tank Farm is located west of Camden Avenue and north of 14th Street in the 200 West Area. The farm contains twelve 100 series and four 200 series, dish bottom design, single-shell tanks built in 1943 and 1944 (Welty, 1988). The 100 series tanks are 75 feet in diameter with an operating capacity of 530,000 gallons (Hanlon, 1996i) (see sketches in Appendix F). The 200 series tanks are 20 feet in diameter with an operating capacity of 55,000 gallons (Hanlon, 1996i). The tanks are constructed of a reinforced concrete shell with a steel liner on the interior bottom and sides. The tanks were designed to hold non-boiling waste at a maximum fluid temperature of $220^{\circ} \mathrm{F}$ (Leach and Stahl, 1993). The dome of each tank is penetrated by risers varying in diameter from 4 to 42 inches. All of the tanks have at least five and half feet of earth cover.

The twelve 100 series tanks were constructed with connecting overflow lines that allowed waste to cascade from tank to tank. The 200 series tanks are not connected by cascade lines. There are four cascade sequences in the U Tank Farm. One cascade sequence is from Tank 241-U-101 to -102 to -103. The second is from Tank 241-U-104 to -105 to -106 . The third is from Tank $241-\mathrm{U}-107$ to -108 . to -109 and the fourth is from Tank $241-\mathrm{U}-110$ to -111 to -112 .

\subsubsection{U Tank Farm Waste and Level History}

The Waste and Level History sketches in Appendix C present the waste history and level history of U Tank Farm.

\subsubsection{U Tank Farm Temperature History}

Interior tank temperature data for $U$ Tank Farm are quite limited compared to the span of time in which the tanks have been operating. Information about the various temperature monitoring devices and their locations throughout history is also quite limited. The information that was available came from the Surveillance Analysis Computer System (SACS) database. The SACS database had several types of temperature data files available. Data from the files were available as far back as mid 1975 .

\subsubsection{U Tank Farm Occurrences}

Only the occurrences determined as significant are included. The reports presented are incomplete because not all of the documentation on occurrences for $U$ Tank Farm could be located.

\subsubsection{U Tank Farm Current Status}

The tanks in U Tank Farm entered service from 1946 to 1956 (Anderson, 1990). The dates the tanks entered service are based on when the tank first received waste or test water. This date may vary in other documents. The total waste volume for all of the tanks is approximately $3,550,000$ gallons as of June 30, 1996. All tanks are out of service. Tanks 241-U-102, -103, -105, -106, -107, -108, -109, $-111,-201,-202,-203$ and -204 are categorized as sound, and Tanks 241-U-101, -104, -110, and -112 are assumed leakers. Tanks $241-\mathrm{U}-103,-105,-106,-107,-108,-109,-111,-203$ and -204 are on watch 


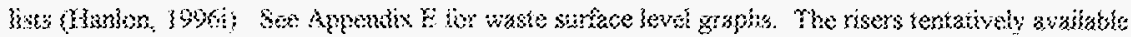

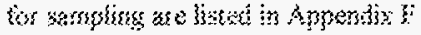

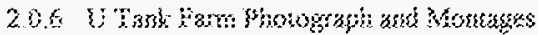

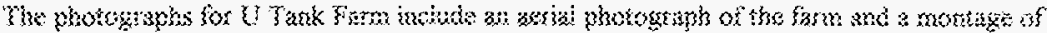

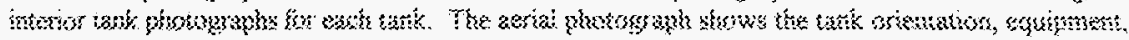

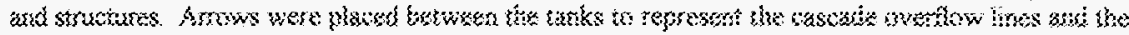

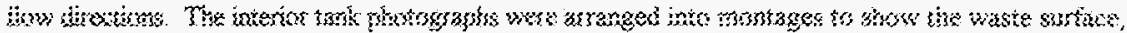

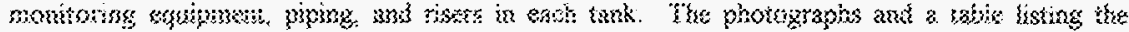

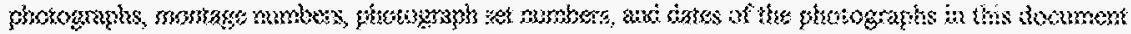
sise in Apperdix s.

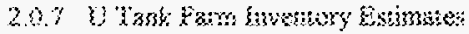

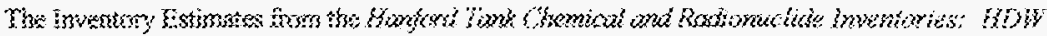

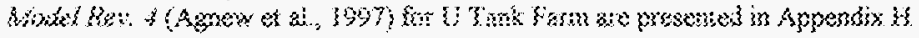




\subsection{Tank 241-U-101}

\subsubsection{Waste and Level History of Tank 241-U-101}

The Waste and Level History sketch in Appendix C presents the waste history and level history of Tank 241-U-101. Between May 1969 and June 1971 six cask loads of experimental fuel elements, shroud tubes and samarium"poison" ceramic balls were added to the tank (Welty, 1988).

\subsubsection{Temperature History of Tank 241-U-101}

Interior tank temperature data for Tank 241-U-101 were recorded by 11 thermocouples. Documentation of the design configuration of the thermocouple tree was not located. The design of the thermocouple tree is unclear and the elevations of the individual thermocouples are unknown. The Surveillance Analysis Computer System (SACS) indicates that the thermocouple tree is located in riser 2 . In the past, other risers and equipment may have been used to monitor the temperature in the tank. However, the thermocouple tree located at riser 2 is the only source of temperature data for this document.

The temperature data were obtained from the SACS database on October 2, 1996. The SACS database contained two file types for temperature data: a historical file and a file with temperature data tied to riser 2. Since there was no way to correlate the data in the historical file with a particular thermocouple, thermocouple tree, or riser, data from this file were not included in this document. Only data from the file that tied the temperature data to riser 2 were used in this document. The earliest data retrieved from SACS were from early July 1994.

Graphs of individual thermocouple data are presented in Appendix D. A graph was created for thermocouples 1, 2, and 10. Thermocouples 3-9 and 11 were not graphed due to lack of data. The following statistical information was taken from all 11 thermocouples. The maximum temperature was $71.6^{\circ} \mathrm{F}$ taken by thermocouple 1 on September 30,1996 . The minimum temperature was $59.72^{\circ} \mathrm{F}$ taken by thermocouple 10 on March 5, 1996. The maximum temperature is labeled as a transcribed data and the minimum temperature is labeled as a good data point within the SACS. The average temperature for all the thermocouples is $66^{\circ} \mathrm{F}$.

\subsubsection{Occurrences for Tank 241-U-101}

No significant occurrences are associated with Tank 241-U-101.

\subsubsection{Current Status of Tank 241-U-101}

Tank 241-U-101 entered service during the first quarter of 1946 (Anderson, 1990) and as of June 30, 1996, stores approximately 25,000 gallons of waste (Hanlon, 1996i). The minimum waste surface level was 3.25 inches on numerous dates from May 24, 1994 through July 27, 1995. The maximum waste surface level was 5.25 inches on September 27, 1996. See Appendix E for details on waste surface level. The tank is out of service with interim stabilization and intrusion prevention completed. The tank is listed as a assumed leaker and is passively ventilated (Hanlon, 1996i). A plan view in Appendix F depicts the approximate riser locations as of October 1, 1996. Tank 241-U-101 


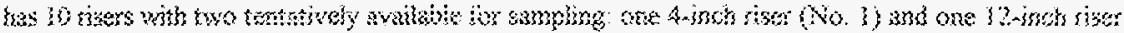

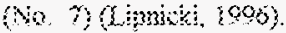

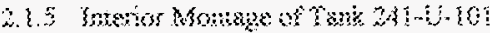

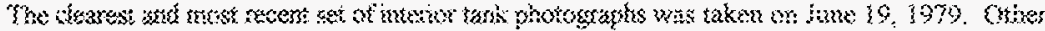

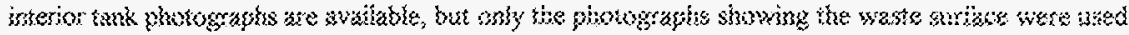

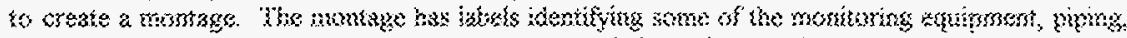

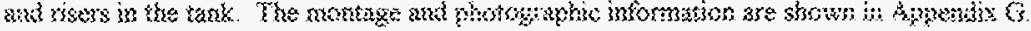

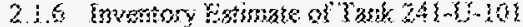

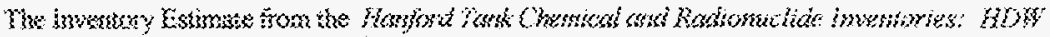

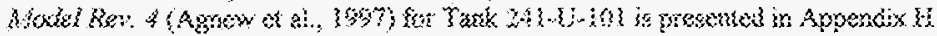




\subsection{Tank 241-U-102}

\subsubsection{Waste and Level History of Tank 241-U-102}

The Waste and Level History sketch in Appendix C presents the waste history and level history of Tank 241-U-102.

\subsubsection{Temperature History of Tank 241-U-102}

Interior tank temperature data for Tank 241-U-102 were recorded by 11 thermocouples attached to one thermocouple tree. Drawing H-2-37332, Rev. 1, indicates that the thermocouple tree is designed as shown on Drawing H-2-34304, Sht. 1, Rev. 6 with 11 thermocouples. The Surveillance Analysis Computer System (SACS) indicates that the thermocouple tree is located in riser 1. In the past, other risers and equipment may have been used to monitor the temperature in the tank. However, the thermocouple tree located at riser 1 is the only source of temperature data for this document.

The temperature data were obtained from the SACS database on October 2, 1996. The SACS database contained two file types for temperature data: a historical file and a file with temperature data tied to riser 1 . Since there was no way to correlate the data in the historical file with a particular thermocouple, thermocouple tree, or riser, data from this file were not included in this document. Only data from the file that tied the temperature data to riser 1 were used in this document. The earliest data retrieved from SACS were from mid March 1993

Graphs of individual thermocouple data are presented in Appendix D. A graph was created for each thermocouple. The following statistical information was taken from all 11 thermocouples. The maximum temperature was $88.16^{\circ} \mathrm{F}$ taken by thermocouple 3 on January 11,1996 . The minimum temperature was $58.8^{\circ} \mathrm{F}$ taken by thermocouple 8 on April 4, 1995. The maximum and minimum temperatures are labeled as good data points within the SACS. The average temperature for all the thermocouples is $82^{\circ} \mathrm{F}$.

\subsubsection{Occurrences for Tank 241-U-102}

No significant occurrences are associated with Tank 241-U-102.

\subsubsection{Current Status of Tank 241-U-102}

Tank 241-U-102 entered service during the second quarter of 1946 (Anderson, 1990) and as of June 30, 1996, stores approximately 374,000 gallons of waste (Hanlon, 1996i). The minimum waste surface level was 130.9 inches on October 1,1995 . The maximum waste surface level was 144.82 inches on October 2, 1996. See Appendix E for details on waste surface level. The tank is out of service with partial interim isolation completed. The tank is listed as sound and is passively ventilated (Hanlon, 1996i). A plan view in Appendix F depicts the approximate riser locations as of October 1, 1996. Tank 241-U-102 has 13 risers with three tentatively available for sampling: two 4-inch risers (Nos. 9 and 19) and one 12-inch riser (No. 7) (Lipnicki, 1996). 


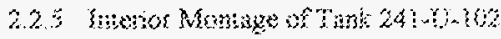

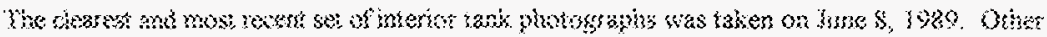

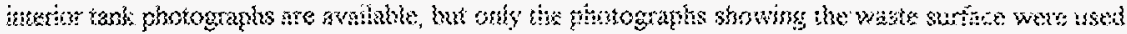

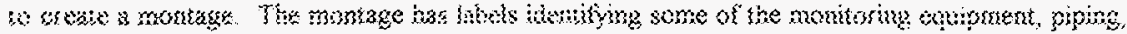

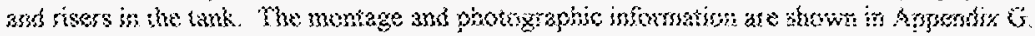

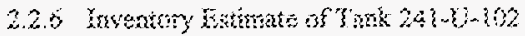

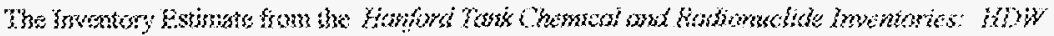

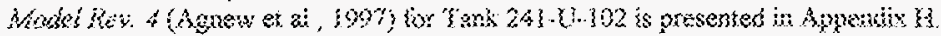




\subsection{Tank 24I-U-103}

\subsubsection{Waste and Level History of Tank 241-U-103}

The Waste and Level History sketch in Appendix C presents the waste history and level history of Tank 241-U-103.

\subsubsection{Temperature History of Tank 241-U-103}

Interior tank temperature data for Tank 241-U-103 were recorded by 11 thermocouples attached to one thermocouple tree. Drawing H-2-37332, Rev. 1, indicates that the thermocouple tree is designed as shown on Drawing H-2-34304, Sht. 1, Rev. 6 with 11 thermocouples. The Surveillance Analysis Computer System (SACS) indicates that the thermocouple tree is located in riser 1. In the past, other risers and equipment may have been used to monitor the temperature in the tank. However, the thermocouple tree located at riser 1 is the only source of temperature data for this document. The temperature data were obtained from the SACS database on October 2, 1996 . The earliest data retrieved from the SACS were from early July 1987.

Graphs of individual thermocouple data are presented in Appendix D. A graph was created for each thermocouple. The following statistical information was taken from all 11 thermocouples. The maximum temperature was $99^{\circ} \mathrm{F}$ taken by thermocouple 3 on January 1, 1988. The minimum temperature was $63.4^{\circ} \mathrm{F}$ taken by thermocouple 11 on April 8, 1993. The maximum and minimum temperatures are labeled as good data points within the SACS. The average temperature for all the thermocouples is $83^{\circ} \mathrm{F}$.

\subsubsection{Occurrences for Tank 241-U-103}

No significant occurrences are associated with Tank 241-U-103.

\subsubsection{Current Status of Tank 241-U-103}

Tank 241-U-103 entered service during the first quarter of 1947 (Anderson, 1990) and as of June 30, 1996, stores approximately 468,000 gallons of waste (Hanlon, 1996i). The minimum waste surface level was 165.8 inches on numerous dates from February 22, 1993 through March 3, 1993. The maximum waste surface level was 179.13 inches on numerous dates from September 13, through September 30, 1996. See Appendix E for details on waste surface level. Tank 241-U-103 was added to the Hydrogen Watch List in January 1991 and the Organics Watch List in May 1994. The tank is out of service with partial interim isolation completed. The tank is listed as sound and is passively ventilated (Hanlon, 1996i). A plan view in Appendix F depicts the approximate riser locations as of October 1, 1996. Tank 241-U-103 has 14 risers with three tentatively available for sampling: one 4-inch riser (No. 9) and two 12-inch risers (No. 2 and 7) (Lipnicki, 1996).

\subsubsection{Interior Montage of Tank 241-U-103}

The clearest and most recent set of interior tank photographs was taken on September 13, 1988 . Other interior tank photographs are available, but only the photographs showing the waste surface were 


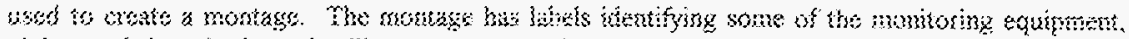

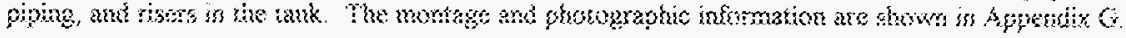

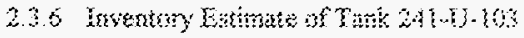

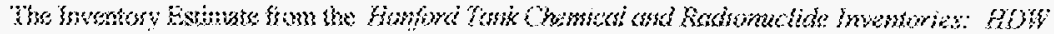

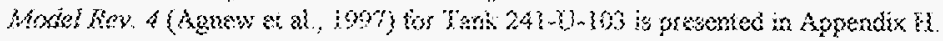




\subsection{Tank 241-U-104}

\subsubsection{Waste and Level History of Tank 241-U-104}

The Waste and Level History sketch in Appendix C presents the waste history and level history of Tank 241-U-104. In 1972, approximately 60 tons of diatomaceous earth was added to this tank (Anderson, 1990).

\subsubsection{Temperature History of Tank 241-U-104}

There was no traceable interior tank temperature data for Tank 241-U-104.

\subsubsection{Occurrences for Tank 241-U-104}

An occurrence report was issued in August 1978 because of increasing activity in a drywell. The activity in this drywell has slowly stabilized and the remaining dry wells associated with this tank have shown no changes during the review period.

\subsubsection{Current Status of Tank 241-U-104}

Tank 241-U-104 entered service during the third quarter of 1947 (Anderson, 1990) and as of June 30, 1996, stores approximately 122,000 gallons of waste (Hanlon, 1996i). The minimum waste surface level was 27.5 inches on October 2, 1996. The maximum waste surface level was 33.75 inches on January 1, 1991. See Appendix E for details on waste surface level. The tank is out of service with interim stabilization and intrusion prevention completed. The tank is listed as a assumed leaker and is passively ventilated (Hanlon, 1996i). A plan view in Appendix F depicts the approximate riser locations as of October 1, 1996. Tank 241-U-104 has 10 risers with three tentatively available for sampling: two 4-inch risers (Nos. 1 and 8) and one 12-inch riser (No. 2) (Lipnicki, 1996).

\subsubsection{Interior Montage of Tank 241-U-104}

The clearest and most recent set of interior tank photographs was taken on August 10, 1989. Other interior tank photographs are available, but only the photographs showing the waste surface were used to create a montage. The montage has labels identifying some of the monitoring equipment, piping, and risers in the tank. The montage and photographic information are shown in Appendix G.

\subsubsection{Inventory Estimate of Tank 241-U-104}

The Inventory Estimate from the Hanford Tank Chemical and Radionuclide Inventories: HDW Model Rev. 4 (Agnew et al., 1997) for Tank 241-U-104 is presented in Appendix H. 


\section{Taminganos}

\subsubsection{Wate and Level Bstong of takk 24:1-jos}

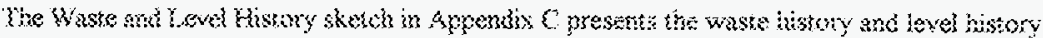

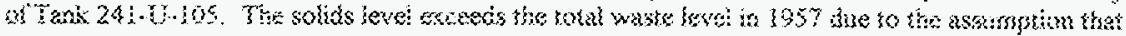

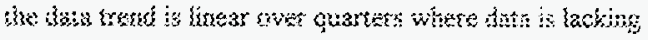

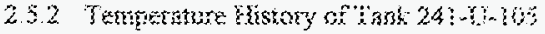

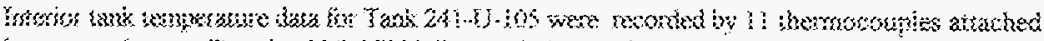

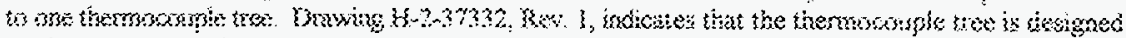

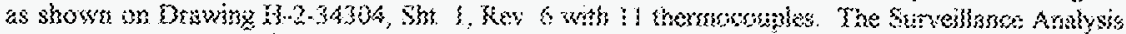

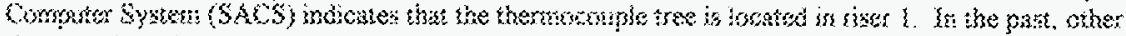

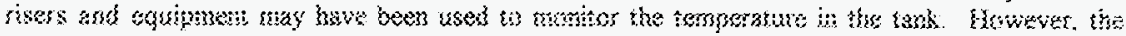

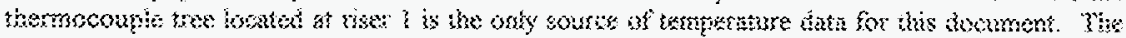

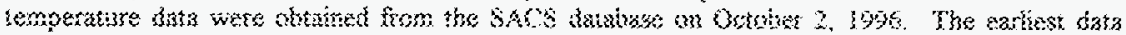

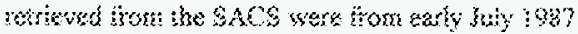

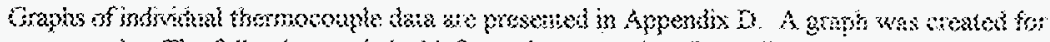

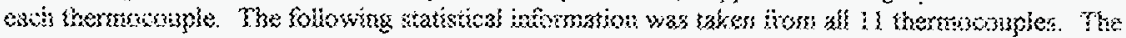

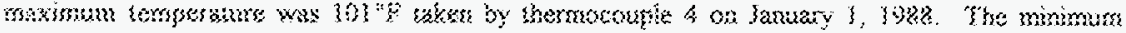

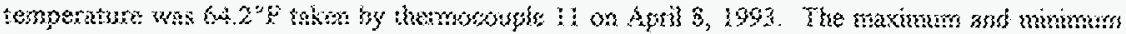

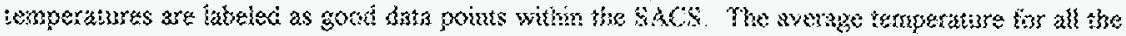
ikemosouplise is $8 A^{2}$ is.

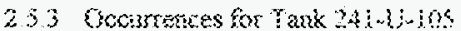

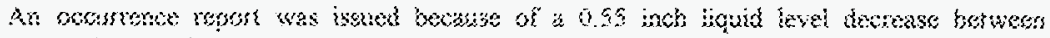

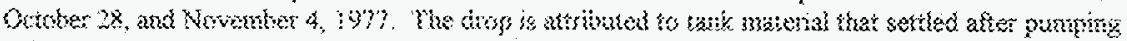
sfort: it Orwher $397 \%$

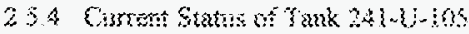

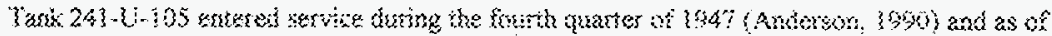

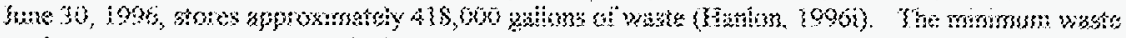

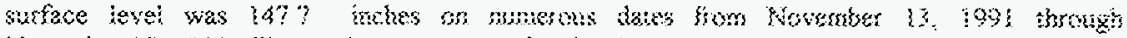

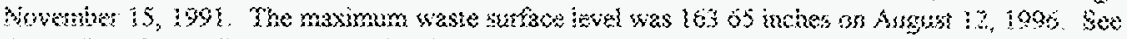

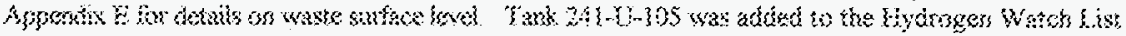

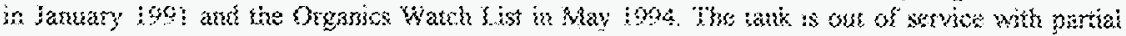

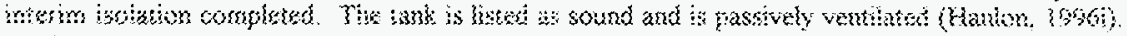

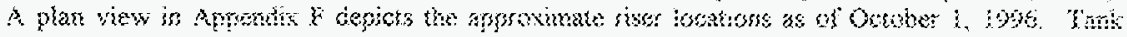

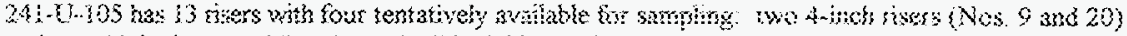

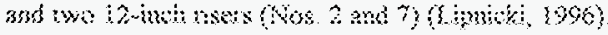




\subsubsection{Interior Montage of Tank 241-U-105}

The clearest and most recent set of interior tank photographs was taken on July 7, 1988. Other interior tank photographs are available, but only the photographs showing the waste surface were used to create a montage. The montage has labels identifying some of the monitoring equipment, piping, and risers in the tank. The montage and photographic information are shown in Appendix G.

2.5.6 Inventory Estimate of Tank 241-U-105

The Inventory Estimate from the Hanford Tank Chemical and Radionuclide Inventories: HDW Model Rev. 4 (Agnew et al., 1997) for Tank 241-U-105 is presented in Appendix H. 


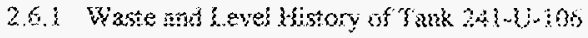

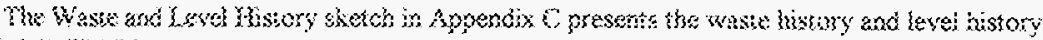
serak $24:-5 \%$ : 36

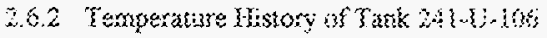

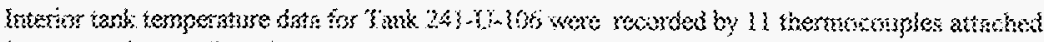

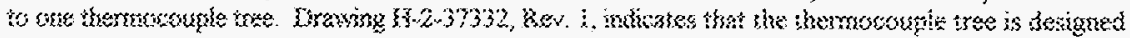

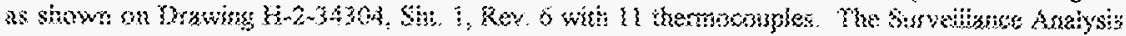

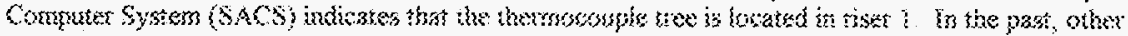

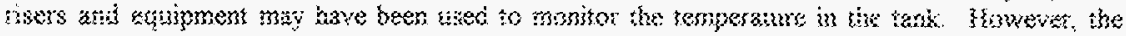

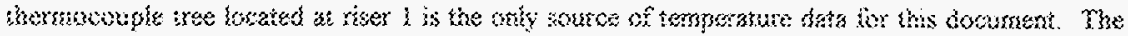

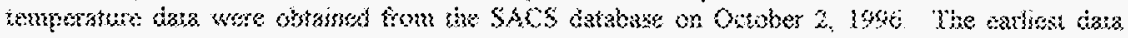
retrieved from the Shs wore from arly buv $190 \%$

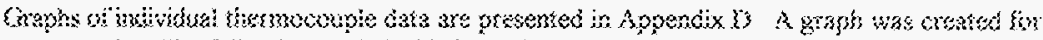

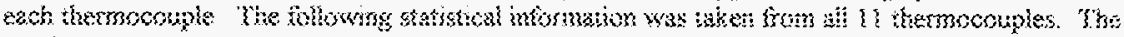

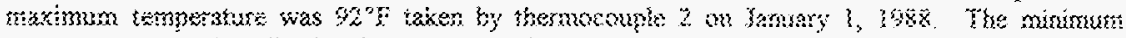

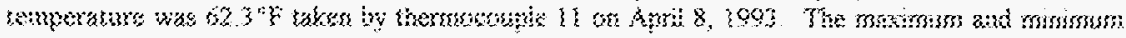

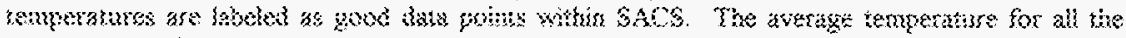
therrocoubles is ?? $\mathrm{F}$.

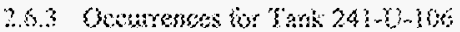

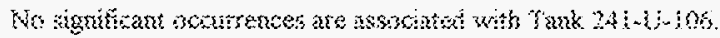

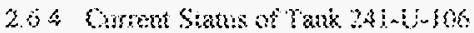

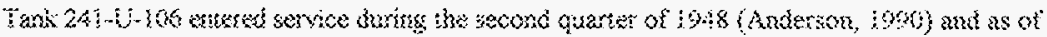

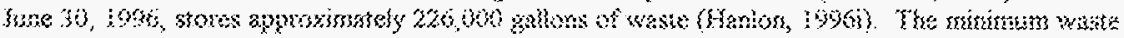

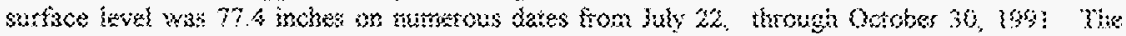

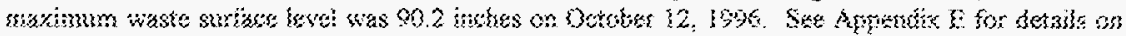

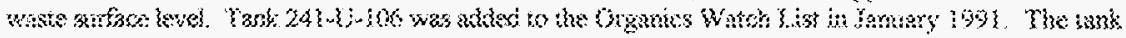

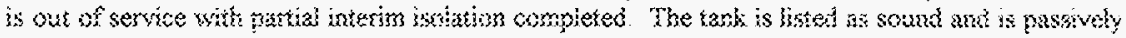

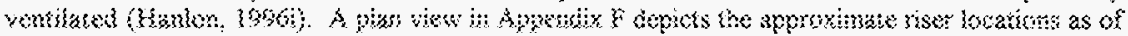

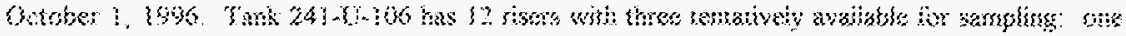

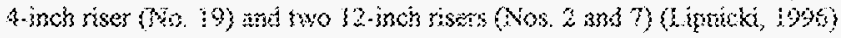

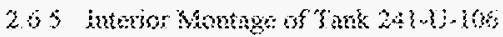

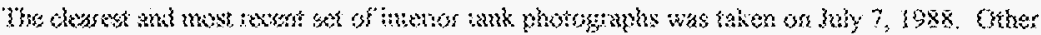

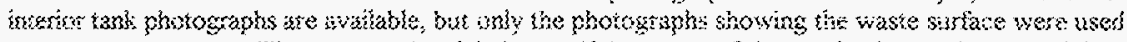

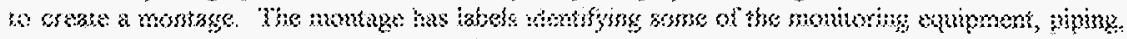

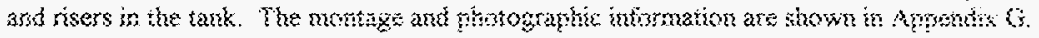


2.6.6 Inventory Estimate of Tank 241-U-106

The Inventory Estimate from the Hanford Tank Chemical and Radionuclide Inventories: $H D W$ Model Rev. 4 (Agnew et al., 1997) for Tank 241-U-106 is presented in Appendix H. 


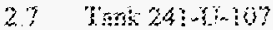

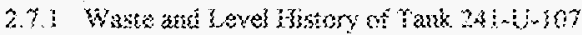

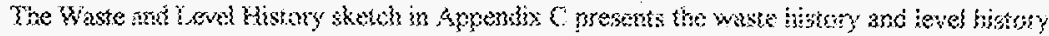

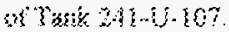

\section{$2 \% 2$ Temperatse Missory on}

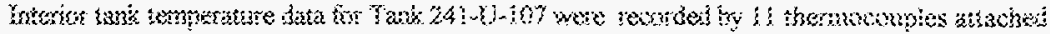

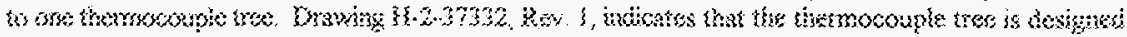

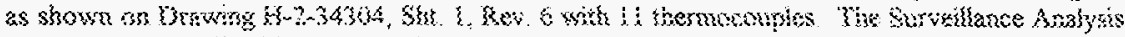

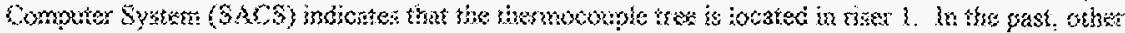

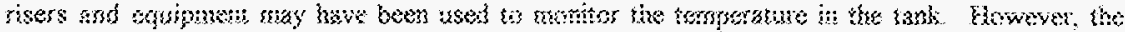

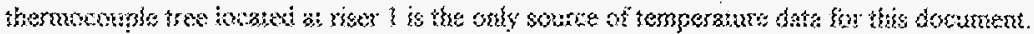

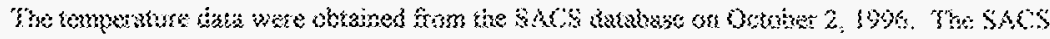

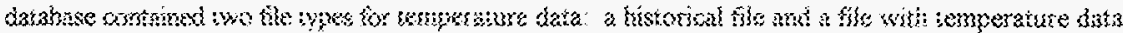

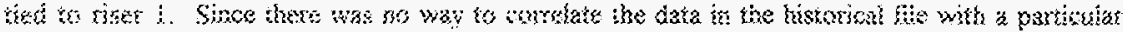

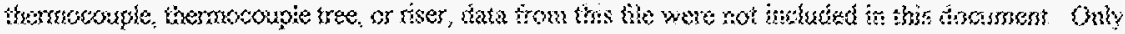

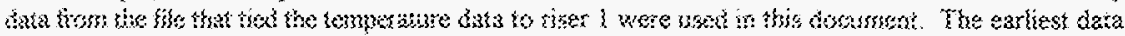
rengered tow SACS wese hom nid Masti : 59 :

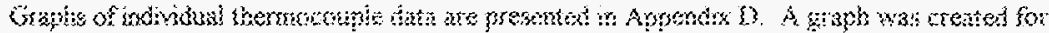

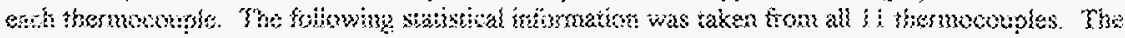

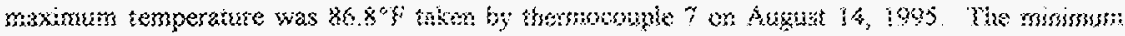

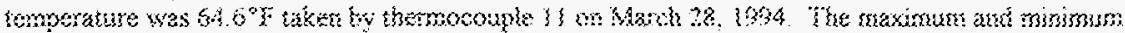

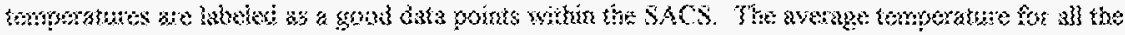
thormocougles is $\% "$ :

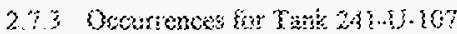

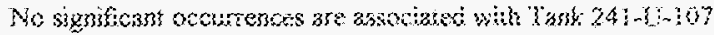

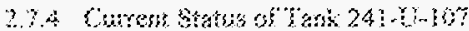

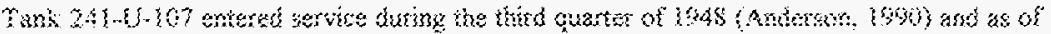

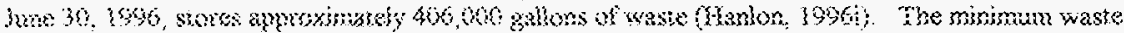

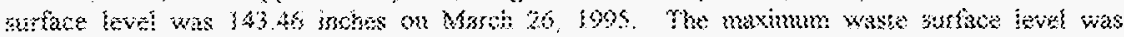

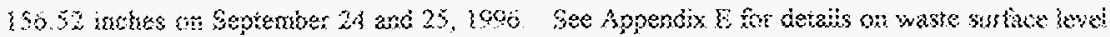

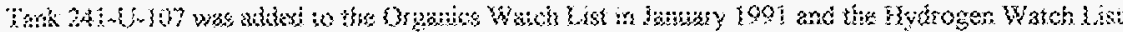

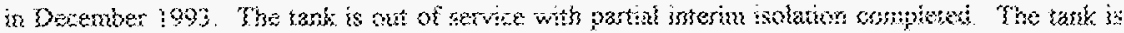

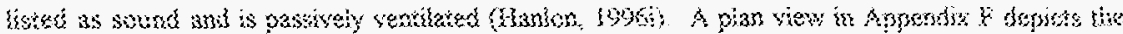

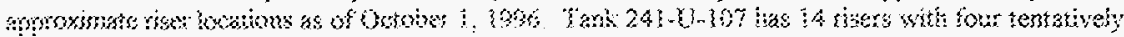

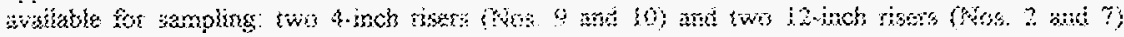
(s.ipurici, isgris) 


\subsubsection{Interior Montage of Tank 241-U-107}

The clearest and most recent set of interior tank photographs was taken on July 7, 1988. Other interior tank photographs are available, but only the photographs showing the waste surface were used to create a montage. The montage has labels identifying some of the monitoring equipment, piping, and risers in the tank. The montage and photographic information are shown in Appendix $G$

\subsubsection{Inventory Estimate of Tank 241-U-107}

The Inventory Estimate from the Hanford Tank Chemical and Radionuclide Inventories: HDW Model Rev. 4 (Agnew et al., 1997) for Tank 241-U-107 is presented in Appendix H. 
$28 \quad$ Tak $241-[1 \cdot 308$

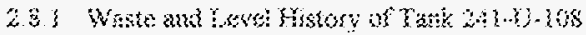

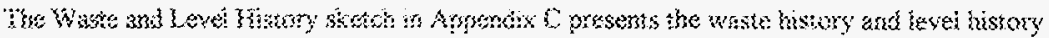

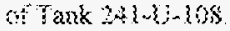

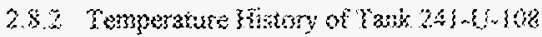

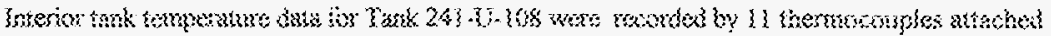

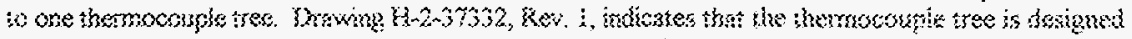

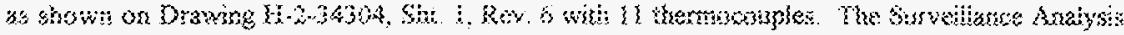

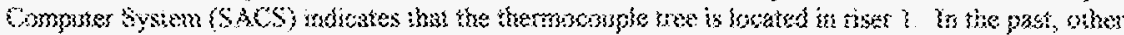

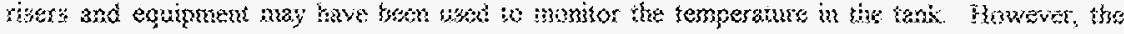

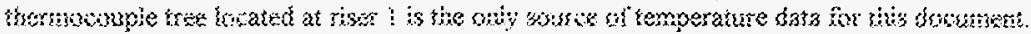

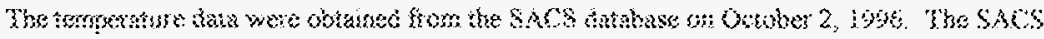

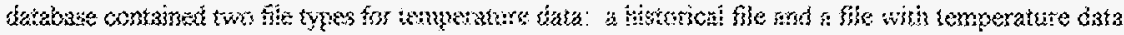

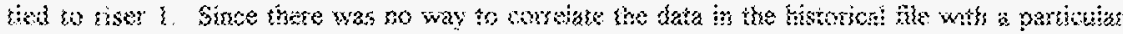

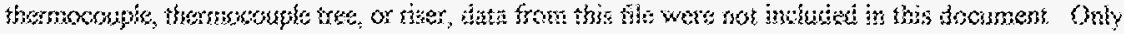

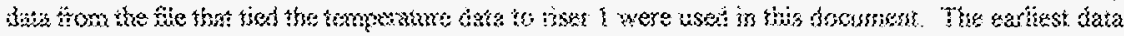

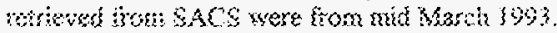

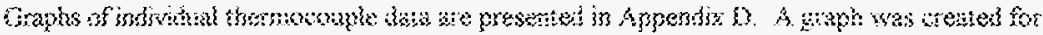

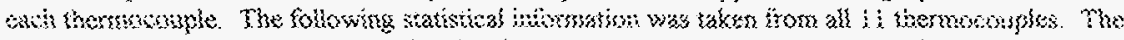

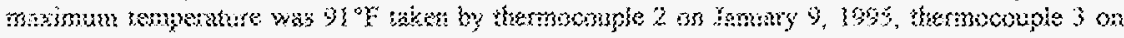

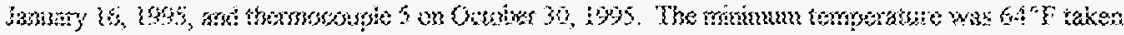

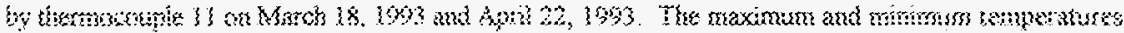

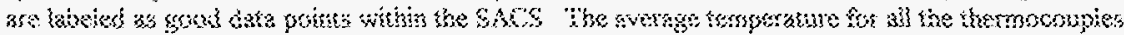
is $83^{\circ} \%$

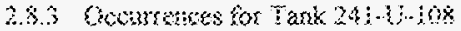

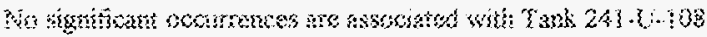

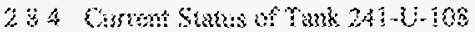

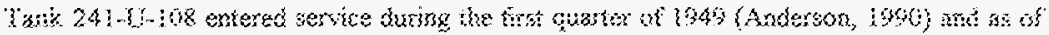

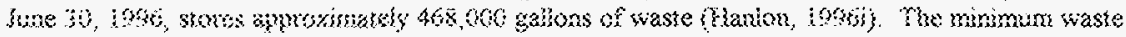

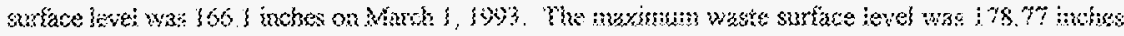

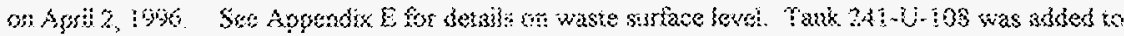

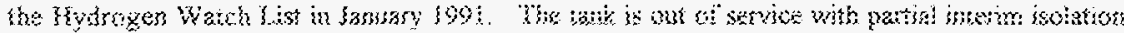

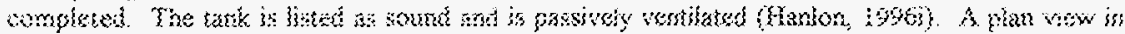

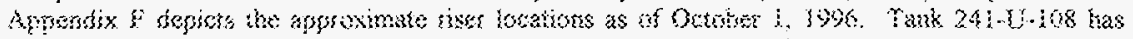

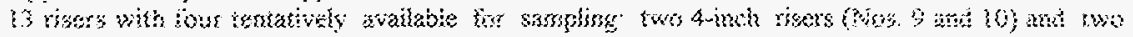

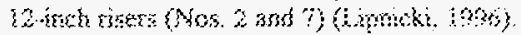


The clearest and most recent set of interior tank photographs was taken on September 12, 1984. Other interior tank photographs are available, but only the photographs showing the waste surface were used to create a montage. The montage has labels identifying some of the monitoring equipment, piping, and risers in the tank. The montage and photographic information are shown in Appendix $\mathrm{G}$.

2.8.6 Inventory Estimate of Tank 241-U-108

The Inventory Estimate from the Hanford Tank Chemical and Radionuclide Inventories: HDW Model Rev. 4 (Agnew et al., 1997) for Tank 241-U-108 is presented in Appendix H. 


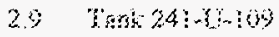

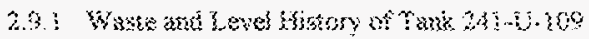

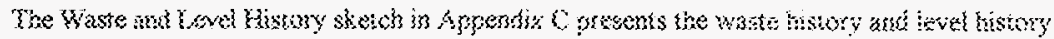

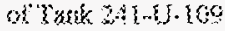

\section{Temenatue Kistory of Tank 24:-13-300}

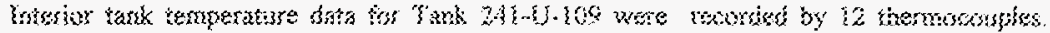

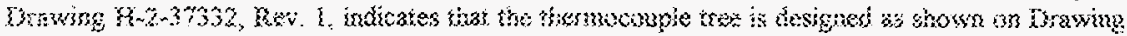

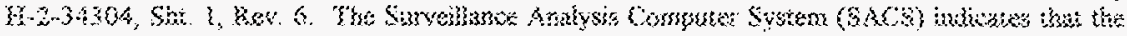

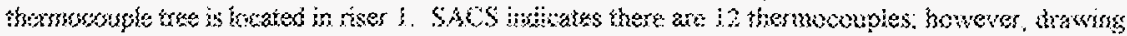

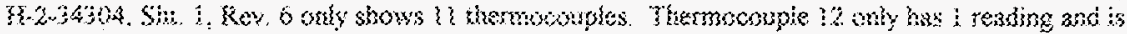

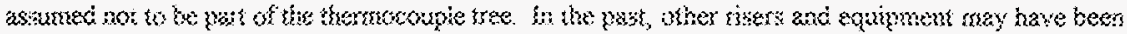

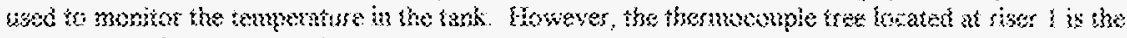

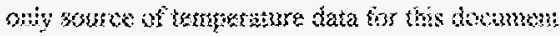

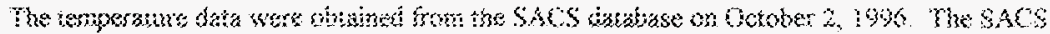

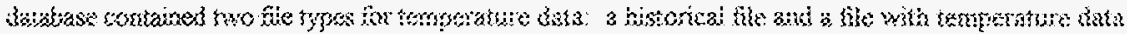

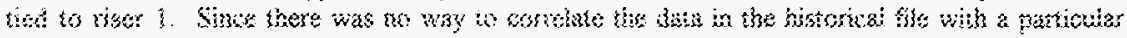

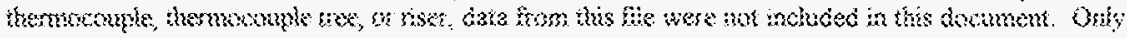

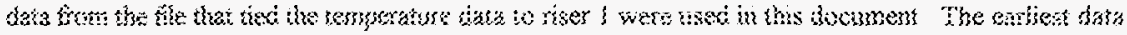

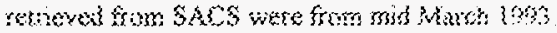

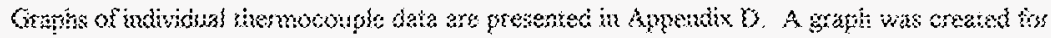

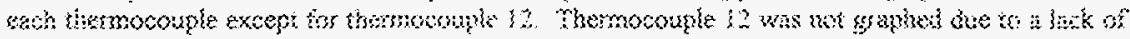

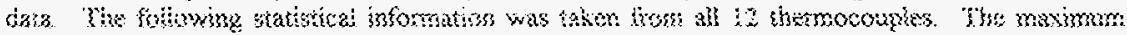

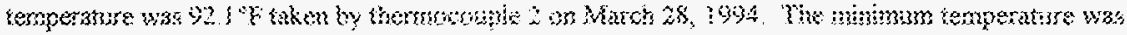

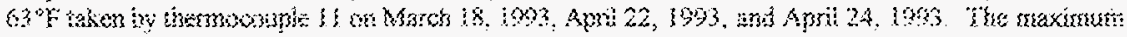

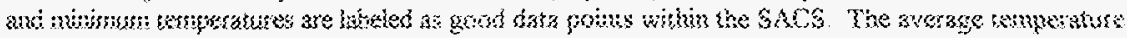

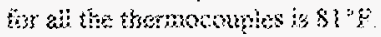

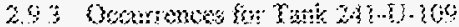

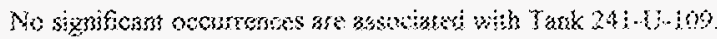

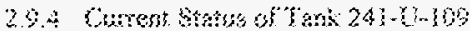

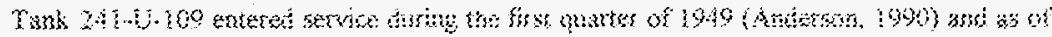

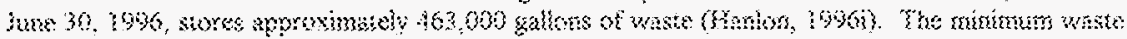

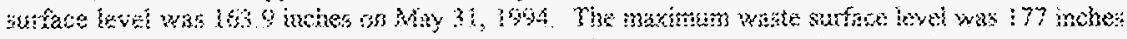

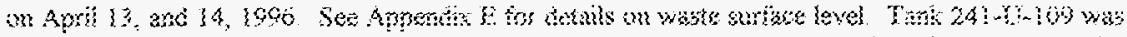

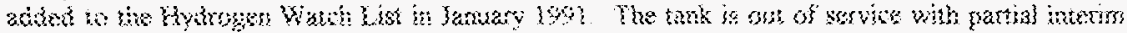

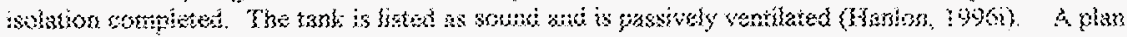

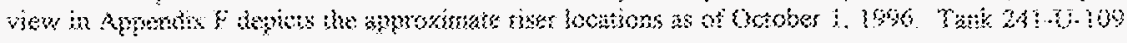


has 15 risers with four tentatively available for sampling: two 4-inch risers (Nos. 10 and 19) and two12-inch risers (Nos. 2 and 7) (Lipnicki, 1996).

\subsubsection{Interior Montage of Tank 241-U-109}

The clearest and most recent set of interior tank photographs was taken on July 7, 1988. Other interior tank photographs are available, but only the photographs showing the waste surface were used to create a montage. The montage has labels identifying some of the monitoring equipment, piping, and risers in the tank. The montage and photographic information are shown in Appendix $G$.

\subsubsection{Inventory Estimate of Tank 241-U-109}

The Inventory Estimate from the Hanford Tank Chemical and Radionuclide Imventories: HDW Model Rev. 4 (Agnew et al., 1997) for Tank 241-U-109 is presented in Appendix H. 


\section{$2,30 \operatorname{Tank} 24:-1-1: 0$}

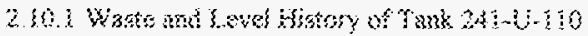

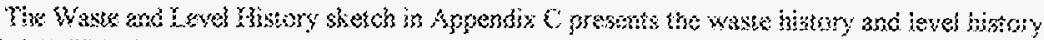

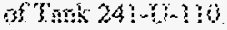

\section{10.2 Temperature History of Tank 2Alwin: :0}

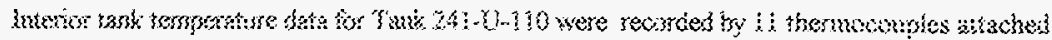

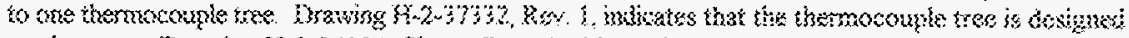

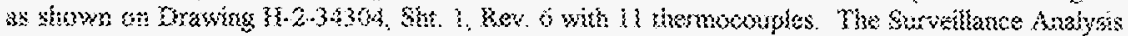

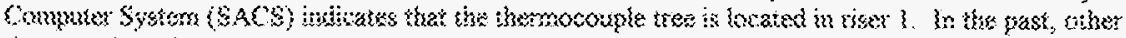

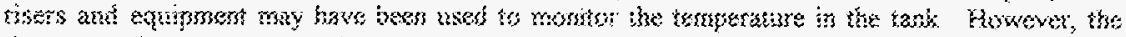

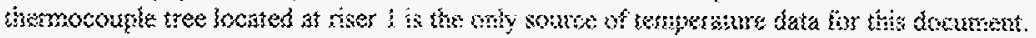

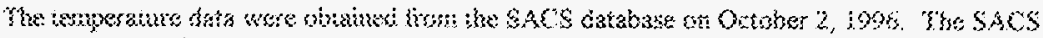

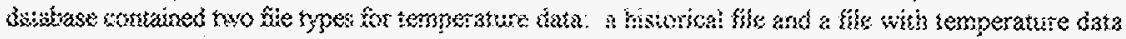

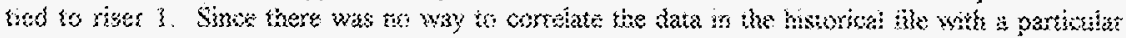

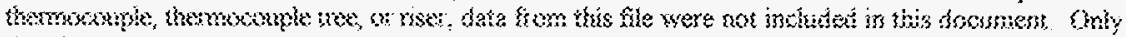

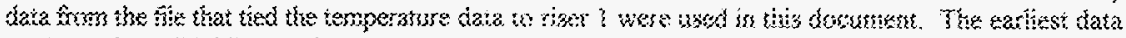
serroved from SACS wate from mid Mstoh 1603

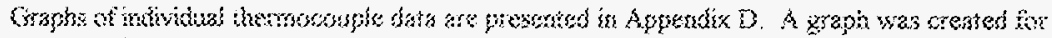

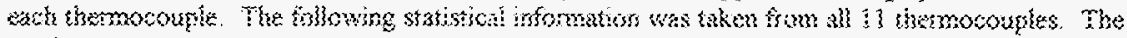

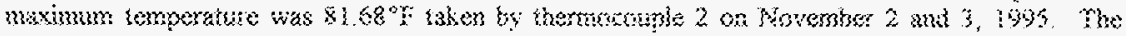

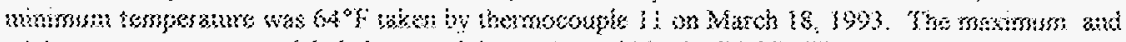

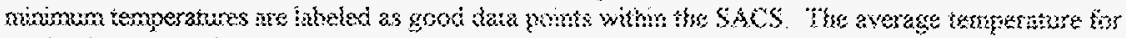
all the thermocoughes is $75^{\circ} \xi$.

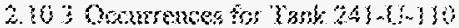

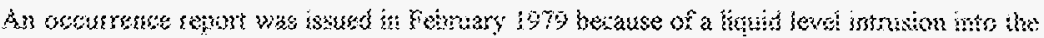

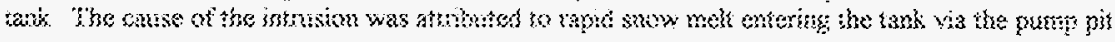

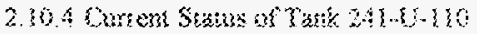

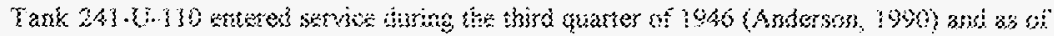

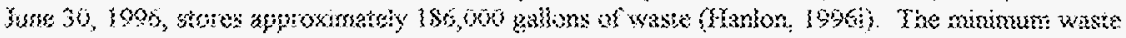

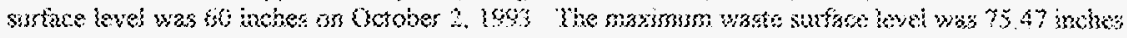

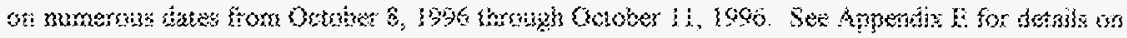

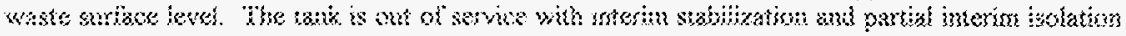

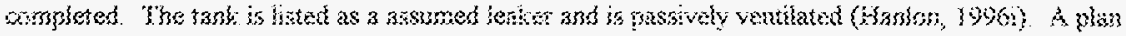

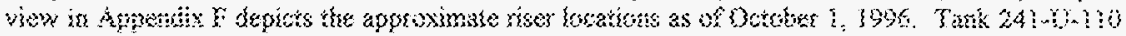

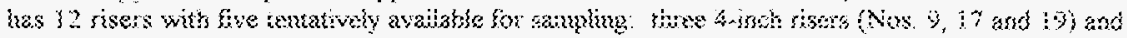

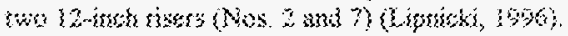


The clearest and most recent set of interior tank photographs was taken on December 11, 1984 . Other interior tank photographs are available, but only the photographs showing the waste surface were used to create a montage. The montage has labels identifying some of the monitoring equipment, piping, and risers in the tank. The montage and photographic information are shown in Appendix G.

\subsubsection{Inventory Estimate of Tank 241-U-110}

The Inventory Estimate from the Hanford Tank Chemical and Radionuclide Inventories: HDW Model Rev. 4 (Agnew et al., 1997) for Tank 241-U-110 is presented in Appendix H. 


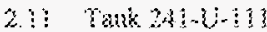

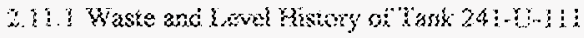

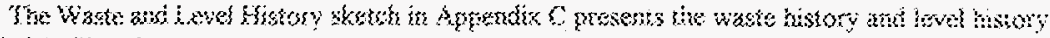
of $\operatorname{tank} 24: \cdot 3):$ :

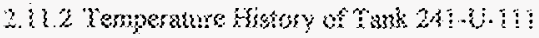

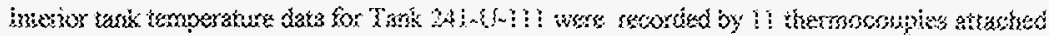

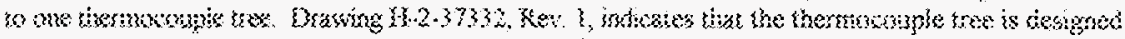

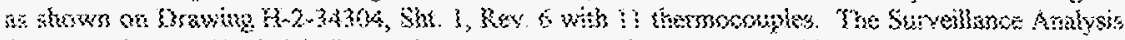

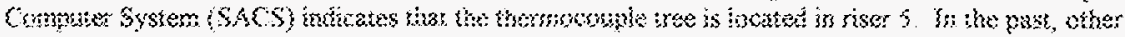

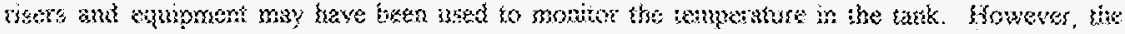

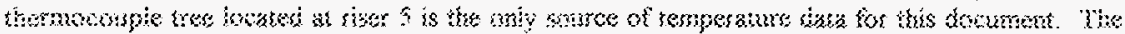

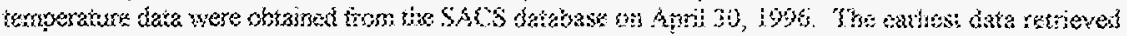
from the SACS were from iare ijne 1903

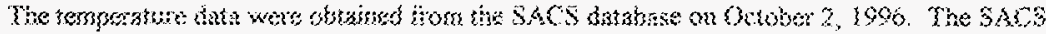

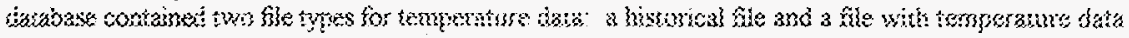

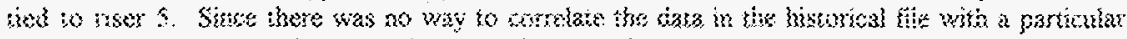

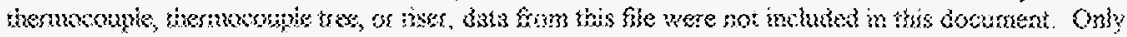

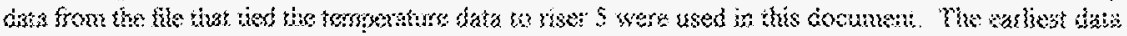

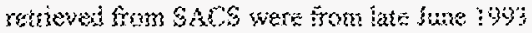

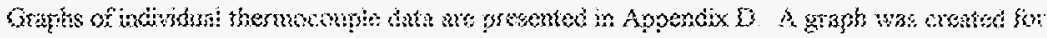

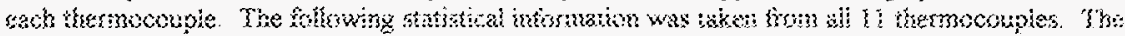

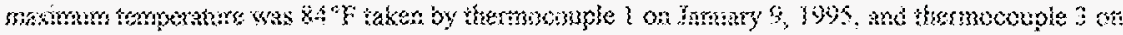

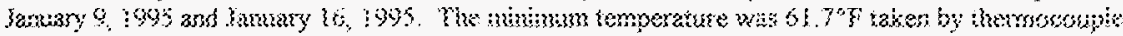

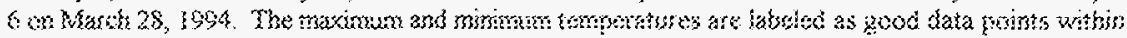

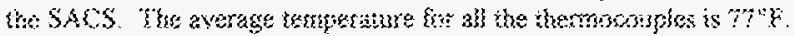

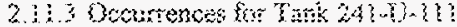

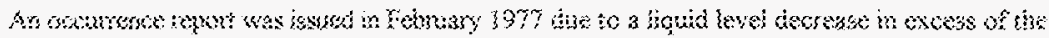

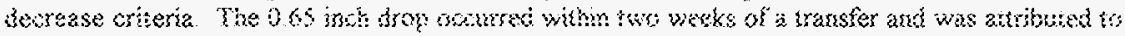

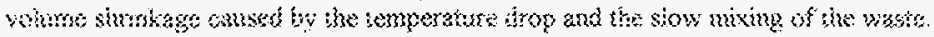

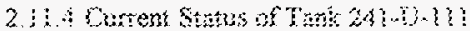

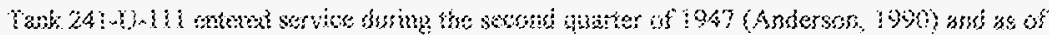

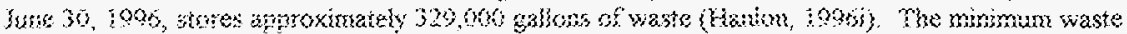

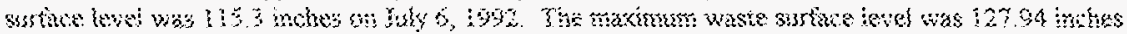

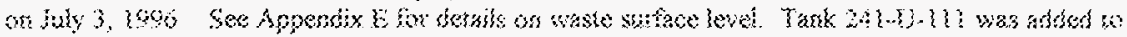

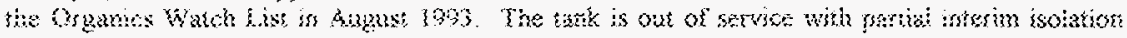

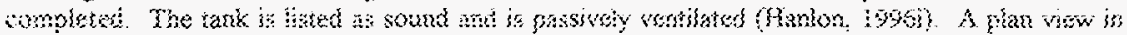

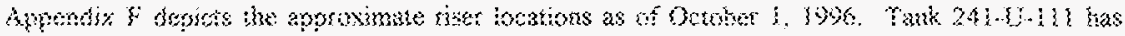


12 risers with five tentatively available for sampling: two 4-inch risers (Nos. 4 and 10) and three 12-inch risers (Nos. 3, 6 and 7) (Lipnicki, 1996).

\subsubsection{Interior Montage of Tank 241-U-111}

The clearest and most recent set of interior tank photographs was taken on June 23, 1988. Other interior tank photographs are available, but only the photographs showing the waste surface were used to create a montage. The montage has labels identifying some of the monitoring equipment, piping, and risers in the tank. The montage and photographic information are shown in Appendix G.

\subsubsection{Inventory Estimate of Tank 241-U-111}

The Inventory Estimate from the Hanford Tank Chemical and Radionuclide Inventories: HDW Model Rev. 4 (Agnew et al., 1997) for Tank 241-U-111 is presented in Appendix H. 
2.12 Tank $2+1 \cdot\} ; \cdot 13$

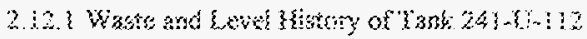

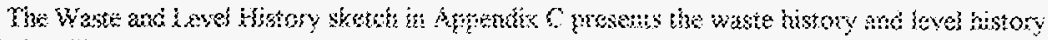
of Brak $24:-112$

\subsubsection{Temperature Sistory of Xuk $24: .3: 1 \%$}

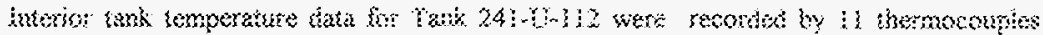

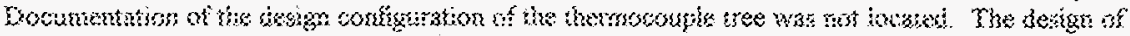

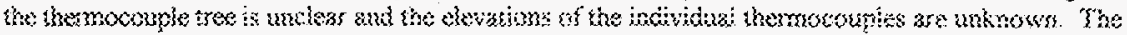

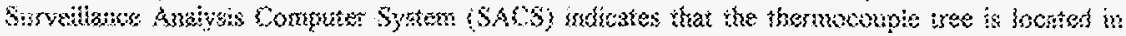

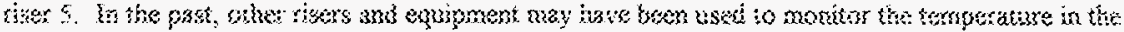

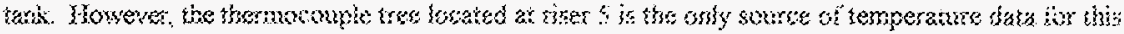
drsasswssit.

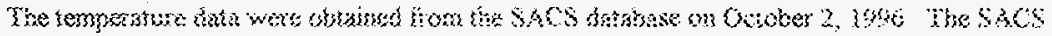

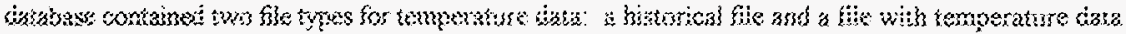

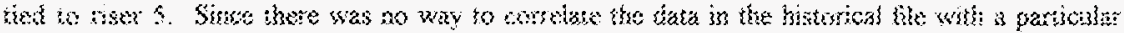

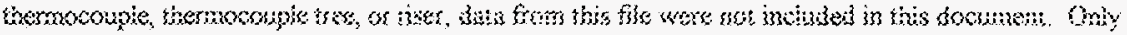

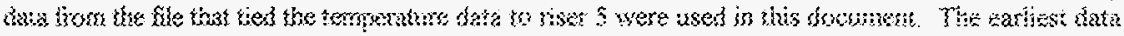

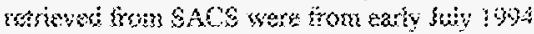

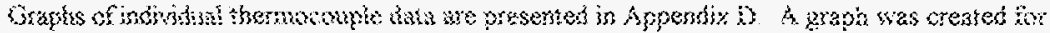

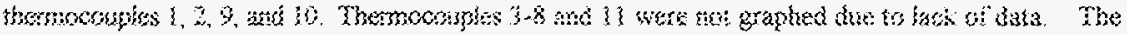

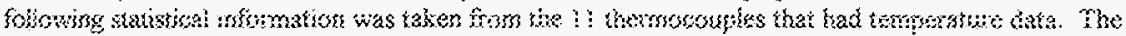

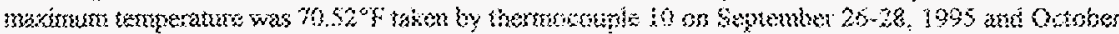

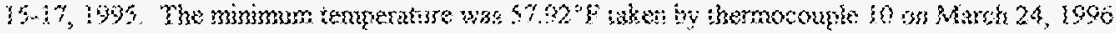

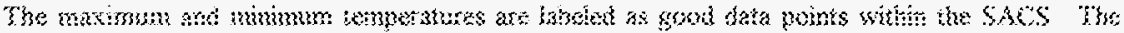

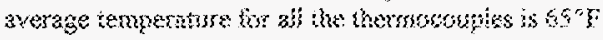

\subsection{2 .3 Gowmess for Tark $24: 5: .1: 2$}

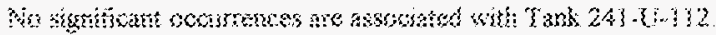

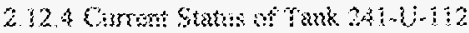

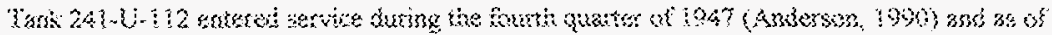

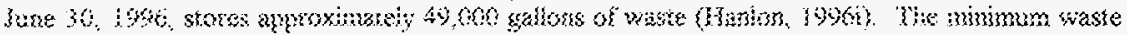

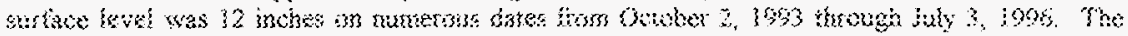

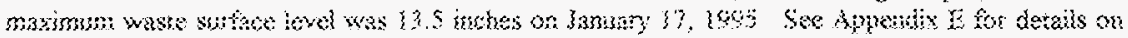

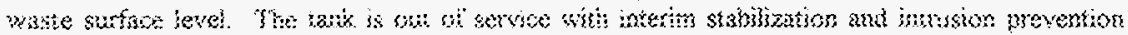

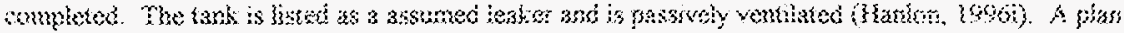

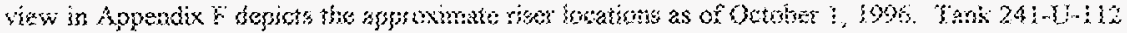

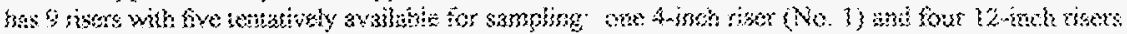

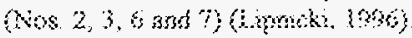




\subsubsection{Interior Montage of Tank 241-U-112}

The clearest and most recent set of interior tank photographs was taken on August 3, 1989. Other interior tank photographs are available, but only the photographs showing the waste surface were used to create a montage. The montage has labels identifying some of the monitoring equipment, piping, and risers in the tank. The montage and photographic information are shown in Appendix G.

2.12.6 Inventory Estimate of Tank 241-U-112

The Inventory Estimate from the Hanford Tank Chemical and Radionuclide Inventories: HDW Model Rev. 4 (Agnew et al., 1997) for Tank 241-U-112 is presented in Appendix H. 


\section{Kank $243-01-201$}

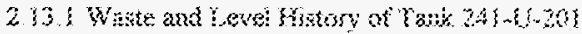

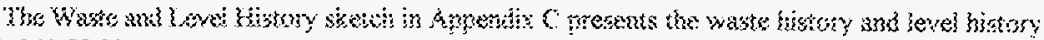

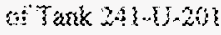

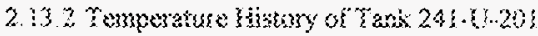

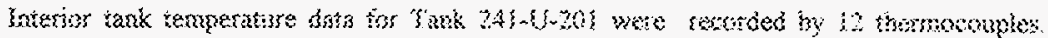

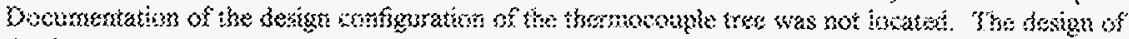

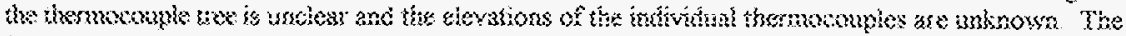

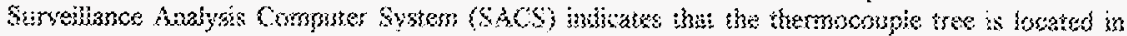

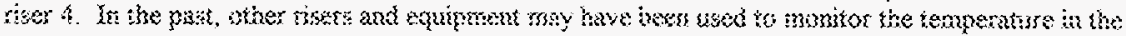

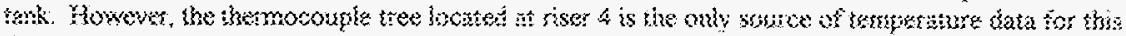
docmment

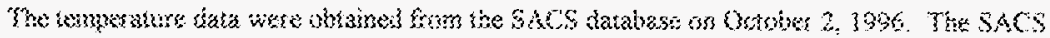

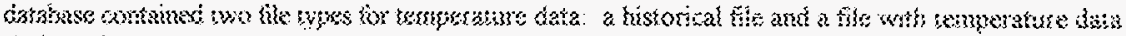

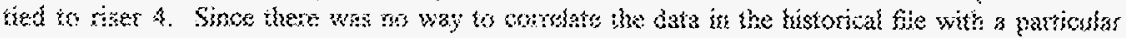

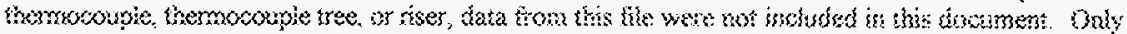

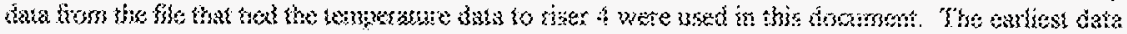

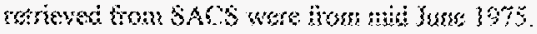

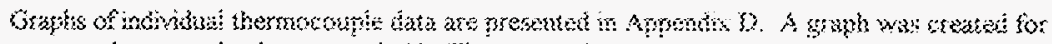

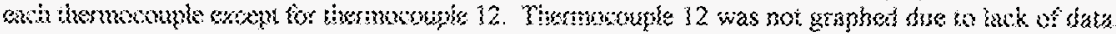

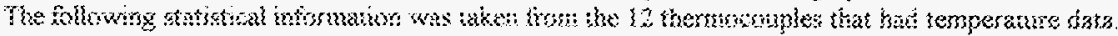

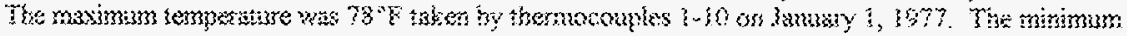

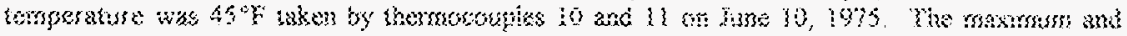

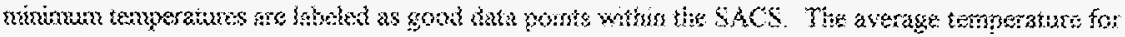
ail the themocouples is $54^{2}:$

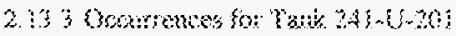

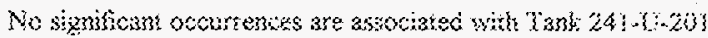

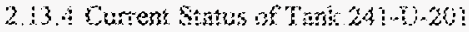

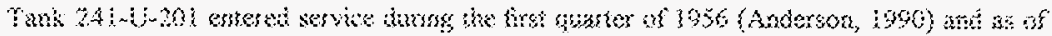

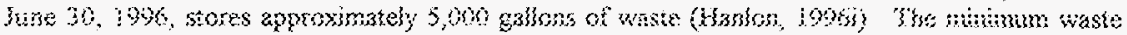

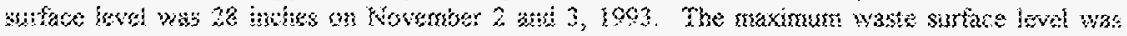

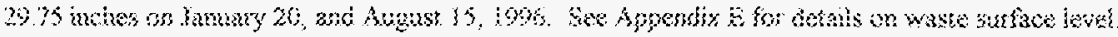

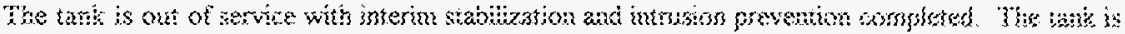

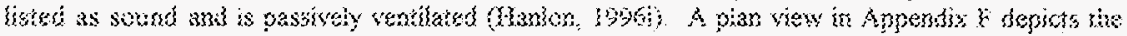

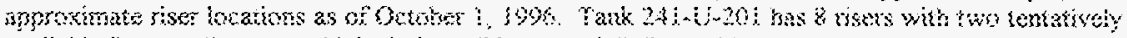

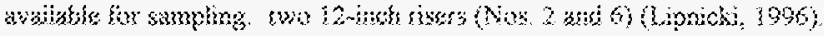


2.13.5 Interior Montage of Tank 241-U-201

The clearest and most recent set of interior tank photographs was taken on August 8, 1989. Other interior tank photographs are available, but only the photographs showing the waste surface were used to create a montage. The montage has labels identifying some of the monitoring equipment, piping, and risers in the tank. The montage and photographic information are shown in Appendix $G$.

2.13.6 Inventory Estimate of Tank 241-U-201

The Inventory Estimate from the Hanford Tank Chemical and Radionuclide Inventories: HDW Model Rev. 4 (Agnew et al., 1997) for Tank 241-U-201 is presented in Appendix H. 


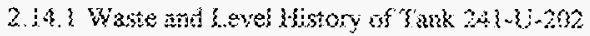

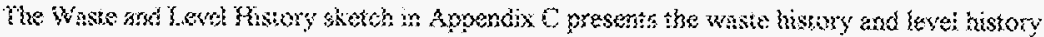
of Tunt $241+3-202$

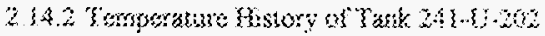

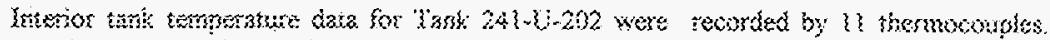

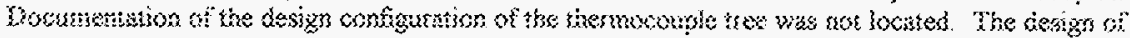

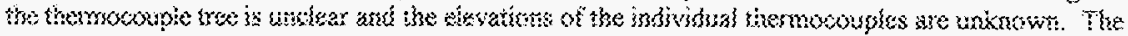

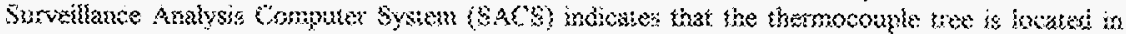

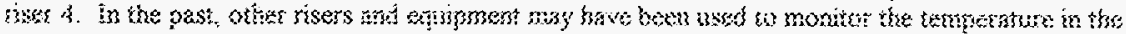

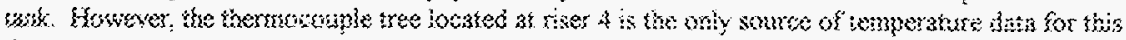
bounex.

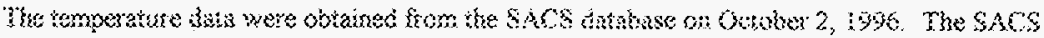

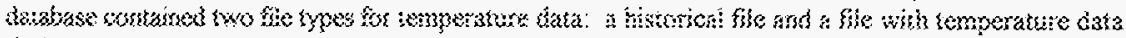

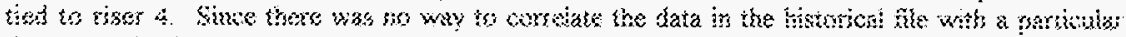

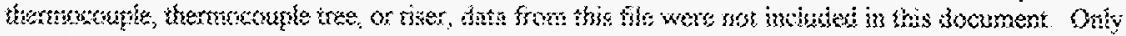

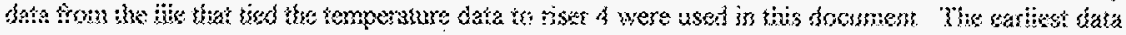

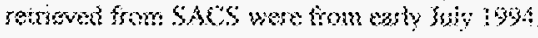

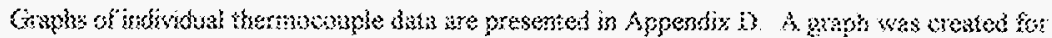

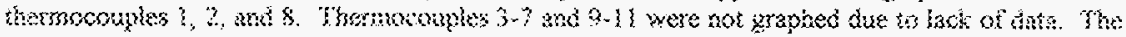

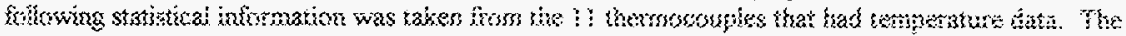

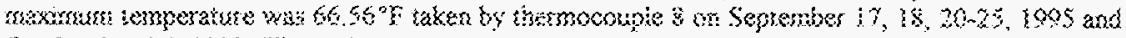

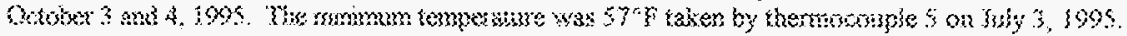

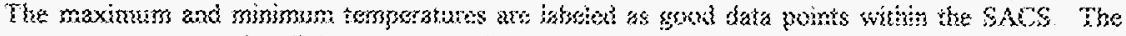

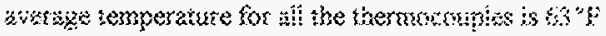

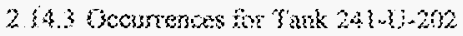

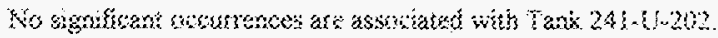

\subsubsection{Current Skarus of Tank $241 \cdot(-202$}

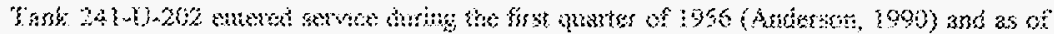

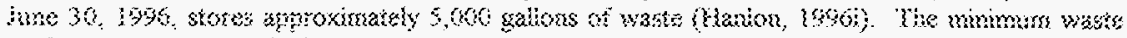

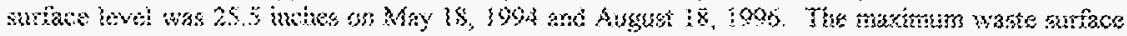

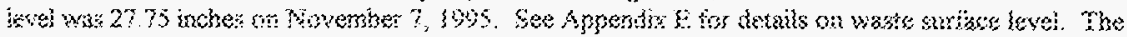

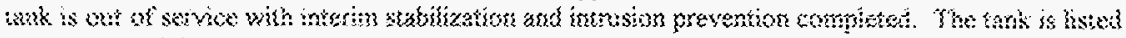

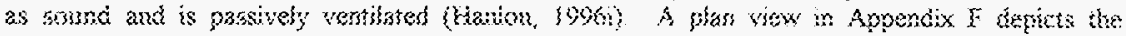

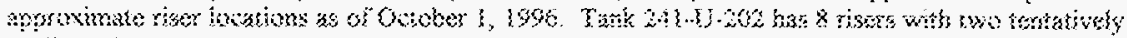

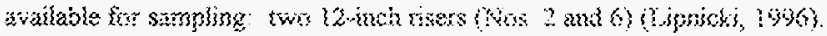


The clearest and most recent set of interior tank photographs was taken on August 8, 1989. Other interior tank photographs are available, but only the photographs showing the waste surface were used to create a montage. The montage has labels identifying some of the monitoring equipment, piping, and risers in the tank. The montage and photographic information are shown in Appendix $G$.

2.14.6 Inventory Estimate of Tank 241-U-202

The Inventory Estimate from the Hanford Tank Chemical and Radionuclide Inventories: HDW Model Rev. 4 (Agnew et al., 1997) for Tank 241-U-202 is presented in Appendix H. 


\subsection{Tank $243 \cdot\{3.203$}

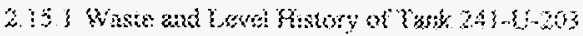

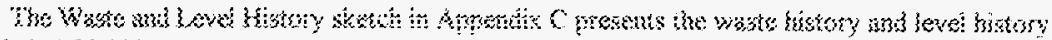
at Tank $24 i-1 ;-2 h\}$

2.352 Tempersare Hetwy of Taxk $263-\{-203$

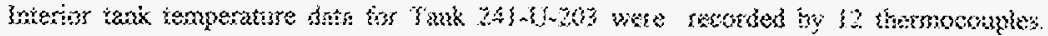

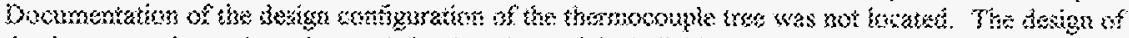

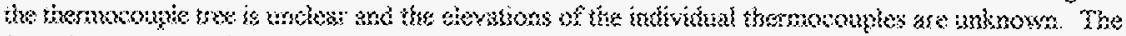

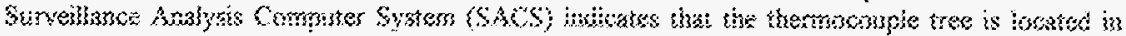

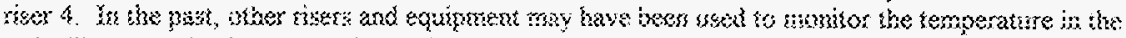

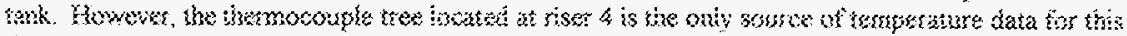
somment.

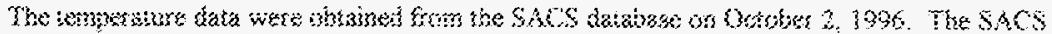

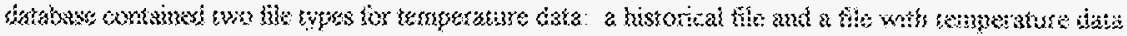

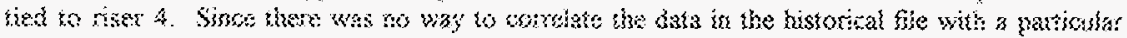

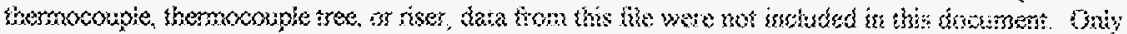

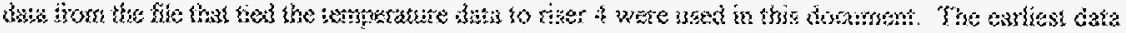

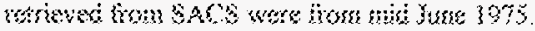

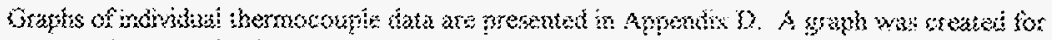

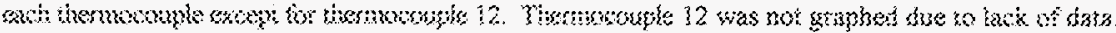

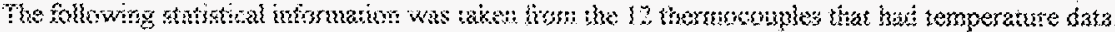

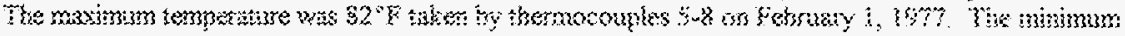

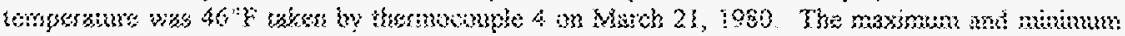

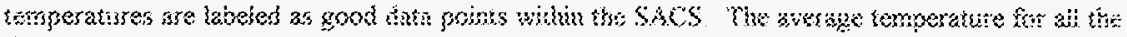
thermocouples is $63^{\prime} \cdot 5$

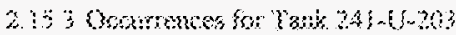

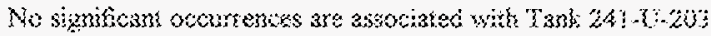

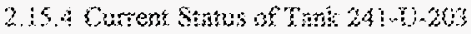

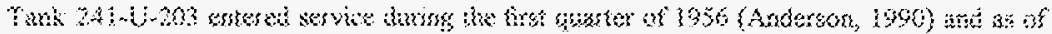

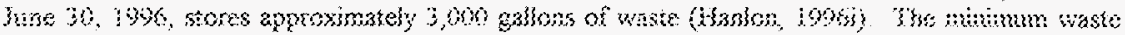

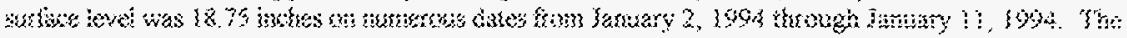

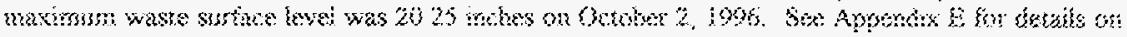

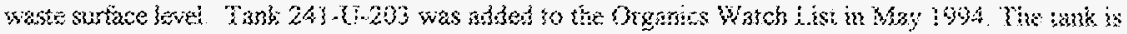

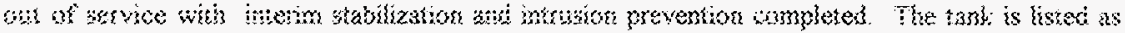

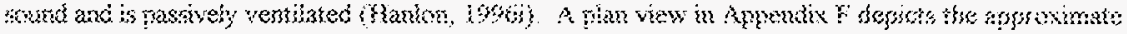

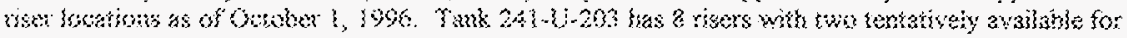

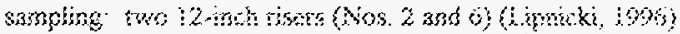


2.15.5 Interior Montage of Tank 241-U-203

The clearest and most recent set of interior tank photographs was taken on June 13, 1989. Other interior tank photographs are available, but only the photographs showing the waste surface were used to create a montage. The montage has labels identifying some of the monitoring equipment, piping, and risers in the tank. The montage and photographic information are shown in Appendix G.

2.15.6 Inventory Estimate of Tank 241-U-203

The Inventory Estimate from the Hanford Tank Chemical and Radiomuclide Inventories: HDW Model Rev. 4 (Agnew et al., 1997) for Tank 241-U-203 is presented in Appendix H. 


\subsection{Tens 241.206}

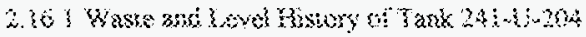

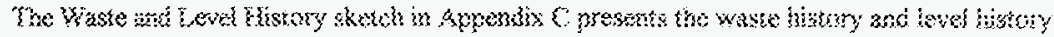

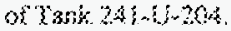

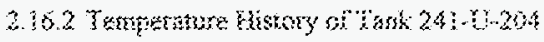

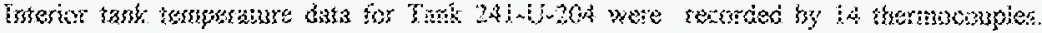

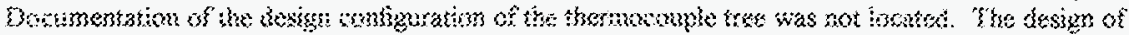

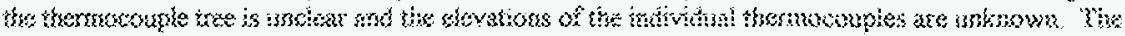

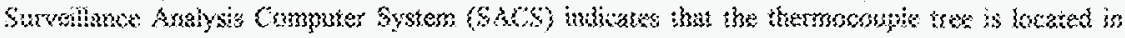

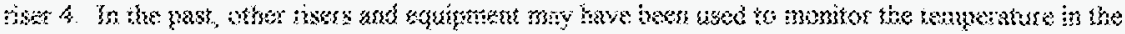

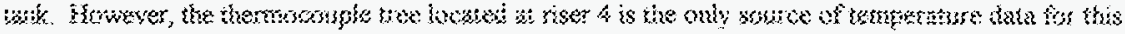
documen.

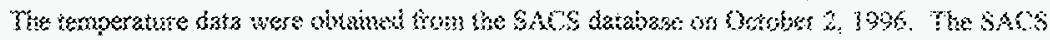

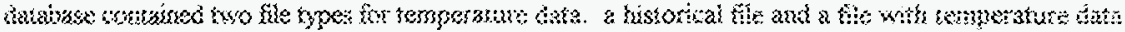

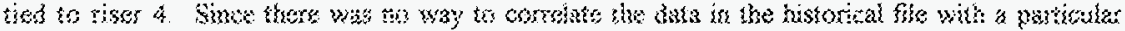

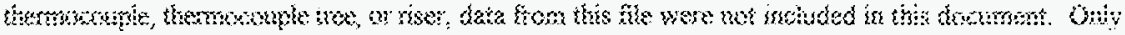

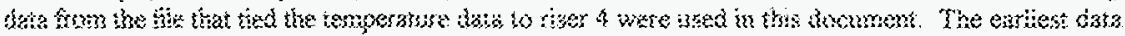
reweved hom 5 \& CS wore from mid han lors

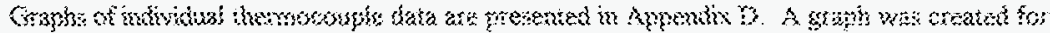

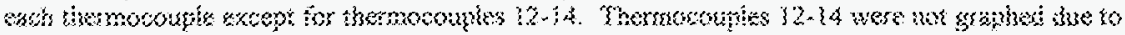

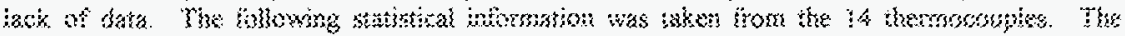

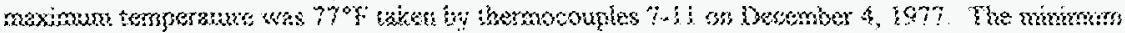

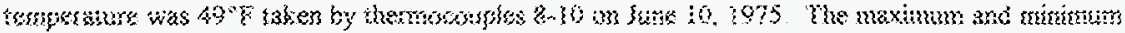

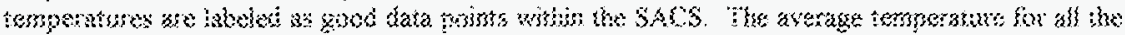
themacomps is $62: \%$.

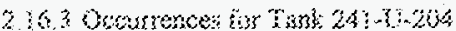

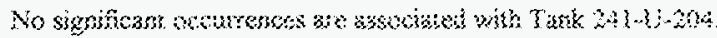

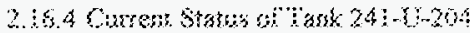

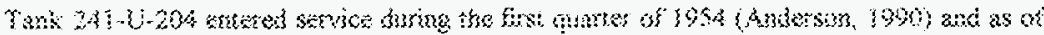

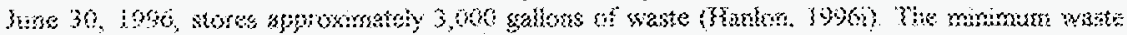

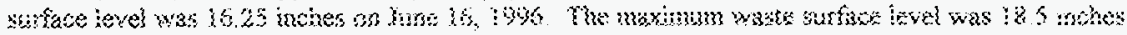

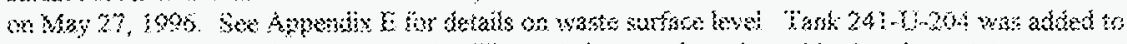

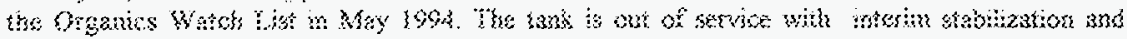

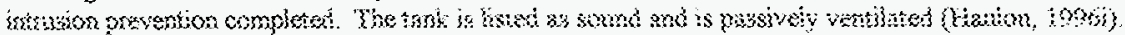

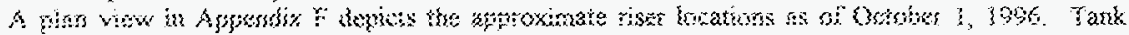

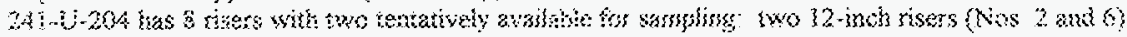
anmiki, 10,ks) 
The clearest and most recent set of interior tank photographs was taken on June 13,1989. Other interior tank photographs are available, but only the photographs showing the waste surface were used to create a montage. The montage has labels identifying some of the monitoring equipment, piping, and risers in the tank. The montage and photographic information are shown in Appendix G.

2.16.6 Inventory Estimate of Tank 241-U-204

The Inventory Estimate from the Hanford Tank Chemical and Radionuclide Inventories: HDW Model Rev. 4 (Agnew et al., 1997) for Tank 241-U-204 is presented in Appendix H. 


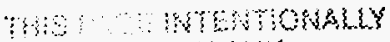
BEF BWAKK 


\section{GLOSSARY}

This glossary of Hanford terminology has been compiled from numerous sources. A lot of the terms have come from Anderson (1990), Jungfleisch (1984) and Agnew et al. (1997). These definitions may conflict with other sources.

IC

$1 \mathrm{C} 1$

$1 \mathrm{C} 2$

$1 \mathrm{CFeCN}$

224

$2 \mathrm{C}$

$2 \mathrm{C} 1$

$2 \mathrm{C} 2$

AlSltCk

A2SltSlr

Active Drywell
First-cycle decontamination waste from the bismuth phosphate $\left(\mathrm{BiPO}_{4}\right)$ process at $\mathrm{B}$ and $\mathrm{T}$ Plants consisting of by-products co-precipitated from a solution containing plutonium (contains $10 \%$ of the original fission product activity and $2 \%$ of the products). By-product cake solution was mixed with product waste and neutralized with $50 \%$ caustic. Coating waste from removing aluminum fuel element cladding was added and comprised about $24 \%$ of the waste.

First-cycle decontamination waste from the bismuth phosphate $\left(\mathrm{BiPO}_{4}\right)$ process, 1944-49 (LANL defined waste \#3)

First-cycle decontamination waste from the bismuth phosphate $\left(\mathrm{BiPO}_{4}\right.$ ) process, 1950-56 (LANL defined waste \#4)

Ferrocyanide sludge produced by in-plant scavenging of 1C supernatant wastes (LANL defined waste \#12)

224-U Waste. $\mathrm{LaF}_{3}$ finishing waste from $\mathrm{BiPO}_{4}$ process and uranium recovery in the 224 buildings by $T$ Plant and B Plant and the Plutonium Finishing Plant (LANL defined waste \#7)

Second-cycle decontamination waste from the bismuth phosphate $\left(\mathrm{BiPO}_{4}\right)$ process at $\mathrm{B}$ and T Plants (see second-cycle decontamination waste)

Second-cycle decontamination waste from the bismuth phosphate $\left(\mathrm{BiPO}_{4}\right.$ ) process, 1944-49 (LANL defined waste \#5)

Second-cycle decontamination waste from the bismuth phosphate $\left(\mathrm{BiPO}_{4}\right)$ process, 1950 -56 (LANL defined waste \#6)

Salt cake waste generated from the 242-A EvaporatorCrystallizer from 1977 until 1980.

Salt slurry waste generated from the 242-A EvaporatorCrystallizer from 1981 until 1994.

Drywell in which radiation readings of greater than 50 counts per second are detected. The readings must be consistent as to 
Andit cirnizer

$A K$

Assumed Yogker

3

br

3

324

$\mathrm{BN}$

BSITKK

Bxisters

Cuscato

Cancir Tanks

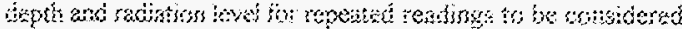
ustios

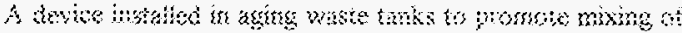

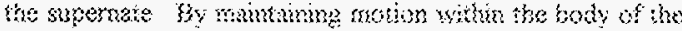

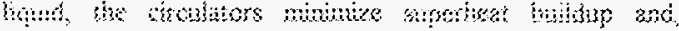

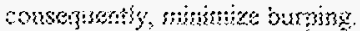

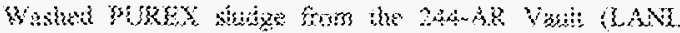
3ested unte

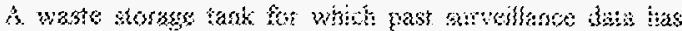

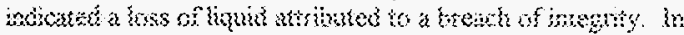

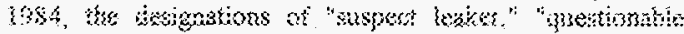

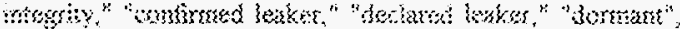
und "bonderling" "were morsed incs one chtegory abled "assurace iesker."

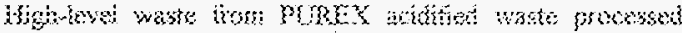

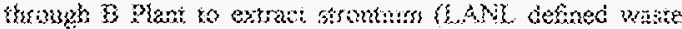
स323

Below grasis

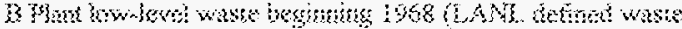
(1)3)

Bench smets.

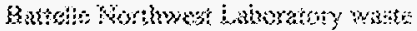

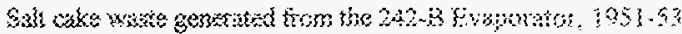

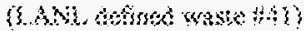

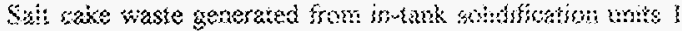

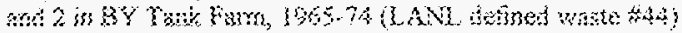

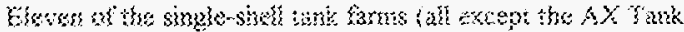

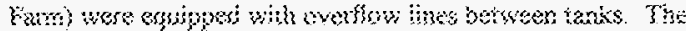

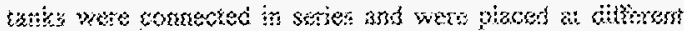

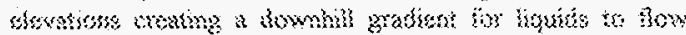

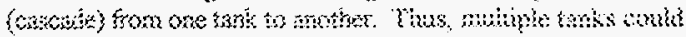

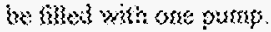

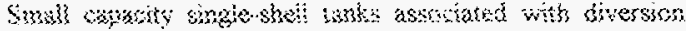

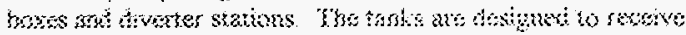


any transfer line clean out, spills or leakage from the boxes, or leakage from the adjacent pipe encasement.

$\mathrm{CC}$

CCPLX

CEM

CPLX

Crib

CSR

CW

CWP1

CWP2

CWP/ZR

CWRI

CWR2

CWZR1

Complexant concentrate waste or concentrated complexant; concentrated product from evaporating dilute complexed waste which contained high concentrations of organic complexants, such as HEDTA, EDTA, and citric acid.

Complexant concentrate or concentrated complexant waste; see CC

Cement (LANL defined waste \#37)

Complexed waste; dilute waste containing relatively high concentrations of organic chelating agents such as EDTA and HEDTA from B Plant waste fractioniztion.

An underground structure filled with aggregate designed to receive liquid waste, usually through a perforated pipe. The filtration and ion exchange properties of the soil in and around the crib were used to contain the radionuclides.

Waste (supernate) from cesium recovery of tank supernate at B Plant (LANL defined waste \#35)

Coating (cladding) waste produced at PUREX from dissolution of Zircaloy or aluminum fuel cladding.

Coating (cladding) waste (PUREX); (LANL defined waste $\# 21$, CWP/Al, 1956-60)

Cladding (coating) waste (PUREX), (LANL defined waste \#22, CWP/Al, 1961-72)

Now called PD or NCRW

REDOX cladding (coating) waste, (LANL defined waste \#15, CWR/Al, 1952-60)

Coating (cladding) waste (REDOX), (LANL defined waste \#16, CWL/Al with some $\mathrm{Zr}, 1961-72$ )

Coating (cladding) waste (PUREX), Zircaloy cladding; 1968-72 (LANL defined waste \#23) 
SARRO

bs:

Ditch

ons.

BWorson $8 \%$

BS:

Brywe:

by

D8

85:

mas

Esaporar $5 \times 4$

Ferropystide

$M 6$

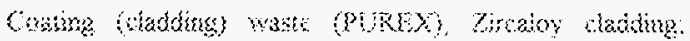

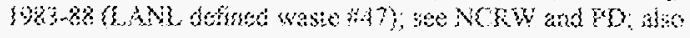
known as choph

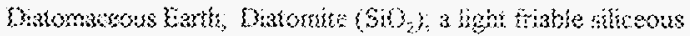

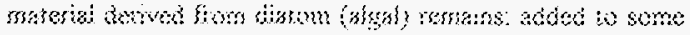

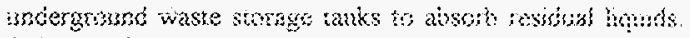

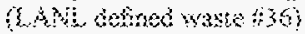

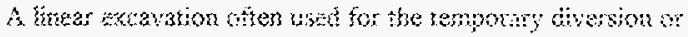
disponal a prosss waste wreams:

Dinte fees for Eraponter

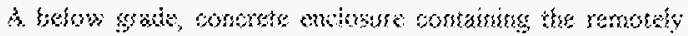

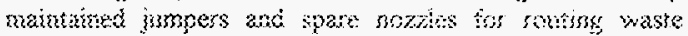
solwow to storage tank farm:

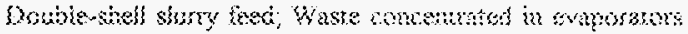

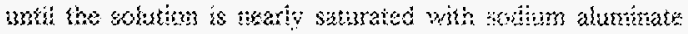

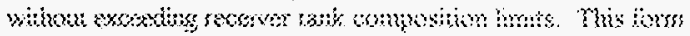

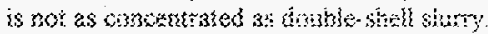

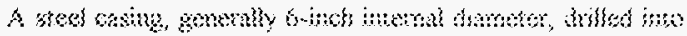

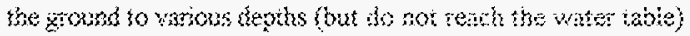

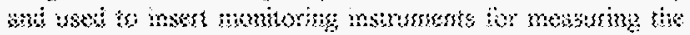

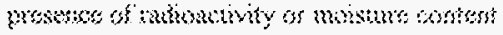

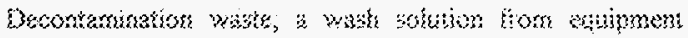

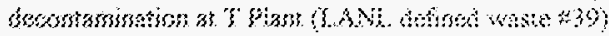

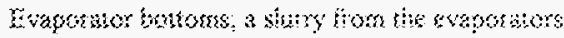

Exaporast text; qurious superratant ifouids whose

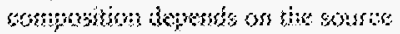

Evaponator fees (posi 3976 siesiymatoris)

Any wate lizubl that con se concentrated to from salt cake,

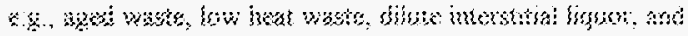
ther ratioactive whste solutions

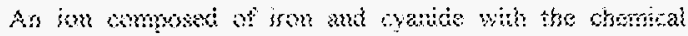

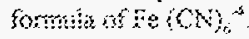

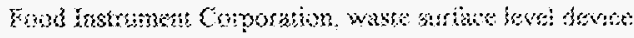


HDRL

HLO

HS

ILL

Inactive Tank

Interim Isolation

Interim Stabilization

Interstitial Liquid

Intrusion Prevention

IX

Knuckle
Hanford defense residual liquor; late 1970s designation for terminal liquors remaining after evaporation; includes complexed and noncomplexed waste, partially neutralized waste, and DSSF (see RESID).

Hanford Laboratory Operations; also, Hanford laboratory operations waste; laboratory waste from the 300 Area

Hot Semiworks (C Plant); a pilot facility with a variety of operations. Also, Hot or Strontium Semiworks waste (LANL defined waste \#28); see SSW.

Interstitial liquid level

A tank that has been removed from liquid-processing service, has been pumped to less than 33,000 gallons of waste, and will be, or is in the process of being, stabilized followed by intrusion prevention. This includes all tanks not in active or active-restricted categories. Also included are inactive spare tanks that would be used if an active tank failed.

An administrative designation reflecting the completion of the physical effort required to minimize the addition of liquids into an inactive storage tank, process vault, sump, catch tank, or diversion box. (In June 1993, "interim isolation" was replaced by "intrusion prevention".)

A tank which contains less than 50,000 gallons of drainable interstitial liquid and less than 5,000 gallons of supernate. If a jet pump was used to achieve interim stabilization, then the jet pump flowrate must have been at or below 0.05 gallons per minute before interim stabilization was completed.

The interstitial liquid within the tanks is the liquid that fills the interstitial (voids) spaces of the solid waste.

An administrative designation reflecting the completion of the physical effort required to minimize the addition of liquids into an inactive storage tank, process vault, catch tank, sump, or diversion box

Ion exchange waste from the cesium recovery process at B Plant

Point where the side wall and the bottom curved surface of a tank meet. 
Level Adustment

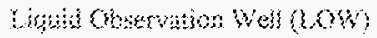

(3)

WI

Mixed wase

BS

BW:

32

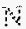

NAB

$\operatorname{sich} x$

mav

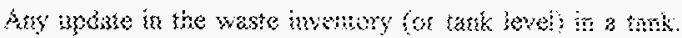

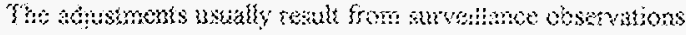
or homisa mosigsions.

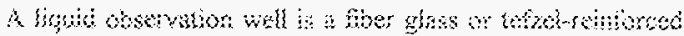

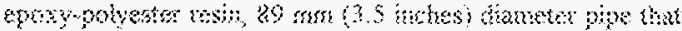

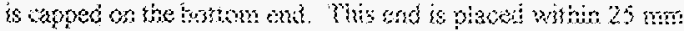

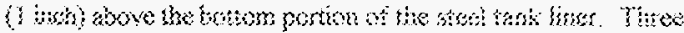

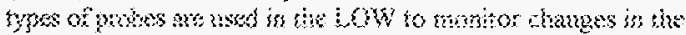

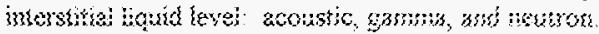

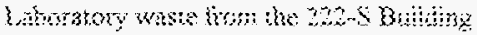

Matiole

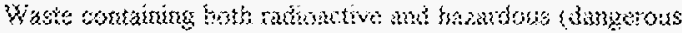

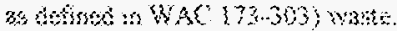

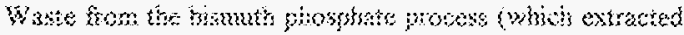

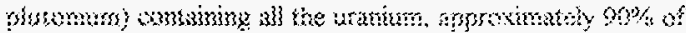

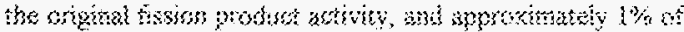

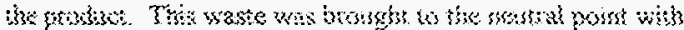
30 wath and inen reated with an wees of somu

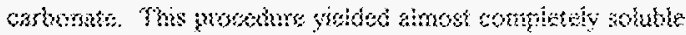

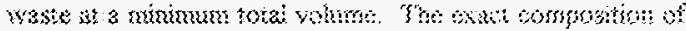

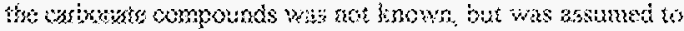
be a unhure phosphate carbonate mixure, The tem. "metal" was the coce wont for phrninen

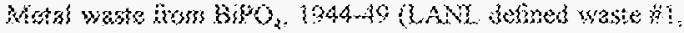
satuc as (NW)

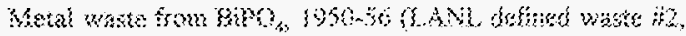
same is $\mathrm{Ar}$ ?

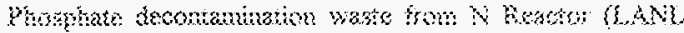
conted wase 340 ?

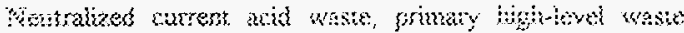

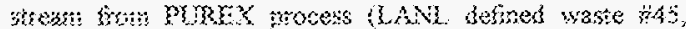

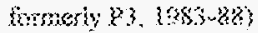

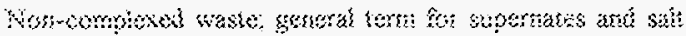

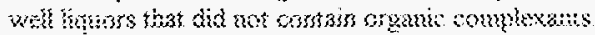

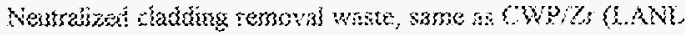

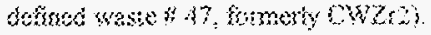


NIT

Non-Complexed

OBSV Port

Out-of-Service-Tank

OWW

OWW1

OWW2

OWW3

$\mathbf{P}$

P1

P2

P2'

P3

Partial Interim Isolation

PASF

PFeCN1

PFeCN2
$\mathrm{HNO}_{3} / \mathrm{KMNO}_{4}$ solution added during evaporator operation (LANL defined waste \#38)

General waste term applied to all Hanford Site liquors not identified as complexed (containing organics)

Observation Port

A tank that does not meet the definition of an in-service tank. Before September 1988, these tanks were defined as inactive. (Note: All single-shell tanks are out of service.)

Organic Wash Waste; The solvent used in PUREX was treated before reuse by washing with potassium permanganate and sodium carbonate, followed by dilute nitric acid.

Organic wash waste, 1956-62, also known as CARB (LANL defined waste \#24)

Organic wash waste, 1963-67 (LANL defined waste \#25)

Organic wash waste, 1968-72 (LANL defined waste \#26)

High-level neutralized acid waste from PUREX

PUREX high-level waste, 1956-62 (LANL defined waste \#17)

PUREX high-level waste, 1963-67 (LANL defined waste \#18)

1968-1972, assigned to P2. (LANL defined waste \#19)

1983-1988, now called PXNAW or NCAW. (LANL defined waste \#45)

The administrative designation for completing the physical effort required for interim isolation, except for isolating the risers and piping that will be required for jet pumping or for other methods of stabilization.

PUREX ammonia scrubber feed (LANL defined waste \#48)

Ferrocyanide sludge produced by in-plant scavenging (using $0.005 \mathrm{M}$ ferrocyanide) of waste from uranium recovery (LANL defined waste \#9)

Same as PFeCNl except $0.0025 \mathrm{M}$ ferrocyanide used (LANL defined waste \#10) 
p.

Ps.

W.

$\Re 2$

W:

Frimany Absition

ks 5

$2 \times 030$

FXNAW

r

$\mathrm{s}$

$\$ 2$

resse

wise

$2 X$

serces

Sasto:

S\$tE3r

$\operatorname{sAS}$

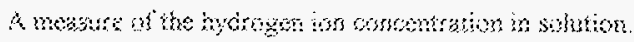

bowken wask tom derex

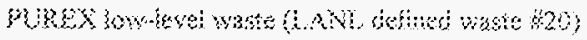

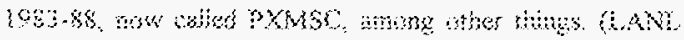
aninod westens

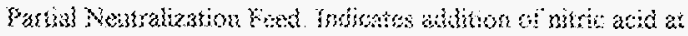

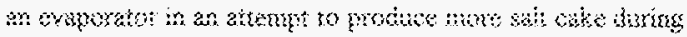
whime seductim.

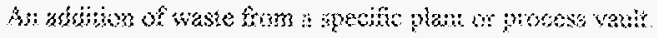

pukex Suge bummems

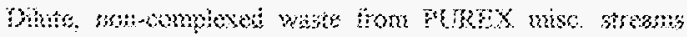
(AN) defned wate 446 , fommly pla)

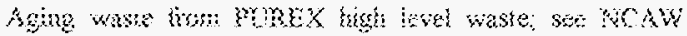

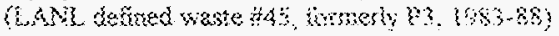

Menhasol wase tom REOOX

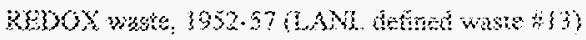

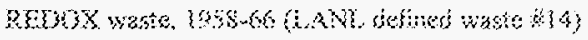

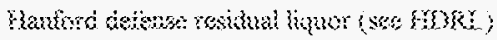

A retcal pipe throuph a tank done aceess at the tank interims.

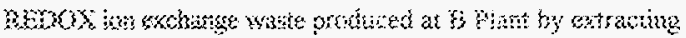

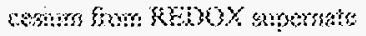

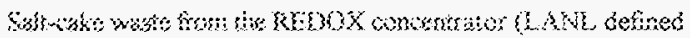
whate 4 is?

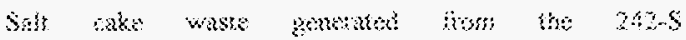

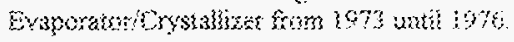

Salt cole wase gonented trom tixe 242 -8

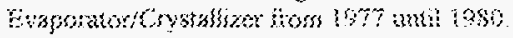

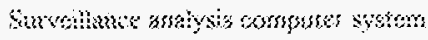


Salt Cake

Salt Well

Scavenged Waste

Self-Concentrating Waste

Sluicing, or sluiced

Slurry

SMM

SMP

SMMS1

SMMS2

SMMT2

Sound

SRR

SST
Crystallized nitrate and other salts deposited in waste tanks, usually after the waste is concentrated by evaporation.

A hole drilled or sluiced into salt cake and lined with a cylindrical screen to permit drainage and jet pumping of interstitial liquids.

Waste which has been treated with ferrocyanide to remove cesium from the supernate by precipitating it into a sludge.

Liquid, high-level radioactive waste whose decaying radionuclides heat the solution sufficiently to boil off (i.e., evaporate) the water, thus concentrating the waste.

To wash with water. At Hanford, this has meant to dissolve or suspend waste in solution using a high pressure water stream.

Insoluble material suspended in water or aqueous solution.

Supernatant Mixing Model (created at LANL) that calculates the composition of tank liquids and concentrates as linear combinations of supernates.

Sludge measuring port

Solids from concentrate calculated by SMM

Solids from concentrate calculated by SMM

Solids from concentrate calculated by SMM

The integrity classification of a waste storage tank for which surveillance data indicate no loss of liquid attributed to a breach of integrity.

Sluiced PUREX sludge from A and AX Tank Farms sent to B Plant to recover strontium from 1967-76 (LANL defined waste \#34). The sludge returned from B Plant was sent to the AR Vault and the supernate was sent to 241-C-105.

Single-shell tank 
Giakhativa

Sispenaran a Bupmonto

$\operatorname{ISXYK}$

MastTSE

haxk ram

Tiss

Torinsu! kiques

Iores

Yl:

$\dddot{32}$

Thexmoryis

Themongle ? ree
The iemoxl or immobilizion, as comploty at possible, of

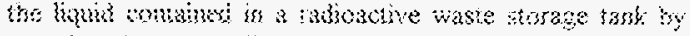

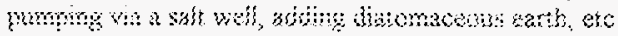

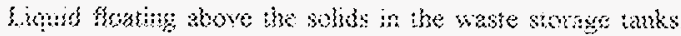

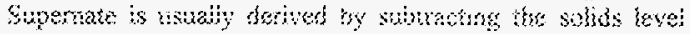

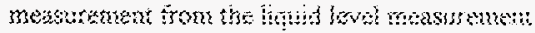

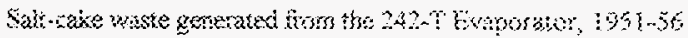

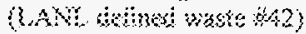

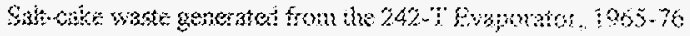

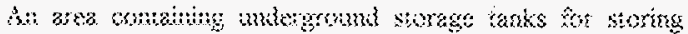
waste.

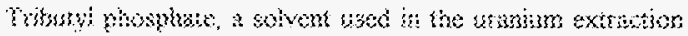

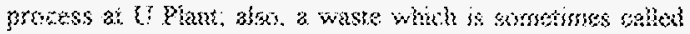
aranum rectery waste (t).

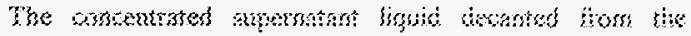

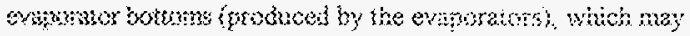

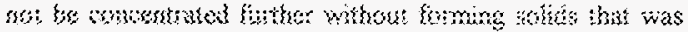

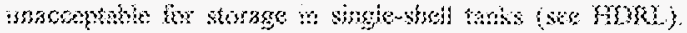

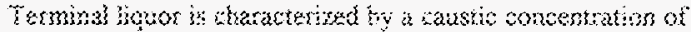

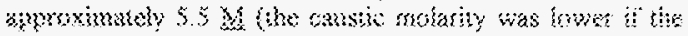

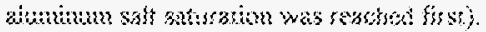

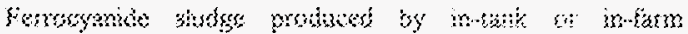

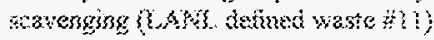

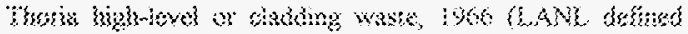
waste wat formery thist?

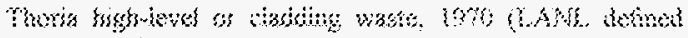

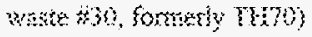

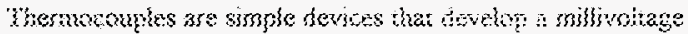

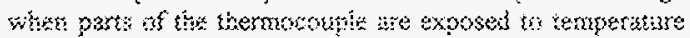

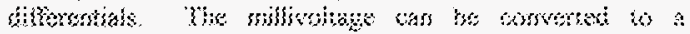
rempertire rating bases apon a spetho nhage versus

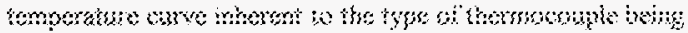

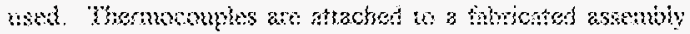
ratied a themempinie tree.

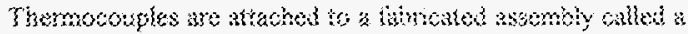

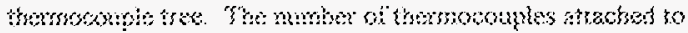


Thorium

TL

TLM

Trench

TRUEX

UNK

UR

Watch List Tank

WC

WESF

WTR

Wyden Amendment

Z the tree varies as a function of the depth of the tank as well as the thermocouple tree design. The thermocouples are spaced at intervals, along trees that have many thermocouples, so that a vertical temperature profile of the tank contents can be developed. The thermocouple tree is installed in a riser and left in place inside the tank.

A chemical element which is fertile material. Fertile means that when it is subjected to radiation in a nuclear reactor, it will be converted, in this case, to ${ }^{233} \mathrm{U}$, a potential fuel.

Terminal Liquor

Tank Layer Model (created at LANL and derived from Waste Status and Transaction Record Summary (Agnew et al., 1996) database) models the volumes of wastes in the tanks.

A linear excavation used for the disposal of solid waste.

Transuranic extraction process

Unknown waste type (LANL defined waste)

Uranium recovery operation in U Plant, 1952-57. Created uranium recovery waste (UR) (LANL defined waste \#8), also known as tributyl phosphate (TBP) waste, and $\mathrm{FeCN}$ (scavenging wastes). See TFeCN and PFeCN.

An underground storage tank requiring special safety precautions because the tank potentially could release highlevel radioactive waste if uncontrolled increases in pressure or temperature occur. Special restrictions have been placed on the tanks by "Safety Measures for Waste Tanks at Hanford Nuclear Reservation," Section 3137, National Defense Authorization Act for Fiscal Year 1991, November 5, 1990, Public Law 101-501 (also called the Wyden Amendment).

Weather cover

Waste Encapsulation and Storage Facility

Water; flush water from miscellaneous sources.

See watch list tank

Waste discharged from $\mathrm{Z}$ Plant (PFP) (LANL defined waste \#27) 


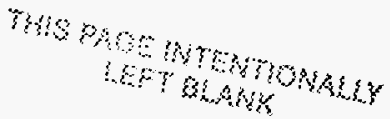




\section{REFERENCES}

Agnew, S.F., R.A. Corbin, T.B. Duran, K.A. Jurgensen, T.P. Ortiz, and B.L. Young; September 1995; Waste Status and Transaction Record Summary for the Southwest Quadrant; WHC-SD-WM-TI-614, Rev. 1; Los Alamos National Laboratory, Los Alamos, New Mexico.

Agnew, S.F., J. Boyer, R.A. Corbin, T.B. Duran, J. FitzPatrick, K.A. Jurgensen, T.P. Ortiz, and B.L Young; 1997; Hanford Tank Chemical and Radionuclide Inventories: HDW Model Rev. 4; LA-UR-96-3860; Los Alamos National Laboratory, Los Alamos, New Mexico.

Alstad, A.T.; December 1993; Riser Configuration Document for Single-Shell Waste Tanks; WHC-SD-RE-TI-053, Rev. 9; Westinghouse Hanford Company, Richland, Washington.

Anderson, J.D.; June 1990; A History of the 200 Areas Tank Farms; WHC-MR-0132; Westinghouse Hanford Company, Richland, Washington.

Ballinger, M.Y., and R.B. Hall; March 1991; A History of Major Hanford Facilities and Processes Involving Radioactive Material; PNL-6964 HEDR; Pacific Northwest Laboratory, Richland, Washington.

Borsheim, G.L., and N.W. Kirch; March 1991; Summary of Single-Shell Tank Waste Stability; WHC-EP-0347; Westinghouse Hanford Company, Richland, Washington.

Brevick, C.H., and J. L. Stroup; January 1997a; Supporting Document for the Historical Tank Content Estimate for S Tank Farm; HNF-SD-WM-ER-323, Rev. 1; Fluor Daniel Northwest, Inc., Richland, Washington.

Brevick, C.H., and J. L. Stroup; January 1997b; Supporting Document for the Historical Tank Content Estimate for SX Tank Farm; HNF-SD-WM-ER-324, Rev. 1; Fluor Daniel Northwest, Inc., Richland, Washington.

Brevick, C.H., and J. L. Stroup; January 1997c; Historical Tank Content Estimate for the Southwest Quadrant of the Hanford 200 West Area; HNF-SD-WM-ER-352, Rev. 1; Fluor Daniel Northwest, Inc., Richland, Washington.

Brevick, C.H., L. A. Gaddis, and W. W. Pickett; June 1994; Historical Tank Content Estimate for the Southwest Quadrant of the Hanford 200 West Area; WHC-SD-WM-ER-352, Rev. Ob; ICF Kaiser Hanford, Richland, Washington.

Brevick, C.H., L.A. Gaddis, and E. D. Johnson; June 1994, Supporting Document for the Historical Tank Content Estimate for U Tank Farm; WHC-SD-WM-ER-325, Rev. 0; ICF Kaiser Hanford, Richland, Washington.

Carter, G.J.; May 1986a; Waste Status Summary, April 1986; RHO-RE-SR-14; Rockwell Hanford Operations, Richland, Washington.

Carter, G.J.; June 1986b; Waste Status Summary, May 1986; RHO-RE-SR-14; Rockwell Hanford Operations, Richland, Washington. 


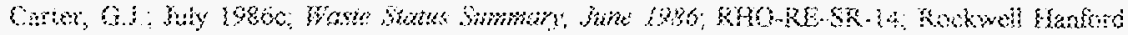
Operations, Richand, Wasibington

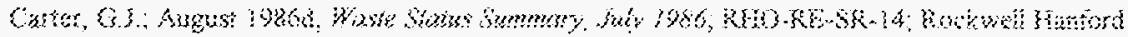

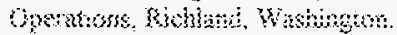

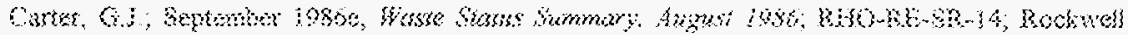

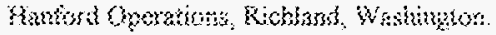

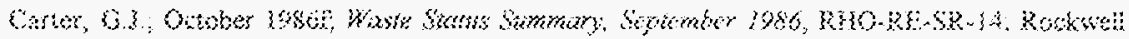

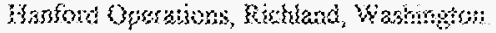

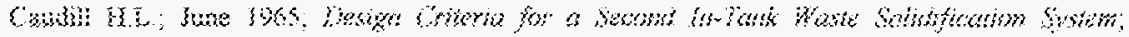

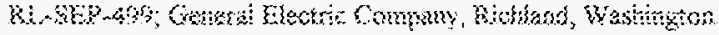

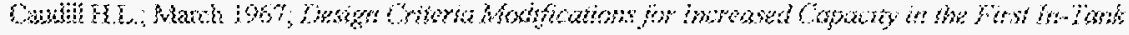

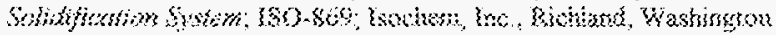

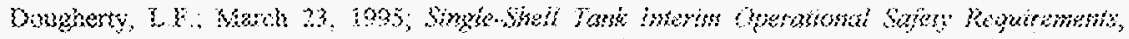

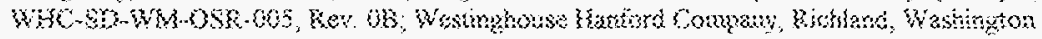

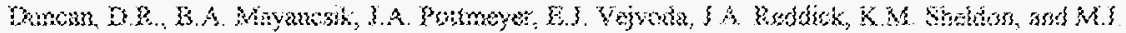

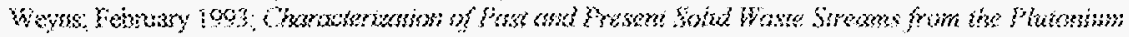

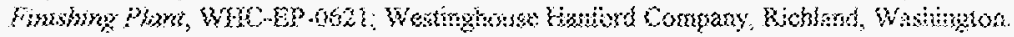

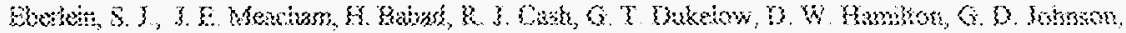

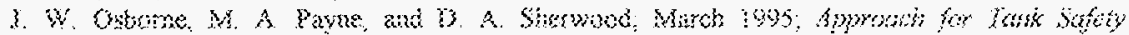

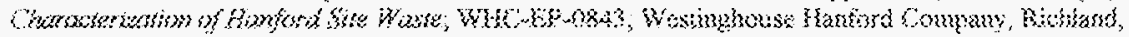
Washingtwon.

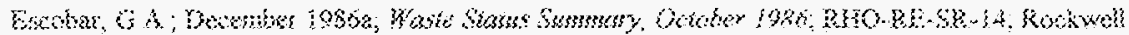

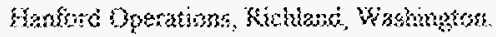

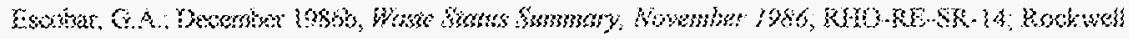

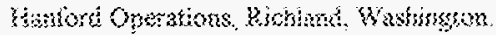

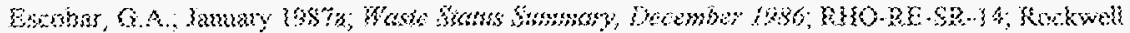
Hantond Oparations, Fichiand. Wiahington.

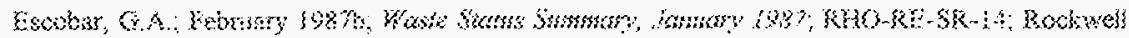

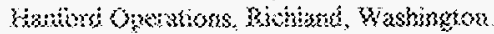

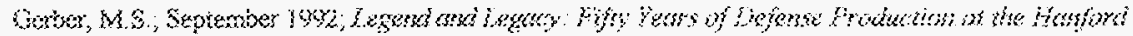

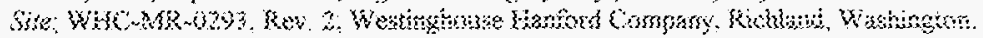

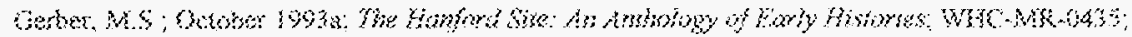

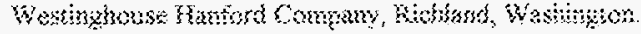


Gerber, M.S.; November 1993b; A Brief History of the PUREX and UO ${ }_{3}$ Facilities; WHC-MR-0437; Westinghouse Hanford Company, Richland, Washington.

Gerber, M.S.; April 1994a; Dramatic Change at T Plant; WHC-MR-0452; Westinghouse Hanford Company, Richland, Washington.

Gerber, M.S.; 1996; Correspondence to C.V. Salois of ICF Kaiser Hanford; Westinghouse Hanford Company, Richland, Washington.

Godfrey, W.L.; June 1965; 242-T Evaporator Facility, Information Mamual; RL-SEP-396; Hanford Atomic Products Operation, General Electric Company, Richland, Washington.

Hanlon, B.M.; March 1990a; Tank Farm Surveillance and Waste Status Summary Report for November 1989; WHC-EP-0182-20; Westinghouse Hanford Company, Richland, Washington.

Hanlon, B.M; March 1990b; Tank Farm Surveillance and Waste Status Summary Report for December 1989; WHC-EP-0182-21; Westinghouse Hanford Company, Richland, Washington.

Hanlon, B.M.; March 1990c; Tank Farm Surveillance and Waste Status Summary Report for January 1990; WHC-EP-0182-22; Westinghouse Hanford Company, Richland, Washington.

Hanlon, B.M; April 1990d; Tank Farm Surveillance and Waste Status Summary Report for February 1990; WHC-EP-0182-23; Westinghouse Hanford Company, Richland, Washington.

Hanlon, B.M; June 1990e; Tank Farm Surveillance and Waste Status Summary Report for March 1990; WHC-EP-0182-24; Westinghouse Hanford Company, Richland, Washington.

Hanlon, B.M; June 1990f; Tank Farm Surveillance and Waste Status Summary Report for April 1990; WHC-EP-0182-25; Westinghouse Hanford Company, Richland, Washington.

Hanlon, B.M ; August 1990g; Tank Farm Surveillance and Waste Status Summary Report for May 1990; WHC-EP-0182-26; Westinghouse Hanford Company, Richland, Washington.

Hanlon, B.M.; September 1990h; Tank Farm Surveillance and Waste Status Summary Report for June 1990; WHC-EP-0182-27; Westinghouse Hanford Company, Richland, Washington.

Hanlon, B.M; November 1990i; Tank Farm Surveillance and Waste Status Summary Report for July 1990; WHC-EP-0182-28; Westinghouse Hanford Company, Richland, Washington.

Hanlon, B.M; January 1991a; Tank Farm Surveillance and Waste Status Summary Report for August 1990; WHC-EP-0182-29; Westinghouse Hanford Company, Richland, Washington.

Hanlon, B.M.; January 1991b; Tank Farm Surveillance and Waste Status Summary Report for November 1990; WHC-EP-0182-32; Westinghouse Hanford Company, Richland, Washington.

Hanlon, B.M.; February 1991c; Tank Farm Surveillance and Waste Status Summary Report for September 1990; WHC-EP-0182-30; Westinghouse Hanford Company, Richland, Washington. 


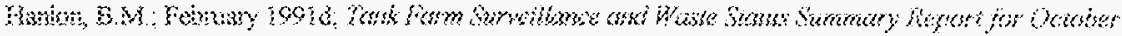

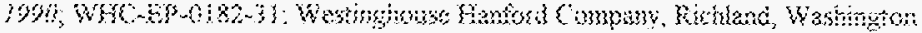

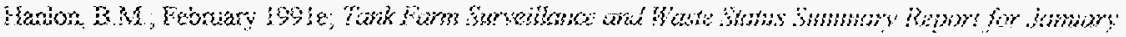

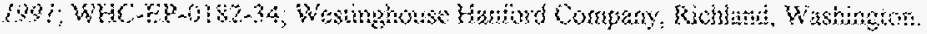

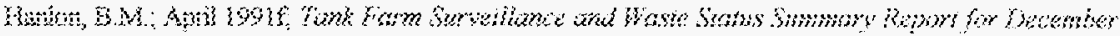

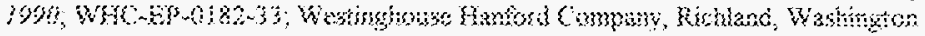

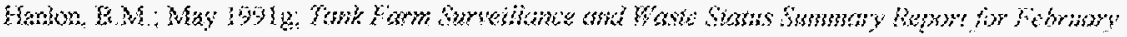

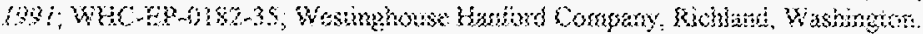

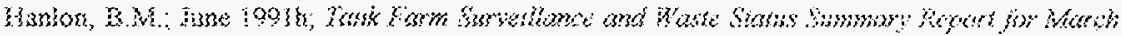

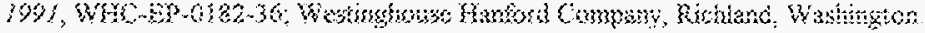

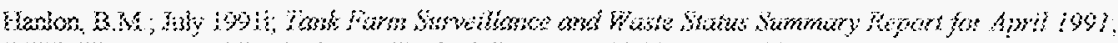

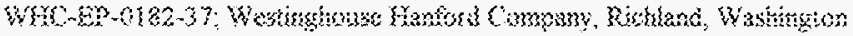

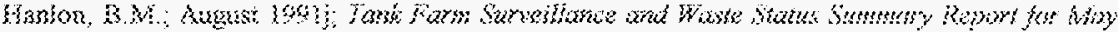

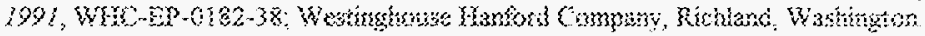

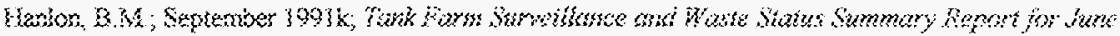

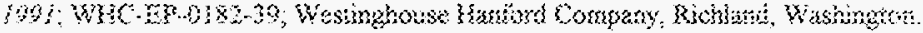

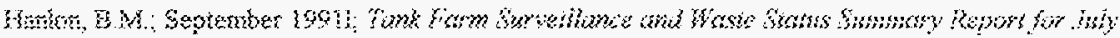

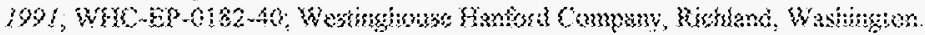

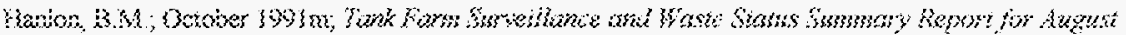

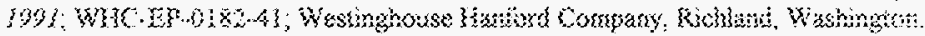

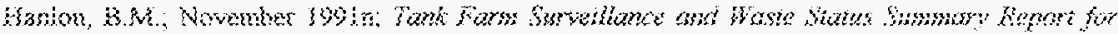
Sopenter 993 ; WACEP

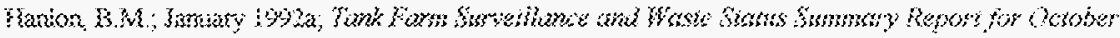

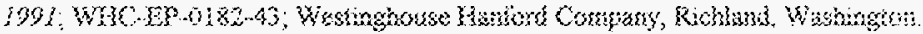

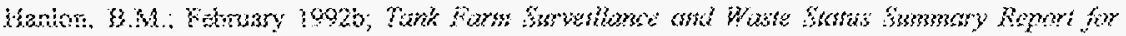

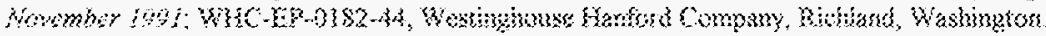

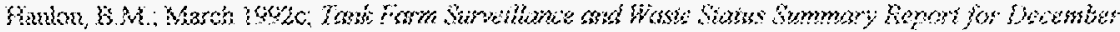

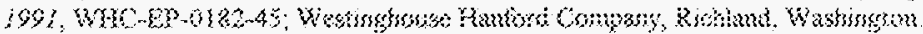

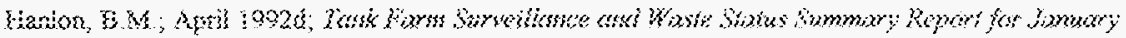

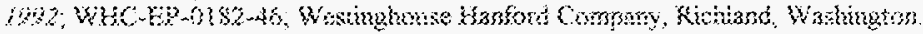

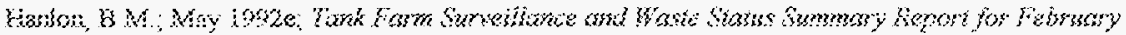

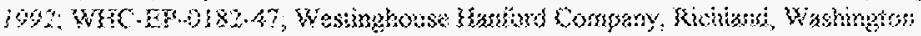


Hanlon, B.M; June 1992f, Tank Farm Surveillance and Waste Status Summary Report for March 1992; WHC-EP-0182-48; Westinghouse Hanford Company, Richland, Washington.

Hanlon, B.M.; July 1992g; Tank Farm Surveillance and Waste Status Summary Report for April 1992 ; WHC-EP-0182-49; Westinghouse Hanford Company, Richland, Washington.

Hanlon, B.M.; August 1992h; Tank Farm Surveillance and Waste Status Summary Report for May 1992; WHC-EP-0182-50; Westinghouse Hanford Company, Richland, Washington.

Hanlon, B.M.; September 1992i; Tank Farm Surveillance and Waste Status Summary Report for June 1992; WHC-EP-0182-51; Westinghouse Hanford Company, Richland, Washington.

Hanlon, B.M.; October 1992j; Tank Farm Surveillance and Waste Status Summary Report for July 1992; WHC-EP-0182-52; Westinghouse Hanford Company, Richland, Washington.

Hanlon, B.M; November 1992k; Tank Farm Surveillance and Waste Status Summary Report for August 1992; WHC-EP-0182-53; Westinghouse Hanford Company, Richland, Washington.

Hanlon, B.M; December 19921; Tank Farm Surveillance and Waste Status Summary Report for September 1992; WHC-EP-0182-54, Westinghouse Hanford Company, Richland, Washington.

Hanlon, B.M.; January 1993a; Tank Farm Surveillance and Waste Status Summary Report for October 1992; WHC-EP-0182-55; Westinghouse Hanford Company, Richland, Washington.

Hanlon, B.M.; February 1993b; Tank Farm Surveillance and Waste Status Summary Report for November 1992; WHC-EP-0182-56; Westinghouse Hanford Company, Richland, Washington.

Hanlon, B.M.; February 1993c; Tank Farm Surveillance and Waste Status Summary Report for December 1992; WHC-EP-0182-57; Westinghouse Hanford Company, Richland, Washington.

Hanlon, B.M.; March 1993d; Tank Farm Surveillance and Waste Status Summary Report for January 1993; WHC-EP-0182-58; Westinghouse Hanford Company, Richland, Washington.

Hanlon, B.M.; April 1993e; Tank Farm Surveillance and Waste Status Summary Report for February 1993; WHC-EP-0182-59; Westinghouse Hanford Company, Richland, Washington.

Hanlon, B.M; May 1993f; Tank Farm Surveillance and Waste Status Summary Report for March 1993; WHC-EP-0182-60; Westinghouse Hanford Company, Richland, Washington.

Hanlon, B.M; July 1993g; Tank Farm Surveillance and Waste Status Summary Report for April 1993; WHC-EP-0182-61; Westinghouse Hanford Company, Richland, Washington.

Hanlon, B.M.; August 1993h; Tank Farm Surveillance and Waste Status Summary Report for May 1993; WHC-EP-0182-62; Westinghouse Hanford Company, Richland, Washington.

Hanlon, B.M.; October 1993i; Tank Farm Surveillance and Waste Status Summary Report for June 1993; WHC-EP-0182-63; Westinghouse Hanford Company, Richland, Washington. 


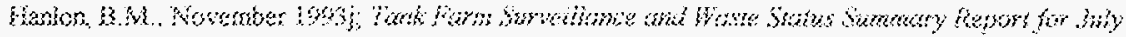

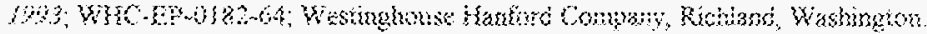

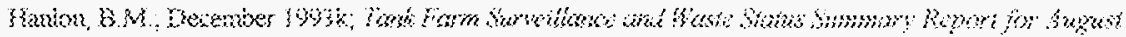

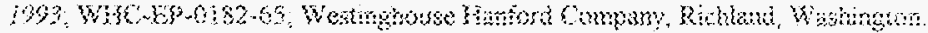

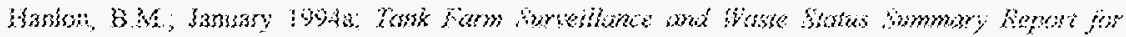

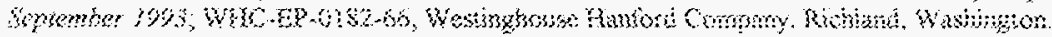

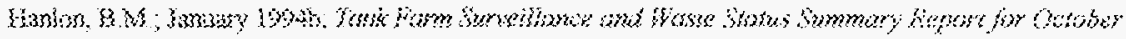

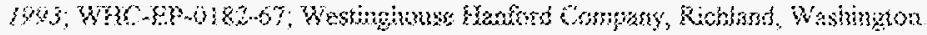

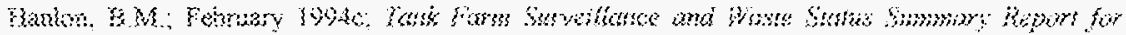

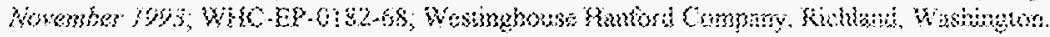

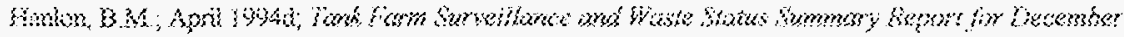

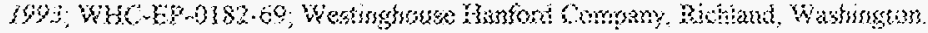

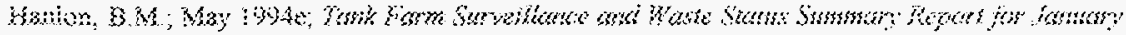

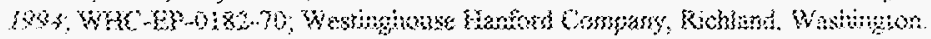

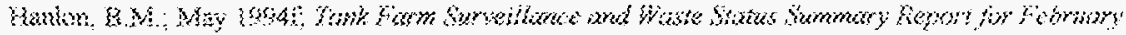

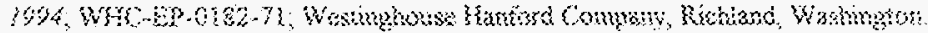

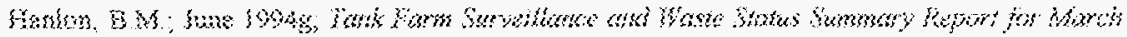

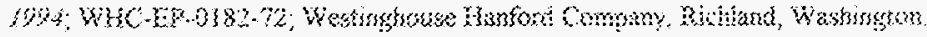

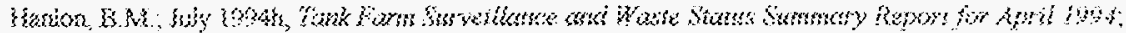

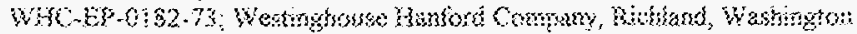

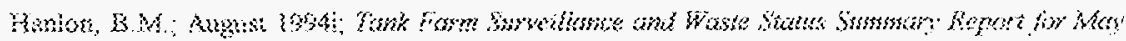

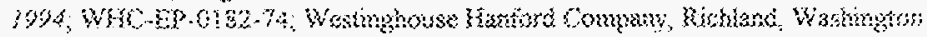

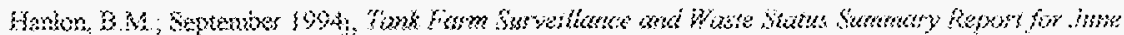

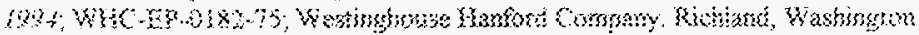

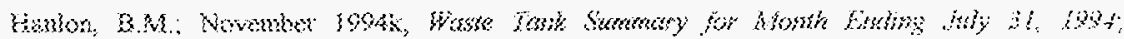

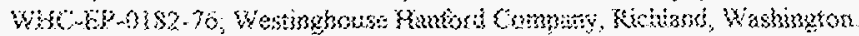

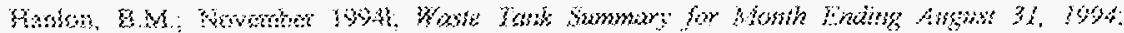

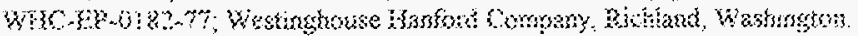

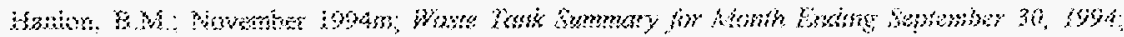

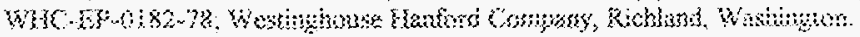

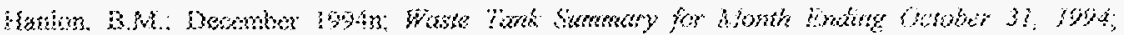

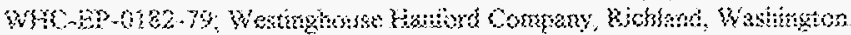


Hanlon, B.M.; January 1995a; Waste Tank Summary for Month Ending November 30, 1994; WHC-EP-0182-80; Westinghouse Hanford Company, Richland, Washington.

Hanlon, B.M; February 1995b; Waste Tank Summary for Month Ending December 31, 1994; WHC-EP-0182-81; Westinghouse Hanford Company, Richland, Washington.

Hanlon, B.M.; March 1995c; Waste Tank Summary for Month Ending January 31, 1995; WHC-EP-0182-82; Westinghouse Hanford Company, Richland, Washington.

Hanlon, B.M.; April 1995d; Waste Tank Summary for Month Ending February 28, 1995; WHC-EP-0182-83; Westinghouse Hanford Company, Richland, Washington.

Hanlon, B.M.; May 1995e; Waste Tank Summary for Month Ending March 31, 1995; WHC-EP-0182-84; Westinghouse Hanford Company, Richland, Washington.

Hanlon, B.M; June 1995f; Waste Tank Summary for Month Ending April 30, 1995; WHC-EP-0182-85; Westinghouse Hanford Company, Richland, Washington.

Hanlon, B.M; July 1995g; Waste Tank Summary for Month Ending May 31, 1995; WHC-EP-0182-86; Westinghouse Hanford Company, Richland, Washington.

Hanlon, B.M; August 1995h; Waste Tank Summary for Month Ending June 30, 1995; WHC-EP-0182-87; Westinghouse Hanford Company, Richland, Washington.

Hanlon, B.M.; September 1995i; Waste Tank Summary for Month Ending July 31, 1995; WHC-EP-0182-88; Westinghouse Hanford Company, Richland, Washington.

Hanlon, B.M.; October 1995j; Waste Tank Summary for Month Ending August 31, 1995; WHC-EP-0182-89; Westinghouse Hanford Company, Richland, Washington.

Hanlon, B.M; December 1995k; Waste Tank Summary for Month Ending September 30, 1995; WHC-EP-0182-90; Westinghouse Hanford Company, Richland, Washington.

Hanlon, B.M.; January 1996a; Waste Tank Summary for Month Ending October 31, 1995; WHC-EP-0182-91; Westinghouse Hanford Company, Richland, Washington.

Hanlon, B.M.; February 1996b; Waste Tank Summary for Month Ending November 30, 1995; WHC-EP-0182-92; Westinghouse Hanford Company, Richland, Washington.

Hanlon, B.M.; February 1996c; Waste Tank Summary for Month Ending December 31, 1995; WHC-EP-0182-93; Westinghouse Hanford Company, Richland, Washington.

Hanlon, B.M; April 1996d; Waste Tank Summary for Month Ending January 31, 1996; WHC-EP-0182-94; Westinghouse Hanford Company, Richland, Washington.

Hanlon, B.M.; April 1996e; Waste Tank Summary for Month Ending February 29, 1996; WHC-EP-0182-95; Westinghouse Hanford Company, Richland, Washington. 


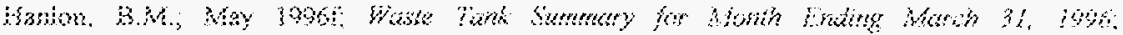

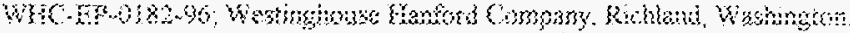

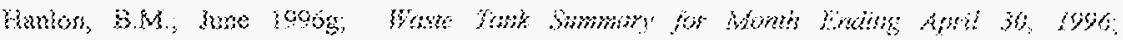

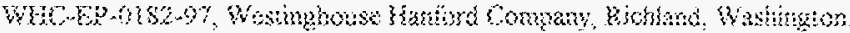

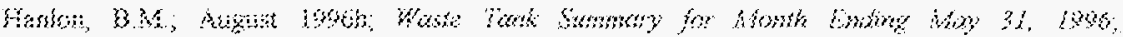

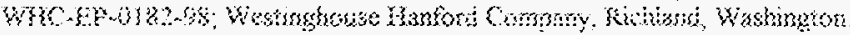

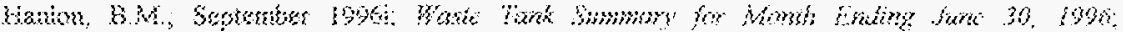

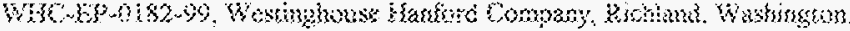

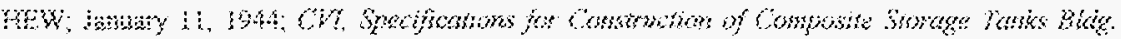

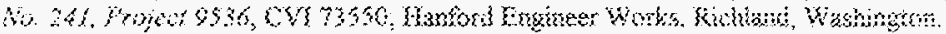

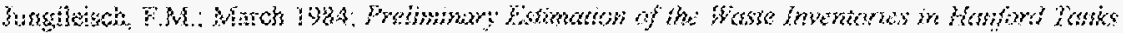

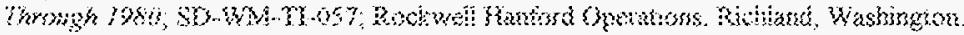

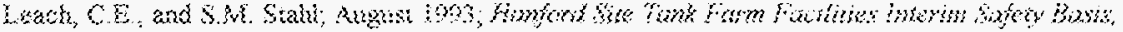

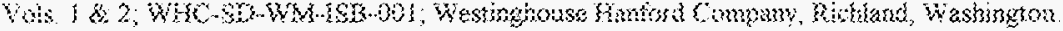

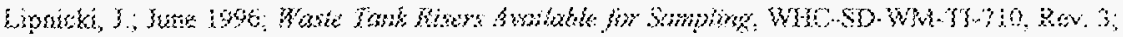

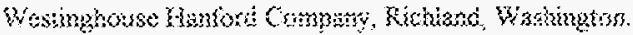

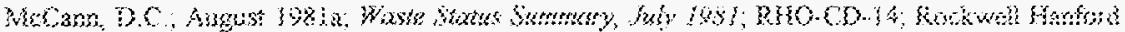

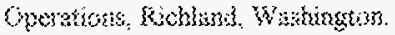

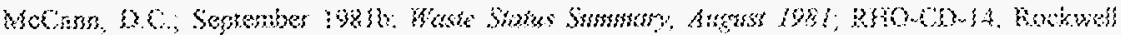

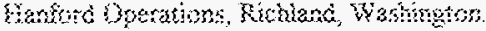

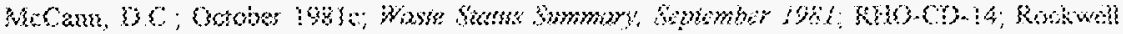
Howori Operatons Richlon Washington.

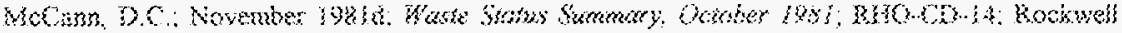
Eankic Oparations, Richanc Wasington.

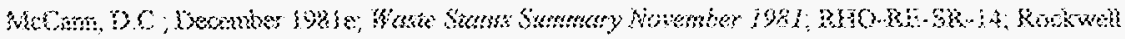

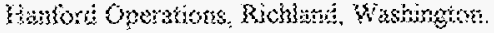

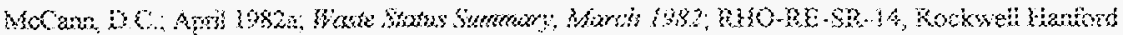
Oprsations, Sithand, Xashineron.

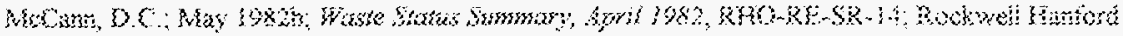

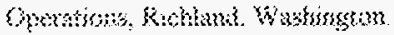

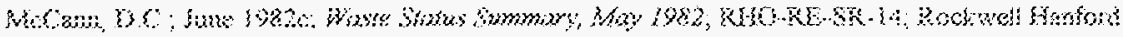

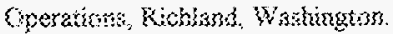


HNF-SD-WM-ER-325, Rev. 1

McCann, D.C.; July 1982d; Waste Status Summary, June 1982; RHO-RE-SR-14; Rockwell Hanford Operations, Richland, Washington.

McCann, D.C.; August 1982e; Waste Status Summary, July 1982; RHO-RE-SR-14; Rockwell Hanford Operations, Richland, Washington.

McCann, D.C.; September 1982f; Waste Status Summary, August 1982; RHO-RE-SR-14; Rockwell Hanford Operations, Richland, Washington.

McCann, D.C.; October 1982g; Waste Status Summary, September 1982; RHO-RE-SR-14; Rockwell Hanford Operations, Richland, Washington.

McCann, D.C.; November 1982h; Waste Status Summary, October 1982; RHO-RE-SR-14; Rockwell Hanford Operations, Richland, Washington.

McCann, D.C.; December 1982i; Waste Status Summary, November 1982; RHO-RE-SR-14; Rockwell Hanford Operations, Richland, Washington.

McCann, D.C.; January 1983a; Waste Status Summary, December 1982; RHO-RE-SR-14; Rockwell Hanford Operations, Richland, Washington.

McCann, D.C.; February 1983b; Waste Status Summary, January 1983; RHO-RE-SR-14; Rockwell Hanford Operations, Richland, Washington.

McCann, D.C.; March 1983c; Waste Status Summary, February 1983; RHO-RE-SR-14; Rockwell Hanford Operations, Richland, Washington.

McCann, D.C.; April 1983d; Waste Status Summary, March 1983; RHO-RE-SR-14; Rockwell Hanford Operations, Richland, Washington.

McCann, D.C.; May 1983e; Waste Status Summary, April 1983; RHO-RE-SR-14; Rockwell Hanford Operations, Richland, Washington.

McCann, D.C.; June 1983f, Waste Status Summary, May 1983; RHO-RE-SR-14; Rockwell Hanford Operations, Richland, Washington.

McCann, D.C.; July 1983g; Waste Status Summary, June 1983; RHO-RE-SR-14; Rockwell Hanford Operations, Richland, Washington.

McCann, D.C.; August 1983h; Waste Status Summary, July 1983; RHO-RE-SR-14; Rockwell Hanford Operations, Richland, Washington.

McCann, D.C.; September 1983i; Waste Status Summary, August 1983; RHO-RE-SR-14; Rockwell Hanford Operations, Richland, Washington.

McCann, D.C.; October 1983j; Waste Status Summary, September 1983; RHO-RE-SR-14; Rockwell Hanford Operations, Richland, Washington. 


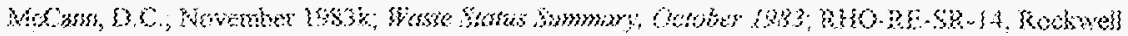

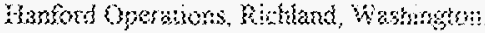

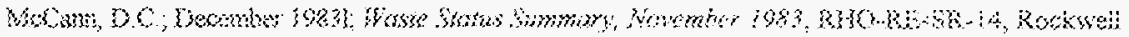

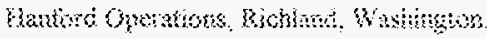

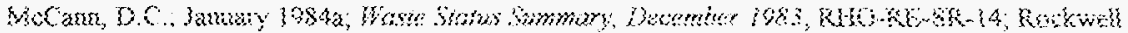

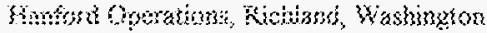

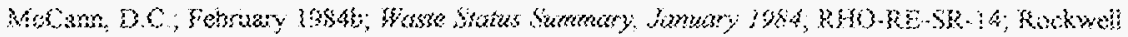

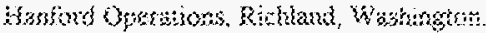

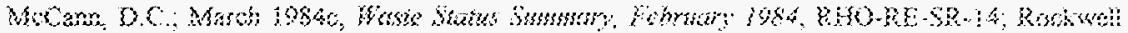

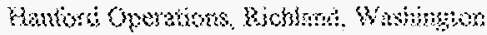

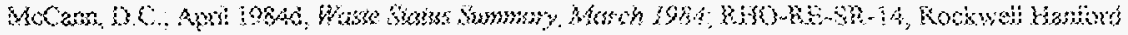

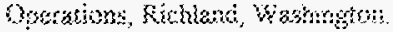

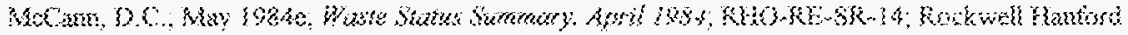
Opentons, Rishond Basingion.

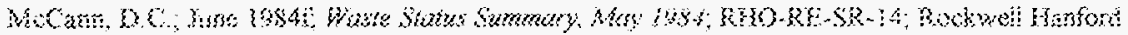
Gperatonit, Rohiso. Wastimptos.

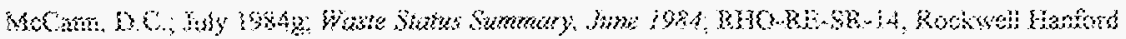

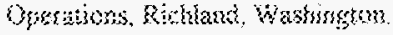

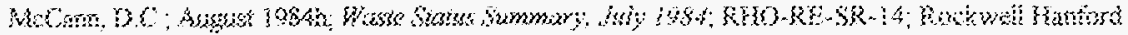

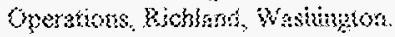

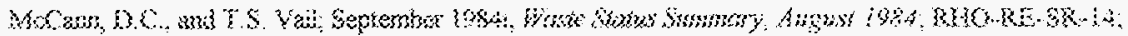

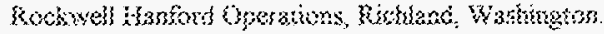

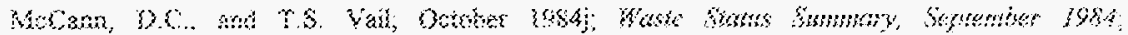

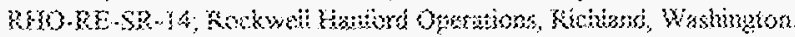

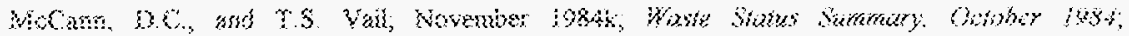

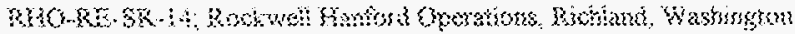

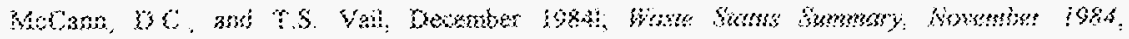

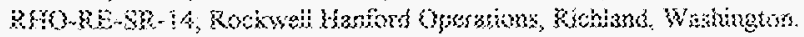

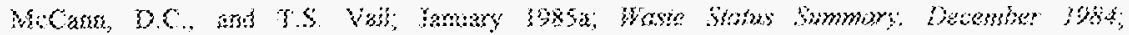

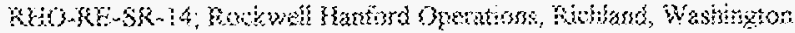

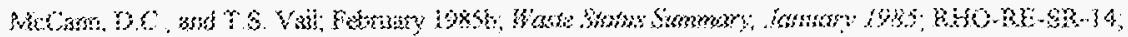

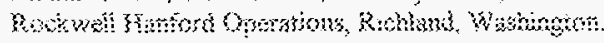


McCann, D.C., and T.S. Vail; March 1985c; Waste Status Summary, February 1985; RHO-RE-SR-14; Rockwell Hanford Operations, Richland, Washington.

Mudd, O.C.; February 1981a; Waste Status Summary, January 1981; RHO-CD-14, Rockwell Hanford Operations, Richland, Washington.

Mudd, O.C.; March 1981b; Waste Status Summary, February 1981; RHO-CD-14; Rockwell Hanford Operations, Richland, Washington.

Mudd, O.C.; April 1981c; Waste Status Summary, March 1981; RHO-CD-14; Rockwell Hanford Operations, Richland, Washington.

Mudd, O.C.; May 1981d; Waste Status Summary, April 1981; RHO-CD-14; Rockwell Hanford Operations, Richland, Washington.

Mudd, O.C.; June 1981e; Waste Status Summary, May 1981; RHO-CD-14; Rockwell Hanford Operations, Richland, Washington.

Mudd, O.C., and D.C. McCann; July 1981f; Waste Status Summary, June 1981; RHO-CD-14; Rockwell Hanford Operations, Richland, Washington.

Pianka, E.W; January 24, 1995; Soil Load above Hanford Waste Storage Tanks; WHC-SD-WM-TI-665, Rev. 0A; Westinghouse Hanford Company, Richland, Washington.

PNL; 1991; Resource Book - Decommissioning of Contaminated Facilities at Hanford; PNL-7008 (originally BNWL-MA-88 in 1975, then PNL-MA-588); Battelle Pacific Northwest Laboratories, Richland, Washington.

Rockwell; August 1985; 200 Areas Fact Book; Rockwell Hanford Company, Richland, Washington.

Rodenhizer, D.G.; 1987; Hanford Waste Tank Sluicing History; SD-WM-TI-302; Westinghouse Hanford Company, Richland, Washington.

Shefcik, J.J.; December 1964; Process Specifications for In-Tank Solidification of Radiochemical Wastes; RL-SEP-115; General Electric Company, Richland, Washington.

Thurman, J.M.; March 1987a; Waste Status Summary, February 1987; RHO-RE-SR-14; Rockwell Hanford Operations, Richland, Washington.

Thurman, J.M.; April 1987b; Waste Status Summary, March 1987; RHO-RE-SR-14; Rockwell Hanford Operations, Richland, Washington.

Thurman, J.M.; May 1987c; Waste Status Summary, April 1987, RHO-RE-SR-14; Rockwell Hanford Operations, Richland, Washington.

Thurman, J.M.; June 1987d; Waste Status Summary, May 1987; RHO-RE-SR-14; Rockwell Hanford Operations, Richland, Washington. 


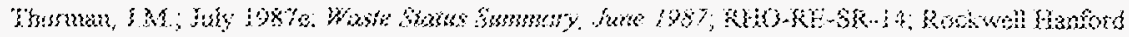
Operatime, Kiniassi, Wiashingme.

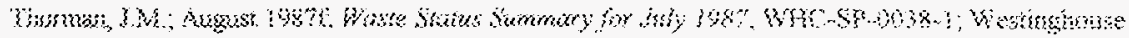

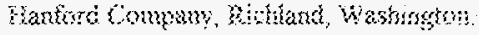

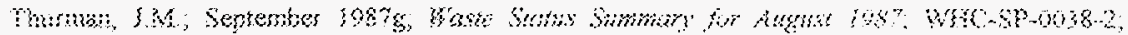

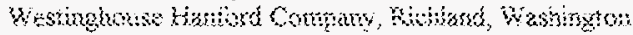

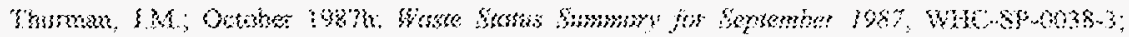

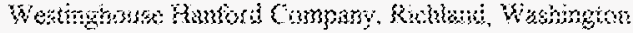

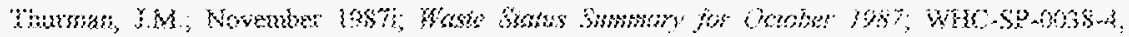
Westinghouse Haxind Company, Eichton, Kashington.

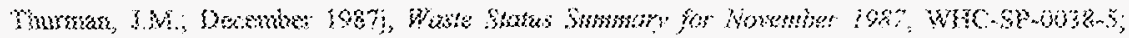

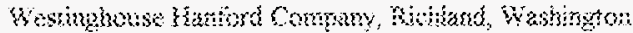

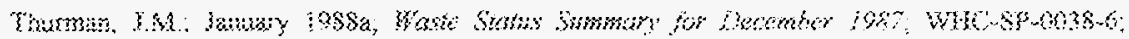

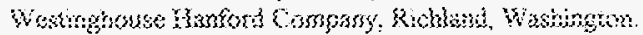

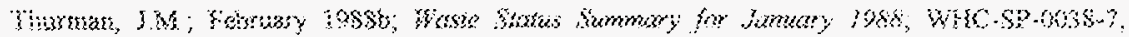

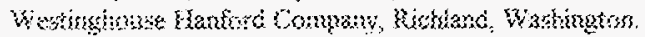

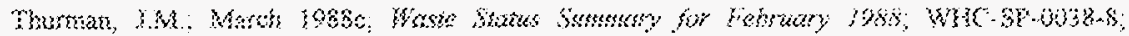

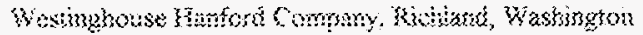

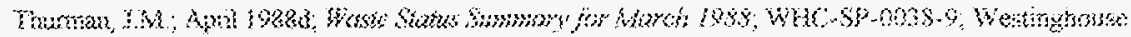

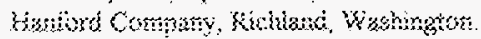

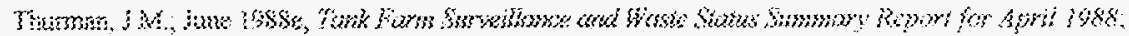

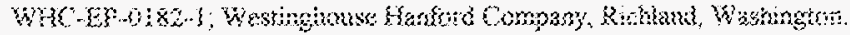

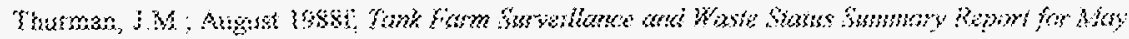

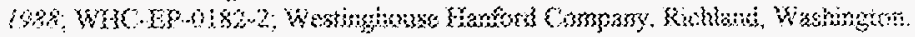

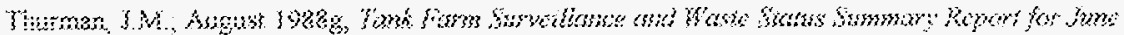

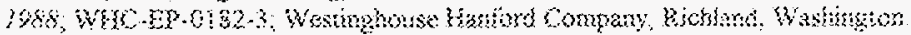

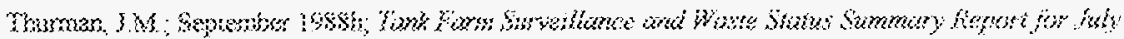

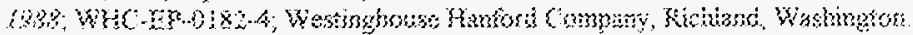

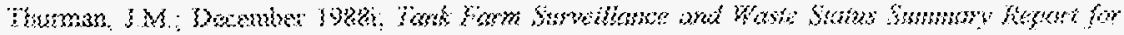

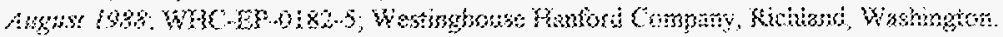

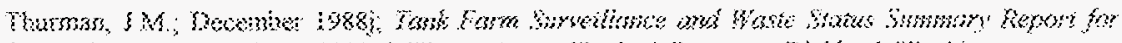
Womber 3 ses: Ws 
Thurman, J.M.; December 1988k; Tank Farm Surveillance and Waste Status Summary Report for October 1988; WHC-EP-0182-7; Westinghouse Hanford Company, Richland, Washington.

Thurman, J.M.; January 1989a; Tank Farm Surveillance and Waste Status Summary Report for November 1988; WHC-EP-0182-8; Westinghouse Hanford Company, Richland, Washington.

Thurman, J.M.; January 1989b; Tank Farm Surveillance and Waste Status Summary Report for December 1988; WHC-EP-0182-9; Westinghouse Hanford Company, Richland, Washington.

Thurman, J.M.; March 1989c; Tank Farm Surveillance and Waste Status Summary Report for January 1989; WHC-EP-0182-10; Westinghouse Hanford Company, Richland, Washington.

Thurman, J.M.; April 1989d; Tank Farm Surveillance and Waste Status Summary Report for February 1989; WHC-EP-0182-11; Westinghouse Hanford Company, Richland, Washington.

Thurman, J.M.; May 1989e; Tank Farm Surveillance and Waste Status Summary Report for March 1989; WHC-EP-0182-12; Westinghouse Hanford Company, Richland, Washington.

Thurman, J.M; June 1989f, Tank Farm Surveillance and Waste Status Summary Report for April 1989; WHC-EP-0182-13; Westinghouse Hanford Company, Richland, Washington.

Thurman, J.M.; July 1989g; Tank Farm Surveillance and Waste Status Summary Report for May 1989; WHC-EP-0182-14; Westinghouse Hanford Company, Richland, Washington.

Thurman, J.M.; August 1989h; Tank Farm Surveillance and Waste Status Summary Report for June 1989; WHC-EP-0182-15; Westinghouse Hanford Company, Richland, Washington.

Thurman, J.M.; September 1989i; Tank Farm Surveillance and Waste Status Summary Report for July 1989; WHC-EP-0182-16; Westinghouse Hanford Company, Richland, Washington.

Thurman, J.M.; October 1989j; Tank Farm Surveillance and Waste Status Summary Report for August 1989; WHC-EP-0182-17; Westinghouse Hanford Company, Richland, Washington.

Thurman, J.M.; November 1989k; Tank Farm Surveillance and Waste Status Summary Report for September 1989; WHC-EP-0182-18; Westinghouse Hanford Company, Richland, Washington.

Thurman, J.M.; February 1990; Tank Farm Surveillance and Waste Status Summary Report for October 1989; WHC-EP-0182-19; Westinghouse Hanford Company, Richland, Washington.

Tran, T.T.; April 27, 1993; Thermocouple Status Single-Shell and Double-Shell Waste Tanks; WHC-SD-WM-TI-553; Westinghouse Hanford Company, Richland, Washington.

U.S. DOE; December 1987; EIS, Disposal of Hanford Defense High Level, Transuranic, and Tank Wastes, Vols. 1-5; DOE/EIS-0113; Department of Energy, Richland, Washington.

Vail, T.S.; April 1985a; Waste Status Summary, March 1985; RHO-RE-SR-14; Rockwell Hanford Operations, Richland, Washington. 


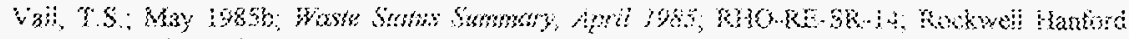
operaten, Bionand, Kashinghon

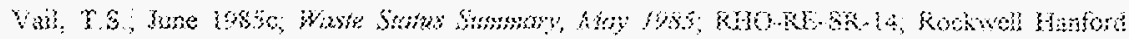

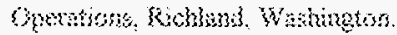

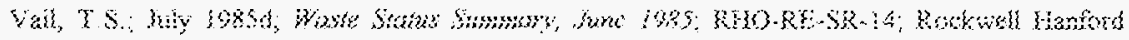

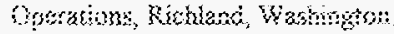

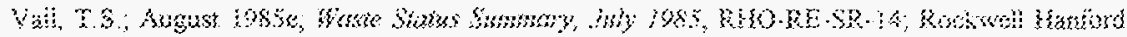

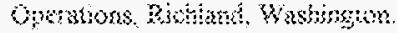

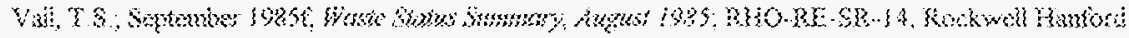
Sheratims, Richiand. Watington.

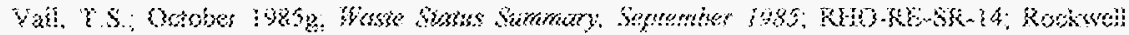
Haskind Operations, Kichand, Washngon.

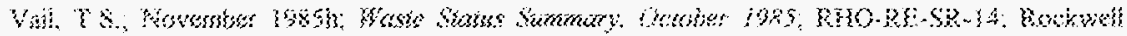

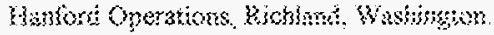

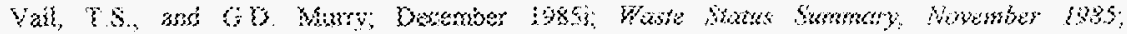

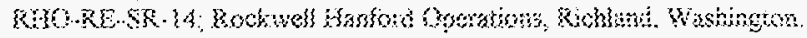

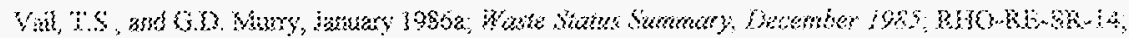

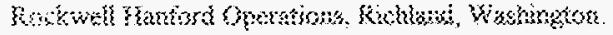

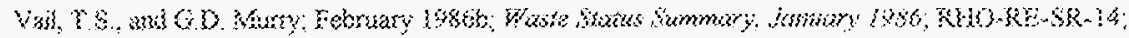

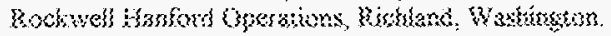

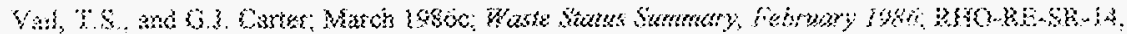

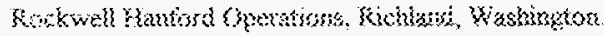

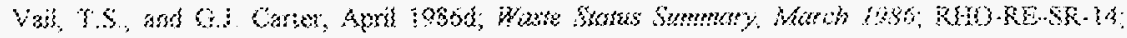

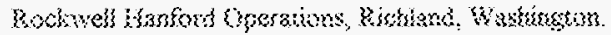

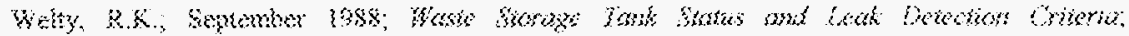

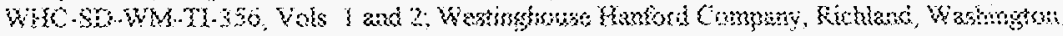

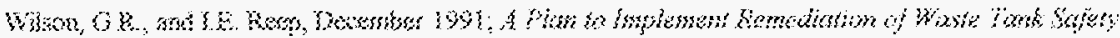

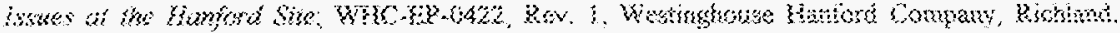
Hashingrom. 


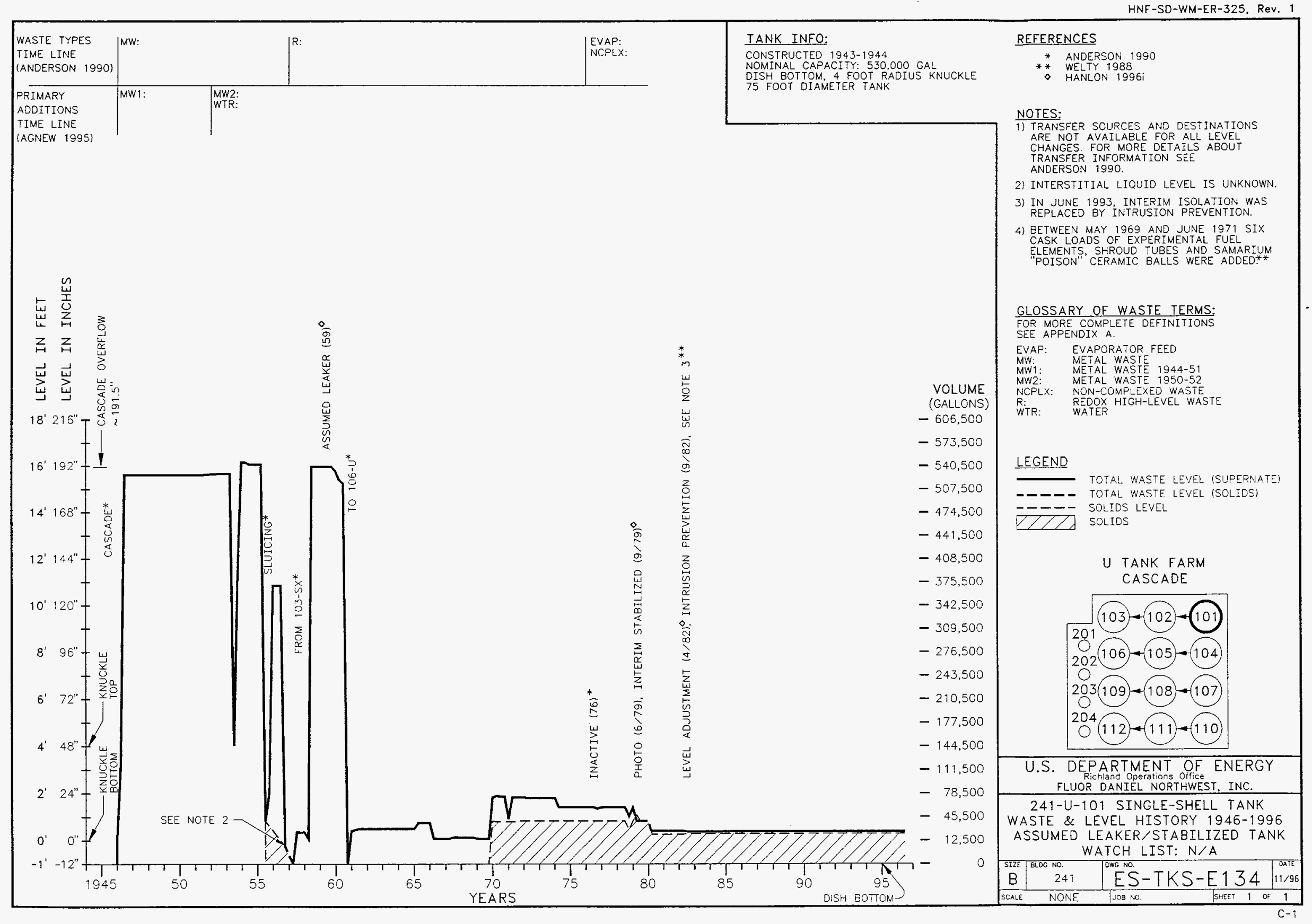




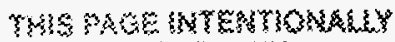

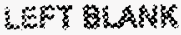





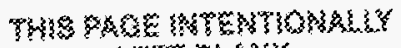

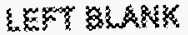




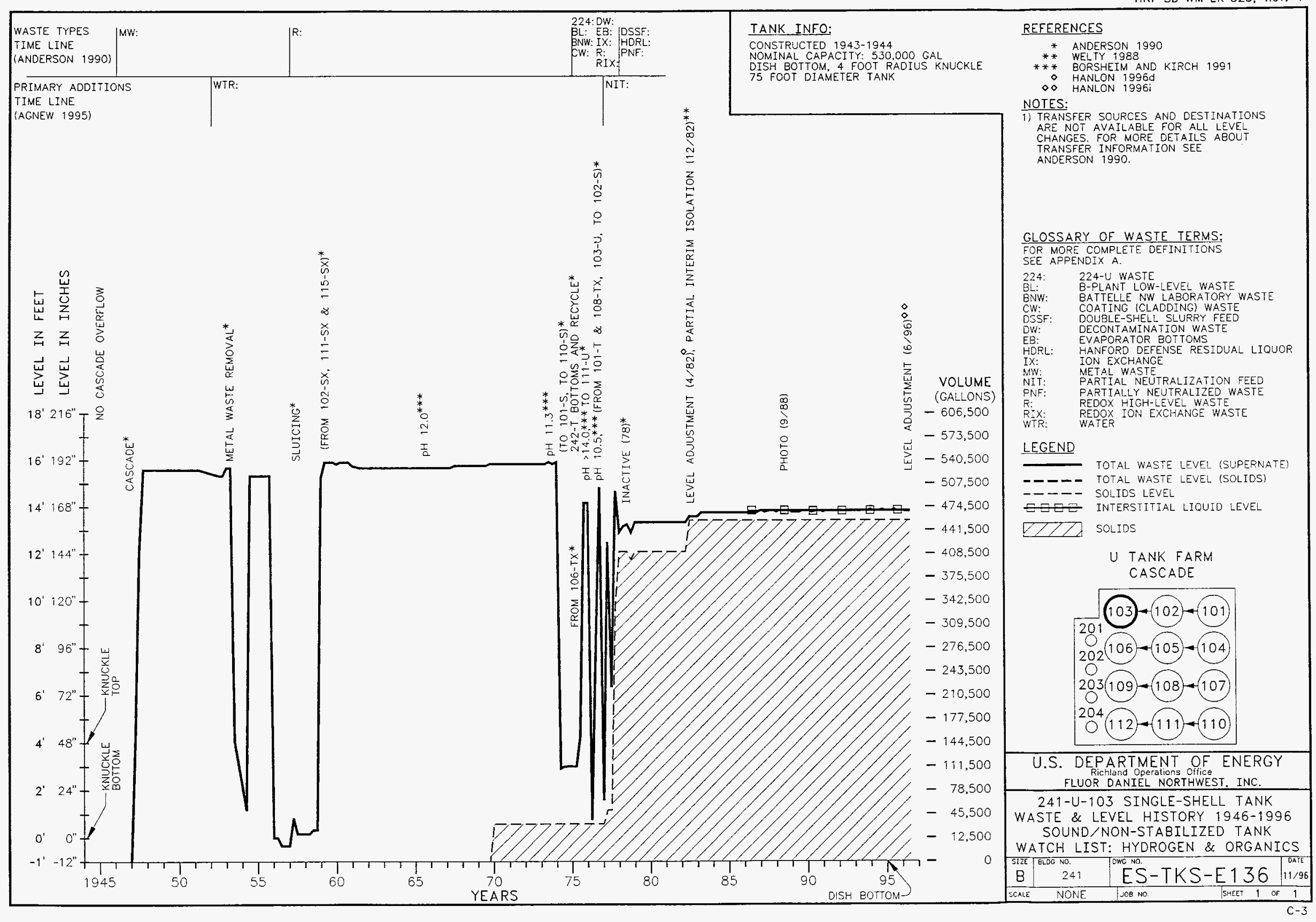




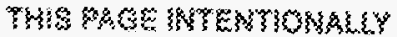

EF" WhK 
HNF-SD-WM-ER-325. Rev. 1

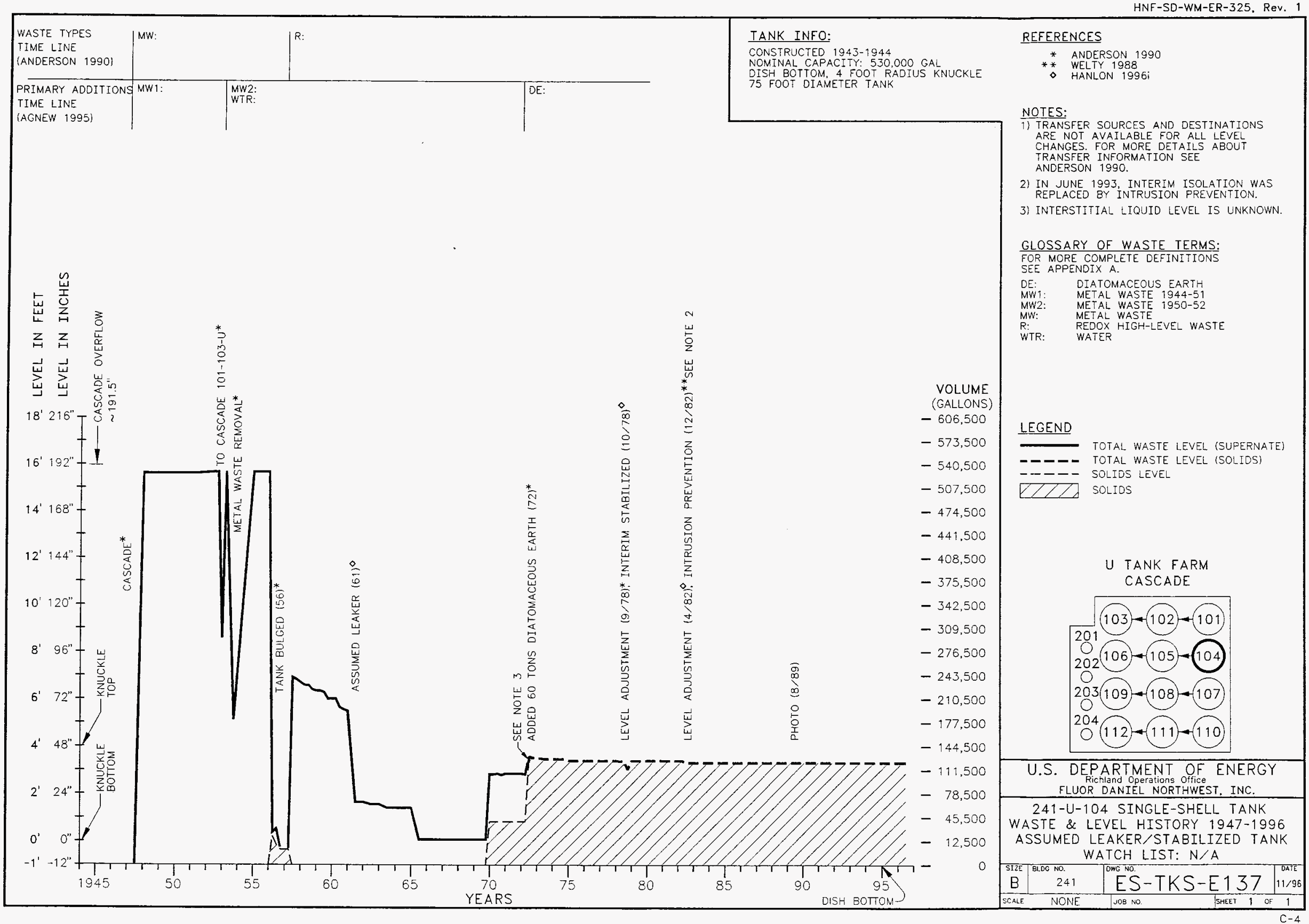




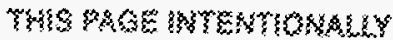
LEF 


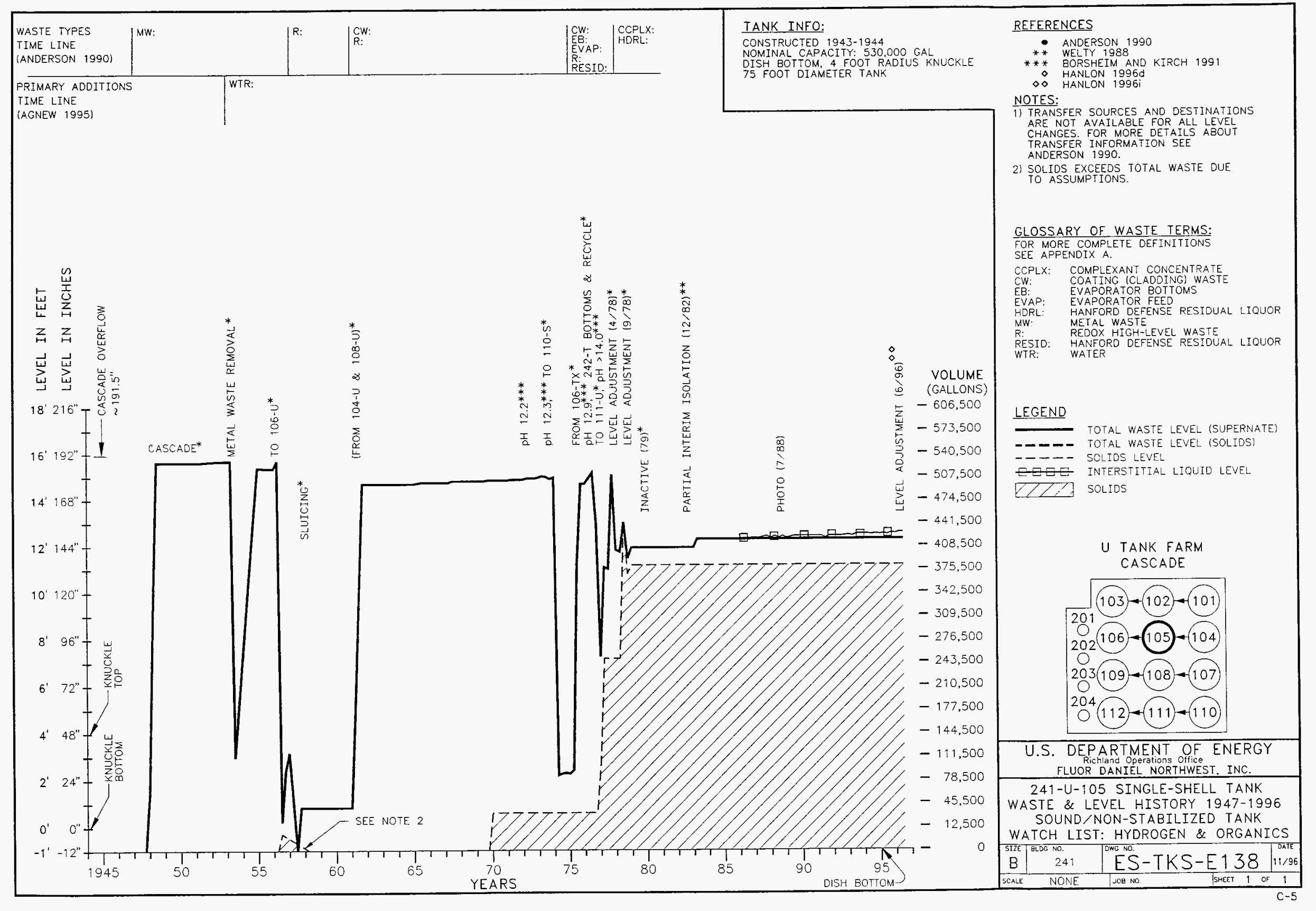




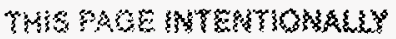

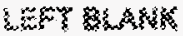




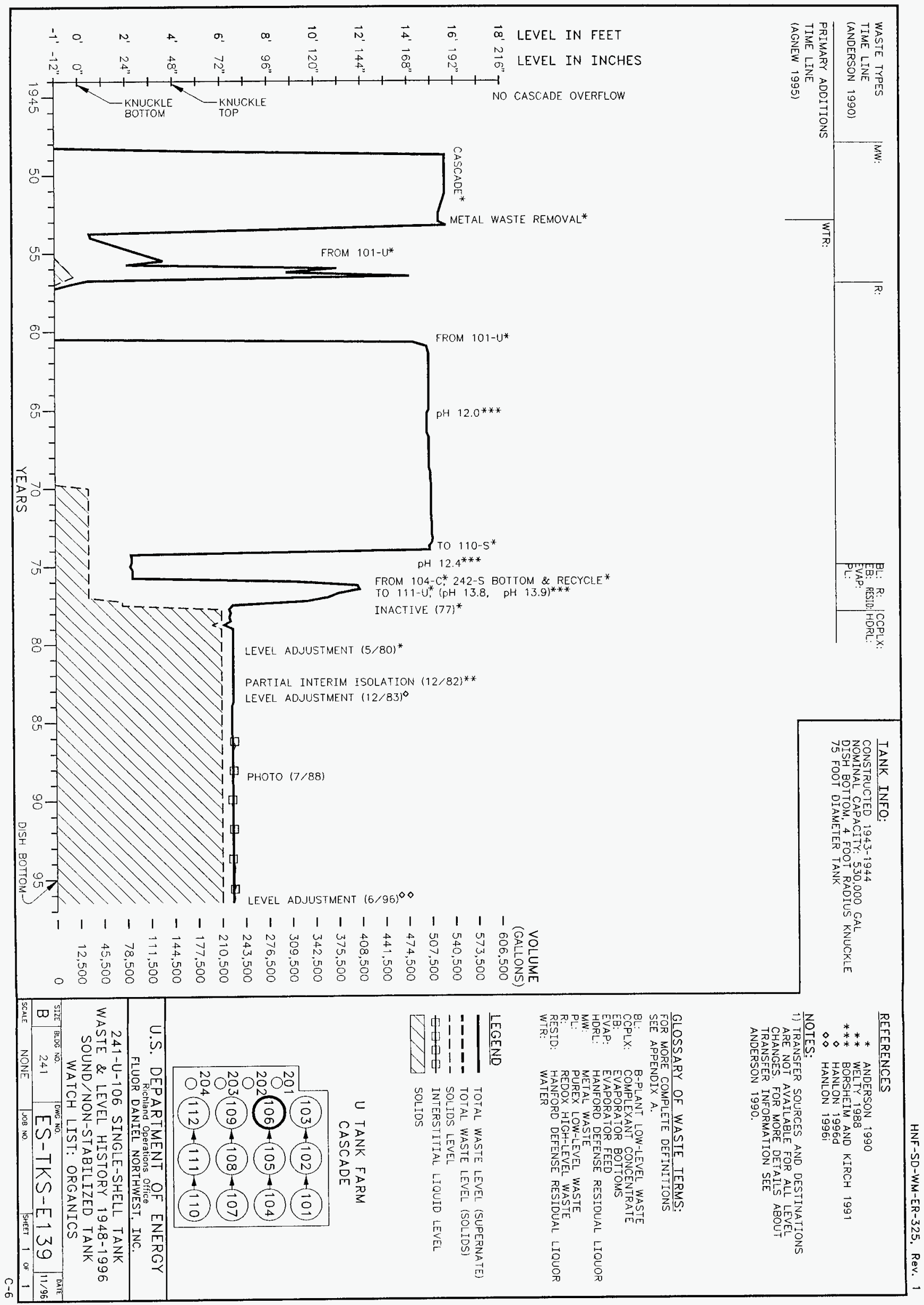




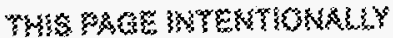
IEFT 


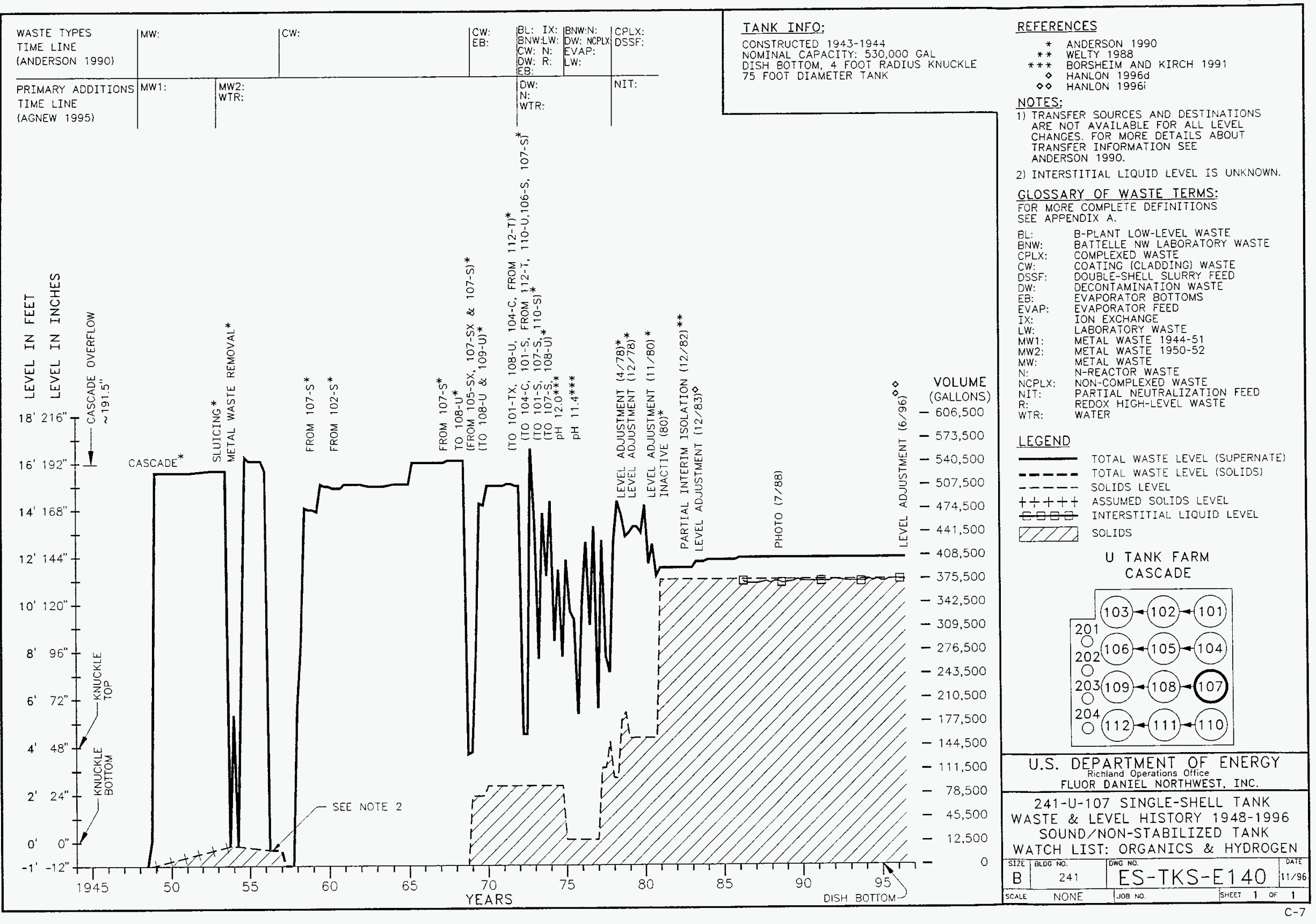




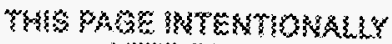
EFr glakK 







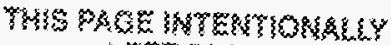
BAFT BLAKK 


\begin{tabular}{|c|c|c|c|c|c|}
\hline $\begin{array}{l}\text { WASTE TYPES } \\
\text { TIME LINE } \\
\text { (ANDERSON 1990) }\end{array}$ & JWW: & $\begin{array}{l}\text { CW: } \\
\text { MW: } \\
\text { R: }\end{array}$ & $\begin{array}{l}C W: \\
E B:\end{array}$ & $\begin{array}{l}\text { LW: } \\
\text { EB: } \\
\text { EVAP: } \\
\text { RESID: } \\
\text { RESI: }\end{array}$ & $\begin{array}{l}\text { HDRL: } \\
\text { NCP:X: } \\
\text { PNF: }\end{array}$ \\
\hline $\begin{array}{l}\text { PRIMARY ADDITION } \\
\text { TIME LINE } \\
\text { (AGNEW 1995) }\end{array}$ & & & & & \\
\hline
\end{tabular}

TANK INFO:

CONSTRUCTED $1943-1944$
NOMINAL CAPACITY 530,000

DISH BOTTOM 4 FOOT RADIUS KNUCKLE

75 FOOT DIAMETER TANK

REFERENCES

* * ANDERSON 1990

作 1991

$\triangle$ HANLON 19960

NOTES:

DESTINATIONS

ARE NOT AVAILABLE FOR ALL LEVEL

TRANSFER INFORMA

GLOSSARY OF WASTE TERMS:

FOR MORE COMPLETE DEFINITIONS

CW: COATING (CLADDING) WASTE

EB: EVAPORAT

点䓀

$z_{i \rightarrow 1}$

岁㞾

$18^{\prime} 216^{\prime \prime}$

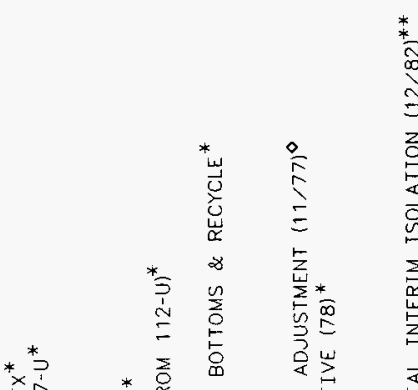

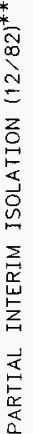

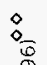

HORL: HANFORA DEFENSE RESIDUAL LIQUOR

NCFLX: NON-COMPLEXED WASTE

PNF:

R: REDOX HIGH-LEVEL WASTE
RESID: HANFORD DEFENSE RESIOUAL LIQUOR

VOLUME

(GALLONS)

$-606,500$

$-573,500$

$-540,500$

$-507,500$

$-474,500$

$14^{\prime} 168^{\prime \prime}$
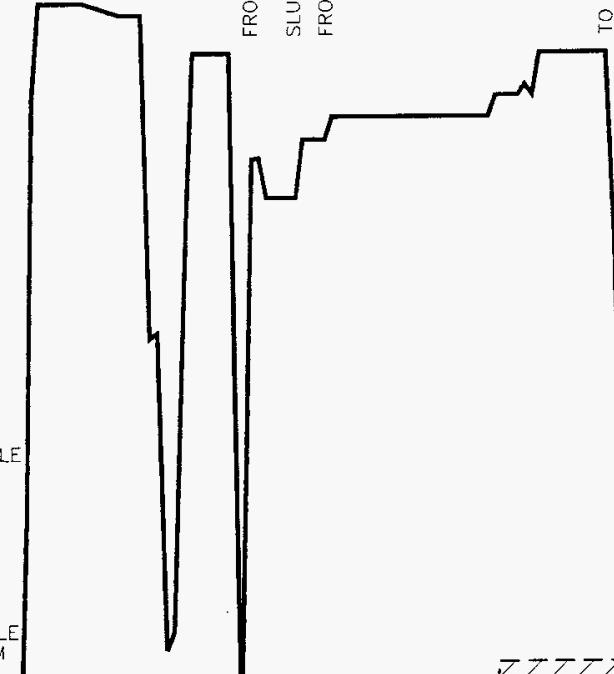

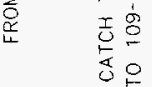
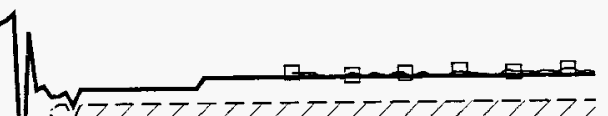

$-441,500$

$-408,500$

$-375,500$

$-342,500$

$-309,500$

$-276,500$

$-243,500$

$-210,500$

$-177,500$

$-144.500$

$-111,500$

- 78,500

- 45,500

- 12,500

$0^{\prime} \quad 0^{\prime \prime}$ KNUCKLE

$1^{1}-12^{\prime \prime}+1$

LEGEND

TOTAL WASTE LEVEL (SUPERNAT

- TOTAL WASTE LEVEL (SOLIDS)

EEE INIERSTITIAL LIOUID LEVEL

V7/C solios

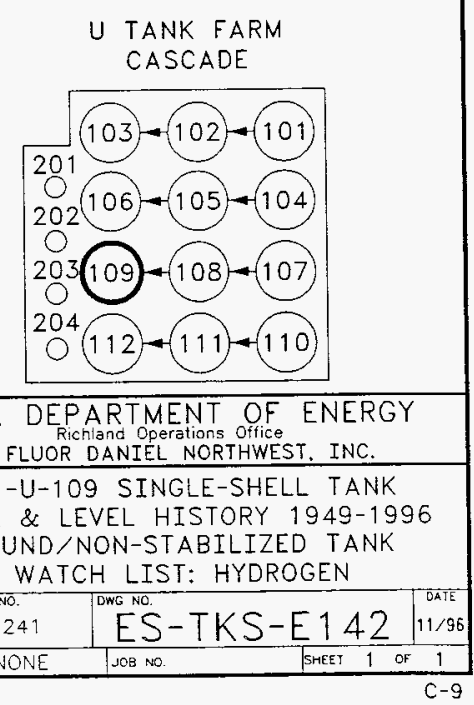


THE PAGE SWF 


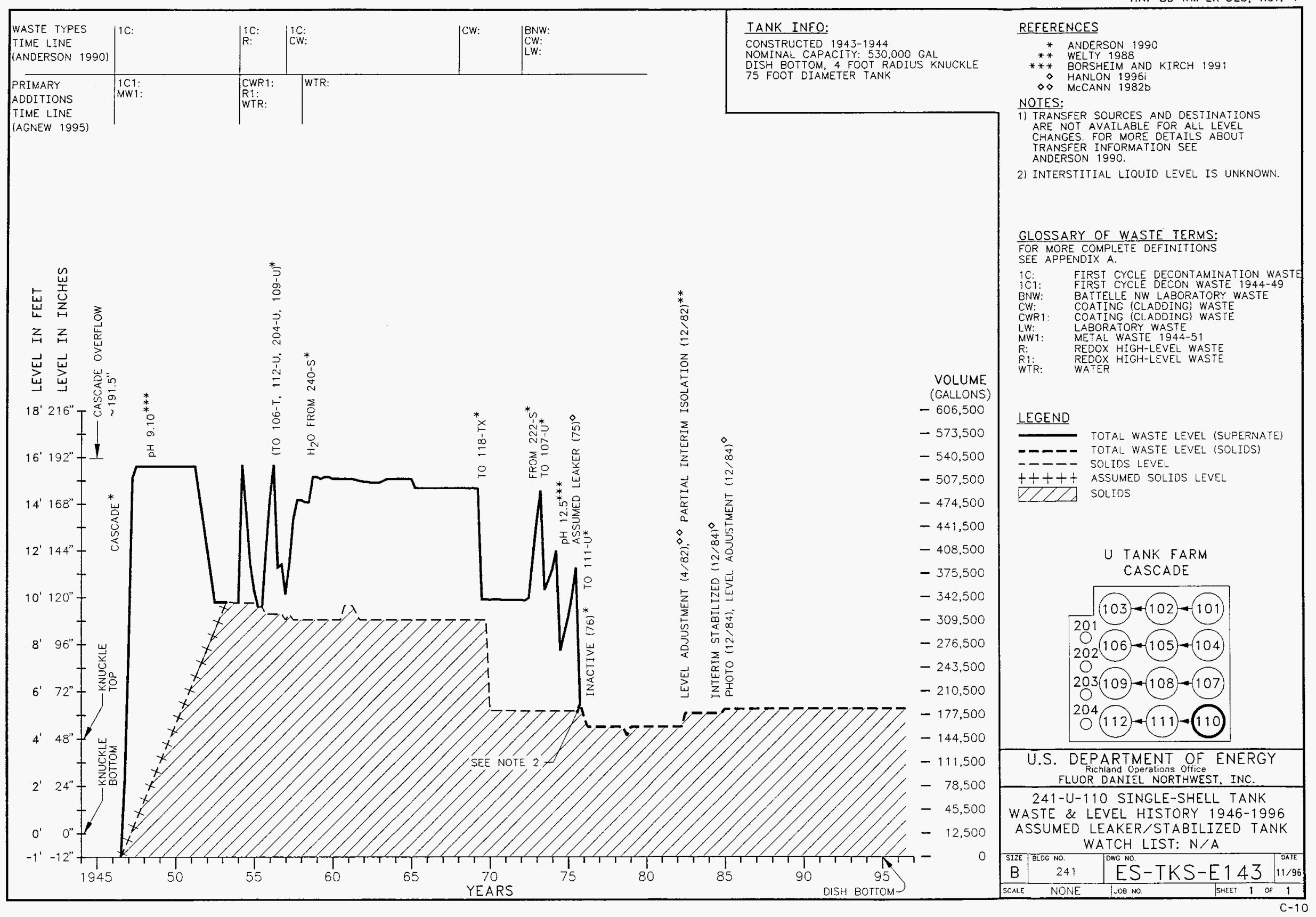




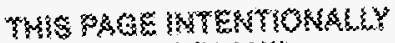

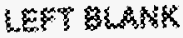




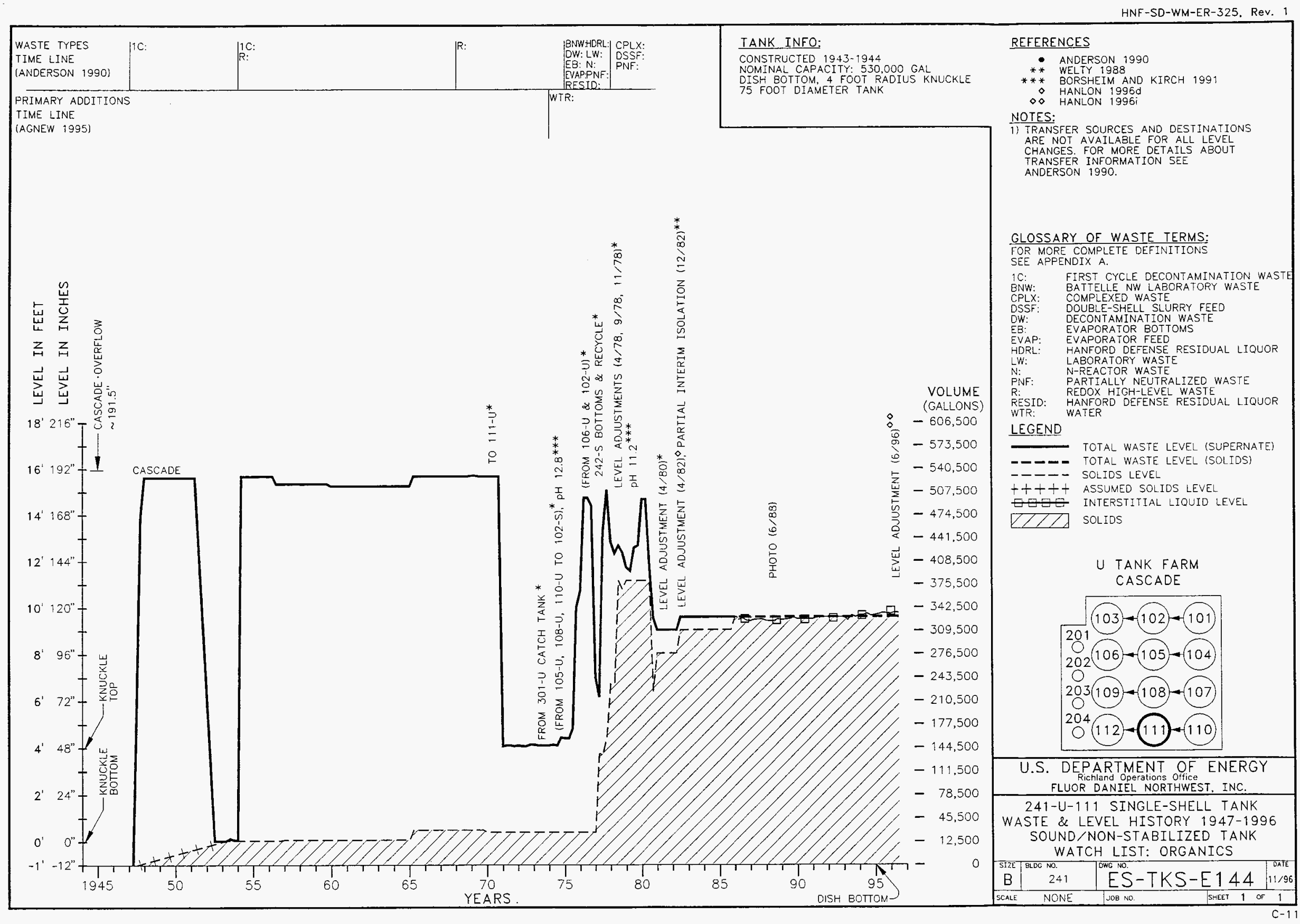




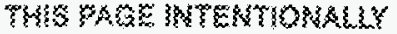

CEFT 


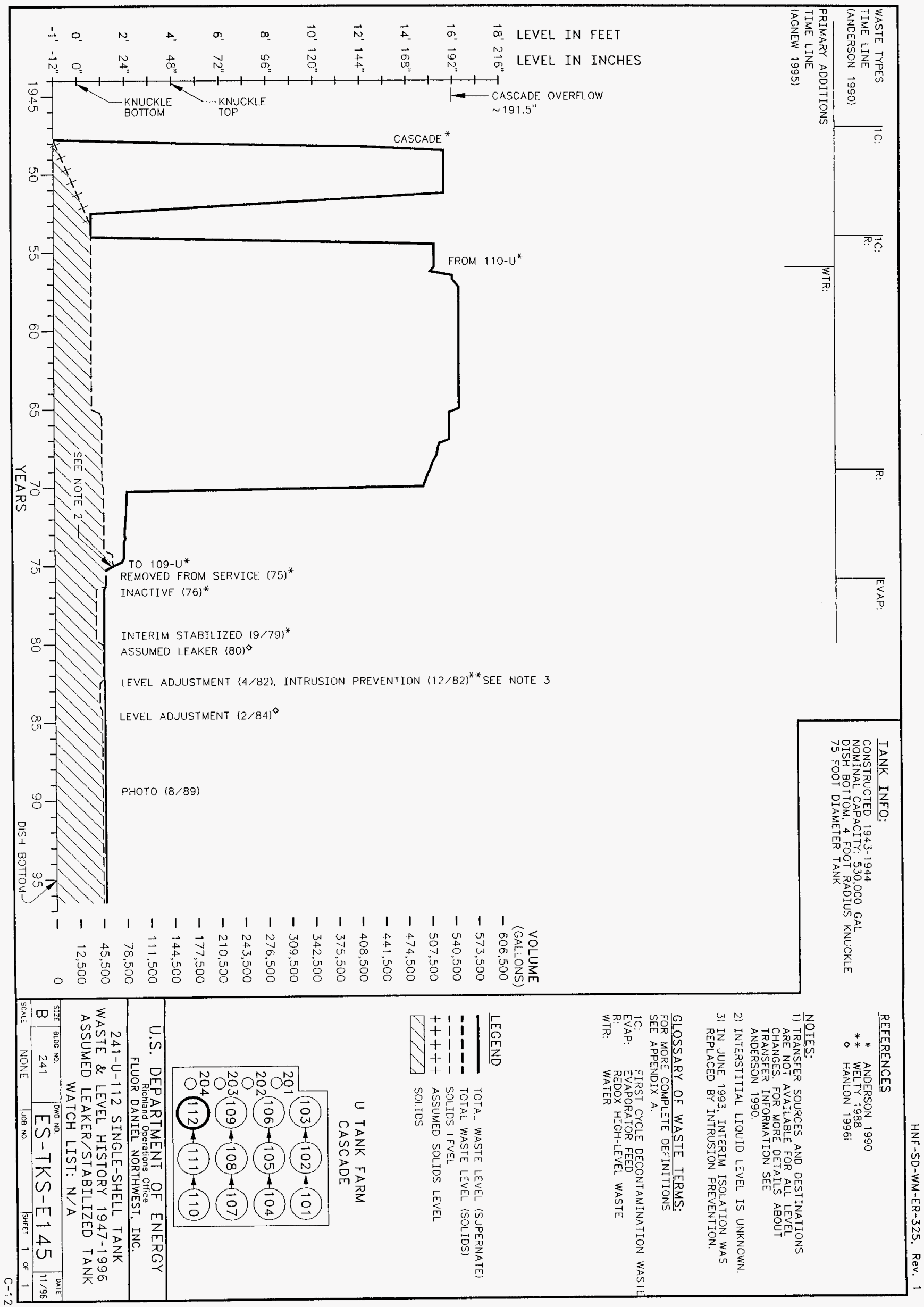




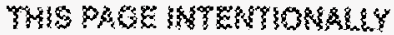
LW \$NAKK 


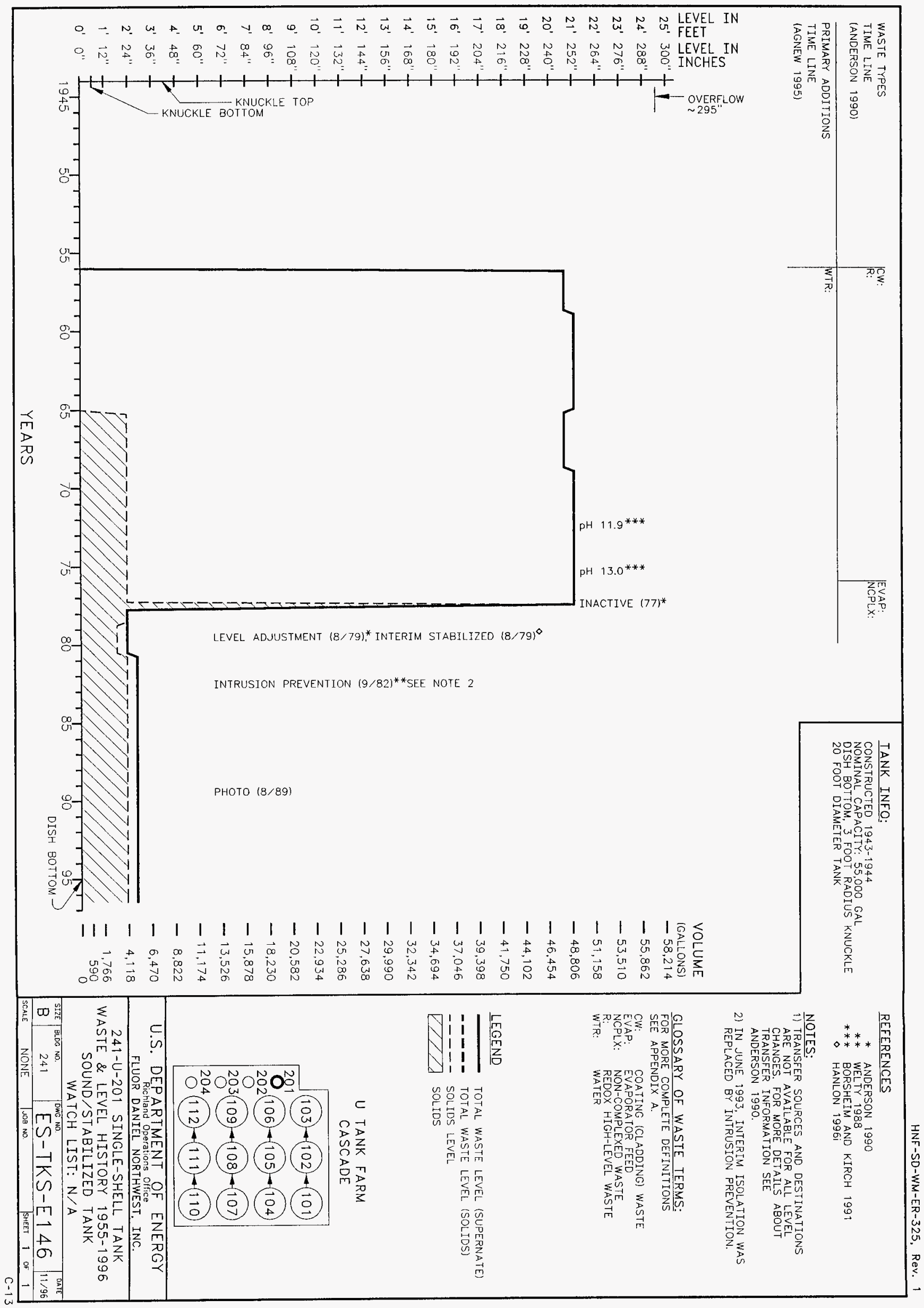




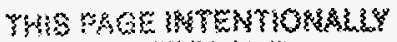

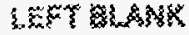




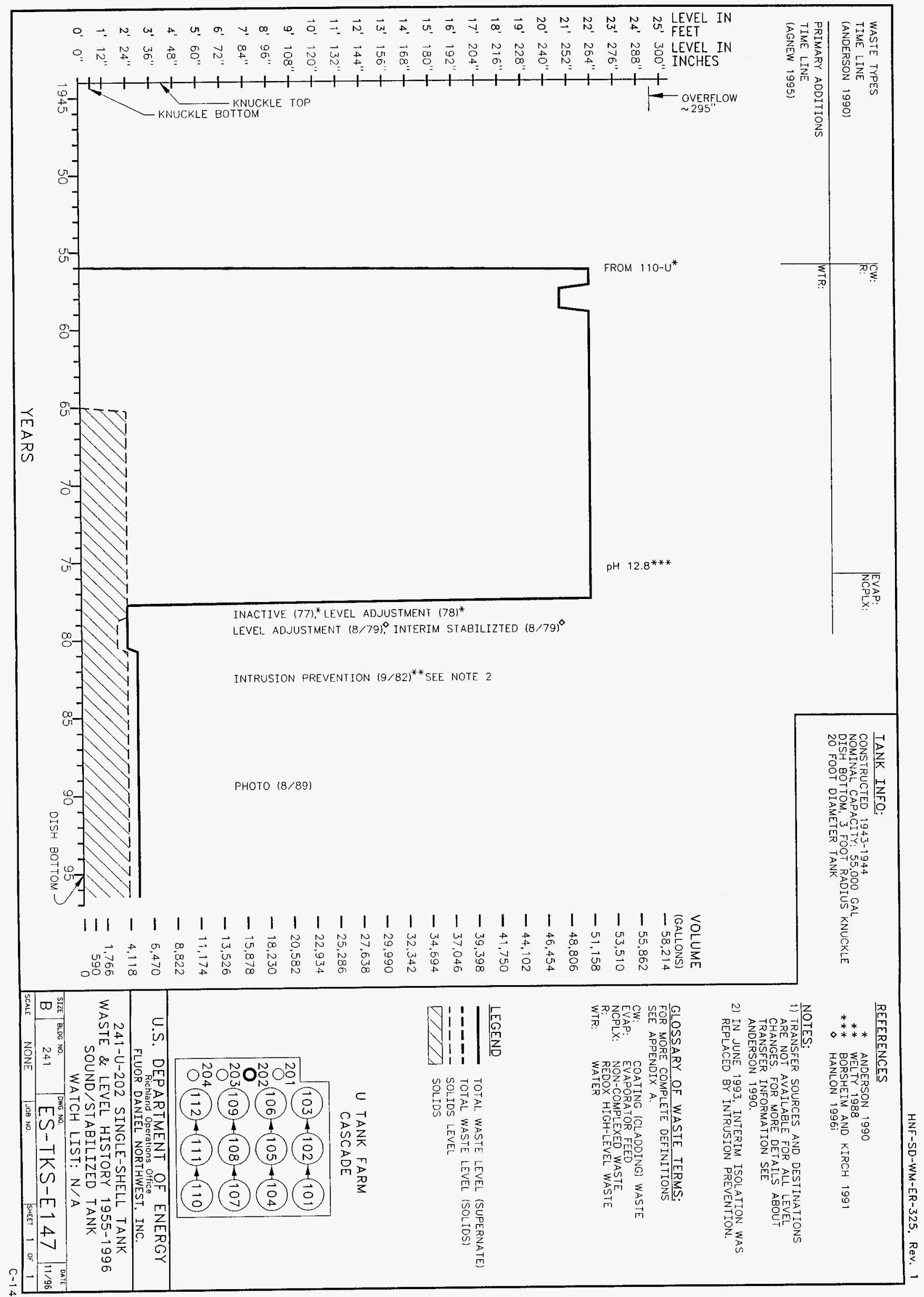




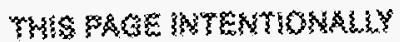

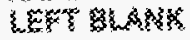




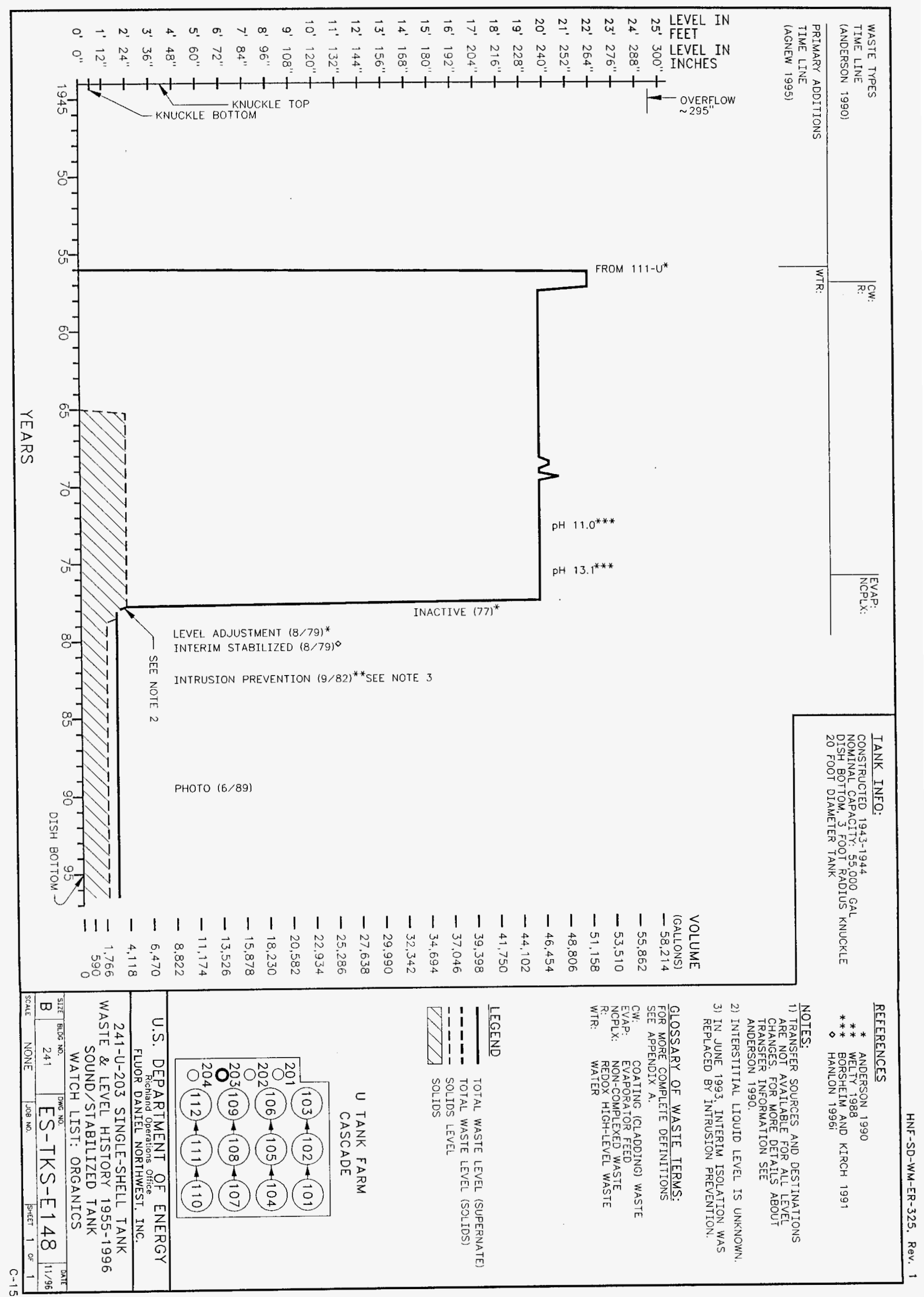




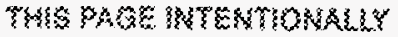

LWF MARS 


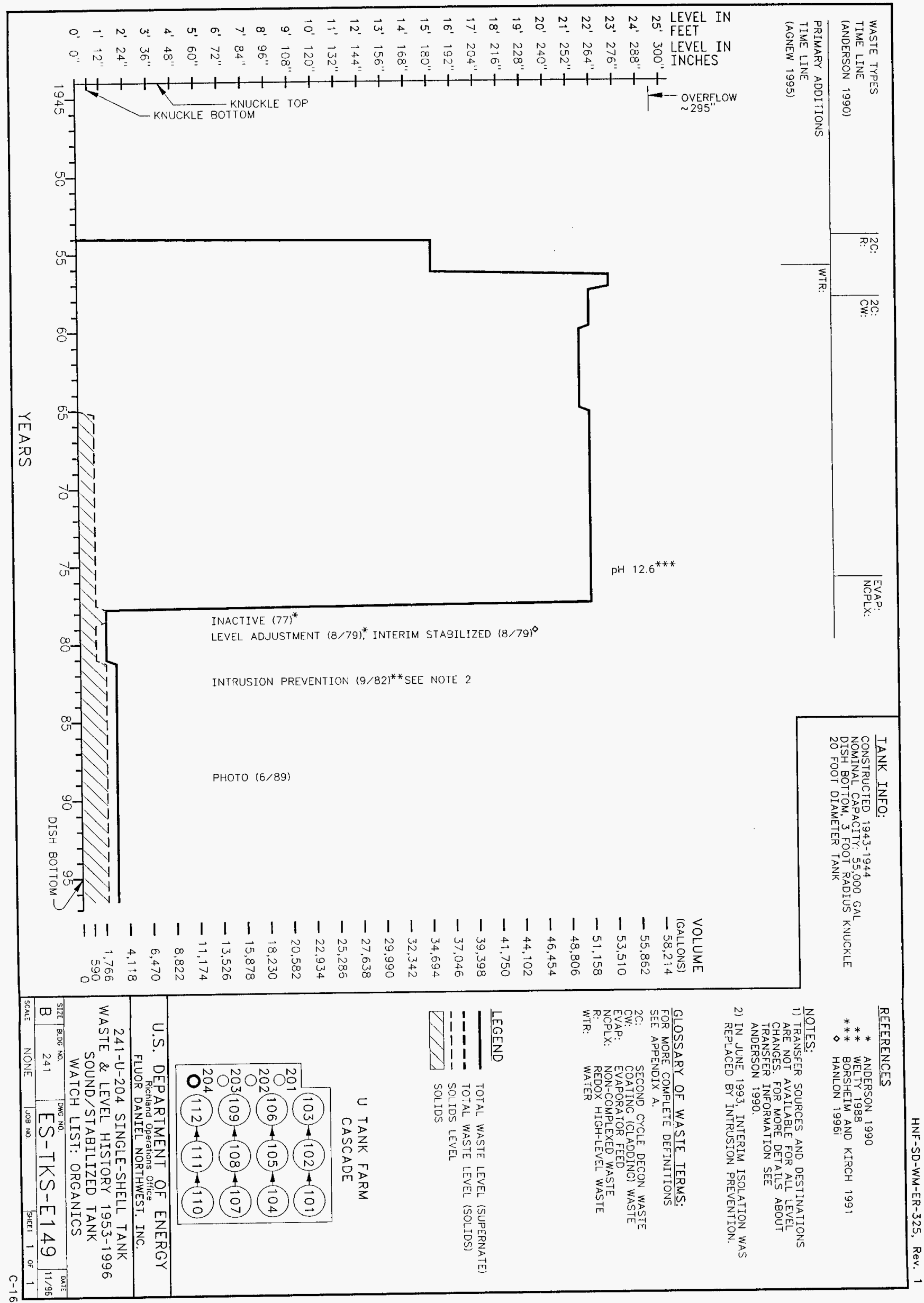




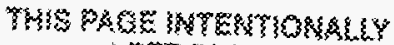
LCE BLARE 
241-U-101 LEVEL HISTORY

HNF-SD-WM-ER-325, Rev. 1

\begin{tabular}{|c|c|c|c|c|}
\hline Year & Total & Total & Solids & Solids \\
\hline & (K gal) & (in) & (K gal) & (in) \\
\hline \multicolumn{5}{|l|}{$1-1944$} \\
\hline \multicolumn{5}{|l|}{2} \\
\hline \multicolumn{5}{|l|}{3} \\
\hline \multicolumn{5}{|l|}{4} \\
\hline \multicolumn{5}{|l|}{$1-1945$} \\
\hline \multicolumn{5}{|l|}{2} \\
\hline \multicolumn{5}{|l|}{3} \\
\hline \multicolumn{5}{|l|}{4} \\
\hline 1-1946 & 119 & 39 & & \\
\hline 2 & 528 & 187 & & \\
\hline 3 & 528 & 187 & & \\
\hline 4 & 528 & 187 & & \\
\hline 1-1947 & 528 & 187 & & \\
\hline 2 & 528 & 187 & & \\
\hline 3 & 528 & 187 & & \\
\hline 4 & 528 & 187 & & \\
\hline 1-1948 & 528 & 187 & & \\
\hline 2 & 528 & 187 & & \\
\hline 3 & 528 & 187 & & \\
\hline 4 & 528 & 187 & & \\
\hline $1-1949$ & 528 & 187 & & \\
\hline 2 & 528 & 187 & & \\
\hline 3 & 528 & 187 & & \\
\hline 4 & 528 & 187 & & \\
\hline $1-1950$ & 528 & 187 & & \\
\hline 2 & 528 & 187 & & \\
\hline 3 & 528 & 187 & & \\
\hline 4 & 528 & 187 & & \\
\hline $1-1951$ & 528 & 187 & & \\
\hline \multicolumn{5}{|l|}{2} \\
\hline \multicolumn{5}{|l|}{3} \\
\hline \multicolumn{5}{|l|}{4} \\
\hline \multicolumn{5}{|l|}{$1-1952$} \\
\hline 2 & 530 & 188 & & \\
\hline 3 & 530 & 188 & & \\
\hline 4 & 530 & 188 & & \\
\hline $1-1953$ & 530 & 188 & & \\
\hline 2 & 146 & 49 & & \\
\hline 3 & 385 & 135 & & \\
\hline 4 & 546 & 194 & & \\
\hline 1-1954 & 546 & 194 & & \\
\hline 2 & 543 & 193 & & \\
\hline 3 & 543 & 193 & & \\
\hline 4 & 543 & 193 & & \\
\hline 1-1955 & 543 & 193 & & \\
\hline 2 & 40 & 10 & 40 & 10 \\
\hline
\end{tabular}

C-17 


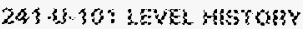

\begin{tabular}{|c|c|c|c|c|}
\hline Yimar & 30 sal & उati & Spliks & Soliass \\
\hline & $p^{s i n}$ & $\{r s\}$ & $k$ ssiti & 6s: \\
\hline & & & & \\
\hline 3 & 73 & 2 & & \\
\hline 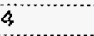 & $3 \%$ & 30 & & \\
\hline Y $19 s 6$ & 3 & 30 & & \\
\hline 2 & $3 \% 3$ & 130 & & \\
\hline 3 & 6 & -3 & 5 & 3 \\
\hline 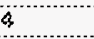 & $i$ & 6 & & \\
\hline $3-\{35\}$ & $\ddot{0}$ & 12 & $\mathrm{\sigma}$ & 3 \\
\hline 2 & 23 & 4 & ) & $\% \%$ \\
\hline 3 & 24 & 4 & 6 & 13 \\
\hline 8 & 24 & 4 & 3 & $-1 \%$ \\
\hline $1-338 \mathrm{~s}$ & 16 & 1 & 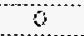 & 3 \\
\hline 2 & 340 & 192 & 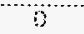 & $-3 \%$ \\
\hline 3 & 530 & 192 & 6 & 12 \\
\hline 4 & 540 & 192 & () & .32 \\
\hline 13959 & 540 & 192 & 0 & 12 \\
\hline 2 & 545 & 192 & 3 & .12 \\
\hline 3 & 540 & 3 & o & 12 \\
\hline 6 & 534 & 38 & 0 & -12 \\
\hline 7.3980 & 521 & 30 & 6 & 12 \\
\hline 2 & 518 & 333 & 0 & -12 \\
\hline 3 & $\theta$ & 32 & i & 32 \\
\hline 5 & 38 & 5 & 0 & -12 \\
\hline \multicolumn{5}{|l|}{$8-3 \leqslant 8\}$} \\
\hline 3 & 38 & in & 0 & .12 \\
\hline \multicolumn{5}{|l|}{3} \\
\hline$\therefore$ & 28 & 6 & 0 & .12 \\
\hline \multicolumn{5}{|l|}{$1-3 \leqslant 82$} \\
\hline 2 & 28 & $\theta$ & 0 & -12 \\
\hline \multicolumn{5}{|l|}{3} \\
\hline a & 28 & 6 & 0 & .32 \\
\hline \multicolumn{5}{|l|}{3.3983} \\
\hline 2 & 29 & 6 & 0 & -12 \\
\hline \multicolumn{5}{|l|}{3} \\
\hline 4 & 23 & 6 & 0 & .12 \\
\hline \multicolumn{5}{|l|}{1.3964} \\
\hline 2 & 23 & 5 & 0 & .3 \\
\hline \multicolumn{5}{|l|}{3} \\
\hline$a$ & 23 & 3 & 0 & .3 \\
\hline T.305 & 37 & 3 & 0 & 12 \\
\hline \multicolumn{5}{|c|}{2} \\
\hline 3 & 37 & 3 & 0 & 12 \\
\hline 4 & 31 & 3 & 0 & .2 \\
\hline $4.3 \$ 06$ & 3 & 1 & 6 & 32 \\
\hline$i$ & 3 & 3 & 0 & -12 \\
\hline 3 & 16 & 3 & 0 & 12 \\
\hline$x$ & 35 & i & 3 & 12 \\
\hline
\end{tabular}

C.8 
241-U-101 LEVEL HISTORY

HNF-SD-WM-ER-325, Rev. 1

\begin{tabular}{|c|c|c|c|c|}
\hline Year & Total & Total & Solids & Solids \\
\hline & (K gal) & (in) & (K gal) & (in) \\
\hline $1-1967$ & 15 & 1 & 0 & -12 \\
\hline 2 & 17 & 2 & 0 & -12 \\
\hline 3 & 17 & 2 & 0 & -12 \\
\hline 4 & 17 & 2 & 0 & -12 \\
\hline $1-1968$ & 17 & 2 & 0 & -12 \\
\hline 2 & 17 & 2 & 0 & -12 \\
\hline 3 & 17 & 2 & 0 & -12 \\
\hline 4 & 15 & 1 & 0 & -12 \\
\hline $1-1969$ & 15 & 1 & 0 & -12 \\
\hline 2 & 15 & 1 & 0 & -12 \\
\hline 3 & 15 & 1 & 0 & -12 \\
\hline 4 & 73 & 22 & 40 & 10 \\
\hline $1-1970$ & 75 & 23 & 39 & 10 \\
\hline 2 & 74 & 22 & 39 & 10 \\
\hline 3 & 74 & 22 & 39 & 10 \\
\hline 4 & 43 & 11 & 39 & 10 \\
\hline $1-1971$ & 73 & 22 & 39 & 10 \\
\hline 2 & 73 & 22 & 39 & 10 \\
\hline 3 & 73 & 22 & 40 & 10 \\
\hline 4 & 73 & 22 & 40 & 10 \\
\hline $1-1972$ & 72 & 22 & 40 & 10 \\
\hline 2 & 72 & 22 & 40 & 10 \\
\hline 3 & 72 & 22 & 40 & 10 \\
\hline 4 & 72 & 22 & 40 & 10 \\
\hline $1-1973$ & 72 & 22 & 40 & 10 \\
\hline 2 & 72 & 22 & 40 & 10 \\
\hline 3 & 72 & 22 & 40 & 10 \\
\hline 4 & 72 & 22 & 40 & 10 \\
\hline $1-1974$ & 59 & 17 & 40 & 10 \\
\hline 2 & 59 & 17 & 40 & 10 \\
\hline 3 & 59 & 17 & 40 & 10 \\
\hline 4 & 59 & 17 & 40 & 10 \\
\hline $1-1975$ & 59 & 17 & 40 & 10 \\
\hline 2 & 59 & 17 & 40 & 10 \\
\hline 3 & 59 & 17 & 40 & 10 \\
\hline 4 & 59 & 17 & 40 & 10 \\
\hline $1-1976$ & 59 & 17 & 40 & 10 \\
\hline 2 & 59 & 17 & 40 & 10 \\
\hline 3 & 57 & 16 & 40 & 10 \\
\hline 4 & 59 & 17 & 40 & 10 \\
\hline $1-1977$ & 59 & 17 & 40 & 10 \\
\hline 2 & 59 & 17 & 40 & 10 \\
\hline 3 & 59 & 17 & 40 & 10 \\
\hline 4 & 59 & 17 & 40 & 10 \\
\hline $1-1978$ & 59 & 17 & 40 & 10 \\
\hline 2 & 59 & 17 & 40 & 10 \\
\hline
\end{tabular}




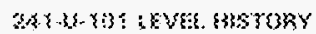

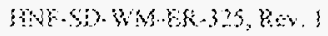

\begin{tabular}{|c|c|c|c|c|}
\hline 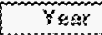 & Tonol & $\tilde{\Gamma} \alpha \Delta \beta$ & 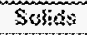 & Swotisss \\
\hline & $\{\mathrm{x} a b\}$ & $\{n\}$ & K a gail & 6 \\
\hline 3 & 47 & 13 & 28 & 6 \\
\hline 4 & 86 & 17 & 40 & 10 \\
\hline$\{x \rightarrow s\} \leqslant$ & 6 & 16 & 33 & 12 \\
\hline$z$ & 4 & 60 & 103 & 9 \\
\hline 3 & 6 & 60 & 40 & 10 \\
\hline 3 & 4 & 39 & 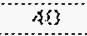 & 0 \\
\hline 101964 & 28 & 5 & 21 & 3 \\
\hline 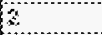 & 28 & 6 & 21 & 3 \\
\hline 3 & 26 & 5 & 21 & 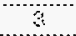 \\
\hline 4 & 28 & 5 & 21 & 3 \\
\hline 1.138$\}$ & 26 & 5 & 23 & 3 \\
\hline 2 & 26 & 3 & 21 & 3 \\
\hline 3 & 26 & 5 & 23 & औ \\
\hline 4 & 20 & 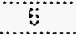 & 21 & 3 \\
\hline 1.1382 & 26 & 5 & 21 & 3 \\
\hline 2 & 25 & 8 & 22 & 3 \\
\hline 3 & 36 & 3 & 22 & 3 \\
\hline 4 & 25 & 8 & 22 & 3 \\
\hline $1-7383$ & 36 & 3 & 22 & 3 \\
\hline$z$ & 25 & 5 & 22 & 3 \\
\hline 6 & 25 & $\leqslant$ & 22 & 3 \\
\hline 4 & 25 & 5 & 22 & 3 \\
\hline - - EBSE & 25 & 3 & 22 & 3 \\
\hline$z$ & 25 & 5 & 22 & 3 \\
\hline 6 & 25 & 3 & 22 & 3 \\
\hline 6 & 85 & 5 & 22 & 3 \\
\hline $00 \otimes 8$ & 25 & 5 & 22 & 3 \\
\hline 3 & $2 \varepsilon$ & 8 & 22 & 3 \\
\hline 3 & 25 & 5 & 22 & 3 \\
\hline 4 & 28 & $s$ & 22 & 3 \\
\hline 3.1980 & 25 & 5 & 22 & 3 \\
\hline 2 & 2 & 6 & 22 & 3 \\
\hline 3 & 25 & 8 & 22 & 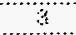 \\
\hline 4 & 23 & $\theta$ & 22 & 3 \\
\hline 1.1987 & 26 & 8 & $a$ & 3 \\
\hline 2 & 4 & 5 & 22 & 3 \\
\hline 3 & 3 & $\varepsilon$ & 2 & 3 \\
\hline 8 & 25 & 5 & 22 & 3 \\
\hline 1.1988 & 29 & \& & 2 & 3 \\
\hline 2 & 26 & 8 & 22 & 3 \\
\hline 3 & 26 & $\xi$ & 2 & 3 \\
\hline 6 & 28 & 5 & $Z z$ & 3 \\
\hline $3.3 \$ 80$ & 36 & 6 & 22 & 3 \\
\hline 2 & 36 & 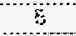 & 22 & 3 \\
\hline \% & 6 & 6 & 22 & 3 \\
\hline 6 & 20 & 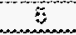 & 22 & 3 \\
\hline
\end{tabular}


241-U-101 LEVEL HISTORY

HNF-SD-WM-ER-325, Rev. 1

\begin{tabular}{|c|c|c|c|c|}
\hline Year & Total & Total & Solids & Solids \\
\hline & (K gal) & (in) & (K gal) & (in) \\
\hline $1-1990$ & 25 & 5 & 22 & 3 \\
\hline 2 & 25 & 5 & 22 & 3 \\
\hline 3 & 25 & 5 & 22 & 3 \\
\hline 4 & 25 & 5 & 22 & 3 \\
\hline 1-1991 & 25 & 5 & 22 & 3 \\
\hline 2 & 25 & 5 & 22 & 3 \\
\hline 3 & 25 & 5 & 22 & 3 \\
\hline 4 & 25 & 5 & 22 & 3 \\
\hline 1-1992 & 25 & 5 & 22 & 3 \\
\hline 2 & 25 & 5 & 22 & 3 \\
\hline 3 & 25 & 5 & 22 & 3 \\
\hline 4 & 25 & 5 & 22 & 3 \\
\hline 1.1993 & 25 & 5 & 22 & 3 \\
\hline 2 & 25 & 5 & 22 & 3 \\
\hline 3 & 25 & 5 & 22 & 3 \\
\hline 4 & 25 & 5 & 22 & 3 \\
\hline 1-1994 & 25 & 5 & 22 & 3 \\
\hline 2 & 25 & 5 & 22 & 3 \\
\hline 3 & 25 & 5 & 22 & 3 \\
\hline 4 & 25 & 5 & 22 & 3 \\
\hline 1-1995 & 25 & 5 & 22 & 3 \\
\hline 2 & 25 & 5 & 22 & 3 \\
\hline 3 & 25 & 5 & 22 & 3 \\
\hline 4 & 25 & 5 & 22 & 3 \\
\hline $1-1996$ & 25 & 5 & 22 & 3 \\
\hline 2 & 25 & 5 & 22 & 3 \\
\hline
\end{tabular}


243-\{3-10\% [K:VE\} HETSY'

HNW

\begin{tabular}{|c|c|c|c|c|c|}
\hline Yesk & To63! & Yastas & So28sks & Solios & $a i$ \\
\hline & Kk zali & ans & $(x \mathrm{gol})$ & fint & $6 n$ \\
\hline \multirow{2}{*}{\multicolumn{6}{|c|}{3.3384}} \\
\hline & & & & & \\
\hline \multicolumn{6}{|l|}{2} \\
\hline \multicolumn{6}{|l|}{3} \\
\hline \multicolumn{6}{|l|}{6} \\
\hline \multicolumn{6}{|l|}{$1 \cdot 1856$} \\
\hline \multicolumn{6}{|l|}{2} \\
\hline \multicolumn{6}{|l|}{3} \\
\hline \multicolumn{6}{|l|}{4} \\
\hline \multicolumn{6}{|l|}{$1-134 \varepsilon$} \\
\hline 2 & 60 & 3 & & & \\
\hline 3 & 213 & 74 & & & \\
\hline 4 & $31 \%$ & 147 & & & \\
\hline $3-3367$ & 523 & 197 & & & \\
\hline 2 & 538 & 187 & & & \\
\hline$a$ & 523 & 187 & & & \\
\hline 4 & 533 & 137 & & & \\
\hline $1.13 \% 6$ & 523 & 807 & & & \\
\hline 2 & 5.3 & 137 & & & \\
\hline 3 & 520 & 18 & & & \\
\hline 8 & 53. & 181 & & & \\
\hline 1396 & 528 & 87 & & & \\
\hline 2 & 523 & $6 \%$ & & & \\
\hline 3 & 528 & 98 & & & \\
\hline 4 & 623 & 39 & & & \\
\hline 1.1390 & 325 & $\theta \%$ & & & \\
\hline 2 & 328 & 36 & & & \\
\hline 3 & 328 & 38 & & & \\
\hline 4 & 226 & $16 \%$ & & & \\
\hline$x-1 \operatorname{sen}$ & 328 & 嬥 & & & \\
\hline \multicolumn{6}{|l|}{$z$} \\
\hline \multicolumn{6}{|l|}{3} \\
\hline \multicolumn{6}{|l|}{9} \\
\hline \multicolumn{6}{|l|}{$3-1352$} \\
\hline$z$ & 860 & 163 & & & \\
\hline 3 & 530 & 368 & & & \\
\hline 3 & 830 & 163 & & & \\
\hline$x-19 s 3$ & 530 & 168 & & & \\
\hline$z$ & $\therefore E$ & 2 & & & \\
\hline \multicolumn{6}{|l|}{3} \\
\hline 4 & 325 & 4 & & & \\
\hline$\{-134 \alpha$ & 546 & 100 & & & \\
\hline 2 & 843 & 393 & & & \\
\hline 3 & 543 & 39 & & & \\
\hline 4 & 543 & 393 & & & \\
\hline $1 . \$ \$ 55$ & 543 & 8 & & & \\
\hline$z$ & 543 & 38 & & & \\
\hline
\end{tabular}


241-U-102 LEVEL HISTORY

\begin{tabular}{|c|c|c|c|c|c|}
\hline Year & Total & Total & Solids & Solids & ILL \\
\hline & (K gal) & (in) & (K gal) & (in) & (in) \\
\hline & & & & & \\
\hline 3 & 5 & -3 & 5 & -3 & \\
\hline 4 & 443 & 157 & & & \\
\hline $1-1956$ & 443 & 157 & & & \\
\hline 2 & 443 & 157 & & & \\
\hline 3 & 443 & 157 & & & \\
\hline 4 & 52 & 14 & 8 & -2 & \\
\hline $1-1957$ & 0 & -12 & 0 & -12 & \\
\hline 2 & 35 & 8 & 0 & -12 & \\
\hline 3 & 35 & 8 & 0 & -12 & \\
\hline 4 & 35 & 8 & 0 & -12 & \\
\hline $1-1958$ & 35 & 8 & 0 & -12 & \\
\hline 2 & 35 & 8 & 0 & -12 & \\
\hline 3 & 35 & 8 & 0 & -12 & \\
\hline 4 & 472 & 167 & 0 & .12 & \\
\hline 1-1959 & 472 & 167 & 0 & -12 & \\
\hline 2 & 472 & 167 & 0 & -12 & \\
\hline 3 & 469 & 166 & 0 & -12 & \\
\hline 4 & 469 & 166 & 0 & -12 & \\
\hline $1-1960$ & 469 & 166 & 0 & -12 & \\
\hline 2 & 469 & 166 & 0 & -12 & \\
\hline 3 & 469 & 166 & 0 & -12 & \\
\hline 4 & 469 & 166 & 0 & -12 & \\
\hline \multicolumn{6}{|l|}{ 1-1961 } \\
\hline 2 & 466 & 165 & 0 & -12 & \\
\hline \multicolumn{6}{|l|}{3} \\
\hline 4 & 466 & 165 & 0 & -12 & \\
\hline \multicolumn{6}{|l|}{$1-1962$} \\
\hline 2 & 466 & 165 & 0 & -12 & \\
\hline \multicolumn{6}{|l|}{3} \\
\hline 4 & 466 & 165 & 0 & -12 & \\
\hline \multicolumn{6}{|l|}{ 1-1963 } \\
\hline 2 & 466 & 165 & 0 & -12 & \\
\hline \multicolumn{6}{|l|}{3} \\
\hline 4 & 466 & 165 & 0 & -12 & \\
\hline \multicolumn{6}{|l|}{$1-1964$} \\
\hline 2 & 466 & 165 & 0 & -12 & \\
\hline \multicolumn{6}{|l|}{3} \\
\hline 4 & 466 & 165 & 0 & -12 & \\
\hline 1-1965 & 475 & 168 & 0 & -12 & \\
\hline \multicolumn{6}{|l|}{2} \\
\hline 3 & 475 & 168 & 0 & -12 & \\
\hline 4 & 475 & 168 & 0 & -12 & \\
\hline 1-1966 & 475 & 168 & 0 & -12 & \\
\hline 2 & 475 & 168 & 0 & -12 & \\
\hline 3 & 475 & 168 & 0 & -12 & \\
\hline 4 & 475 & 168 & 0 & -12 & \\
\hline
\end{tabular}




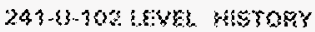

Fiv-so-wh-sy-32\% ken?

\begin{tabular}{|c|c|c|c|c|c|}
\hline Yeas & Total & Tskas & Solisis & Seloves & kn \\
\hline & S goll & $\{a\}$ & (x $x a s$ & (ins) & tin? \\
\hline & & & & & \\
\hline $1-\{36 \gamma$ & 475 & 68 & 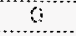 & 2 & \\
\hline 2 & 478 & 69 & 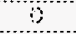 & $\because 2$ & \\
\hline 3 & $47 ?$ & 56 & $a$ & 2 & \\
\hline 6 & 477 & 63 & j & $2 \%$ & \\
\hline 3.3962 & $47 ?$ & 06 & a & 2 & \\
\hline 2 & 477 & 138 & ) & -3 & \\
\hline 3 & $47 ?$ & 66 & $\gamma$ & 22 & \\
\hline 4 & 477 & 163 & 3 & 32 & \\
\hline 1.3960 & $47 ?$ & $6 s$ & $a$ & 32 & \\
\hline$z$ & 477 & 63 & 3 & -12 & \\
\hline 3 & $47 ?$ & 69 & $a$ & 12 & \\
\hline$a$ & 47 & 63 & $4 !$ & 10 & \\
\hline$p-10 \% t$ & $4 ?$ & 36 & 43 & 76 & \\
\hline$z$ & $4 \%$ & 363 & 41 & 30 & \\
\hline 3 & 48 & 69 & 41 & 10 & \\
\hline 4 & 40 & 68 & 41 & 30 & \\
\hline $1-10 x y$ & 67 & 33 & 41 & 36 & \\
\hline$z$ & 479 & 170 & 43 & 10 & \\
\hline 3 & 479 & 170 & 43 & $i y$ & \\
\hline$\$$ & 480 & 30 & 43 & 13 & \\
\hline 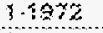 & 682 & 370 & 43 & 13 & \\
\hline$\hat{z}$ & 480 & 37 & 43 & 13 & \\
\hline 3 & $68 !$ & 370 & 43 & 7 & \\
\hline 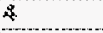 & $48 !$ & 780 & 46 & 13 & \\
\hline 1,79$) 3$ & 48 & 30 & 43 & 13 & \\
\hline 2 & 475 & 10 & 62 & 13 & \\
\hline 3 & 473 & 35 & 43 & 13 & \\
\hline 4 & 48 & $10 \theta$ & 36 & 13 & \\
\hline $13-1376$ & 8 & $3 y$ & 43 & 13 & \\
\hline 2 & $3 ?$ & 31 & 86 & 31 & \\
\hline$a$ & 36 & 32 & 43 & 31 & \\
\hline 4 & 101 & 32 & 36 & 33 & \\
\hline $3-13) 5$ & 36 & 32 & 43 & 13 & \\
\hline 2 & 228 & 86 & 36 & $3 ?$ & \\
\hline 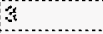 & (16) & 34 & 43 & 31 & \\
\hline 4 & 381 & $13 \alpha$ & $a s$ & $?$ & \\
\hline $3-33\}$ & 323 & 42 & 43 & 11 & \\
\hline 2 & 437 & 158 & $\therefore 3$ & 31 & \\
\hline 3 & 493 & 77 & 43 & 11 & \\
\hline 4 & 334 & 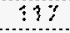 & 83 & 31 & \\
\hline$\{-\{3\} ?$ & 497 & 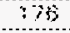 & 33 & 11 & \\
\hline 2 & 407 & 18 & $A:$ & ? & \\
\hline 3 & 484 & 35 & 43 & 11 & \\
\hline 4 & 400 & 43 & 263 & 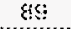 & \\
\hline $3-1378$ & 497 & 75 & 428 & 151 & \\
\hline 2 & 473 & 79 & 326 & 35 & \\
\hline
\end{tabular}


241-U-102 LEVEL HISTORY

HNF-SD-WM-ER-325, Rev. 1

\begin{tabular}{|c|c|c|c|c|c|}
\hline Year & Total & Total & Solids & Solids & ILL \\
\hline & (K gal) & (in) & (K gal) & (in) & (in) \\
\hline 3 & 410 & 145 & 410 & 145 & \\
\hline 4 & 425 & 150 & 421 & 149 & \\
\hline 1-1979 & 450 & 159 & 422 & 149 & \\
\hline 2 & 450 & 159 & 422 & 149 & \\
\hline 3 & 378 & 133 & 378 & 133 & \\
\hline 4 & 378 & 133 & 378 & 133 & \\
\hline $1-1980$ & 378 & 133 & 378 & 133 & \\
\hline 2 & 378 & 133 & 378 & 133 & \\
\hline 3 & 378 & 133 & 378 & 133 & \\
\hline 4 & 378 & 133 & 378 & 133 & \\
\hline $1-1981$ & 378 & 133 & 378 & 133 & \\
\hline 2 & 378 & 133 & 378 & 133 & \\
\hline 3 & 378 & 133 & 378 & 133 & \\
\hline 4 & 378 & 133 & 378 & 133 & \\
\hline $1-1982$ & 378 & 133 & 378 & 133 & \\
\hline 2 & 374 & 131 & 356 & 125 & \\
\hline 3 & 374 & 131 & 356 & 125 & \\
\hline 4 & 374 & 131 & 356 & 125 & \\
\hline $1-1983$ & 374 & 131 & 356 & 125 & \\
\hline 2 & 374 & 131 & 356 & 125 & \\
\hline 3 & 374 & 131 & 356 & 125 & \\
\hline 4 & 374 & 131 & 356 & 125 & \\
\hline 1-1984 & 374 & 131 & 356 & 125 & \\
\hline 2 & 374 & 131 & 356 & 125 & \\
\hline 3 & 374 & 131 & 356 & 125 & \\
\hline 4 & 374 & 131 & 356 & 125 & \\
\hline $1-1985$ & 374 & 131 & 356 & 125 & \\
\hline 2 & 374 & 131 & 356 & 125 & \\
\hline 3 & 374 & 131 & 356 & 125 & \\
\hline 4 & 374 & 131 & 356 & 125 & \\
\hline 1-1986 & 374 & 131 & 356 & 125 & 140 \\
\hline 2 & 374 & 131 & 356 & 125 & 140 \\
\hline 3 & 374 & 131 & 356 & 125 & 140 \\
\hline 4 & 374 & 131 & 356 & 125 & 139 \\
\hline $1-1987$ & 374 & 131 & 356 & 125 & 139 \\
\hline 2 & 374 & 131 & 356 & 125 & \\
\hline 3 & 374 & 131 & 356 & 125 & 140 \\
\hline 4 & 374 & 131 & 356 & 125 & 138 \\
\hline $1-1988$ & 374 & 131 & 356 & 125 & 140 \\
\hline 2 & 374 & 131 & 356 & 125 & 139 \\
\hline 3 & 374 & 131 & 356 & 125 & 138 \\
\hline 4 & 374 & 131 & 356 & 125 & 139 \\
\hline $1-1989$ & 374 & 131 & 356 & 125 & \\
\hline 2 & 374 & 131 & 356 & 125 & 140 \\
\hline 3 & 374 & 131 & 356 & 125 & 139 \\
\hline 4 & 374 & 131 & 356 & 125 & 138 \\
\hline
\end{tabular}


203-43-302:66re Hascosy

\begin{tabular}{|c|c|c|c|c|c|}
\hline Yyas & Taks & Fotas & Solitis & solis & Ka. \\
\hline & $k \mathrm{kadl}$ & (3is) & Kusti & $m$ & $\sin \}$ \\
\hline & & & & & \\
\hline $1-59030$ & 374 & 30 & $36 \%$ & 35 & 136 \\
\hline 2 & 34 & ช3! & 356 & 36 & \\
\hline 3 & $3 / 4$ & 39 & 360 & 75 & 136 \\
\hline A & 34 & $73 !$ & 356 & 36 & 30 \\
\hline$f-3496$ & $3 y$ & 139 & 366 & 35 & 16 \\
\hline$\dot{z}$ & 374 & 834 & 356 & $2 g^{2}$ & 138 \\
\hline 3 & 374 & 33 & 368 & 325 & 160 \\
\hline$\alpha$ & 376 & 135 & 356 & 36 & 136 \\
\hline 1.1992 & $3 \pi$ & $13:$ & 366 & 325 & \\
\hline 2 & 376 & 131 & 356 & $33^{2}$ & \\
\hline 3 & $3 / 4$ & 13 & 356 & 23 & 139 \\
\hline 4 & 324 & $33:$ & 366 & 36 & 135 \\
\hline $1-1933$ & $3 / 4$ & $73:$ & 350 & 25 & 136 \\
\hline 2 & 373 & 331 & 360 & 725 & 130 \\
\hline 3 & $3 \% 4$ & 33 & 356 & 25 & 136 \\
\hline$a$ & $37 A$ & 33 & 366 & 326 & 132 \\
\hline $1-995$ & 374 & 33 & 386 & 75 & 33 \\
\hline 2 & 37 & 131 & 366 & 328 & 132 \\
\hline 3 & 370 & 131 & 356 & 25 & 336 \\
\hline 9 & 374 & 33 & 360 & 125 & 140 \\
\hline 1. & 378 & 131 & 346 & 25 & 336 \\
\hline$z$ & 37 & $13 \%$ & 360 & 925 & 139 \\
\hline 3 & 378 & 831 & 358 & 25 & 336 \\
\hline 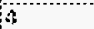 & 32 & 3 & 360 & 325 & 138 \\
\hline $1-3960$ & 306 & 31 & 354 & 35 & 335 \\
\hline 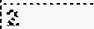 & 34 & $3 \%$ & 365 & $3 \mathrm{~s}$ & 139 \\
\hline
\end{tabular}


241-U-103 LEVEL HISTORY

HNF-SD-WM-ER-325, Rev. 1

\begin{tabular}{|c|c|c|c|c|c|}
\hline Year & Total & Total & Solids & Solids & ILL \\
\hline & (K gal) & (in) & (K gal) & (in) & (in) \\
\hline \multirow{2}{*}{\multicolumn{6}{|c|}{$1-1944$}} \\
\hline \multirow{2}{*}{\multicolumn{6}{|c|}{2}} \\
\hline & & & & & \\
\hline \multicolumn{6}{|l|}{3} \\
\hline \multicolumn{6}{|l|}{4} \\
\hline \multicolumn{6}{|l|}{$1-1945$} \\
\hline \multicolumn{6}{|l|}{2} \\
\hline \multicolumn{6}{|l|}{3} \\
\hline \multicolumn{6}{|l|}{4} \\
\hline \multicolumn{6}{|l|}{$1-1946$} \\
\hline \multicolumn{6}{|l|}{2} \\
\hline \multicolumn{6}{|l|}{3} \\
\hline \multicolumn{6}{|l|}{4} \\
\hline $1-1947$ & 151 & 50 & & & \\
\hline 2 & 410 & 145 & & & \\
\hline 3 & 528 & 187 & & & \\
\hline 4 & 528 & 187 & & & \\
\hline $1-1948$ & 528 & 187 & & & \\
\hline 2 & 528 & 187 & & & \\
\hline 3 & 528 & 187 & & & \\
\hline 4 & 528 & 187 & & & \\
\hline $1-1949$ & 528 & 187 & & & \\
\hline 2 & 528 & 187 & & & \\
\hline 3 & 528 & 187 & & & \\
\hline 4 & 528 & 187 & & & \\
\hline $1-1950$ & 528 & 187 & & & \\
\hline 2 & 528 & 187 & & & \\
\hline 3 & 528 & 187 & & & \\
\hline 4 & 528 & 187 & & & \\
\hline 1-1951 & 528 & 187 & & & \\
\hline \multicolumn{6}{|l|}{2} \\
\hline \multicolumn{6}{|l|}{3} \\
\hline \multicolumn{6}{|l|}{4} \\
\hline \multicolumn{6}{|l|}{ 1-1952 } \\
\hline 2 & 519 & 184 & & & \\
\hline 3 & 519 & 184 & & & \\
\hline 4 & 530 & 188 & & & \\
\hline $1-1953$ & 530 & 188 & & & \\
\hline 2 & 147 & 49 & & & \\
\hline \multicolumn{6}{|l|}{3} \\
\hline \multicolumn{6}{|l|}{4} \\
\hline $1-1954$ & 52 & 14 & & & \\
\hline 2 & 519 & 184 & & & \\
\hline 3 & 519 & 184 & & & \\
\hline 4 & 519 & 184 & & & \\
\hline 1-1955 & 519 & 184 & & & \\
\hline 2 & 519 & 184 & & & \\
\hline
\end{tabular}




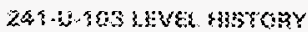

\begin{tabular}{|c|c|c|c|c|c|}
\hline$Y \otimes \otimes:$ & Sostas & Tod & Sobiols & Solises & 11 \\
\hline & adi & (kn) & $\{\xi \beta a d\}$ & ini & (n) \\
\hline & & & & & \\
\hline 3 & 59 & $3 \$ 3$ & & & \\
\hline$x$ & 13 & $\sigma$ & & & \\
\hline $4-3 \mathrm{sisj}$ & 13 & 0 & & & \\
\hline 8 & 3 & -4 & & & \\
\hline 3 & 3 & 6 & & & \\
\hline$y$ & 1 & -4 & & & \\
\hline $8-3657$ & 30 & 16 & & & \\
\hline 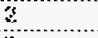 & 3 & 2 & & & \\
\hline 3 & 13 & 2 & & & \\
\hline 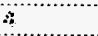 & 18 & 2 & & & \\
\hline 1-3958 & 16 & $\pi$ & 3 & .8 & \\
\hline s & 24 & 4 & 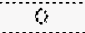 & 32 & \\
\hline 3 & 24 & 4 & 3 & 12 & \\
\hline 4 & $5 ! ?$ & 3 & $a$ & 12 & \\
\hline $3-1959$ & 536 & 96 & 3 & 12 & \\
\hline 2 & 538 & 31 & $\theta$ & 132 & \\
\hline 3 & 68 & 391 & 3 & 72 & \\
\hline स & 335 & 100 & 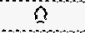 & 32 & \\
\hline $1-1356$ & की & 93 & 8 & .12 & \\
\hline 2 & 539 & 191 & $\Omega$ & 32 & \\
\hline 3 & 38 & 101 & 0 & 32 & \\
\hline 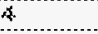 & 333 & 169 & $\theta$ & $3 z$ & \\
\hline \multicolumn{6}{|l|}{$3-3931$} \\
\hline 2 & 330 & 102 & 6 & 13 & \\
\hline \multicolumn{6}{|l|}{3} \\
\hline 4 & 530 & 368 & 6 & 13 & \\
\hline $3 . \$ \$ 2$ & 630 & 185 & 0 & -13 & \\
\hline \multicolumn{6}{|l|}{2} \\
\hline 3 & 630 & 385 & 0 & 32 & \\
\hline \multicolumn{6}{|l|}{3} \\
\hline \multicolumn{6}{|l|}{11963} \\
\hline 2 & 30 & 386 & $a$ & 12 & \\
\hline \multicolumn{6}{|l|}{3} \\
\hline 4 & 830 & 386 & $\dddot{6}$ & 42 & \\
\hline \multicolumn{6}{|l|}{1.1964} \\
\hline 2 & 830 & 386 & 6 & 12 & \\
\hline \multicolumn{6}{|l|}{3} \\
\hline 4 & 530 & 386 & 6 & -12 & \\
\hline 7.1955 & 530 & 388 & & & \\
\hline \multicolumn{6}{|l|}{2} \\
\hline 3 & 530 & 188 & $\%$ & $-1 \%$ & \\
\hline 4 & 536 & 360 & 6 & 12 & \\
\hline $3 \cdot 1966$ & 530 & 380 & 0 & $-Y \%$ & \\
\hline 2 & 530 & 386 & Q & 12 & \\
\hline 3 & 630 & 180 & 0 & 12 & \\
\hline 4 & 330 & 138 & 0 & .32 & \\
\hline
\end{tabular}


241-U-103 LEVEL HISTORY

\begin{tabular}{|c|c|c|c|c|c|}
\hline Year & Total & Total & Solids & Solids & ILL \\
\hline & (K gal) & (in) & (K gal) & (in) & (in) \\
\hline $1-1967$ & 530 & 188 & 0 & -12 & \\
\hline 2 & 531 & 189 & 0 & .12 & \\
\hline 3 & 531 & $\overline{189}$ & 0 & -12 & \\
\hline 4 & 531 & 189 & 0 & -12 & \\
\hline $1-1968$ & 531 & 189 & 0 & -12 & \\
\hline 2 & 531 & 189 & 0 & .12 & \\
\hline 3 & 531 & 189 & 0 & -12 & \\
\hline 4 & 532 & 189 & 0 & -12 & \\
\hline $1-1969$ & 532 & 189 & 0 & -12 & \\
\hline 2 & 533 & 189 & 0 & -12 & \\
\hline 3 & 534 & 190 & 0 & -12 & \\
\hline 4 & 534 & 190 & 32 & 7 & \\
\hline $1-1970$ & $5 \overline{34}$ & 190 & 32 & 7 & \\
\hline 2 & 534 & 190 & 32 & 7 & \\
\hline 3 & 534 & 190 & 32 & 7 & \\
\hline 4 & 535 & 190 & 32 & 7 & \\
\hline $1-1971$ & 535 & 190 & 32 & 7 & \\
\hline 2 & 535 & 190 & 32 & 7 & \\
\hline 3 & 536 & 190 & 32 & 7 & \\
\hline 4 & 536 & 190 & 32 & 7 & \\
\hline $1-1972$ & 535 & 190 & 32 & 7 & \\
\hline 2 & 536 & 190 & 32 & 7 & \\
\hline 3 & 536 & 190 & 32 & 7 & \\
\hline 4 & 536 & 190 & 32 & 7 & \\
\hline $1-1973$ & 536 & 190 & 32 & 7 & \\
\hline 2 & 538 & 191 & 32 & 7 & \\
\hline 3 & 536 & 190 & 32 & 7 & \\
\hline 4 & 537 & 191 & 32 & 7 & \\
\hline $1-1974$ & 108 & 35 & 32 & 7 & \\
\hline 2 & 111 & 36 & 32 & 7 & \\
\hline 3 & 111 & 36 & 32 & 7 & \\
\hline 4 & 112 & 36 & 32 & 7 & \\
\hline $1-1975$ & 112 & 36 & 32 & 7 & \\
\hline 2 & 153 & 51 & 32 & 7 & \\
\hline 3 & 480 & 170 & 32 & 7 & \\
\hline 4 & 480 & 170 & 32 & 7 & \\
\hline 1-1976 & 37 & 9 & 32 & 7 & \\
\hline 2 & 277 & 96 & 32 & 7 & \\
\hline$\sqrt{3}$ & 502 & 178 & 32 & 7 & \\
\hline 4 & 65 & 19 & 32 & 7 & \\
\hline 1-1977 & 425 & 150 & 51 & 14 & \\
\hline 2 & 222 & 76 & 51 & 14 & \\
\hline 3 & 497 & 176 & 334 & 117 & \\
\hline 4 & 439 & 155 & 411 & 145 & \\
\hline $1-1978$ & 447 & 158 & 411 & 145 & \\
\hline 2 & 450 & 159 & 411 & 145 & \\
\hline
\end{tabular}


SAYKL-\{DS LEVE MGTOEY

\begin{tabular}{|c|c|c|c|c|c|}
\hline Year & Total & Tsto & Sotos & Schists & Ell \\
\hline & $k 3 a k$ & $m$ & $\mathrm{Kadi}$ & (nkt & $\mathrm{ind}$ \\
\hline & & & & & \\
\hline 3 & 440 & 35 & 395 & $4 !$ & \\
\hline 4 & 453 & 60 & 413 & 345 & \\
\hline 3.3979 & 68 & 6 & 41 & 66 & \\
\hline 2 & 253 & 60 & 433 & 36 & \\
\hline 3 & 483 & 30 & $47 ?$ & $6 s$ & \\
\hline 6 & 453 & 160 & 413 & 145 & \\
\hline $1-19880$ & 453 & 60 & $47 ?$ & 45 & \\
\hline$z$ & 456 & 360 & $4 ! 3$ & 45 & \\
\hline 3 & 453 & 160 & म'? & 45 & \\
\hline 3 & $A \varepsilon^{3}$ & 180 & $4 ! 3$ & 36 & \\
\hline $19 \mathrm{~s}$ & 483 & 180 & 418 & 146 & \\
\hline 2 & 480 & 780 & 411 & $3 t s$ & \\
\hline 3 & 453 & 360 & $\therefore:$ & $a j$ & \\
\hline 3 & 463 & 780 & 411 & 38 & \\
\hline 1002 & 403 & 360 & $1:$ & 36 & \\
\hline 2 & $49 ?$ & 768 & 485 & 163 & \\
\hline 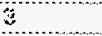 & $45 ?$ & 183 & 45 & 161 & \\
\hline 3 & 361 & 163 & 455 & $16 ?$ & \\
\hline 1333 & 406 & 186 & 365 & $18:$ & \\
\hline 2 & 460 & ats & 458 & 361 & \\
\hline 3 & 406 & $18 \xi$ & 855 & 160 & \\
\hline 4 & 465 & 36 & 435 & 391 & \\
\hline 1.3964 & 486 & 168 & 465 & $16 !$ & \\
\hline 2 & 466 & 35 & 463 & 161 & \\
\hline 3 & 406 & 46 & 468 & $18 !$ & \\
\hline 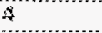 & 405 & 35 & 655 & 164 & \\
\hline $1-3 \leq k \mathrm{~s}$ & $6 \theta \theta$ & $6 s$ & 205 & $16 !$ & \\
\hline 3 & 405 & $\$ 53$ & 435 & 369 & \\
\hline 3 & $66 \theta$ & $Q_{i}$ & 305 & $16 !$ & \\
\hline 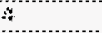 & 463 & 335 & 453 & 361 & \\
\hline $0-3 \leq 68$ & $66 t$ & $6 s$ & 185 & $16 !$ & 178 \\
\hline 3 & $40 \div 3$ & $\$ 5$ & 455 & 169 & 373 \\
\hline 3 & 260 & 165 & 355 & $16 !$ & 89 \\
\hline 4 & 4033 & 36 & 455 & 369 & 33 \\
\hline $1-3 \leq 6$ & 688 & 66 & 155 & $16 !$ & $1 ?$ \\
\hline 3 & 4033 & 106 & 455 & 161 & \\
\hline 3 & 668 & 166 & 135 & $10 !$ & 78 \\
\hline 4 & 4033 & 36 & 455 & 361 & 37 \\
\hline $1-3 \leq 68$ & 968 & 66 & 455 & $96 !$ & 178 \\
\hline 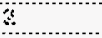 & 4633 & 36 & 265 & 161 & 373 \\
\hline 3 & $9 \theta$ & 68 & 465 & $35 !$ & 178 \\
\hline 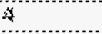 & 4033 & $\therefore b$ & 456 & $16 !$ & 37 \\
\hline $1-3 \leq \leqslant 53$ & $4 \Leftrightarrow$ & :6E & 455 & $18:$ & \\
\hline 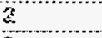 & 463 & (6) & 455 & $19 !$ & 17 \\
\hline 3 & 408 & $\$ 6$ & 358 & $3 \notin:$ & 73 \\
\hline 4 & 463 & 60 & 455 & 51 & 13 \\
\hline
\end{tabular}


241-U-103 LEVEL HISTORY

HNF-SD-WM-ER-325, Rev. 1

\begin{tabular}{|c|c|c|c|c|c|}
\hline Year & Total & Total & Solids & Solids & ILL \\
\hline & (K gal) & (in) & (K gal) & (in) & (in) \\
\hline $1-1990$ & 468 & 166 & 455 & 161 & 177 \\
\hline 2 & 468 & 166 & 455 & 161 & \\
\hline 3 & 468 & 166 & 455 & 161 & 178 \\
\hline 4 & 468 & 166 & 455 & 161 & 177 \\
\hline 1-1991 & 468 & 166 & 455 & 161 & 178 \\
\hline 2 & 468 & 166 & 455 & 161 & 178 \\
\hline 3 & 468 & 166 & 455 & 161 & 178 \\
\hline 4 & 468 & 166 & 455 & 161 & 178 \\
\hline 1.1992 & 468 & 166 & 455 & 161 & \\
\hline 2 & 468 & 166 & 455 & 161 & \\
\hline 3 & 468 & 166 & 455 & 161 & \\
\hline 4 & 468 & 166 & 455 & 161 & 178 \\
\hline 1-1993 & 468 & 166 & 455 & 161 & 178 \\
\hline 2 & 468 & 166 & 455 & 161 & 178 \\
\hline 3 & 468 & 166 & 455 & 161 & 178 \\
\hline 4 & 468 & 166 & 455 & 161 & 179 \\
\hline $1-1994$ & 468 & 166 & 455 & 161 & 178 \\
\hline 2 & 468 & 166 & 455 & 161 & 178 \\
\hline 3 & 468 & 166 & 455 & 161 & 179 \\
\hline 4 & 468 & 166 & 455 & 161 & 178 \\
\hline 1-1995 & 468 & 166 & 455 & 161 & 178 \\
\hline 2 & 468 & 166 & 455 & 161 & 179 \\
\hline 3 & 468 & 166 & 455 & 161 & 178 \\
\hline 4 & 468 & 166 & 455 & 161 & 178 \\
\hline 1-1996 & 468 & 166 & 455 & 161 & 178 \\
\hline 2 & 468 & $1 \overline{66}$ & 455 & 161 & 178 \\
\hline
\end{tabular}


2Q3-\{\}-104 LEYE\} WISTOKY

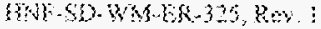

\begin{tabular}{|c|c|c|c|c|}
\hline Yeat & Torn & (ssk) & solita & Solids \\
\hline & $\{x<3\}$ & in & in sall & in \\
\hline \multirow{2}{*}{\multicolumn{5}{|c|}{$1-3 \$ 94$}} \\
\hline & & & & \\
\hline \multicolumn{5}{|l|}{2} \\
\hline \multicolumn{5}{|l|}{3} \\
\hline \multicolumn{5}{|l|}{4} \\
\hline \multicolumn{5}{|l|}{$3-\{3<\&$} \\
\hline \multicolumn{5}{|l|}{2} \\
\hline \multicolumn{5}{|l|}{ an } \\
\hline \multicolumn{5}{|l|}{4} \\
\hline \multicolumn{5}{|l|}{13356} \\
\hline \multicolumn{5}{|l|}{2} \\
\hline \multicolumn{5}{|l|}{3} \\
\hline \multicolumn{5}{|l|}{4} \\
\hline \multicolumn{5}{|l|}{1.3943} \\
\hline \multicolumn{5}{|l|}{2} \\
\hline 3 & 253 & 87 & & \\
\hline 4 & 636 & $83 ?$ & & \\
\hline $8 \cdot 35 \$ 6$ & 528 & $3 \%$ & & \\
\hline 2 & 536 & $83 ?$ & & \\
\hline 3 & 528 & 36 & & \\
\hline 4 & 62 & B? & & \\
\hline 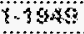 & 528 & 3 & & \\
\hline$z$ & 82 & $B ?$ & & \\
\hline 3 & 528 & 36 & & \\
\hline i & 820 & $3 \%$ & & \\
\hline $1-1950$ & 328 & 8 & & \\
\hline 3 & 826 & $\{B\}$ & & \\
\hline 3 & 328 & $8 \%$ & & \\
\hline 4 & 520 & 387 & & \\
\hline 1.1353 & 532 & 187 & & \\
\hline \multicolumn{5}{|l|}{2} \\
\hline \multicolumn{5}{|l|}{3} \\
\hline \multicolumn{5}{|l|}{6} \\
\hline \multicolumn{5}{|l|}{ 1. $\{\$ 3 \% 2$} \\
\hline 2 & 530 & 383 & & \\
\hline 3 & $\$ 30$ & 188 & & \\
\hline 8 & 296 & 503 & & \\
\hline $3-1903$ & 630 & 18 & & \\
\hline \multicolumn{5}{|l|}{2} \\
\hline 3 & 132 & 62 & & \\
\hline \multicolumn{5}{|l|}{6} \\
\hline \multicolumn{5}{|l|}{$1-1956$} \\
\hline \multicolumn{5}{|l|}{2} \\
\hline 3 & & & & \\
\hline 4 & 530 & 58 & & \\
\hline $1-1 \operatorname{sos}$ & $8 \$$ & $3 B$ & & \\
\hline 2 & $63 n$ & 36 & & \\
\hline
\end{tabular}


241-U-104 LEVEL HISTORY

HNF-SD-WM-ER-325, Rev. 1

\begin{tabular}{|c|c|c|c|c|}
\hline Year & Total & Total & Solids & Solids \\
\hline & (K gal) & (in) & (K gal) & (in) \\
\hline 3 & 530 & 188 & & \\
\hline 4 & 530 & 188 & & \\
\hline 1-1956 & 25 & 5 & 20 & 3 \\
\hline 2 & 30 & 6 & 8 & -2 \\
\hline 3 & 2 & -4 & 1 & -4 \\
\hline 4 & 2 & -4 & 1 & -4 \\
\hline 1-1957 & 2 & -4 & 1 & -4 \\
\hline 2 & 241 & 83 & 0 & -12 \\
\hline 3 & 238 & 82 & 0 & -12 \\
\hline \multicolumn{5}{|l|}{4} \\
\hline 1-1958 & 230 & 79 & 0 & -12 \\
\hline 2 & 230 & 79 & 0 & -12 \\
\hline 3 & 224 & 77 & 0 & -12 \\
\hline 4 & 222 & 76 & 0 & -12 \\
\hline 1-1959 & 222 & 76 & 0 & -12 \\
\hline 2 & 220 & 75 & 0 & -12 \\
\hline 3 & 211 & 72 & 0 & -12 \\
\hline 4 & 211 & 72 & 0 & -12 \\
\hline $1-1960$ & 211 & 72 & 0 & -12 \\
\hline 2 & 199 & 68 & 0 & -12 \\
\hline 3 & 196 & 67 & 0 & -12 \\
\hline 4 & 194 & 66 & 0 & -12 \\
\hline \multicolumn{5}{|l|}{$1-1961$} \\
\hline 2 & 67 & 20 & 0 & -12 \\
\hline \multicolumn{5}{|l|}{3} \\
\hline 4 & 67 & 20 & 0 & -12 \\
\hline \multicolumn{5}{|l|}{$1-1962$} \\
\hline 2 & 64 & 19 & 0 & -12 \\
\hline \multicolumn{5}{|l|}{3} \\
\hline 4 & 64 & 19 & 0 & -12 \\
\hline \multicolumn{5}{|l|}{$1-1963$} \\
\hline 2 & 59 & 17 & 0 & -12 \\
\hline \multicolumn{5}{|l|}{3} \\
\hline 4 & 59 & 17 & 0 & -12 \\
\hline \multicolumn{5}{|l|}{$1-1964$} \\
\hline 2 & 59 & 17 & 0 & -12 \\
\hline \multicolumn{5}{|l|}{3} \\
\hline 4 & 59 & 17 & 0 & -12 \\
\hline \multicolumn{5}{|l|}{$1-1965$} \\
\hline 2 & 15 & 1 & 0 & -12 \\
\hline 3 & 15 & 1 & 0 & -12 \\
\hline 4 & 15 & 1 & 0 & -12 \\
\hline $1-1966$ & 15 & 1 & 0 & -12 \\
\hline 2 & 15 & 1 & 0 & -12 \\
\hline 3 & 15 & 1 & 0 & -12 \\
\hline 4 & 15 & 1 & 0 & -12 \\
\hline
\end{tabular}




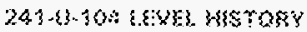

130-SO-Wh-6k-395 Row:

\begin{tabular}{|c|c|c|c|c|}
\hline Ysat & Toses & $7 \leqslant s: 3\}$ & Snliks & Soloses \\
\hline & $\{\mathrm{K}$ \&is $\}$ & is & $\left\{\begin{array}{l}3 s i\} \\
\end{array}\right.$ & $(\mathrm{s})$ \\
\hline & & & & \\
\hline $1.9 \$ 67$ & 85 & 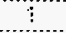 & 0 & 12 \\
\hline 2 & 3 & $i$ & 8 & .12 \\
\hline 3 & 3 & $\dddot{3}$ & 6 & 12 \\
\hline 4 & 15 & 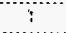 & 0 & 22 \\
\hline $1-7358$ & 5 & 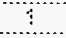 & 0 & 12 \\
\hline 2 & 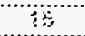 & $\because$ & 0 & .2 \\
\hline 3 & 36 & $\vdots$ & 6 & $\cdot: 2$ \\
\hline 4 & 5 & 3 & 0 & .2 \\
\hline $3-73 s \mathrm{~s}$ & 36 & $\because$ & 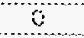 & 12 \\
\hline 2 & 35 & $\vdots$ & 0 & 32 \\
\hline 4 & 36 & 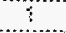 & 0 & $.7 \bar{z}$ \\
\hline 4 & 100 & $3 a$ & to & 10 \\
\hline $3-4820$ & 300 & 34 & 46 & 30 \\
\hline 2 & $30 ?$ & 34 & 36 & 36 \\
\hline 3 & 108 & 34 & 49 & 36 \\
\hline 4 & 10 & 34 & 46 & 16 \\
\hline $3-\{0\}$ & 107 & 34 & 4 & 36 \\
\hline 2 & 107 & 34 & 36 & (i) \\
\hline 3 & 107 & 34 & 40 & 36 \\
\hline 4 & 107 & 34 & 36 & 19 \\
\hline $7-1932$ & 108 & 3 & 40 & 30 \\
\hline 2 & $13\}$ & 43 & 33 & 43 \\
\hline 3 & 123 & $6 \%$ & 33 & 22 \\
\hline$a$ & 8 & 42 & 28 & 42 \\
\hline 9.1973 & 38 & 32 & 23 & 22 \\
\hline 2 & 21 & 42 & 127 & 42 \\
\hline 3 & $2 \%$ & 32 & $2 ?$ & 42 \\
\hline 3 & 3 & $4 \%$ & 21 & 42 \\
\hline$x-137 x$ & $2 ?$ & 3 & $2 ?$ & 42 \\
\hline 2 & $3 y$ & 42 & 121 & 42 \\
\hline 3 & 27 & 32 & $2 ?$ & 42 \\
\hline 8 & $2 \xi$ & 41 & 23 & 43 \\
\hline$\gamma-13 \gamma k$ & 725 & 33 & 25 & 41 \\
\hline 2 & $2 \varepsilon$ & $d 1$ & $2 \%$ & 23 \\
\hline 3 & 725 & 31 & 25 & 31 \\
\hline 3 & 28 & 41 & 25 & 43 \\
\hline Y-\{B\}E & 725 & 41 & 25 & $4 ?$ \\
\hline 2 & 128 & 41 & 25 & 41 \\
\hline 3 & 125 & 41 & 25 & 41 \\
\hline 3 & 185 & 41 & 26 & 41 \\
\hline$\{-103\}$ & 725 & $\$ 1$ & 25 & 41 \\
\hline 2 & 316 & 41 & 25 & 41 \\
\hline 3 & 825 & $\therefore 1$ & 25 & 43 \\
\hline 3 & $3 \mathrm{se}$ & 41 & 36 & 41 \\
\hline $2-1978$ & 25 & 33 & 32 & 33 \\
\hline 2 & 325 & 41 & 136 & 41 \\
\hline
\end{tabular}


241-U-104 LEVEL HISTORY

HNF-SD-WM-ER-325, Rev. 1

\begin{tabular}{|c|c|c|c|c|}
\hline Year & Total & Total & Solids & Solids \\
\hline & (K gal) & (in) & (K gall) & (in) \\
\hline 3 & 113 & 37 & $11 \overline{3}$ & 37 \\
\hline 4 & 125 & 41 & 125 & $\overline{41}$ \\
\hline $1-1979$ & 125 & 41 & 125 & 41 \\
\hline 2 & 125 & 41 & 125 & 41 \\
\hline 3 & 125 & 41 & 125 & 41 \\
\hline 4 & 125 & 41 & 125 & 41 \\
\hline $1-1980$ & 125 & 41 & 125 & 41 \\
\hline 2 & 125 & 41 & 125 & 41 \\
\hline 3 & 125 & 41 & 125 & 41 \\
\hline 4 & 125 & 41 & 125 & 41 \\
\hline 1-1981 & 125 & 41 & 125 & 41 \\
\hline 2 & 125 & 41 & 125 & 41 \\
\hline 3 & 125 & 41 & 125 & 41 \\
\hline 4 & 125 & 41 & 125 & 41 \\
\hline 1-1982 & 125 & 41 & 125 & 41 \\
\hline 2 & 122 & 40 & 122 & 40 \\
\hline 3 & 122 & 40 & 122 & 40 \\
\hline 4 & 122 & 40 & 122 & 40 \\
\hline $1-1983$ & 122 & 40 & 122 & 40 \\
\hline 2 & 122 & 40 & 122 & 40 \\
\hline 3 & 122 & $4 \overline{0}$ & 122 & 40 \\
\hline 4 & 122 & 40 & 122 & 40 \\
\hline $1-1984$ & 122 & 40 & 122 & 40 \\
\hline 2 & 122 & 40 & 122 & 40 \\
\hline 3 & 122 & 40 & 122 & 40 \\
\hline 4 & 122 & 40 & 122 & 40 \\
\hline $1-1985$ & 122 & 40 & 122 & 40 \\
\hline 2 & 122 & 40 & 122 & 40 \\
\hline 3 & 122 & 40 & 122 & 40 \\
\hline 4 & 122 & 40 & 122 & 40 \\
\hline $1-1986$ & 122 & 40 & 122 & 40 \\
\hline 2 & 122 & 40 & 122 & 40 \\
\hline 3 & 122 & 40 & 122 & 40 \\
\hline 4 & 122 & 40 & 122 & 40 \\
\hline 1.1987 & 122 & 40 & 122 & 40 \\
\hline 2 & 122 & 40 & 122 & 40 \\
\hline 3 & 122 & 40 & 122 & 40 \\
\hline 4 & 122 & 40 & 122 & 40 \\
\hline $1-1988$ & 122 & 40 & 122 & 40 \\
\hline 2 & 122 & 40 & 122 & $\overline{40}$ \\
\hline 3 & 122 & 40 & 122 & 40 \\
\hline 4 & 122 & 40 & 122 & 40 \\
\hline $1-1989$ & 122 & 40 & 122 & 40 \\
\hline 2 & 122 & 40 & 122 & 40 \\
\hline 3 & 122 & 40 & 122 & 40 \\
\hline 4 & 122 & 40 & 122 & 40 \\
\hline
\end{tabular}




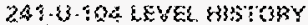

\begin{tabular}{|c|c|c|c|c|}
\hline Y४⿻s & Toral & Total & 86150 & Solitus \\
\hline & $\{k s \mathrm{~s}\}$ & ins & $\left\{K_{3} \quad 2 \times\right\}$ & (6)!? \\
\hline & & & & \\
\hline $1-7330$ & 122 & 40 & 122 & (16) \\
\hline 2 & $2 z$ & 4 & 122 & 40 \\
\hline 3 & 132 & 60 & $12 \%$ & 40 \\
\hline 4 & 122 & 40 & 122 & 60 \\
\hline $3-19341$ & 122 & 60 & 122 & $A 6$ \\
\hline 2 & 122 & 4 & 122 & 6 \\
\hline 3 & 122 & 60 & $\% \%$ & $A 6$ \\
\hline 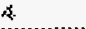 & 122 & 40 & 12 & 40 \\
\hline $1-1492$ & 322 & 30 & $22 \%$ & 40 \\
\hline 2 & 122 & 40 & $\$ 2$ & 40 \\
\hline 3 & 122 & 60 & $2 \%$ & 40 \\
\hline a & 122 & 40 & 2 & 60 \\
\hline $1-3993$ & 122 & 40 & 122 & $\$ 0$ \\
\hline 2 & $: 22$ & $x\}$ & 122 & 40 \\
\hline 3 & 32 & 60 & 22 & 40 \\
\hline 4 & 82 & $a$ & 22 & 40 \\
\hline $3 . \xi 394$ & $12 \%$ & 40 & 122 & $4 n$ \\
\hline 2 & 122 & 40 & 122 & 40 \\
\hline 3 & $32 \%$ & 60 & 22 & 40 \\
\hline 4 & $\{2\}$ & 40 & 122 & 40 \\
\hline $3-8935$ & 12 & 6 & 122 & 30 \\
\hline 2 & 122 & 40 & 122 & 40 \\
\hline 3 & 32 & 60 & 122 & 40 \\
\hline 4 & 123 & 40 & 322 & 40 \\
\hline $3-1336$ & 322 & 60 & 122 & 46 \\
\hline 2 & 122 & 40 & 122 & 61 \\
\hline
\end{tabular}




\begin{tabular}{|c|c|c|c|c|c|}
\hline & & & 781 & 619 & 2 \\
\hline & & & 981 & OZS & SS6L-1 \\
\hline & & & 981 & OZS & $t$ \\
\hline & & & & & $\varepsilon$ \\
\hline & & & & & $z$ \\
\hline & & & & & $t G 6 L-l$ \\
\hline & & & & & $t$ \\
\hline & & & & & $\varepsilon$ \\
\hline & & & $9 \varepsilon$ & டレ & $z$ \\
\hline & & & 881 & $0 \varepsilon \subseteq$ & ES6L-L \\
\hline & & & 881 & $0 \varepsilon 9$ & $t$ \\
\hline & & & 881 & 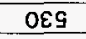 & $\varepsilon$ \\
\hline & & & 881 & $0 \varepsilon 9$ & $z$ \\
\hline & & & & & Z96L-L \\
\hline & & & & & t \\
\hline & & & & & $\varepsilon$ \\
\hline & & & & & $\bar{z}$ \\
\hline & & & $\angle 81$ & 829 & LG6L-L \\
\hline & & & $\angle 8 L$ & 829 & $t$ \\
\hline & & & $\angle 81$ & 829 & $\varepsilon$ \\
\hline & & & $\angle 81$ & 879 & $z$ \\
\hline & & & $\angle 81$ & 829 & $0961-1$ \\
\hline & & & $\angle 81$ & 829 & $t$ \\
\hline & & & $\angle 81$ & 879 & $\boldsymbol{\varepsilon}$ \\
\hline & & & $\angle 8 l$ & 829 & $\bar{z}$ \\
\hline & & & $\angle 81$ & 829 & $666 \mathrm{~L}-\mathrm{l}$ \\
\hline & & & $\angle 81$ & $8 Z 9$ & $t$ \\
\hline & & & $\angle 81$ & 829 & $\varepsilon$ \\
\hline & & & $\angle 81$ & $82 \overline{9}$ & 2 \\
\hline & & & OII & $\nabla \downarrow \varepsilon$ & $8+6 L-1$ \\
\hline & & & 81 & 29 & $t$ \\
\hline & & & & & $\varepsilon$ \\
\hline & & & & & $z$ \\
\hline & & & & & $\angle t 6 L-L$ \\
\hline & & & & & $t$ \\
\hline & & & & & $\varepsilon$ \\
\hline & & & & & $\bar{z}$ \\
\hline & & & & & $906 L-L$ \\
\hline & & & & & $t$ \\
\hline & & & & & $E$ \\
\hline & & & & & Z \\
\hline & & & & & St6L-L \\
\hline & & & & & $t$ \\
\hline & & & & & $\varepsilon$ \\
\hline & & & & & $\zeta$ \\
\hline & & & & & $t \$ 6 L-L$ \\
\hline & & & & & \\
\hline (U!) & (u!) & $\left(\mathrm{je6}^{\mathrm{e}} \mathrm{x}\right)$ & (UI!) & (1е6 X) & \\
\hline 17! & spylos & sp!jos & |810। & $1810 \perp$ & $18 \theta \lambda$ \\
\hline
\end{tabular}




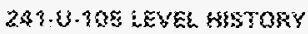

\begin{tabular}{|c|c|c|c|c|c|}
\hline Yast & Total & $308 \mathrm{~s}$ & Söksk & 30 tids & $\$ 2 !$ \\
\hline & kns? & 39 & 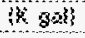 & (3ss) & fing \\
\hline & & & & & \\
\hline 3 & 598 & 18 & & & \\
\hline 4 & 619 & 384 & & & \\
\hline $3-73366$ & 830 & 18 & & & \\
\hline 2 & 20 & 3 & 3 & 3 & \\
\hline 3 & $\$ 2$ & 23 & & & \\
\hline 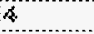 & $3 \%$ & 38 & & & \\
\hline $3.735 ?$ & 8 & 13 & & & \\
\hline 2 & 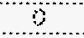 & 12 & & & \\
\hline 3 & 40 & 10 & & & \\
\hline$a$ & 60 & 10 & & & \\
\hline 3.7958 & 40 & 30 & 8 & 12 & \\
\hline 2 & 60 & 10 & 8 & 12 & \\
\hline 3 & 40 & 86 & 8 & 12 & \\
\hline 4 & 60 & 30 & 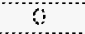 & 12 & \\
\hline $1-73 \$ 3$ & 40 & 8 & 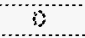 & 32 & \\
\hline 2 & 60 & 36 & 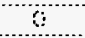 & 3 & \\
\hline 3 & 4) & (1) & $b$ & -12 & \\
\hline 6 & 30 & 36 & 0 & 12 & \\
\hline $1-1380$ & 30 & 10 & 8 & 12 & \\
\hline 2 & 30 & 30 & 0 & 12 & \\
\hline 3 & 30 & 30 & 0 & -12 & \\
\hline 4 & 40 & 36 & 0 & 12 & \\
\hline$(1-336\}$ & 85 & 63 & 0 & $-2 z$ & \\
\hline \multicolumn{6}{|l|}{2} \\
\hline 8 & 497 & 76 & 0 & .32 & \\
\hline \multicolumn{6}{|l|}{4} \\
\hline \multicolumn{6}{|l|}{3362} \\
\hline 2 & 497 & 176 & 0 & 12 & \\
\hline \multicolumn{6}{|l|}{$\mathrm{s}$} \\
\hline 4 & 497 & 178 & 0 & 12 & \\
\hline \multicolumn{6}{|l|}{ ?. 1963} \\
\hline 2 & $\$ 97$ & 138 & 3 & 12 & \\
\hline \multicolumn{6}{|l|}{3} \\
\hline G & 407 & 133 & 0 & 32 & \\
\hline \multicolumn{6}{|l|}{$8-3962$} \\
\hline 2 & 497 & 36 & 0 & 12 & \\
\hline \multicolumn{6}{|c|}{3} \\
\hline 6 & 497 & 178 & o & 32 & \\
\hline \multicolumn{6}{|l|}{$2-3565$} \\
\hline 2 & 458 & 37 & 3 & 32 & \\
\hline 3 & 495 & 177 & 0 & .12 & \\
\hline$\omega$ & 493 & 37 & 3 & 32 & \\
\hline $8-3366$ & 493 & 17 & 0 & .12 & \\
\hline 2 & 493 & 17 & 8 & 32 & \\
\hline 3 & 493 & $? ?$ & 0 & -18 & \\
\hline 4 & 696 & 3 & 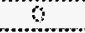 & 12 & \\
\hline
\end{tabular}


241-U-105 LEVEL HISTORY

HNF-SD-WM-ER-325, Rev. 1

\begin{tabular}{|c|c|c|c|c|c|}
\hline Year & Total & Total & Solids & Solids & ILL \\
\hline & (K gal) & (in) & (K gal) & (in) & (in) \\
\hline & & & & & \\
\hline $1-1967$ & 499 & 177 & 0 & -12 & \\
\hline 2 & 501 & 178 & 0 & -12 & \\
\hline 3 & 501 & 178 & 0 & -12 & \\
\hline 4 & 501 & 178 & 0 & -12 & \\
\hline $1-1968$ & 501 & 178 & 0 & -12 & \\
\hline 2 & 501 & 178 & 0 & -12 & \\
\hline 3 & 501 & 178 & 0 & -12 & \\
\hline 4 & 501 & 178 & 0 & -12 & \\
\hline $1-1969$ & 501 & 178 & 0 & -12 & \\
\hline 2 & 501 & 178 & 0 & -12 & \\
\hline 3 & 502 & 178 & 0 & -12 & \\
\hline 4 & 502 & 178 & 32 & 7 & \\
\hline $1-1970$ & 502 & 178 & 32 & 7 & \\
\hline 2 & 502 & 178 & 32 & 7 & \\
\hline 3 & 502 & 178 & 32 & 7 & \\
\hline 4 & 502 & 178 & 32 & 7 & \\
\hline $1-1971$ & 503 & 178 & 32 & 7 & \\
\hline 2 & 503 & 178 & 32 & 7 & \\
\hline 3 & 503 & 178 & 32 & 7 & \\
\hline 4 & 503 & 178 & 32 & 7 & \\
\hline $1-1972$ & 505 & 179 & 32 & 7 & \\
\hline 2 & 505 & 179 & 32 & 7 & \\
\hline 3 & 505 & 179 & 32 & 7 & \\
\hline 4 & 506 & 179 & 32 & 7 & \\
\hline $1-1973$ & 508 & 180 & 32 & 7 & \\
\hline 2 & 507 & 180 & 32 & 7 & \\
\hline 3 & 504 & 179 & 32 & 7 & \\
\hline 4 & 506 & 179 & 32 & 7 & \\
\hline $1-1974$ & 85 & 26 & 32 & 7 & \\
\hline 2 & 87 & 27 & 32 & 7 & \\
\hline 3 & 88 & 27 & 32 & 7 & \\
\hline 4 & 87 & 27 & 32 & 7 & \\
\hline 1-1975 & 92 & 29 & 32 & 7 & \\
\hline 2 & 381 & 134 & 32 & 7 & \\
\hline 3 & 497 & 176 & 32 & 7 & \\
\hline 4 & 497 & 176 & 32 & 7 & \\
\hline $1-1976$ & 505 & 179 & 32 & 7 & \\
\hline 2 & 513 & 182 & 32 & 7 & \\
\hline 3 & 439 & 155 & 32 & 7 & \\
\hline 4 & 252 & 87 & 106 & 34 & \\
\hline 1-1977 & 378 & 133 & 249 & 86 & \\
\hline 2 & 376 & 132 & 249 & 86 & \\
\hline 3 & 510 & 181 & 249 & 86 & \\
\hline 4 & 403 & 142 & 249 & 86 & \\
\hline $1-1978$ & 400 & 141 & 249 & 86 & \\
\hline 2 & 442 & 156 & 442 & 156 & \\
\hline
\end{tabular}




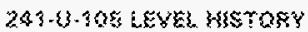

\begin{tabular}{|c|c|c|c|c|c|}
\hline Y\$s\$s & TWL: & Toral & Gestiks & 3sshikis & $\leqslant \alpha$ \\
\hline & ik ssis & the? & soli & (ins & 6 \\
\hline & & & & & \\
\hline$x$ & $3 \leqslant 7$ & 339 & 333 & 33 & \\
\hline 4 & 606 & 330 & 383 & 33 & \\
\hline $3-Y 370$ & 36 & 143 & 333 & 134 & \\
\hline 2 & 606 & 330 & $38\}$ & 334 & \\
\hline 3 & 806 & 143 & 333 & 134 & \\
\hline 6 & 600 & 133 & 383 & 334 & \\
\hline 3.1830 & 40 & 133 & 33 & 334 & \\
\hline 2 & 60 & 83 & $3 \mathrm{a}$ & 33 & \\
\hline 3 & 406 & 33 & 331 & 334 & \\
\hline 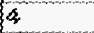 & 606 & 33 & 331 & 336 & \\
\hline $1-1581$ & 40 & 143 & 381 & 334 & \\
\hline 2 & 608 & 343 & 321 & 334 & \\
\hline 3 & 406 & 193 & 303 & 334 & \\
\hline$a$ & 606 & 333 & 361 & 734 & \\
\hline 1.5382 & $4 \infty$ & 133 & 393 & 134 & \\
\hline$z$ & 606 & 33 & 361 & $\sqrt{34}$ & \\
\hline 3 & 40 & 83 & 383 & 134 & \\
\hline$a$ & 66 & 343 & 361 & 734 & \\
\hline$x-19 s 6$ & 418 & $? ?$ & 383 & $13 x$ & \\
\hline 2 & 36 & 34 & הor & 34 & \\
\hline 3 & 418 & $\beta\}$ & 38 & 13 & \\
\hline a & 330 & 34 & 336 & 734 & \\
\hline 1.1284 & 438 & 33 & $38 ?$ & 13 & \\
\hline 2 & 43 & 34 & 331 & 134 & \\
\hline 3 & 43 & $3 \%$ & $38 \%$ & 3 & \\
\hline 4 & 430 & 33 & 333 & 34 & \\
\hline 3.1985 & 632 & 337 & 383 & 134 & \\
\hline 2 & 48 & $4 ?$ & 385 & 33 & \\
\hline 3 & 618 & 137 & 381 & 134 & \\
\hline स & $4 ! 8$ & $a ?$ & 385 & 338 & \\
\hline $3-\gamma 98 \mathrm{~B}$ & 598 & 137 & 351 & 334 & 160 \\
\hline 2 & 418 & $4 ?$ & 385 & 133 & 360 \\
\hline 3 & 518 & 147 & 331 & 334 & 360 \\
\hline$\alpha$ & $4 ! 5$ & 19 & 301 & 134 & 30 \\
\hline $3-\gamma 987$ & 413 & 54 & 381 & 33 & 60 \\
\hline 2 & $4: 8$ & 14 & 335 & 333 & \\
\hline$a$ & 453 & 147 & $33 !$ & 34 & 3 \\
\hline 4 & 418 & 187 & 381 & 334 & 16 \\
\hline $3-\gamma 3888$ & 493 & $14 \%$ & $3 \otimes !$ & 34 & 31 \\
\hline 2 & 918 & 13 & 381 & 134 & $\$ 6$ \\
\hline$a$ & सा & 34 & $3 \& !$ & 134 & $3\}$ \\
\hline$a$ & 318 & 36 & 383 & 134 & 60 \\
\hline $3-73 \times 3$ & 418 & 34 & $38 !$ & 134 & \\
\hline 2 & 418 & 36 & $3 B !$ & $3 s$ & 181 \\
\hline 3 & 418 & 343 & उEY & 33 & Ys! \\
\hline 4 & $41 B$ & 36? & 333 & 34 & 36 \\
\hline
\end{tabular}


241-U-105 LEVEL HISTORY

HNF-SD-WM-ER-325, Rev. 1

\begin{tabular}{|c|c|c|c|c|c|}
\hline Year & Total & Total & Solids & Solids & ILL \\
\hline & (K gal) & (in) & (K gal) & (in) & (in) \\
\hline $1-1990$ & 418 & 147 & 381 & 134 & 161 \\
\hline 2 & 418 & 147 & 381 & 134 & \\
\hline 3 & 418 & 147 & 381 & 134 & 161 \\
\hline 4 & 418 & $1 \overline{4} \overline{7}$ & 381 & 134 & 161 \\
\hline $1-1991$ & 418 & 147 & 381 & 134 & 161 \\
\hline 2 & 418 & 147 & 381 & 134 & 160 \\
\hline 3 & 418 & 147 & 381 & 134 & 161 \\
\hline 4 & 418 & 147 & 381 & 134 & 161 \\
\hline 1-1992 & 418 & 147 & 381 & 134 & \\
\hline 2 & 418 & 147 & 381 & 134 & 161 \\
\hline 3 & 418 & 147 & 381 & 134 & \\
\hline 4 & 418 & 147 & 381 & 134 & 161 \\
\hline $1-1993$ & 418 & 147 & 381 & 134 & 161 \\
\hline 2 & 418 & 147 & 381 & 134 & 162 \\
\hline 3 & 418 & 147 & 381 & 134 & 162 \\
\hline 4 & 418 & 147 & 381 & 134 & $\overline{162}$ \\
\hline $1-1994$ & 418 & 147 & 381 & 134 & $1 \overline{62}$ \\
\hline 2 & 418 & 147 & 381 & 134 & 162 \\
\hline 3 & 418 & 147 & 381 & 134 & 162 \\
\hline 4 & 418 & 147 & 381 & 134 & 162 \\
\hline $1-1995$ & 418 & 147 & 381 & 134 & 162 \\
\hline 2 & 418 & 147 & 381 & 134 & 162 \\
\hline 3 & 418 & 147 & 381 & 134 & 163 \\
\hline 4 & 418 & $14 \overline{7}$ & 381 & 134 & 162 \\
\hline $1-1996$ & 418 & 147 & 381 & 134 & 163 \\
\hline 2 & 418 & 147 & 381 & 134 & 163 \\
\hline
\end{tabular}


2410106 kena HISTOKY

\begin{tabular}{|c|c|c|c|c|c|}
\hline Yssast & Yosat & Totai & Snkos & Sotids & 4 \\
\hline & K $\{a i l$ & $6 s k$ & $k_{y \rightarrow l}$ & $\{m$ & ins \\
\hline \multicolumn{6}{|l|}{$3-3 \$<4$} \\
\hline \multirow{2}{*}{\multicolumn{6}{|c|}{$\%$}} \\
\hline & & & & & \\
\hline \multicolumn{6}{|l|}{3} \\
\hline \multicolumn{6}{|l|}{4} \\
\hline \multicolumn{6}{|l|}{$\because-3 \leqslant 45$} \\
\hline \multicolumn{6}{|l|}{2} \\
\hline \multicolumn{6}{|l|}{3} \\
\hline \multicolumn{6}{|l|}{ a. } \\
\hline \multicolumn{6}{|l|}{$3-3 \$<35$} \\
\hline \multicolumn{6}{|l|}{2} \\
\hline \multicolumn{6}{|l|}{3} \\
\hline \multicolumn{6}{|l|}{4} \\
\hline \multicolumn{6}{|l|}{$9.130\}$} \\
\hline \multicolumn{6}{|l|}{2} \\
\hline \multicolumn{6}{|l|}{3} \\
\hline \multicolumn{6}{|l|}{4} \\
\hline \multicolumn{6}{|l|}{$p-y 3 a$} \\
\hline 2 & 152 & 85 & & & \\
\hline 3 & 523 & 37 & & & \\
\hline 4 & 528 & 87 & & & \\
\hline $3-3330$ & 523 & 337 & & & \\
\hline 2 & 528 & 4 & & & \\
\hline 3 & 523 & 33 & & & \\
\hline 4 & 528 & $8 \%$ & & & \\
\hline 33350 & 523 & 33 & & & \\
\hline 2 & 528 & $8 \%$ & & & \\
\hline 3 & 823 & 33 & & & \\
\hline 4 & 63 & $8 \%$ & & & \\
\hline $8335 ?$ & 523 & 37 & & & \\
\hline \multicolumn{6}{|l|}{2} \\
\hline \multicolumn{6}{|l|}{3} \\
\hline \multicolumn{6}{|l|}{$A$} \\
\hline \multicolumn{6}{|l|}{$1-3362$} \\
\hline$z$ & 673 & 134 & & & \\
\hline 3 & 513 & 184 & & & \\
\hline 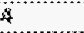 & 633 & 134 & & & \\
\hline $4-3383$ & 530 & 182 & & & \\
\hline 3 & 268 & 100 & & & \\
\hline 3 & 28 & 8 & & & \\
\hline$\$$ & 30 & 6 & & & \\
\hline \multicolumn{6}{|l|}{$3 \operatorname{sis} 4$} \\
\hline 3 & & & & & \\
\hline 3 & & & & & \\
\hline 4 & & & & & \\
\hline 1.3955 & & & & & \\
\hline 3 & 13 & 40 & & & \\
\hline
\end{tabular}


241-U-106 LEVEL HISTORY

HNF-SD-WM-ER-325, Rev. 1

\begin{tabular}{|c|c|c|c|c|c|}
\hline Year & Total & Total & Solids & Solids & ILL \\
\hline & (K gal) & (in) & (K gal) & (in) & (in) \\
\hline$\overline{3}$ & 80 & 25 & & & \\
\hline 4 & 375 & 132 & & & \\
\hline 1-1956 & 304 & 106 & & & \\
\hline 2 & 478 & 169 & 6 & -2 & \\
\hline 3 & 26 & 5 & & & \\
\hline 4 & 1 & -4 & 0 & -12 & \\
\hline $1-1957$ & 0 & -12 & 0 & -12 & \\
\hline 2 & 0 & -12 & 0 & -12 & \\
\hline 3 & 0 & -12 & & -12 & \\
\hline 4 & 0 & -12 & 0 & -12 & \\
\hline $1-1958$ & 0 & -12 & 0 & -12 & \\
\hline 2 & 0 & -12 & 0 & -12 & \\
\hline 3 & 0 & -12 & 0 & -12 & \\
\hline 4 & 0 & -12 & 0 & -12 & \\
\hline $1-1959$ & 0 & -12 & 0 & -12 & \\
\hline 2 & 0 & -12 & 0 & -12 & \\
\hline 3 & 0 & -12 & 0 & -12 & \\
\hline 4 & 0 & -12 & 0 & -12 & \\
\hline $1-1960$ & 0 & -12 & 0 & -12 & \\
\hline 2 & 0 & -12 & 0 & -12 & \\
\hline 3 & 483 & 171 & 0 & -12 & \\
\hline 4 & 502 & 178 & 0 & -12 & \\
\hline \multicolumn{6}{|l|}{ 1-1961 } \\
\hline 2 & 505 & 179 & 0 & -12 & \\
\hline \multicolumn{6}{|l|}{3} \\
\hline 4 & 505 & 179 & 0 & -12 & \\
\hline \multicolumn{6}{|l|}{$1-1962$} \\
\hline 2 & 505 & 179 & 0 & -12 & \\
\hline \multicolumn{6}{|l|}{3} \\
\hline 4 & 505 & 179 & 0 & -12 & \\
\hline \multicolumn{6}{|l|}{$1-1963$} \\
\hline 2 & 505 & 179 & 0 & -12 & \\
\hline \multicolumn{6}{|l|}{3} \\
\hline 4 & 505 & 179 & 0 & -12 & \\
\hline \multicolumn{6}{|l|}{1.1964} \\
\hline 2 & 505 & 179 & 0 & -12 & \\
\hline \multicolumn{6}{|l|}{3} \\
\hline 4 & 505 & 179 & 0 & -12 & \\
\hline $1-1965$ & 502 & 178 & 0 & -12 & \\
\hline \multicolumn{6}{|l|}{2} \\
\hline 3 & 502 & 178 & 0 & -12 & \\
\hline 4 & 502 & 178 & 0 & -12 & \\
\hline $1-1966$ & 502 & 178 & 0 & -12 & \\
\hline 2 & 502 & 178 & 0 & -12 & \\
\hline 3 & 505 & 179 & 0 & -12 & \\
\hline 4 & 505 & 179 & 0 & -12 & \\
\hline
\end{tabular}




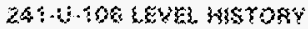

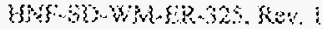

\begin{tabular}{|c|c|c|c|c|c|}
\hline Yon: & $(0 \mathrm{t})$ & Tmat & Sokiss & Soliks & mik \\
\hline & 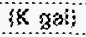 & $6 s !$ & $(x, 3531$ & $3 \sin$ & ini \\
\hline 3.956$\}$ & $60 \%$ & 13 & 0 & -12 & \\
\hline 2 & 306 & 78 & $a$ & 12 & \\
\hline 3 & 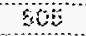 & 3 & 3 & 12 & \\
\hline 4 & 506 & 13 & $a$ & 12 & \\
\hline 3.3956 & 508 & 13 & 3 & 22 & \\
\hline 2 & 506 & 13 & 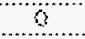 & \} 2 & \\
\hline 3 & 500 & 13 & 0 & .3 & \\
\hline 6 & 507 & 120 & $a$ & .82 & \\
\hline 1.1969 & 501 & 180 & 0 & .2 & \\
\hline$z$ & 507 & 120 & 0 & 32 & \\
\hline 3 & 505 & 190 & 0 & 28 & \\
\hline A & 503 & 120 & 20 & 5 & \\
\hline 1.3960 & 508 & 100 & 26 & 5 & \\
\hline p & 508 & 130 & 26 & 5 & \\
\hline 3 & 508 & 180 & 26 & 5 & \\
\hline * & 603 & $\$ 6$ & 28 & 5 & \\
\hline$x-1973$ & 508 & $\$ 6$ & 8 & 5 & \\
\hline 2 & 6033 & 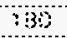 & 28 & 5 & \\
\hline 3 & 60 & 16 & 8 & 5 & \\
\hline 4 & 6633 & 30 & 28 & 5 & \\
\hline $3-7372$ & $50 \mathrm{~s}$ & $3 ?$ & 28 & 8 & \\
\hline 2 & 503 & 133 & 23 & 5 & \\
\hline 3 & 603 & $18 ?$ & 26 & 5 & \\
\hline 4 & 503 & 131 & 28 & 5 & \\
\hline $3-43 \geqslant a$ & 610 & 381 & 26 & 6 & \\
\hline 2 & 809 & 181 & 26 & 3 & \\
\hline 3 & 605 & 378 & 26 & 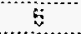 & \\
\hline 6 & 866 & 178 & 26 & 8 & \\
\hline $\mid-\{3\}$ & 85 & 28 & 26 & 3 & \\
\hline 2 & 86 & 27 & 26 & $\varepsilon$ & \\
\hline 3 & 36 & 78 & 20 & 3 & \\
\hline 4 & $E A$ & 28 & 26 & 8 & \\
\hline 1.3ots & $3 ?$ & 27 & 20 & 3 & \\
\hline 2 & 83 & 23 & 26 & 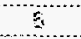 & \\
\hline 3 & $3 ?$ & 27 & 20 & 3 & \\
\hline$\$$ & 36 & 110 & 26 & 3 & \\
\hline 3.3978 & $60 \mathrm{~s}$ & 42 & 26 & 5 & \\
\hline 2 & 466 & $\therefore 3$ & 28 & 5 & \\
\hline 3 & $3 ?$ & 42 & 28 & 5 & \\
\hline 4 & 362 & 27 & 28 & 5 & \\
\hline 1-3\$\%? & 36 & 136 & $? 3$ & 23 & \\
\hline 2 & 27 & 28 & 73 & 22 & \\
\hline 3 & $2 \pi$ & 76 & 211 & 32 & \\
\hline$x$ & 224 & $\gamma$ & 21 & 3 & \\
\hline $4-1533\}$ & 223 & 78 & 213 & 3 & \\
\hline$\hat{z}$ & 224 & 3 & 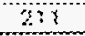 & $7 \%$ & \\
\hline
\end{tabular}


241-U-106 LEVEL, HISTORY

\begin{tabular}{|c|c|c|c|c|c|}
\hline Year & Total & Total & Solids & Solids & ILL \\
\hline & (K gal) & (in) & (K gal) & (in) & (in) \\
\hline & & & & & \\
\hline 3 & 215 & 74 & 198 & 67 & \\
\hline 4 & 227 & 78 & 211 & 72 & \\
\hline $1-1979$ & 227 & 78 & 211 & 72 & \\
\hline 2 & 227 & 78 & 211 & 72 & \\
\hline 3 & 227 & 78 & 211 & 72 & \\
\hline 4 & 227 & 78 & 211 & 72 & \\
\hline $1-1980$ & 227 & 78 & 211 & 72 & \\
\hline 2 & 227 & 78 & 211 & 72 & \\
\hline 3 & 227 & 78 & 211 & 72 & \\
\hline 4 & 227 & 78 & 211 & 72 & \\
\hline $1-1981$ & 227 & 78 & 211 & 72 & \\
\hline 2 & 227 & 78 & 211 & 72 & \\
\hline 3 & 227 & 78 & 211 & 72 & \\
\hline 4 & 227 & 78 & 211 & 72 & \\
\hline $1-1982$ & 227 & 78 & 211 & 72 & \\
\hline 2 & 227 & 78 & 211 & 72 & \\
\hline 3 & 227 & 78 & 211 & 72 & \\
\hline 4 & 227 & 78 & 211 & 72 & \\
\hline $1-1983$ & 227 & 78 & 211 & 72 & \\
\hline 2 & 227 & 78 & 211 & 72 & \\
\hline 3 & 227 & 78 & 211 & 72 & \\
\hline 4 & 225 & 77 & 211 & 72 & \\
\hline $1-1984$ & 225 & 77 & 211 & 72 & \\
\hline 2 & 225 & 77 & 211 & 72 & \\
\hline 3 & 225 & 77 & 211 & 72 & \\
\hline 4 & 225 & 77 & 211 & 72 & \\
\hline $1-1985$ & 225 & 77 & 211 & 72 & \\
\hline 2 & 225 & 77 & 211 & 72 & \\
\hline 3 & 225 & 77 & 211 & 72 & \\
\hline 4 & 226 & 78 & 211 & 72 & \\
\hline $1-1986$ & 226 & 78 & 211 & 72 & 90 \\
\hline 2 & 226 & 78 & 211 & 72 & 91 \\
\hline 3 & 226 & 78 & 211 & 72 & 90 \\
\hline 4 & 226 & 78 & 211 & 72 & 90 \\
\hline $1-1987$ & 226 & 78 & 211 & 72 & 90 \\
\hline 2 & 226 & 78 & 211 & 72 & \\
\hline 3 & 226 & 78 & 211 & 72 & 90 \\
\hline 4 & 226 & 78 & 211 & 72 & 90 \\
\hline $1-1988$ & 226 & 78 & 211 & 72 & 90 \\
\hline 2 & 226 & 78 & 211 & 72 & 90 \\
\hline 3 & 226 & 78 & 211 & 72 & 89 \\
\hline 4 & 226 & 78 & 211 & 72 & 90 \\
\hline $1-1989$ & 226 & 78 & 211 & 72 & \\
\hline 2 & 226 & 78 & 211 & 72 & 90 \\
\hline 3 & 226 & 78 & 211 & 72 & 90 \\
\hline 4 & 226 & 78 & 211 & 72 & 90 \\
\hline
\end{tabular}


24:-24-106 \&EVE METORY

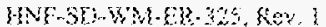

\begin{tabular}{|c|c|c|c|c|c|}
\hline Yisss: & Total & Totas & Sadus & Soliss & in \\
\hline & $\{k$ wsit & (6n)! & $\{x, \mathrm{j} a\}$ & (in) & Sine? \\
\hline & & & & & \\
\hline $1-19380$ & 278 & 73 & $29 !$ & 72 & 85 \\
\hline 2 & 226 & 78 & 233 & 72 & \\
\hline$y$ & 28 & 33 & $2 \%$ & 72 & 90 \\
\hline 4 & 228 & 78 & 233 & 32 & 90 \\
\hline $3-x 3 p 1$ & 226 & 73 & $21 !$ & 72 & 50 \\
\hline 2 & 228 & 78 & 233 & 73 & 60 \\
\hline$a$ & 228 & 73 & 29 & $7 z$ & 60 \\
\hline$\Leftrightarrow$ & 228 & 78 & 233 & 72 & $\$ 9$ \\
\hline $1-1332$ & 226 & 33 & 211 & 72 & \\
\hline 2 & 226 & 76 & 213 & $\%$ & \\
\hline 3 & 225 & 73 & 213 & 72 & \\
\hline 6 & 226 & 76 & 233 & $\%$ & Q4) \\
\hline 3.3933 & 223 & 33 & $21\}$ & 72 & 00 \\
\hline 2 & 230 & 78 & 233 & 2 & 80 \\
\hline 3 & 220 & 73 & 211 & 72 & 20 \\
\hline 0 & 260 & 78 & खर & 2 & 43 \\
\hline $3-3394$ & 226 & 73 & 211 & 72 & 93 \\
\hline 2 & 236 & 76 & $2 ?$ & 2 & 93 \\
\hline 3 & 226 & 73 & 211 & 22 & 20 \\
\hline a & 223 & 78 & 211 & $\because z$ & 39 \\
\hline $7-3 \leqslant s$ & 228 & 78 & 211 & 72 & 90 \\
\hline a & 228 & 78 & $2 ! !$ & 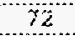 & 31 \\
\hline 3 & 226 & 78 & 211 & 73 & $\theta 0$ \\
\hline$x$ & 225 & 78 & $2 !:$ & 72 & 30 \\
\hline $1-34835$ & 28 & 78 & 231 & 32 & 90 \\
\hline 2 & 225 & 78 & $2 ! \vdots$ & $\gamma \check{2}$ & 30 \\
\hline
\end{tabular}


241-U-107 LEVEL HISTORY

\begin{tabular}{|c|c|c|c|c|c|}
\hline Year & Total & Total & Solids & Solids & ILL \\
\hline & (K gal) & (in) & (K gal) & (in) & (in) \\
\hline \multirow{2}{*}{\multicolumn{6}{|c|}{$1-1944$}} \\
\hline \multirow{2}{*}{\multicolumn{6}{|c|}{2}} \\
\hline \multirow{2}{*}{\multicolumn{6}{|c|}{3}} \\
\hline & & & & & \\
\hline \multicolumn{6}{|l|}{4} \\
\hline \multicolumn{6}{|l|}{ 1-1945 } \\
\hline \multicolumn{6}{|l|}{2} \\
\hline \multicolumn{6}{|l|}{3} \\
\hline \multicolumn{6}{|l|}{4} \\
\hline \multicolumn{6}{|l|}{ 1-1946 } \\
\hline \multicolumn{6}{|l|}{2} \\
\hline \multicolumn{6}{|l|}{3} \\
\hline \multicolumn{6}{|l|}{4} \\
\hline \multicolumn{6}{|l|}{$1-1947$} \\
\hline \multicolumn{6}{|l|}{2} \\
\hline \multicolumn{6}{|l|}{3} \\
\hline \multicolumn{6}{|l|}{4} \\
\hline \multicolumn{6}{|l|}{$1-1948$} \\
\hline \multicolumn{6}{|l|}{2} \\
\hline 3 & 16 & 1 & & & \\
\hline 4 & 528 & 187 & & & \\
\hline $1-1949$ & 528 & 187 & & & \\
\hline 2 & 528 & 187 & & & \\
\hline 3 & 528 & 187 & & & \\
\hline 4 & 528 & 187 & & & \\
\hline $1-1950$ & 528 & 187 & & & \\
\hline 2 & 528 & 187 & & & \\
\hline 3 & 528 & 187 & & & \\
\hline 4 & 528 & 187 & & & \\
\hline 1-1951 & 528 & 187 & & & \\
\hline \multicolumn{6}{|l|}{2} \\
\hline \multicolumn{6}{|l|}{3} \\
\hline \multicolumn{6}{|l|}{4} \\
\hline \multicolumn{6}{|l|}{$1-1952$} \\
\hline 2 & 530 & 188 & & & \\
\hline 3 & 530 & 188 & & & \\
\hline 4 & 530 & 188 & & & \\
\hline 1-1953 & 530 & 188 & & & \\
\hline 2 & 530 & 188 & & & \\
\hline 3 & 6 & -2 & 6 & -2 & \\
\hline 4 & 189 & 64 & & & \\
\hline 1-1954 & 8 & -2 & 8 & -2 & \\
\hline 2 & 278 & 97 & & & \\
\hline 3 & 549 & 195 & & & \\
\hline 4 & 543 & 193 & & & \\
\hline 1-1955 & 543 & 193 & & & \\
\hline 2 & 543 & 193 & & & \\
\hline
\end{tabular}


249.43 .107 \&YVG HSTORY

\begin{tabular}{|c|c|c|c|c|c|}
\hline Sesss & Tota: & $1 \times k$ & Solss: & Sonks & $32:$ \\
\hline & kgai & (n) & 83 & $\{s s\}$ & bis \\
\hline & & & & & \\
\hline 3 & 543 & 393 & & & \\
\hline 4 & 330 & 188 & & & \\
\hline $1-3 \operatorname{sis} 6$ & 3 & 3 & $\vdots$ & .4 & \\
\hline$z$ & 2 & 4 & 3 & 4 & \\
\hline 3 & $\because$ & 3 & $\vdots$ & 4 & \\
\hline 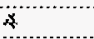 & 3 & -4 & 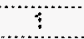 & 6 & \\
\hline $1-7 \leq 43$ & 6 & 12 & 6 & .12 & \\
\hline 2 & 3 & -32 & 0 & 12 & \\
\hline 3 & 0 & 12 & 0 & .12 & \\
\hline 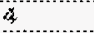 & 200 & 63 & 0 & 12 & \\
\hline 1.7953 & 235 & 39 & 0 & -12 & \\
\hline 2 & 477 & 366 & 0 & 12 & \\
\hline 3 & 475 & 738 & 8 & $-1 \%$ & \\
\hline 4 & 475 & 368 & $\theta$ & -8 & \\
\hline 1.1359 & 472 & 337 & ) & $\because 2$ & \\
\hline 2 & 516 & 381 & 6 & 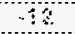 & \\
\hline 3 & 538 & 130 & 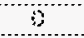 & -2 & \\
\hline 4 & $56 \%$ & ta! & 6 & +2 & \\
\hline $3 .\{360$ & $\$ 35$ & 173 & 3 & 2 & \\
\hline 2 & 368 & Ys & 8 & 13 & \\
\hline a & 335 & $n 3$ & 3 & 12 & \\
\hline 4 & 310 & 8 & 6 & 2 & \\
\hline \multicolumn{6}{|l|}{3353} \\
\hline 2 & 510 & 61 & $\%$ & 13 & \\
\hline \multicolumn{6}{|l|}{3} \\
\hline 4 & 30 & 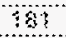 & 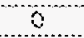 & 12 & \\
\hline \multicolumn{6}{|l|}{$3 \cdot 335$} \\
\hline 2 & 306 & 160 & 0 & 12 & \\
\hline \multicolumn{6}{|l|}{3} \\
\hline 4 & $3 \Omega 8$ & 150 & 0 & 12 & \\
\hline \multicolumn{6}{|l|}{$3 \cdot 3363$} \\
\hline 2 & $5 \Omega 8$ & 130 & 6 & -13 & \\
\hline \multicolumn{6}{|l|}{3} \\
\hline 4 & 510 & $13 !$ & 6 & 12 & \\
\hline \multicolumn{6}{|l|}{$1 \times 3 \leqslant 64$} \\
\hline 2 & 510 & $78 !$ & 0 & .12 & \\
\hline \multicolumn{6}{|l|}{3} \\
\hline 4 & 510 & $78 !$ & 6 & 12 & \\
\hline $7-3 \$ 65$ & 841 & 192 & 0 & -12 & \\
\hline \multicolumn{6}{|l|}{. } \\
\hline 3 & 831 & 393 & 6 & .2 & \\
\hline 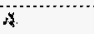 & $54 \%$ & 382 & 6 & 12 & \\
\hline $1-3 \leq 565$ & 843 & 392 & 0 & 12 & \\
\hline 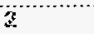 & $64\}$ & 392 & 0 & -12 & \\
\hline 3 & 643 & 132 & 0 & 12 & \\
\hline 8 & 64 & 342 & 3 & -32 & \\
\hline
\end{tabular}


241-U-107 LEVEL HISTORY

HNF-SD-WM-ER-325, Rev. 1

\begin{tabular}{|c|c|c|c|c|c|}
\hline Year & Total & Total & Solids & Solids & ILL \\
\hline & (K gal) & (in) & (K gal) & (in) & (in) \\
\hline $1-1967$ & 541 & 192 & 0 & -12 & \\
\hline 2 & 543 & 193 & 0 & -12 & \\
\hline 3 & 543 & 193 & 0 & -12 & \\
\hline 4 & 543 & 193 & 0 & -12 & \\
\hline $1-1968$ & 543 & 193 & 0 & -12 & \\
\hline 2 & 543 & 193 & 0 & -12 & \\
\hline 3 & 134 & 44 & 0 & -12 & \\
\hline 4 & 136 & 45 & 76 & 23 & \\
\hline 1-1969 & 271 & 94 & 76 & 23 & \\
\hline 2 & 482 & 171 & 76 & 23 & \\
\hline 3 & 479 & 170 & 76 & 23 & \\
\hline 4 & 508 & 180 & 90 & 28 & \\
\hline $1-1970$ & 508 & 180 & 90 & 28 & \\
\hline 2 & 508 & 180 & 90 & 28 & \\
\hline 3 & 508 & 180 & 90 & 28 & \\
\hline 4 & 508 & 180 & 90 & 28 & \\
\hline $1-1971$ & 509 & 181 & 90 & 28 & \\
\hline 2 & 509 & 181 & 90 & 28 & \\
\hline 3 & 508 & 180 & 90 & 28 & \\
\hline 4 & 508 & 180 & 90 & 28 & \\
\hline $1-1972$ & 160 & 54 & 90 & 28 & \\
\hline 2 & 160 & 54 & 90 & 28 & \\
\hline 3 & 560 & 199 & 90 & 28 & \\
\hline 4 & 458 & 162 & 90 & 28 & \\
\hline $1-1973$ & 266 & 92 & 90 & 28 & \\
\hline 2 & 470 & 166 & 90 & 28 & \\
\hline 3 & 380 & 134 & 90 & 28 & \\
\hline 4 & 485 & 172 & 90 & 28 & \\
\hline $1-1974$ & 290 & 101 & 90 & 28 & \\
\hline 2 & 388 & 137 & 90 & 28 & \\
\hline 3 & 267 & 93 & 90 & 28 & \\
\hline 4 & 403 & 142 & 15 & 1 & \\
\hline $1-1975$ & 332 & 116 & 15 & 1 & \\
\hline 2 & 321 & 112 & 15 & 1 & \\
\hline 3 & 189 & 64 & 15 & 1 & \\
\hline 4 & 345 & 121 & 15 & 1 & \\
\hline $1-1976$ & 428 & 151 & 15 & 1 & \\
\hline 2 & 312 & 109 & 15 & 1 & \\
\hline 3 & 450 & 159 & 15 & 1 & \\
\hline 4 & 197 & 67 & 15 & 1 & \\
\hline 1-1977 & 431 & 152 & 114 & 37 & \\
\hline 2 & 268 & 93 & 114 & 37 & \\
\hline 3 & 246 & 85 & 150 & 50 & \\
\hline 4 & 428 & 151 & 101 & 32 & \\
\hline $1-1978$ & 486 & 172 & 101 & 32 & \\
\hline 2 & 466 & 165 & 180 & 61 & \\
\hline
\end{tabular}




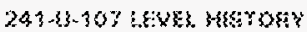

\begin{tabular}{|c|c|c|c|c|c|}
\hline Yess & Tora & Yosal & Gstiks & Sustids & $k \beta$ \\
\hline & \& sisis & 1 & $x y b 6$ & (ini) & in \\
\hline & & & & & \\
\hline 3 & $4.3 \%$ & 384 & 130 & 55 & \\
\hline स & 432 & 158 & 96 & 62 & \\
\hline 3.9979 & 460 & 33 & $\because 36$ & 32 & \\
\hline 2 & 436 & 39 & 68 & 3 & \\
\hline 3 & $A 2$ & 35 & 30 & 32 & \\
\hline 3 & 484 & 36 & 68 & 82 & \\
\hline $3-19336$ & 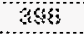 & $3(3)$ & 36 & 32 & \\
\hline 2 & 425 & 150 & 96 & 6 & \\
\hline 3 & 360 & 34 & 60 & 32 & \\
\hline 6 & 333 & 138 & $3 \%$ & 132 & \\
\hline $3-3933$ & $30 !$ & 330 & 375 & 32 & \\
\hline 3 & 331 & 33 & 33 & 32 & \\
\hline 3 & 39 & 30 & 373 & 32 & \\
\hline 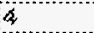 & 331 & 333 & 335 & 132 & \\
\hline 1.7832 & $33 !$ & 30 & 373 & 132 & \\
\hline$\ddot{z}$ & 331 & 330 & 336 & 132 & \\
\hline 3 & 331 & 38 & 373 & 132 & \\
\hline 4 & 331 & 130 & 376 & 132 & \\
\hline 9.9983 & $20 !$ & $34 !$ & 375 & 182 & \\
\hline 2 & $60 !$ & 34 & 376 & 332 & \\
\hline 3 & $40 !$ & $34 !$ & 375 & 132 & \\
\hline 9 & 402 & 342 & 336 & 332 & \\
\hline$y-138$ & $40 \%$ & 142 & 375 & $13 \%$ & \\
\hline 2 & 36 & $3 \%$ & 36 & 32 & \\
\hline 3 & 302 & 162 & 335 & 33 & \\
\hline 8 & 362 & 342 & 38 & 332 & \\
\hline - -13s8 & $30\rangle$ & 162 & 378 & $\{3$ & \\
\hline 2 & 362 & 342 & 36 & 332 & \\
\hline 3 & 402 & 342 & 378 & 32 & \\
\hline$\$$ & 305 & 340 & 376 & 32 & \\
\hline $1-198 \varepsilon$ & 408 & 163 & 378 & 132 & 142 \\
\hline 2 & 365 & 340 & 375 & 332 & 162 \\
\hline 3 & 405 & 143 & 378 & 132 & 142 \\
\hline 3 & 300 & 340 & $3 \%$ & 332 & 142 \\
\hline $1+1927$ & 406 & 343 & 336 & 32 & 162 \\
\hline 2 & 108 & 343 & 38 & 32 & \\
\hline 3 & 406 & 343 & 375 & 32 & 340 \\
\hline 3 & 36 & 383 & 37 & 332 & 142 \\
\hline 3.3038 & 496 & 103 & 376 & 3 & 343 \\
\hline 2 & 400 & 343 & 35 & 332 & 143 \\
\hline 3 & 406 & 103 & 37 & 3 & 342 \\
\hline 3 & 460 & 33 & 35 & 33 & \\
\hline 3.1353 & 406 & 803 & 376 & $3 \%$ & \\
\hline 2 & 266 & 343 & 35 & 32 & 143 \\
\hline 3 & 430 & 43 & 375 & 132 & 144 \\
\hline 3 & 66 & 43 & 375 & 132 & 193 \\
\hline
\end{tabular}


241-U-107 LEVEL HISTORY

HNF-SD-WM-ER-325, Rev. 1

\begin{tabular}{|c|c|c|c|c|c|}
\hline Year & Total & Total & Solids & Solids & ILL \\
\hline & (K gal) & (in) & (K gal) & (in) & (in) \\
\hline $1-1990$ & 406 & 143 & 375 & 132 & 143 \\
\hline 2 & 406 & 143 & 375 & 132 & \\
\hline 3 & 406 & 143 & 375 & 132 & 143 \\
\hline 4 & 406 & 143 & 375 & 132 & 143 \\
\hline 1-1991 & 406 & 143 & 375 & 132 & 143 \\
\hline 2 & 406 & 143 & 375 & 132 & 143 \\
\hline 3 & 406 & 143 & 375 & 132 & 143 \\
\hline 4 & 406 & 143 & 375 & 132 & 144 \\
\hline $1-1992$ & 406 & 143 & 375 & 132 & \\
\hline 2 & 406 & 143 & 375 & 132 & \\
\hline 3 & 406 & 143 & 375 & 132 & \\
\hline 4 & 406 & 143 & 375 & 132 & 143 \\
\hline $1-1993$ & 406 & 143 & 375 & 132 & 143 \\
\hline 2 & 406 & 143 & 375 & 132 & 143 \\
\hline 3 & 406 & 143 & 375 & 132 & 143 \\
\hline 4 & 406 & 143 & 375 & 132 & 143 \\
\hline $1-1994$ & 406 & 143 & 375 & 132 & 144 \\
\hline 2 & 406 & 143 & 375 & 132 & 143 \\
\hline 3 & 406 & 143 & 375 & 132 & 144 \\
\hline 4 & 406 & 143 & 375 & 132 & 143 \\
\hline 1.1995 & 406 & 143 & 375 & 132 & 143 \\
\hline 2 & 406 & 143 & 375 & 132 & 144 \\
\hline 3 & 406 & 143 & 375 & 132 & 144 \\
\hline 4 & 406 & 143 & 375 & 132 & 144 \\
\hline $1-1996$ & 406 & 143 & 375 & 132 & 144 \\
\hline 2 & 406 & 143 & 375 & 132 & 144 \\
\hline
\end{tabular}


24 Y. 15. 30 \&EVE MUTOKY

\begin{tabular}{|c|c|c|c|c|c|}
\hline Toss & Tosw: & Ts\}<s\} & $5>3 i s 39$ & 50605 & $33 !$ \\
\hline & 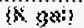 & mi & K yoil & (in) & $(m)$ \\
\hline \multicolumn{6}{|l|}{$Y-39+4$} \\
\hline \multicolumn{6}{|l|}{ 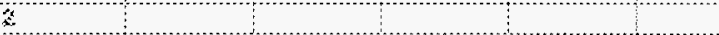 } \\
\hline \multicolumn{6}{|l|}{3} \\
\hline \multicolumn{6}{|l|}{4} \\
\hline \multicolumn{6}{|l|}{ 3.1sust } \\
\hline \multicolumn{6}{|l|}{2} \\
\hline \multicolumn{6}{|l|}{3} \\
\hline \multicolumn{6}{|l|}{3} \\
\hline \multicolumn{6}{|l|}{3.1048} \\
\hline \multicolumn{6}{|l|}{2} \\
\hline \multicolumn{6}{|l|}{3} \\
\hline \multicolumn{6}{|l|}{3} \\
\hline \multicolumn{6}{|l|}{$3-394 ?$} \\
\hline \multicolumn{6}{|l|}{2} \\
\hline \multicolumn{6}{|l|}{3} \\
\hline \multicolumn{6}{|l|}{$\$$} \\
\hline \multicolumn{6}{|l|}{$3-3 \$ 8 B$} \\
\hline \multicolumn{6}{|l|}{ 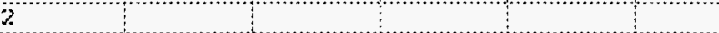 } \\
\hline \multicolumn{6}{|l|}{3} \\
\hline \multicolumn{6}{|l|}{4} \\
\hline $3-4 \$ 63$ & 68 & 33 & & & \\
\hline 2 & 528 & $3 \%$ & & & \\
\hline 3 & 826 & 36 & & & \\
\hline 4 & 523 & 38 & & & \\
\hline 3.1556 & 626 & 63 & & & \\
\hline 2 & 528 & 367 & & & \\
\hline 3 & 328 & 63 & & & \\
\hline 4. & 522 & 3 & & & \\
\hline$\{956\}$ & 528 & 67 & & & \\
\hline \multicolumn{6}{|l|}{2} \\
\hline 3 & & & & & \\
\hline 4 & & & & & \\
\hline$\{-135\}$ & & & & & \\
\hline$z$ & 530 & 163 & & & \\
\hline 3 & 536 & 188 & & & \\
\hline 3 & 630 & 58 & & & \\
\hline $1-3 \operatorname{ses}$ & 530 & $\$ 88$ & & & \\
\hline 8 & 333 & 778 & & & \\
\hline 3 & 458 & 162 & & & \\
\hline 4 & & & & & \\
\hline $1-3564$ & & & & & \\
\hline 2 & & & & & \\
\hline 3 & 52 & 136 & & & \\
\hline 4 & $5 \approx 2$ & 338 & & & \\
\hline W $\$ \$ 5$ & 532 & 136 & & & \\
\hline 2 & $6 \% 2$ & $3 \leqslant 6$ & & & \\
\hline
\end{tabular}


241-U-108 LEVEL HISTORY

HNF-SD-WM-ER-325, Rev. 1

\begin{tabular}{|c|c|c|c|c|c|}
\hline Year & Total & Total & Solids & Solids & ILL \\
\hline & (K gal) & (in) & (K gal) & (in) & (in) \\
\hline & & & & & \\
\hline 3 & 552 & 196 & & & \\
\hline 4 & 530 & 188 & & & \\
\hline 1-1956 & 1 & -4 & 1 & -4 & \\
\hline 2 & 2 & -4 & 1 & -4 & \\
\hline 3 & 2 & -4 & 1 & -4 & \\
\hline 4 & 0 & -12 & 0 & -12 & \\
\hline $1-1957$ & 0 & -12 & 0 & -12 & \\
\hline 2 & 0 & -12 & 0 & -12 & \\
\hline 3 & 0 & -12 & 0 & -12 & \\
\hline 4 & 0 & -12 & 0 & -12 & \\
\hline $1-1958$ & 0 & -12 & 0 & -12 & \\
\hline 2 & 0 & -12 & 0 & -12 & \\
\hline 3 & 0 & -12 & 0 & -12 & \\
\hline 4 & 0 & -12 & 0 & -12 & \\
\hline $1-1959$ & 0 & -12 & 0 & 12 & \\
\hline 2 & 182 & 62 & 0 & -12 & \\
\hline 3 & 182 & 62 & 0 & -12 & \\
\hline 4 & 182 & 62 & 0 & -12 & \\
\hline $1-1960$ & 182 & 62 & 0 & -12 & \\
\hline 2 & 316 & 110 & 0 & -12 & \\
\hline 3 & 316 & 110 & 0 & -12 & \\
\hline 4 & 420 & 148 & 0 & -12 & \\
\hline \multicolumn{6}{|l|}{$1-1961$} \\
\hline 2 & 420 & 148 & 0 & -12 & \\
\hline \multicolumn{6}{|l|}{3} \\
\hline 4 & 299 & 104 & 0 & -12 & \\
\hline \multicolumn{6}{|l|}{ 1-1962 } \\
\hline 2 & 295 & 103 & 0 & -12 & \\
\hline \multicolumn{6}{|l|}{3} \\
\hline 4 & 508 & 180 & 0 & -12 & \\
\hline \multicolumn{6}{|l|}{$1-1963$} \\
\hline 2 & 246 & 85 & 0 & -12 & \\
\hline \multicolumn{6}{|l|}{3} \\
\hline 4 & 246 & 85 & 0 & -12 & \\
\hline \multicolumn{6}{|l|}{ 1-1964 } \\
\hline 2 & 444 & 157 & 0 & -12 & \\
\hline \multicolumn{6}{|l|}{3} \\
\hline 4 & 507 & 180 & 0 & -12 & \\
\hline \multicolumn{6}{|l|}{$1-1965$} \\
\hline 2 & 508 & 180 & 0 & -12 & \\
\hline 3 & 508 & 180 & 0 & -12 & \\
\hline 4 & 508 & 180 & 0 & -12 & \\
\hline $1-1966$ & 508 & 180 & 0 & -12 & \\
\hline 2 & 508 & 180 & 0 & -12 & \\
\hline 3 & 508 & 180 & 0 & -12 & \\
\hline 4 & 508 & 180 & 0 & -12 & \\
\hline
\end{tabular}




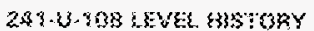

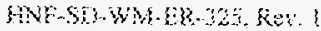

\begin{tabular}{|c|c|c|c|c|c|}
\hline Yeas & Tots: & $7 a x a$ & $50 \mathrm{i} \delta \mathrm{s}$ & ser8siss & 33 \\
\hline & K ga: & t6: & $k \mathrm{gal}$ & (is) & tet? \\
\hline $3-393$ & 308 & 86 & $\%$ & 12 & \\
\hline 2 & $5: 0$ & 369 & 0 & $-1 \%$ & \\
\hline 3 & 310 & $\$ 3\}$ & 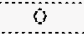 & 32 & \\
\hline 4 & 510 & 138 & 8 & .12 & \\
\hline 1.1968 & 510 & 181 & 0 & 12 & \\
\hline 2 & 231 & 72 & $\alpha$ & -12 & \\
\hline 3 & 102 & 142 & 6 & -12 & \\
\hline 4 & 04 & 38 & 0 & -12 & \\
\hline $1-7 \$ 65$ & 64 & 83 & $j$ & 12 & \\
\hline 2 & 827 & 387 & 6 & .12 & \\
\hline 3 & 523 & $x 35$ & 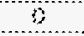 & $: 2$ & \\
\hline \& & $52 \Omega$ & $1 s 5$ & 28 & $\ddot{E}$ & \\
\hline $3-43 \geqslant 0$ & 327 & 35 & 28 & 6 & \\
\hline 2 & 522 & 189 & $2 \mathrm{~s}$ & $\varepsilon$ & \\
\hline 3 & $\$ 22$ & 35 & 28 & 6 & \\
\hline 4 & 524 & 168 & 29 & 8 & \\
\hline $3-33 ? 3$ & 523 & 36 & 28 & 6 & \\
\hline$z$ & 323 & $\$ 86$ & & & \\
\hline 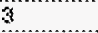 & 323 & 106 & 29 & $\varepsilon$ & \\
\hline 6 & 323 & 160 & 23 & 8 & \\
\hline $3 \cdot\} 373$ & 523 & 185 & 28 & 6 & \\
\hline 2 & 83 & 20 & 23 & 8 & \\
\hline 3 & 207 & 83 & 28 & 8 & \\
\hline 4 & 433 & 163 & 23 & 6 & \\
\hline 3.3873 & 435 & 164 & 28 & 5 & \\
\hline 2 & 436 & 164 & 23 & $\theta$ & \\
\hline 3 & 432 & 160 & 28 & 5 & \\
\hline \& & 93 & 39 & 23 & 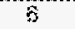 & \\
\hline $2 \cdot .933$ & 300 & 32 & 28 & 5 & \\
\hline 2 & 301 & 32 & 23 & $\hat{b}$ & \\
\hline 3 & 601 & 32 & 28 & 3 & \\
\hline 4 & 301 & 32 & 29 & 6 & \\
\hline$\gamma \cdot 1375$ & 101 & 32 & 29 & 8 & \\
\hline$z$ & 301 & 32 & 28 & 6 & \\
\hline 3 & $28 \theta$ & $8 z$ & 28 & 8 & \\
\hline$a$ & 56 & 600 & 28 & 6 & \\
\hline$\{-15\} 6$ & 508 & 86 & 200 & 86 & \\
\hline$z$ & 516 & 36 & 20 & 68 & \\
\hline 3 & 513 & 52 & 800 & 89 & \\
\hline 4 & 486 & 373 & 273 & 30 & \\
\hline$\{-13 ;\}$ & 481 & 103 & 200 & 30 & \\
\hline$z$ & 452 & 56 & 260 & 30 & \\
\hline 3 & 450 & 153 & 200 & 90 & \\
\hline 4 & 463 & 160 & 200 & 30 & \\
\hline 1.3336 & $4 \% 3$ & 100 & 200 & 30 & \\
\hline 2 & 468 & 162 & 26 & 06 & \\
\hline
\end{tabular}


241-U-108 LEVEL HISTORY

\begin{tabular}{|c|c|c|c|c|c|}
\hline Year & Total & Total & Solids & Solids & ILL \\
\hline & (K gal) & (in) & (K gal) & (in) & (in) \\
\hline 3 & 446 & 158 & 248 & 86 & \\
\hline 4 & 458 & 162 & 263 & 91 & \\
\hline $1-1979$ & $\overline{461}$ & 163 & 263 & 91 & \\
\hline 2 & 461 & 163 & 263 & 91 & \\
\hline 3 & 461 & 163 & 444 & 157 & \\
\hline 4 & 461 & 163 & 444 & 157 & \\
\hline $1-1980$ & 461 & 163 & 444 & 157 & \\
\hline 2 & 461 & 163 & 444 & 157 & \\
\hline 3 & 461 & 163 & 444 & 157 & \\
\hline 4 & 461 & 163 & 444 & 157 & \\
\hline 1-1981 & 461 & 163 & 444 & 157 & \\
\hline 2 & $4 \overline{61}$ & 163 & 444 & 157 & \\
\hline 3 & 461 & 163 & 444 & 157 & \\
\hline 4 & 461 & 163 & 444 & 157 & \\
\hline $1-1982$ & 461 & $1 \overline{63}$ & 444 & 157 & \\
\hline 2 & 461 & 163 & 444 & 157 & \\
\hline 3 & 461 & $1 \overline{63}$ & 444 & 157 & \\
\hline 4 & 461 & 163 & 444 & 157 & \\
\hline $1-1983$ & 461 & 163 & 444 & 157 & \\
\hline 2 & 461 & 163 & 444 & 157 & \\
\hline 3 & 461 & 163 & 444 & 157 & \\
\hline 4 & 468 & 166 & 444 & 157 & \\
\hline $7-1984$ & 468 & 166 & 444 & 157 & \\
\hline 2 & 468 & 166 & 444 & 157 & \\
\hline 3 & 468 & 166 & 444 & 157 & \\
\hline 4 & 468 & 166 & 444 & 157 & \\
\hline $1-1985$ & 468 & 166 & 444 & 157 & \\
\hline 2 & 468 & 166 & $4 \overline{44}$ & 157 & \\
\hline 3 & 468 & 166 & 444 & 157 & \\
\hline 4 & 468 & 166 & 444 & 157 & \\
\hline $1-1986$ & 468 & 166 & 444 & 157 & 178 \\
\hline 2 & 468 & 166 & 444 & 157 & 179 \\
\hline 3 & 468 & 166 & 444 & 157 & 178 \\
\hline 4 & 468 & 166 & 444 & 157 & 178 \\
\hline $1-1987$ & 468 & 166 & 444 & 157 & 178 \\
\hline 2 & 468 & $1 \overline{66}$ & 444 & 157 & \\
\hline 3 & 468 & 166 & 444 & 157 & 178 \\
\hline 4 & 468 & 166 & 444 & 157 & 178 \\
\hline $1-1988$ & 468 & $16 \overline{6}$ & 444 & 157 & 179 \\
\hline 2 & 468 & 166 & 444 & 157 & 178 \\
\hline 3 & 468 & 166 & 444 & 157 & 179 \\
\hline 4 & 468 & 166 & 444 & 157 & 179 \\
\hline $1-1989$ & 468 & 166 & 444 & 157 & \\
\hline 2 & 468 & 166 & 444 & 157 & 178 \\
\hline 3 & 468 & 166 & 444 & 157 & 179 \\
\hline 4 & 468 & 166 & 444 & 157 & 178 \\
\hline
\end{tabular}




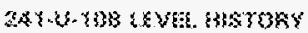

\begin{tabular}{|c|c|c|c|c|c|}
\hline Yeat & Tatas & Satal & Solkis & selkus: & B). \\
\hline & \& gaik & $\{m\}$ & (K $\xi \xi k)$ & (3s) & $\{$ ini $\}$ \\
\hline 1.1300 & 468 & 166 & $64 \alpha$ & 337 & 738 \\
\hline 2 & 468 & 105 & 464 & $\{5\}$ & \\
\hline 3 & 408 & 166 & $4 \alpha$ & 167 & 39 \\
\hline 4 & 463 & 103 & 464 & \&S? & 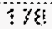 \\
\hline (2.393? & 458 & 886 & 64 & 35 & 33 \\
\hline 2 & 468 & .63 & 444 & $85 \%$ & \\
\hline 3 & 488 & $6 \%$ & $4 A$ & $35 \%$ & 170 \\
\hline 4 & 586 & 163 & 444 & 85 & 18 \\
\hline 7.35542 & 488 & $16 \%$ & 4.4 & 367 & \\
\hline$z$ & $\operatorname{sen}$ & 183 & 444 & $45 ?$ & \\
\hline 3 & $4 \$ 8$ & 106 & 6.4. & $3 \leqslant 7$ & \\
\hline 3 & $\$ 86$ & 165 & 436 & $85 ?$ & 36 \\
\hline 1.1350 & 468 & 106 & $3 \$ 4$ & $15 \%$ & 733 \\
\hline 3 & $\$ 86$ & 36 & 314 & $15 ?$ & 378 \\
\hline 3 & 458 & 106 & 344 & $\Leftrightarrow 8$ & 73 \\
\hline$\beta$ & 480 & 360 & 44 & 153 & 173 \\
\hline 3.1344 & 458 & 860 & $\beta \leqslant$ & 137 & 779 \\
\hline 2 & सह & 100 & 444 & 153 & 179 \\
\hline 3 & 468 & 160 & $\beta \alpha \alpha$ & 137 & 378 \\
\hline 3 & 488 & 106 & 424 & 57 & 372 \\
\hline $3-3935$ & 662 & 166 & 424 & 57 & 178 \\
\hline 2 & 488 & 100 & 444 & $\vdots 53$ & 379 \\
\hline 3 & 686 & 186 & 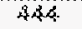 & 37 & 179 \\
\hline$\xi$ & 408 & 180 & 484 & $\vdots 57$ & 376 \\
\hline $3-3095$ & 656 & 186 & $A B S$ & 87 & 178 \\
\hline 2 & ASS & 186 & 444 & $\$ 57$ & 379 \\
\hline
\end{tabular}


241-U-109 LEVEL HISTORY

HNF-SD-WM-ER-325, Rev. 1

\begin{tabular}{|c|c|c|c|c|c|}
\hline Year & Total & Total & Solids & Solids & ILL \\
\hline & (K gal) & (in) & (K gal) & (in) & (in) \\
\hline \multicolumn{6}{|l|}{$1-1944$} \\
\hline \multicolumn{6}{|l|}{2} \\
\hline \multicolumn{6}{|l|}{3} \\
\hline \multicolumn{6}{|l|}{4} \\
\hline \multicolumn{6}{|l|}{$1-1945$} \\
\hline \multicolumn{6}{|l|}{2} \\
\hline \multicolumn{6}{|l|}{3} \\
\hline \multicolumn{6}{|l|}{4} \\
\hline \multicolumn{6}{|l|}{$1-1946$} \\
\hline \multicolumn{6}{|l|}{2} \\
\hline \multicolumn{6}{|l|}{3} \\
\hline \multicolumn{6}{|l|}{4} \\
\hline \multicolumn{6}{|l|}{ 1-1947 } \\
\hline \multicolumn{6}{|l|}{2} \\
\hline \multicolumn{6}{|l|}{3} \\
\hline \multicolumn{6}{|l|}{4} \\
\hline \multicolumn{6}{|l|}{$1-1948$} \\
\hline \multicolumn{6}{|l|}{2} \\
\hline \multicolumn{6}{|l|}{3} \\
\hline \multicolumn{6}{|l|}{4} \\
\hline $1-1949$ & 150 & 50 & & & \\
\hline 2 & 455 & 161 & & & \\
\hline 3 & 528 & 187 & & & \\
\hline 4 & 528 & 187 & & & \\
\hline $1-1950$ & 528 & 187 & & & \\
\hline 2 & 528 & 187 & & & \\
\hline 3 & 528 & 187 & & & \\
\hline 4 & 528 & 187 & & & \\
\hline 1-1951 & 528 & 187 & & & \\
\hline \multicolumn{6}{|l|}{2} \\
\hline \multicolumn{6}{|l|}{3} \\
\hline 4 & & & & & \\
\hline $1-1952$ & & & & & \\
\hline 2 & 519 & 184 & & & \\
\hline 3 & 519 & 184 & & & \\
\hline 4 & 519 & 184 & & & \\
\hline 1-1953 & 519 & 184 & & & \\
\hline 2 & 276 & 96 & & & \\
\hline 3 & 280 & 97 & & & \\
\hline 4 & 44 & 11 & & & \\
\hline 1-1954 & 58 & 17 & & & \\
\hline 2 & & & & & \\
\hline 3 & 363 & 127 & & & \\
\hline 4 & 490 & 174 & & & \\
\hline 1-1955 & 490 & 174 & & & \\
\hline 2 & 490 & 174 & & & \\
\hline
\end{tabular}




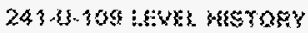

\begin{tabular}{|c|c|c|c|c|c|}
\hline Year & toss & Soss & Sossists & Soshigs & 32 \\
\hline & \{k ss? & ani & $838 s$ & ins & $6 \mathrm{mi}$ \\
\hline & & & & & \\
\hline 3 & 498 & 134 & & & \\
\hline 4 & 400 & 14 & & & \\
\hline $1-128 x$ & 480 & 374 & & & \\
\hline 2 & 0 & 12 & & & \\
\hline 3 & 136 & $6 \alpha$ & & & \\
\hline 3 & 410 & 368 & & & \\
\hline 1007 & 433 & 345 & & & \\
\hline 2 & 381 & 830 & & & \\
\hline 3 & 381 & 33 & & & \\
\hline 4 & $36 !$ & 134 & & & \\
\hline $1.196 \mathrm{~B}$ & 30 & 134 & 6 & 12 & \\
\hline 2 & $38 \%$ & 134 & 0 & -2 & \\
\hline 3 & 426 & 36 & 0 & 32 & \\
\hline 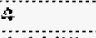 & 425 & 60 & 0 & -\{\} & \\
\hline $8-3 \leq s 9$ & 426 & 160 & 0 & 12 & \\
\hline 3 & $42 \mathrm{E}$ & 160 & 0 & -12 & \\
\hline 3 & 642 & 168 & 0 & $-3 \%$ & \\
\hline 3 & 442 & 160 & 0 & -12 & \\
\hline $3-19 k 5$ & 402 & 36 & $\theta$ & 32 & \\
\hline$z$ & 442 & 350 & 0 & -12 & \\
\hline 3 & 642 & 158 & $a$ & -33 & \\
\hline a & $4 a$ & 150 & 0 & -12 & \\
\hline \multicolumn{6}{|l|}{$3.106 ?$} \\
\hline 2 & 442 & 350 & 6 & 12 & \\
\hline \multicolumn{6}{|l|}{3} \\
\hline$\beta$ & 442 & 858 & i) & $\because 2$ & \\
\hline \multicolumn{6}{|l|}{$1 \times 1922$} \\
\hline 2 & 462 & 58 & $j$ & 2 & \\
\hline \multicolumn{6}{|l|}{3} \\
\hline A & $\$ 42$ & 35 & 3 & 12 & \\
\hline \multicolumn{6}{|l|}{$1-\$ 5893$} \\
\hline 2 & 442 & 85 & 3 & 12 & \\
\hline \multicolumn{6}{|l|}{3} \\
\hline s. & $4 A \%$ & $\$ s$ & 0 & 12 & \\
\hline \multicolumn{6}{|l|}{$1-1 \leqslant 8 \alpha$} \\
\hline 3 & $4 A\rangle$ & 85 & 3 & 12 & \\
\hline \multicolumn{6}{|l|}{3} \\
\hline 4 & $4 A 2$ & 858 & 0 & 12 & \\
\hline $1-3585$ & 486 & $\$ 2$ & 38 & $\xi$ & \\
\hline \multicolumn{6}{|l|}{2} \\
\hline 3 & 458 & 182 & $a s$ & ह1 & \\
\hline 4 & 468 & 152 & 35 & $B$ & \\
\hline 1.3966 & 406 & $\$ 65$ & 36 & 8 & \\
\hline 2 & 453 & $\$ 62$ & 35 & $B$ & \\
\hline 3 & 490 & 176 & 35 & 8 & \\
\hline 4 & 490 & 76 & 35 & 8 & \\
\hline
\end{tabular}


241-U-109 LEVEL HISTORY

\begin{tabular}{|c|c|c|c|c|c|}
\hline Year & Total & Total & Solids & Solids & ILL \\
\hline & (K gal) & (in) & (K gal) & (in) & (in) \\
\hline 1-1967 & 490 & 174 & 35 & 8 & \\
\hline 2 & 490 & 174 & 35 & 8 & \\
\hline 3 & 490 & 174 & 35 & 8 & \\
\hline 4 & 490 & 174 & 35 & 8 & \\
\hline 1-1968 & 490 & 174 & 35 & 8 & \\
\hline 2 & 490 & 174 & 35 & 8 & \\
\hline \multicolumn{6}{|l|}{3} \\
\hline 4 & 490 & 174 & 35 & 8 & \\
\hline 1-1969 & 345 & 121 & 35 & 8 & \\
\hline 2 & 62 & 18 & 35 & 8 & \\
\hline 3 & 63 & 18 & 35 & 8 & \\
\hline 4 & 316 & 110 & 48 & 13 & \\
\hline $1-1970$ & 315 & 110 & 48 & 13 & \\
\hline 2 & 315 & 110 & 48 & 13 & \\
\hline 3 & 314 & 110 & 48 & 13 & \\
\hline 4 & 314 & 110 & 48 & 13 & \\
\hline $1-1971$ & 314 & 110 & 48 & 13 & \\
\hline 2 & 314 & 110 & 48 & 13 & \\
\hline 3 & 314 & 110 & 48 & 13 & \\
\hline 4 & 314 & 110 & 48 & 13 & \\
\hline $1-1972$ & 314 & 110 & 48 & 13 & \\
\hline 2 & 316 & 110 & 48 & 13 & \\
\hline 3 & 316 & 110 & & -5 & \\
\hline 4 & 328 & 115 & 48 & 13 & \\
\hline $1-1973$ & 329 & 115 & 48 & 13 & \\
\hline 2 & 332 & 116 & 48 & 13 & \\
\hline 3 & 329 & 115 & 48 & 13 & \\
\hline 4 & 330 & 115 & 48 & 13 & \\
\hline 1-1974 & 127 & 42 & 48 & 13 & \\
\hline 2 & 127 & 42 & 48 & 13 & \\
\hline 3 & 127 & 42 & 48 & 13 & \\
\hline 4 & 153 & 51 & 48 & 13 & \\
\hline $1-1975$ & 156 & 52 & 48 & 13 & \\
\hline 2 & 156 & 52 & 48 & 13 & \\
\hline 3 & 161 & 54 & 48 & 13 & \\
\hline 4 & 513 & 182 & 48 & 13 & \\
\hline $1-1976$ & 505 & 179 & 256 & 89 & \\
\hline 2 & 508 & 180 & 255 & 88 & \\
\hline 3 & 513 & 182 & 255 & 88 & \\
\hline 4 & 376 & 132 & 373 & 131 & \\
\hline 1-1977 & 499 & 177 & 263 & 91 & \\
\hline 2 & 455 & 161 & 263 & 91 & \\
\hline 3 & 458 & 162 & 263 & 91 & \\
\hline 4 & 450 & 159 & 440 & 155 & \\
\hline $1-1978$ & 450 & 159 & 444 & 157 & \\
\hline 2 & 453 & 160 & 444 & 157 & \\
\hline
\end{tabular}




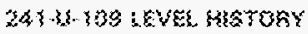

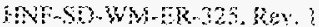

\begin{tabular}{|c|c|c|c|c|c|}
\hline Yen & $T\{s\} 3\}$ & Ts:t:B\} & S08858 & Sintivs & $3 i\}$ \\
\hline & $\left\{\begin{array}{l}3 \times\{\} \\
0\end{array}\right.$ & (n) & 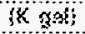 & ma! & $\{30\}$ \\
\hline & & & & & \\
\hline 3 & $40 \%$ & 167 & $\therefore \& 2$ & 153 & \\
\hline$\theta$ & 465 & 31 & 448 & $15 \%$ & \\
\hline Y.1Sts & 486 & $\because 6$ & $\$ 44$ & $35 \%$ & \\
\hline 3 & 465 & ७ל่ & 468 & 367 & \\
\hline 3 & 485 & $\Leftrightarrow ?$ & 344 & 353 & \\
\hline 4 & 450 & 31 & 468 & 367 & \\
\hline $1-1380$ & 685 & 31 & $A 44$ & 36 & \\
\hline 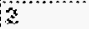 & 265 & 31 & 424 & $35 \%$ & \\
\hline 3 & 655 & 63 & 434 & 357 & \\
\hline ; & 455 & 61 & 404 & $35 \%$ & \\
\hline 3.1983 & 456 & 36 & 444 & 357 & \\
\hline 3 & 460 & 63 & 444 & $\{5\}$ & \\
\hline 3 & 466 & 60 & 344 & $15 \%$ & \\
\hline 4 & 455 & 63 & 344 & 353 & \\
\hline 3.8382 & 456 & 163 & 444 & $35 \%$ & \\
\hline 2 & 455 & 163 & 344 & $35\rangle$ & \\
\hline 3 & 465 & 61 & 244 & 357 & \\
\hline 4 & 455 & 183 & 648 & 167 & \\
\hline $3-7333$ & $\$ 3$ & 164 & 444 & 357 & \\
\hline 3 & 483 & 18 & 444 & 357 & \\
\hline$z$ & 863 & 364 & 446 & 857 & \\
\hline 4 & 483 & $\theta$ & 334 & 357 & \\
\hline $3.33 B 3$ & 463 & 64 & 446 & $35 ?$ & \\
\hline 2 & $4 \beta 3$ & 6 & $3+4$ & $38 \%$ & \\
\hline 3 & 283 & 64 & 346 & $\{i\}$ & \\
\hline 6 & 453 & $6 \alpha$ & 334 & $38 \%$ & \\
\hline $3 \cdot 3386$ & 403 & 104 & $4 x$ & $35 \%$ & \\
\hline 2 & 453 & 60 & 34 & 367 & \\
\hline 3 & 453 & 34 & 46 & $\langle 5\rangle$ & \\
\hline 5 & 463 & 164 & 344 & 357 & \\
\hline 3.3386 & 403 & 36 & 468 & $35\rangle$ & 7 \\
\hline 2 & 463 & 64 & $3 \times 4$ & 35 & 17 \\
\hline 3 & 403 & 164 & 68 & $35 \%$ & 37 \\
\hline 4 & 463 & 164 & 444 & 35 & 3 \\
\hline $1-3 \leq \leqslant 8\rangle$ & 403 & 168 & 6,3 & $\langle 5\rangle$ & 36 \\
\hline 3 & 463 & 164 & 444 & $15 \%$ & \\
\hline 3 & 403 & 164 & 648 & $35 \%$ & 36 \\
\hline H & 463 & 194 & 444 & $15 ?$ & 86 \\
\hline $1-1 \leq \leqslant 8$ & 683 & 364 & 648 & 367 & 7 \\
\hline 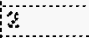 & 463 & 164 & $4 a A$ & $3 ?$ & 17 \\
\hline 3 & 433 & 364 & 633 & 36 & $1 \%$ \\
\hline$x$ & 463 & 184 & 484 & $10 ?$ & 17 \\
\hline i-3sks! & 453 & 163 & 434 & 16 & \\
\hline 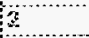 & 463 & $18 x$ & 431 & 15 & 126 \\
\hline 3 & 953 & iss & 434 & $5 \%$ & 37 \\
\hline 2 & 483 & 364 & $\triangle A A$ & 37 & 37 \\
\hline
\end{tabular}


241-U-109 LEVEL HISTORY

HNF-SD-WM-ER-325, Rev, 1

\begin{tabular}{|l|c|c|c|c|c|}
\hline Year & Total & Total & Solids & Solids & ILL \\
\hline & (K gal) & (in) & (K gal) & (in) & (in) \\
\hline $1-1990$ & & & & & \\
\hline 2 & 463 & 164 & 444 & 157 & 176 \\
\hline 3 & 463 & 164 & 444 & 157 & \\
\hline 4 & 463 & 164 & 444 & 157 & 177 \\
\hline $1-1991$ & 463 & 164 & 444 & 157 & 176 \\
\hline 2 & 463 & 164 & 444 & 157 & 176 \\
\hline 3 & 463 & 164 & 444 & 157 & 176 \\
\hline 4 & 463 & 164 & 444 & 157 & 177 \\
\hline $1-1992$ & 463 & 164 & 444 & 157 & 177 \\
\hline 2 & 463 & 164 & 444 & 157 & \\
\hline 3 & 463 & 164 & 444 & 157 & \\
\hline 4 & 463 & 164 & 444 & 157 & \\
\hline $1-1993$ & 463 & 164 & 444 & 157 & 176 \\
\hline 2 & 463 & 164 & 444 & 157 & 176 \\
\hline 3 & 463 & 164 & 444 & 157 & 178 \\
\hline 4 & 463 & 164 & 444 & 157 & 177 \\
\hline $1-1994$ & 463 & 164 & 444 & 157 & 177 \\
\hline 2 & 463 & 164 & 444 & 157 & 177 \\
\hline 3 & 463 & 164 & 444 & 157 & 177 \\
\hline 4 & 463 & 164 & 444 & 157 & 177 \\
\hline $1-1995$ & 463 & 164 & 444 & 157 & 177 \\
\hline 2 & 463 & 164 & 444 & 157 & 177 \\
\hline 3 & 463 & 164 & 444 & 157 & 178 \\
\hline 4 & 463 & 164 & 444 & 157 & 178 \\
\hline $1-1996$ & 463 & 164 & 444 & 157 & 177 \\
\hline 2 & 463 & 164 & 444 & 157 & 177 \\
\hline & & 164 & 444 & 157 & 176 \\
\hline
\end{tabular}




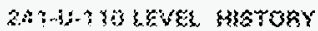

\begin{tabular}{|c|c|c|c|c|}
\hline Ysiss & Tolss! & Ts\{as\} & Sit2isss & singos \\
\hline & KK $38 a d ?$ & 6 & $(\mathrm{x} p \mathrm{k}$ & (in) \\
\hline \multicolumn{5}{|l|}{$1-33 \times 4$} \\
\hline \multicolumn{5}{|l|}{4} \\
\hline \multicolumn{5}{|l|}{3} \\
\hline \multicolumn{5}{|l|}{ 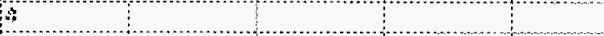 } \\
\hline \multicolumn{5}{|l|}{$8-38 x y$} \\
\hline \multicolumn{5}{|l|}{ 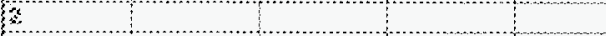 } \\
\hline \multicolumn{5}{|l|}{3} \\
\hline \multicolumn{5}{|l|}{$\theta$} \\
\hline \multicolumn{5}{|l|}{1.1340} \\
\hline \multicolumn{5}{|l|}{2} \\
\hline 3 & 30 & 26 & & \\
\hline 3 & $2 x$ & 34 & & \\
\hline $3-8942$ & 532 & 382 & & \\
\hline 2 & 528 & 887 & & \\
\hline 3 & 528 & 387 & & \\
\hline 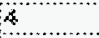 & 528 & $\{3 ?$ & & \\
\hline $1-7 G \alpha \beta$ & 838 & 387 & & \\
\hline 2 & $22 B$ & $38 ?$ & & \\
\hline 3 & 828 & 387 & & \\
\hline 3 & 623 & $38 \%$ & & \\
\hline $1-3943$ & $\because 38$ & $38 \%$ & & \\
\hline 3 & $82 B$ & $8 B$ & & \\
\hline 3 & $8 x$ & $38 \%$ & & \\
\hline in & 523 & $13 ?$ & & \\
\hline $3 .(953)$ & 83 & $38 \%$ & & \\
\hline 2 & 223 & $3 ?$ & & \\
\hline 3 & 620 & $3 \Leftrightarrow \theta$ & & \\
\hline 4 & 523 & $33 \%$ & & \\
\hline $3 \cdot \operatorname{ts} 5\}$ & 828 & $38 \%$ & & \\
\hline \multicolumn{5}{|l|}{$\ddot{z}$} \\
\hline \multicolumn{5}{|l|}{3} \\
\hline \multicolumn{5}{|l|}{4} \\
\hline \multicolumn{5}{|l|}{$3 \cdot+952$} \\
\hline 2 & 335 & 118 & & \\
\hline 3 & 336 & 178 & & \\
\hline 4 & 335 & 130 & & \\
\hline 3.5533 & 338 & $3 \xi \xi$ & 330 & 133 \\
\hline 2 & $33 \%$ & 136 & 336 & 118 \\
\hline 3 & 336 & 33 & 35 & 19 \\
\hline 4 & 333 & ?? & 335 & 13 \\
\hline 1.1954 & 830 & $3\{8$ & $a b$ & $3 \%$ \\
\hline 2 & 433 & 164 & 335 & $3 \%$ \\
\hline 3 & 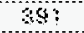 & 318 & 35 & $3 \%$ \\
\hline 4 & 353 & 124 & 385 & 137 \\
\hline $3-Y 355$ & 328 & 115 & 323 & 175 \\
\hline 2 & 325 & 115 & 323 & 135 \\
\hline 3 & 630 & 35 & 313 & 111 \\
\hline
\end{tabular}


241-U-110 LEVEL HISTORY

HNF-SD-WM-ER-325, Rev. 1

\begin{tabular}{|c|c|c|c|c|}
\hline Year & Total & Total & Solids & Solids \\
\hline & (K gal) & (in) & (K gal) & (in) \\
\hline 4 & 484 & 171 & 319 & 111 \\
\hline $1-1956$ & 530 & 188 & 319 & 111 \\
\hline 2 & 385 & 135 & 319 & 111 \\
\hline 3 & 389 & 137 & 319 & 111 \\
\hline 4 & 347 & 122 & 311 & 109 \\
\hline $1-1957$ & 392 & 138 & 319 & 111 \\
\hline 2 & 453 & 160 & 311 & 109 \\
\hline 3 & 480 & 170 & 311 & 109 \\
\hline 4 & 480 & 170 & 311 & 109 \\
\hline $1-1958$ & 477 & 169 & 311 & 109 \\
\hline 2 & 477 & 169 & 311 & 109 \\
\hline 3 & 513 & 182 & 311 & 109 \\
\hline 4 & 513 & 182 & 311 & 109 \\
\hline 1-1959 & 510 & 181 & 311 & 109 \\
\hline 2 & 513 & 182 & 311 & 109 \\
\hline 3 & 513 & 182 & 311 & 109 \\
\hline 4 & 510 & 181 & 311 & 109 \\
\hline $1-1960$ & 510 & 181 & 311 & 109 \\
\hline 2 & 510 & 181 & 311 & 109 \\
\hline 3 & 510 & 181 & 331 & 116 \\
\hline 4 & 510 & 181 & 331 & 116 \\
\hline 1-1961 & 510 & 181 & 331 & 116 \\
\hline \multicolumn{5}{|l|}{2} \\
\hline 3 & 507 & 180 & 311 & 109 \\
\hline \multicolumn{5}{|l|}{4} \\
\hline \multicolumn{5}{|l|}{ 1-1962 } \\
\hline 2 & 505 & 179 & 311 & 109 \\
\hline \multicolumn{5}{|l|}{3} \\
\hline 4 & 505 & 179 & 311 & 109 \\
\hline \multicolumn{5}{|l|}{$1-1963$} \\
\hline 2 & 510 & 181 & 311 & 109 \\
\hline \multicolumn{5}{|l|}{3} \\
\hline 4 & 510 & 181 & 311 & 109 \\
\hline \multicolumn{5}{|l|}{$1-1964$} \\
\hline 2 & 510 & 181 & 311 & 109 \\
\hline \multicolumn{5}{|l|}{3} \\
\hline 4 & 510 & 181 & 311 & 109 \\
\hline $1-1965$ & 497 & 176 & 311 & 109 \\
\hline \multicolumn{5}{|l|}{2} \\
\hline 3 & 497 & 176 & 311 & 109 \\
\hline 4 & 497 & 176 & 311 & 109 \\
\hline $1-1966$ & 497 & 176 & 311 & 109 \\
\hline 2 & 497 & 176 & 311 & 109 \\
\hline 3 & 497 & 176 & 311 & 109 \\
\hline 4 & 497 & 176 & 311 & 109 \\
\hline $1-1967$ & 497 & 176 & 311 & 109 \\
\hline 2 & 497 & 176 & 311 & 109 \\
\hline
\end{tabular}

C-63 


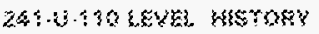

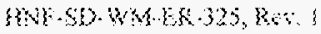

\begin{tabular}{|c|c|c|c|c|}
\hline Yeax & atsl & Toks & Sstids & Scsidst \\
\hline & $\mathrm{K} \$ 3$ & (kors & 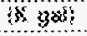 & $\mathrm{mb}$ \\
\hline & & & & \\
\hline 3 & $40 ?$ & 78 & 30 & 60 \\
\hline 4 & $3 \%$ & 38 & औ? & 103 \\
\hline 1.5968 & 437 & 32 & 311 & 108 \\
\hline 2 & $3 \%$ & 386 & $4 ! 9$ & $10 ?$ \\
\hline 3 & 437 & 36 & 313 & 69 \\
\hline 4 & 40 & $3 \times 6$ & $3: 1$ & 193 \\
\hline 3.5963 & 436 & 36 & 313 & 69 \\
\hline 2 & 340 & 19 & 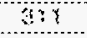 & 33 \\
\hline 8 & 300 & 30 & $3 ! 3$ & as \\
\hline 2 & 388 & 19 & 106 & 62 \\
\hline $3-1376$ & 30 & 119 & 82 & 82 \\
\hline 2 & 340 & 319 & 36 & 62 \\
\hline$x$ & 338 & 319 & 24 & 62 \\
\hline 4 & 335 & $1 ! 3$ & 138 & 32 \\
\hline $3.33 \% 3$ & 336 & 313 & 34 & 82 \\
\hline 2 & 335 & 13 & 186 & 32 \\
\hline 3 & 363 & 83 & 33 & 6 \\
\hline 4 & 380 & 19 & 33 & 62 \\
\hline 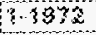 & 363 & 38 & 83 & 82 \\
\hline$z$ & 342 & 46 & 183 & 63 \\
\hline 3 & 393 & 40 & 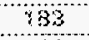 & 82 \\
\hline$A$ & $3+8$ & 96 & 183 & 62 \\
\hline 1.9373 & 483 & 35 & 183 & 82 \\
\hline$x$ & $3 \%$ & 34 & 383 & 62 \\
\hline 3 & $36 ?$ & 123 & 183 & 02 \\
\hline$x$ & 362 & $12 x$ & 38 & 62 \\
\hline 13998 & 408 & 364 & 138 & 02 \\
\hline 2 & $20 E$ & 93 & 63 & 62 \\
\hline 3 & 233 & 302 & 383 & 62 \\
\hline 4 & $3 ! 5$ & 310 & 363 & 62 \\
\hline $3-3938$ & 246 & 328 & 183 & 82 \\
\hline 2 & $38 s$ & 130 & 63 & 32 \\
\hline 3 & 165 & 86 & $3 s$ & 86 \\
\hline$\theta$ & 17 & 63 & 35 & 38 \\
\hline 1396 & 64 & $6 x$ & 16 & 8 \\
\hline 2 & 63 & 34 & 30 & 56 \\
\hline 3 & 31 & 54 & 361 & $\$ 4$ \\
\hline$\beta$ & $\Leftrightarrow$ & 34 & 363 & 58 \\
\hline 1.1978 & $43 !$ & 54 & $36 !$ & 64 \\
\hline 2 & 180 & 53 & 161 & 84 \\
\hline 3 & 861 & 84 & 86 & 64 \\
\hline \& & $38 \%$ & 64 & 63 & 64 \\
\hline 1.1378 & 181 & 84 & 81 & 54 \\
\hline 2 & 68 & 34 & 36 & 54 \\
\hline 3 & 193 & 83 & 143 & 50 \\
\hline$x$ & 18 & 6 & 189 & 33 \\
\hline $1-3533$ & 31 & 84 & $7 E !$ & 54 \\
\hline
\end{tabular}

C-63 
241-U-110 LEVEL HISTORY

HNF-SD-WM-ER-325, Rev. 1

\begin{tabular}{|c|c|c|c|c|}
\hline Year & Total & Total & Solids & Solids \\
\hline & (K gal) & (in) & (K gal) & (in) \\
\hline 2 & 161 & 54 & 161 & 54 \\
\hline 3 & 161 & 54 & 161 & 54 \\
\hline 4 & 161 & 54 & 161 & 54 \\
\hline $1-1980$ & 161 & 54 & 161 & 54 \\
\hline 2 & 161 & 54 & 161 & 54 \\
\hline 3 & 161 & 54 & 161 & 54 \\
\hline 4 & 161 & 54 & 161 & 54 \\
\hline 1-1981 & $1 \overline{61}$ & 54 & 161 & 54 \\
\hline 2 & 161 & 54 & 161 & 54 \\
\hline 3 & 161 & $5 \overline{4}$ & 161 & 54 \\
\hline 4 & 161 & 54 & 161 & 54 \\
\hline $1-1982$ & 161 & 54 & 161 & 54 \\
\hline 2 & 180 & 61 & 180 & 61 \\
\hline 3 & 180 & 61 & 180 & 61 \\
\hline 4 & 180 & 61 & 180 & 61 \\
\hline 1-1983 & 180 & 61 & 180 & 61 \\
\hline 2 & 180 & 61 & 180 & 61 \\
\hline 3 & 180 & 61 & 180 & 61 \\
\hline 4 & 180 & 61 & 180 & 61 \\
\hline 1-1984 & 180 & 61 & 180 & 61 \\
\hline 2 & 180 & 61 & 180 & 61 \\
\hline 3 & 180 & 61 & 180 & 61 \\
\hline 4 & 186 & 63 & 186 & 63 \\
\hline $1-1985$ & 186 & 63 & 186 & 63 \\
\hline 2 & 186 & 63 & 186 & 63 \\
\hline 3 & 186 & 63 & 186 & 63 \\
\hline 4 & 186 & 63 & 186 & 63 \\
\hline 1-1986 & 186 & 63 & 186 & 63 \\
\hline 2 & 186 & 63 & 186 & 63 \\
\hline 3 & 186 & 63 & 186 & 63 \\
\hline 4 & 186 & 63 & 186 & 63 \\
\hline 1-1987 & 186 & 63 & 186 & 63 \\
\hline 2 & 186 & 63 & 186 & 63 \\
\hline 3 & 186 & 63 & 186 & 63 \\
\hline 4 & 186 & 63 & 186 & 63 \\
\hline 1-1988 & 186 & 63 & 186 & 63 \\
\hline 2 & 186 & 63 & 186 & 63 \\
\hline 3 & 186 & 63 & 186 & 63 \\
\hline 4 & 186 & 63 & 186 & 63 \\
\hline 1-1989 & 186 & 63 & 186 & 63 \\
\hline 2 & 186 & 63 & 186 & 63 \\
\hline 3 & 186 & 63 & 186 & 63 \\
\hline 4 & 186 & 63 & 186 & 63 \\
\hline $1-1990$ & 186 & 63 & 186 & 63 \\
\hline 2 & 186 & 63 & 186 & 63 \\
\hline 3 & 186 & 63 & 186 & 63 \\
\hline 4 & 186 & 63 & 186 & 63 \\
\hline
\end{tabular}




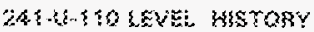

\begin{tabular}{|c|c|c|c|c|}
\hline You: & కตi & Tot & Solids & Solids \\
\hline & |k gati & $3 n !$ & K gall & $\{(s s)$ \\
\hline & & & & \\
\hline $3-1931$ & 366 & 83 & 186 & 63 \\
\hline$\%$ & 336 & 63 & 366 & 63 \\
\hline 3 & 386 & 83 & 180 & 63 \\
\hline 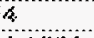 & 336 & 63 & 366 & 63 \\
\hline $1-7532$ & 836 & 63 & 80 & $\theta$ \\
\hline 2 & 36 & 63 & 166 & 63 \\
\hline 3 & 36 & 63 & 186 & 63 \\
\hline 4 & 186 & 63 & 186 & 63 \\
\hline 1.1953 & $\$ 80$ & 33 & 130 & 6 \\
\hline 2 & 86 & 53 & 386 & 63 \\
\hline 3 & 186 & 63 & 130 & $\$$ \\
\hline 4 & $: 85$ & 83 & 188 & 63 \\
\hline $1-3954$ & 186 & 63 & 138 & 53 \\
\hline 2 & 180 & ta & 186 & 80 \\
\hline 3 & 36 & 83 & 136 & 33 \\
\hline 6 & 88 & 6 & 1 \&6 & 83 \\
\hline $1-7335$ & 38 & 83 & 135 & 63 \\
\hline$z$ & 186 & 6 & 1s & 63 \\
\hline 3 & 383 & 83 & 36 & 63 \\
\hline 6 & 186 & 63 & 36 & 63 \\
\hline $3-4335$ & 318 & 83 & 30 & 53 \\
\hline 2 & 186 & 33 & 36 & 33 \\
\hline
\end{tabular}


241-U-111 LEVEL HISTORY

HNF-SD-WM-ER-325, Rev. 1

\begin{tabular}{|c|c|c|c|c|c|}
\hline Year & Total & Total & Solids & Solids & ILL \\
\hline & (K gai) & (in) & (K gal) & (in) & (in) \\
\hline \multicolumn{6}{|l|}{$1-1944$} \\
\hline \multicolumn{6}{|l|}{2} \\
\hline \multicolumn{6}{|l|}{3} \\
\hline \multicolumn{6}{|l|}{4} \\
\hline \multicolumn{6}{|l|}{ 1-1945 } \\
\hline \multicolumn{6}{|l|}{2} \\
\hline \multicolumn{6}{|l|}{3} \\
\hline \multicolumn{6}{|l|}{4} \\
\hline \multicolumn{6}{|l|}{$1-1946$} \\
\hline \multicolumn{6}{|l|}{2} \\
\hline \multicolumn{6}{|l|}{3} \\
\hline \multicolumn{6}{|l|}{4} \\
\hline \multicolumn{6}{|c|}{$1-1947$} \\
\hline 2 & 208 & 71 & & & \\
\hline 3 & 472 & 167 & & & \\
\hline 4 & 528 & 187 & & & \\
\hline 1-1948 & 528 & 187 & & & \\
\hline 2 & 528 & 187 & & & \\
\hline 3 & 528 & 187 & & & \\
\hline 4 & 528 & 187 & & & \\
\hline $1-1949$ & 528 & 187 & & & \\
\hline 2 & 528 & 187 & & & \\
\hline 3 & 528 & 187 & & & \\
\hline 4 & 528 & 187 & & & \\
\hline $1-1950$ & 528 & 187 & & & \\
\hline 2 & 528 & 187 & & & \\
\hline 3 & 528 & 187 & & & \\
\hline 4 & 528 & 187 & & & \\
\hline $1-1951$ & 528 & 187 & & & \\
\hline \multicolumn{6}{|l|}{2} \\
\hline \multicolumn{6}{|l|}{3} \\
\hline \multicolumn{6}{|l|}{4} \\
\hline \multicolumn{6}{|l|}{$1-1952$} \\
\hline 2 & 14 & 1 & & & \\
\hline 3 & 14 & 1 & & & \\
\hline 4 & 14 & 1 & & & \\
\hline $1-1953$ & 14 & 1 & 14 & 1 & \\
\hline 2 & 17 & 2 & 14 & 1 & \\
\hline 3 & 15 & 1 & 14 & 1 & \\
\hline 4 & 15 & 1 & 14 & 1 & \\
\hline 1.1954 & 530 & 188 & 14 & 1 & \\
\hline 2 & 530 & 188 & 14 & 1 & \\
\hline 3 & 530 & 188 & 14 & 1 & \\
\hline 4 & 530 & 188 & 14 & 1 & \\
\hline $1-1955$ & 530 & 188 & 14 & 1 & \\
\hline 2 & 530 & 188 & 14 & 1 & \\
\hline
\end{tabular}




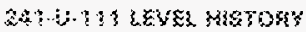

\begin{tabular}{|c|c|c|c|c|c|}
\hline Yoa: & Tors! & Totst & Solids & Saliss & id \\
\hline & 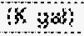 & mi & $x \mathrm{as})$ & (wis & ling \\
\hline & & & & & \\
\hline 3 & 630 & 888 & 3 & 1 & \\
\hline 4 & 86 & 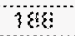 & $a$ & $?$ & \\
\hline $7.7 \$ 56$ & 530 & 38 & 3 & 1 & \\
\hline 2 & 819 & 184 & 14 & $\vdots$ & \\
\hline 3 & 673 & 134 & 30 & 5 & \\
\hline 4 & 519 & 34 & 5 & $\vdots$ & \\
\hline $3-\gamma 3 s ?$ & 593 & 36 & 35 & 1 & \\
\hline 2 & 513 & 34 & 35 & $\vdots$ & \\
\hline 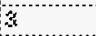 & 819 & 186 & 35 & 3 & \\
\hline 4 & 619 & 124 & 75 & 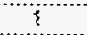 & \\
\hline $3-13 r s$ & $\$ 16$ & 186 & 15 & 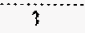 & \\
\hline 2 & 010 & 324 & 35 & 1 & \\
\hline 3 & 28 & 386 & 15 & 3 & \\
\hline 4 & 816 & $\$ 24$ & 5 & $i$ & \\
\hline $7.7 \$ 58$ & 619 & 184 & 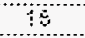 & 3 & \\
\hline 2 & 539 & 184 & 3 & $y$ & \\
\hline 3 & $5 ? 3$ & 884 & 8 & 1 & \\
\hline 4 & 836 & 386 & 35 & $y$ & \\
\hline 5.7800 & $5 \times 8$ & 833 & 3 & 1 & \\
\hline 2 & 838 & 186 & 36 & 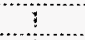 & \\
\hline 3 & $6 \$ 8$ & 433 & 35 & 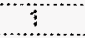 & \\
\hline 4 & 536 & 186 & 35 & 3 & \\
\hline$\{-\{90\}$ & $6 \mathrm{~s}$ & 433 & 13 & 3 & \\
\hline \multicolumn{6}{|l|}{2} \\
\hline 3 & $5 \times 5$ & 433 & 35 & 1 & \\
\hline \multicolumn{6}{|l|}{6} \\
\hline \multicolumn{6}{|l|}{$3-3362$} \\
\hline 2 & 56 & 83 & 35 & 3 & \\
\hline \multicolumn{6}{|l|}{$a$} \\
\hline 4 & 536 & 33 & 95 & 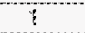 & \\
\hline \multicolumn{6}{|l|}{1363} \\
\hline 2 & $5: 6$ & 33 & 35 & 1 & \\
\hline \multicolumn{6}{|l|}{3} \\
\hline 4 & 516 & 133 & 15 & $i$ & \\
\hline \multicolumn{6}{|l|}{$(3.1964$} \\
\hline 2 & 516 & 133 & 15 & $y$ & \\
\hline \multicolumn{6}{|l|}{3} \\
\hline 4 & 518 & 133 & 9 & $i$ & \\
\hline 3.1368 & 550 & 183 & 29 & 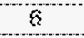 & \\
\hline \multicolumn{6}{|l|}{2} \\
\hline 3 & 530 & 183 & 23 & 6 & \\
\hline 4 & 530 & 68 & 23 & 8 & \\
\hline 7.3966 & 530 & 183 & 23 & 6 & \\
\hline 2 & 530 & 180 & 23 & 6 & \\
\hline$z$ & $\$ 0$ & 333 & 23 & $s$ & \\
\hline 4 & 330 & $8 \theta$ & 28 & 8 & \\
\hline
\end{tabular}


241-U-111 LEVEL HISTORY

\begin{tabular}{|c|c|c|c|c|c|}
\hline Year & Total & Total & Solids & Solids & ILL \\
\hline & (K gal) & (in) & (K gal) & (in) & (in) \\
\hline $1-1967$ & 530 & 188 & 29 & 6 & \\
\hline 2 & 530 & 188 & 29 & 6 & \\
\hline 3 & 530 & 188 & 29 & 6 & \\
\hline 4 & 530 & 188 & 29 & 6 & \\
\hline 1-1968 & 530 & 188 & 29 & 6 & \\
\hline 2 & 530 & 188 & 29 & 6 & \\
\hline 3 & 530 & 188 & 29 & 6 & \\
\hline 4 & 531 & 189 & 29 & 6 & \\
\hline 1-1969 & 531 & 189 & 29 & 6 & \\
\hline 2 & 530 & 188 & 29 & 6 & \\
\hline 3 & 530 & 188 & 29 & 6 & \\
\hline 4 & 530 & 188 & 26 & 5 & \\
\hline $1-1970$ & 530 & 188 & 26 & 5 & \\
\hline 2 & 530 & 188 & 26 & 5 & \\
\hline 3 & 530 & 188 & 26 & 5 & \\
\hline 4 & 147 & 49 & 26 & 5 & \\
\hline \begin{tabular}{|l|}
1.1971 \\
\end{tabular} & 148 & 49 & 26 & 5 & \\
\hline 2 & 148 & 49 & 26 & 5 & \\
\hline 3 & 147 & 49 & 26 & 5 & \\
\hline 4 & 148 & 49 & 26 & 5 & \\
\hline \begin{tabular}{|l|}
$1-1972$ \\
\end{tabular} & 147 & 49 & 26 & 5 & \\
\hline 2 & 147 & 49 & 26 & 5 & \\
\hline 3 & 149 & 50 & 26 & 5 & \\
\hline 4 & 149 & 50 & 26 & 5 & \\
\hline $1-1973$ & 148 & 49 & 26 & 5 & \\
\hline 2 & 148 & 49 & 26 & 5 & \\
\hline 3 & 148 & 49 & 26 & 5 & \\
\hline 4 & 148 & 49 & 26 & 5 & \\
\hline \begin{tabular}{|l|}
$1-1974$ \\
\end{tabular} & 149 & 50 & 26 & 5 & \\
\hline 2 & 148 & 49 & 26 & 5 & \\
\hline 3 & 159 & 53 & 26 & 5 & \\
\hline 4 & 158 & 53 & 26 & 5 & \\
\hline \begin{tabular}{|l|}
$1-1975$ \\
\end{tabular} & 158 & 53 & 26 & 5 & \\
\hline 2 & 172 & 58 & 26 & 5 & \\
\hline 3 & 343 & 120 & 26 & 5 & \\
\hline 4 & 367 & 129 & 26 & 5 & \\
\hline $1-1976$ & 499 & 177 & 26 & 5 & \\
\hline 2 & 499 & 177 & 26 & 5 & \\
\hline 3 & 488 & 173 & 26 & 5 & \\
\hline 4 & 244 & 84 & 26 & 5 & \\
\hline $1-1977$ & 216 & 74 & 136 & 45 & \\
\hline 2 & 450 & 159 & 136 & 45 & \\
\hline 3 & 510 & 181 & 161 & 54 & \\
\hline 4 & 436 & 154 & 235 & 81 & \\
\hline $1-1978$ & 420 & 148 & 235 & 81 & \\
\hline 2 & 431 & 152 & 381 & 134 & \\
\hline
\end{tabular}




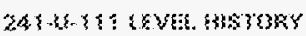

\begin{tabular}{|c|c|c|c|c|c|}
\hline $482 x$ & (stis) & Toid & Solikis & Satios & SLL \\
\hline & x noil & $\{s s\}$ & (k sssi) & (in) & $\{i n\}$ \\
\hline & & & & & \\
\hline 3 & $4:$ & 34 & 863 & 50 & \\
\hline 4 & 400 & $34 !$ & 383 & 134 & \\
\hline $1.9 ? 9$ & 395 & 339 & 36 & 34 & \\
\hline 2 & 620 & 161 & 303 & 34 & \\
\hline 3 & $43 !$ & 35 & 38 & 134 & \\
\hline$a$ & $43 \%$ & 176 & 34 & 134 & \\
\hline 2.1380 & 49 & 38 & 33 & 134 & \\
\hline 2 & 402 & 132 & 303 & 13 & \\
\hline 3 & 328 & 33 & 26 & 39 & \\
\hline$a$ & 311 & 10 & 288 & $6 \%$ & \\
\hline$\gamma-358 \gamma$ & $3 ! 1$ & 103 & 273 & 37 & \\
\hline$z$ & 393 & 10 & 289 & $6 \%$ & \\
\hline 3 & 311 & 103 & 273 & $3 ?$ & \\
\hline 3 & 312 & 103 & 218 & 9 & \\
\hline $8-3 \leq \leqslant 2$ & 313 & 109 & 878 & $3 ?$ & \\
\hline 3 & 323 & 785 & $31 !$ & 30 & \\
\hline 3 & 328 & 15 & 311 & 10s & \\
\hline 3 & 323 & 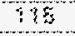 & 311 & 16 & \\
\hline 1.1983 & 368 & 135 & 311 & 108 & \\
\hline 2 & 323 & 78 & $31 !$ & 169 & \\
\hline 3 & 38 & 135 & $33 !$ & 103 & \\
\hline 4 & 328 & $Y 8$ & $3 ! !$ & 108 & \\
\hline $1-3 \$ \$ 4$ & 324 & 336 & 35 & 108 & \\
\hline 2 & 323 & 18 & 311 & 108 & \\
\hline 3 & $32 \mathrm{~s}$ & 33 & औi & $\$ 03$ & \\
\hline 6 & 320 & 318 & $3 ! 3$ & 108 & \\
\hline $1+1985$ & 320 & 36 & $3 !$ & $\$ 03$ & \\
\hline 2 & 320 & 116 & 393 & $\$ 09$ & \\
\hline 3 & 323 & 35 & 31 & $\$ 00$ & \\
\hline$a$ & 329 & 31 & 328 & 35 & \\
\hline $1-3966$ & 329 & 13 & 323 & 178 & 126 \\
\hline in & 326 & 116 & 36 & 135 & 123 \\
\hline 3 & 329 & 13 & 323 & 38 & 120 \\
\hline 4 & 323 & $3 \xi$ & as & 316 & 125 \\
\hline $1-3 \leqslant 67$ & 323 & 13 & 323 & 115 & 26 \\
\hline$z$ & 329 & 136 & at & 15 & \\
\hline 3 & 329 & 115 & 322 & 115 & 26 \\
\hline 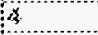 & 328 & $3 ! 5$ & $12 \mathrm{x}$ & 35 & 125 \\
\hline 1.75333 & 328 & 36 & 326 & 115 & 125 \\
\hline$z$ & 328 & 3 & \$2\% & 115 & 325 \\
\hline 3 & 326 & 118 & 326 & 135 & 126 \\
\hline 4 & 328 & 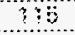 & 323 & 15 & 120 \\
\hline $3-19339$ & 320 & 116 & 38 & 135 & \\
\hline 2 & 328 & 85 & 328 & 318 & 325 \\
\hline 3 & $32 \%$ & 336 & 329 & 315 & 13 \\
\hline 2 & 328 & 35 & 320 & 315 & 128 \\
\hline
\end{tabular}


241-U-111 LEVEL HISTORY

\begin{tabular}{|c|c|c|c|c|c|}
\hline Year & Total & Total & Solids & Solids & ILL \\
\hline & (K gal) & (in) & (K gal) & (in) & (in) \\
\hline $1-1990$ & 329 & 115 & 329 & 115 & 126 \\
\hline 2 & 329 & 115 & 329 & 115 & \\
\hline 3 & 329 & 115 & 329 & 115 & 126 \\
\hline 4 & 329 & 115 & 329 & 115 & 126 \\
\hline 1-1991 & 329 & 115 & 329 & 115 & 127 \\
\hline 2 & 329 & 115 & 329 & 115 & 127 \\
\hline 3 & 329 & 115 & 329 & 115 & 127 \\
\hline 4 & 329 & 115 & 329 & 115 & 127 \\
\hline 1-1992 & 329 & 115 & 329 & 115 & \\
\hline 2 & 329 & 115 & 329 & 115 & \\
\hline 3 & 329 & 115 & 329 & 115 & \\
\hline 4 & 329 & 115 & 329 & 115 & 127 \\
\hline 1-1993 & 329 & 115 & 329 & 115 & 125 \\
\hline 2 & 329 & 115 & 329 & 115 & 128 \\
\hline 3 & 329 & 115 & 329 & 115 & 127 \\
\hline 4 & 329 & 115 & 329 & 115 & 128 \\
\hline 1-1994 & 329 & 115 & 329 & 115 & 128 \\
\hline 2 & 329 & 115 & 329 & 115 & 129 \\
\hline 3 & 329 & 115 & 329 & 115 & 128 \\
\hline 4 & 329 & 115 & 329 & 115 & 128 \\
\hline $1-1995$ & 329 & 115 & 329 & 115 & 128 \\
\hline 2 & 329 & 115 & 329 & 115 & 129 \\
\hline 3 & 329 & 115 & 329 & 115 & 129 \\
\hline 4 & 329 & 115 & 329 & 115 & 129 \\
\hline 1-1996 & 329 & 115 & 329 & 115 & 129 \\
\hline 2 & 329 & 115 & 329 & 115 & 129 \\
\hline
\end{tabular}


249.8 .792 LEVE WISTOSBY

\begin{tabular}{|c|c|c|c|c|}
\hline$Y * 68$ & (nst & $7 n s ;$ & Solists & Sekso: \\
\hline & ox gall & roxal & $(x, 3 a)$ & (in: \\
\hline \multirow{2}{*}{\multicolumn{5}{|c|}{$1-3 \$ x A$}} \\
\hline & & & & \\
\hline \multicolumn{5}{|l|}{$i$} \\
\hline \multicolumn{5}{|l|}{3} \\
\hline \multicolumn{5}{|l|}{4} \\
\hline \multicolumn{5}{|l|}{$1-39 x\}$} \\
\hline \multicolumn{5}{|l|}{2} \\
\hline \multicolumn{5}{|l|}{3} \\
\hline \multicolumn{5}{|l|}{4} \\
\hline \multicolumn{5}{|l|}{1.3345} \\
\hline \multicolumn{5}{|l|}{2} \\
\hline \multicolumn{5}{|l|}{3} \\
\hline \multicolumn{5}{|l|}{ A } \\
\hline \multicolumn{5}{|l|}{3.8347} \\
\hline \multicolumn{5}{|l|}{2} \\
\hline \multicolumn{5}{|l|}{8} \\
\hline 3 & (1) & 56 & & \\
\hline $3-1343$ & ?3! & $3 y$ & & \\
\hline 2 & 528 & $\{3\}$ & & \\
\hline 8 & $2 i$ & 30 & & \\
\hline 4 & 628 & 337 & & \\
\hline $1-1 \$ 43$ & 64 & 38 & & \\
\hline$z$ & 628 & $3 \%$ & & \\
\hline 3 & 328 & 187 & & \\
\hline$a$ & 628 & 307 & & \\
\hline $1+953$ & 62 & 337 & & \\
\hline$z$ & 328 & $30 \%$ & & \\
\hline 3 & 625 & 387 & & \\
\hline 4 & 328 & 387 & & \\
\hline $7-7955$ & $62 \mathrm{~S}$ & 387 & & \\
\hline \multicolumn{5}{|l|}{2} \\
\hline \multicolumn{5}{|l|}{3} \\
\hline \multicolumn{5}{|l|}{4} \\
\hline \multicolumn{5}{|l|}{7.1953} \\
\hline 2 & 32 & $?$ & & \\
\hline 3 & 32 & $\gamma$ & & \\
\hline 4 & 32 & $?$ & & \\
\hline $7 . \$ \$ 53$ & 32 & $y$ & 32 & $?$ \\
\hline 2 & 34 & 3 & 32 & $y$ \\
\hline 3 & 34 & 8 & 32 & $?$ \\
\hline 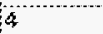 & 32 & $?$ & 32 & $y$ \\
\hline$x-135 s$ & 283 & $2 !$ & 32 & $?$ \\
\hline$z$ & 534 & 122 & 32 & $y$ \\
\hline 3 & 514 & 32 & 32 & $?$ \\
\hline 6 & 514 & 62 & 32 & $\%$ \\
\hline 3.1855 & 30 & 362 & 32 & 7 \\
\hline$z$ & 313 & 38 & 3 & $y$ \\
\hline
\end{tabular}


241-U-112 LEVEL. HISTORY

HNF-SD-WM-ER-325, Rev. 1

\begin{tabular}{|c|c|c|c|c|}
\hline Year & Total & Total & Solids & Solids \\
\hline & (K gal) & Total & (K gal) & (in) \\
\hline & & & & \\
\hline 3 & 514 & 182 & 32 & 7 \\
\hline 4 & 514 & 182 & 32 & 7 \\
\hline $1-1956$ & 509 & 181 & 32 & 7 \\
\hline 2 & 540 & 192 & 32 & 7 \\
\hline 3 & 540 & 192 & 32 & 7 \\
\hline \multicolumn{5}{|l|}{4} \\
\hline $1-1957$ & 549 & 195 & 32 & 7 \\
\hline 2 & 549 & 195 & 32 & 7 \\
\hline 3 & 549 & 195 & 32 & 7 \\
\hline \multicolumn{5}{|l|}{4} \\
\hline $1-1958$ & 549 & 195 & 32 & 7 \\
\hline 2 & 549 & 195 & 32 & 7 \\
\hline 3 & 549 & 195 & 32 & 7 \\
\hline 4 & 549 & 195 & 32 & 7 \\
\hline $1-1959$ & 549 & 195 & 32 & 7 \\
\hline 2 & 549 & 195 & 32 & 7 \\
\hline 3 & 549 & 195 & 32 & 7 \\
\hline 4 & 549 & 195 & 32 & 7 \\
\hline $1-1960$ & 549 & 195 & 32 & 7 \\
\hline 2 & $54 \overline{9}$ & 195 & 32 & 7 \\
\hline 3 & 549 & 195 & 32 & 7 \\
\hline 4 & 549 & 195 & 32 & 7 \\
\hline \multicolumn{5}{|l|}{ 1-1961 } \\
\hline 2 & 549 & 195 & 32 & 7 \\
\hline \multicolumn{5}{|l|}{3} \\
\hline 4 & 549 & 195 & 32 & 7 \\
\hline \multicolumn{5}{|l|}{\begin{tabular}{|l|}
$1-1962$ \\
\end{tabular}} \\
\hline 2 & 549 & 195 & 32 & 7 \\
\hline \multicolumn{5}{|l|}{3} \\
\hline 4 & 549 & 195 & 32 & 7 \\
\hline \multicolumn{5}{|l|}{ 1-1963 } \\
\hline 2 & 549 & 195 & 32 & 7 \\
\hline \multicolumn{5}{|l|}{3} \\
\hline 4 & 549 & 195 & 32 & 7 \\
\hline \multicolumn{5}{|l|}{$1-1964$} \\
\hline 2 & 549 & 195 & 32 & 7 \\
\hline \multicolumn{5}{|l|}{3} \\
\hline 4 & 549 & 195 & 32 & 7 \\
\hline $1-1965$ & 535 & 190 & 46 & 12 \\
\hline \multicolumn{5}{|l|}{2} \\
\hline 3 & 535 & 190 & 46 & 12 \\
\hline 4 & 535 & 190 & 46 & 12 \\
\hline $1-1966$ & 535 & 190 & 46 & 12 \\
\hline 2 & 535 & 190 & 46 & 12 \\
\hline 3 & 535 & 190 & 46 & 12 \\
\hline 4 & 535 & 190 & 46 & 12 \\
\hline
\end{tabular}




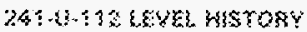

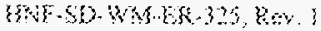

\begin{tabular}{|c|c|c|c|c|}
\hline Yesss & Totst: & Toss & Soliss & Sotins \\
\hline & s $3 a+t$ & tret & $\{x \in s\}$ & ins \\
\hline 7.3587 & 521 & 38 & 36 & 12 \\
\hline$z$ & 616 & $3 \xi 1$ & 40 & 12 \\
\hline 3 & 61 & $3 B 3$ & 36 & 12 \\
\hline$a$ & $63 \%$ & 340 & 40 & 32 \\
\hline$(1-: 968$ & 314 & $3 B 2$ & 36 & 12 \\
\hline$z$ & 833 & $38 !$ & 40 & 12 \\
\hline 3 & 013 & 331 & 46 & 32 \\
\hline$\beta$ & $60 \%$ & 360 & 40 & 3 \\
\hline $1-1364$ & $\$ 66$ & 19 & 56 & 2 \\
\hline 2 & $s 02$ & 178 & 48 & 3 \\
\hline 3 & 300 & 17 & 68 & 2 \\
\hline 4 & $49 \mathrm{~s}$ & 78 & 48 & 13 \\
\hline 1.3370 & 81 & 25 & 88 & 33 \\
\hline 2 & 20 & 25 & 48 & 3 \\
\hline 3 & 80 & 85 & 8 & 3 \\
\hline 4 & 80 & 28 & 48 & 13 \\
\hline $9.337 ?$ & 79 & 28 & $\Delta \theta$ & 30 \\
\hline 2 & 76 & 4 & 43 & 33 \\
\hline 3 & 73 & 23 & 88 & 33 \\
\hline \multicolumn{5}{|l|}{$a$} \\
\hline 8.1572 & 78 & 23 & 68 & 13 \\
\hline 2 & 76 & $x$ & 43 & 33 \\
\hline 3 & $7 \%$ & 23 & 88 & 33 \\
\hline 4 & 3 & 23 & 43 & 13 \\
\hline$\gamma-1383$ & 73 & 23 & 48 & 13 \\
\hline 2 & 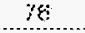 & 23 & 30 & 13 \\
\hline 3 & 35 & 23 & 63 & 13 \\
\hline 4 & $y$ & 25 & 48 & 3 \\
\hline$x-10 y x$ & 35 & 23 & 60 & 3 \\
\hline 3 & 7 & 23 & 80 & $! ?$ \\
\hline 3 & 33 & 22 & 60 & 3 \\
\hline ?... & 62 & 3 & $E 2$ & 18 \\
\hline $1 .\{9\} 5$ & 31 & is & $5 !$ & 14 \\
\hline 3 & 51 & 14 & $5 !$ & 16 \\
\hline 3 & 53 & 34 & $5 ?$ & $: 4$ \\
\hline 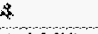 & $\leqslant 1$ & 18 & $\xi !$ & 16 \\
\hline 1.1075 & 51 & is & $5 !$ & 14 \\
\hline 2 & 48 & 3 & 37 & 9 \\
\hline 3 & 48 & 33 & 37 & 0 \\
\hline 4 & 48 & 3 & 37 & 9 \\
\hline $1.10 \% 7$ & 48 & 13 & $3 ?$ & 2 \\
\hline 2 & 28 & 13 & 37 & 9 \\
\hline 3 & 48 & 13 & 37 & 2 \\
\hline ; & $\star \bullet$ & 30 & ij & 9 \\
\hline 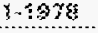 & 43 & 13 & $3 ?$ & 3 \\
\hline$z$ & $\therefore \&$ & 3 & 37 & 3 \\
\hline
\end{tabular}


241-U-112 LEVEL HISTORY

HNF-SD-WM-ER-325, Rev. 1

\begin{tabular}{|c|c|c|c|c|}
\hline Year & Total & Total & Solids & Solids \\
\hline & (K gal) & Total & ( $K$ gal) & (in) \\
\hline 3 & 48 & 13 & 37 & 9 \\
\hline 4 & 48 & 13 & 37 & 9 \\
\hline 1-1979 & 48 & 13 & 37 & 9 \\
\hline 2 & 48 & 13 & 37 & 9 \\
\hline 3 & 48 & 13 & 37 & 9 \\
\hline 4 & 48 & 13 & 46 & 12 \\
\hline $1-1980$ & 48 & 13 & 46 & 12 \\
\hline 2 & 48 & 13 & 46 & 12 \\
\hline 3 & 48 & 13 & 46 & 12 \\
\hline 4 & 48 & 13 & 46 & 12 \\
\hline $1-1981$ & 48 & 13 & 46 & 12 \\
\hline 2 & 48 & 13 & 46 & 12 \\
\hline 3 & 48 & 13 & 46 & 12 \\
\hline 4 & 48 & 13 & 46 & 12 \\
\hline $1-1982$ & 48 & 13 & 46 & 12 \\
\hline 2 & 49 & 13 & 42 & 11 \\
\hline 3 & 49 & 13 & 42 & 11 \\
\hline 4 & 49 & 13 & 42 & 11 \\
\hline $1-1983$ & 49 & 13 & 42 & 11 \\
\hline 2 & 49 & 13 & 42 & 11 \\
\hline 3 & 49 & 13 & 42 & 11 \\
\hline 4 & 49 & 13 & 42 & 11 \\
\hline 1-1984 & 49 & 13 & 45 & 12 \\
\hline 2 & 49 & 13 & 45 & 12 \\
\hline 3 & 49 & 13 & 45 & 12 \\
\hline 4 & 49 & 13 & 45 & 12 \\
\hline 1-1985 & 49 & 13 & 45 & 12 \\
\hline 2 & 49 & 13 & 45 & 12 \\
\hline 3 & 49 & 13 & 45 & 12 \\
\hline 4 & 49 & 13 & 45 & 12 \\
\hline 1-1986 & 49 & 13 & 45 & 12 \\
\hline 2 & 49 & 13 & 45 & 12 \\
\hline 3 & 49 & 13 & 45 & 12 \\
\hline 4 & 49 & 13 & 45 & 12 \\
\hline $1-1987$ & 49 & 13 & 45 & 12 \\
\hline 2 & 49 & 13 & 45 & 12 \\
\hline 3 & 49 & 13 & 45 & 12 \\
\hline 4 & 49 & 13 & 45 & 12 \\
\hline $1-1988$ & 49 & 13 & 45 & 12 \\
\hline 2 & 49 & 13 & 45 & 12 \\
\hline 3 & 49 & $1 \overline{3}$ & 45 & 12 \\
\hline 4 & 49 & 13 & 45 & 12 \\
\hline $1-1989$ & 49 & 13 & 45 & 12 \\
\hline 2 & 49 & 13 & 45 & 12 \\
\hline 3 & 49 & 13 & 45 & 12 \\
\hline 4 & 49 & 13 & 45 & 12 \\
\hline
\end{tabular}

C-75 


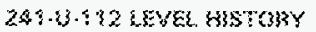

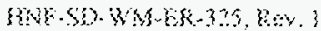

\begin{tabular}{|c|c|c|c|c|}
\hline Yoss & Tols & ratal & solus & Sulting \\
\hline & $\{k, \beta a !$ & Yoka & ix gas & (ivt) \\
\hline $3-79 s o$ & $\$ 0$ & 13 & 45 & 32 \\
\hline 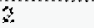 & 49 & 13 & 65 & 12 \\
\hline 3 & 30 & 53 & 45 & $1 \%$ \\
\hline 4 & 48 & 3 & 65 & 12 \\
\hline 1.3254 & 69 & 33 & 35 & 38 \\
\hline 2 & 45 & 13 & 45 & 32 \\
\hline 3 & 69 & 33 & 43 & $9 \%$ \\
\hline 4 & 48 & 3 & 65 & 32 \\
\hline 1.1932 & 49 & 33 & 43 & $1 \%$ \\
\hline 2 & 48 & 3 & 45 & 33 \\
\hline 3 & 48 & 33 & $x$ & 12 \\
\hline 4 & 43 & 3 & 45 & 32 \\
\hline $3-5933$ & 48 & 3 & 45 & 12 \\
\hline 2 & 48 & 3 & 45 & 12 \\
\hline 3 & 36 & 33 & 46 & 12 \\
\hline 4 & 43 & 33 & 48 & 12 \\
\hline $1-1996$ & $\$ s$ & 3 & 45 & 12 \\
\hline 2 & 43 & 3 & 45 & 3 \\
\hline 3 & 43 & 3 & 45 & 2 \\
\hline 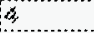 & 43 & 33 & 45 & 3 \\
\hline 4.1985 & 43 & 3 & 45 & 12 \\
\hline 2 & 43 & 3 & 55 & 32 \\
\hline 3 & 49 & 3 & 48 & 3 \\
\hline 4 & 45 & 33 & 85 & 3 \\
\hline$\$ . \$ 836$ & 49 & 8 & 45 & 3 \\
\hline 2 & 63 & 33 & 45 & 32 \\
\hline
\end{tabular}


241-U-201 LEVEL HISTORY

HNF-SD-WM-ER-325, Rev. 1

\begin{tabular}{|c|c|c|c|c|}
\hline Year & Total & Total & Solids & Solids \\
\hline & (K gal) & (in) & (K gal) & (in) \\
\hline & & & & \\
\hline \multicolumn{5}{|l|}{1.1954} \\
\hline \multicolumn{5}{|l|}{2} \\
\hline \multicolumn{5}{|l|}{3} \\
\hline \multicolumn{5}{|l|}{4} \\
\hline \multicolumn{5}{|l|}{$1-1955$} \\
\hline \multicolumn{5}{|l|}{2} \\
\hline \multicolumn{5}{|l|}{3} \\
\hline \multicolumn{5}{|l|}{4} \\
\hline $1-1956$ & 48 & 248 & & \\
\hline 2 & 48 & 248 & & \\
\hline 3 & 48 & 248 & & \\
\hline 4 & 48 & 248 & & \\
\hline 1-1957 & 48 & 248 & & \\
\hline 2 & 48 & 248 & & \\
\hline 3 & 48 & 248 & & \\
\hline 4 & 48 & 248 & & \\
\hline $1-1958$ & 48 & 248 & 0 & 0 \\
\hline 2 & 48 & 248 & 0 & 0 \\
\hline 3 & 48 & 248 & 0 & 0 \\
\hline 4 & 49 & 253 & 0 & 0 \\
\hline $1-1959$ & 49 & 253 & 0 & 0 \\
\hline 2 & 49 & 253 & 0 & 0 \\
\hline 3 & 49 & 253 & 0 & 0 \\
\hline 4 & 49 & 253 & 0 & 0 \\
\hline $1-1960$ & 49 & 253 & 0 & 0 \\
\hline 2 & 49 & 253 & 0 & 0 \\
\hline 3 & 49 & 253 & 0 & 0 \\
\hline 4 & 49 & 253 & 0 & 0 \\
\hline 1-1961 & 49 & 253 & 0 & 0 \\
\hline \multicolumn{5}{|l|}{2} \\
\hline 3 & 49 & 253 & 0 & 0 \\
\hline \multicolumn{5}{|l|}{4} \\
\hline \multicolumn{5}{|l|}{$1-1962$} \\
\hline 2 & 49 & 253 & 0 & 0 \\
\hline \multicolumn{5}{|l|}{3} \\
\hline 4 & 49 & 253 & 0 & 0 \\
\hline \multicolumn{5}{|l|}{$1-1963$} \\
\hline 2 & 49 & 253 & 0 & 0 \\
\hline \multicolumn{5}{|l|}{3} \\
\hline 4 & 49 & 253 & 0 & 0 \\
\hline \multicolumn{5}{|l|}{$1-1964$} \\
\hline 2 & 49 & 253 & 0 & 0 \\
\hline \multicolumn{5}{|l|}{3} \\
\hline 4 & 49 & 253 & 0 & 0 \\
\hline $1-1965$ & 48 & 248 & 4 & 23 \\
\hline 2 & & & & \\
\hline
\end{tabular}


2434.205 : $2 \mathrm{VE}$ MSTORY

\begin{tabular}{|c|c|c|c|c|}
\hline$Y * x\}$ & $\{\sin \}$ & nosi & Sosts & Sofis: \\
\hline & $\mathrm{x}$ gat & $\{k n\}$ & \&K gai & 46 \\
\hline & & & & \\
\hline 3 & 38 & 248 & 4 & 23 \\
\hline 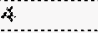 & 43 & 248 & 4 & 23 \\
\hline $7-7 \leq 60$ & 38 & 248 & 4 & 23 \\
\hline$\%$ & 43 & 208 & 4 & 23 \\
\hline 3 & 36 & 248 & 4 & 23 \\
\hline 4 & 48 & 208 & 4 & 33 \\
\hline$\{-\} \$ 00\}$ & 36 & 248 & 4 & 23 \\
\hline 2 & 48 & 268 & 6 & 23 \\
\hline 3 & $\$ 6$ & 248 & 4 & 23 \\
\hline 4 & 48 & 208 & 5 & 23 \\
\hline $1-\{988$ & 43 & 248 & 4 & 23 \\
\hline 2 & 65 & 208 & 4 & 3 \\
\hline 3 & 48 & 243 & 4 & 23 \\
\hline 4 & 86 & 283 & 4 & 23 \\
\hline$\{-\$ 366$ & xe: & 363 & 4 & 23 \\
\hline 3 & 40 & 26 & 4 & 20 \\
\hline 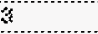 & AS & 263 & 4 & 23 \\
\hline 4 & 43 & $2 \theta$ & 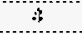 & 20 \\
\hline $3-1320$ & As & 253 & 4 & 23 \\
\hline$z$ & 43 & 25 & 4 & 20 \\
\hline 3 & $4 \mathrm{~s}$ & 253 & 6 & 23 \\
\hline 4 & 63 & 28 & 4 & 23 \\
\hline $3-3333$ & 48 & 263 & 4 & 23 \\
\hline 2 & 43 & 263 & $\$$ & 23 \\
\hline 3 & 4 & 20 & 4 & 23 \\
\hline 4 & 80 & 263 & 4 & 23 \\
\hline 1.1333 & 48 & 253 & 3 & 23 \\
\hline 2 & $\$ 8$ & 263 & 4 & 23 \\
\hline 3 & 48 & 25 & 4 & 23 \\
\hline 4 & 39 & 253 & 4 & 23 \\
\hline 1.3333 & 48 & $2 \$ 3$ & 4 & 23 \\
\hline 2 & 49 & 263 & 4 & 23 \\
\hline 3 & 48 & 253 & 3 & 23 \\
\hline 4 & $\$ 5$ & 263 & 4 & 23 \\
\hline 71334 & 48 & 283 & 4 & 23 \\
\hline 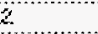 & SS: & 363 & 4 & 23 \\
\hline 3 & 43 & 28 & 3 & 23 \\
\hline 4 & 48 & 353 & 4 & 23 \\
\hline 4333 & 49 & 253 & 4 & 23 \\
\hline 2 & 46 & 263 & 4 & 23 \\
\hline 3 & 49 & 233 & 4 & 23 \\
\hline 6 & 46 & 363 & 4 & 23 \\
\hline 13376 & 49 & 253 & 4 & 23 \\
\hline 2 & $\star 9$ & 203 & 4 & 34 \\
\hline 3 & 49 & 203 & 4 & 23 \\
\hline 4 & 80 & $26 a$ & 4 & 3 \\
\hline
\end{tabular}


241-U-201 LEVEL HISTOAY

HNF-SD-WM-ER-325, Rev. 1

\begin{tabular}{|c|c|c|c|c|}
\hline Year & Total & Total & Solids & Solids \\
\hline & (K gal) & (in) & (K gal) & (in) \\
\hline $1-1977$ & 49 & 253 & 4 & 23 \\
\hline 2 & 49 & 253 & 45 & 233 \\
\hline 3 & 4 & 23 & 4 & 23 \\
\hline 4 & 4 & 23 & 4 & 23 \\
\hline 1-1978 & 4 & 23 & 4 & 23 \\
\hline 2 & 4 & 23 & 4 & 23 \\
\hline 3 & 4 & 23 & 3 & 18 \\
\hline 4 & 4 & 23 & 3 & 18 \\
\hline $1-1979$ & 4 & 23 & 3 & 18 \\
\hline 2 & 4 & 23 & 3 & 18 \\
\hline 3 & 4 & 23 & 3 & 18 \\
\hline 4 & 4 & 23 & 3 & 18 \\
\hline $1-1980$ & 4 & 23 & 3 & 18 \\
\hline 2 & 4 & 23 & 3 & 18 \\
\hline 3 & 5 & 29 & 4 & 23 \\
\hline 4 & 5 & 29 & 4 & 23 \\
\hline 1-1981 & 5 & 29 & 4 & 23 \\
\hline 2 & 5 & 29 & 4 & 23 \\
\hline 3 & 5 & 29 & 4 & 23 \\
\hline 4 & 5 & 29 & 4 & 23 \\
\hline $1-1982$ & 5 & 29 & 4 & 23 \\
\hline 2 & 5 & 29 & 4 & 23 \\
\hline 3 & 5 & 29 & 4 & 23 \\
\hline 4 & 5 & 29 & 4 & 23 \\
\hline $1-1983$ & 5 & 29 & 4 & 23 \\
\hline 2 & 5 & 29 & 4 & 23 \\
\hline 3 & 5 & 29 & 4 & 23 \\
\hline 4 & 5 & 29 & 4 & 23 \\
\hline \begin{tabular}{|l|}
$1-1984$ \\
\end{tabular} & 5 & 29 & 4 & 23 \\
\hline 2 & 5 & 29 & 4. & 23 \\
\hline 3 & 5 & 29 & 4 & 23 \\
\hline 4 & 5 & 29 & 4 & 23 \\
\hline $1-1985$ & 5 & 29 & 4 & 23 \\
\hline 2 & 5 & 29 & 4 & 23 \\
\hline 3 & 5 & 29 & 4 & 23 \\
\hline 4 & 5 & 29 & 4 & 23 \\
\hline 1-1986 & 5 & 29 & 4 & 23 \\
\hline 2 & 5 & 29 & 4 & 23 \\
\hline 3 & 5 & 29 & 4 & 23 \\
\hline 4 & 5 & 29 & 4 & 23 \\
\hline $1-1987$ & 5 & 29 & 4 & 23 \\
\hline 2 & 5 & 29 & 4 & 23 \\
\hline 3 & 5 & 29 & 4 & 23 \\
\hline 4 & 5 & 29 & 4 & 23 \\
\hline 1.1988 & 5 & 29 & 4 & 23 \\
\hline 2 & 5 & 29 & 4 & 23 \\
\hline
\end{tabular}




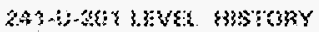

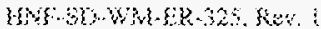

\begin{tabular}{|c|c|c|c|c|}
\hline Ysist & Tos6: & Tsks\} & $506 \%$ & Sonkits \\
\hline$\cdots$ & 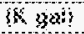 & mi & $(\mathrm{kgAl}\}$ & mi \\
\hline & & & & \\
\hline 3 & 8 & 28 & $\because$ & wa \\
\hline 4 & 6 & 23 & 4 & 28 \\
\hline $3-3 \leq \leqslant \leq 9$ & 5 & 89 & $\because$ & 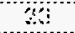 \\
\hline s. & 6 & 33 & 4 & 38 \\
\hline 3 & 5 & 28 & $a$ & wa \\
\hline 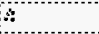 & 6 & 33 & 4 & 38 \\
\hline$x-3 s \leqslant s$ & 5 & 28 & 4 & wa \\
\hline 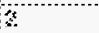 & 5 & 23 & 4 & 23 \\
\hline 3 & 5 & 29 & $a$ & $x$ \\
\hline 4 & 6 & 23 & 4 & 23 \\
\hline 3.2983 & 3 & 20 & 4 & 23 \\
\hline 2 & 5 & 23 & 4 & 23 \\
\hline 3 & 5 & 3 & 3 & 23 \\
\hline 4 & 3 & 28 & 4 & 23 \\
\hline $3.3 \mathrm{SZ}$ & 5 & 3 & 4 & 23 \\
\hline 2 & 8 & 23 & 4 & 23 \\
\hline 3 & 6 & 3 & 4 & 23 \\
\hline 4 & 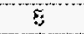 & 28 & 6 & 23 \\
\hline $3-\gamma 333$ & 6 & 3 & 4 & 23 \\
\hline 2 & $\xi$ & 63 & 4 & 23 \\
\hline 3 & 8 & 23 & 4 & 23 \\
\hline 4 & 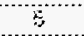 & 28 & $\theta$ & 23 \\
\hline $3-3393$ & 6 & 83 & 4 & 23 \\
\hline 2 & 5 & 8 & $\ldots$ & 36 \\
\hline 3 & 6 & 3 & 4 & 28 \\
\hline 4 & 8 & 8 & $a$ & 23 \\
\hline 1.1305 & 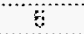 & 23 & 4 & 23 \\
\hline 2 & 8 & 19 & 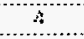 & 3 \\
\hline 3 & 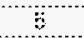 & 23 & 4 & 23 \\
\hline 8 & 8 & 38 & 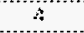 & 23 \\
\hline $1 .-\$ 998$ & 3 & 23 & 4 & 28 \\
\hline 2 & 5 & 29 & $\because$ & $\therefore$ \\
\hline
\end{tabular}


241-U-202 LEVEL HISTORY

HNF-SD-WM-ER-325, Rev. 1

\begin{tabular}{|c|c|c|c|c|}
\hline Year & Total & Total & Solids & Solids \\
\hline & (K gal) & (in) & ( $\mathrm{K}$ gal) & (in) \\
\hline \multirow{2}{*}{\multicolumn{5}{|c|}{$1-1954$}} \\
\hline & & & & \\
\hline \multicolumn{5}{|l|}{2} \\
\hline \multicolumn{5}{|l|}{3} \\
\hline \multicolumn{5}{|l|}{4} \\
\hline \multicolumn{5}{|l|}{$1-1955$} \\
\hline \multicolumn{5}{|l|}{2} \\
\hline \multicolumn{5}{|l|}{3} \\
\hline \multicolumn{5}{|l|}{4} \\
\hline 1.1956 & 51 & 263 & & \\
\hline 2 & 51 & 263 & & \\
\hline 3 & 51 & 263 & & \\
\hline 4 & 51 & 263 & & \\
\hline $1-1957$ & 51 & 263 & & \\
\hline 2 & 48 & 248 & & \\
\hline 3 & 48 & 248 & & \\
\hline 4 & 48 & 248 & & \\
\hline $1-1958$ & 48 & 248 & 0 & 0 \\
\hline 2 & 48 & 248 & 0 & 0 \\
\hline 3 & 48 & 248 & 0 & 0 \\
\hline 4 & 51 & 263 & 0 & 0 \\
\hline $1-1959$ & 51 & 263 & 0 & 0 \\
\hline 2 & 51 & 263 & 0 & 0 \\
\hline 3 & 51 & 263 & 0 & 0 \\
\hline 4 & 51 & 263 & 0 & 0 \\
\hline $1-1960$ & 51 & 263 & 0 & 0 \\
\hline 2 & 51 & 263 & 0 & 0 \\
\hline 3 & 51 & 263 & 0 & 0 \\
\hline 4 & 51 & 263 & 0 & 0 \\
\hline $1-1961$ & 51 & 263 & 0 & 0 \\
\hline \multicolumn{5}{|l|}{2} \\
\hline 3 & 51 & 263 & 0 & 0 \\
\hline \multicolumn{5}{|l|}{4} \\
\hline \multicolumn{5}{|l|}{$1-1962$} \\
\hline 2 & 51 & 263 & 0 & 0 \\
\hline \multicolumn{5}{|l|}{3} \\
\hline 4 & 51 & 263 & 0 & 0 \\
\hline \multicolumn{5}{|l|}{$1-1963$} \\
\hline 2 & 51 & 263 & 0 & 0 \\
\hline \multicolumn{5}{|l|}{3} \\
\hline 4 & 51 & 263 & 0 & 0 \\
\hline \multicolumn{5}{|l|}{$1-1964$} \\
\hline 2 & 51 & 263 & 0 & 0 \\
\hline \multicolumn{5}{|l|}{3} \\
\hline 4 & 51 & 263 & 0 & 0 \\
\hline $1-1965$ & 51 & 263 & 4 & 23 \\
\hline 2 & & & & \\
\hline
\end{tabular}


203-0-80\% LEV6 HISTORY

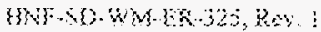

\begin{tabular}{|c|c|c|c|c|}
\hline Tsist? & 3orge & Thtos: & Solnts & Sabsts \\
\hline & $(5,32)$ & (int) & $\{\mathrm{xga}\}$ & (in) \\
\hline & & & & \\
\hline 3 & $5 !$ & 283 & 3 & 23 \\
\hline 6 & $?$ & 263 & 4 & 23 \\
\hline x-12kis & 6? & 263 & 4 & 23 \\
\hline 2 & 8 & 263 & 4 & 23 \\
\hline 3 & 61 & 283 & 3 & 23 \\
\hline 6 & 8 & 283 & 4 & 23 \\
\hline y-196\% & 3 & 263 & 4 & 33 \\
\hline 2 & 3 & 283 & 4 & 23 \\
\hline 3 & 3 & 263 & 4 & 23 \\
\hline 4 & $6 \%$ & 233 & 4 & 23 \\
\hline $136 \mathrm{D}$ & 81 & 203 & 4 & 23 \\
\hline 2 & 63 & 263 & 6 & 23 \\
\hline 3 & 53 & 233 & s & 23 \\
\hline$\$$ & 67 & 233 & 6 & 23 \\
\hline 13963 & 51 & 283 & 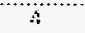 & 3 \\
\hline 2 & 51 & 233 & 4 & 23 \\
\hline 3 & 81 & 203 & 4 & 3 \\
\hline * & 67 & 233 & 4 & 23 \\
\hline 1.3533 & 51 & $28 z$ & 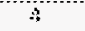 & 3 \\
\hline 2 & 51 & 63 & 4 & 23 \\
\hline 3 & 51 & $2 \theta$ & 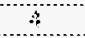 & 23 \\
\hline 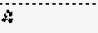 & sy & 263 & 4 & 23 \\
\hline$p-3 \leqslant\} q$ & 51 & 264 & 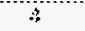 & 30 \\
\hline 3 & 59 & 263 & 4 & 23 \\
\hline 3 & $3 !$ & 26 & 4 & 23 \\
\hline 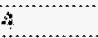 & 5 & 203 & 4 & 23 \\
\hline$\{.3 \leqslant\} 2$ & 53 & 263 & 4 & 23 \\
\hline 3 & $\xi$ & 203 & 4 & 23 \\
\hline 3 & $\$ 3$ & 26 & $\therefore$ & 23 \\
\hline 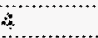 & 8 & 263 & 4 & 23 \\
\hline 3.3923 & 53 & 263 & 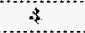 & 23 \\
\hline 2 & 8 & 203 & 4 & 23 \\
\hline 3 & 53 & 26 & 4 & 23 \\
\hline 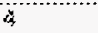 & 81 & 203 & 4 & 23 \\
\hline 1.3926 & 51 & 28 & 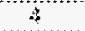 & 20 \\
\hline 2 & 81 & 203 & 4 & 23 \\
\hline 3 & 51 & 28 & 4 & 23 \\
\hline 4 & 1 & 203 & 4 & 23 \\
\hline 1.3975 & 51 & 28 & 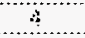 & 20 \\
\hline 2 & 81 & 233 & 4 & 23 \\
\hline 3 & 51 & 263 & 4 & 23 \\
\hline$a$ & 3 & 233 & 4 & 23 \\
\hline 1.1970 & 63 & 263 & 4 & 23 \\
\hline 2 & 64 & 233 & 6 & 23 \\
\hline 3 & 53 & 2an & s & 30 \\
\hline$x$ & 68 & 233 & 6 & 28 \\
\hline
\end{tabular}

6. 
241-U-202 LEVEL HISTORY

HNF-SD-WM-ER-325, Rev. 1

\begin{tabular}{|c|c|c|c|c|}
\hline Year & Total & Total & Solids & Solids \\
\hline & (K gal) & (in) & (K gal) & (in) \\
\hline 1.1977 & 51 & 263 & 4 & 23 \\
\hline 2 & 51 & 263 & 4 & 23 \\
\hline 3 & 4 & 23 & 4 & 23 \\
\hline 4 & 4 & 23 & 4 & 23 \\
\hline $1-1978$ & 4 & 23 & 4 & 23 \\
\hline 2 & 4 & 23 & 4 & 23 \\
\hline 3 & 4 & 23 & 3 & 18 \\
\hline 4 & 4 & 23 & 3 & 18 \\
\hline $1-1979$ & 4 & 23 & 3 & 18 \\
\hline 2 & 4 & 23 & 3 & 18 \\
\hline 3 & 4 & 23 & 3 & 18 \\
\hline 4 & 4 & 23 & 3 & 18 \\
\hline $1-1980$ & 4 & 23 & 3 & 18 \\
\hline 2 & 4 & 23 & 3 & 18 \\
\hline 3 & 5 & 29 & 4 & 23 \\
\hline 4 & 5 & 29 & 4 & 23 \\
\hline $1-1981$ & 5 & 29 & 4 & 23 \\
\hline 2 & 5 & 29 & 4 & 23 \\
\hline 3 & 5 & 29 & 4 & 23 \\
\hline 4 & 5 & 29 & 4 & 23 \\
\hline 1-1982 & 5 & 29 & 4 & 23 \\
\hline 2 & 5 & 29 & 4 & 23 \\
\hline 3 & 5 & 29 & 4 & 23 \\
\hline 4 & 5 & 29 & 4 & 23 \\
\hline 1.1983 & 5 & 29 & 4 & 23 \\
\hline 2 & 5 & 29 & 4 & 23 \\
\hline 3 & 5 & 29 & 4 & 23 \\
\hline 4 & 5 & 29 & 4 & 23 \\
\hline $1-1984$ & 5 & 29 & 4 & 23 \\
\hline 2 & 5 & 29 & 4 & 23 \\
\hline 3 & 5 & 29 & 4 & 23 \\
\hline 4 & 5 & 29 & 4 & 23 \\
\hline $1-1985$ & 5 & 29 & 4 & 23 \\
\hline 2 & 5 & 29 & 4 & 23 \\
\hline 3 & 5 & 29 & 4 & 23 \\
\hline 4 & 5 & 29 & 4 & 23 \\
\hline $1-1986$ & 5 & 29 & 4 & 23 \\
\hline 2 & 5 & 29 & 4 & 23 \\
\hline 3 & 5 & 29 & 4 & 23 \\
\hline 4 & 5 & 29 & 4 & 23 \\
\hline 1-1987 & 5 & 29 & 4 & 23 \\
\hline 2 & 5 & 29 & 4 & 23 \\
\hline 3 & 5 & 29 & 4 & 23 \\
\hline 4 & 5 & 29 & 4 & 23 \\
\hline $1-1988$ & 5 & 29 & 4 & 23 \\
\hline 2 & 5 & 29 & 4 & 23 \\
\hline
\end{tabular}




\begin{tabular}{|c|c|c|c|c|}
\hline 22 & 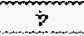 & 86 & $\bar{s}$ & 2 \\
\hline 82 & $y$ & 87 & 8 & 5851.1 \\
\hline $2 z$ & $\dot{y}$ & $8 \%$ & 3 & $\$$ \\
\hline 82 & 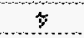 & 68 & 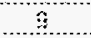 & c \\
\hline 20 & 8 & 8 & 8 & 2 \\
\hline 82 & $\forall$ & 82 & 6 & $368\}$ \\
\hline$\theta ?$ & 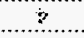 & 86 & 3 & s. \\
\hline 82 & 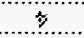 & 82 & 6 & 3 \\
\hline 28 & 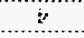 & 88 & $\bar{z}$ & $z$ \\
\hline 82 & 8 & $8 \%$ & 8 & $+6 \varepsilon_{2}-4$ \\
\hline$\varepsilon$ & $x$ & 3 & $\hat{z}$ & 6 \\
\hline $8 z$ & 3 & $8 \%$ & 8 & 5 \\
\hline$\varepsilon$ & $z$ & 31 & 6 & $z$ \\
\hline $8 z$ & $b$ & 6 & $\ddot{3}$ & $668 i-i$ \\
\hline$\theta$ & $k$ & 32 & $\hat{3}$ & 6 \\
\hline 8 & $b$ & 86 & 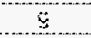 & 8 \\
\hline 8 & 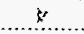 & $3 z$ & $\mathrm{~B}$ & $z$ \\
\hline$\theta$ & 6 & 86 & $\mathrm{~s}$ & $2661-8$ \\
\hline$\varepsilon$ & $y$ & $3 \%$ & 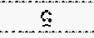 & 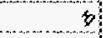 \\
\hline$\%$ & 6 & $6 z$ & 5 & 8 \\
\hline \& & 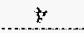 & 62 & $s$ & $z$ \\
\hline$E z$ & 6 & $8 z$ & 5 & $1684-6$ \\
\hline$\Leftrightarrow$ & $\dot{t}$ & 62 & s & 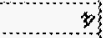 \\
\hline 22 & 6 & 67 & 3 & 8 \\
\hline$\varepsilon z$ & 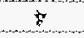 & 82 & 9 & 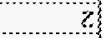 \\
\hline 82 & $t$ & 67 & 3 & $0 \& 8 k-\varepsilon$ \\
\hline$\varepsilon z$ & t. & 8 & s & 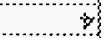 \\
\hline 82 & 8 & 62 & 3 & $\Leftrightarrow$ \\
\hline $8 z$ & $\hat{\varepsilon}$ & 82 & 9 & 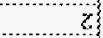 \\
\hline 82 & $y$ & 67 & 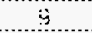 & $6 \varepsilon_{1}-4$ \\
\hline $2 z$ & 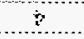 & 68 & 5 & 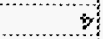 \\
\hline 82 & 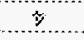 & $6 ?$ & 6 & $c$ \\
\hline & & & & \\
\hline 198 & $180 \times 3$ & 6 & $\{03\}$ & \\
\hline sples & sgyos. & 30308 & masa & सखि口 \\
\hline
\end{tabular}


241-U-203 LEVEL HISTORY

HNF-SD-WM-ER-325, Rev. 1

\begin{tabular}{|c|c|c|c|c|}
\hline Year & Total & Total & Solids & Solids \\
\hline & (K gal) & (in) & (K gal) & (in) \\
\hline \multicolumn{5}{|l|}{ 1-1954 } \\
\hline \multicolumn{5}{|l|}{2} \\
\hline \multirow{2}{*}{\multicolumn{5}{|c|}{3}} \\
\hline \multirow{2}{*}{\multicolumn{5}{|c|}{4}} \\
\hline \multirow{2}{*}{\multicolumn{5}{|c|}{ 1-1955 }} \\
\hline \multirow{2}{*}{\multicolumn{5}{|c|}{2}} \\
\hline \multirow{2}{*}{\multicolumn{5}{|c|}{3}} \\
\hline \multirow{2}{*}{\multicolumn{5}{|c|}{4}} \\
\hline & & & & \\
\hline 1-1956 & 51 & 263 & 0 & 0 \\
\hline 2 & 51 & 263 & 0 & 0 \\
\hline 3 & 51 & 263 & 0 & 0 \\
\hline 4 & 51 & 263 & 0 & 0 \\
\hline $1-1957$ & 51 & 263 & 0 & 0 \\
\hline 2 & 46 & 238 & 0 & 0 \\
\hline 3 & 46 & 238 & 0 & 0 \\
\hline 4 & 46 & 238 & 0 & 0 \\
\hline $1-1958$ & 46 & 238 & 0 & 0 \\
\hline 2 & 46 & 238 & 0 & 0 \\
\hline 3 & 46 & 238 & 0 & 0 \\
\hline 4 & 46 & 238 & 0 & 0 \\
\hline 1-1959 & 46 & 238 & 0 & 0 \\
\hline 2 & 46 & 238 & 0 & 0 \\
\hline 3 & 46 & 238 & 0 & 0 \\
\hline 4 & 46 & 238 & 0 & 0 \\
\hline $1-1960$ & 46 & 238 & 0 & 0 \\
\hline 2 & 46 & 238 & 0 & 0 \\
\hline 3 & 46 & 238 & 0 & 0 \\
\hline 4 & 46 & 238 & 0 & 0 \\
\hline $1-1961$ & 46 & 238 & 0 & 0 \\
\hline \multicolumn{5}{|l|}{2} \\
\hline 3 & 46 & 238 & 0 & 0 \\
\hline \multicolumn{5}{|l|}{4} \\
\hline \multicolumn{5}{|l|}{$1-1962$} \\
\hline 2 & 46 & 238 & 0 & 0 \\
\hline \multicolumn{5}{|l|}{3} \\
\hline 4 & 46 & 238 & 0 & 0 \\
\hline \multicolumn{5}{|l|}{$1-1963$} \\
\hline 2 & 46 & 238 & 0 & 0 \\
\hline \multicolumn{5}{|l|}{3} \\
\hline 4 & 46 & 238 & 0 & 0 \\
\hline \multicolumn{5}{|l|}{$1-1964$} \\
\hline 2 & 46 & 238 & 0 & 0 \\
\hline \multicolumn{5}{|l|}{3} \\
\hline 4 & 46 & 238 & 0 & 0 \\
\hline $1-1965$ & 46 & 238 & 4 & 23 \\
\hline 2 & & & & \\
\hline
\end{tabular}


243-43.303 6EYG HESTRY

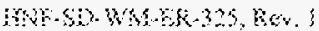

\begin{tabular}{|c|c|c|c|c|}
\hline yes & Total & Borst & Sstide & Susicss \\
\hline & w $g l l$ & sins & K $3 x !$ & $\mathrm{mi}$ \\
\hline 3 & 48 & 238 & 3 & 3 \\
\hline A & 45 & 236 & 4 & 23 \\
\hline $3-19386$ & 68 & 233 & 3 & 20 \\
\hline 2 & 45 & 238 & $a$ & 23 \\
\hline 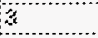 & 58 & 238 & 3 & 23 \\
\hline$\alpha$ & 48 & 238 & 4 & 23 \\
\hline $3-195 \%$ & $\Delta 6$ & 233 & 3 & 28 \\
\hline 2 & 48 & 238 & 4 & 23 \\
\hline a & $\therefore 8$ & 233 & 4 & 23 \\
\hline 4 & 48 & 230 & 4 & 23 \\
\hline $3 \cdot 3358$ & 46 & 238 & 4 & 23 \\
\hline 2 & $4 ?$ & 863 & 6 & 23 \\
\hline 3 & Ai & 243 & 4 & 23 \\
\hline 8 & 86 & 238 & 4 & 23 \\
\hline 1.3968 & 40 & 233 & 4 & 23 \\
\hline 2 & 38 & $2 s \xi$ & 4 & 33 \\
\hline 3 & 43 & 233 & 4 & 23 \\
\hline$x$ & 36 & $2 \pi$ & 4 & 33 \\
\hline $1-1930$ & 43 & 238 & 4 & 23 \\
\hline 3 & 45 & 31 & $\therefore$ & 23 \\
\hline 3 & 23 & 233 & 4 & 83 \\
\hline 4 & 40 & 210 & $A$ & 23 \\
\hline $3-393$ & 36 & 232 & 4 & 23 \\
\hline 2 & 48 & 230 & 4 & 23 \\
\hline 3 & 69 & 236 & 3 & 2 \\
\hline 6 & $4 s$ & 230 & 3 & 23 \\
\hline $3-39 \gamma z$ & 48 & 232 & 4 & 2 \\
\hline 2 & 48 & 200 & 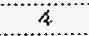 & 23 \\
\hline 3 & 46 & 232 & 3 & 3 \\
\hline 6 & 90 & 238 & 4 & 23 \\
\hline $1-\{3\}$ & 46 & 236 & 4 & $\alpha$ \\
\hline 2 & 40 & 233 & 4 & 23 \\
\hline 3 & 46 & 338 & 4 & 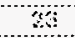 \\
\hline 3 & 38 & 238 & 4 & 23 \\
\hline $13 \% 4$ & 46 & 238 & 4 & 2 \\
\hline 3 & 38 & 336 & 4 & 23 \\
\hline 3 & 43 & 238 & 4 & 23 \\
\hline \$ & 46 & 236 & 4 & 23 \\
\hline $3.12 \% 5$ & 43 & 238 & 4 & 23 \\
\hline 2 & 36 & 233 & 3 & 23 \\
\hline 3 & 48 & 238 & 4 & 23 \\
\hline 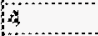 & 46 & $23 \mathrm{x}$ & s & 23 \\
\hline $1-3 \mathrm{~s} \%$ & 40 & 233 & 4 & 23 \\
\hline 3 & $\$ 6$ & 234 & 3 & 23 \\
\hline 3 & 45 & 2333 & 6 & 23 \\
\hline 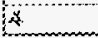 & 86 & $3 \Leftrightarrow$ & 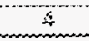 & 23 \\
\hline
\end{tabular}


241-U-203 LEVEL HISTORY

HNF-SD-WM-ER-325, Rev. 1

\begin{tabular}{|c|c|c|c|c|}
\hline Year & Total & Total & Solids & Solids \\
\hline & (K gal) & (in) & (K gal) & (in) \\
\hline $1-1977$ & 46 & 238 & 4 & 23 \\
\hline 2 & 46 & 238 & 4 & 23 \\
\hline 3 & 4 & 23 & 4 & 23 \\
\hline 4 & 3 & 18 & 3 & 18 \\
\hline $1-1978$ & 3 & 18 & 3 & 18 \\
\hline 2 & 3 & 18 & 3 & 18 \\
\hline 3 & 3 & 18 & 2 & 13 \\
\hline 4 & 3 & 18 & 2 & 13 \\
\hline $1-1979$ & 3 & 18 & 2 & 13 \\
\hline 2 & 3 & 18 & 2 & 13 \\
\hline 3 & 3 & 18 & 2 & 13 \\
\hline 4 & 3 & 18 & 2 & 13 \\
\hline $1-1980$ & 3 & 18 & 2 & 13 \\
\hline 2 & 3 & 18 & 2 & 13 \\
\hline 3 & 3 & 18 & 2 & 13 \\
\hline 4 & 3 & 18 & 2 & 13 \\
\hline $1-1981$ & 3 & 18 & 2 & 13 \\
\hline 2 & 3 & 18 & 2 & 13 \\
\hline 3 & 3 & 18 & 2 & 13 \\
\hline 4 & 3 & 18 & 2 & 13 \\
\hline $1-1982$ & 3 & 18 & 2 & 13 \\
\hline 2 & 3 & 18 & 2 & 13 \\
\hline 3 & 3 & 18 & 2 & 13 \\
\hline 4 & 3 & 18 & 2 & 13 \\
\hline $1-1983$ & 3 & 18 & 2 & 13 \\
\hline 2 & 3 & 18 & 2 & 13 \\
\hline 3 & 3 & 18 & 2 & 13 \\
\hline 4 & 3 & 18 & 2 & 13 \\
\hline $1-1984$ & 3 & 18 & 2 & 13 \\
\hline 2 & 3 & 18 & 2 & 13 \\
\hline 3 & 3 & 18 & 2 & 13 \\
\hline 4 & 3 & 18 & 2 & 13 \\
\hline $1-1985$ & 3 & 18 & 2 & 13 \\
\hline 2 & 3 & 18 & 2 & 13 \\
\hline 3 & 3 & 18 & 2 & 13 \\
\hline 4 & 3 & 18 & 2 & 13 \\
\hline $1-1986$ & 3 & 18 & 2 & 13 \\
\hline 2 & 3 & 18 & 2 & 13 \\
\hline 3 & 3 & 18 & 2 & 13 \\
\hline 4 & 3 & 18 & 2 & 13 \\
\hline $1-1987$ & 3 & 18 & 2 & 13 \\
\hline 2 & 3 & 18 & 2 & 13 \\
\hline 3 & 3 & 18 & 2 & 13 \\
\hline 4 & 3 & 18 & 2 & 13 \\
\hline $1-1988$ & 3 & 18 & 2 & 13 \\
\hline 2 & 3 & 18 & 2 & 13 \\
\hline
\end{tabular}




\begin{tabular}{|c|c|c|c|c|}
\hline$\varepsilon l$ & 6 & 51 & 8 & $z$ \\
\hline 81 & $z$ & $6 \mathrm{i}$ & $\hat{8}$ & $965 \mathrm{~s} \cdot 3$ \\
\hline$E 6$ & 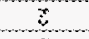 & $\$$ & $\varepsilon$ & 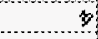 \\
\hline 81 & 7 & $\theta$ & f & 5 \\
\hline ol & $z$ & $8:$ & $\xi$ & $z$ \\
\hline$\varepsilon 1$ & 7 & 6 & $\hat{8}$ & 9686 \\
\hline $0 i$ & 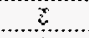 & 8 & $\varepsilon$ & $\geqslant$ \\
\hline$\varepsilon !$ & $?$ & 9 & $\hat{8}$ & 3 \\
\hline et & 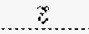 & $8:$ & $\varepsilon$ & 6 \\
\hline $8:$ & $?$ & $9:$ & $\theta$ & $\$ 8 \varepsilon k-\varepsilon$ \\
\hline Q & 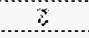 & 81 & $\varepsilon$ & $\gamma$ \\
\hline 82 & $z$ & 85 & 8 & 2 \\
\hline 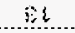 & 2 & 81 & $\varepsilon$ & $z$ \\
\hline 82 & 6 & 85 & 8 & $8888-1$ \\
\hline Et & 2 & 21 & $\varepsilon$ & 7 \\
\hline 81 & 6 & $8:$ & $\bar{\varepsilon}$ & $\varepsilon$ \\
\hline is & $\therefore$ & $8:$ & $\varepsilon$ & $z$ \\
\hline 83 & 6 & $8:$ & $\bar{E}$ & $2888-3$ \\
\hline 83 & 2 & $2:$ & 2 & $?$ \\
\hline 8 & $z$ & $8:$ & $E$ & $\varepsilon$ \\
\hline 85 & 2 & 61 & $\therefore$ & 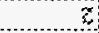 \\
\hline 81 & $z$ & $8:$ & 8 & $3658-3$ \\
\hline 53 & $\vec{c}$ & 88 & 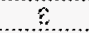 & 6 \\
\hline 21 & $z$ & 86 & 8 & $\varepsilon$ \\
\hline $8:$ & 2 & 89 & 8 & $\because$ \\
\hline 21 & $z$ & 38 & 8 & $6035\}$ \\
\hline $5:$ & 2 & $a !$ & $\varepsilon$ & 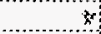 \\
\hline $8:$ & $z$ & $3 i$ & 8 & $\varepsilon$ \\
\hline $5:$ & 8 & $\theta k$ & $\varepsilon$ & 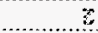 \\
\hline$\varepsilon$ & $z$ & $3 i$ & $\theta$ & ESOS- \\
\hline E & $z$ & 84 & $\Leftrightarrow$ & 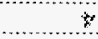 \\
\hline $8 !$ & $?$ & $3 \xi$ & $\hat{z}$ & 6 \\
\hline & & & & \\
\hline$\{6\}$ & mes $y$ & $\$ s$ & $300 \times 6$ & \\
\hline s\}yos & sososs & mol & mol & we \\
\hline
\end{tabular}


241-U-204 LEVEL HISTORY

\begin{tabular}{|c|c|c|c|c|}
\hline Year & Total & Total & Solids & Solids \\
\hline & (K gal) & (in) & (K gal) & (in) \\
\hline $1-1954$ & 35 & 182 & & \\
\hline 2 & 35 & 182 & & \\
\hline 3 & 35 & 182 & & \\
\hline 4 & 35 & 182 & & \\
\hline 1-1955 & 35 & 182 & & \\
\hline 2 & 35 & 182 & & \\
\hline 3 & 35 & 182 & & \\
\hline 4 & 35 & 182 & & \\
\hline $1-1956$ & 35 & 182 & & \\
\hline 2 & 53 & 273 & & \\
\hline 3 & 53 & 273 & & \\
\hline 4 & 53 & 273 & & \\
\hline $1-1957$ & 53 & 273 & & \\
\hline 2 & 51 & 263 & & \\
\hline 3 & 51 & 263 & & \\
\hline 4 & 51 & 263 & & \\
\hline $1-1958$ & 51 & 263 & 0 & 0 \\
\hline 2 & 51 & 263 & 0 & 0 \\
\hline 3 & 51 & 263 & 0 & 0 \\
\hline 4 & 51 & 263 & 0 & 0 \\
\hline 1.1959 & 51 & 263 & 0 & 0 \\
\hline 2 & 51 & 263 & 0 & 0 \\
\hline 3 & 51 & 263 & 0 & 0 \\
\hline 4 & 50 & 258 & 0 & 0 \\
\hline $1-1960$ & 50 & 258 & 0 & 0 \\
\hline 2 & 50 & 258 & 0 & 0 \\
\hline 3 & 50 & 258 & 0 & 0 \\
\hline 4 & 50 & 258 & 0 & 0 \\
\hline $1-1961$ & 50 & 258 & 0 & 0 \\
\hline \multicolumn{5}{|l|}{2} \\
\hline 3 & 50 & 258 & 0 & 0 \\
\hline \multicolumn{5}{|l|}{4} \\
\hline \multicolumn{5}{|l|}{$1-1962$} \\
\hline 2 & 50 & 258 & 0 & 0 \\
\hline \multicolumn{5}{|l|}{3} \\
\hline 4 & 50 & 258 & 0 & 0 \\
\hline \multicolumn{5}{|l|}{$1-1963$} \\
\hline 2 & 50 & 258 & 0 & 0 \\
\hline \multicolumn{5}{|l|}{3} \\
\hline 4 & 50 & 258 & 0 & 0 \\
\hline \multicolumn{5}{|l|}{$1-1964$} \\
\hline 2 & 50 & 258 & 0 & 0 \\
\hline \multicolumn{5}{|l|}{3} \\
\hline 4 & 50 & 258 & 0 & 0 \\
\hline $1-1965$ & 51 & 263 & 1 & 8 \\
\hline 2 & & & & \\
\hline
\end{tabular}




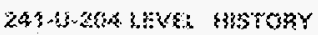

\begin{tabular}{|c|c|c|c|c|}
\hline Yese & Tnost & Totss: & Somsss & Snoss \\
\hline & $\beta 3$ soi & (kit) & 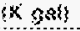 & $\mathrm{kn}$ \\
\hline & & & & \\
\hline 3 & $3 !$ & 28 & $\because$ & 8 \\
\hline 4 & $3 !$ & 283 & $\because$ & 3 \\
\hline $1.7 \$ \$ 6$ & $6 !$ & 283 & 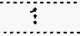 & 8 \\
\hline 2 & 31 & 286 & 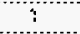 & 3 \\
\hline 3 & 51 & 283 & $\dddot{u}$ & 8 \\
\hline 4 & 73 & 283 & 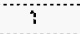 & 3 \\
\hline$\{-\{\$ \$\}$ & 51 & 283 & 3 & $\because$ \\
\hline 2 & $8\}$ & 8 & 3 & 8 \\
\hline 3 & 5 & 253 & $\xi$ & 3 \\
\hline 4 & 81 & $8 \mathrm{~s}$ & $?$ & 8 \\
\hline 5.7509 & 51 & 253 & 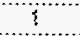 & 3 \\
\hline 2 & 51 & $2 a$ & $?$ & 8 \\
\hline 3 & 58 & 253 & $\xi$ & 6 \\
\hline 4 & 31 & 28 & 1 & 8 \\
\hline $3+8360$ & 81 & 203 & 3 & 8 \\
\hline 3 & $5 !$ & 263 & 3 & 8 \\
\hline 3 & $\xi$ & 283 & 3 & 8 \\
\hline 8 & 53 & 263 & $?$ & 8 \\
\hline 3.1370 & $8 !$ & 203 & 1 & 6 \\
\hline 2 & 51 & 263 & 1 & 3 \\
\hline 3 & $5 !$ & 283 & 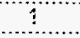 & 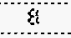 \\
\hline 4 & 51 & 263 & $\because$ & 3 \\
\hline 3.13$\} 1$ & $5 !$ & 283 & 3 & $\theta$ \\
\hline$z$ & $5 !$ & 883 & 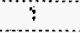 & 3 \\
\hline 3 & $5 !$ & 263 & 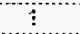 & $\because$ \\
\hline 4 & $5 !$ & 263 & $\because$ & 3 \\
\hline $1 \cdot 9932$ & $5 !$ & 289 & 3 & 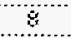 \\
\hline$z$ & 53 & 263 & $i$ & 3 \\
\hline 3 & $5 ?$ & 239 & 1 & 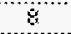 \\
\hline 8 & 53 & $88 \mathrm{~s}$ & $\dddot{u}$ & 3 \\
\hline $19 \$ 33$ & $3 !$ & 28 & 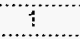 & 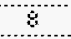 \\
\hline$z$ & 53 & tss & 1 & 3 \\
\hline 3 & 38 & 253 & 4 & 4 \\
\hline 4 & 83 & 86 & 1 & 6 \\
\hline $1-987 \not$ & 81 & 233 & 4 & 8 \\
\hline 2 & 5 & $78 \mathrm{~s}$ & $i$ & 3 \\
\hline 3 & 38 & 253 & 4 & 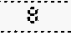 \\
\hline 8 & 53 & 283 & $\because$ & 3 \\
\hline $1-\$ 98$ & $5 ?$ & 263 & 4 & 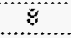 \\
\hline$z$ & 5 & 88 & 9 & 3 \\
\hline 3 & $5 !$ & 213 & 4 & 8 \\
\hline 3 & 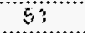 & 863 & $\because$ & 3 \\
\hline $10 \%$ & $\$$ & 238 & 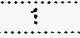 & 8 \\
\hline$z$ & 51 & 283 & $\because$ & 3 \\
\hline 3 & $5 !$ & 283 & $\vdots$ & 8 \\
\hline 4 & 51 & 263 & 3 & 8 \\
\hline
\end{tabular}


HNF-SD-WM-ER-325, Rev. 1

241-U-204 LEVEL HISTORY

\begin{tabular}{|c|c|c|c|c|}
\hline Year & Total & Total & Solids & Solids \\
\hline & (K gal) & (in) & (K gal) & (in) \\
\hline $1-1977$ & 51 & 263 & 1 & 8 \\
\hline 2 & 51 & 263 & 1 & 8 \\
\hline 3 & 2 & 13 & 2 & 13 \\
\hline 4 & 2 & 13 & 2 & 13 \\
\hline $1-1978$ & 2 & 13 & 2 & 13 \\
\hline 2 & 2 & 13 & 2 & 13 \\
\hline 3 & 2 & 13 & 1 & 8 \\
\hline 4 & 2 & 13 & 1 & 8 \\
\hline 1-1979 & 2 & 13 & 1 & 8 \\
\hline 2 & 2 & 13 & 1 & 8 \\
\hline 3 & 2 & 13 & 1 & 8 \\
\hline 4 & 2 & 13 & 1 & 8 \\
\hline $1-1980$ & 2 & 13 & 1 & 8 \\
\hline 2 & 2 & 13 & 1 & 8 \\
\hline 3 & 2 & 13 & 1 & 8 \\
\hline 4 & 2 & 13 & 1 & 8 \\
\hline 1-1981 & 3 & 18 & 2 & 13 \\
\hline 2 & 3 & 18 & 2 & 13 \\
\hline 3 & 3 & 18 & 2 & 13 \\
\hline 4 & 3 & 18 & 2 & 13 \\
\hline $1-1982$ & 3 & 18 & 2 & 13 \\
\hline 2 & 3 & 18 & 2 & 13 \\
\hline 3 & 3 & 18 & 2 & 13 \\
\hline 4 & 3 & 18 & 2 & 13 \\
\hline 1-1983 & 3 & 18 & 2 & 13 \\
\hline 2 & 3 & 18 & 2 & 13 \\
\hline 3 & 3 & 18 & 2 & 13 \\
\hline 4 & 3 & 18 & 2 & 13 \\
\hline 1-1984 & 3 & 18 & 2 & 13 \\
\hline 2 & 3 & 18 & 2 & 13 \\
\hline 3 & 3 & 18 & 2 & 13 \\
\hline 4 & 3 & 18 & 2 & 13 \\
\hline 1.1985 & 3 & 18 & 2 & 13 \\
\hline 2 & 3 & 18 & 2 & 13 \\
\hline 3 & 3 & 18 & 2 & 13 \\
\hline 4 & 3 & 18 & 2 & 13 \\
\hline $1-1986$ & 3 & 18 & 2 & 13 \\
\hline 2 & 3 & 18 & 2 & 13 \\
\hline 3 & 3 & 18 & 2 & 13 \\
\hline 4 & 3 & 18 & 2 & 13 \\
\hline $1-1987$ & 3 & 18 & 2 & 13 \\
\hline 2 & 3 & 18 & 2 & 13 \\
\hline 3 & 3 & 18 & 2 & 13 \\
\hline 4 & 3 & 18 & 2 & 13 \\
\hline $1-1988$ & 3 & 18 & 2 & 13 \\
\hline 2 & 3 & 18 & 2 & 13 \\
\hline
\end{tabular}


243-33.204 6EY\& HETORY

\begin{tabular}{|c|c|c|c|c|}
\hline$Y \cos x$ & Toral & उकo & 3olicis & Onfids \\
\hline & \& \&sil & kns & H gis: & iss? \\
\hline & & & & \\
\hline 3 & 3 & 13 & 2 & 13 \\
\hline 4 & 3 & 88 & 2 & 13 \\
\hline $3-\gamma 3 \$ s$ & 3 & 3 & 2 & 33 \\
\hline 2 & 3 & 8 & 2 & 83 \\
\hline 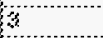 & $\ddot{3}$ & 3 & 2 & 33 \\
\hline 3 & 3 & 3 & 2 & 13 \\
\hline $3-\gamma 330$ & 3 & 8 & 2 & 33 \\
\hline$z$ & 3 & 3 & 2 & 33 \\
\hline 3 & 3 & : & 2 & 33 \\
\hline$s$ & 3 & 38 & 2 & 83 \\
\hline 10.393 & 3 & 38 & 2 & 33 \\
\hline$z$ & 3 & 12 & 2 & 33 \\
\hline 3 & 3 & 8 & $z$ & 13 \\
\hline 13 & 3 & 36 & 2 & 43 \\
\hline 1.9932 & 3 & 38 & 2 & 3 \\
\hline$\vec{z}$ & 3 & 36 & 2 & 3 \\
\hline 3 & 3 & 8 & $\ddot{z}$ & 3 \\
\hline 4 & 3 & 38 & 2 & 3 \\
\hline $1 . \$ \$ \$ 3$ & 3 & 18 & 2 & 13 \\
\hline 2 & 3 & 18 & s. & 3 \\
\hline 3 & 3 & 3 & 2 & 3 \\
\hline 4 & 3 & 18 & 2 & 3 \\
\hline$p-333 A$ & 3 & 3 & 2 & 33 \\
\hline 2 & 3 & 8 & 2 & 83 \\
\hline 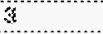 & 3 & 3 & 2 & 13 \\
\hline 4 & 3 & 3 & 2 & 13 \\
\hline $7-339 a$ & 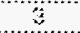 & 3 & 2 & 13 \\
\hline 2 & 3 & 3 & 2 & 13 \\
\hline 3 & 3 & 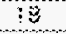 & 2 & 33 \\
\hline 6 & 3 & 3 & 2 & 73 \\
\hline z. 1386 & 3 & 0 & 2 & 33 \\
\hline 2 & 3 & $\therefore 3$ & 2 & 13 \\
\hline
\end{tabular}




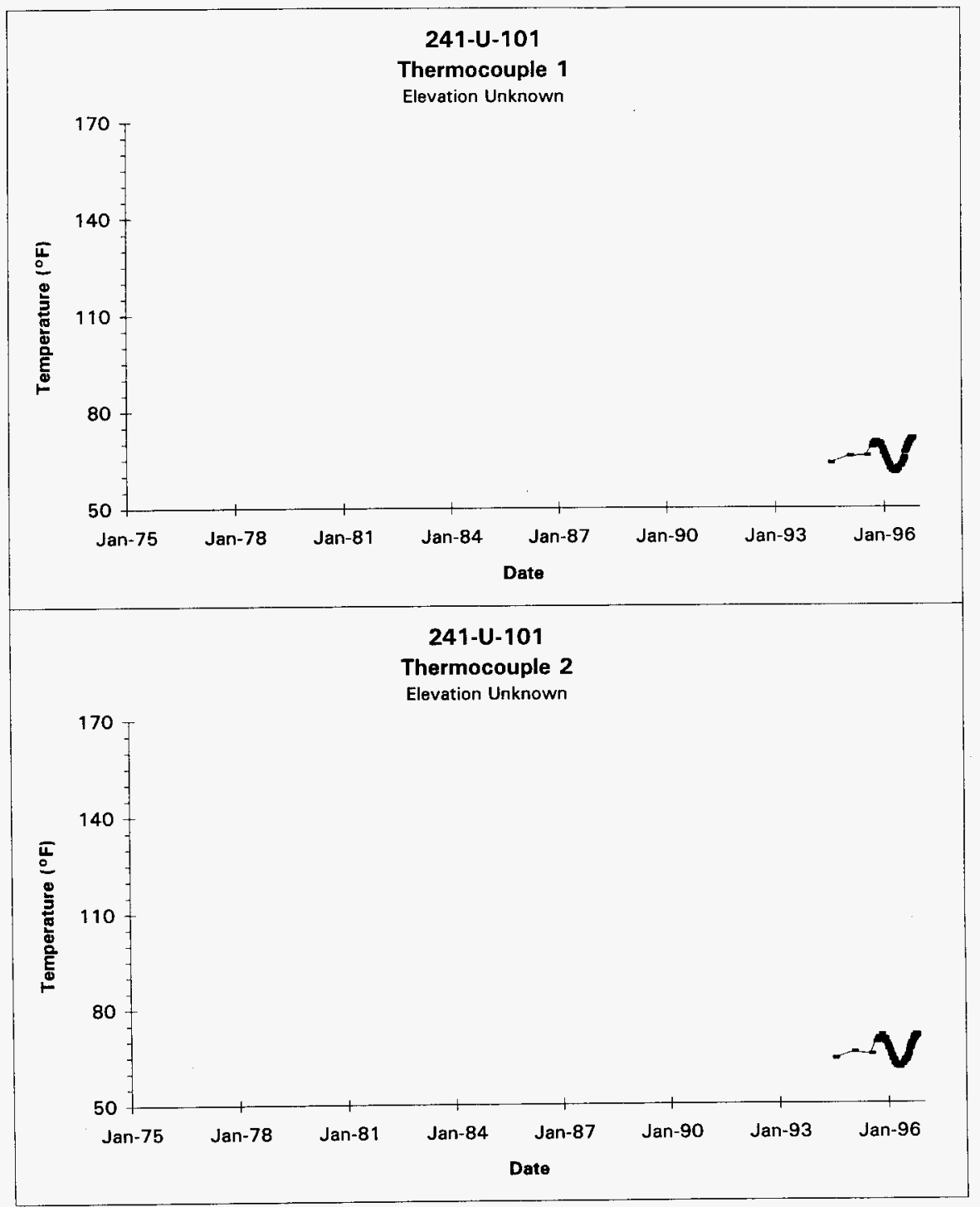

Data obtained from LMHC Surveillance Analysis Computer System (SACS), Oct 2, 1996.

D-1 


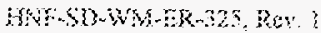

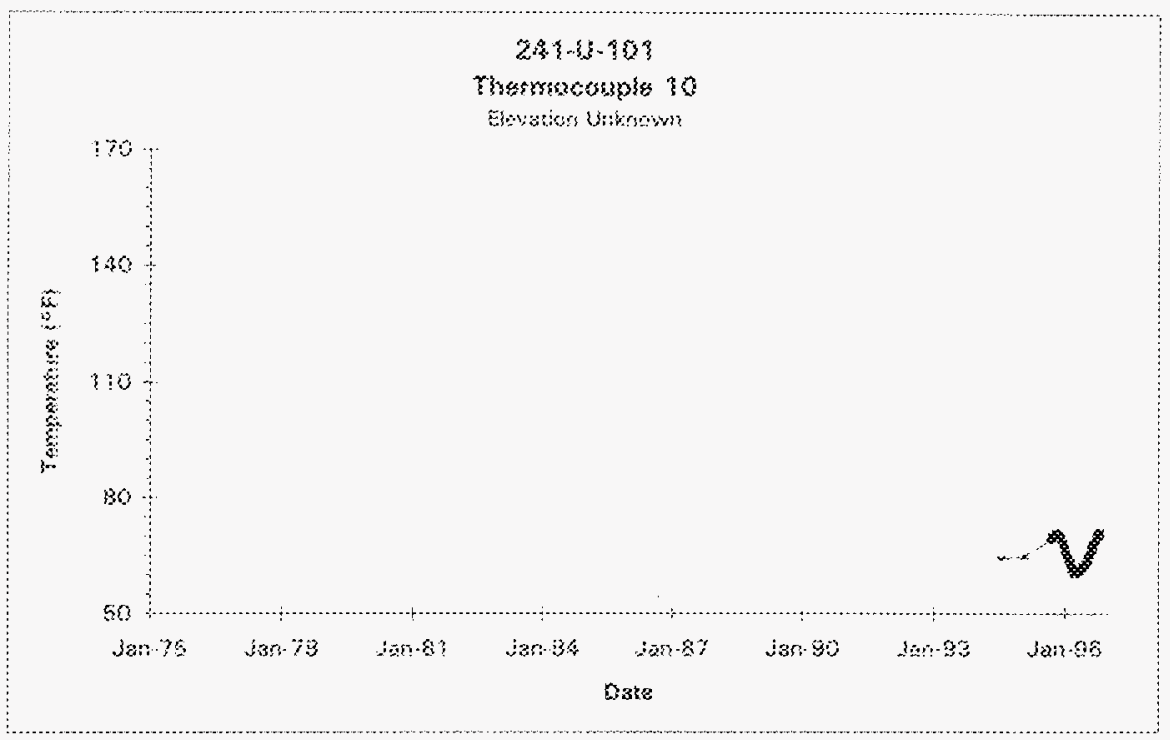

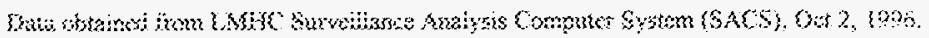
n. 2 


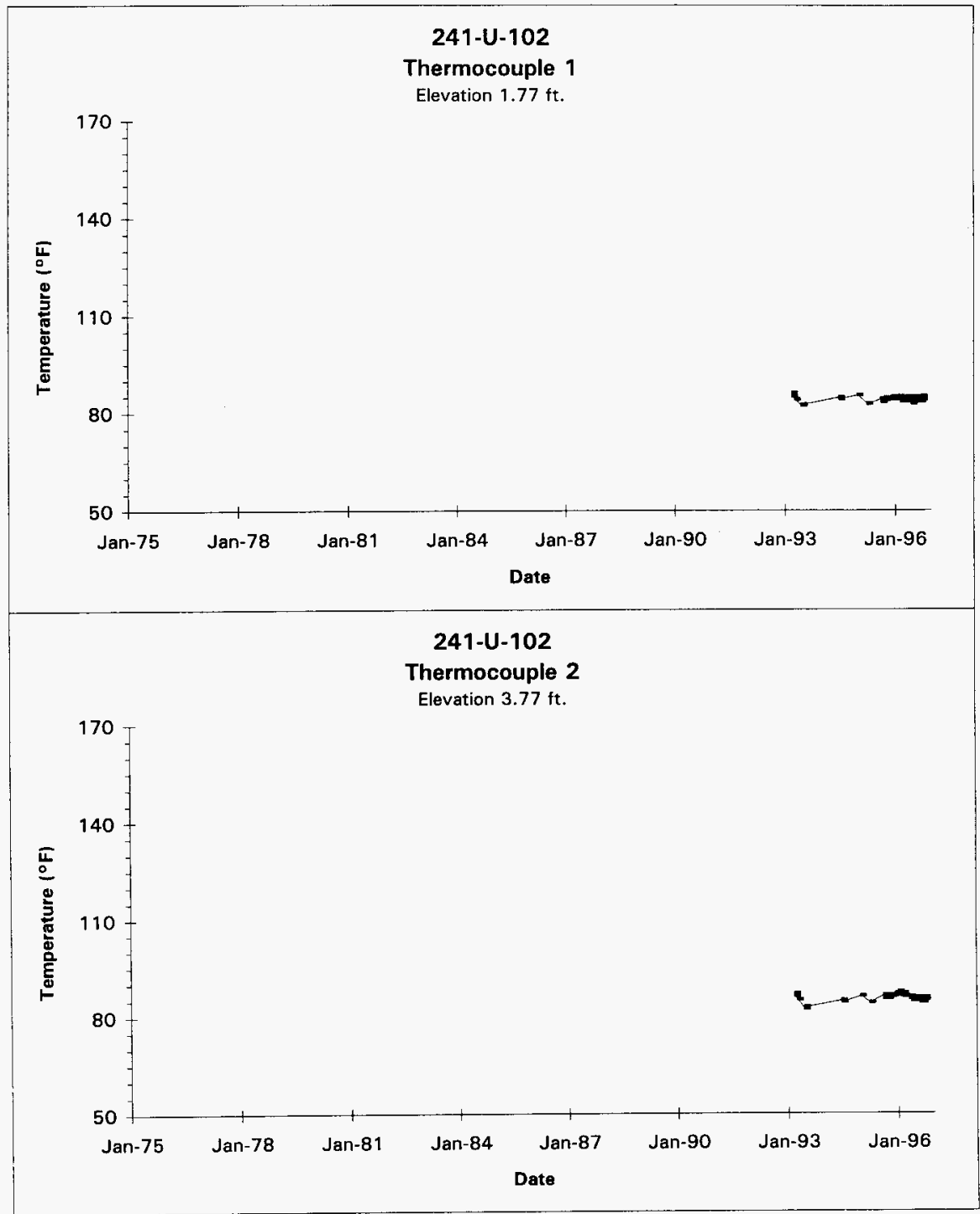

Data obtained from LMHC Surveillance Analysis Computer System (SACS), Oct 2, 1996.

D-3 


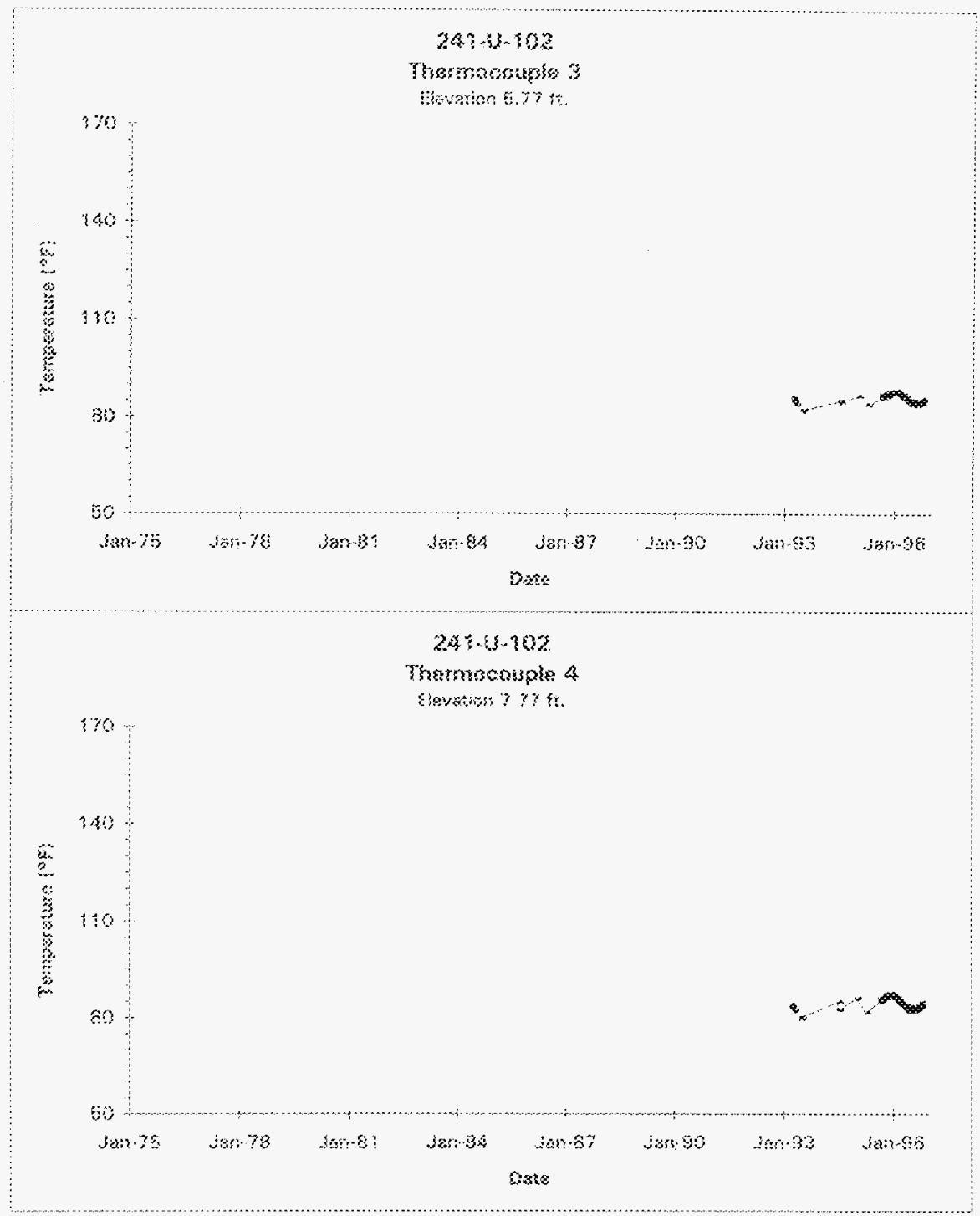

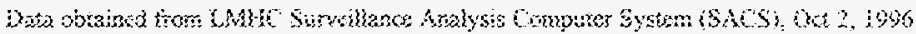
ons 
HNF-SD-WM-ER-325, Rev. 1

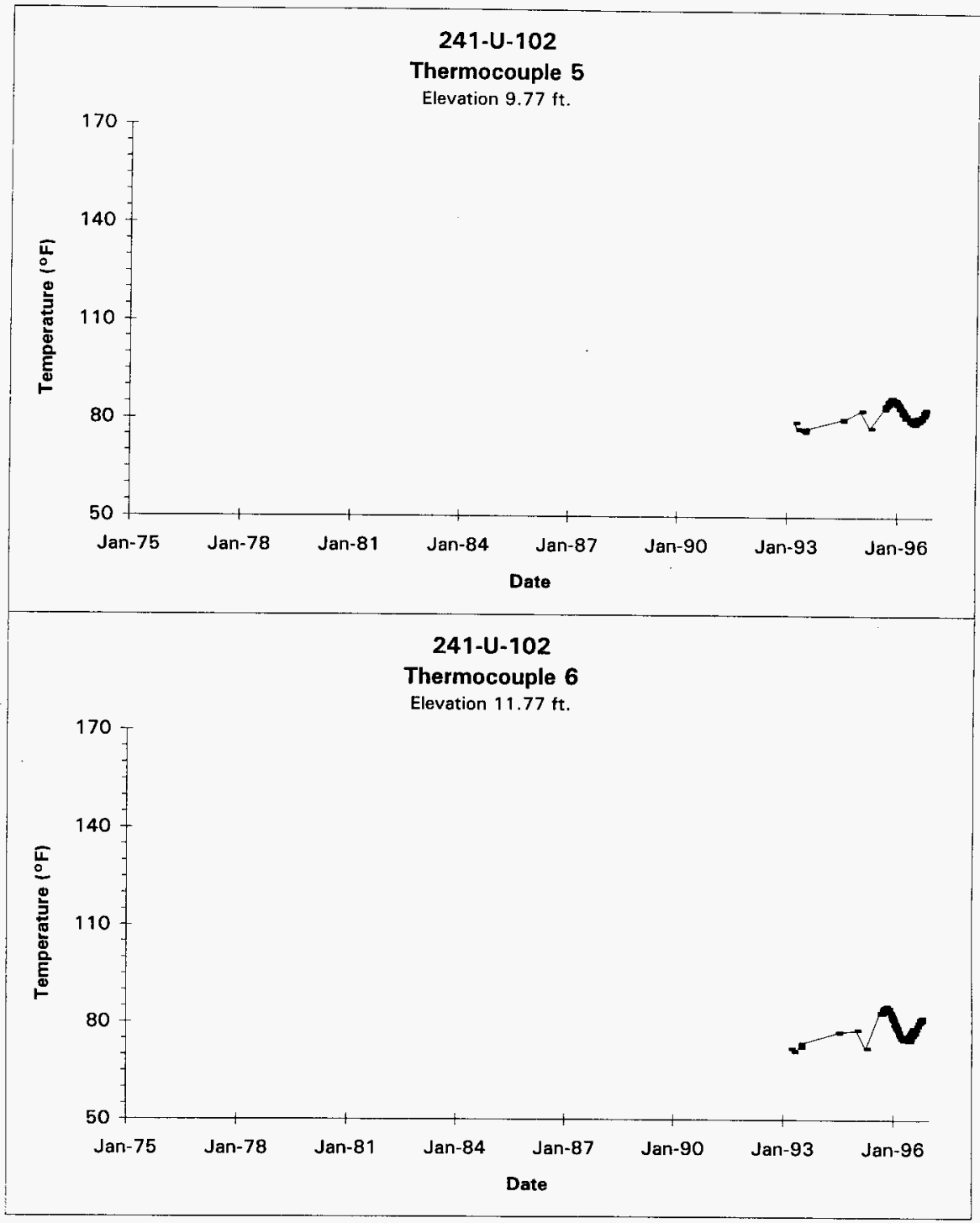

Data obtained from LMHC Surveillance Analysis Computer System (SACS), Oct 2, 1996.

D-5 


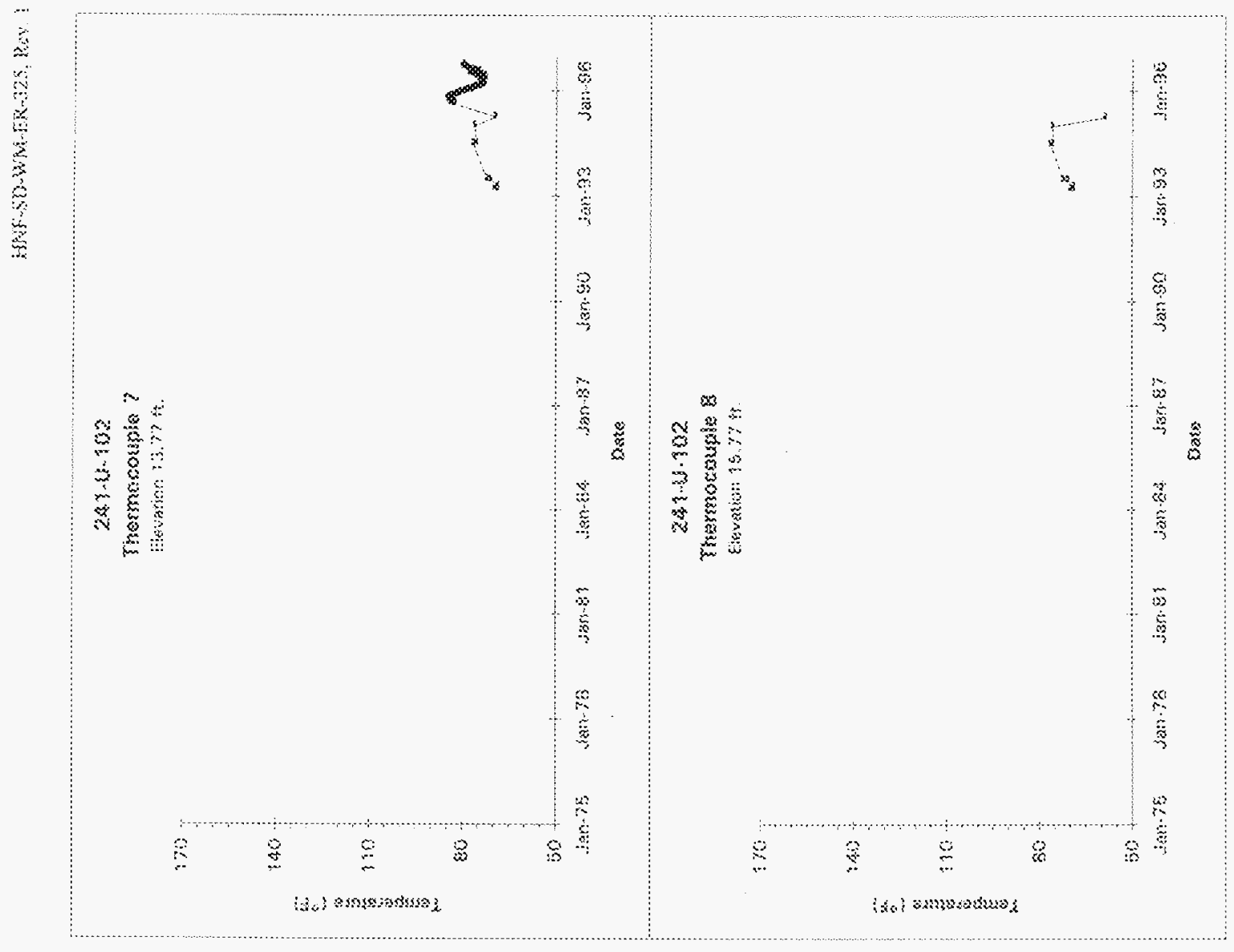

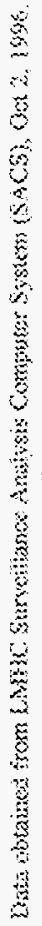




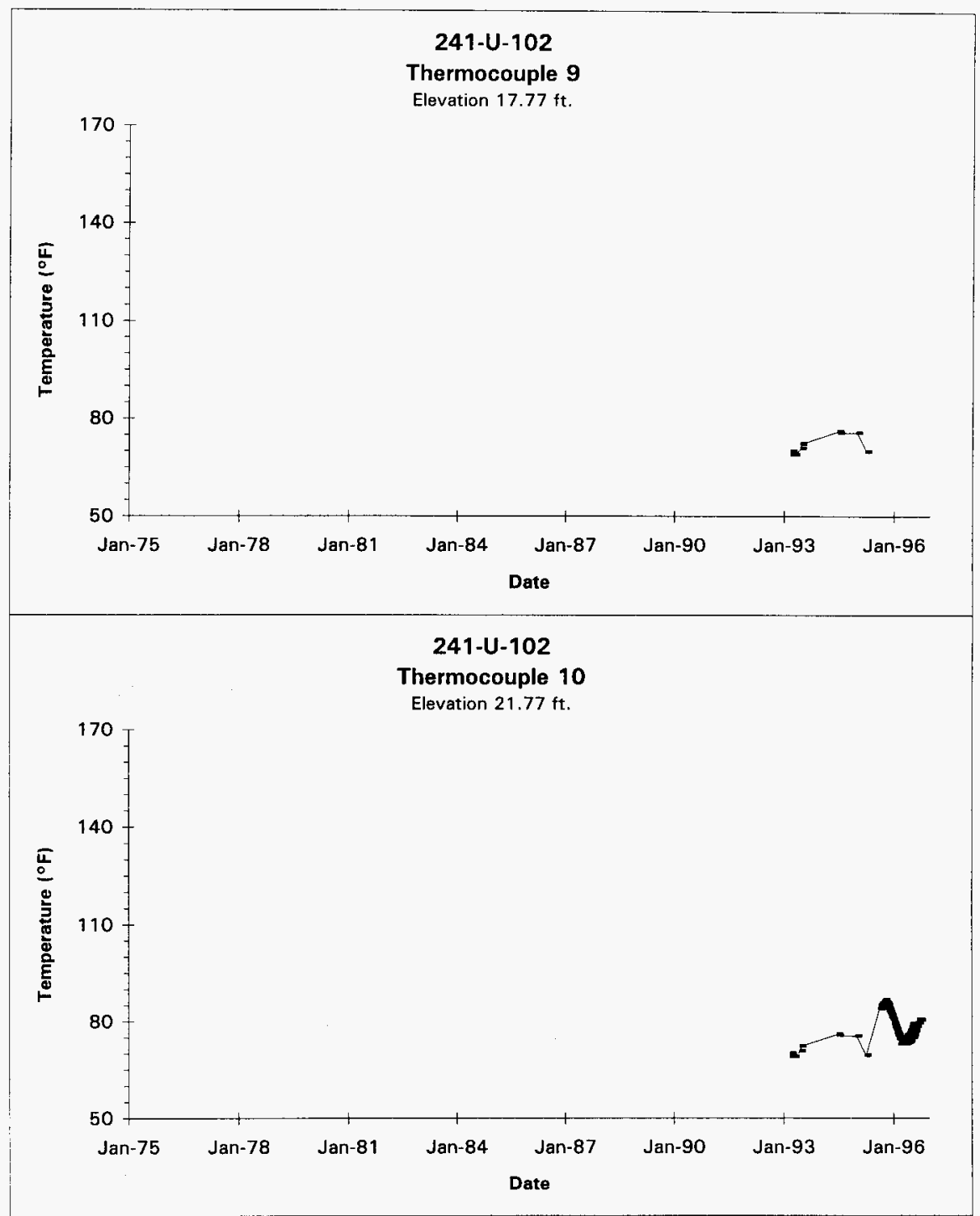

Data obtained from LMHC Surveillance Analysis Computer System (SACS), Oct 2, 1996.

D-7 


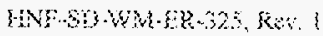

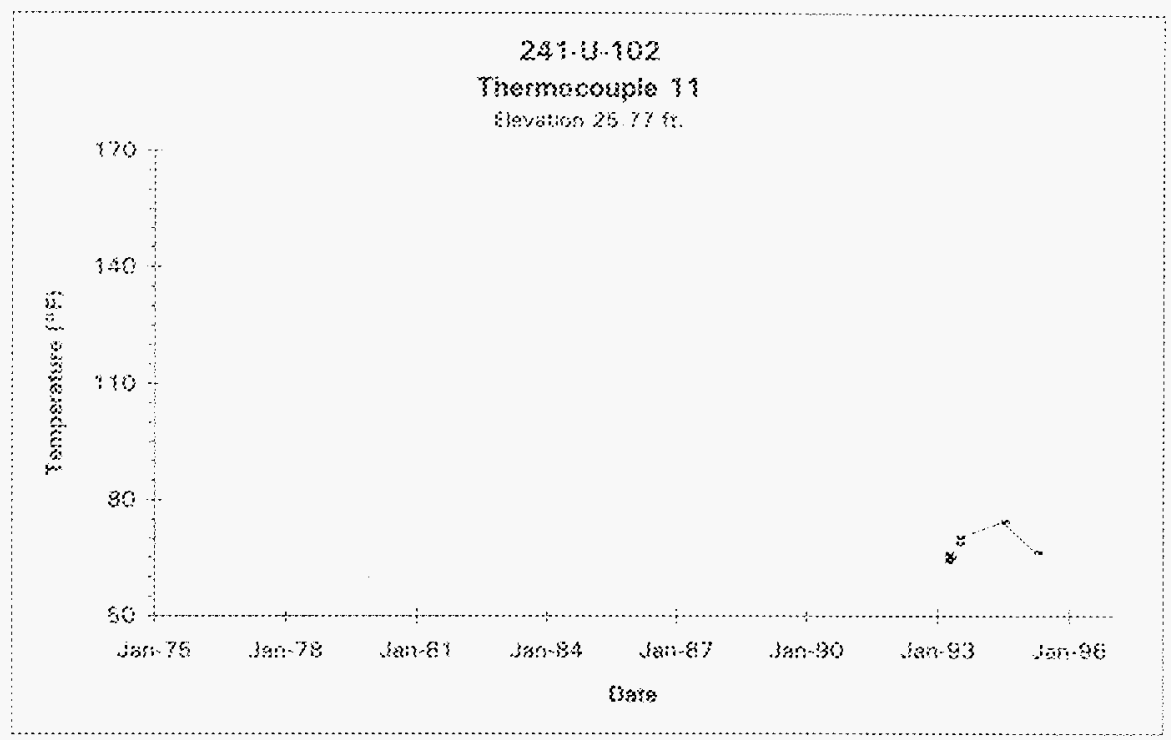

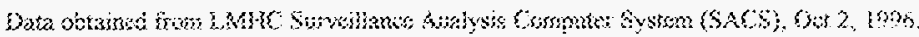




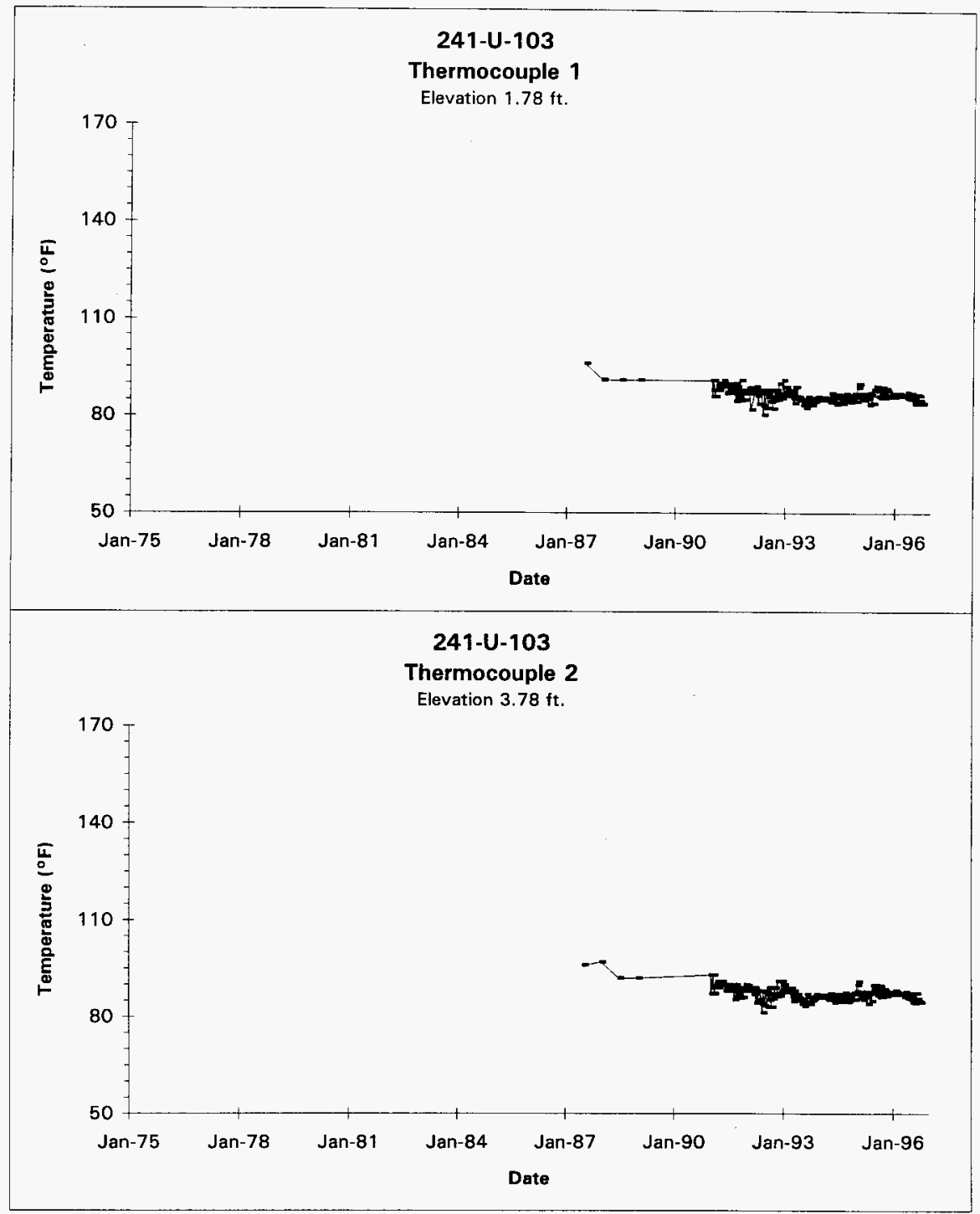

Data obtained from LMHC Surveillance Analysis Computer System (SACS), Oct 2, 1996.

D-9 


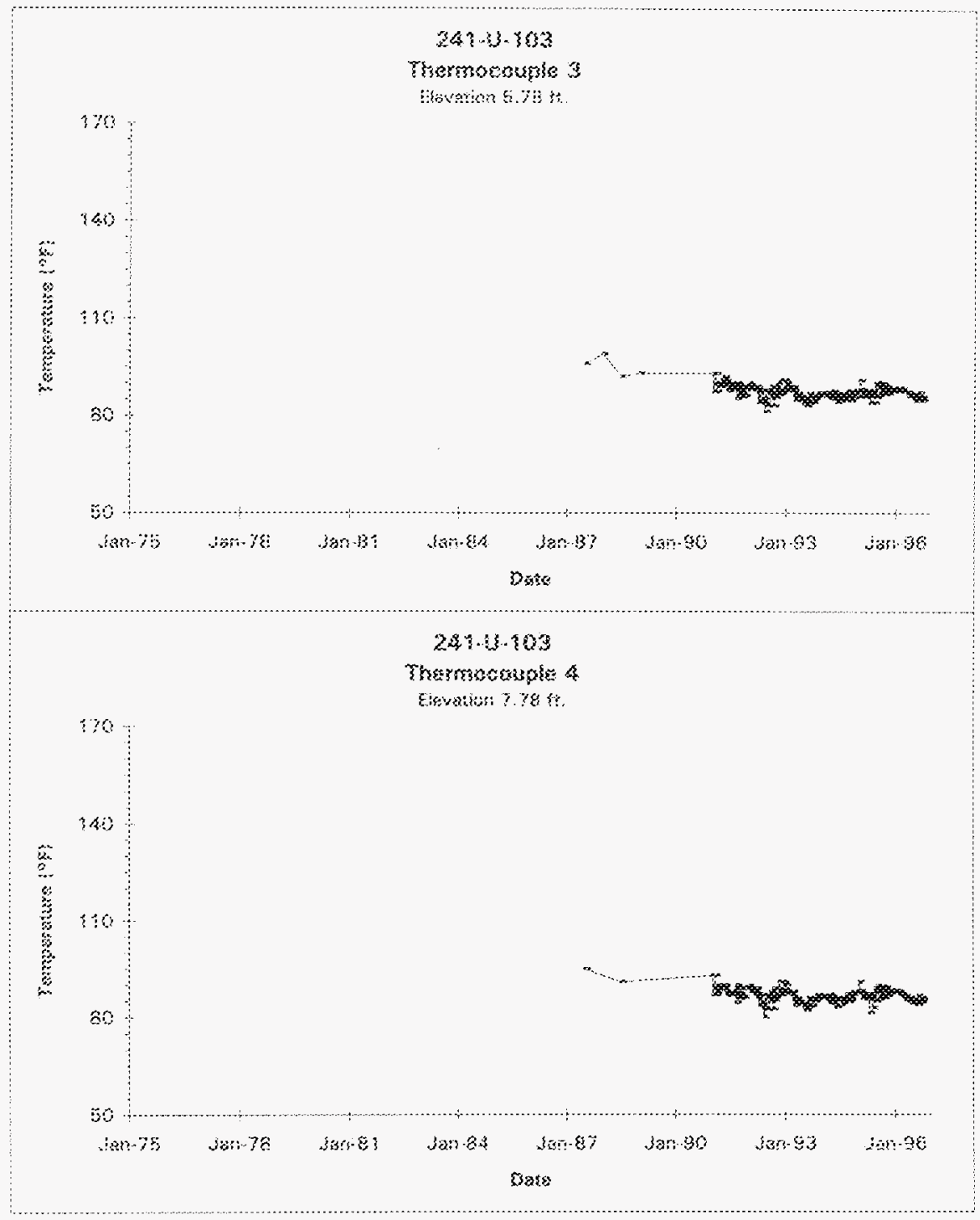

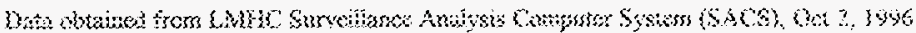
3.30 


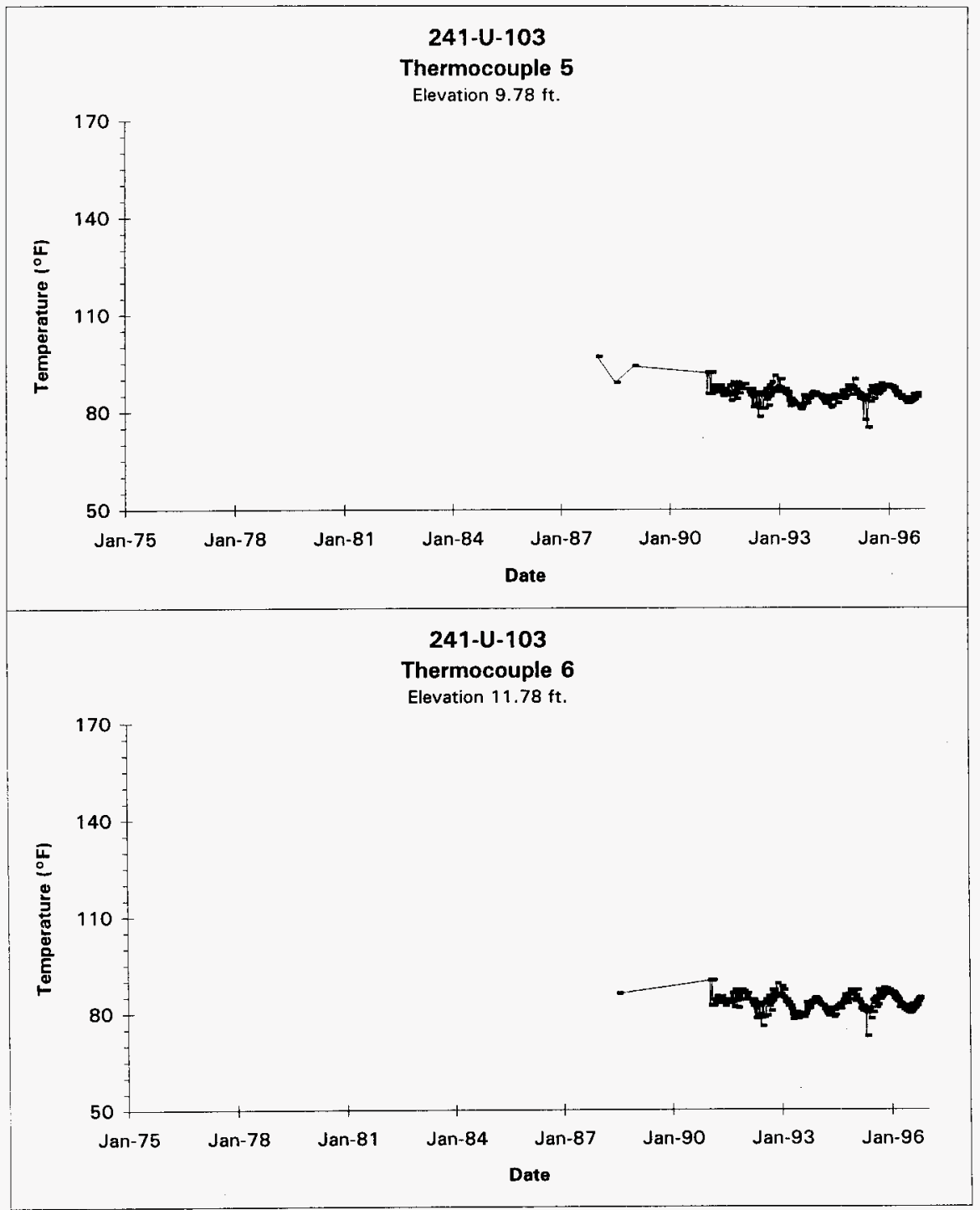

Data obtained from LMHC Surveillance Analysis Computer System (SACS), Oct 2, 1996

$$
\text { D-11 }
$$




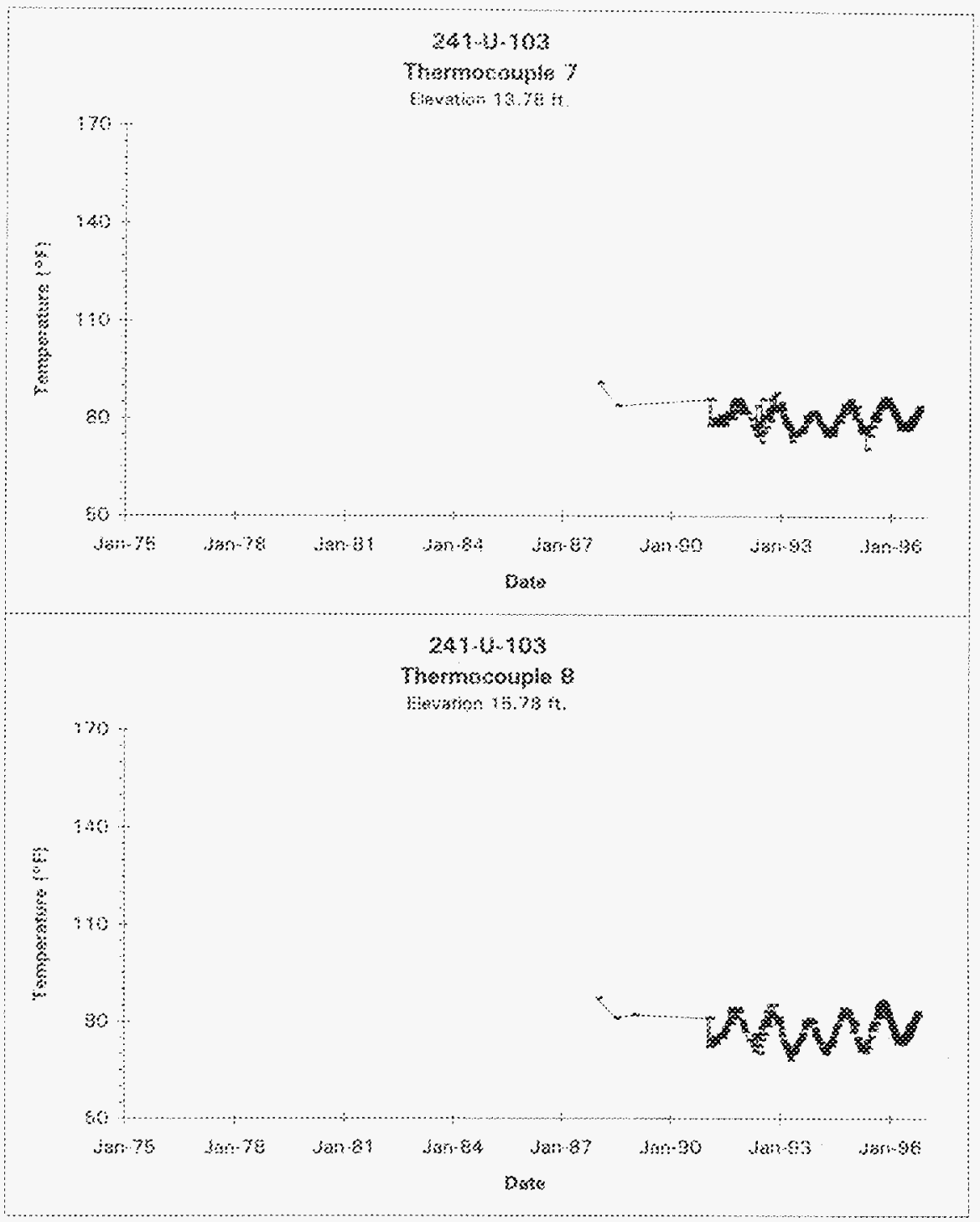

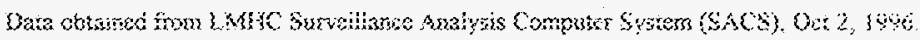




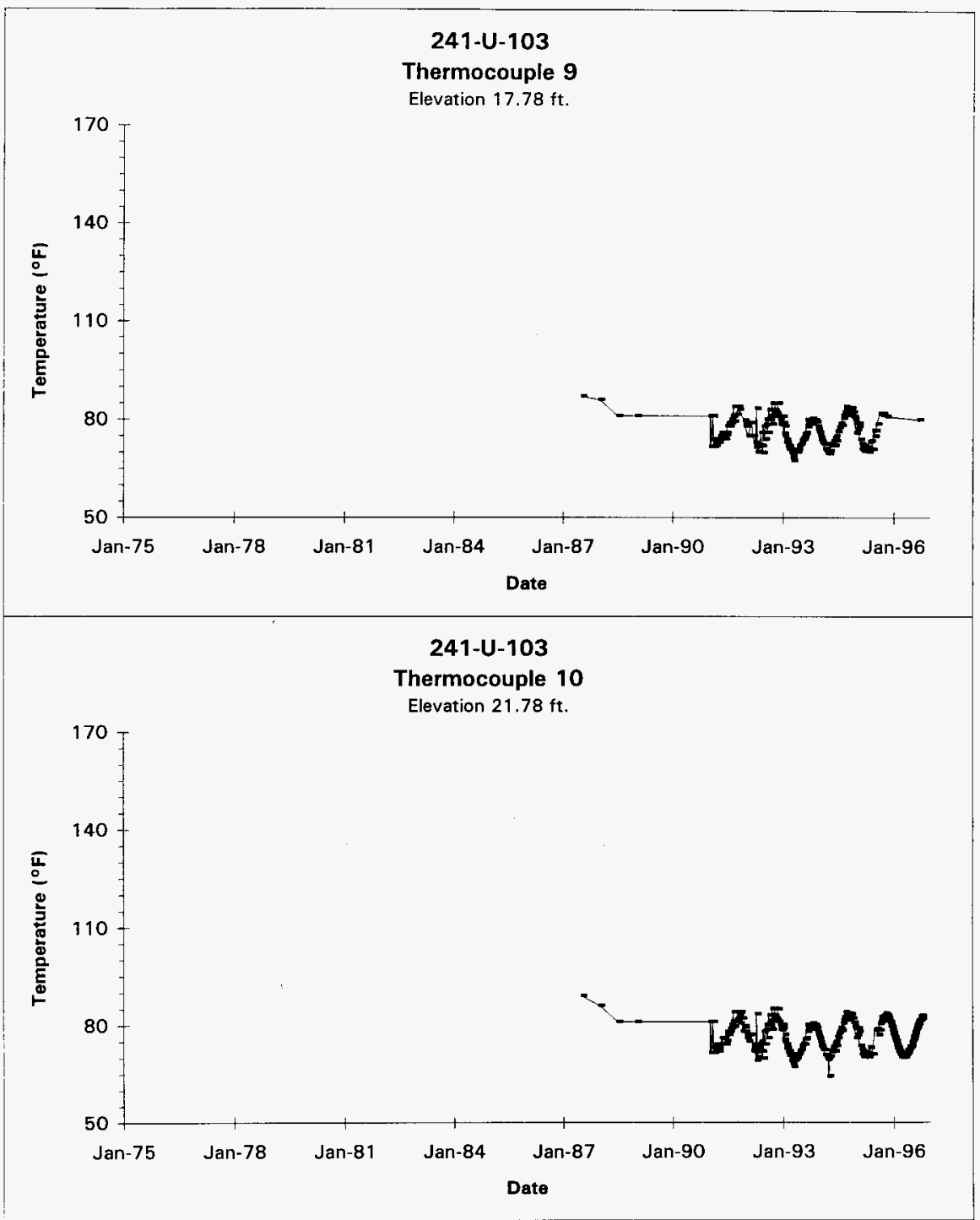

Data obtained from LMHC Surveillance Analysis Computer System (SACS), Oct 2, 1996

D-13 


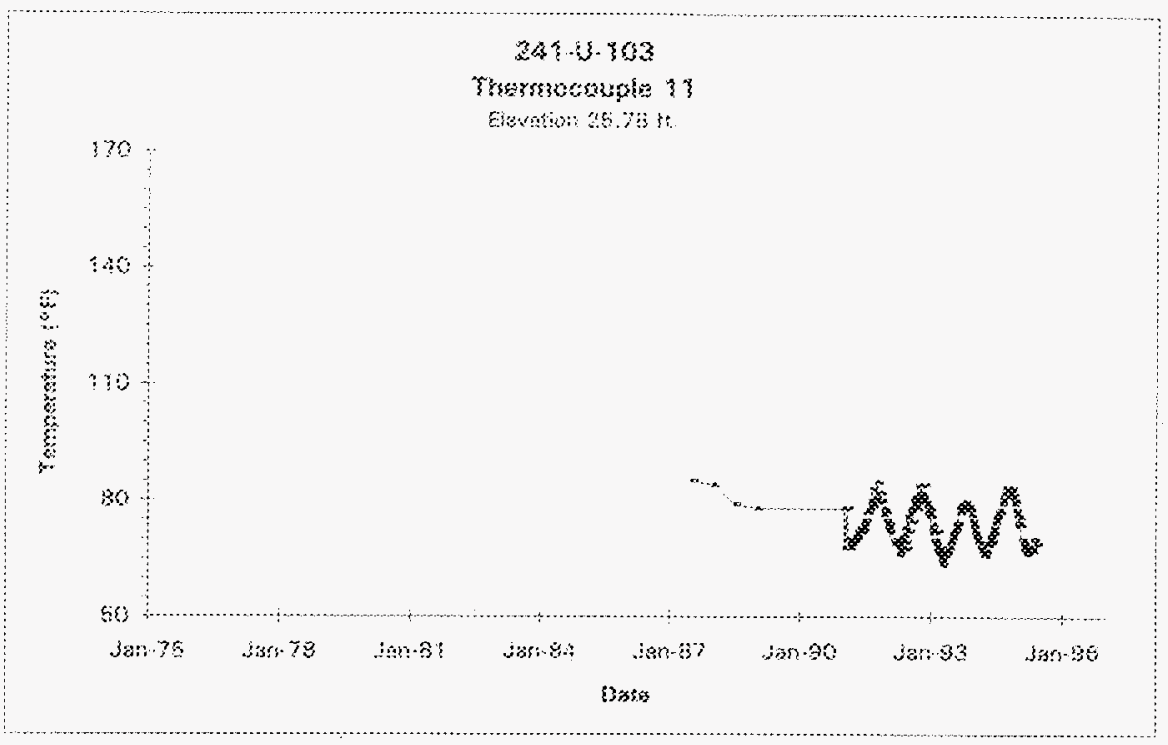

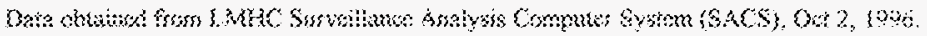




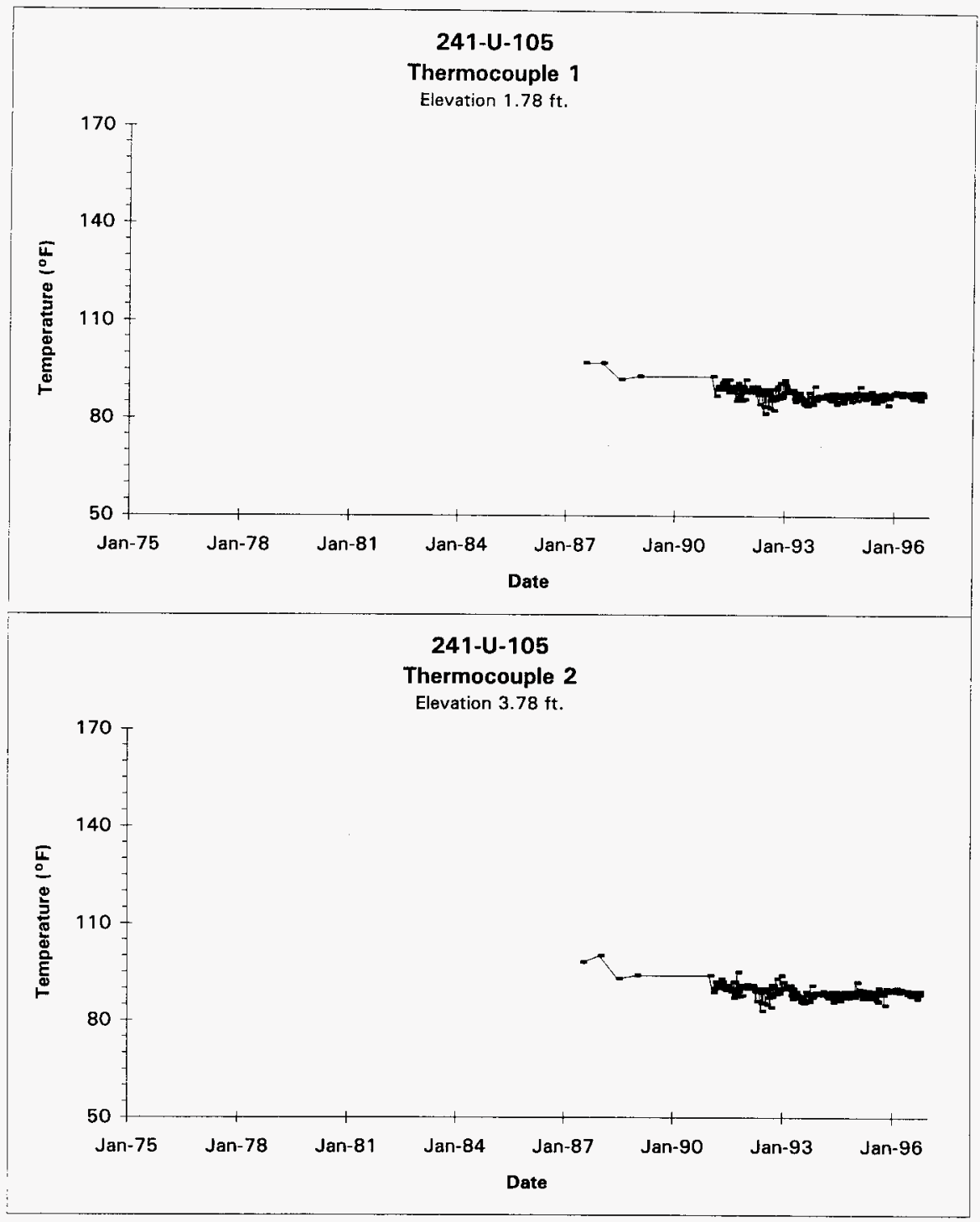

Data obtained from LMHC Surveillance Analysis Computer System (SACS), Oct 2, 1996.

D-15 


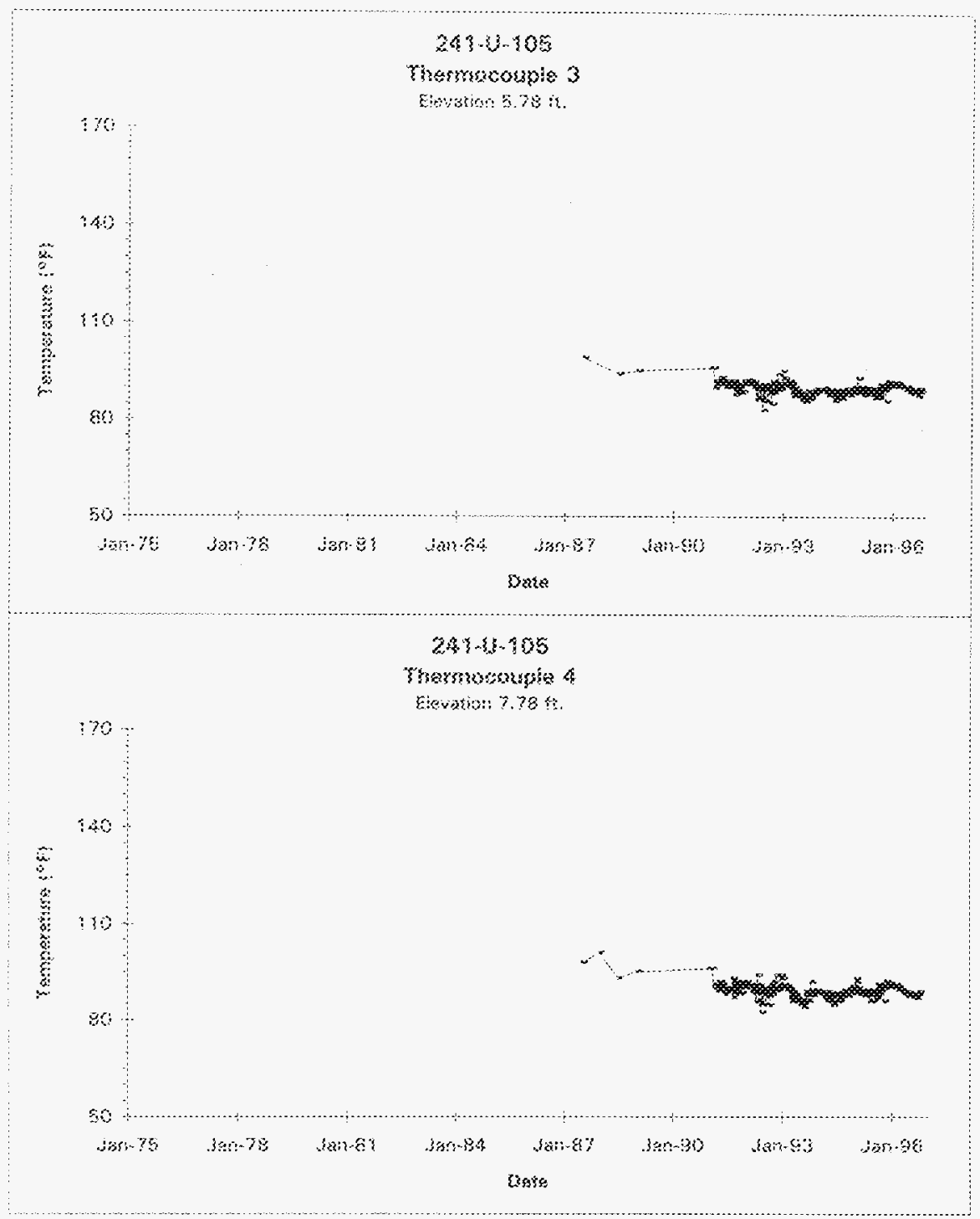

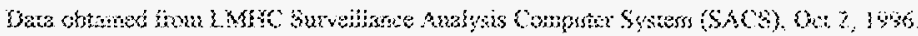
Dints 


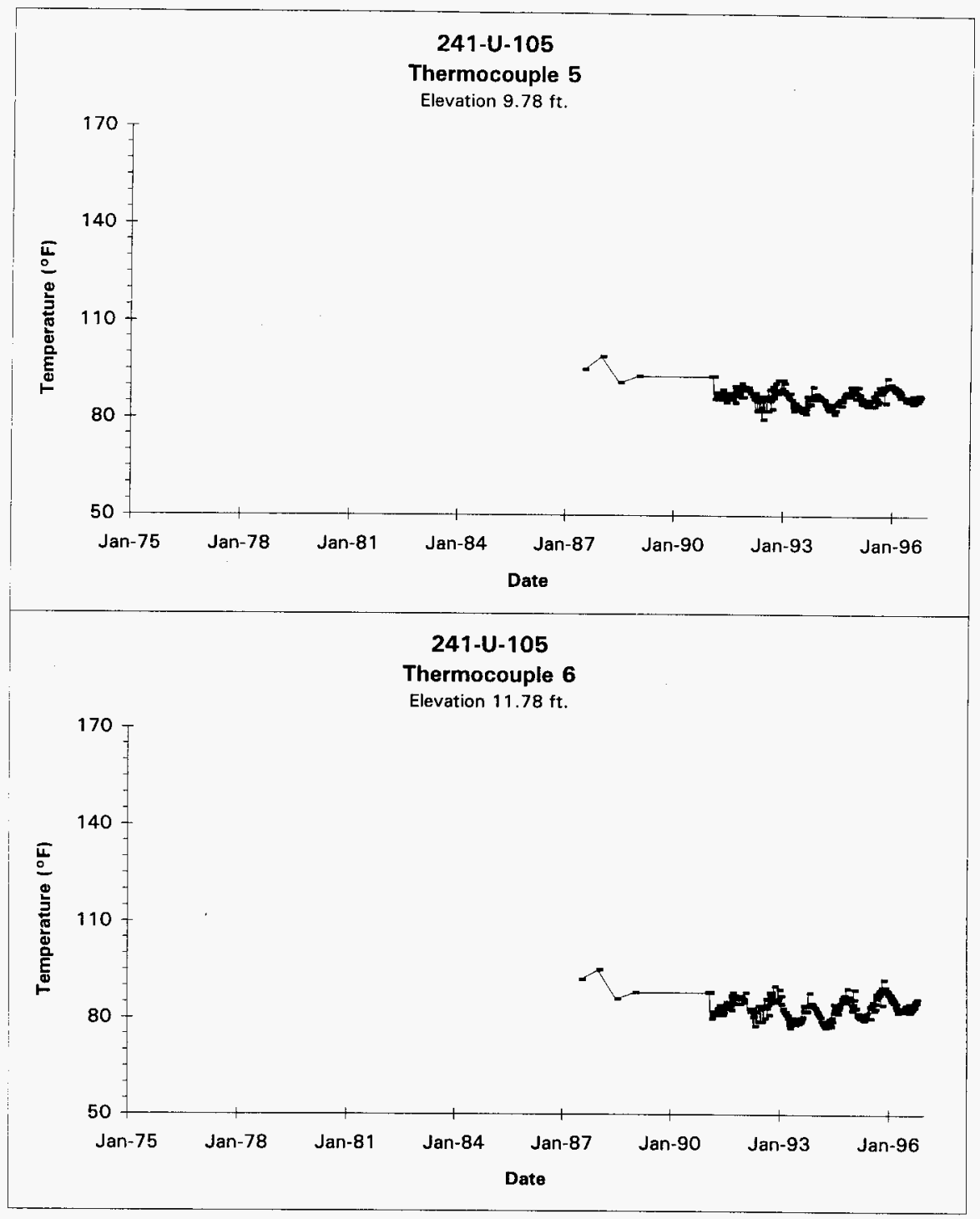

Data obtained from LMHC Surveillance Analysis Computer System (SACS), Oct 2, 1996.

D-17 


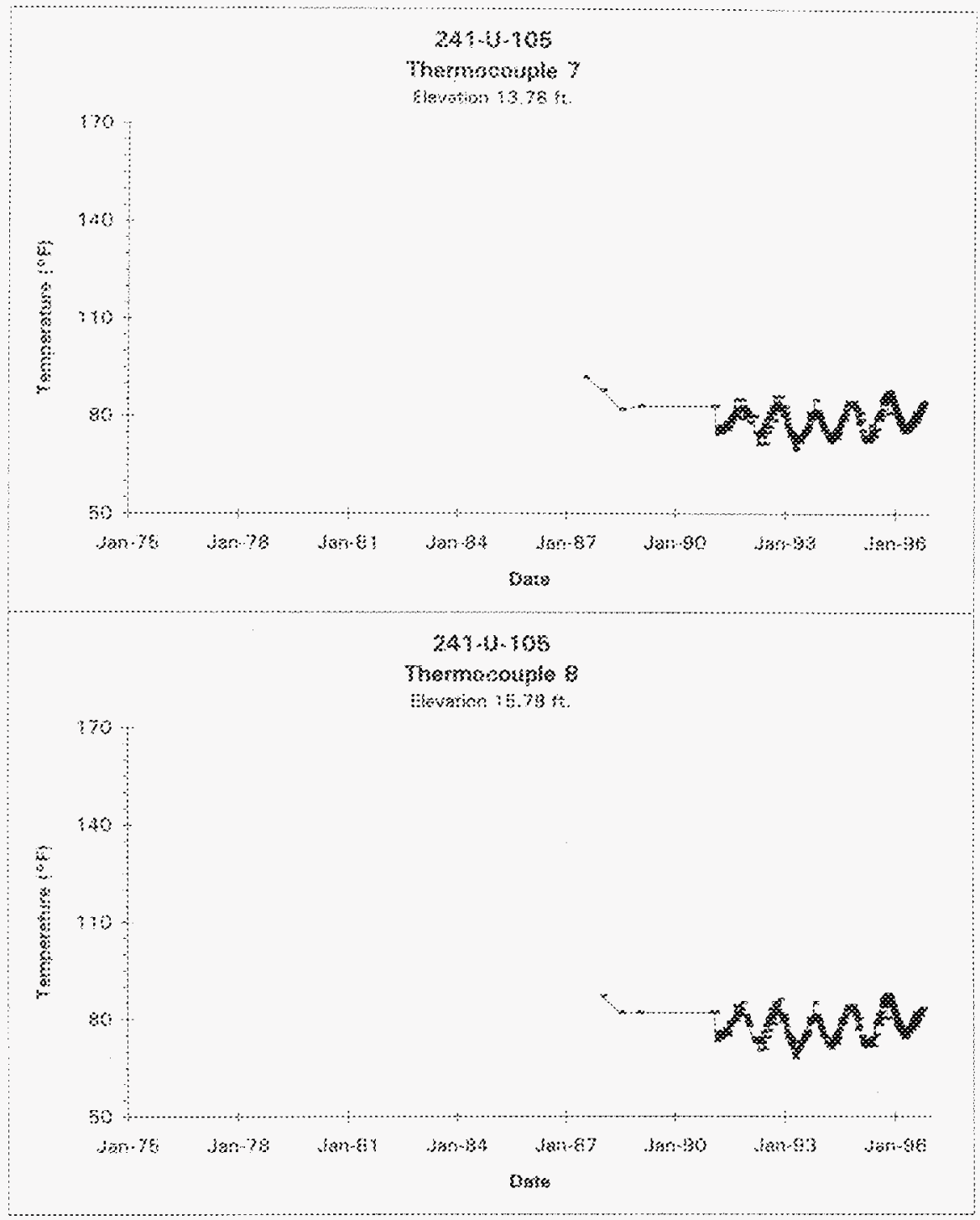

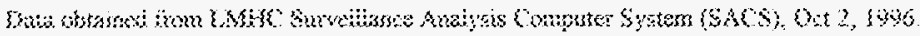
(3-1\% 


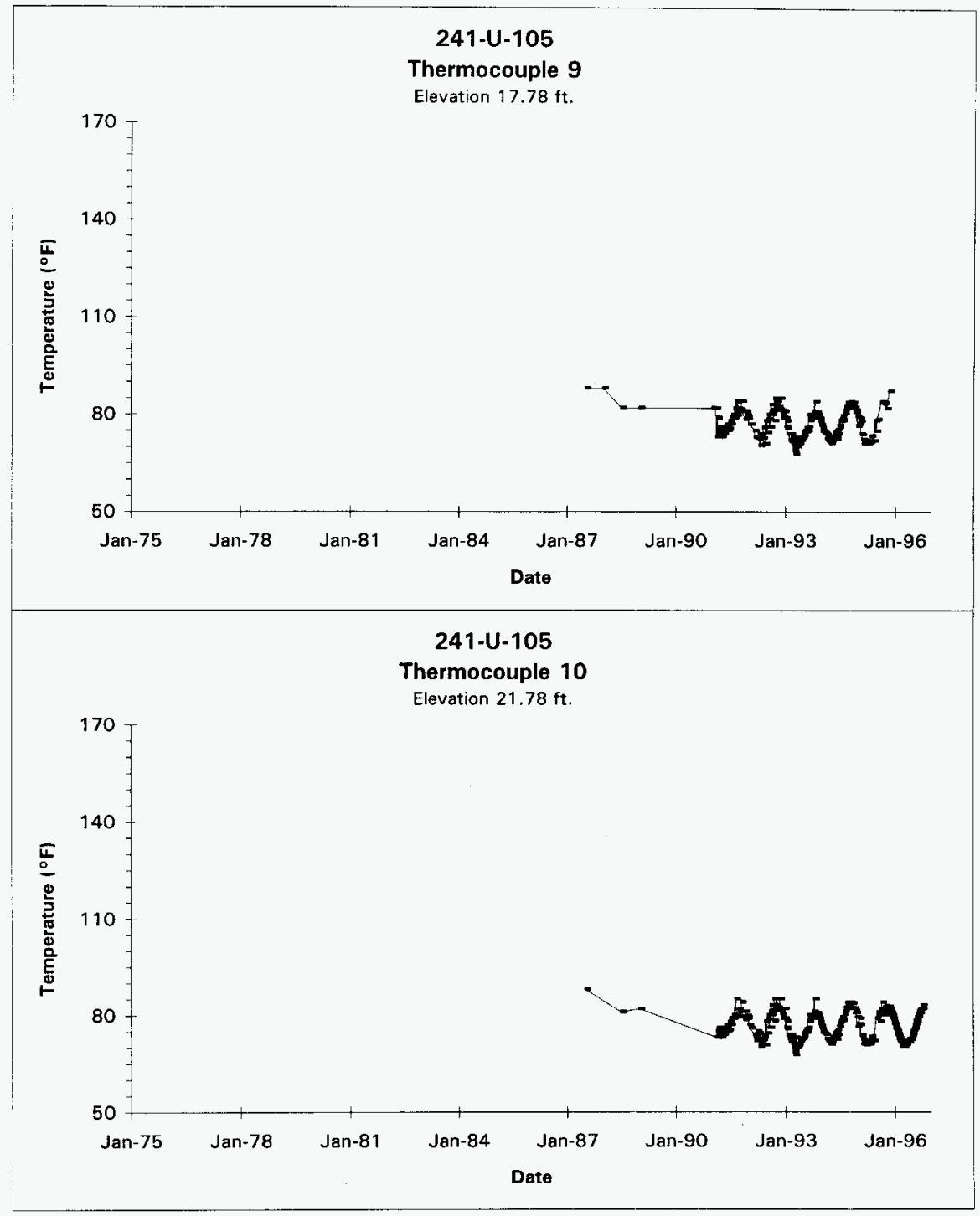

Data obtained from LMHC Surveillance Analysis Computer System (SACS), Oct 2, 1996.

$$
\text { D-19 }
$$




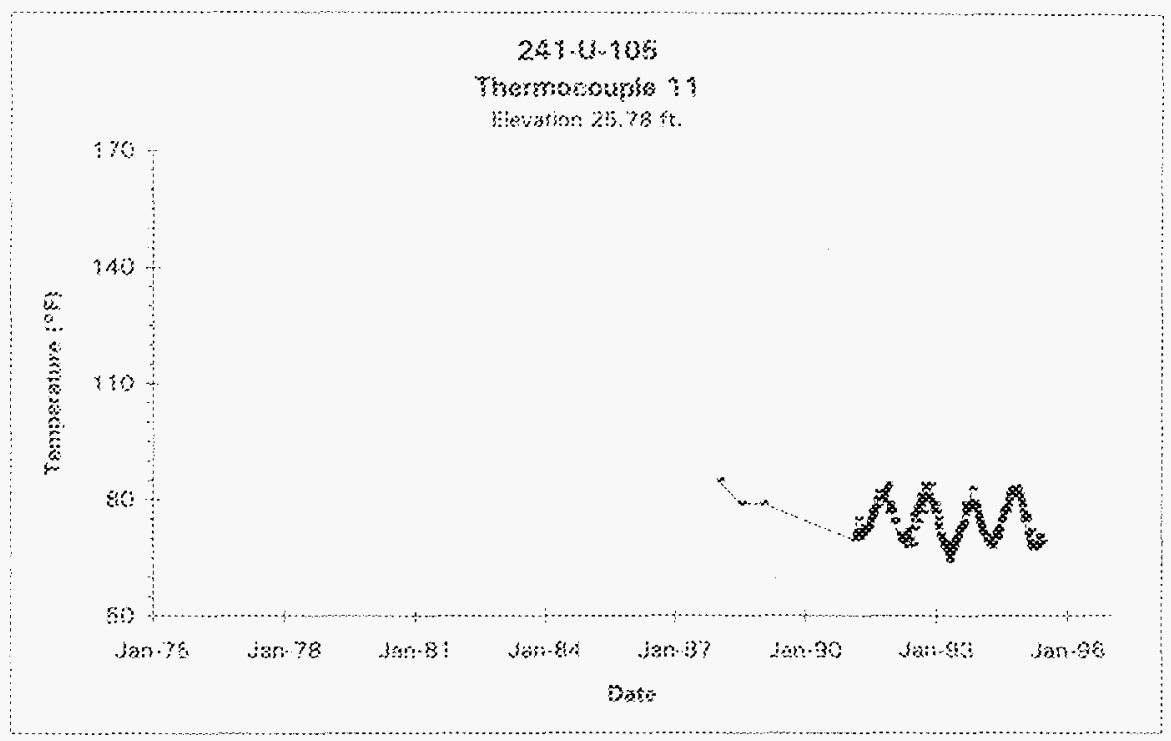

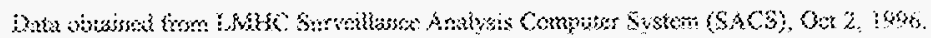
b. 20 


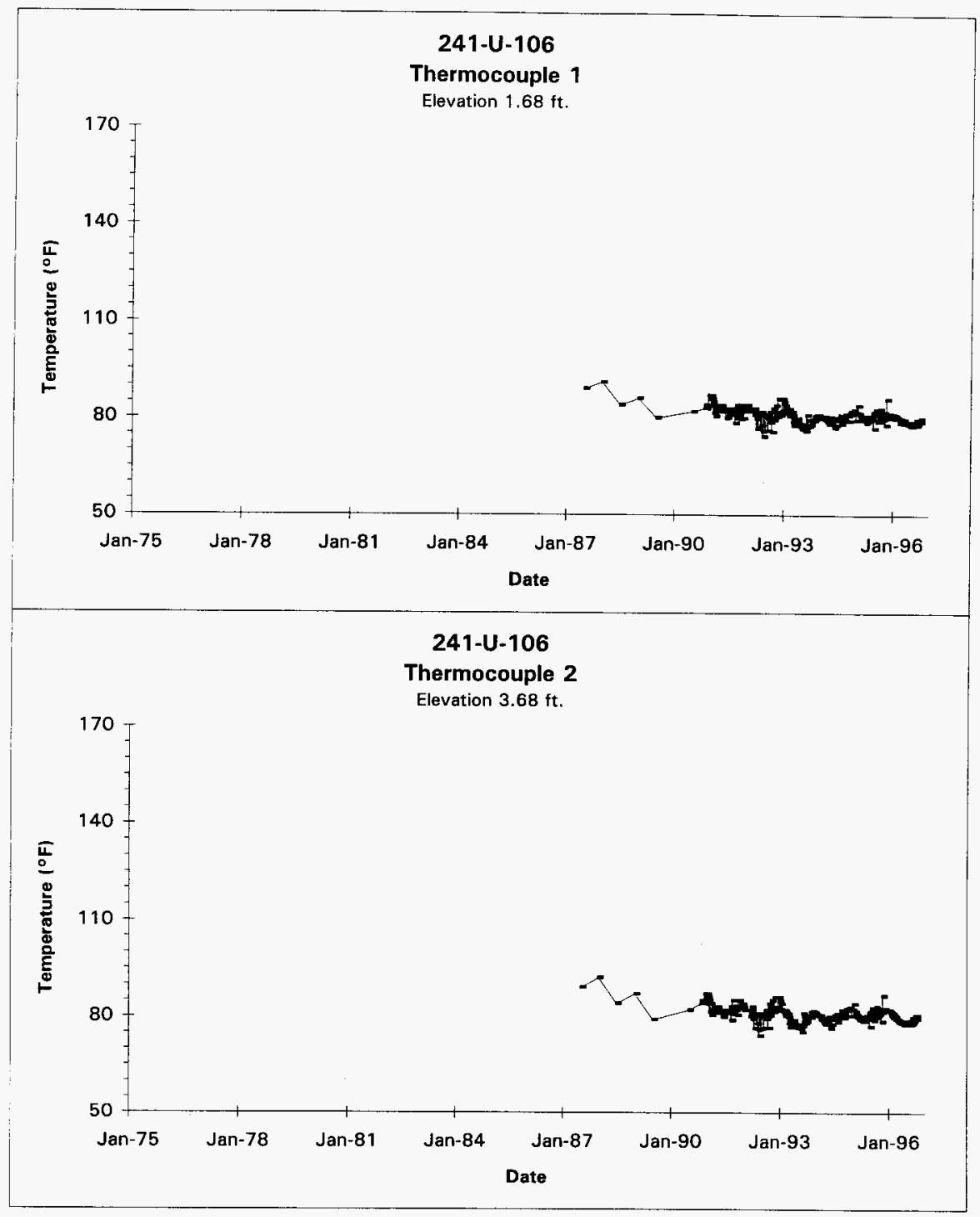

Data obtained from LMHC Surveillance Analysis Computer System (SACS), Oct 2, 1996.

D-21 


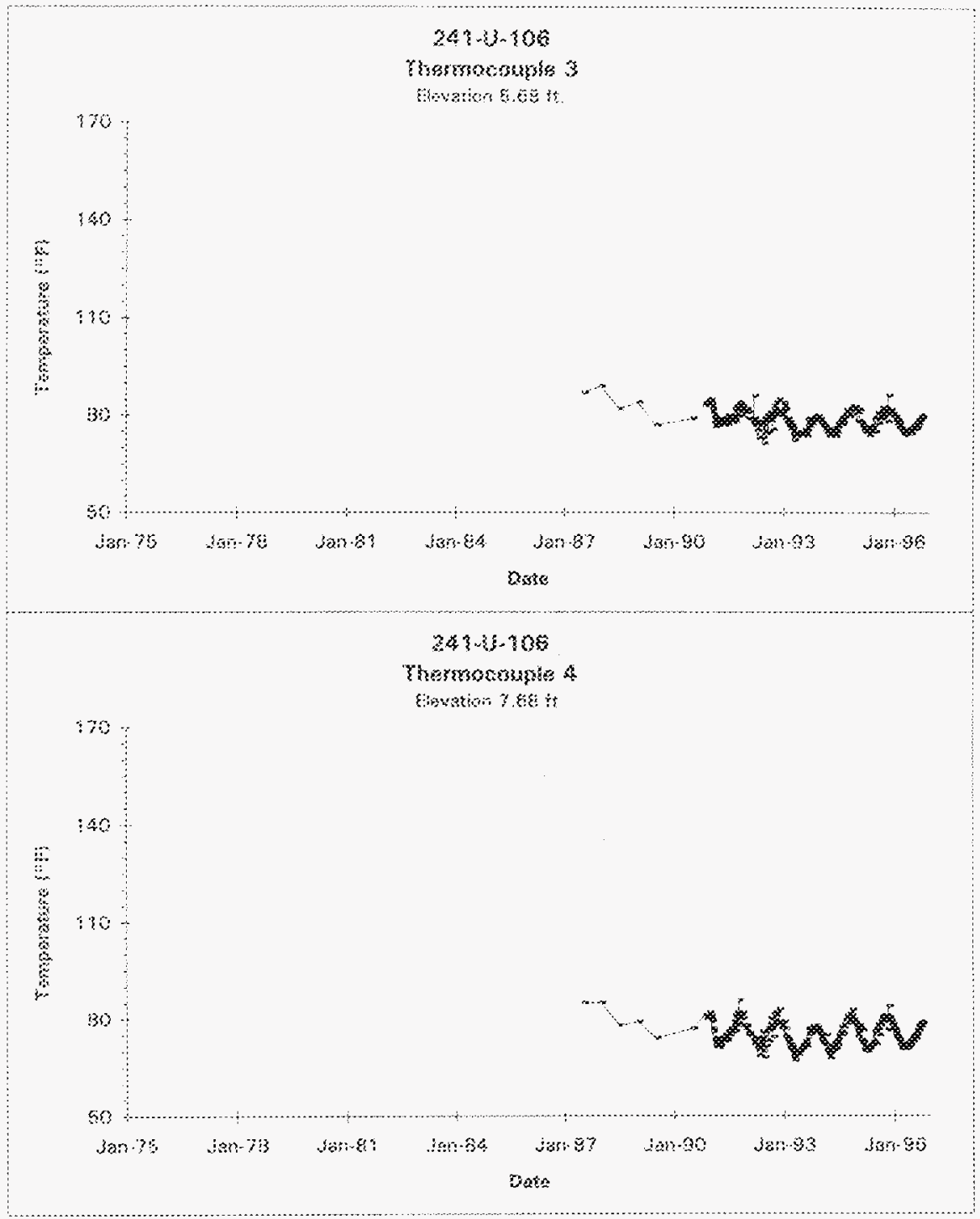

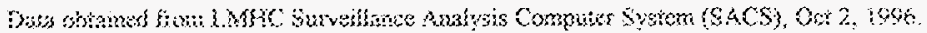




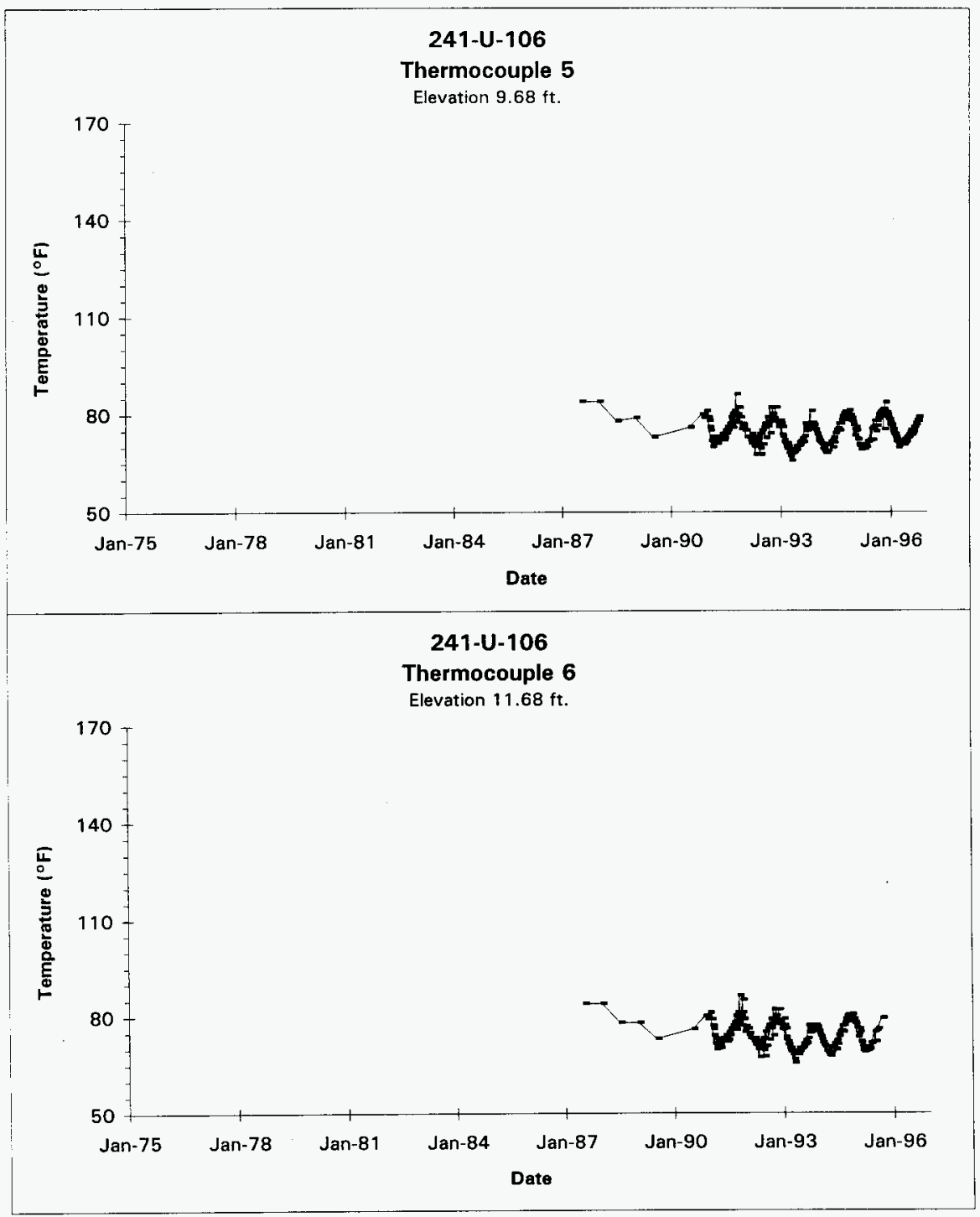

Data obtained from LMHC Surveillance Analysis Computer System (SACS), Oct 2, 1996.

D-23 


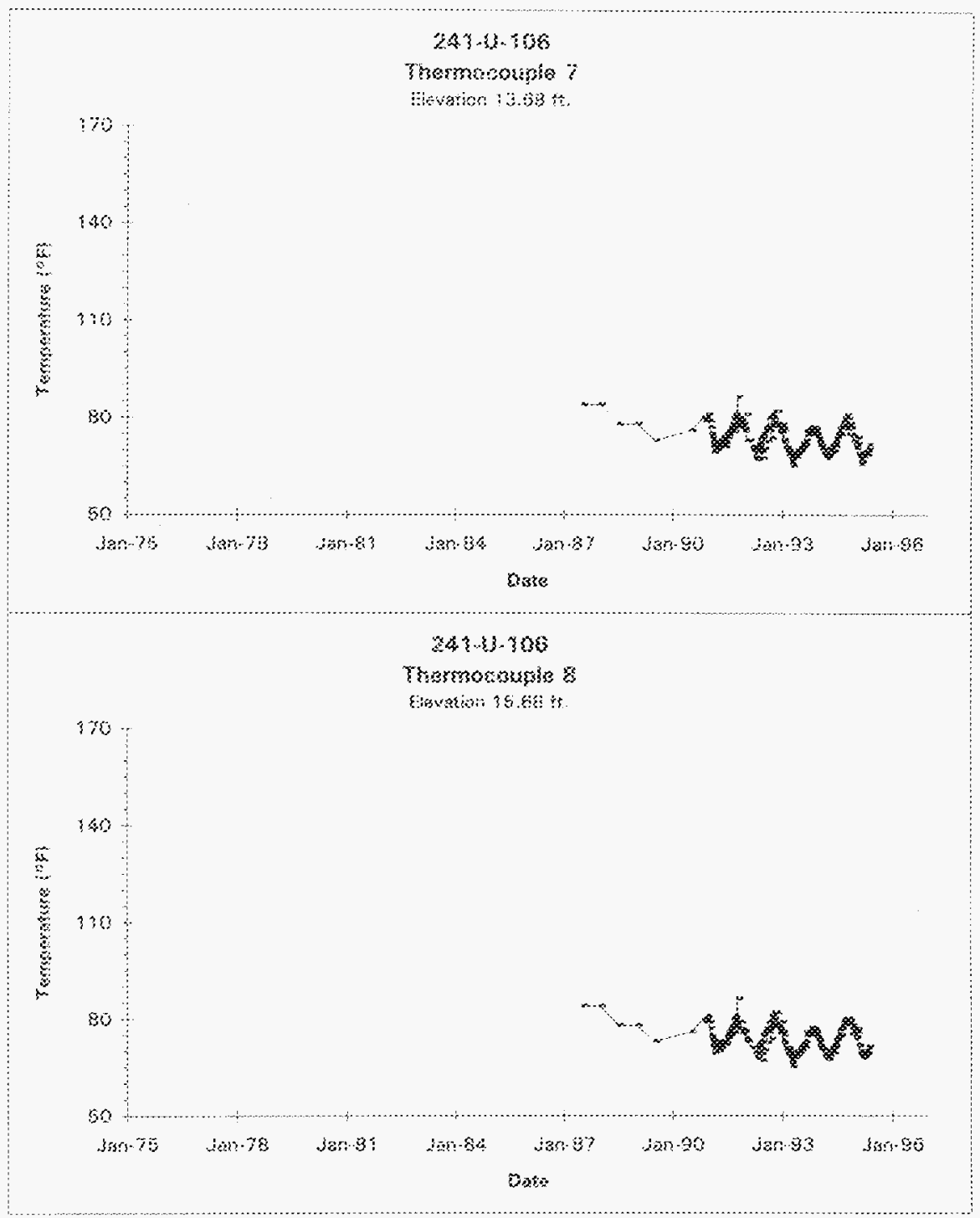

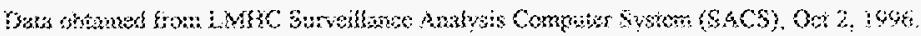




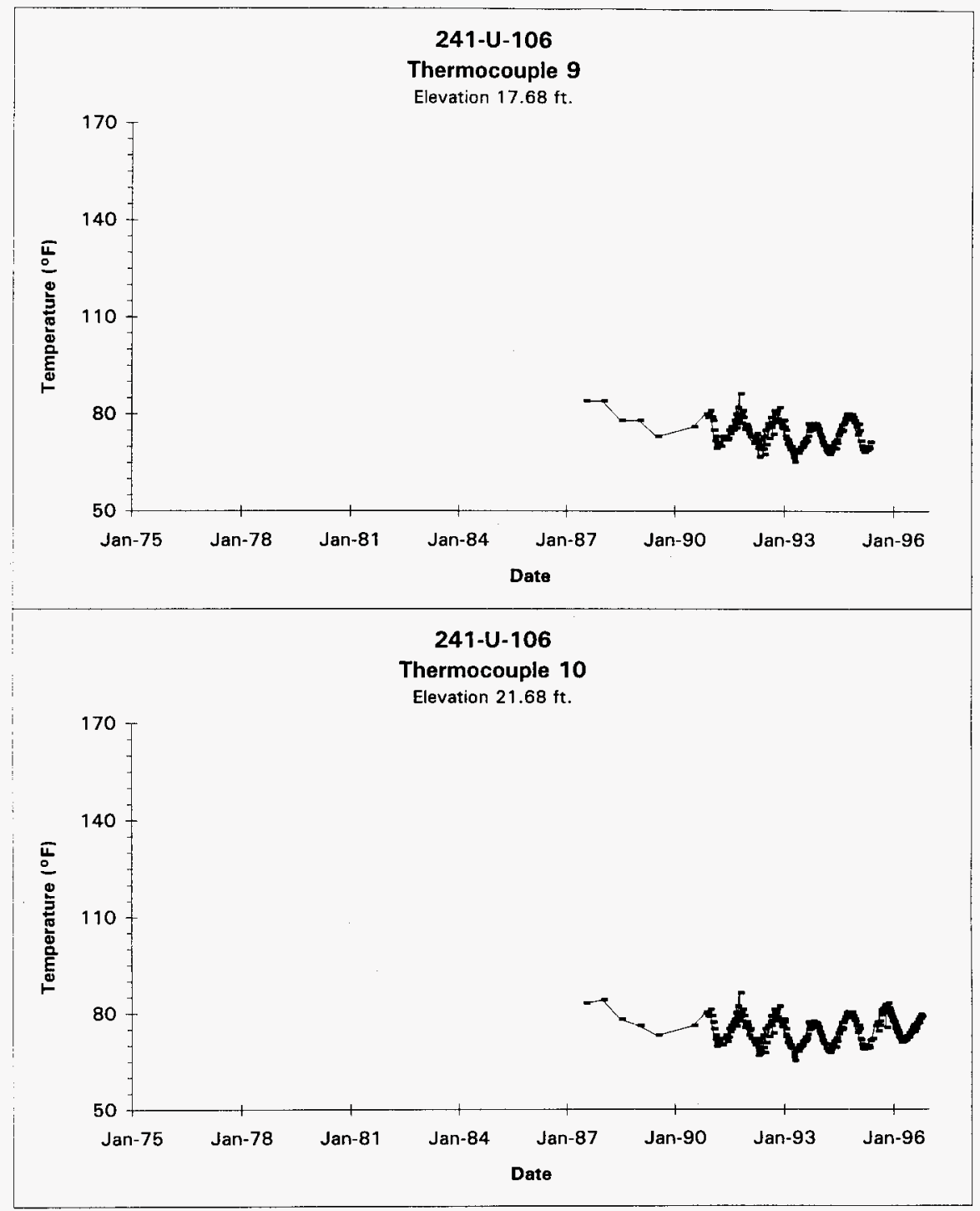

Data obtained from LMHC Surveillance Analysis Computer System (SACS), Oct 2, 1996.

D-25 


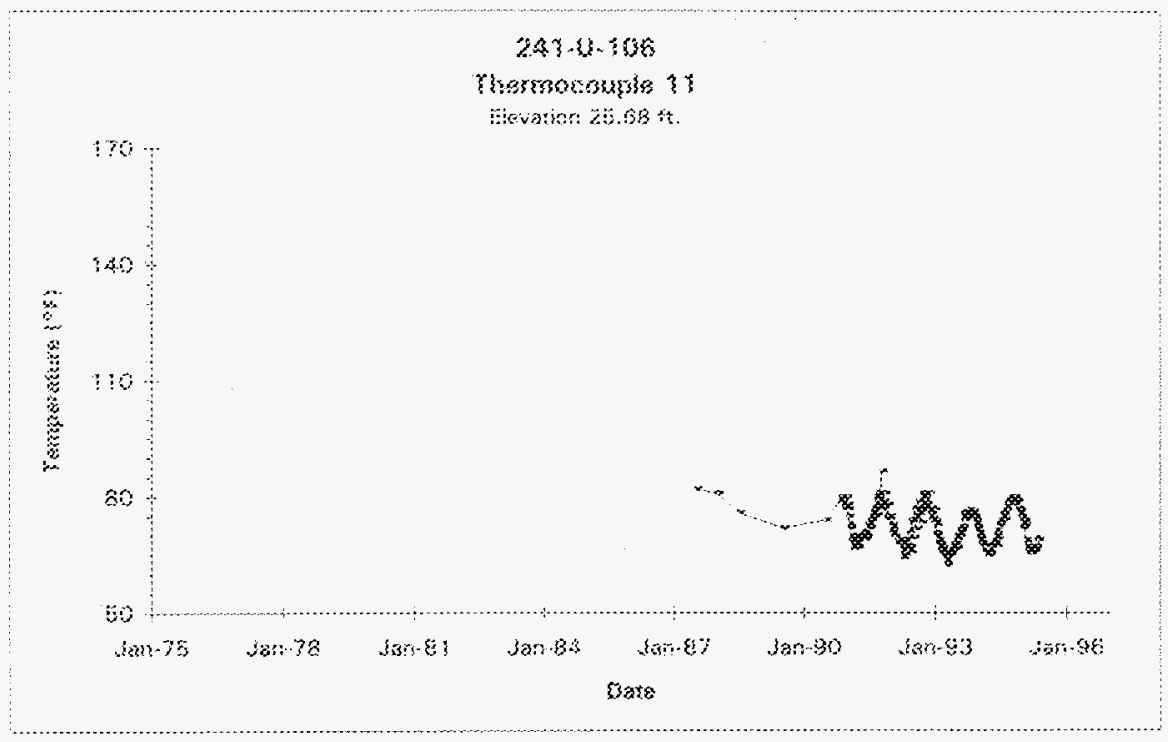




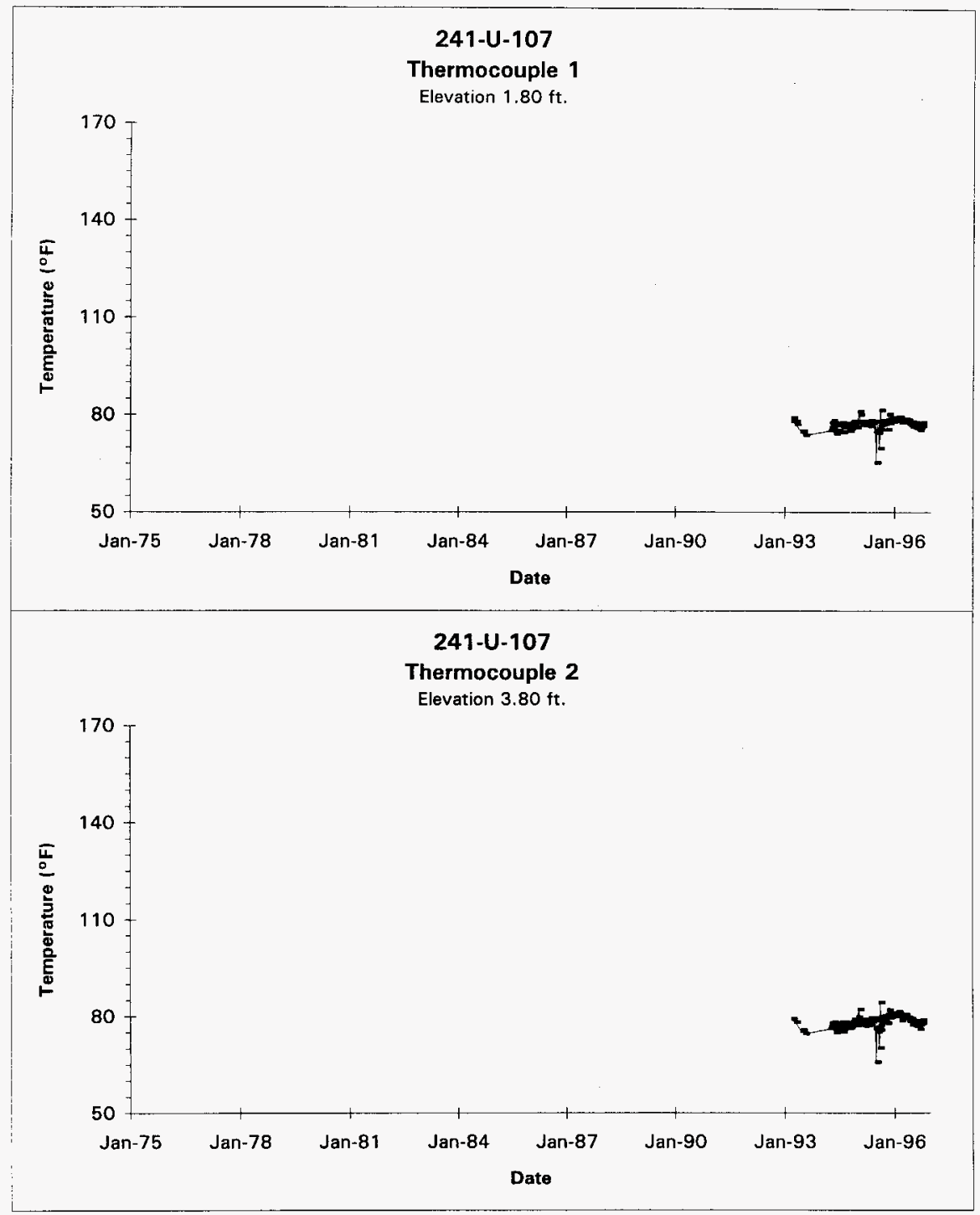

Data obtained from LMHC Surveillance Analysis Computer System (SACS), Oct 2, 1996.

D-27 


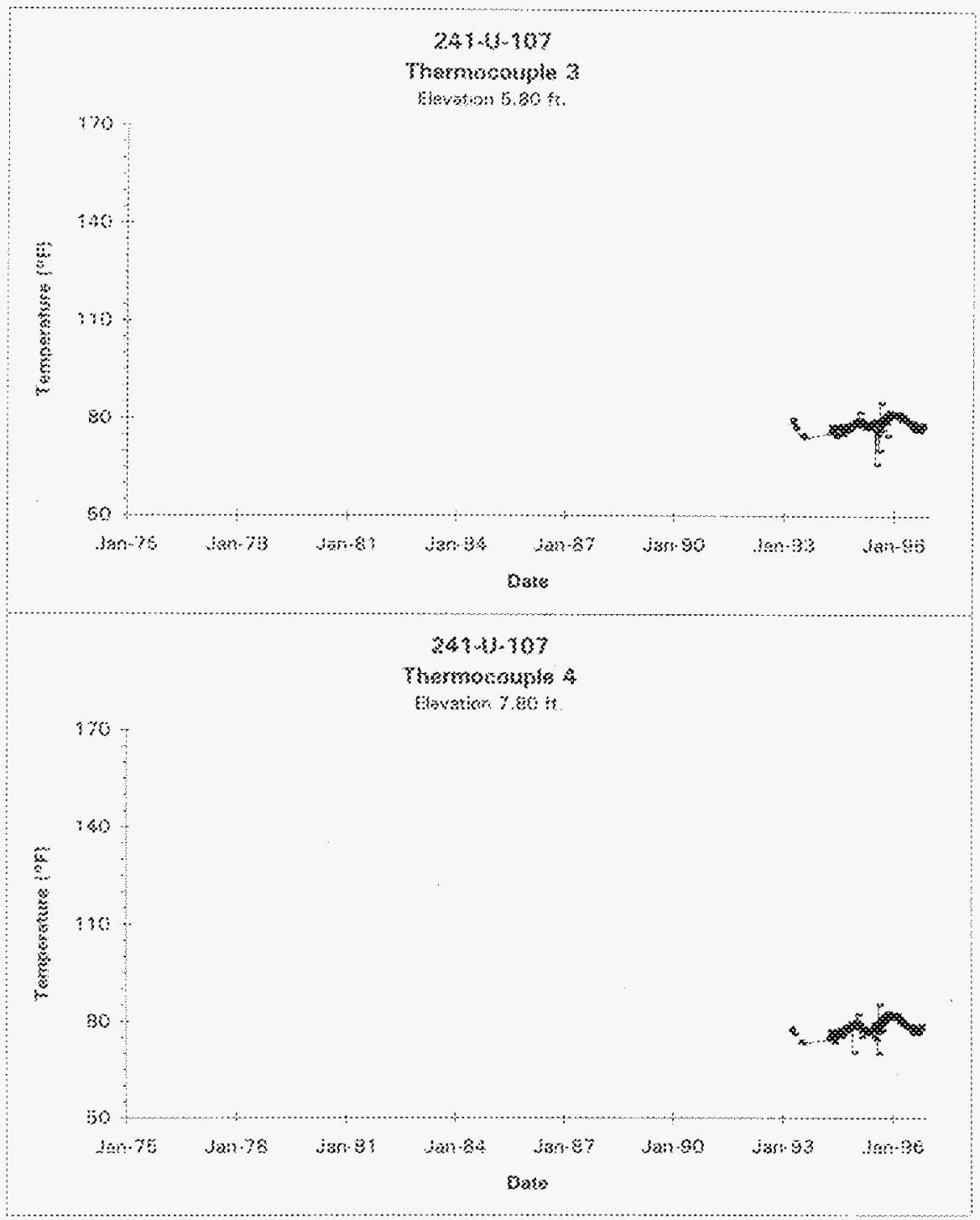

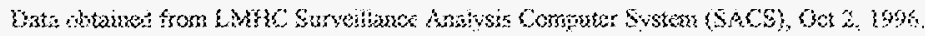


HNF-SD-WM-ER-325, Rev. I

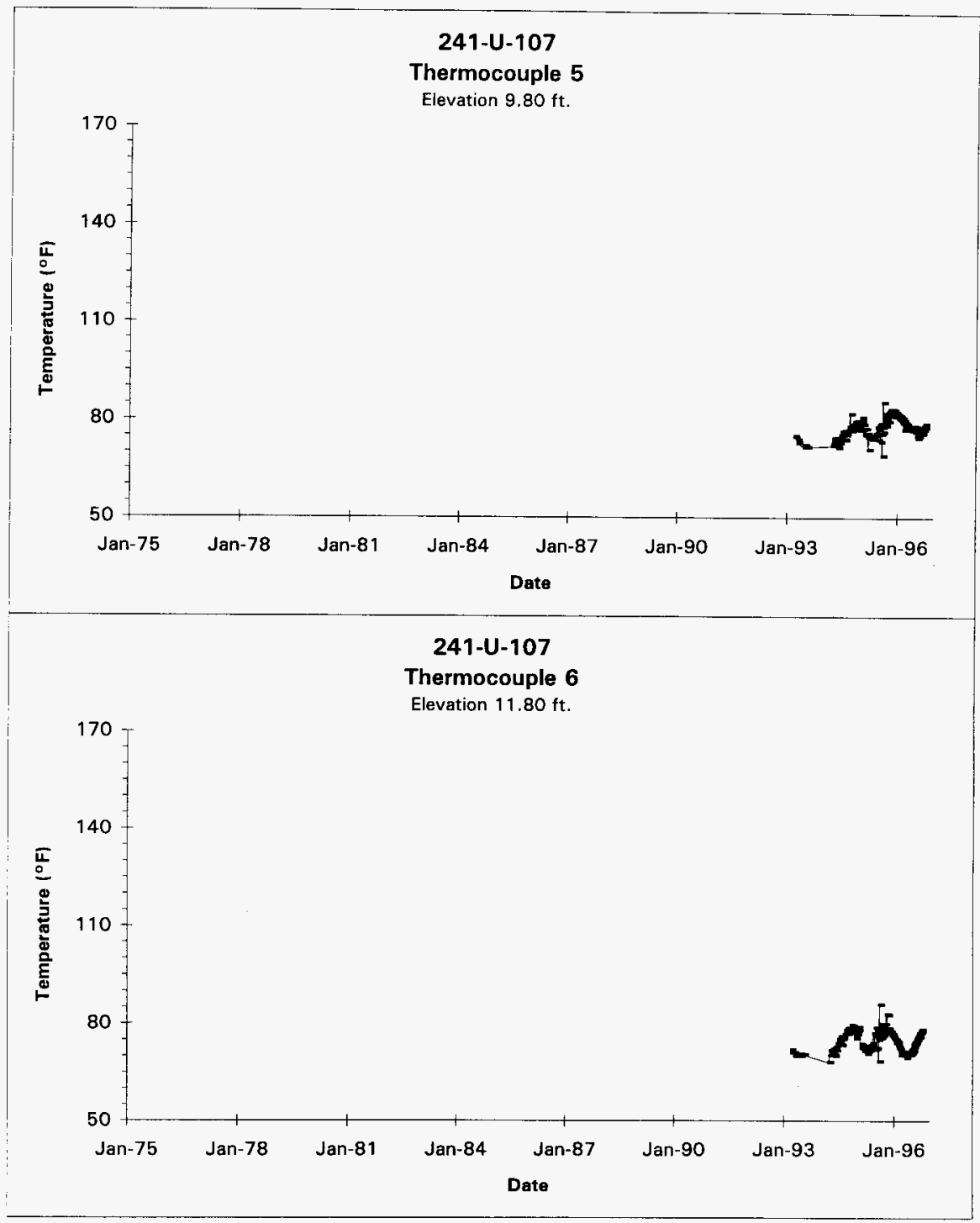

Data obtained from LMHC Surveillance Analysis Computer System (SACS), Oct 2, 1996.

D-29 


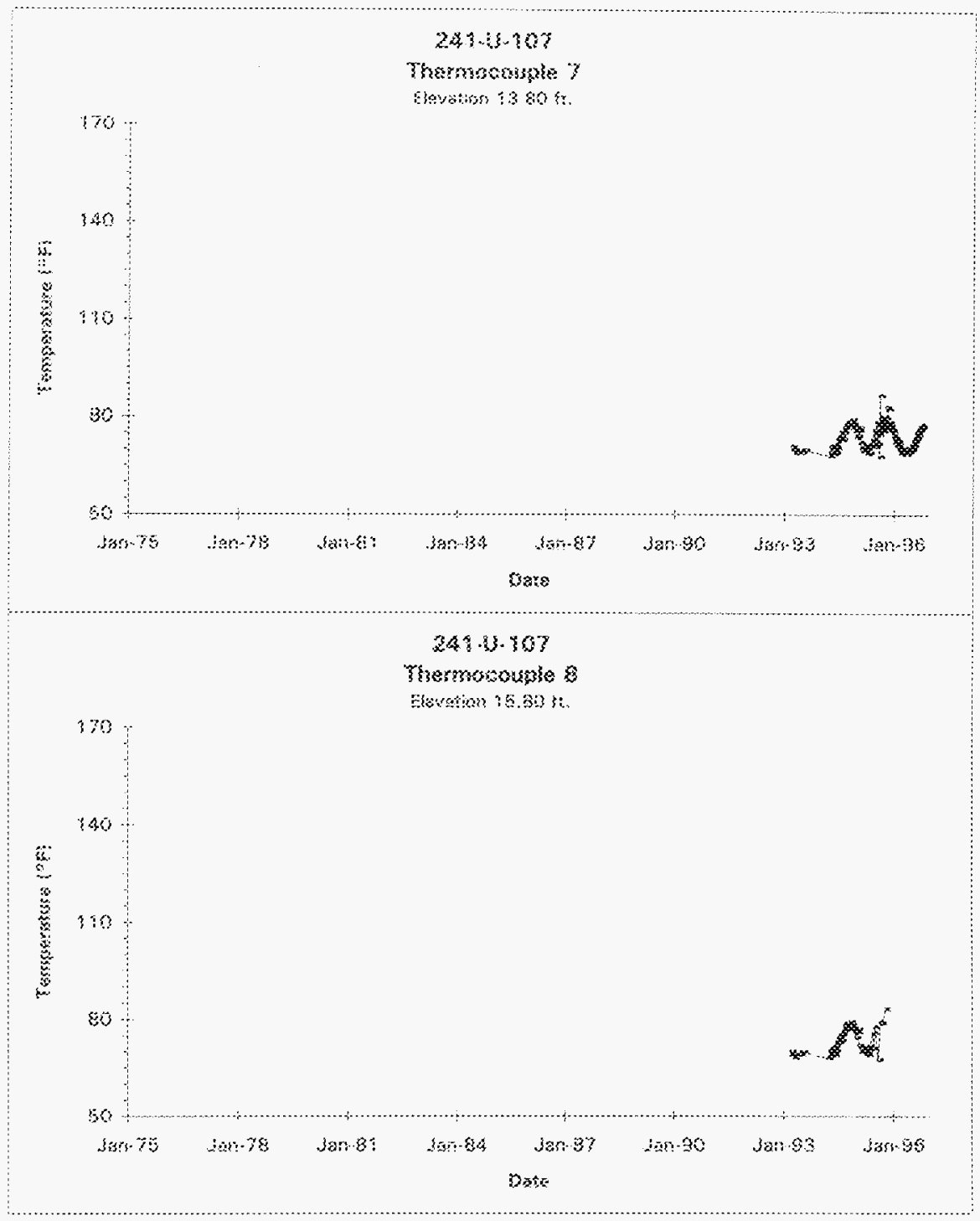

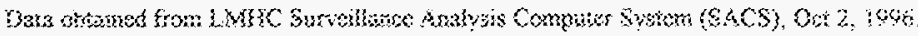

530 


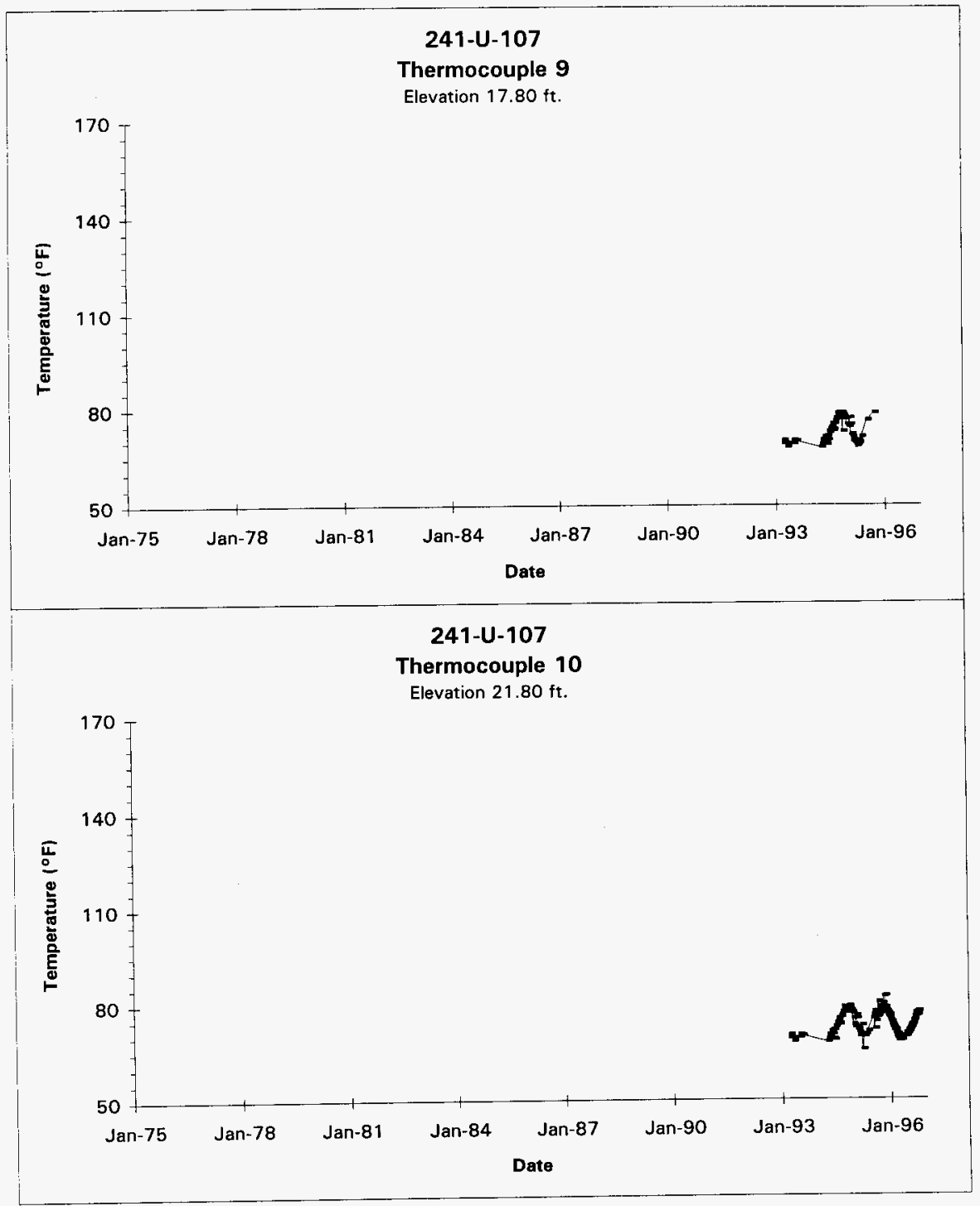

Data obtained from LMHC Surveillance Analysis Computer System (SACS), Oct 2, 1996.

\section{D-31}




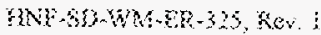

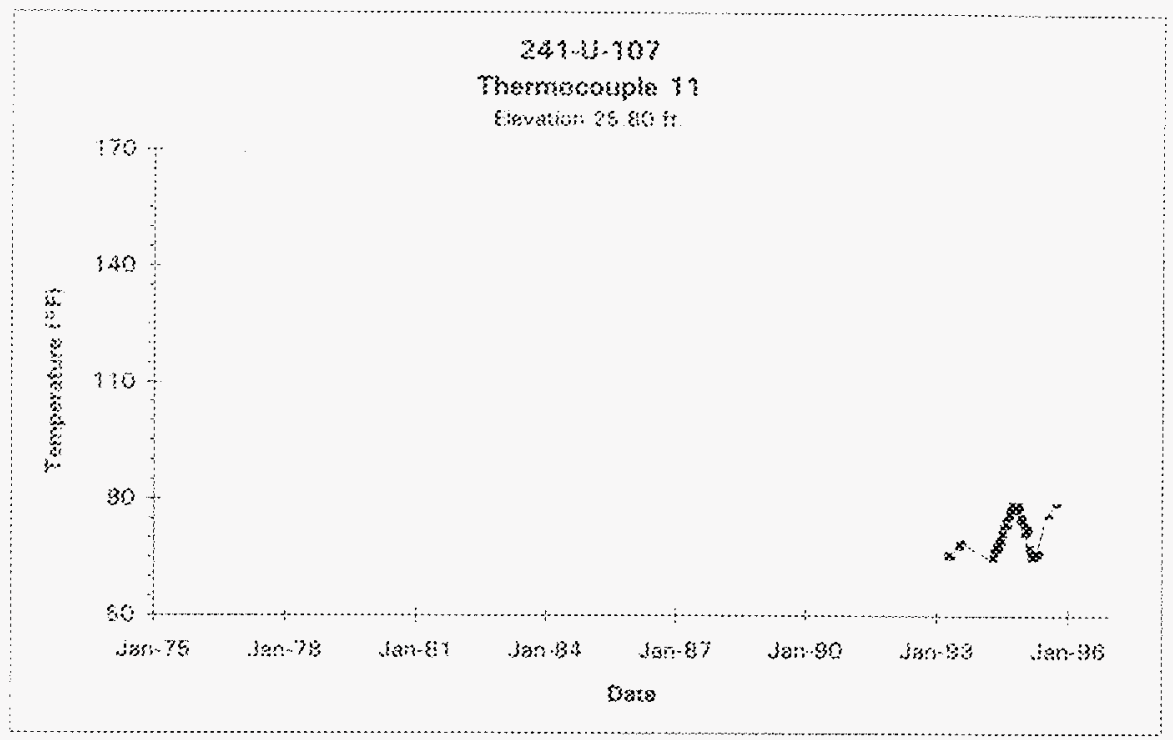

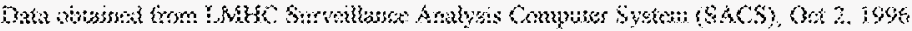

0.32 


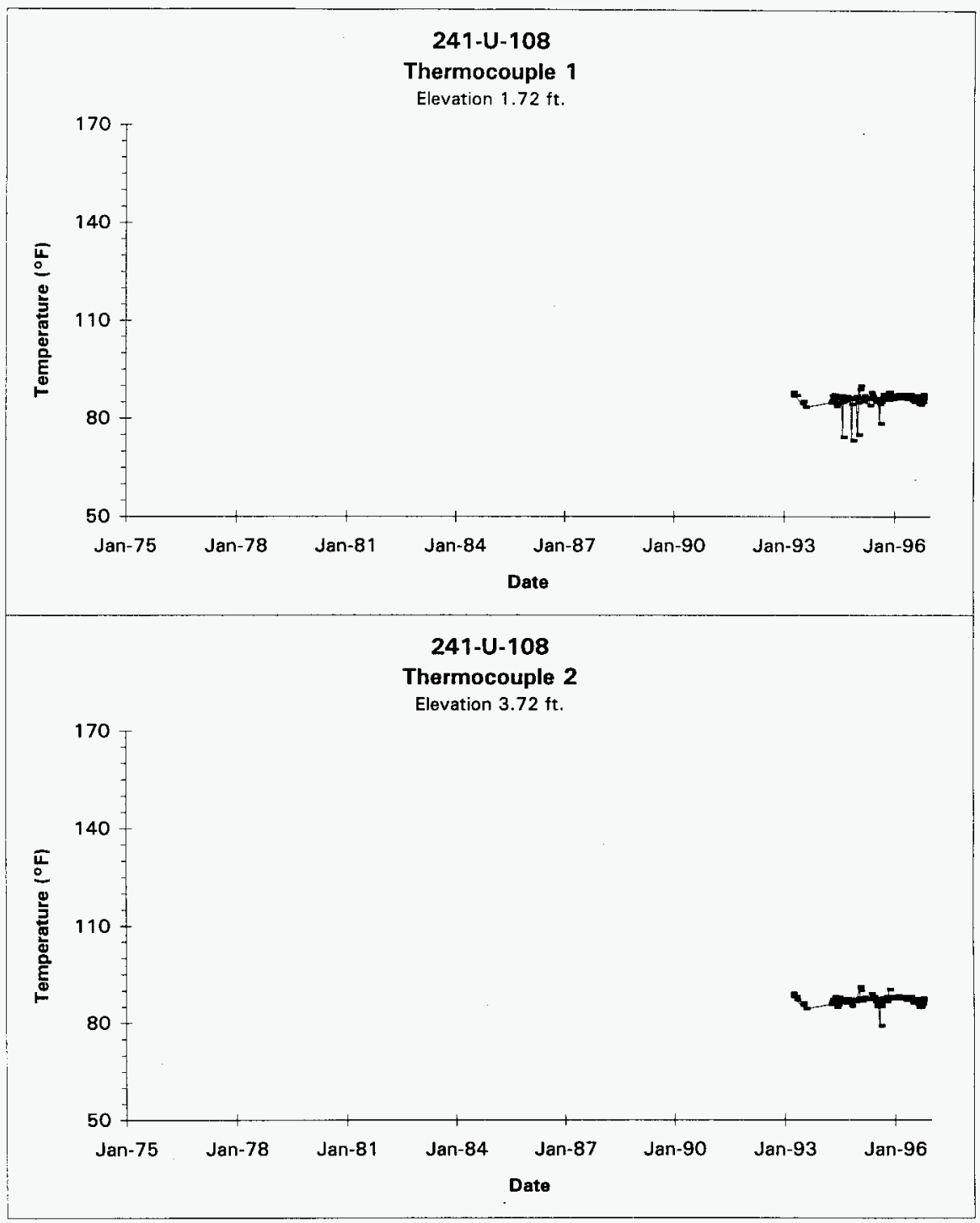

Data obtained from LMHC Surveillance Analysis Computer System (SACS), Oct 2, 1996.

D-33 


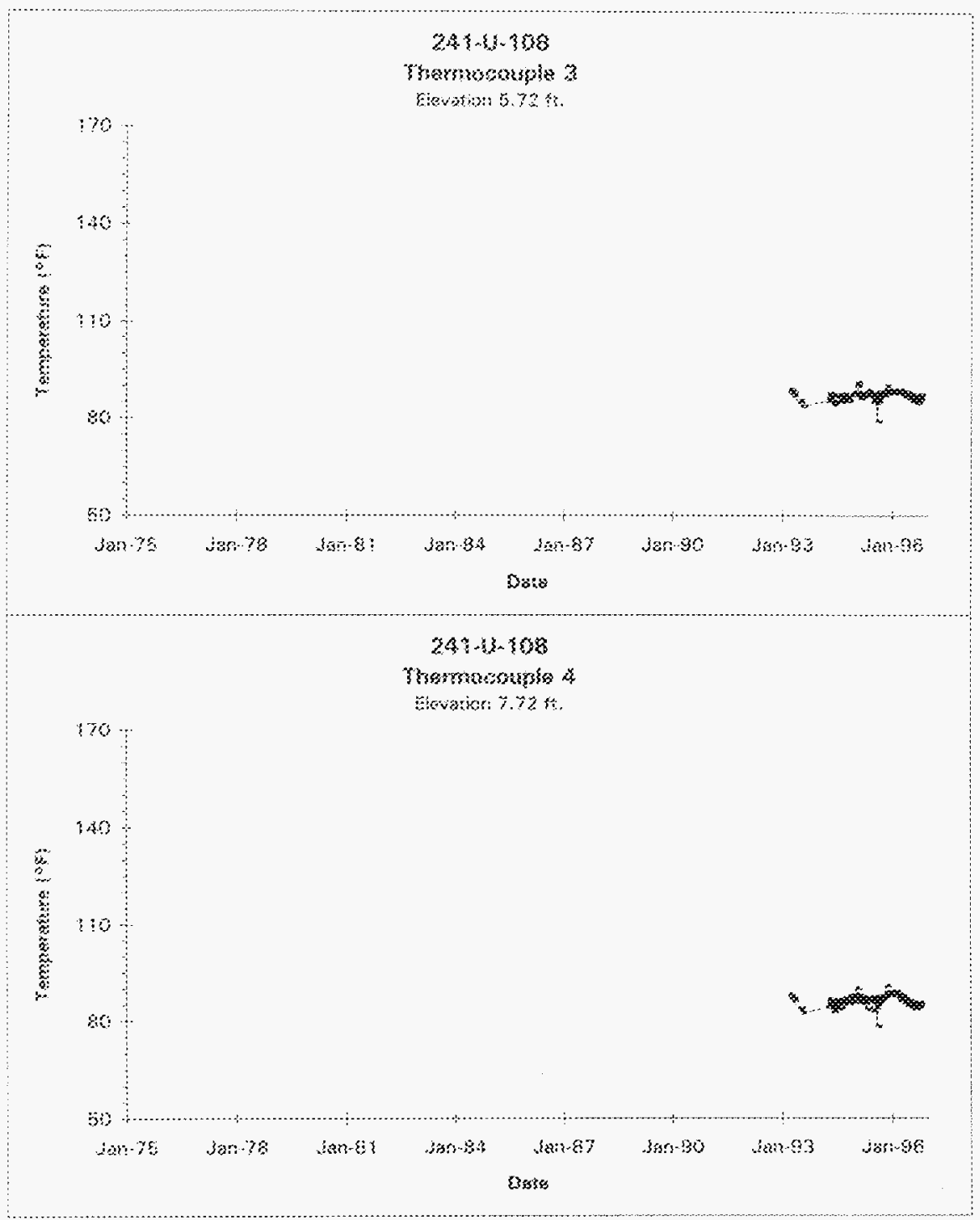

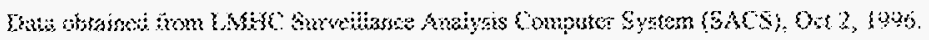

(3-34 


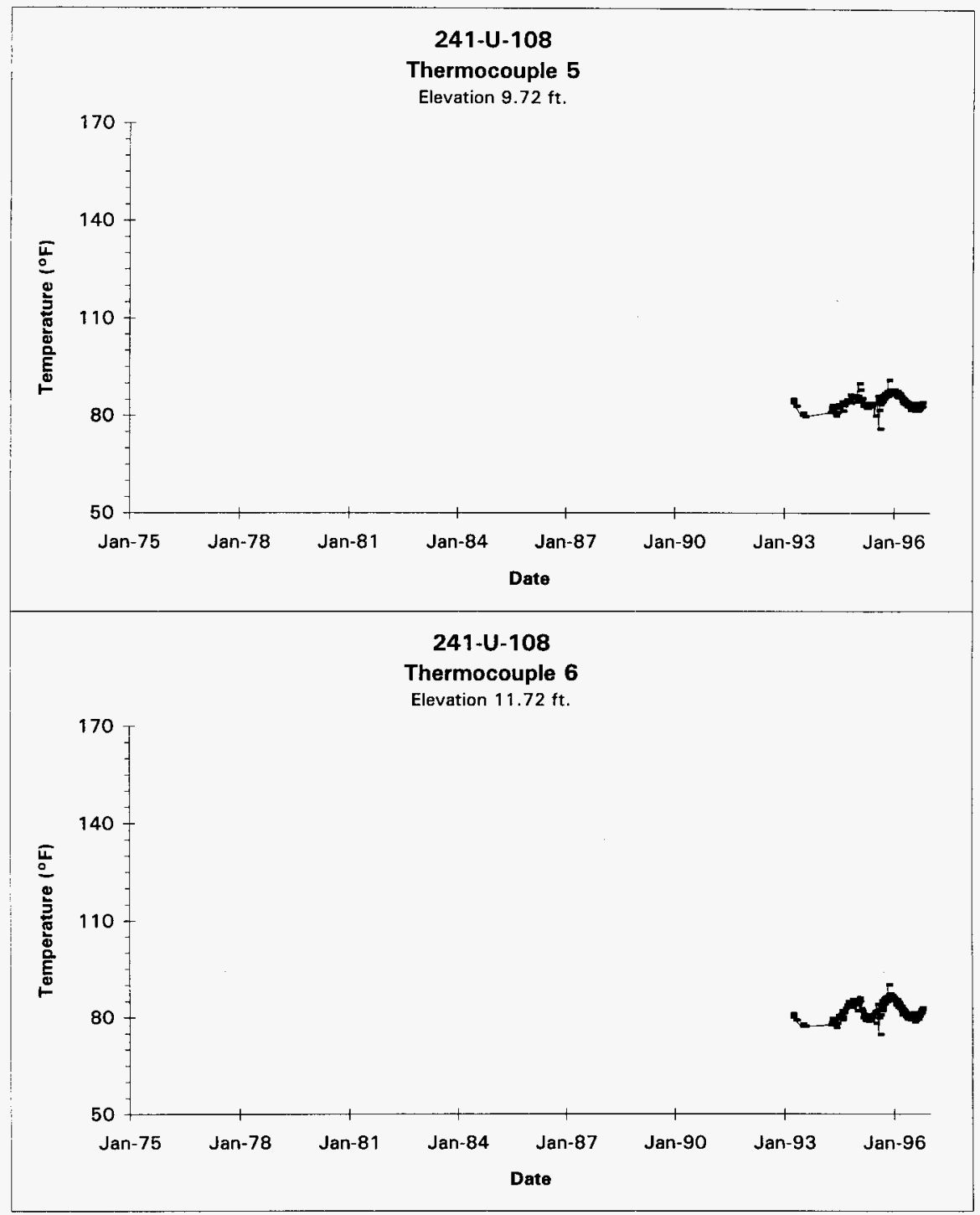

Data obtained from LMHC Surveillance Analysis Computer System (SACS), Oct 2, 1996.

D-35 


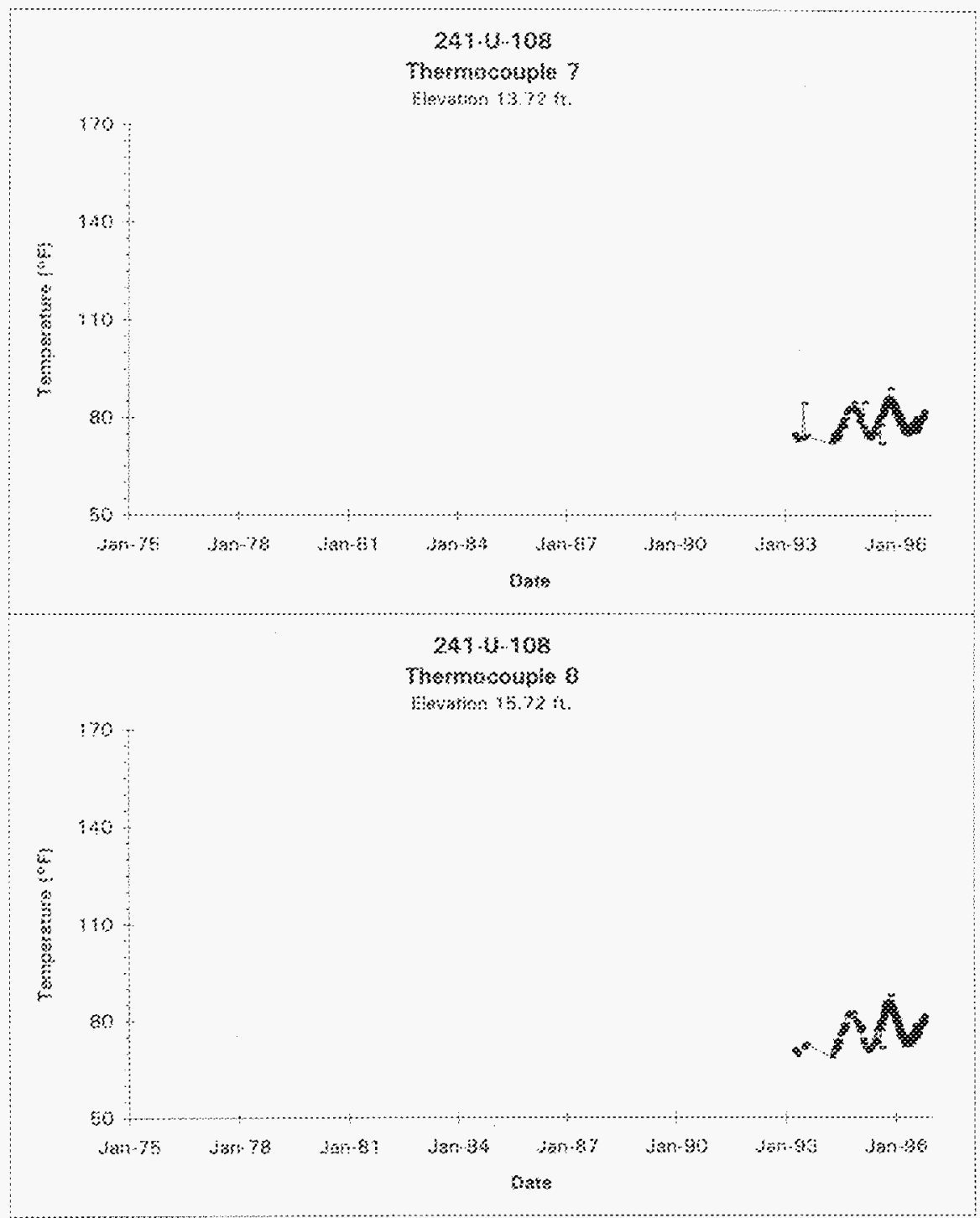

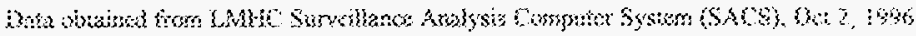
Do 36 
HNF-SD-WM-ER-325, Rev. 1

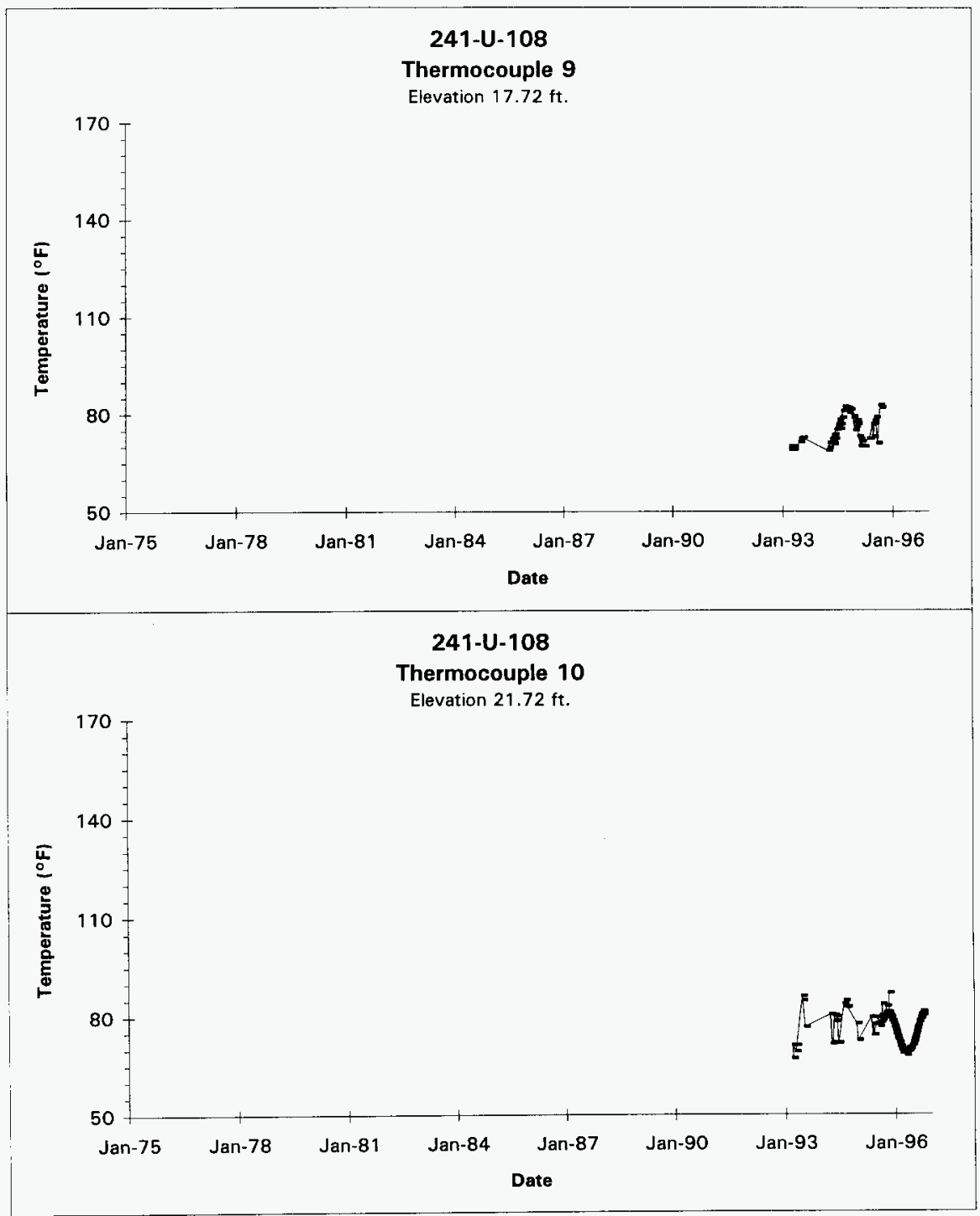

Data obtained from LMHC Surveillance Analysis Computer System (SACS), Oct 2, 1996.

D-37 


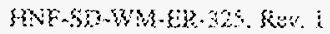

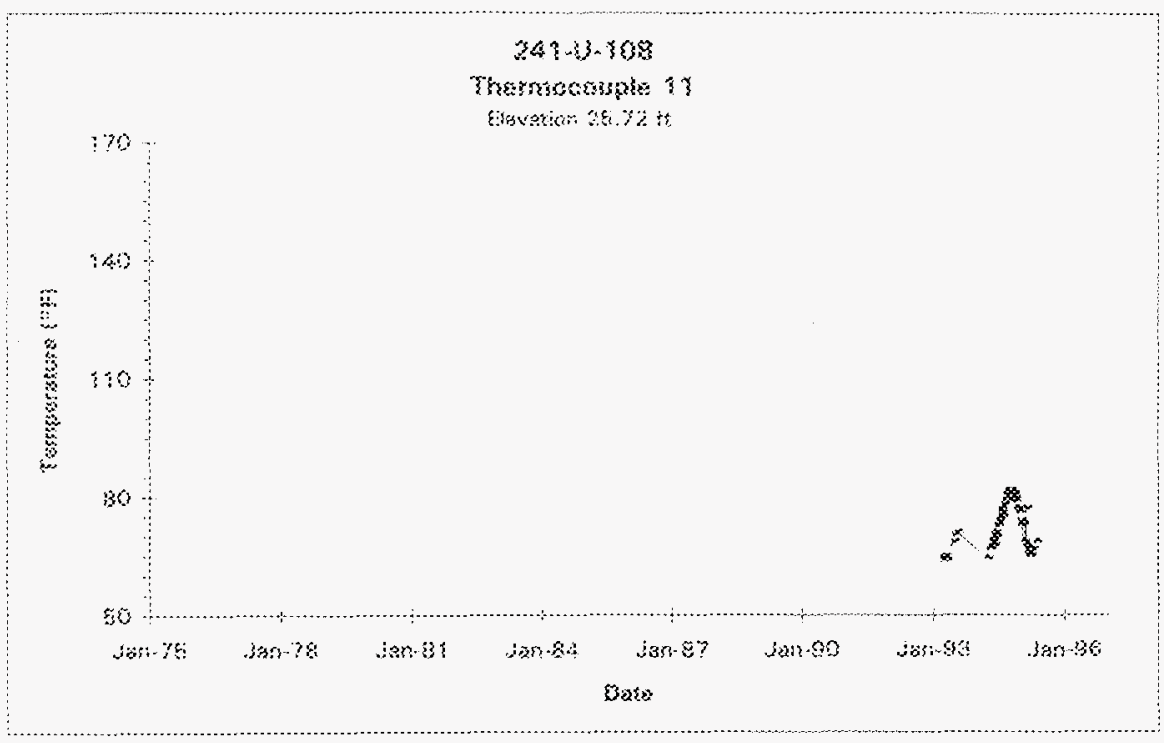

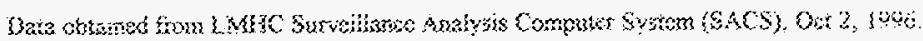

D. 38 


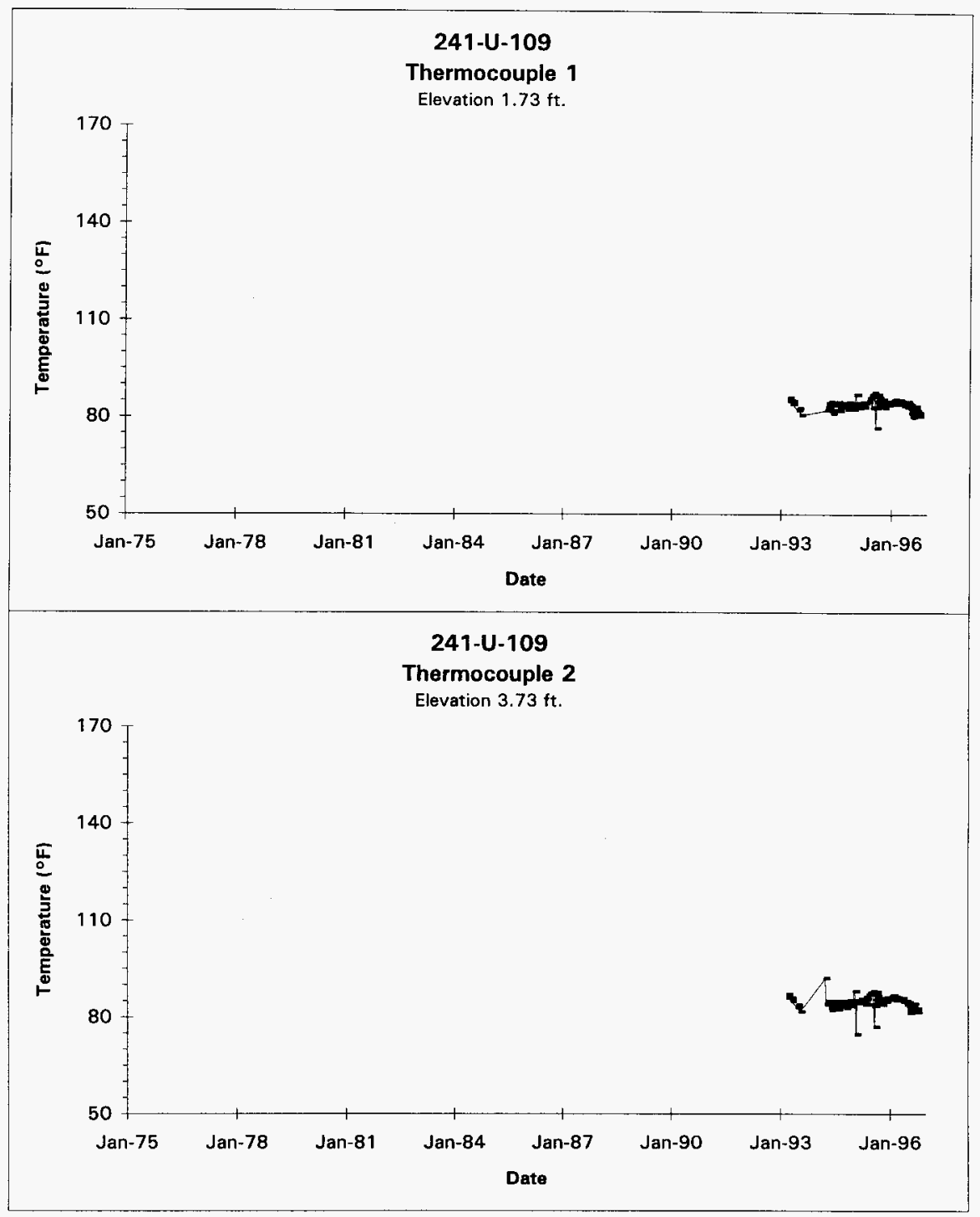

Data obtained from LMHC Surveillance Analysis Computer System (SACS), Oct 2, 1996.

D-39 


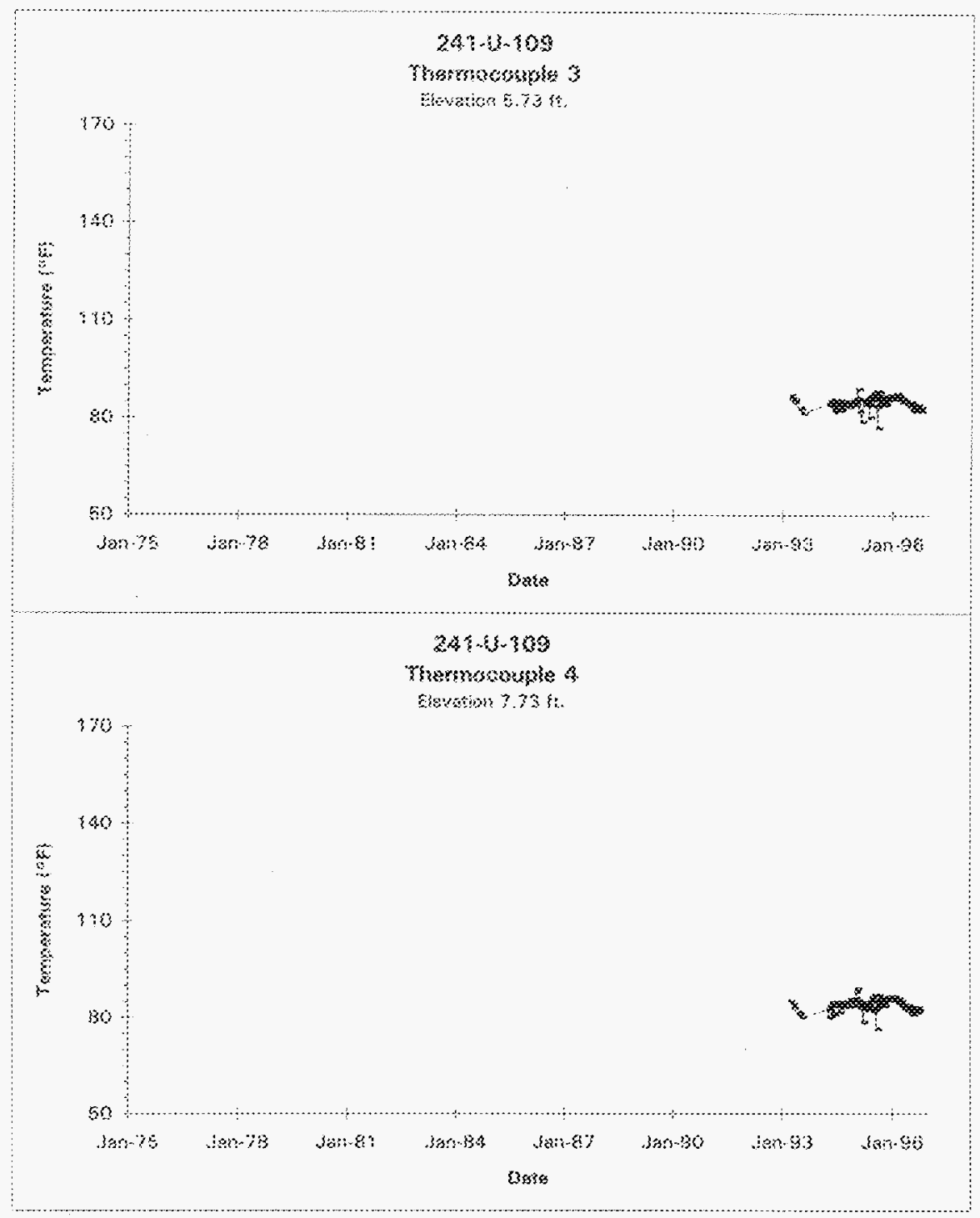

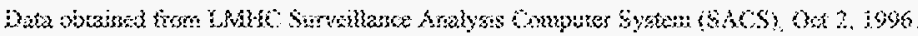
O) 10 


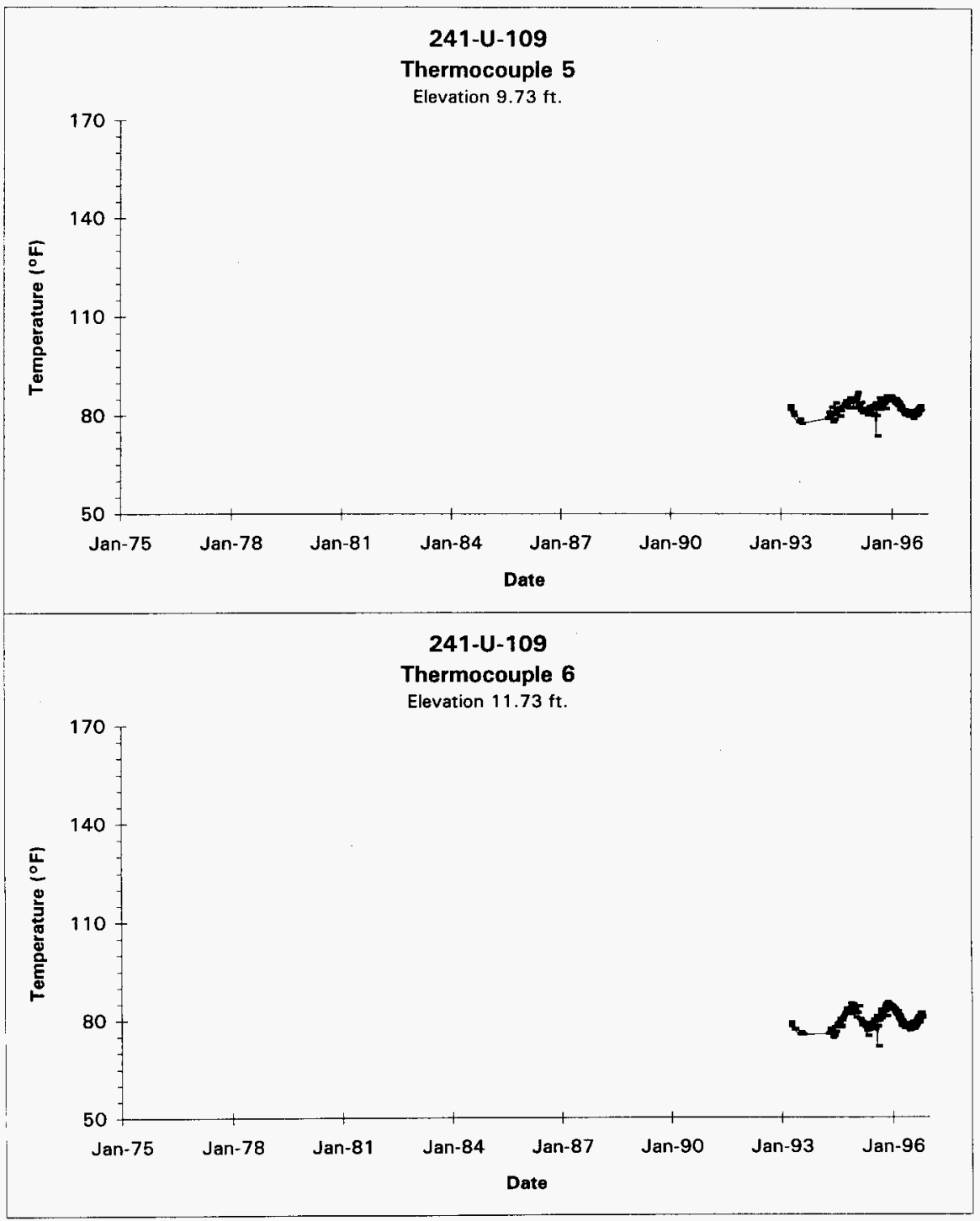

Data obtained from LMHC Surveillance Analysis Computer System (SACS), Oct 2, 1996. 


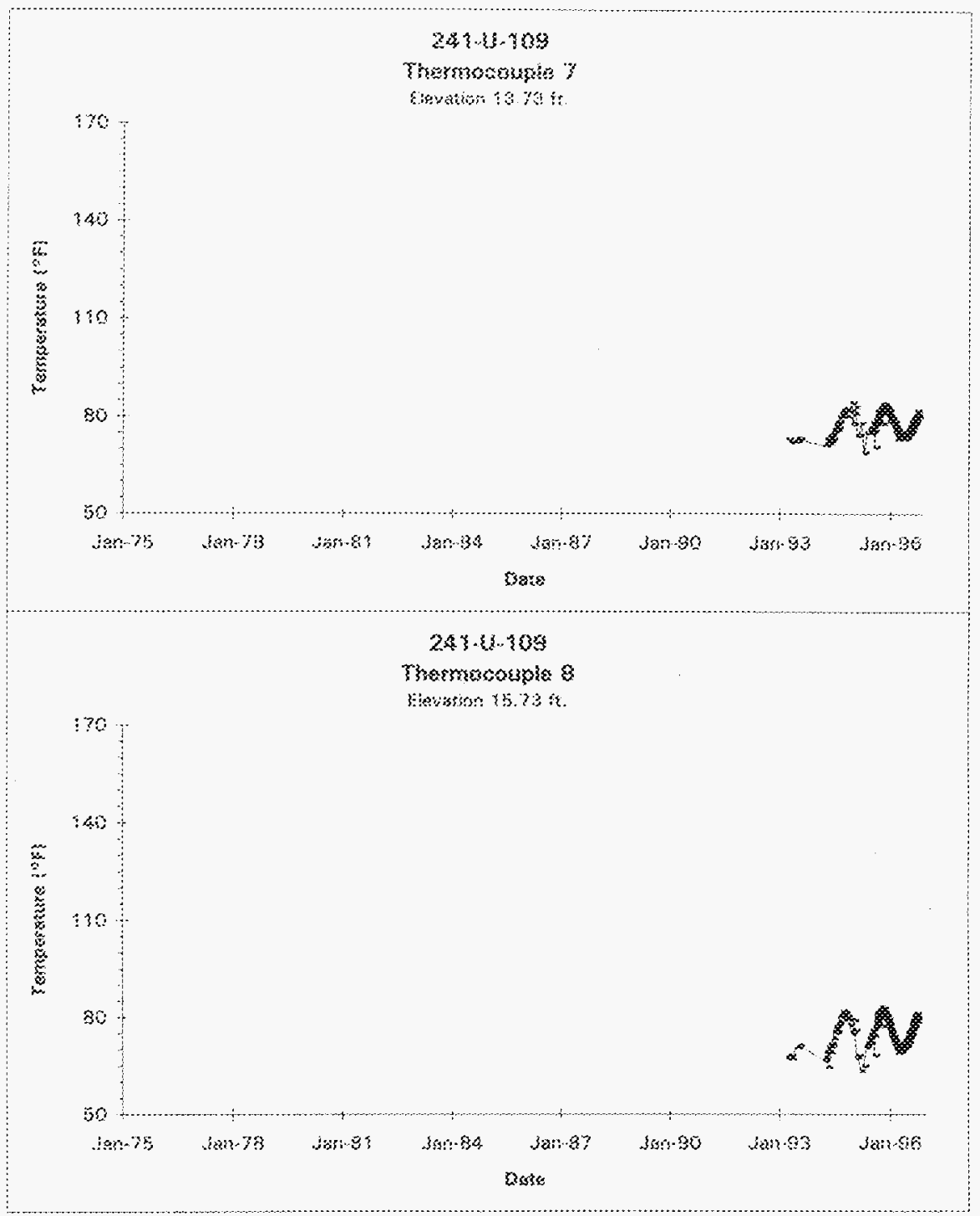

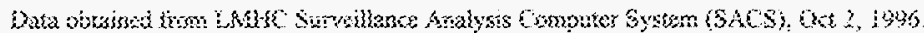
(3) $\}$ 
HNF-SD-WM-ER-325, Rev. 1

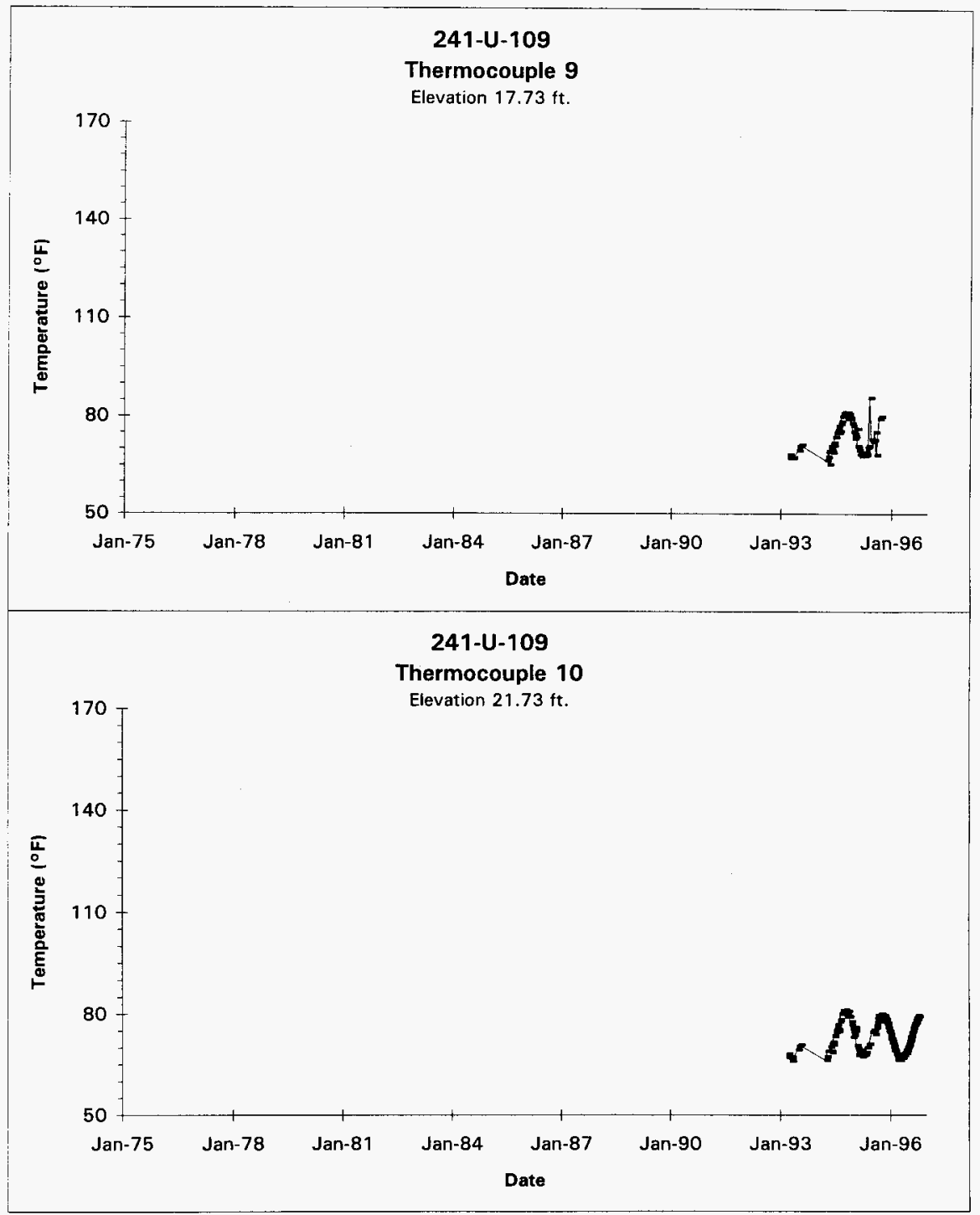

Data obtained from LMHC Surveillance Analysis Computer System (SACS), Oct 2, 1996.

D-43 


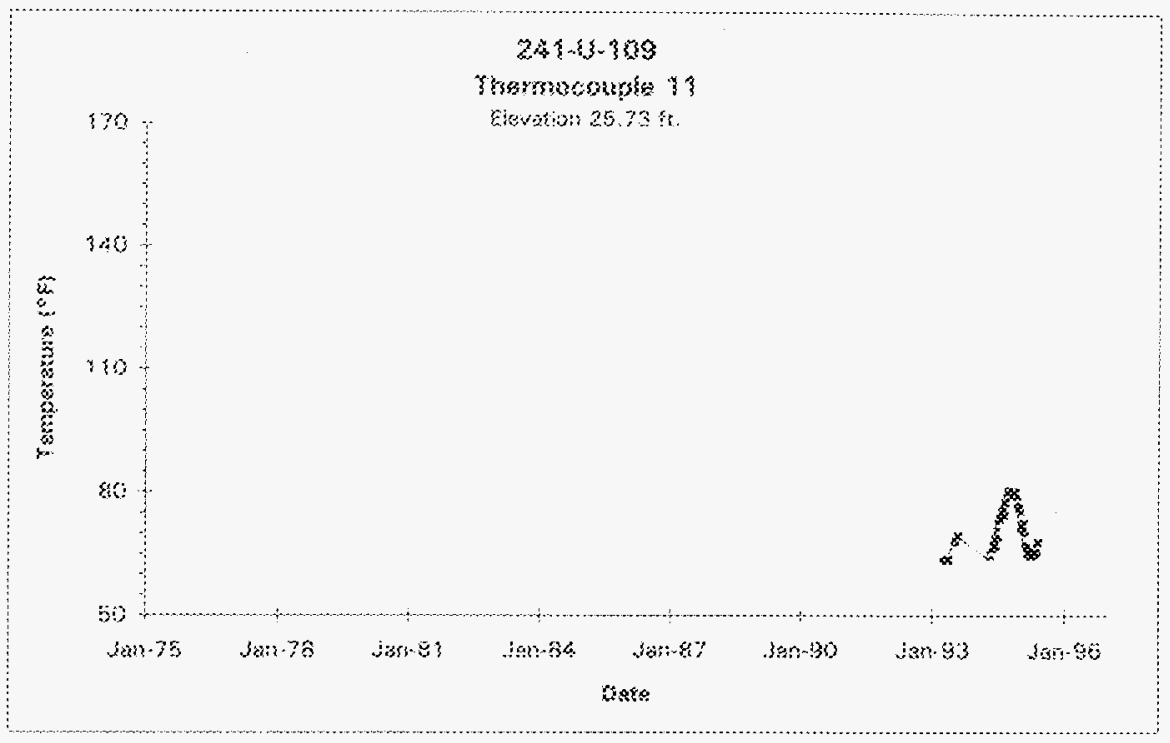

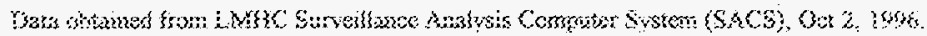




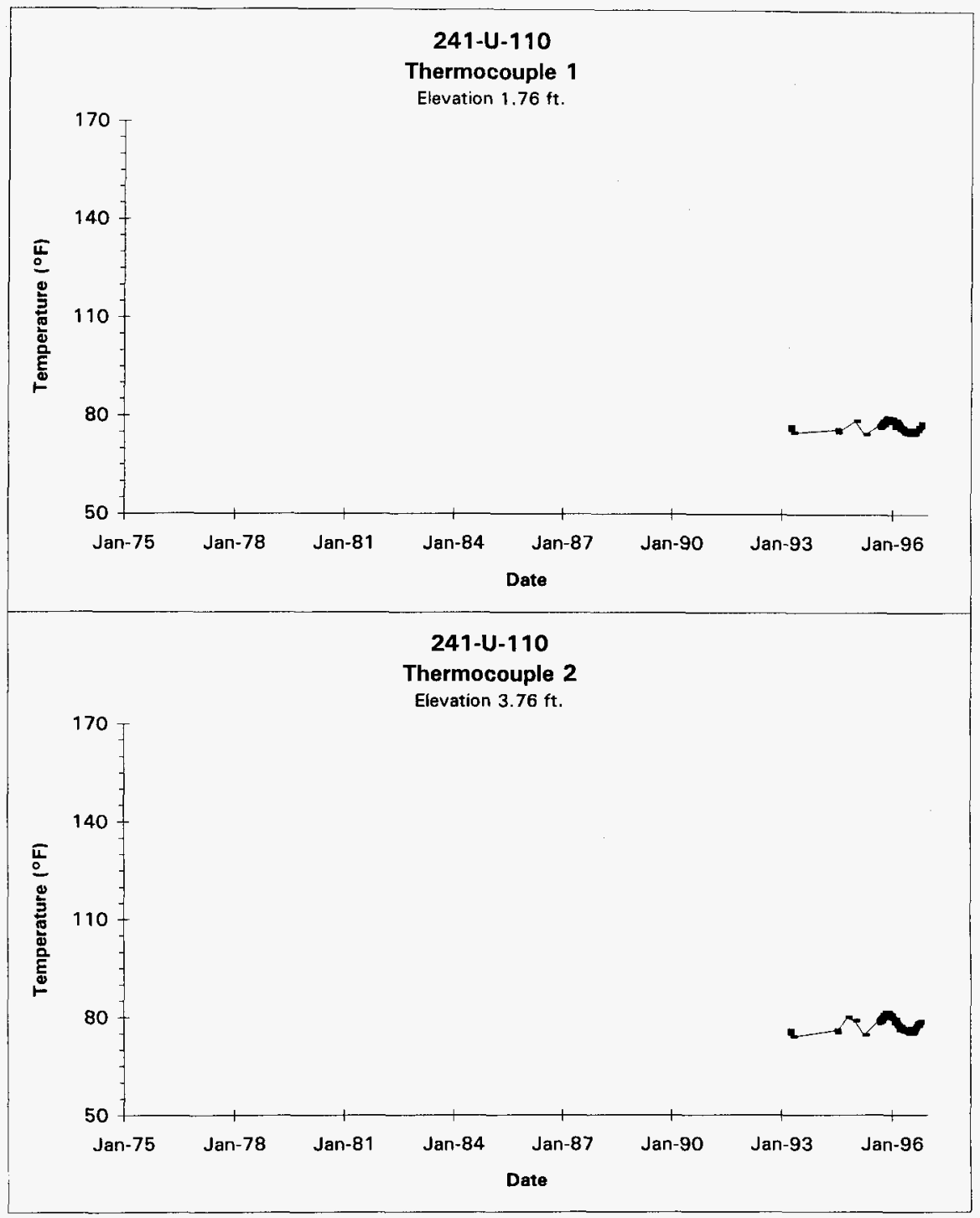

Data obtained from LMHC Surveillance Analysis Computer System (SACS), Oct 2, 1996.

$$
\text { D-45 }
$$




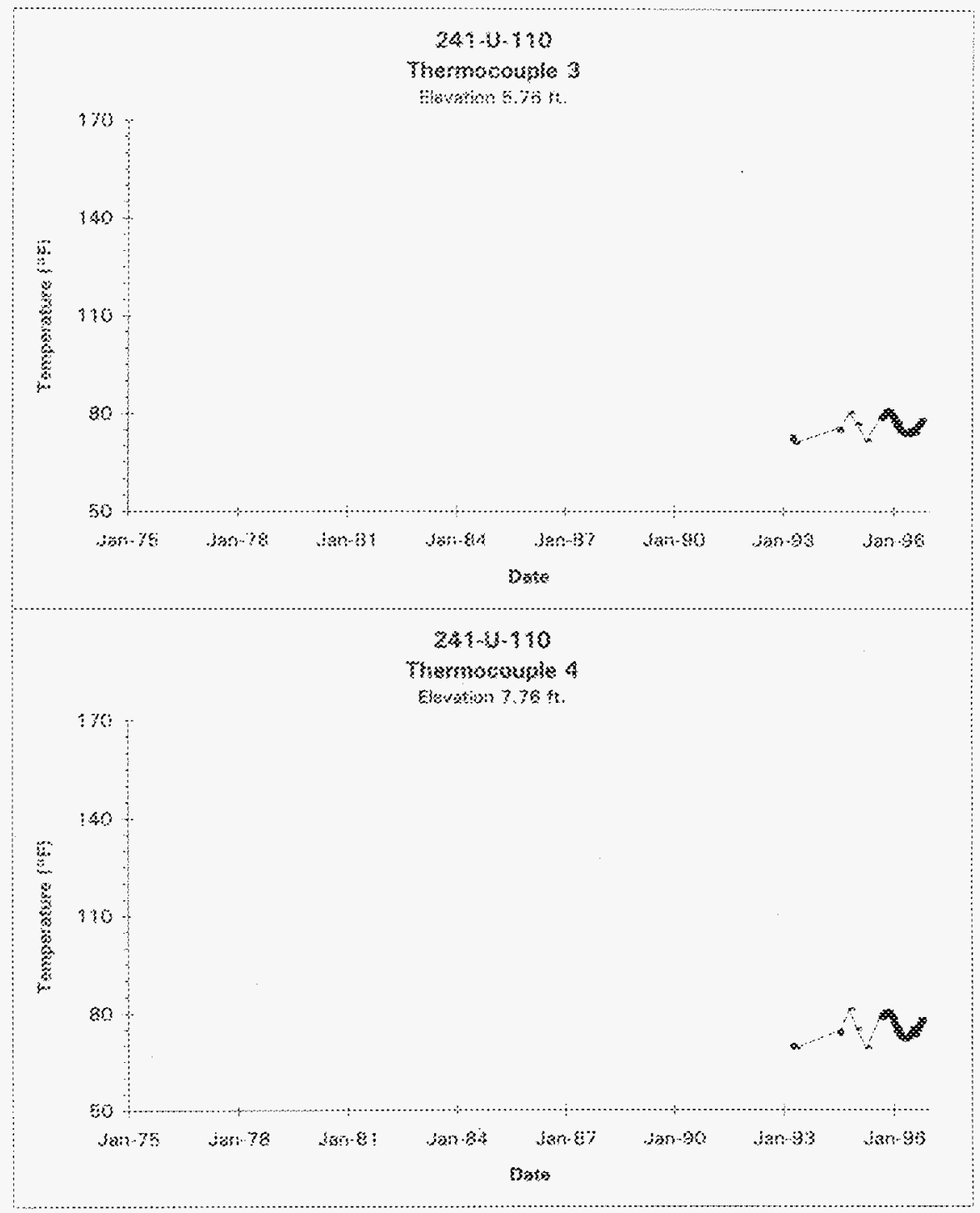

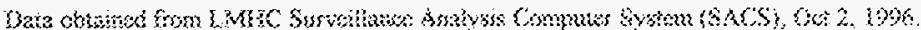


HNF-SD-WM-ER-325, Rev. 1

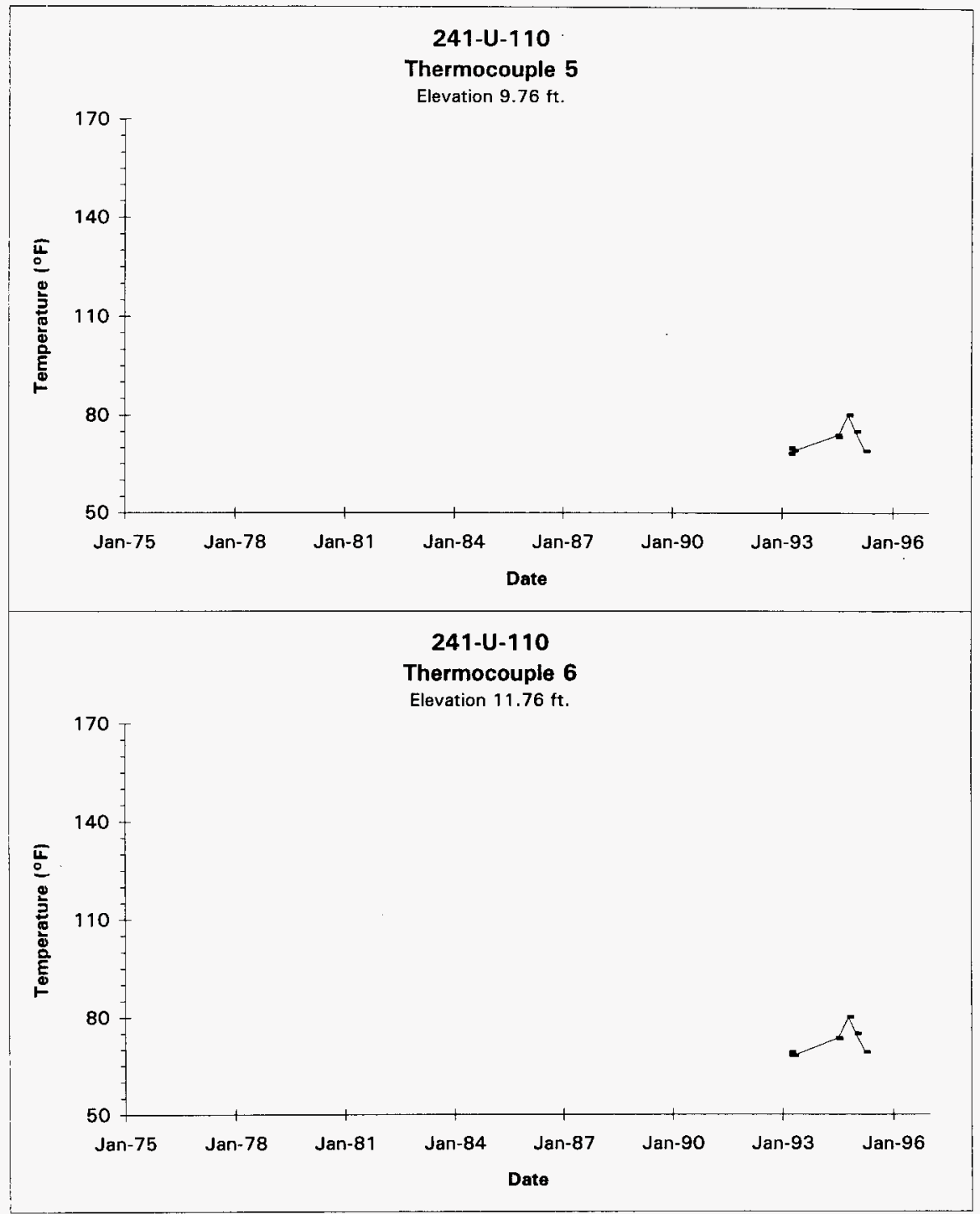

Data obtained from LMHC Surveillance Analysis Computer System (SACS), Oct 2, 1996.

D-47 


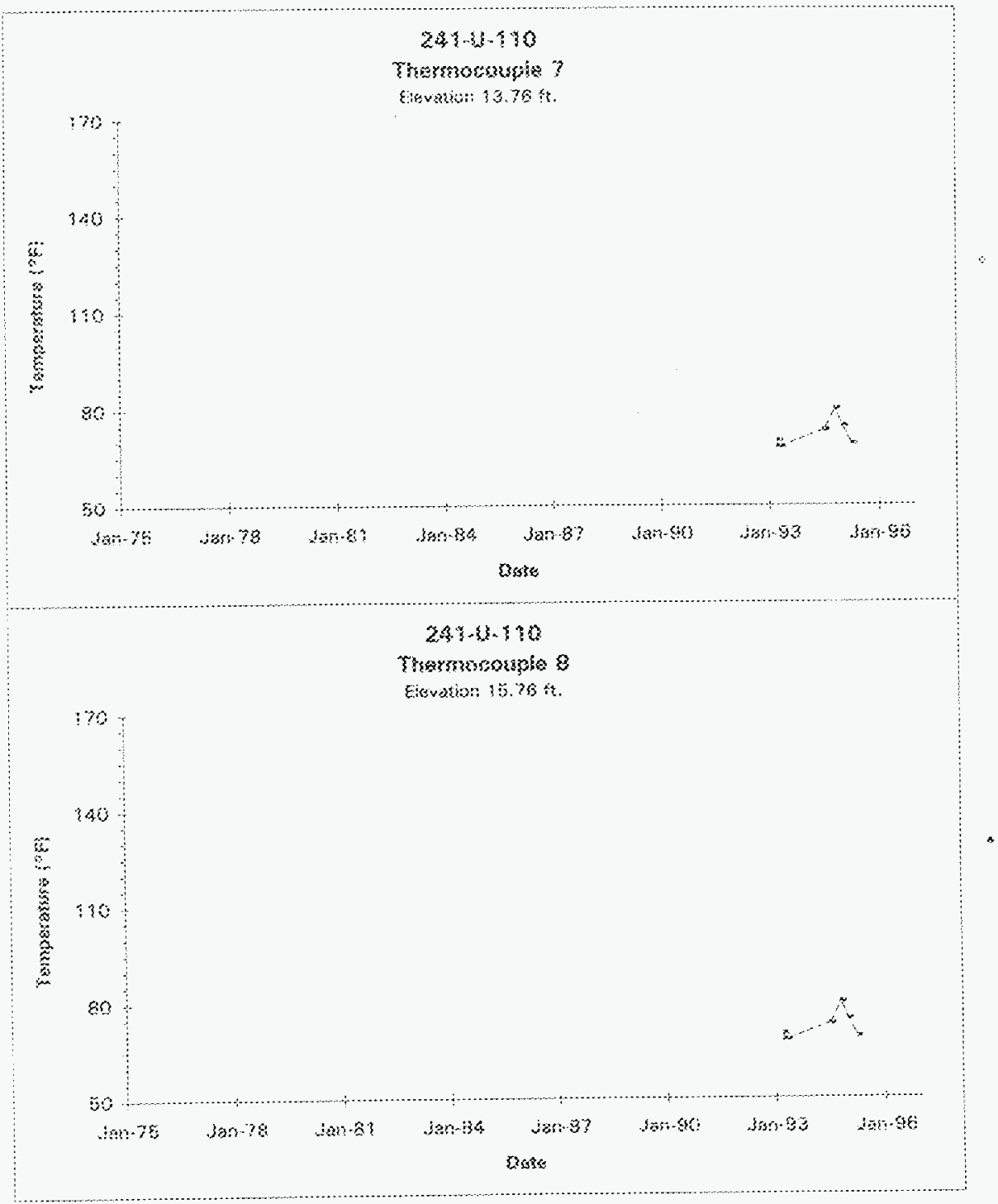

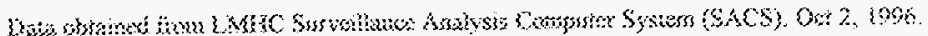


HNF-SD-WM-ER-325, Rev. 1

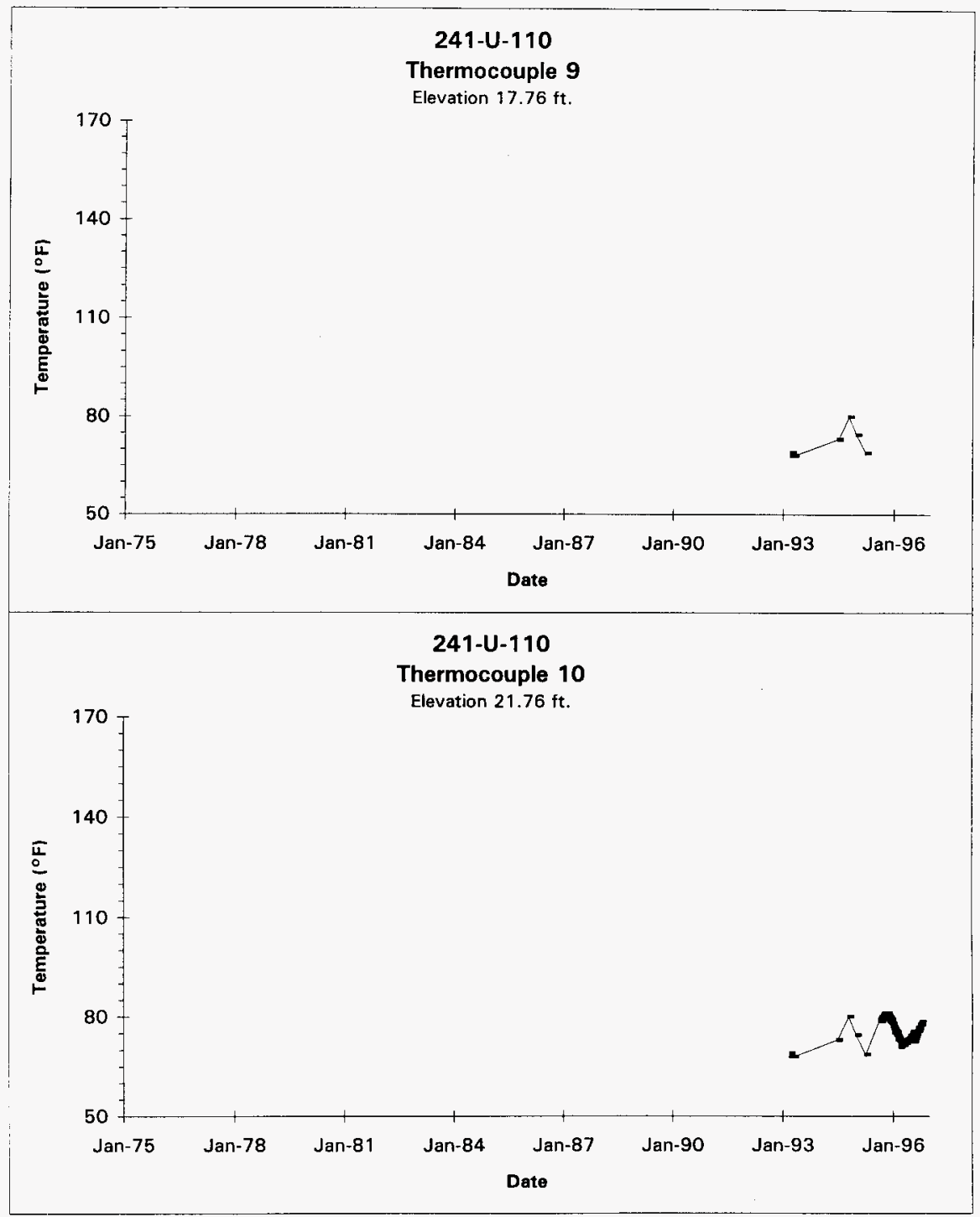

Data obtained from LMHC Surveillance Analysis Computer System (SACS), Oct 2, 1996.

D-49 


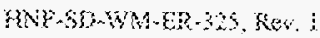

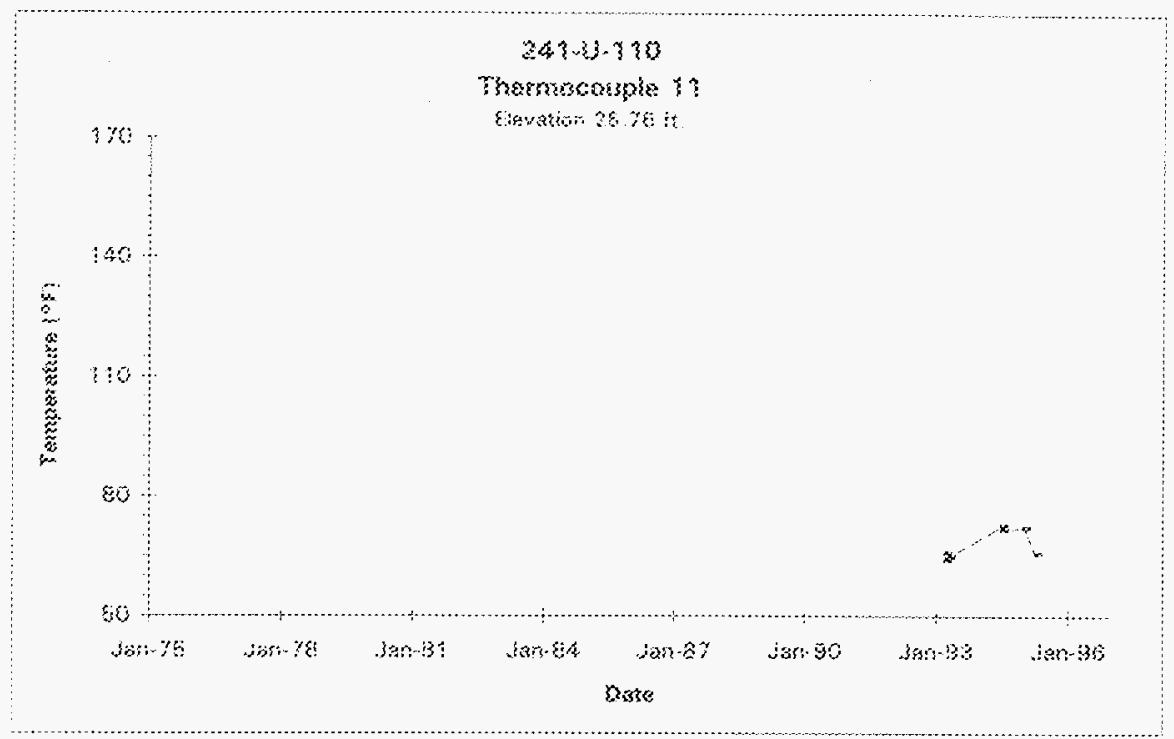

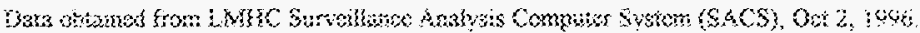

5.50 
HNF-SD-WM-ER-325, Rev. 1

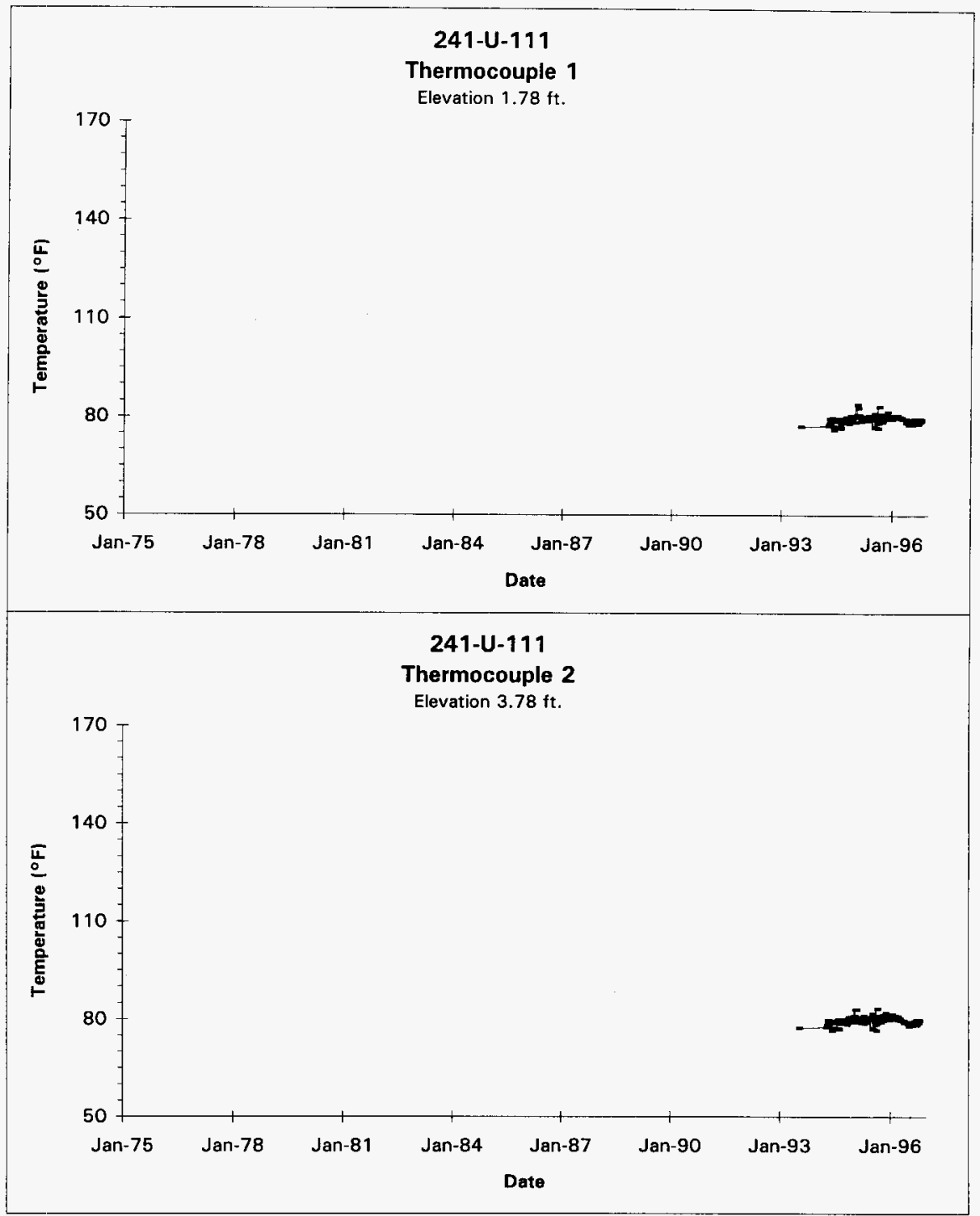

Data obtained from LMHC Surveillance Analysis Computer System (SACS), Oct 2, 1996.

D-51 


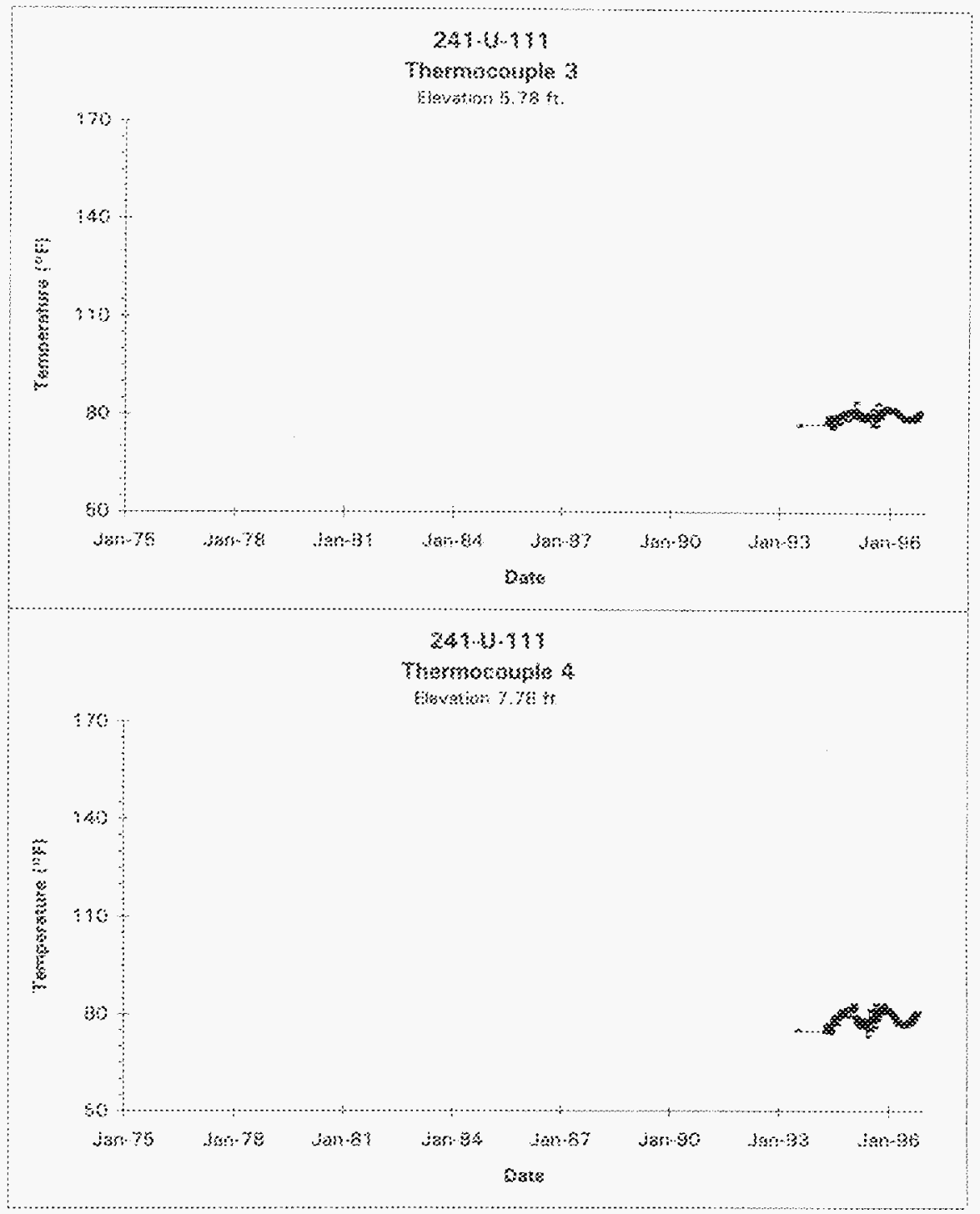

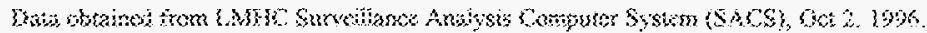




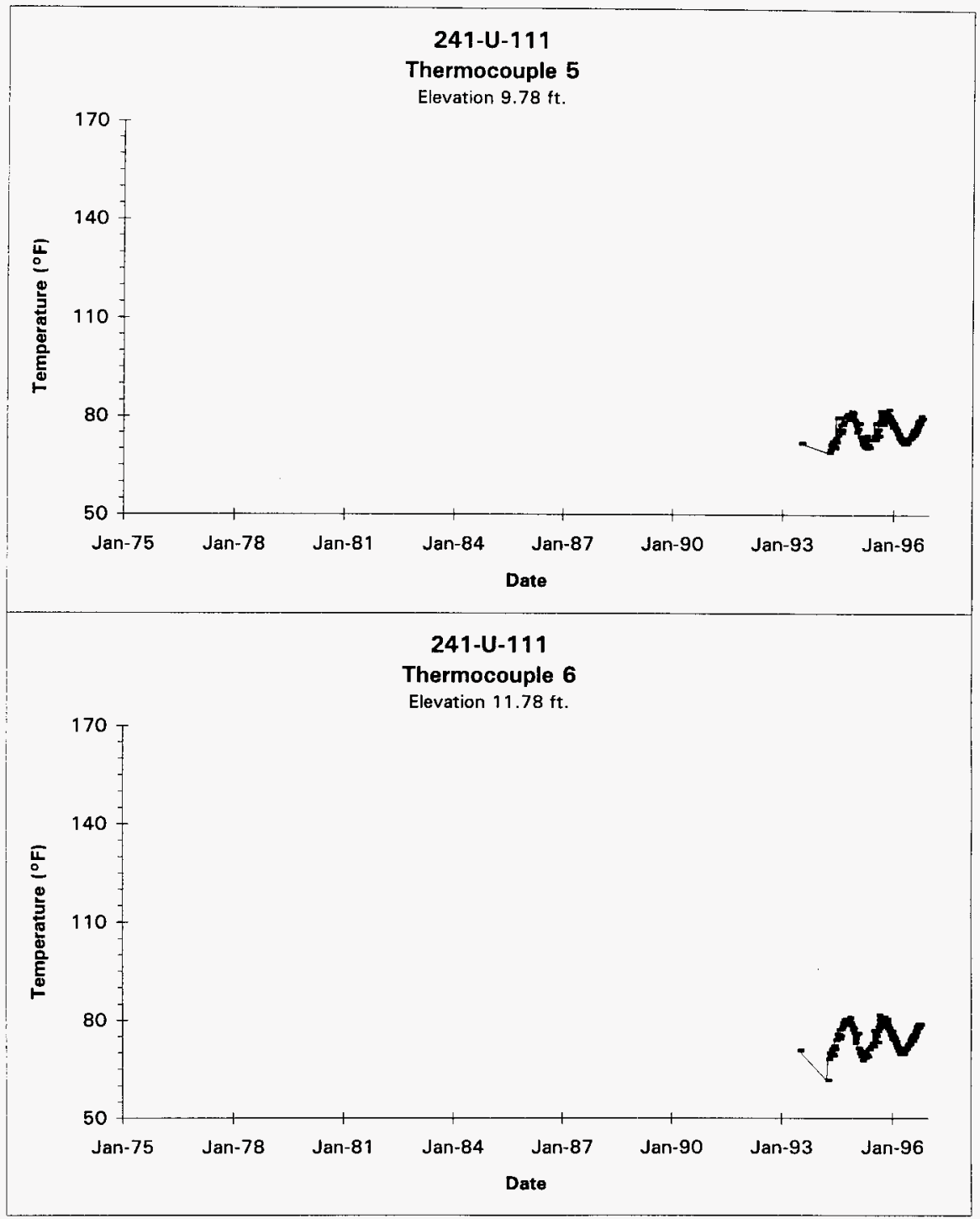

Data obtained from LMHC Surveillance Analysis Computer System (SACS), Oct 2, 1996. 


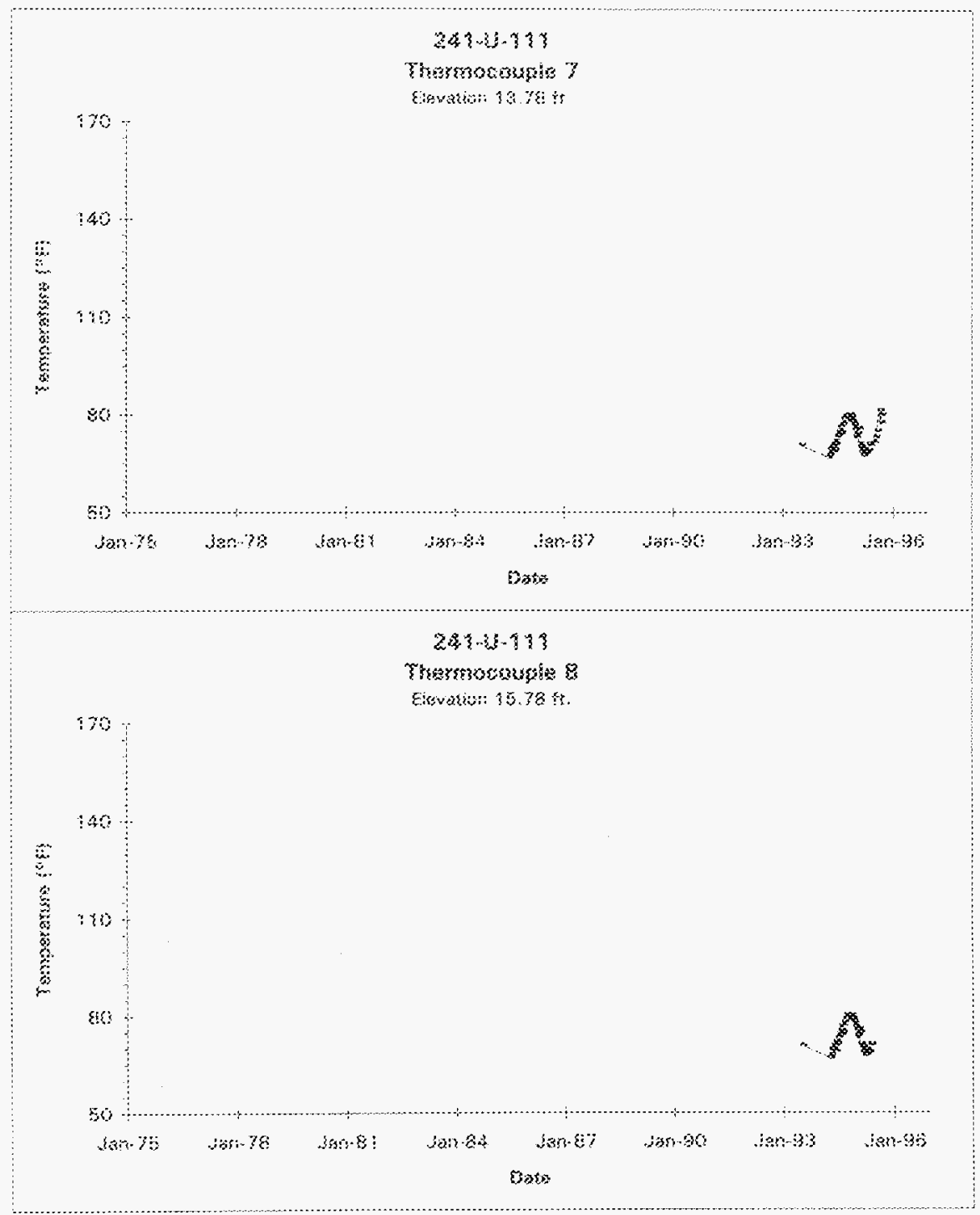

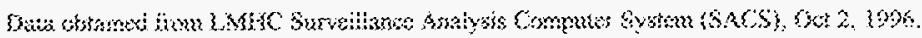
$5 \%$ 


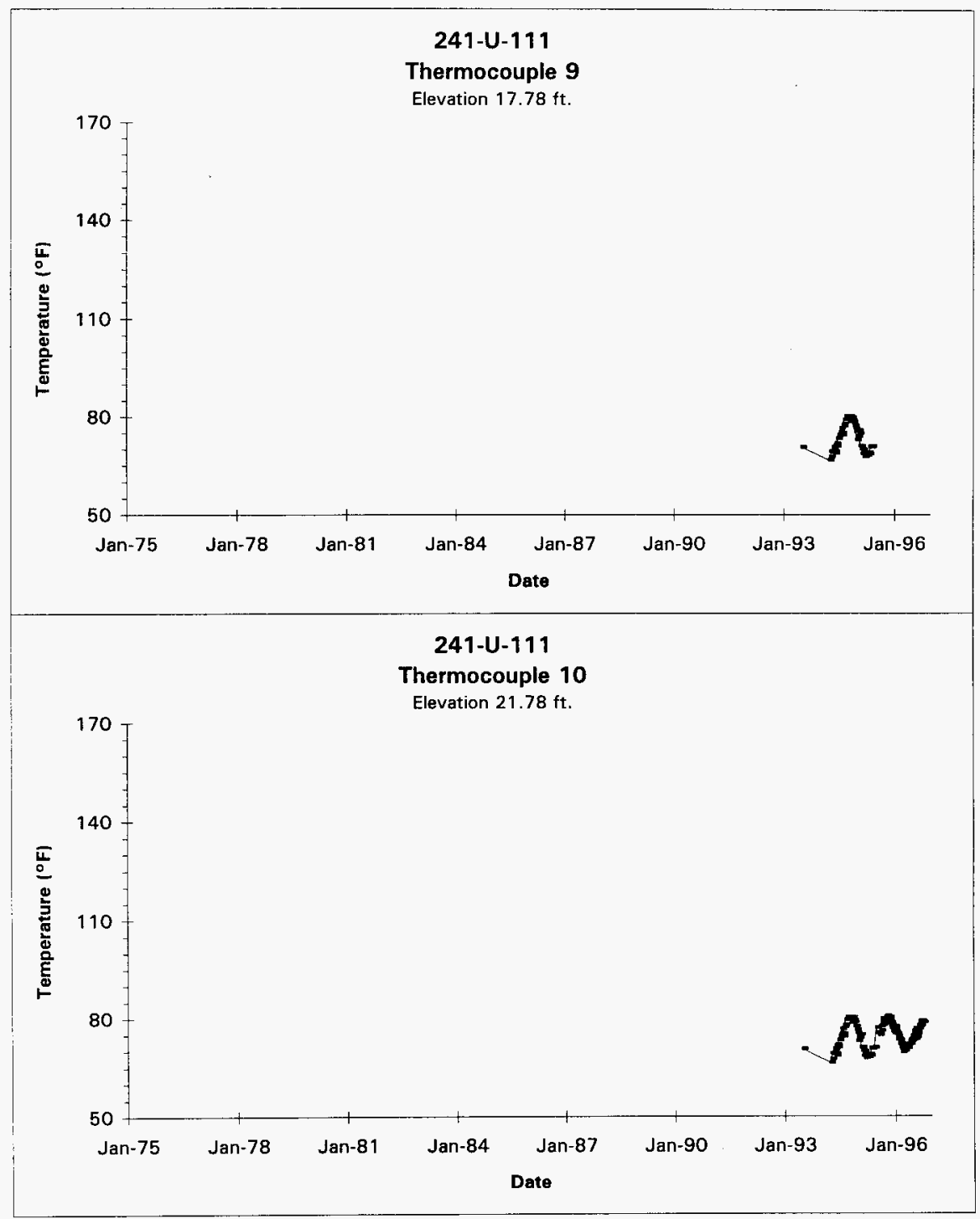

Data obtained from LMHC Surveillance Analysis Computer System (SACS), Oct 2, 1996.

$$
\text { D-55 }
$$




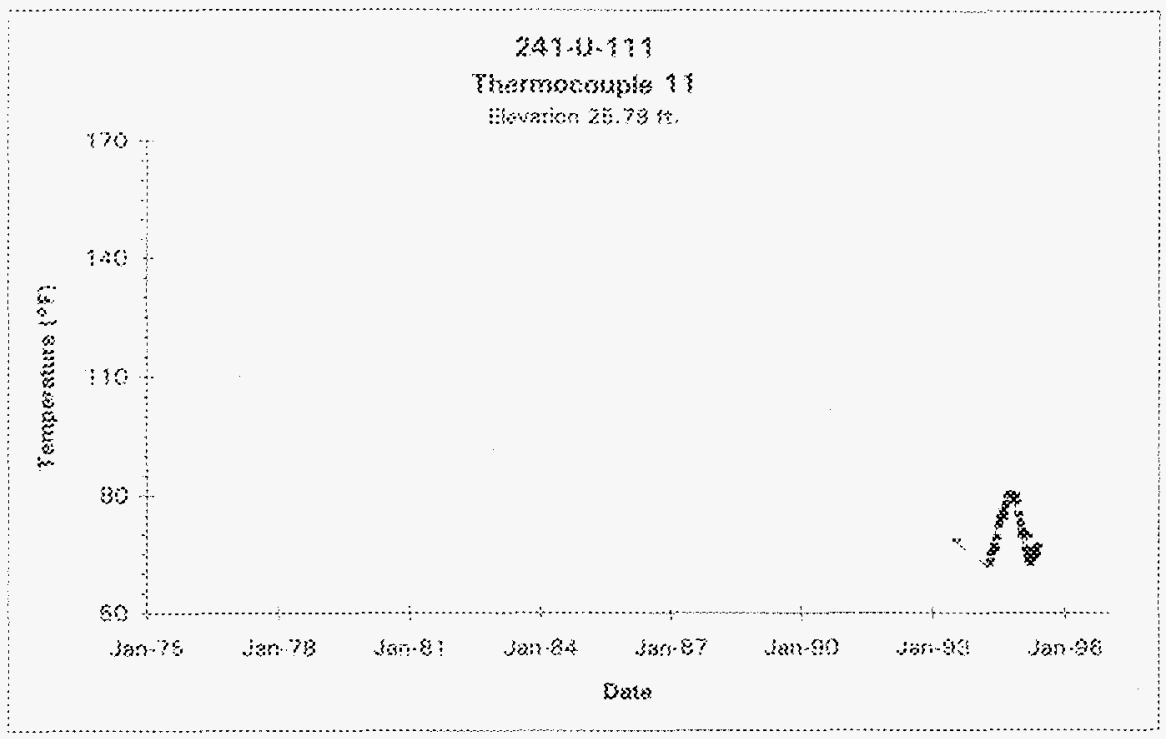

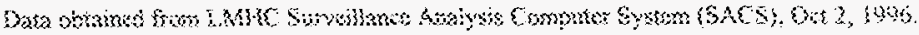
प) 


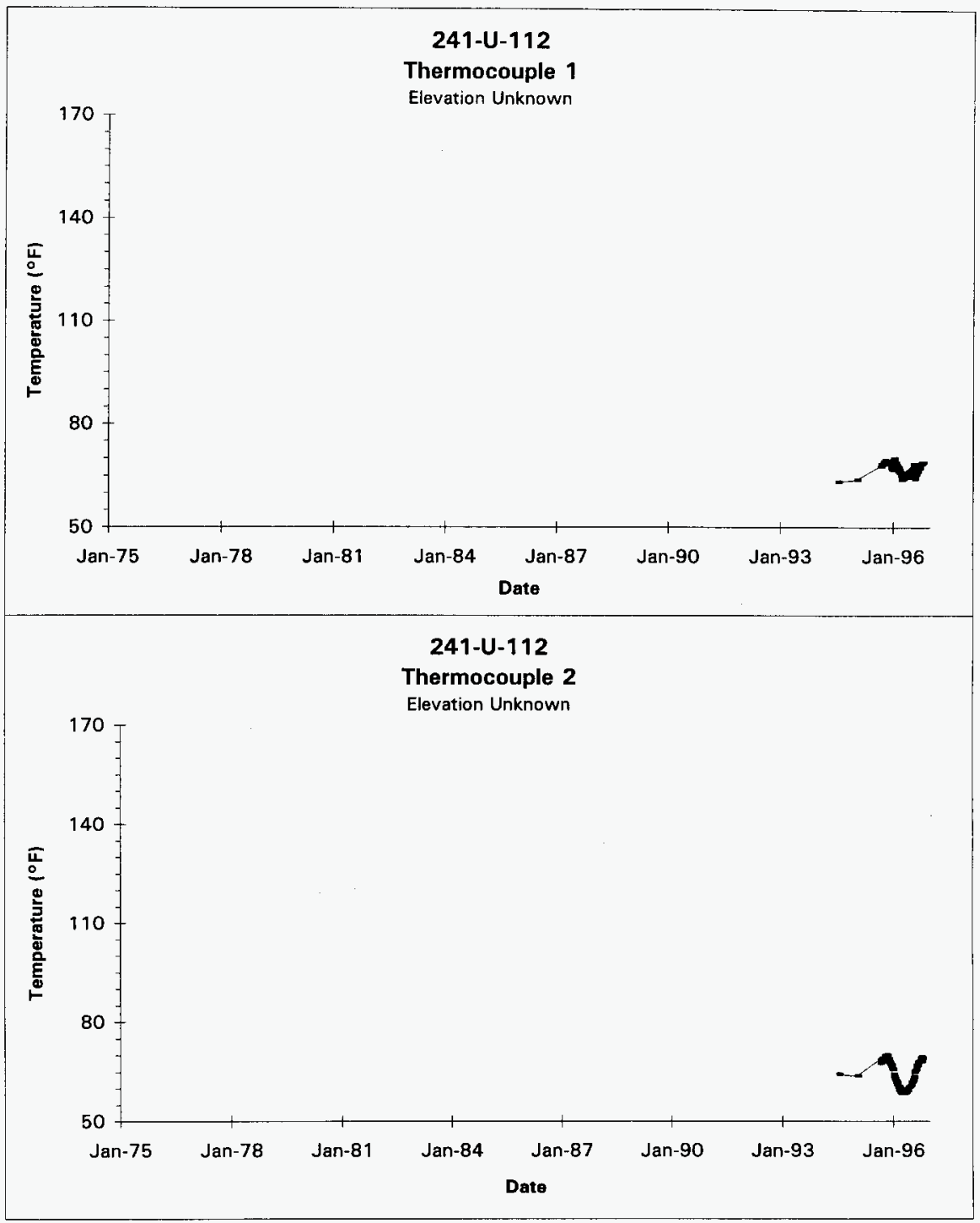

Data obtained from LMHC Surveillance Analysis Computer System (SACS), Oct 2, 1996. 


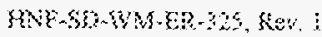

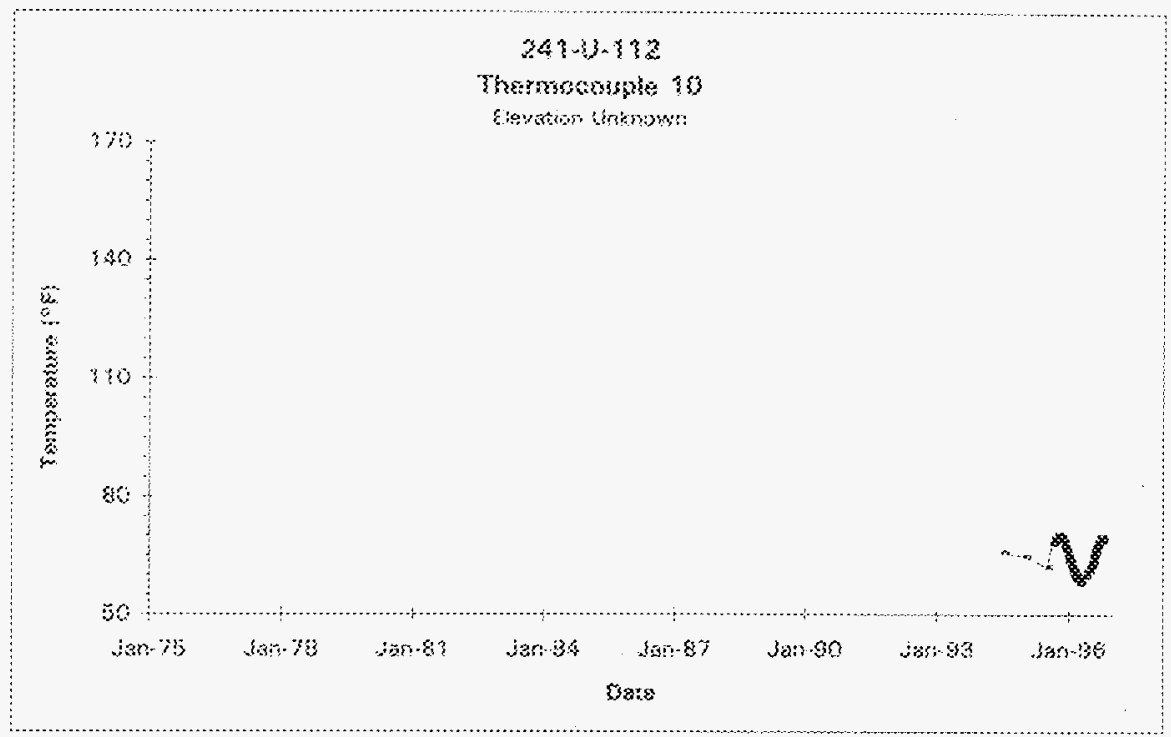

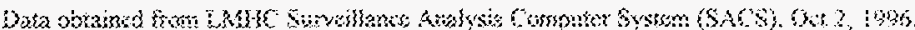

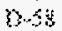


HNF-SD-WM-ER-325, Rev. 1

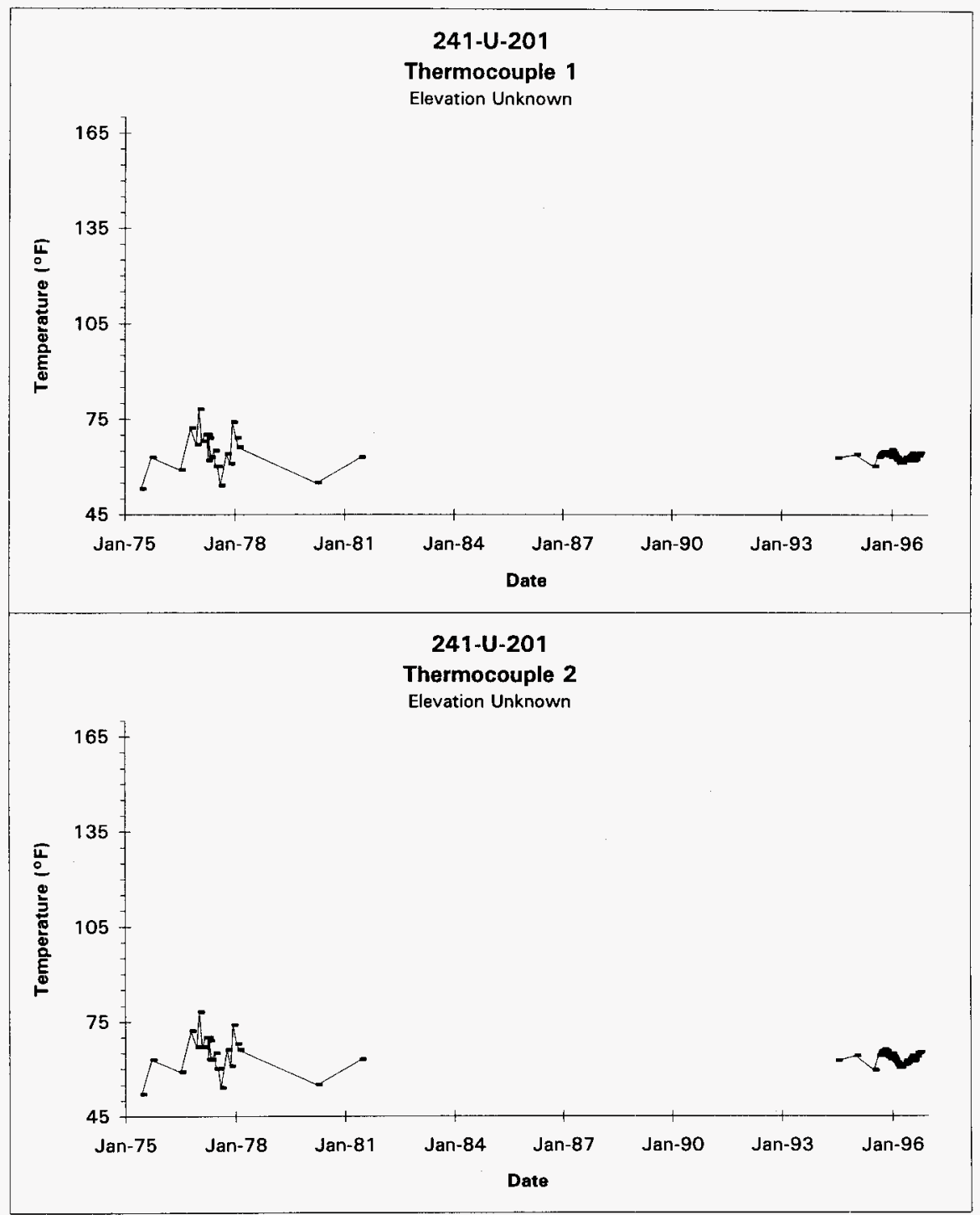

Data obtained from LMHC Surveillance Analysis Computer System (SACS), Oct 2, 1996.

D-59 


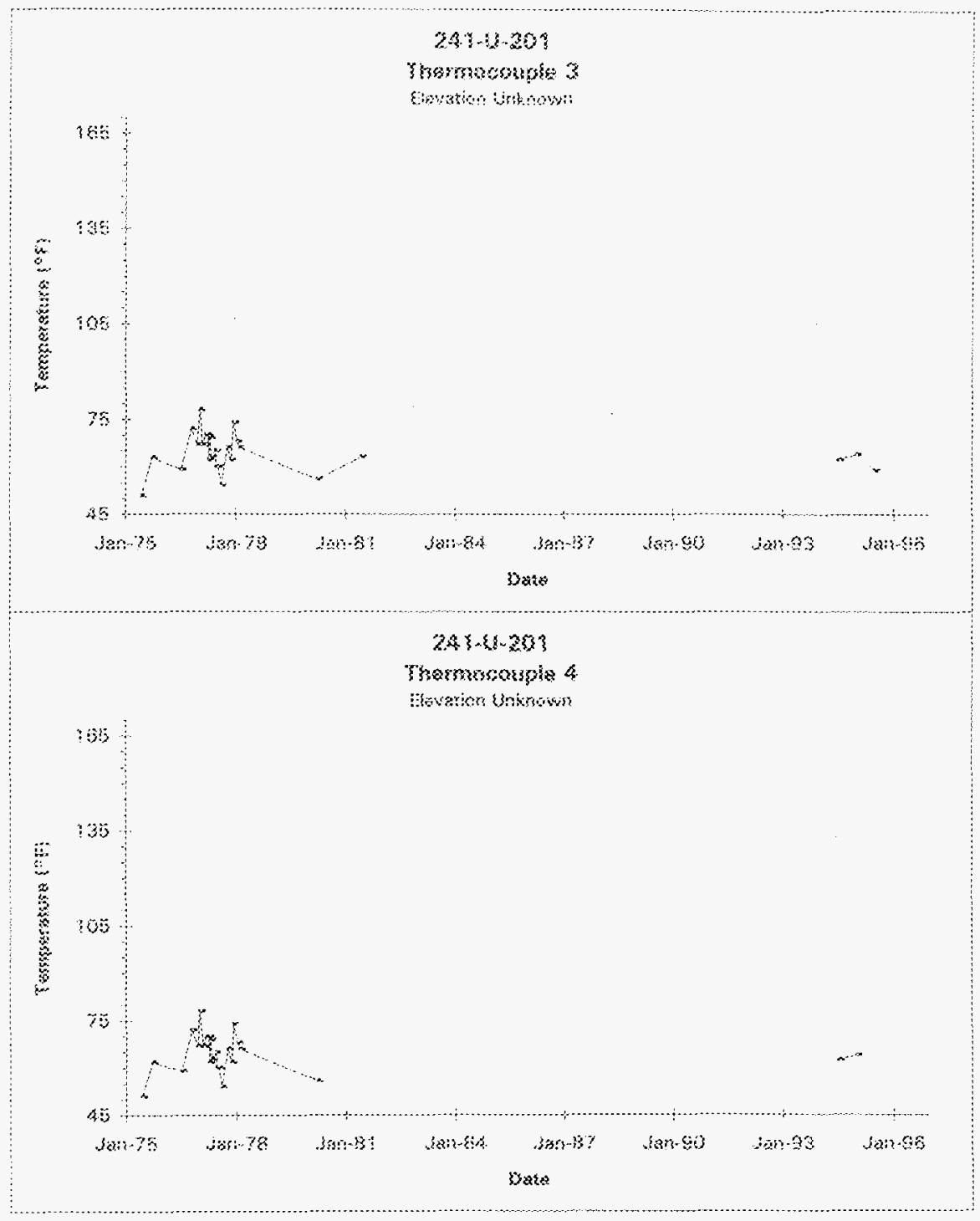

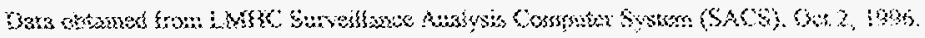
D 60 


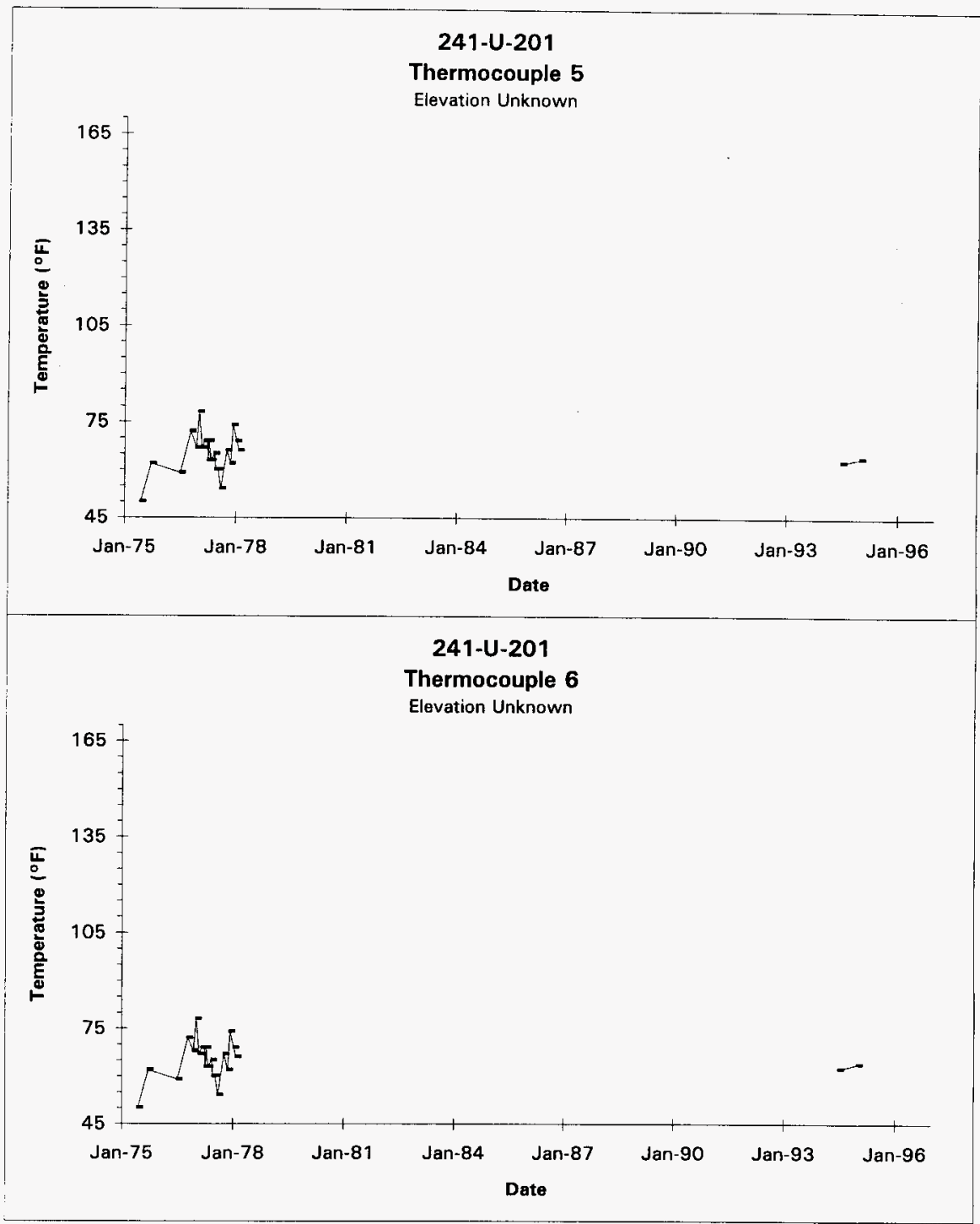

Data obtained from LMHC Surveillance Analysis Computer System (SACS), Oct 2, 1996. 


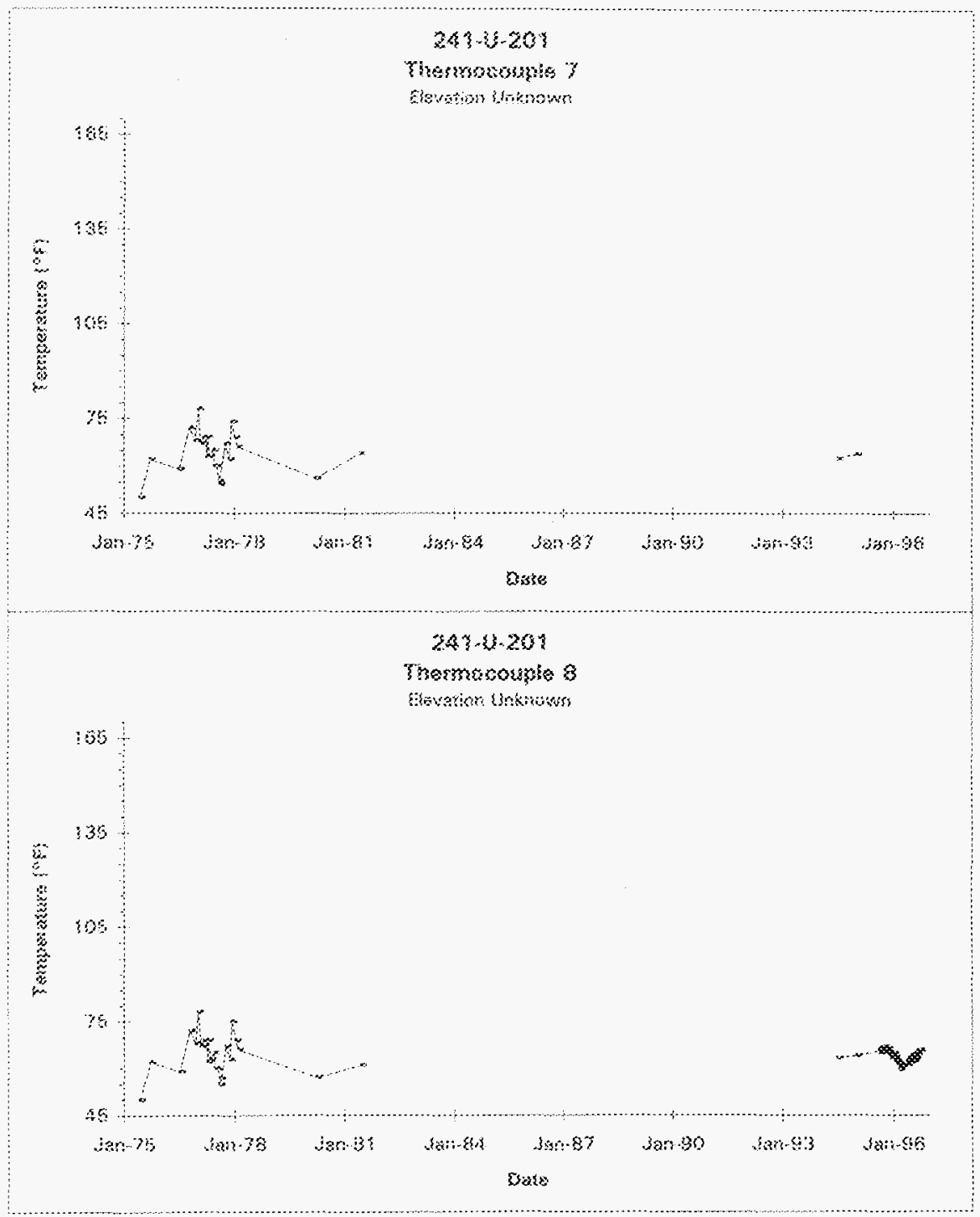

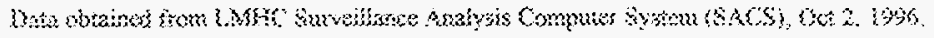


HNF-SD-WM-ER-325, Rev. 1

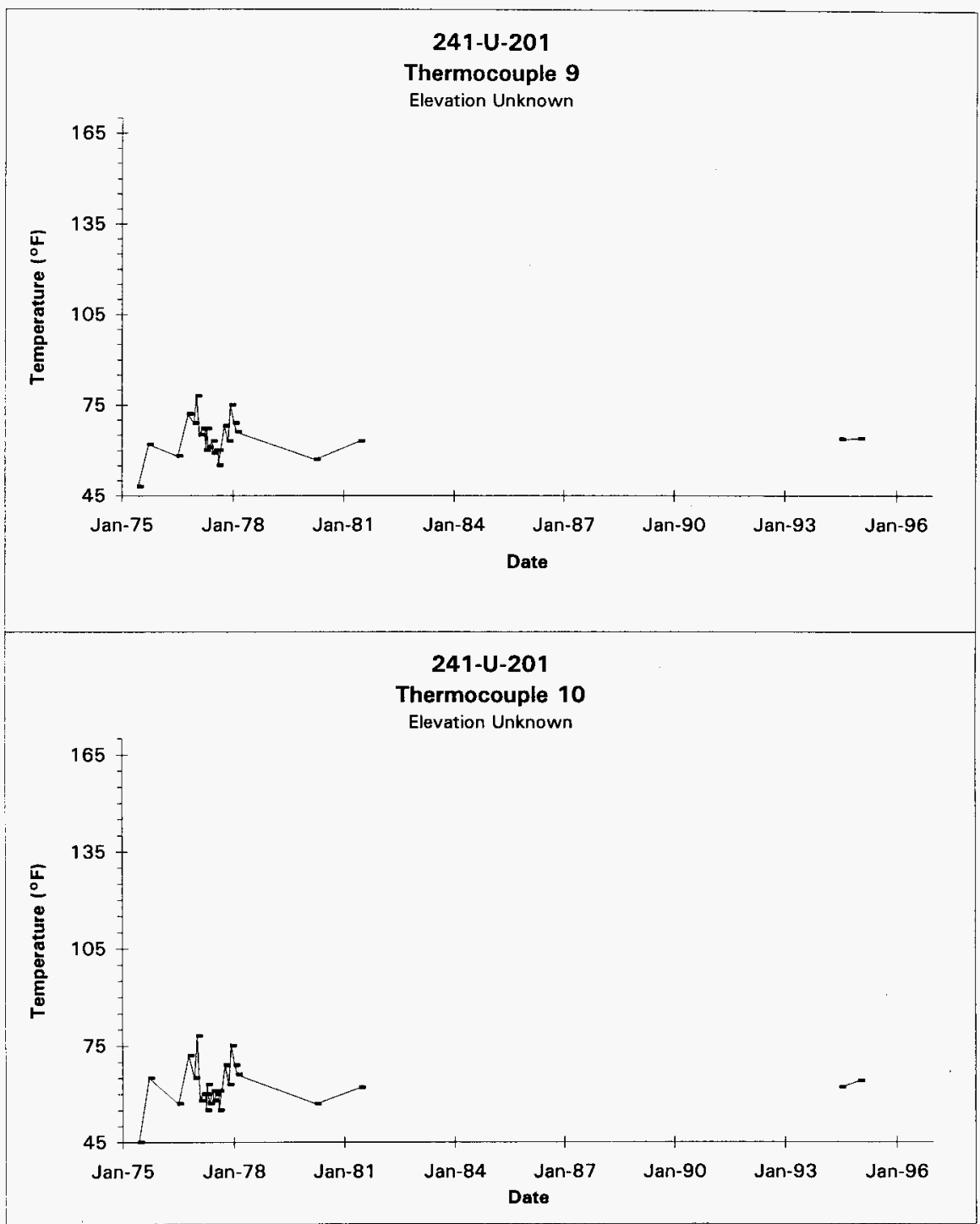

Data obtained from LMHC Surveillance Analysis Computer System (SACS), Oct 2, 1996.

$$
\text { D-63 }
$$




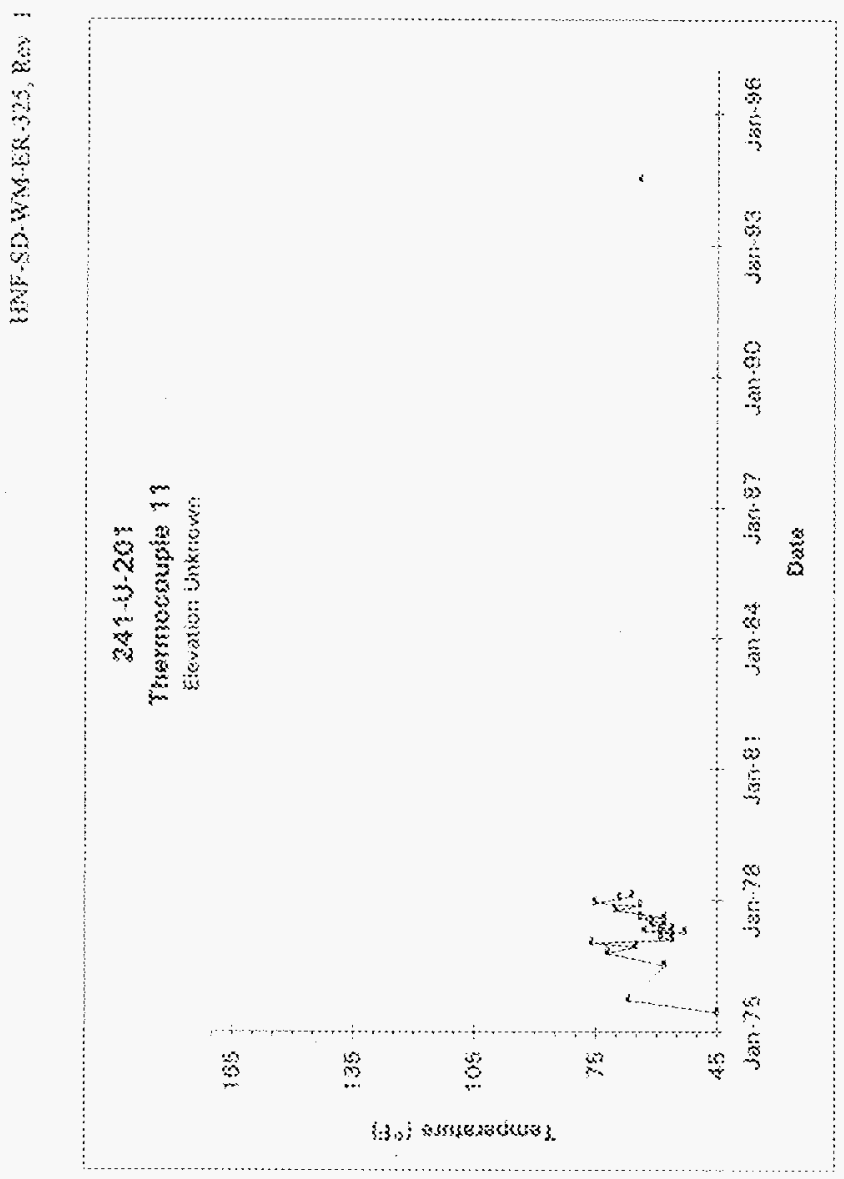

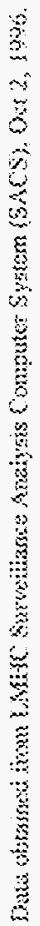


HNF-SD-WM-ER-325, Rev. 1

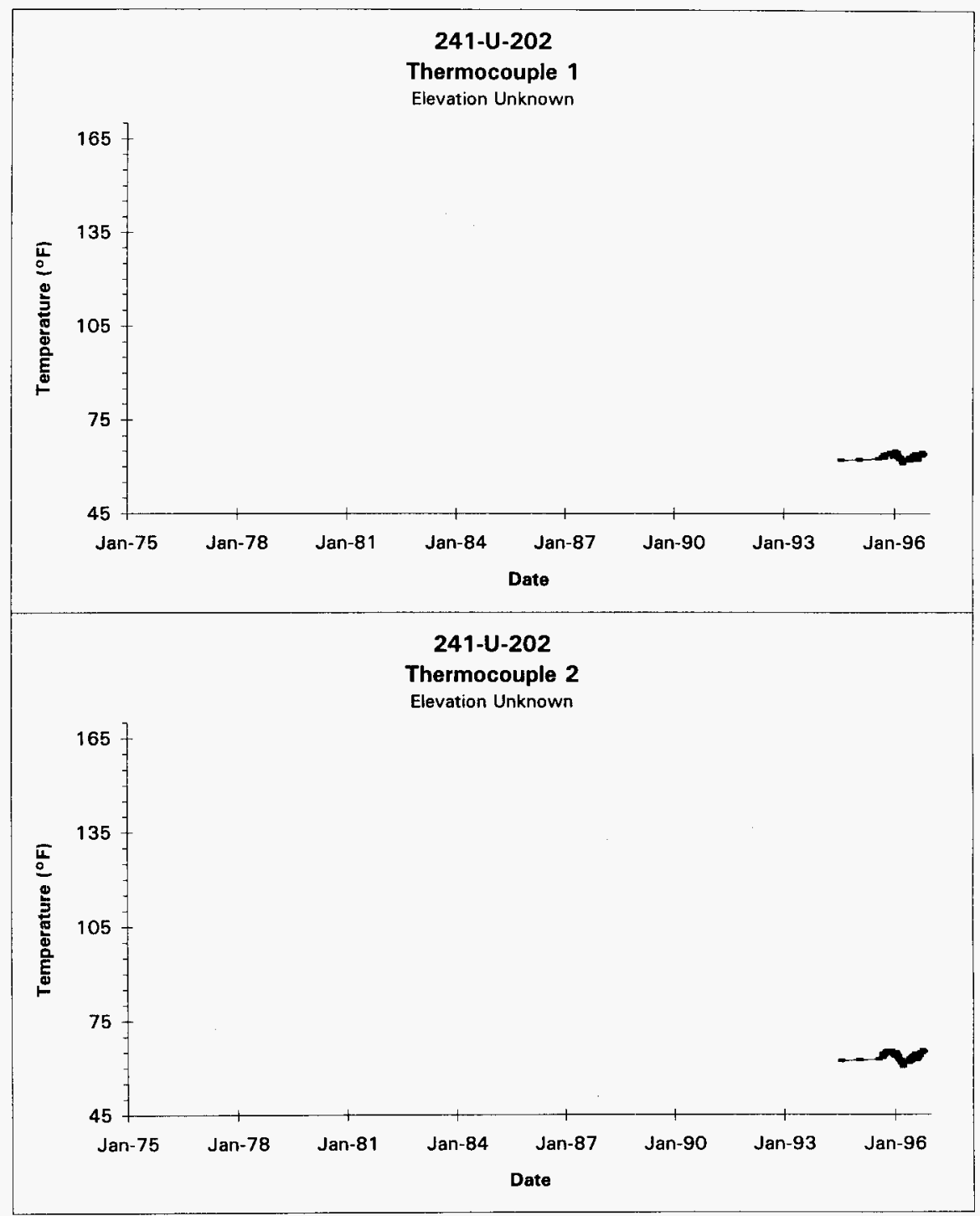

Data obtained from LMHC Surveillance Analysis Computer System (SACS), Oct 2, 1996.

D-65 


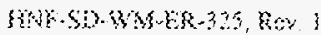

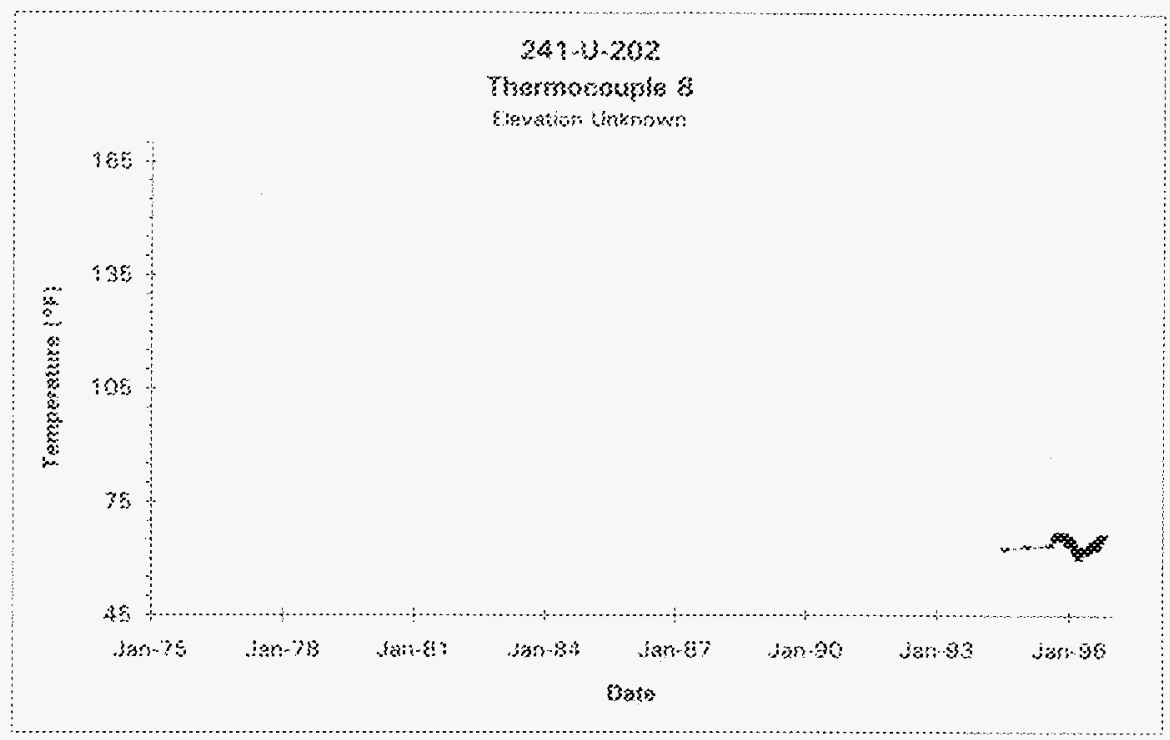

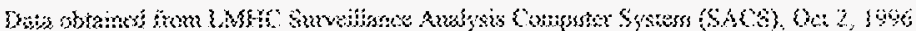
is -156 
HNF-SD-WM-ER-325, Rev. 1

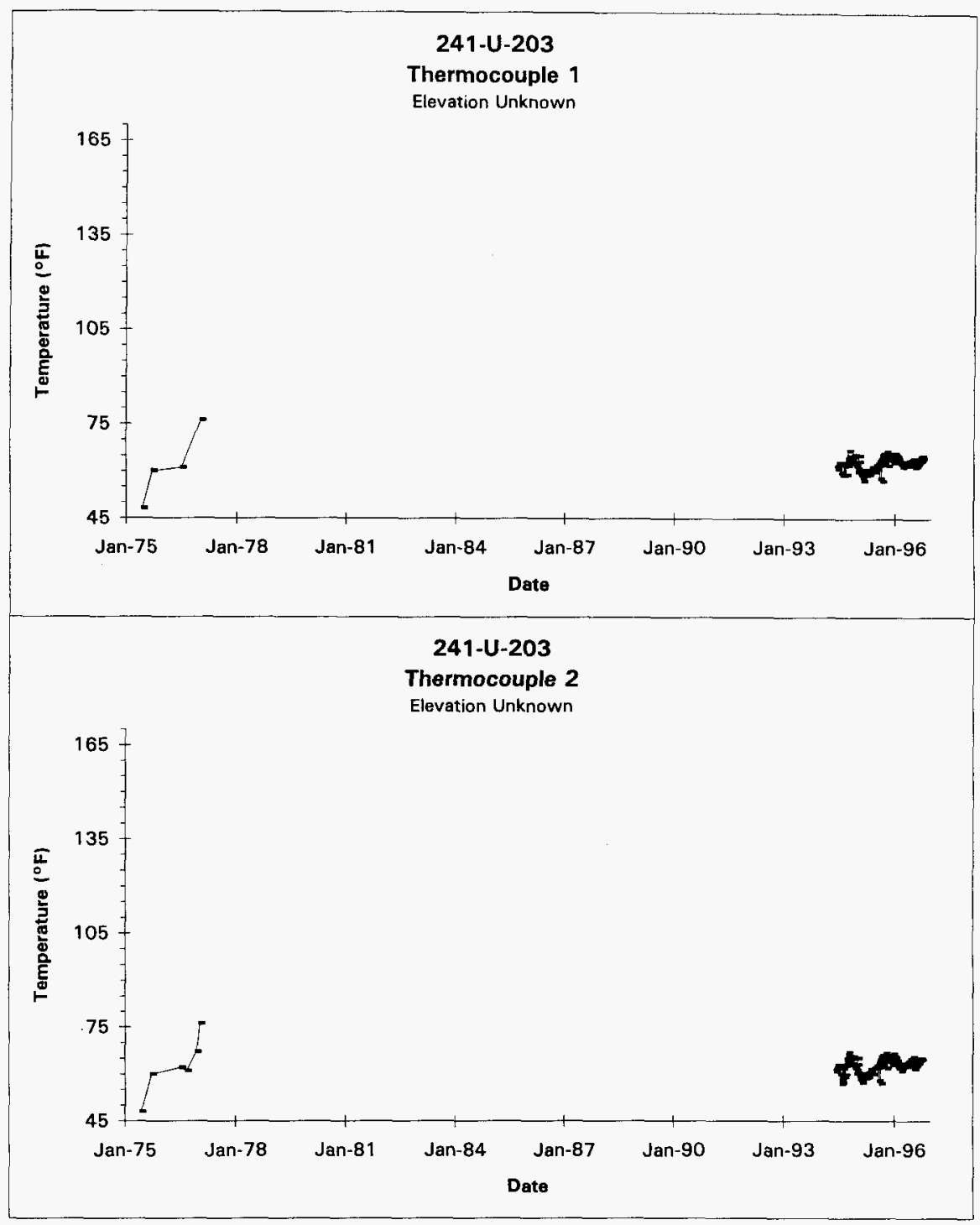

Data obtained from LMHC Surveillance Analysis Computer System (SACS), Oct 2, 1996.

$$
\text { D-67 }
$$




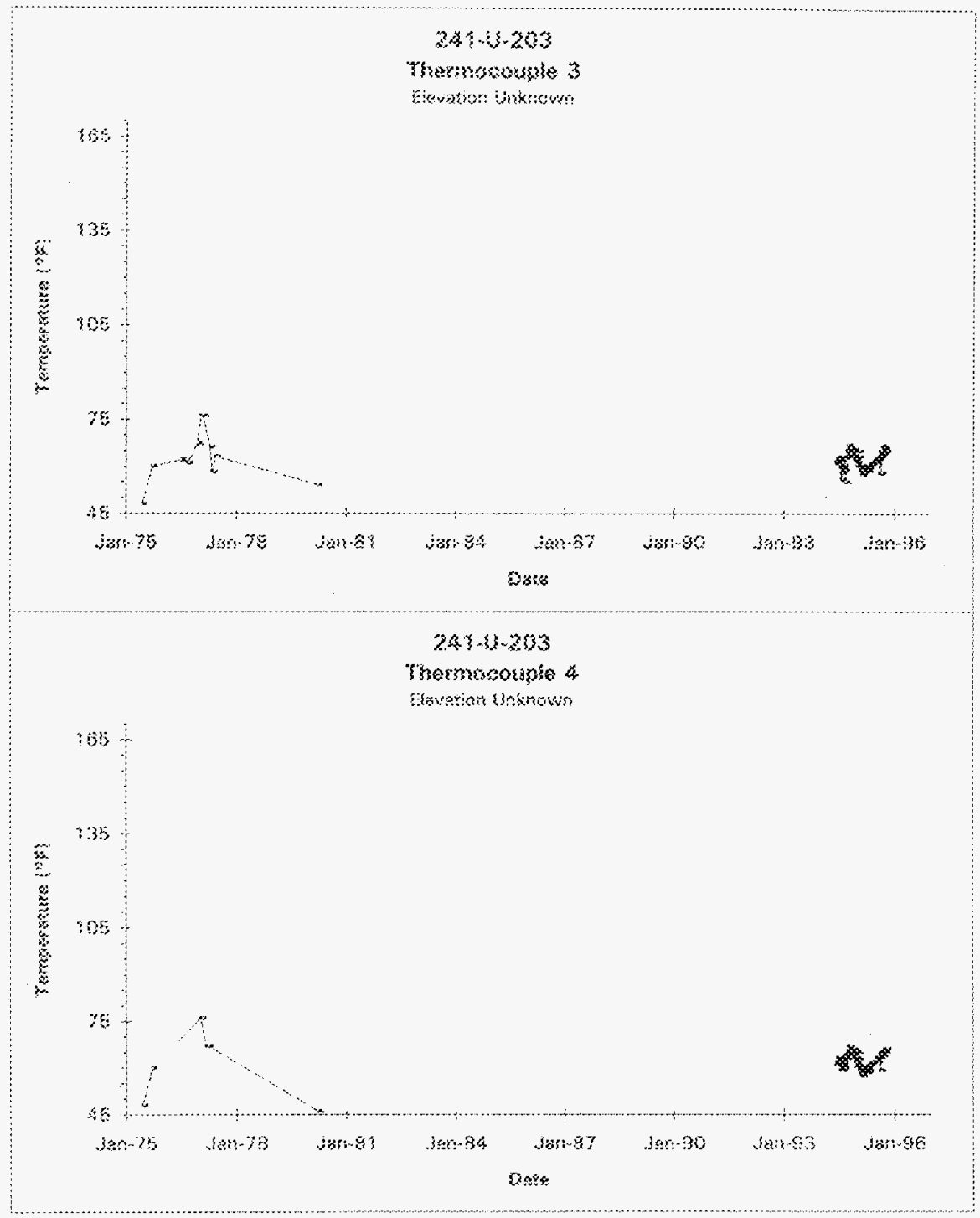

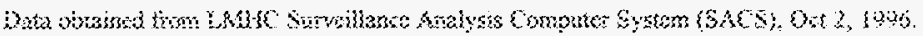


HNF-SD-WM-ER-325, Rev. 1

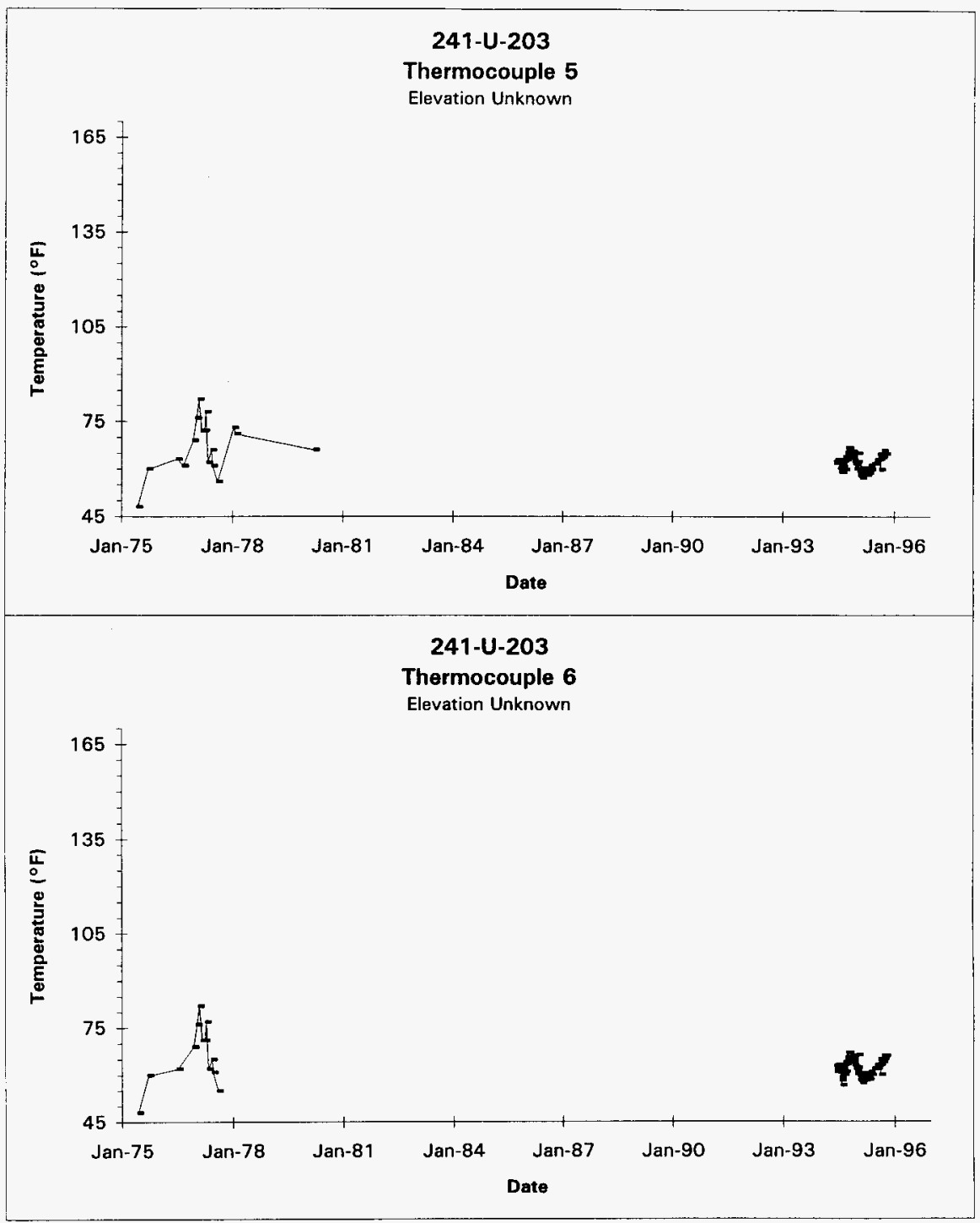

Data obtained from LMHC Surveillance Analysis Computer System (SACS), Oct 2, 1996.

D-69 


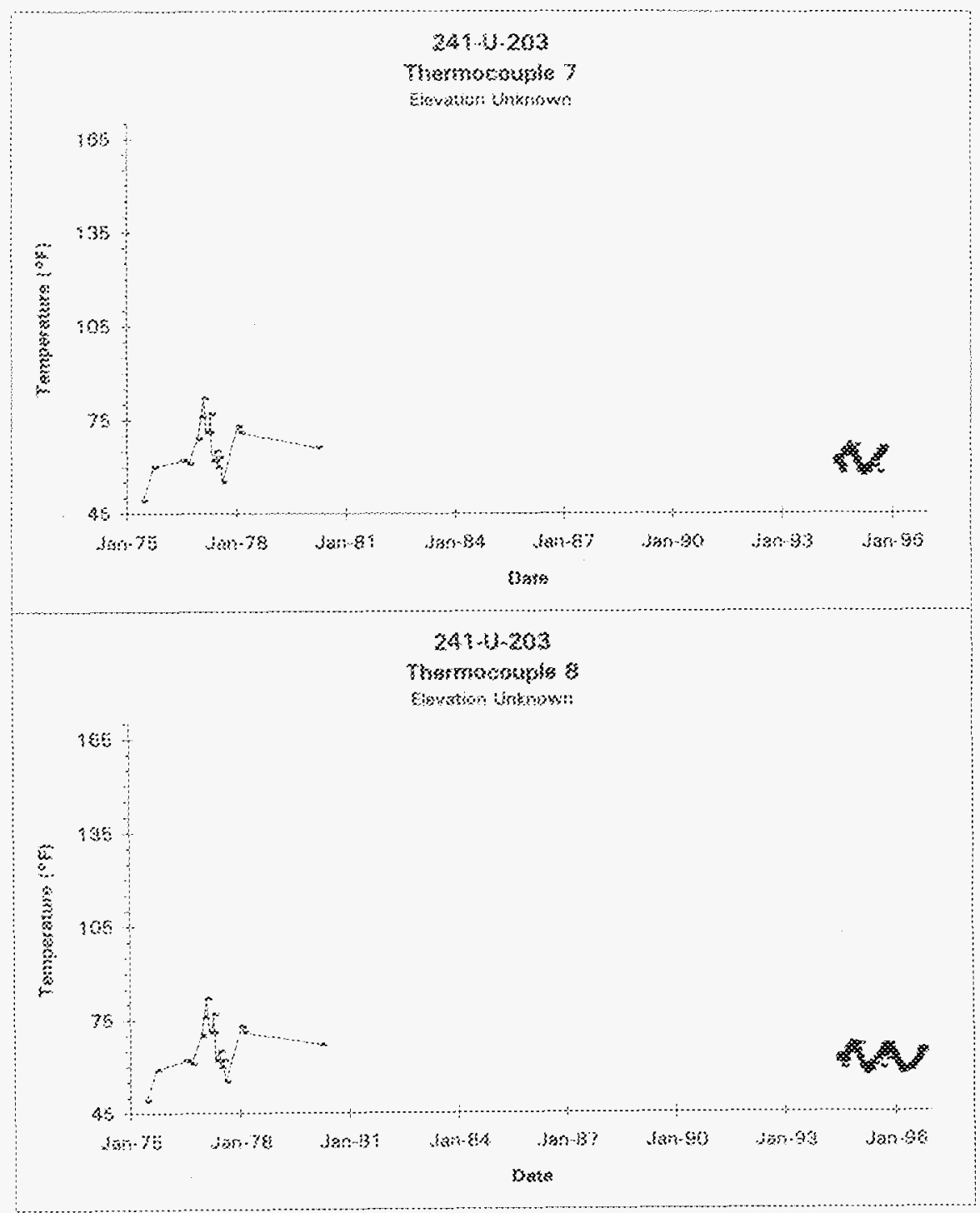

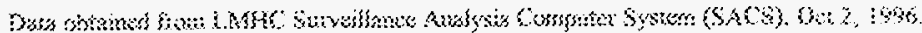


HNF-SD-WM-ER-325, Rev. I

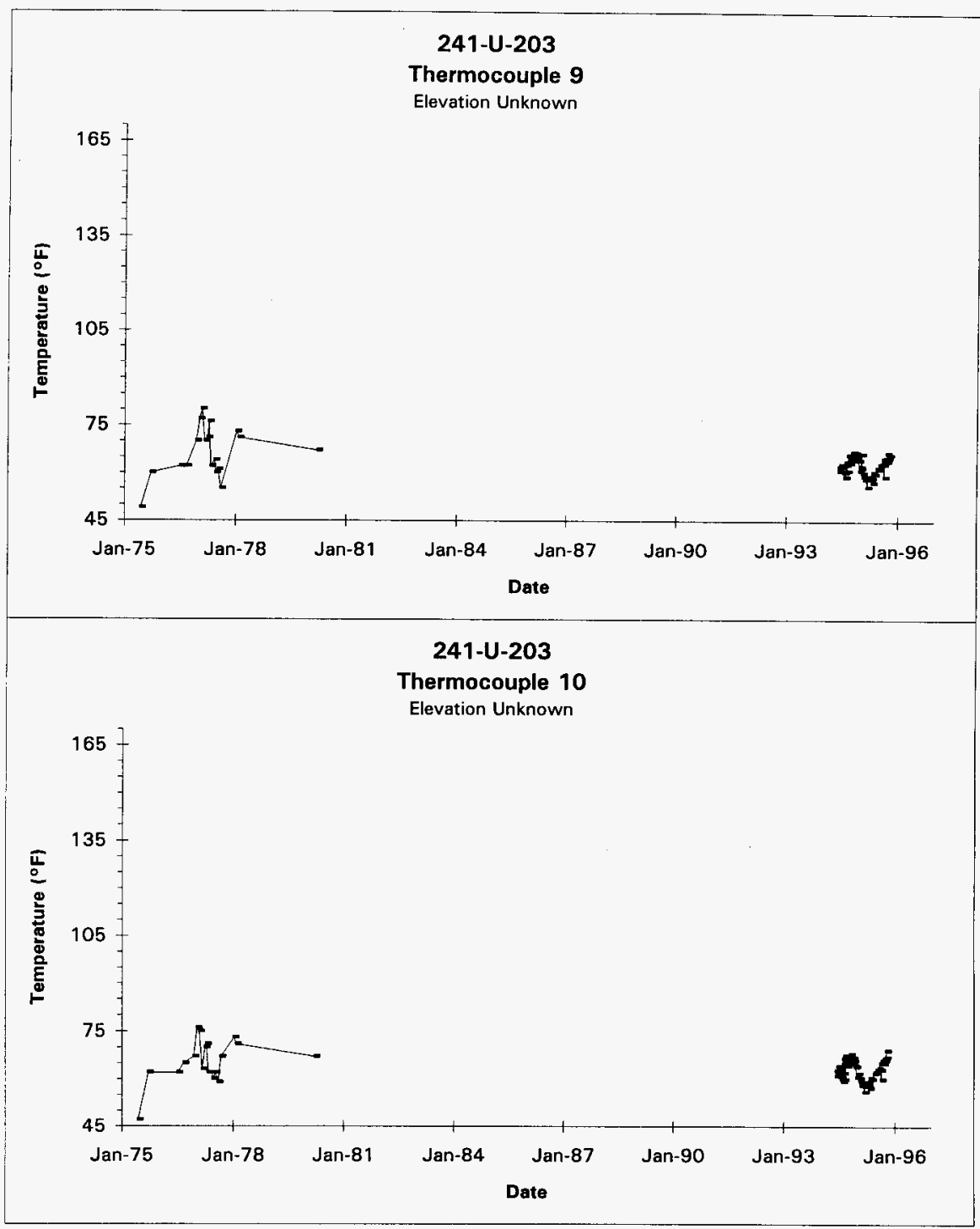

Data obtained from LMHC Surveillance Analysis Computer System (SACS), Oct 2, 1996.

D-71 


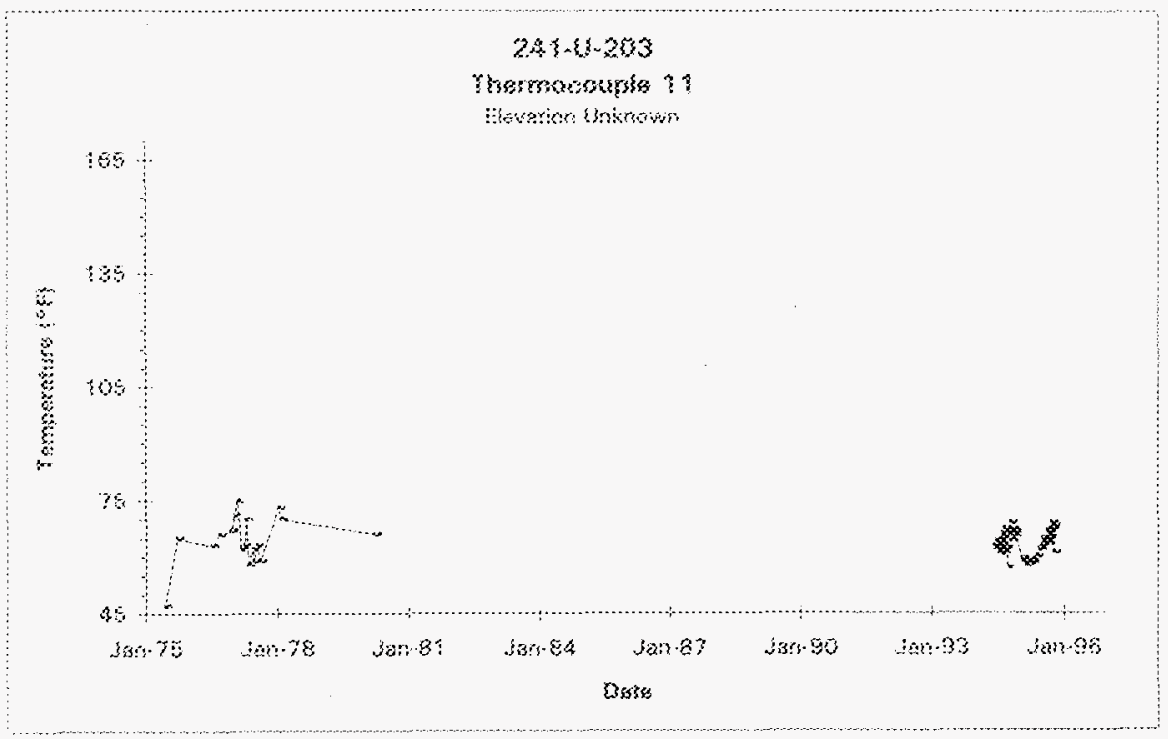

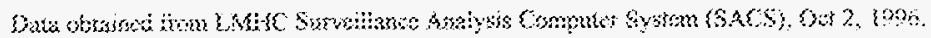
0.72 


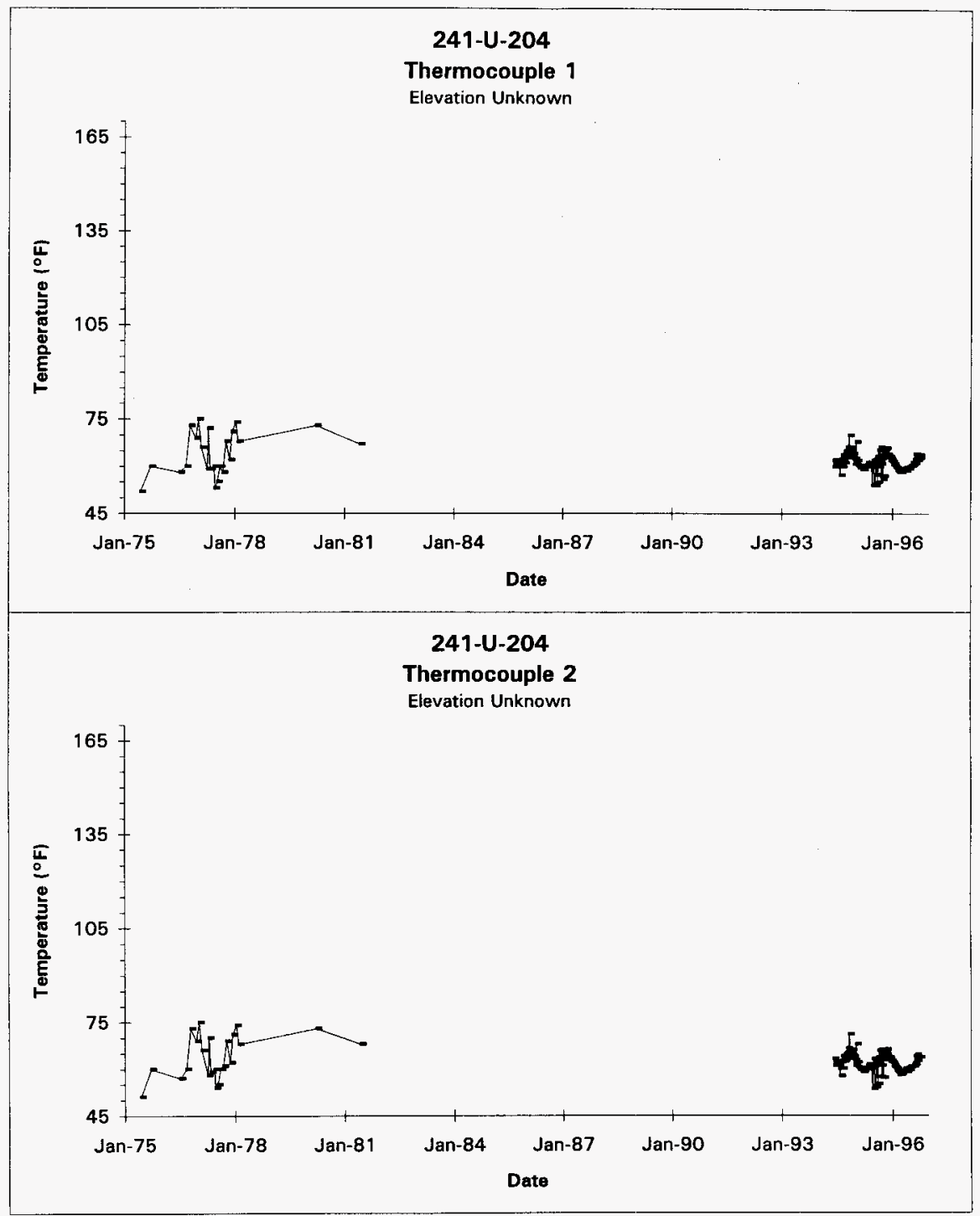

Data obtained from LMHC Surveillance Analysis Computer System (SACS), Oct 2, 1996.

D-73 
MNE-ST-WM-ER-2S Kor:

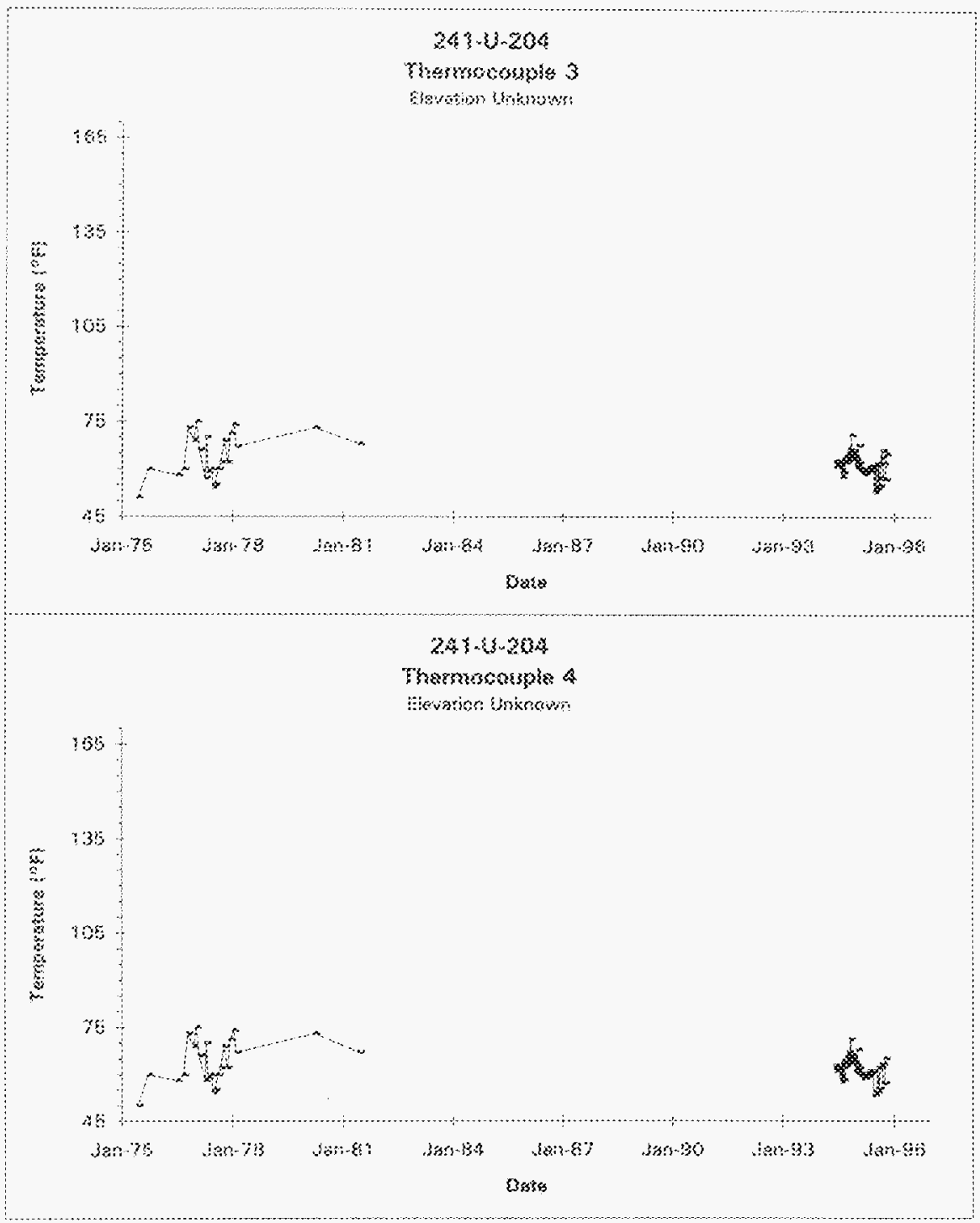

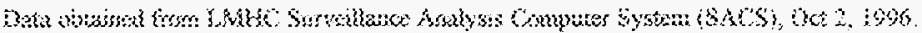
\{), $\rightarrow$ ? 


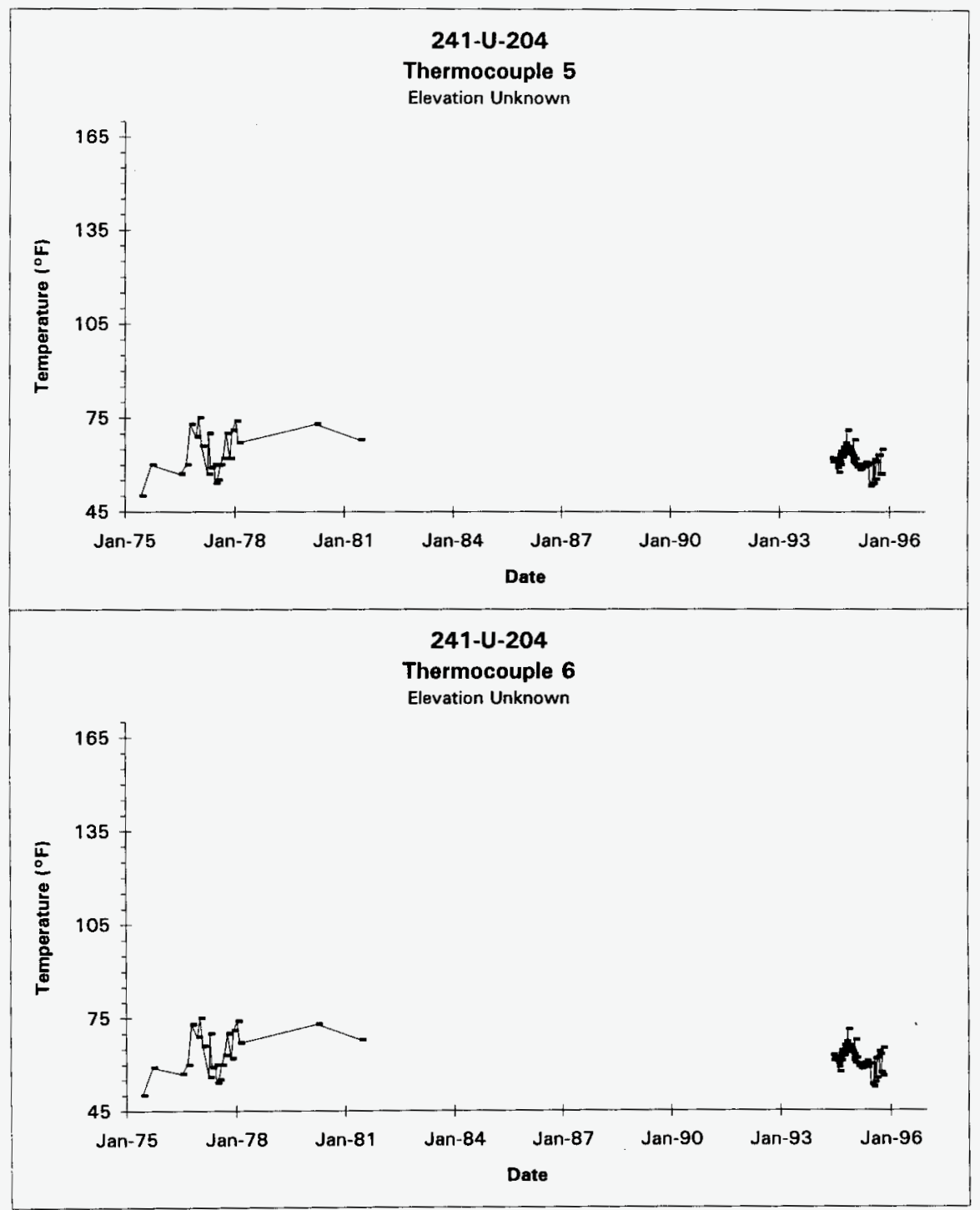

Data obtained from LMHC Surveillance Analysis Computer System (SACS), Oct 2, 1996.

D-75 


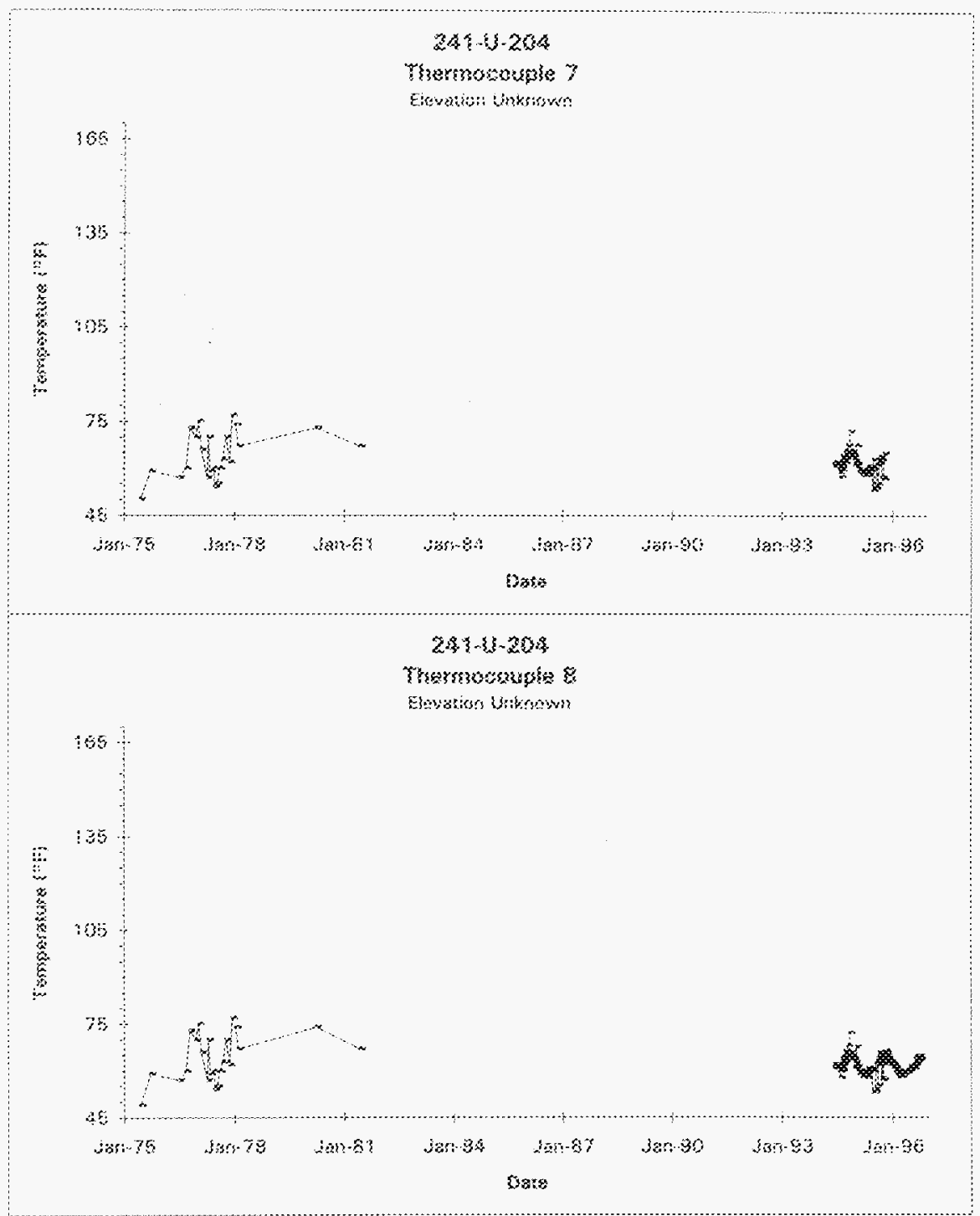

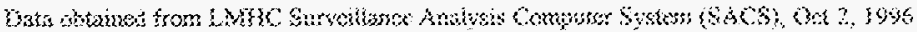

$\$ 3.76$ 


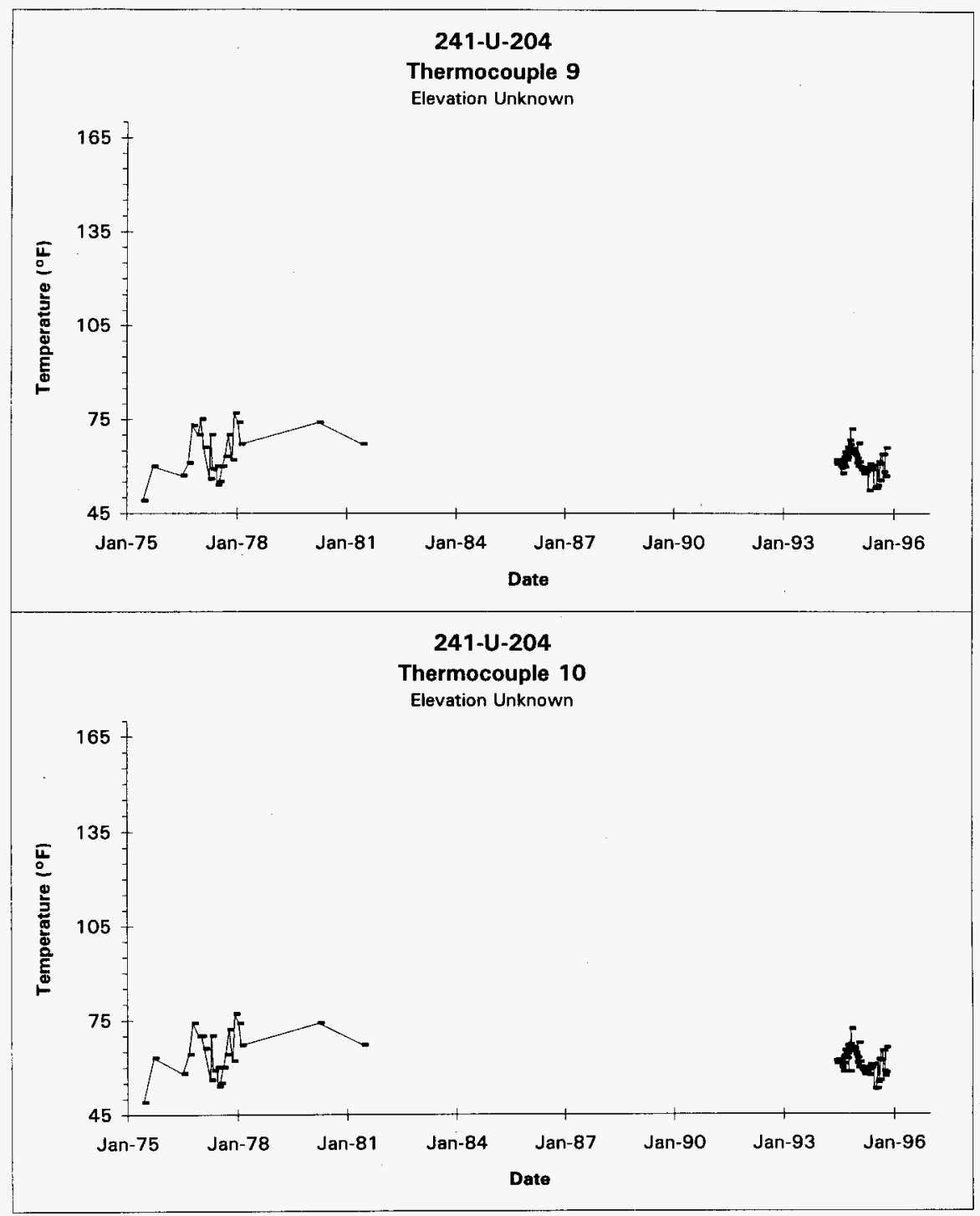

Data obtained from LMHC Surveillance Analysis Computer System (SACS), Oct 2, 1996.

$$
\text { D-77 }
$$




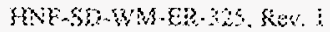

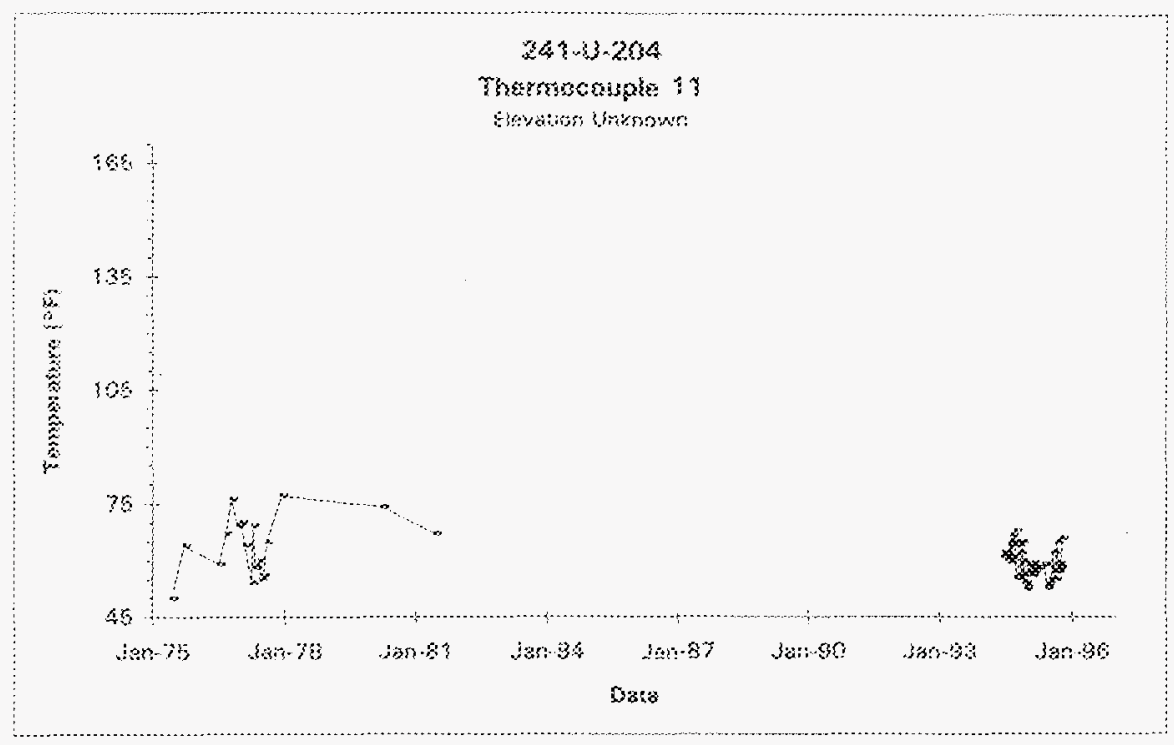

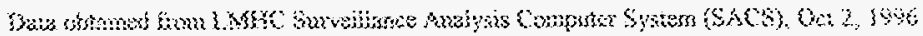
Ti. 


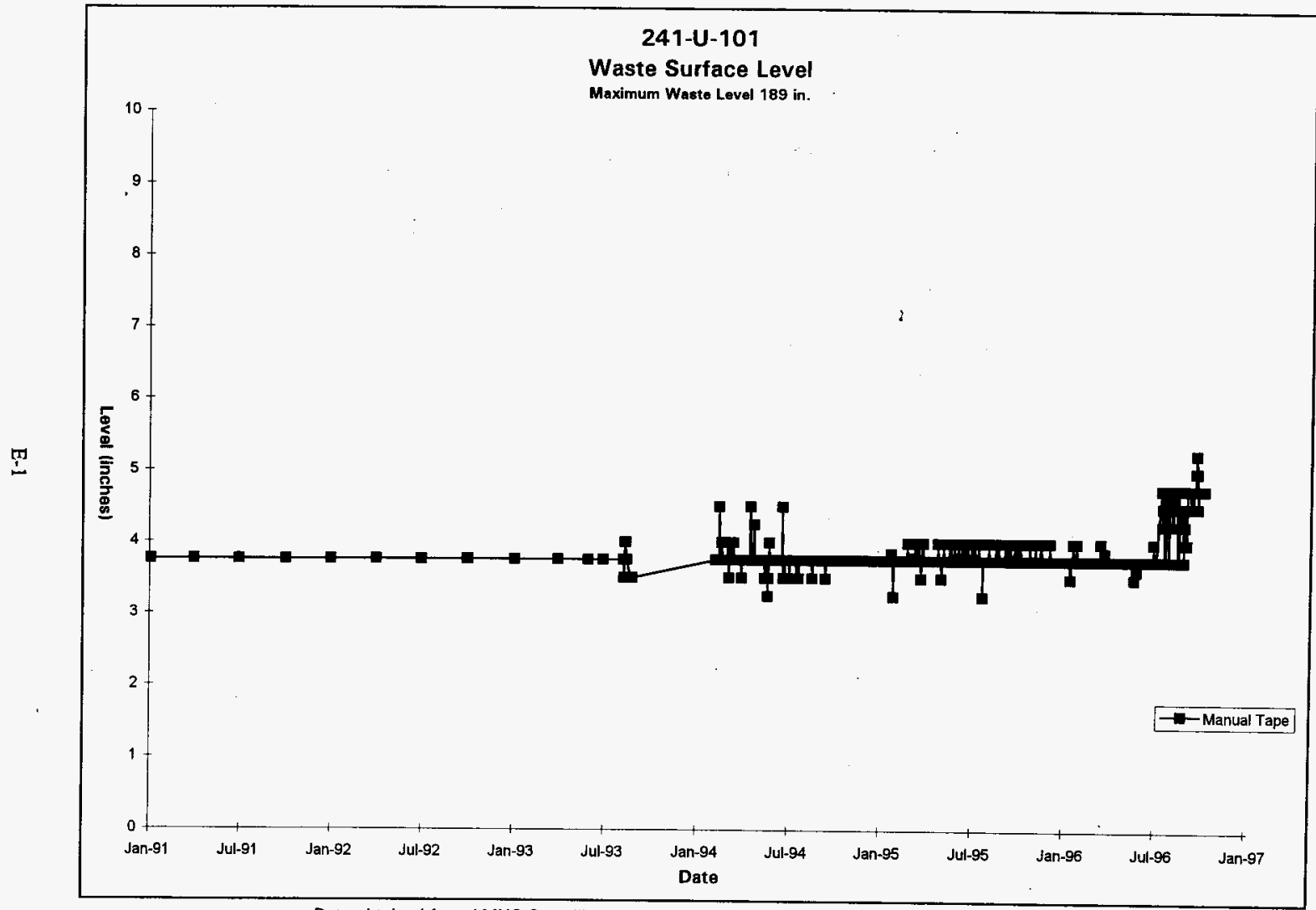

Data obtained from LMHC Surveillance Analysis Computer System (SACS), October 14, 1996. 


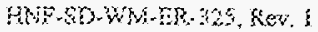

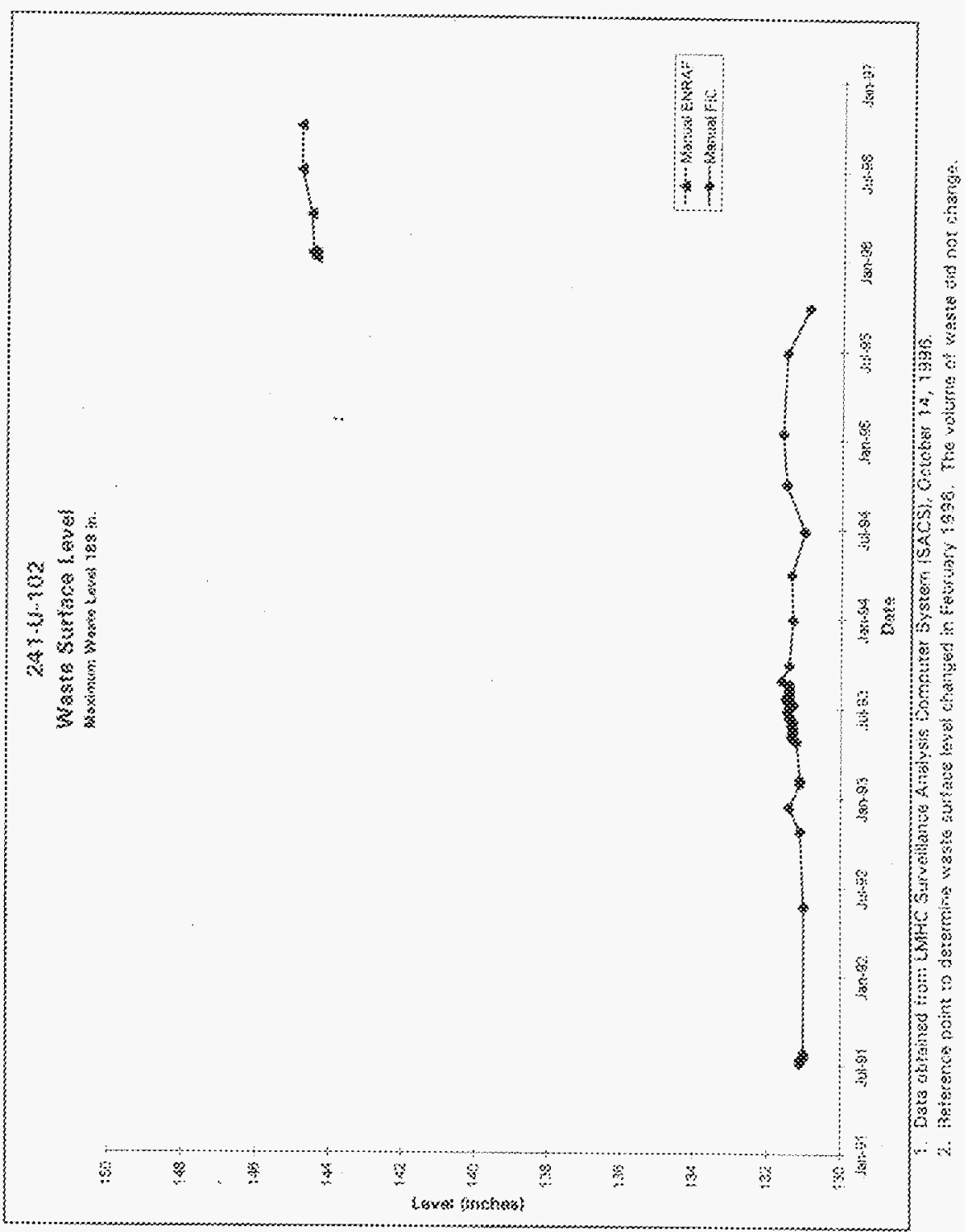




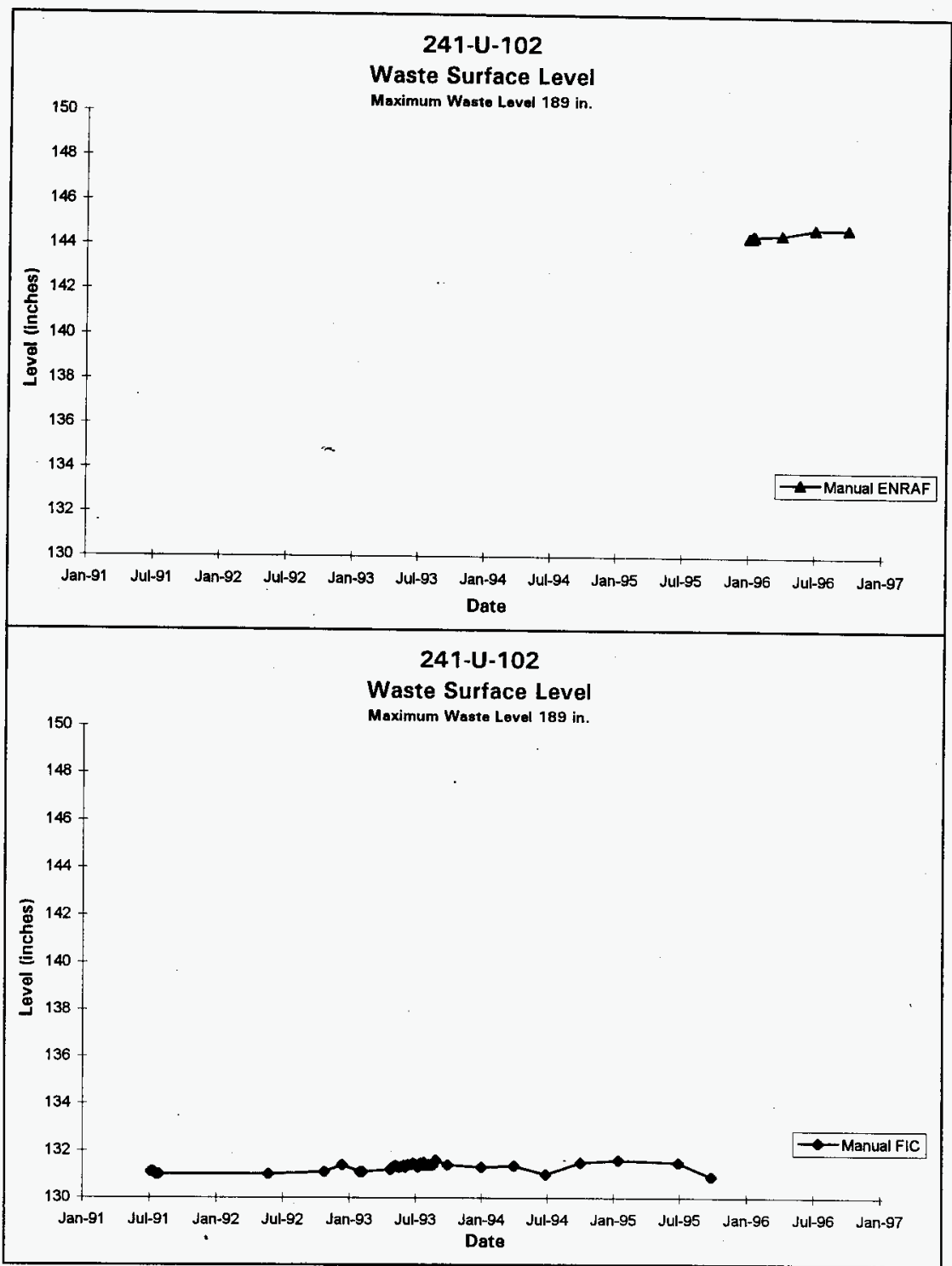

1. Data obtained from LMHC Surveillance Analysis Computer System (SACS), October 14, 1996.

2. Reference point to determine waste surface level changed in February 1996. The volume of waste did not change. 


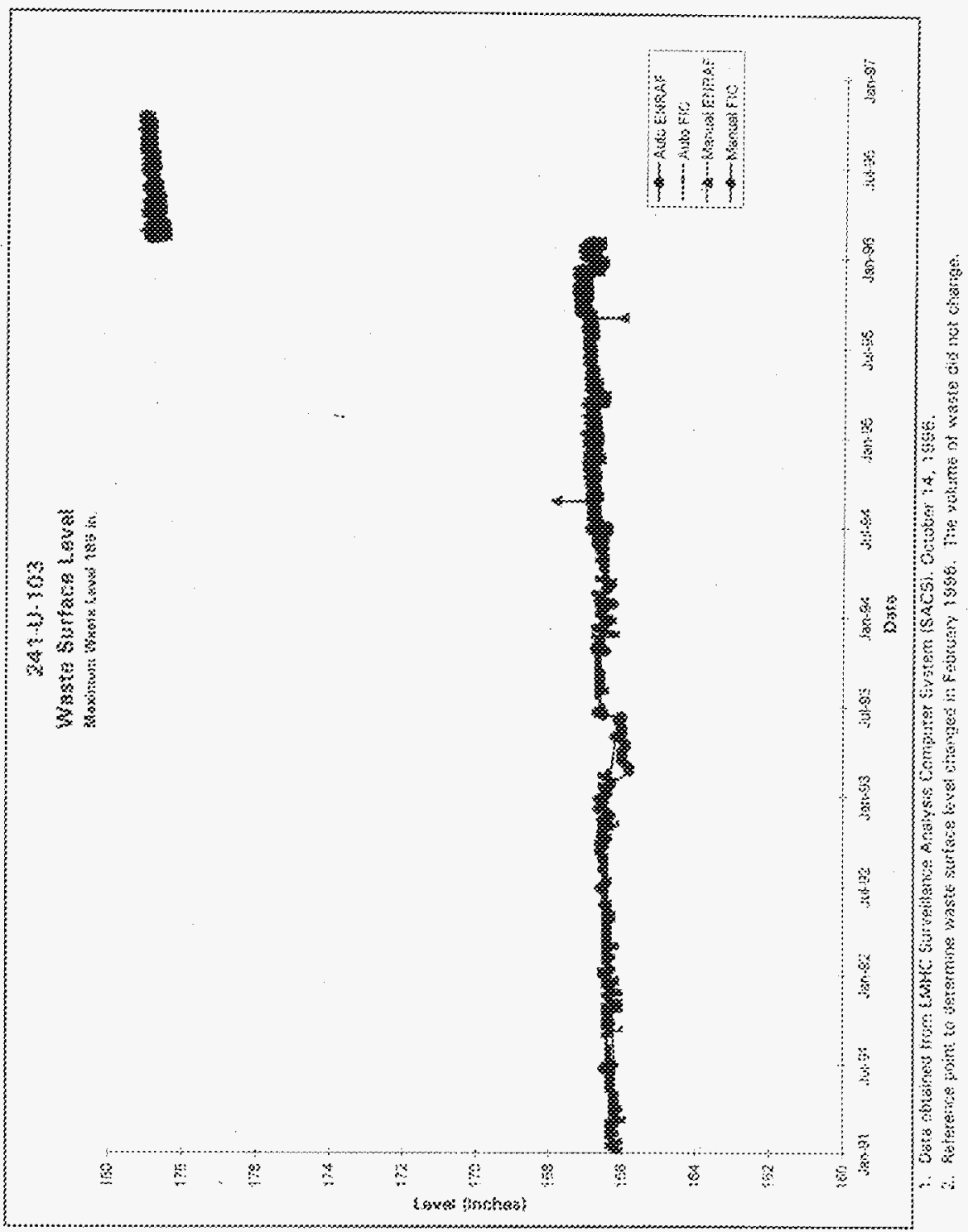




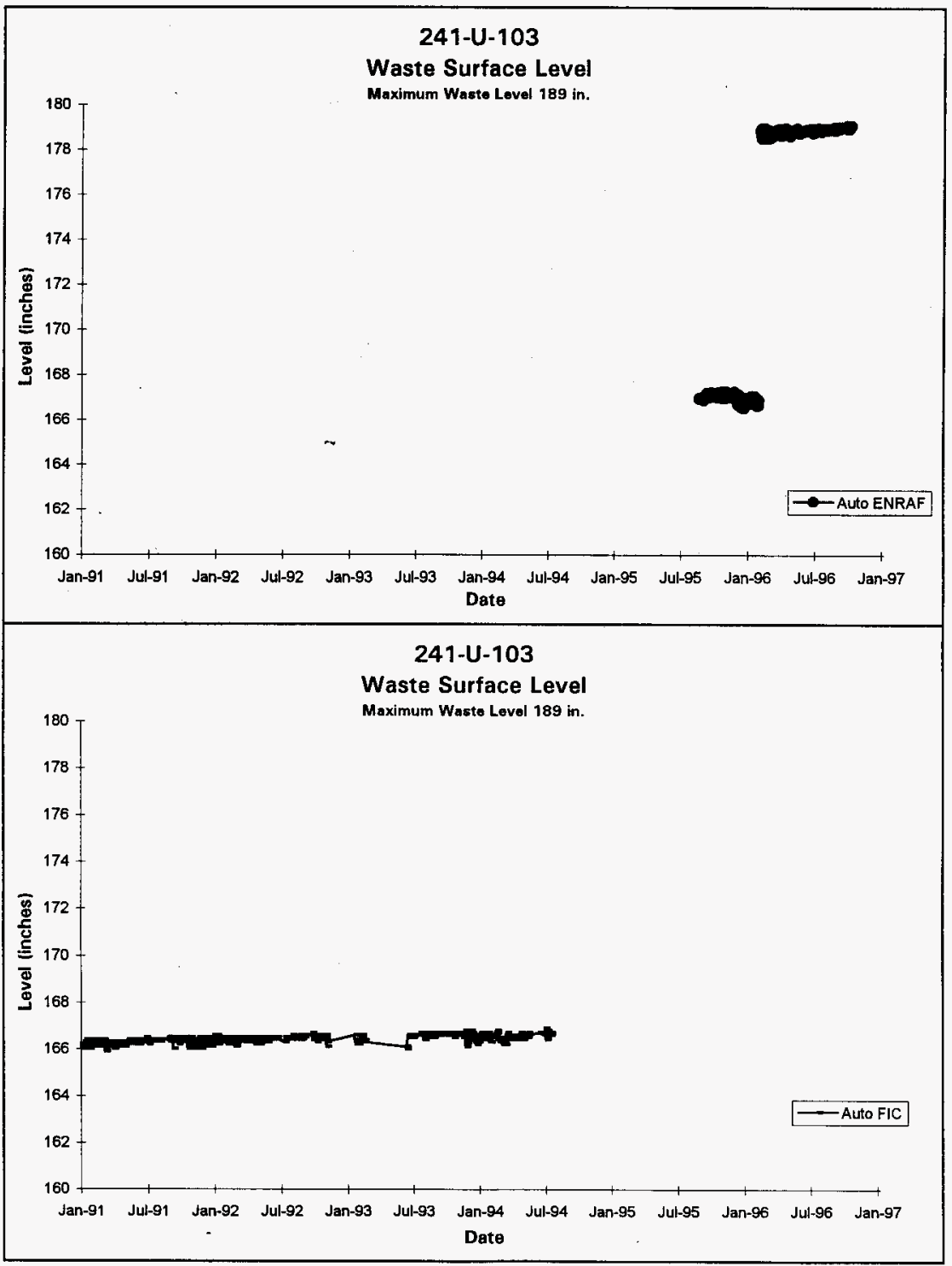

1. Data obtained from LMHC Surveillance Analysis Computer System (SACS), October 14, 1996.

2. Reference point to determine waste surface level changed in February 1996. The volume of waste did not change. 


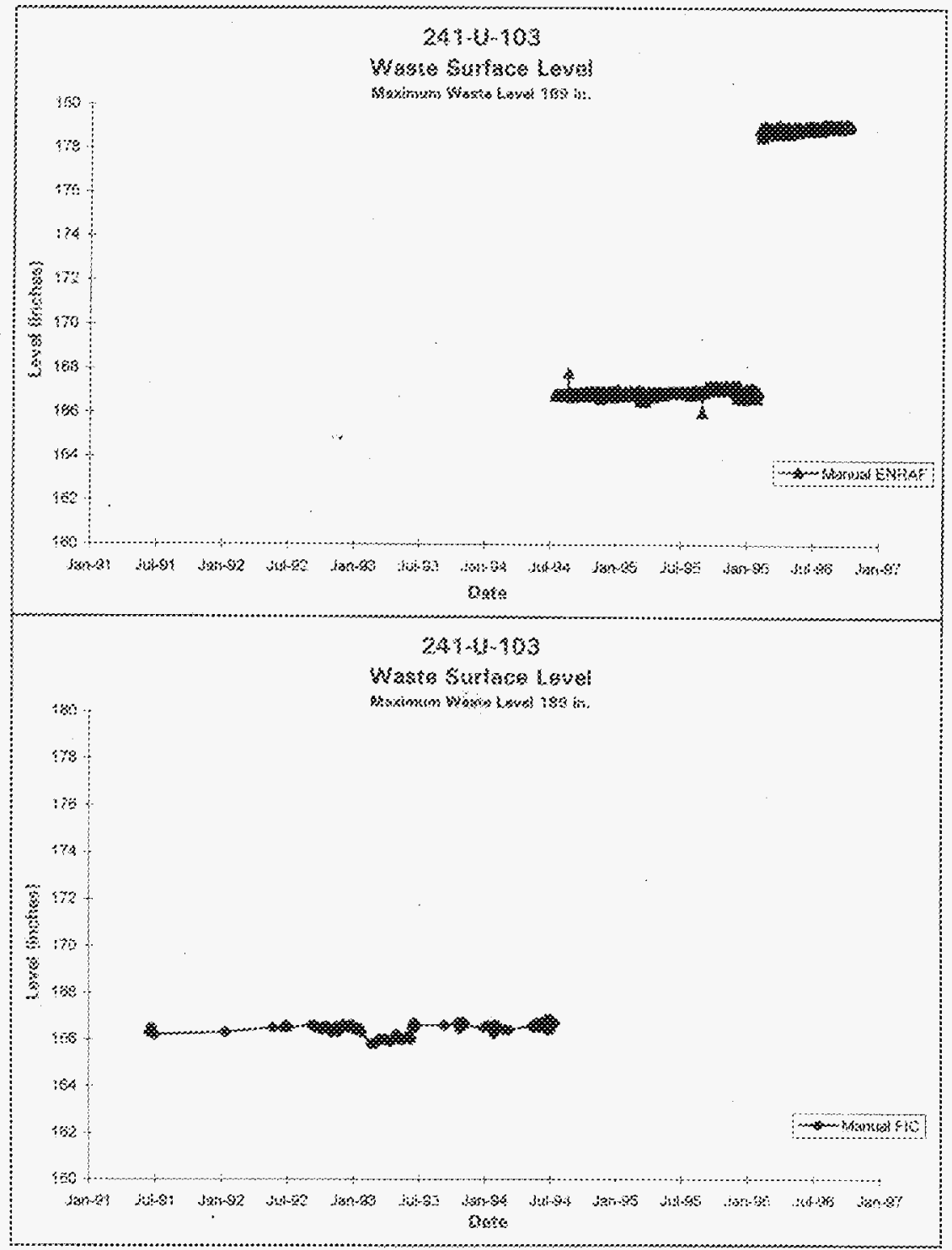

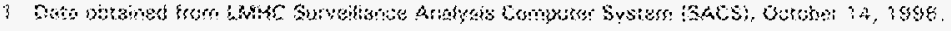

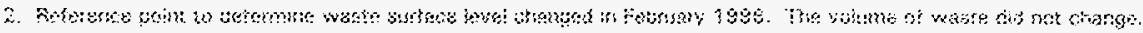

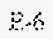




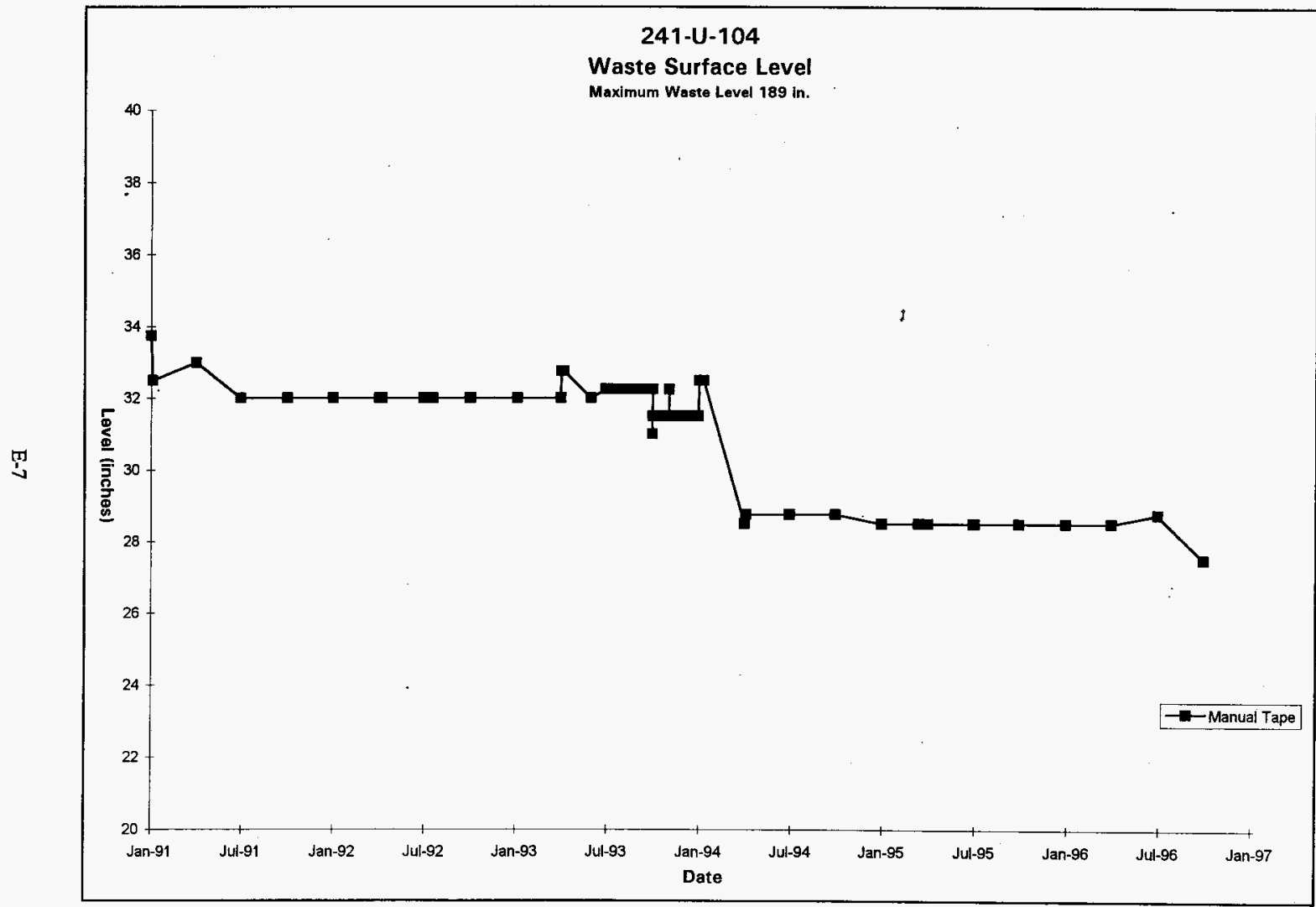

Data obtained from LMHC Surveillance Analysis Computer System (SACS), October 14, 1996. 
MUF-SO-WM.GD.32 KE. I

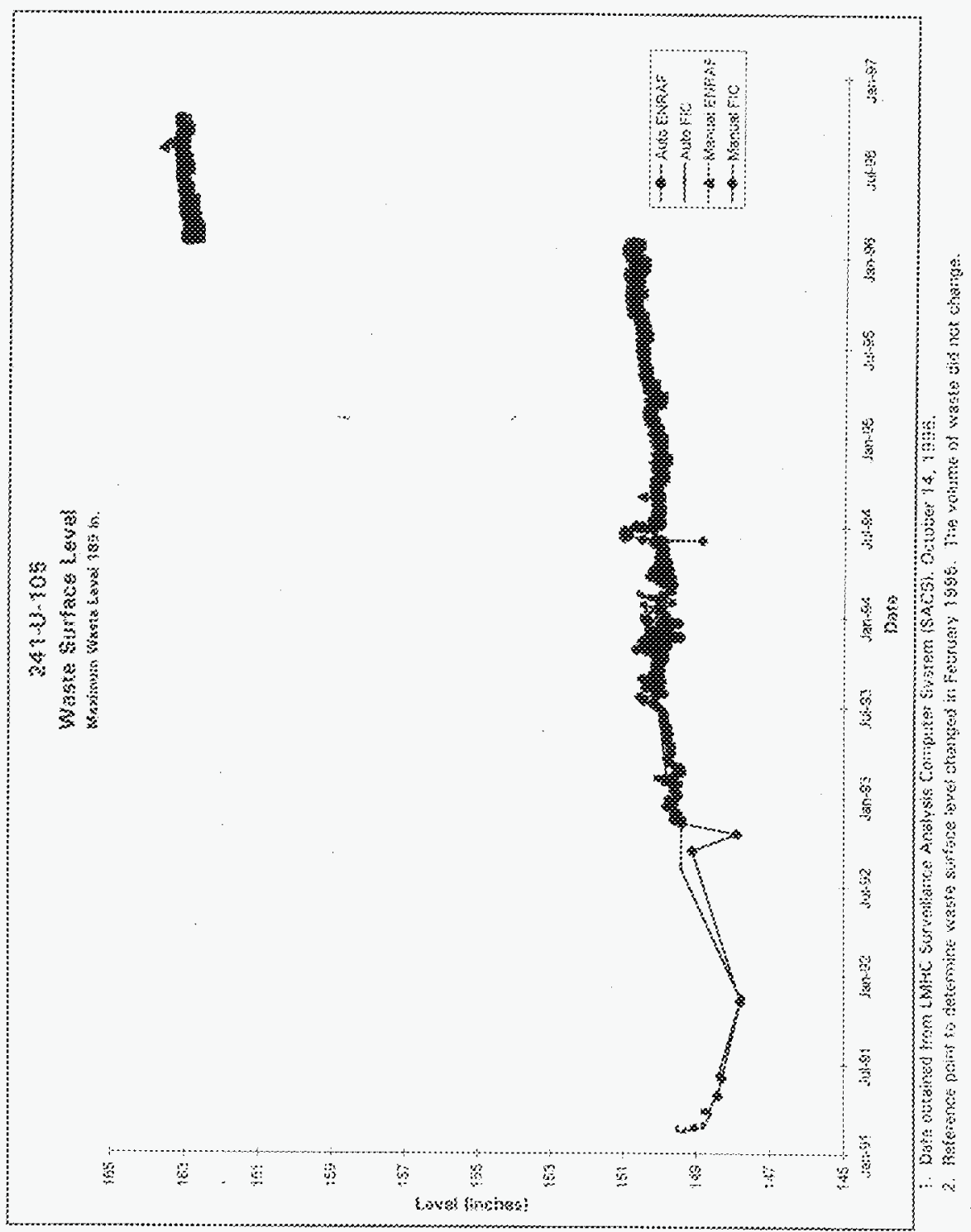




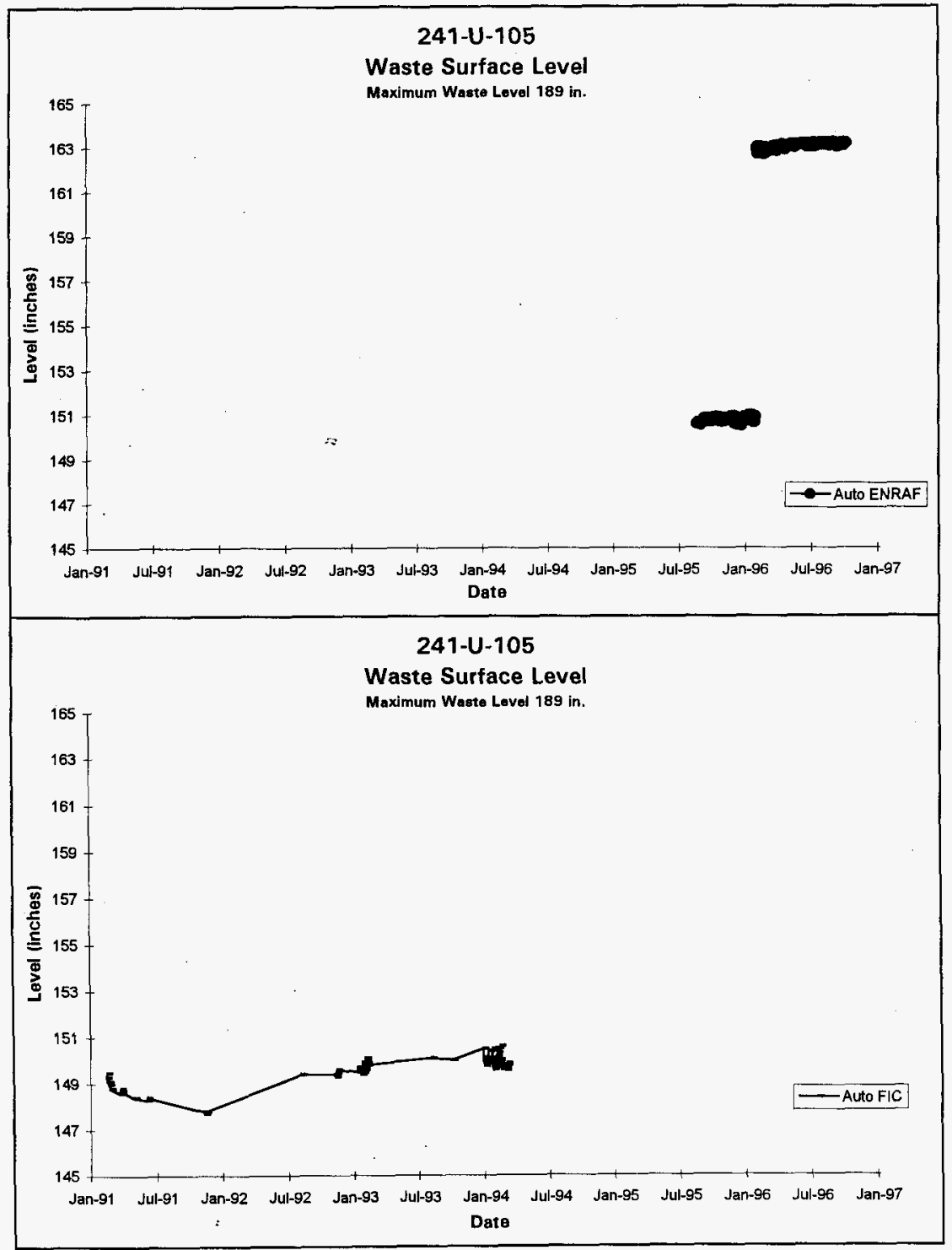

1. Data obtained from LMHC Surveillance Analysis Computer System (SACS), October 14, 1996.

2. Reference point to determine waste surface level changed in February 1996. The volume of waste did not change. 


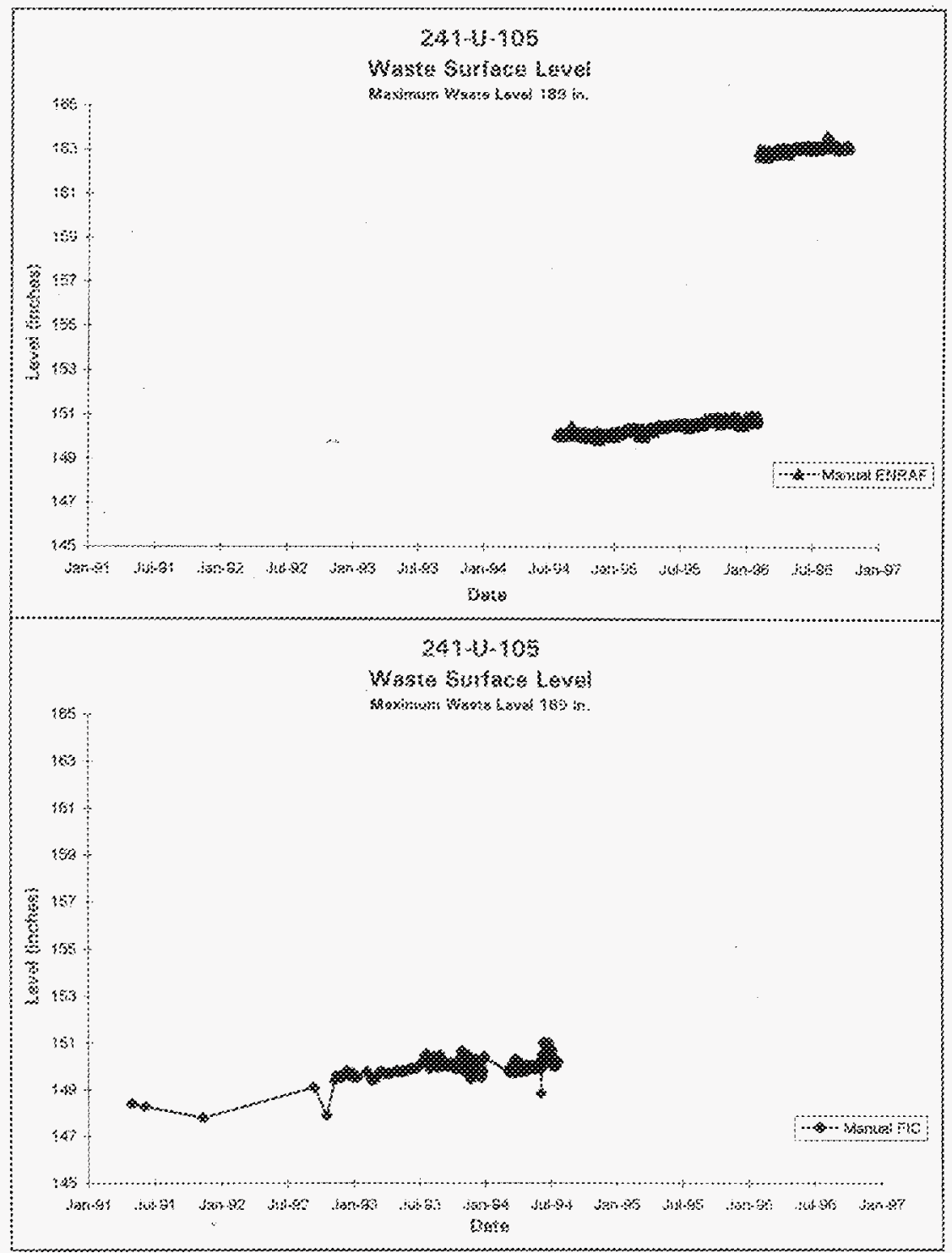

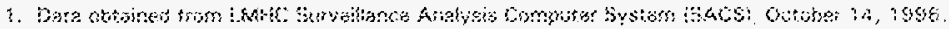

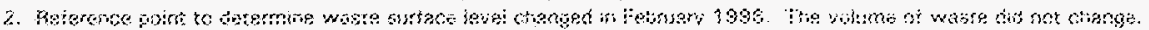




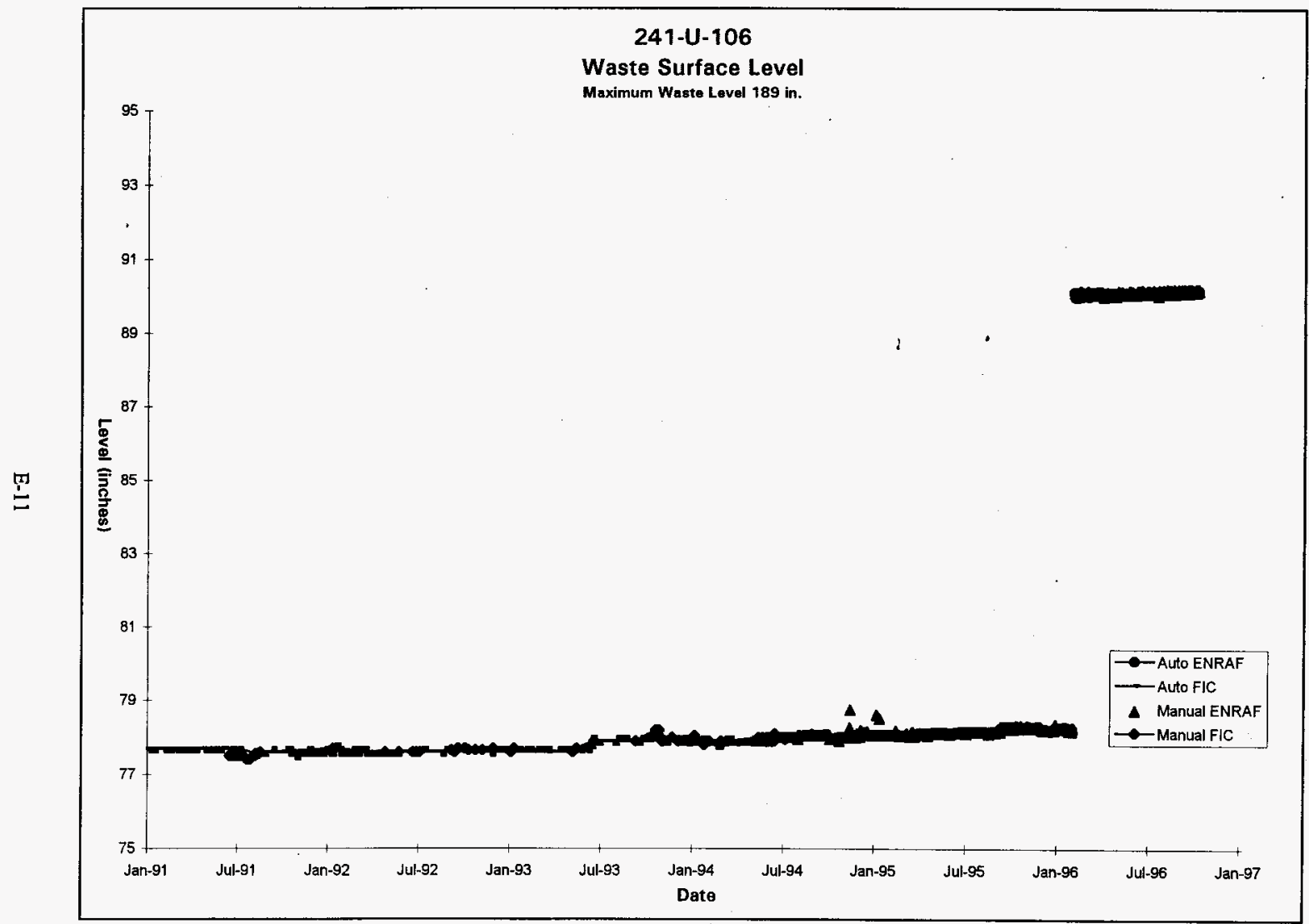

1. Data obtained from LMHC Surveillance Analysis Computer System [SACS], October 14, 1996.

2. Reference point to determine waste surface level changed in February 1996. The volume of waste did not change. 


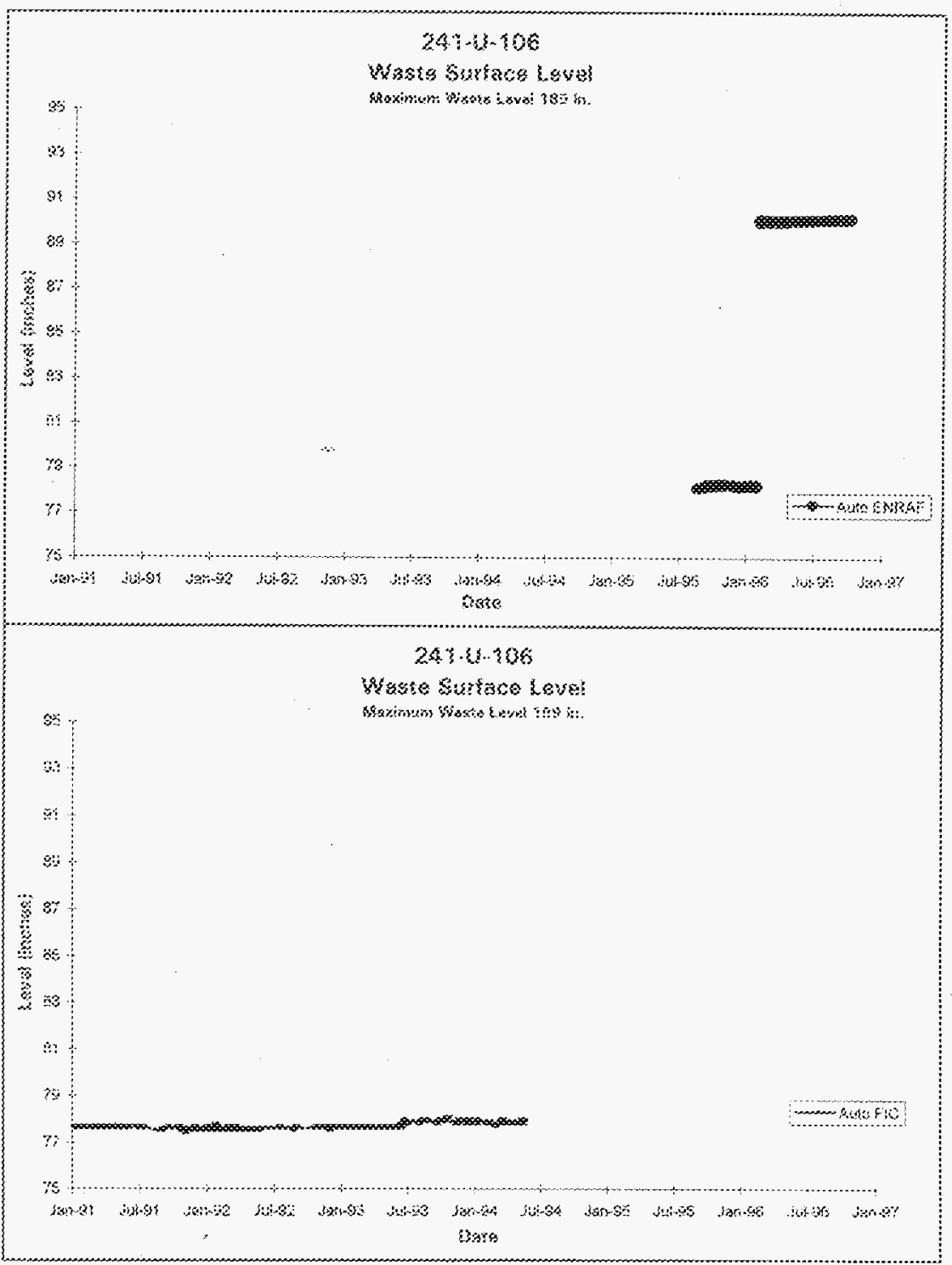

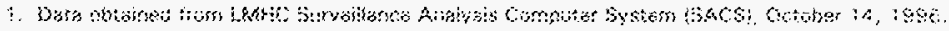

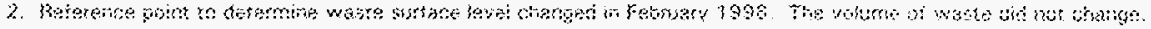




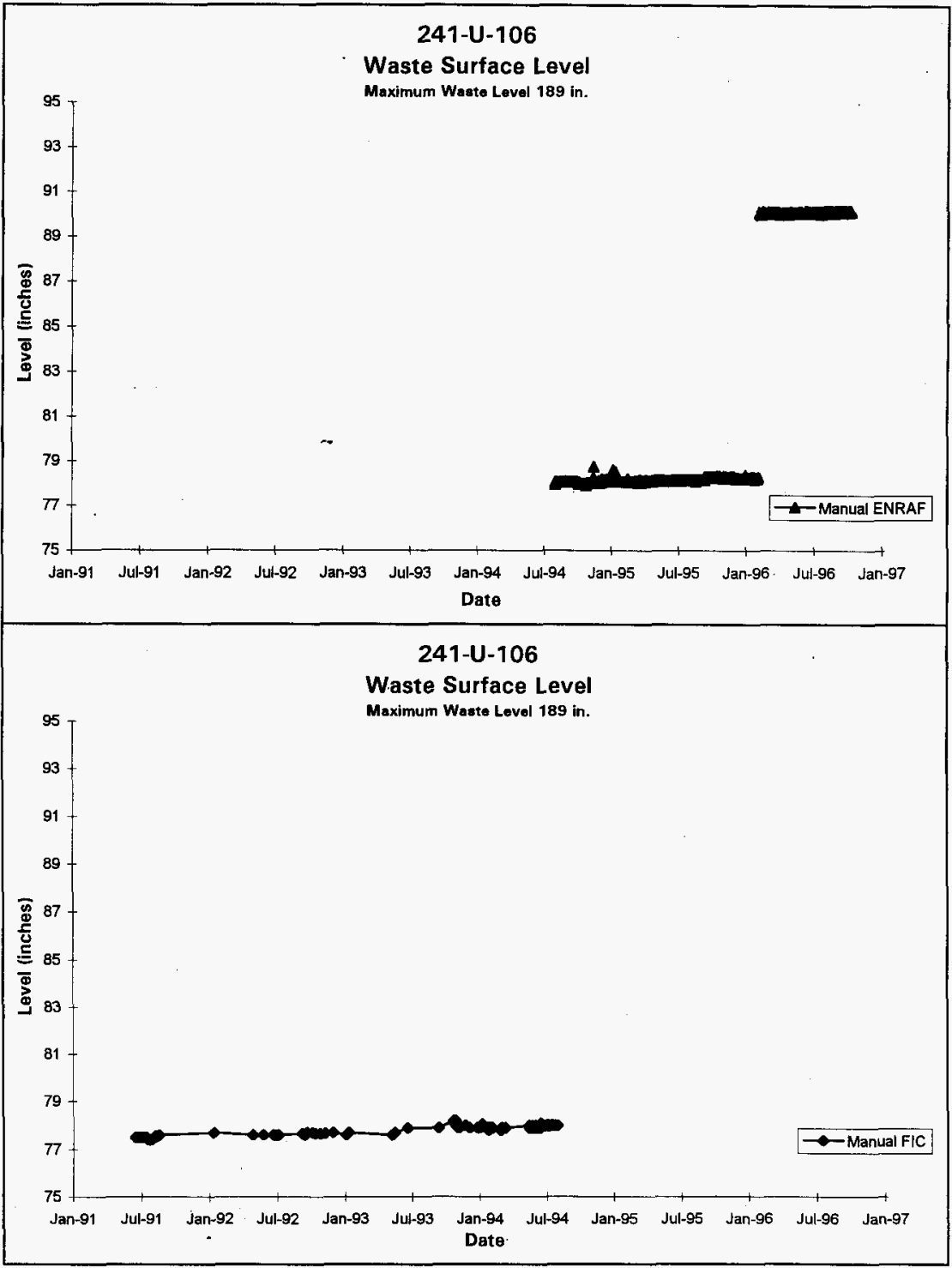

1. Data obtained from LMHC Surveiliance Analysis Computer System (SACS), October 14, 1996.

2. Reference point to determine waste surface level changed in February 1996. The volume of waste did not change. 


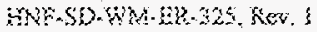

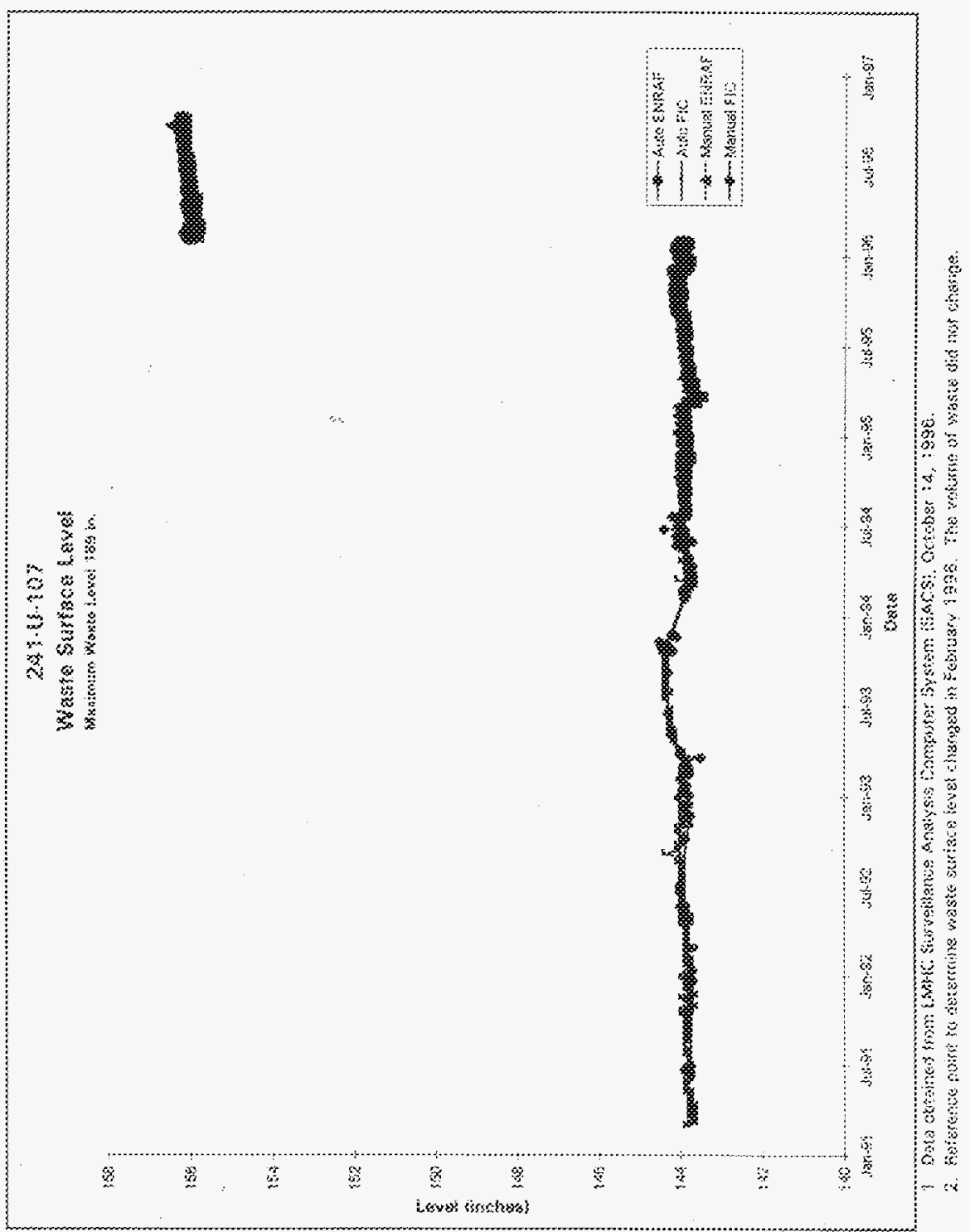




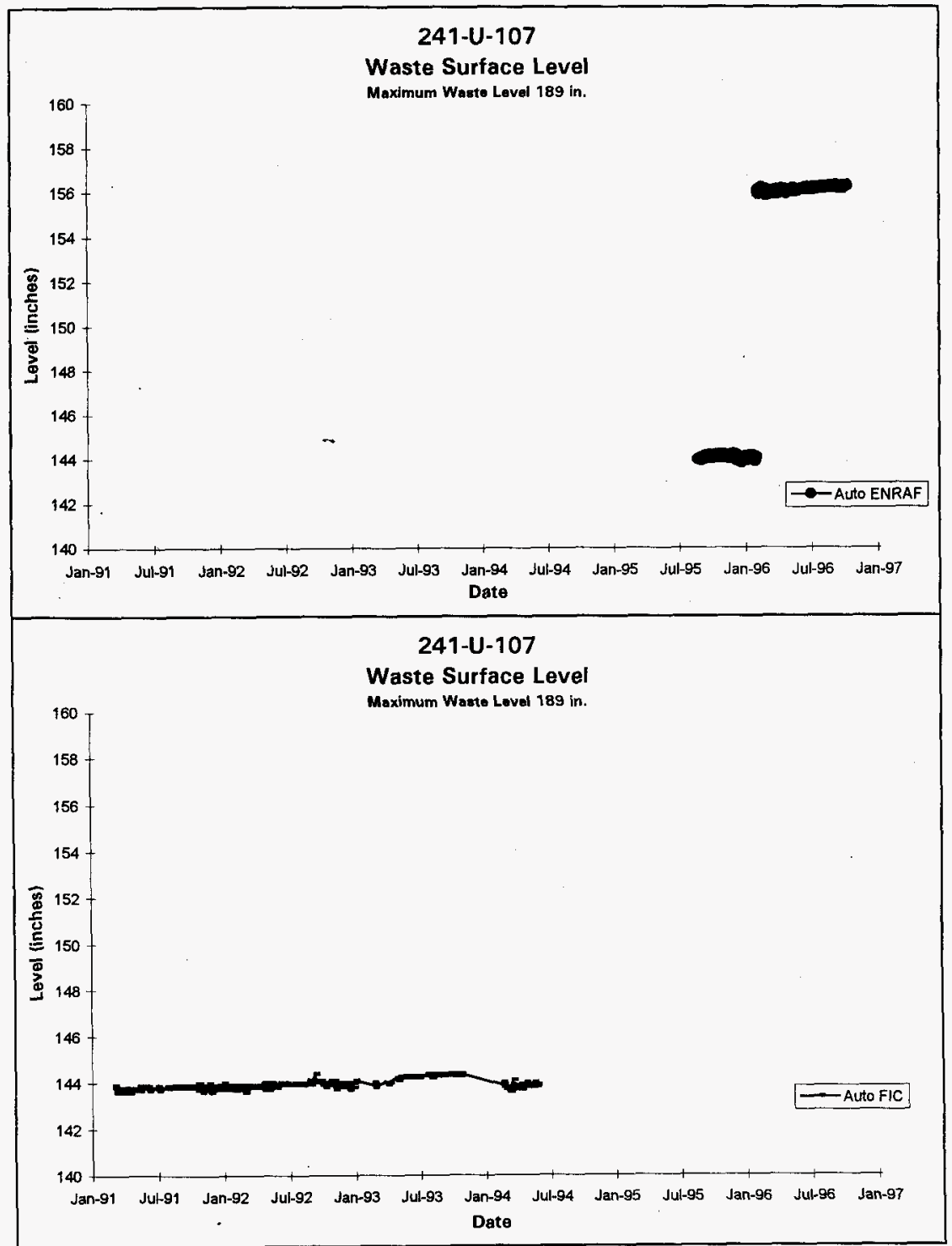

1. Data obtained from LMHC (formerly WHC) Surveillance Analysis Computer System (SACS), October $14,1996$.

2. Reference point to determine waste surface level changed in February 1996. The volume of waste did not change. 
$4 \%$

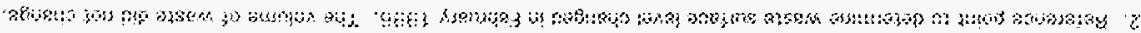

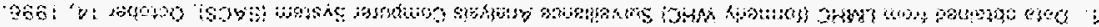

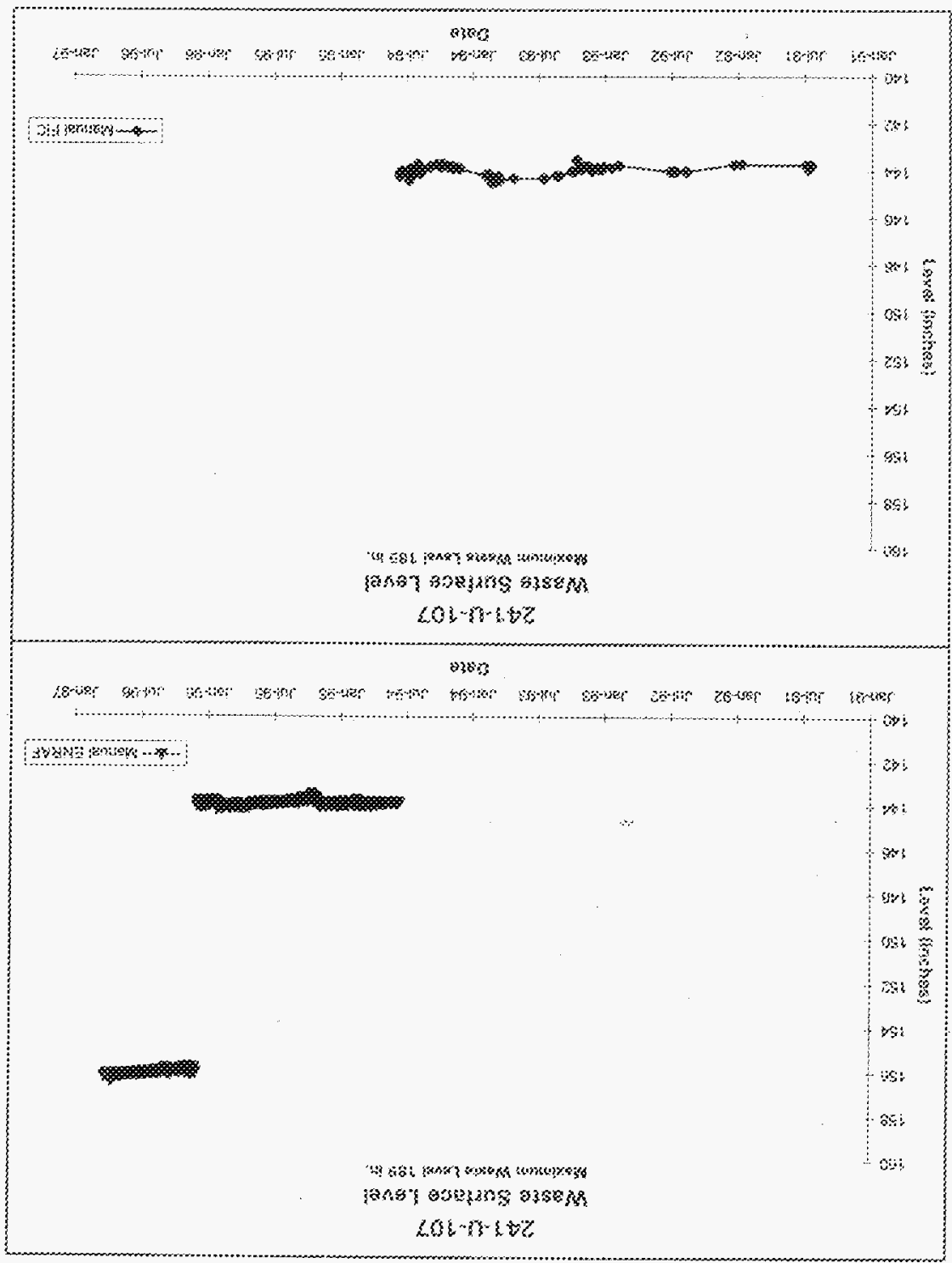


HNF-SD-WM-ER-325, Rev. 1

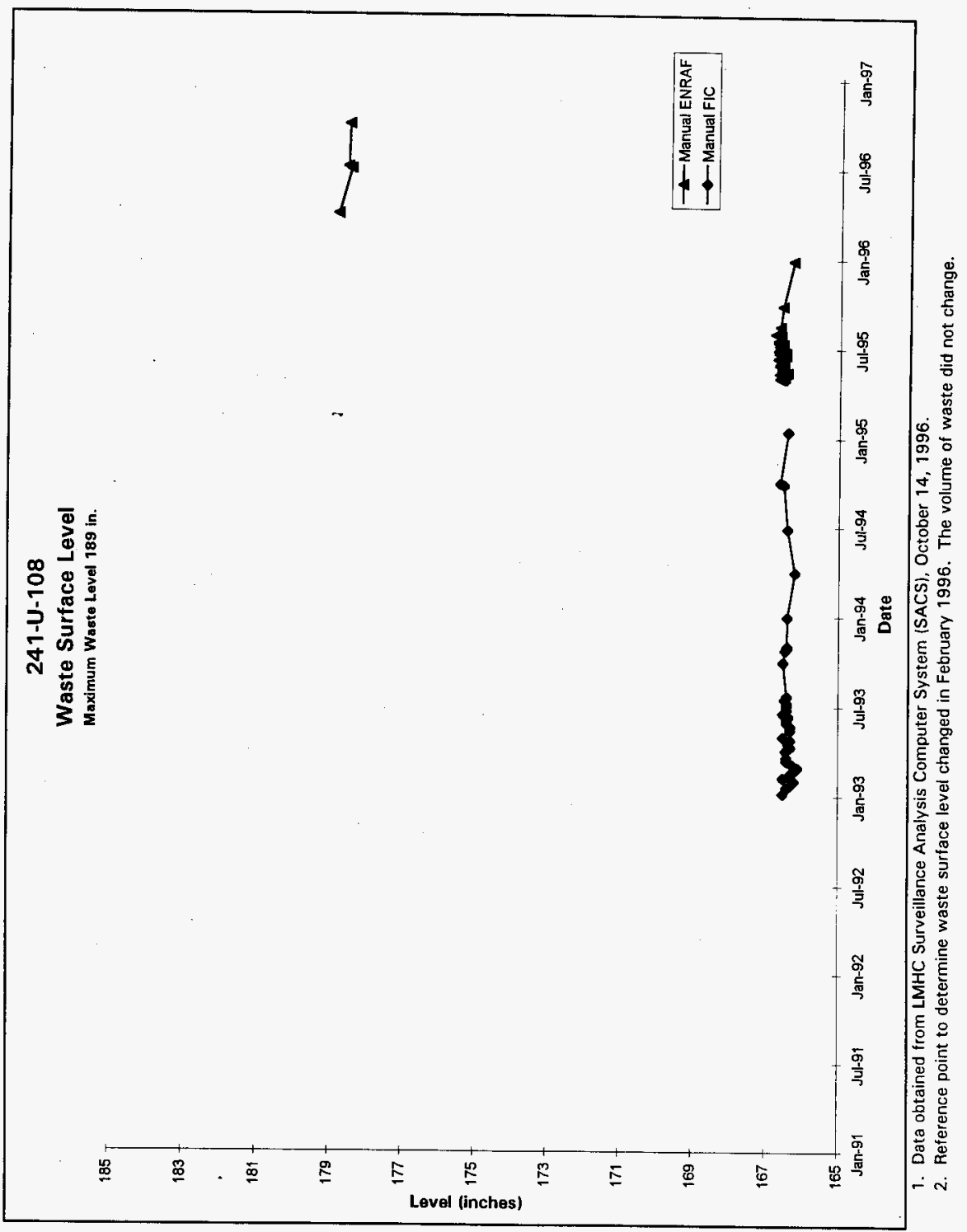

E-17 


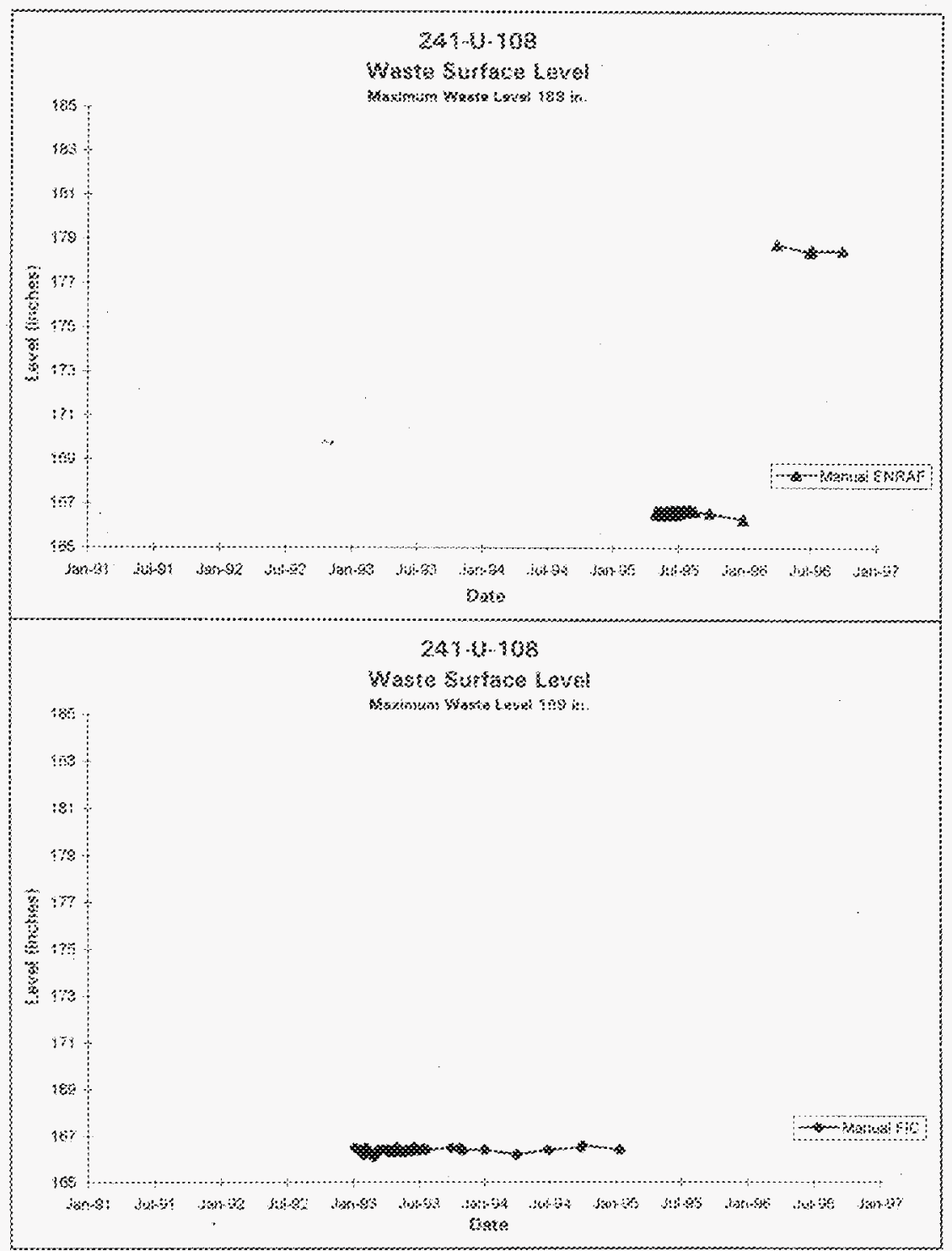

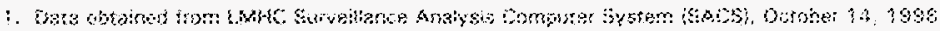

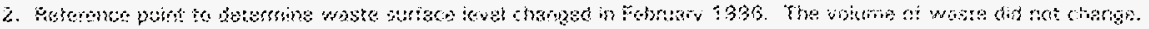




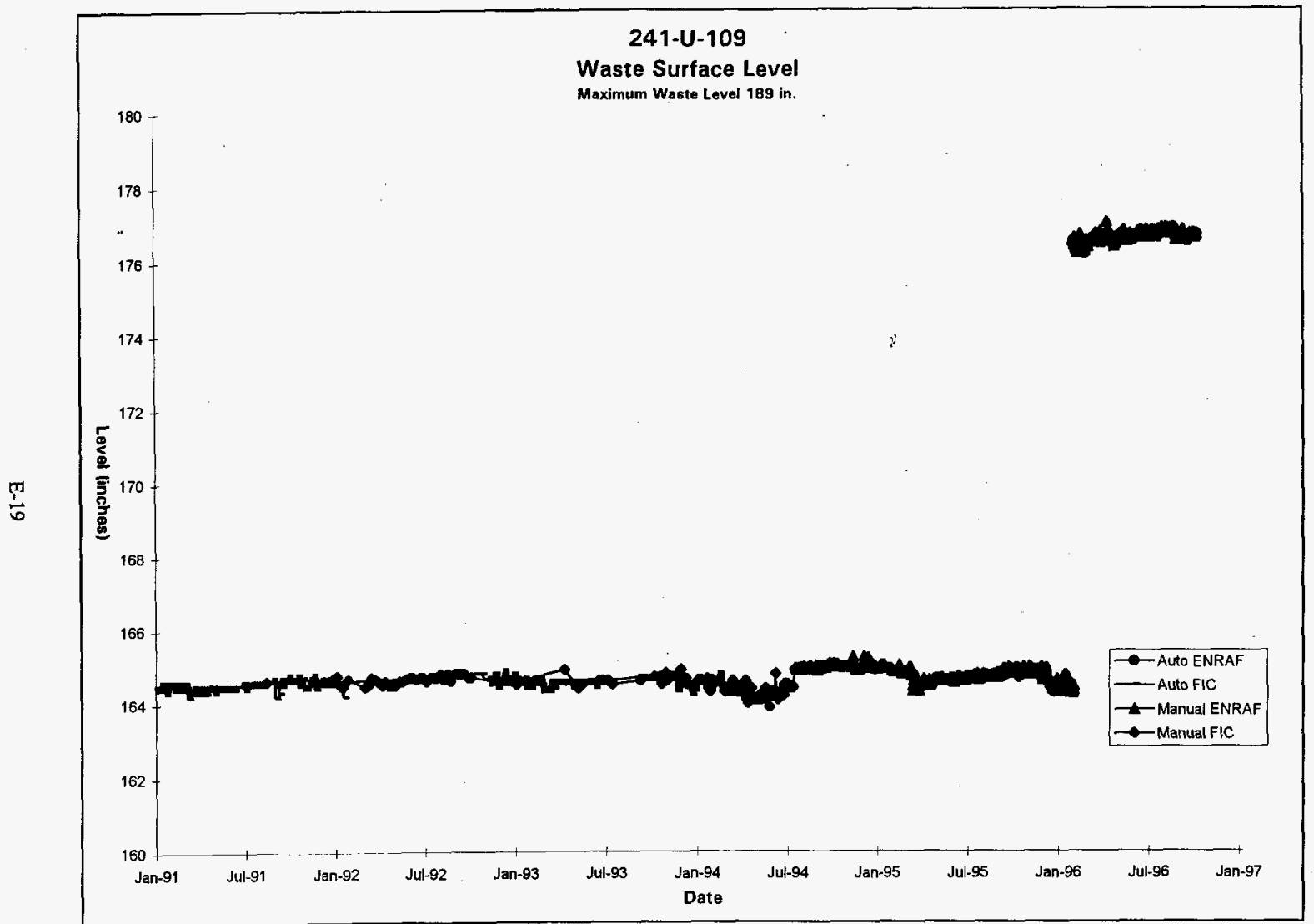

1. Data obtained from LMHC Surveillance Analysis Computer System (SACS), October 14, 1996.

2. Reference point to determine waste surface level changed in February 1996. The volume of waste did not change. 


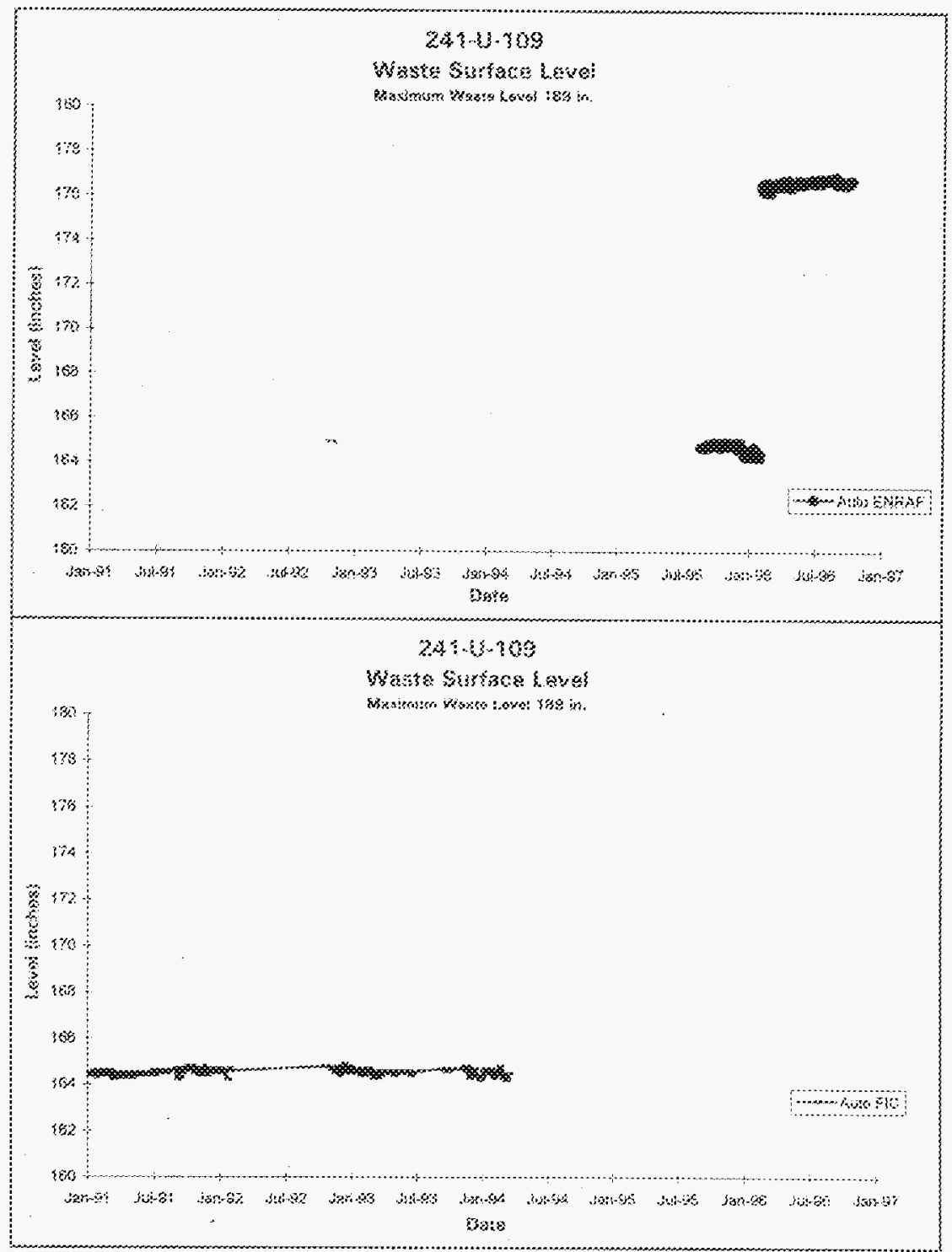

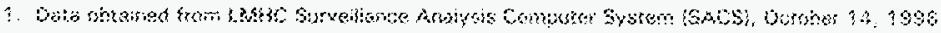

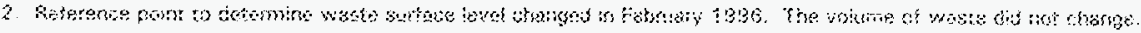




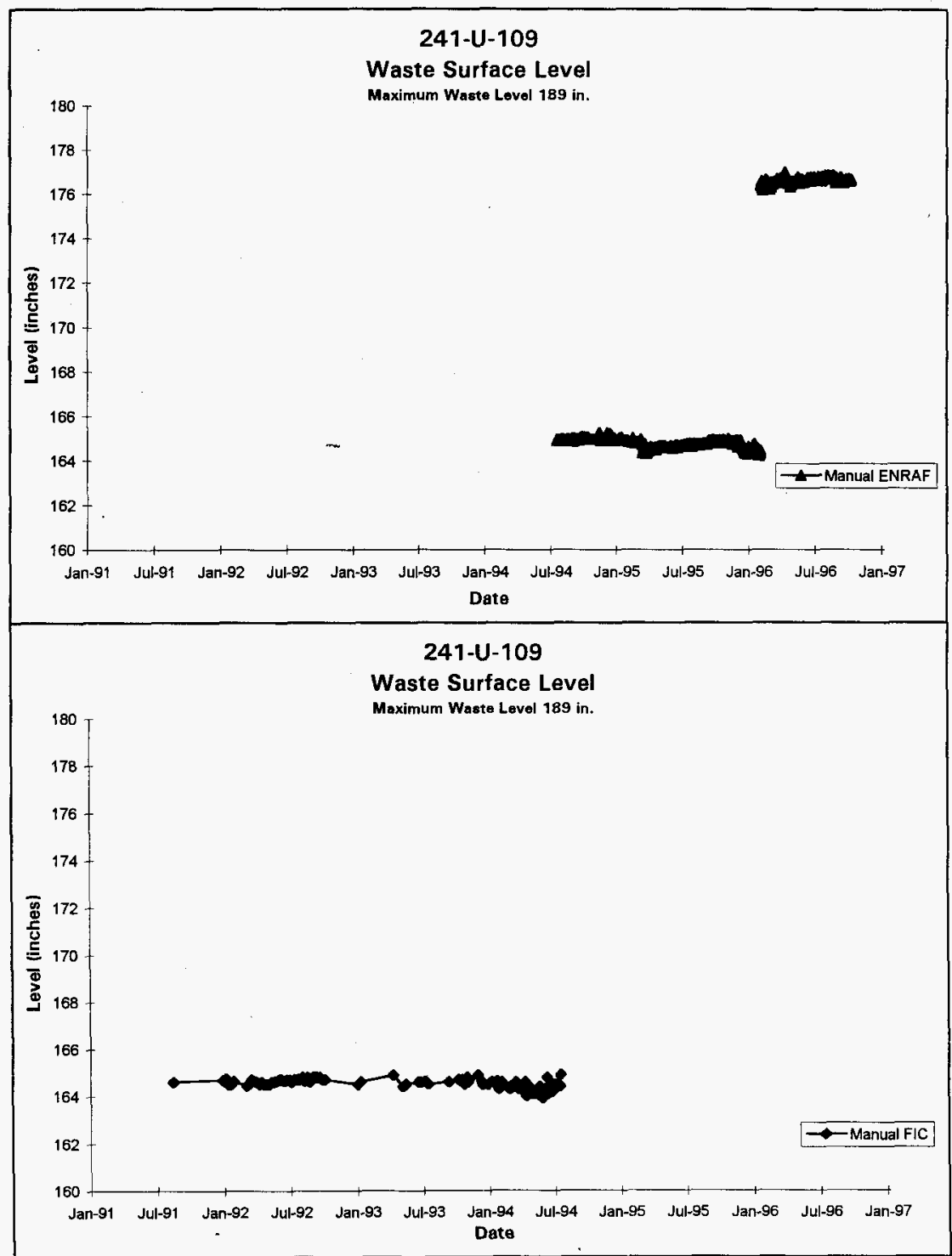

1. Data obtained from LMHC Surveillance Analysis Computer System (SACS), October 14, 1996.

2. Reference point to determine waste surface level changed in February 1996. The volume of waste did not change. 


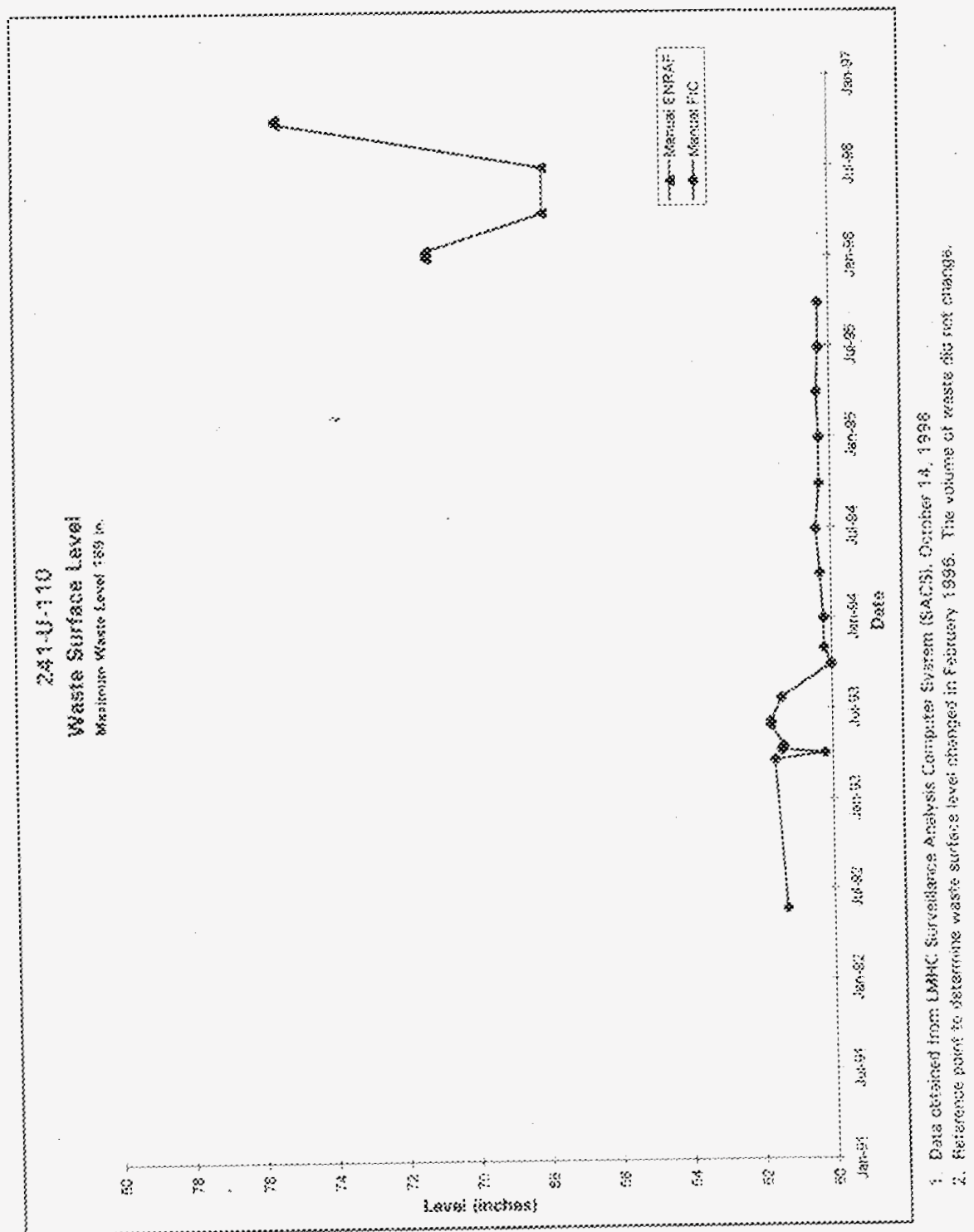




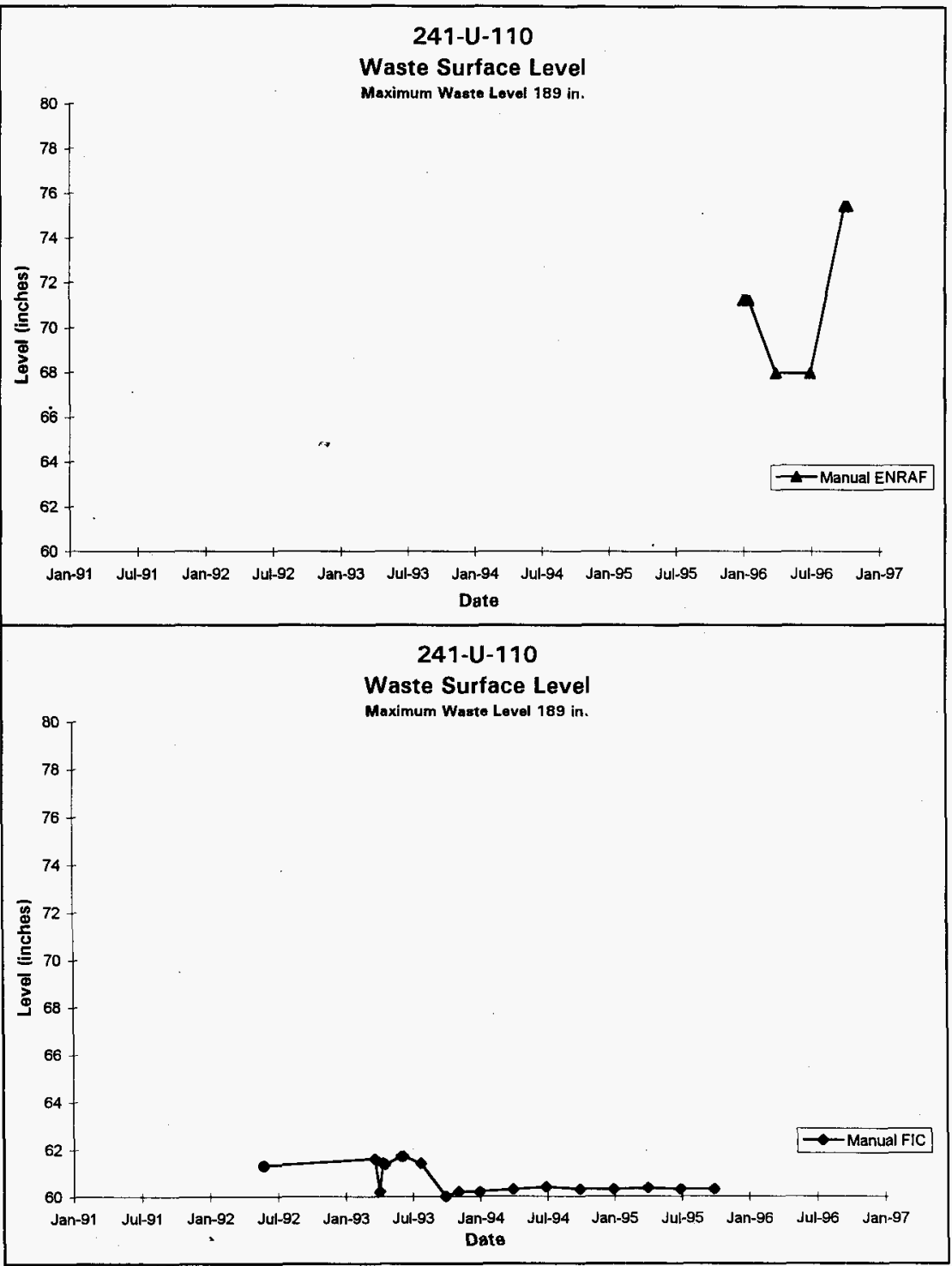

1. Data obtained from LMHC Surveillance Analysis Computer System (SACS), October 14, 1996.

2. Reference point to determine waste surface level changed in February 1996. The volume of waste did not change. 


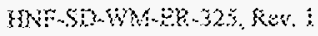

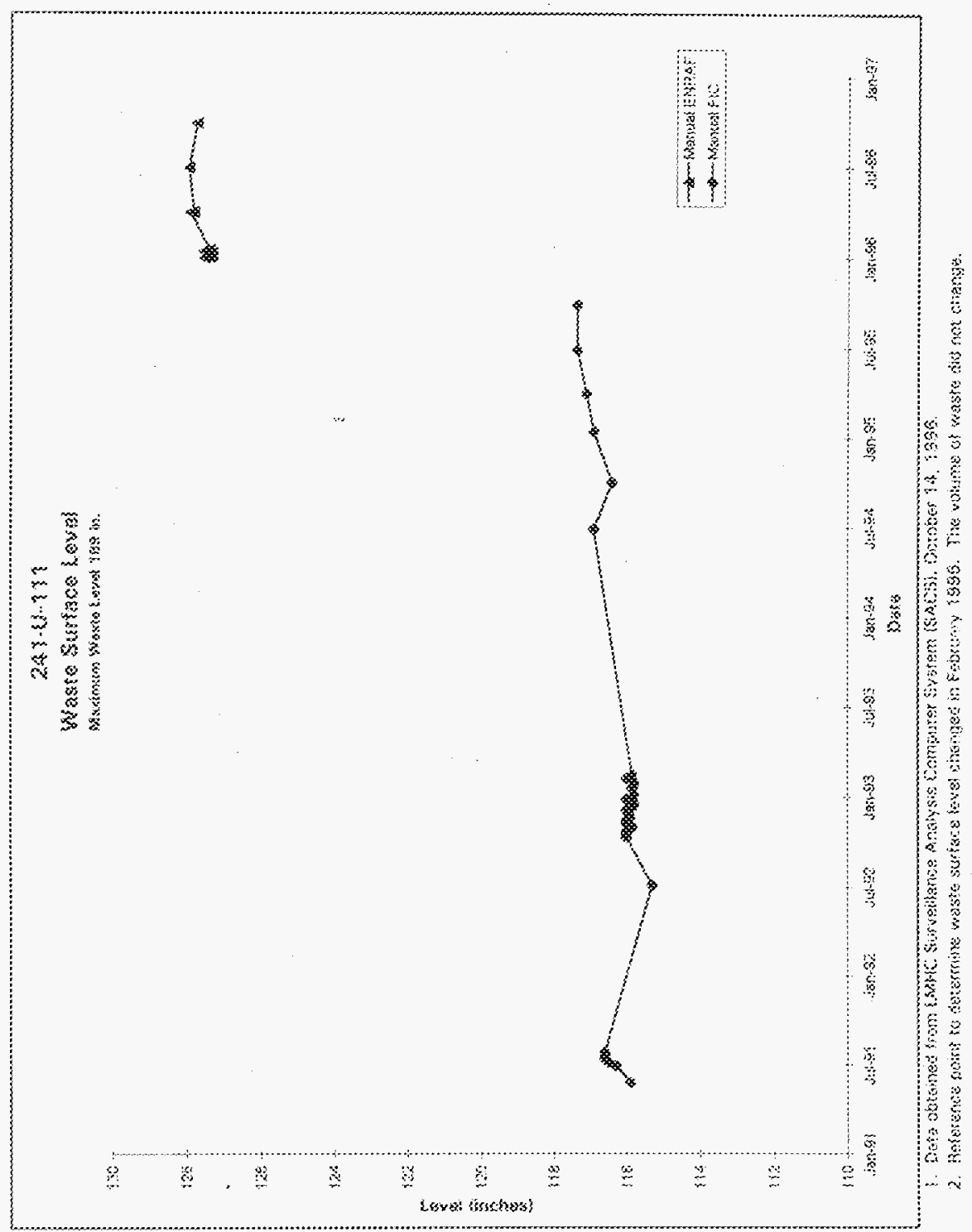




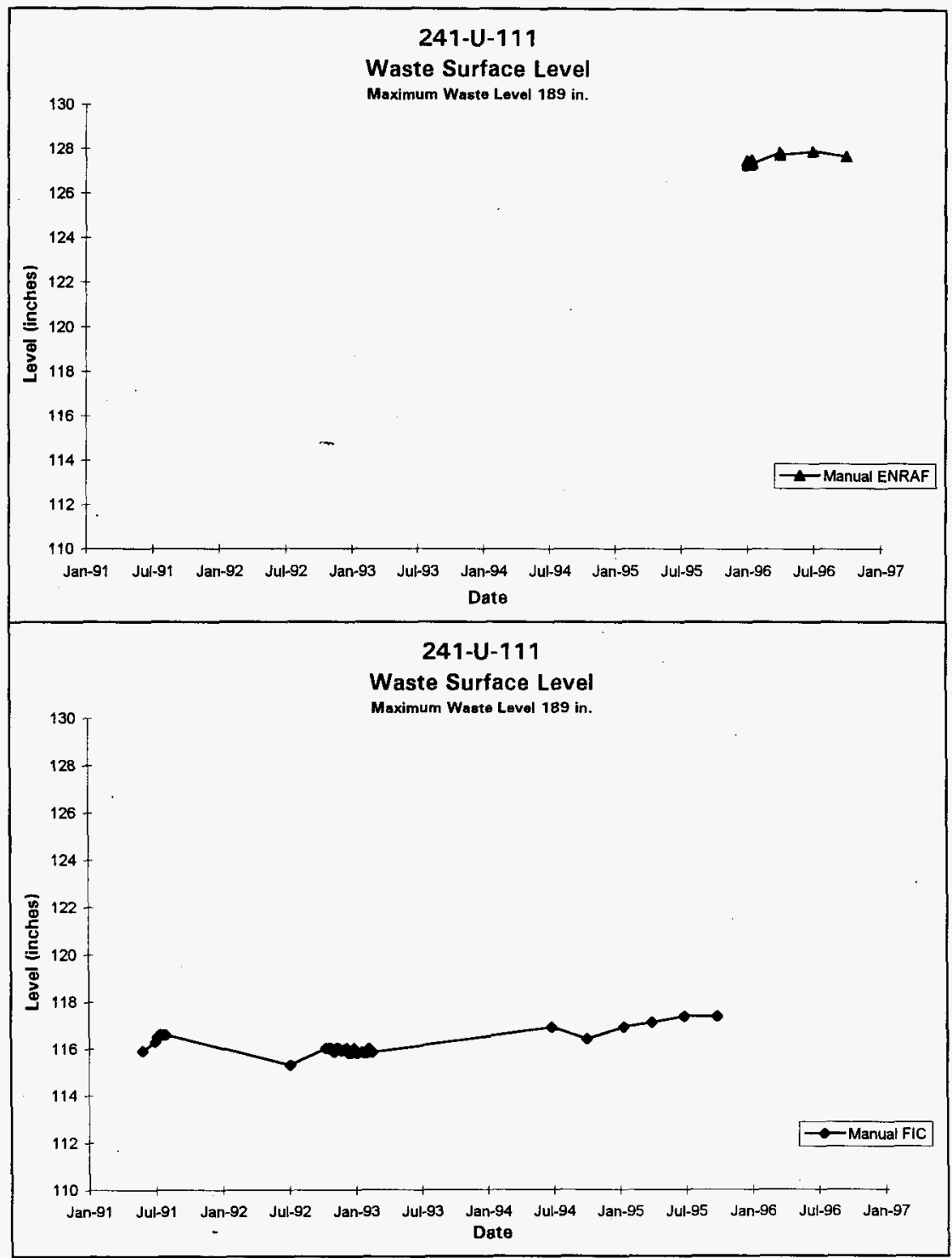

1. Data obtained from LMHC Surveillance Analysis Computer System [SACS], October 14, 1996.

2. Reference point to determine waste surface tevel changed in February 1996. The volume of waste did not change. 
WNF-ST-WM-EA-325, Yev ?

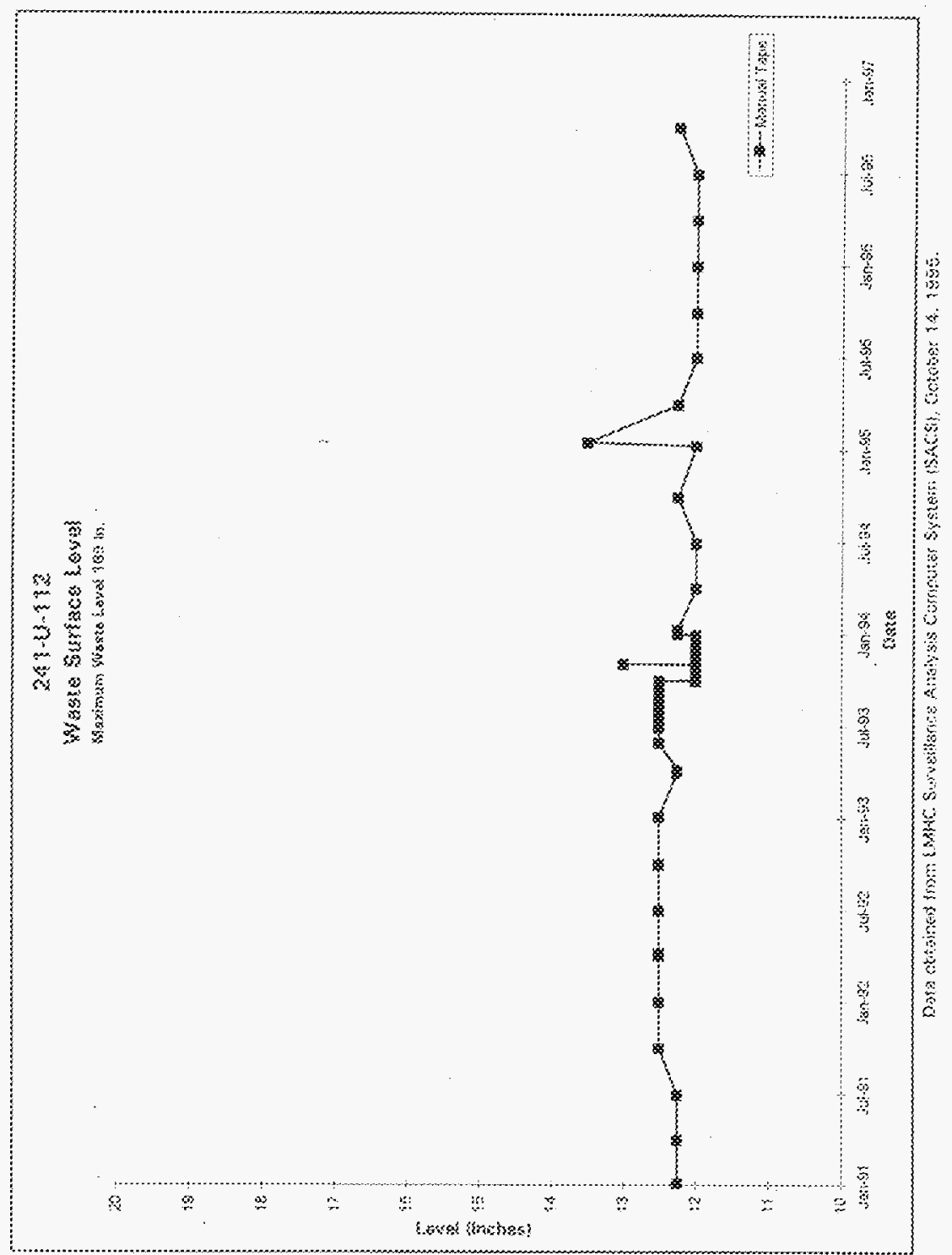




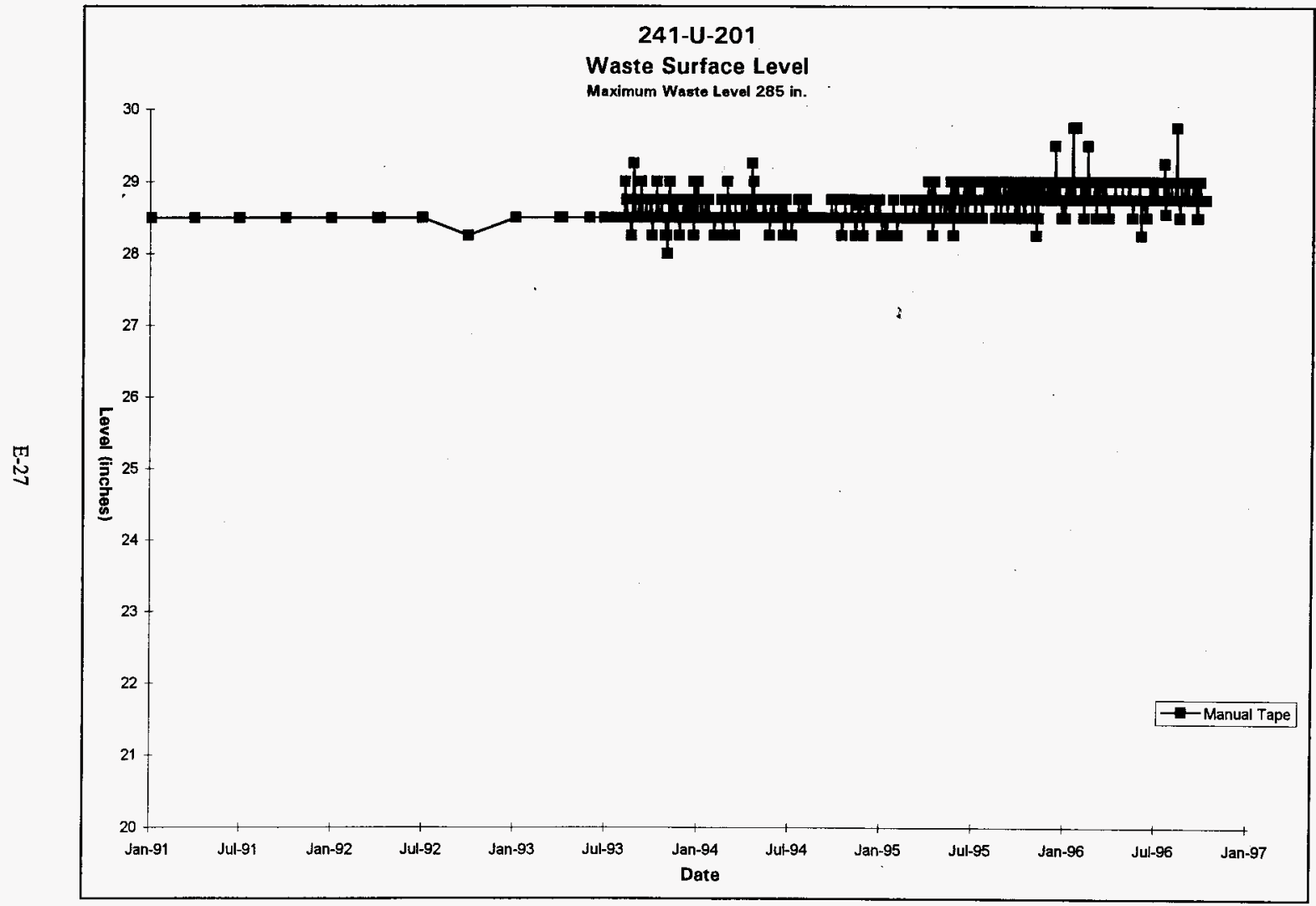

Data obtained from LMHC Surveillance Analysis Computer System (SACS), October 14, 1996. 


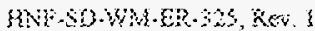

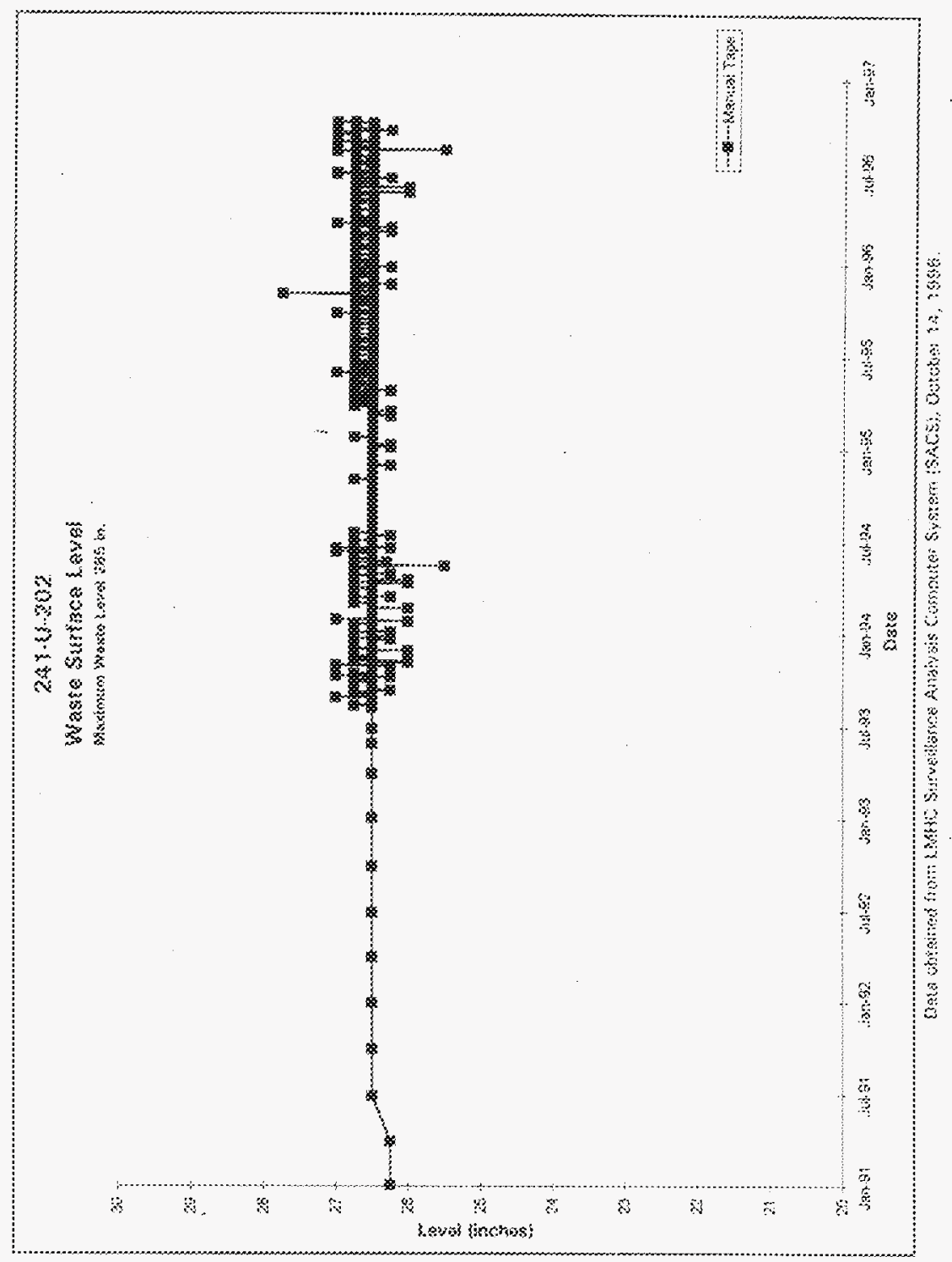




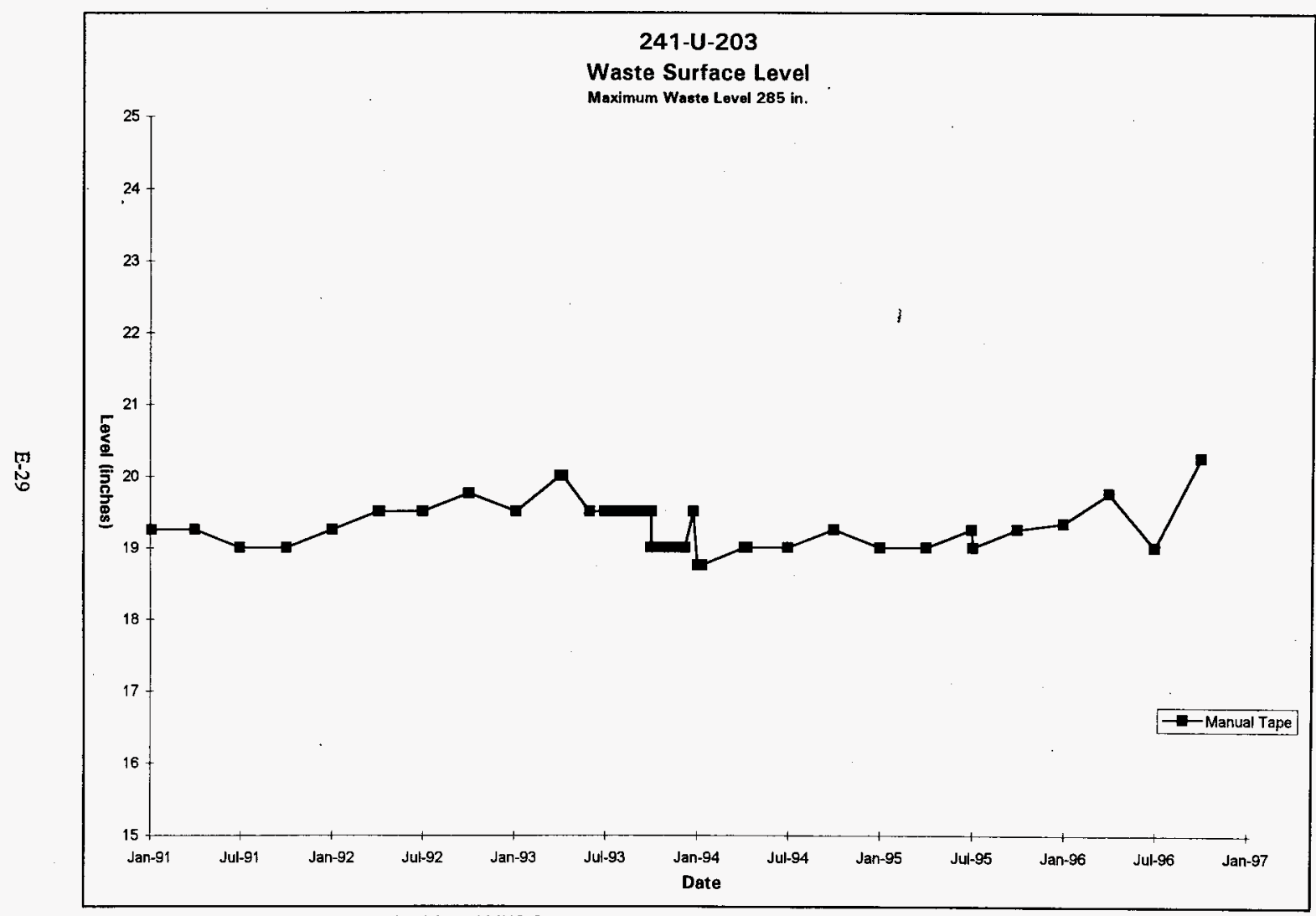

Data obtained from LMHC Surveillance Analysis Computer System (SACS), October 14, 1996. 


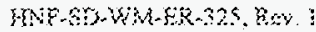

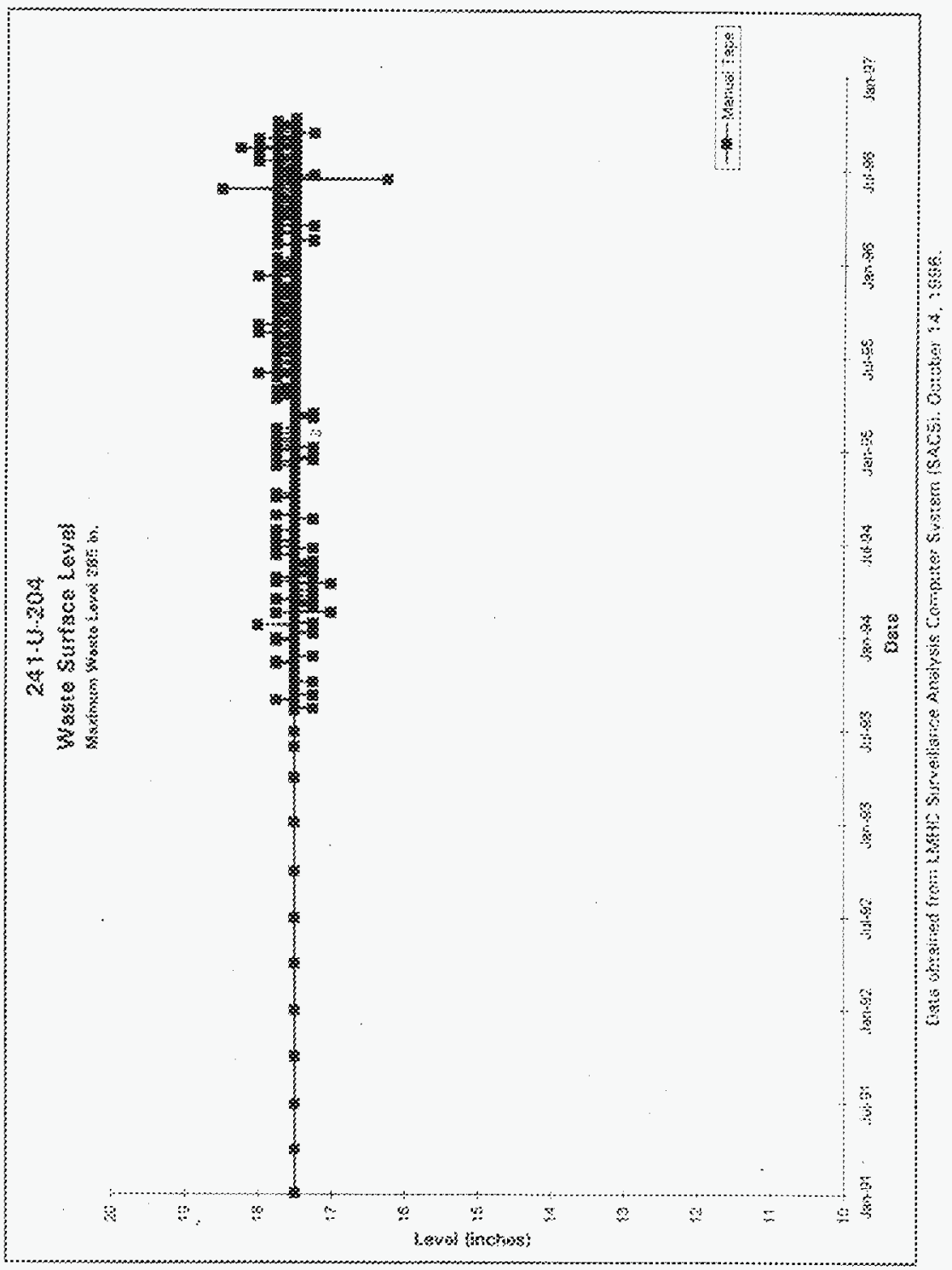


HNF-SD-WM-ER-325, Rev, 1

Intentionally left blank.

F-1 


$$
241-U-101
$$

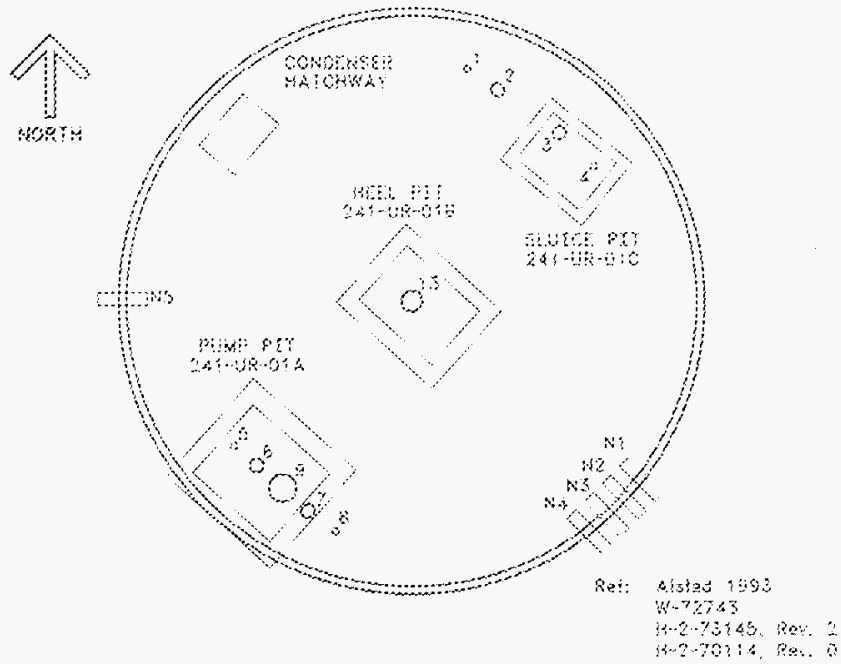

\section{TANK RTSER EOCATRON}

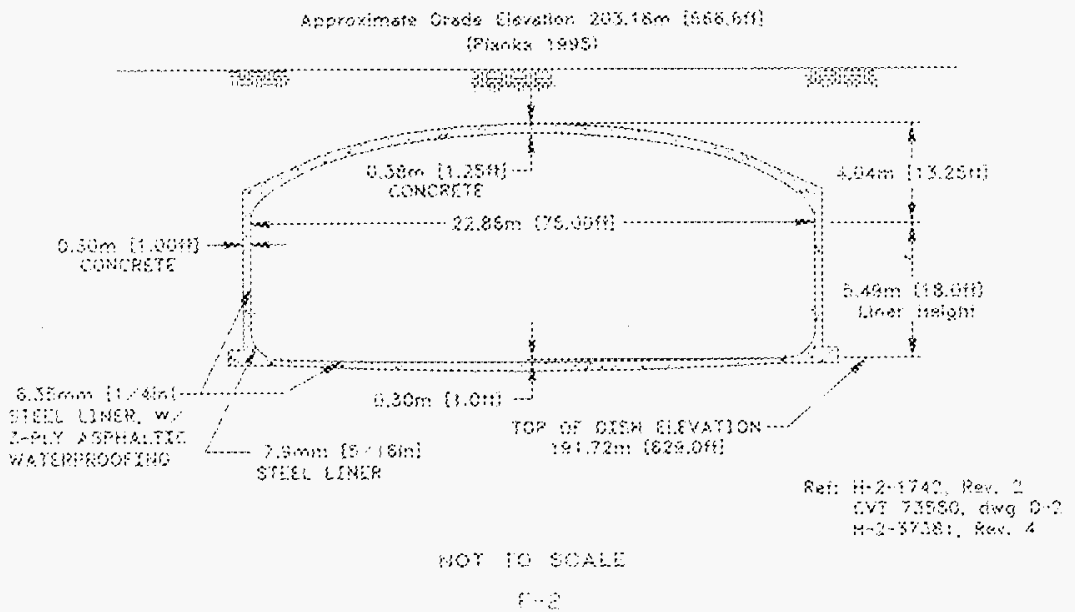




\begin{tabular}{|c|c|c|c|}
\hline NO. & 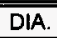 & SAMPLING* & DESCRIPTION AND COMMENTS \\
\hline$\overline{1}$ & 4" & $\bar{x}$ & BREATHER FILTER [BM CEO-37527 12/8/86] \\
\hline 2 & $12^{\prime \prime}$ & & TEMPERATURE PROBE \\
\hline 3 & $12^{\prime \prime}$ & & SLUICE NOZZLE, WC \\
\hline 4 & $4 "$ & & RECIRCULATING DIP LEG, WC \\
\hline 5 & 4" & & RECIRCULATING DIP LEG, WC \\
\hline 6 & 12" & & SLUICE NOZZLE, WC \\
\hline 7 & $12^{\prime \prime}$ & $\bar{x}$ & B-222 OBSV PORT \\
\hline 8 & $4^{\prime \prime}$ & & LIQUID LEVEL REEL [BM CEO-37527 12/8/86] \\
\hline 9 & $42^{\prime \prime}$ & & SLUDGE PUMP, WC \\
\hline 13 & $36^{\prime \prime}$ & & HEEL JET, WC \\
\hline $\mathrm{N} 1$ & $3^{n}$ & & INLET CUT \& CAPPED IN B' CAISSON \\
\hline $\mathrm{N} 2$ & $3^{\prime \prime}$ & & INLET CUT \& CAPPED IN 8' CAISSON \\
\hline N3 & $3^{\prime \prime}$ & & SPARE \\
\hline N4 & 3" & & SPARE \\
\hline N5 & 3" & & OVERFLOW CUT \& CAPPED \\
\hline
\end{tabular}

Ref: Alstad 1993, Lipnicki 1996, \& H-2-73145, Rev. 2.

If there was a discrepancy between the documents and the drawings, the drawings took preceden Comments placed in $\square$ denote Engineering Change Notices (ECN) made against the reference drawings.

- Denotes risers tentatively available for sampling (Lipnicki 1996) 


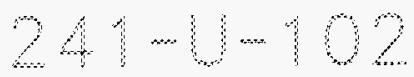

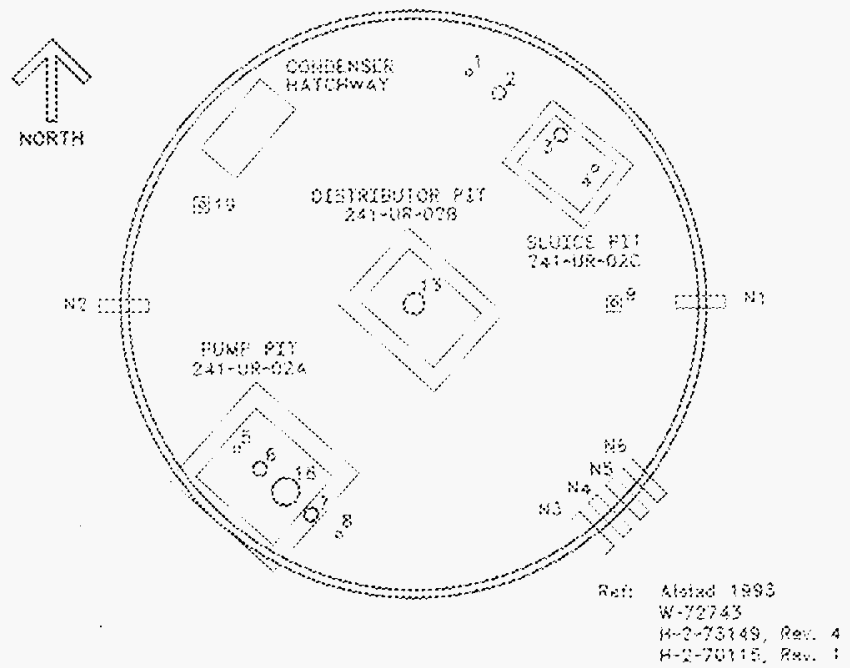

TANK RSES LOCATMON

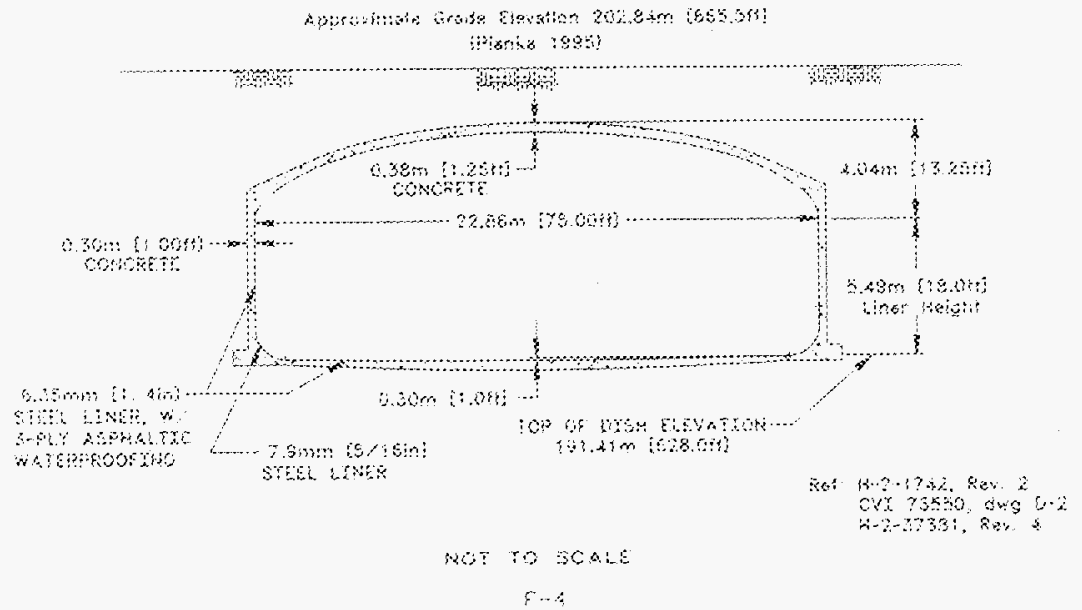


HNF-SD-WM-ER-325, Rev. 1

\begin{tabular}{|c|c|c|c|}
\hline NO. & DIA. & SAMPLING* & DESCRIPTION AND COMMENTS \\
\hline 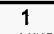 & 4" & & TEMPERATURE PROBE \\
\hline 2 & $12^{\prime \prime}$ & & B-436 LOW \\
\hline 3 & $12^{\prime \prime}$ & & SLUICE NOZZLE, WC \\
\hline 4 & $4 "$ & & DIP LEG, WC \\
\hline 5 & $4^{\prime \prime}$ & & DIP LEG, WC \\
\hline 6 & 12" & & SLUICE NOZZLE, WC \\
\hline 7 & $12^{\prime \prime}$ & $x$ & B-222 OBSV PORT \\
\hline 8 & 4" & & $\begin{array}{l}\text { FIC [BM CEO-37528 12/11/86] [ENRAF } 854 \text { ECN- } \\
62594411 / 17 / 95]\end{array}$ \\
\hline 9 & $4 "$ & $\bar{x}$ & BREATHER FILTER \\
\hline 13 & $36^{\prime \prime}$ & & SALTWELL PUMP \\
\hline 18 & $42^{\prime \prime}$ & & SLUDGE PUMP, WC \\
\hline 19 & $4 "$ & $\bar{x}$ & SMP [BM CEO-37528 12/11/86] \\
\hline $20^{* *}$ & $12^{\prime \prime}$ & & SPARE \\
\hline N1 & 3 & & INLET \\
\hline N2 & $3^{\prime \prime}$ & & OUTLET \\
\hline N3 & $4^{\prime \prime}$ & & SPARE \\
\hline N4 & $4^{\prime \prime}$ & & SPARE \\
\hline N5 & $4 "$ & & SPARE \\
\hline N6 & $4^{\prime \prime}$ & & SPARE \\
\hline
\end{tabular}

Ref: Alstad 1993, Lipnicki 1996, \& H-2-73149, Rev. 4.

If there was a discrepancy between the documents and the drawings, the drawings took preceden Comments placed in $[$ denote Engineering Change Notices (ECN) made against the reference drawings.

- Denotes risers tentatively available for sampling (Lipnicki 1996)

** The table in H-2-73149, rev. 4 lists the riser; however, the figure does not show a locat 


\section{$241 \cdots \cup-103$}

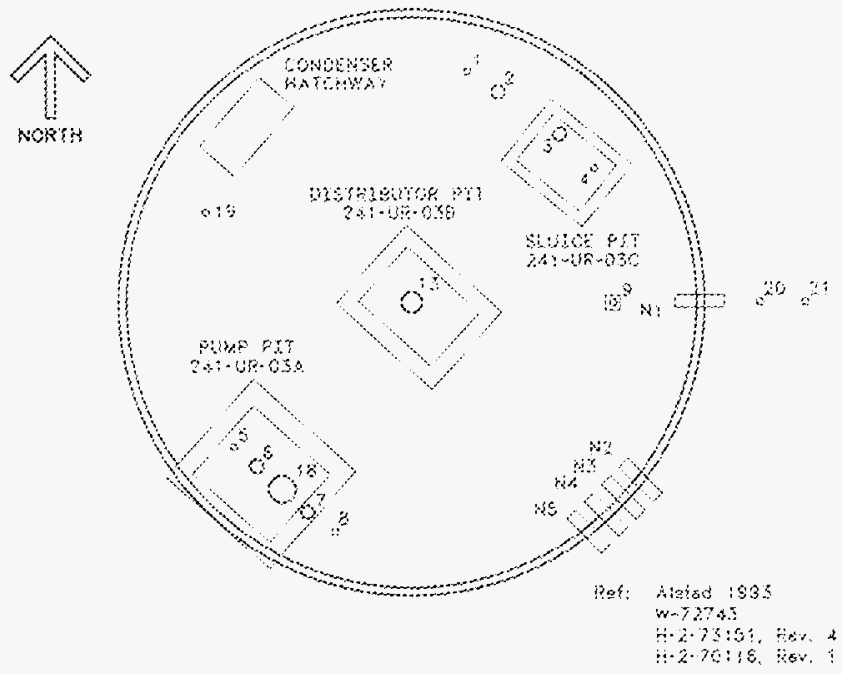

TANK RTSER LOCATION

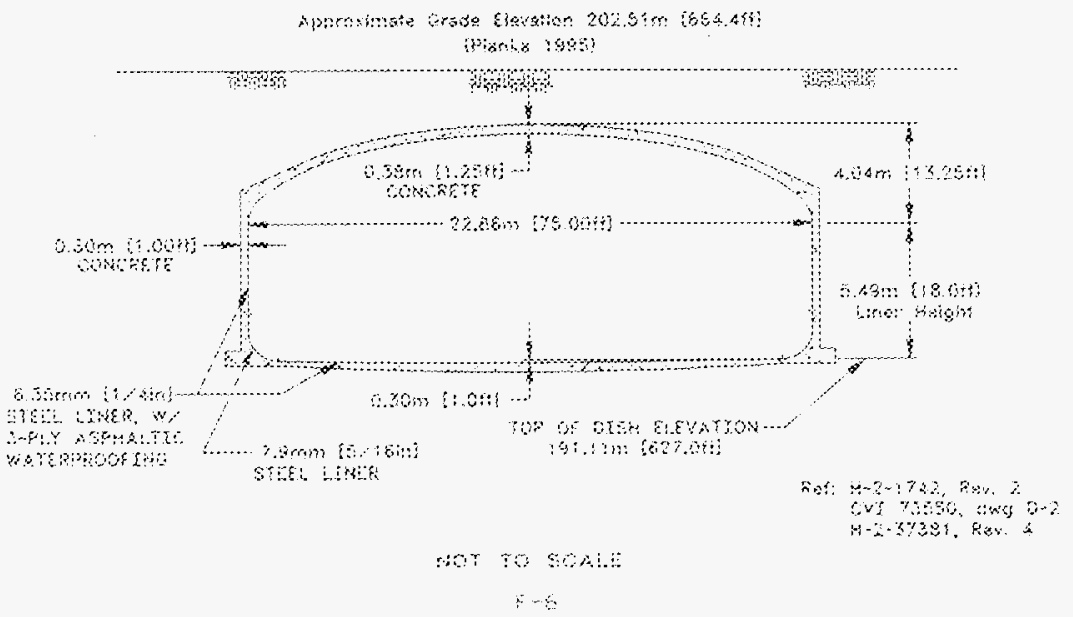




\begin{tabular}{|c|c|c|c|}
\hline NO. & DIA. & SAMPLING* & DESCRIPTION AND COMMENTS \\
\hline 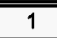 & 4" & & TEMPERATURE PROBE [BM CEO-37529 12/11/86] \\
\hline 2 & $12^{\prime \prime}$ & $\bar{x}$ & B-222 OBSV PORT \\
\hline 3 & $12^{\prime \prime}$ & & SLUICE NOZZLE, WC \\
\hline 4 & 4" & & DIP LEG, WC \\
\hline 5 & $4^{n}$ & & DIP LEG, WC \\
\hline 6 & $12^{\prime \prime}$ & & SLUICE NOZZLE, WC \\
\hline 7 & $12^{\prime \prime}$ & $\bar{x}$ & DIP TUBES, WC \\
\hline 8 & $4^{\prime \prime}$ & & FIC [ENRAF 854 ECN-608150 7/12/94] \\
\hline 9 & $4^{\prime \prime}$ & $x$ & $\begin{array}{l}\text { BREATHER FILTER [BM CEO-37529 } 12 / 11 / 86] \\
\text { [STANDARD HYDROGEN MONITOR SYSTEM i } \\
\text { BREATHER FILTER ECN-W369-021 } 1 / 23 / 95]\end{array}$ \\
\hline 13 & $36 "$ & & SALTWELL PUMP, WC \\
\hline 18 & 42" & & SLUDGE PUMP, WC \\
\hline 19 & 4" & & B-436 LOW \\
\hline 20 & 2" & & CLEANOUT CAPPED \\
\hline 21 & $2 "$ & & CLEANOUT CAPPED \\
\hline N1 & $3^{\text {nenen }}$ & & INLET \\
\hline N2 & $3^{n+n}$ & & SPARE \\
\hline N3 & $3^{m+\hbar k}$ & & SPARE \\
\hline $\mathrm{N4}$ & $3^{m+* *}$ & & SPARE \\
\hline N5 & $3^{n+1 * \hbar}$ & & SPARE \\
\hline
\end{tabular}

Ref: Alstad 1993, Lipnicki 1996, \& H-2-73151, Rev. 4.

If there was a discrepancy between the documents and the drawings, the drawings took preceden Comments placed in [] denote Engineering Change Notices (ECN) made against the reference drawings.

* Denotes risers tentatively available for sampling (Lipnicki 1996)

** The diameters were taken from HW-72743. 


$$
\text { a }
$$

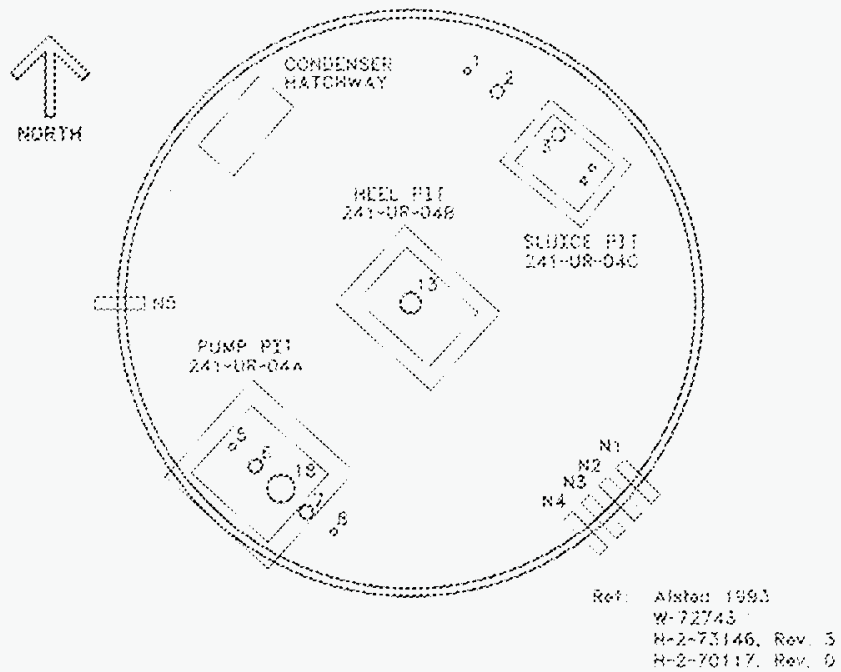

\section{JAN RESE LOCATMON}

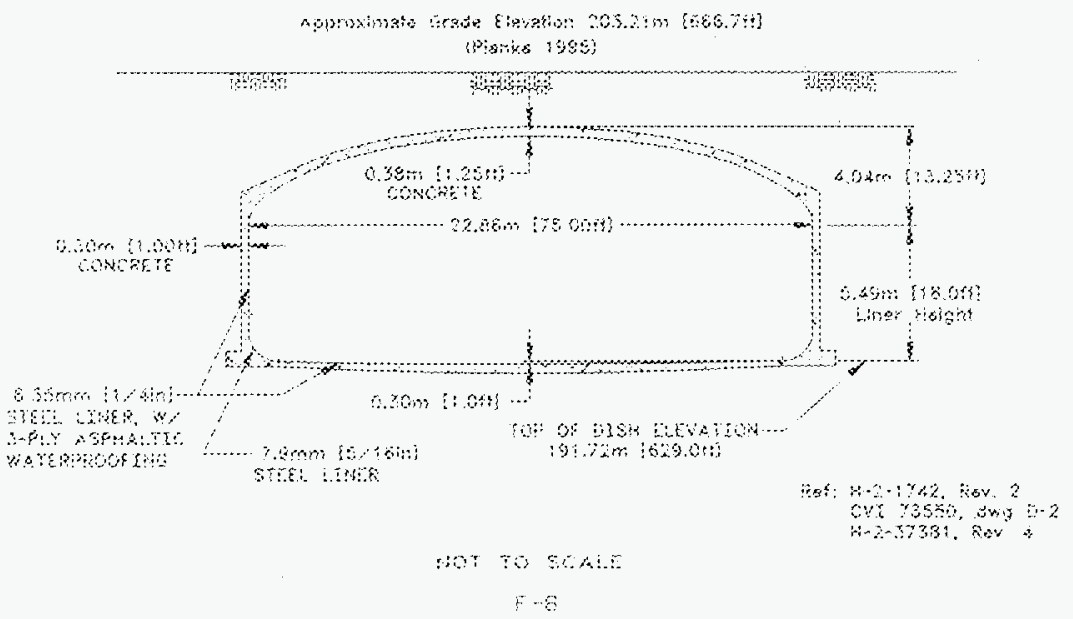




\begin{tabular}{|c|c|c|c|}
\hline No. & DIA. & SAMPLING* & DESCRIPTION AND COMMENTS \\
\hline 1 & 4" & $\underline{x}$ & BREATHER FILTER [BM CEO-37530 12/8/86] \\
\hline 2 & $12^{\prime \prime}$ & $x$ & B-222 OBSV PORT \\
\hline 3 & $12^{\prime \prime}$ & & SLUICE NOZZLE, WC \\
\hline 4 & $4^{\prime \prime}$ & & RECIRCULATING DIP LEG, WC \\
\hline 5 & 4" & & RECIRCULATING DIP LEG, WC \\
\hline 6 & $12^{\prime \prime}$ & & SLUICE NOZZLE, WC \\
\hline 7 & $12^{\prime \prime}$ & & LIQUID LEVEL REEL \\
\hline 8 & 4" & $\mathbf{x}$ & LIQUID LEVEL REEL \\
\hline 13 & $36^{\prime \prime}$ & & HEEL JET, WC \\
\hline 18 & $42^{\prime \prime}$ & & SLUDGE PUMP, WC \\
\hline N1 & 3" & & INLET CUT \& CAPPED IN 8' CAISSON \\
\hline N2 & $3^{\prime \prime}$ & & INLET CUT \& CAPPED IN 8' CAISSON \\
\hline N3 & 3" & & INLET CUT \& CAPPED IN 8' CAISSON \\
\hline N4 & 3" & & SPARE CAPPED \\
\hline N5 & 3" & & OVERFLOW CUT \& CAPPED \\
\hline
\end{tabular}

Ref: Alstad 1993, Lipnicki 1996, \& H-2-73146, Rev. 3.

If there was a discrepancy between the documents and the drawings, the drawings took preceden Comments placed in D denote Engineering Change Notices (ECN) made against the reference drawings.

* Denotes risers tentatively available for sampling (Lipnicki 1996) 


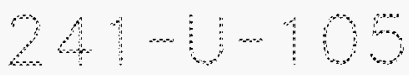

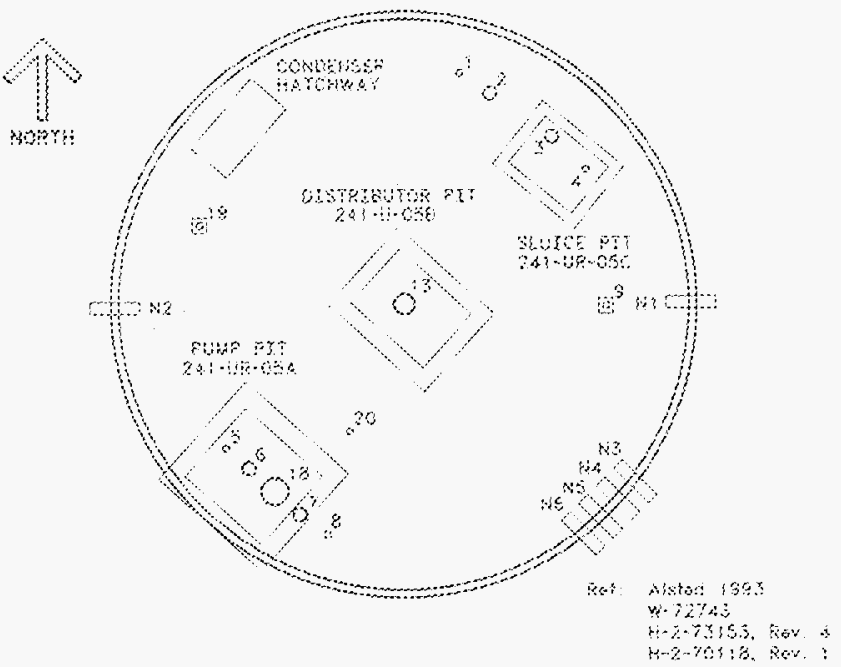

TAK RSER LOCATION

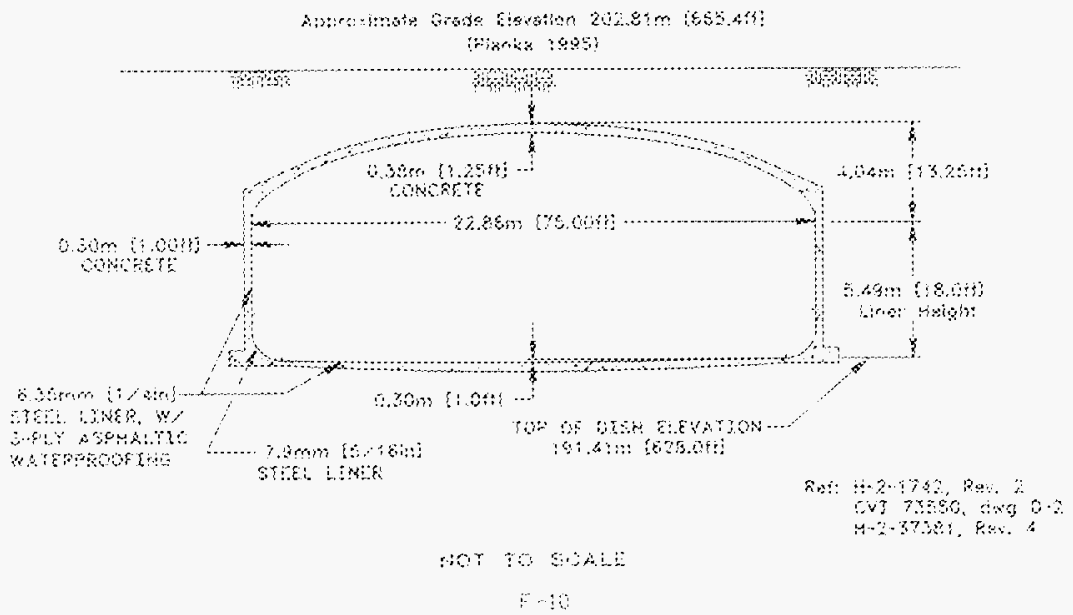


HNF-SD-WM-ER-325, Rev. 1

\begin{tabular}{|c|c|c|c|}
\hline NO. & DIA. & SAMPLING* & DESCRIPTION AND COMMENTS \\
\hline 1 & $4^{\prime \prime}$ & & $\begin{array}{l}\text { LIQUID LEVEL WELL "A" [BM CEO-37531 } 12 / 11 / 86] \\
{[\text { [TEMPERATURE PROBE ECN-628741 } 1 / 3 / 96]}\end{array}$ \\
\hline 2 & $12 "$ & $\mathbf{x}$ & $\begin{array}{l}\text { IS LIQUID LEVEL WELL "A" [BLIND FLANGE W/ 4" X 4" } \\
\text { SPOOL ASSEMBLY } 11 \text { TO 4" X 12" ADAPTER @ } \\
\text { BOTTOM OF CAISSON ECN-628741 1/3/96] }\end{array}$ \\
\hline 3 & $12 "$ & & SLUICE NOZZLE, WC \\
\hline 4 & 4" & & RECIRCULATING DIP LEG, WC \\
\hline 5 & 4" & & RECIRCULATING DIP LEG, WC \\
\hline 6 & $12^{\prime \prime}$ & & SLUICE NOZZLE, WC \\
\hline 7 & $12^{\prime \prime}$ & $\bar{x}$ & B-222 OBSV PORT \\
\hline 8 & 4" & & FIC [ENRAF 854 ECN-608149 7/12/94] \\
\hline 9 & $4^{\prime \prime}$ & $\mathbf{x}$ & $\begin{array}{l}\text { BREATHER FILTER [BM CEO-37531 } 12 / 11 / 86] \\
\text { [STANDARD HYDROGEN MONITOR SYSTEM } / \\
\text { BREATHER FILTER ECN-W369-021 } 1 / 23 / 95] \\
\end{array}$ \\
\hline 13 & $36^{\prime \prime}$ & & DISTRIBUTOR PIT USED FOR SALTWELL PUMPING, W \\
\hline 18 & $42^{\prime \prime}$ & & SLUDGE PUMP, WC \\
\hline 19 & $4^{\prime \prime}$ & & B-436 LOW \\
\hline 20 & 4" & $x$ & $\begin{array}{l}\text { LIQUID LEVEL REEL [BLIND FLANGE W/ 4" } \times \text { 4" SPOOL } \\
\text { ASSEMBLY } 8 \text { ECN-628741 } 1 / 3 / 96]\end{array}$ \\
\hline N1 & $3^{n \prime}$ & & INLET \\
\hline N2 & 3" & & OUTLET \\
\hline N3 & 4" & & SPARE \\
\hline $\mathrm{N4}$ & 4" & & SPARE \\
\hline N5 & 4" & & SPARE \\
\hline N6 & 4" & & SPARE \\
\hline
\end{tabular}

Ref: $\quad$ Alstad 1993, Lipnicki 1996, \& H-2-73153, Rev. 4.

If there was a discrepancy between the documents and the drawings, the drawings took preceden Comments placed in D denote Engineering Change Notices (ECN) made against the reference drawings.

* Denotes risers tentatively available for sampling (Lipnicki 1996) 


$$
241-4-106
$$

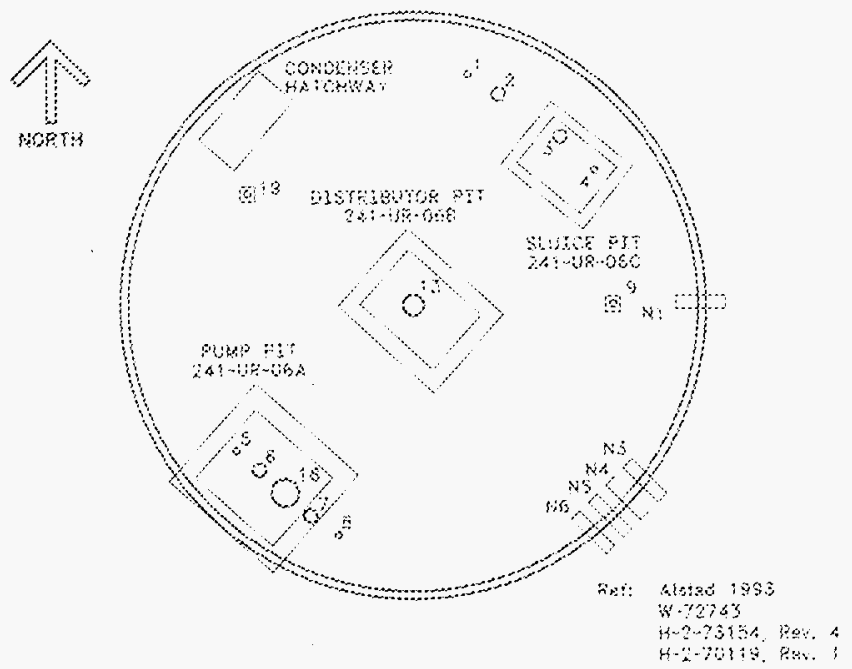

TAN RTSER LOCATION

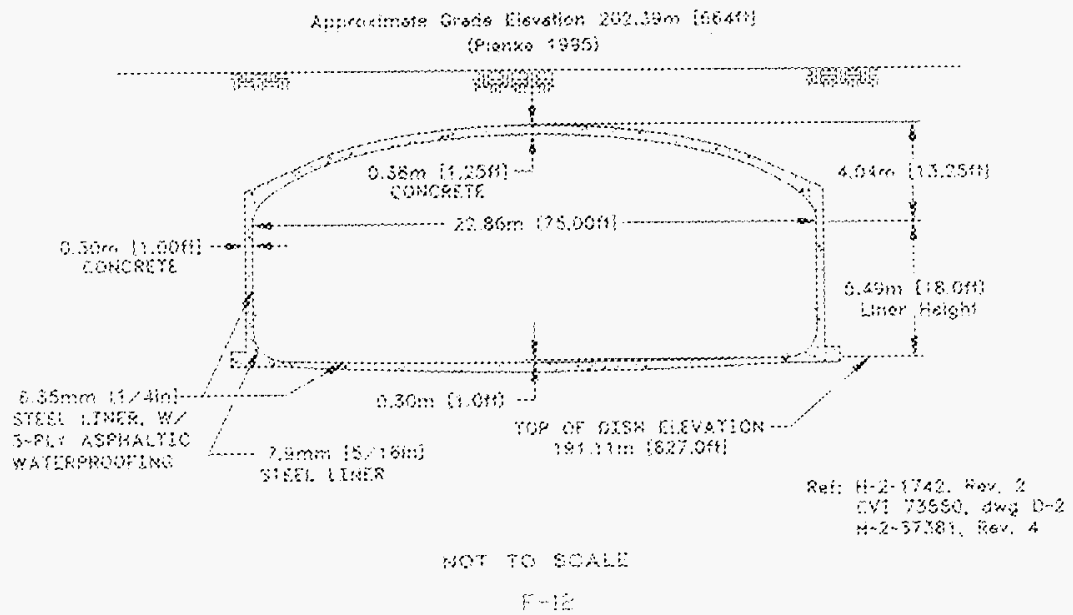




\begin{tabular}{|c|c|c|c|}
\hline NO. & DIA. & SAMPLING* & DESCRIPTION AND COMMENTS \\
\hline 1 & $4 "$ & & TEMPERATURE PROBE [BM CEO-37531 12/11/86] \\
\hline 2 & $12 "$ & $x$ & $\begin{array}{l}\text { OBSV PORT IINSTALL HEATED VAPOR PROBE \& } 12 \times \\
4 \text { ADAPTER, REMOVE COMPLETE ASSEMBLY WITHIN } \\
90 \text { DAYS OF SAMPLING ECN-618246L 2/7/95] }\end{array}$ \\
\hline 3 & $12^{\prime \prime}$ & & SLUICE NOZZLE, WC \\
\hline 4 & 4" & & RECIRCULATION LINE DRIP LEG, WC \\
\hline 5 & $4^{\prime \prime}$ & & RECIRCULATION LINE DRIP LEG, WC \\
\hline 6 & $12^{\prime \prime}$ & & SLUICE NOZZLE, WC \\
\hline 7 & $12^{\prime \prime}$ & $\bar{x}$ & B-222 OBSV PORT \\
\hline 8 & 4" & & FIC [ENRAF 854 ECN-608148 7/12/94] \\
\hline 9 & $4 "$ & & B-436 LOW [BM CEO-37531 12/11/86] \\
\hline 13 & $36 "$ & & DISTRIBUTOR JET, WC \\
\hline 18 & $42^{\prime \prime}$ & & SLUDGE PUMP, WC \\
\hline 19 & $4 "$ & $\bar{x}$ & BREATHER FILTER \\
\hline N1 & $3^{\prime \prime}$ & & INLET \\
\hline N3 & $4 "$ & & SPARE \\
\hline $\mathrm{N4}$ & 4". & & SPARE \\
\hline N5 & $4 "$ & & SPARE \\
\hline N6 & $4 "$ & & SPARE \\
\hline
\end{tabular}

Ref: $\quad$ Alstad 1993, Lipnicki 1996, \& H-2-73154, Rev. 4.

If there was a discrepancy between the documents and the drawings, the drawings took preceden Comments placed in [] denole Engineering Change Notices (ECN) made against the reference drawings.

- Denotes risers tentatively available for sampling (Lipnicki 1996) 


$$
\begin{array}{ll}
m \\
3
\end{array}
$$

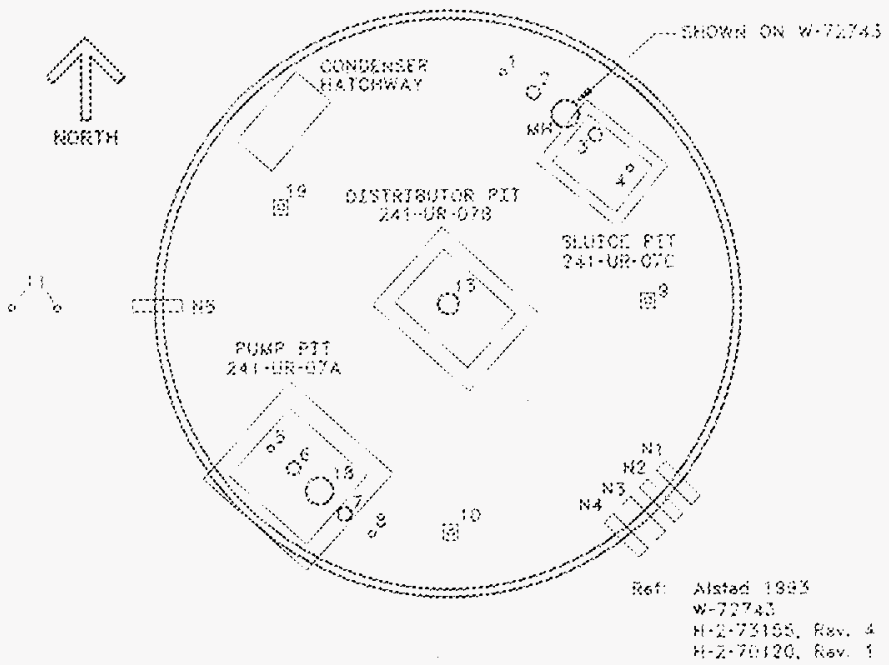

\section{TANK RTSER LOCATSON}

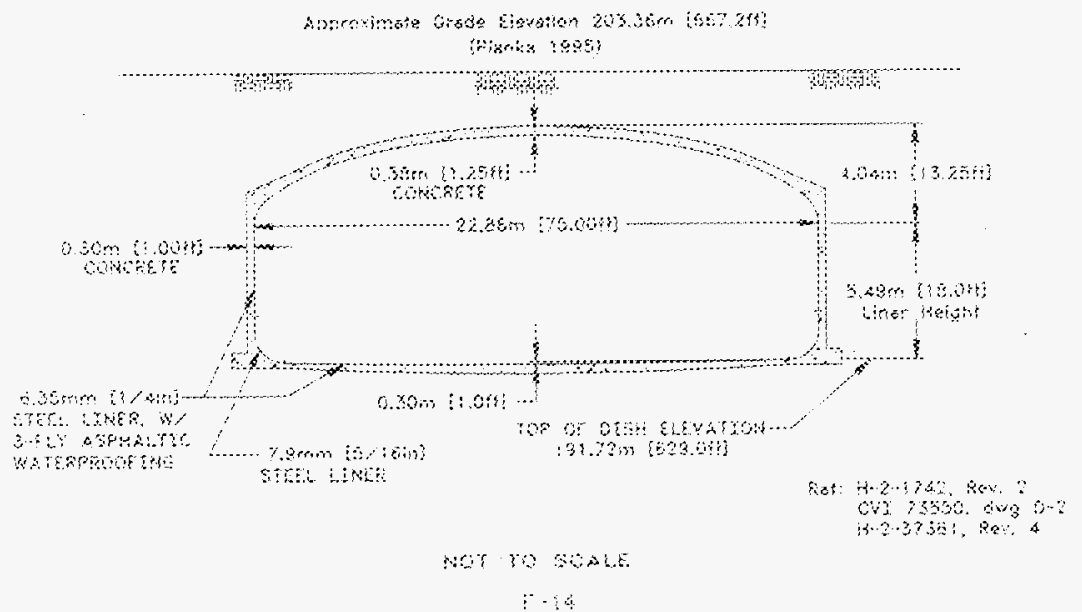




\begin{tabular}{|c|c|c|c|}
\hline No. & DIA. & SAMPLING* & DESCRIPTION AND COMMENTS \\
\hline 1 & $4 "$ & & TEMPERATURE PROBE [BM CEO-37531 12/11/86] \\
\hline 2 & $12^{\prime \prime}$ & $x$ & BLIND FLANGE \\
\hline 3 & 12" & & SLUICE NOZZLE, WC \\
\hline 4 & 4" & & RECIRCULATION LINE DIP LEG, WC \\
\hline 5 & 4" & & RECIRCULATION LINE DIP LEG, WC \\
\hline 6 & $12^{\prime \prime}$ & & SLUICE NOZZLE, WC \\
\hline 7 & $12^{\prime \prime}$ & $x$ & B-222 OBSV PORT \\
\hline 8 & 4" & & FIC [ENRAF 854 ECN-608147 $7 / 12 / 94]$ \\
\hline 9 & $4 "$ & $\bar{x}$ & BLIND FLANGE [BM CEO-37531 12/11/86] \\
\hline 10 & $4^{\prime \prime}$ & $x$ & $\begin{array}{l}\text { BREATHER FILTER [STANDARD HYDROGEN } \\
\text { MONITOR SYSTEM / BREATHER FILTER ECN-W369- } \\
021 \text { 1/23/95] }\end{array}$ \\
\hline 11 & 2" & & $\begin{array}{l}\text { CLEAN OUT, QTY. 2, NO ELEVATIONS OR } \\
\text { COORDINATES GIVEN }\end{array}$ \\
\hline 13 & $12^{\prime \prime}$ & & DISTRIBUTOR JET \\
\hline 18 & 42" & & SLUDGE PUMP, WC \\
\hline 19 & $4 "$ & & B-436 LOW \\
\hline N1 & $3^{\prime \prime}$ & & INLET SEALED IN DIVERSION BOX 241-U-153 \\
\hline N2 & $3^{\prime \prime}$ & & INLET SEALED IN DIVERSION BOX 241-U-153 \\
\hline N3 & $3^{\prime \prime}$ & & INLET SEALED IN DIVERSION BOX 241-U-153 \\
\hline N4 & 3" & & SPARE, CAPPED \\
\hline N5 & 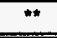 & & OVERFLOW \\
\hline
\end{tabular}

Ref: $\quad$ Alstad 1993, Lipnicki 1996, \& H-2-73155, Rev. 4.

If there was a discrepancy between the documents and the drawings, the drawings took preceden Comments placed in [] denote Engineering Change Notices (ECN) made against the reference drawings.

* Denotes risers tentatively available for sampling (Lipnicki 1996)

* No diameter given. 


\section{$24 \div-108$}

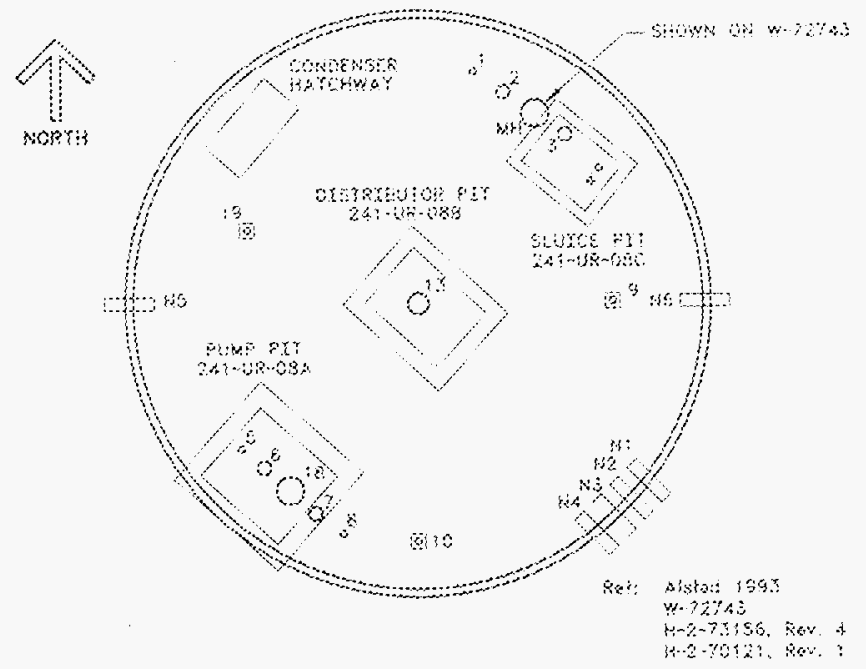

\section{TANK RESE LOCATMON}

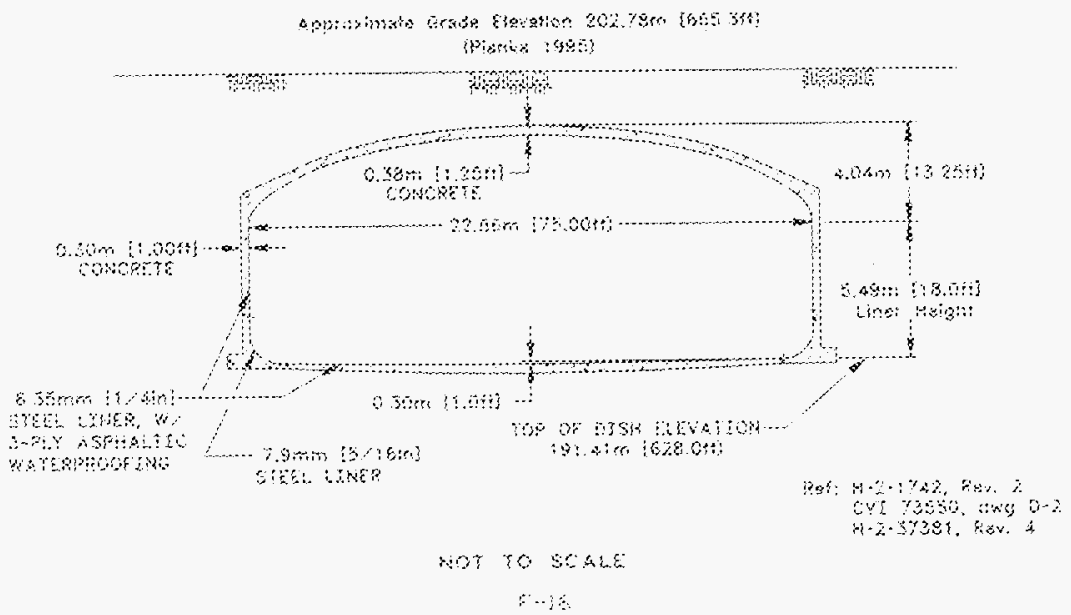




\begin{tabular}{|c|c|c|c|}
\hline NO. & DIA. & SAMPLING* & DESCRIPTION AND COMMENTS \\
\hline 1 & 4" & & TEMPERATURE PROBE [BM CEO-37531 12/11/86] \\
\hline 2 & $12^{\prime \prime}$ & $x$ & BLIND FLANGE \\
\hline 3 & $12^{\prime \prime}$ & & SLUICE NOZZLE, WC \\
\hline 4 & $4 "$ & & RECIRCULATION LINE DIP LEGS, WC \\
\hline 5 & 4" & & RECIRCULATION LINE DIP LEGS, WC \\
\hline 6 & $12^{\prime \prime}$ & & SLUICE NOZZLE, WC \\
\hline 7 & $12^{\prime \prime}$ & $x$ & B-222 OBSV PORT \\
\hline 8 & 4" & & FIC [ENRAF 854 ECN-620751 2/27/95] \\
\hline 9 & $4^{\prime \prime}$ & $\underline{x}$ & SMP [BM CEO-37531 12/11/86] \\
\hline 10 & 4" & $\mathrm{x}$ & $\begin{array}{l}\text { BREATHER FILTER [STANDARD HYDROGEN } \\
\text { MONITOR SYSTEM / BREATHER FILTER ECN-W369- } \\
0211 / 23 / 95 \text { ] }\end{array}$ \\
\hline 13 & $12^{\prime \prime}$ & & DISTRIBUTOR JET FOR SALTWELL PUMPING \\
\hline 18 & $42^{\prime \prime}$ & & SLUDGE PUMP, WC \\
\hline 19 & 4" & & B-436 LOW \\
\hline N1 & 3" & & SPARE, CAPPED \\
\hline N2 & $3 "$ & & SPARE, CAPPED \\
\hline N3 & $3^{\prime \prime}$ & & SPARE, CAPPED \\
\hline N4 & 3" & & SPARE, CAPPED \\
\hline N5 & 3" & & OUTLET OVERFLOW \\
\hline N6 & 3" & & INLET OVERFLOW \\
\hline
\end{tabular}

Ref: $\quad$ Alstad 1993, Lipnicki 1996, \& H-2-73156, Rev. 4.

If there was a discrepancy between the documents and the drawings, the drawings took preceden Comments placed in $\square$ denote Engineering Change Notices (ECN) made against the reference drawings.

- Denotes risers tentatively available for sampling (Lipnicki 1996) 


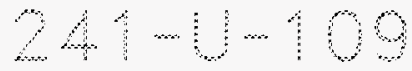

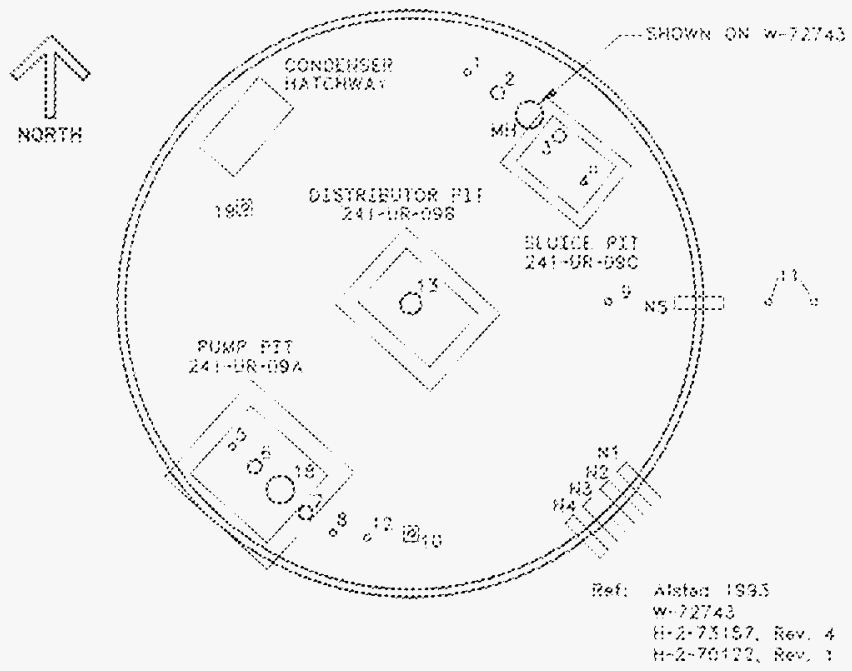

TANK RISER LOCATRON

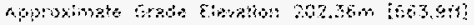

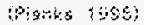

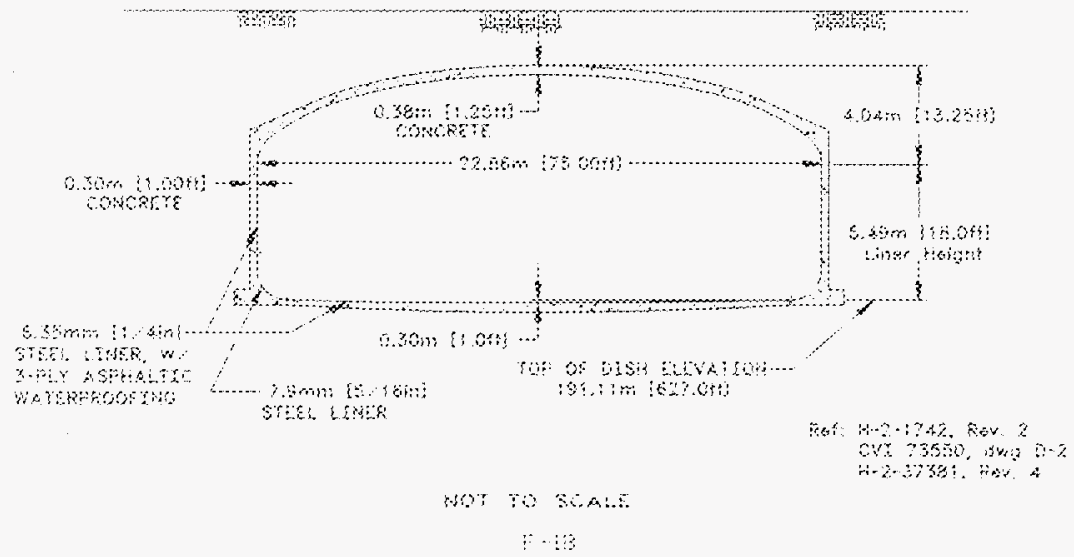




\begin{tabular}{|c|c|c|c|}
\hline \multicolumn{4}{|r|}{$241-U-109$} \\
\hline No. & DIA. & SAMPLING* & DESCRIPTION AND COMMENTS \\
\hline 1 & $\overline{4^{\prime \prime}}$ & & TEMPERATURE PROBE [BM CEO-37531 12/11/86] \\
\hline 2 & $12^{\prime \prime}$ & $\bar{x}$ & BLIND FLANGE \\
\hline 3 & $12^{\prime \prime}$ & & SLUICE NOZZLE, WC \\
\hline 4 & 4" & & RECIRCULATION LINE DIP LEGS, WC \\
\hline 5 & 4" & & RECIRCULATION LINE DIP LEGS, WC \\
\hline 6 & 12" & & SLUICE NOZZLE, WC \\
\hline 7 & $12^{\prime \prime}$ & $\bar{x}$ & B-222 OBSV PORT \\
\hline 8 & 4" & & FIC [ENRAF 854 ECN-608142 $7 / 12 / 94]$ \\
\hline 9 & $4 "$ & & Q-436 LOW [BM CEO-37531 $12 / 11 / 86]$ \\
\hline 10 & $4^{\prime \prime}$ & $x$ & $\begin{array}{l}\text { BREATHER FILTER [STANDARD HYDROGEN } \\
\text { MONITOR SYSTEM / BREATHER FILTER ECN-W369- } \\
0211 / 23 / 95 \text { ] }\end{array}$ \\
\hline 11 & $2^{\prime \prime}$ & & CLEAN OUT LINES, CAPPED \\
\hline 12 & $4^{\prime \prime}$ & & SALTWELL \\
\hline 13 & 12" & & DISTRIBUTOR JET \\
\hline 18 & $42^{\prime \prime}$ & & SLUDGE PUMP, WC \\
\hline 19 & 4" & $\bar{x}$ & SMP \\
\hline $\mathrm{N} 1$ & 3" & & SPARE, CAPPED \\
\hline N2 & 3" & & SPARE, CAPPED \\
\hline N3 & $3^{\prime \prime}$ & & SPARE, CAPPED \\
\hline N4 & 3" & & SPARE, CAPPED \\
\hline N5 & 3" & & NLET OVERFLOW \\
\hline
\end{tabular}

Ref: Alstad 1993, Lipnicki 1996, \& H-2-73157, Rev. 4.

If there was a discrepancy between the documents and the drawings, the drawings took preceden Comments placed in D denote Engineering Change Notices (ECN) made against the reference drawings.

* Denotes risers tentatively available for sampling (Lipnicki 1996) 


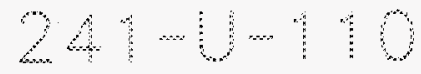

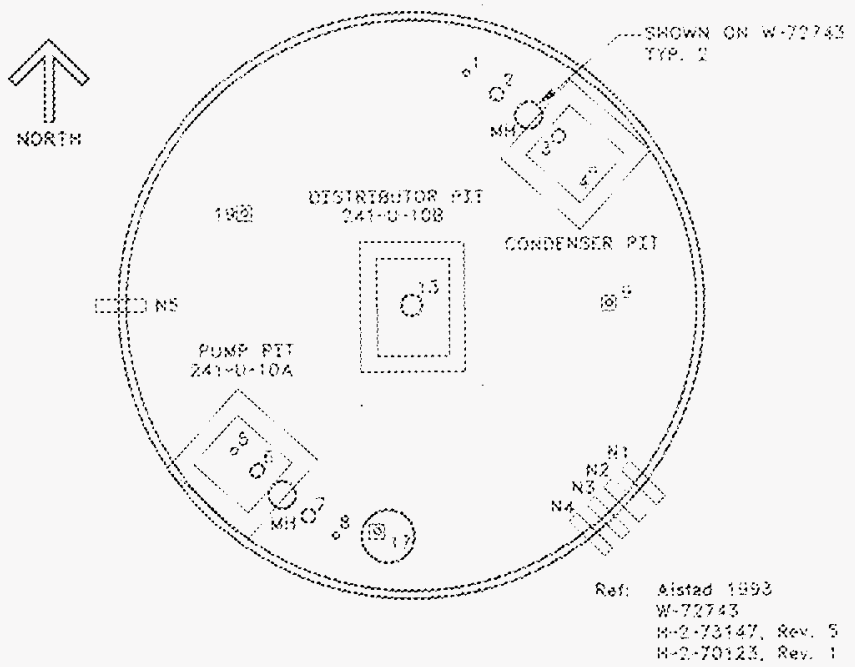

TAN RSER LOCATON

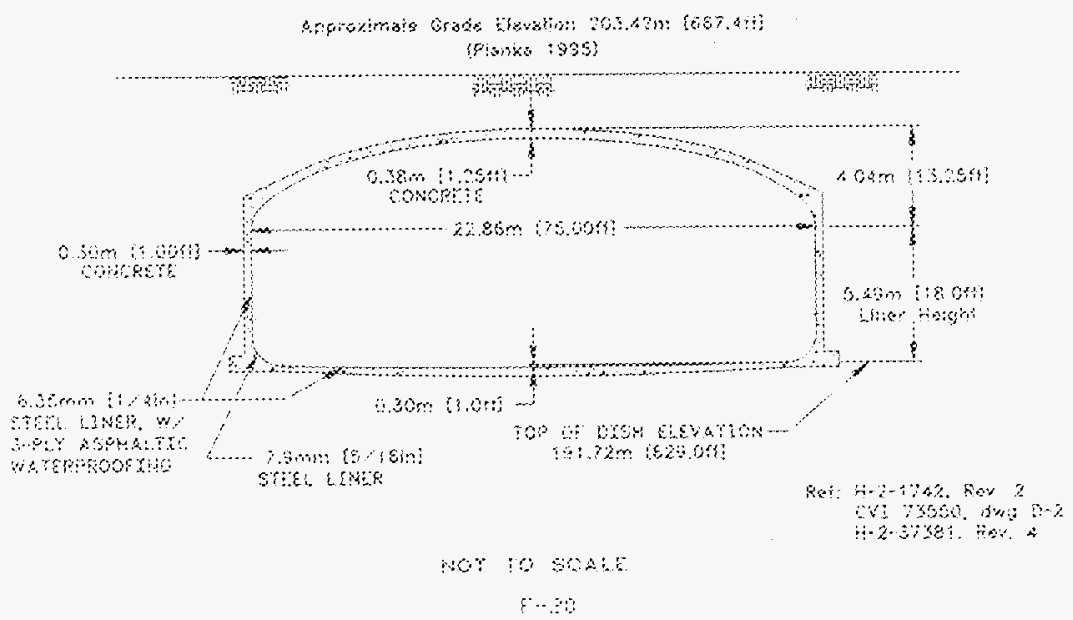




\begin{tabular}{|c|c|c|c|}
\hline NO. & DIA. & SAMPLING* & DESCRIPTION AND COMMENTS \\
\hline 1 & 4" & & TEMPERATURE PROBE \\
\hline 2 & $12^{\prime \prime}$ & $\mathrm{x}$ & B-222 OBSV PORT \\
\hline 3 & $12^{\prime \prime}$ & & WC \\
\hline 4 & 4" & & WC \\
\hline 5 & $4^{1 \pm *}$ & & RECIRCULATION LINE DIP TUBE, WC \\
\hline 6 & $12^{\prime \prime}$ & & PUMP, WC \\
\hline 7 & $12 "$ & $\bar{x}$ & OBSV PORT \\
\hline 8 & 4" & & $\begin{array}{l}\text { FIC [BM CEO-37532 12/11/86] [ENRAF 854 ECN- } \\
62646711 / 17 / 95]\end{array}$ \\
\hline 9 & 4" & $x$ & BREATHER FILTER [BM CEO-37532 12/11/86] \\
\hline 13 & $12^{\prime \prime}$ & & SALTWELL PUMP \\
\hline 17 & 4" & $x$ & BLIND FLANGE \\
\hline 19 & $4 "$ & $\bar{x}$ & BLANK \\
\hline N1 & $3^{n}$ & & NLET LINE BLANKED IN DIVERSION BOX 241-U-153 \\
\hline N2 & $3^{n}$ & & INLET LINE BLANKED IN DIVERSION BOX 241-U-153 \\
\hline N3 & $3^{n}$ & & INLET LINE BLANKED IN DIVERSION BOX 241-U-153 \\
\hline N4 & 3" & & SPARE, CAPPED \\
\hline N5 & 3" & & OVERFLOW \\
\hline
\end{tabular}

Ref: $\quad$ Alstad 1993, Lipnicki 1996, \& H-2-73147, Rev. 5.

If there was a discrepancy between the documents and the drawings, the drawings took preceden Comments placed in [] denote Engineering Change Notices (ECN) made against the reference drawings.

- Denotes risers tentatively available for sampling (Lipnicki 1996)

** Drawing $\mathrm{H}-2-73147$, rev. 5 refers to this riser as 3" diameter; however, drawings $\mathrm{W}-72$ and $\mathrm{H}-2-70123$, rev. 1 refer to this riser as 4 " diameter. 


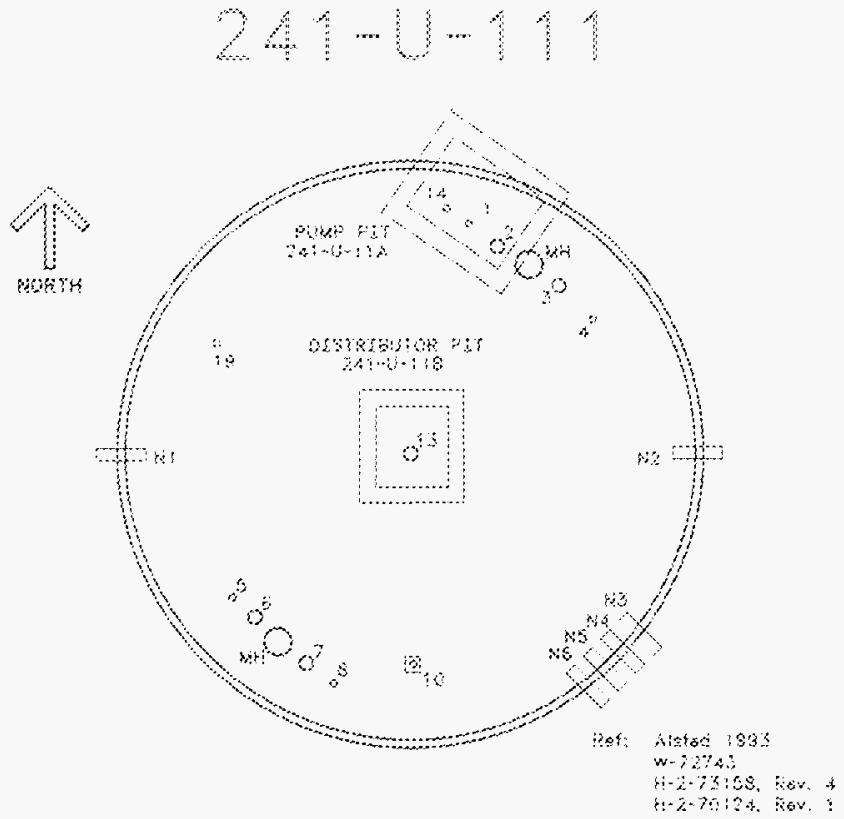

\section{TAN RTSER LOCATION}

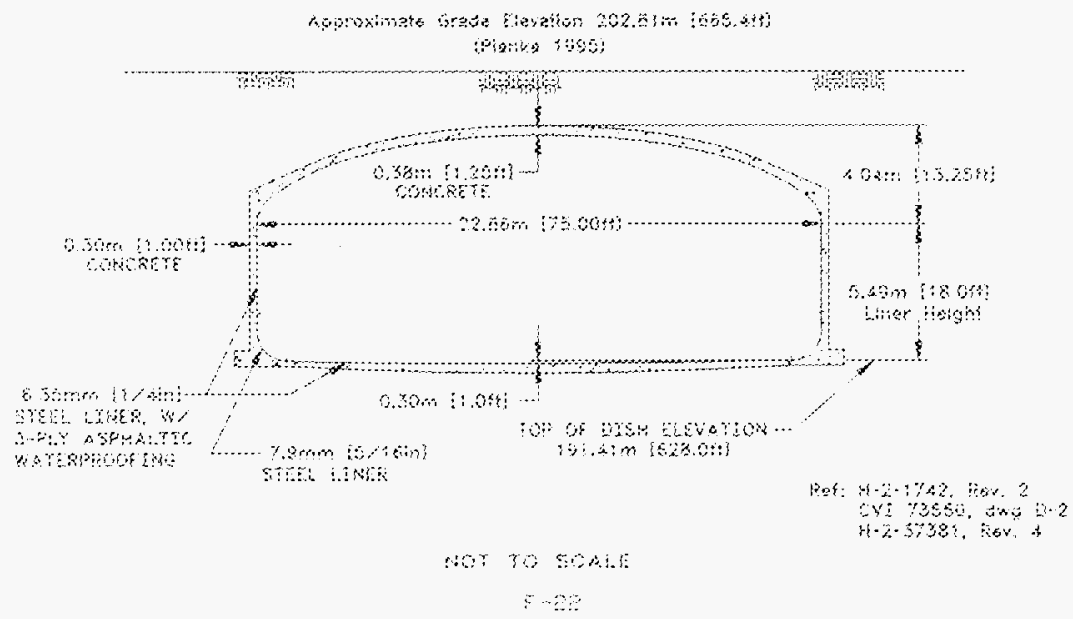




\begin{tabular}{|c|c|c|c|}
\hline NO. & DIA. & SAMPLING* & DESCRIPTION AND COMMENTS \\
\hline$\overline{1}$ & 4" & & DIP LEGS, WC \\
\hline 2 & $12^{\prime \prime}$ & & PUMP, WC \\
\hline 3 & $12 "$ & $\bar{x}$ & BLIND FLANGE \\
\hline 4 & $4^{\prime \prime}$ & $x$ & $\begin{array}{l}\text { SPARE [INSTALL HEATED VAPOR PROBE, REMOVE } \\
\text { WITHIN } 90 \text { DAYS OF SAMPLING ECN-614485L } \\
10 / 24 / 94 \text { ] }\end{array}$ \\
\hline 5 & $4^{\prime \prime}$ & & TEMPERATURE PROBE [BM CEO-37533 12/11/86] \\
\hline 6 & $12^{\prime \prime}$ & $\bar{x}$ & BLIND FLANGE \\
\hline 7 & $12^{\prime \prime}$ & $\bar{x}$ & B-222 OBSV PORT \\
\hline 8 & 4" & & FIC [ENRAF 854 ECN-626468 $11 / 17 / 95]$ \\
\hline 10 & $4 "$ & $\bar{x}$ & BREATHER FILTER \\
\hline 13 & $12 "$ & & SALTWELL PUMP \\
\hline 14 & $4 "$ & & SPARE, WC \\
\hline 19 & $4^{\prime \prime}$ & & B-436 LOW [BM CEO-37533 12/11/86] \\
\hline N1 & 3" & & OUTLET OVERFLOW \\
\hline N2 & 3" & & INLET OVERFLOW \\
\hline N3 & 3" & & SPARE \\
\hline N4 & 3" & & SPARE \\
\hline N5 & $3 "$ & & SPARE \\
\hline N6 & 3" & & SPARE \\
\hline
\end{tabular}

Ref: $\quad$ Alstad 1993, Lipnicki 1996, \& H-2-73158, Rev. 4.

If there was a discrepancy between the documents and the drawings, the drawings took preceden Comments placed in D denote Engineering Change Notices (ECN) made against the reference drawings.

* Denotes risers tentatively available for sampling (Lipnicki 1996) 


$$
\begin{array}{lllll}
4 & &
\end{array}
$$

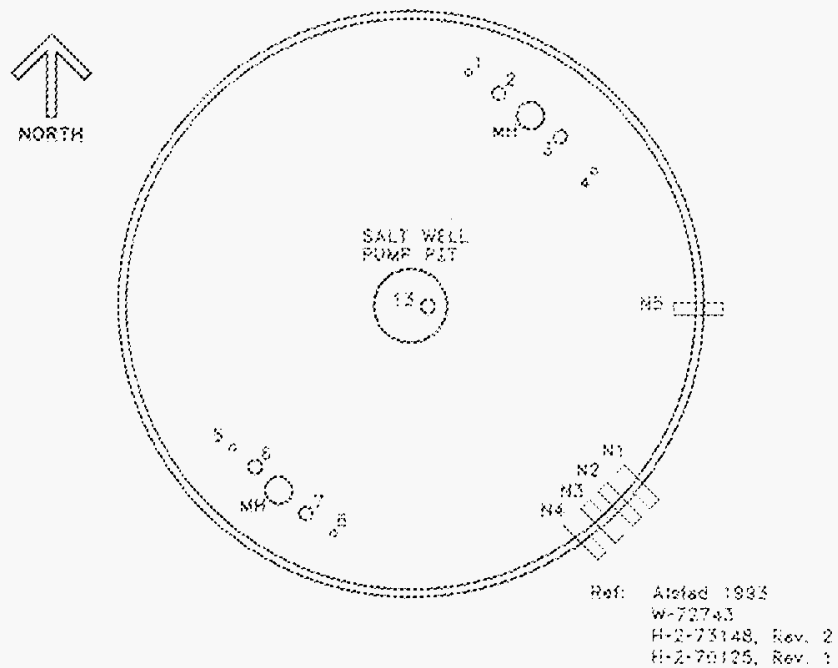

\section{TANK RTSER LOCATRON}

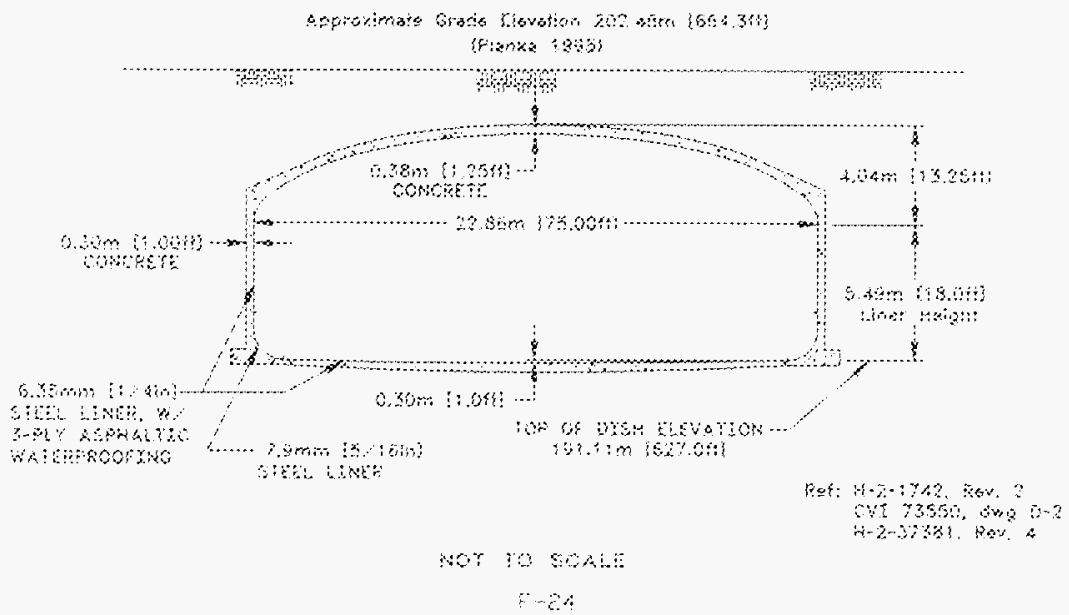


HNF-SD-WM-ER-325, Rev. 1

\begin{tabular}{|c|c|c|c|}
\hline NO. & DIA. & SAMPLING* & DESCRIPTION AND COMMENTS \\
\hline 1 & $4^{\prime \prime \prime}$ & $\bar{x}$ & BREATHER FILTER [BM CEO-37534 12/8/86] \\
\hline 2 & $12^{\prime \prime}$ & $\mathrm{x}$ & BLIND FLANGE \\
\hline 3 & $12^{\prime \prime}$ & $\bar{x}$ & BLIND FLANGE \\
\hline 4 & $4 "$ & & CUT \& CAPPED BG \\
\hline 5 & $4 "$ & & TEMPERATURE PROBE \\
\hline 6 & $12^{\prime \prime}$ & $x$ & BLIND FLANGE \\
\hline$\overline{7}$ & $12^{\prime \prime}$ & $\bar{x}$ & B-222 OBSV PORT \\
\hline 8 & $4^{\prime \prime}$ & & LIQUID LEVEL REEL \\
\hline 13 & $12^{\prime \prime}$ & & SALTWELLL PUMP, WC \\
\hline N1 & 3" & & SPARE, CAPPED \\
\hline N2 & 3" & & SPARE, CAPPED \\
\hline N3 & 3" & & SPARE, CAPPED \\
\hline N4 & $3^{\prime \prime}$ & & SPARE, CAPPED \\
\hline N5 & $3^{\prime \prime}$ & & FILL LINE, CAPPED IN 8' CAISSON \\
\hline
\end{tabular}

Ref: $\quad$ Alstad 1993, Lipnicki 1996, \& H-2-73148, Rev. 2.

If there was a discrepancy between the documents and the drawings, the drawings took preceden Comments placed in $]$ denote Engineering Change Notices (ECN) made against the reference drawings.

- Denotes risers tentatively available for sampling (Lipnicki 1996) 


\section{$241-4-201$}
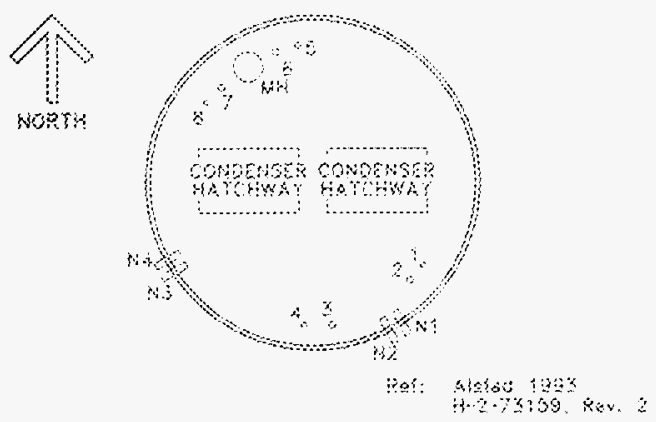

YANK ASER LOCATOM

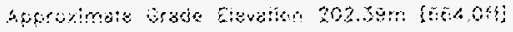

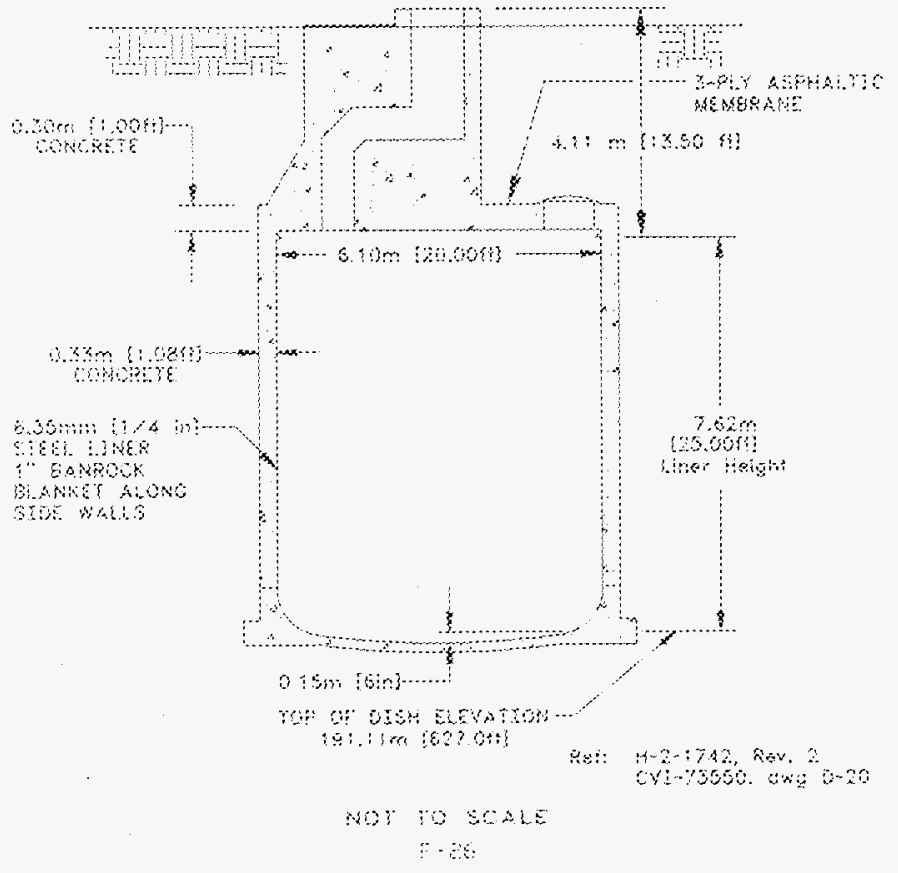


HNF-SD-WM-ER-325, Rev. 1

\begin{tabular}{|c|c|c|c|}
\hline NO. & DIA. & SAMPLING* & DESCRIPTION AND COMMENTS \\
\hline 1 & $4 "$ & & LIQUID LEVEL REEL \\
\hline 2 & $12^{\prime \prime}$ & $x$ & \\
\hline 3 & $12 "$ & & \\
\hline 4 & $4^{\prime \prime}$ & & TEMPERATURE PROBE \\
\hline 5 & 4" & & BLIND FLANGE \\
\hline 6 & $12^{\prime \prime}$ & $\bar{x}$ & B-222 OBSV PORT \\
\hline 7 & $12^{\prime \prime}$ & & DIP TUBES, CAPPED \\
\hline 8 & 4" & & BREATHER FILTER \\
\hline N1 & 3" & & LINE V-487, BLANKED IN DIVERSION BOX 241-U-252 \\
\hline N2 & $3^{\prime \prime}$ & & LINE V-488, BLANKED IN DIVERSION BOX 241-U-252 \\
\hline N3 & 3" & & CAPPED \\
\hline N4 & 3" & & CAPPED \\
\hline
\end{tabular}

Ref: $\quad$ Alstad 1993, Lipnicki 1996, \& H-2-73159, Rev. 2.

If there was a discrepancy between the documents and the drawings, the drawings took preceden Comments placed in 0 denote Engineering Change Notices (ECN) made against the reference drawings.

- Denotes risers tentatively available for sampling (Lipnicki 1996) 


\section{$241-U-202$}
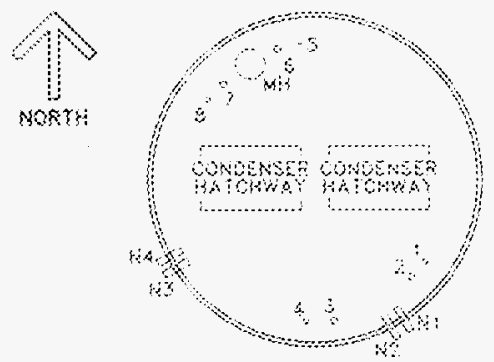

Let: Alstor 1995

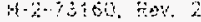

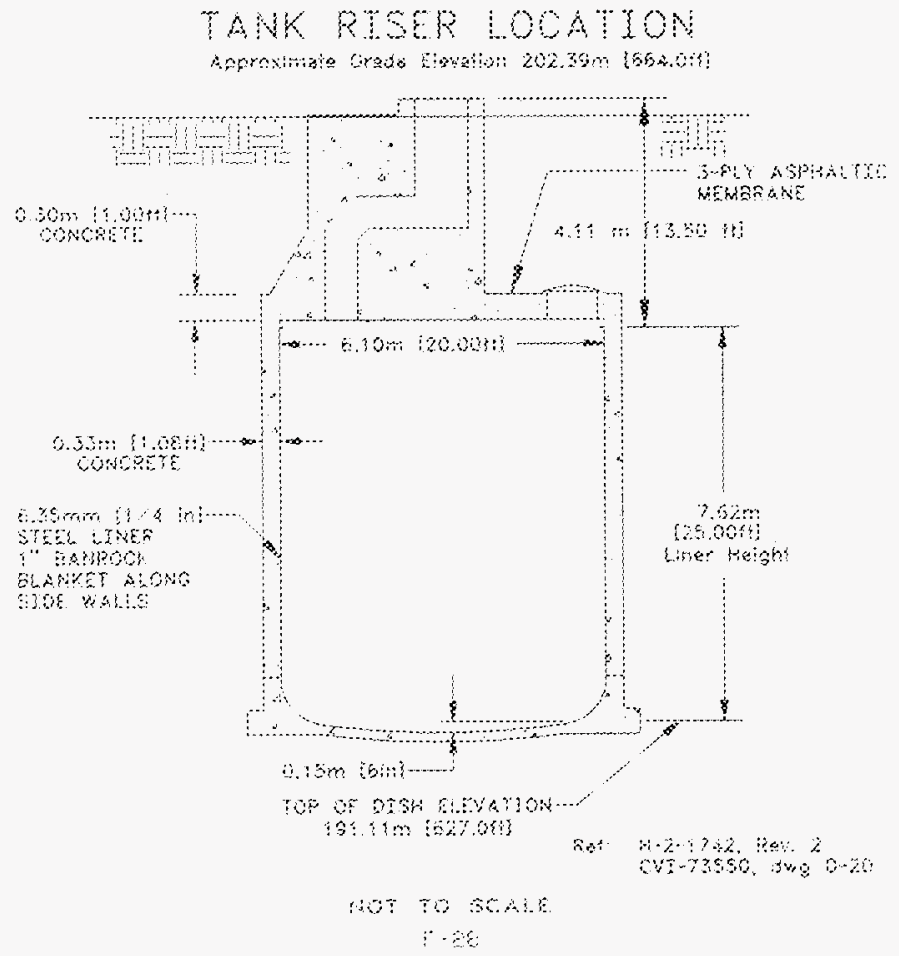




\begin{tabular}{|c|c|c|c|}
\hline NO. & $\overline{D I A}$ & SAMPLING* & DESCRIPTION AND COMMENTS \\
\hline 1 & 4" & & LIQUID LEVEL REEL \\
\hline 2 & $12^{\prime \prime}$ & $\underline{x}$ & \\
\hline 3 & $12^{\prime \prime}$ & & \\
\hline 4 & 4" & & TEMPERATURE PROBE \\
\hline 5 & 4" & & BLIND FLANGE \\
\hline 6 & $12 "$ & $\bar{x}$ & B-222 OBSV PORT \\
\hline 7 & $12^{\prime \prime}$ & & DIP TUBES, CAPPED \\
\hline 8 & $4^{\prime \prime}$ & & BREATHER FILTER \\
\hline N1 & 3" & & LINE V-487, BLANKED IN DIVERSION BOX 241-U-252 \\
\hline N2 & 3" & & LINE V-488, BLANKED IN DIVERSION BOX 241-U-252 \\
\hline N3 & 3" & & CAPPED \\
\hline N4 & $3^{\prime \prime}$ & & CAPPED \\
\hline
\end{tabular}

Ref:

Alstad 1993, Lipnicki 1996, \&-2-73160, Rev. 2.

If there was a discrepancy between the documents and the drawings, the drawings took preceden Comments placed in $\square$ denote Engineering Change Notices (ECN) made against the reference drawings.

* Denotes risers tentatively available for sampling (Lipnicki 1996) 


$$
{ }^{4}+\cdots+\cdots
$$
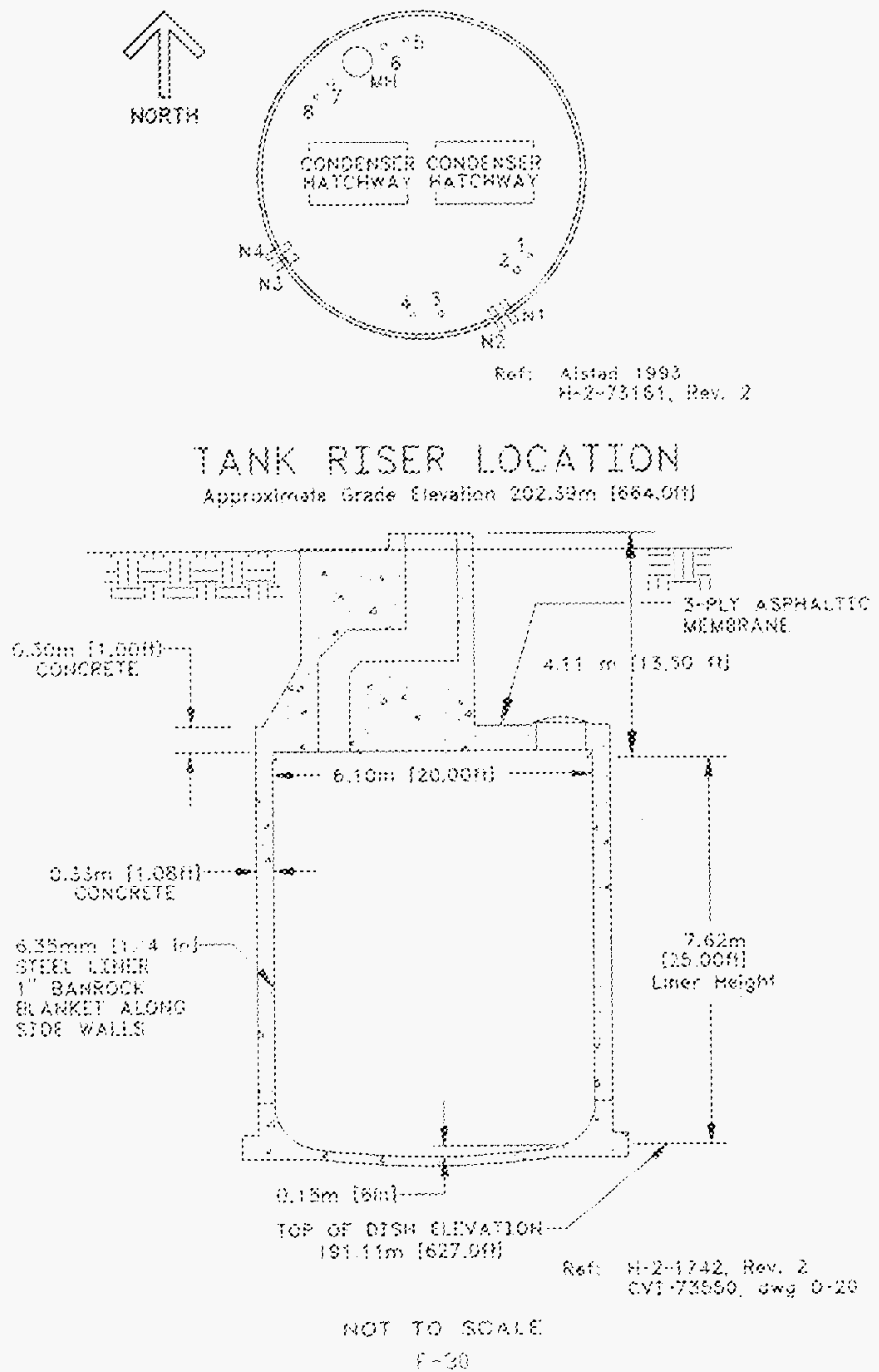


\begin{tabular}{|c|c|c||l||}
\hline \multicolumn{2}{|l||}{} \\
\hline \hline NO. & DIA. & SAMPLING* & \multicolumn{1}{|c||}{ DESCRIPTION AND COMMENTS } \\
\hline 1 & $4^{\prime \prime}$ & & LIQUID LEVEL REEL \\
\hline 2 & $12^{\prime \prime}$ & $X$ & \\
\hline 3 & $12^{\prime \prime}$ & & \\
\hline 4 & $4^{\prime \prime}$ & & TEMPERATURE PROBE \\
\hline 5 & $4^{\prime \prime}$ & & BLIND FLANGE \\
\hline 6 & $12^{\prime \prime}$ & $\mathrm{X}$ & B-222 OBSV PORT \\
\hline 7 & $12^{\prime \prime}$ & & DIP TUBES, CAPPED \\
\hline 8 & $4^{\prime \prime}$ & & BREATHER FILTER \\
\hline N1 & $3^{\prime \prime}$ & & LINE V-487, BLANKED IN DIVERSION BOX 241-U-252 \\
\hline N2 & $3^{\prime \prime}$ & & LINE V-488, BLANKED IN DIVERSION BOX 241-U-252 \\
\hline N3 & $3^{\prime \prime}$ & & CAPPED \\
\hline N4 & $3^{\prime \prime}$ & & CAPPED \\
\hline
\end{tabular}

Ref: $\quad$ Alstad 1993, Lipnicki 1996, \& H-2-73161, Rev. 2.

If there was a discrepancy between the documents and the drawings, the drawings took preceden Comments placed in [ denote Engineering Change Notices (ECN) made against the reference drawings.

- Denotes risers tentatively available for sampling (Lipnicki 1996) 


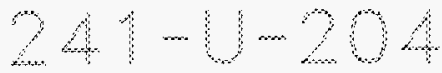
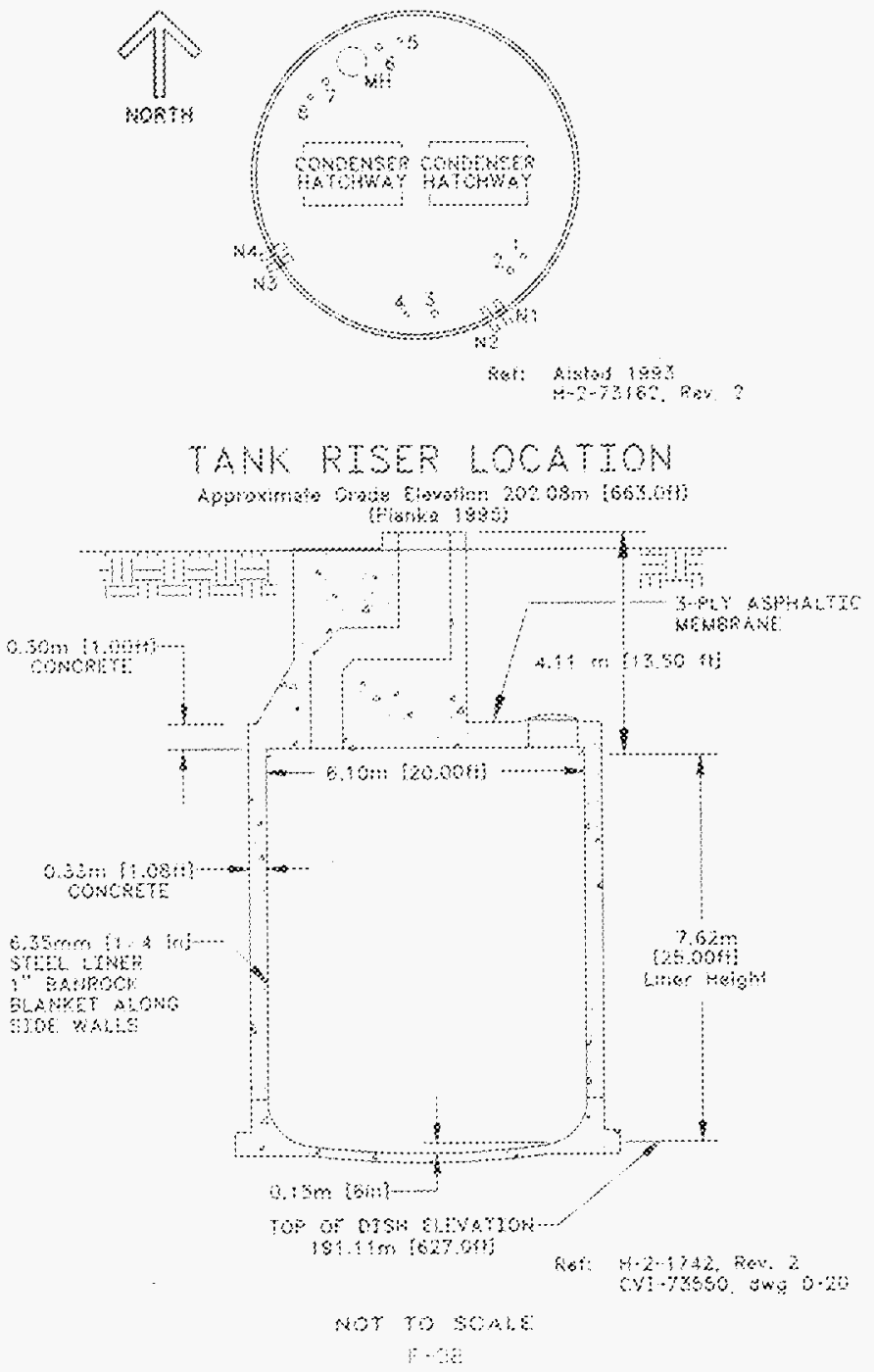


\begin{tabular}{|c|c|c|c|}
\hline No. & DIA. & SAMPLING* & DESCRIPTION AND COMMENTS \\
\hline 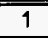 & $4 "$ & & LIQUID LEVEL REEL \\
\hline 2 & $12^{\prime \prime}$ & $x$ & \\
\hline 3 & $12^{\prime \prime}$ & & \\
\hline 4 & 4" & & TEMPERATURE PROBE \\
\hline 5 & $4 "$ & & BLIND FLANGE \\
\hline 6 & $12^{\prime \prime}$ & $\bar{x}$ & B-222 OBSV PORT \\
\hline 7 & $12^{\prime \prime}$ & & DIP TUBES, CAPPED \\
\hline 8 & 4" & & BREATHER FILTER \\
\hline N1 & $3^{\prime \prime}$ & & LINE V-487, BLANKED IN DIVERSION BOX 241-U-252 \\
\hline N2 & $3^{4}$ & & LINE V-488, BLANKED IN DIVERSION BOX 241-U-252 \\
\hline N3 & 3" & & CAPPED \\
\hline N4 & $3^{\prime \prime}$ & & CAPPED \\
\hline
\end{tabular}

Ref: $\quad$ Alstad 1993, Lipnicki 1996, \& H-2-73162, Rev. 2.

If there was a discrepancy between the documents and the drawings, the drawings took preceden Comments placed in [] denote Engineering Change Notices (ECN) made against the reference drawings.

* Denotes risers tentatively available for sampling (Lipnicki 1996) 
THS PAE WTETOMRLY BCFT QEAWK 


\section{U TANK FARM PHOTOS}

\begin{tabular}{|c|c|c|c|}
\hline (14HW & Homser\% & 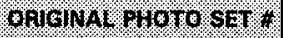 & o4t5 \\
\hline U Farm Aerial Photo & N/A & $93030994-308 \mathrm{CN}$ & $N / A$ \\
\hline 241-U-101 & $94041033-1 \mathrm{CN}$ & 87062 & $6 / 19 / 79$ \\
\hline $241-U-102$ & $94041033-2 \mathrm{CN}$ & 89060831 & $6 / 8 / 89$ \\
\hline $241-U-103$ & $94041033-3 \mathrm{CN}$ & 88090946 & $9 / 13 / 88$ \\
\hline $241-U-104$ & $94041033-4 \mathrm{CN}$ & 89081042 & $8 / 10 / 89$ \\
\hline $241-U-105$ & $94041033-13 \mathrm{CN}$ & 8803818 & $7 / 7 / 88$ \\
\hline $241-U-106$ & $94041033-14 \mathrm{CN}$ & 8803817 & $7 / 7 / 88$ \\
\hline $241-U-107$ & $94041033-15 \mathrm{CN}$ & 8803659 & $7 / 7 / 88$ \\
\hline $241-U-108$ & $94041033-16 \mathrm{CN}$ & 8406173 & $9 / 12 / 84$ \\
\hline $241-U-109$ & $94041033-10 \mathrm{CN}$ & 8803660 & $7 / 7 / 88$ \\
\hline 241-U-110 & $94041033-9 \mathrm{CN}$ & 8408357 & $12 / 11 / 84$ \\
\hline $241-U-111$ & $94041033-8 \mathrm{CN}$ & 8803551 & $6 / 23 / 88$ \\
\hline $241-U-112$ & $94041033-7 \mathrm{CN}$ & 89080355 & $8 / 3 / 89$ \\
\hline 241-U-201 & $94041033-12 \mathrm{CN}$ & 89080840 & $8 / 8 / 89$ \\
\hline 241-U-202 & $94041033-11 \mathrm{CN}$ & 89080841 & $8 / 8 / 89$ \\
\hline 241-U-203 & $94041033-41 \mathrm{CN}$ & 89061338 & $6 / 13 / 89$ \\
\hline 241-U-204 & $94041033-42 \mathrm{CN}$ & 89061337 & $6 / 13 / 89$ \\
\hline
\end{tabular}




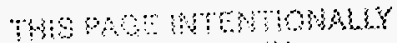
BE BLAn 


\section{U TANK FARM}

FNF-3HWW-GR-32s, Bew:

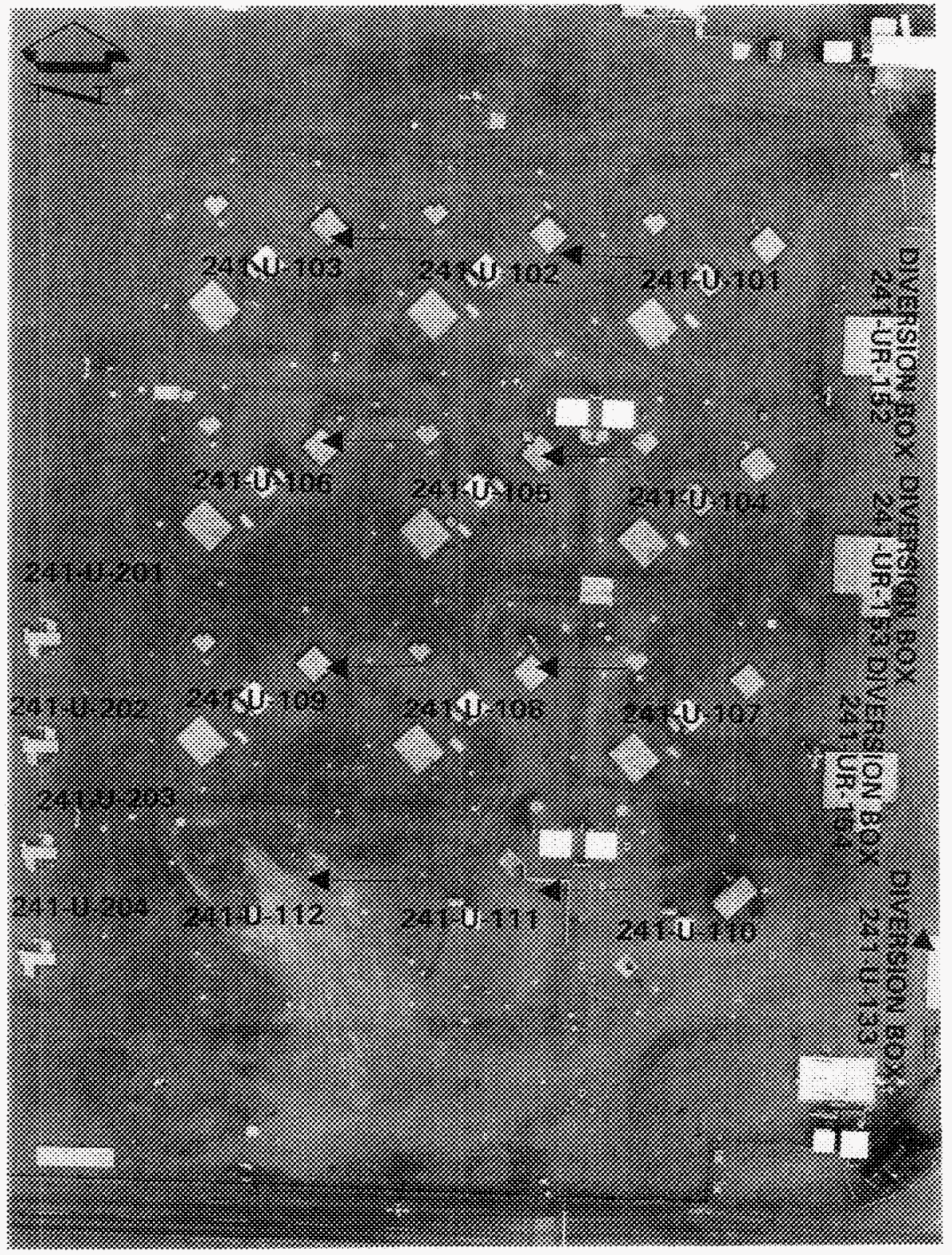




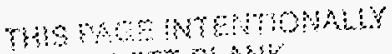
Ser bisk 


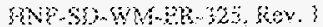
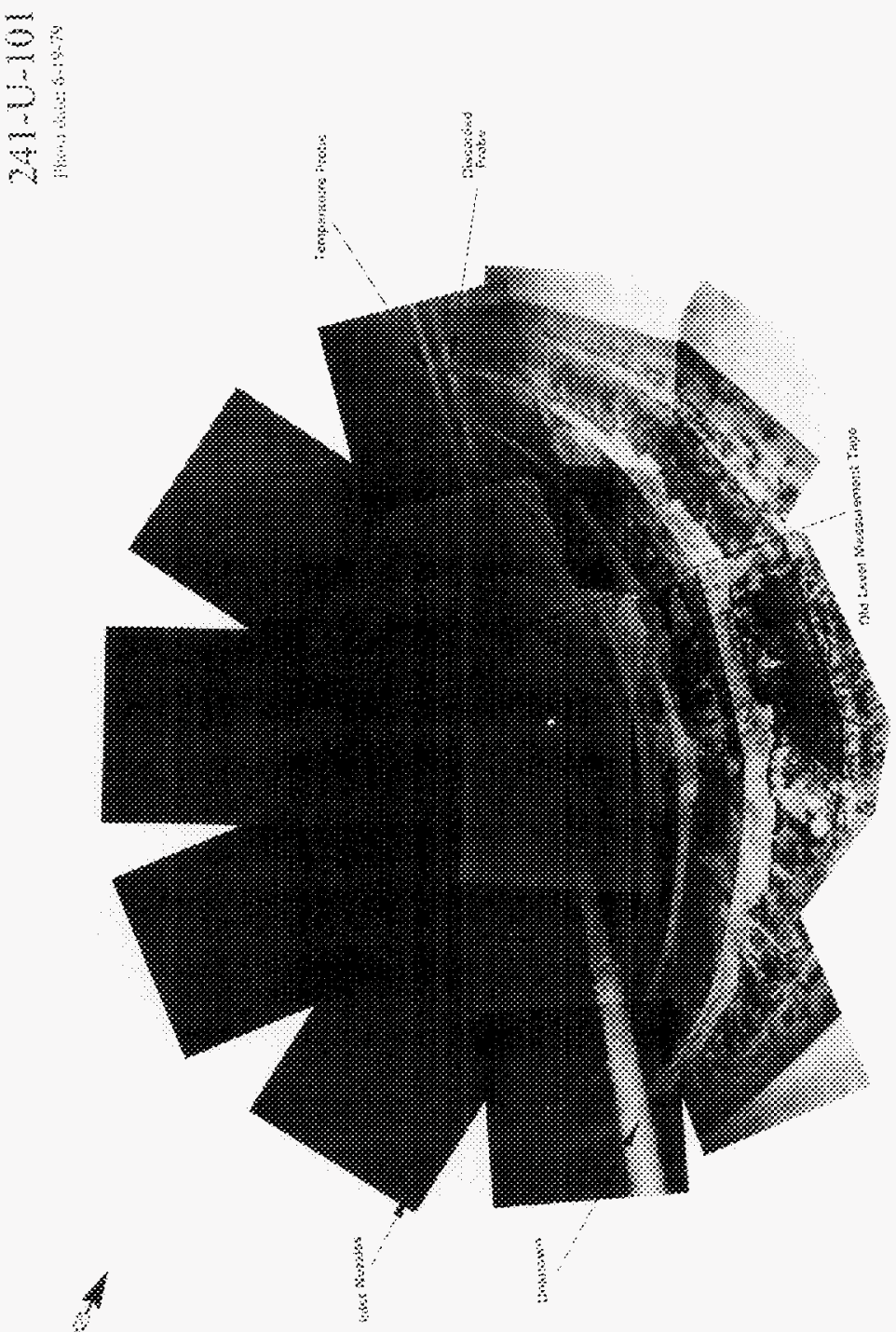


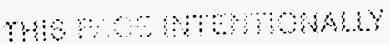
GF SLAKK 


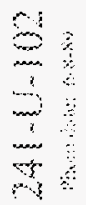

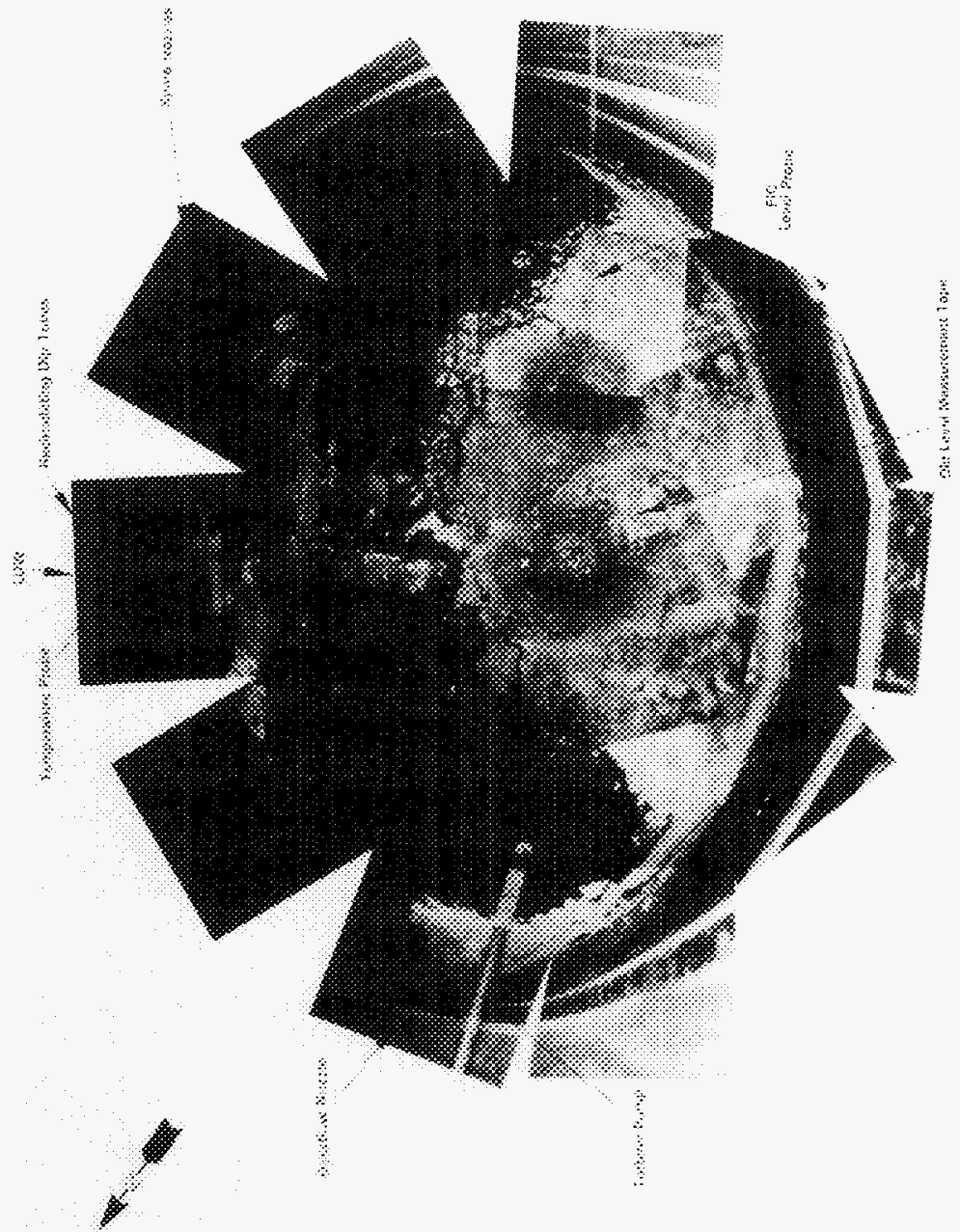


The pos armonomay MCT SURKK 
$\frac{9}{3}$

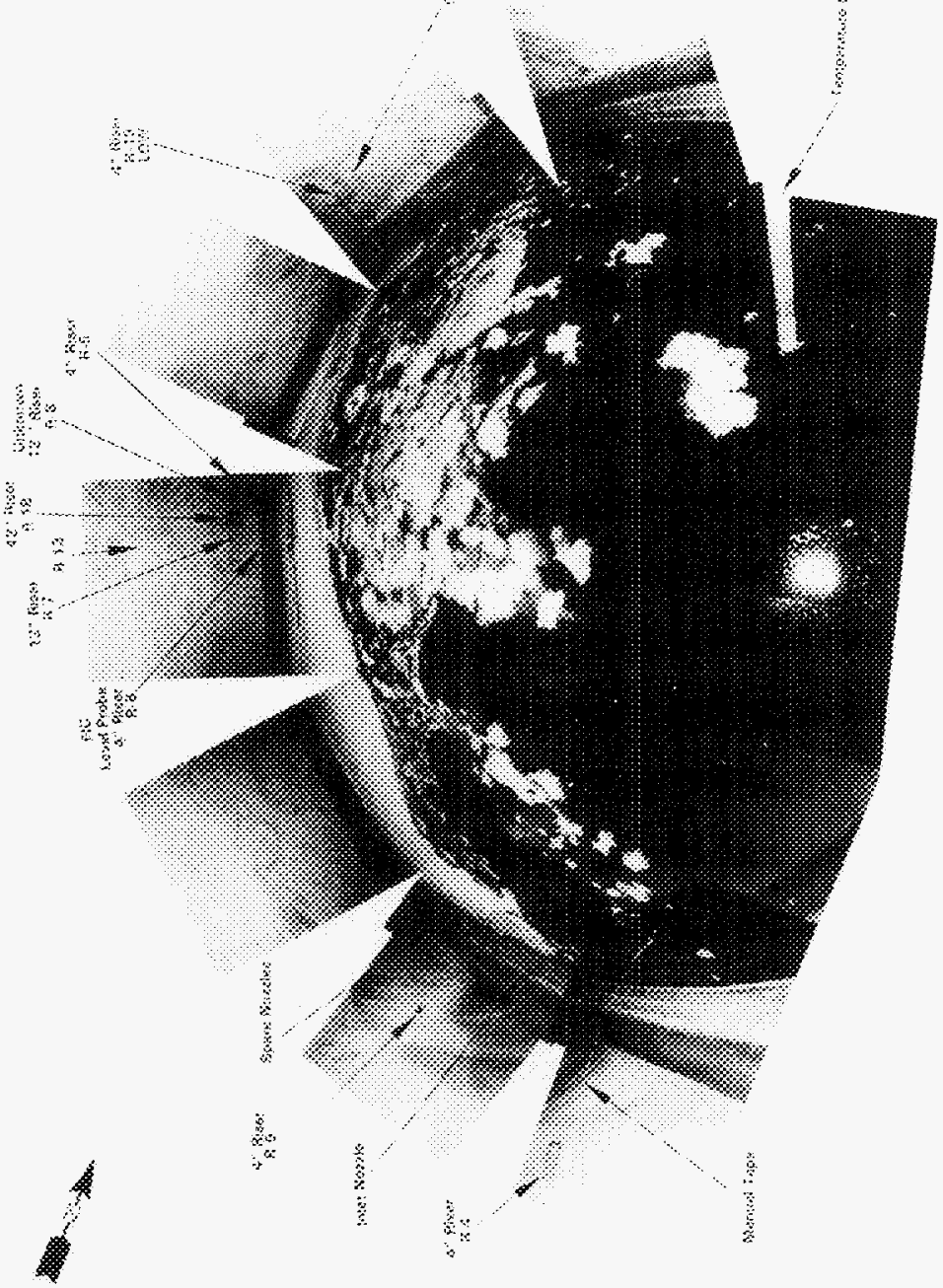




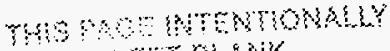
G) $\triangle 4 \mathrm{AK}$ 
Me.3WWR-OR kev

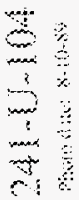

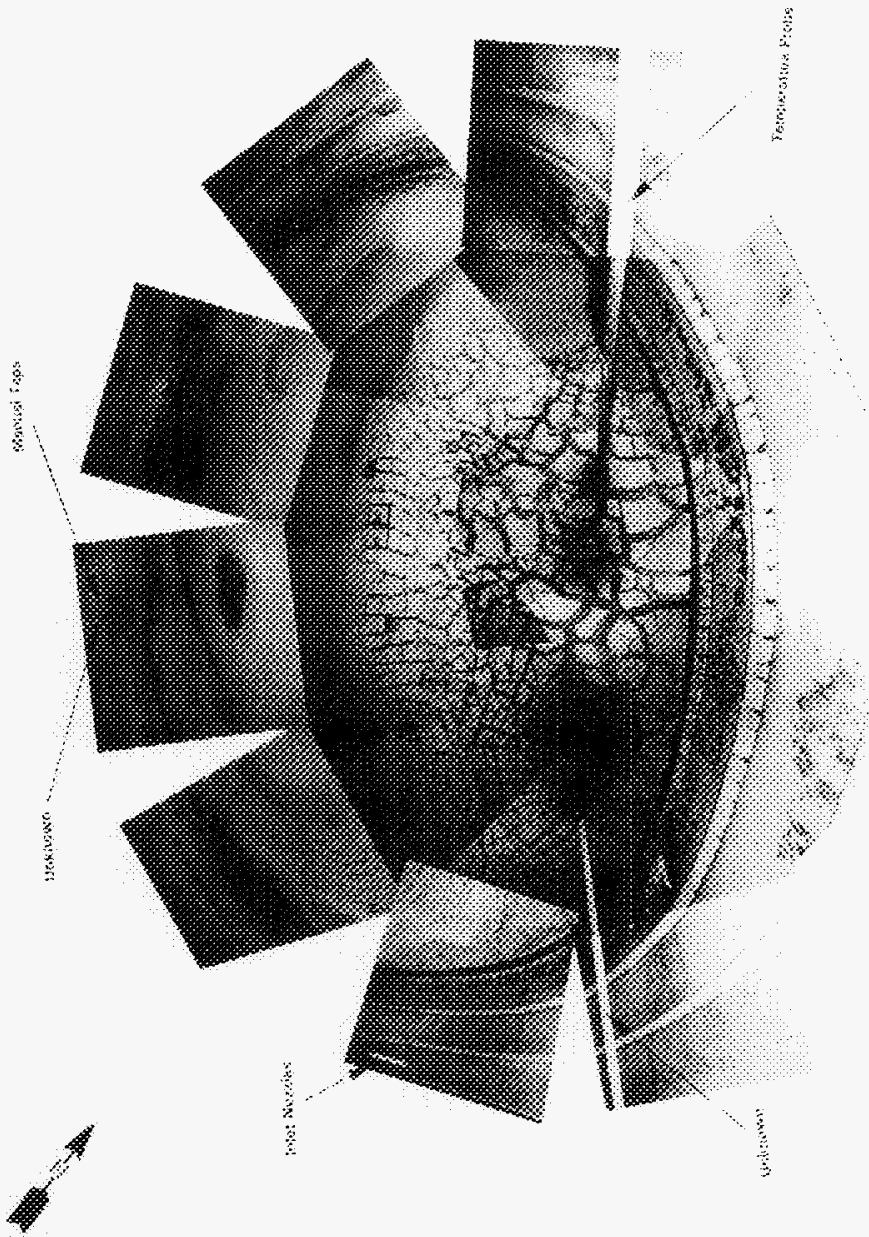


THO POE WTENTOMALY AF $\triangle$ SLKK 


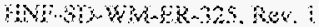

3

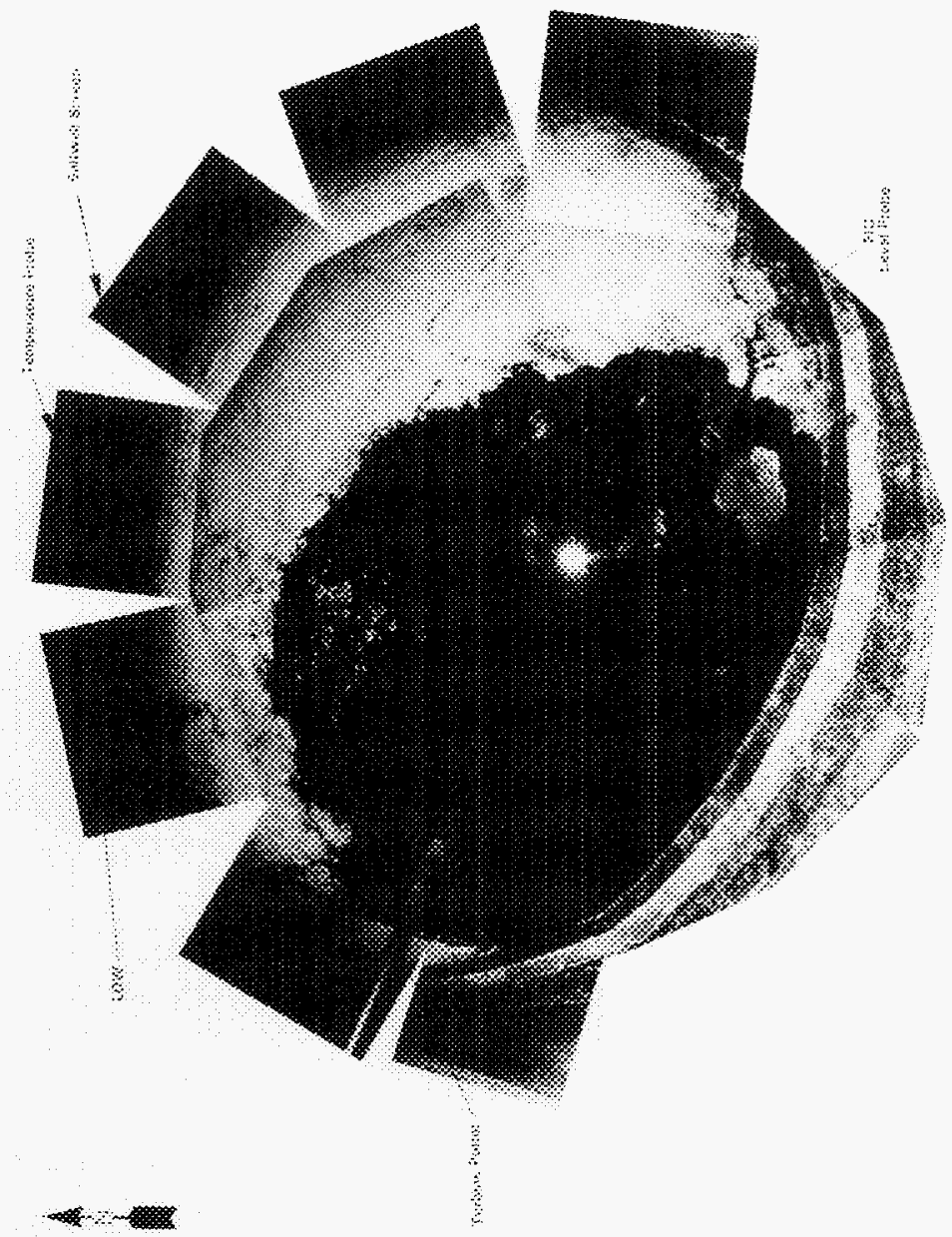


THS HOW MONTONALY GEF BLANK 


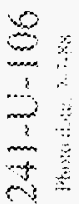

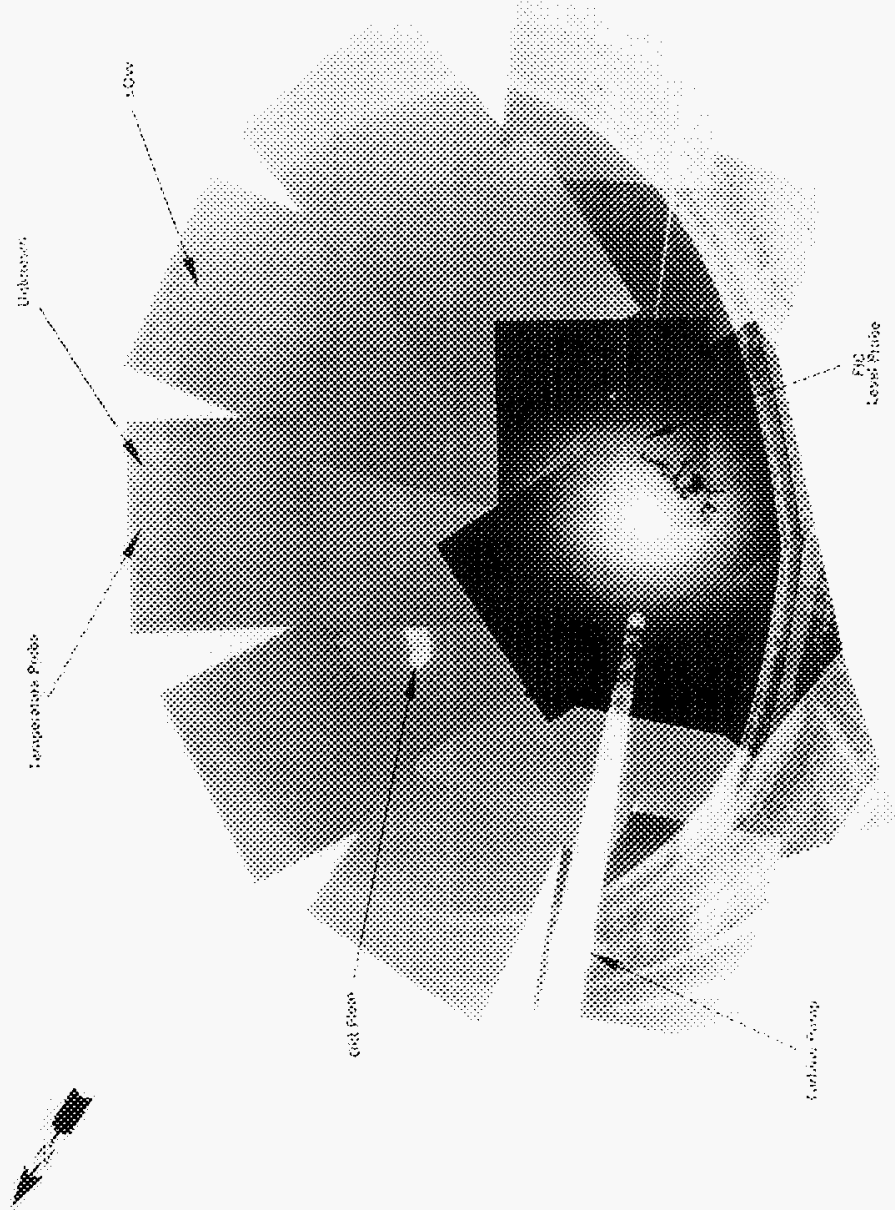


TMS WOE MTEMENAEY L.:Y BLAMK 
$\frac{m}{2}$






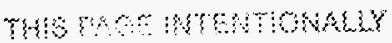
AF $\triangle B A K$ 


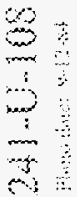

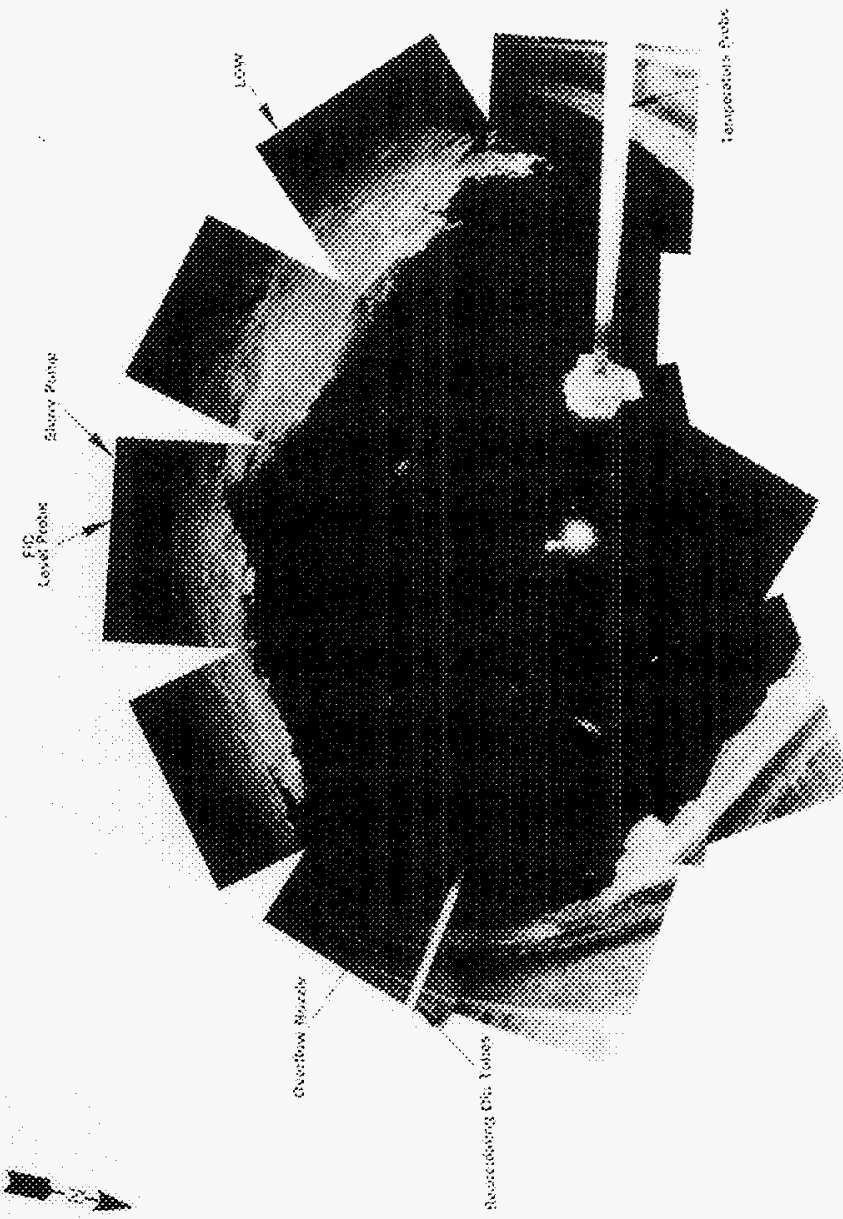


THS MOE WTEMONALY AFI DAMK 


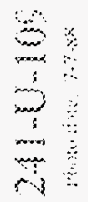

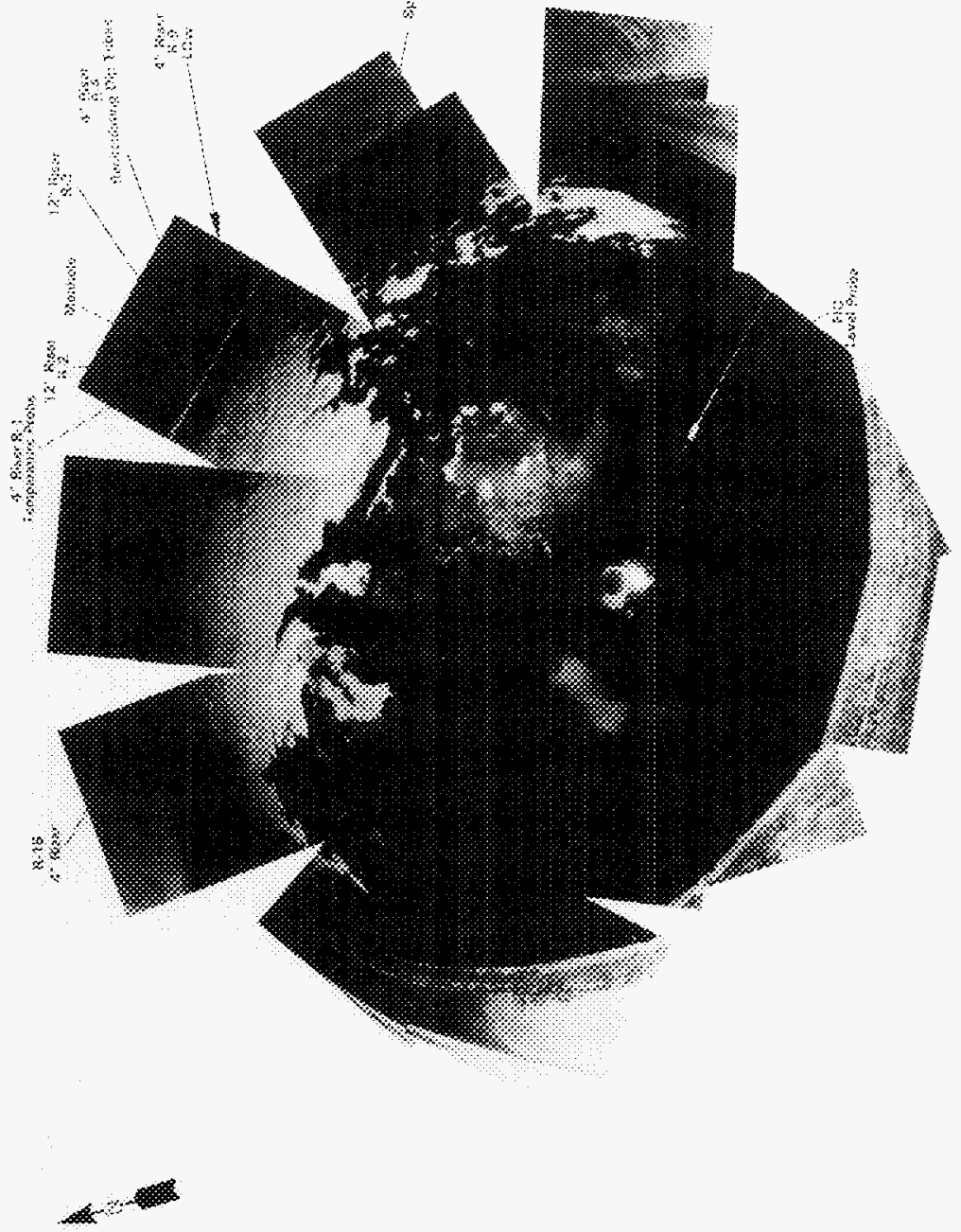




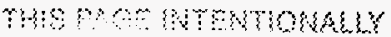

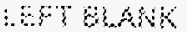




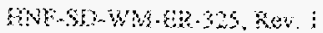

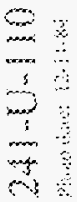

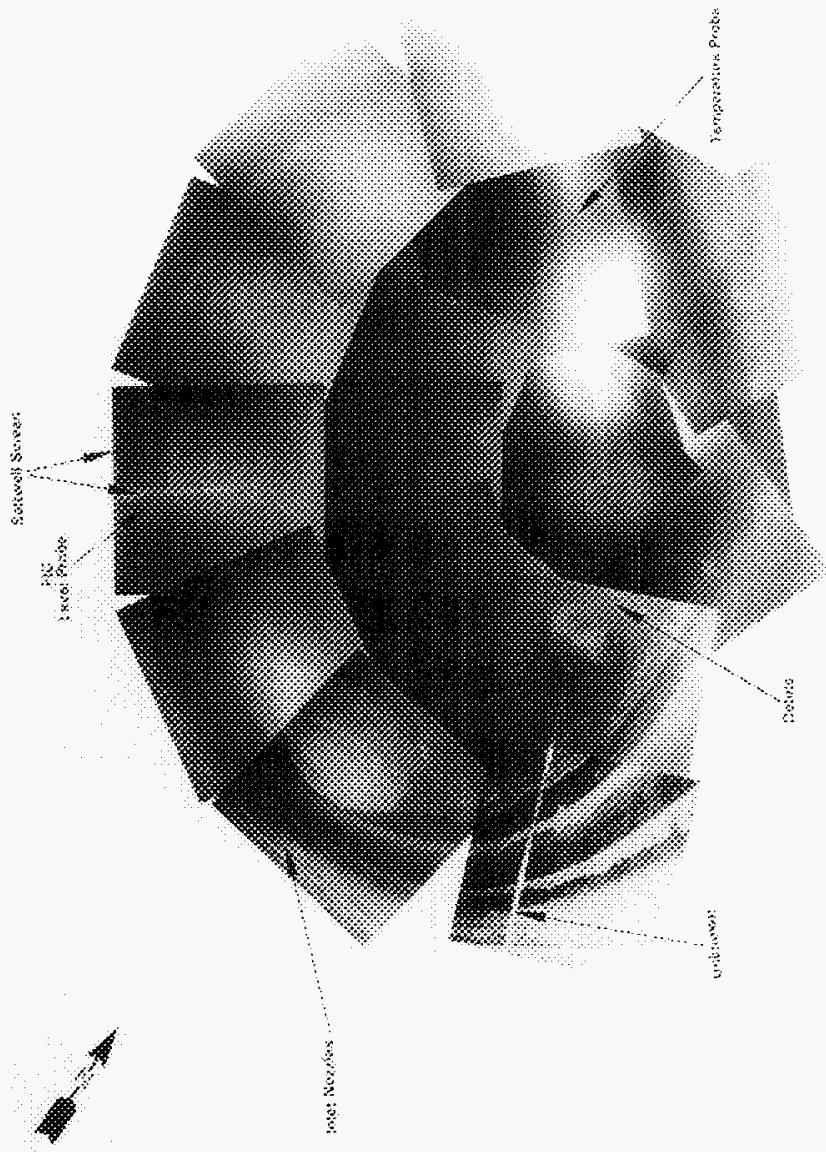




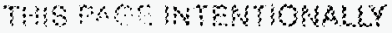
WI $\triangle \mathrm{AMK}$ 


$$
\frac{3}{3}
$$




THS WO nTmNTOMAMY ETY QUANG 


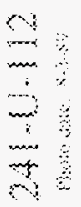

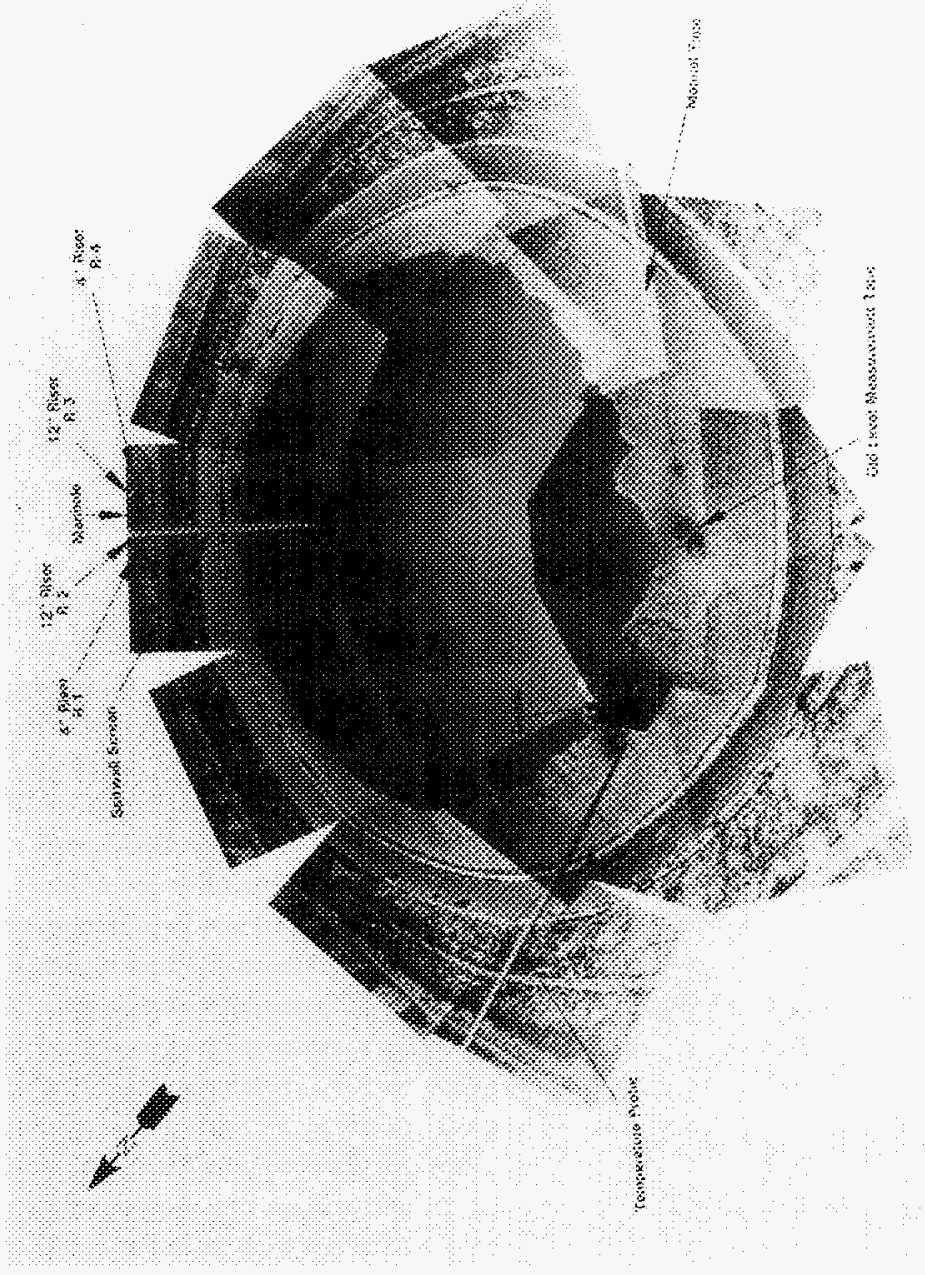




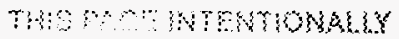

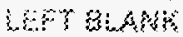



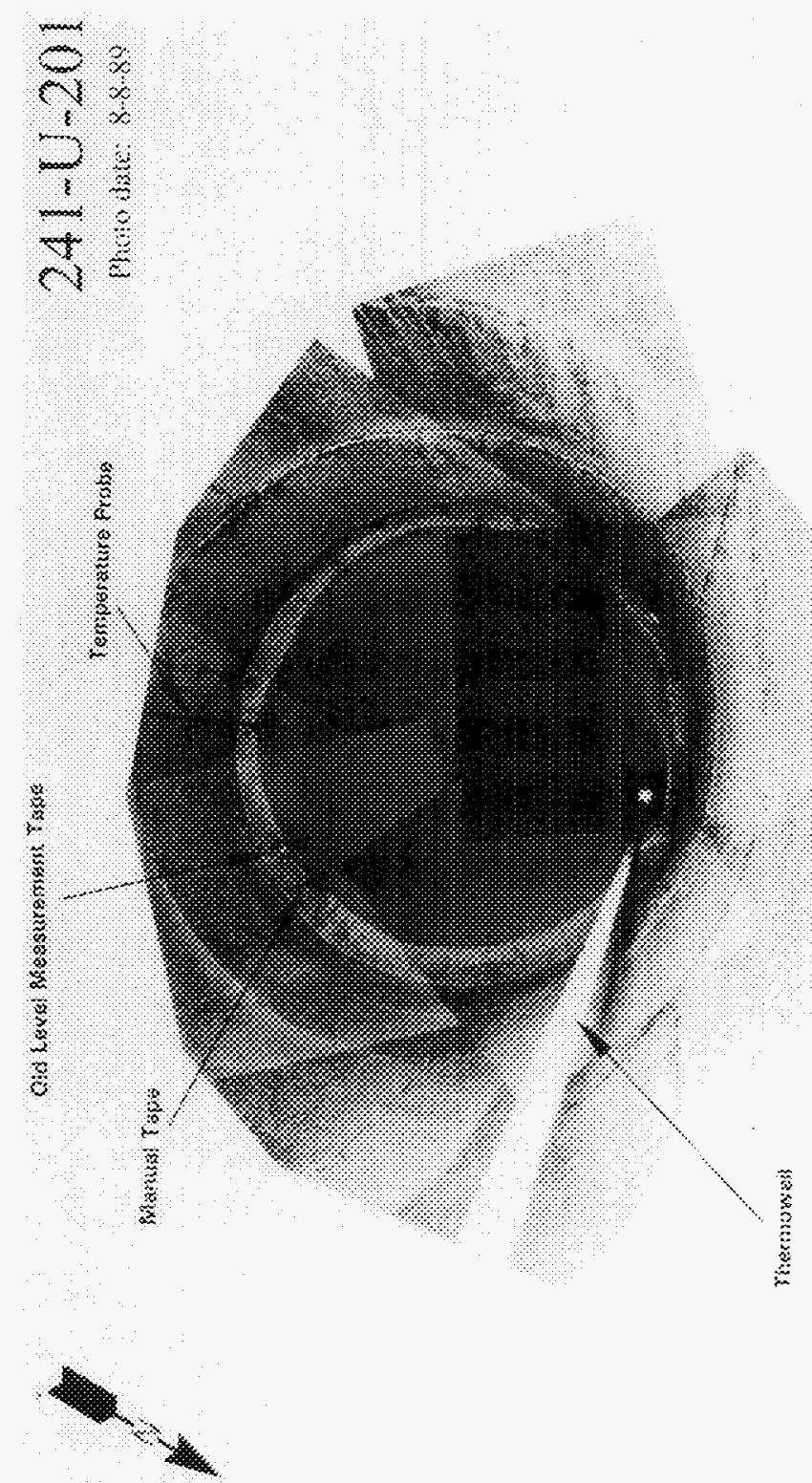


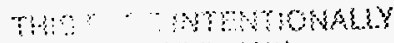
BW DLAM 

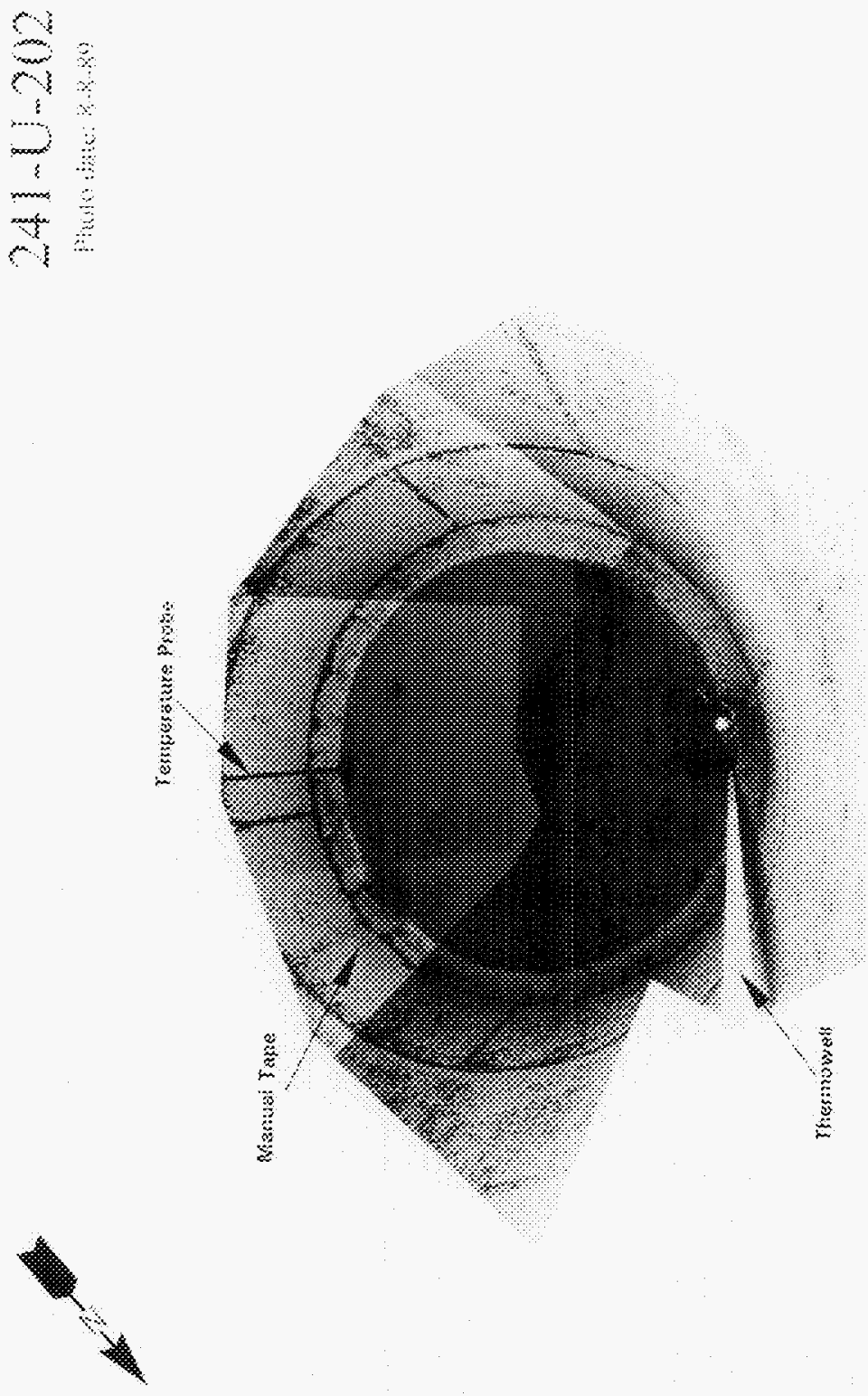


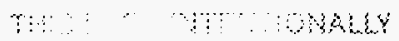

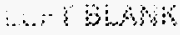






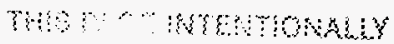
L) S BLANK 

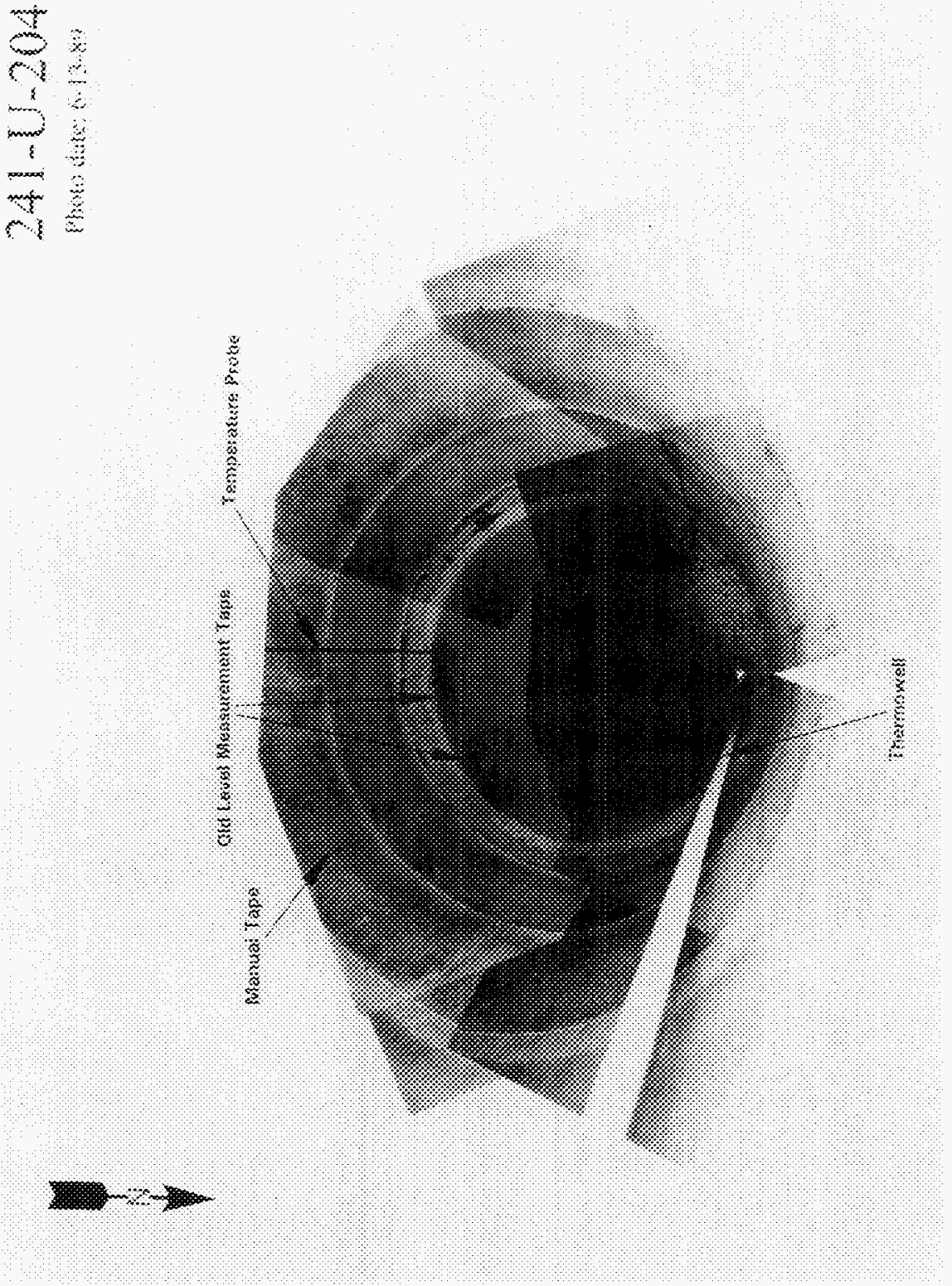


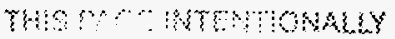

B.P BLANK 


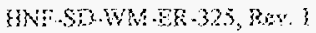

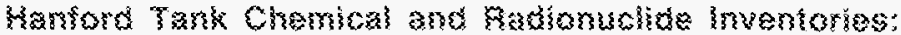

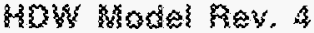

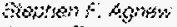 \\ raness sojer \\ robsen, a const

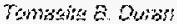 \\ inth S. Fizount

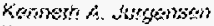

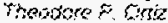 \\ Sionnis !. Foing

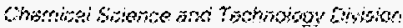

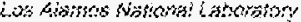

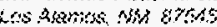 \\ donsong tosi
}

\section{Executive surnorary}

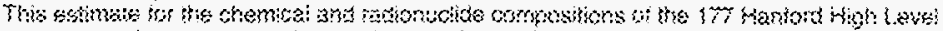

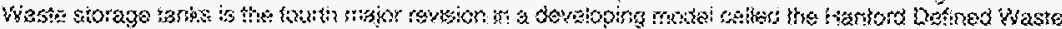

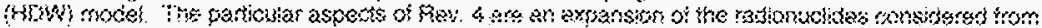

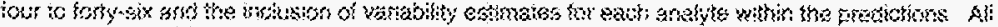

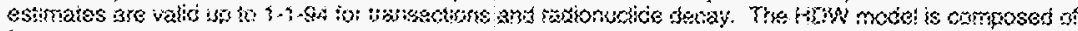
tow pars:

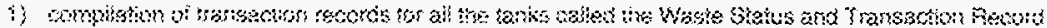
Summory (wStss):

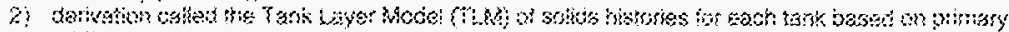
additime of waste;

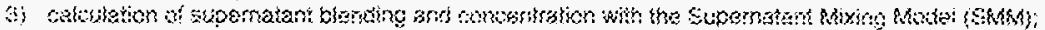
arot

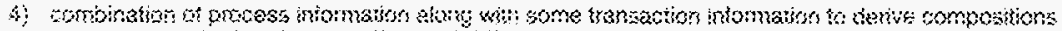

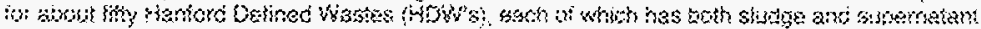
isyer:

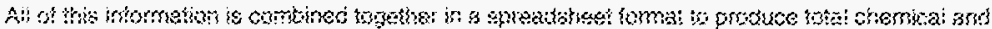

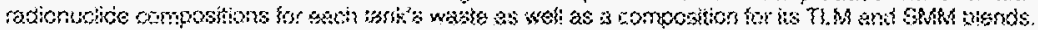

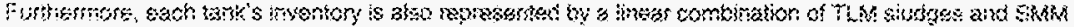

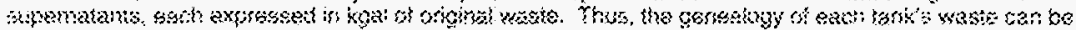

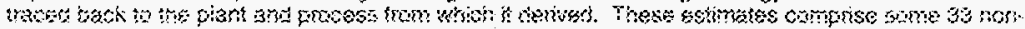

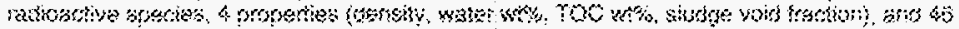

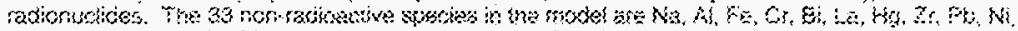

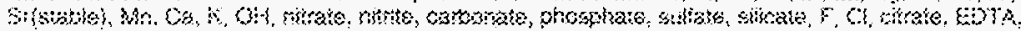

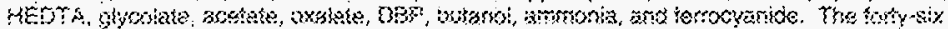

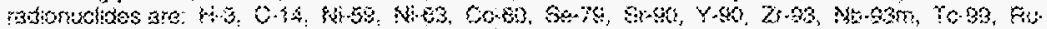

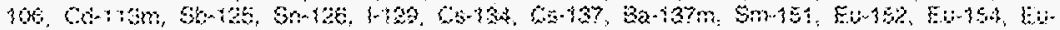

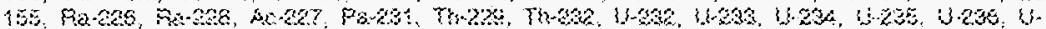

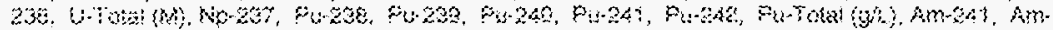

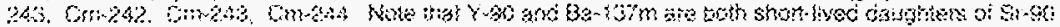

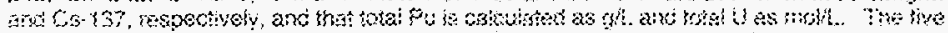

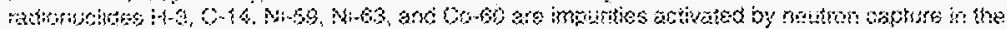

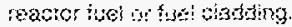

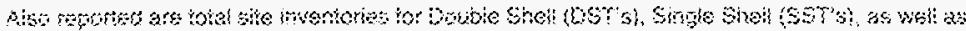

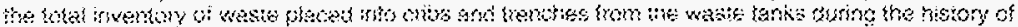

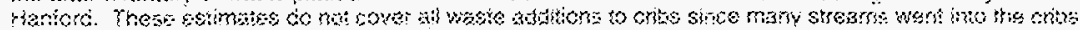

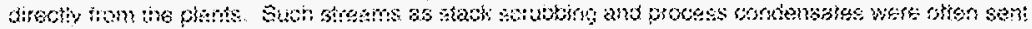
direoty ro onters rom the pibts. 


\section{boxnswiedgments}

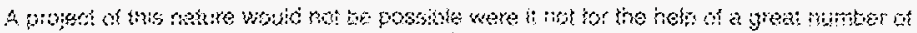

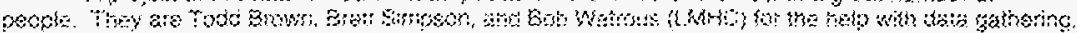

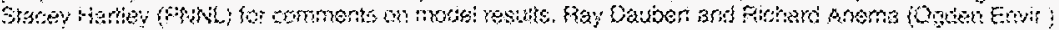

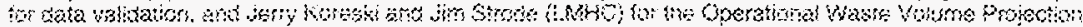

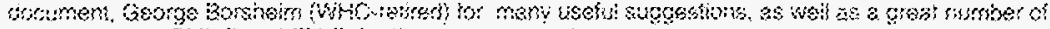

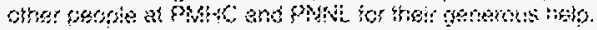

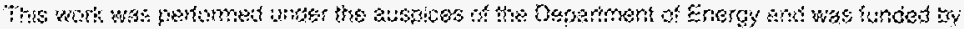

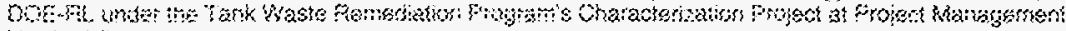

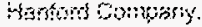

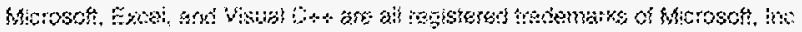




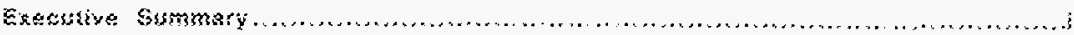

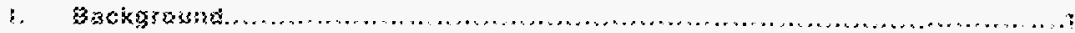

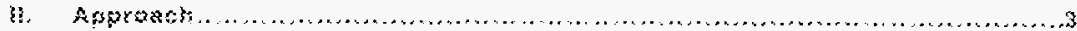

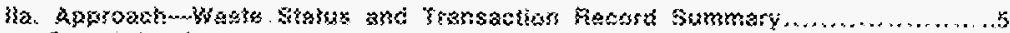
Casade transters

Trandatian anderion

thW evacoratcr nx:ste:

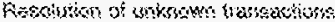

Evel tistspongiss

vaticaton ot weras

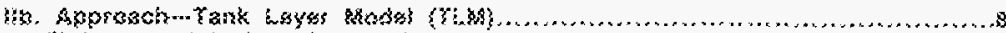

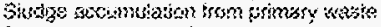

Solonke acoumustion

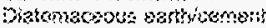

Sorits not induded in Thw

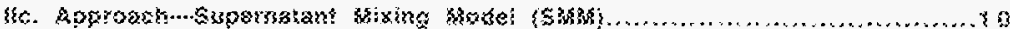

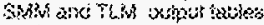
impiementax of on

isansotion precessins:

Ancilisy momation

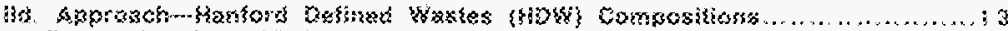

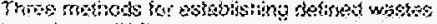

knowiedas OP Prexse

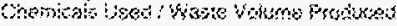

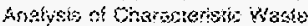

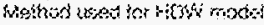

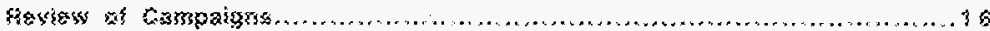

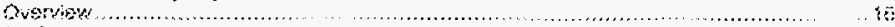

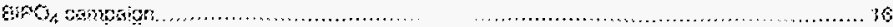

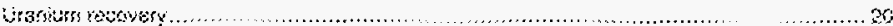

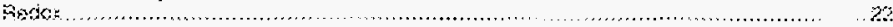

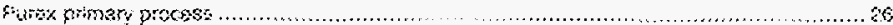

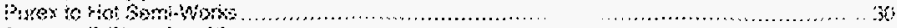

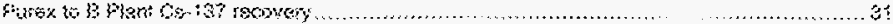

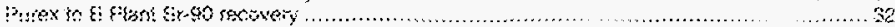

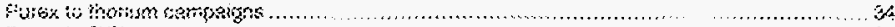

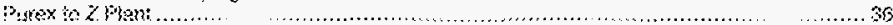

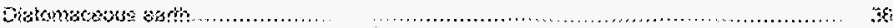

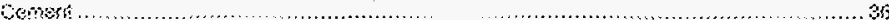

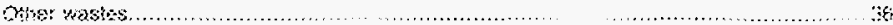

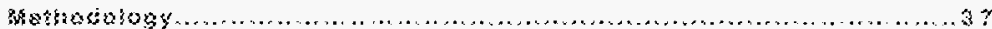

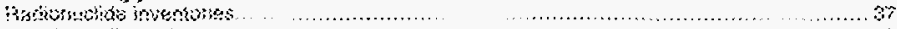

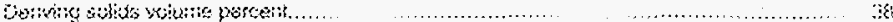

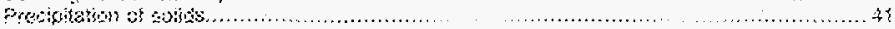

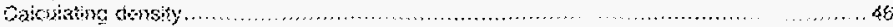

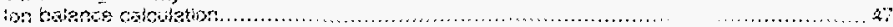

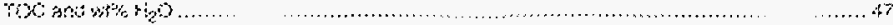

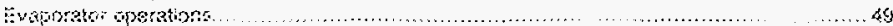

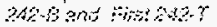

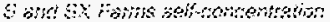

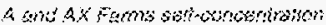




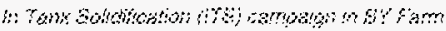

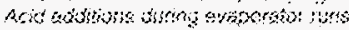

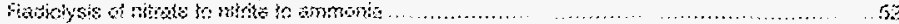

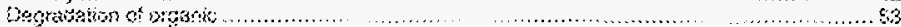

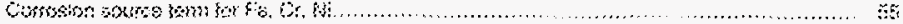

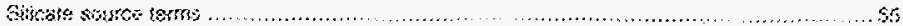

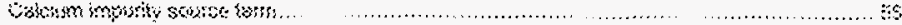

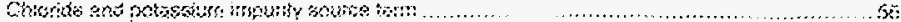

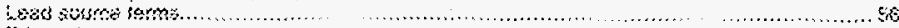

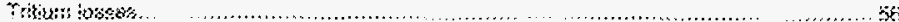

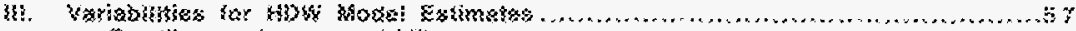

Quasthrawon ai poress vaitibitis

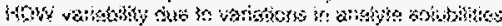

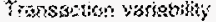

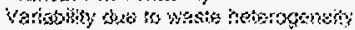

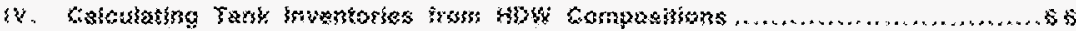

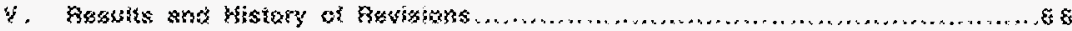

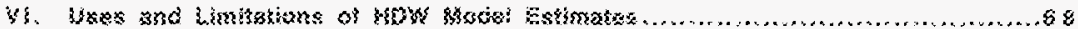

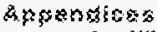

A. $\{3 X Y\},\{s\}$

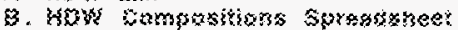

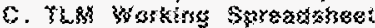

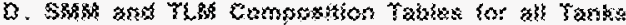

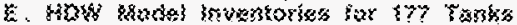

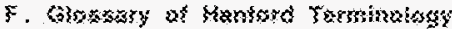

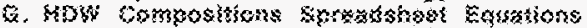

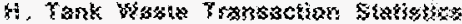




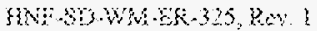

\section{Eackeroumb}

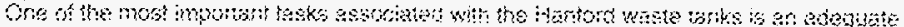

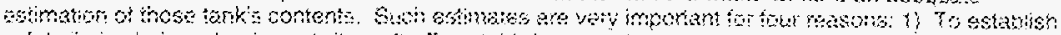

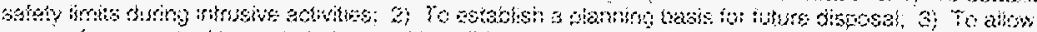

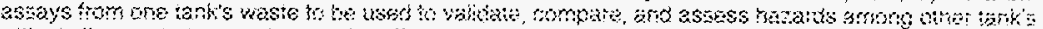

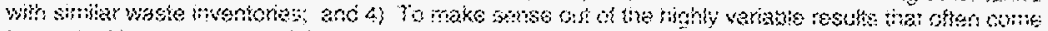

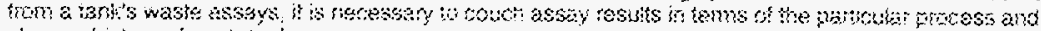
storece hishon of eact hank.

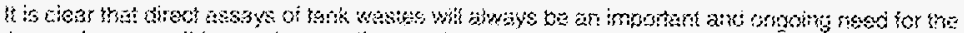

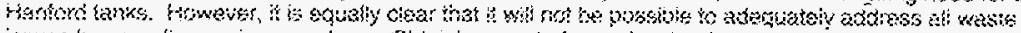

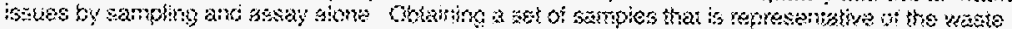

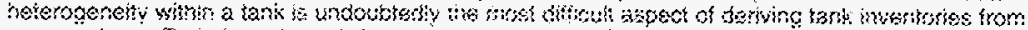

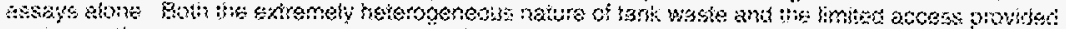

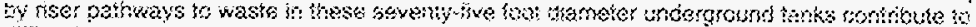

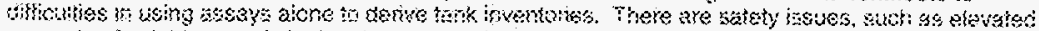

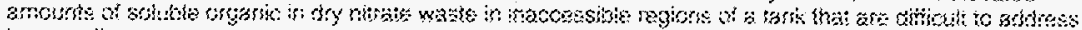
by armping atone.

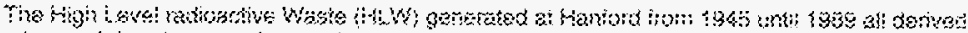

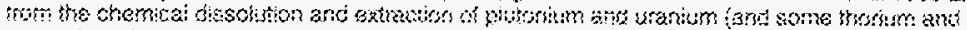

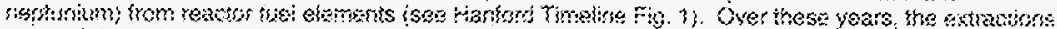

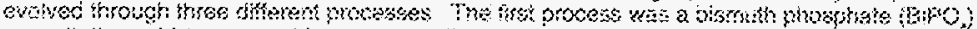

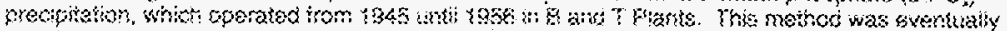

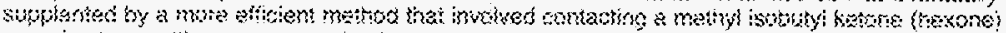

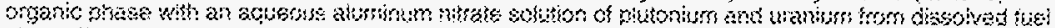

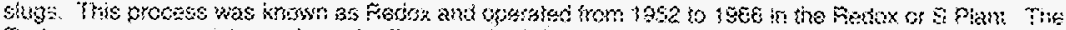

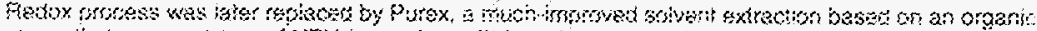

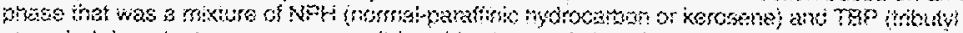

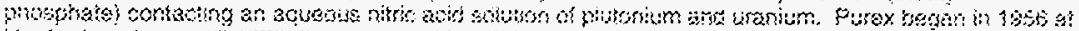

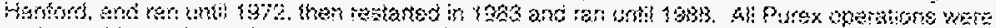
pertormed in the Furex Pists, or a piant.

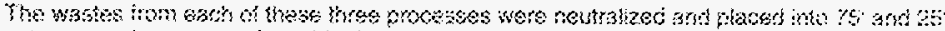

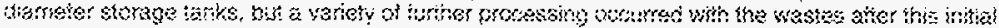

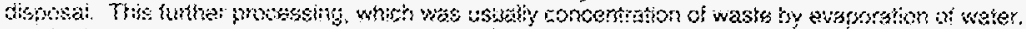

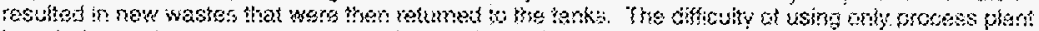

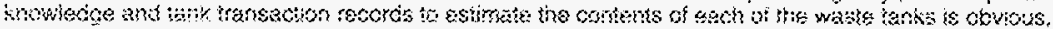

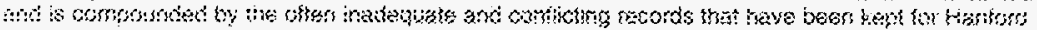
intos.

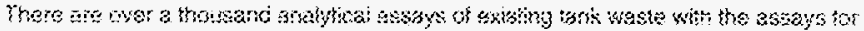

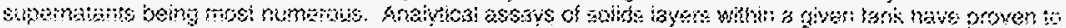

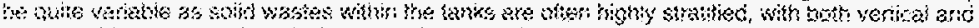

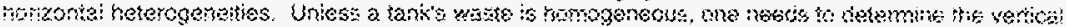

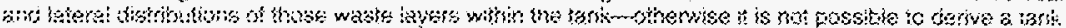

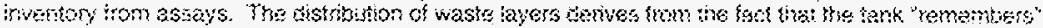

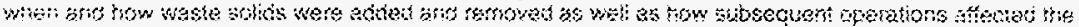

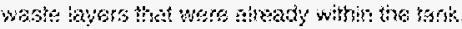

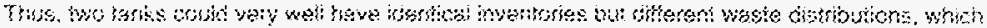

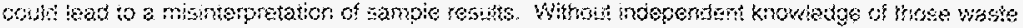

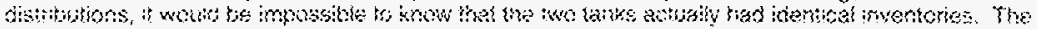

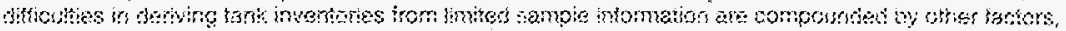

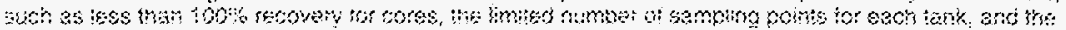

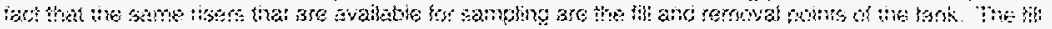

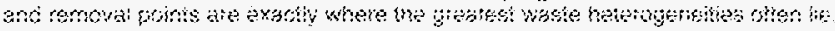




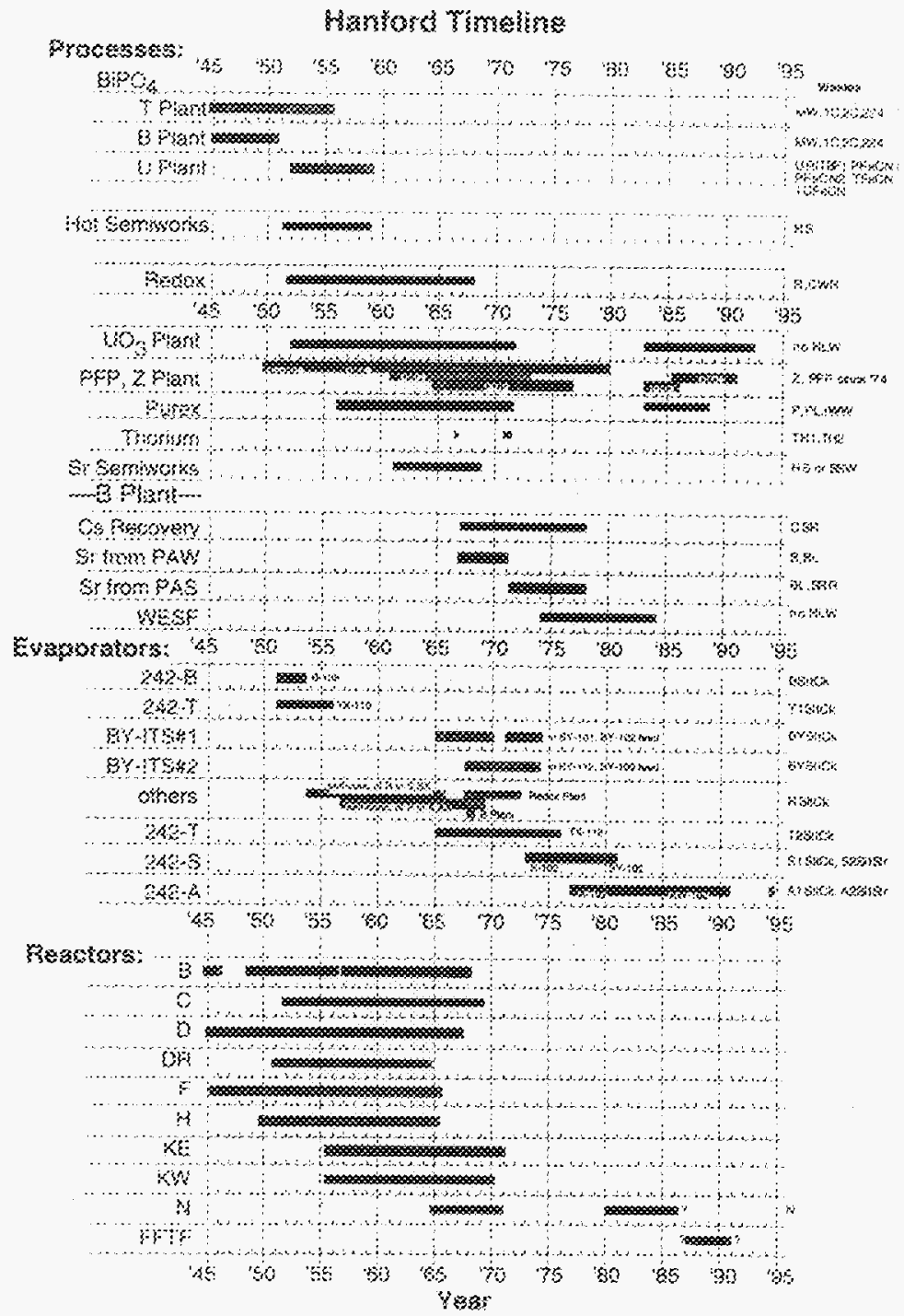

sy. r. Hownof Timsthe 


\section{Spovessen}

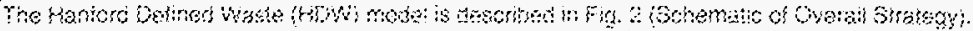

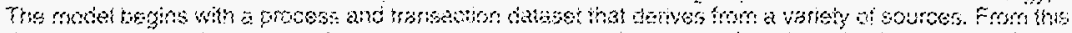

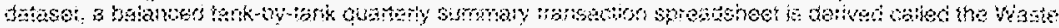

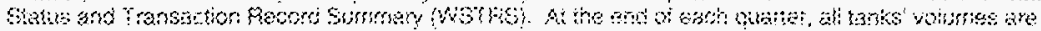

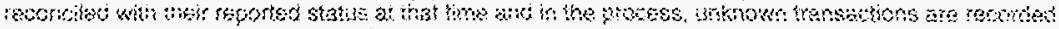

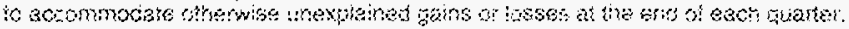

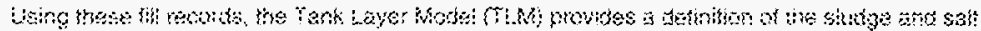

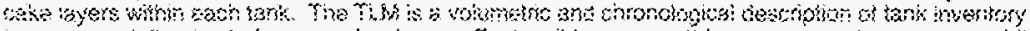

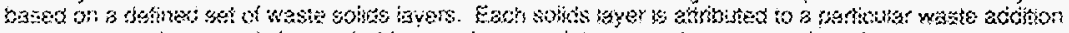

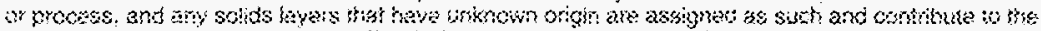

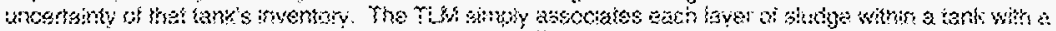

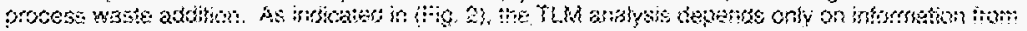
WeThe

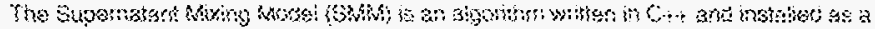

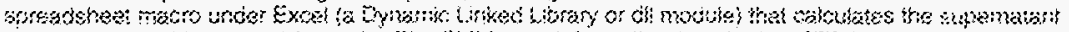

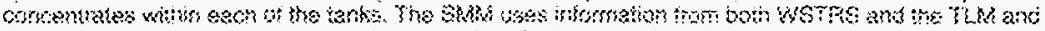

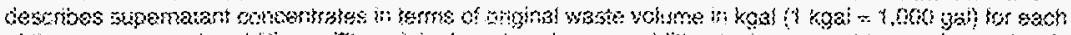

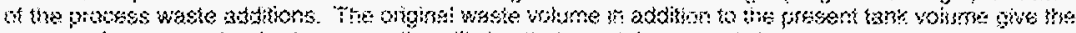

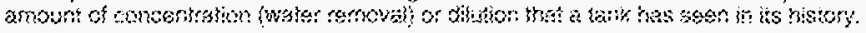

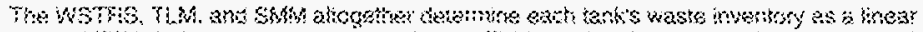

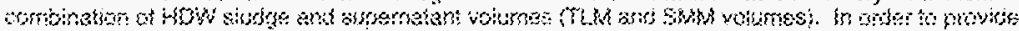

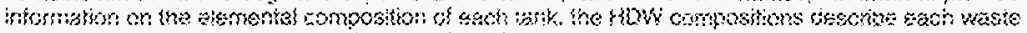

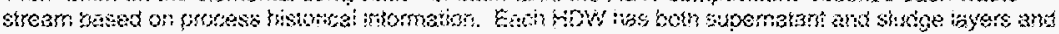

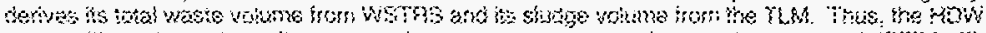

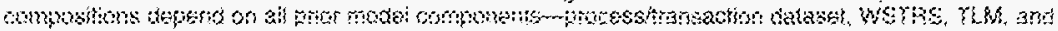
SBSss.

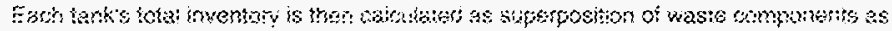

where

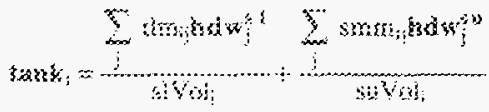

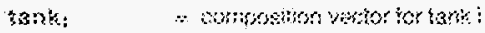

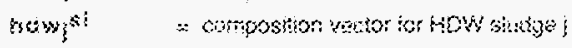

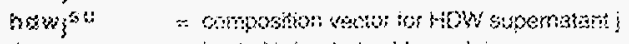

$$
\begin{aligned}
& \text { this }
\end{aligned}
$$

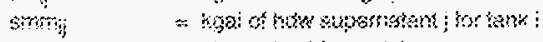

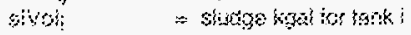

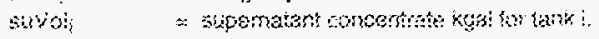




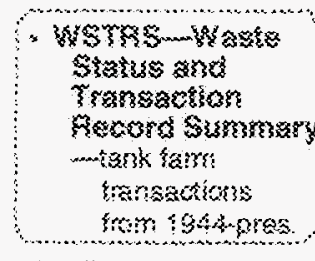

o Thos Tank knyer hoth

-.-siudger

-wall cakjes

-raver mondogy

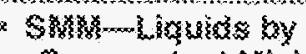

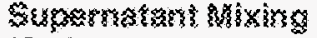
mord

--issurme irsel moing

-3urr: of EDW sts: .... corosontrator: factor.

\section{- Frocks sm mosetion Marast}

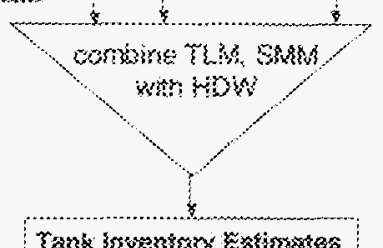

\& HDW-Harrord

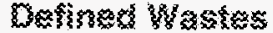

miwo byos to sasi HEW

mis MDW's:

$\rightarrow$ ? Bipon

25 Lraribm feorivery

$=4$ Hedox

$\therefore$ Es Pirsix

$\therefore$ 2 Thuri:

$>4$ sat Caks:

$>$ datomaostss antn (OE)

$>$ cameni(O)

$\rightarrow 56 \mathrm{~W}$ and 4

$\therefore \quad x \mathrm{H}$

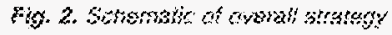

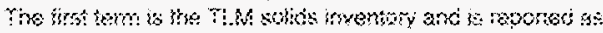

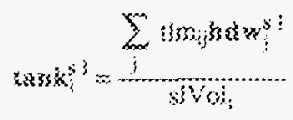

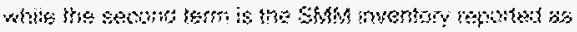




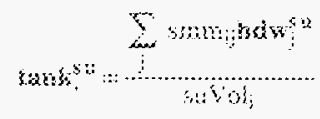

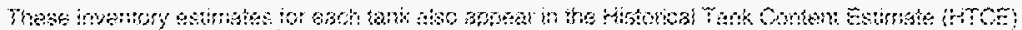
rapons tor ach of tour cusisme."

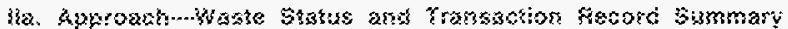

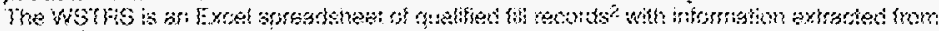

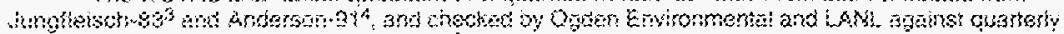

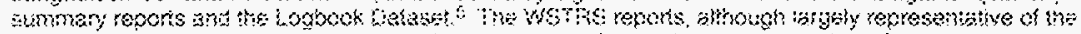

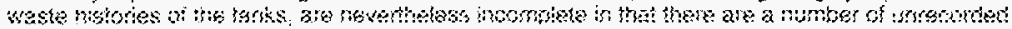

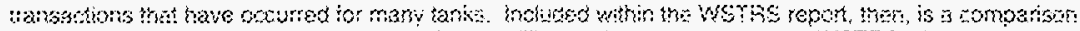

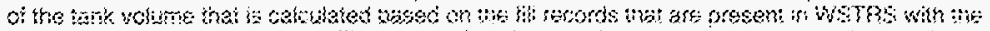

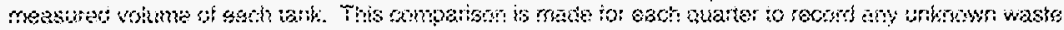

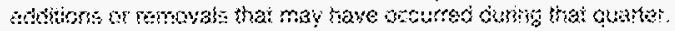

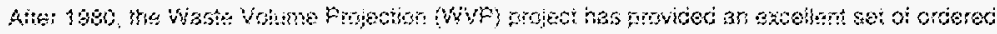
mansogtons.

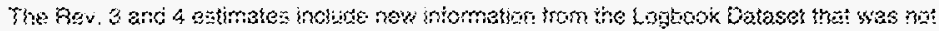

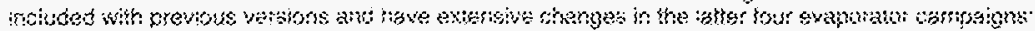

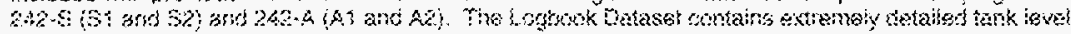

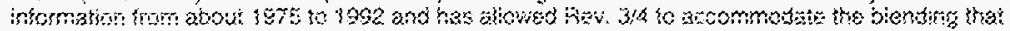

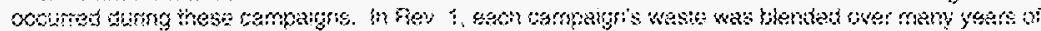

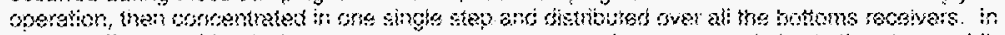

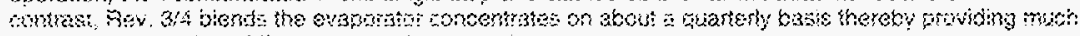

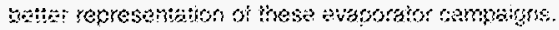

\section{C... Carcade transters}

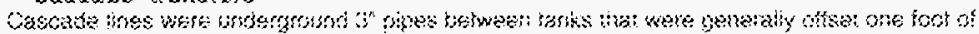

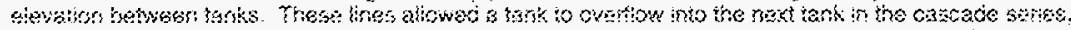

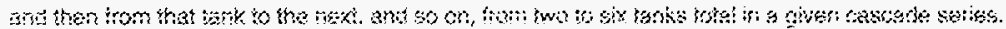

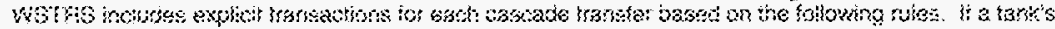

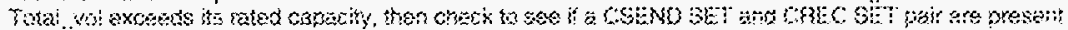

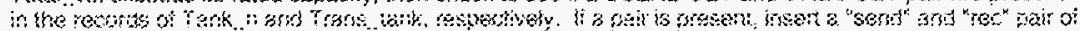

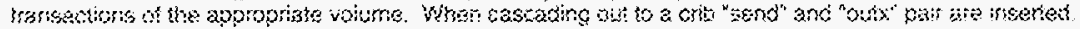

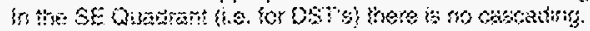

\section{....Yรansatian: arsterings}

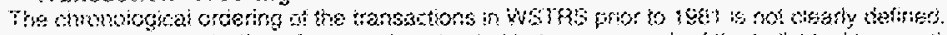

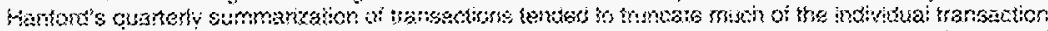

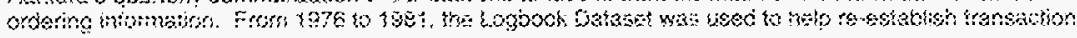

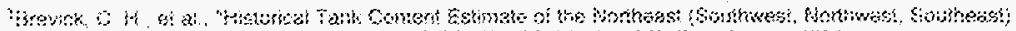

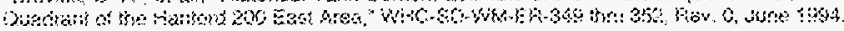

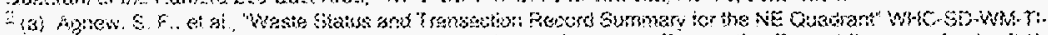

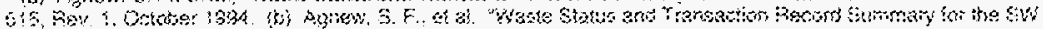

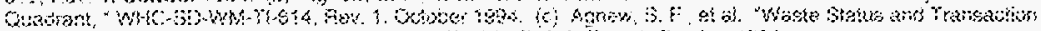

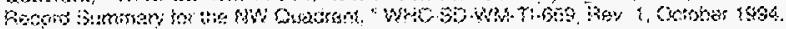

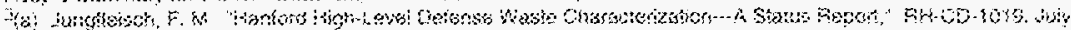

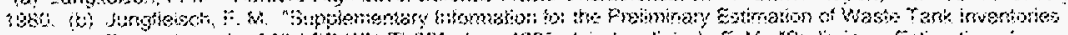

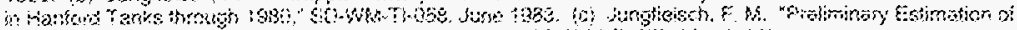

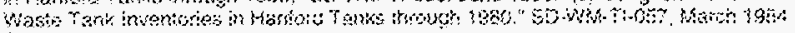

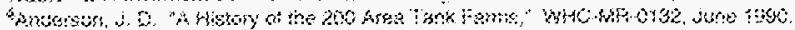

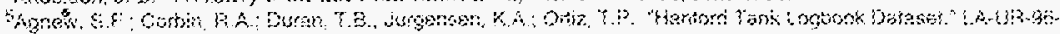

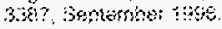




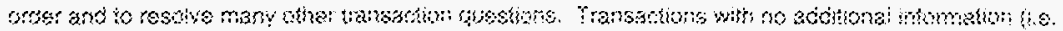

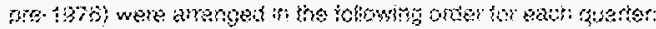

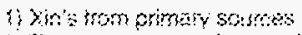

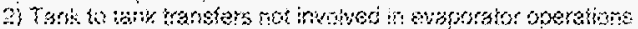

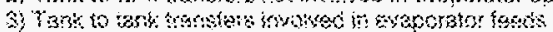

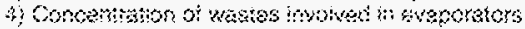

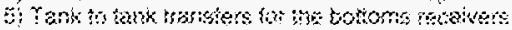

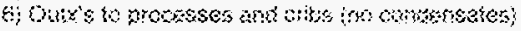

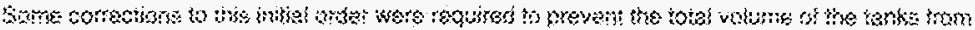

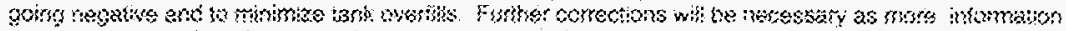

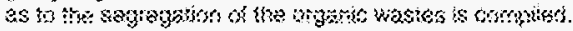

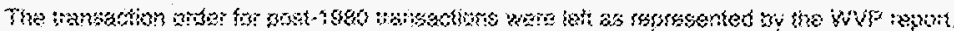

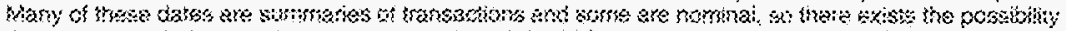

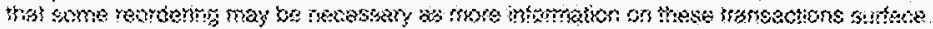

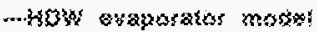

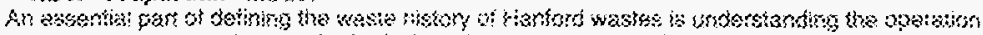

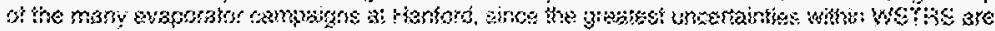

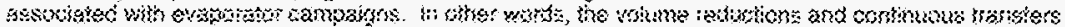

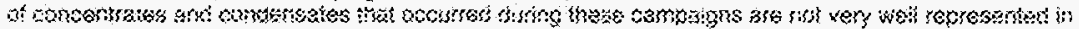
yeis?

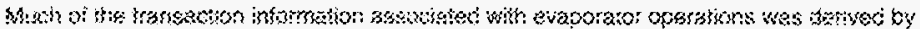

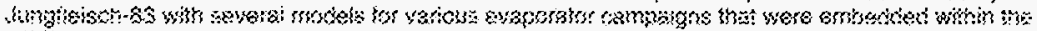

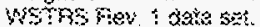

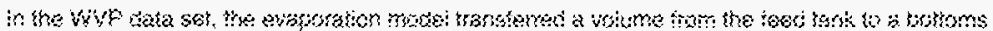

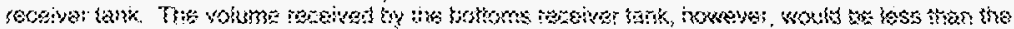

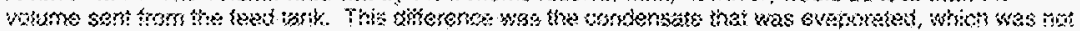
wastivisly insulec.

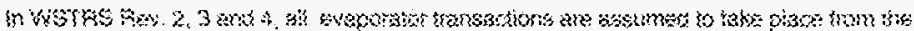

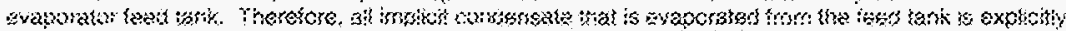

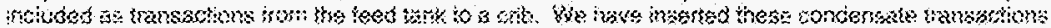

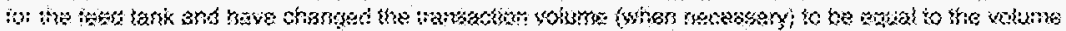

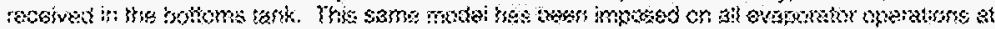

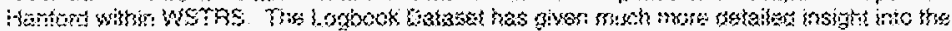

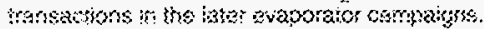

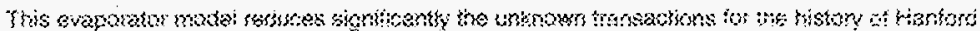

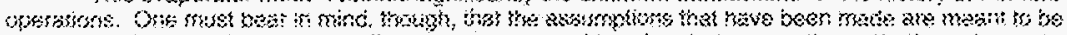

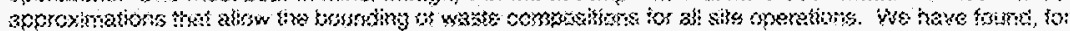

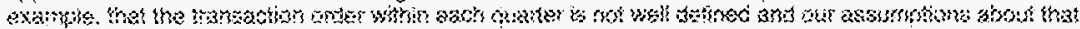
ares are vary approstivaks.

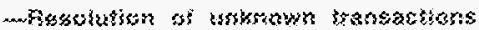

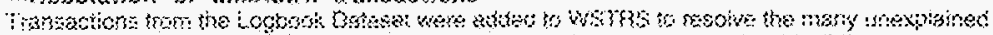

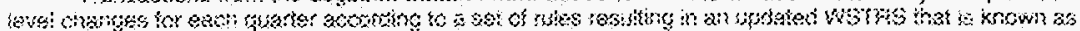

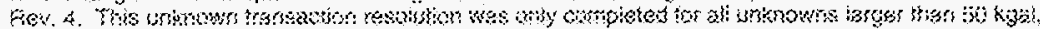

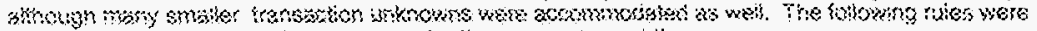

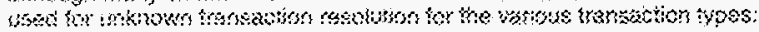




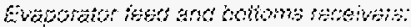

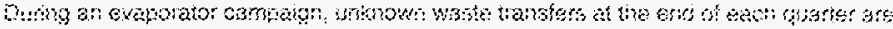

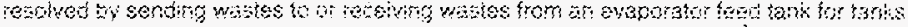

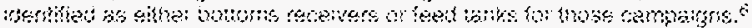

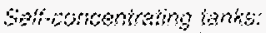

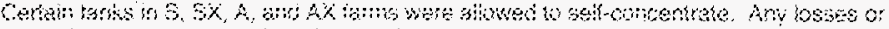

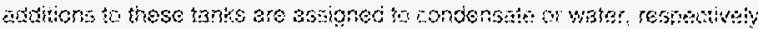

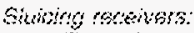

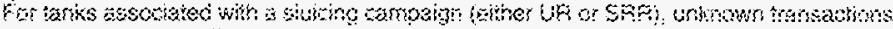

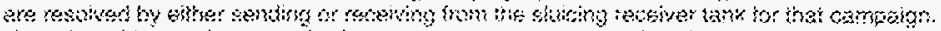

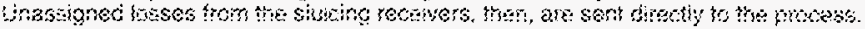

Sah-wak piwnsing anw stathothon:

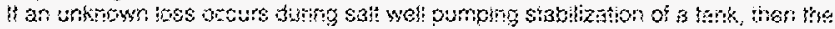

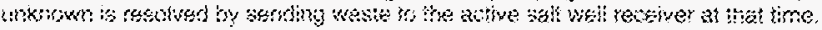

bistivical isse of tank:

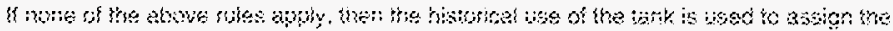

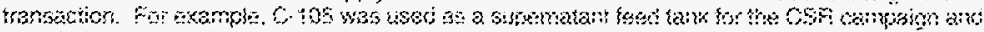

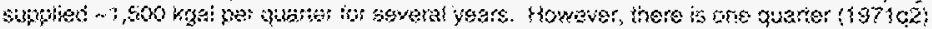

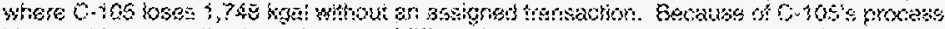

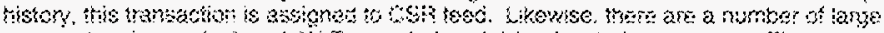

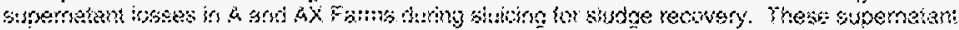

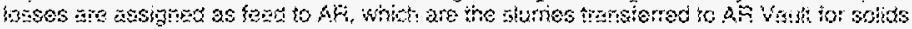

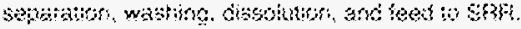

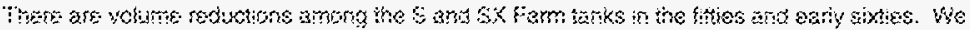

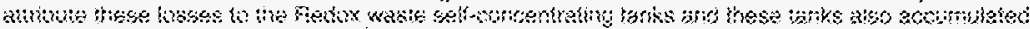

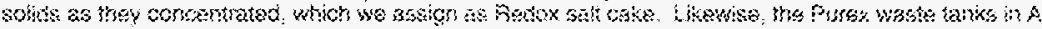

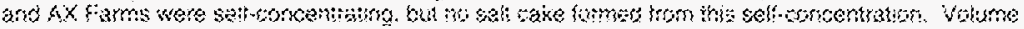

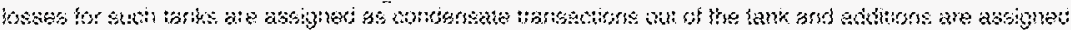
35 wist in.

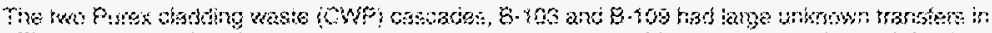

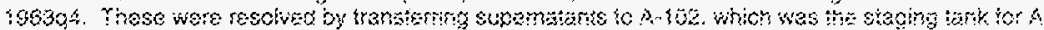

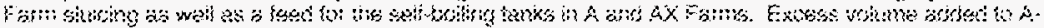

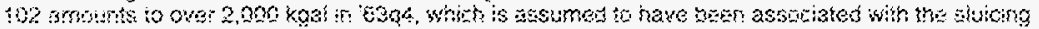

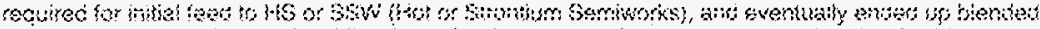

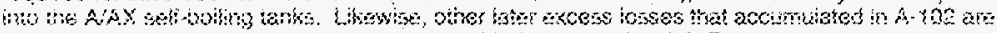

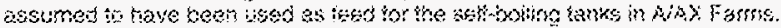

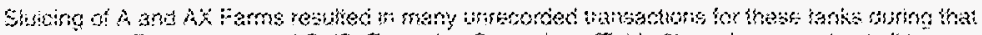

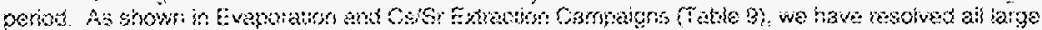

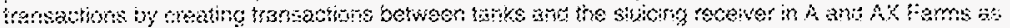

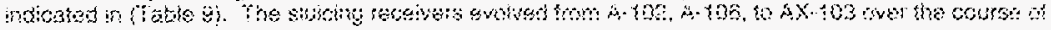
ive esmoeigns

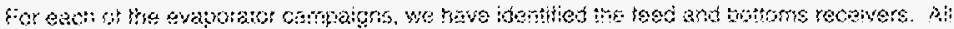

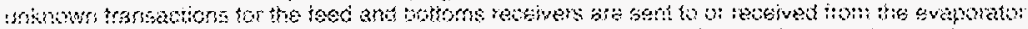

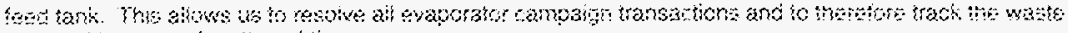
whorstions as a iunction of time.

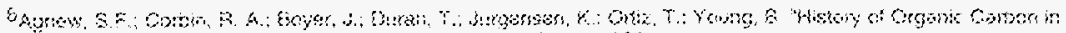

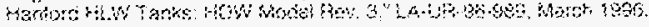




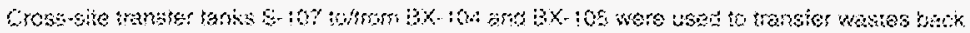

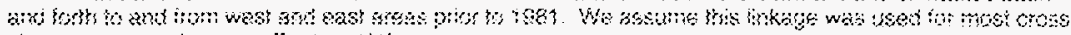

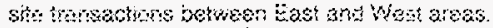

\section{- Leve\} discragancies}

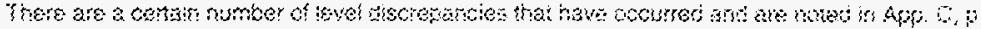
C.35.

\section{-..vertherion of wasks}

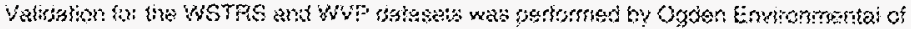

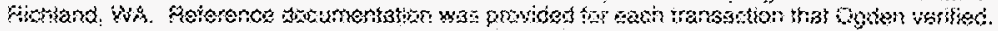

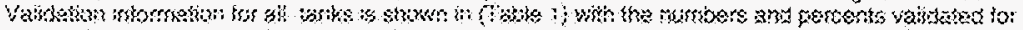

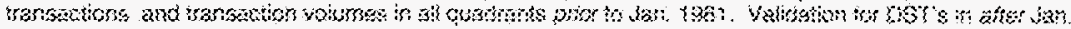

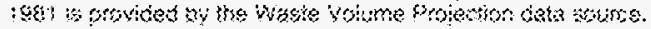

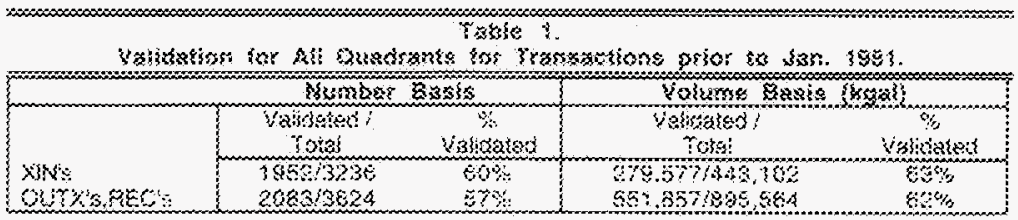

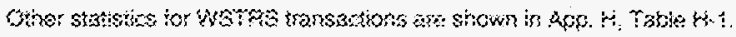

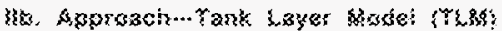

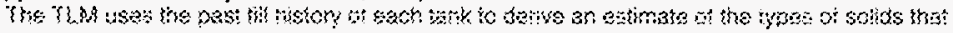

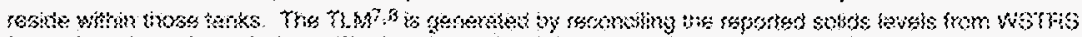

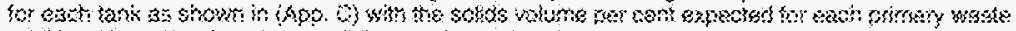

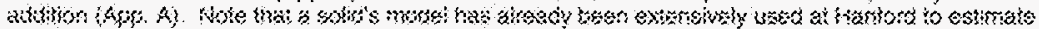

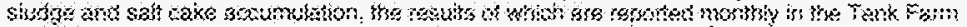

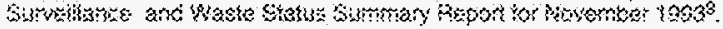

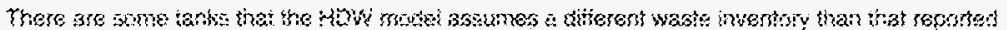

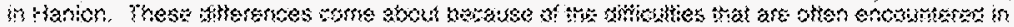

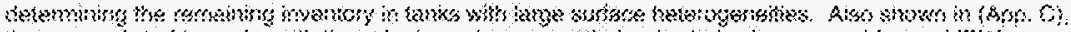

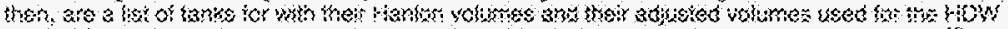

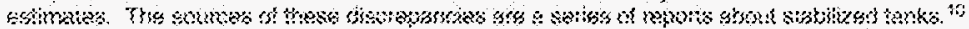

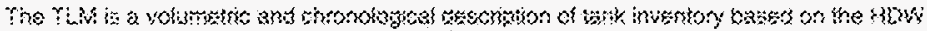

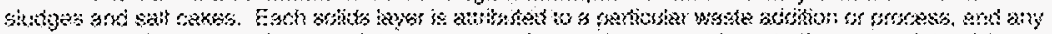

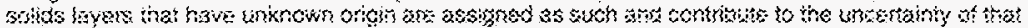

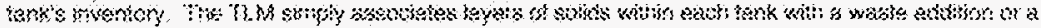
poress ampaign.

"Q SQ Whe

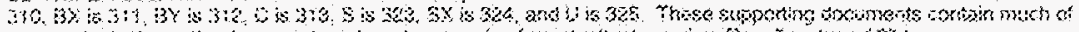

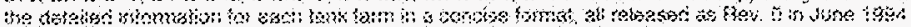

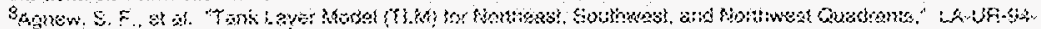

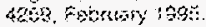

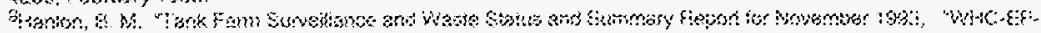

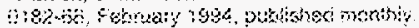

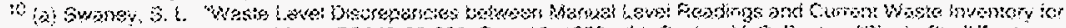

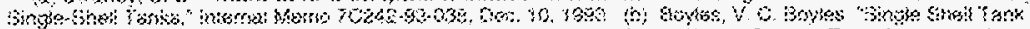

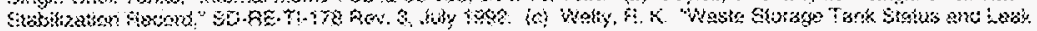

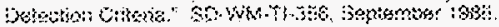




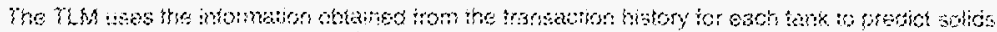

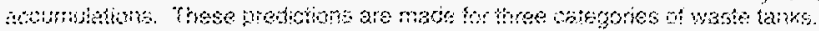

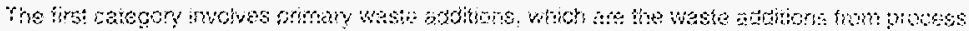

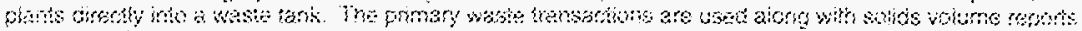

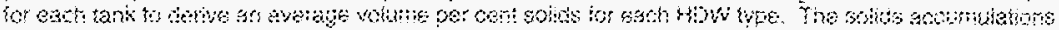

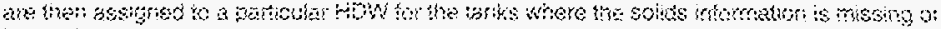
inconsistem?.

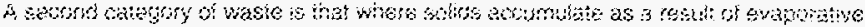

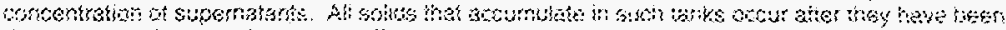

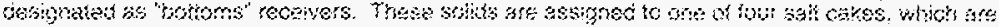

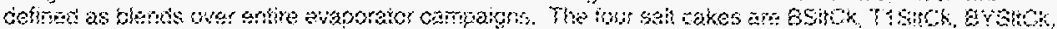

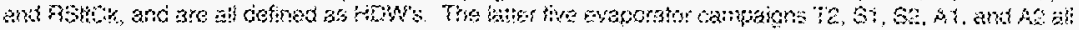

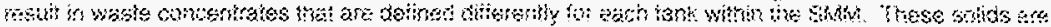

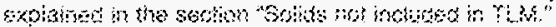

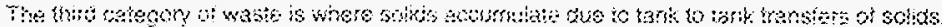

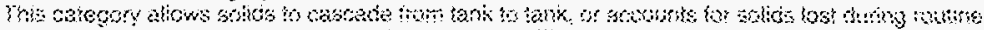

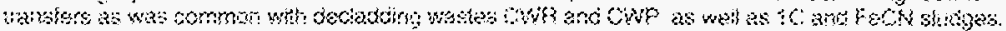

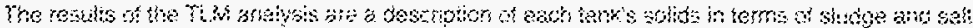

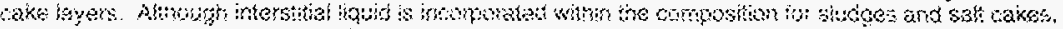

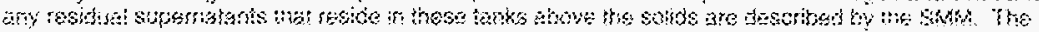

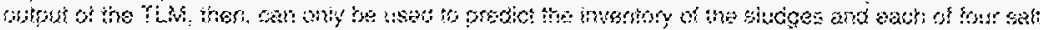

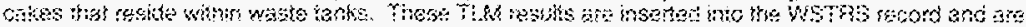

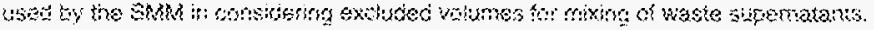

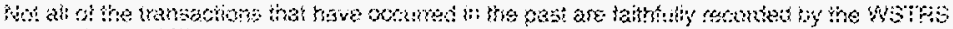

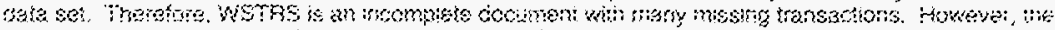

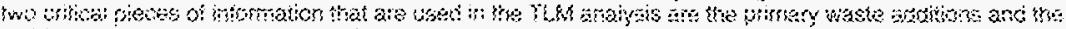

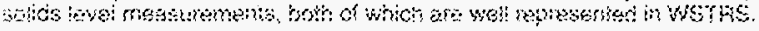

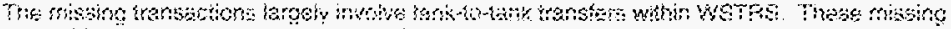

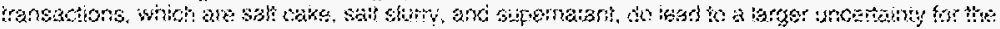

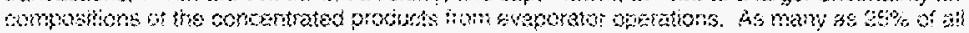

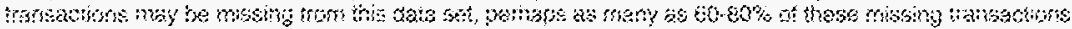

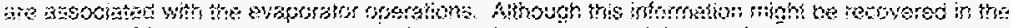

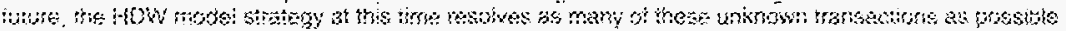
wht the ules stedes and

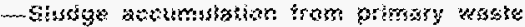

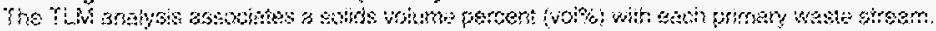

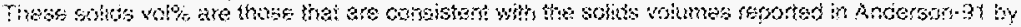

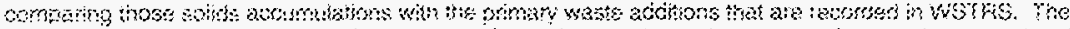

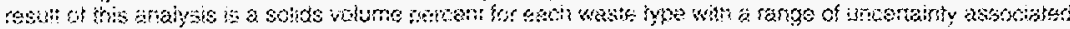

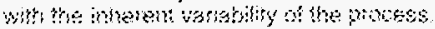

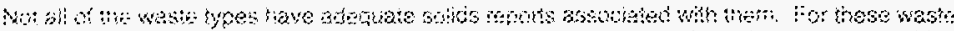

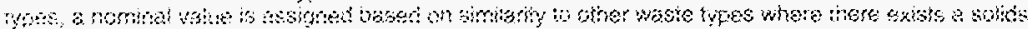

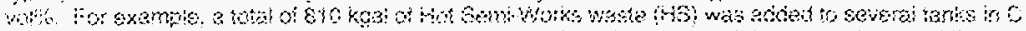

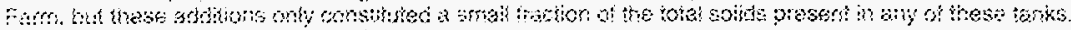

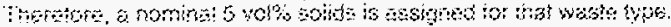

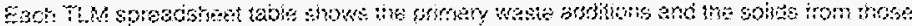

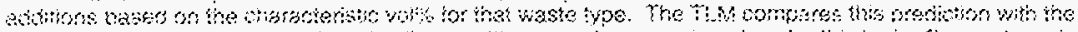

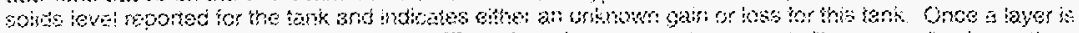

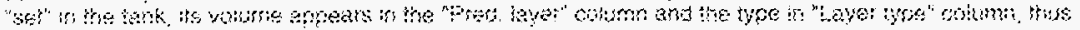




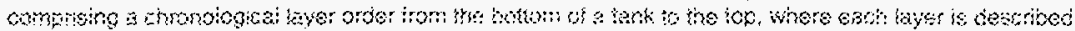

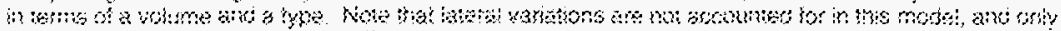

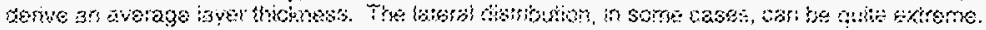

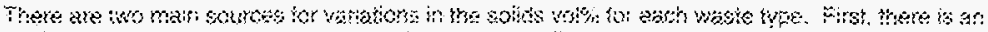

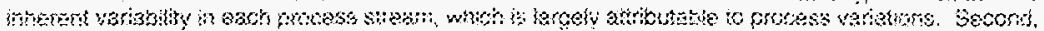

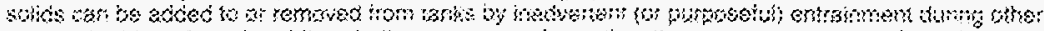

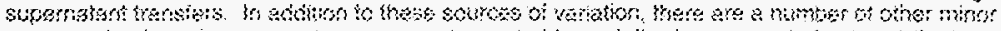

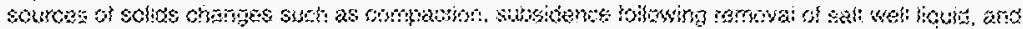

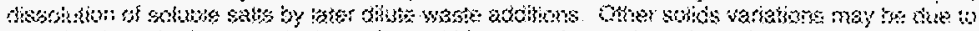

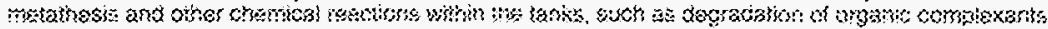
ver birfxe.

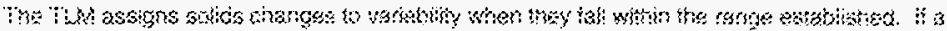

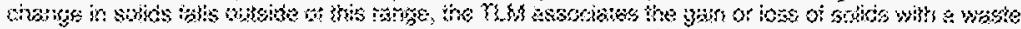

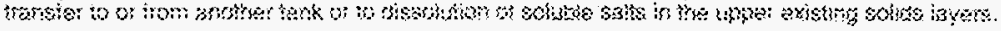

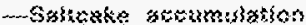

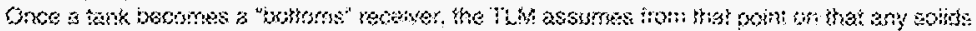

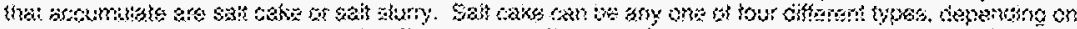

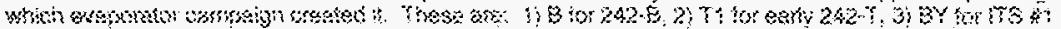

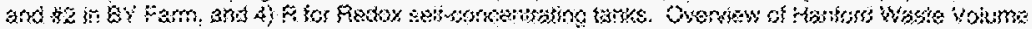

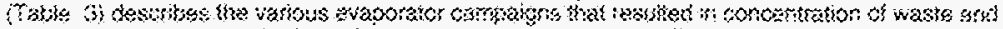

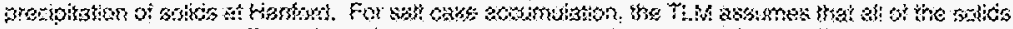

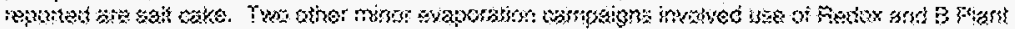

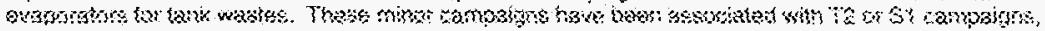
respoctivety.

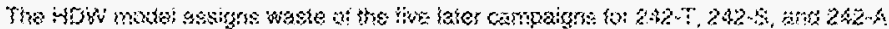

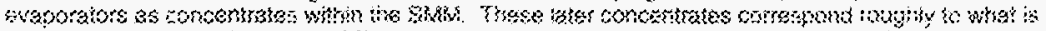

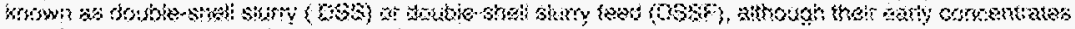

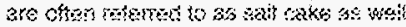

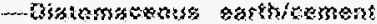

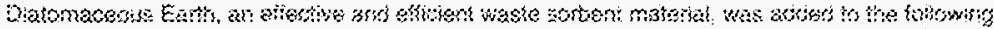

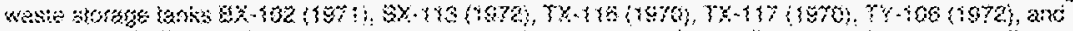

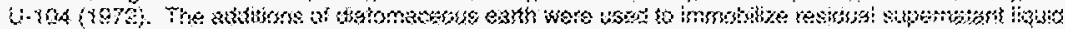

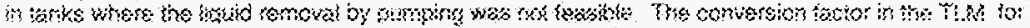

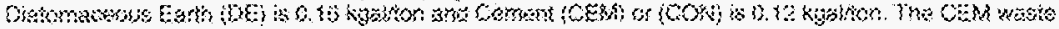

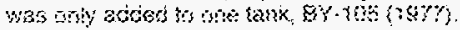

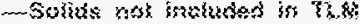

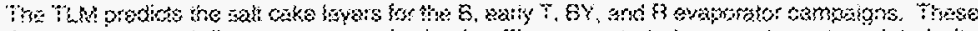

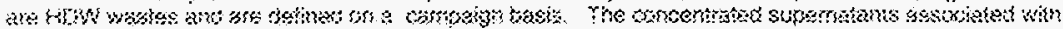

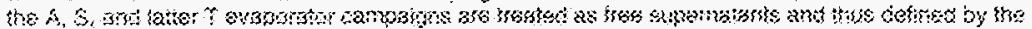

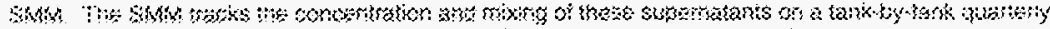

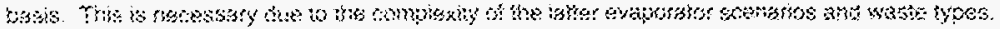

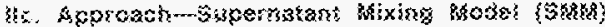

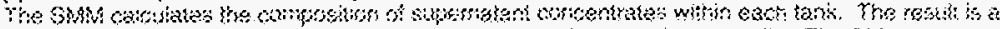

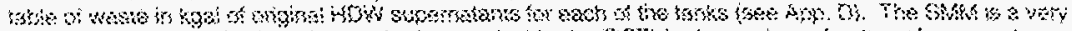

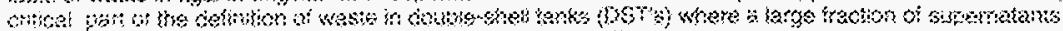

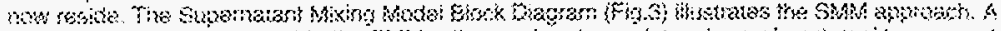

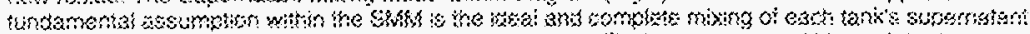

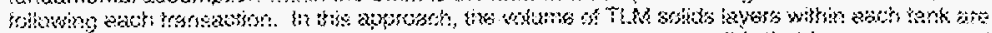

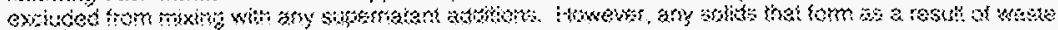

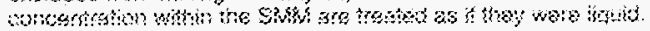




\section{Supermant mxing hotes S100k आ3agran:}

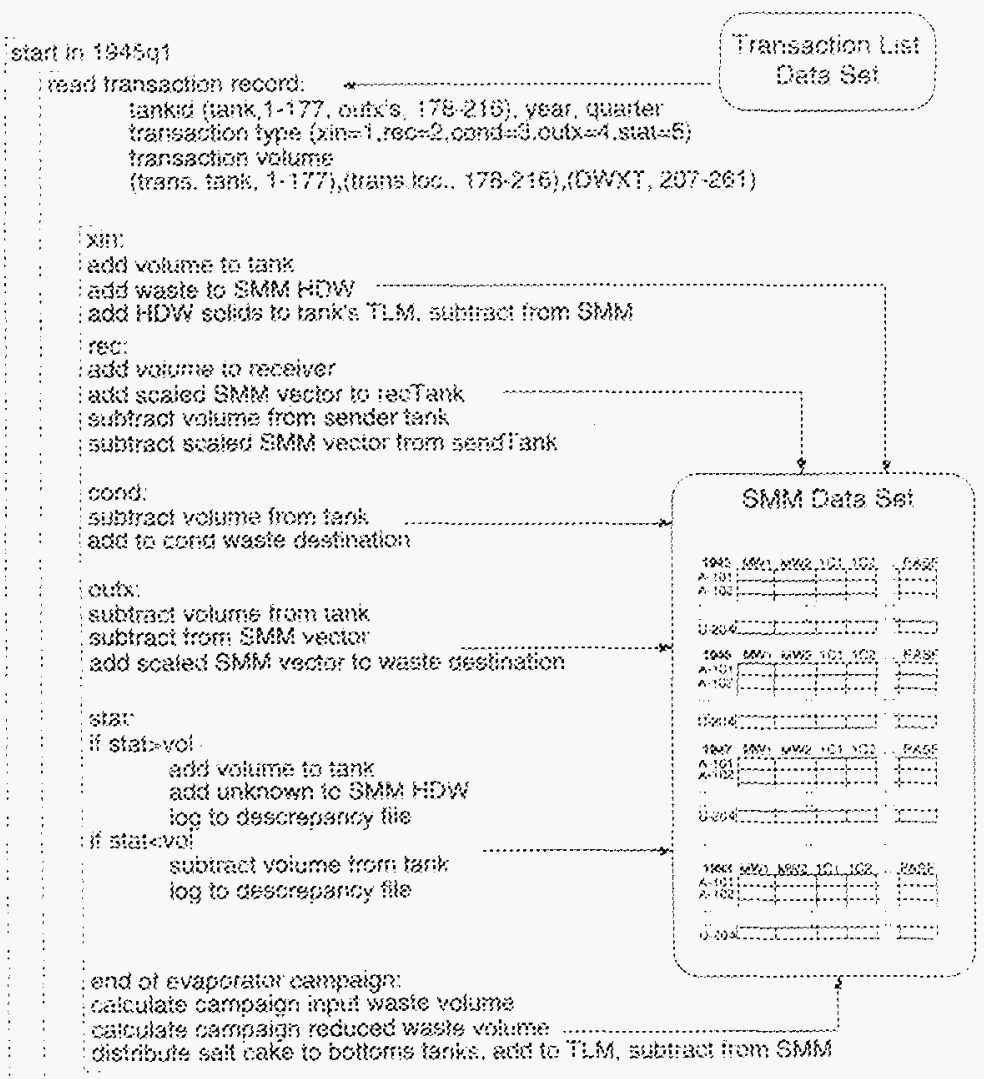

nexi tratsongh

and in $1333 \% 4$

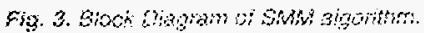

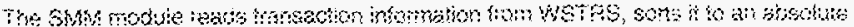

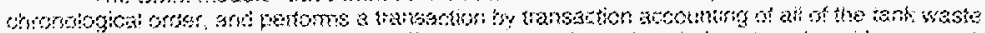

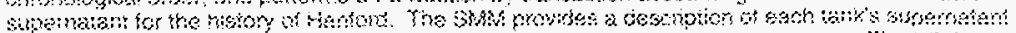

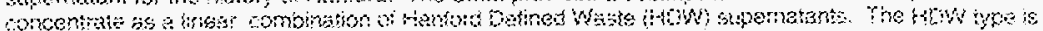

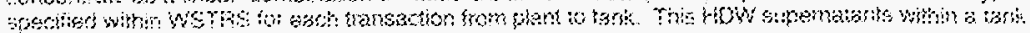




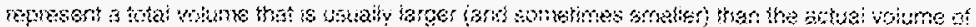

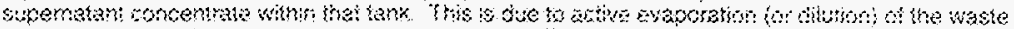

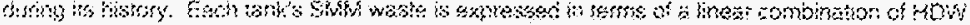

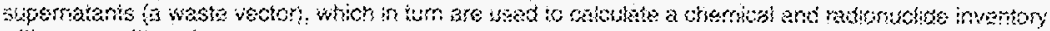

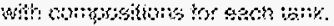

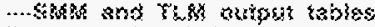

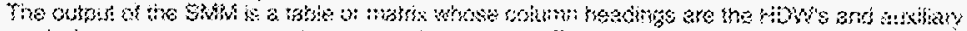

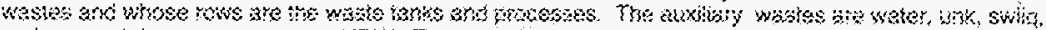

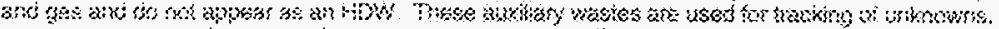

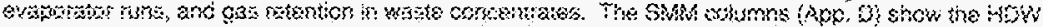

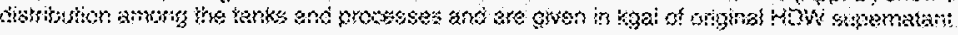

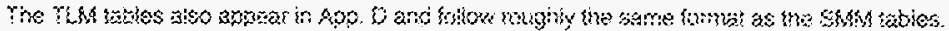

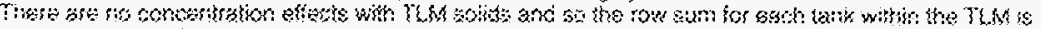

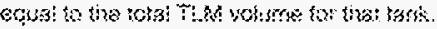

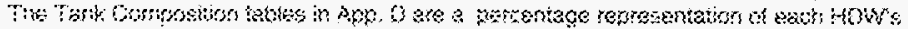

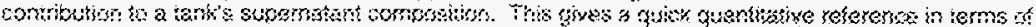

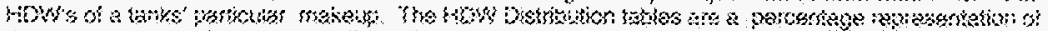

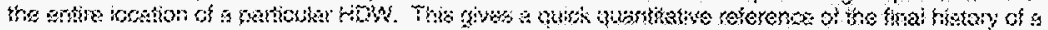

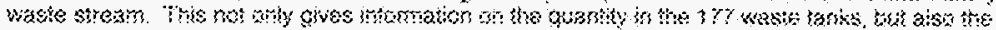

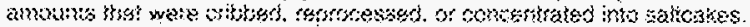

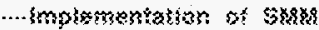

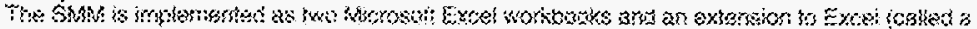

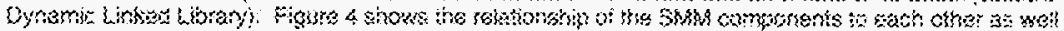

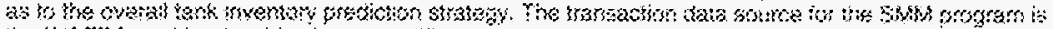

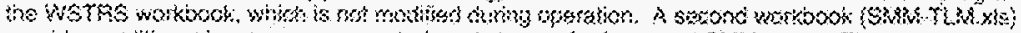

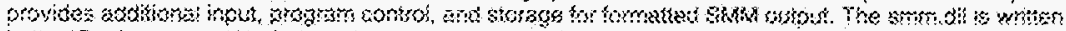

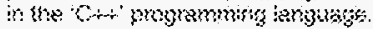

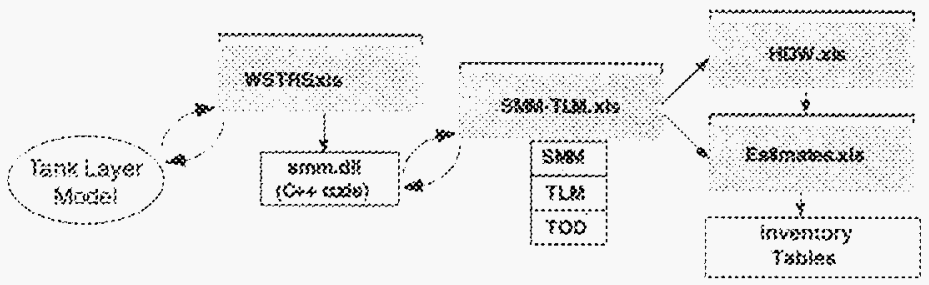

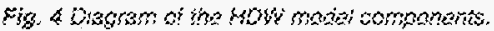

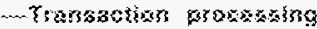

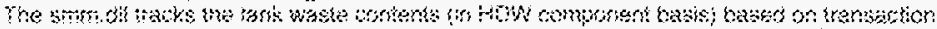

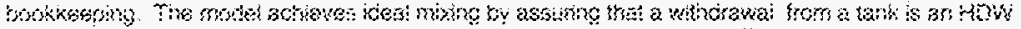

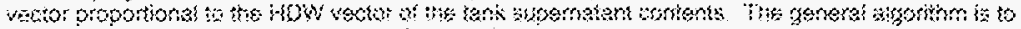

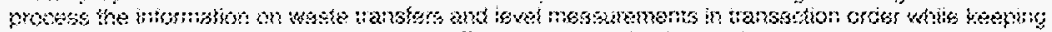

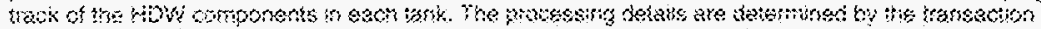

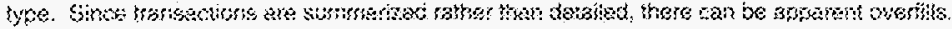

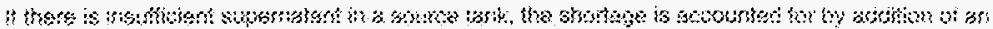

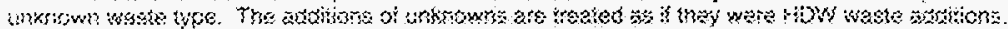

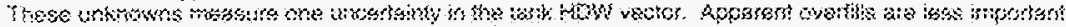

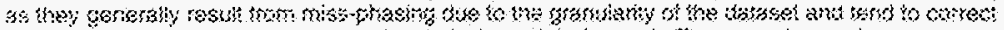

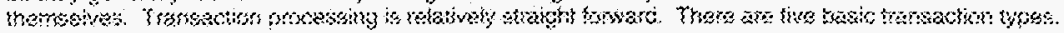




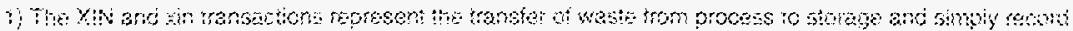

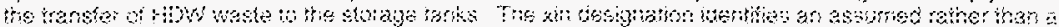

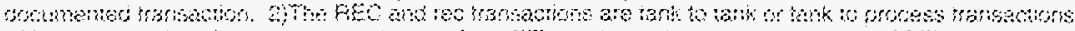

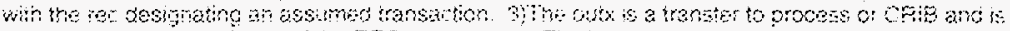

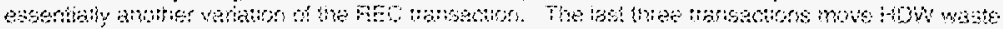

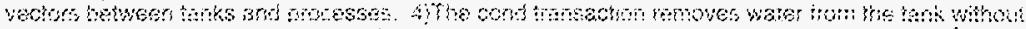

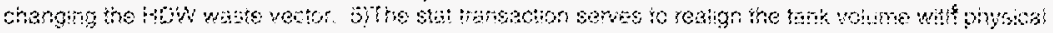
matstroments:

Ancinasy insormstion

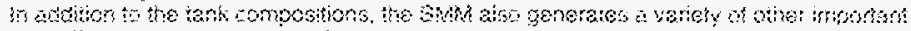

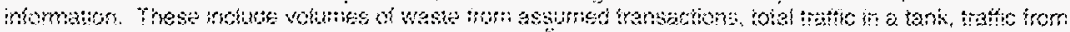

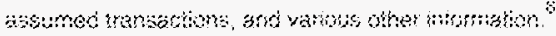

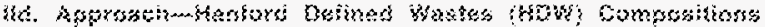

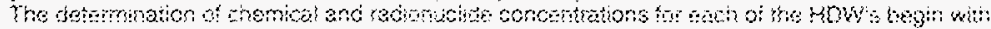

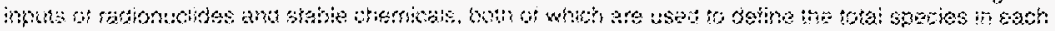

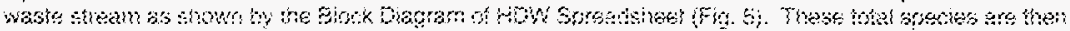

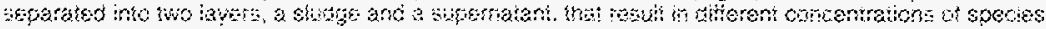
fin the wo byess.

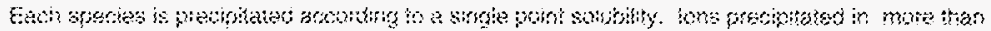

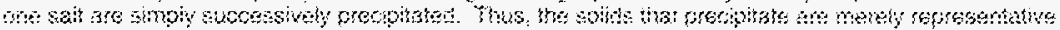

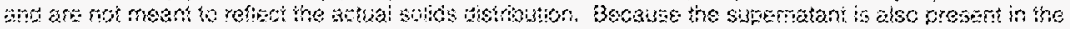

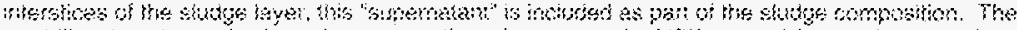

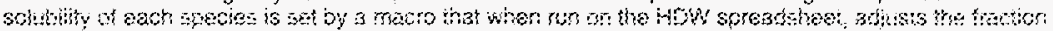

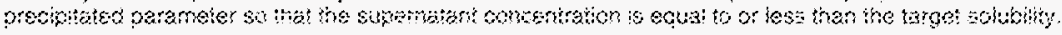

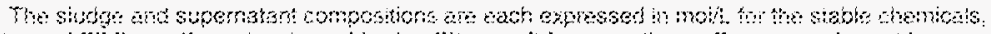

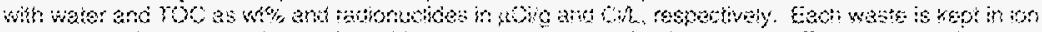

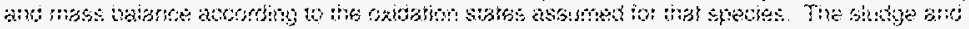

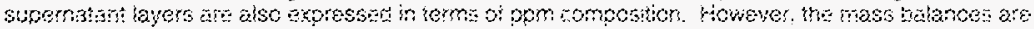

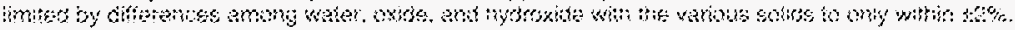

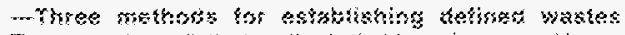

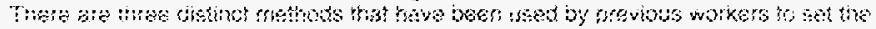

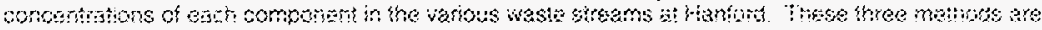

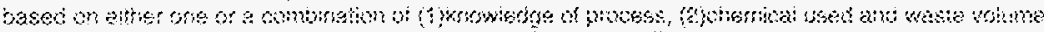

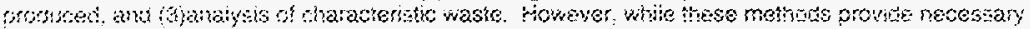

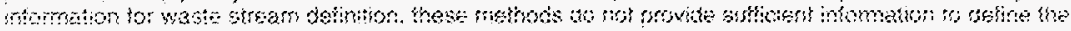
wase stomis.

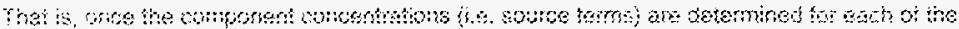

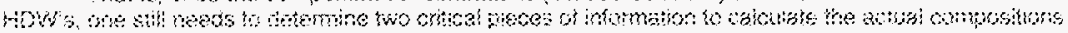

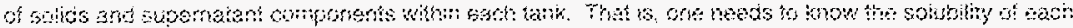

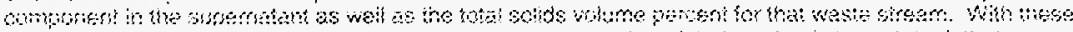

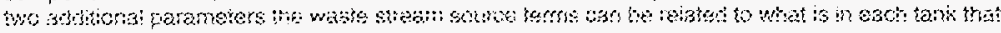
werved thos wates

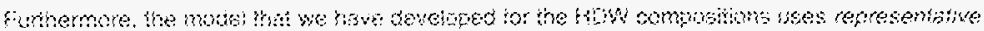

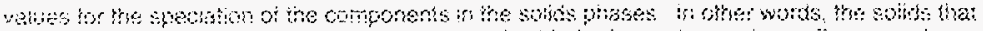

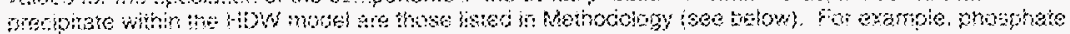

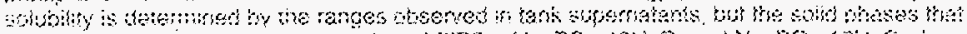

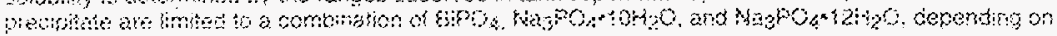

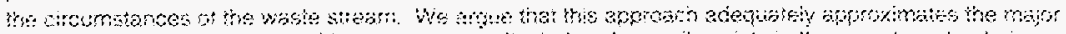

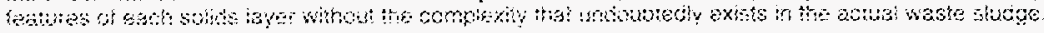



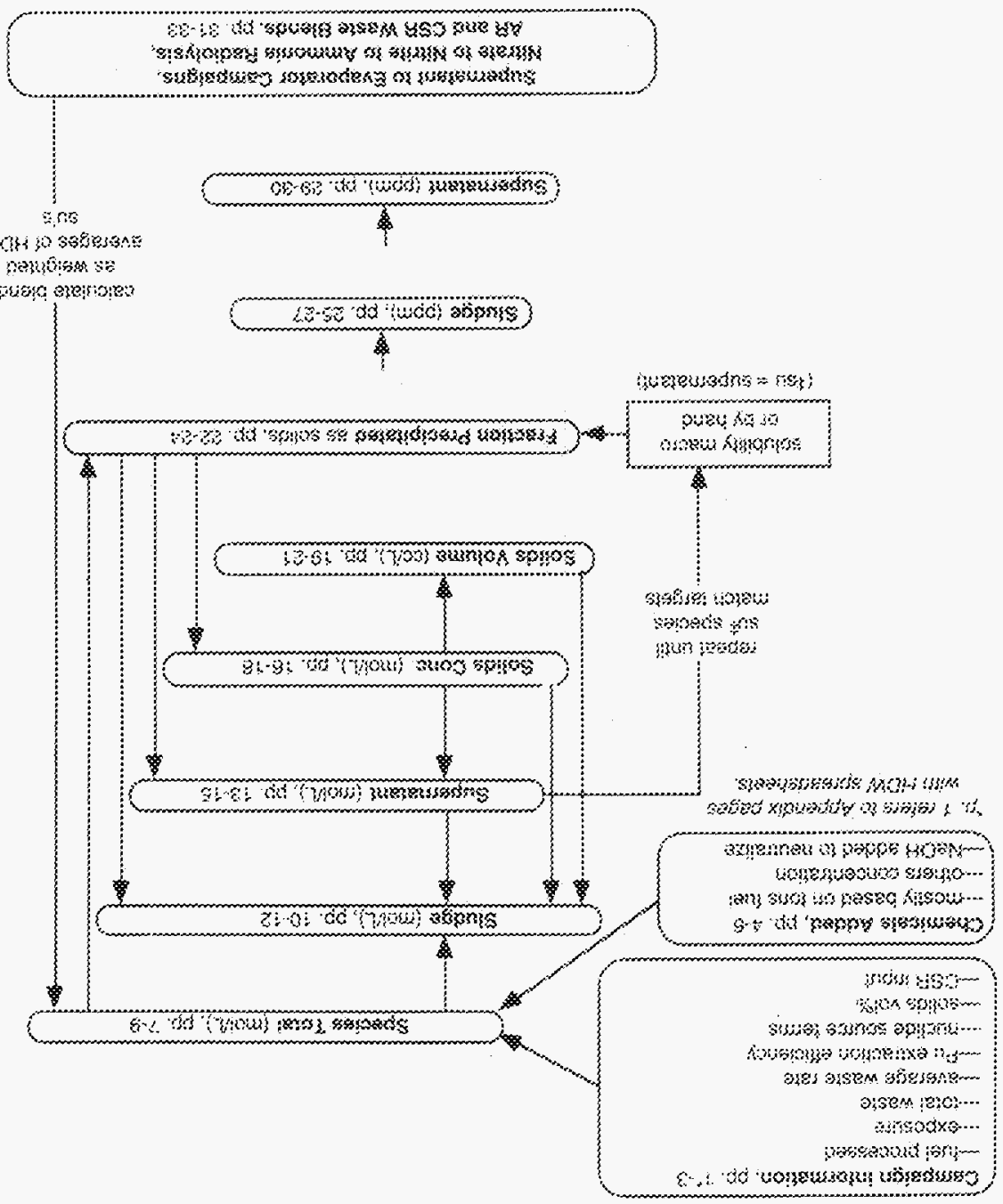

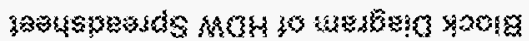




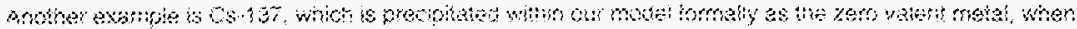

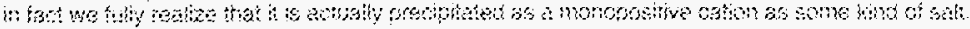

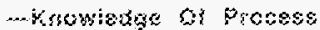

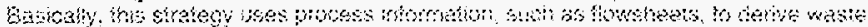

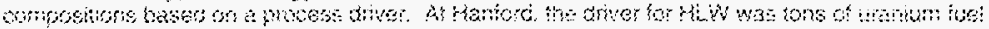

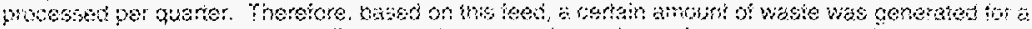

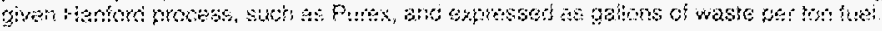

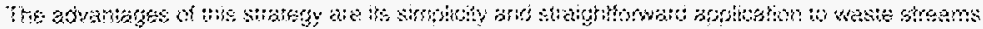

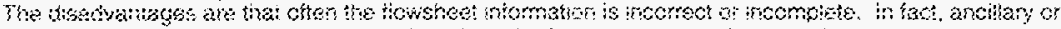

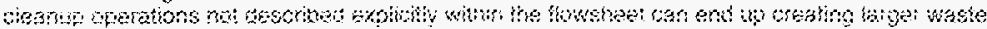

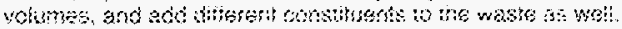

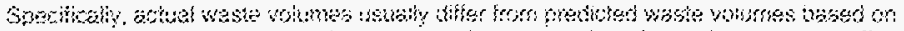

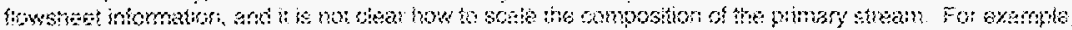

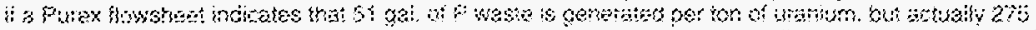

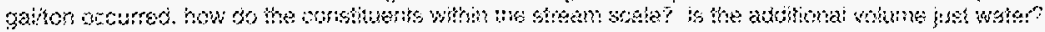

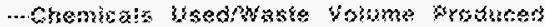

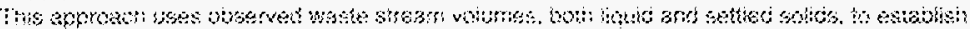

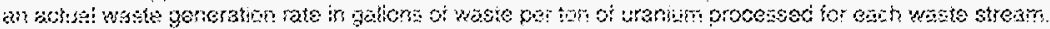

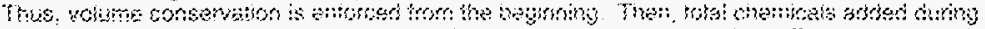

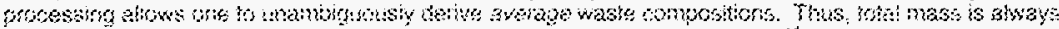

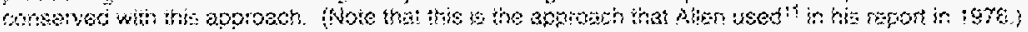

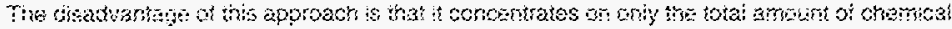

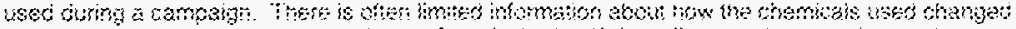

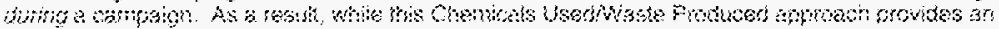

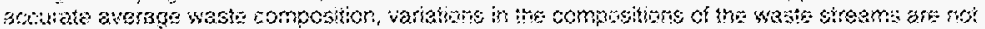

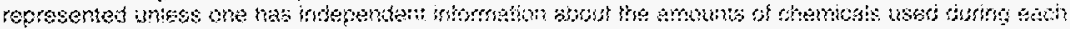

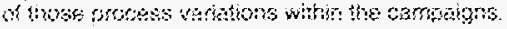

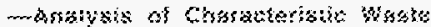

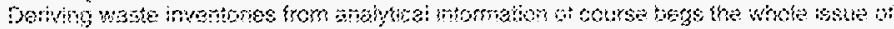

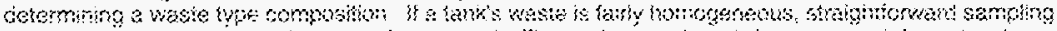

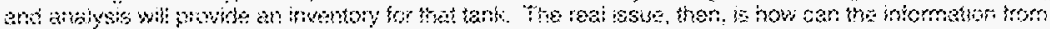

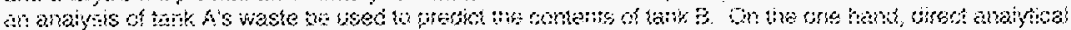

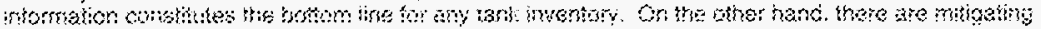

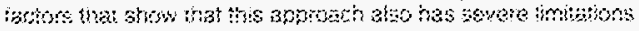

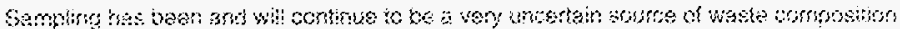

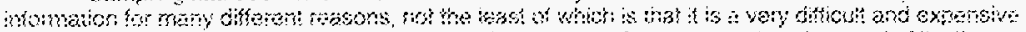

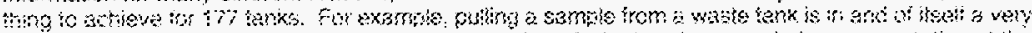

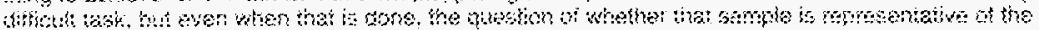

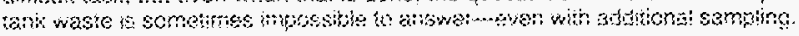

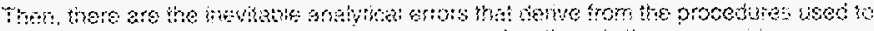

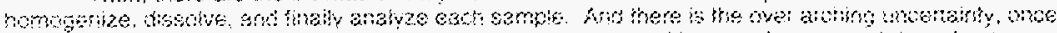

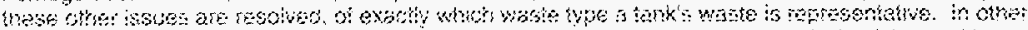

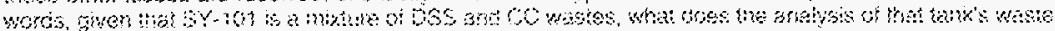

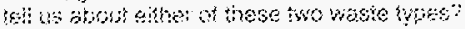

\section{mbahod used kas HoW moral}

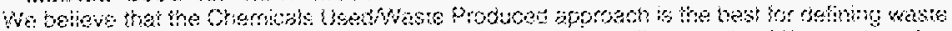

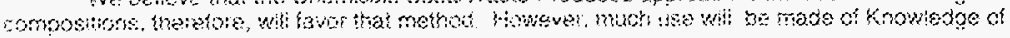

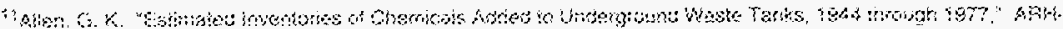

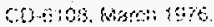




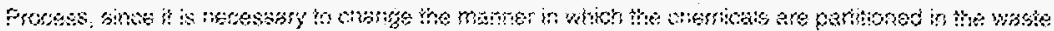

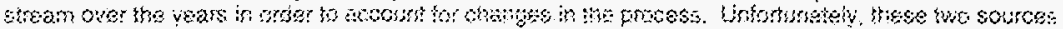

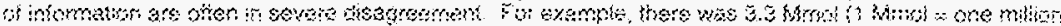

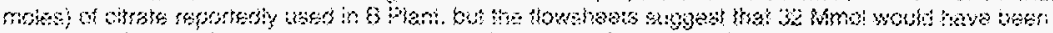

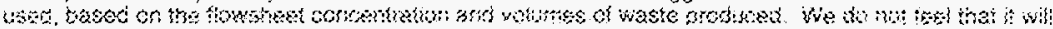

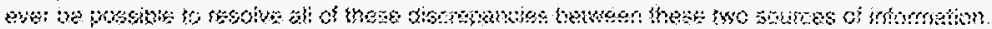

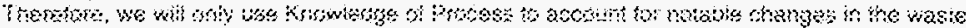

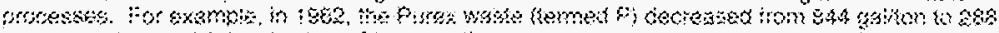

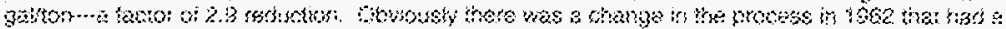

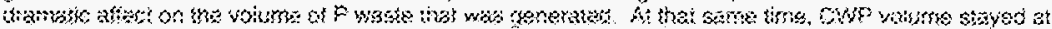

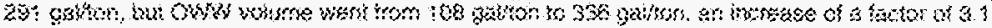

\section{Fowisw at onmpaigne}

\section{-overview}

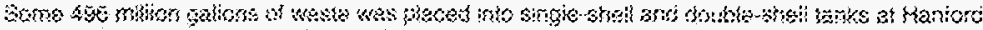

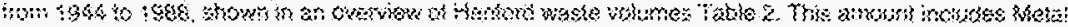

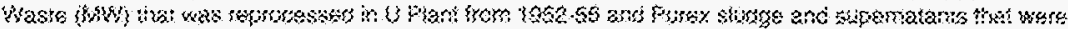

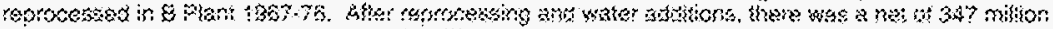

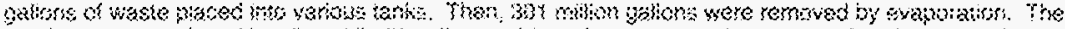

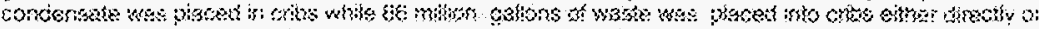

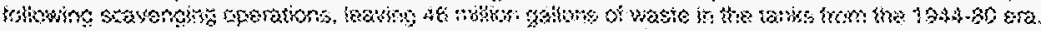

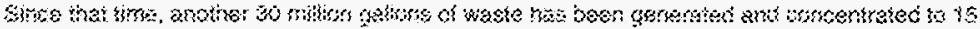

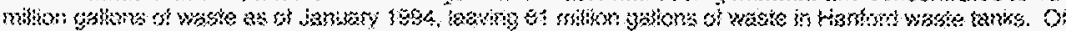

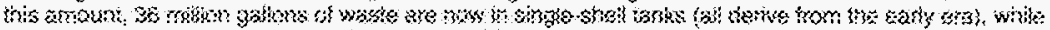

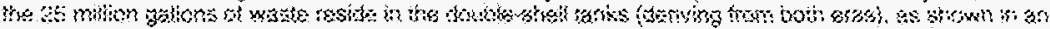

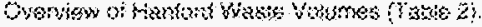

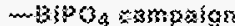

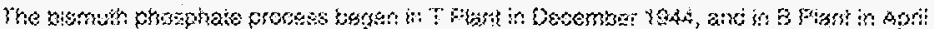

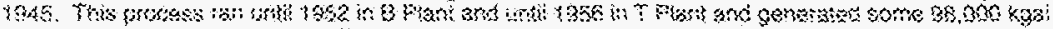

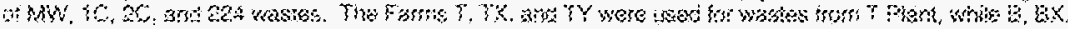

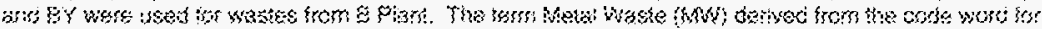

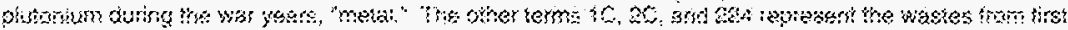

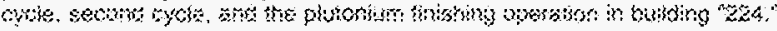

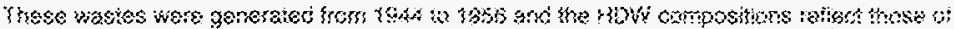

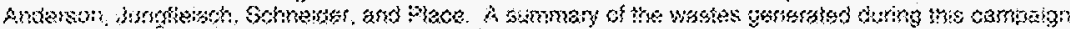

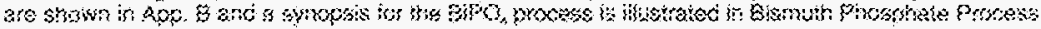
Symosis of:

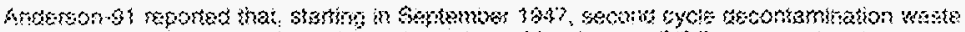

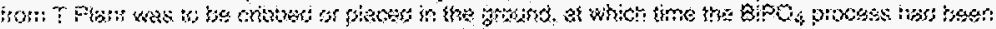

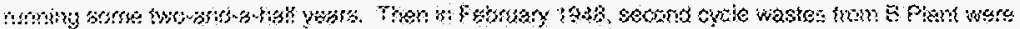

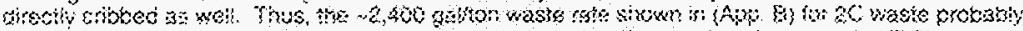

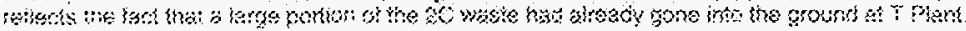

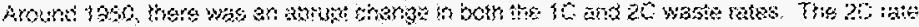

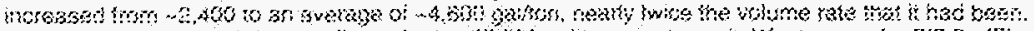

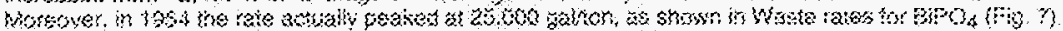

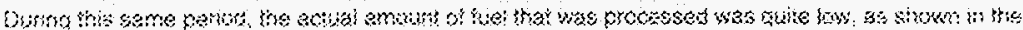

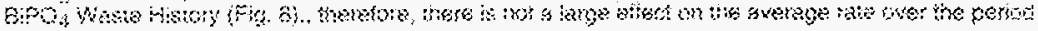

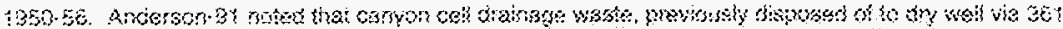

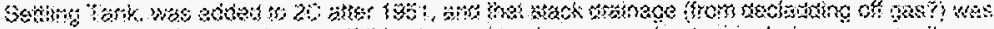

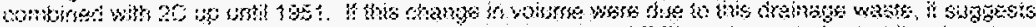

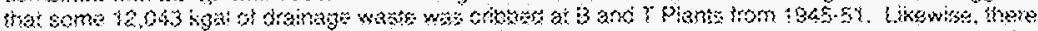

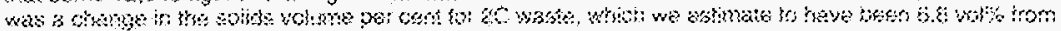

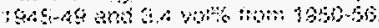




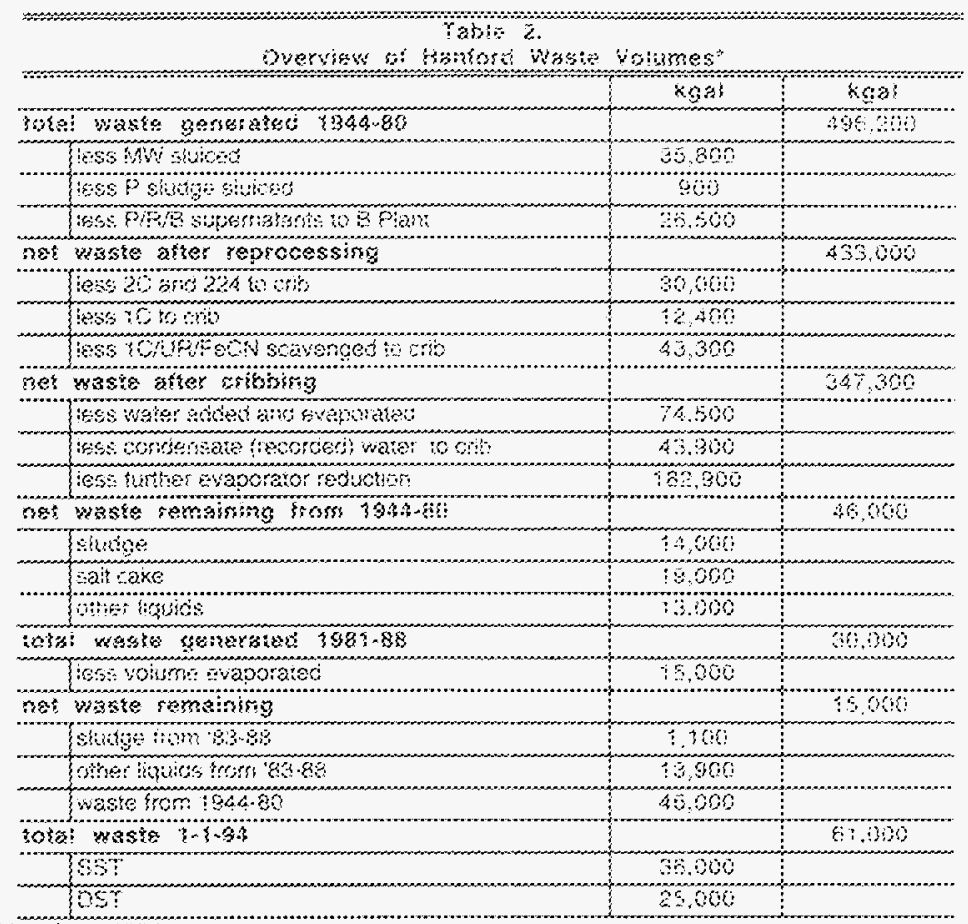

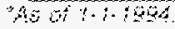

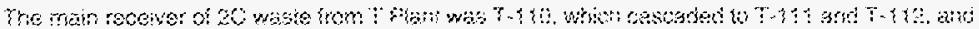
then wo vous whe from 8 ?

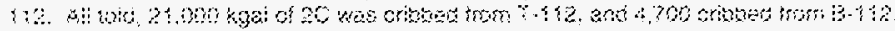

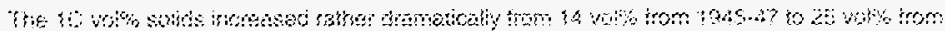

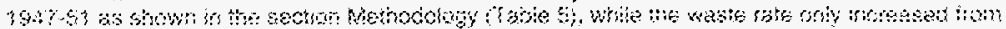

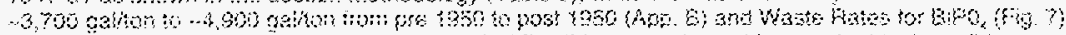

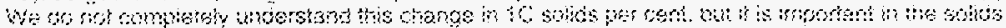

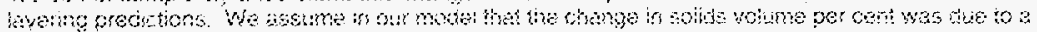

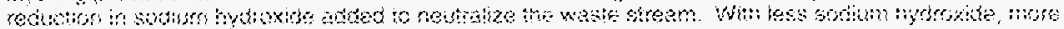

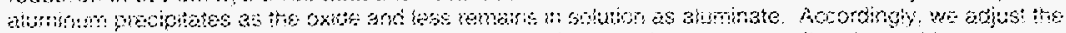

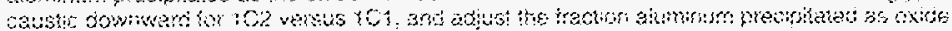

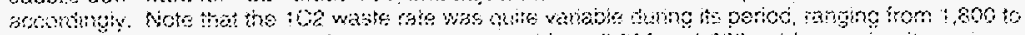

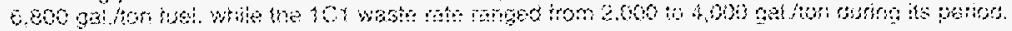

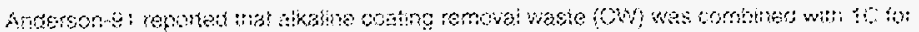

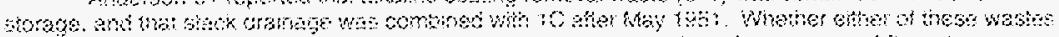

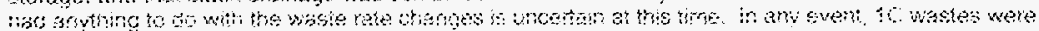

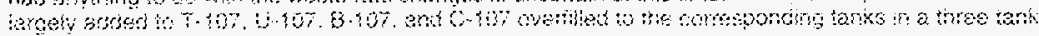
acosios. 


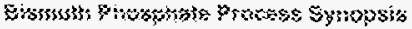

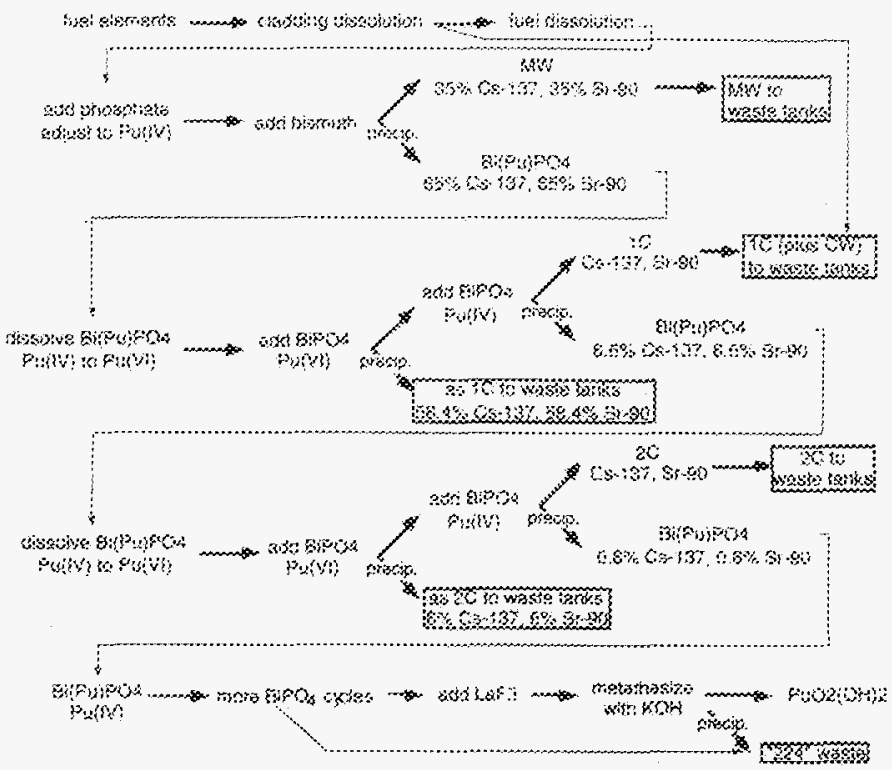

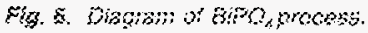

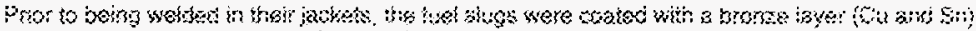

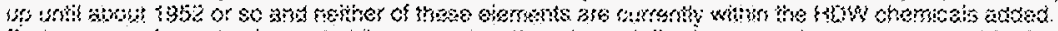

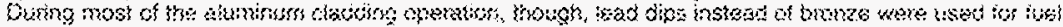

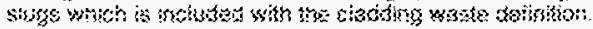

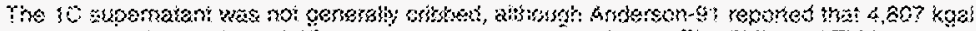

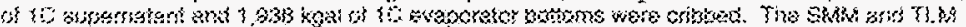

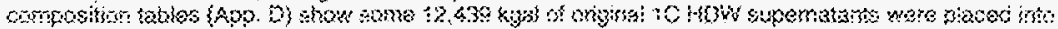

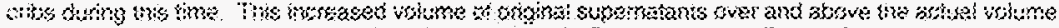

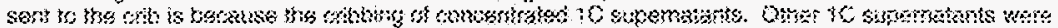

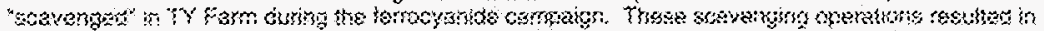

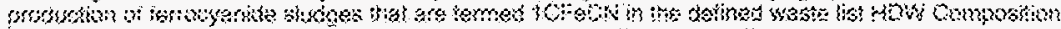

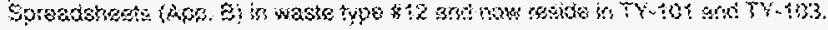

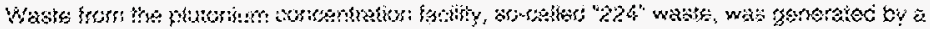

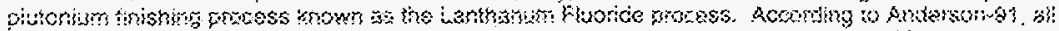

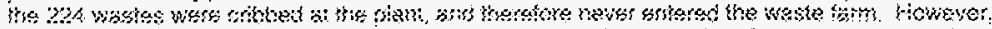

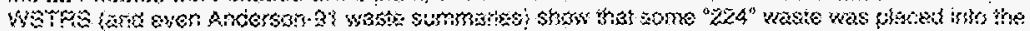

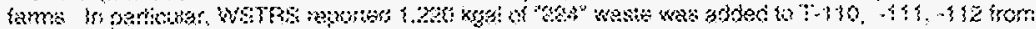

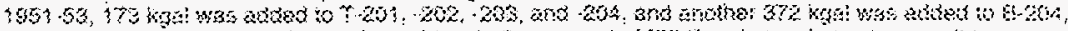

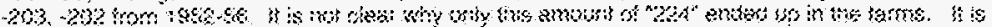

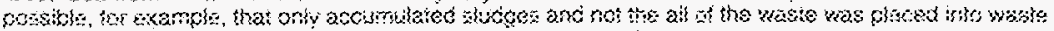

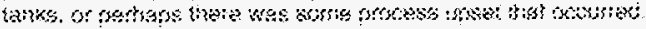




\section{Waste Ristas sor 33004}

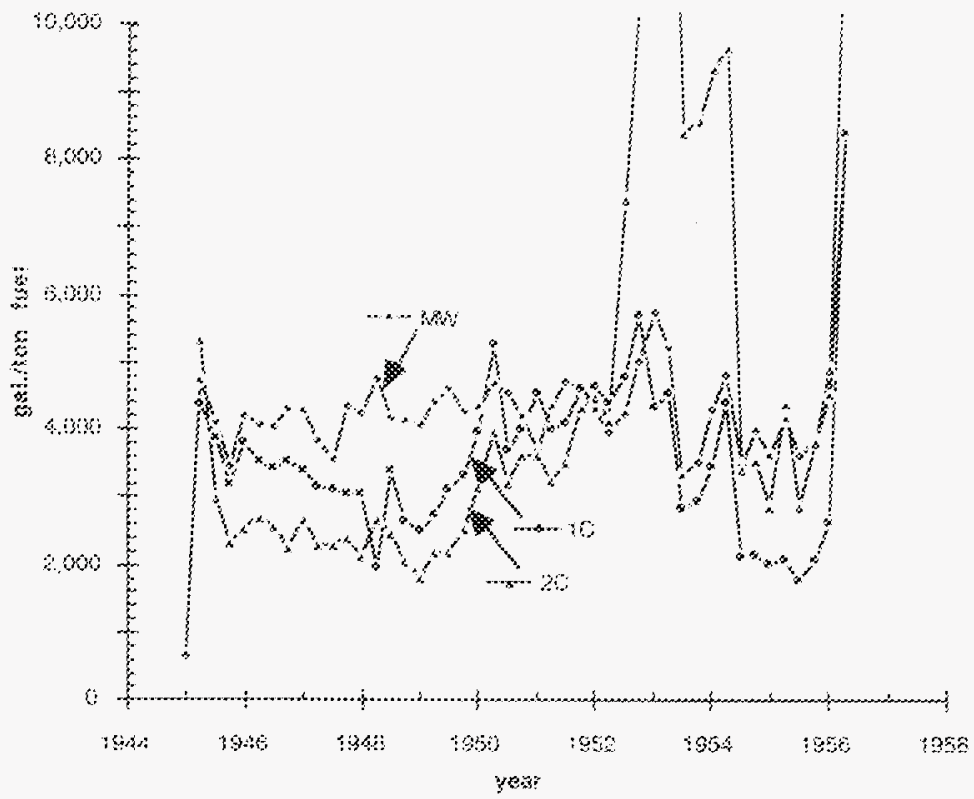

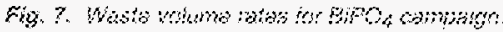

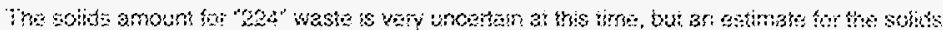

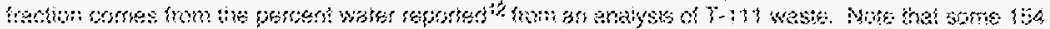

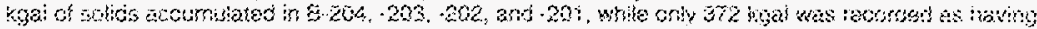

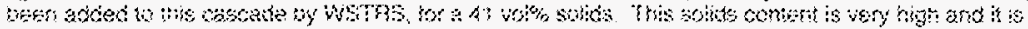

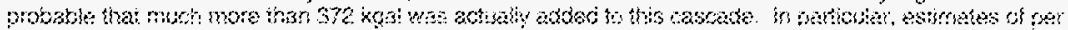

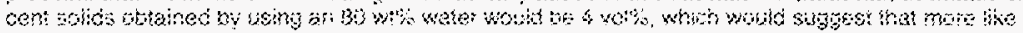
3.

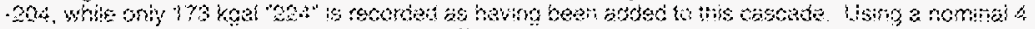

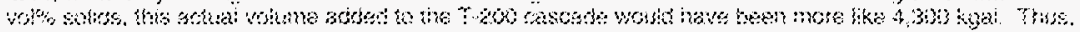

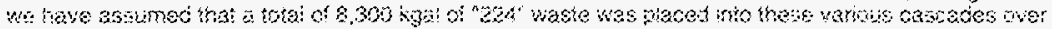
the bisting on ine rowess.

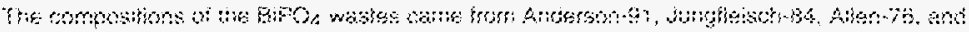

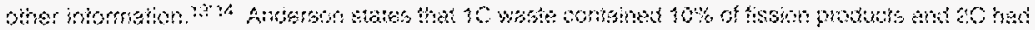

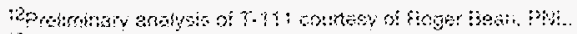

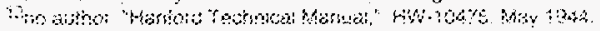




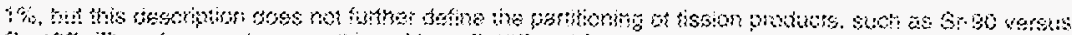

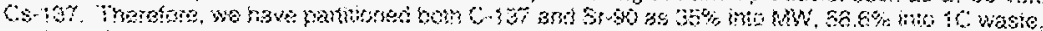

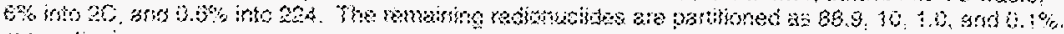
respertiveit.

\section{Bifor waste isstory}

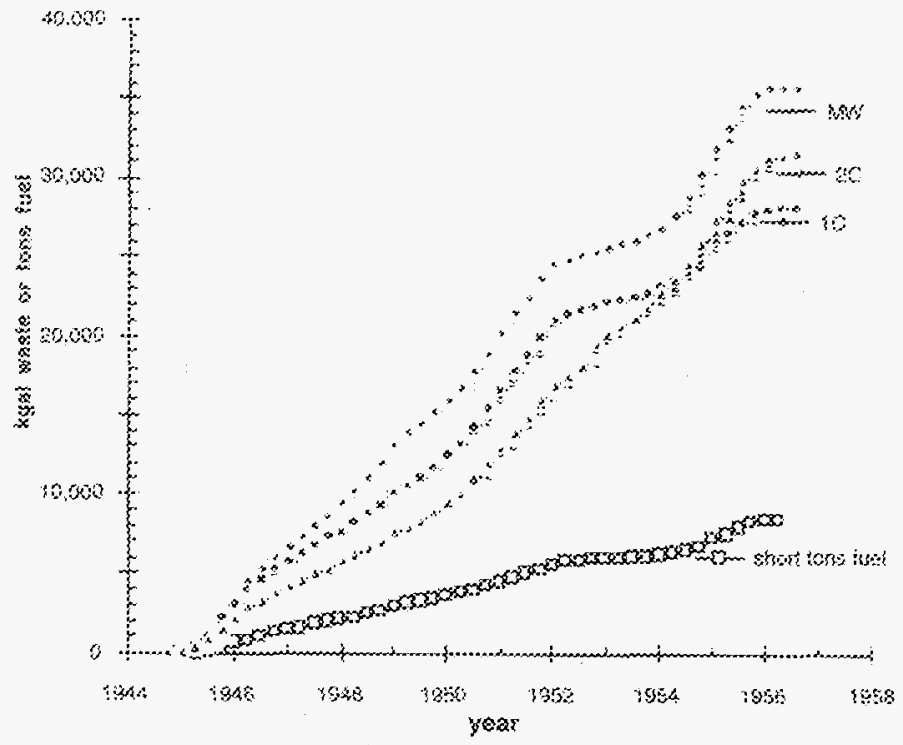

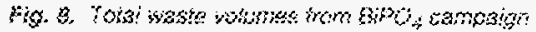

\section{--Branisum reconory}

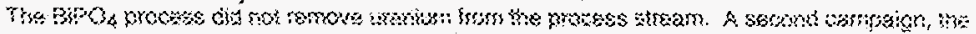

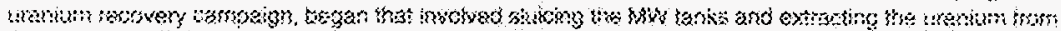

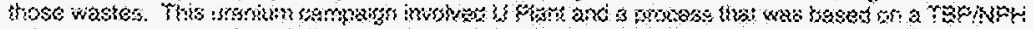

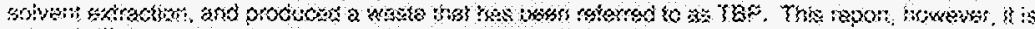

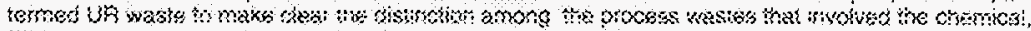

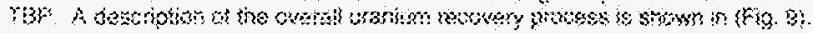

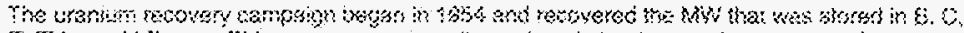

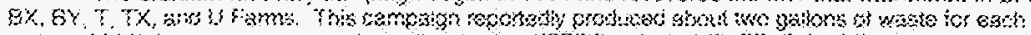

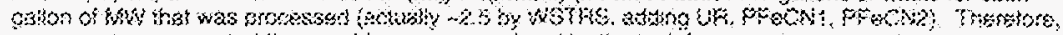

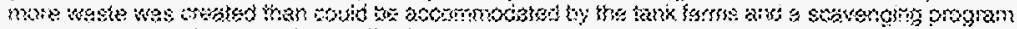

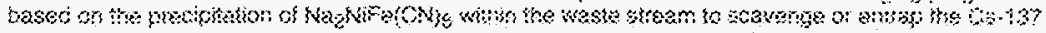

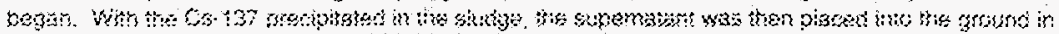

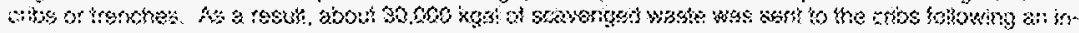

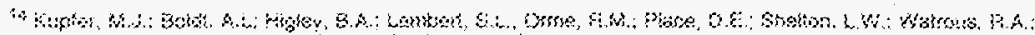

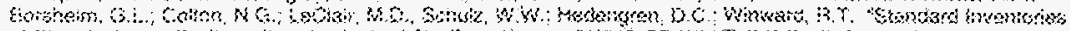

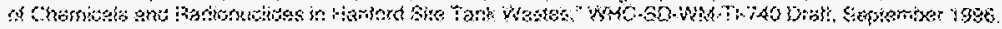




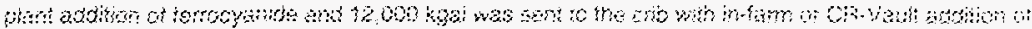

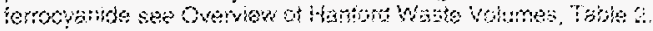

\section{Urankum facovery mocess symogsis}

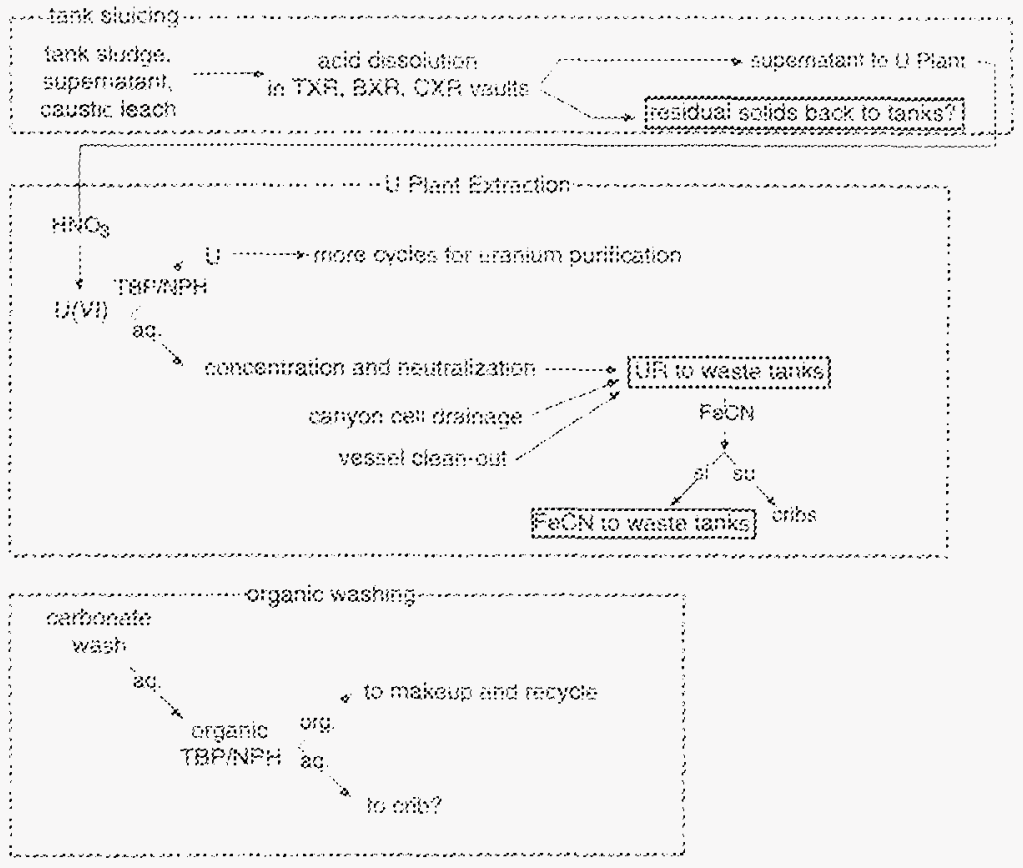

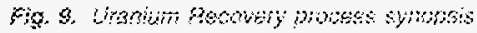

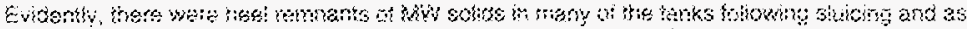

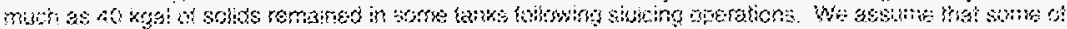

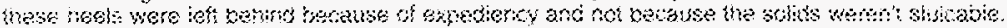

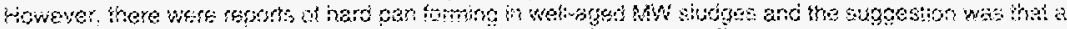

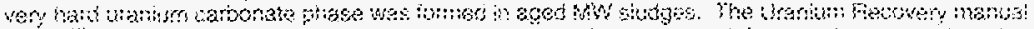

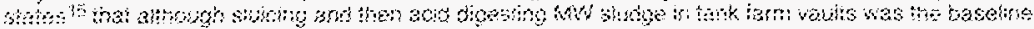

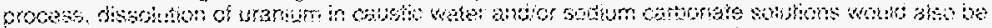

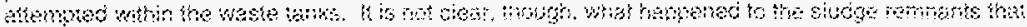

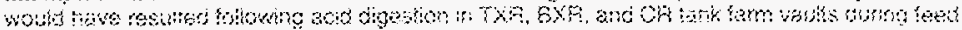

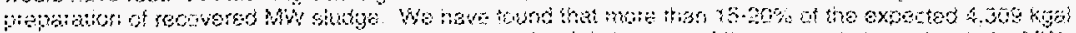

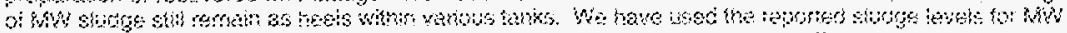

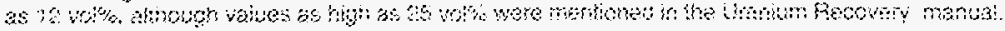

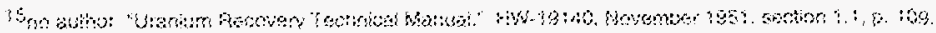




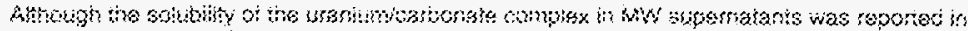

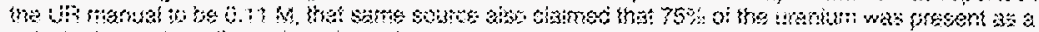

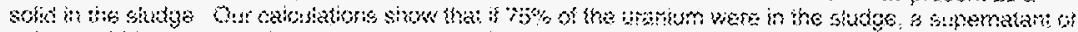

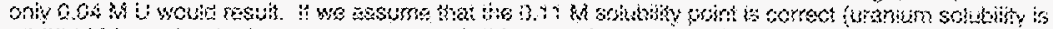

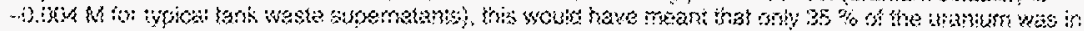

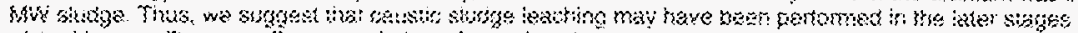

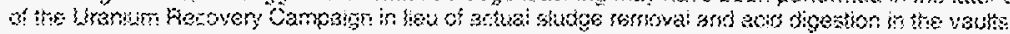

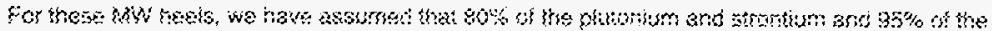

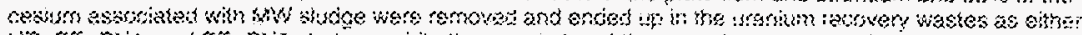

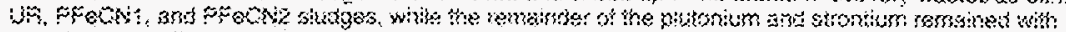

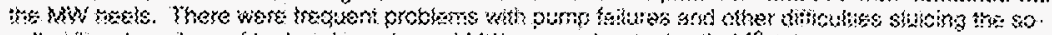
raties "row

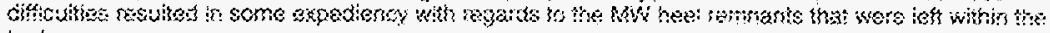
Kank:

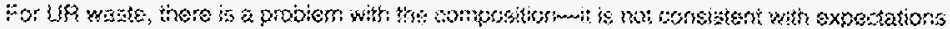

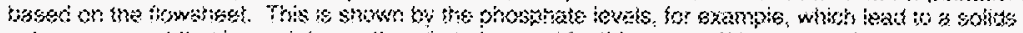

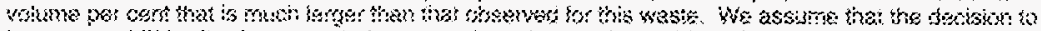

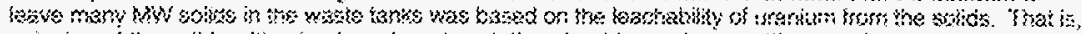

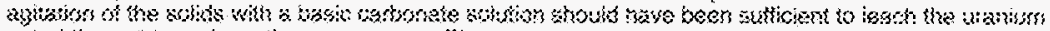

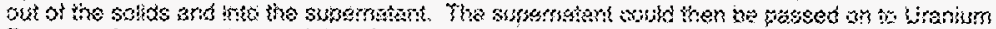

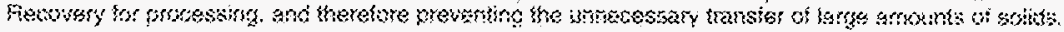

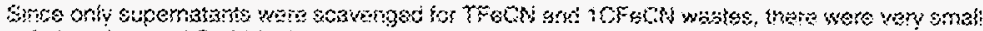

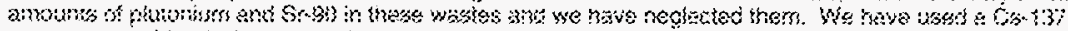

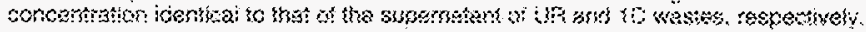

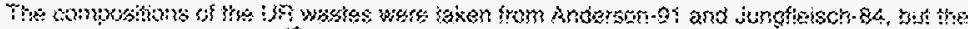

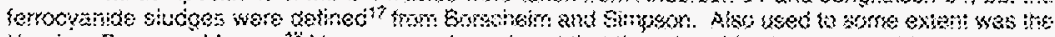

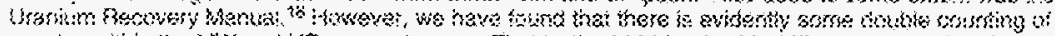

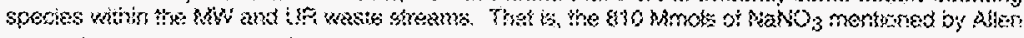

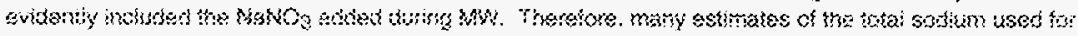

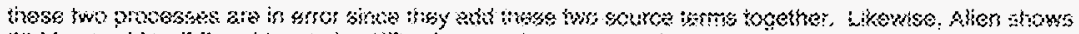

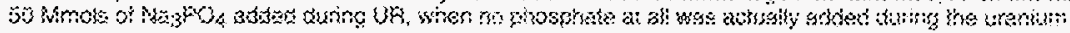

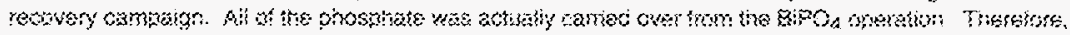

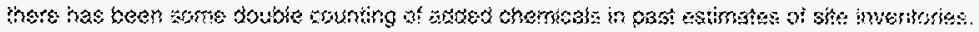

\section{…}

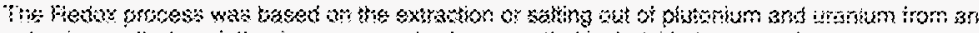

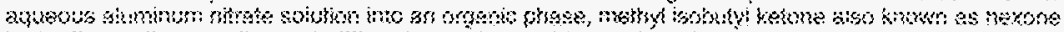

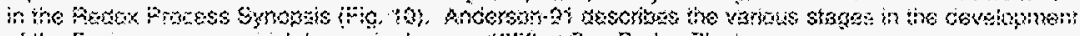

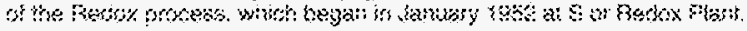

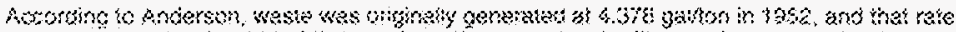

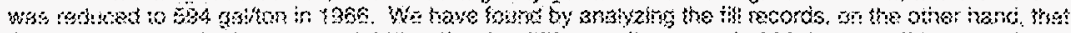

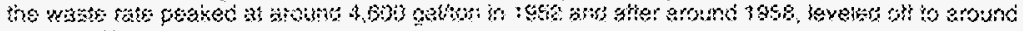

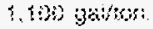

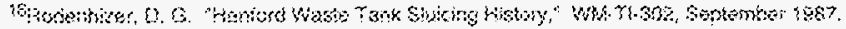

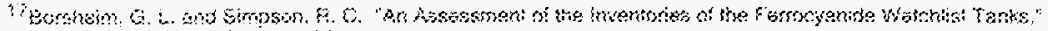

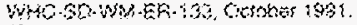

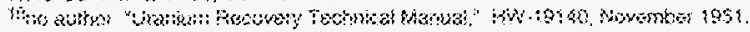


Bastor Promes syopera

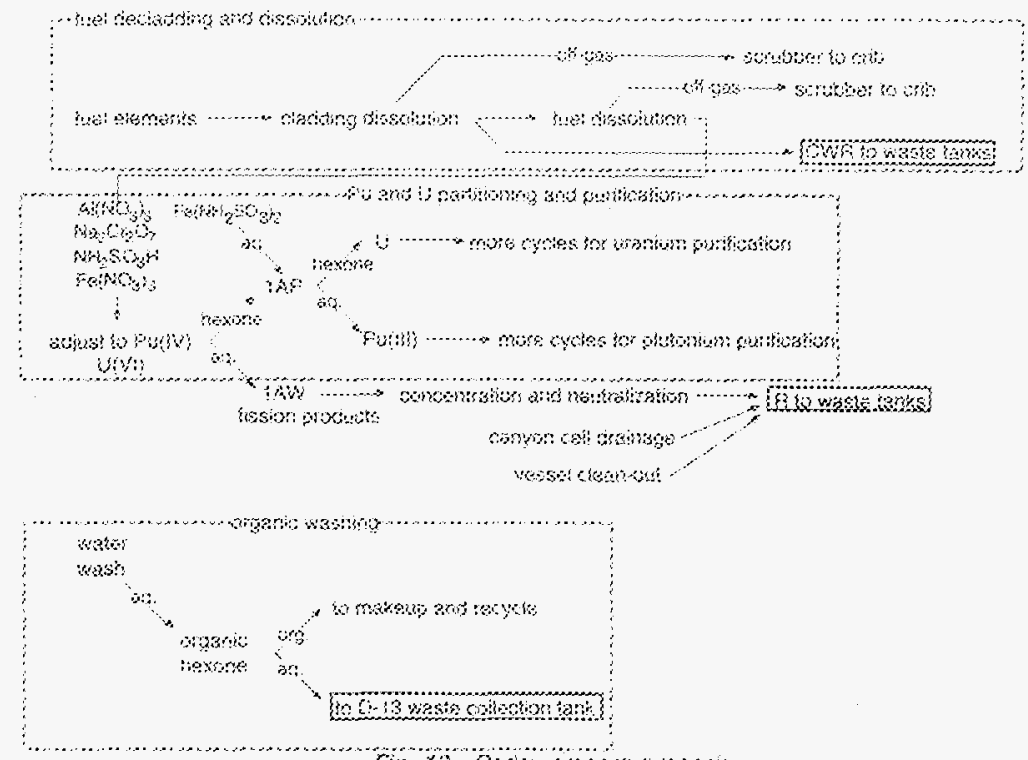

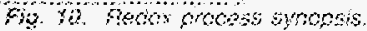

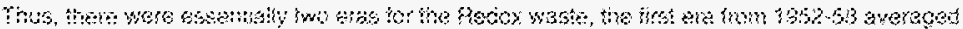

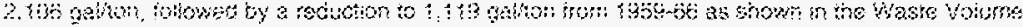

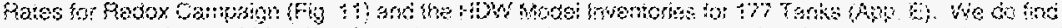

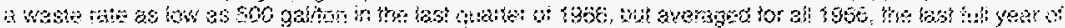

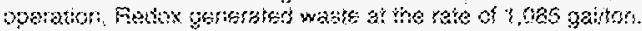

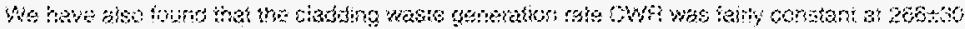

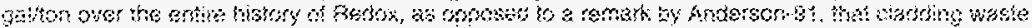

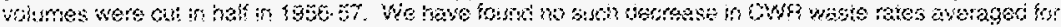

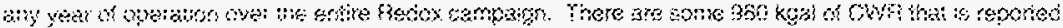

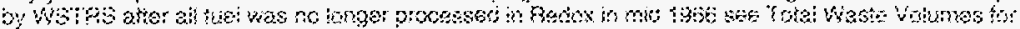

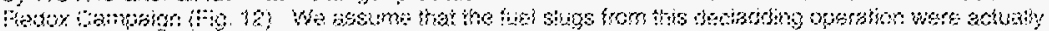

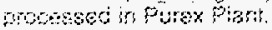

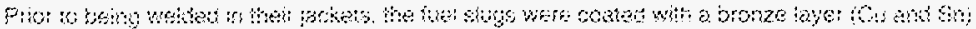

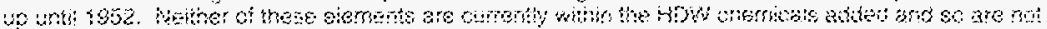

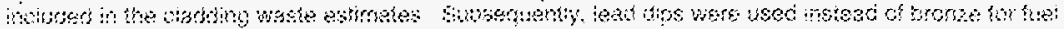

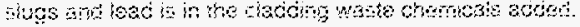

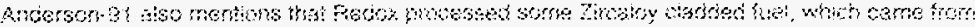

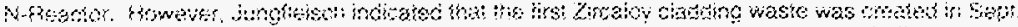

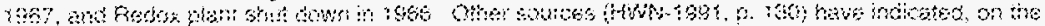

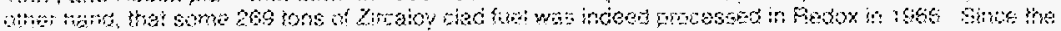

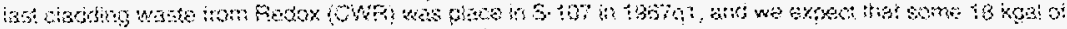

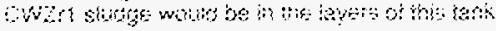




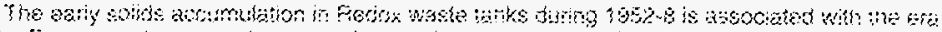

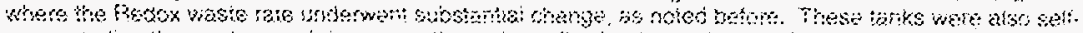

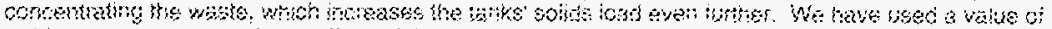

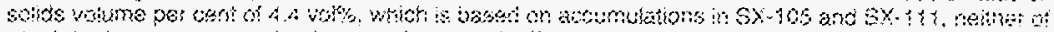

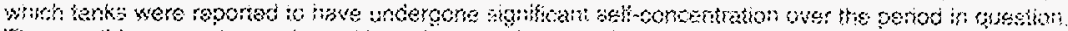

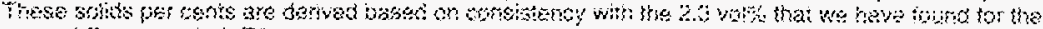

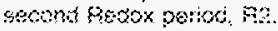

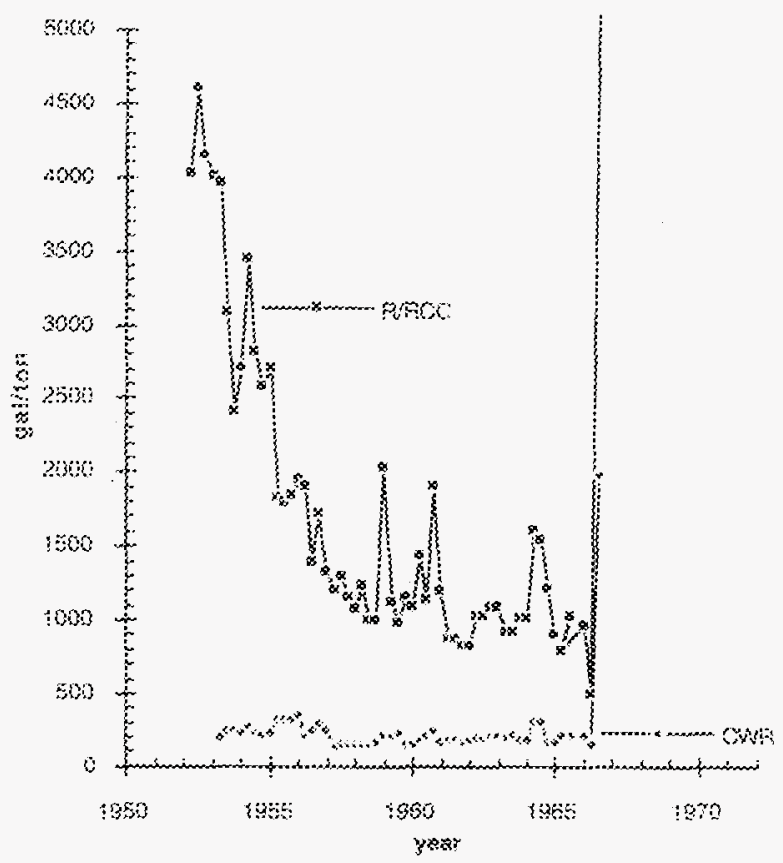

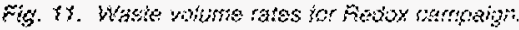

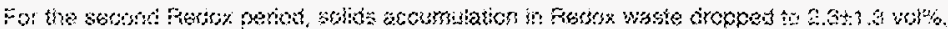

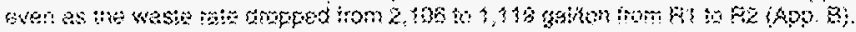

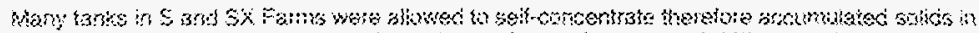

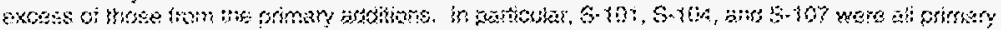

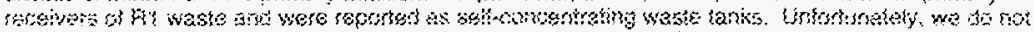

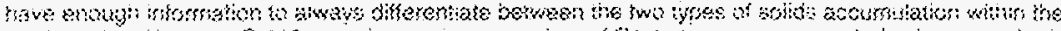

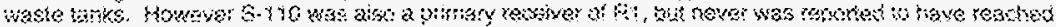

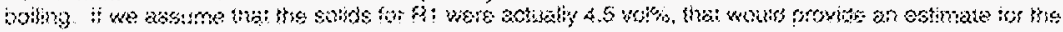




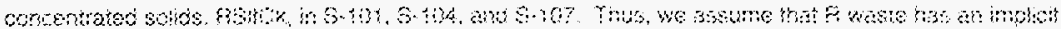

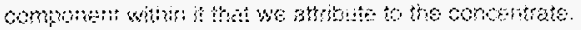

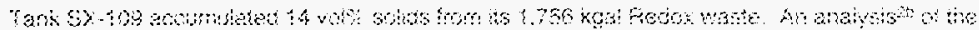

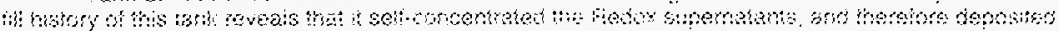

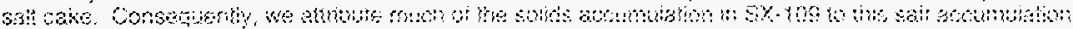

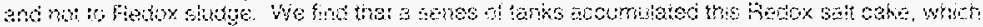

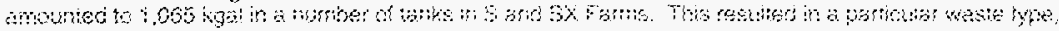

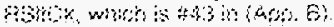

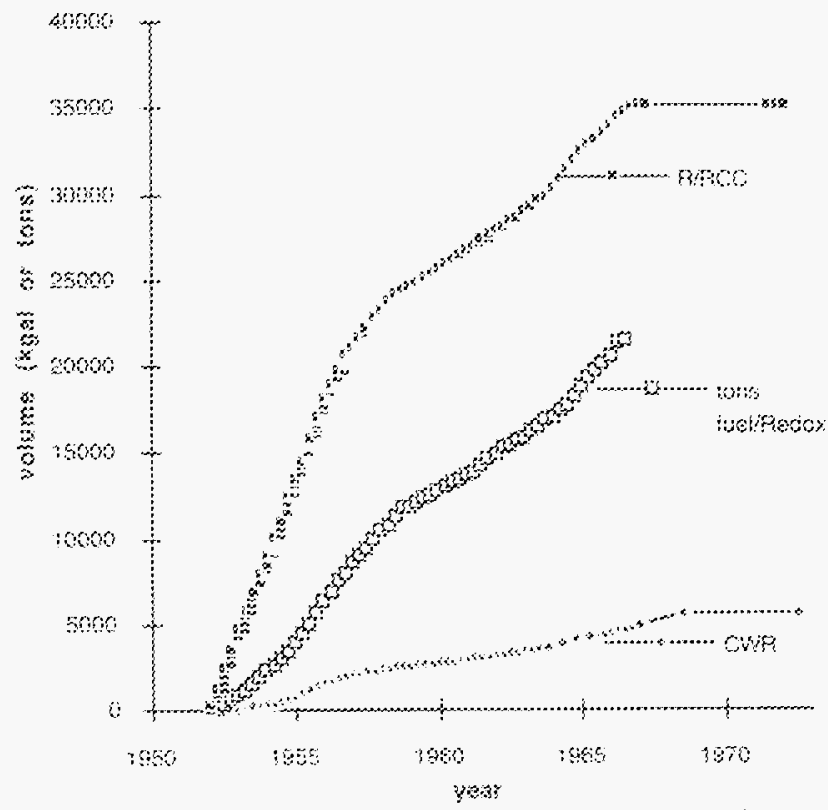

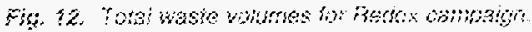

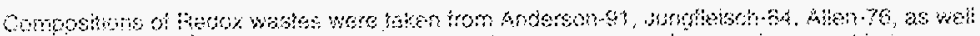

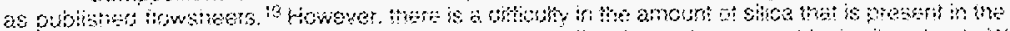

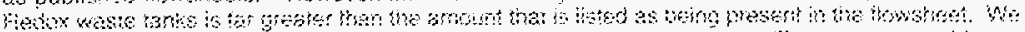

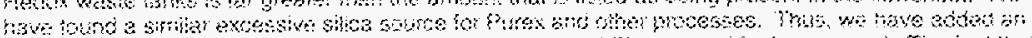

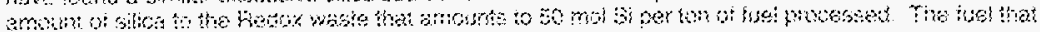

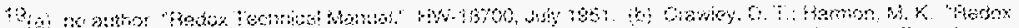

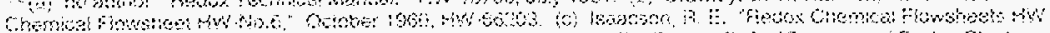

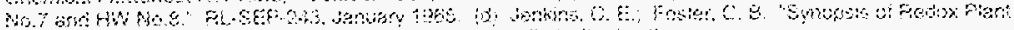

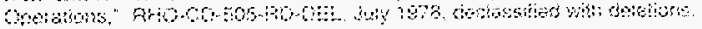




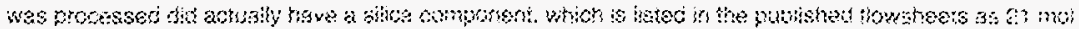

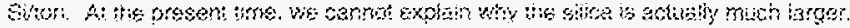

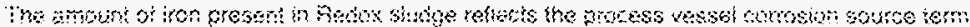

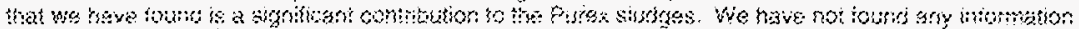

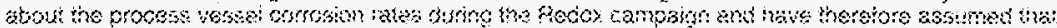
Ha ratas are idstios! wht butrec.

\section{pojex jorimaty pressess}

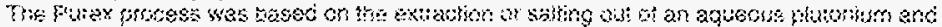

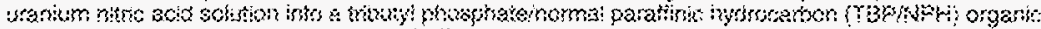

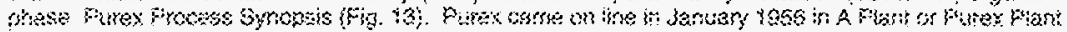

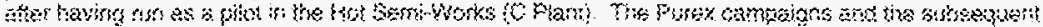

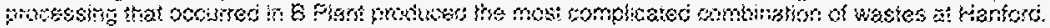

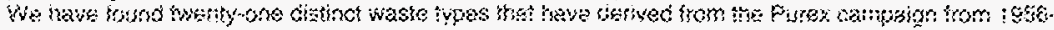
安.

\section{Purex Procoss synogsis}

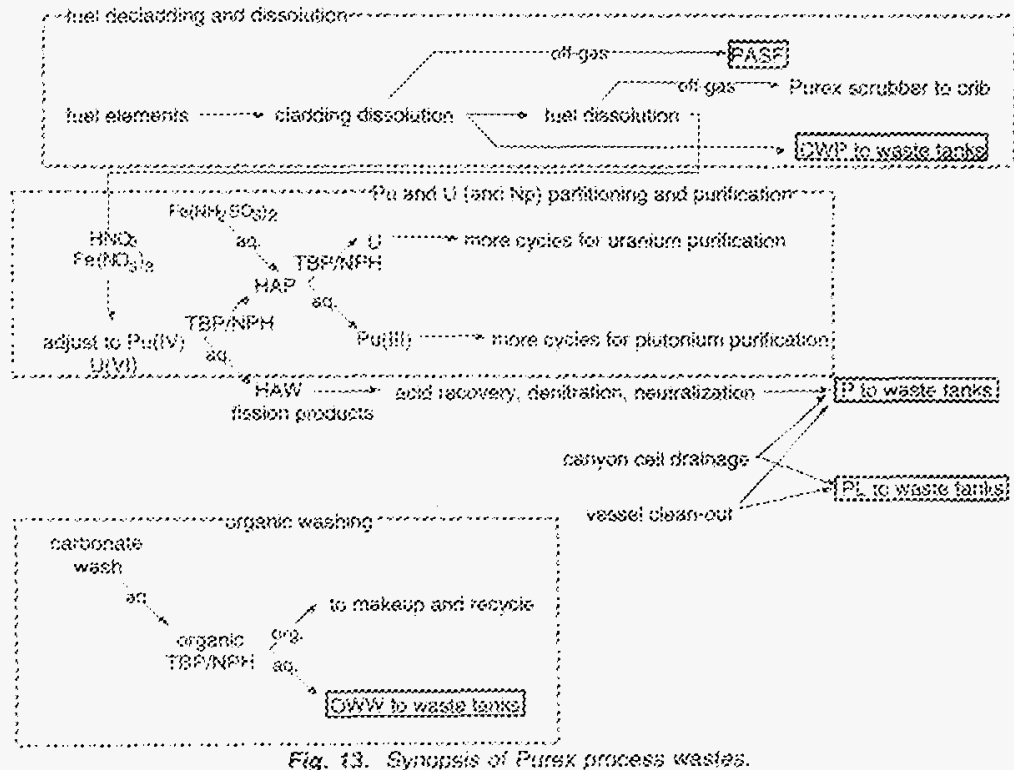

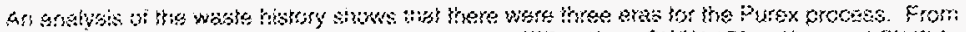

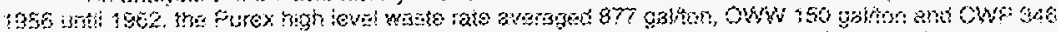

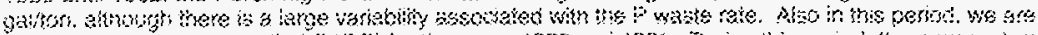

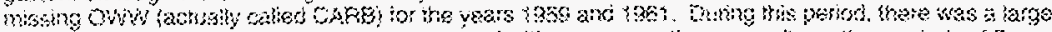

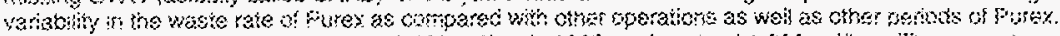

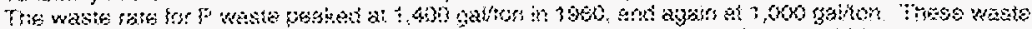

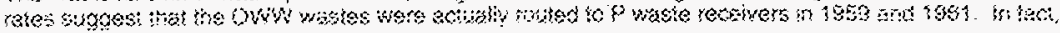




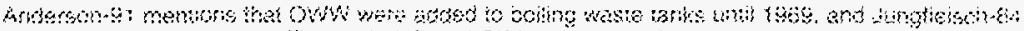

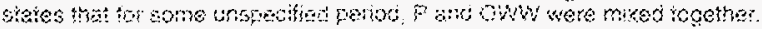

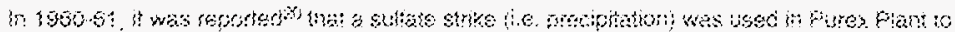

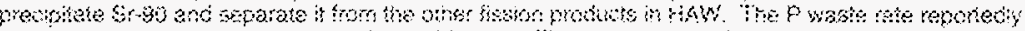

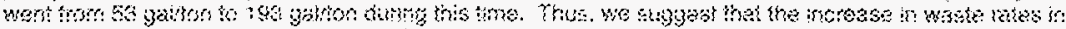

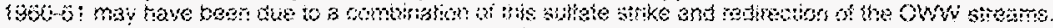

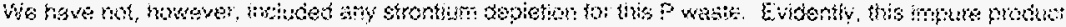

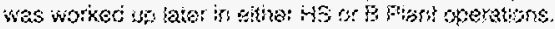

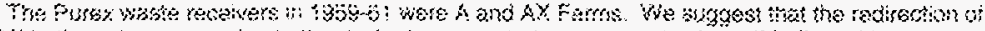

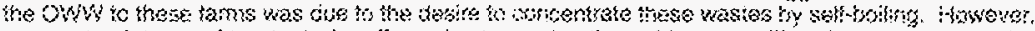

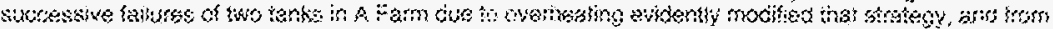

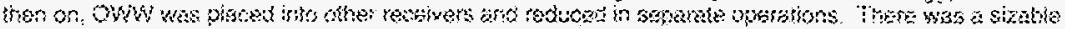

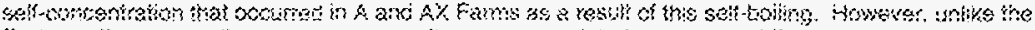

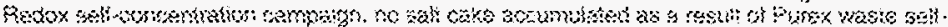

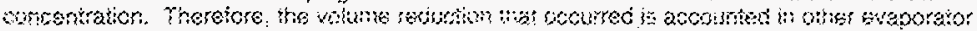
Qxingusions

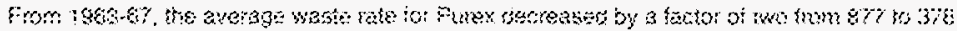

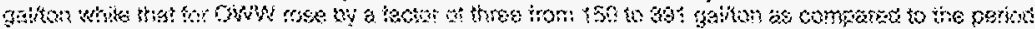

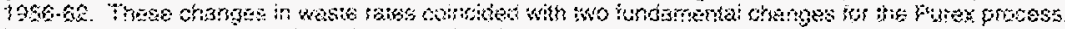

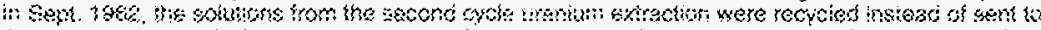

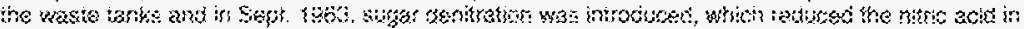

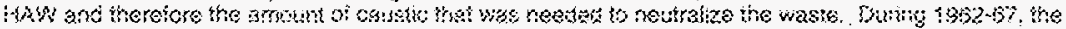

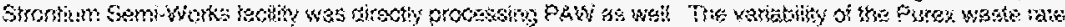

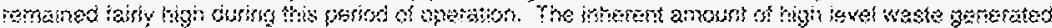

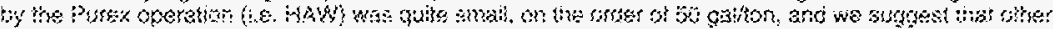

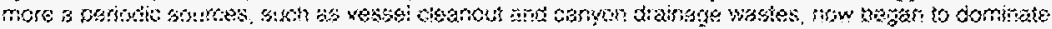
cyot the priman procsss waste.

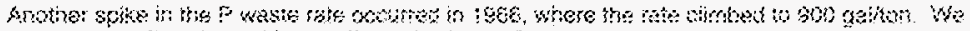

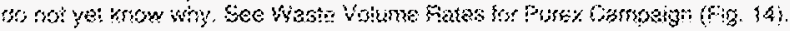

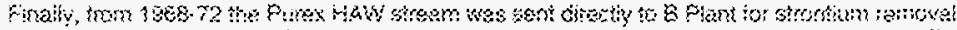

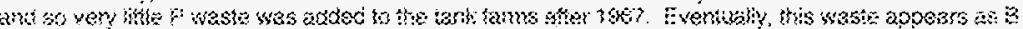

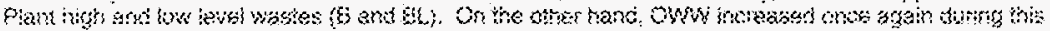
vatrer era io 575 35iton.

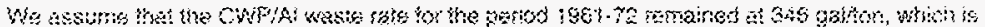

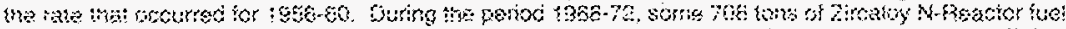

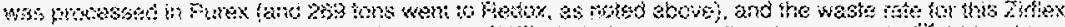

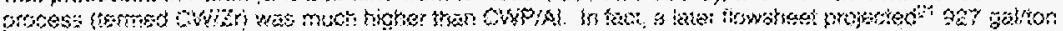

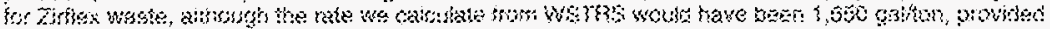

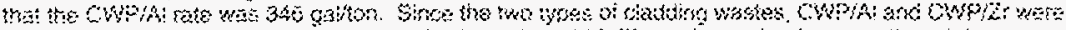

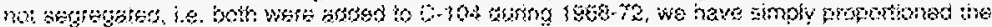

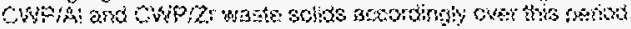

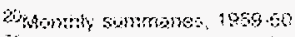

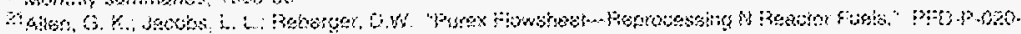
volas. 5est $198 \mathrm{~s}$
} 

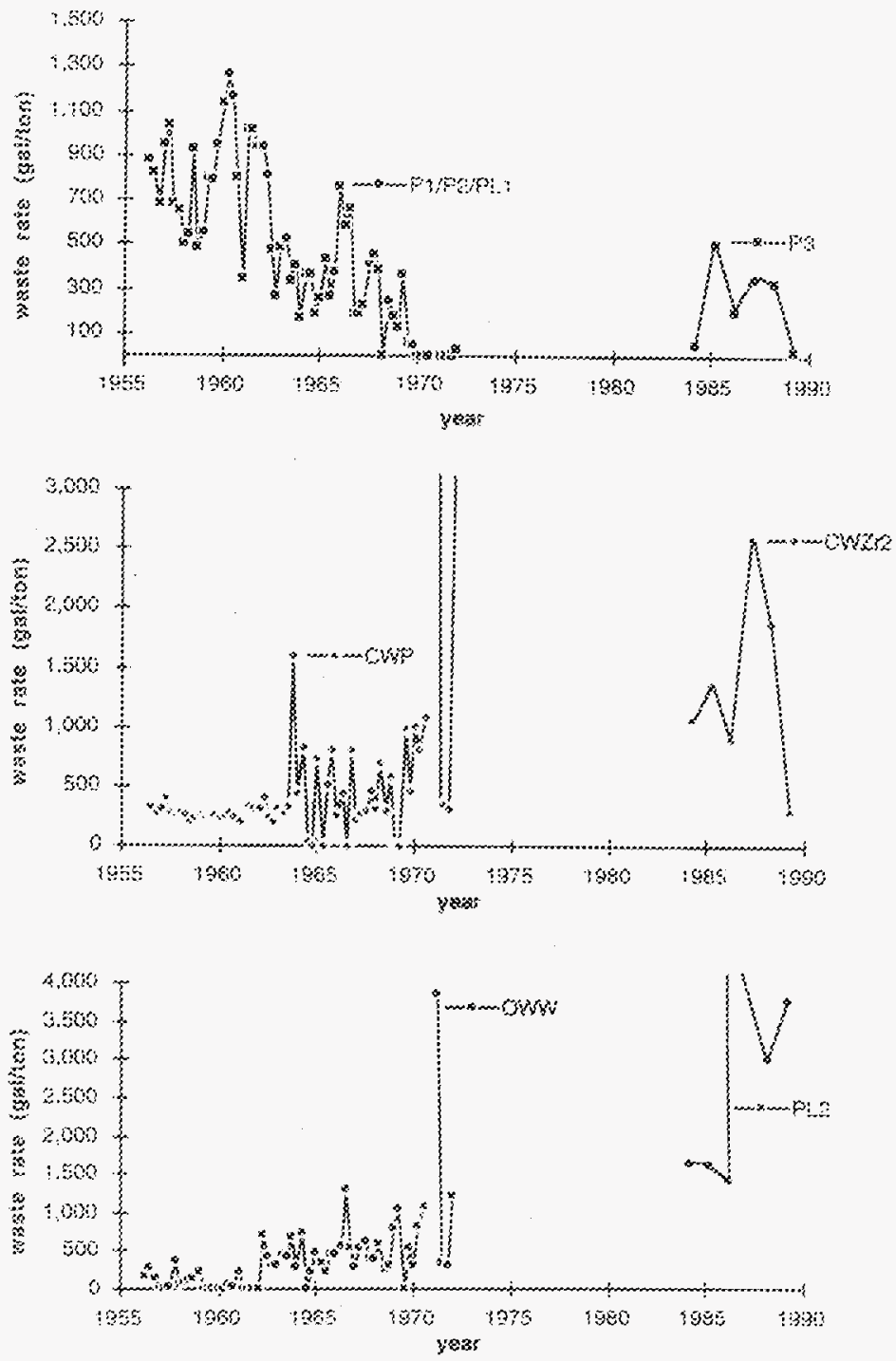

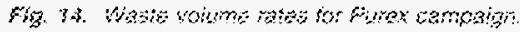




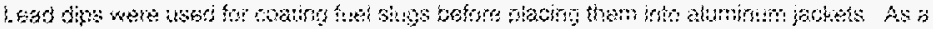

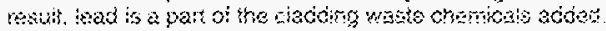

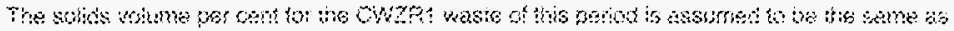

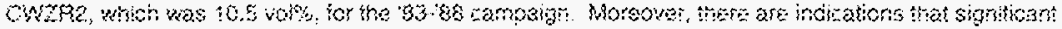

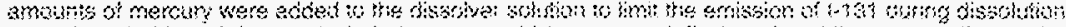

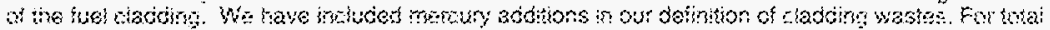

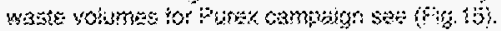

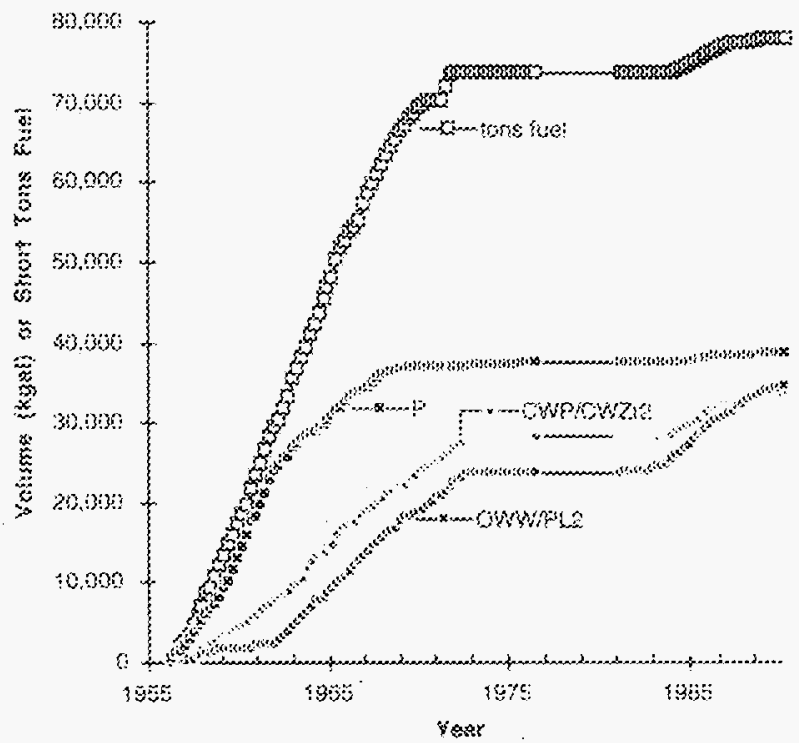

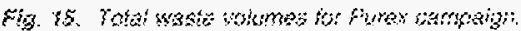

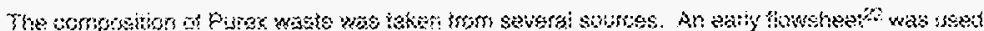

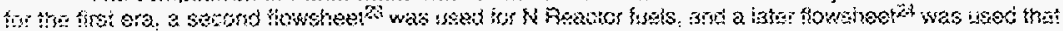

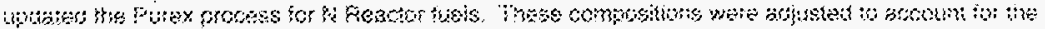

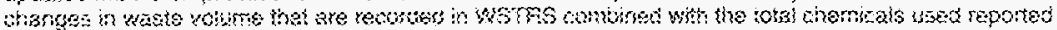

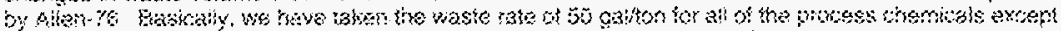

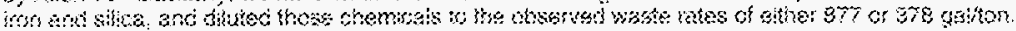

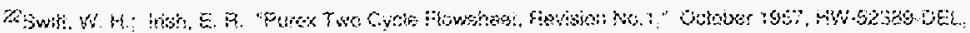
betististod wet chetions

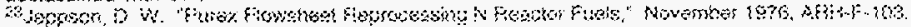

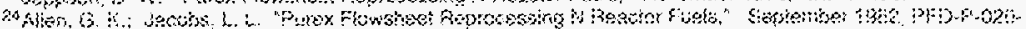
âs? 


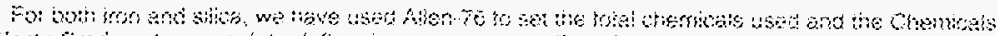

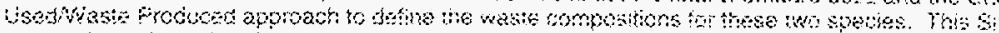

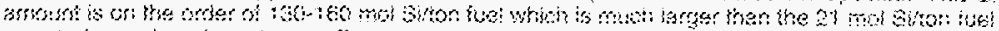

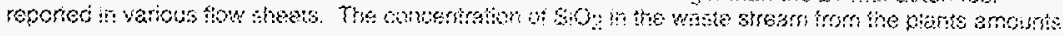

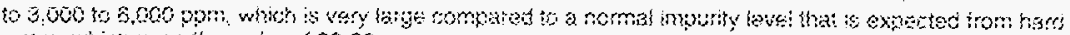
watet, which ss on the order of an-3r ppin

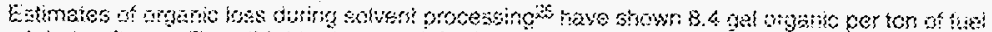

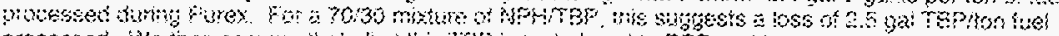

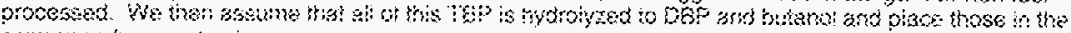
corresponsirg watio streams.

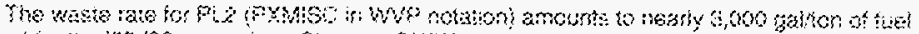

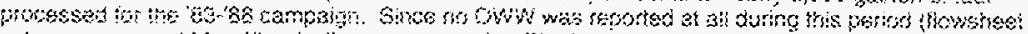

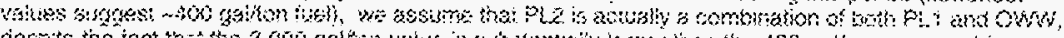

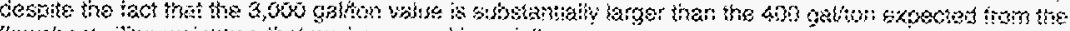
thwshed The weightng that we have ued is as bllows.

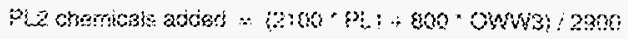

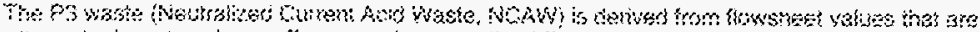

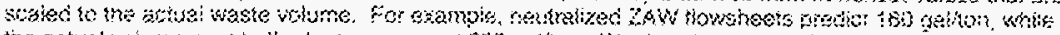

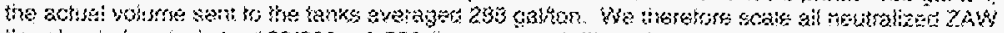

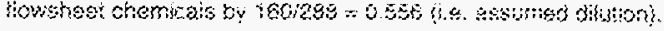

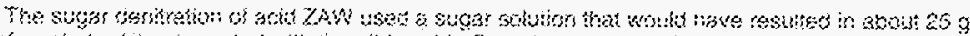

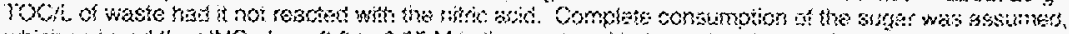

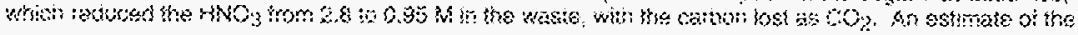

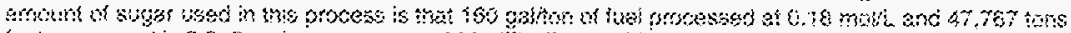

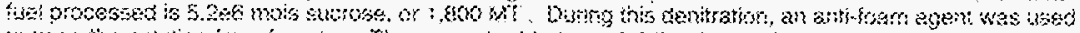

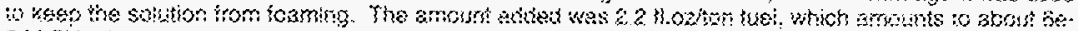

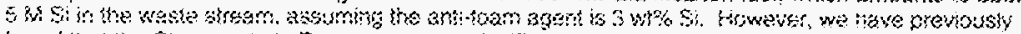

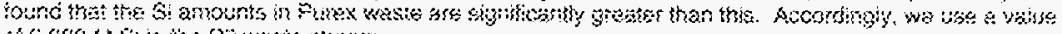

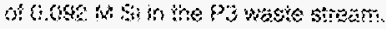

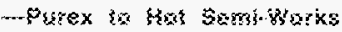

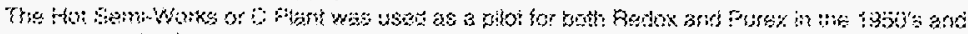

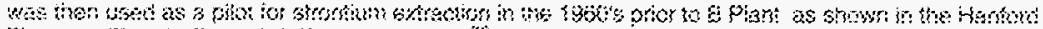

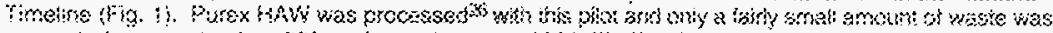

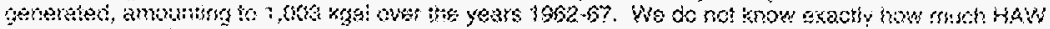

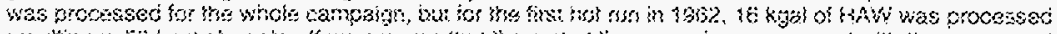

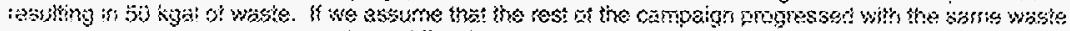

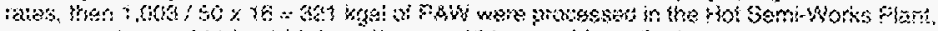

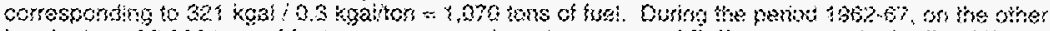

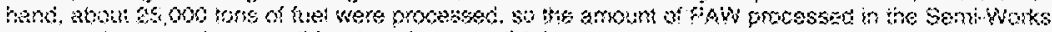

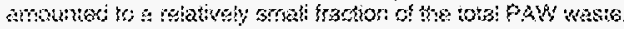

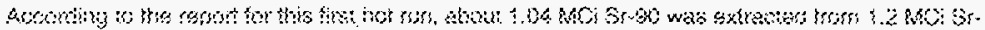

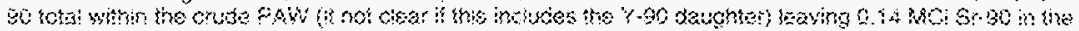

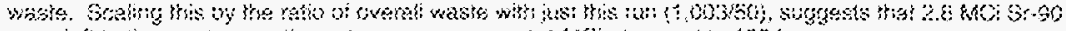

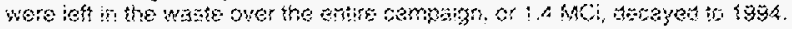

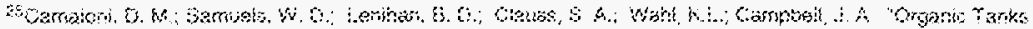

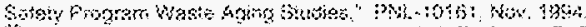

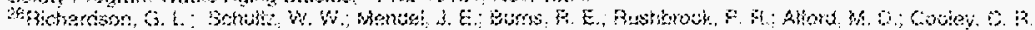

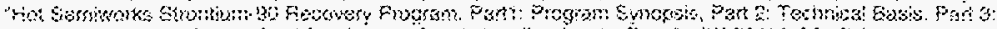

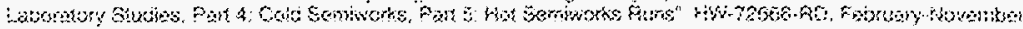
30
} 


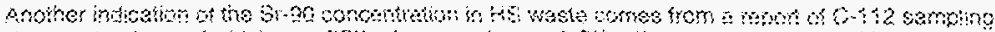

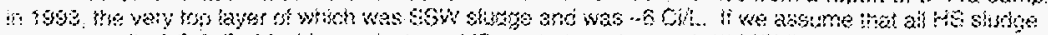

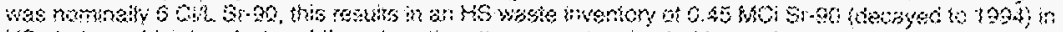

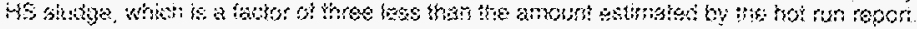

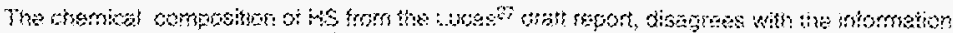

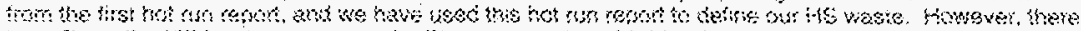

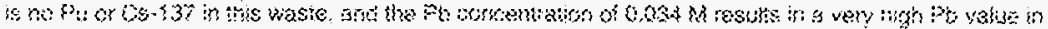

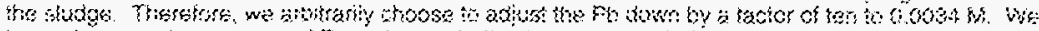

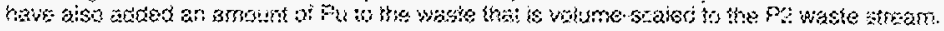

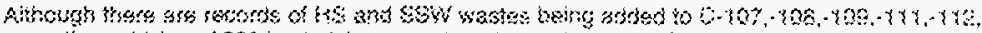

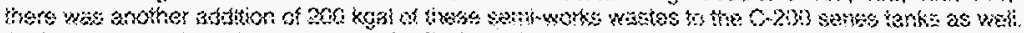

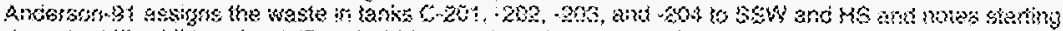

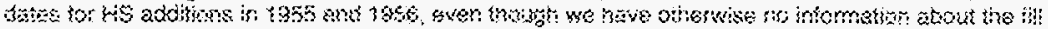

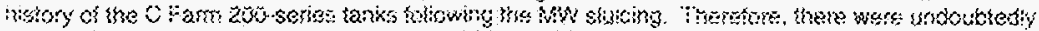

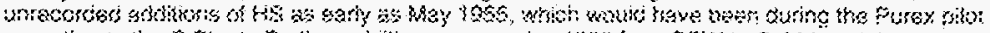

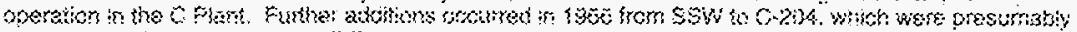

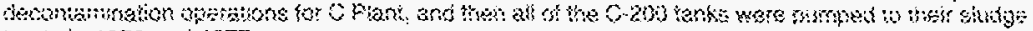
nots in $\{870$ sho $197 \%$

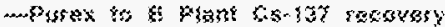

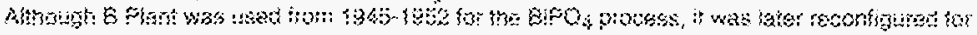

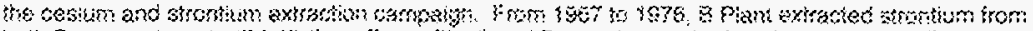

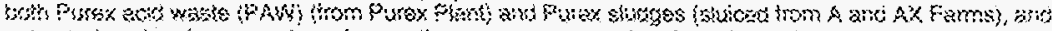

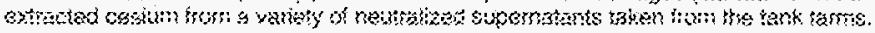

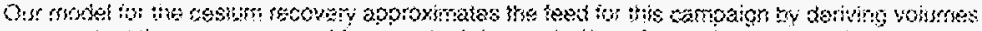

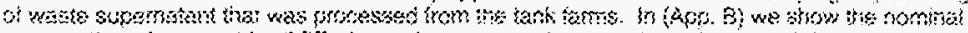

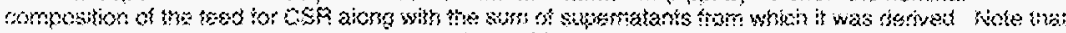

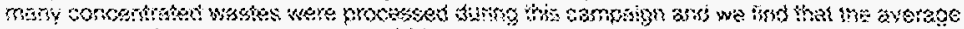

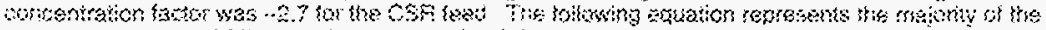

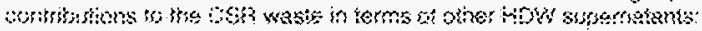

$$
\begin{aligned}
& \text { BAR in }
\end{aligned}
$$

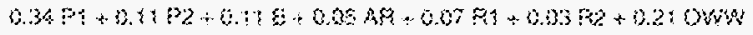

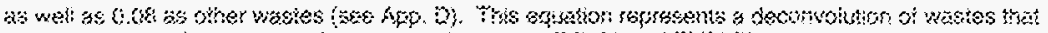

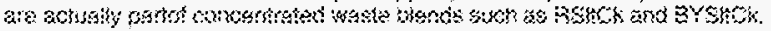

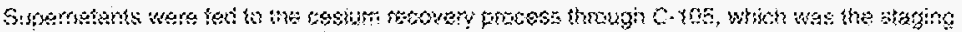

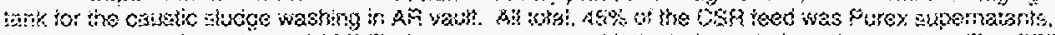

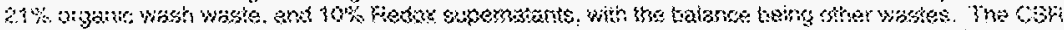

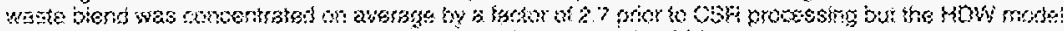

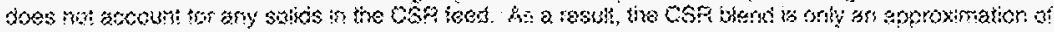

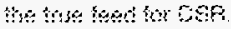

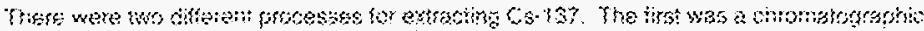

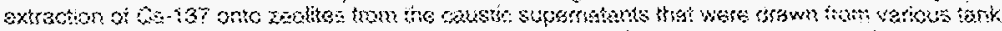

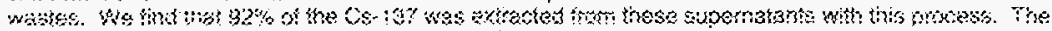

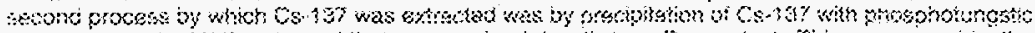

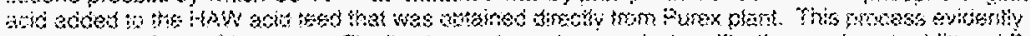

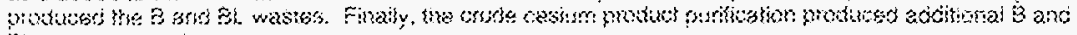
3. wastess as wet.

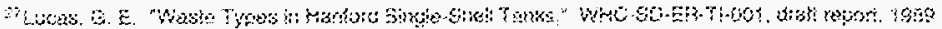




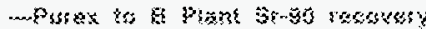

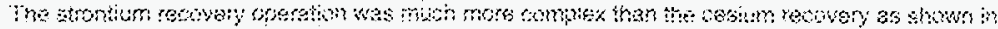

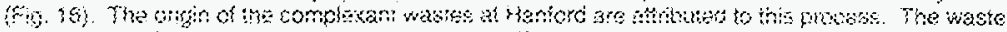

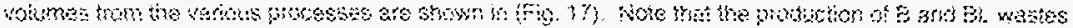

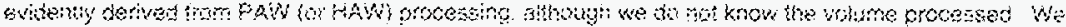

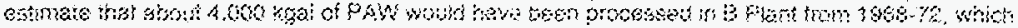

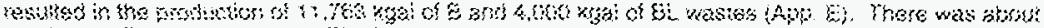

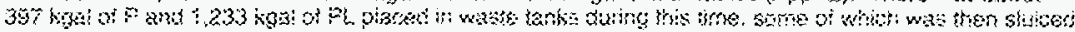

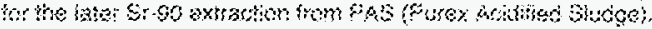

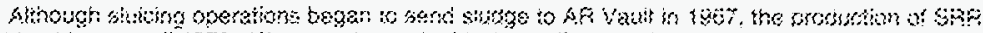

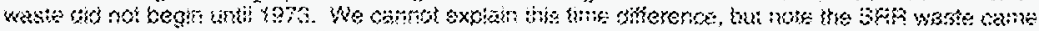

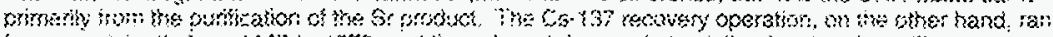

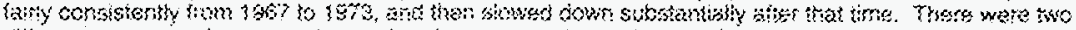

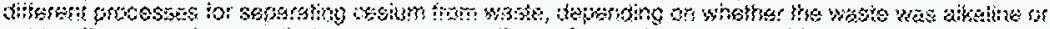

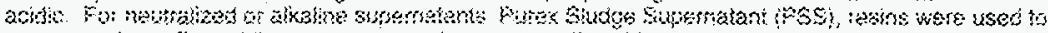

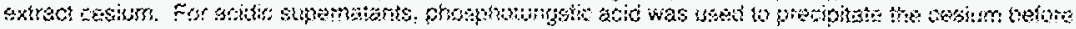
nathesibion.

$$
\begin{aligned}
& 8 \text { wasta trom pap }
\end{aligned}
$$

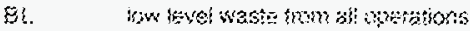

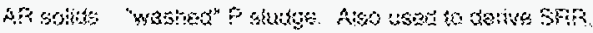

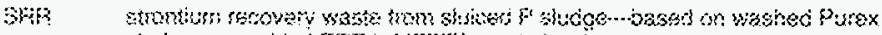

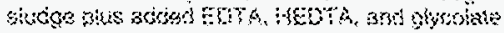

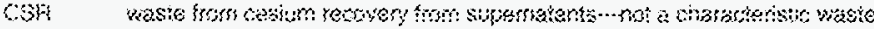

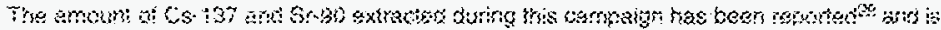

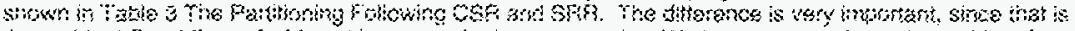

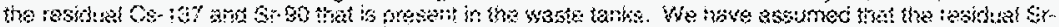

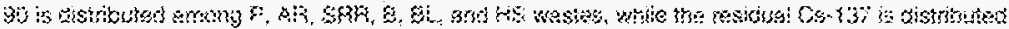
arseng $C S h$ and $a$ wasters.

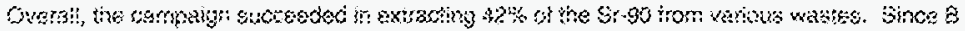

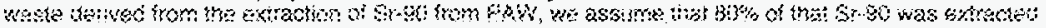

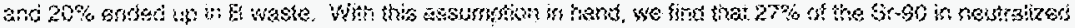

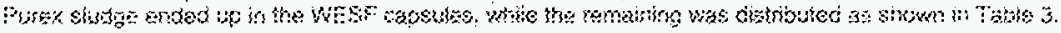

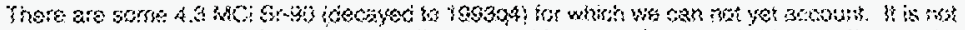

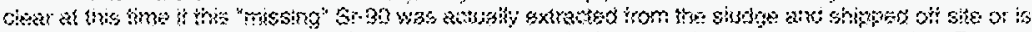

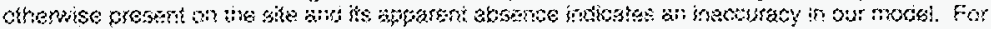

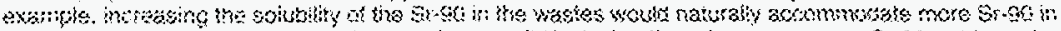

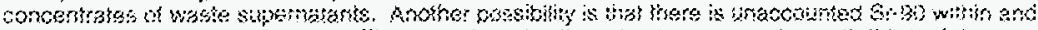

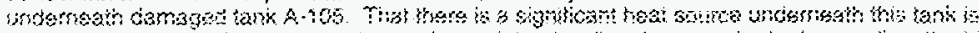

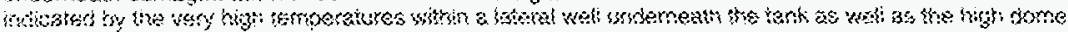

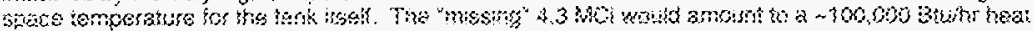

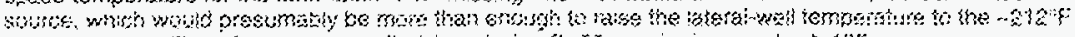

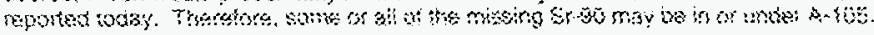

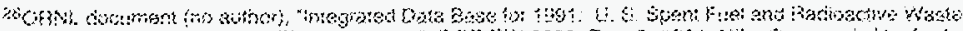

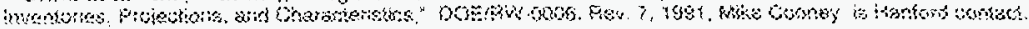




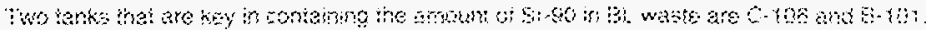

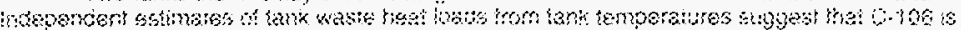

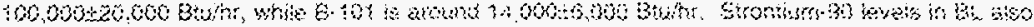

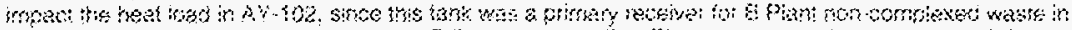

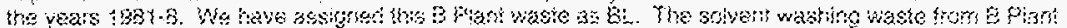

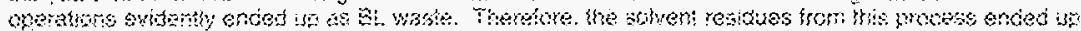
in : thase lariks:

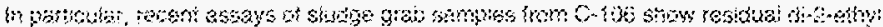

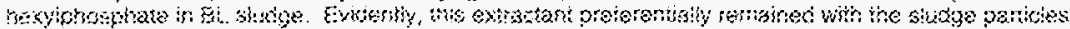

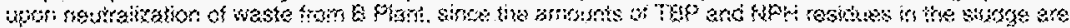

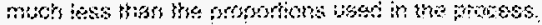

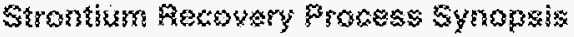
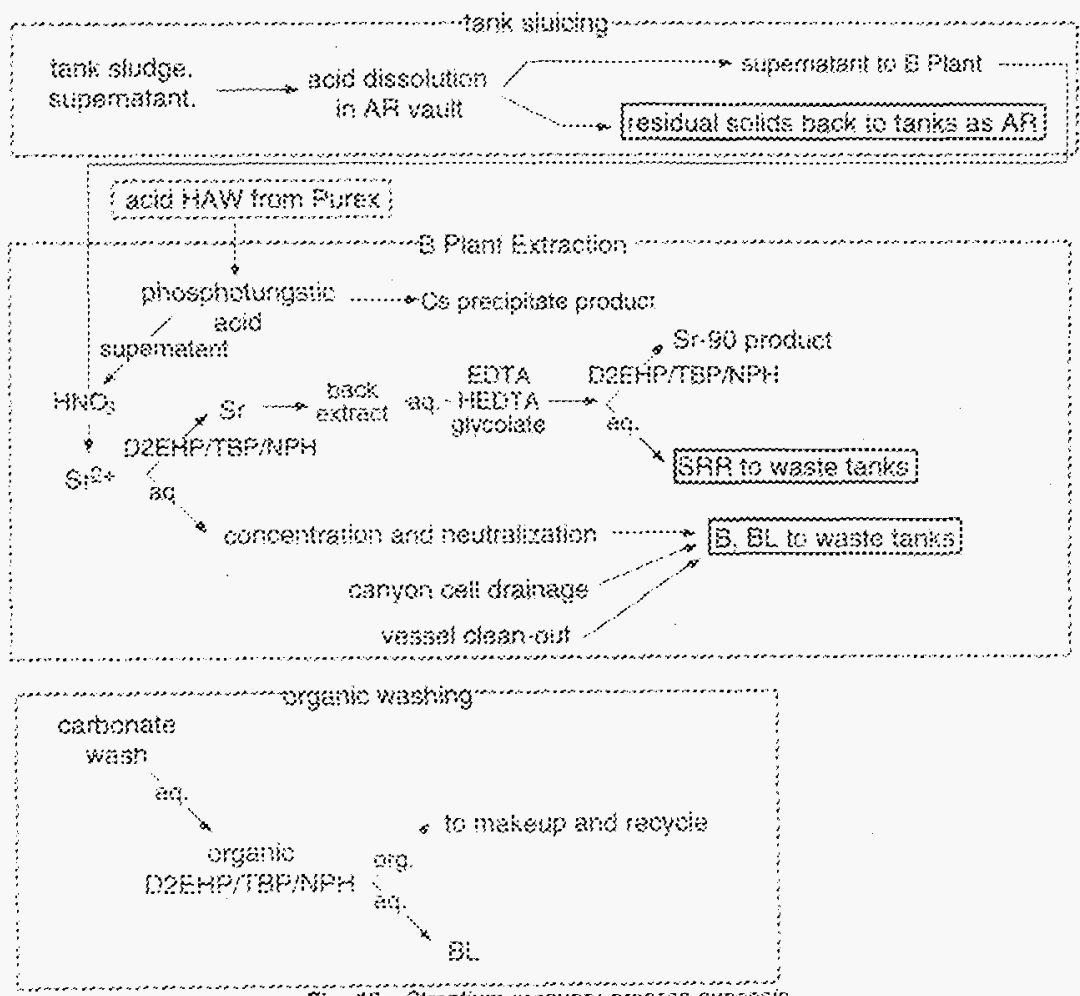

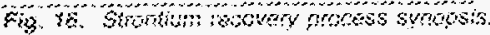

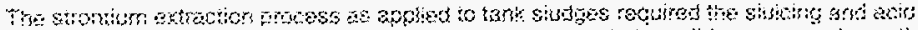

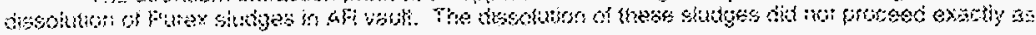




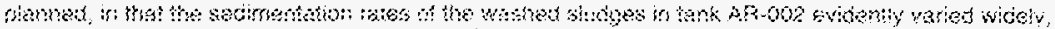

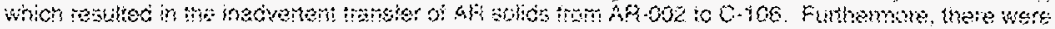

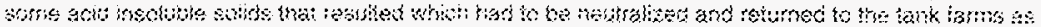

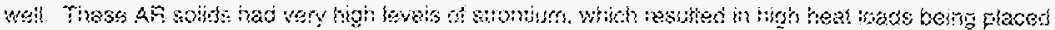

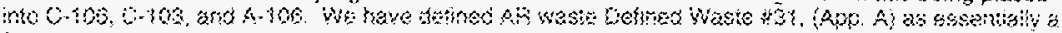

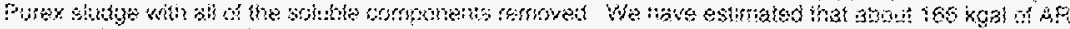

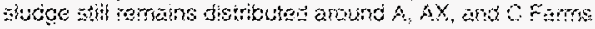

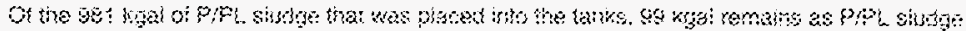

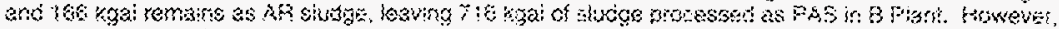

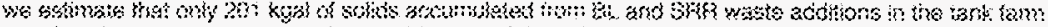

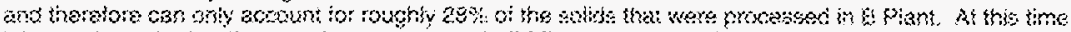

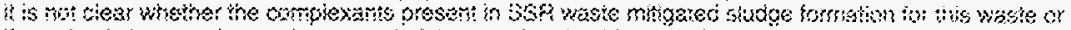

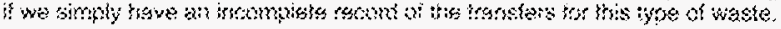

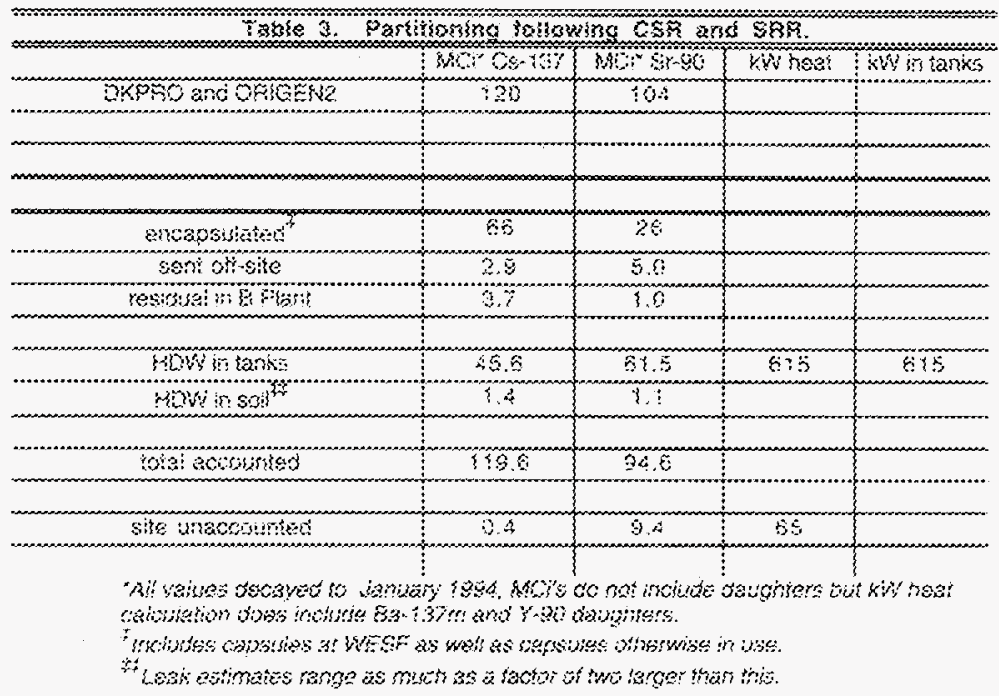

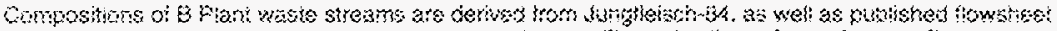

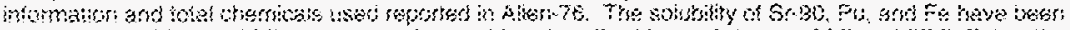

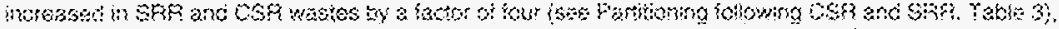

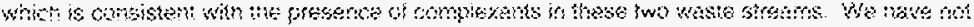

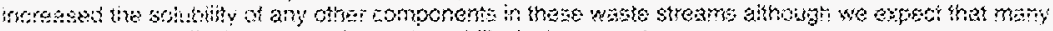

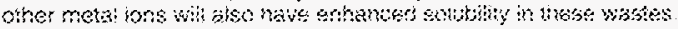

\section{Wurex to thorium sompaigns}

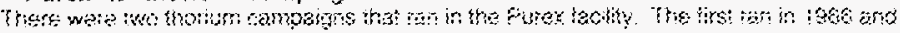

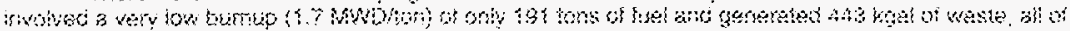

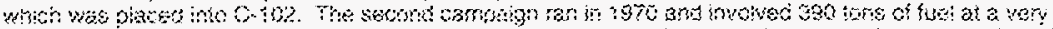

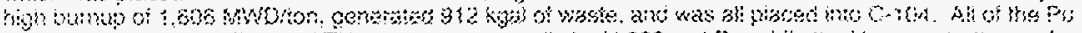

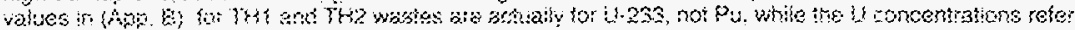

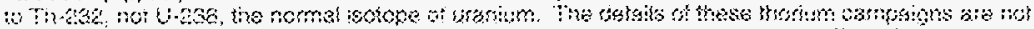

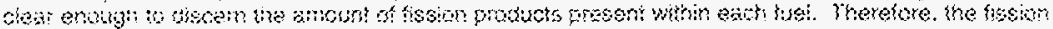

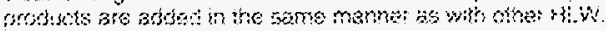



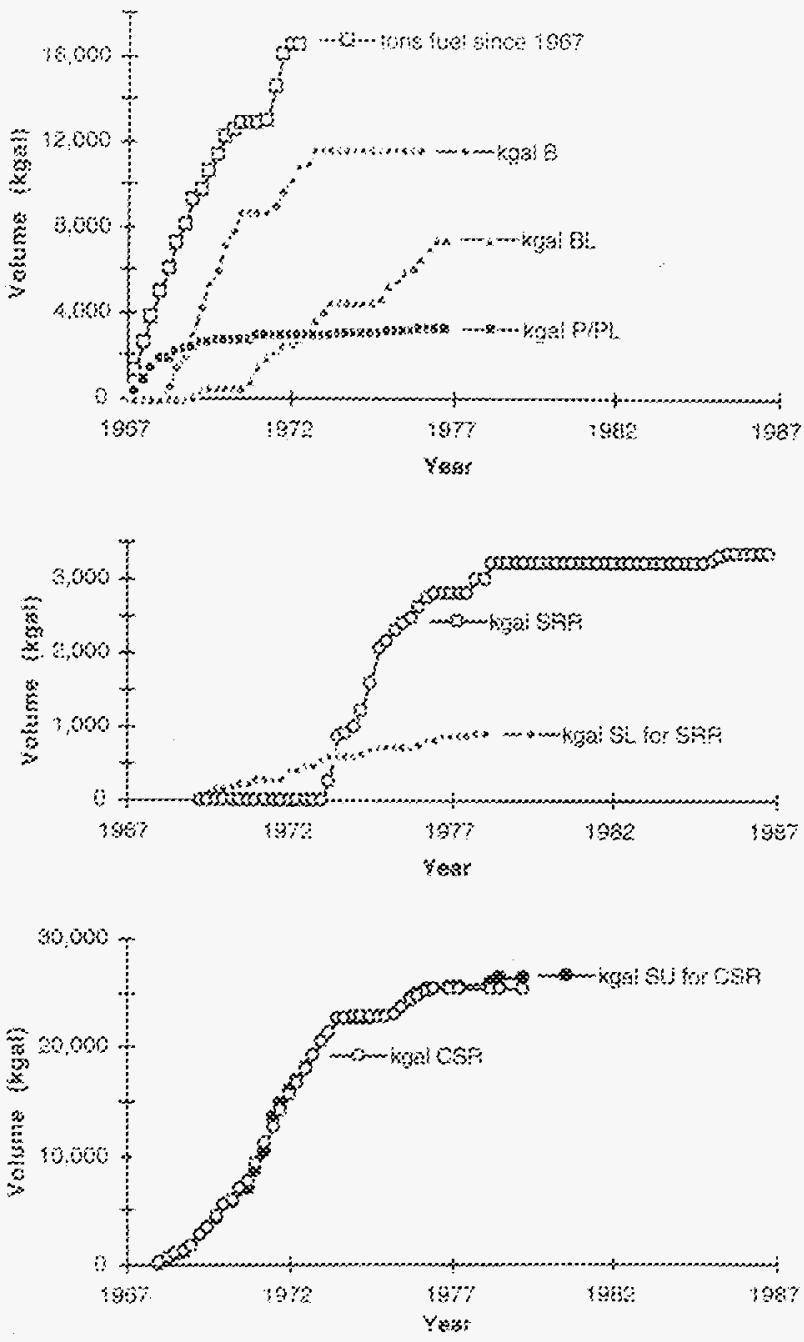

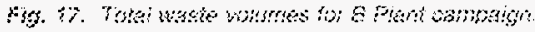




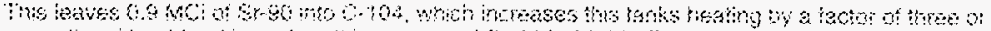

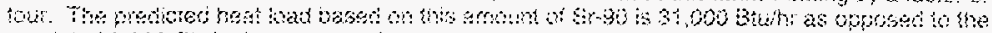

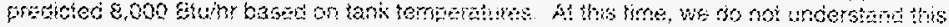
istirapany

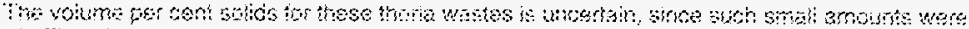

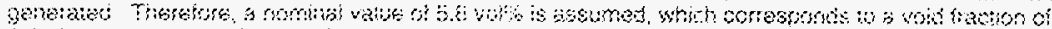

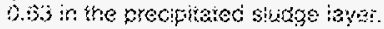

-..purex :0 2 piant

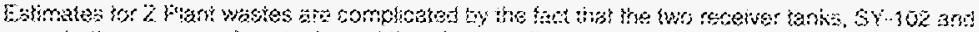

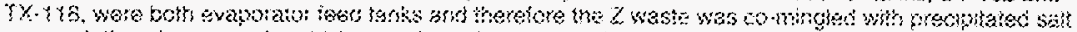

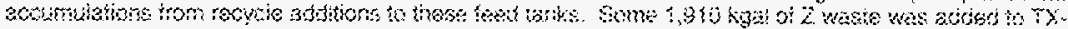

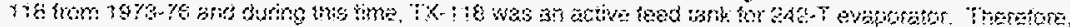

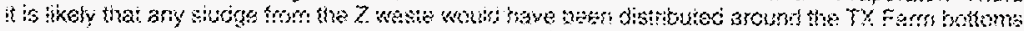
rontivers.

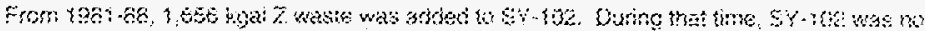

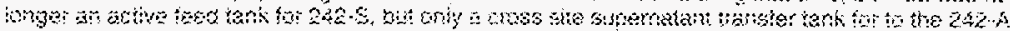

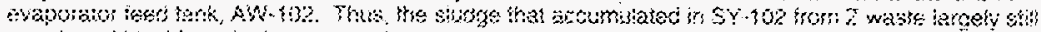

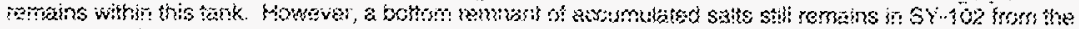

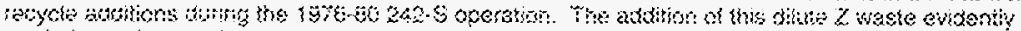

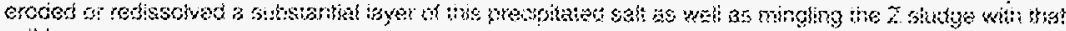
soall baver.

\section{W.. Bhatorkesous earti:}

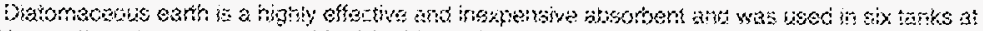

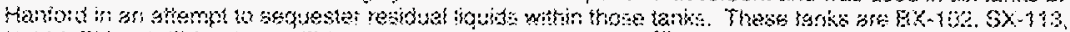

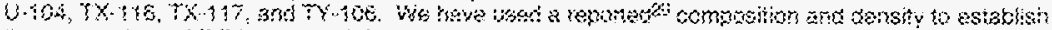

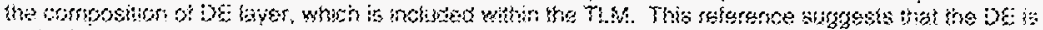

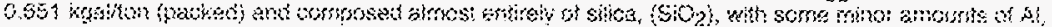

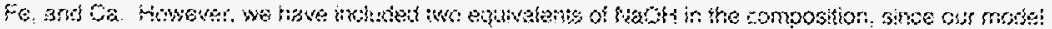

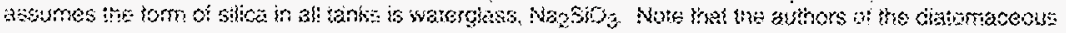

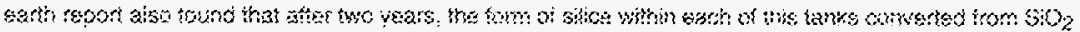

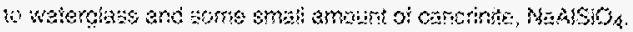

\section{mentersen?}

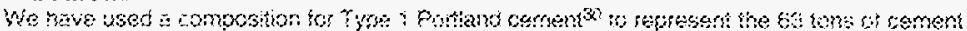

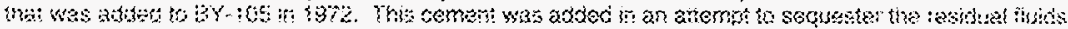

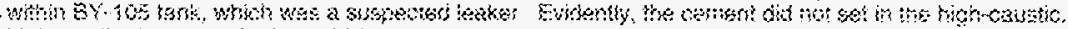

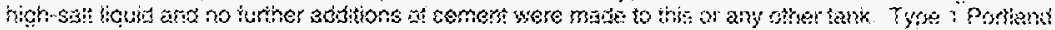

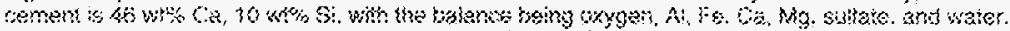

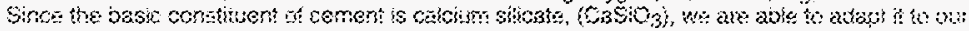

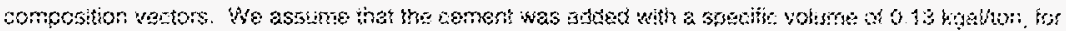

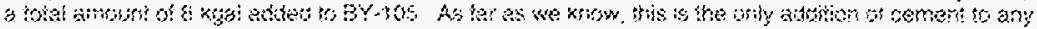
marst at istatent.

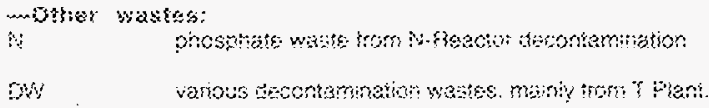

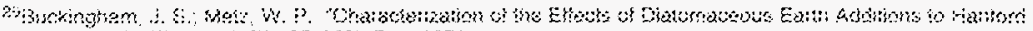

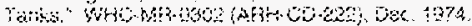

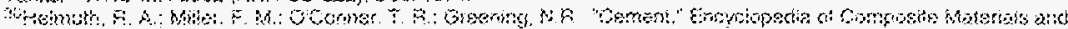

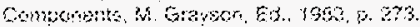


Sais siam!

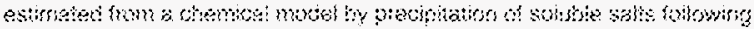

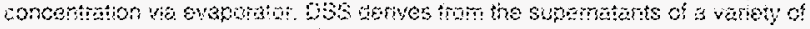

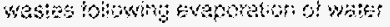

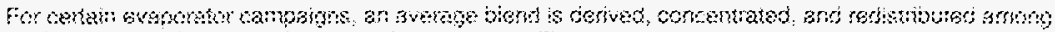

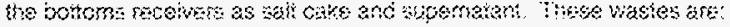

astok

$\because 1560 \%$

Fistork

Brsuk

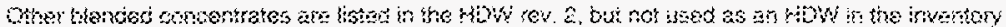

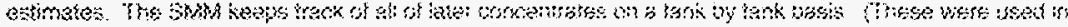
HSTSt E3as. I:
Tobrow
Sisick
62 sinsir
A, $3: 0 \%$
Arsisis
EFropix
SFimatix

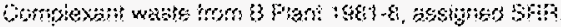

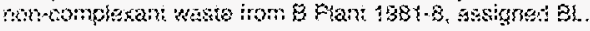

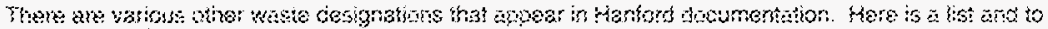

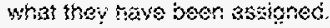

\begin{tabular}{|c|c|}
\hline coskiv & 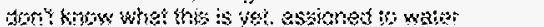 \\
\hline C.4) & 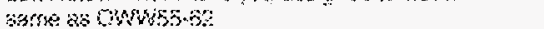 \\
\hline 5 & Sambe as ati cakes or boht conjentrates \\
\hline Noti. & 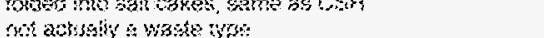 \\
\hline 政 & 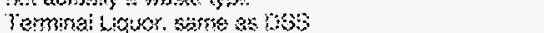 \\
\hline -अ:3: & 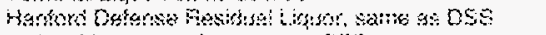 \\
\hline GFSO & residiol bruor cat bo satto as 405 \\
\hline $5 x$ & 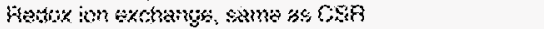 \\
\hline FGS: & same 35 supersstant rom 3 , sems to $65 \%$ \\
\hline S1X & 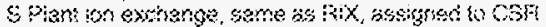 \\
\hline S:2:S & S! Srinds, Samb an AR wibst \\
\hline 356 & \\
\hline CSPE: & \\
\hline & \\
\hline & \\
\hline
\end{tabular}

\section{\$3exhesseshogy}

-... Hedinnasstite invesiaries

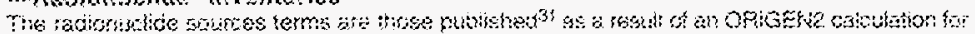

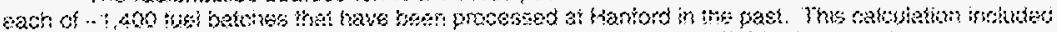

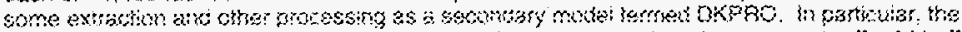

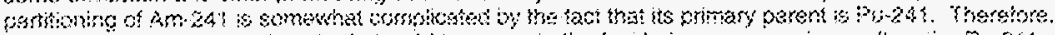

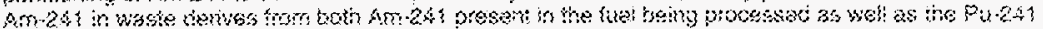

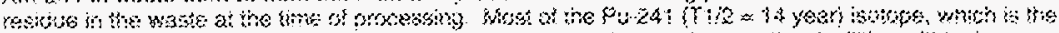

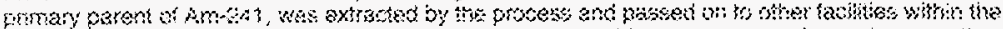

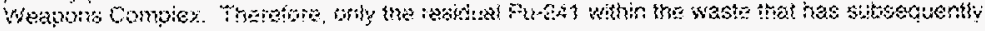

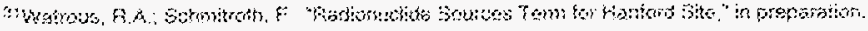




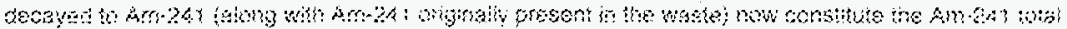
in weske sams.

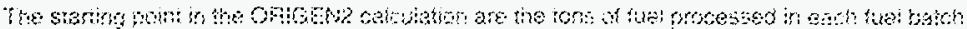
an the hW

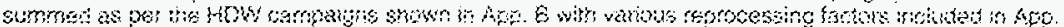

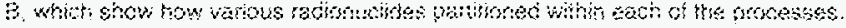

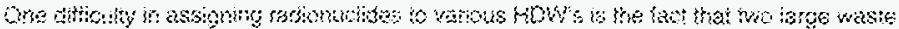

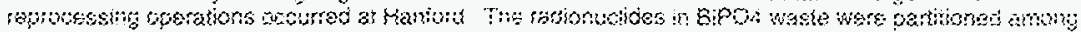

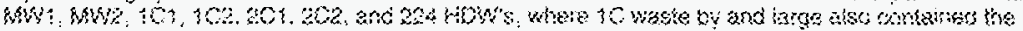

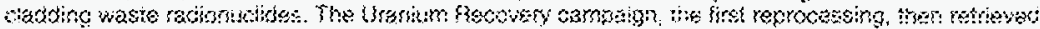

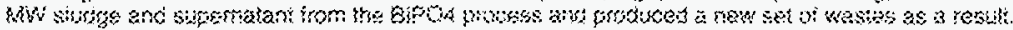

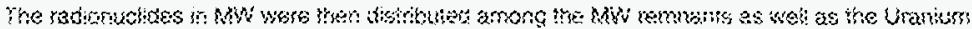

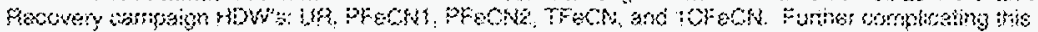

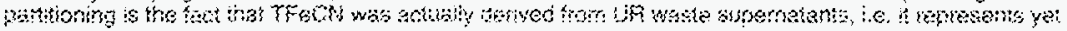

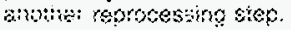

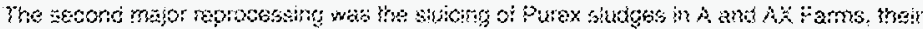

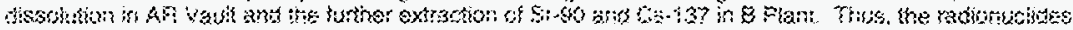

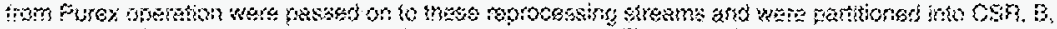

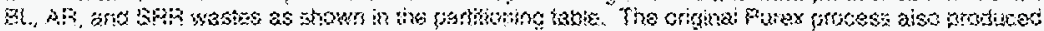

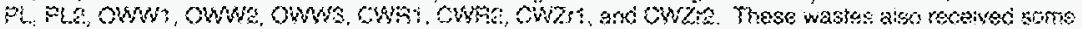

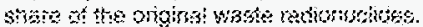

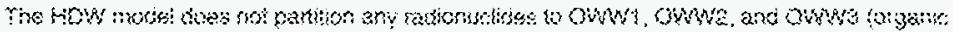

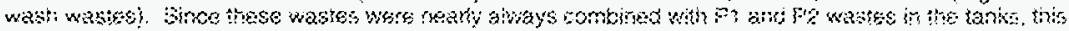

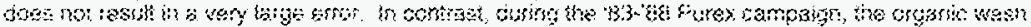

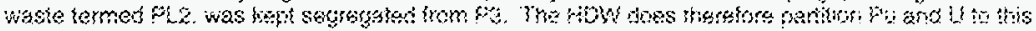

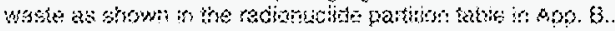

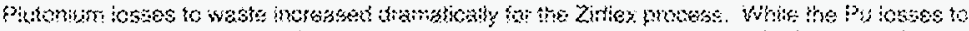

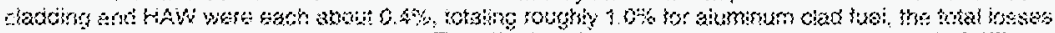

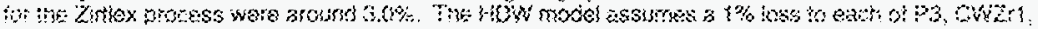

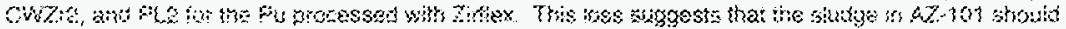

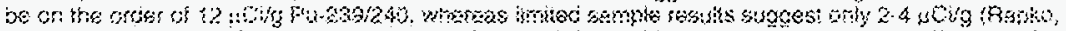

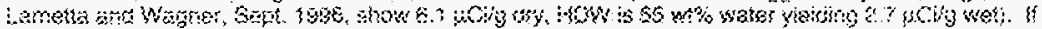

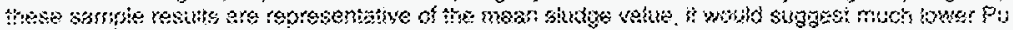
osses to watte binan $: \%$

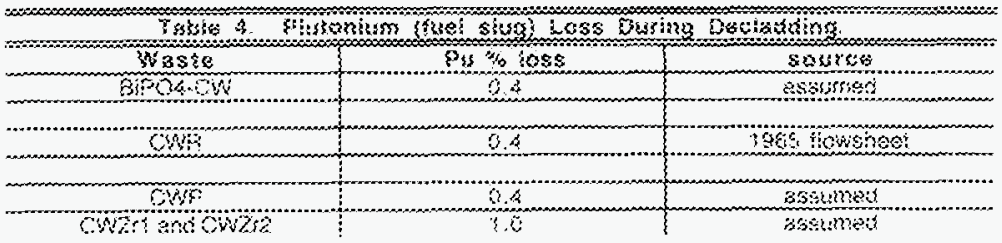

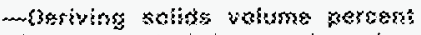

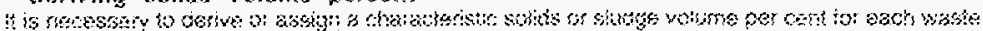

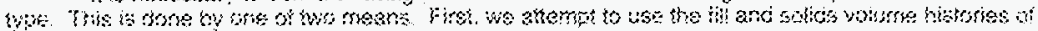

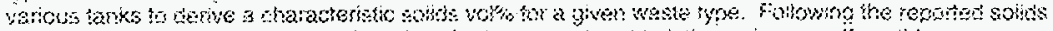

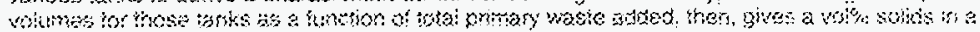

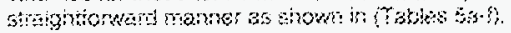




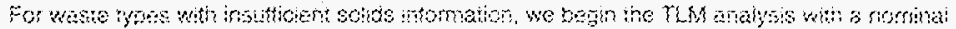

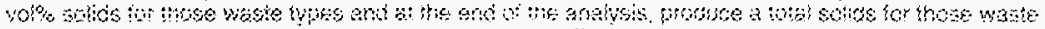

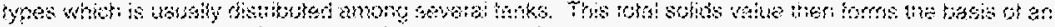

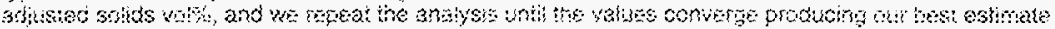

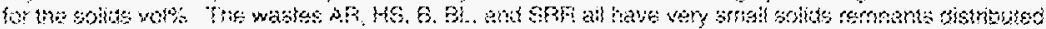

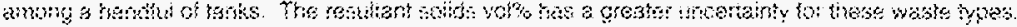

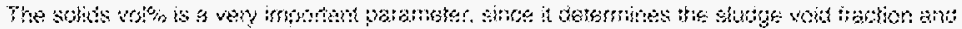

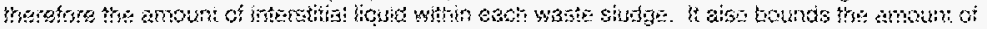

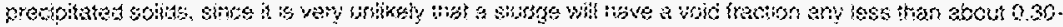
(i. AS.

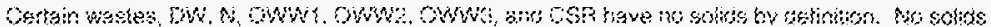

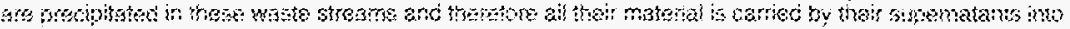

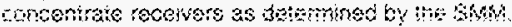

\begin{tabular}{|c|c|c|c|c|c|c|c|c|}
\hline $\operatorname{ses} x$ & stats & $5 \leqslant 5$ & $\operatorname{ans}$ & $3\}$ & wasks fysos & gari.rss. & $a \approx 0.851$. & $\forall 01 \%$ \\
\hline$: 3-\rightarrow 60$ & 1645 & 2 & 1646 & 2 & 30 & 3530 & $2 \%$ & 138 \\
\hline $6+76$ & 1940 & 2 & $134 ?$ & it & 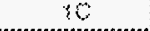 & 3580 & 233 & 14.5 \\
\hline 7.307 & 1945 & 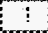 & $194 ?$ & 4 & 10 & $35 \mathrm{G}$ & 201 & 12.5 \\
\hline 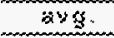 & 3345 & 3 & $\{54\}$ & 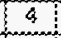 & 15 & \$7 55 & \&52 & Y3.? \\
\hline & & & & & & & & \\
\hline $3 x-169$ & $104 B$ & 3 & 4553 & $?$ & $3:$ & $3 \$ 306$ & $43 ?$ & 275 \\
\hline 6.987 & 1947 & 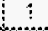 & 194 & 4 & 10 & $35 E$ & 399 & 25. \\
\hline $7 x \cdot 100$ & 1946 & $;$ & 1050 & 2 & 30 & sose & 72 & ceidi \\
\hline 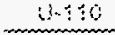 & 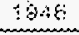 & 3 & 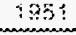 & C. & 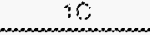 & 3364 & 636 & tis : \\
\hline 2. & $39 \$$ & 3 & $13 \div 3$ & $z$ & 10 & 3606 & $3 B \leqslant 6$ & 243 \\
\hline
\end{tabular}

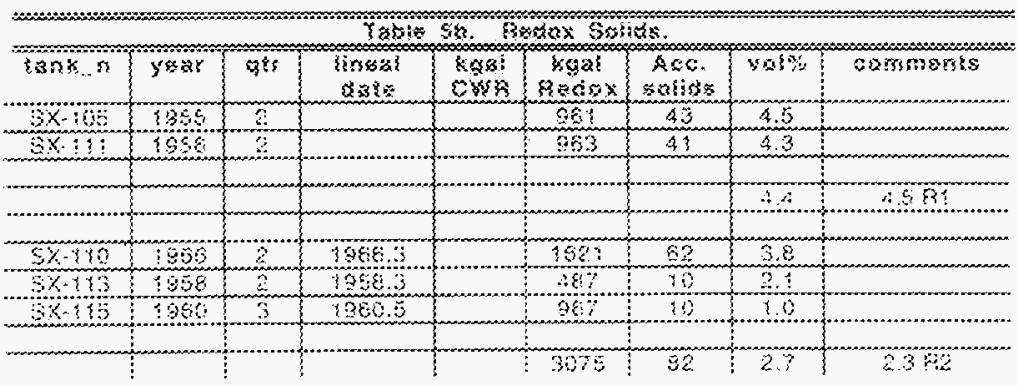




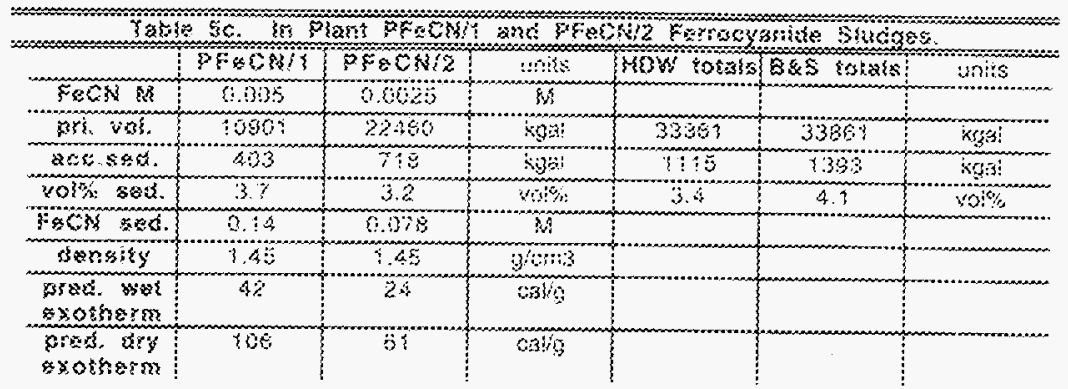

\begin{tabular}{|c|c|c|c|c|}
\hline waste lype & ESTE & $\begin{array}{l}\text { psimary } \\
\text { volsssso }\end{array}$ & $\begin{array}{c}\text { acountis } \\
\text { solics }\end{array}$ & $v 0 \% \%$ solits \\
\hline Fand & $60 B$ & $36\}$ & 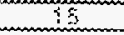 & 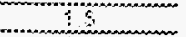 \\
\hline & $5-309$ & 263 & 46 & 6 \\
\hline & 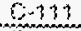 & 32 & 45 & 3.5 \\
\hline & 812 & $4.43 \%$ & 61 & 3 \\
\hline resn & 943: & 31152 & $3 \$ 1$ & 3.4 \\
\hline
\end{tabular}

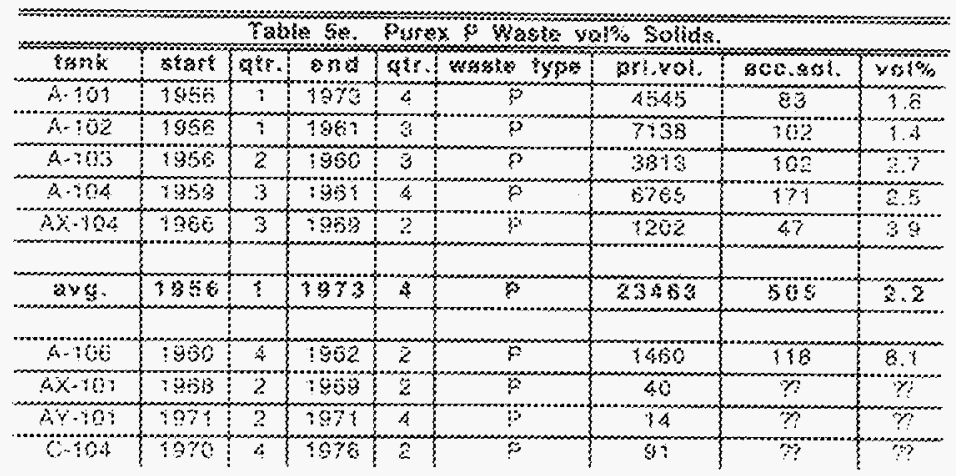




\begin{tabular}{|c|c|c|c|c|c|c|c|c|}
\hline \multicolumn{2}{|c|}{ Tapiat 5$\}$} & \multicolumn{7}{|c|}{ 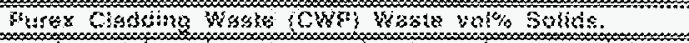 } \\
\hline karsk & slart\} & sts. & end & $31:$ & waskb tyos & privol. & $302.9 \mathrm{~s}\}$. & vol\% \\
\hline $0.10 \%$ & 1360 & 4 & 1362 & 3 & Gnon & 660 & 85 & 86 \\
\hline $0.3 \%$ & 1986 & $\ddot{2}$ & 1366 & 3 & 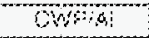 & 79 & 35 & $\because 3$ \\
\hline 6108 & 1966 & Y & 1357 & 2 & ONot & 1116 & 91 & 8\}$. \\
\hline$C \cdot 105$ & 457 & 3 & 1380 & $\ddot{Z}$ & CAPIA! & 8330 & 252 & 84 \\
\hline a163 & 1358 & 2 & TaEs & 2 & OAISA & 320 & 28 & 6.7 \\
\hline & & & & & & & & \\
\hline $33 \div 3$. & 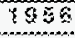 & ? & $1 \$ \leqslant 5$ & $z$ & EV\%। & $\$ 307$ & 671 & 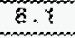 \\
\hline & & & & & & & & \\
\hline $0-10 \%$ & $408 \Omega$ & 3 & 7365 & $\ddot{z}$ & CKMIB! & 5465 & 364 & 14 \\
\hline 6.104 & $\$ 595$ & 4 & 370 & 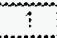 & $\mathrm{CNP} 2$ & 535 & & \\
\hline $6-104$ & 3970 & 3 & 992 & 3 & CWPin & 3316 & 608 & 26 \\
\hline & & & & & & & & \\
\hline$\varphi \cdot Y\}^{2}$ & $7: 355$ & 3 & 1959 & 4 & WWPIALZ! & 6448 & $?$ & $Y$ \\
\hline $6 \cdot 10 \%$ & 196 & 3 & 1362 & 2 & Qnomin & 1364 & $\because$ & ? \\
\hline 0.109 & $368 ?$ & 2 & .391 & 2 & OWOAS & 606 & 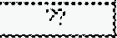 & $z^{2}$ \\
\hline 6111 & 3657 & $y$ & 3360 & 4 & CWNis! & 347 & $?$ & $?$ \\
\hline $6: 12$ & 1350 & 3 & $196 !$ & 2 & WWH & 256 & $?$ & $\%$ \\
\hline
\end{tabular}

\section{mbreciptistion of sutids}

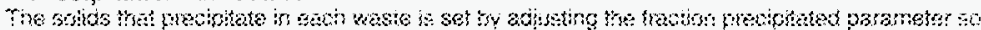

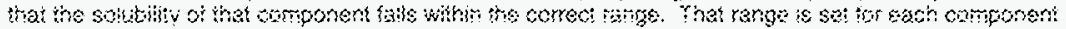

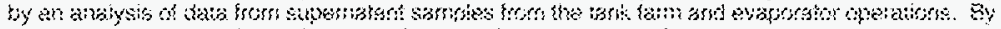

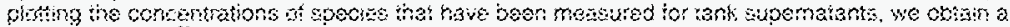

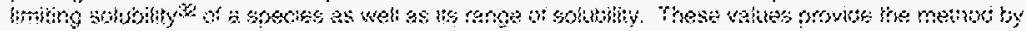

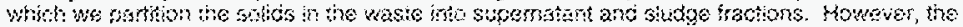

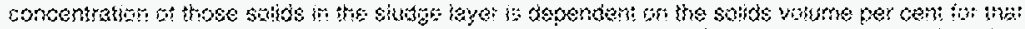

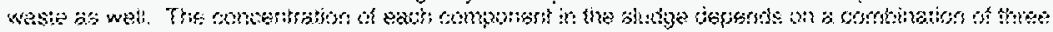

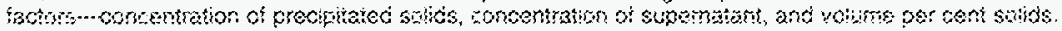

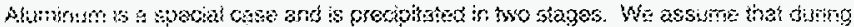

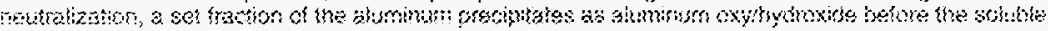

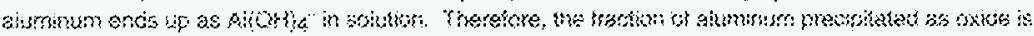

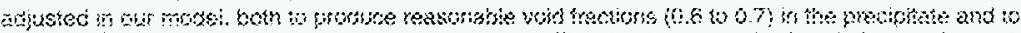

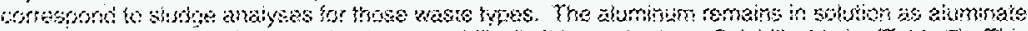

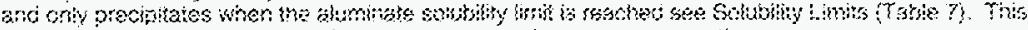

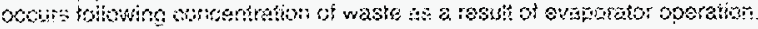

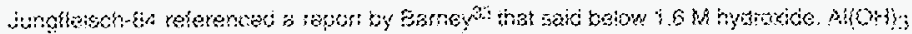

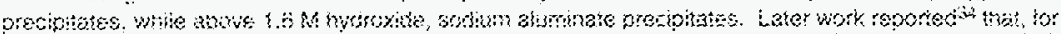

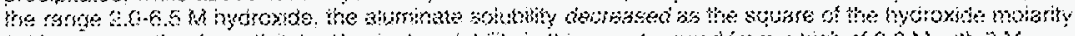

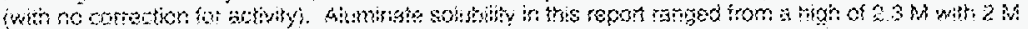

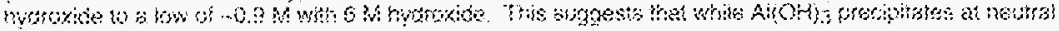

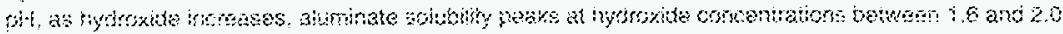

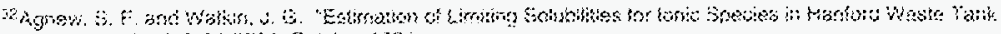

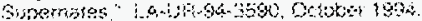

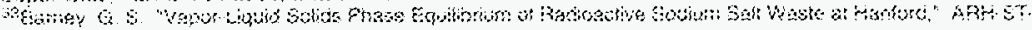

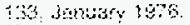

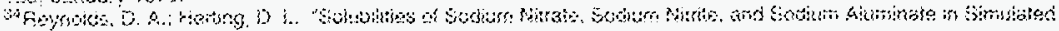

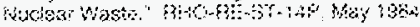




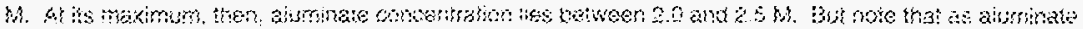

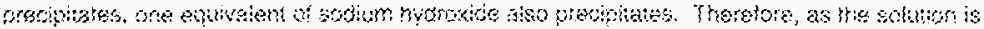

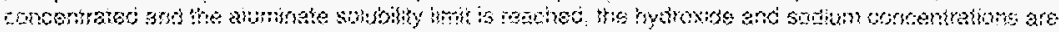

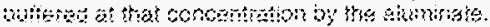

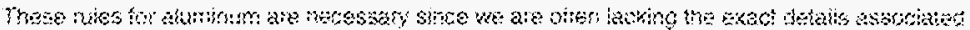

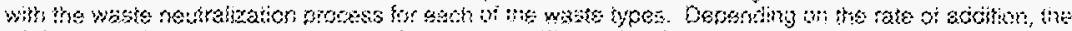

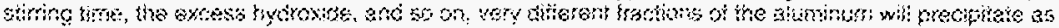

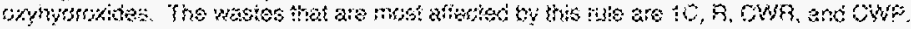

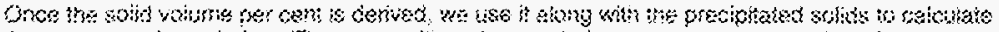

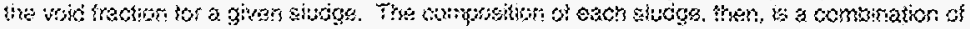

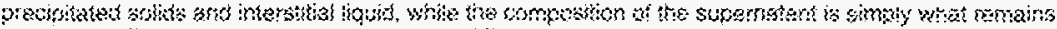

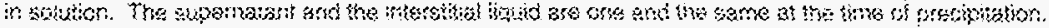

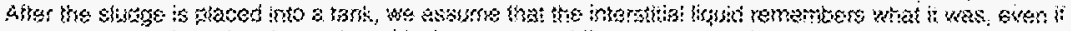

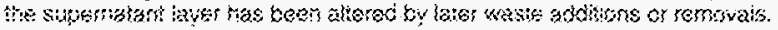

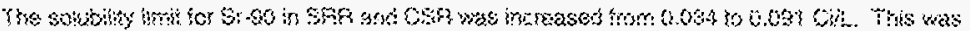

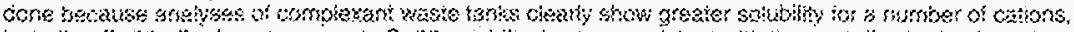

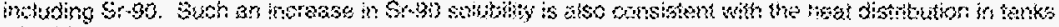

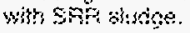




\begin{tabular}{|c|c|c|c|c|}
\hline & Tasth $42, \quad$ in & michists & AONSS & und Species precipitated. \\
\hline Alremisals & $\begin{array}{l}\text { defisad } \\
\text { precigiates }\end{array}$ & $04 s$ & $120 \times$ & oumsments \\
\hline 4003 & SaNo6 & & 9 & 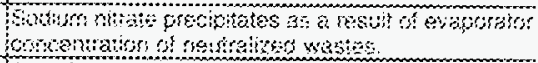 \\
\hline \multirow[t]{2}{*}{ 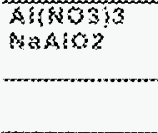 } & 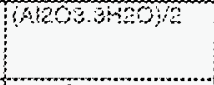 & 1.3 & 3 & 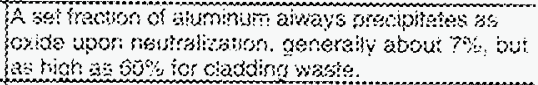 \\
\hline & $\operatorname{siat} 2$ & 3 & 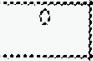 & Ony after combentation owe dumbate \\
\hline 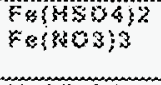 & Fo(0) & 3 & 6 & 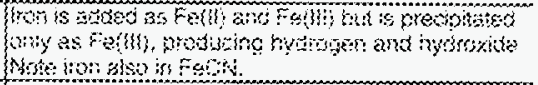 \\
\hline $\operatorname{Manc503}$ & Cromis & 3 & 1.5 & 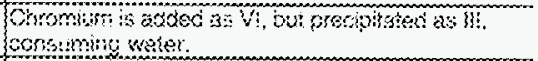 \\
\hline \multirow[t]{3}{*}{ KIFDN } & spos & & 0 & 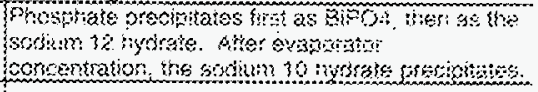 \\
\hline & 3300040620 & & 0 & \\
\hline & 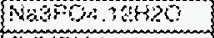 & & 3 & \\
\hline $\operatorname{200} 0302$ & 260, & & 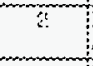 & $\begin{array}{l}\text { Whom } \\
\text { Hadong }\end{array}$ \\
\hline \multirow[t]{2}{*}{ N15OS } & Mioniz & 2 & 3 & 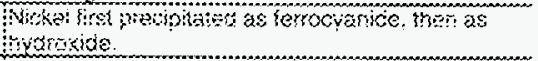 \\
\hline & 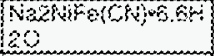 & & 6.8 & \\
\hline NoOK & & & 3.5 & Wo potonatois \\
\hline Nasoz & Maks\% & & 0 & 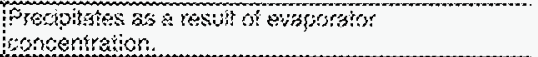 \\
\hline \multirow[t]{2}{*}{202633} & 6203.7160 & & 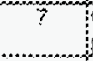 & 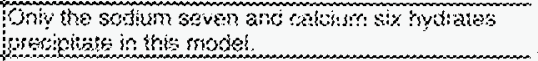 \\
\hline & Ca603.5itas & & 3 & \\
\hline \multirow[t]{3}{*}{833904} & spes & & 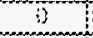 & 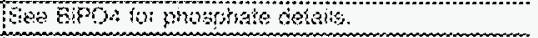 \\
\hline & Masolatoras & & 80 & Wa is ssed 3s surogte to whetever sathon sctuatly \\
\hline & 100004,12426 & & 32 & 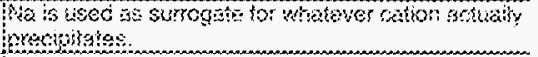 \\
\hline$M=2004$ & Meson & & 80 & Even trough metaftesis is ke\%, Nos is used as \\
\hline Na2s:30 & 092603 & 6 & $\theta$ & 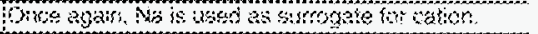 \\
\hline Me2AIFS & Saises & & 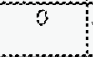 & assume sil sif hyotolyzes o sticete. \\
\hline MaF & $\mathrm{NBF}$ & & 0 & SSE 13 as cotion sinmpgate \\
\hline$\$ 3001$ & औS & & 2 & Wo nocpitated. \\
\hline 2.86106$) 3$ & 1.63 & & 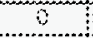 & 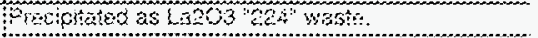 \\
\hline BSB & & & 8 & Mot nerspinato: \\
\hline
\end{tabular}




\begin{tabular}{|c|c|c|c|c|}
\hline \multicolumn{5}{|c|}{ 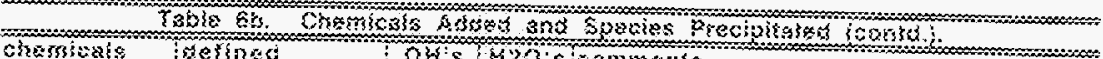 } \\
\hline $\begin{array}{l}\text { chessisiats } \\
\text { astign }\end{array}$ & Dernes & 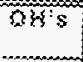 & $M \geqslant 0.3$ & Tammssis \\
\hline $\mathrm{RO3}$ & Kastos & & 8 & 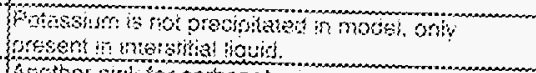 \\
\hline$\theta x(k 53) 2$ & 60,6,kta0 & & 8 & Asothe: wisik or cartorsets. \\
\hline KMnos & monos & & 0 & 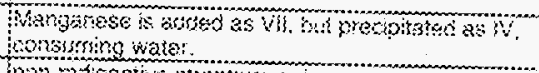 \\
\hline$\$ 4\{303\}$ & Srowrye & & 3 & 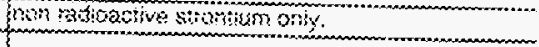 \\
\hline 05604 & 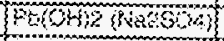 & & $\ddot{\vdots}$ & \\
\hline 33665607 & Montivtas & & 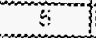 & Mot preapinisso. \\
\hline HSESTA & MOBOBA & & 6 & Mini noeponatsol. \\
\hline MBSERTA & NBSHEDTA & & 3 & Wol Grectoisatest. \\
\hline Mgiyasikgs & & & 0 & Sot propotizies \\
\hline Hacetatz & Na kestate & & 8 & Sot grssipuates: \\
\hline S2nxaste & No7OXjatais & & 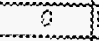 & Propitatad in 204 weste \\
\hline 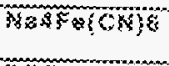 & 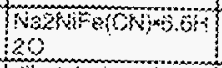 & & 6 & 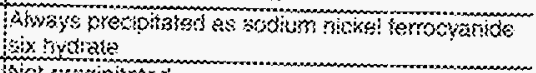 \\
\hline$D p^{p}$ & abutys pirsschate & & 3 & 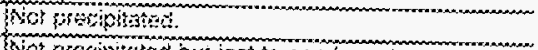 \\
\hline Erstistss & 166 & & & Not onseiplitsted but lost to onsenseate. \\
\hline $5 .+4$ & NaOSs & & & Folows Carfonale. \\
\hline$(5 ; \cdot 51\}$ & 5.46 & & & 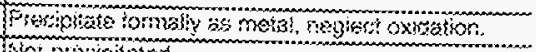 \\
\hline$\gamma e+38$ & 639 & & & Wot piesoritates \\
\hline $213 !$ & 13 & & & 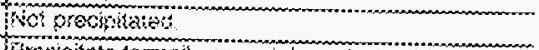 \\
\hline $5 s-337$ & $64-67$ & & & 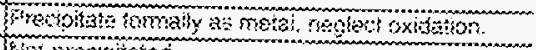 \\
\hline $3 y-23 \%$ & 40.237 & & & Wrot peophared \\
\hline 3 & 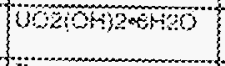 & & 7 & 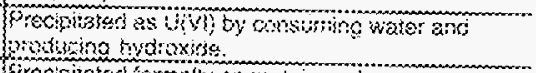 \\
\hline 35 & 1 & & & 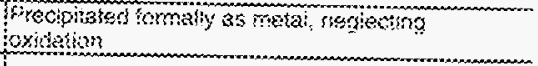 \\
\hline & & & & \\
\hline
\end{tabular}




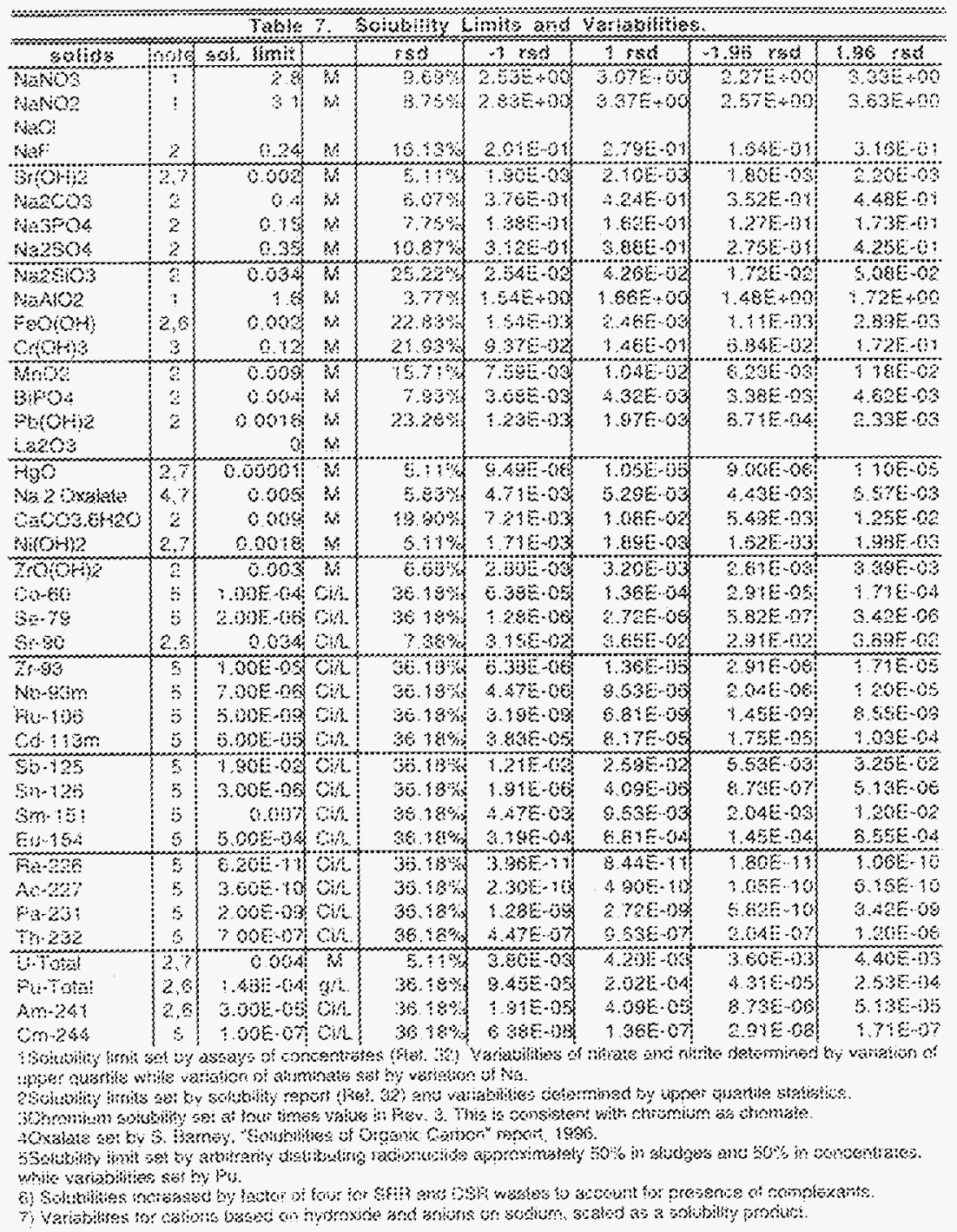




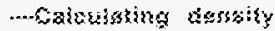

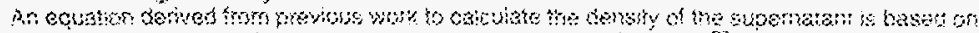

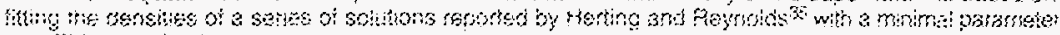
se This poutum st:

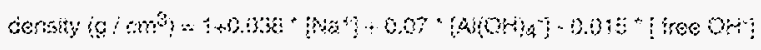

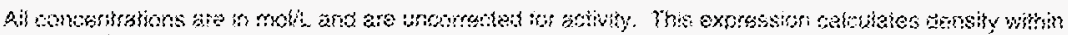

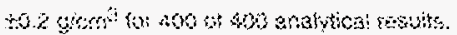

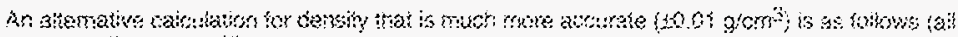
concentrations in mollit:

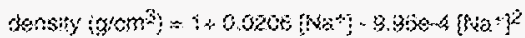

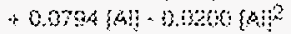

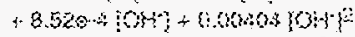

$$
\begin{aligned}
& +0.0304\left[\mathrm{MO}_{3}\right]+2 \mathrm{Am}+\left[\mathrm{NO}_{3} \mathrm{~W}^{2}\right.
\end{aligned}
$$

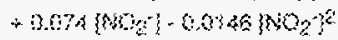

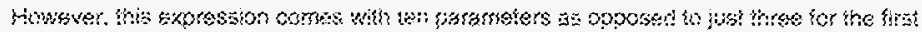
expression. We wit wse the simpiss sxoresson tor the why.

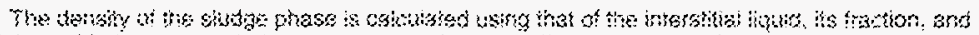

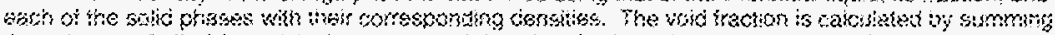

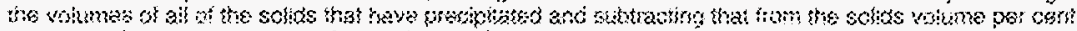

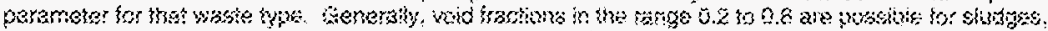

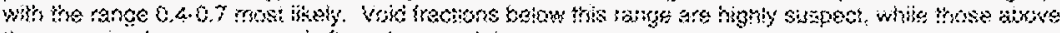

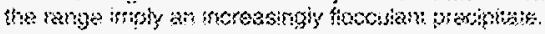

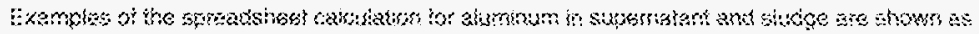

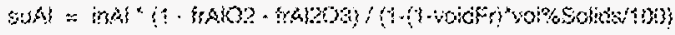

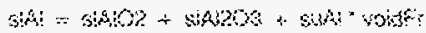

where

$$
\begin{aligned}
& \text { suat mith al al sopsematant }
\end{aligned}
$$

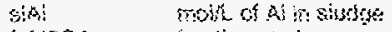

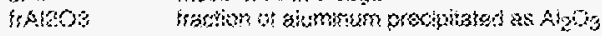

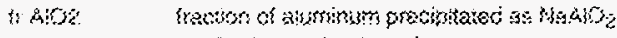

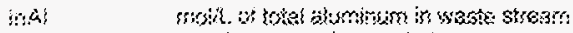

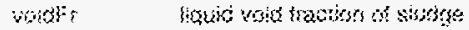

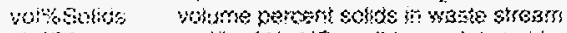

$$
\begin{aligned}
& \text { SlA }
\end{aligned}
$$

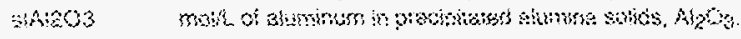

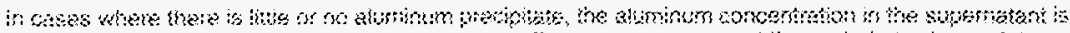

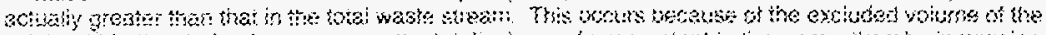

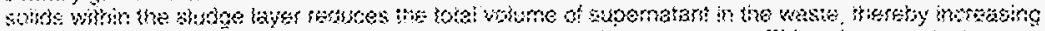

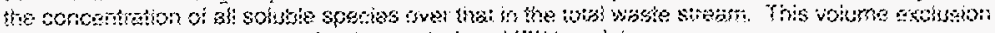

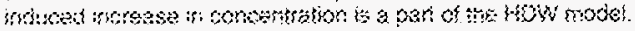

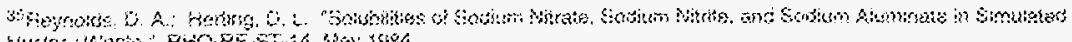

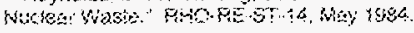


men Maknose satsistion

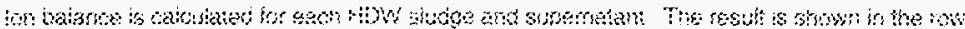

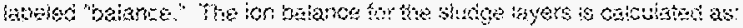

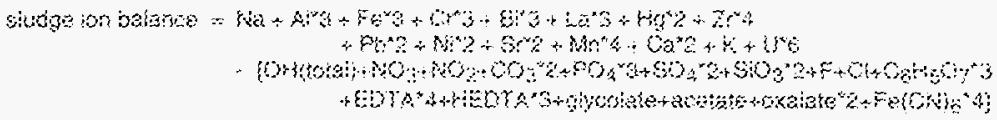

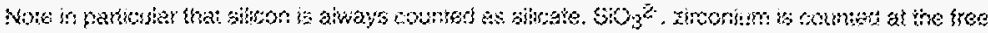

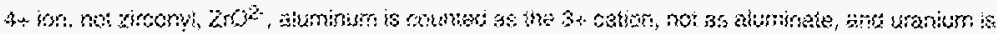

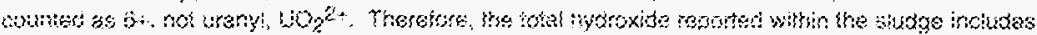

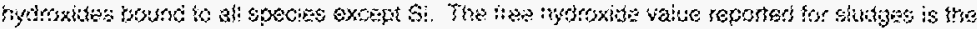

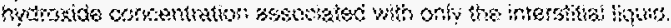

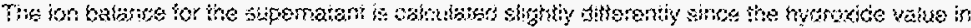

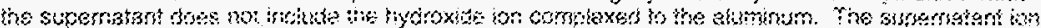

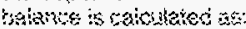

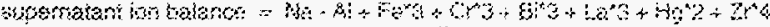

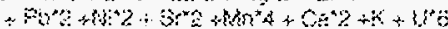

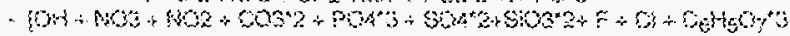

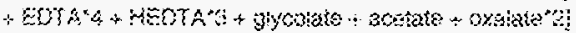

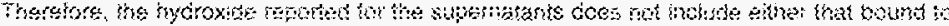

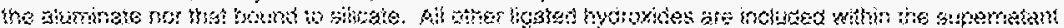

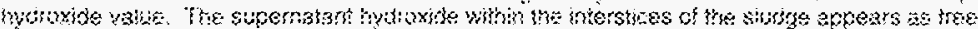
tydrexide.

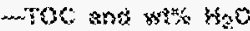

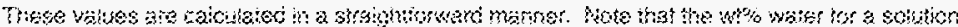

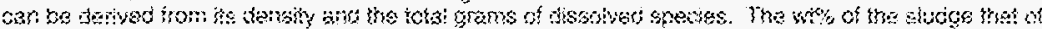

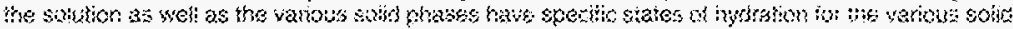

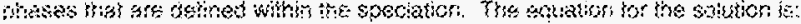

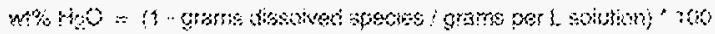

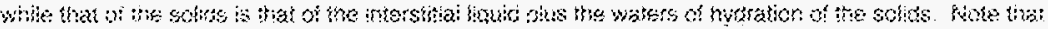

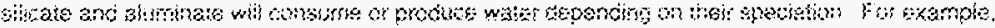

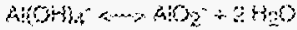

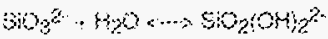

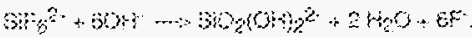

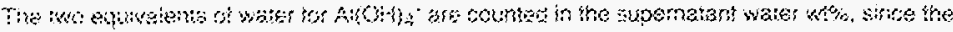

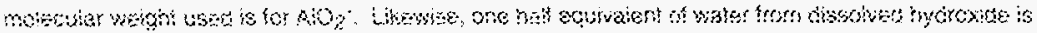
mokedes, smos

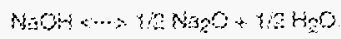

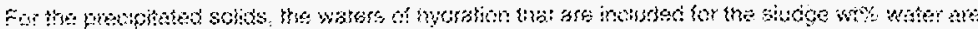

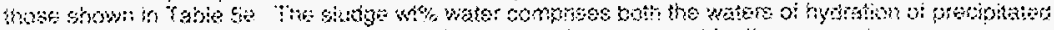

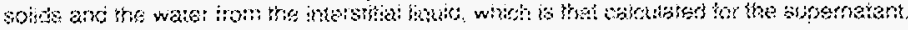




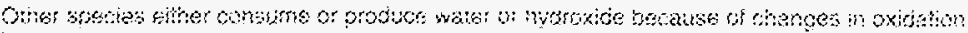
sisie. These at:

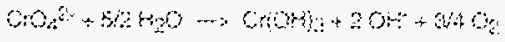

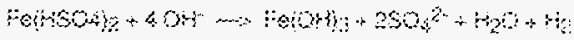

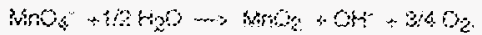

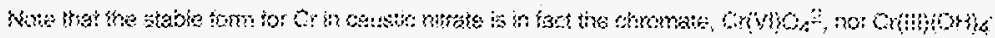

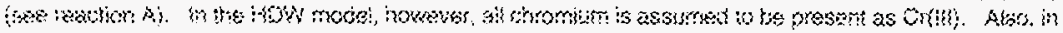

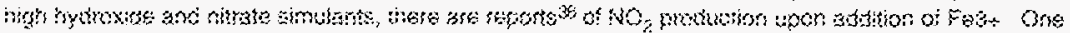

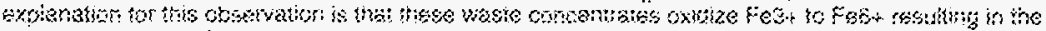

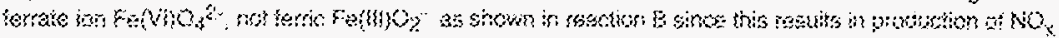

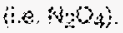

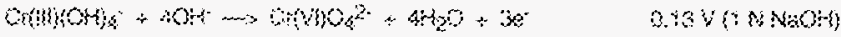

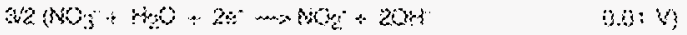

i.

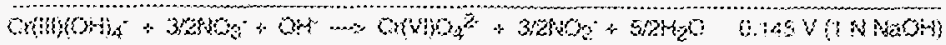

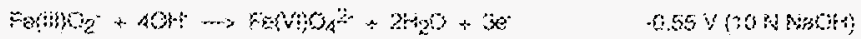

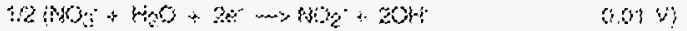

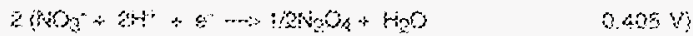

8

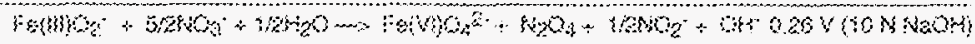

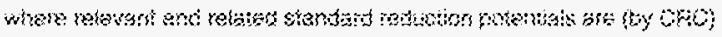

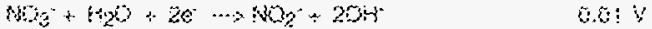

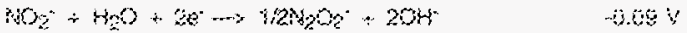

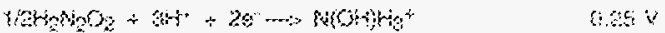

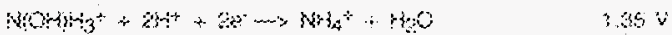

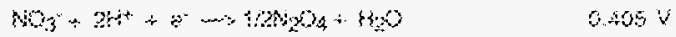

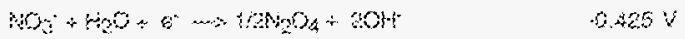

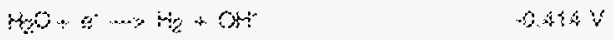

$$
\begin{aligned}
& \text { Hec. }
\end{aligned}
$$

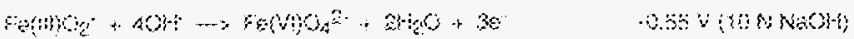

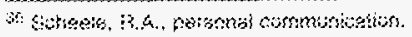




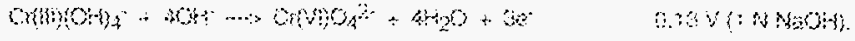

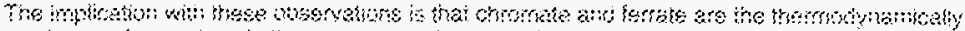

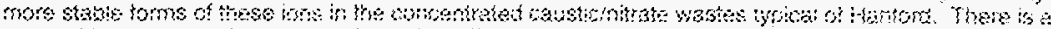

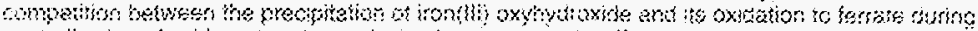

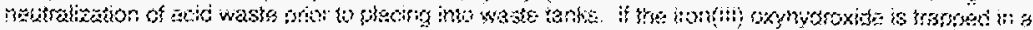

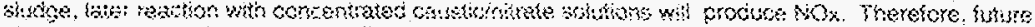

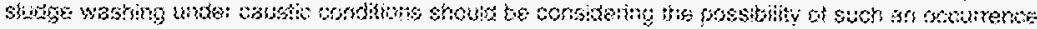

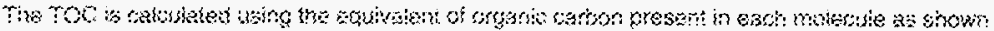

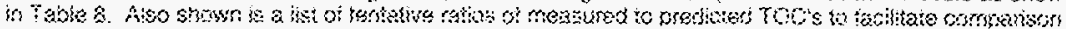

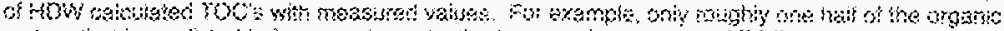

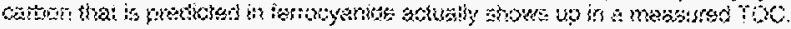

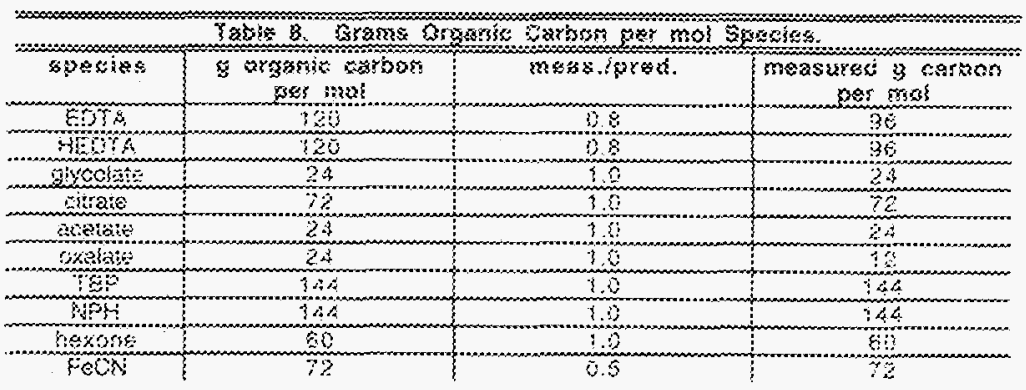

\section{-avaporstar sperstions}

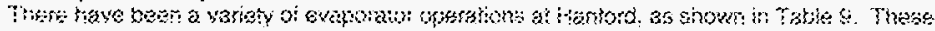

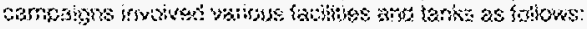

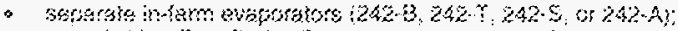

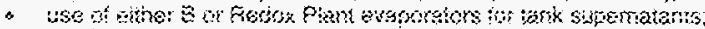

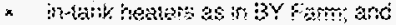

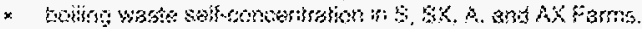

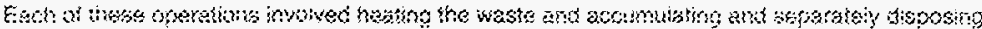

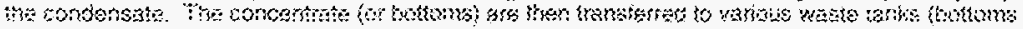

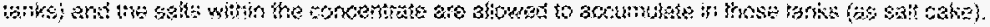

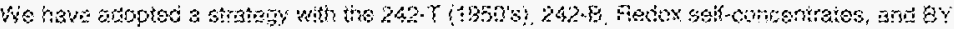

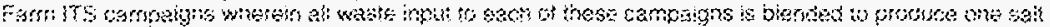

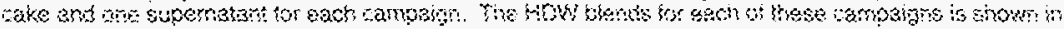

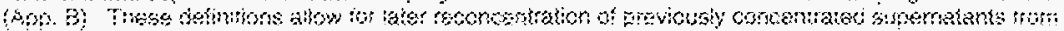
aach Eanpaigr.

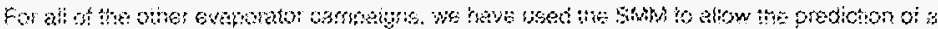

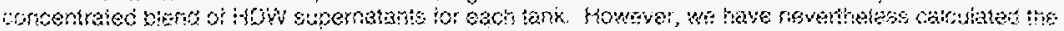

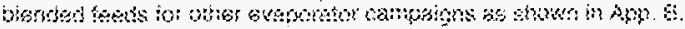

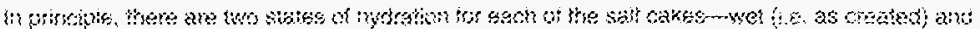

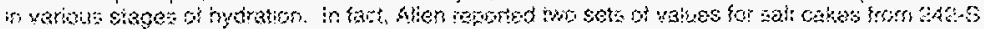

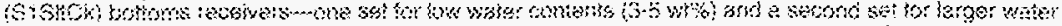

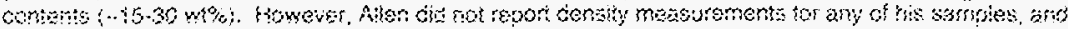




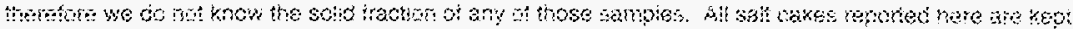

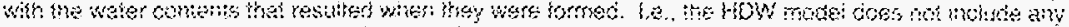

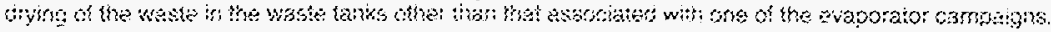



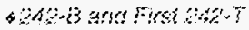

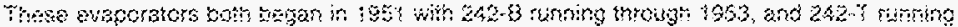

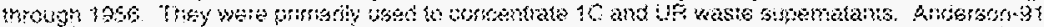

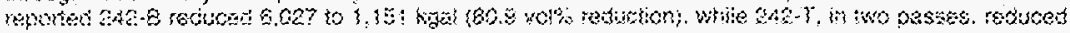

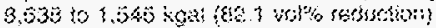

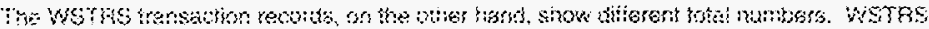

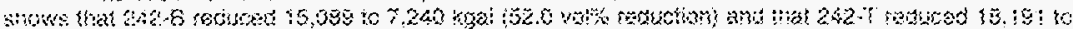

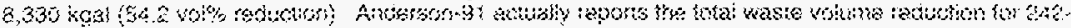

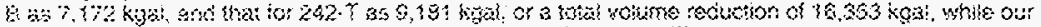

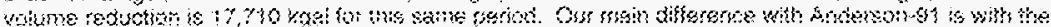

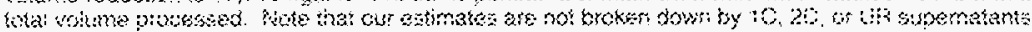




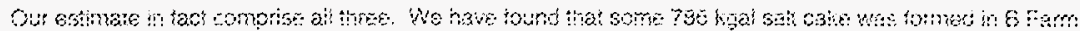

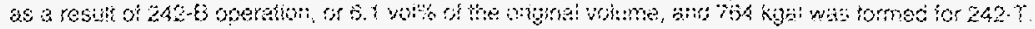

45 and sx fams entonesntath

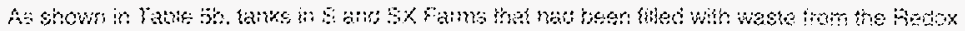

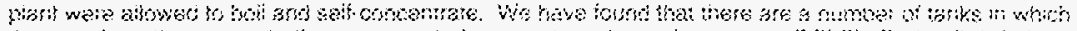

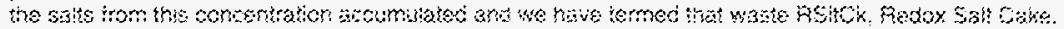

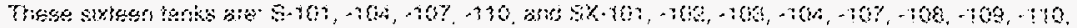

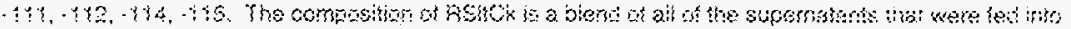

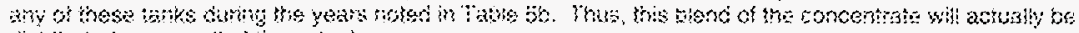
distribsed anoing al on thess tarks.

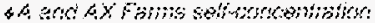

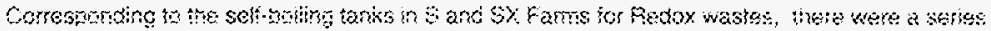

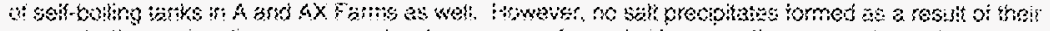

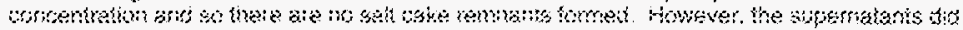

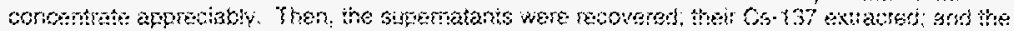

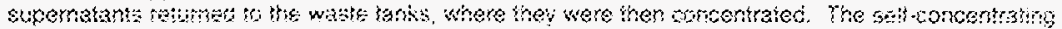

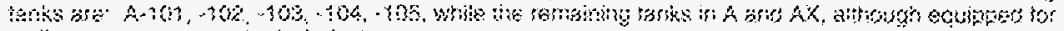
buking waske, never ackubly boheo.

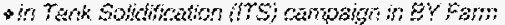

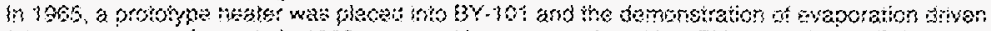

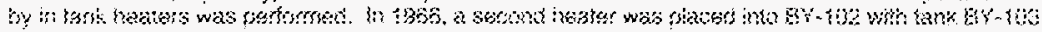

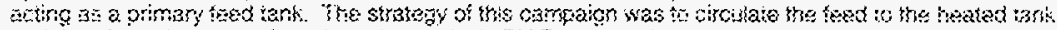

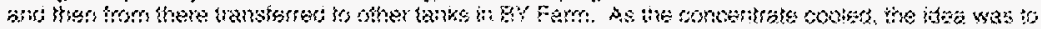

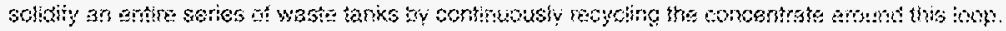

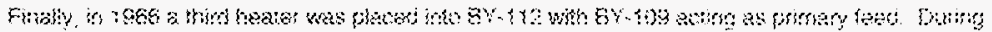

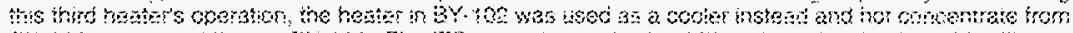

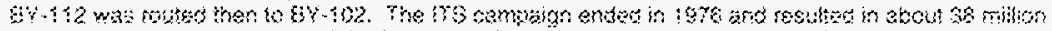

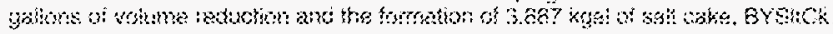

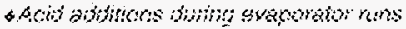

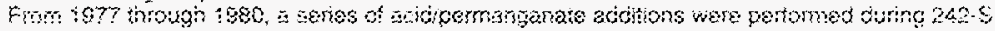

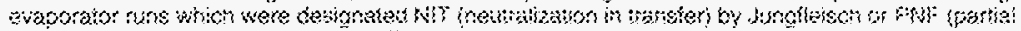

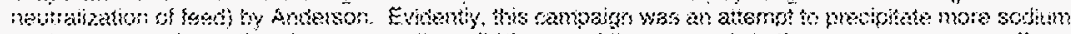

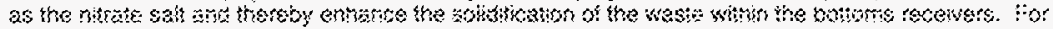

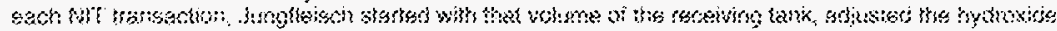

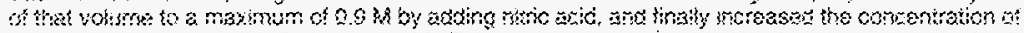

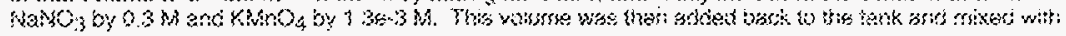

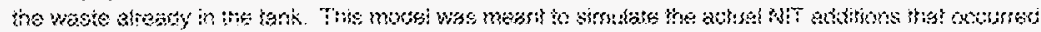

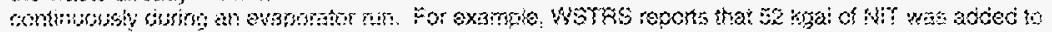

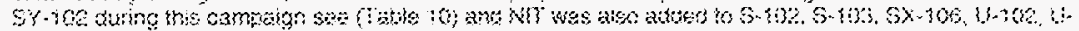

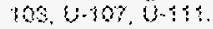

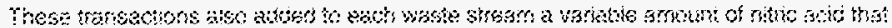

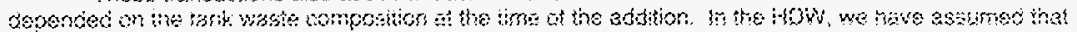

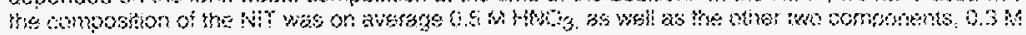

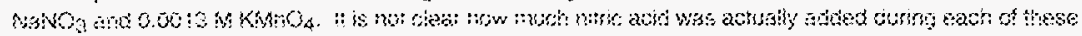

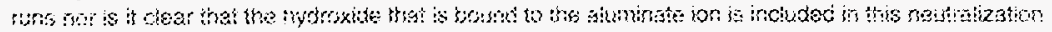
seritote 


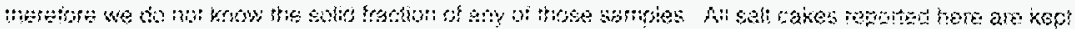

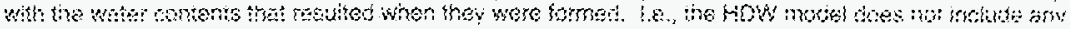

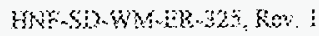

\begin{tabular}{|c|c|c|c|}
\hline \multicolumn{4}{|c|}{ 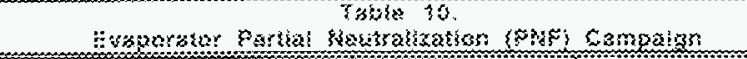 } \\
\hline Sonk & SCA: MIT & Trom & 10 \\
\hline $3 Y-102$ & 52 & $1977 ! 6$ & $1377 \div 6$ \\
\hline $1-302$ & 29 & 4977?5 & 1976 \\
\hline $6 \sqrt[613]{3}$ & 26 & 1377.?5 & 1577.75 \\
\hline 3-Y.3 & 220 & $13 \%$ & $3600 \% 5$ \\
\hline $6-10 \%$ & 760 & 1976 & 3686.75 \\
\hline 8-106 & 63 & 6795 & 397975 \\
\hline 1.93? & 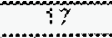 & 976 & 30398 \\
\hline $6 \times 106$ & 338 & 39865 & $33 B 076$ \\
\hline kgosis roles & $8>A$ & 1\$7?.75 & 1383.75 \\
\hline
\end{tabular}

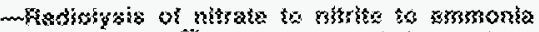

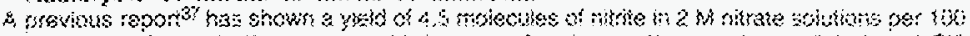

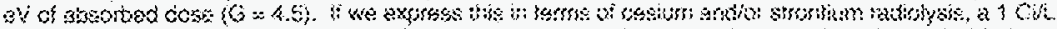

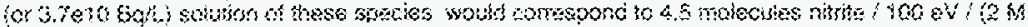

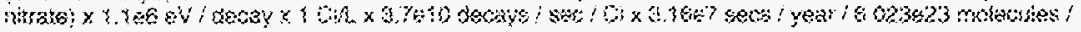
mol whict is

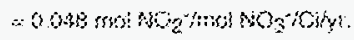

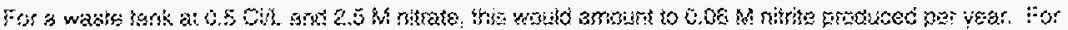

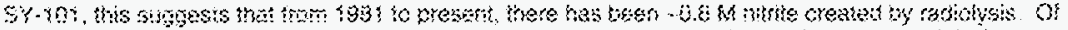

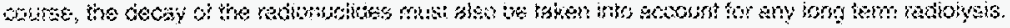

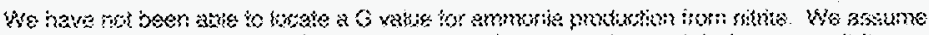

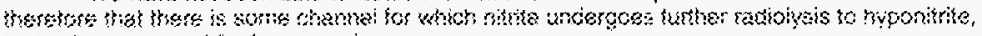

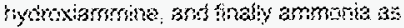

$$
\begin{aligned}
& \text { 530. red rad. }
\end{aligned}
$$

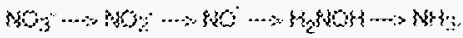

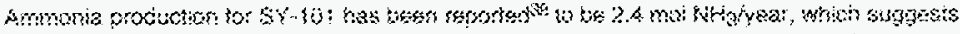

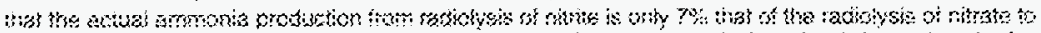

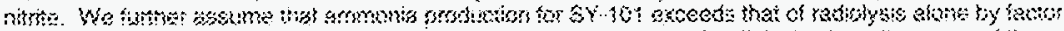

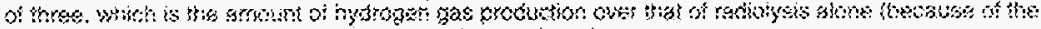

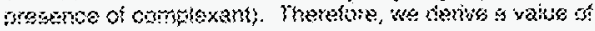

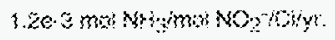

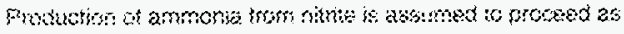

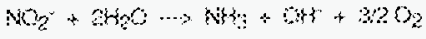

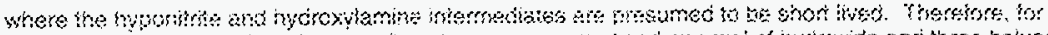

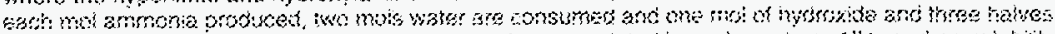

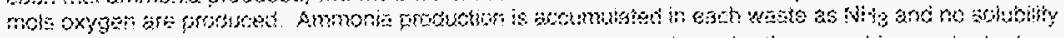

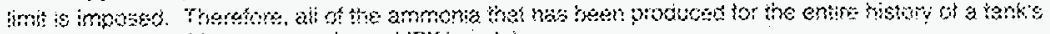

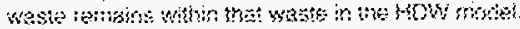

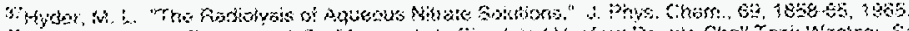

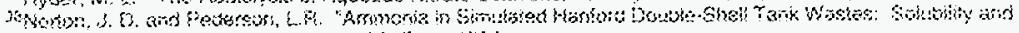

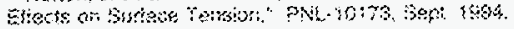




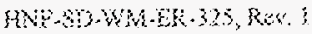

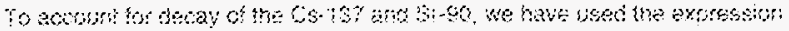

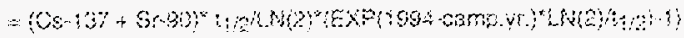

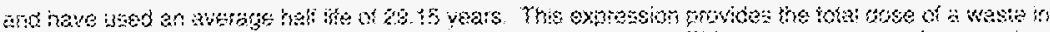

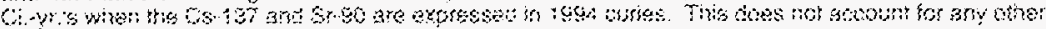

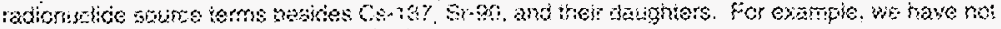

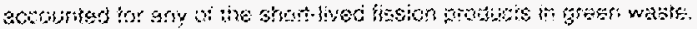

\section{masgrassion of ongsic}

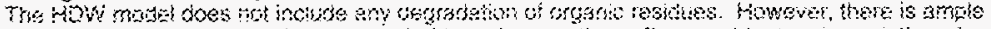

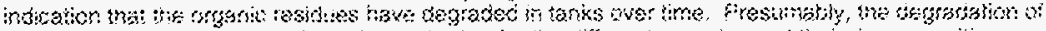

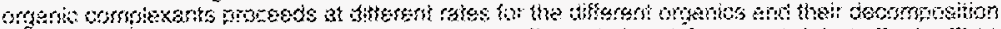

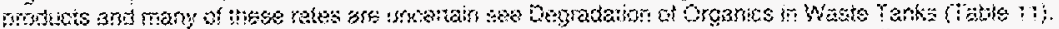

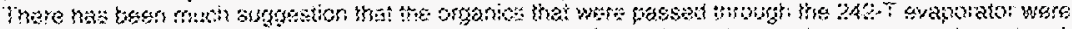

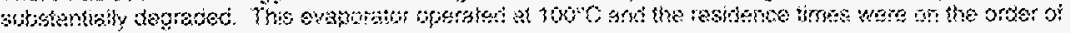
33 hors.

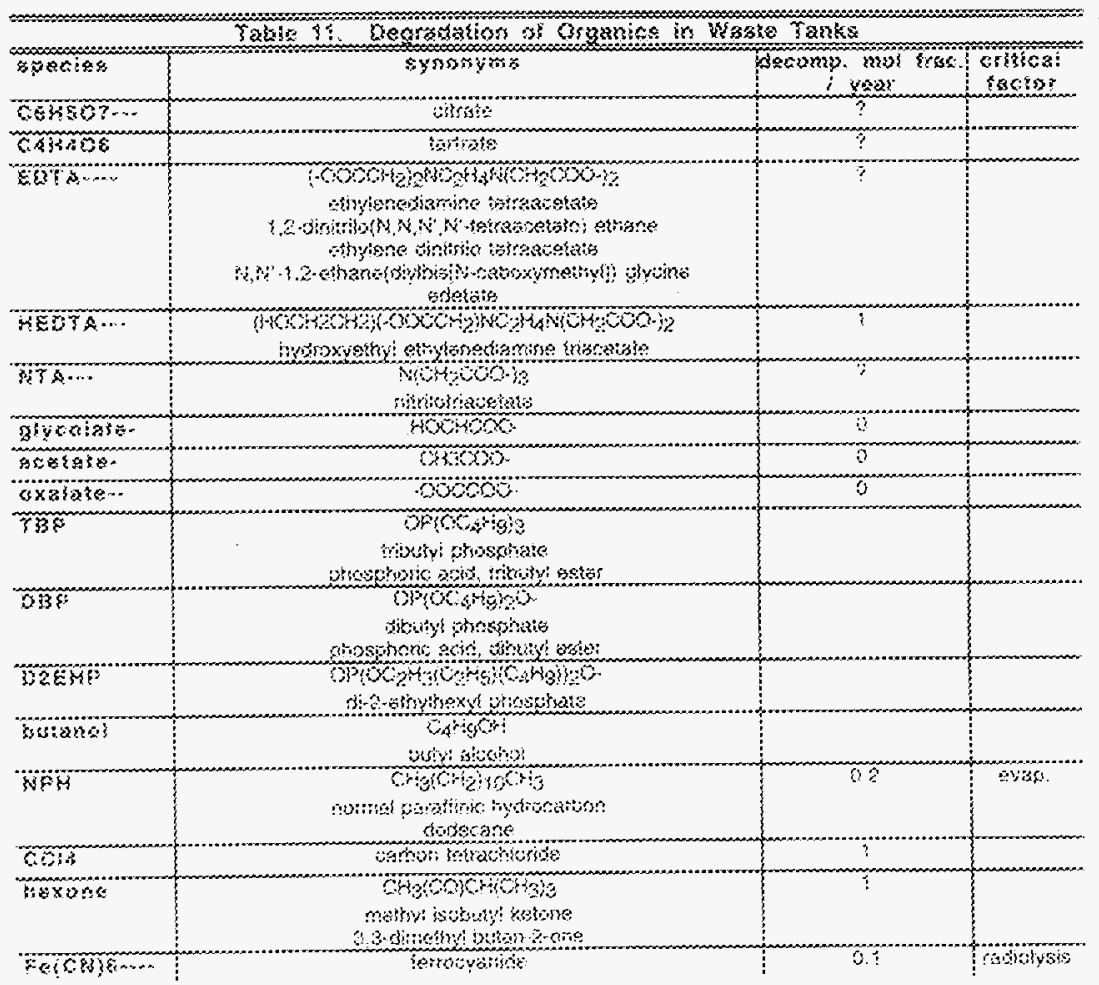


aci-t

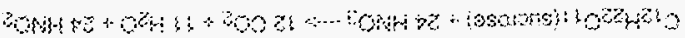

$$
\begin{aligned}
& \mathrm{O}+\mathrm{H}+\mathrm{N}<\mathrm{B}+\mathrm{O}+\mathrm{m}
\end{aligned}
$$

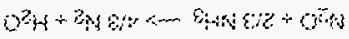

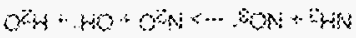

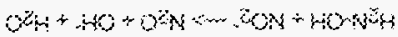

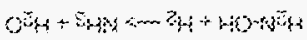

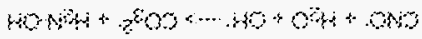

$$
\begin{aligned}
& 20 \mathrm{n}+\infty \mathrm{Non}+\mathrm{No}
\end{aligned}
$$

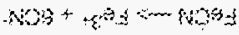

$$
\begin{aligned}
& \text { soledoden 5... sumon } \\
& \text { SWHWHA } \div-50
\end{aligned}
$$

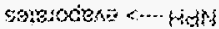

$$
\begin{aligned}
& \text { saterodens <-- polens: }
\end{aligned}
$$

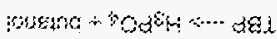

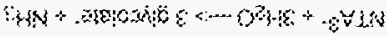

.7W

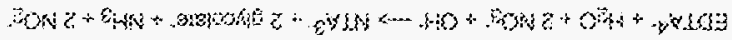

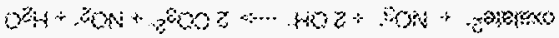

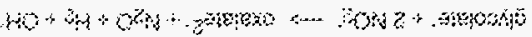

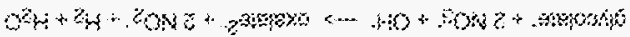

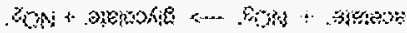

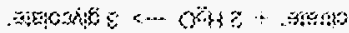

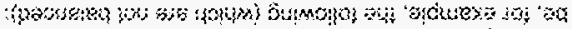

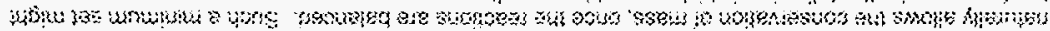

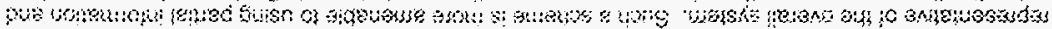

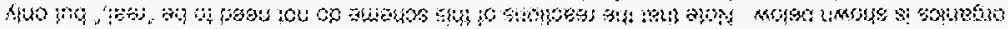

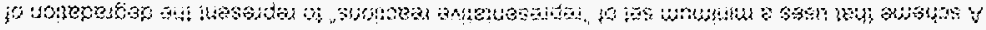

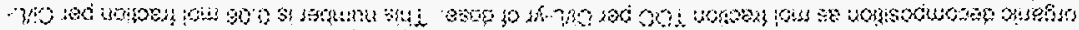

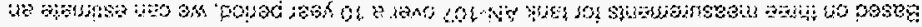




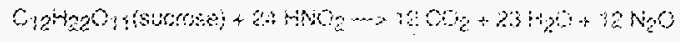

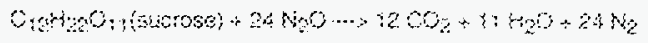

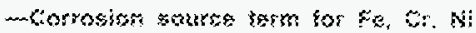

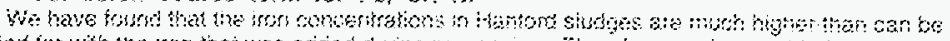

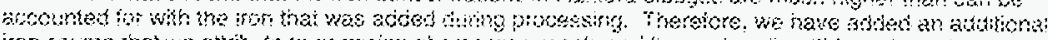

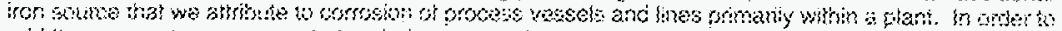

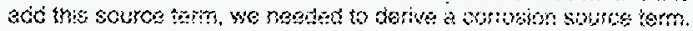

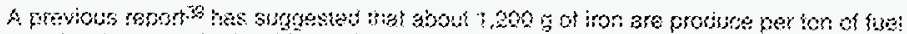

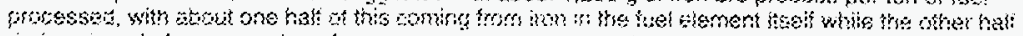

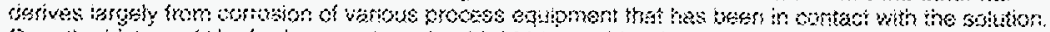

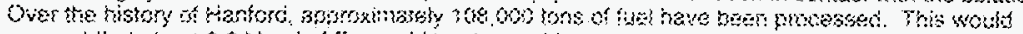

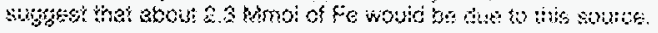

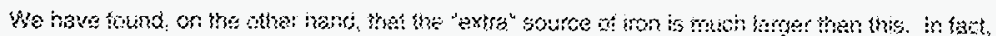

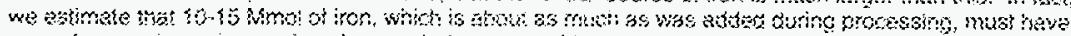

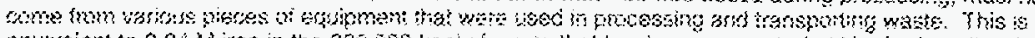

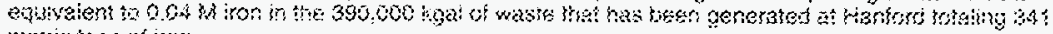
newatis tors of isost.

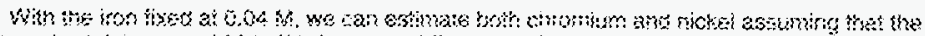

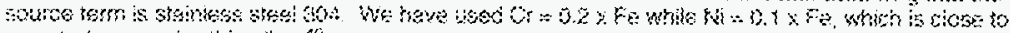
rephes tanges to this allow.

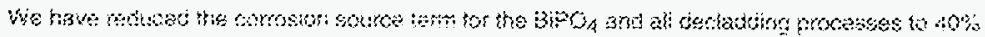

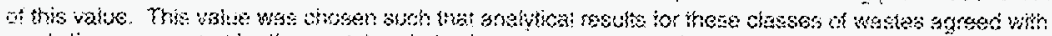

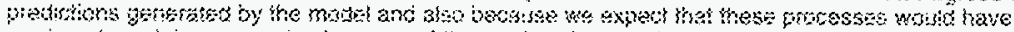

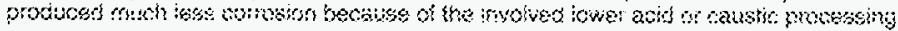

\section{Thsibicats xauree terms}

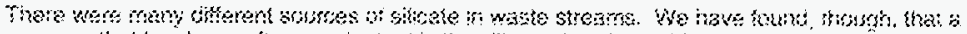

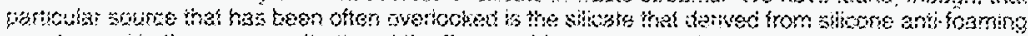

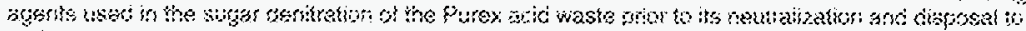
isns.

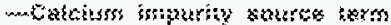

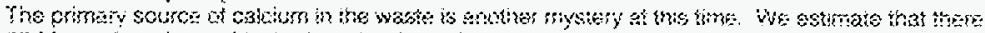

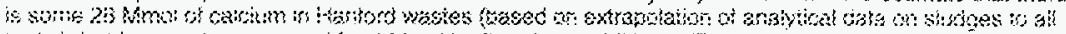

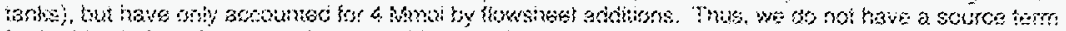

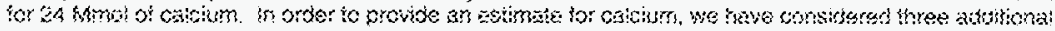
soures.

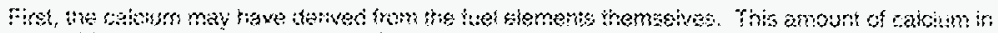

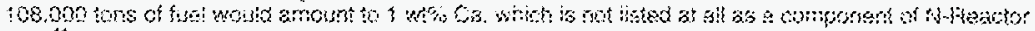

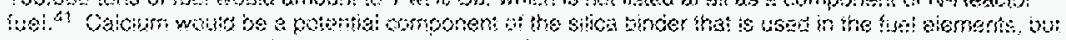

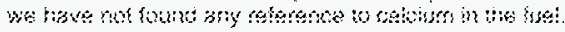

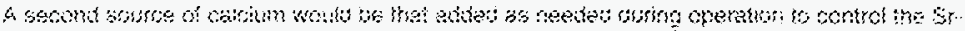

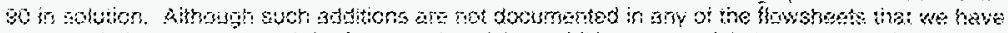

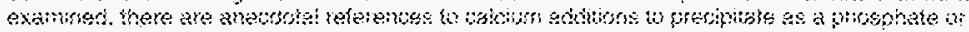

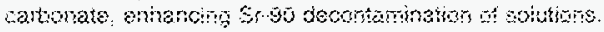

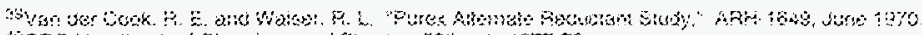

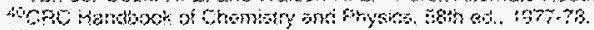

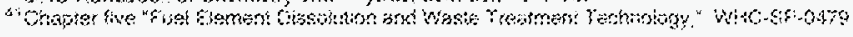




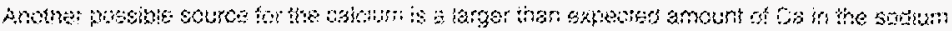

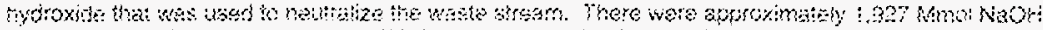

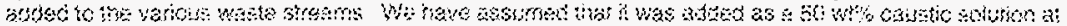

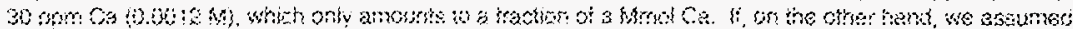

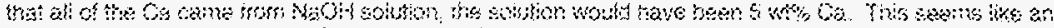

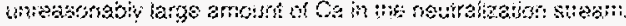

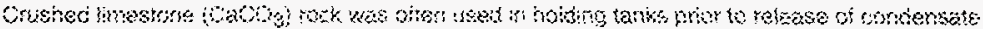

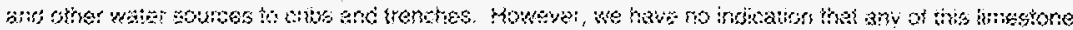

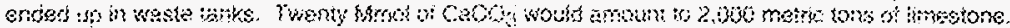

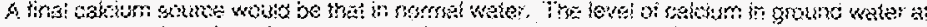

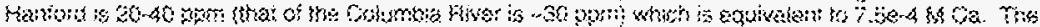

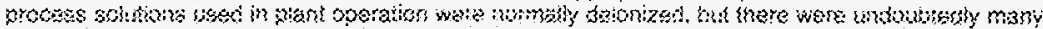

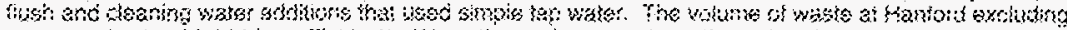

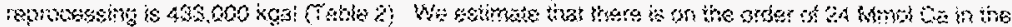

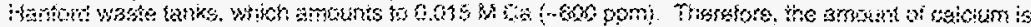

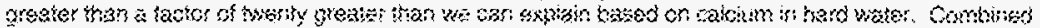

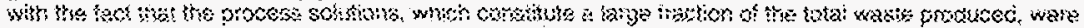

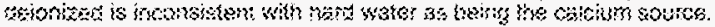

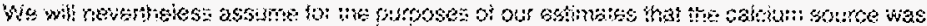

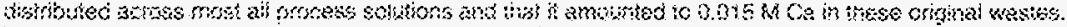

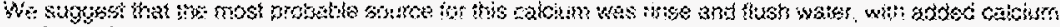

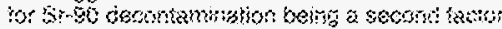

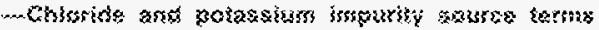

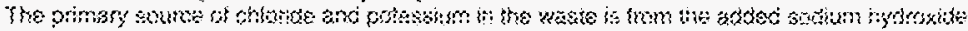

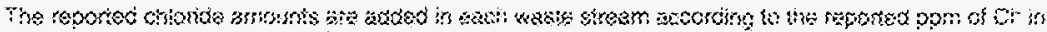

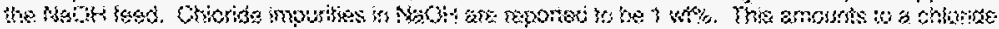

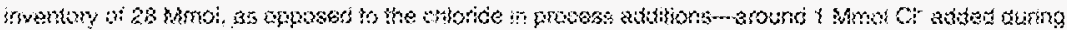

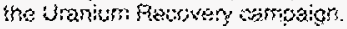

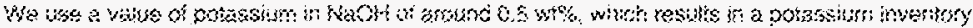
of is smols for all whits

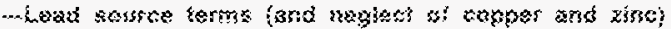

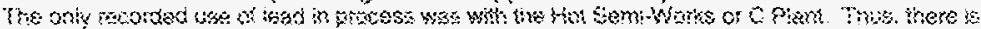

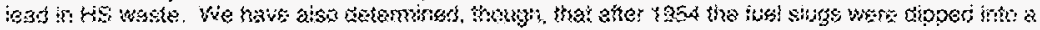

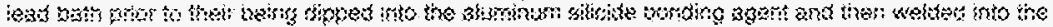

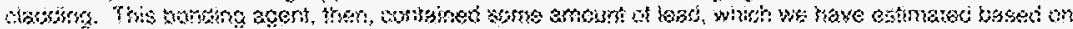

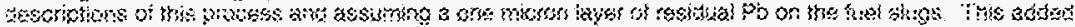

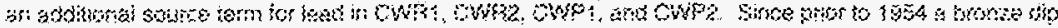

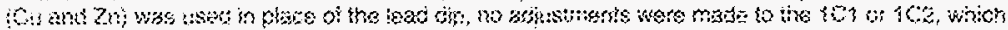

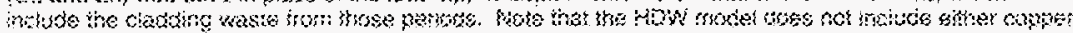

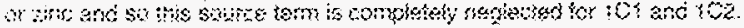

\section{Trisksm iosses}

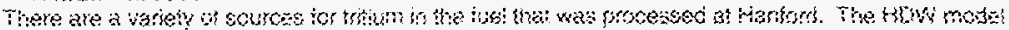

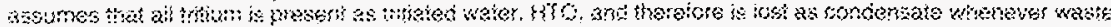

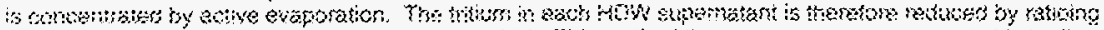

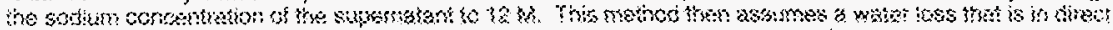

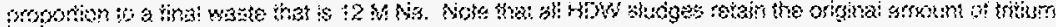

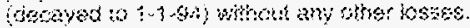




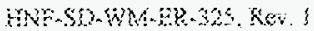

\section{Varbbitites fo: HOW Bhodel Extimates}

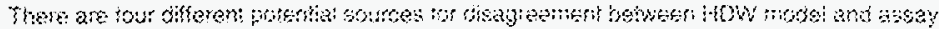

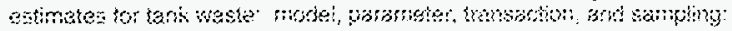

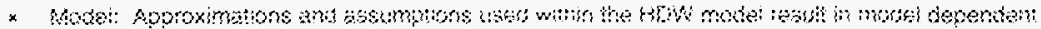

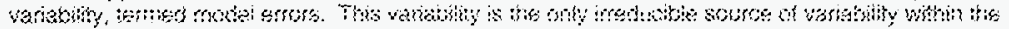

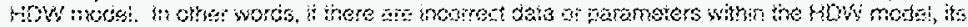

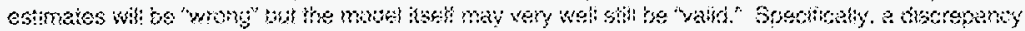

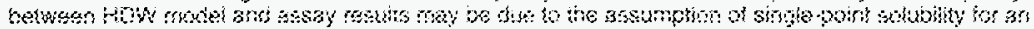

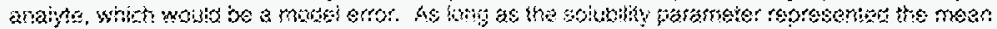

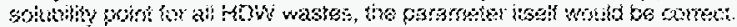

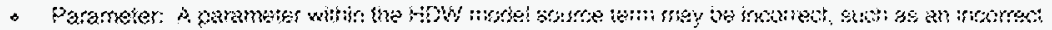

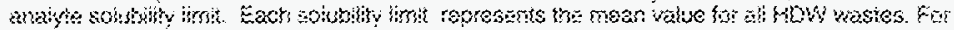

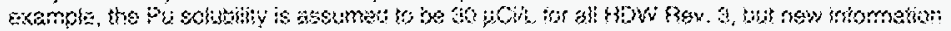

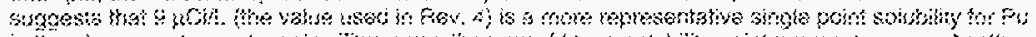

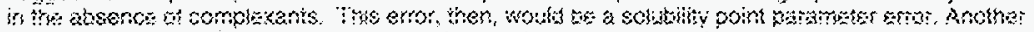

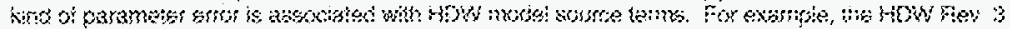

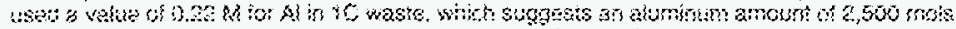

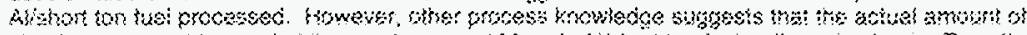

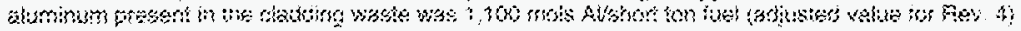

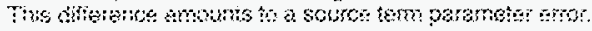

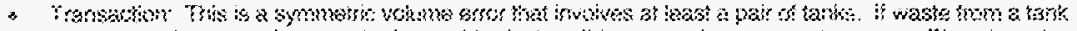

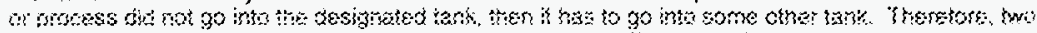

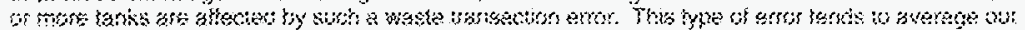

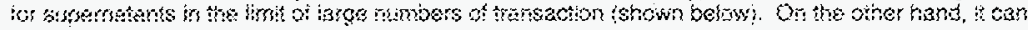

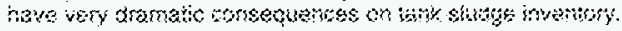

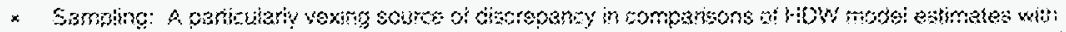

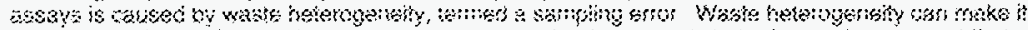

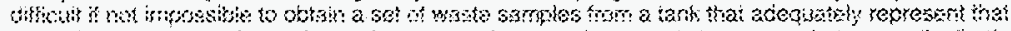

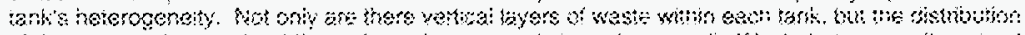

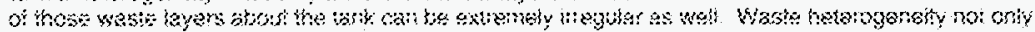

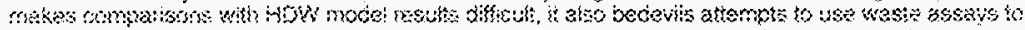

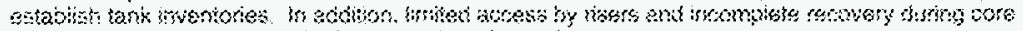

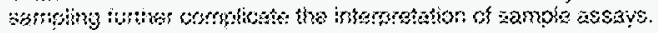

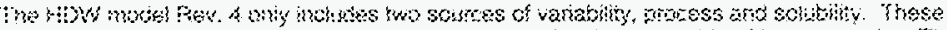

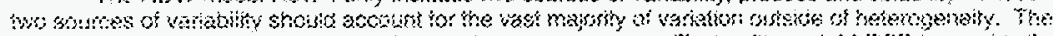

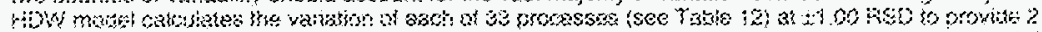

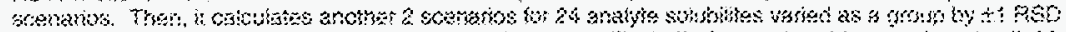

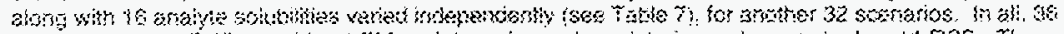

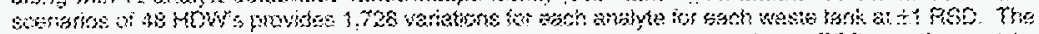

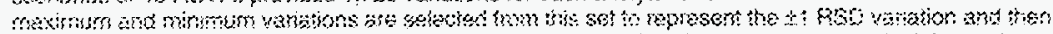

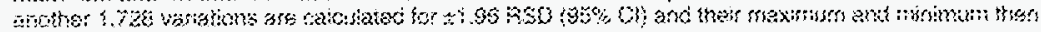

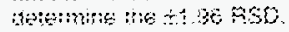

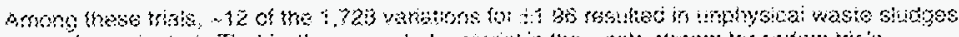

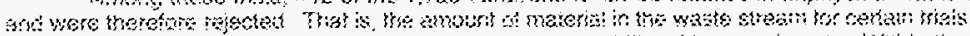

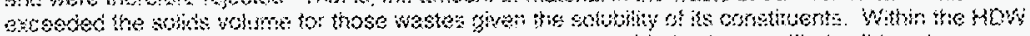

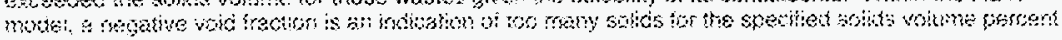
it the wats.

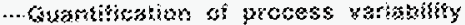

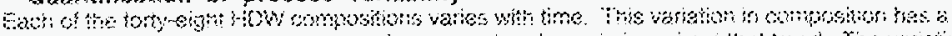

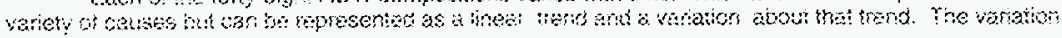




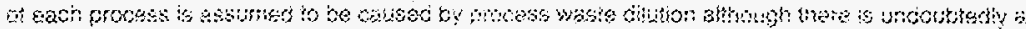

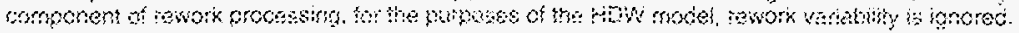

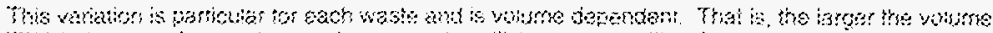

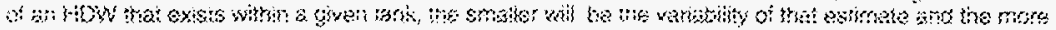

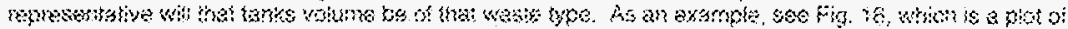

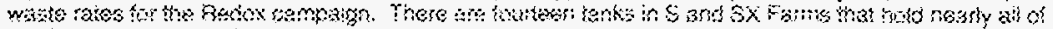

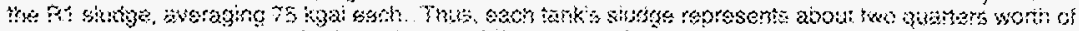

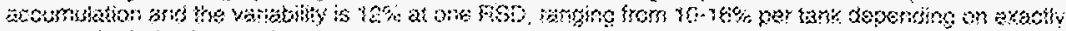

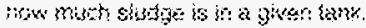

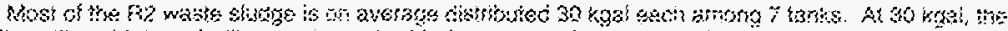

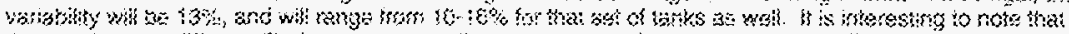

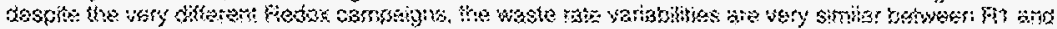
Fi:

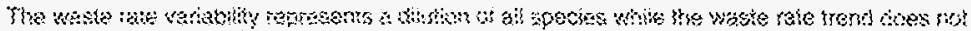

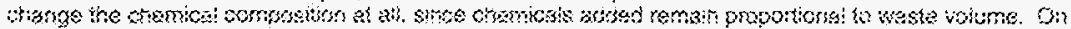

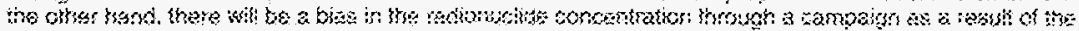

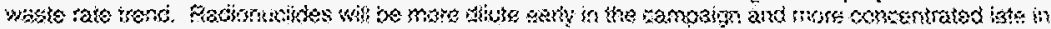

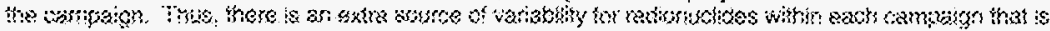

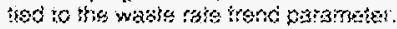

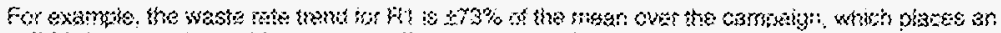

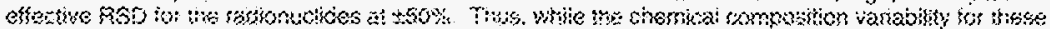

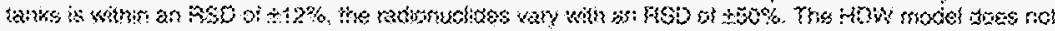

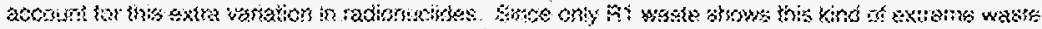

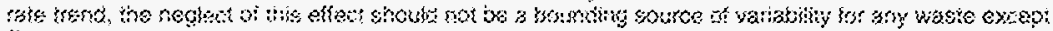
?.

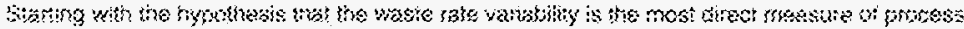

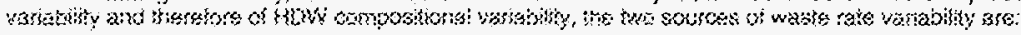

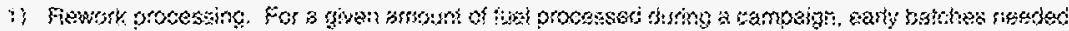

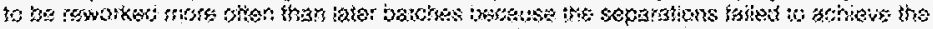

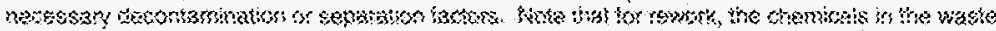

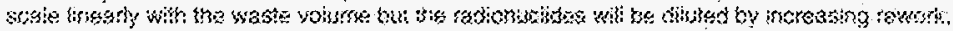

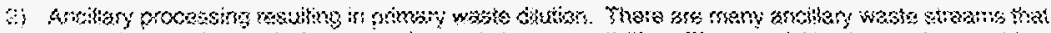

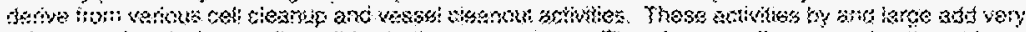

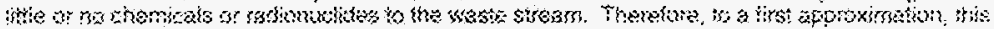

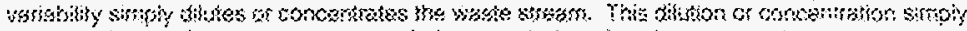

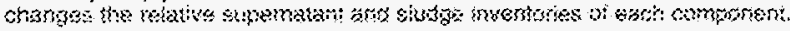

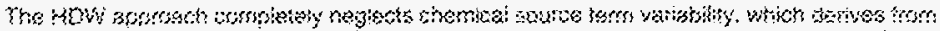

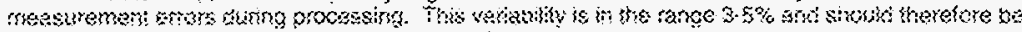

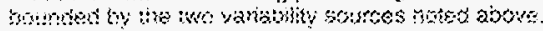

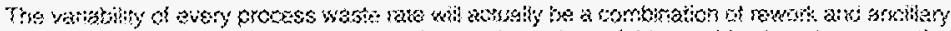

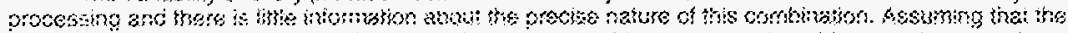

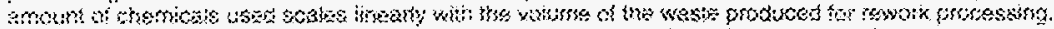

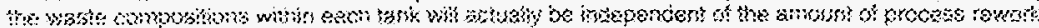

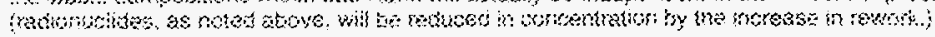




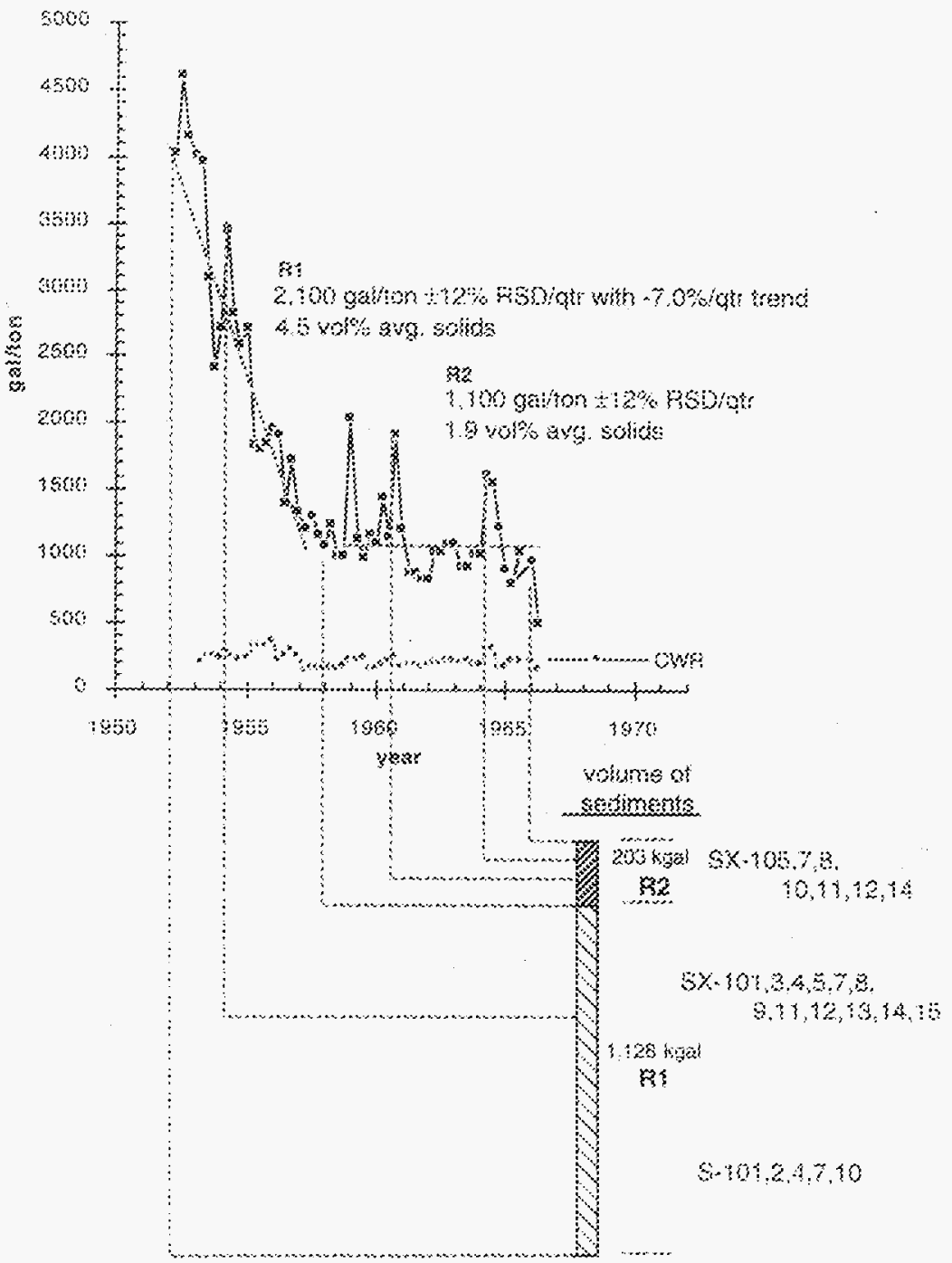

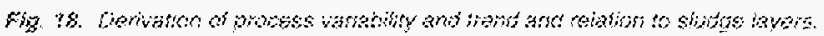




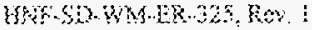

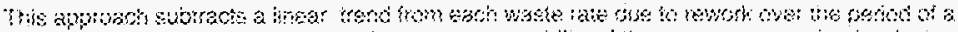

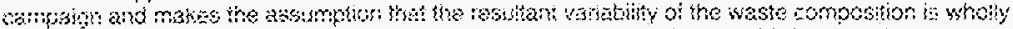

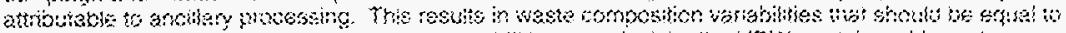

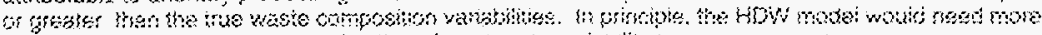

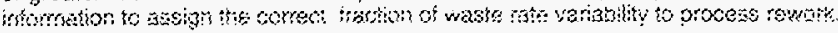

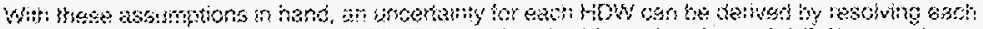

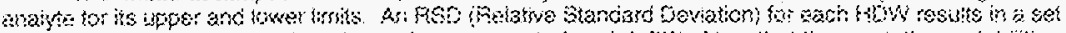

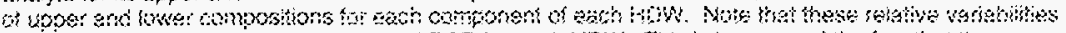

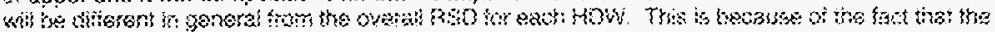

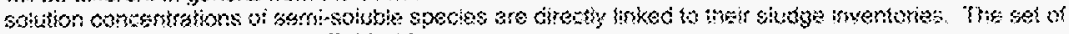

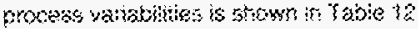

\begin{tabular}{|c|c|c|c|c|c|c|}
\hline HDW 1 \%कe & 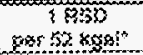 & $\begin{array}{l}3.35655 \\
\text { gsi } 42533\end{array}$ & 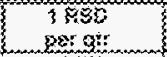 & $\begin{array}{c}\text { swets: } \\
\text { perasy }\end{array}$ & $\begin{array}{c}\text { wosbe rese } \\
\text { xssuss? }\end{array}$ & 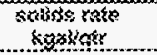 \\
\hline What & $\$ 8$ & $106 \%$ & 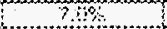 & 946 & 86 & 92,9 \\
\hline $\mathrm{Nak}$ & $2 S \%$ & $243 \%$ & 36 & 0,8 & 817 & 0 \\
\hline 4 & Es & $396 \%$ & $44 \%$ & $\therefore 86$ & 583 & 560 \\
\hline 3 & 36.0 & Eथ & RBO & 38 & 82 & 15 \\
\hline 21 & $5.4 \%$ & 363 & $36 \%$ & $\therefore \%$ & 485 & 30 \\
\hline$\alpha$ & $2.3 \%$ & $24 \%$ & $15.5 \%$ & 13.8 & 100 & 340 \\
\hline 23 & $60^{2}$ & 2746 & 3 & & & \\
\hline WOE & $12^{36}$ & $35 \%$ & 216 & 746 & $303 !$ & 386 \\
\hline i & $13.2 \%$ & $36 \%$ & $147 \%$ & $5 \%$ & 923 & d!. \\
\hline 2 & $76 \%$ & 153 & $251 \%$ & 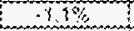 & $3 \%$ & $6 \%$ \\
\hline SWF! & 36 & $325 \%$ & SOA\% & $61\} \%$ & 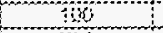 & S \\
\hline 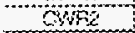 & $0,5 \%$ & $3 \%$ & $8 \%$ & 320 & $5 \%$ & 26 \\
\hline 8 & $208 \%$ & $325 \%$ & 326 & $0.6 \%$ & $\$ 86$ & 23.6 \\
\hline$\theta$ & $335 \%$ & $5 \times$ & $44 \%$ & $86 \%$ & 483 & 326 \\
\hline$F L$ & $16 \%$ & $28 \%$ & $85,0 \%$ & 382 & 3 & 28 \\
\hline 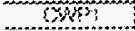 & $80 \%$ & $33 . \%$ & $33 \%$ & $\therefore 3 \%$ & 303 & $24 ?$ \\
\hline Mow & $35.5 \%$ & $19 \%$ & 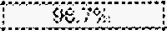 & 37 & 56 & 161 \\
\hline 3046 & $35 \mathrm{~s}$ & 93 & + & & & \\
\hline ovols & $38 \%$ & 320 & 766 & $39 \%$ & 255 & 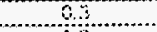 \\
\hline Ovise & 676 & 134 & 458 & $0.6 \%$ & $513 \%$ & 68 \\
\hline and & $868 \%$ & 21, & 30 今\% & $8 \%$ & 33 & 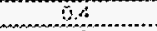 \\
\hline$z$ & $39 \%$ & $\$ 816 \%$ & $86 \%$ & $37 \%$ & 835 & 19 \\
\hline 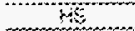 & 139 & $38 \mathrm{~d}$ & 3 & & & \\
\hline 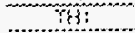 & 339 & $664 \%$ & 4 & & & \\
\hline ithe & $32 \%$ & 654 & 5 & & & \\
\hline$B$ & $67 \%$ & 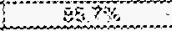 & $106 \%$ & 3310 & 82 & 08 \\
\hline$E L$ & $37 \%$ & $3 \%$ & $363 \%$ & $20 \%$ & 80 & 32 \\
\hline 80 & $36 \%$ & $360 \%$ & Q36\% & $\because 2$ & 503 & $\therefore 6$ \\
\hline 13 & $33 \%$ & 301 & 722 & $105 \%$ & 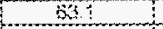 & 25 \\
\hline 12 & $295 \%$ & 3730 & B:S: & $43 \%$ & 37 & 3 \\
\hline कor & 563 & $966^{*}$ & $1 \% 6^{*}$ & $25 \%$ & 25 & 23 \\
\hline For & $30^{9}$ & 137 & $\$ 8 m$ & $3.5 \%$ & 38 & مع \\
\hline
\end{tabular}

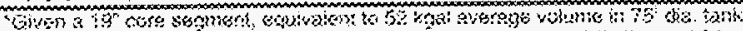

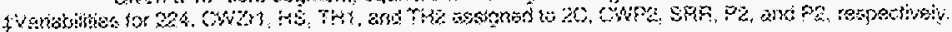

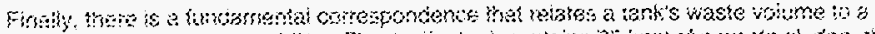

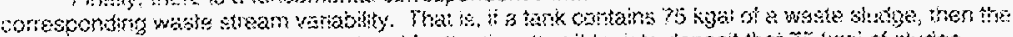

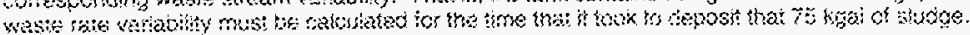

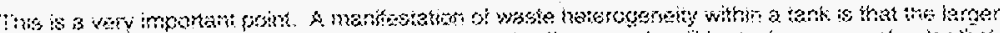

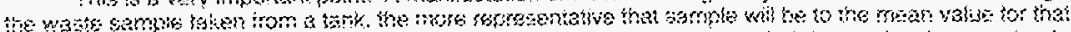

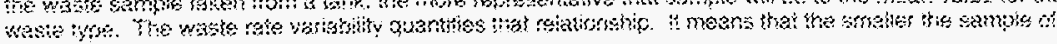




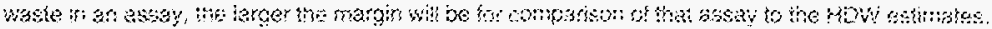

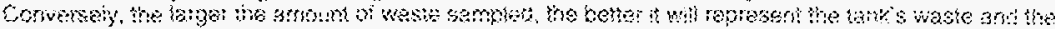

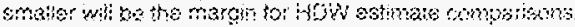

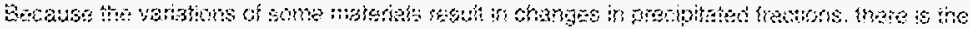

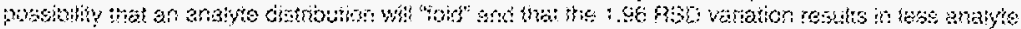

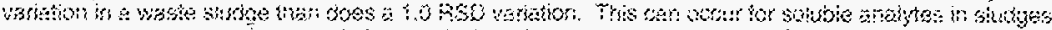

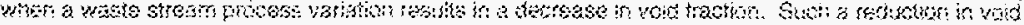

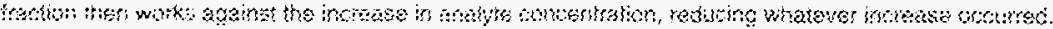

The expossin tor a siughe andigte is

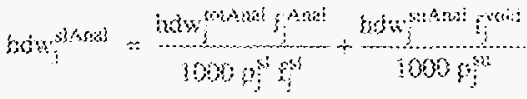

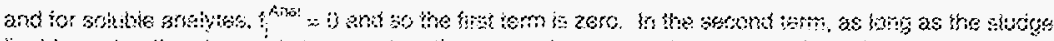

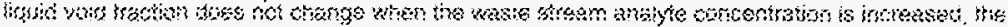

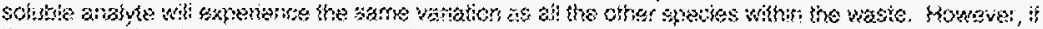

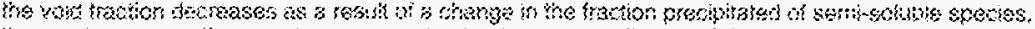

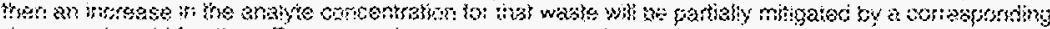

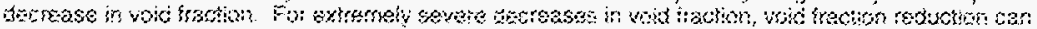

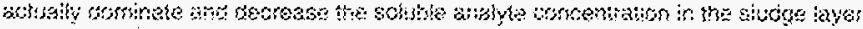

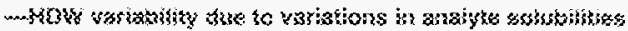

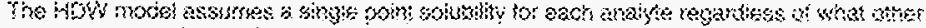

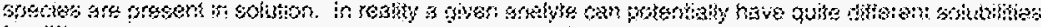

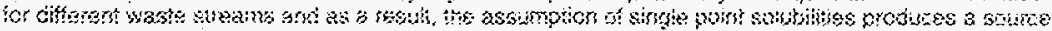

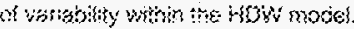

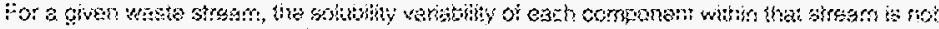

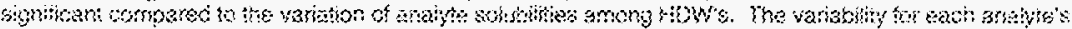

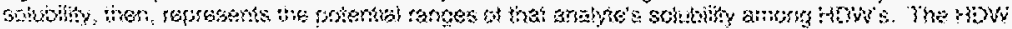

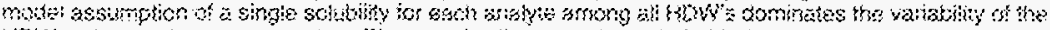

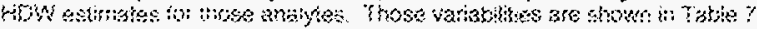

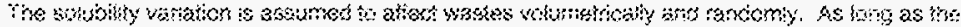

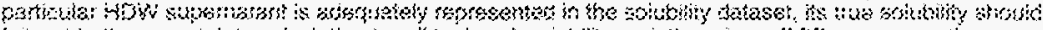

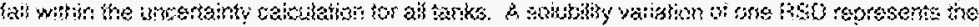

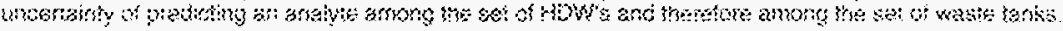

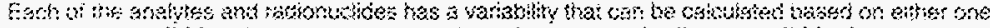

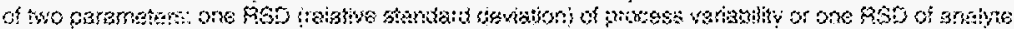

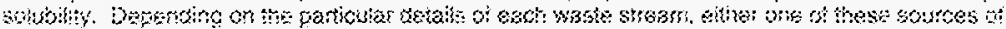

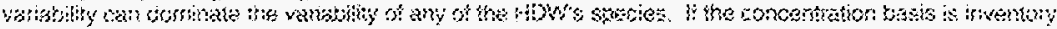

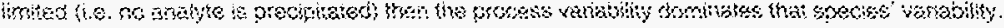

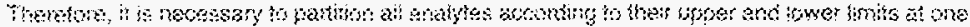

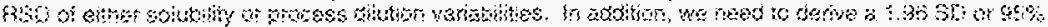

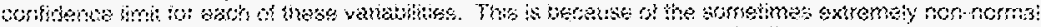
distowions :

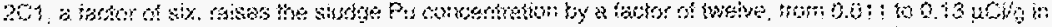

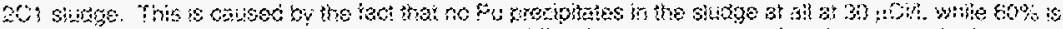

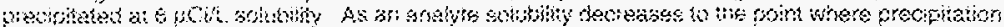

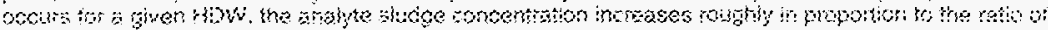

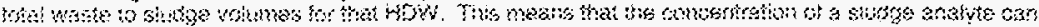

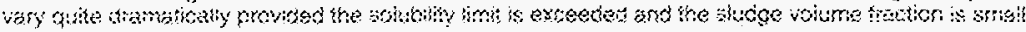




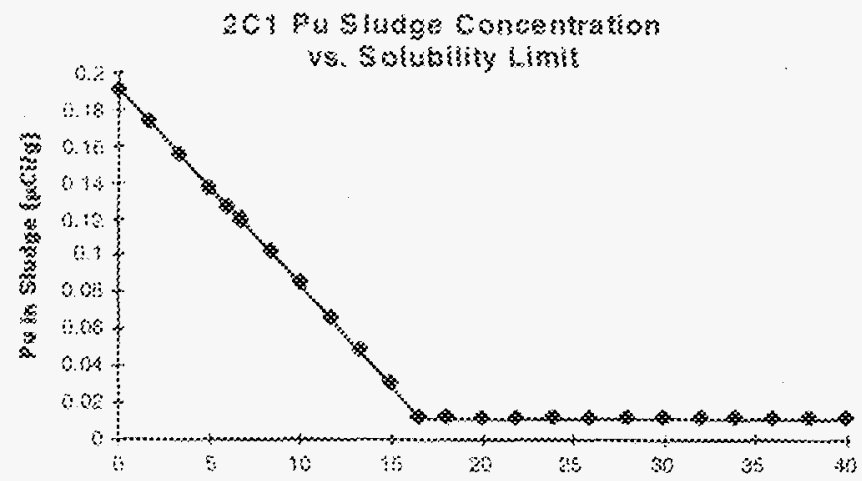

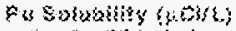

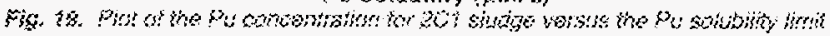

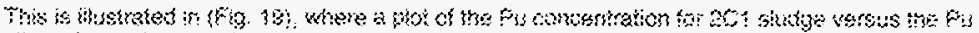

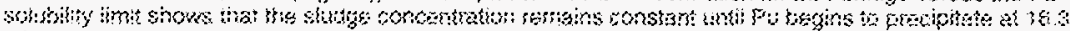

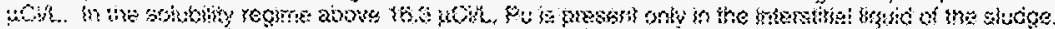

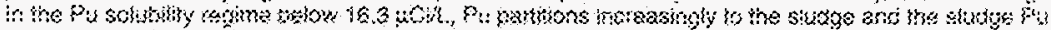

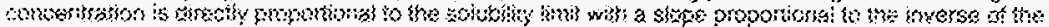

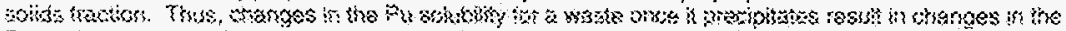

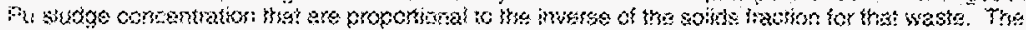

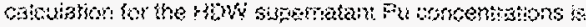

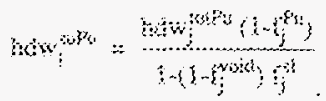

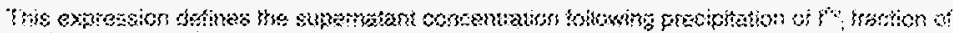

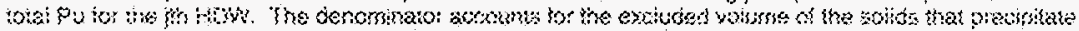

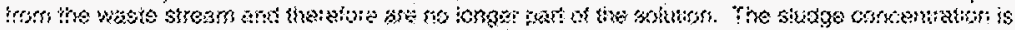
akicistated iss

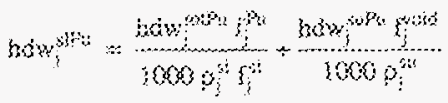

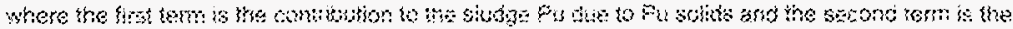

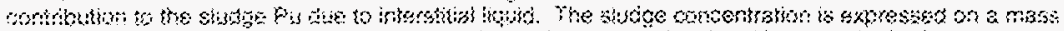

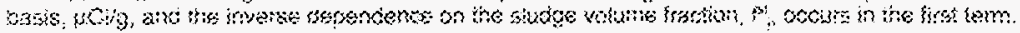

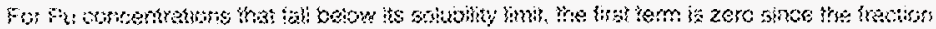
oreciptatod is zaro as

$$
\text { Fin }
$$

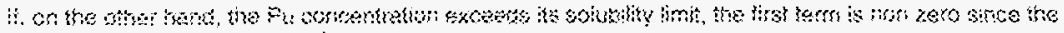

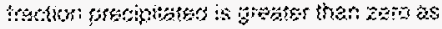


sinese

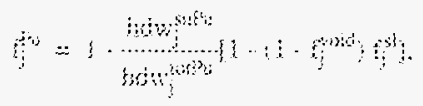

$\operatorname{sic}$

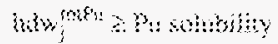

\begin{tabular}{|c|c|c|}
\hline $4 w_{j} ; t=$ & $\because$ & 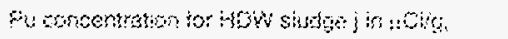 \\
\hline suf?: & $\therefore$ & 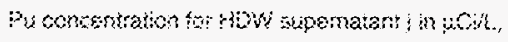 \\
\hline 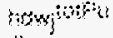 & $\therefore$ & 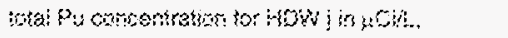 \\
\hline & 2 & 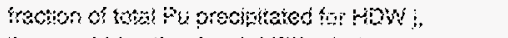 \\
\hline & $\therefore$ & 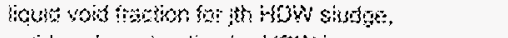 \\
\hline & $\because$ & 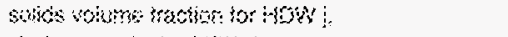 \\
\hline & $\therefore$ & 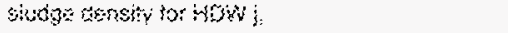 \\
\hline & $\because$ & 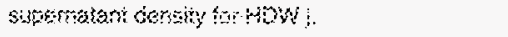 \\
\hline
\end{tabular}

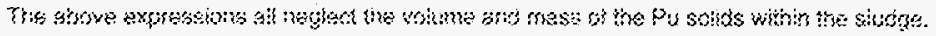

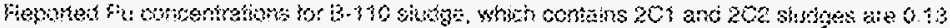

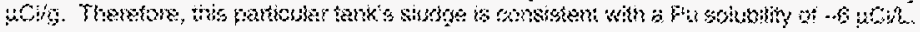

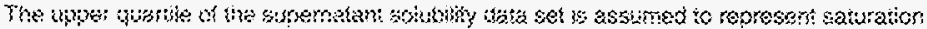

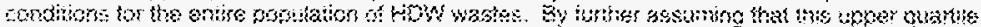

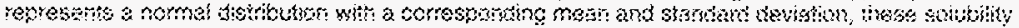

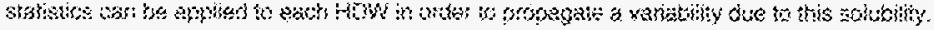

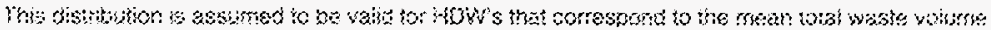

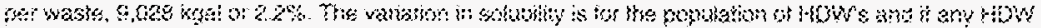

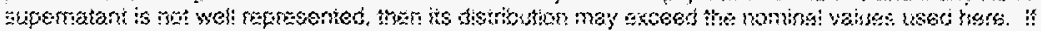

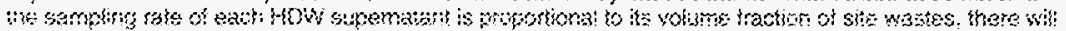

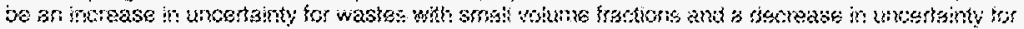

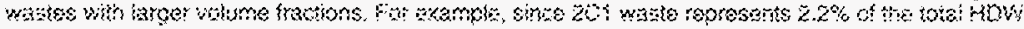

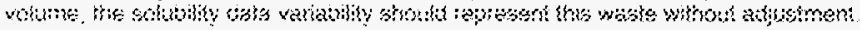

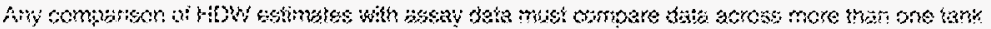

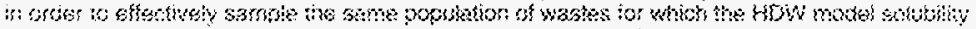

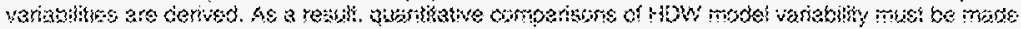

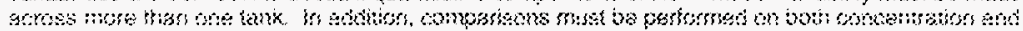

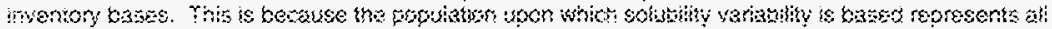

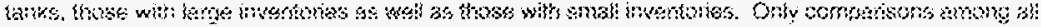

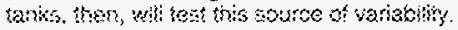

\section{-..rianadaction varizbistsy}

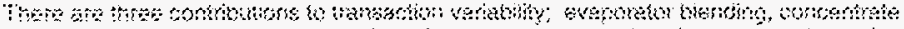

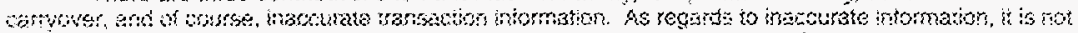

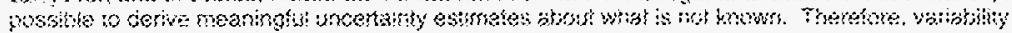

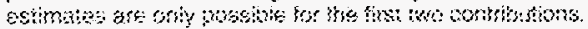

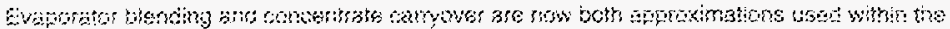

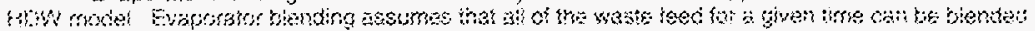

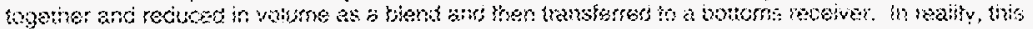

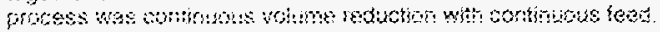

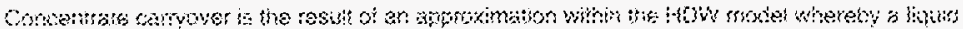

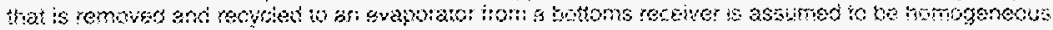




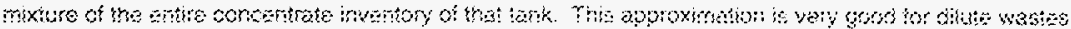

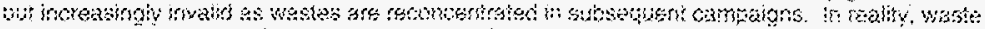

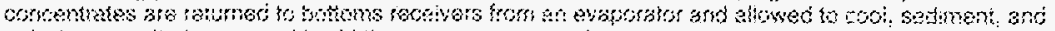

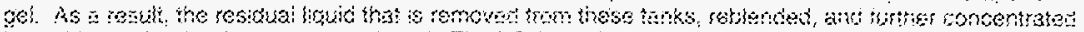

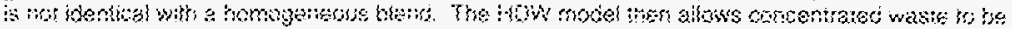

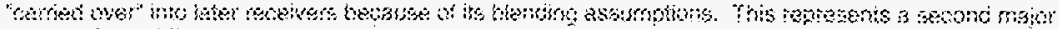

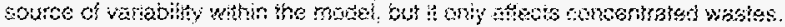

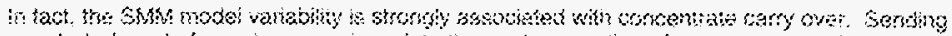

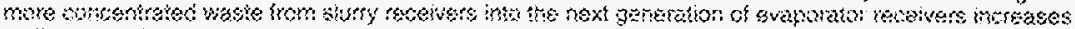

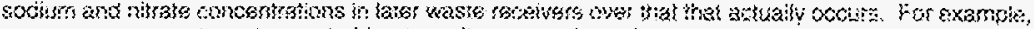

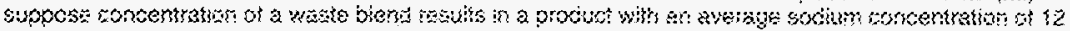

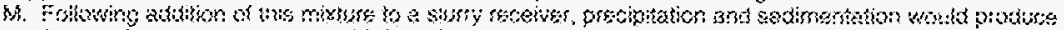

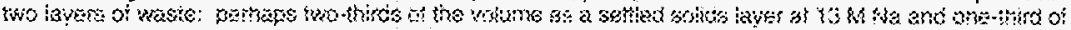

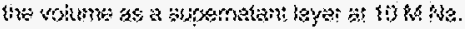

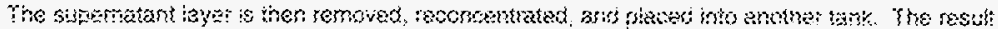

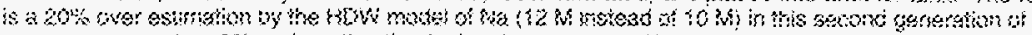

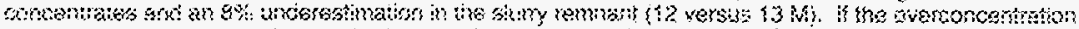

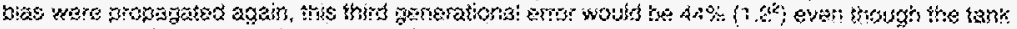

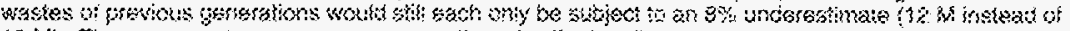

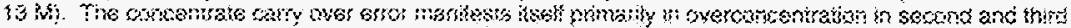

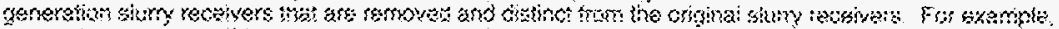

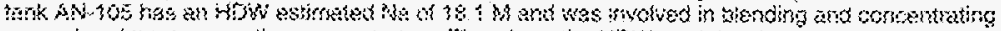

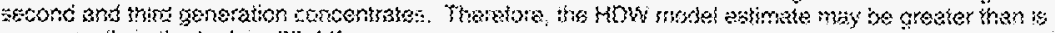

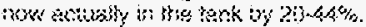

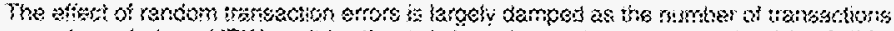

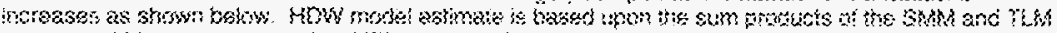

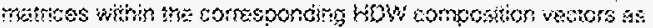

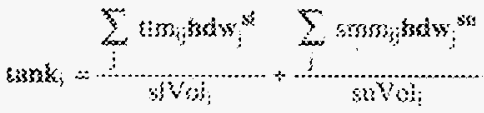

whens

\begin{tabular}{|c|c|c|}
\hline 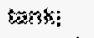 & $=$ & somecstich vecter icr tont: \\
\hline molws & $\because$ & 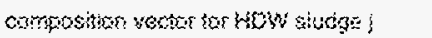 \\
\hline hosw & $=$ & 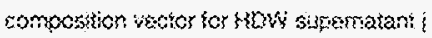 \\
\hline 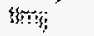 & $=$ & kad of hots sudge / tor tarks: \\
\hline smsin & $\Rightarrow$ & kgal ot how supemzant ! for tank: \\
\hline strot & $\because$ & sudge knat ior lank: \\
\hline wat & $\because$ & susematan roncentide kgat to tarik \\
\hline
\end{tabular}

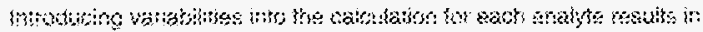

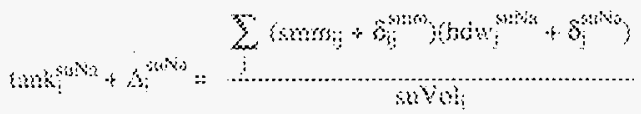

whore

$$
\begin{aligned}
& \therefore \text { in thin }
\end{aligned}
$$

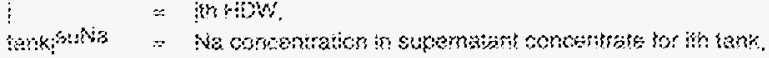




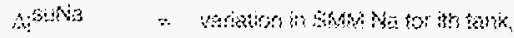

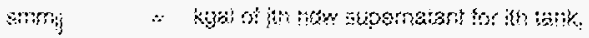

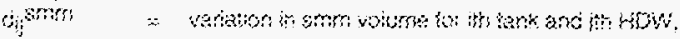

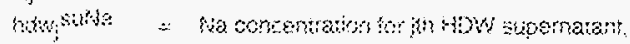

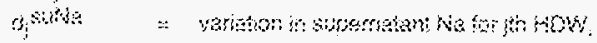

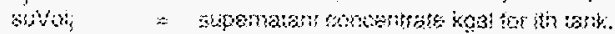

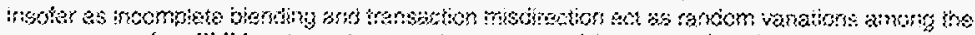

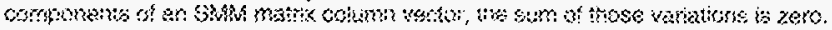

$$
s_{i}=0
$$

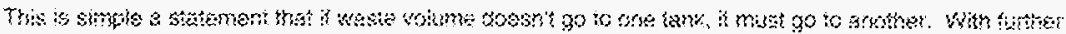

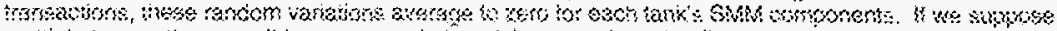

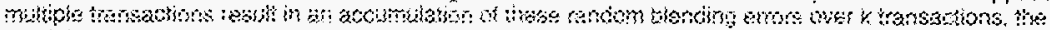
:astist is

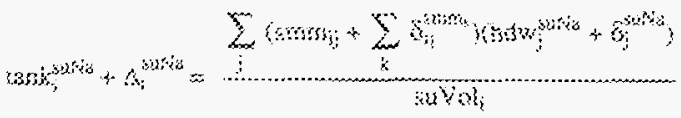

witese

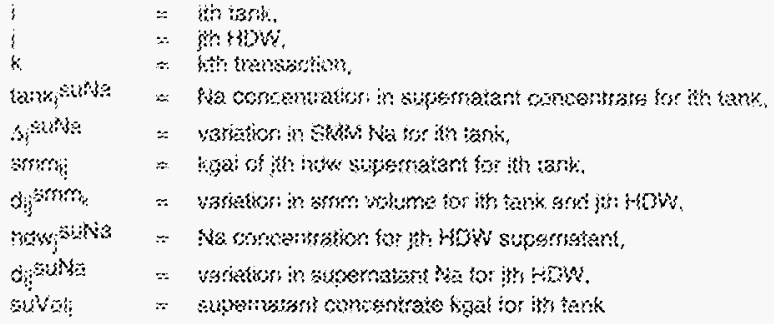

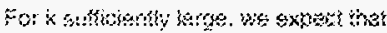

$$
\sum_{i}^{\infty} \pi_{i}: 0
$$

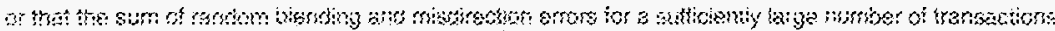

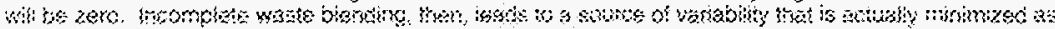

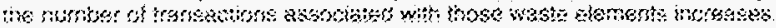

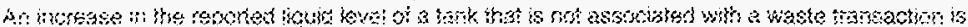

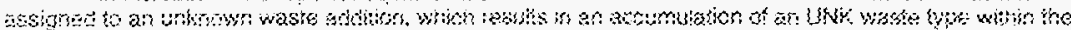

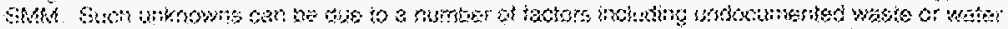

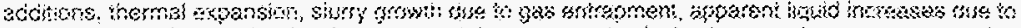

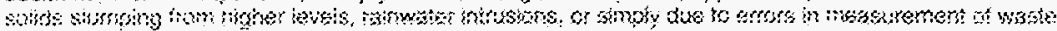

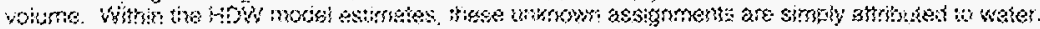

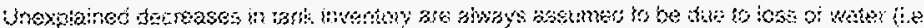

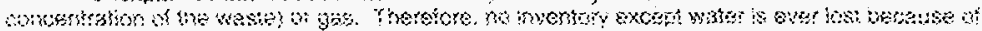




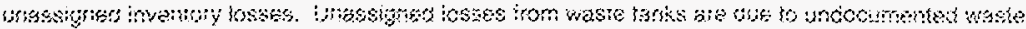

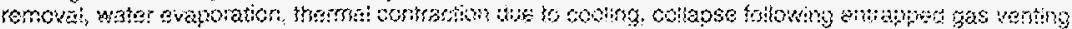

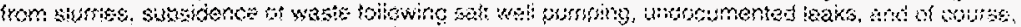

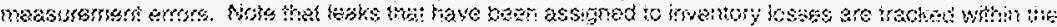
HoW rosst.

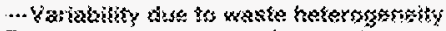

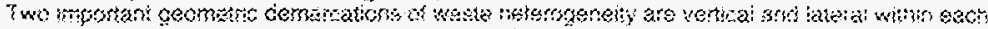

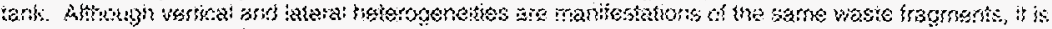

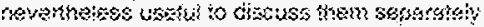

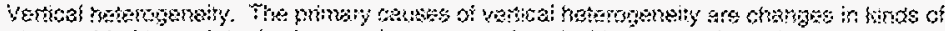

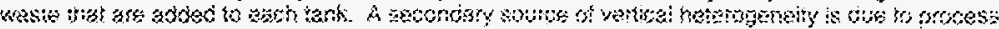

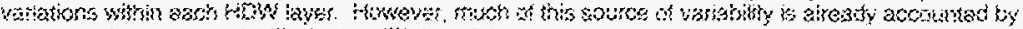

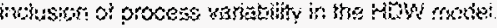

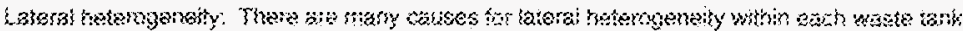

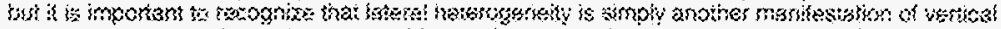

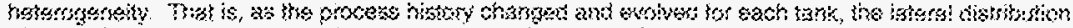

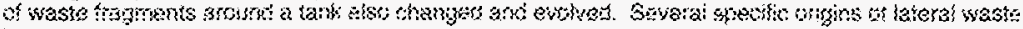

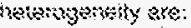

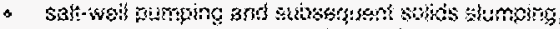

- knjizer sedimenton and sunpirn.

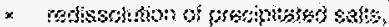

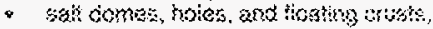

- bouk powhe unter risers and

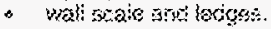

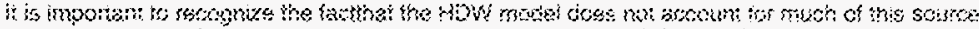

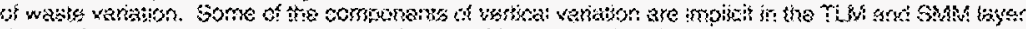

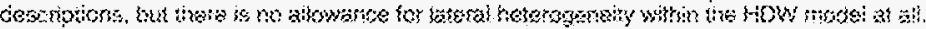

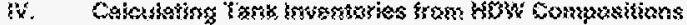

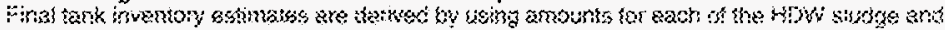

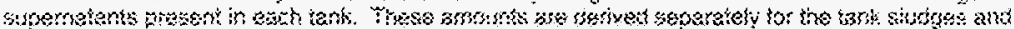

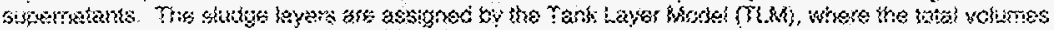

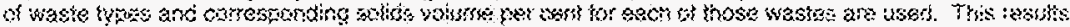

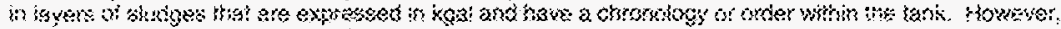

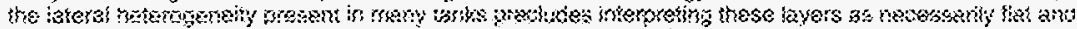

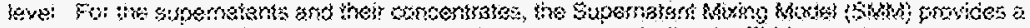

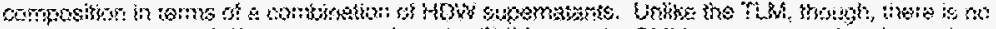

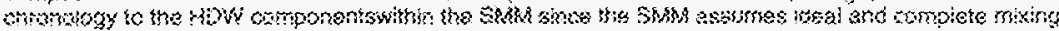

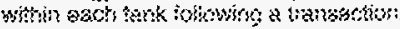

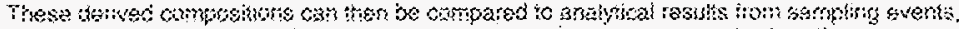

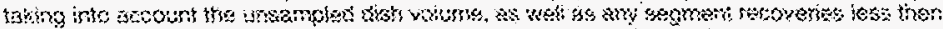

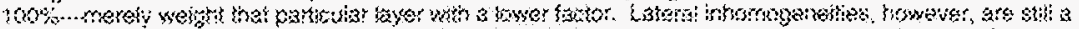

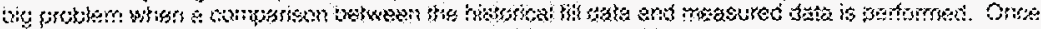

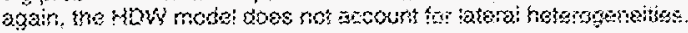

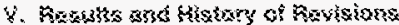

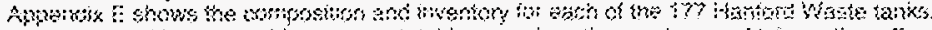

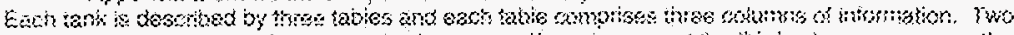

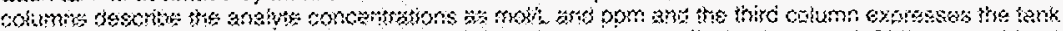

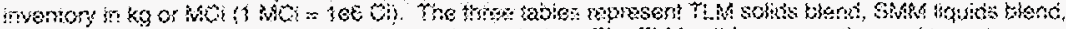

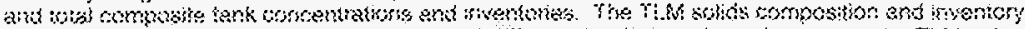

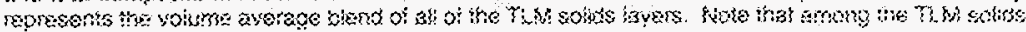




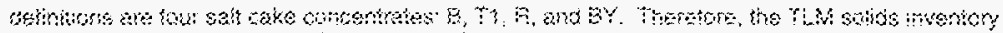

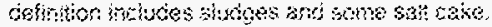

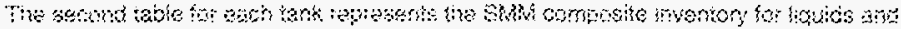

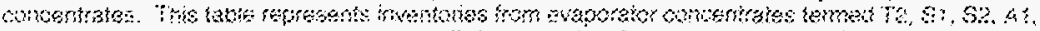

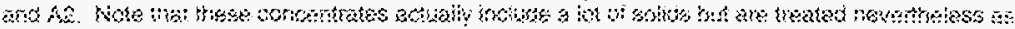

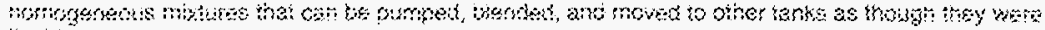
ings.

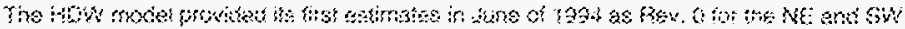

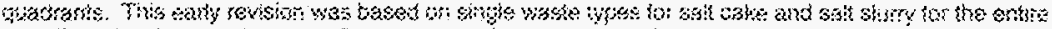

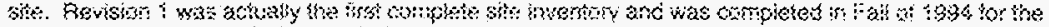

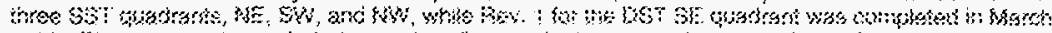

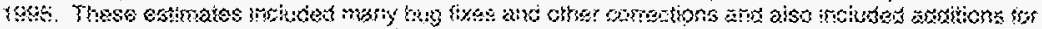

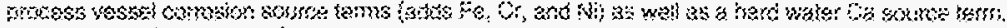

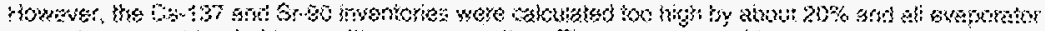

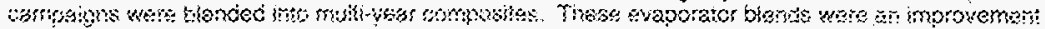

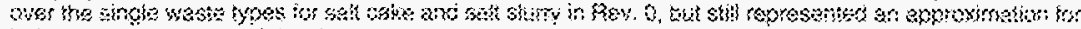

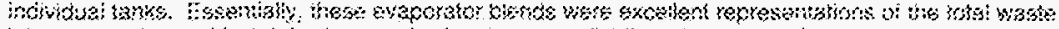

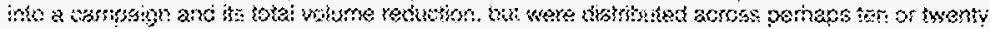

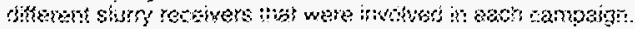

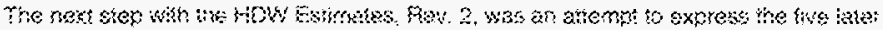

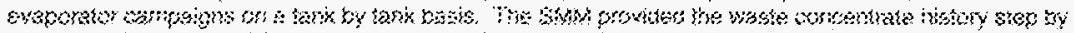

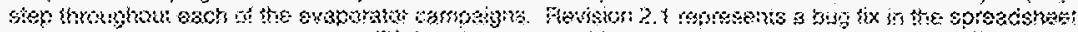

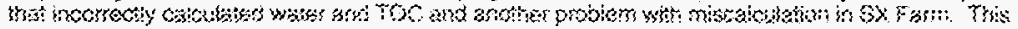

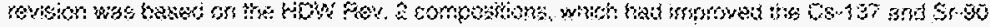

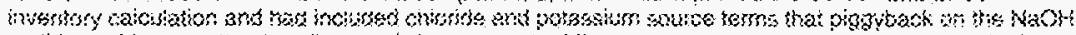

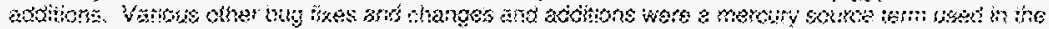

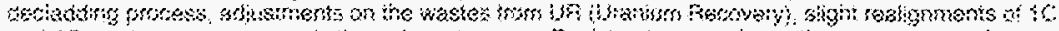

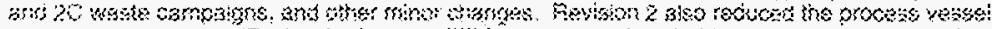

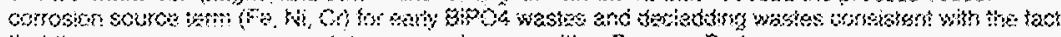

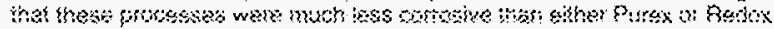

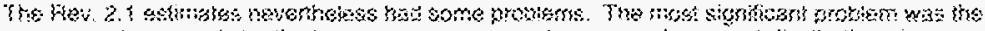

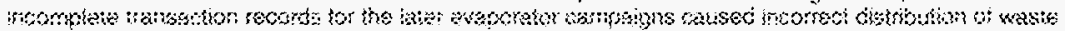

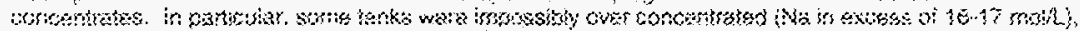

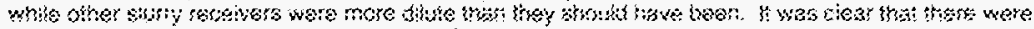

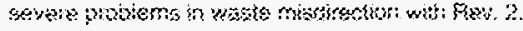

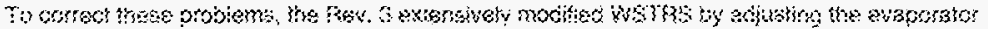

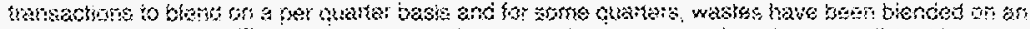

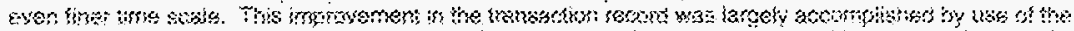

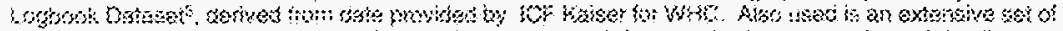

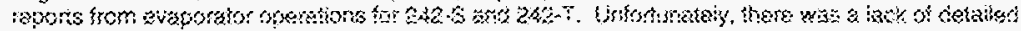

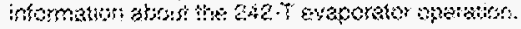

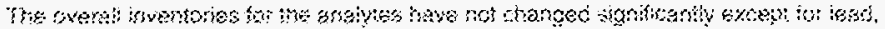

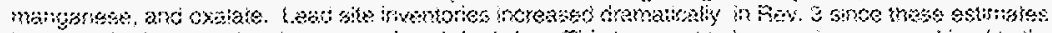

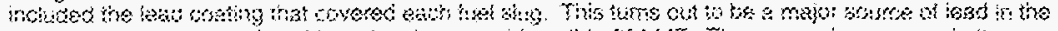

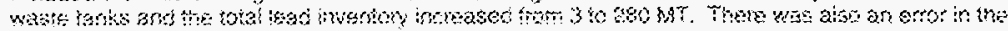

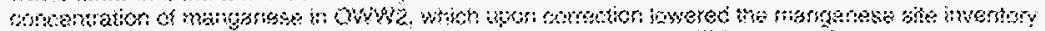

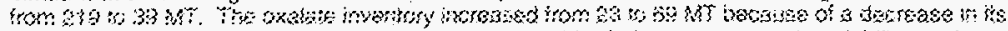

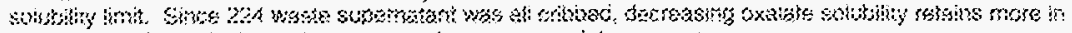

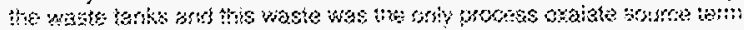




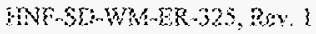

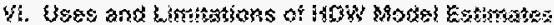

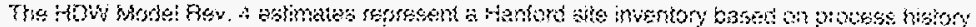

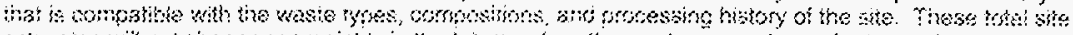

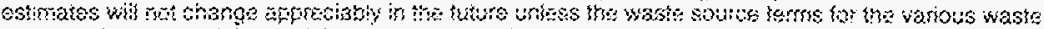

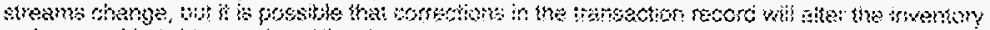

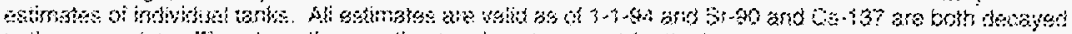

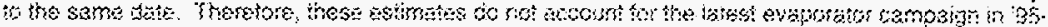

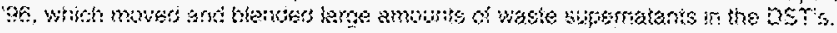

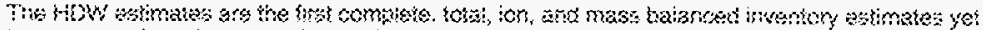

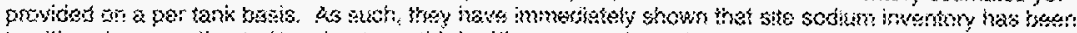

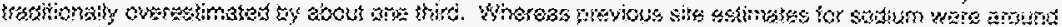

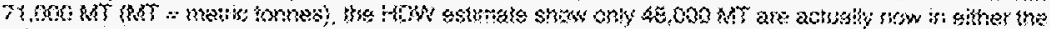

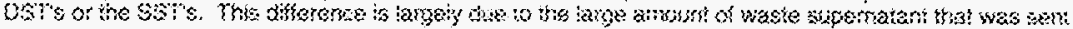

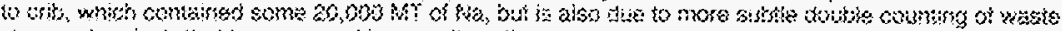

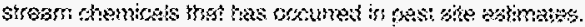

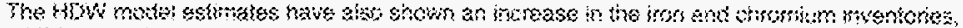

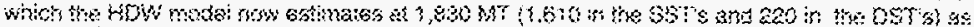

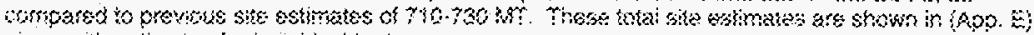

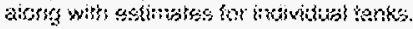

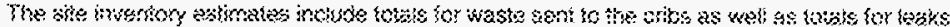

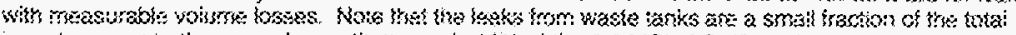

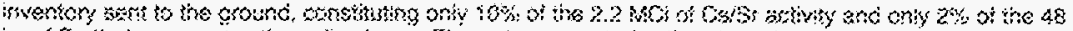

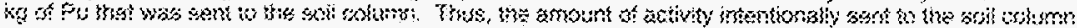

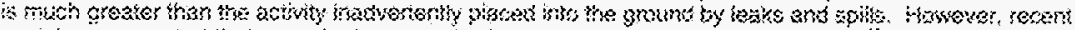

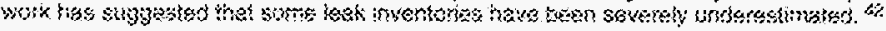

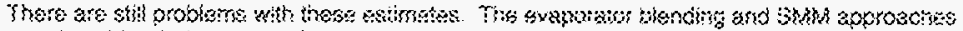

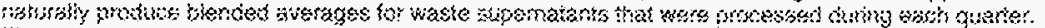

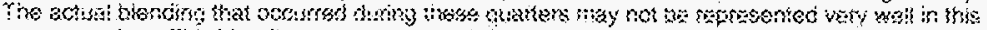

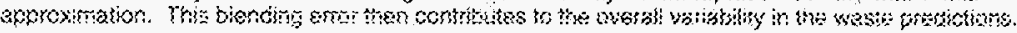

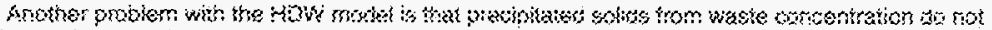

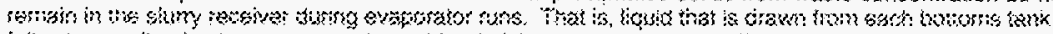

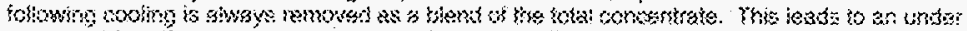

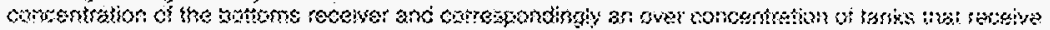

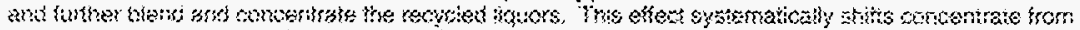

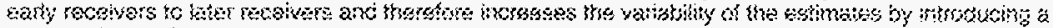

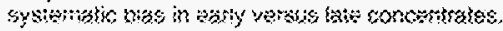

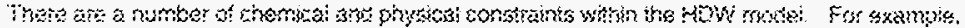

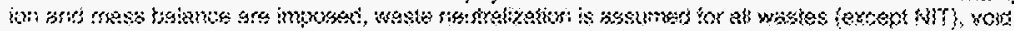

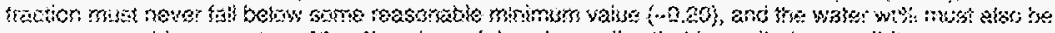

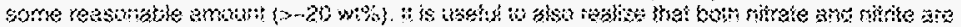

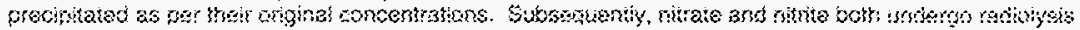

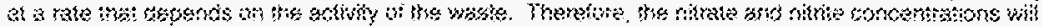

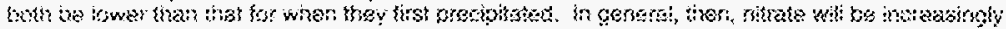

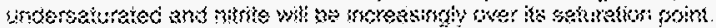

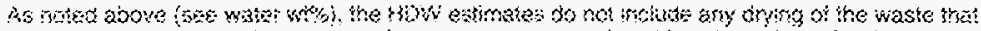

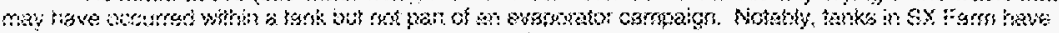

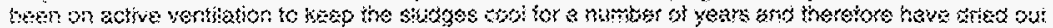

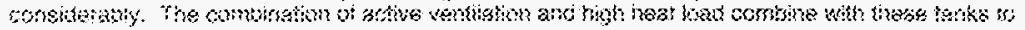

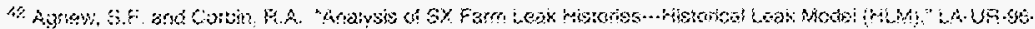
$35 \%$ ovtober isge
} 


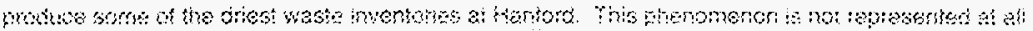
whth the mow moces.

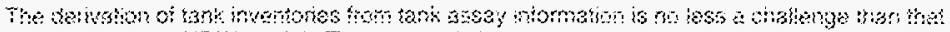

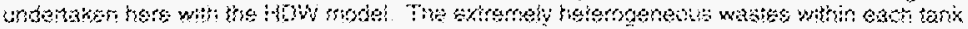

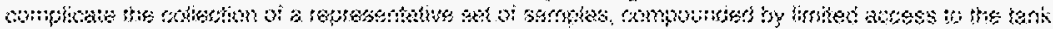

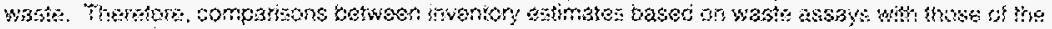

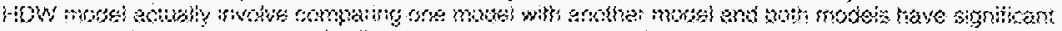

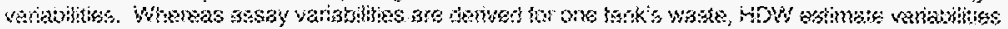

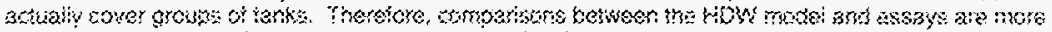

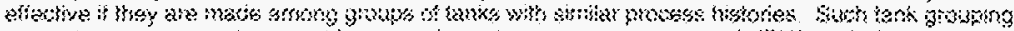

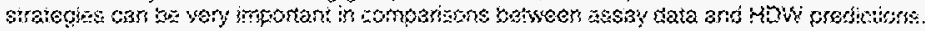

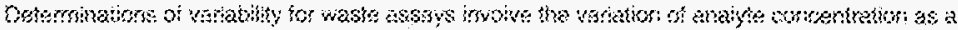

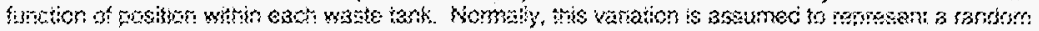

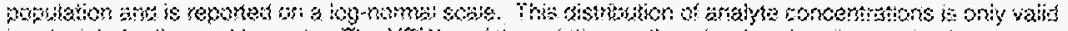

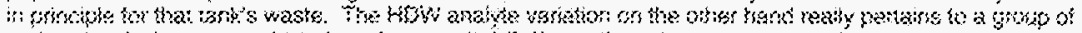

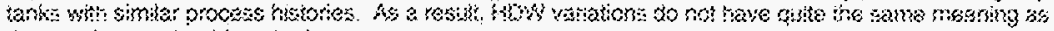

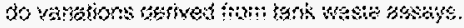




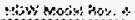

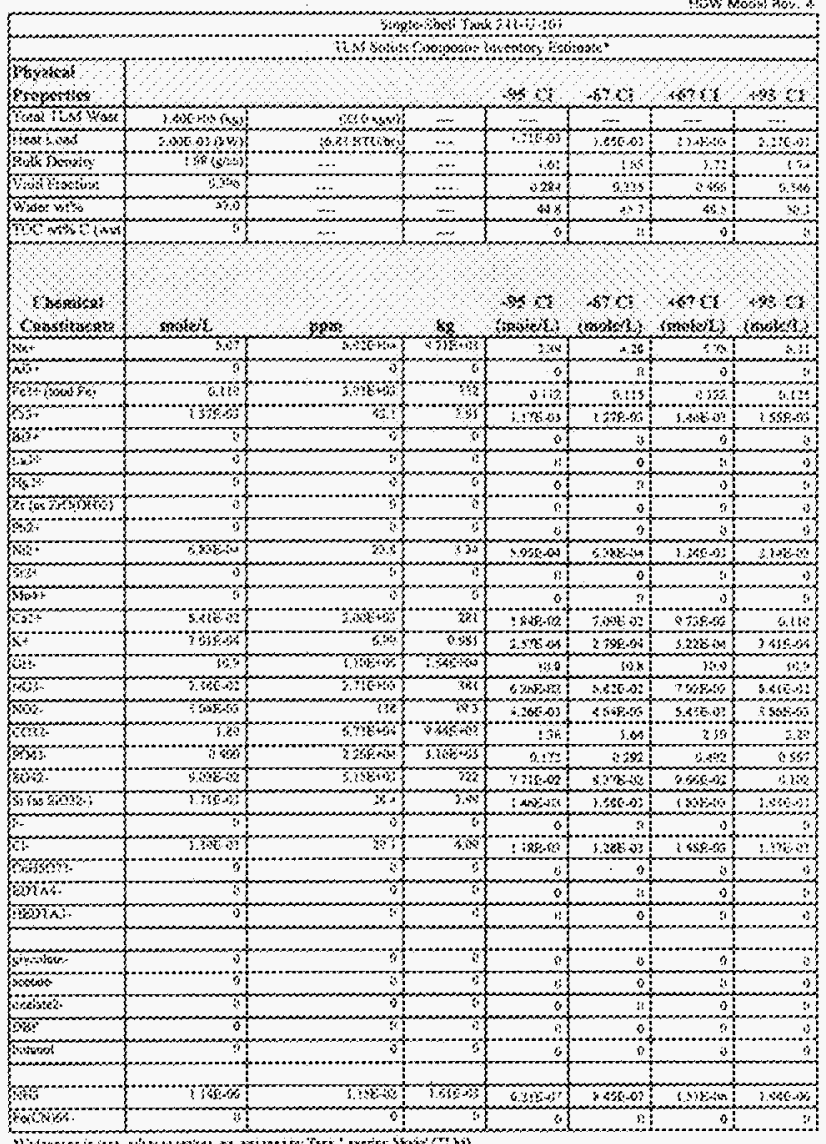

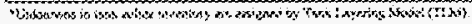




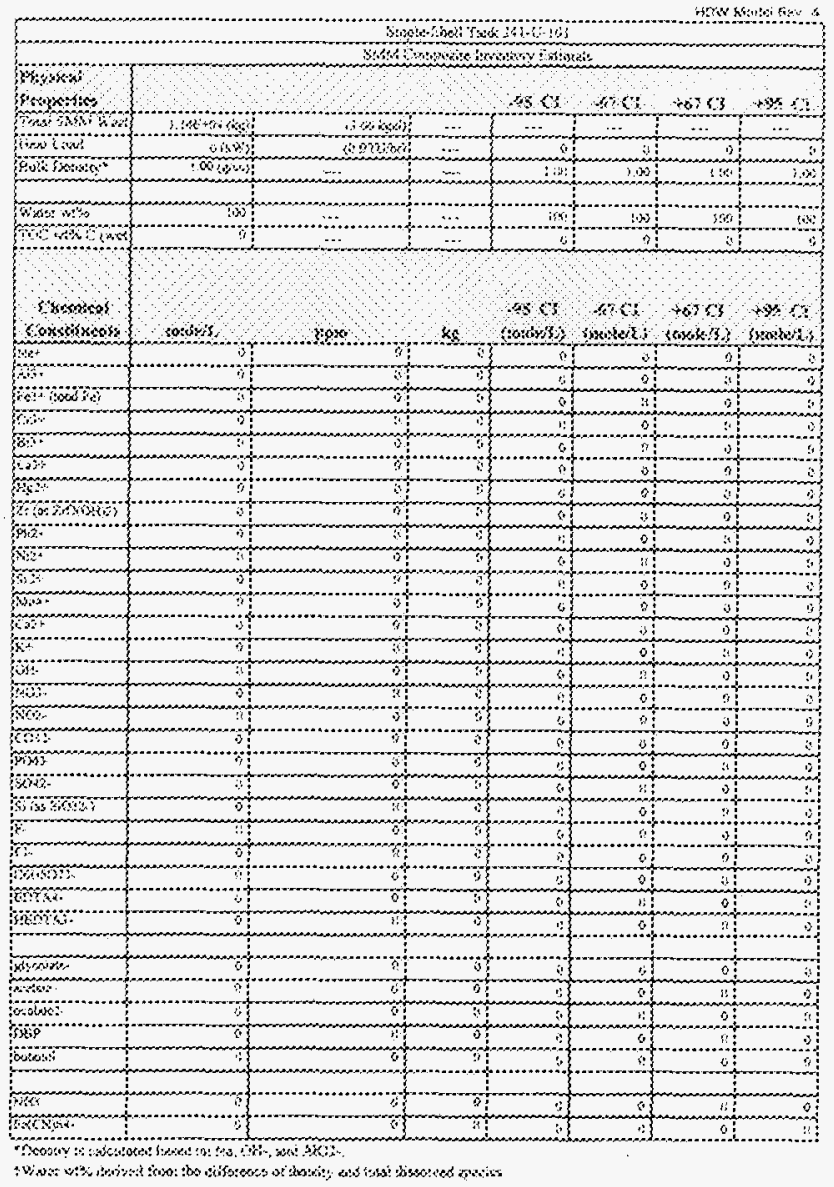




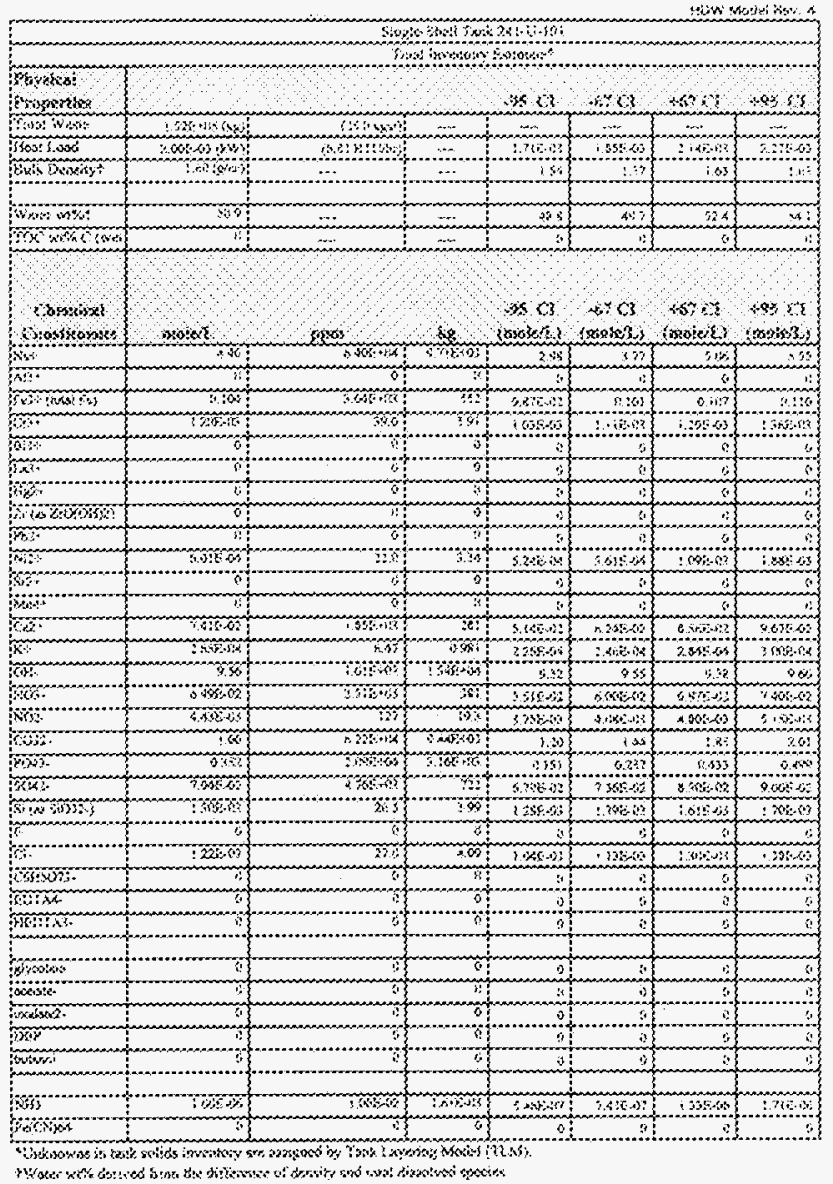


HEG

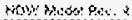

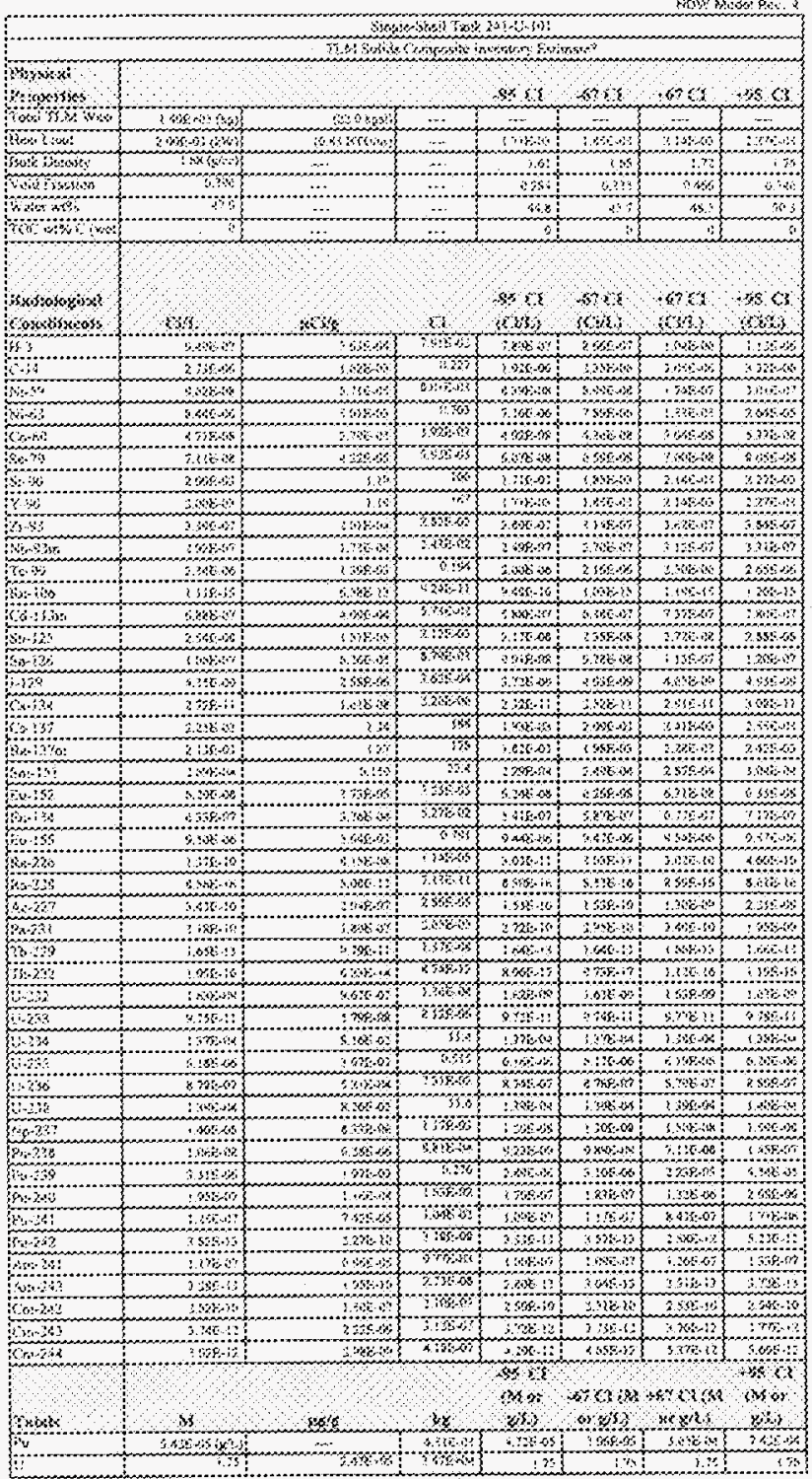

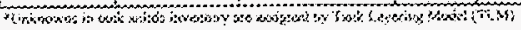




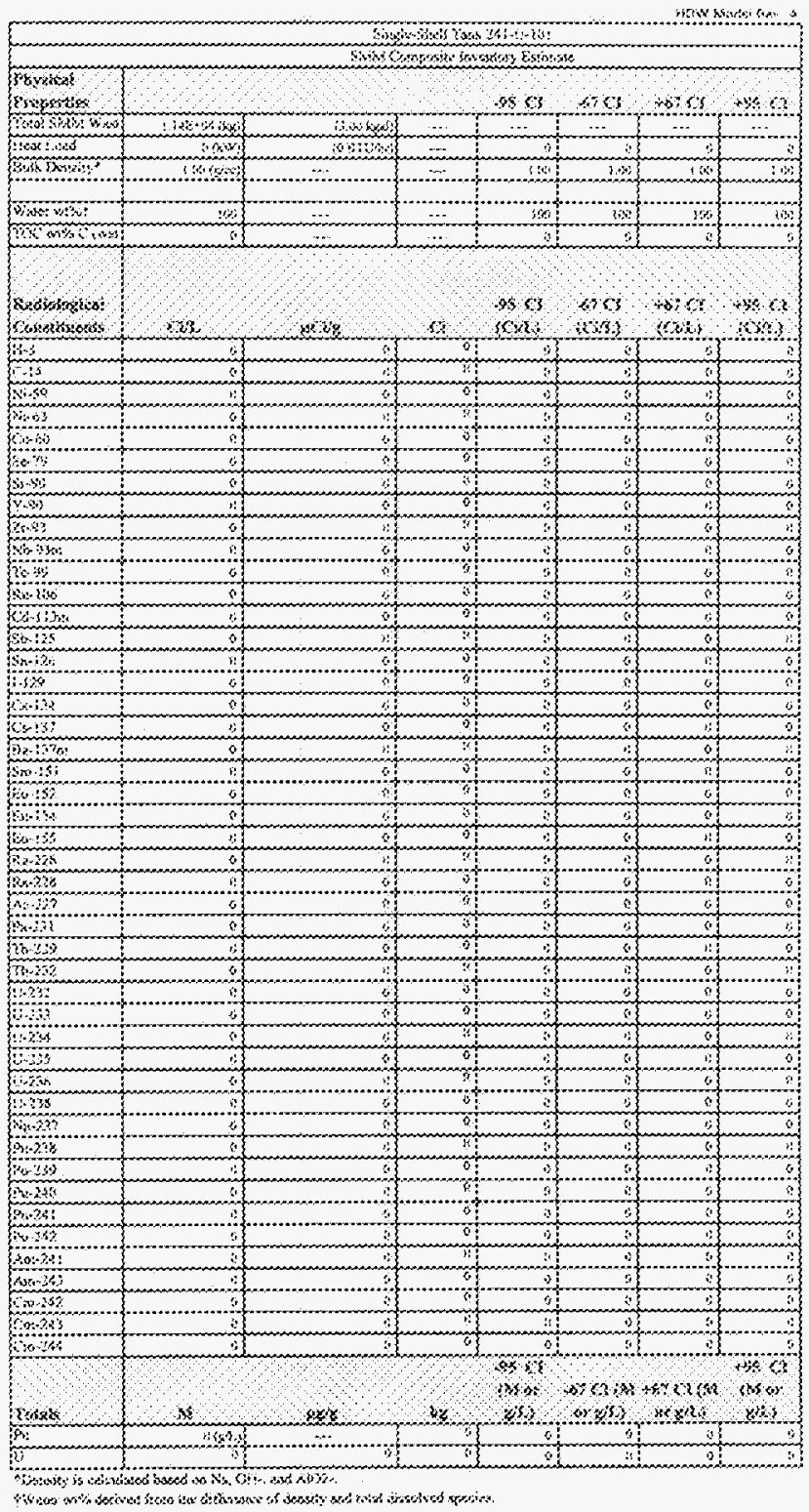




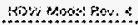

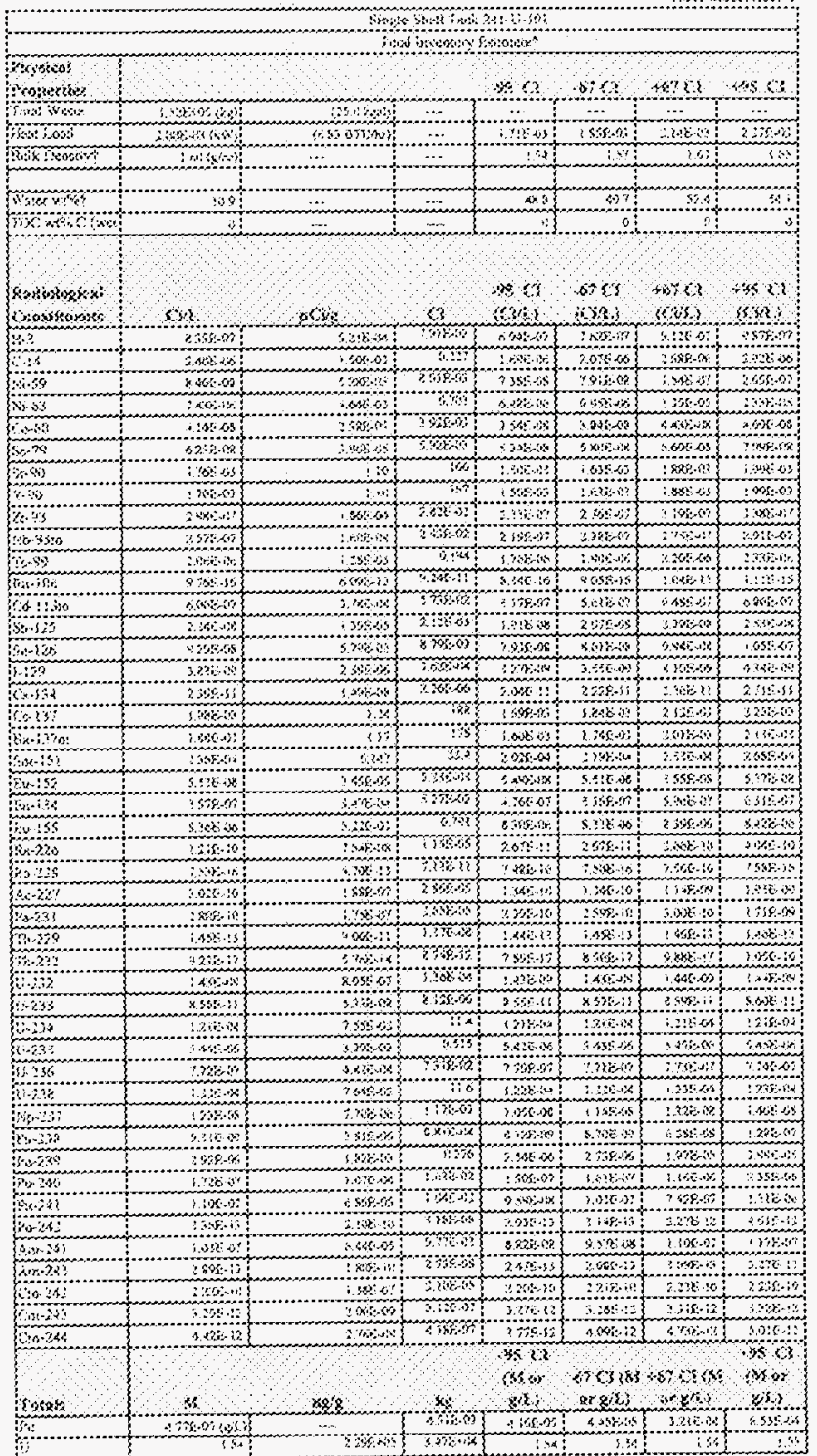

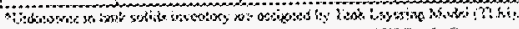

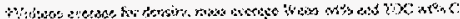


Siovi Mosid hos 4

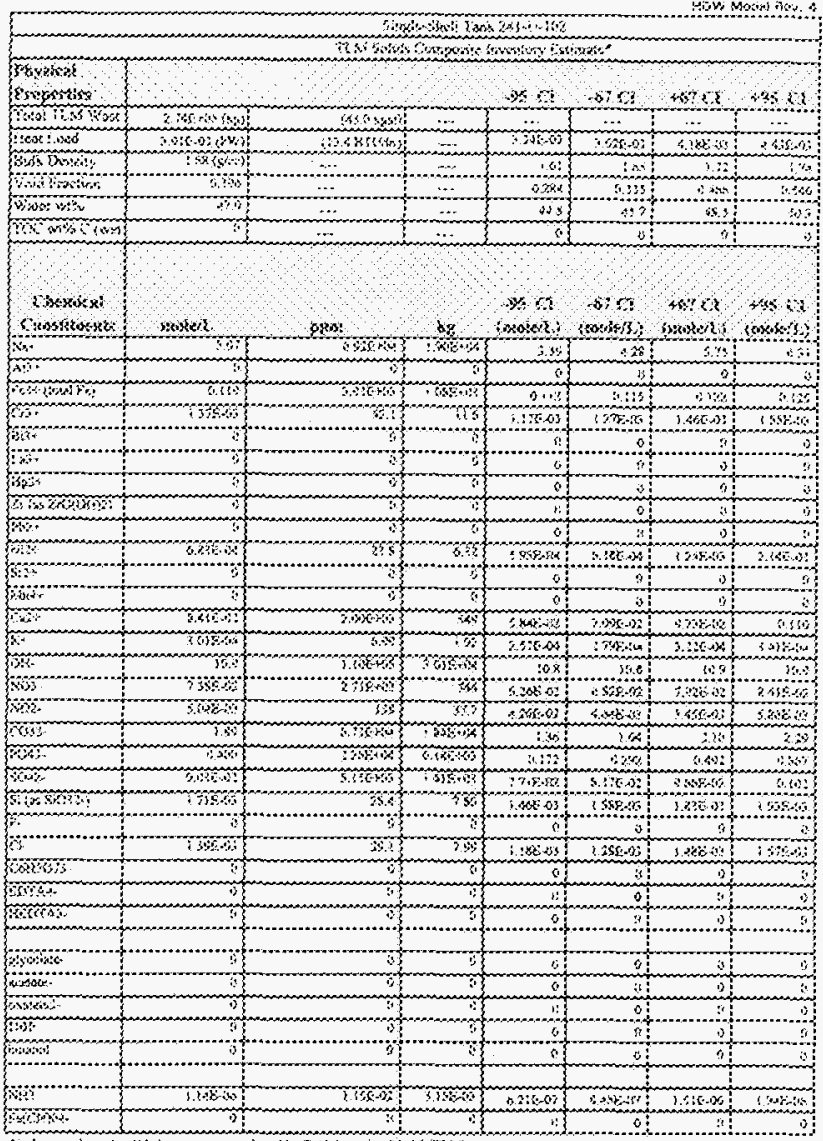

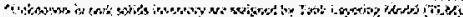


How Mosis for 4

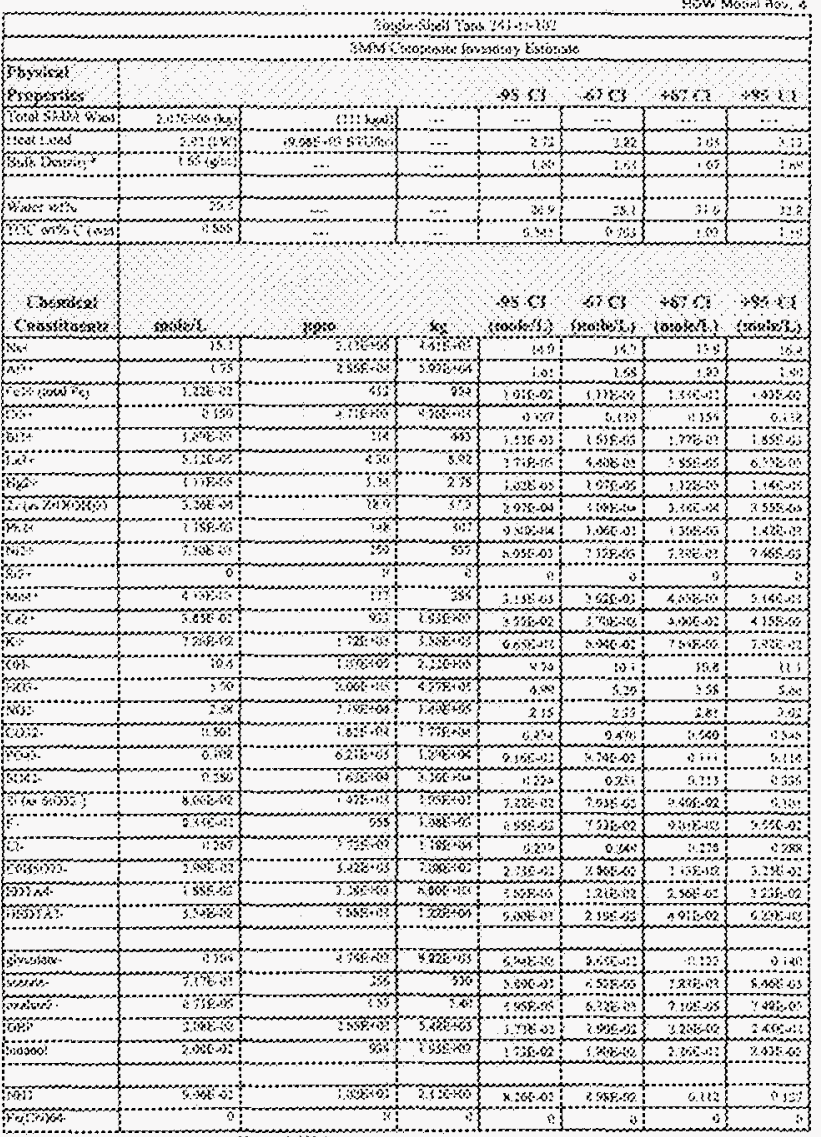

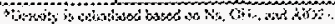

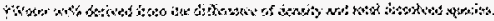









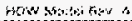

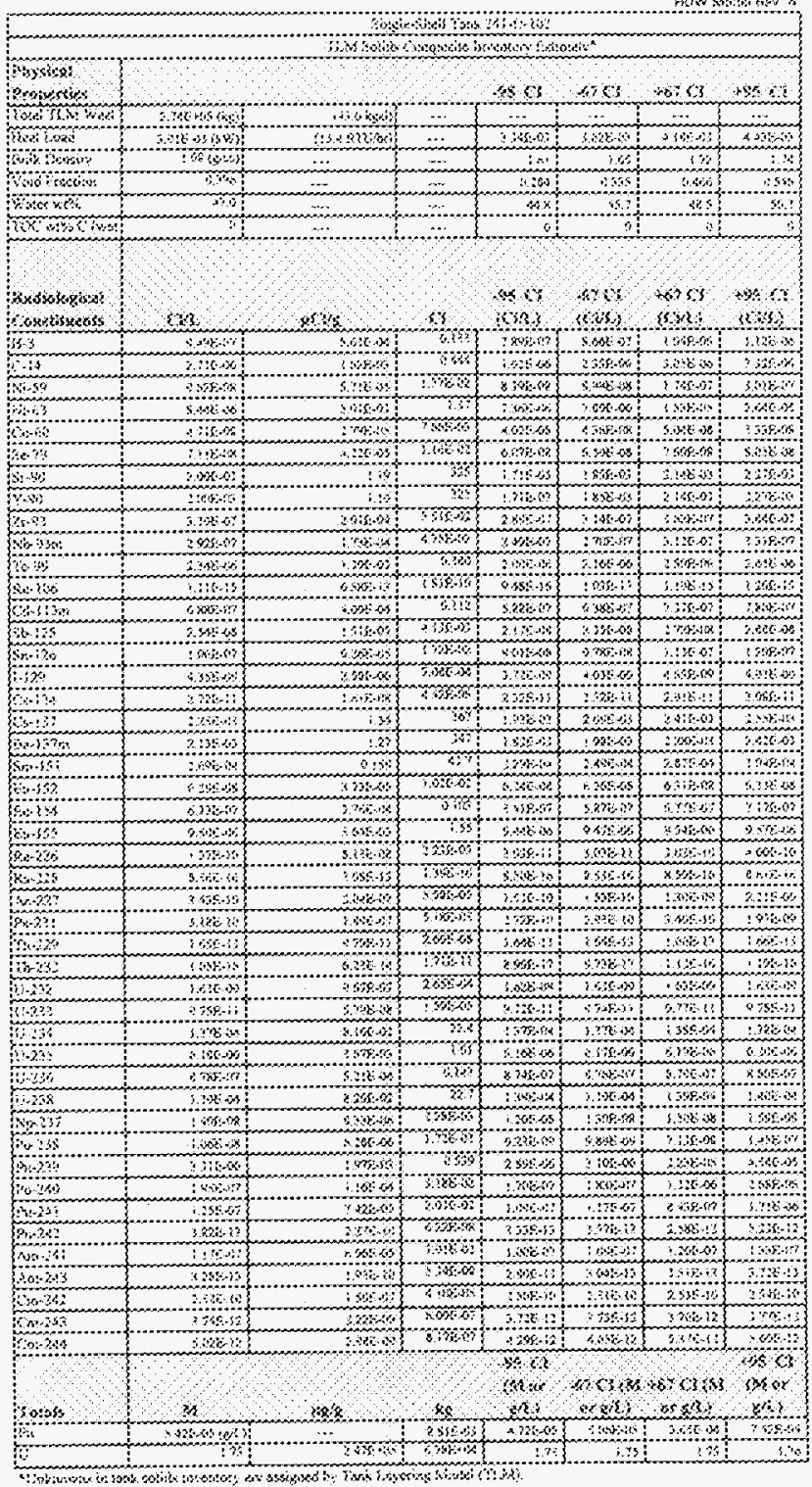




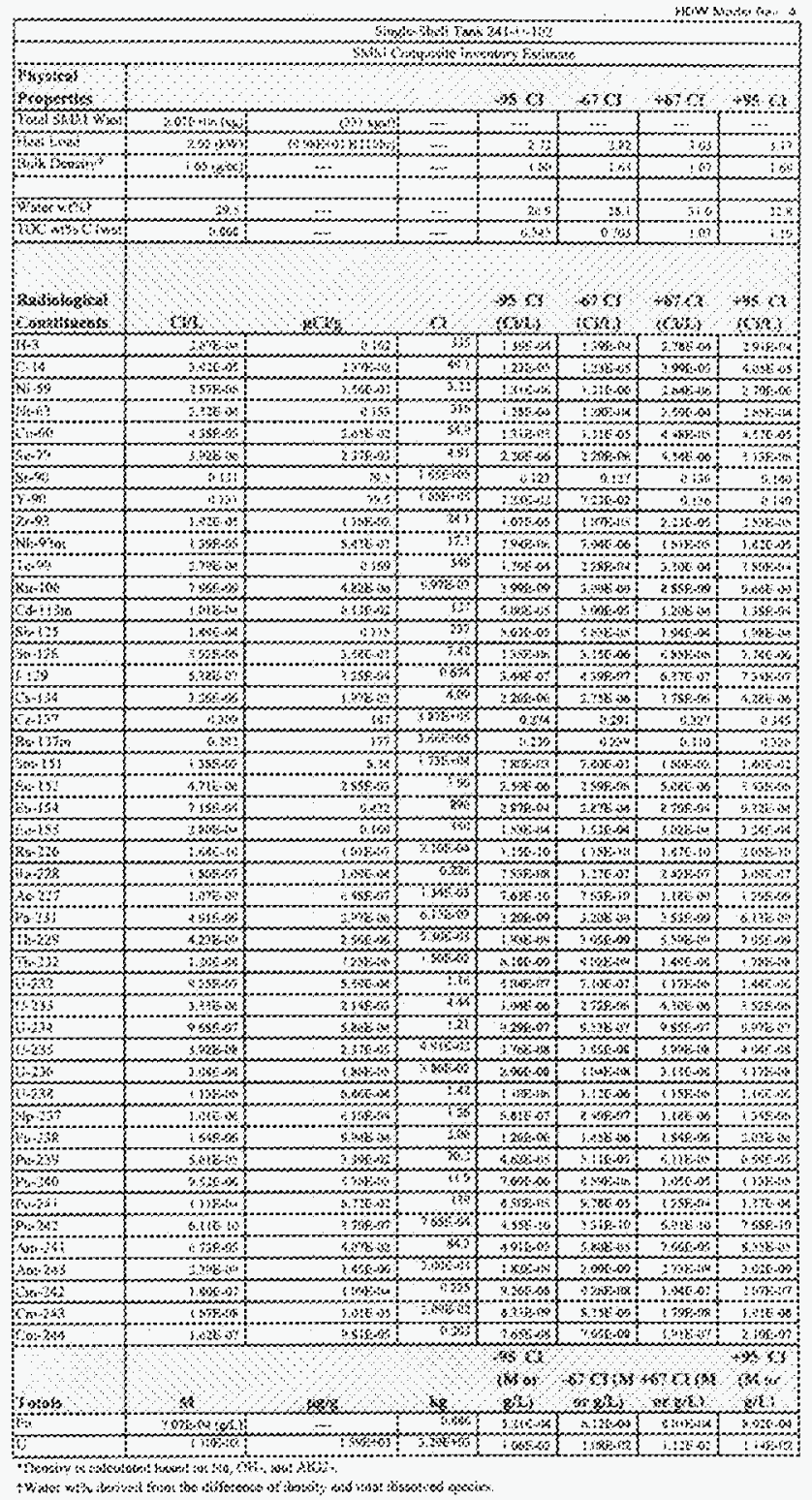




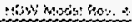

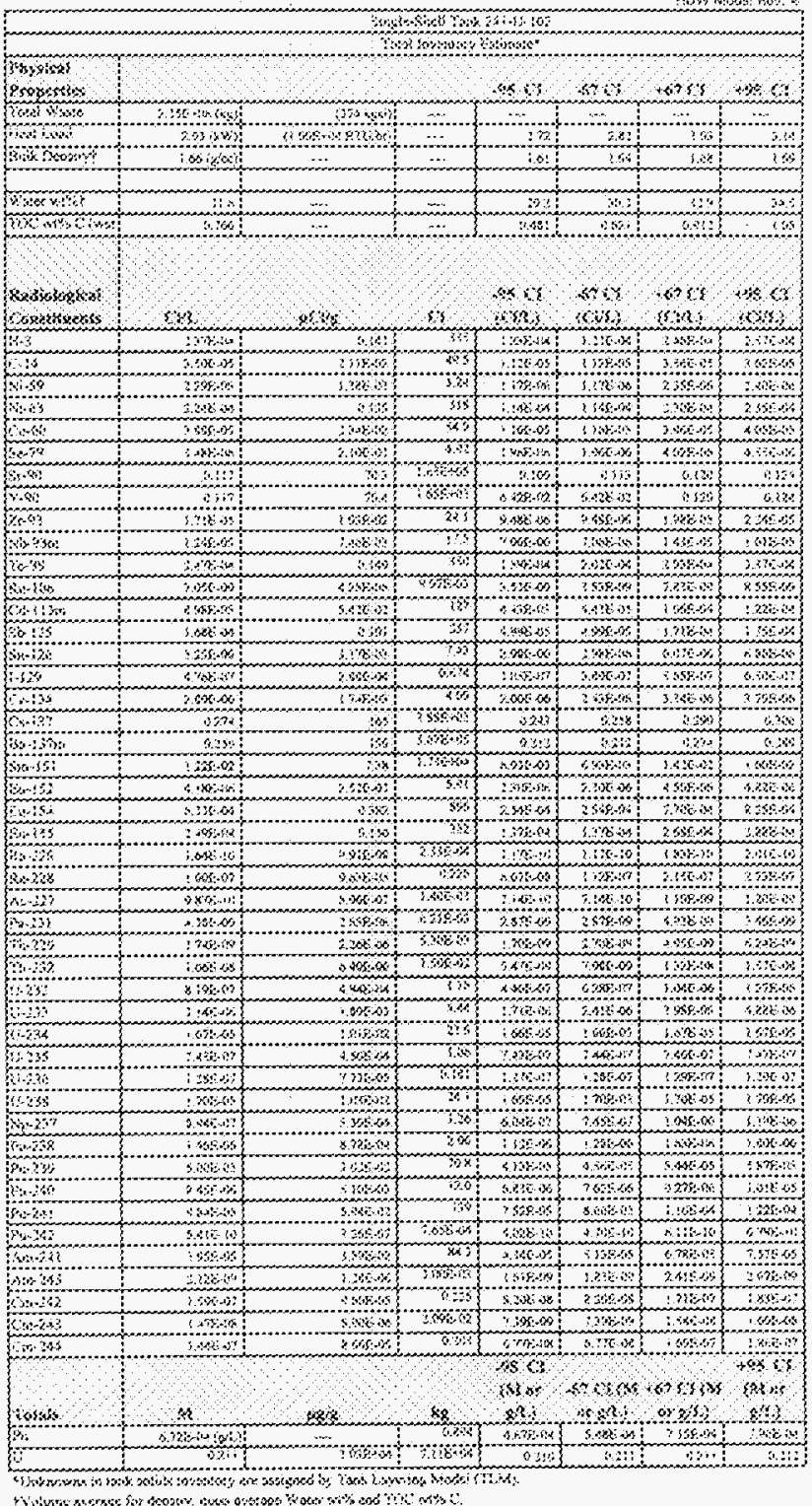


Hith noos! bos

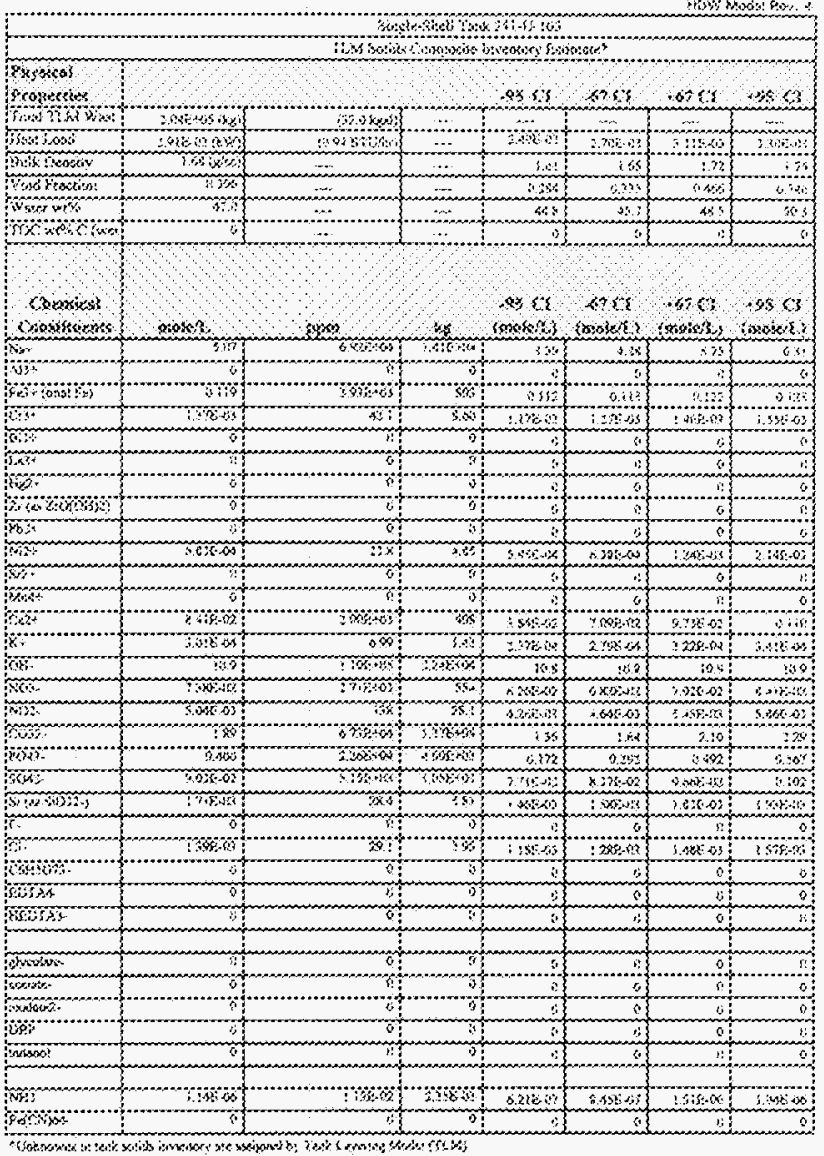


(i) sistol 9 sid

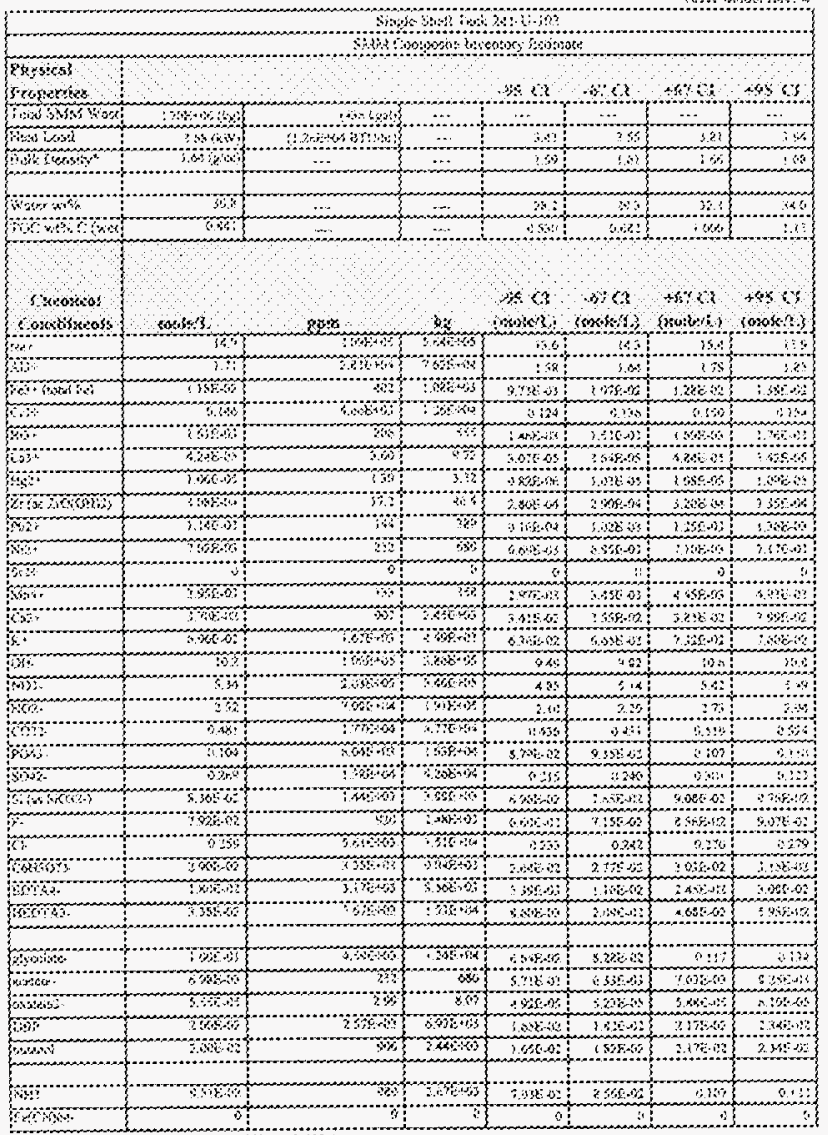

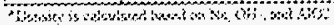

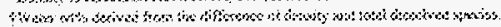


sions nowes nes

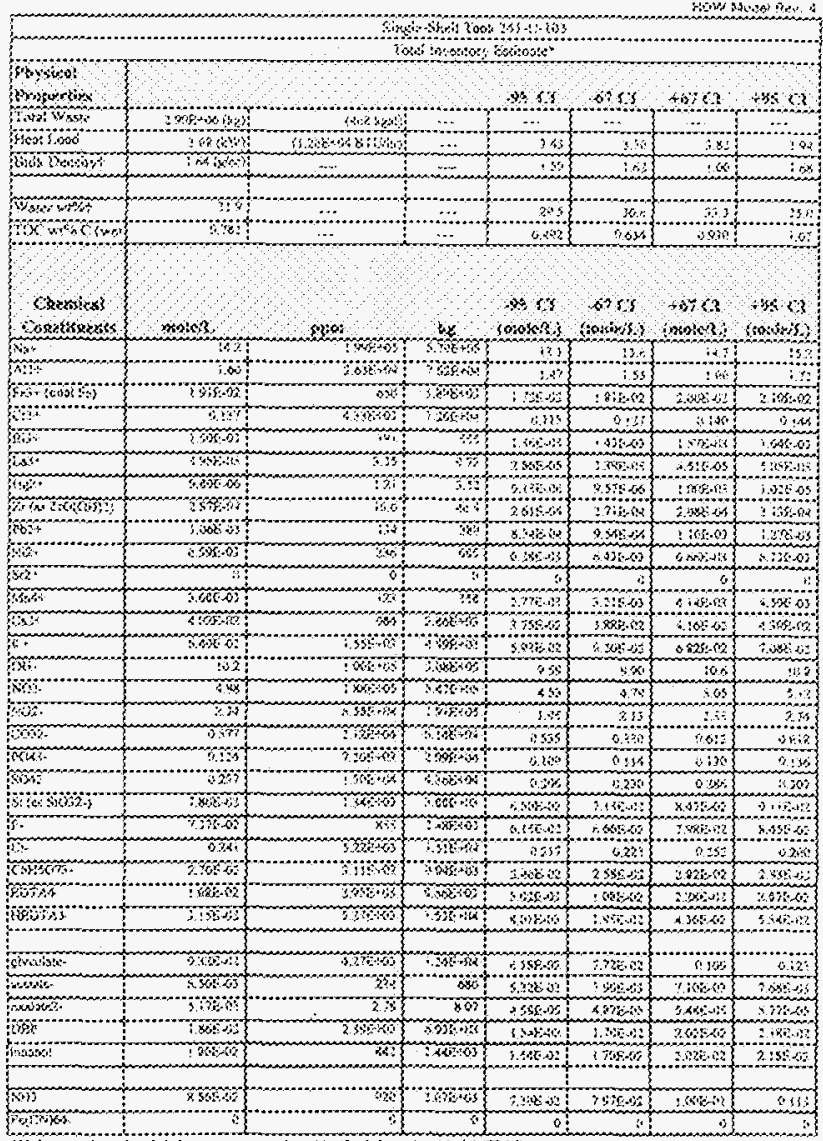

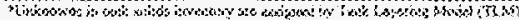

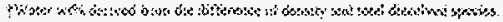




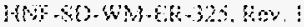

Bow histed sow.



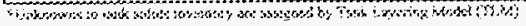




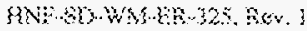

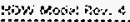

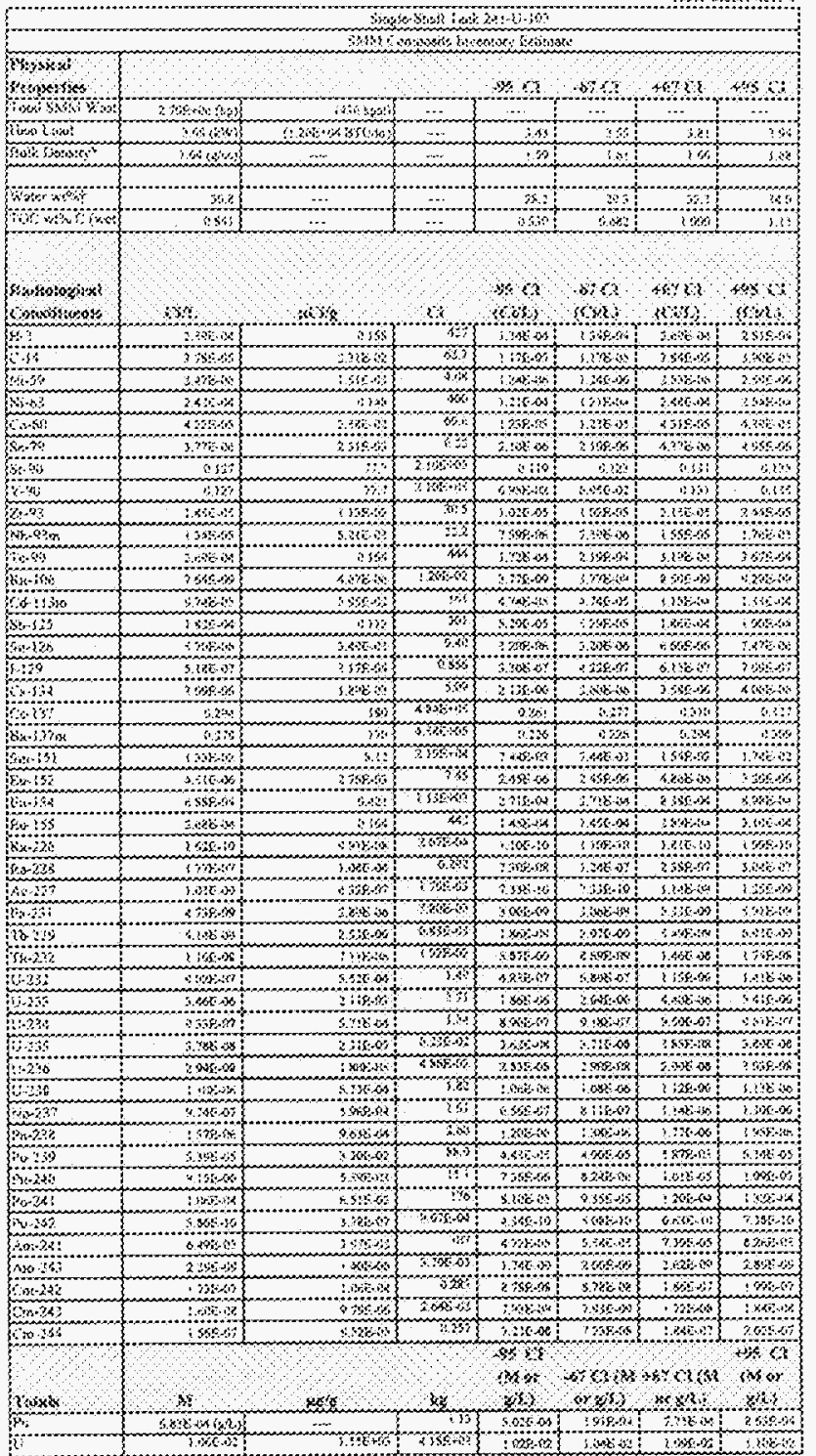

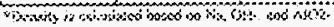

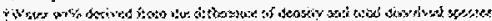




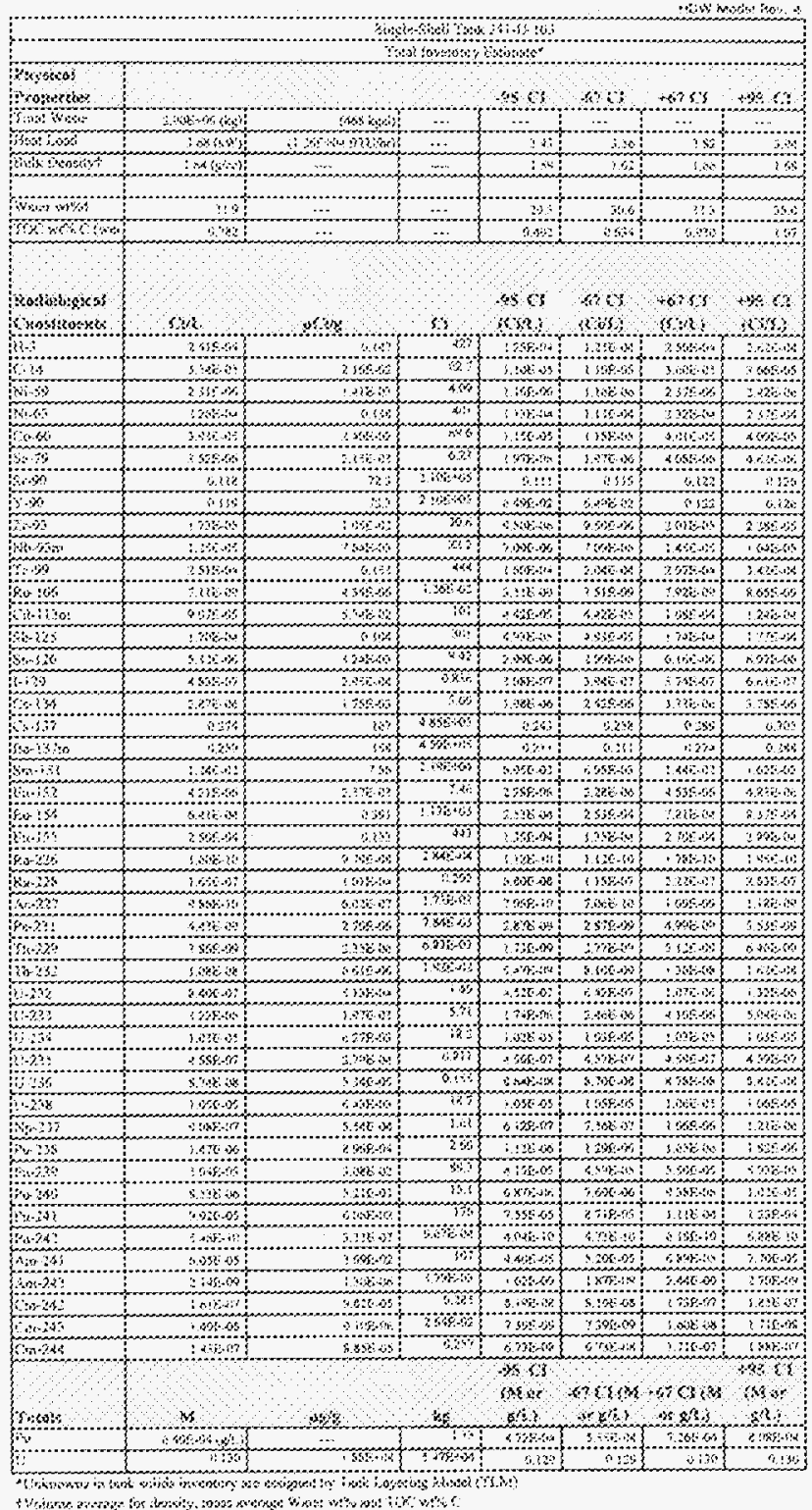




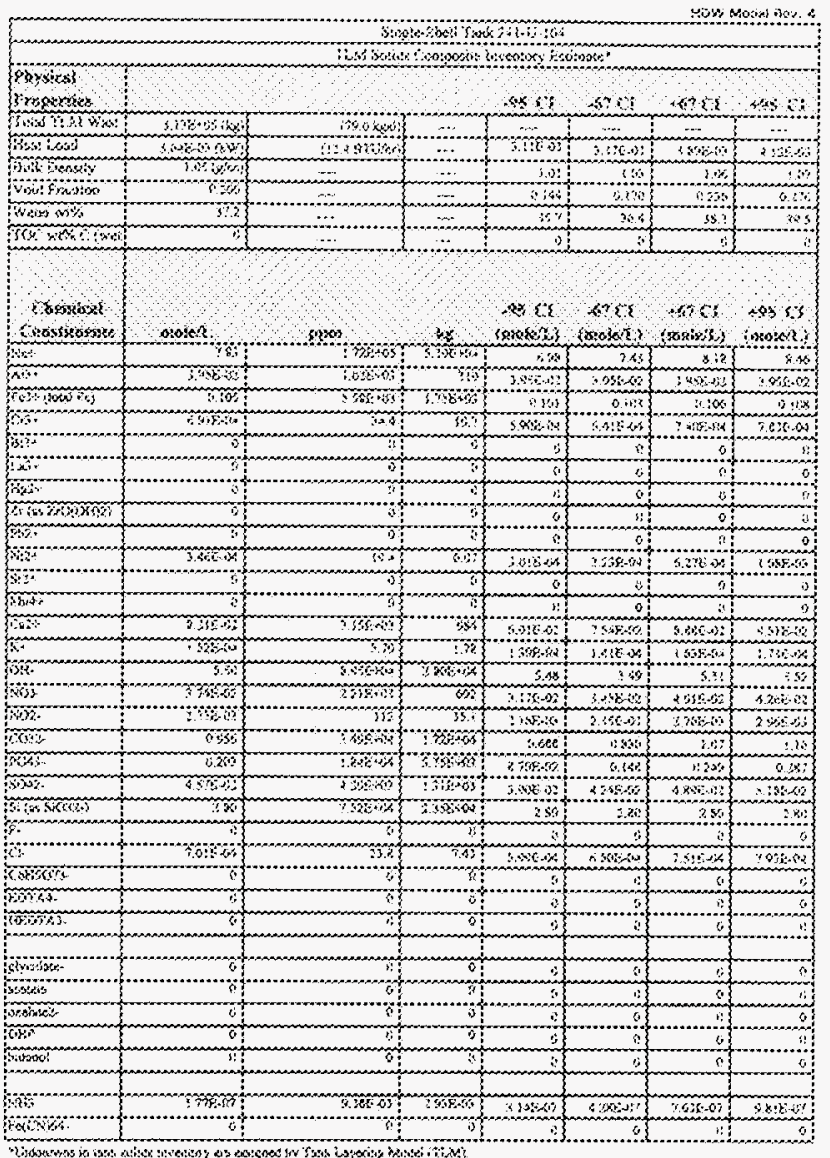

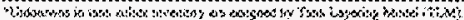


nipe histation so

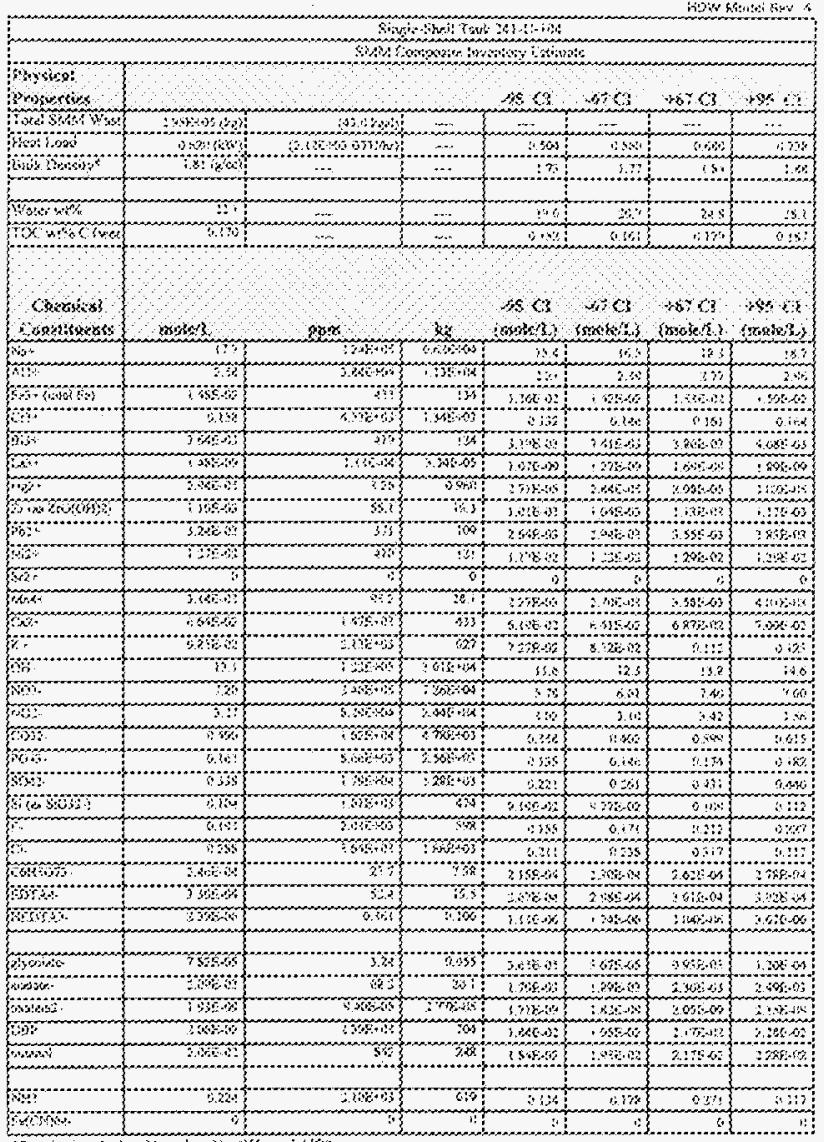

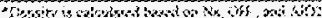

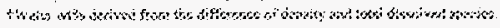




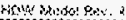

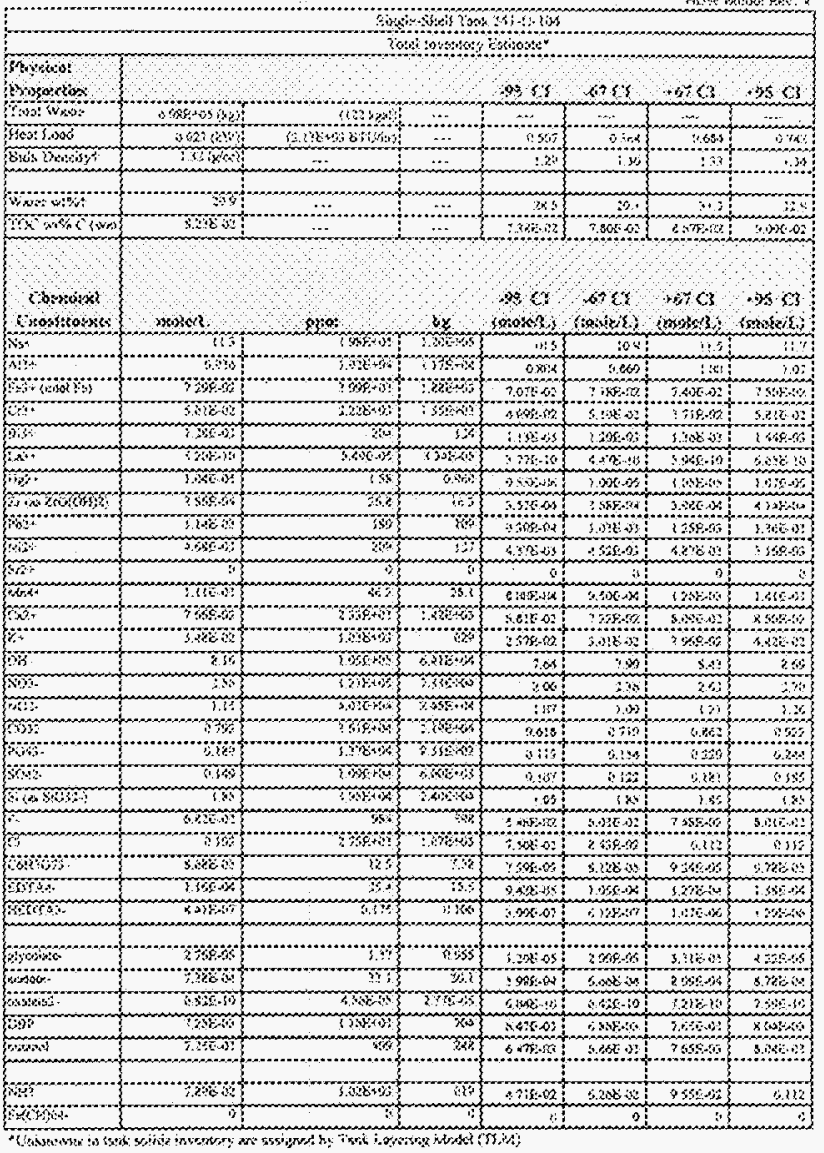

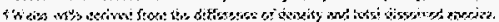


an: $20: 902.2$

\begin{tabular}{|c|c|c|c|c|c|c|c|}
\hline & & S1, nosto & 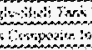 & 26, ofy & bog: & & \\
\hline $\begin{array}{l}\text { Poysics } \\
\text { Protorsies }\end{array}$ & & & & \&s & $\Rightarrow c x$ & $\mathrm{sel}^{+1}$ & $0 \times$ \\
\hline 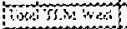 & metsos & Wossis & (m) & & $\cdots$ & $\cdots$ & 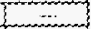 \\
\hline Dlesi tura: & oquspos & assongmin & 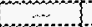 & 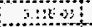 & $3 x+1$ & 1906 & $(1+1)$ \\
\hline 5300009 & otsow & & $\cdots$ & $a i$ & 80 & $1 * 3$ & $\leq 1$ \\
\hline Whosm & $\mathrm{H}$ & & $\because$ & n:at: & $\therefore: \cdots$ & : & 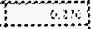 \\
\hline moresta & 3 & & $\cdots$ & $6=$ & ; & 32 & 3 \\
\hline womot & & & ח & & 0 & & 8 \\
\hline 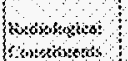 & 361 & 30 & s & का & कos & कo $x<$ & कs X \\
\hline$\frac{1}{4}$ & $4 \times, 8,7$ & $460, \alpha$ & Tis & काto & arots & $5 \times 20$ & nas \\
\hline 6 & 396 & $328=6$ & Ats & $m$ & istess & and & Doths \\
\hline Nis & $2 x 6$ & $4+5$ & 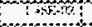 & asess & 40 & 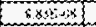 & $\therefore \%$ \\
\hline rosis & $32 s$ & 1006 & $\cdots$ & $3 x$ & 2ntos & 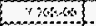 & Exts \\
\hline $\cos _{10}$ & nowit & $3 x$ & Wh: & ind & 2184 & ang & resses \\
\hline \% & mitwe & $3+45$ & Bote & and & Anst & issess & acters \\
\hline 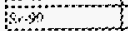 & 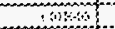 & tets & is & $x 0 x+4$ & 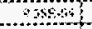 & Spest & $1+1$ \\
\hline$\cdots$ & (6) & and & 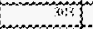 & Esfin & sem & ixess & 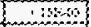 \\
\hline$x$ & 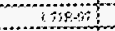 & 15xts: & (3) & inters & $350,+2 ?$ & antons & sen \\
\hline por & SOE & सtक & 336 & $\therefore x 450 \%$ & $3 \times$ & 136 & isstens \\
\hline f...6\% & $(6,6)+1$ & sises & 65 & inowh & SN $N$ & Intos & Wow \\
\hline and & Q & 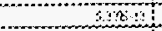 & Mont & $065: 6$ & $20 \%$ & S6:E o: & Biscis \\
\hline$\because+13 n$ & As: & $3 \times 1$ & notit & $29 t-6$ & $2 x+1$ & $3: \div 0: 3$ & $\therefore \mathrm{AS}$ \\
\hline 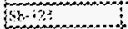 & 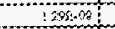 & ats & $\$ 40$ & insts & $10 \%, 00$ & SFEtR & asas \\
\hline Go: & 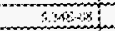 & s:ses & 3.684 & 41604 & 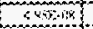 & S?E: & ossons \\
\hline ? & 3200 & ind & 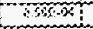 & 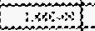 & *ass & 346 & XYLU: \\
\hline 134 & $1 \times 0: 1$ & 3010 & Clines & (15) & 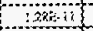 & $42: 1$ & $0 x$ \\
\hline $8 \%$ & 46 & 50 & $m$ & stosis & Qsis & 230 & Inys \\
\hline Bun & 8 and? & $\ldots$ & 8 & 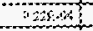 & $x \times 6$ & 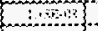 & :Hos \\
\hline 619 & istopa & 3 & 48 & 3306 & $m$ & issty & : \\
\hline Fut & $3.6 \%$ & 3,86 & 4360 & $3: 3,04$ & MEst & $36 \pi$ & antso \\
\hline 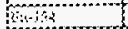 & $3 \%+$ & $\theta e$ & Dxpm & $\therefore$ : & nes? & (14t,is & .060 \\
\hline wis & ssitsto & 606 & $\infty$ & $6 \infty$ & sistos & S2016 & s.xptat: \\
\hline$x+2 x$ & sag:! & 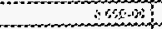 & mos & (6si: & $36 \mathrm{~s}, \mathrm{~B}$ & 60 & 93916 \\
\hline $0302 ?$ & 40896 & GAs: & $36+1$ & $4 x a x+6$ & xiteis & WS6 & Aswis \\
\hline $4-13$ & mols & (ntsy) & 3006 & (3ndi & YFA & $5 \times 1$ & $i 30+3$ \\
\hline sin & ato & 4001 & $7 n 0 \%$ & 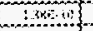 & inde & 17500 & 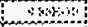 \\
\hline 30 & expas & Y4st:- & mostonst & 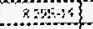 & aisx:21 & ant; & \&ten \\
\hline $5 \%$ & 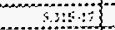 & 800,3 & 86 & 401 & 440 & SoN1: & (5) \\
\hline 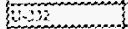 & 82310 & ssin & 36 & $2+10$ & $x+2015$ & exsons & Sncid \\
\hline 6,10 & 4040,13 & asks & 790 & $46 \mathrm{H}$ & ssgat & 4 & tors: \\
\hline a:? & 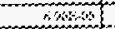 & Sots & 35 & \$NE & Sostoss & $0076-6$ & $4 \mathrm{Q}, \mathrm{s}$ \\
\hline 3 & $315 \%$ & $30+1$ & कर से & Pifen & $\sin \alpha$ & $\begin{array}{l}2 \\
250\end{array}$ & $\therefore \leqslant \infty$ \\
\hline 3 & 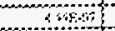 & 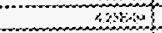 & 283 & Astis & 36stiv & AS65 & stan \\
\hline 38 & Bates & $\$ 4012$ & ii & $00 \mathrm{acos}$ & 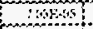 & andes & 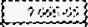 \\
\hline 60 & 300 & Oses & 2500 & asmens & Sxest & $3 \omega x+3$ & 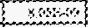 \\
\hline nos & Sat & 5,000 & $3 \times 6$ & $165, W$ & arisene & 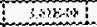 & $\begin{array}{l}3 \times 482 \\
0\end{array}$ \\
\hline and & 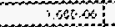 & 10502 & 年: & सron & innos & 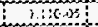 & 8696 \\
\hline$\cdots$ & $\therefore \times 9 \%$ & $0 \times 40$ & $m$ & $26 \leq 43$ & 42460 & s\$? & 3.80 is \\
\hline$(x+i s i$ & (a)s:s & cosks & 3040 & SWow & $5 \times x+2$ & nest & $x+6 n$ \\
\hline $\mathrm{F}_{i}-3 \mathrm{~s}^{2}$ & nti & 34 & $5 \mathrm{mos}$ & AE? & isstess & $36 \mathrm{~B}$ & \$B,ix \\
\hline $6 n$ & $\$ \times 648$ & 50 & : & (toses & 3916-ins & is:an & Yos \\
\hline$x_{0} \cdot 3$ & 66 & $15+3\}$ & mis & 3064 & $1 \times 5,1$ & $785-15$ & atin \\
\hline $4 \times 34$ & 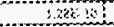 & $\mathrm{mes}$ & W & 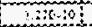 & (zhsis & $32 \mathrm{t} k \mathrm{6}$ & $(8+4)$ \\
\hline rates & $\sin (1)$ & sise & $3 \mathrm{now}$ & $: x 0 \%$ iz & $3 x_{1}$ & $100-1$ & (n)t:3 \\
\hline sot & \&N+? & $3+164$ & 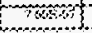 & 2042 & Sus: & AEt? & 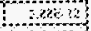 \\
\hline & & & & os o & $\alpha \times c s \times 3$ & 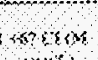 & Nons \\
\hline Kosos & (n) & $x>2$ & $x$ & 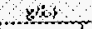 & tos & (w) 45 & os \\
\hline 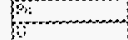 & 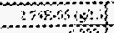 & & Bation & $2350+3$ & 356 & $: 804$ & 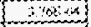 \\
\hline & 620 & nom & 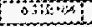 & $\therefore 3 \times 3$ & 6281 & $0 \times 5$ & 306 \\
\hline
\end{tabular}

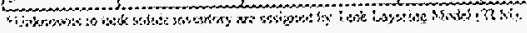




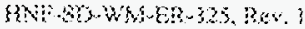

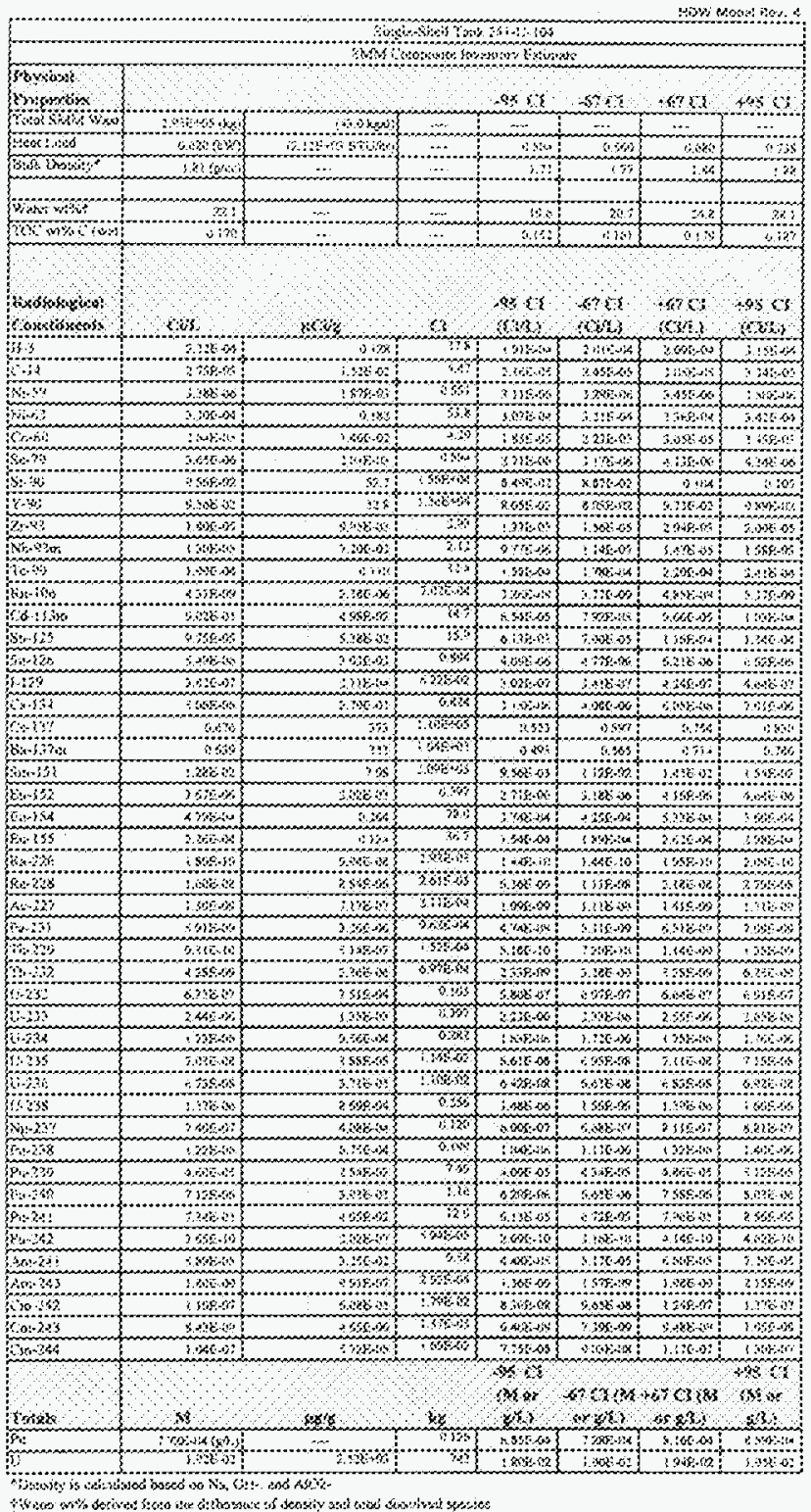


whithoses:

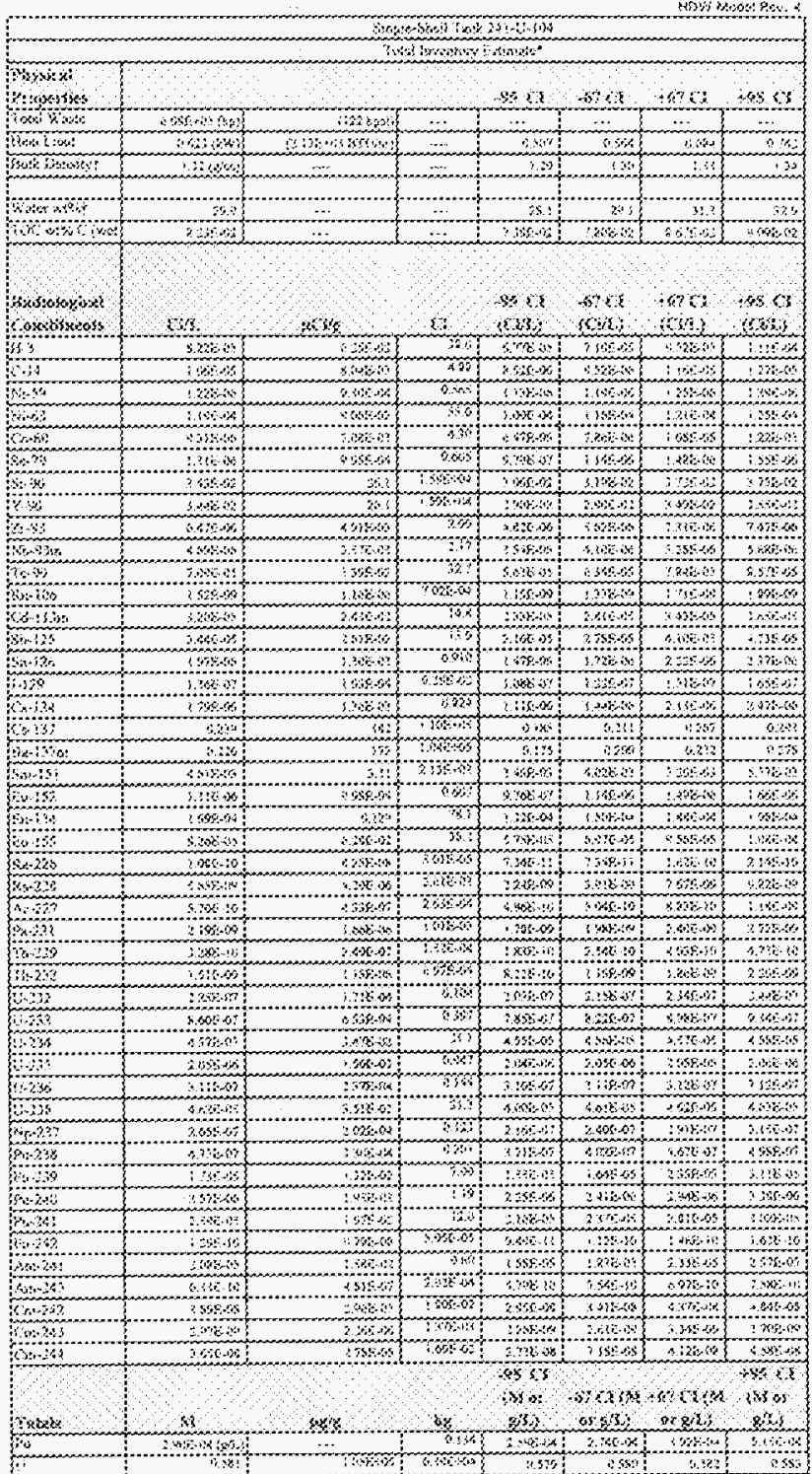

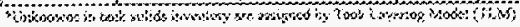

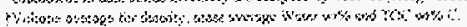




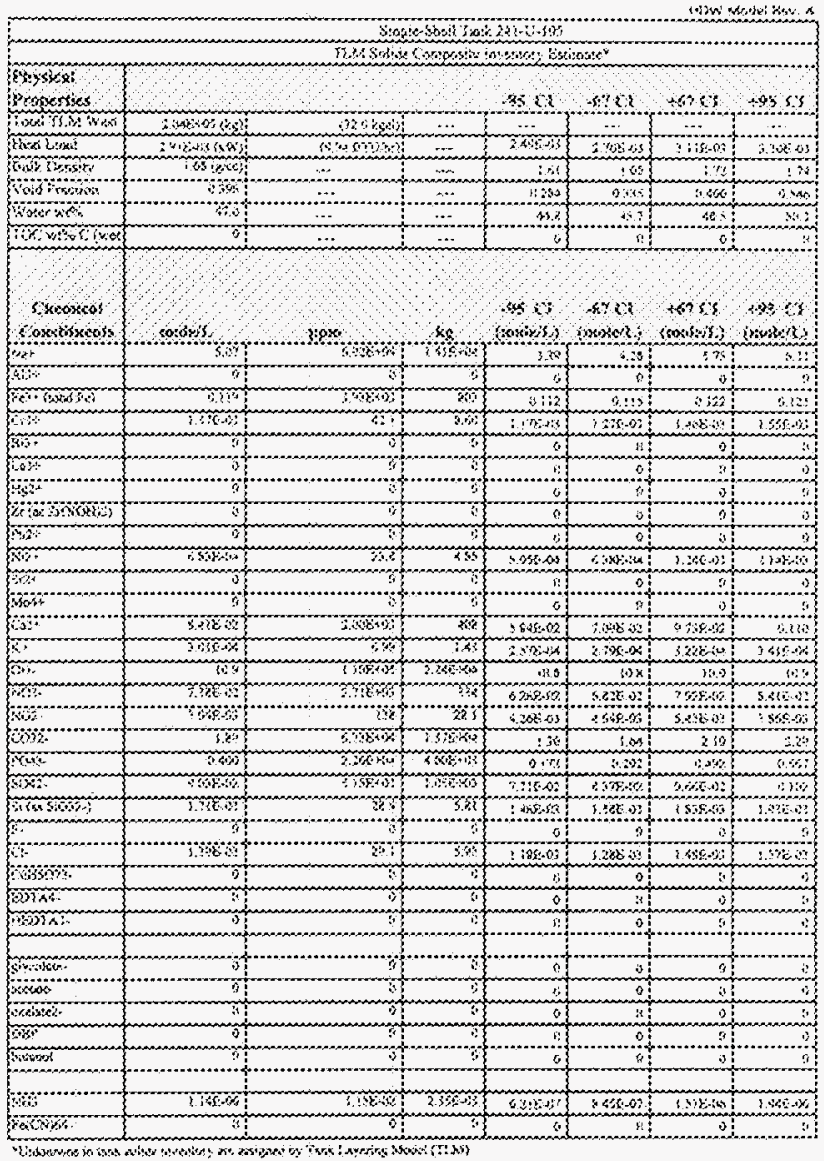




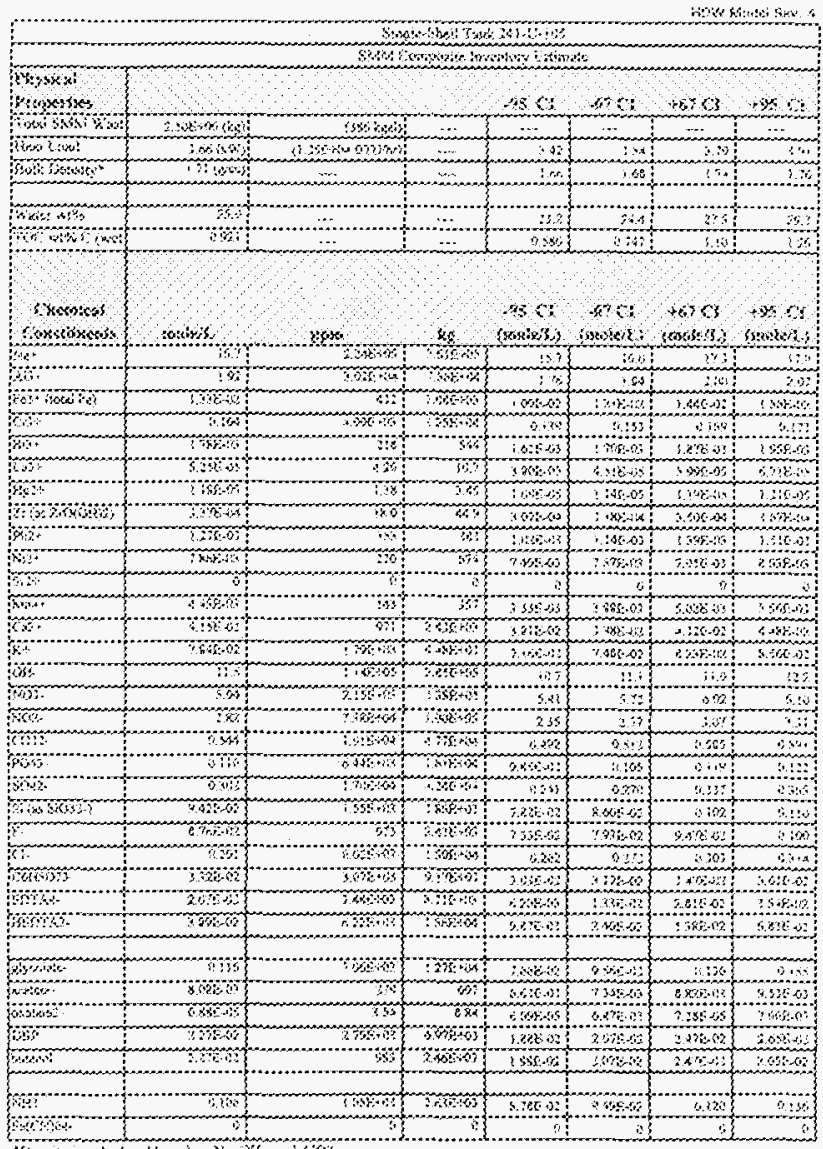

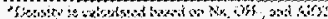

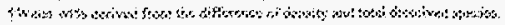




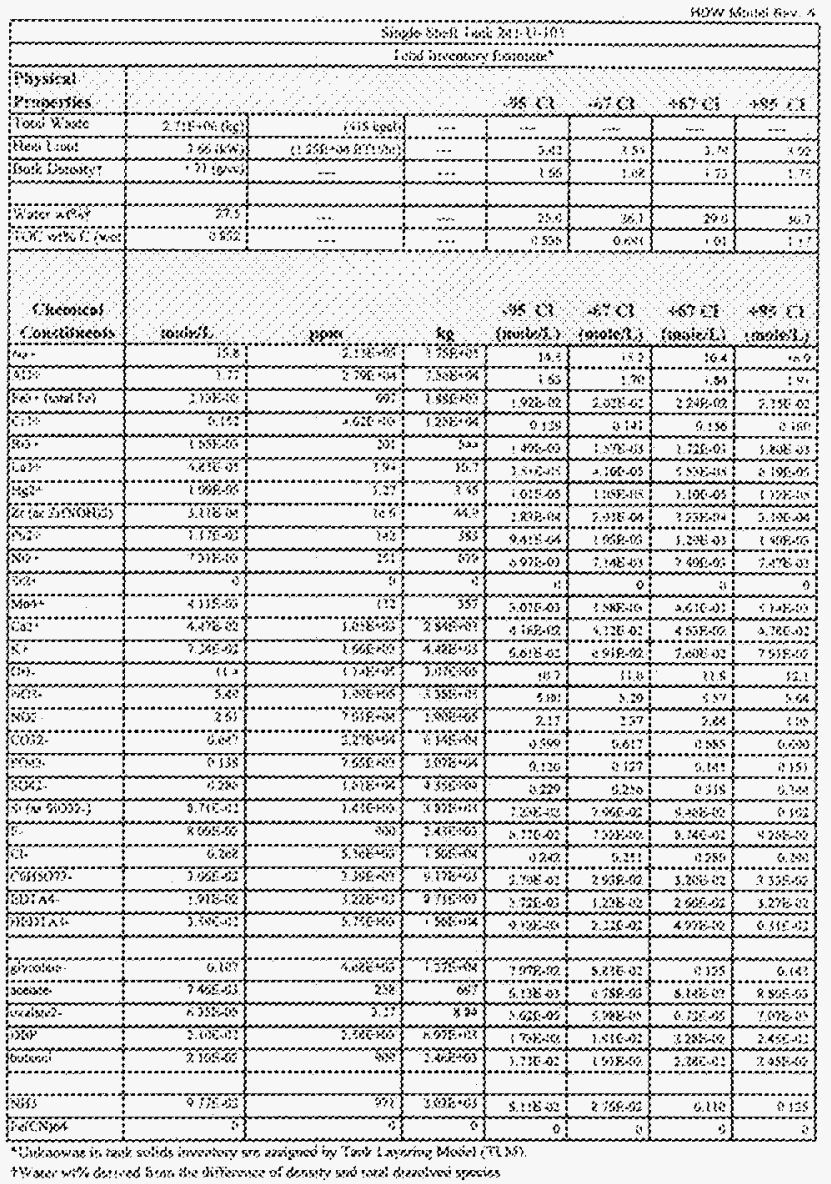


Hewomentos, ker:

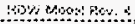

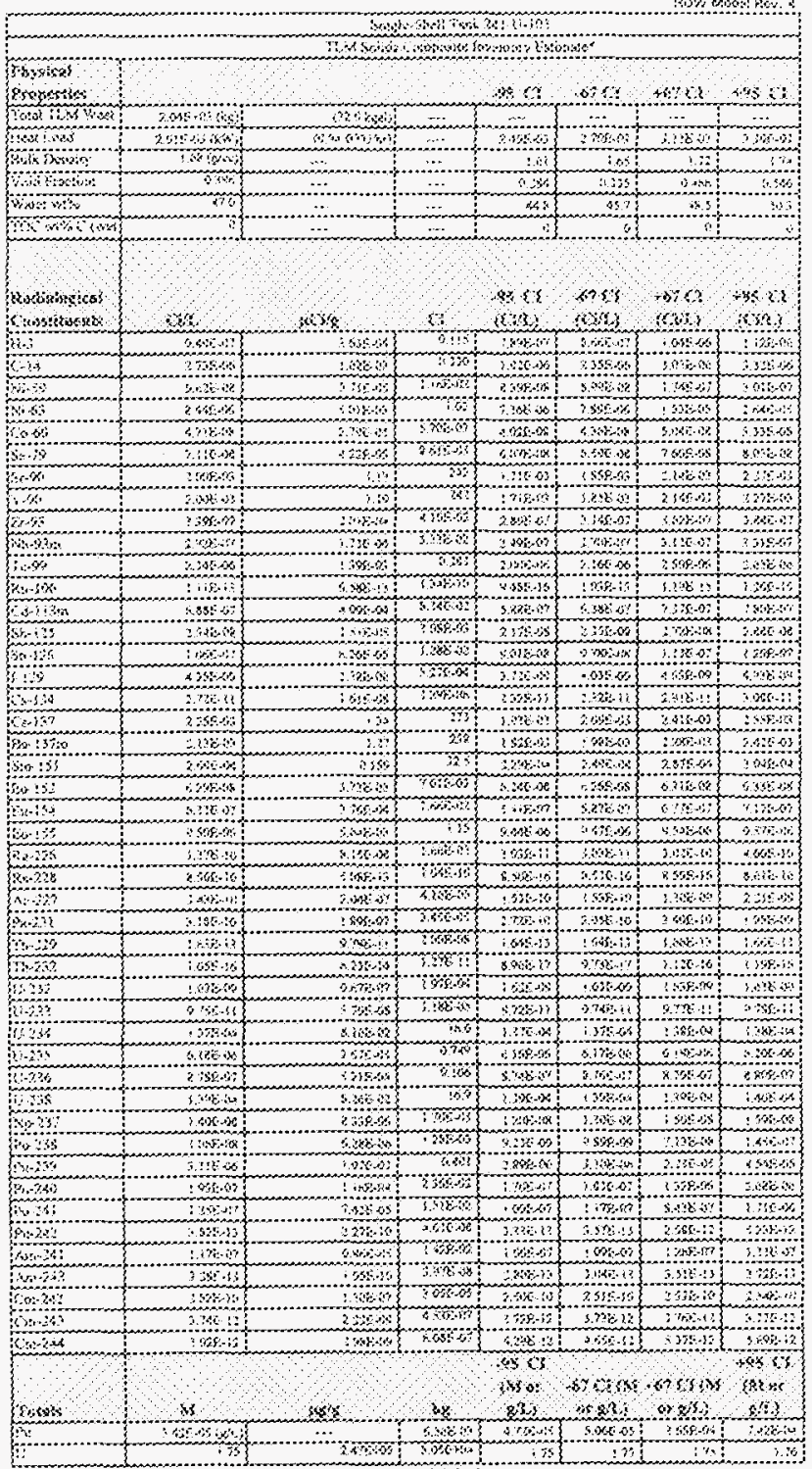

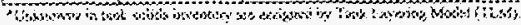




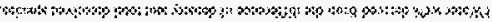

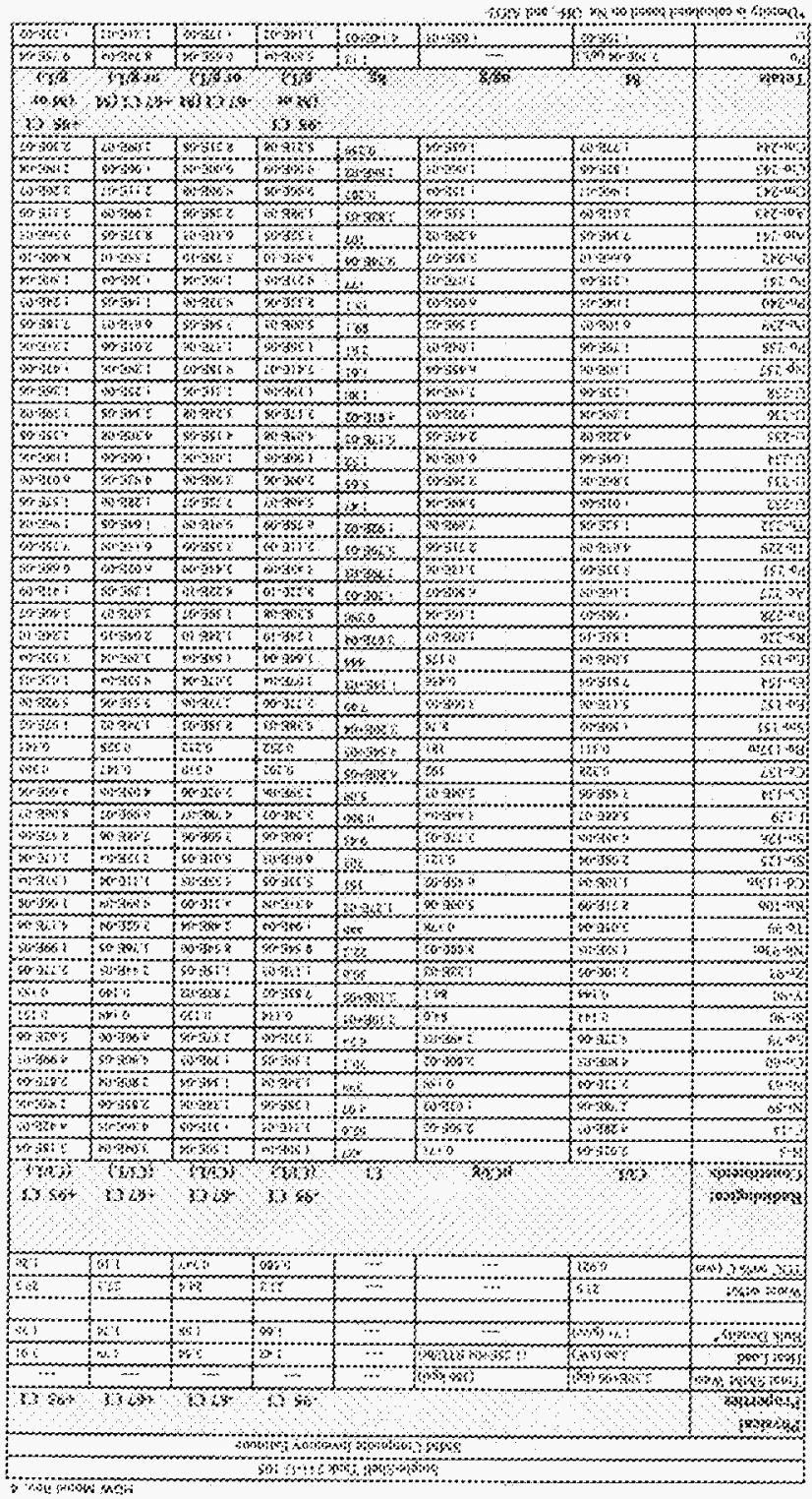




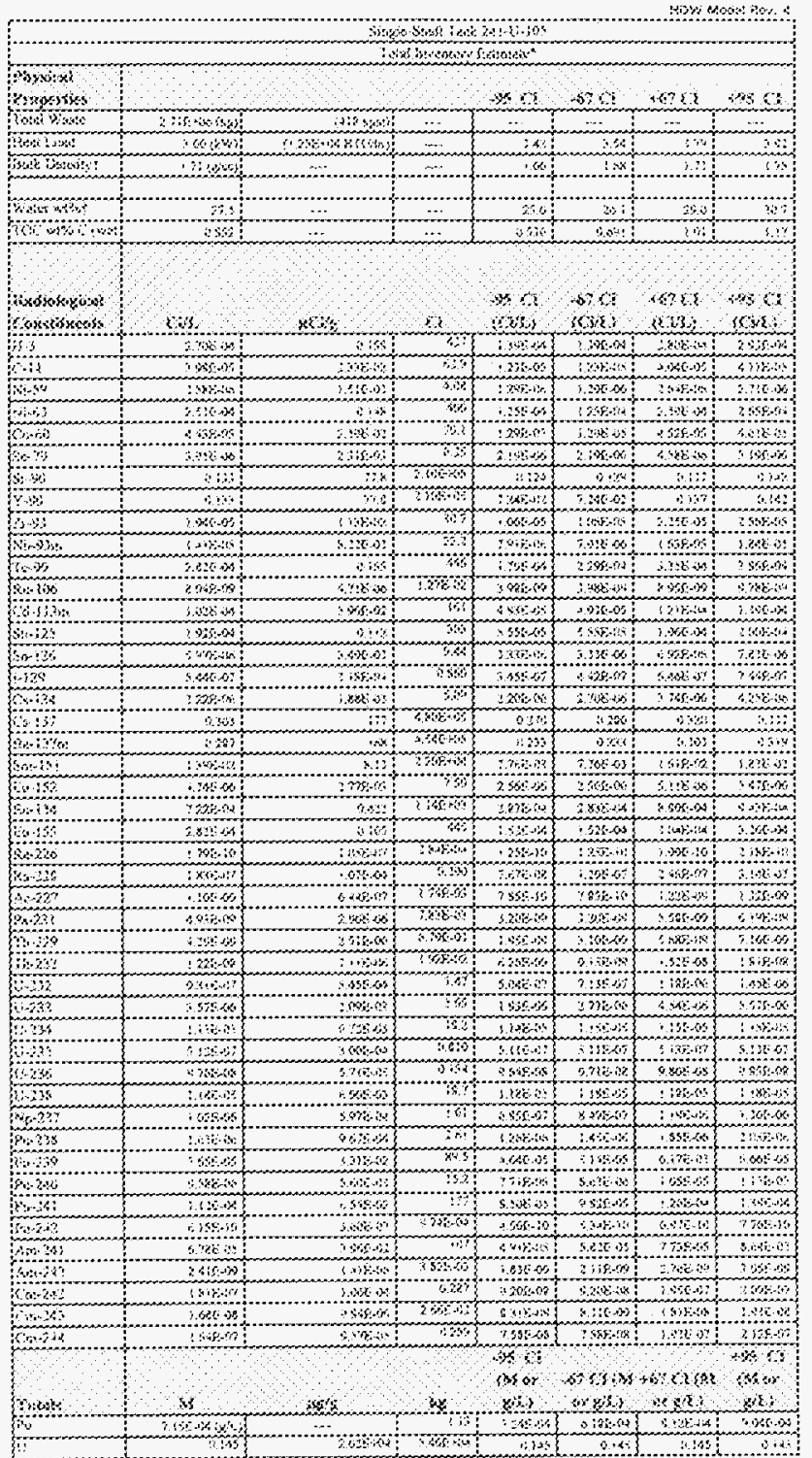

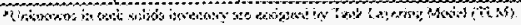

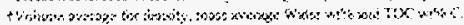




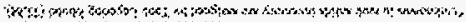






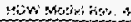

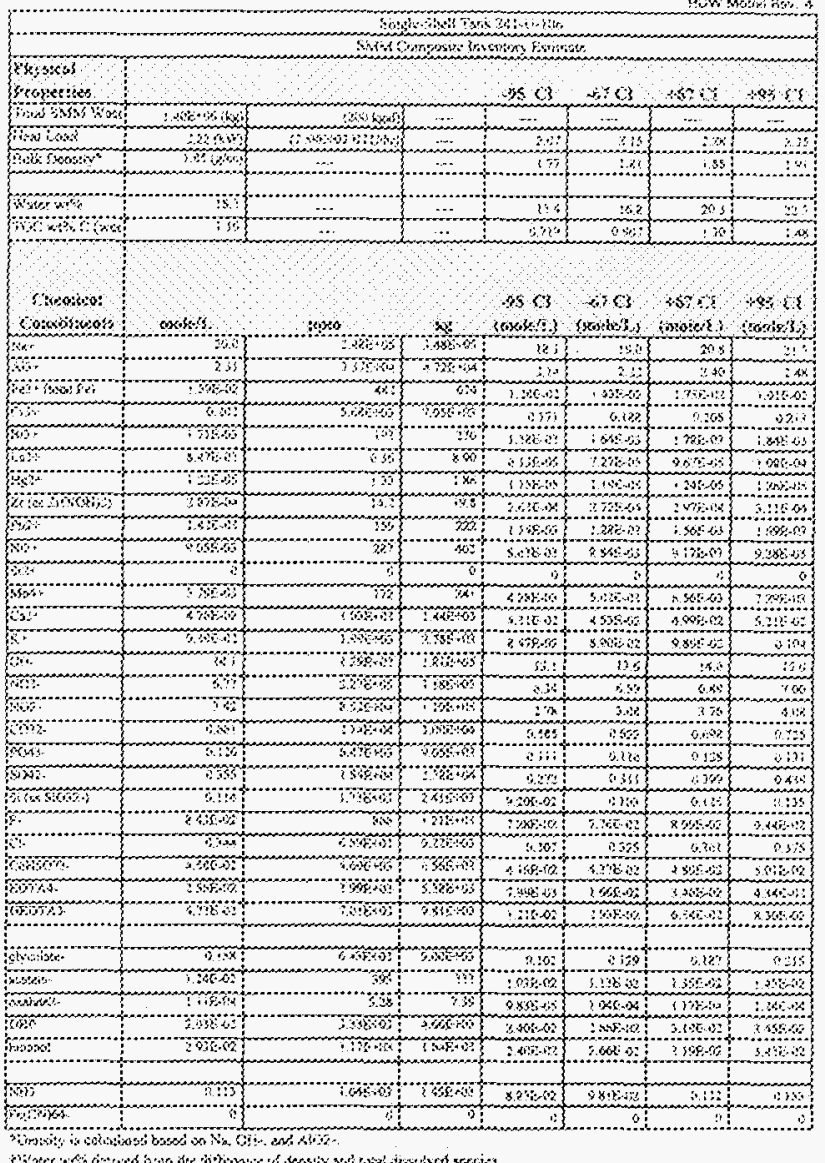


how Mood mos

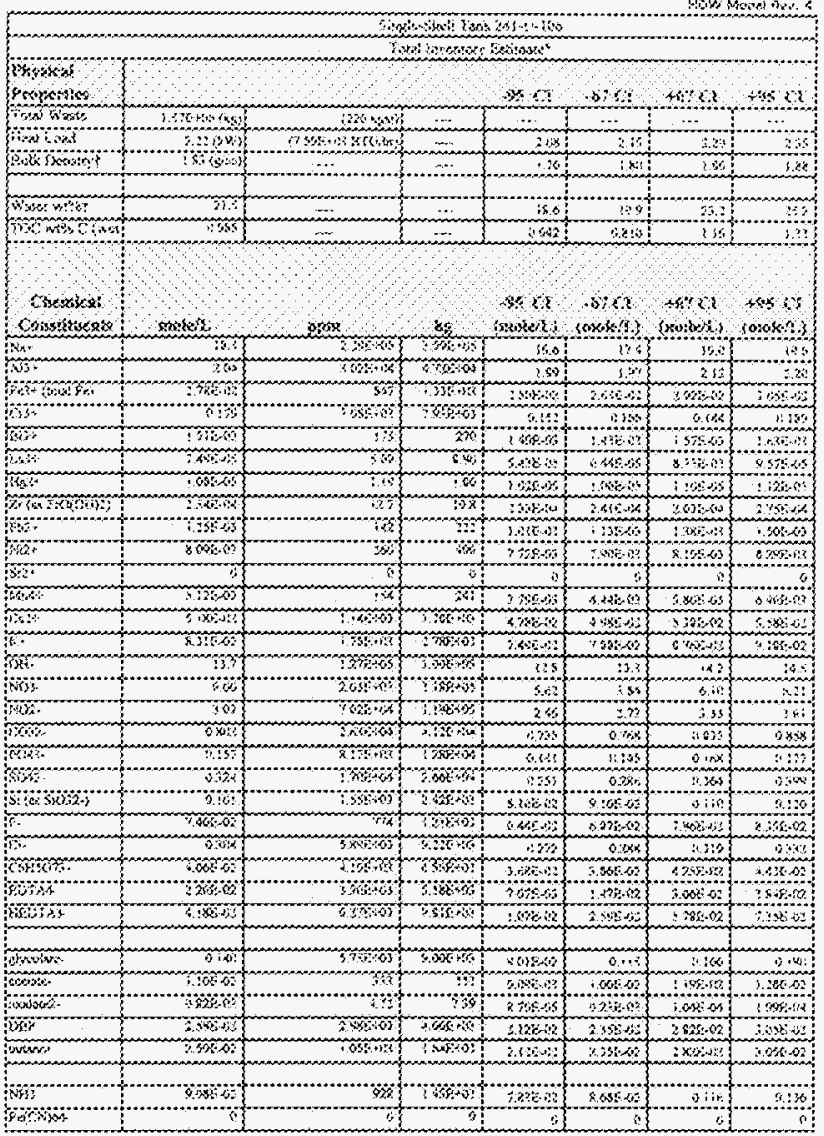

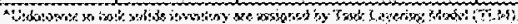

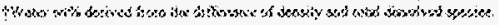




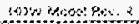

\begin{tabular}{|c|c|c|c|c|c|c|c|}
\hline & & & & & & & \\
\hline & & 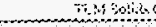 & 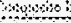 & cotons & & & \\
\hline Gebel & & & & & & & \\
\hline oroptride & & & & 25 & $67 \mathrm{Cg}$ & 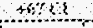 & $100 \times$ \\
\hline HAnvo & $(x+y)$ & tritsosis? & & $\cdots$ & $\ldots$ & & 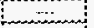 \\
\hline As, $;, 01$ & 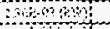 & (4), arthes & & 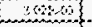 & and & 240,0 & $2 \cos 2$ \\
\hline Wobrons: & $36 x+4$ & & & $\therefore: 1$ & 18 & $\therefore$ & $\vdots 2$ \\
\hline Whenow & $1 \%$ & & $\cdots$ & s, & $6 \%$ & $\therefore$ an: & $x+\infty$ \\
\hline 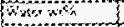 & nis? & $\cdots$ & & 263 & $\$ 1:$ & 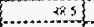 & $\$ 3$ \\
\hline arowarinot & & 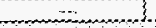 & & 25 & & i. & \\
\hline wes: & & & & $\%$ & 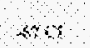 & ass & 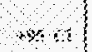 \\
\hline $\cos :$ & $s i$ & 60 & $\mathrm{~s}$ & $2 x_{3}$ & $6 x$ & sine & $18\}$ \\
\hline 5.5 & $\therefore$ An? & 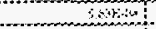 & and & $280,40 ?$ & 1.0S: & $456 x$ & S.20 \\
\hline 6 & 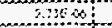 & 620 & 3 & $126-6$ & Brotr. & $1008 \times 10$ : & $1310-14$ \\
\hline 60 & $2 x+68$ & Fign: & 60,0 & $2 x+4$ & 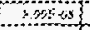 & WEt-O & 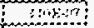 \\
\hline 6 & antes & Gets & $2 n$ & 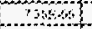 & noto & axist: & $300 x$ \\
\hline ones & and & 2900 & axo? & toget & 360 & sase $x$ & $\therefore 3$ \\
\hline 60 & (i) & $+20+6$ & 600 & $4062+6$ & Bass & Yoras & acts \\
\hline$\infty$ & 36 & $\therefore 3$ & 15 & insto & 30 & 214023 & $221+6$ \\
\hline 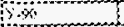 & soges & 39 & $m$ & 61601 & $(s \leq y+z)$ & $21 \times 6$ & $200 \%$ \\
\hline $3 x+5$ & $284-97$ & myth & $3 x+2$ & $2 \times 39$ & $2066 \times 1$ & $\forall x+1$ & xset \\
\hline man: & Hokt & as & की & 245 & $300-2 !$ & $36 \%$ & sted \\
\hline$\sqrt{6 \infty}$ & 2,44 & (1) & 6 & mans & Entists & St: & $26+5$ \\
\hline (1) fos & $\therefore$ a & $6 \times 64$ & (20) & 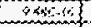 & 003 & i:osin & 546 \\
\hline $6+6 m$ & sseisi & $\infty 8$ & Hit & \&\$s & sons & ingl? & esto: \\
\hline 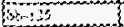 & 26\% & 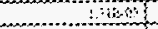 & 2004 & 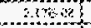 & 2450 & a:As & soson \\
\hline Enes & Wt & $8 x+3$ & 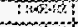 & asts & $47 \mathrm{sin}$ & 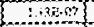 & Wested \\
\hline 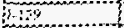 & 500 & 86 & nat & Sou & $2,6 \times+2$ & 2000 & Abovs \\
\hline $6+1)^{2}$ & En: & astes & 306 & $3 \mathrm{san}$ & So, & Enel & 2,16014 \\
\hline ary & asp & 3 & 23 & inyt & Jat 1 & 26062 & 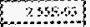 \\
\hline सesios & सd & 32 & 21 & $\therefore 9563\}$ & QSEE: & : 586 & 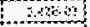 \\
\hline En- 5 & Exos & 213 & Bt & Q & zxtats & Antwa & 0004 \\
\hline Evis? & 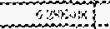 & Whas & nका & 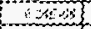 & K.os & otis-as & Drots \\
\hline sion & $\therefore 356$ & $+x+4$ & 640 & 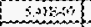 & $3 m, 9$ & serts & $2800:$ \\
\hline 69 & 58 & 86 & 65 & $045 * 6$ & 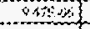 & 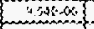 & Anen: \\
\hline ses 2 & 3740 & DSess & $2 \mathrm{Q}, \mathrm{s}$ & meiti & 510212 & 1) & $\phi \alpha+\infty$ \\
\hline $3 x-24$ & $56 \mathrm{c}$ & segse & xantes? & S\$: & $350-6$ & 895 & 8460 \\
\hline 42 & $(6,10$ & 30653 & 36 & Hoi & $136 \%$ & Betsol & $2 \times 16$ \\
\hline m? & Siketst & (x) & 7304 & Antili: & 898 & 360010 & $\therefore$ sses \\
\hline $30 \%$ & $m 4: 3$ & an: & $20 \mathrm{~m}$ & astis & $345+3$ & sist, ! & (1, \\
\hline 36 & 63 & spore & Tonet? & 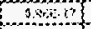 & srest? & s: & (s)tis \\
\hline 25 & isstes & $8 x+4$ & ANow & 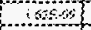 & $\therefore$ Giter & 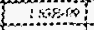 & 6,212 \\
\hline 33 & 59811 & $5 x+0$ & 60606 & $2 x+3\}$ & 27841 & 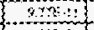 & 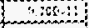 \\
\hline $62 \%$ & inn & $36 x$ & 16 & (1) & :378s & $\therefore$ STE & $\therefore \times p-1:$ \\
\hline 113 & $\therefore 5$ & :FE & 62 & antith & 60 & 8 wititis & sists \\
\hline \%3 & stets & 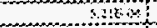 & 3600 & $\therefore \leqslant 0$ & 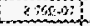 & xits & 80000 \\
\hline $3 x$ & 30,4 & $281+0$ & 3 & Soles & 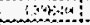 & xas os & anst \\
\hline $6-2 x$ & SAlow & Staws & 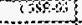 & 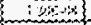 & $\therefore$ Oes: & sns:-2s & sothts \\
\hline$x_{1}, 23$ & \&\&s & Asts & 3064 & 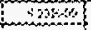 & $280+\infty 1$ & axp & 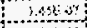 \\
\hline 19 & $3 x+\infty$ & mo & 6,36 & 2004 & $\therefore$ atis & $\therefore 21605$ & asition \\
\hline$\beta_{n}+6$ & sest & stest & Xxple & 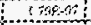 & $52 x+3$ & 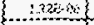 & 年 \\
\hline 3 & $3 \mathrm{~kg}$ & Nos & 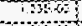 & 1401 & 11004 & 04560 & $\therefore: 18$ \\
\hline Was? & *:! & 2104 & 364 & $\therefore 261$ & S & asy? & 50,12 \\
\hline$\% 24$ & sinton & $\therefore N \& \%$ & it) & 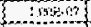 & suke! & A.ten: & 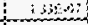 \\
\hline Ax & $3 x+1$ & $38+1$ & onsts & 24,13 & $3046+13$ & 359619 & $\sin 3$ \\
\hline$(20-44$ & $260<1$ & 260 & Ans: & +6110 & 38 is & $2 x+1,1$ & 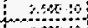 \\
\hline $60 \times 25=$ & 35012 & 241 & rast & 211:3 & 43 & *non & $\therefore$ insis \\
\hline 6,24 & ste & BSOS & 404,7 & SOSE; & $A+n$ & $5 \mathrm{Nat}\}$ & 6006 \\
\hline & (n) & & bo & sen & 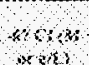 & Yerk & $\begin{array}{l}\text { tat } \\
\text { os os } \\
\text { ght }\end{array}$ \\
\hline m & $8564 \times 4$ & & $6 x+6$ & 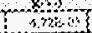 & 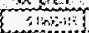 & iotina & $8+4(x)$ \\
\hline & 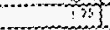 & $3 \times 306$ & $706 \%$ & 13 & ans & 4 & $\cdots$ \\
\hline
\end{tabular}

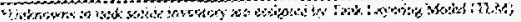




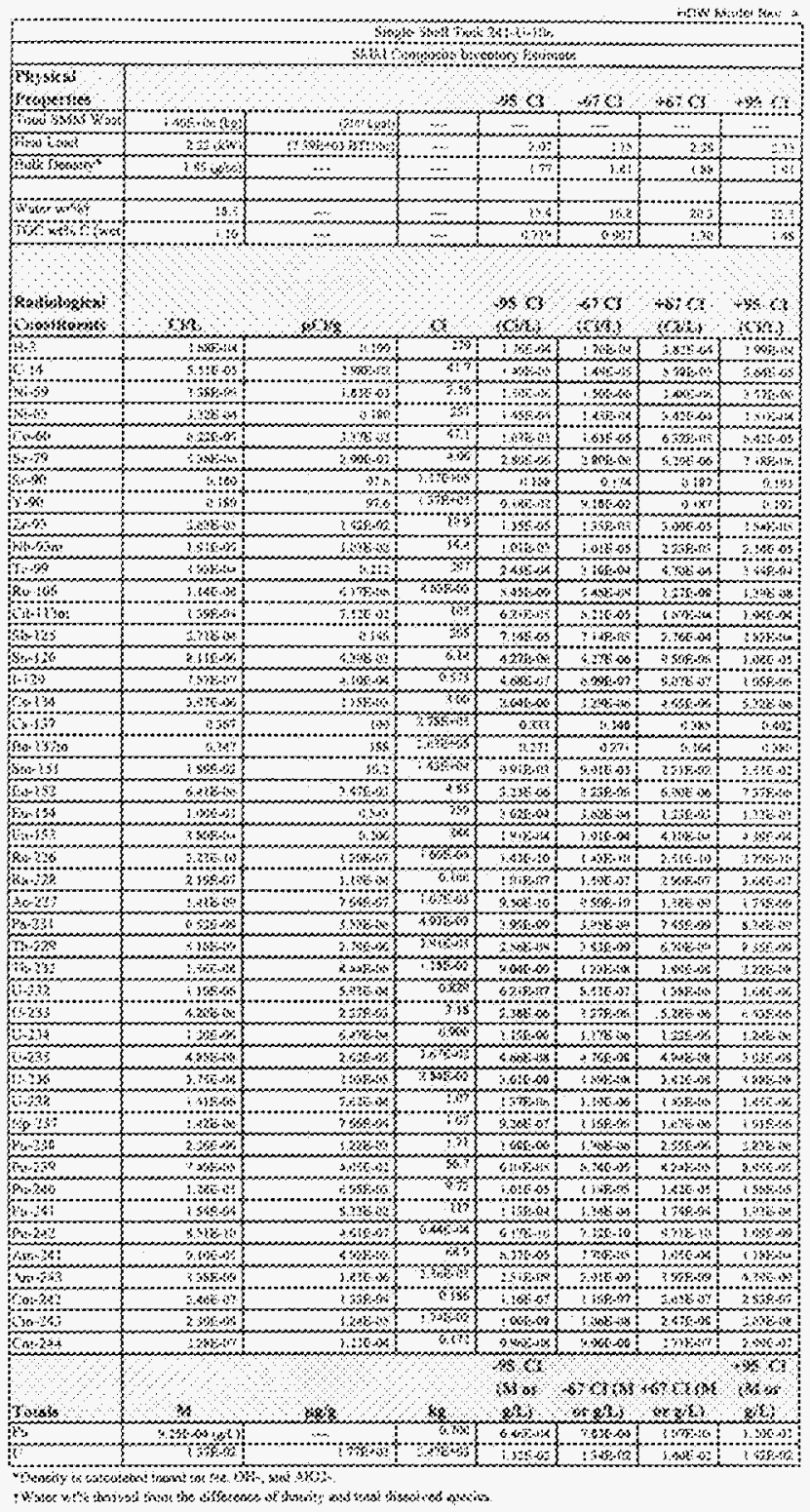




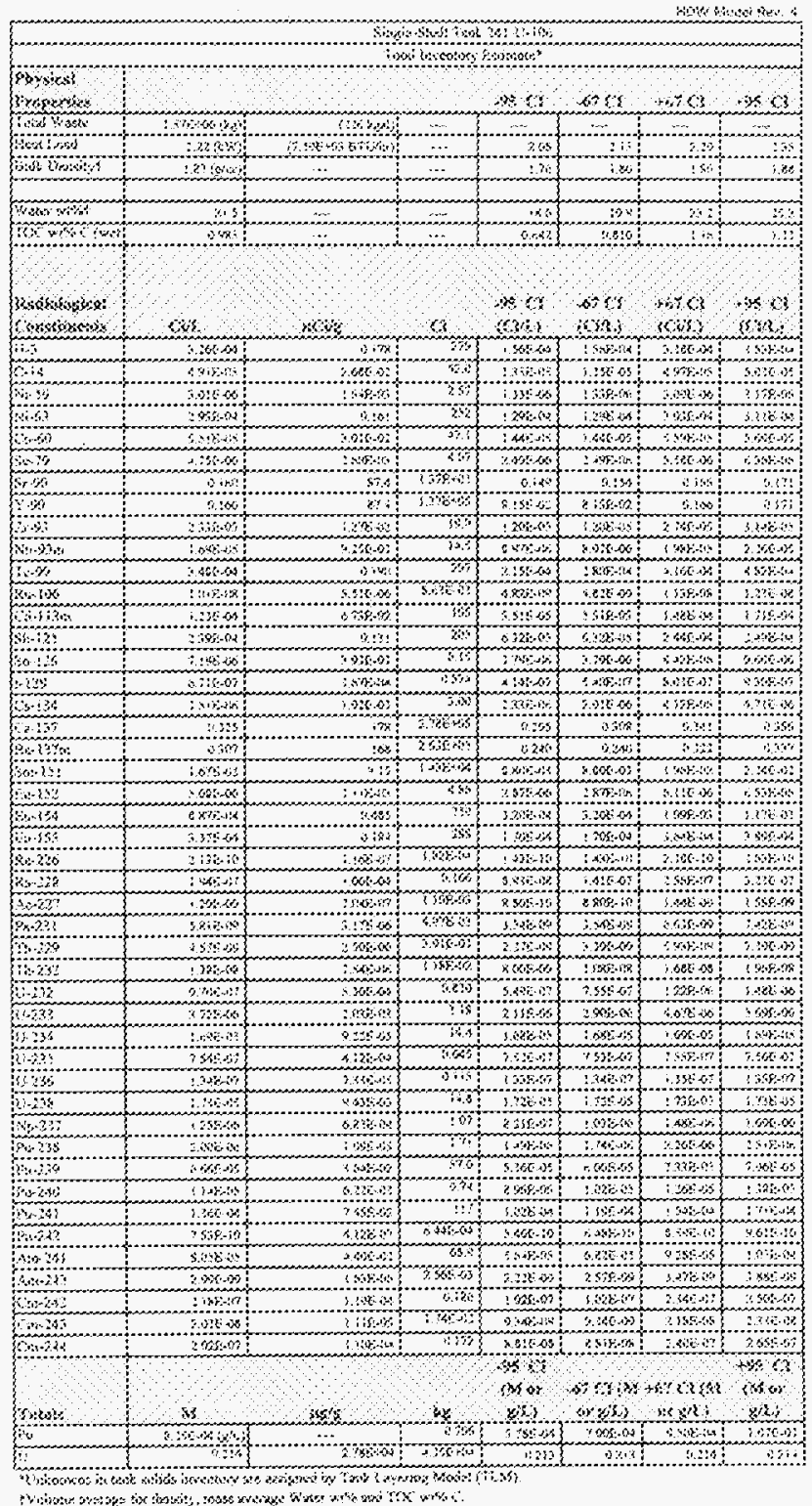




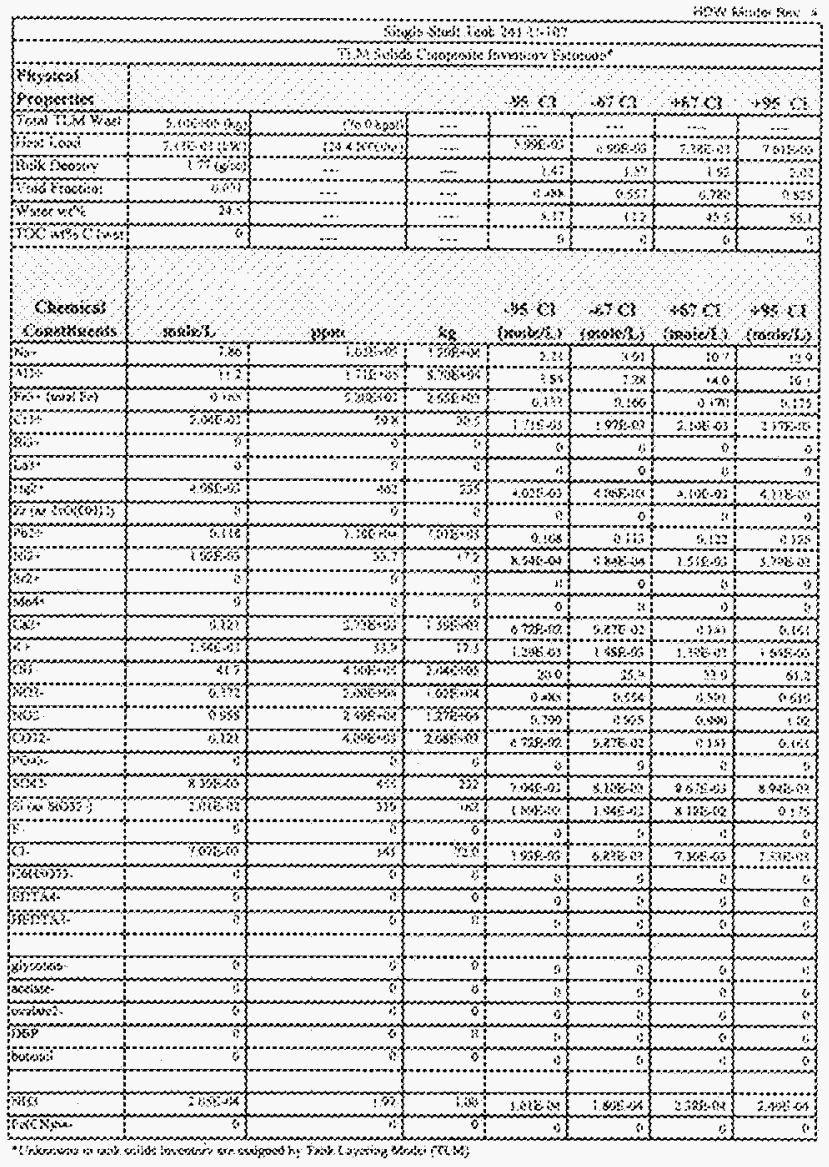




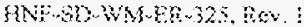

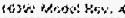

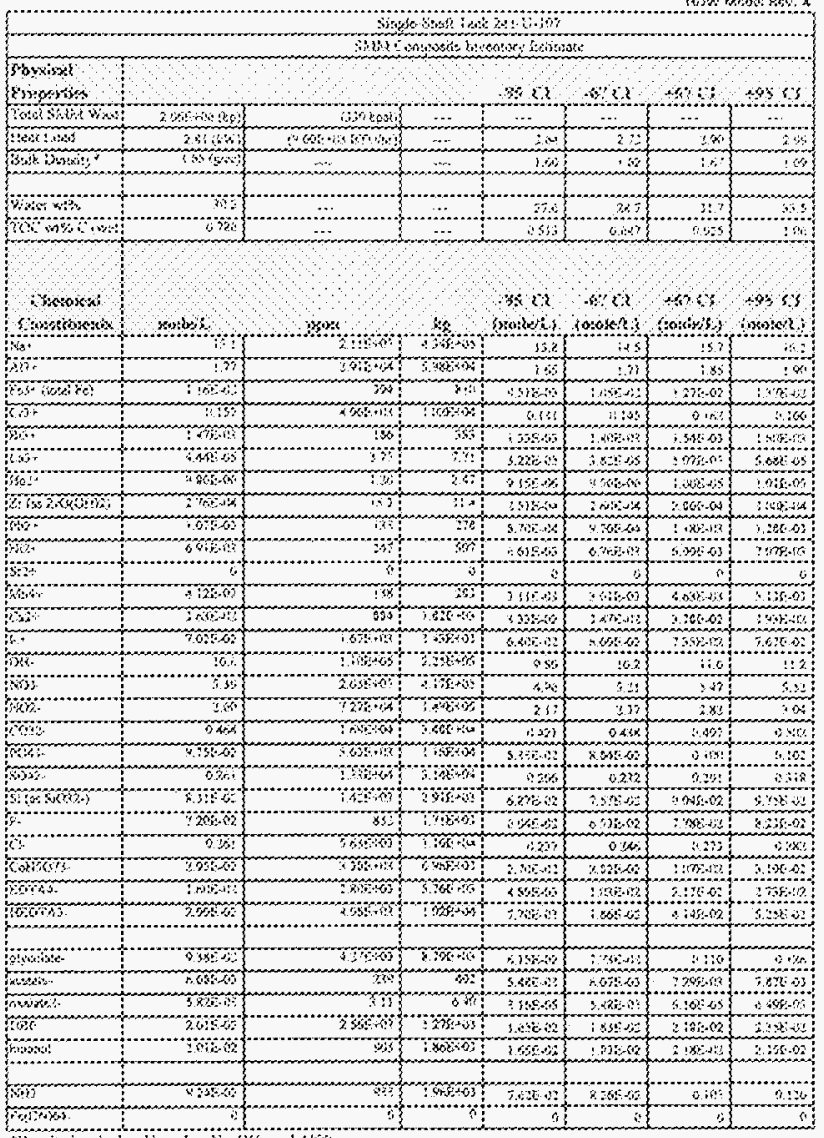

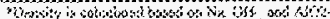

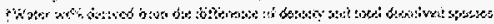




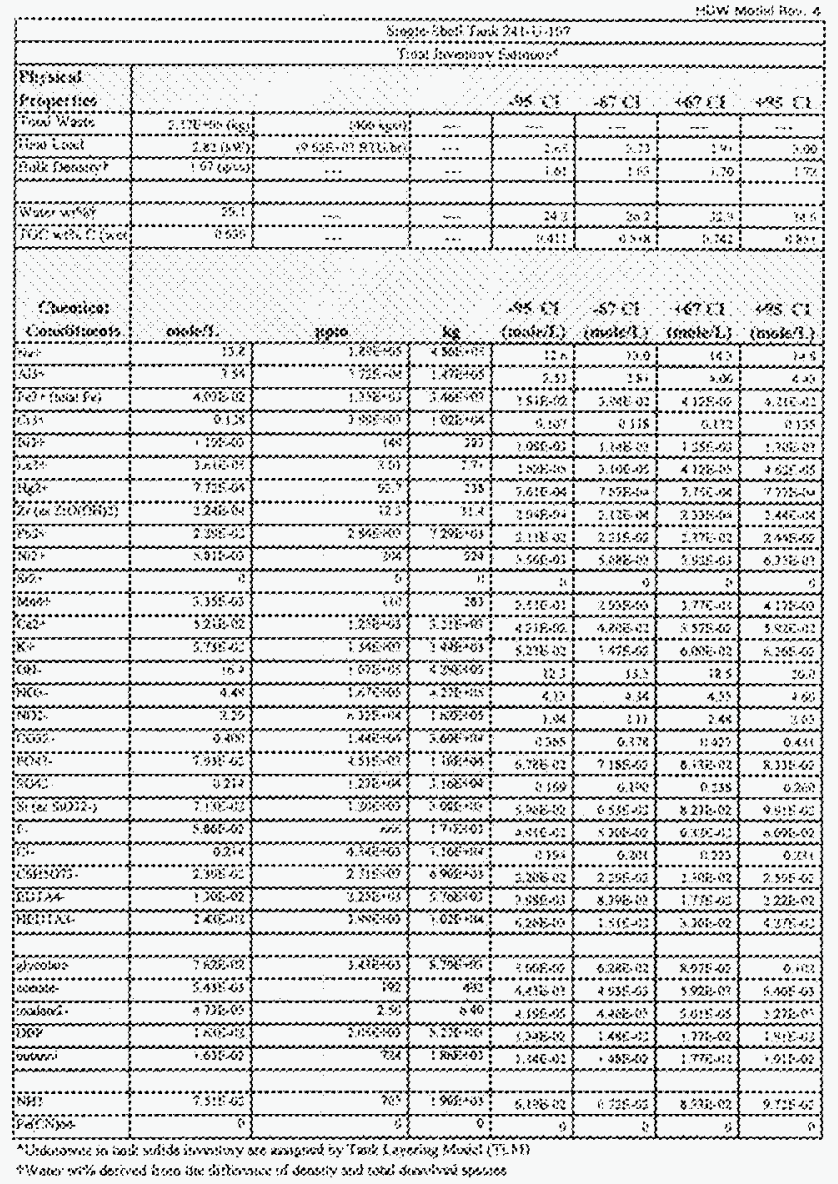


Hifidedesen

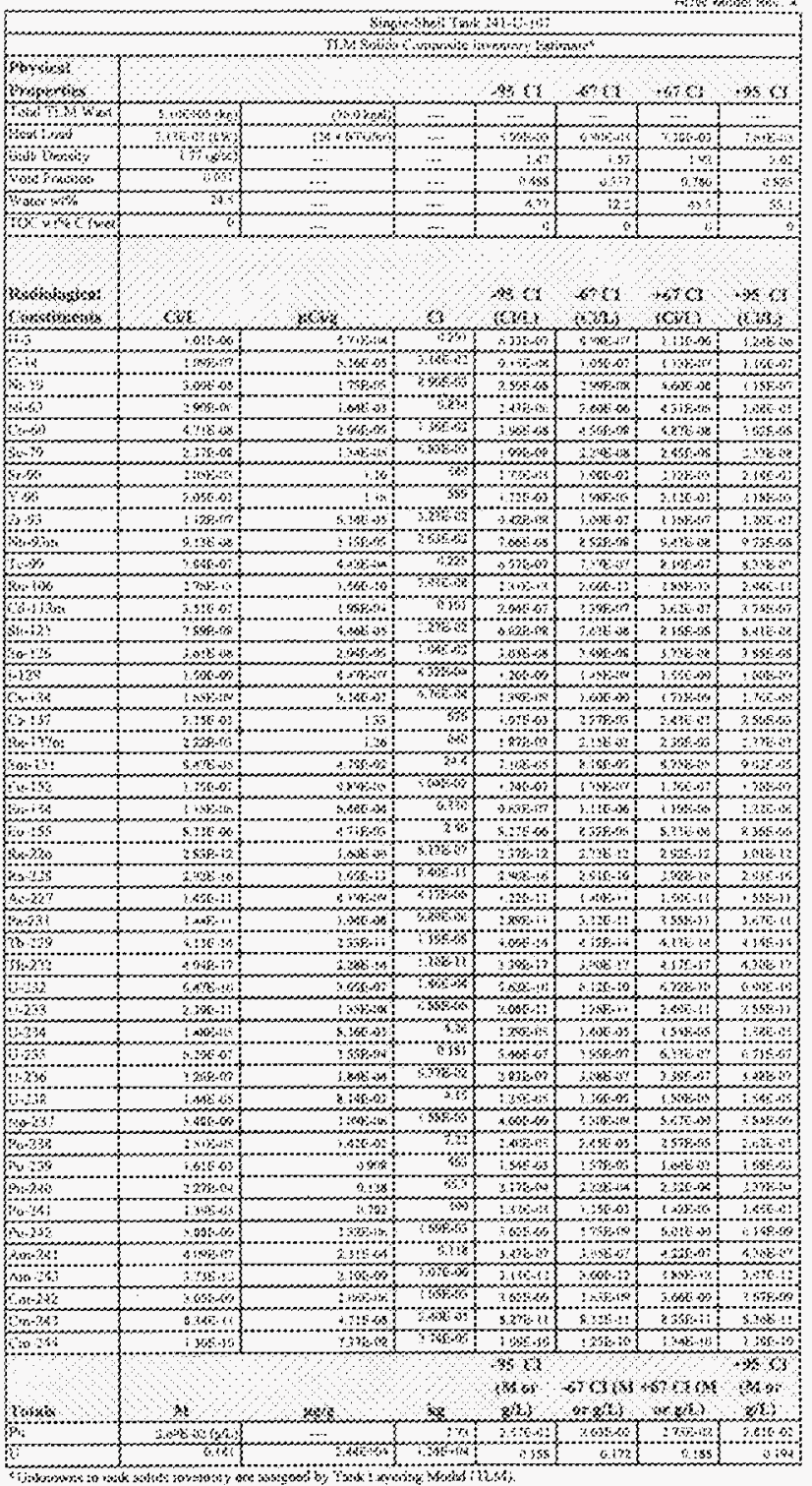




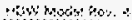

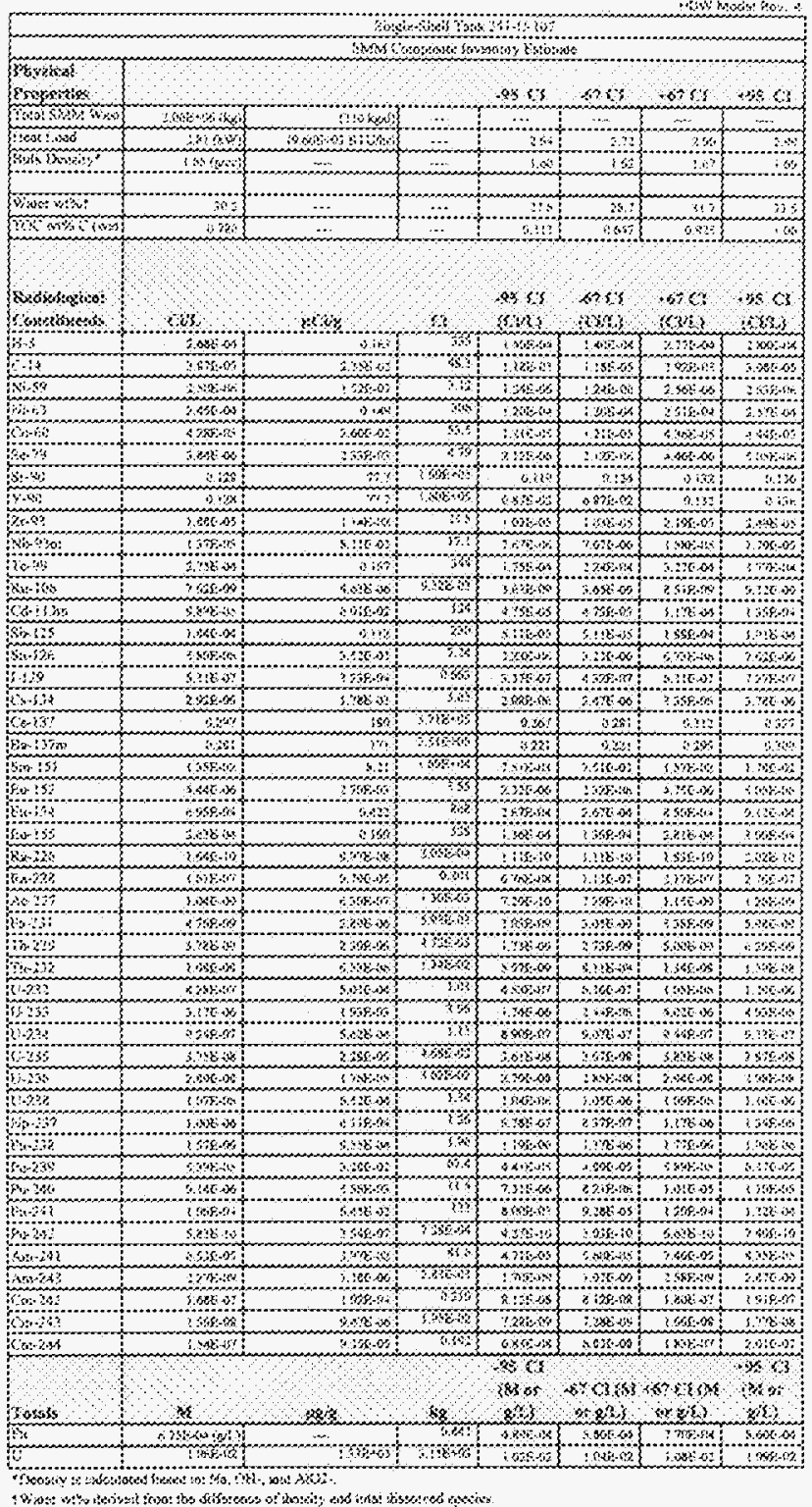


Sow motis ines

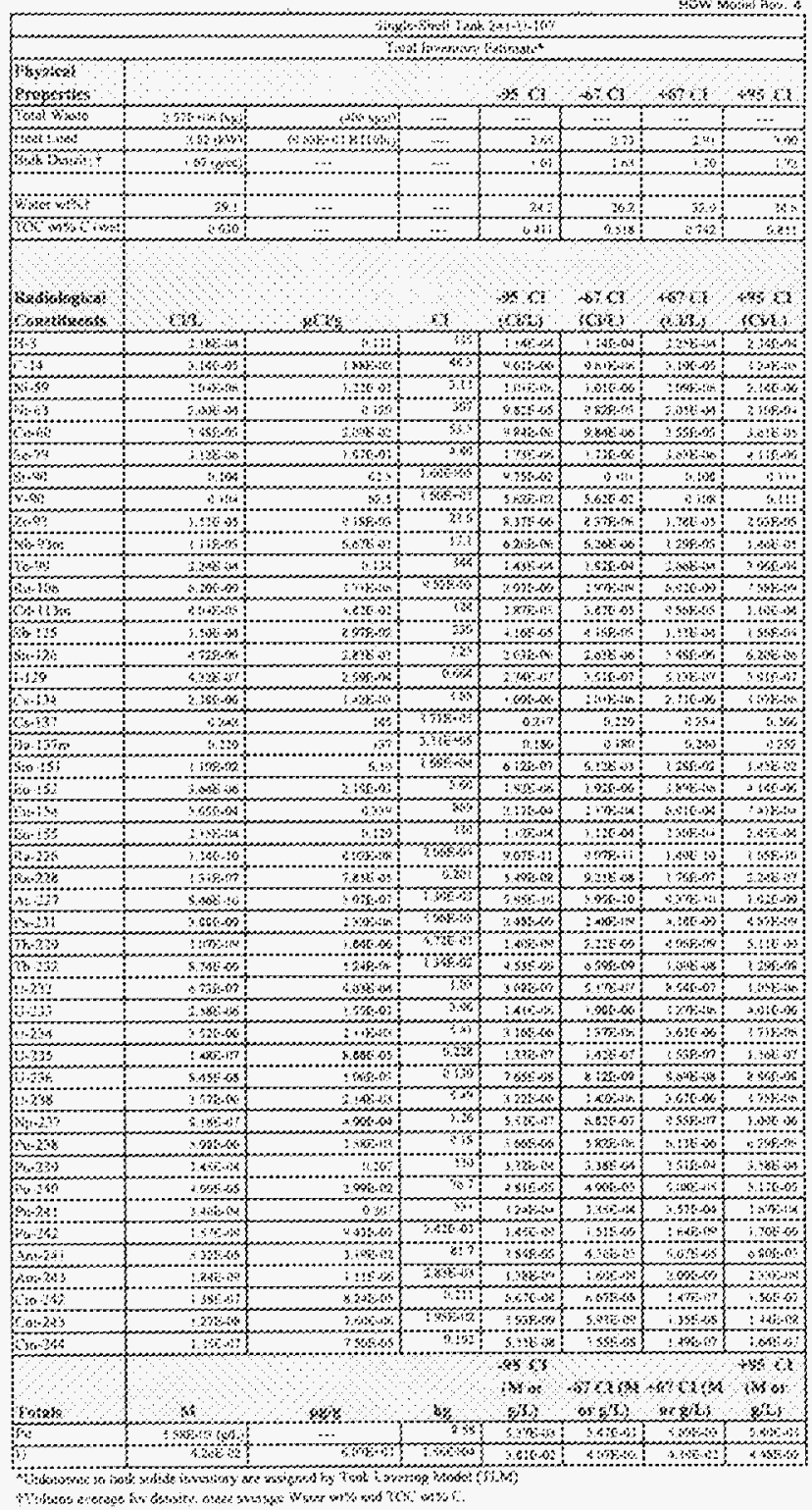




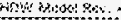

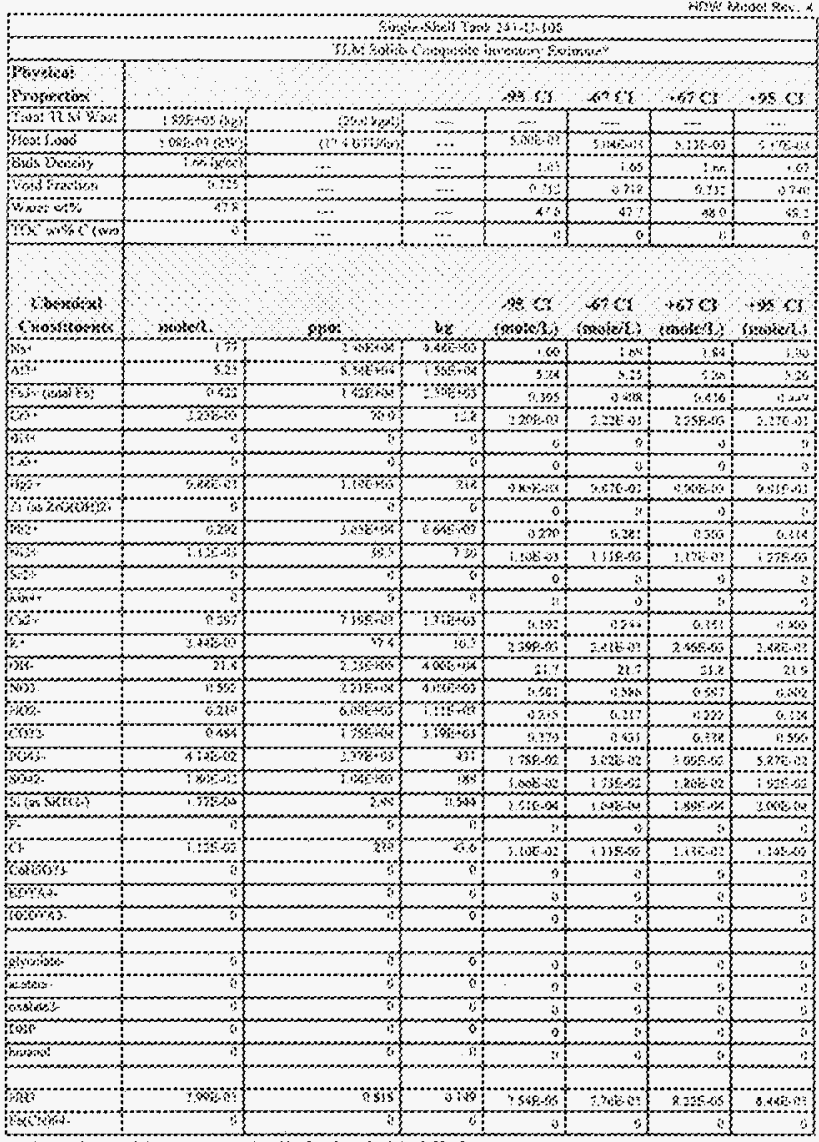

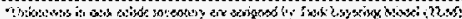




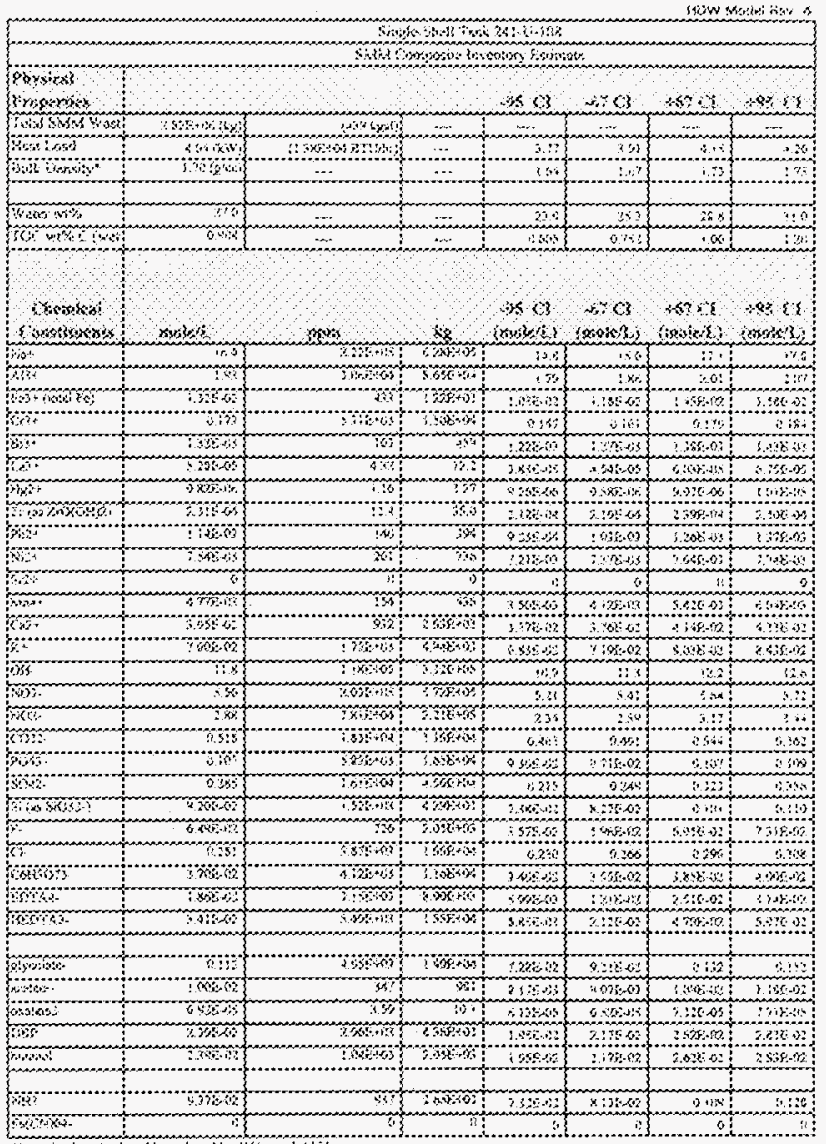

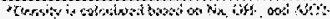

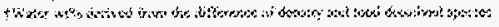




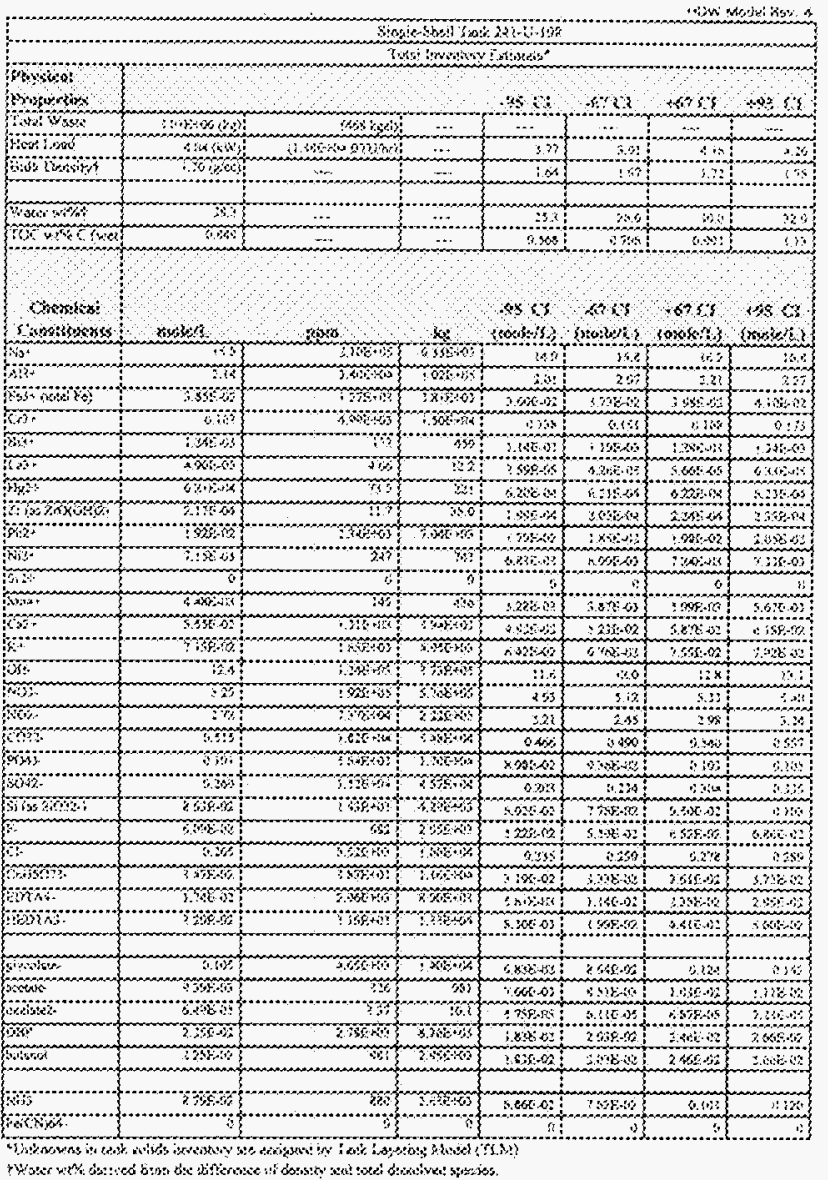




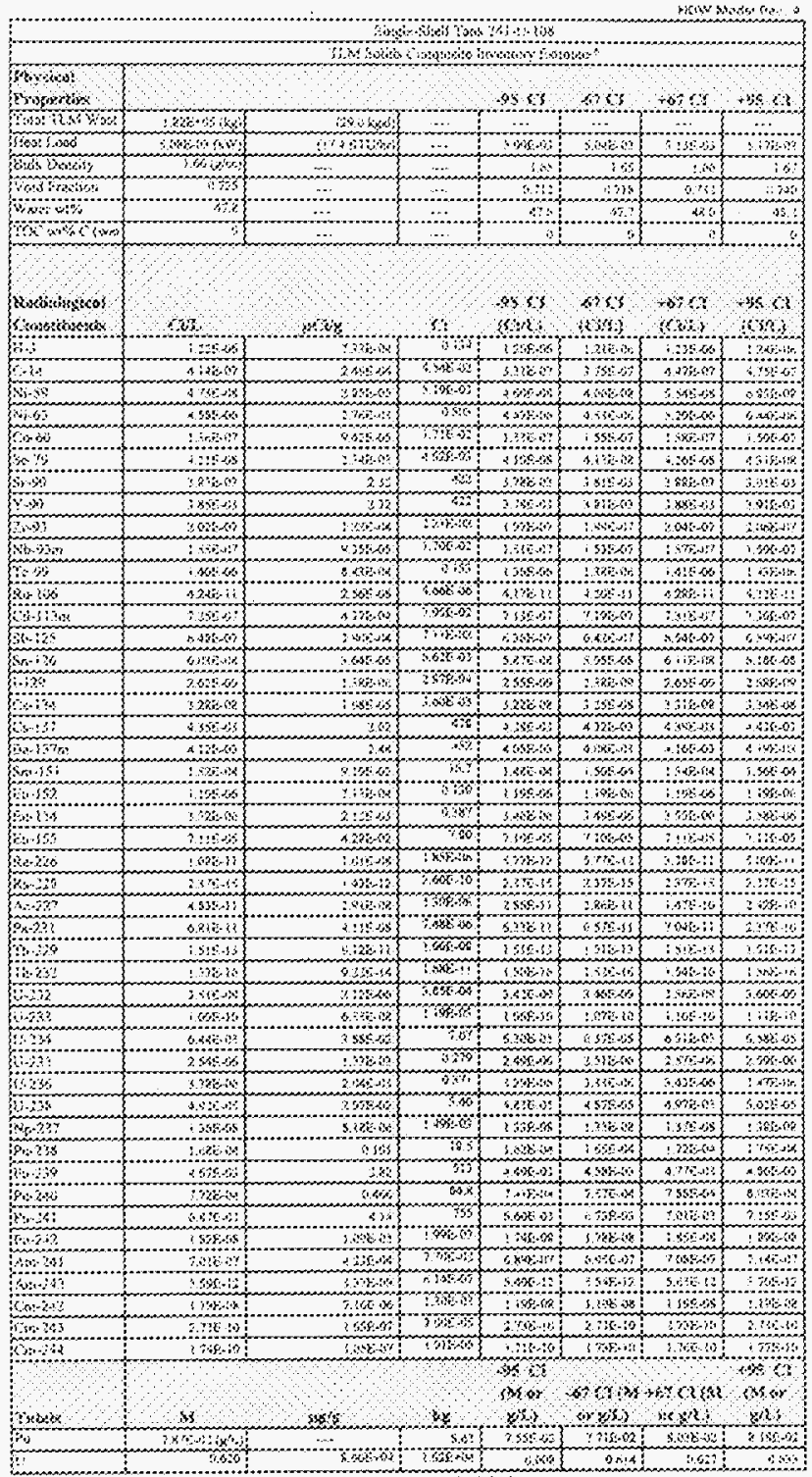

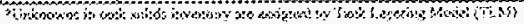




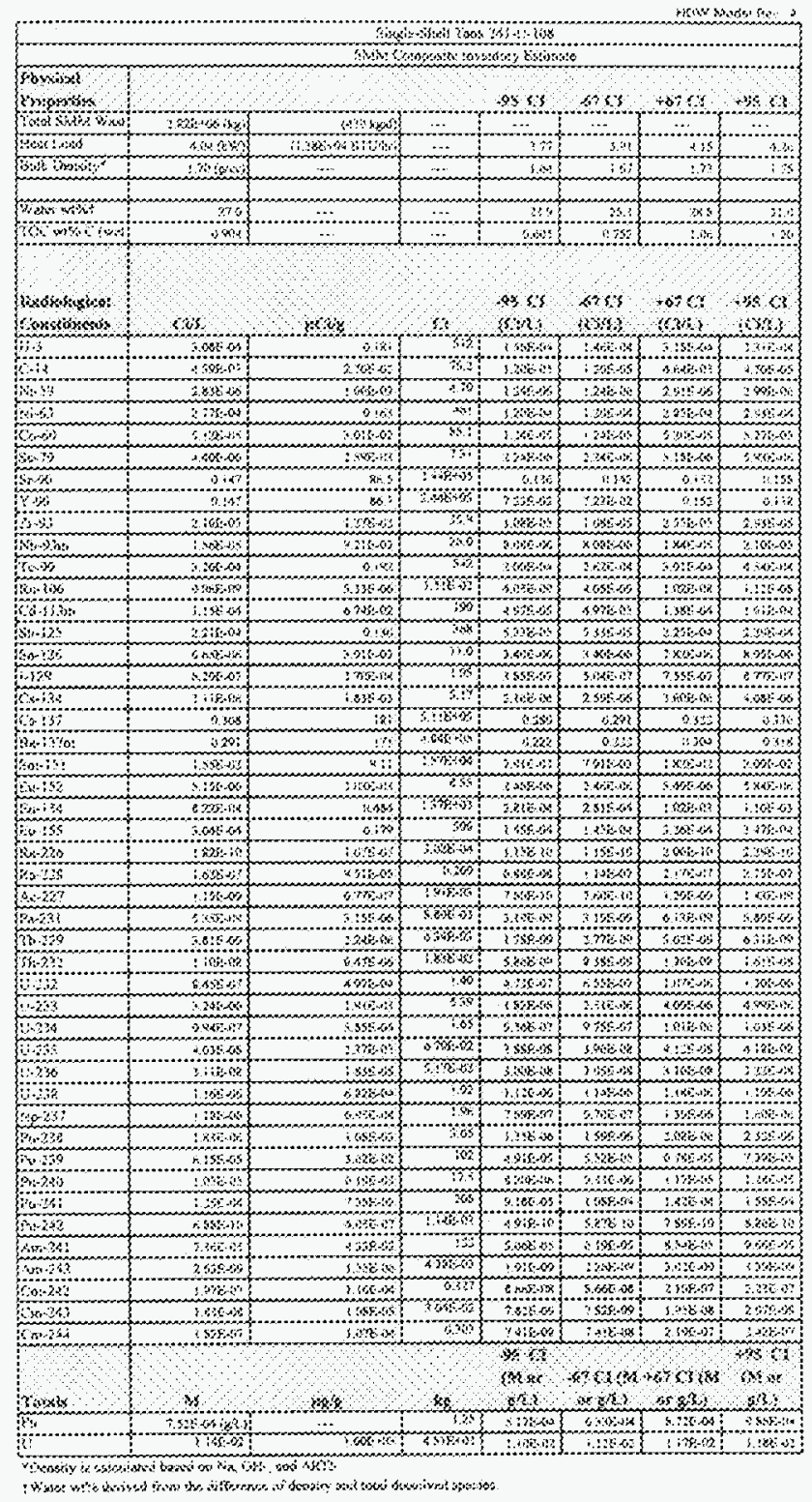


wys thot gs:

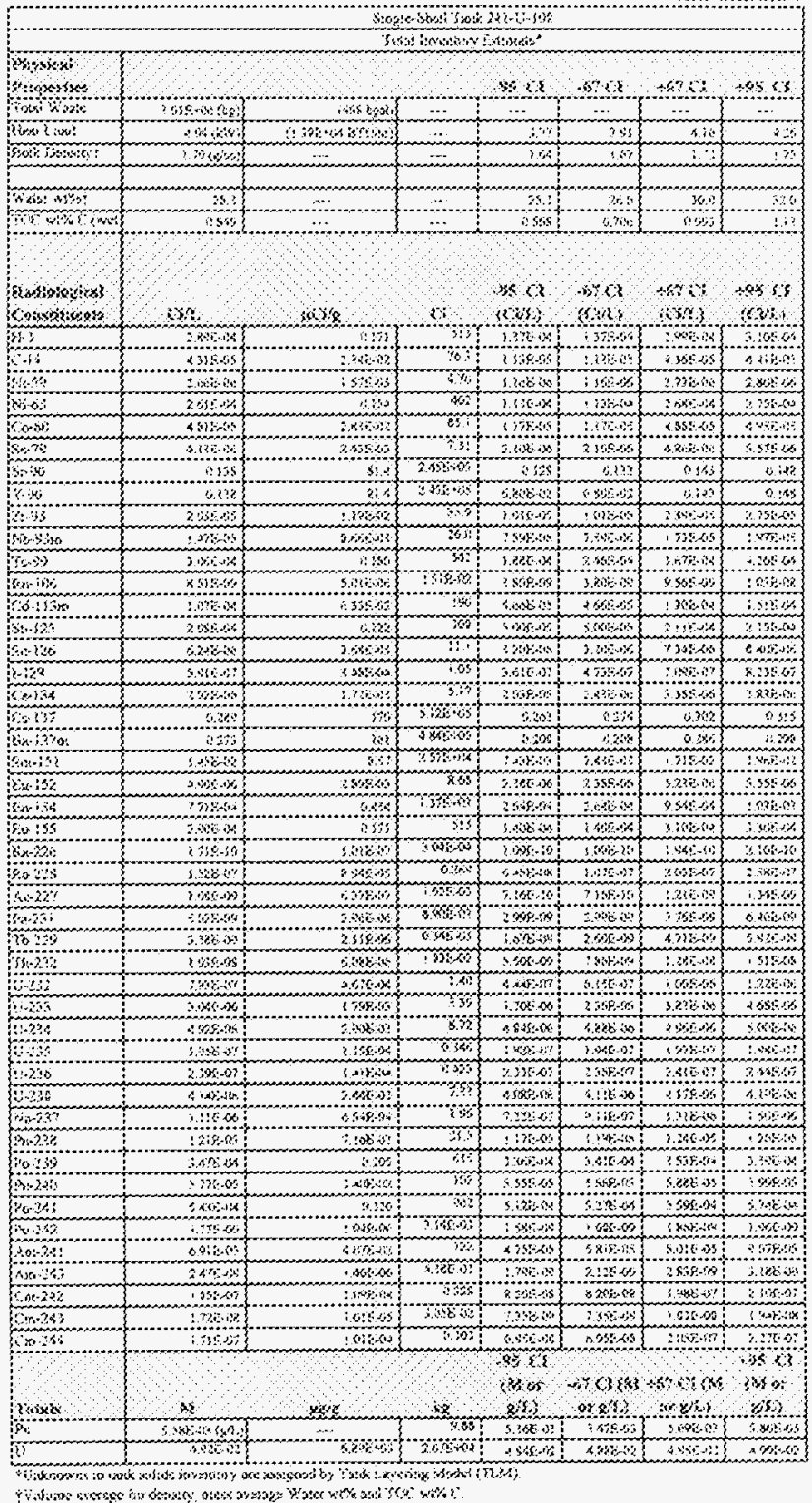




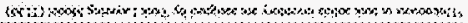

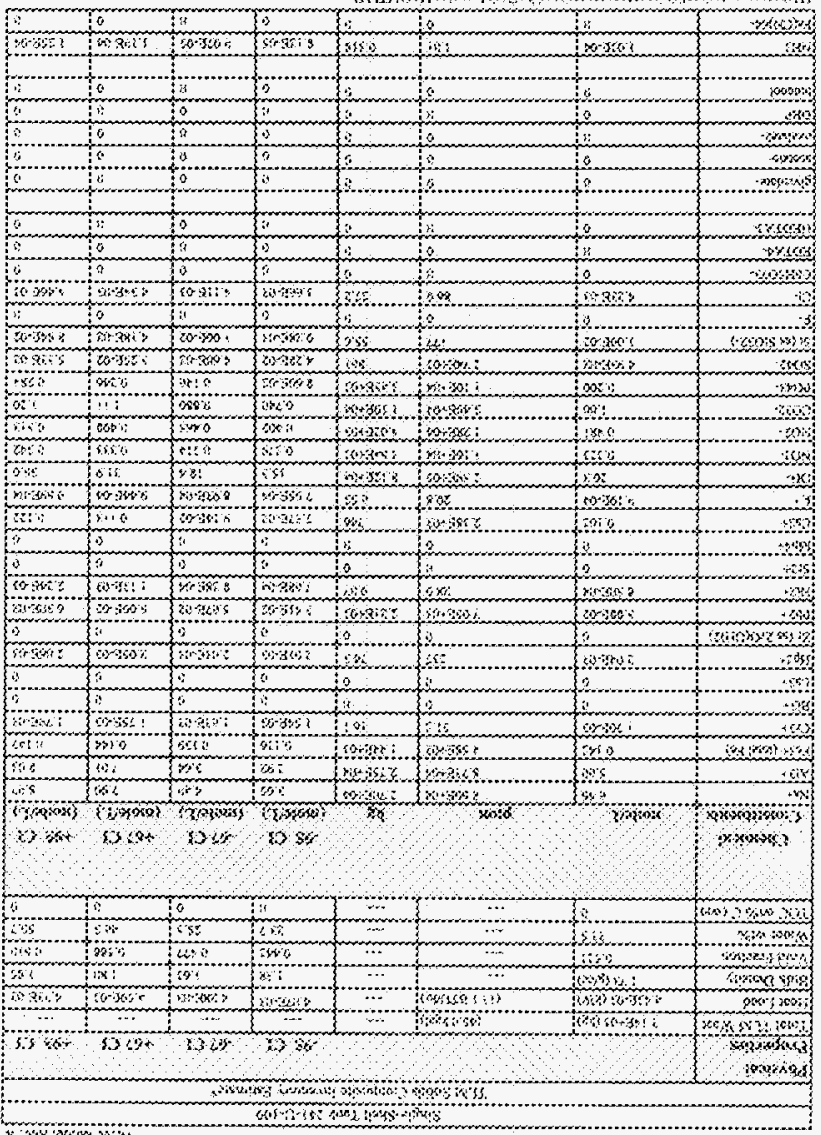

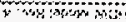




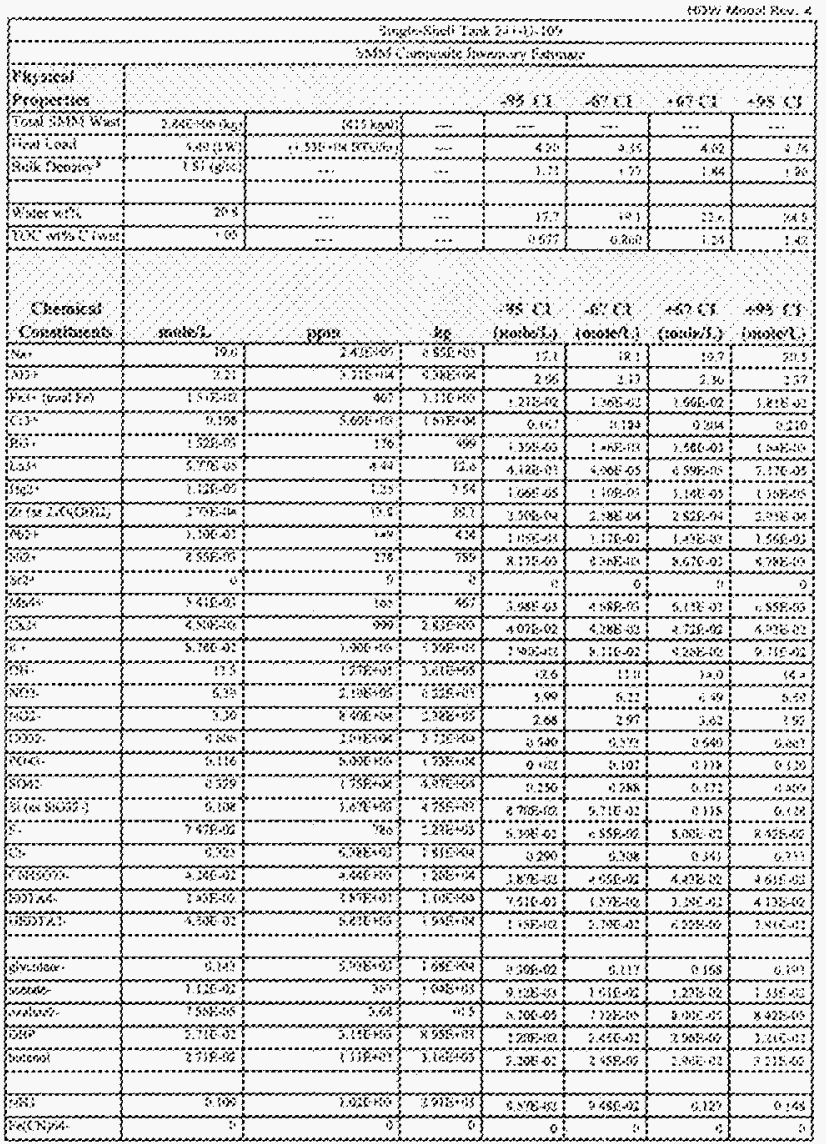

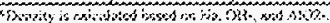

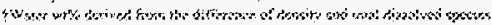




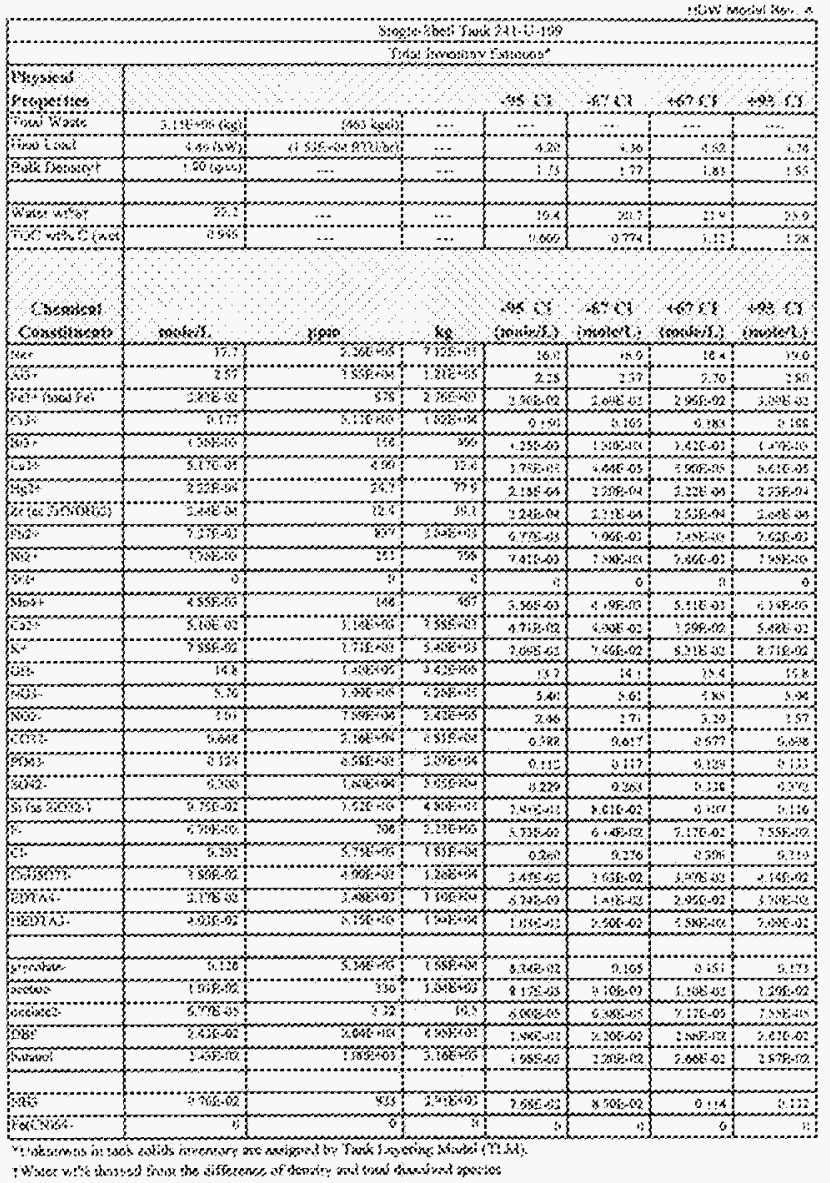




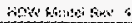



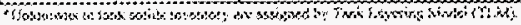




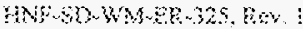

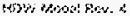

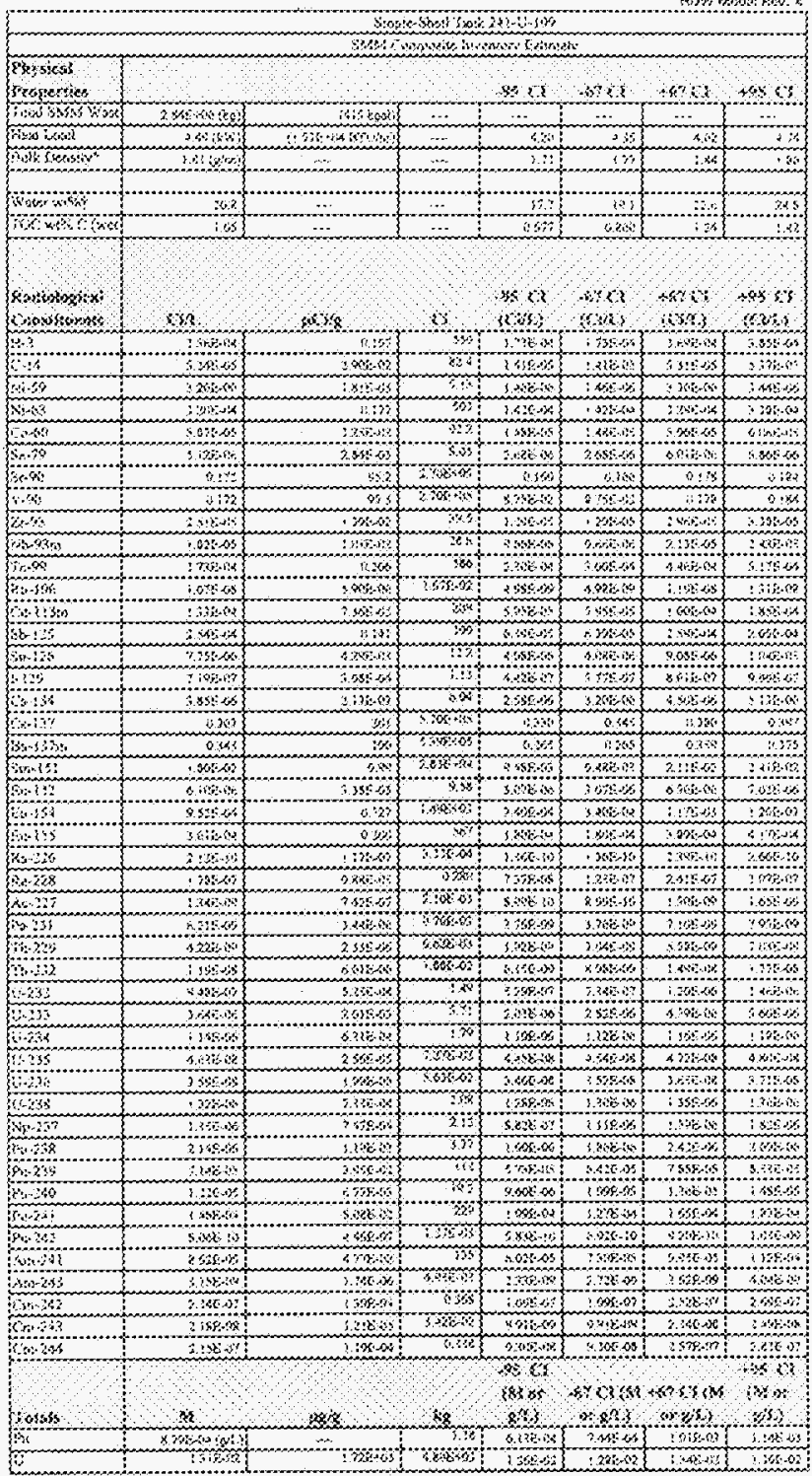

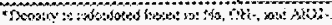

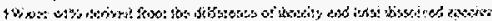


Hovimote gov :



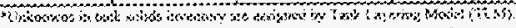

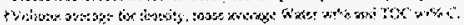




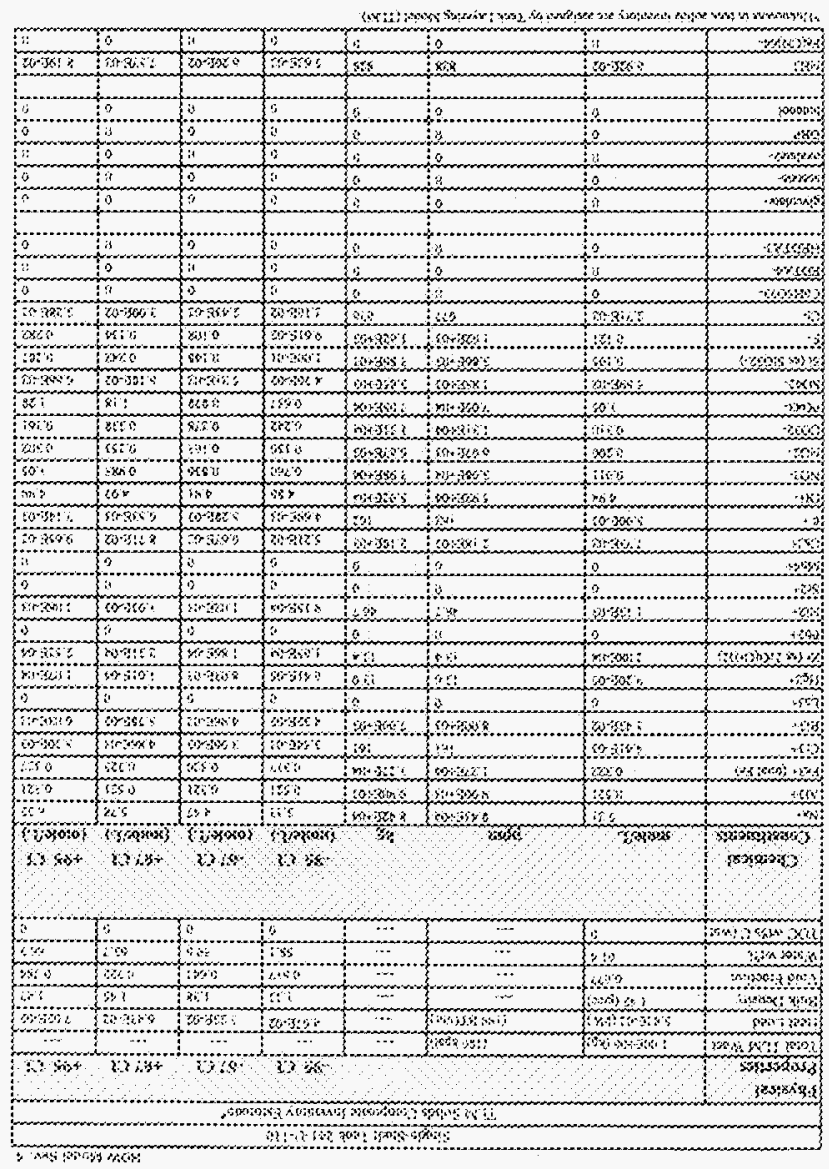




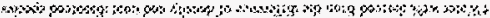

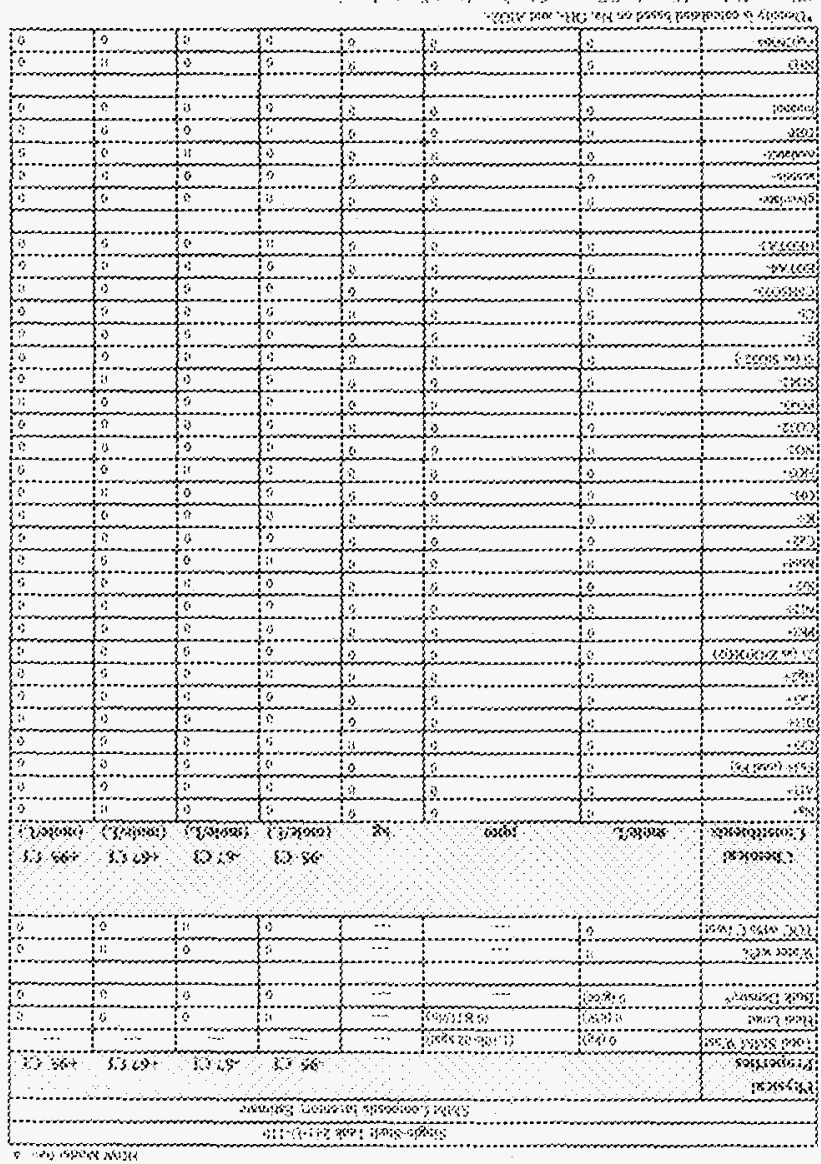




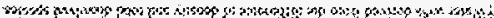

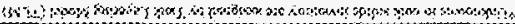

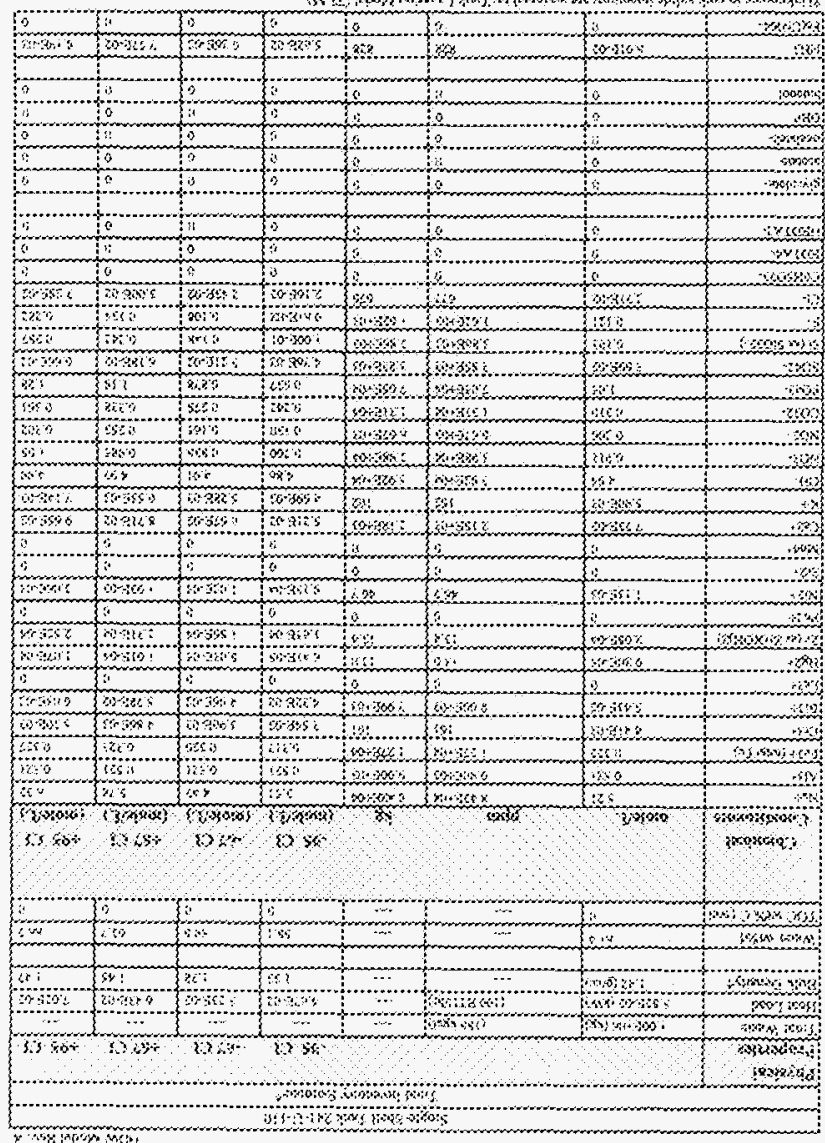


mistest $8 x$

\begin{tabular}{|c|c|c|c|c|c|c|c|}
\hline & & $22+45,40+6$ & oodoosto to & wetos es & wasces & & \\
\hline bisoses & & & & & & & \\
\hline rsoinctes & & & & 352 & $\therefore 8$ & 48 & $05<3$ \\
\hline whons & atcos & issiendid? & $\cdots$ & & $\ldots$ & $\cdots$ & $\cdots$ \\
\hline Hom isse & Stow 6 & atathes & - & $40 \times$ & 30 & 946 & 300 \\
\hline oxh shetsos & $1,26 \times 3$ & & 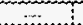 & $1: 3$ & 936 & $: 4$ & 13 \\
\hline Thotsanat & $6 n$ & & $\cdots$ & ans & 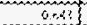 & $m$ & $7 x$ \\
\hline Whot wh & $\%$ & & $\cdots$ & sis & 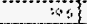 & 63.7 & \\
\hline ardasen & & & $\cdots$ & 3 & a & 3 & \\
\hline Shotolosex & & & & $3 \times x$ & क्र & $-\infty$ & $0 \mathrm{~s} s$ \\
\hline Gonotsonots & an: & 8 & $y$ & (2) 33 & onds & (sts) & Qus, \\
\hline$\because 3$ & sints & $2 x y$ & 84 & 2606 & 35142\} & 49600 & 594 \\
\hline 3 & 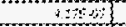 & 2000 & 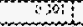 & 2003 & $x_{0}$ & Shat & $02180 \%$ \\
\hline wers & 50040 & $2 x+3$ & Wht & mons & ;ntos & nat: & $3 \times+x$ \\
\hline$x-\theta$ & $2 \times x_{t}+2,3$ & 360 & $m$ & $20 \% * 3$ & 73060 & $40 \% \%$ & 100600 \\
\hline wait: & $\therefore \alpha, \alpha$ & $m$ & 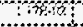 & moss & and & Trass & xomo \\
\hline (5, & 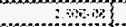 & ists & 403 & $210 \times$ & $2 \times 45$ & ingensens & enstos \\
\hline 606 & s5es & 42: & $8 \sin$ & $3 x \times 03$ & $6 \tan$ & iosets & 890009 \\
\hline$\%$ & $0 m a n$ & 35 & CWF & 36 & $(x, x+3)$ & +6000 & Cx+es \\
\hline 8 & int & 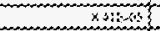 & $30+60^{2}$ & $1+x+2)$ & 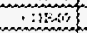 & 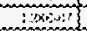 & Whos \\
\hline tor 350 & Sat & ats & 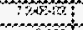 & wris & stost & $\therefore 60$ & :im-1! \\
\hline $0, \infty$ & ans & .Y.4. & 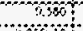 & kes & Cssis & $3 x$ & 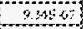 \\
\hline Givifits. & S5sest & 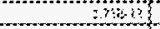 & 4 & ene-is & 54010 & 4.85 .16 & 4010 is \\
\hline (a):so & 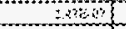 & 30 & 01 & $A B G$ & $3 x+3$ & 360 & and \\
\hline G, & $24 x+2$ & Entsis & $6+6$ & $(3,(x), y)$ & $\times 3$ & 250,1 & $\therefore 806$ \\
\hline $8+-120$ & 3764 & 40 & INNB & KF: & 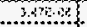 & Fts & non \\
\hline $\mathrm{m}$ & Ans & 686 & 0063 & 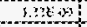 & 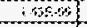 & mestat & ants \\
\hline$M A B$ & Q35:53 & 6063 & 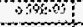 & Sts.:1 & x<12 11 & 16sts & 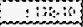 \\
\hline re? & 36 & 31 & $36+6$ & $6 x+4$ & $(0,2,1$ & $x \sin 6$ & $06+6$ \\
\hline Binding & 23406 & $\therefore 3$ & Wor & (⿻) & $6 n$ & a.tens? & sos:s \\
\hline $8 \mathrm{x} \cdot 51$ & S $\triangle \mathrm{E}$ & (ritew: & $m$ & FEN & sests & 6,696 & 217985 \\
\hline $0+152$ & $(6,10)$ & (nss: & whor & S: & ass & Sive & (s) 20 \\
\hline (w) & $23 \mathrm{E}$ & 306 & 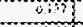 & |sist-3i\} & 400 & $2350+13$ & 30160 \\
\hline Fens & $3 x+4$ & 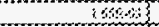 & 16 & 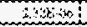 & $240+3$ & 3356 & atrontic \\
\hline (xisis & $2660+11$ & SOE & Whos & $m \times 1$ & (5tis & $4+611$ & 61511 \\
\hline 9023 & 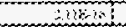 & 601 & Won & MFsk & 606 & a110s & ate-ie \\
\hline $4 \times$ & sen:: & ness & 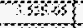 & stose: & se-iis & 208615 & $+2 k$, \\
\hline mi & 130 & 3640 & Mo6 & An: in & (158-id! & (1) & 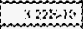 \\
\hline 60 & Satis & NGOH & $25 x+4$ & 4644 & 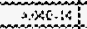 & solet & $3+6+4$ \\
\hline max & 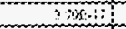 & Any & When & $3: 851$ & s.s? & 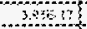 & सyst3 \\
\hline 6 & Bysts & FAt: & mos & sasin & Yoes & $3+5 \mathrm{e}-496$ & $320+19$ \\
\hline 29 & $234:$ & istess & $3 \mathrm{SO}_{3}$ & $21001:$ & Henia & सेखी & 320.16 \\
\hline 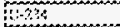 & 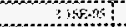 & $2, \leq \leq 1$ & 23 & $0,00,0$ & intain: & $3(60)+3$ & 32166 \\
\hline (ns & ax & 30 & 13 & and & 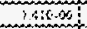 & (n) & $\therefore 4 \%$ \\
\hline 60 & 2050 & Wois? & mis & 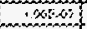 & stan? & wa & 2368 \\
\hline $8 \%$ & $324+6$ & $2 \times 001$ & 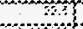 & ings? & Ners & atsos & 3,3426 \\
\hline $5+2-23$ & s.9itens & $\therefore \times s$ & 3 & iYsess & $\therefore$ its $\infty$ & 5200 in & 5060 \\
\hline 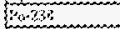 & $4 \mathrm{xa}+\mathrm{p}$ & Wn: & 3006 & nians & Natus & (i) $0(-1):$ & (3) \\
\hline 6420 & .3050s & (xtk & bic & 30 & $\therefore 2160$ & Ays! & $5+2,4$ \\
\hline $0,0<2$ & $8 \mathrm{mith}$ & GXENA & $m$ & 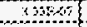 & $\therefore 776$ & 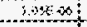 & 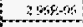 \\
\hline o & Axts & 00,05 & $\ldots$ & Ees? & $238 t-18$ & 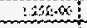 & 1640 \\
\hline $51-224$ & At: & $200+4$ & 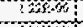 & 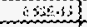 & (3):3 & :xitnin! & $B+\infty:::$ \\
\hline$\alpha x=-25:$ & axisos & $2 \sec 3$ & Ant & 36on: & 200, & Ans & 4 SWE: \\
\hline 486 & (3St) & $8: 3-i i$ & Non & mis:? & $65 \% 3$ & anstis & itne.: \\
\hline 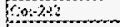 & 021611 & s.m. & arta & (ISP-13 & Q12til & 5,40013 & $8 \times 3 x-1:$ \\
\hline Cout i & 2,618 & asts & SHet & 208 & $21+13$ & $4 x+3$ & 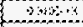 \\
\hline On:3i & $\therefore$ 7.1.13 & 2603 & N3.6. & $2+40-13$ & 16061 & Ins & 3015 \\
\hline$\gamma_{0} \times{ }_{1}$ & & & $3 x$ & $\begin{array}{l}40 \\
\alpha \beta\end{array}$ & $\begin{array}{l}\text { sed } \\
\text { oros }\end{array}$ & 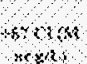 & $\begin{array}{l}18<< \\
\text { os or } \\
\text { ys }\end{array}$ \\
\hline soxis & Ast 4 tas & 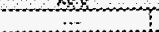 & $0,0\}$ & Sogs & (9894 & staws & 804 \\
\hline & wos? & 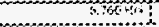 & ostos & Q⿻一⿻口卄日? & ata & 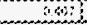 & $\therefore \%$ \\
\hline
\end{tabular}

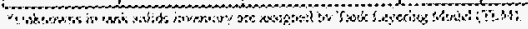




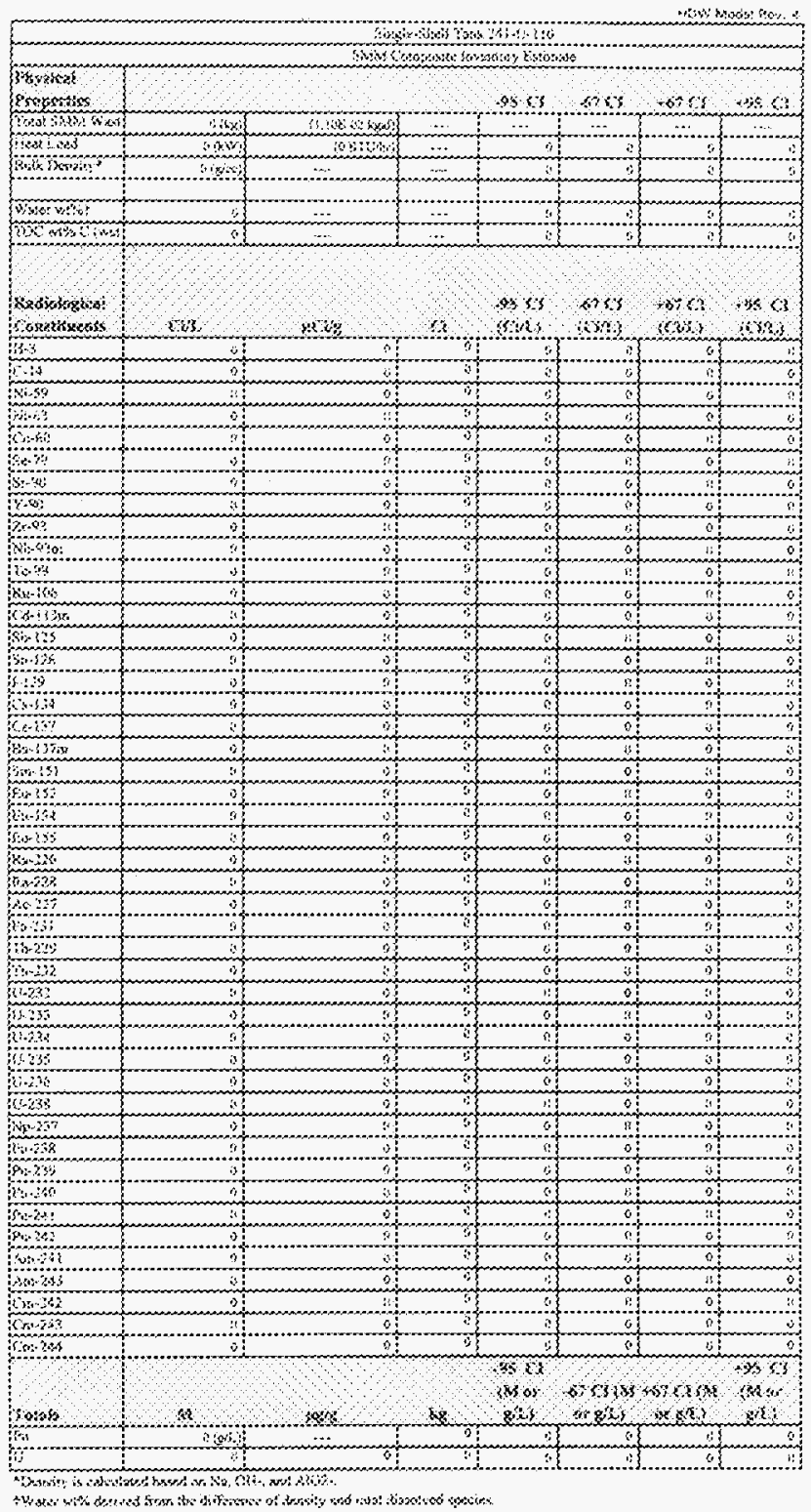


Houn shen in: 0

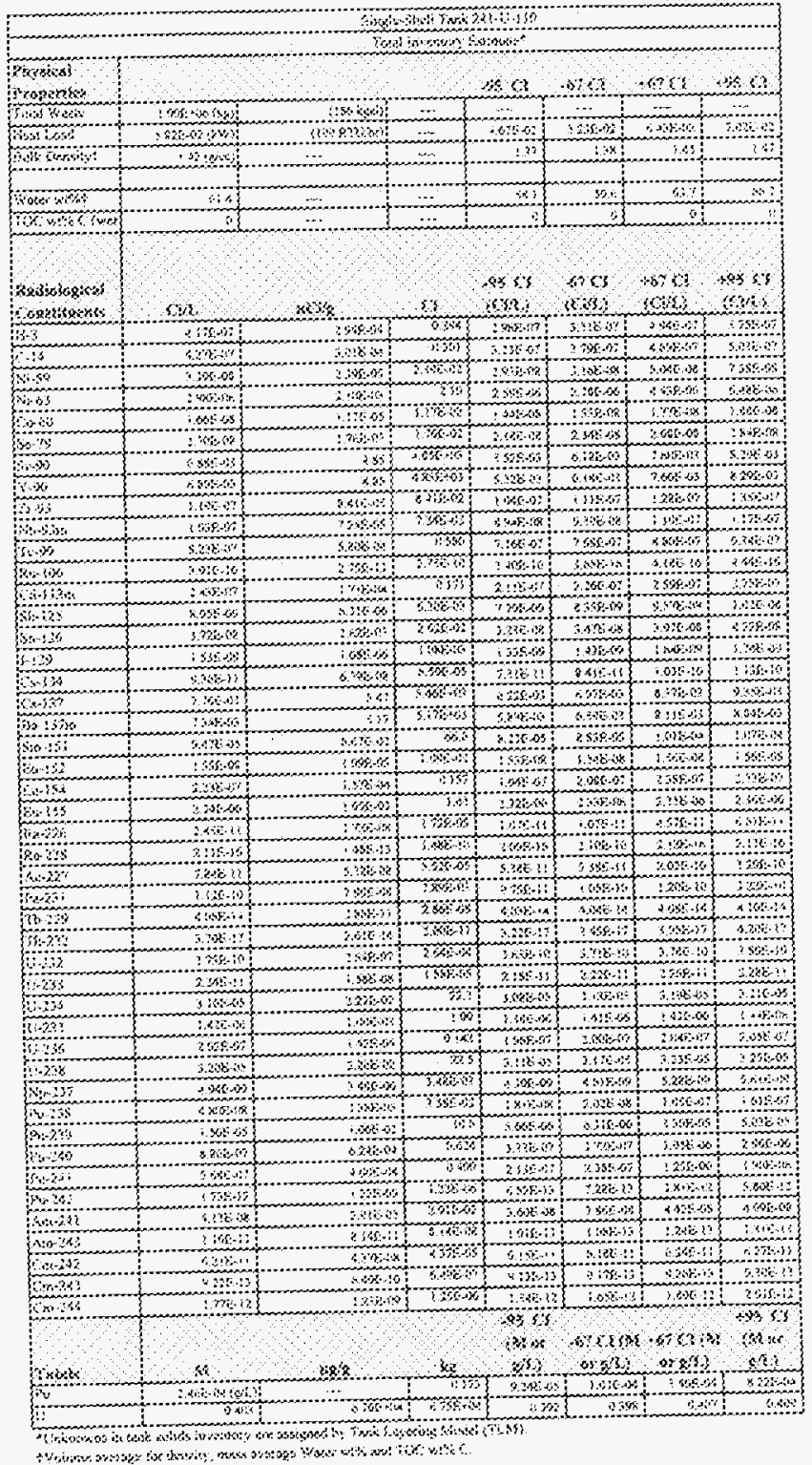




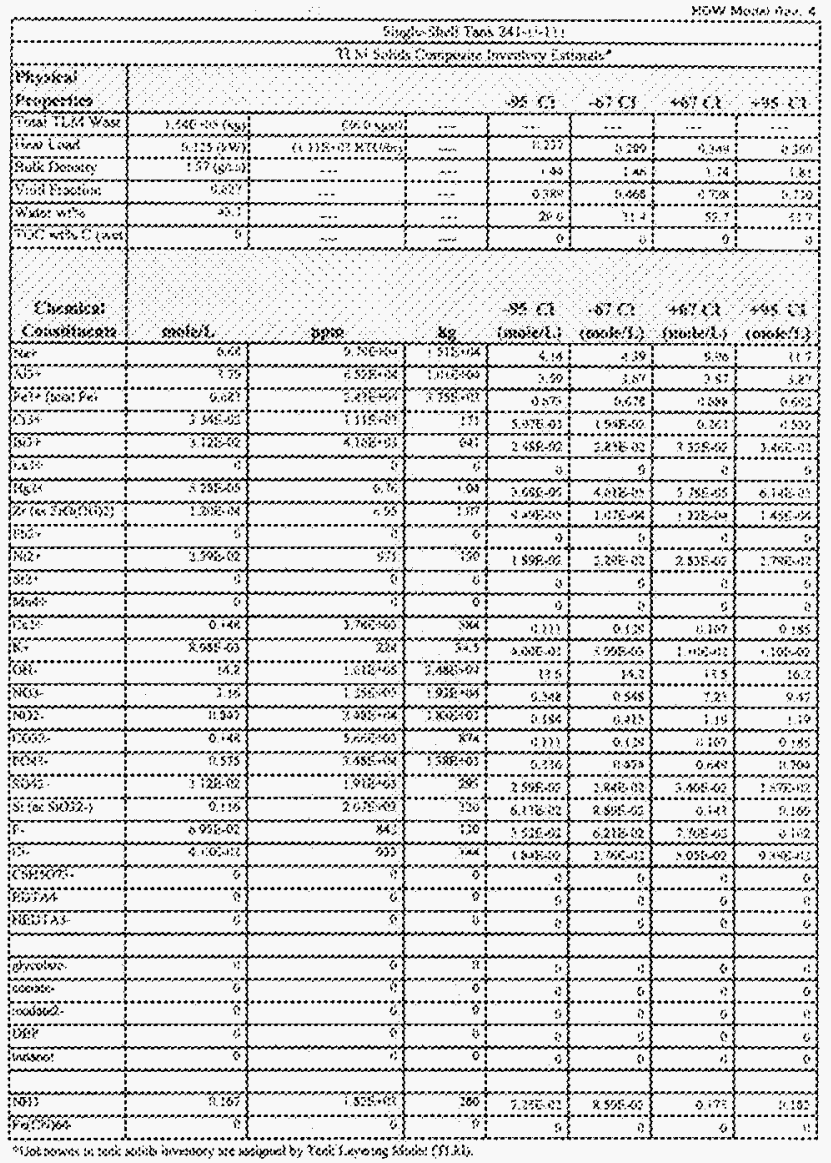


How bortat nit.

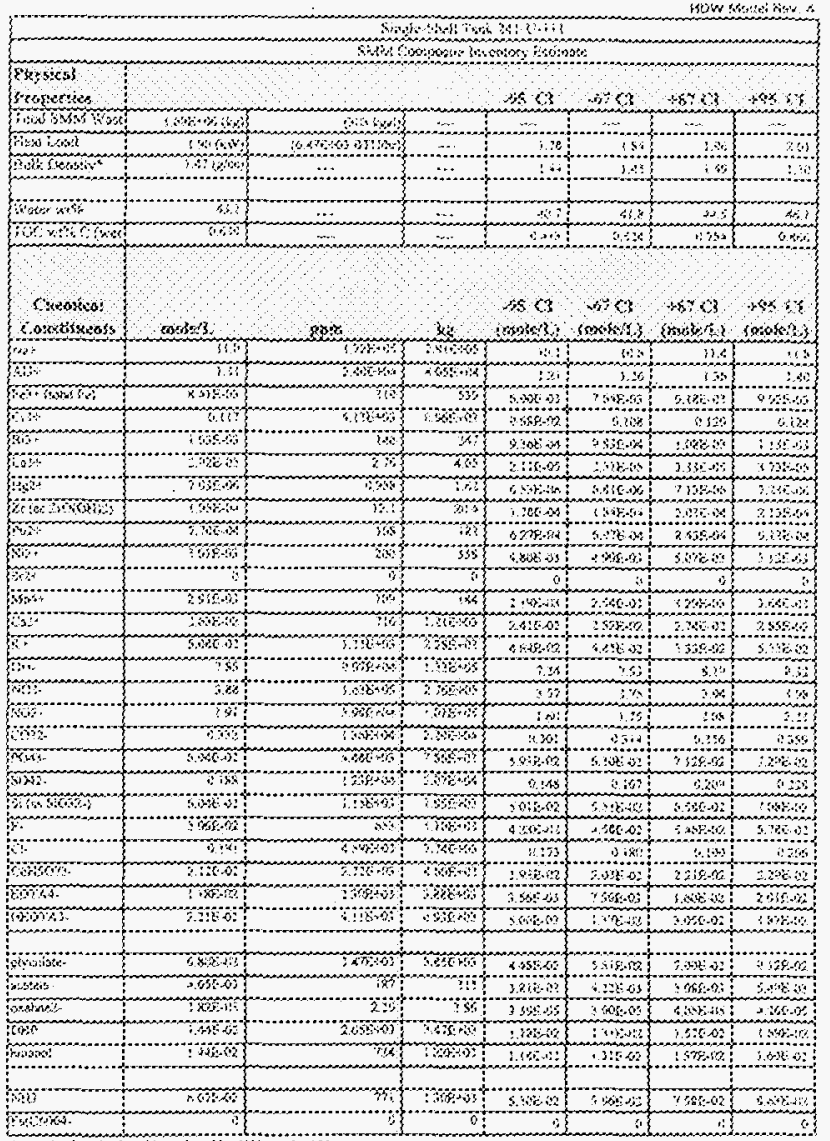

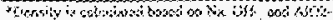

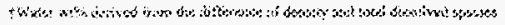




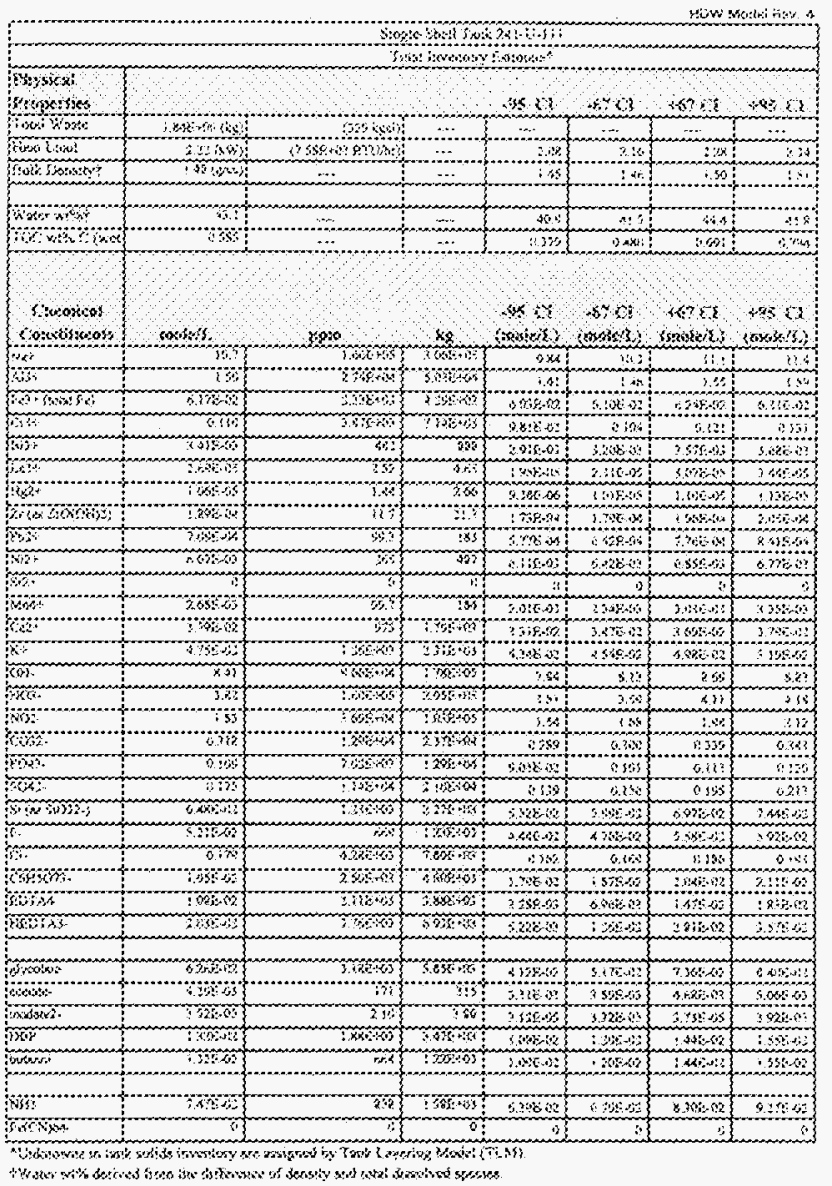


How Heder Re'

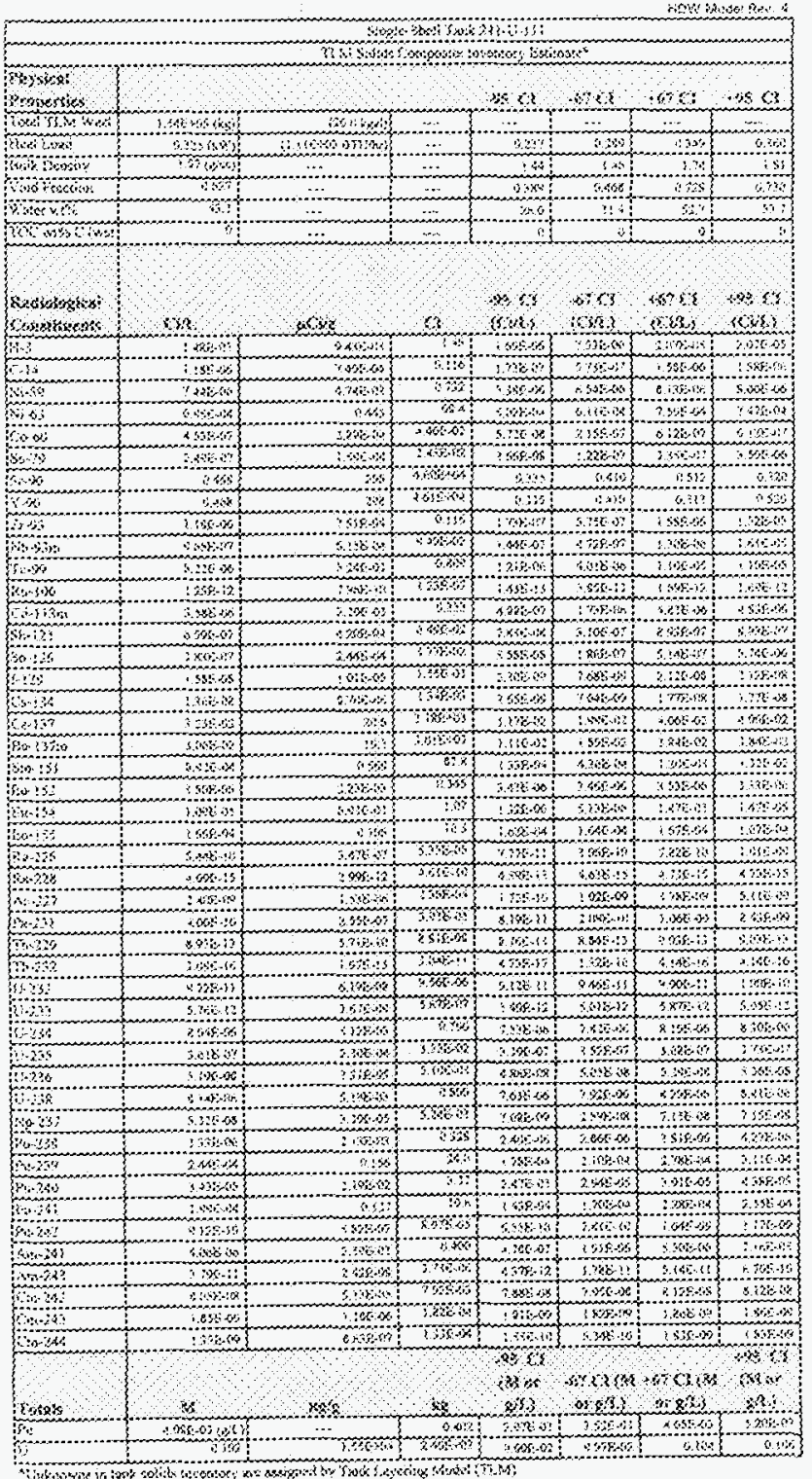




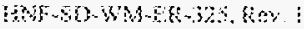

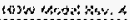

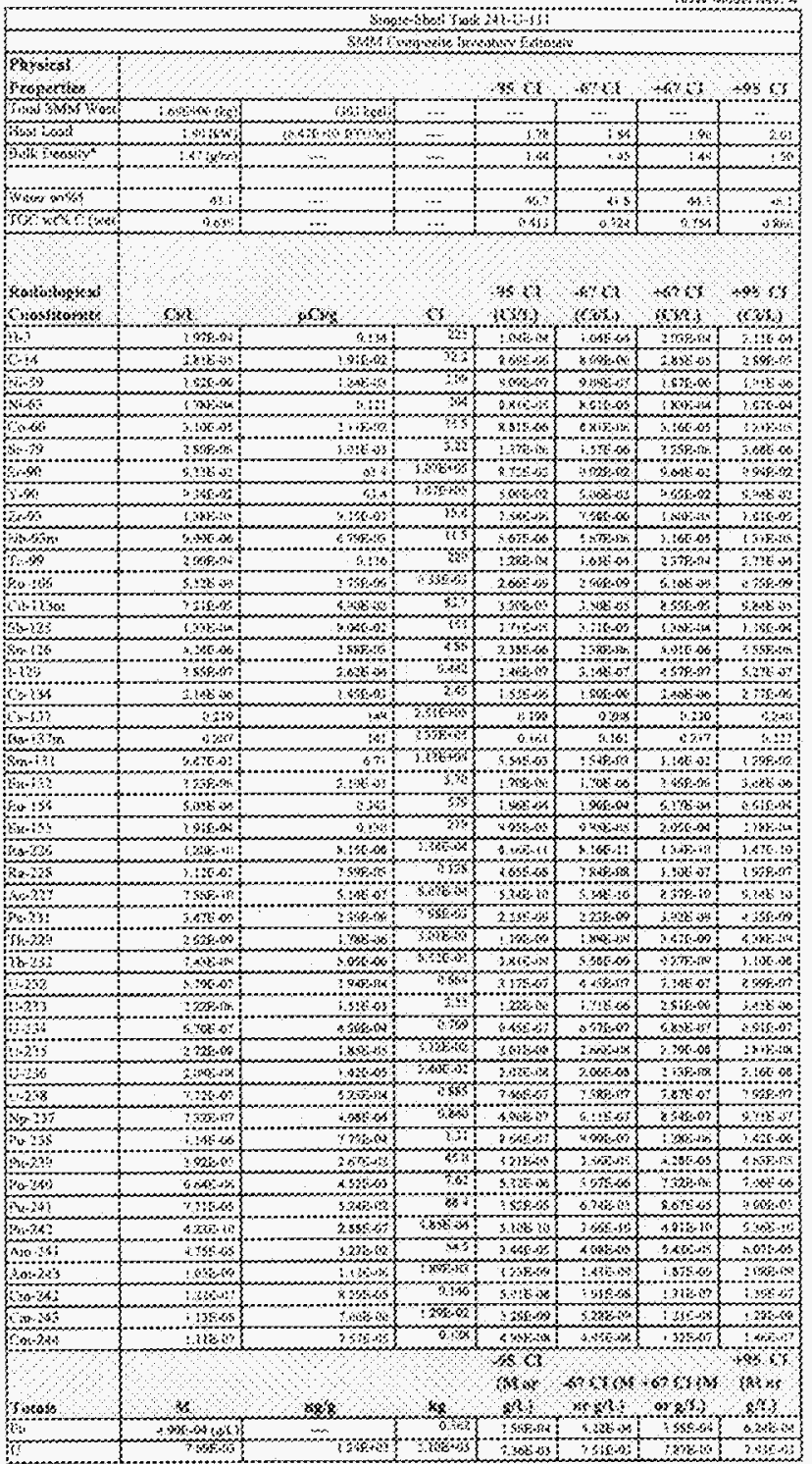

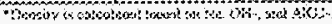

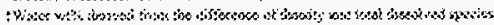




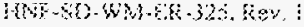

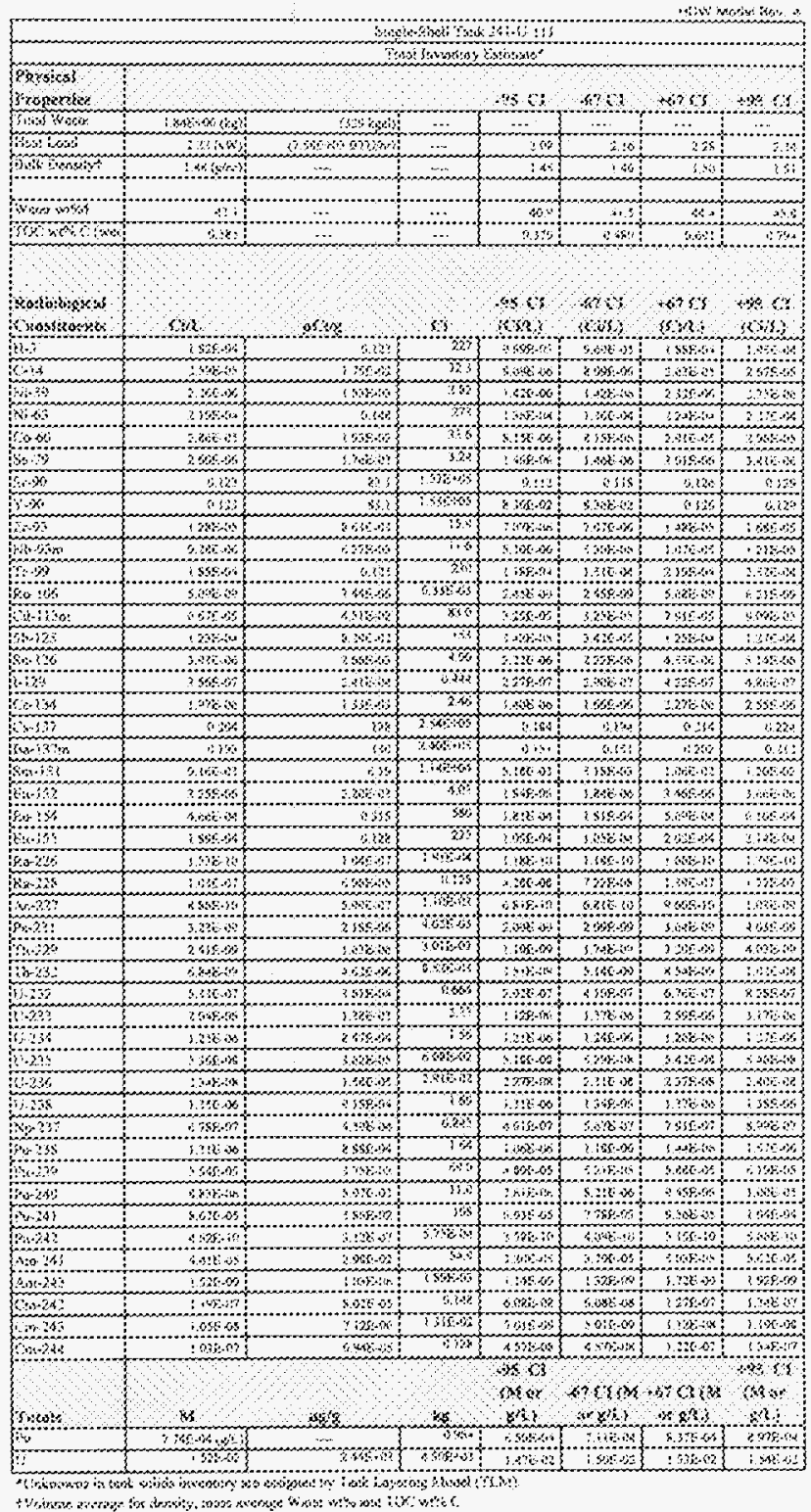




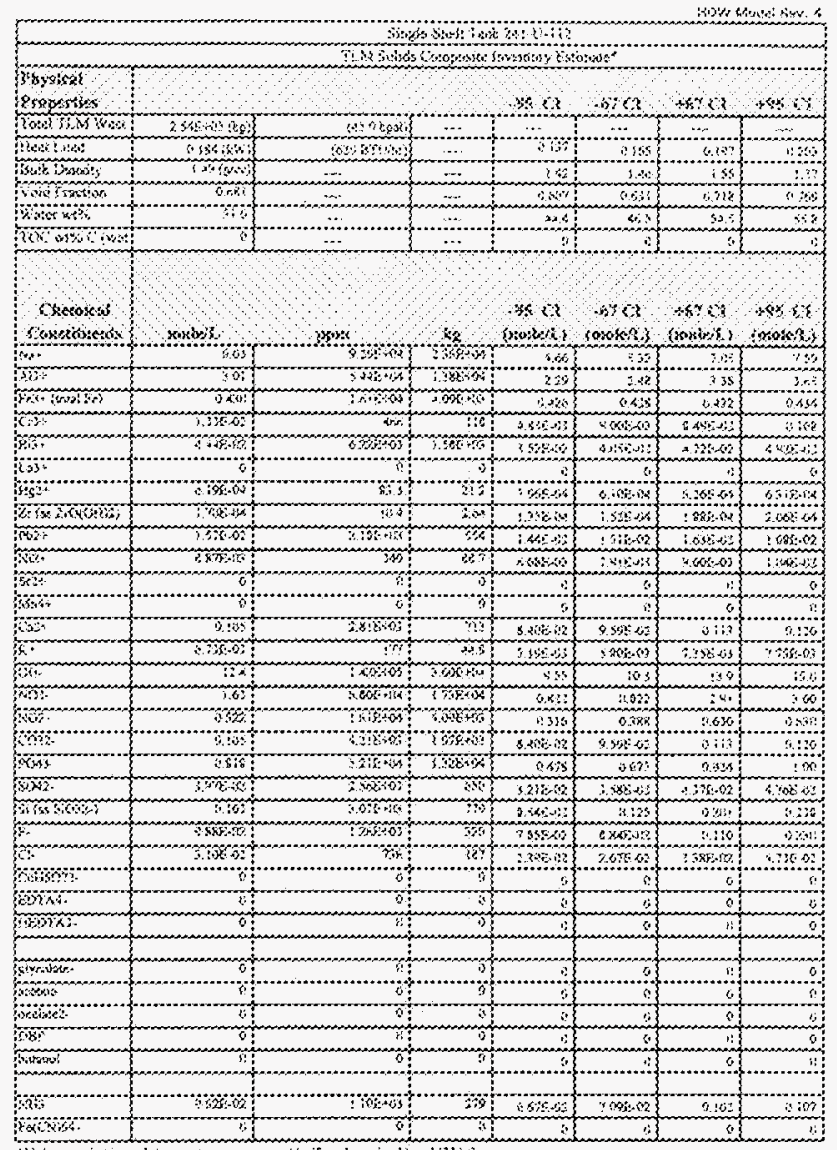

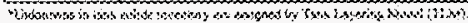




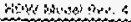

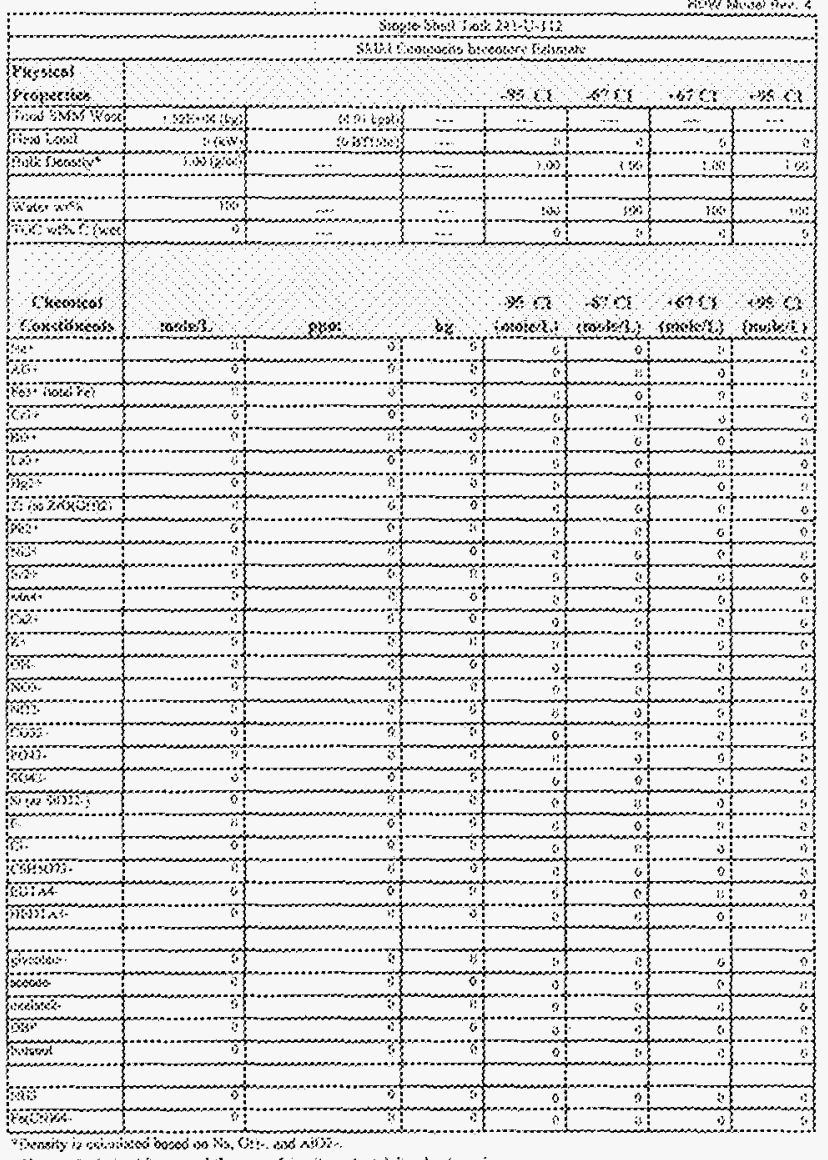

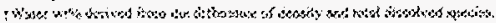




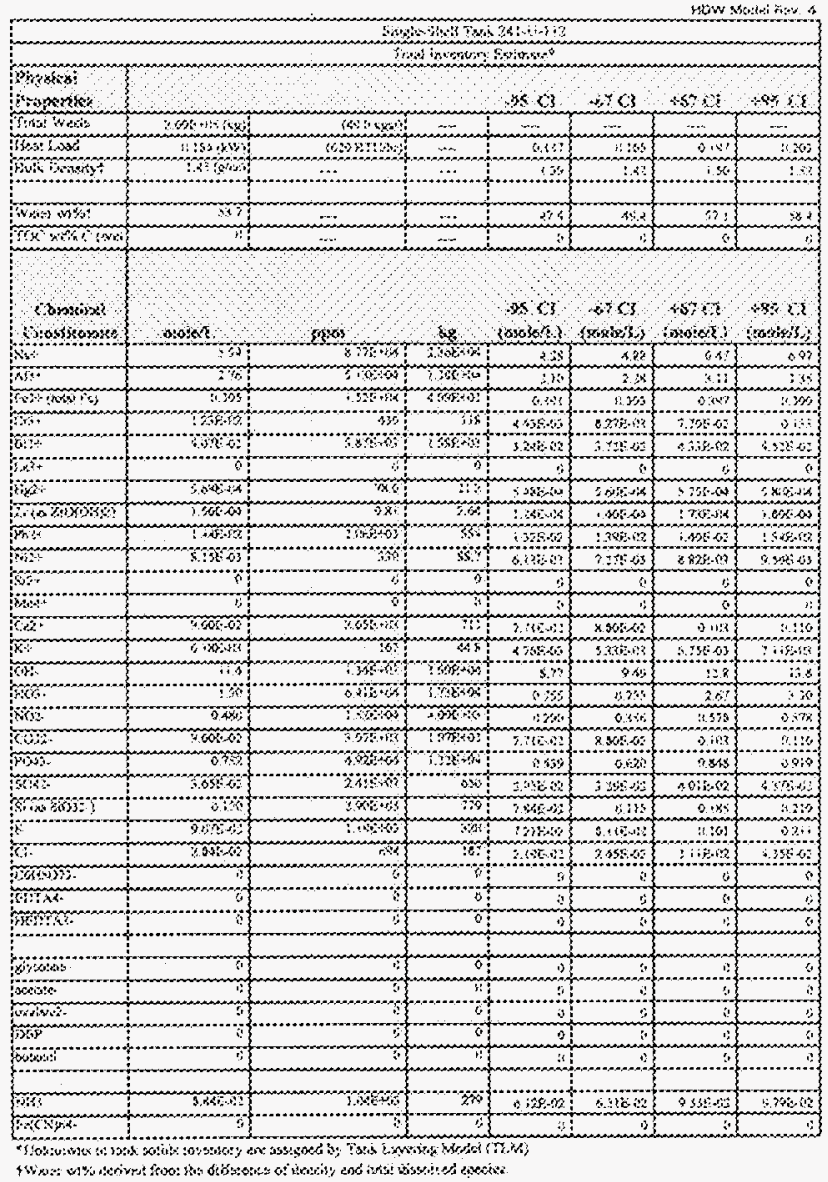


(x)pespans?

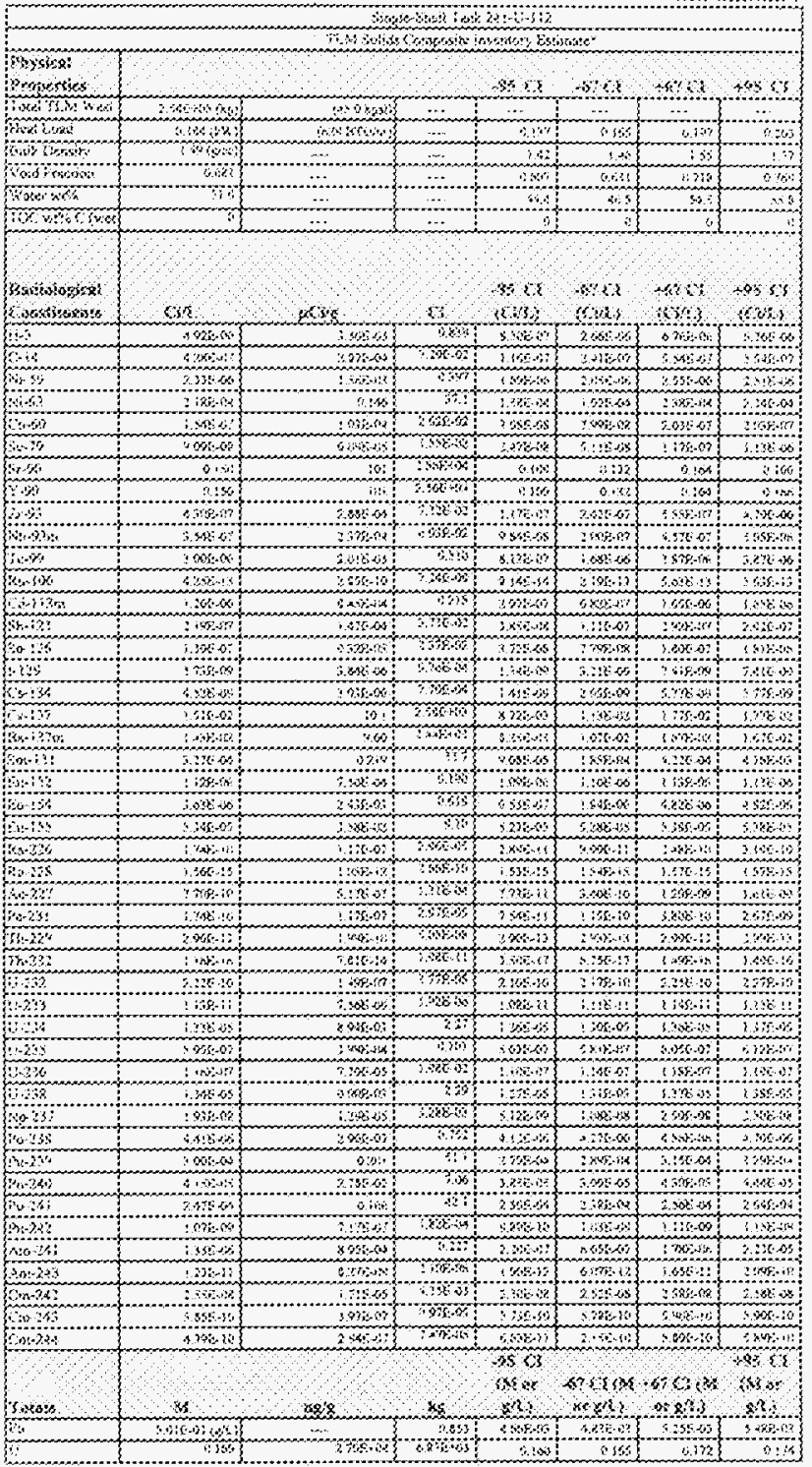

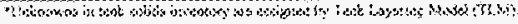




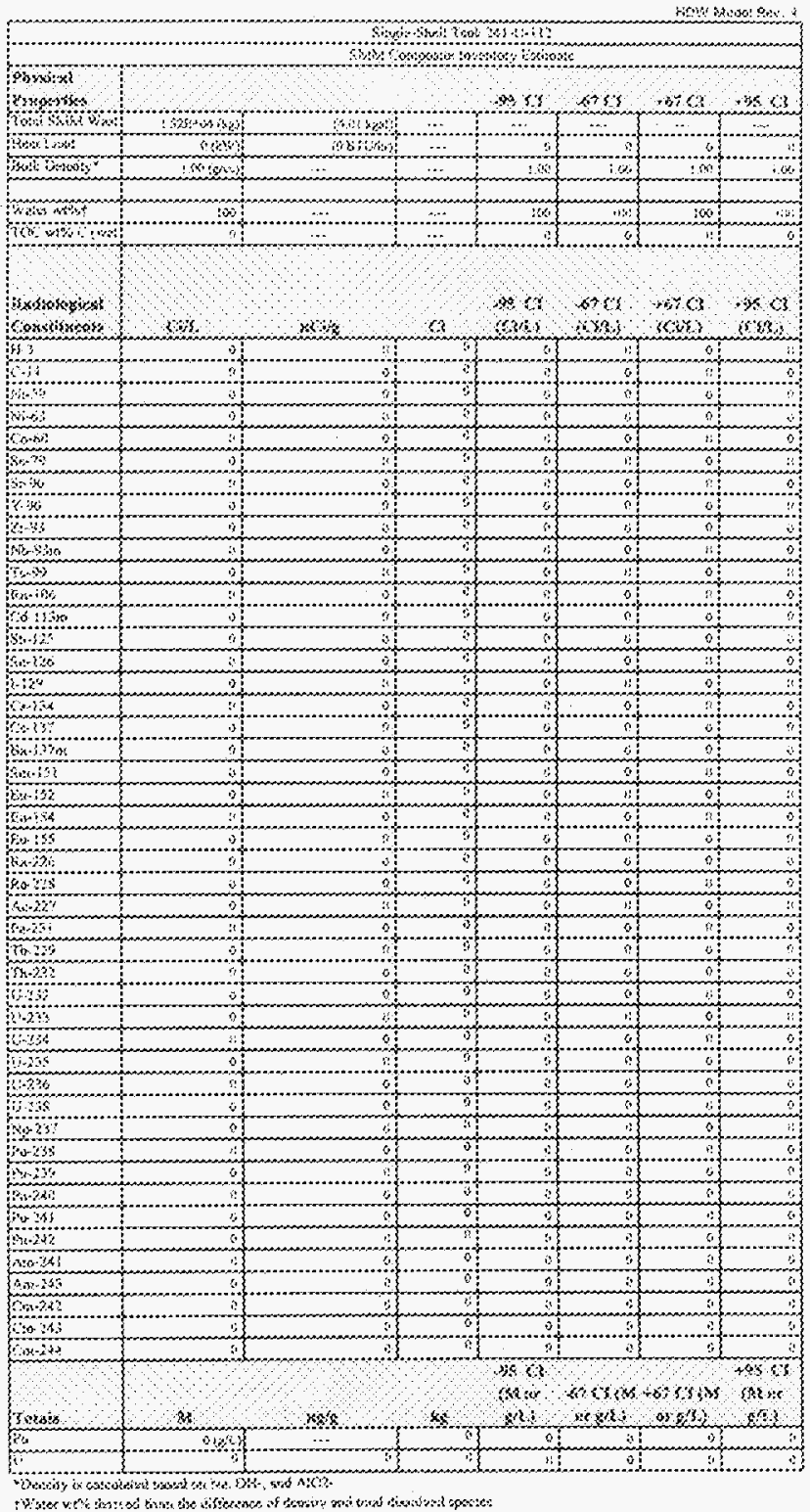




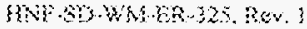

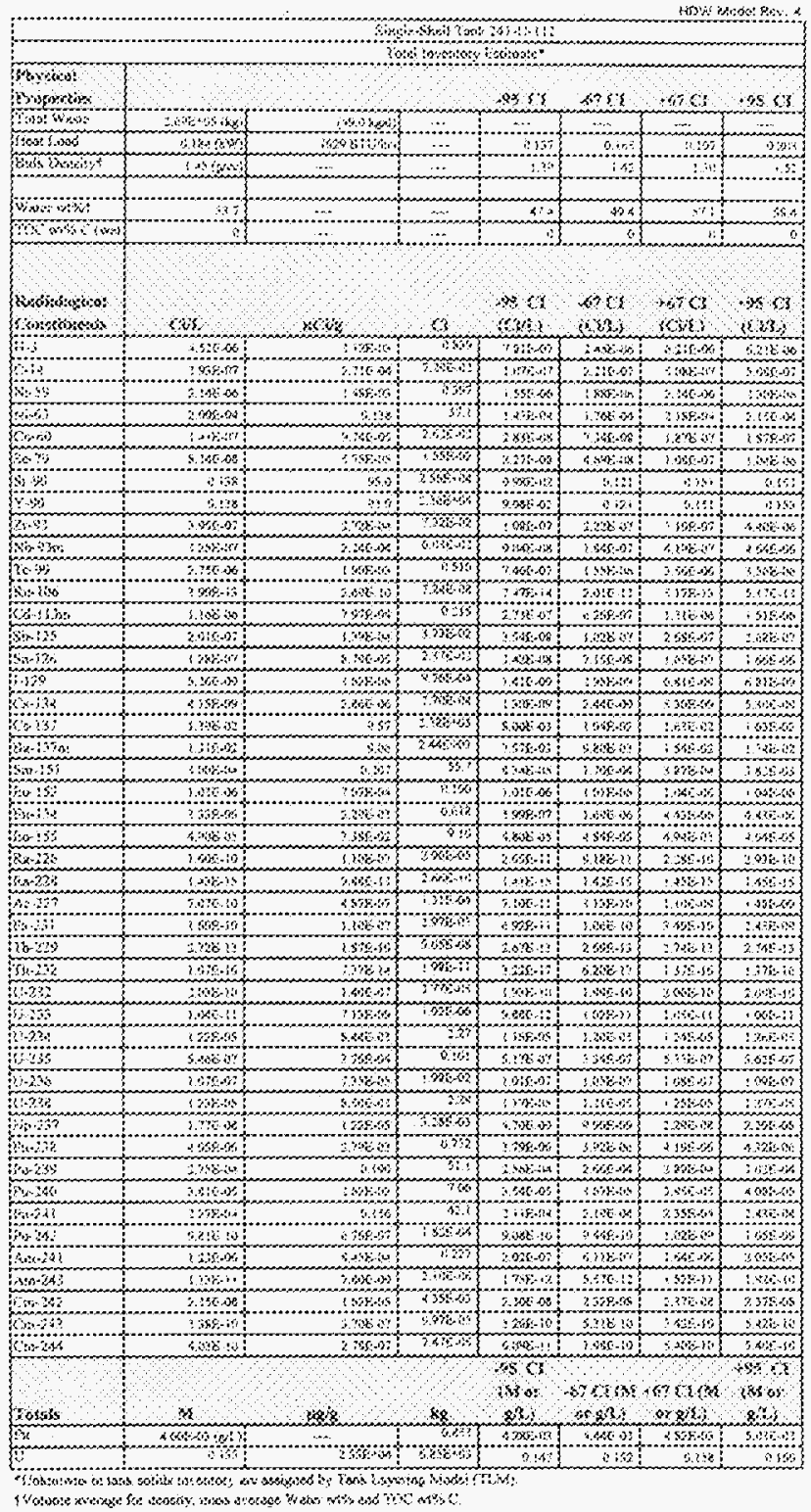




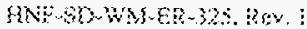

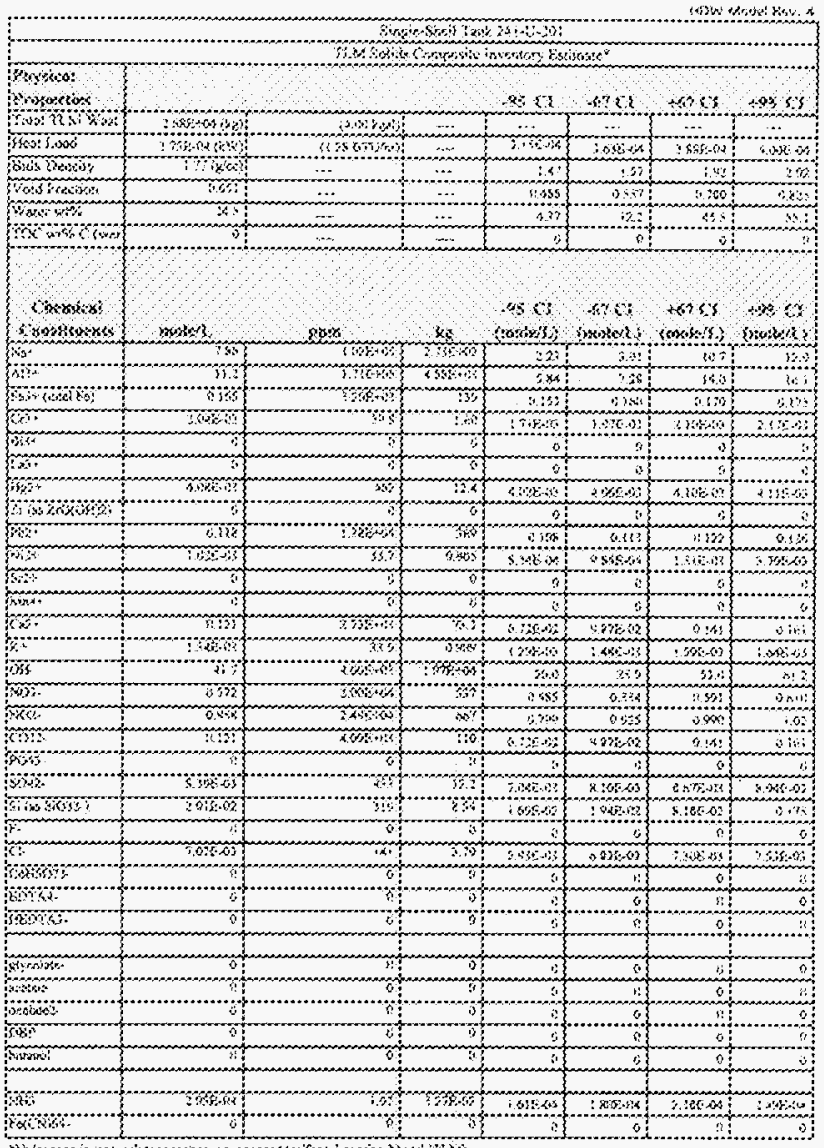

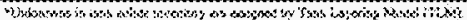




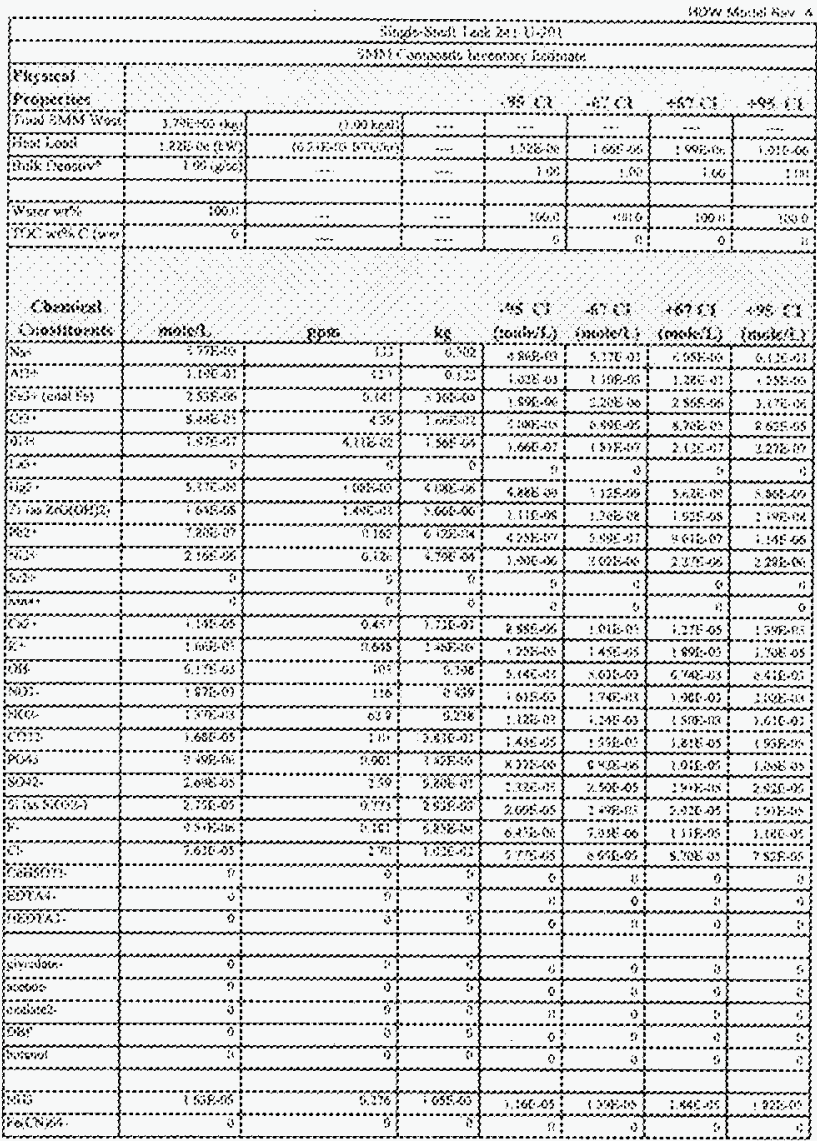

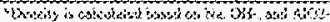

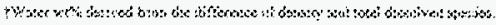




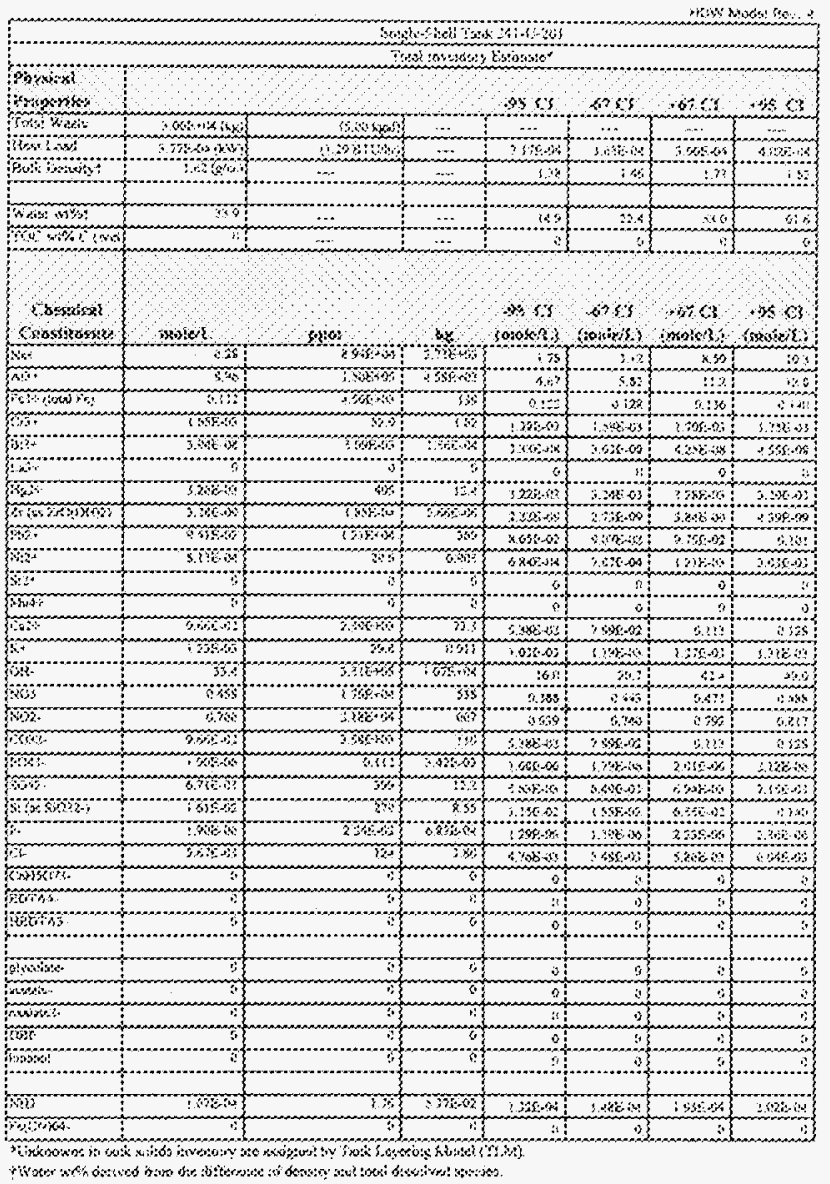




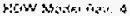

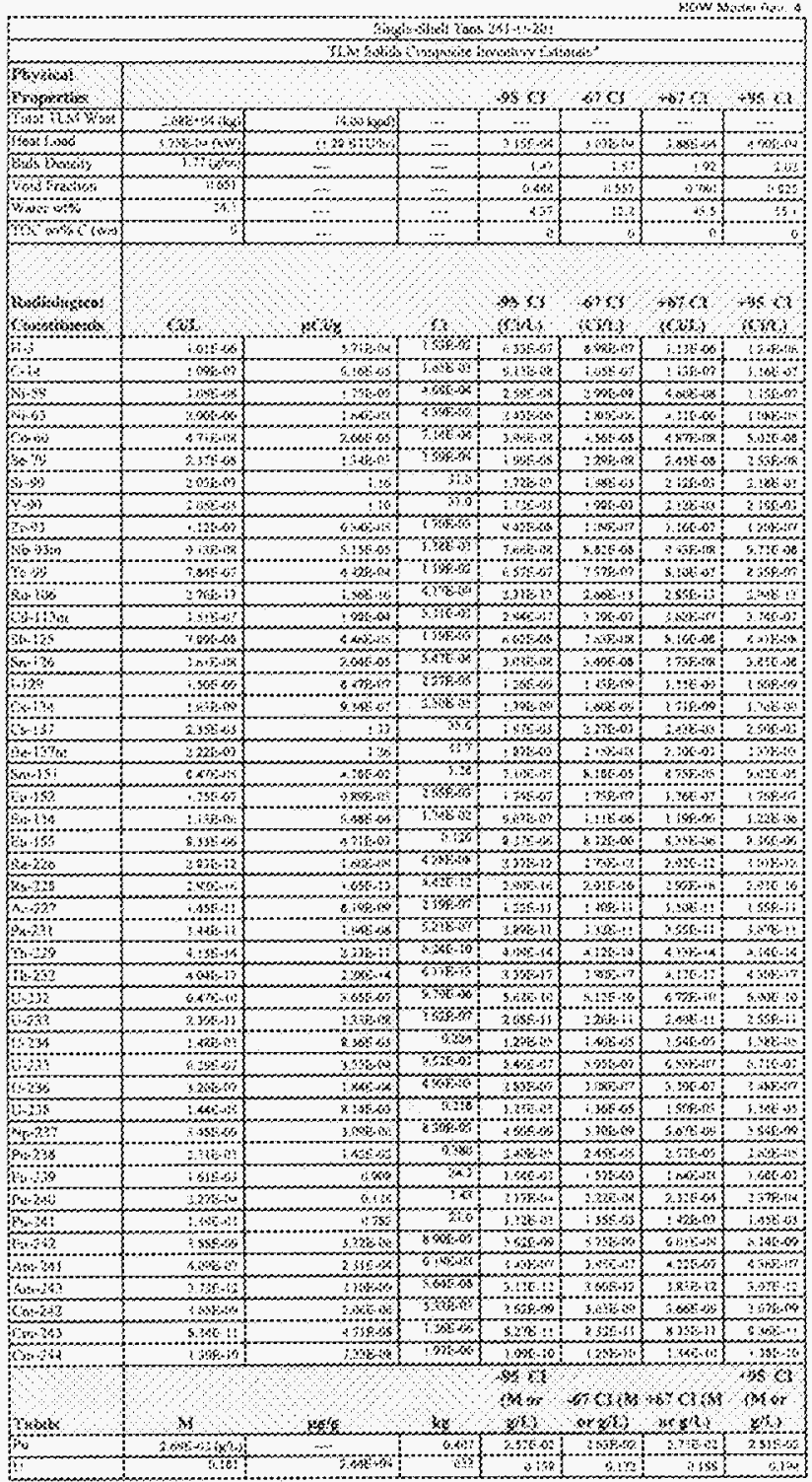

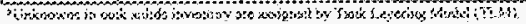




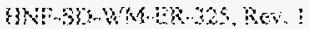

MN soses 90..

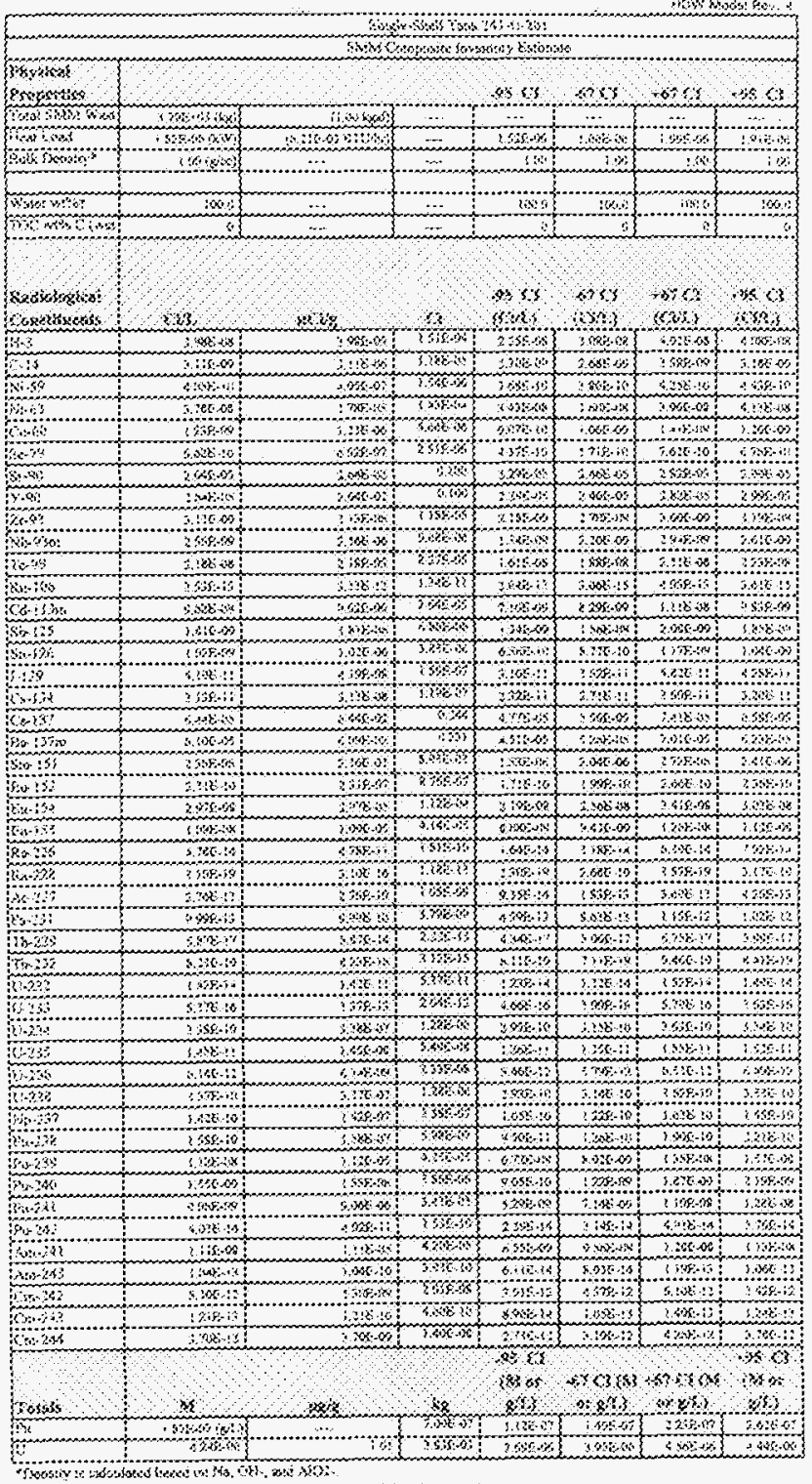

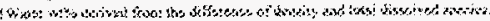




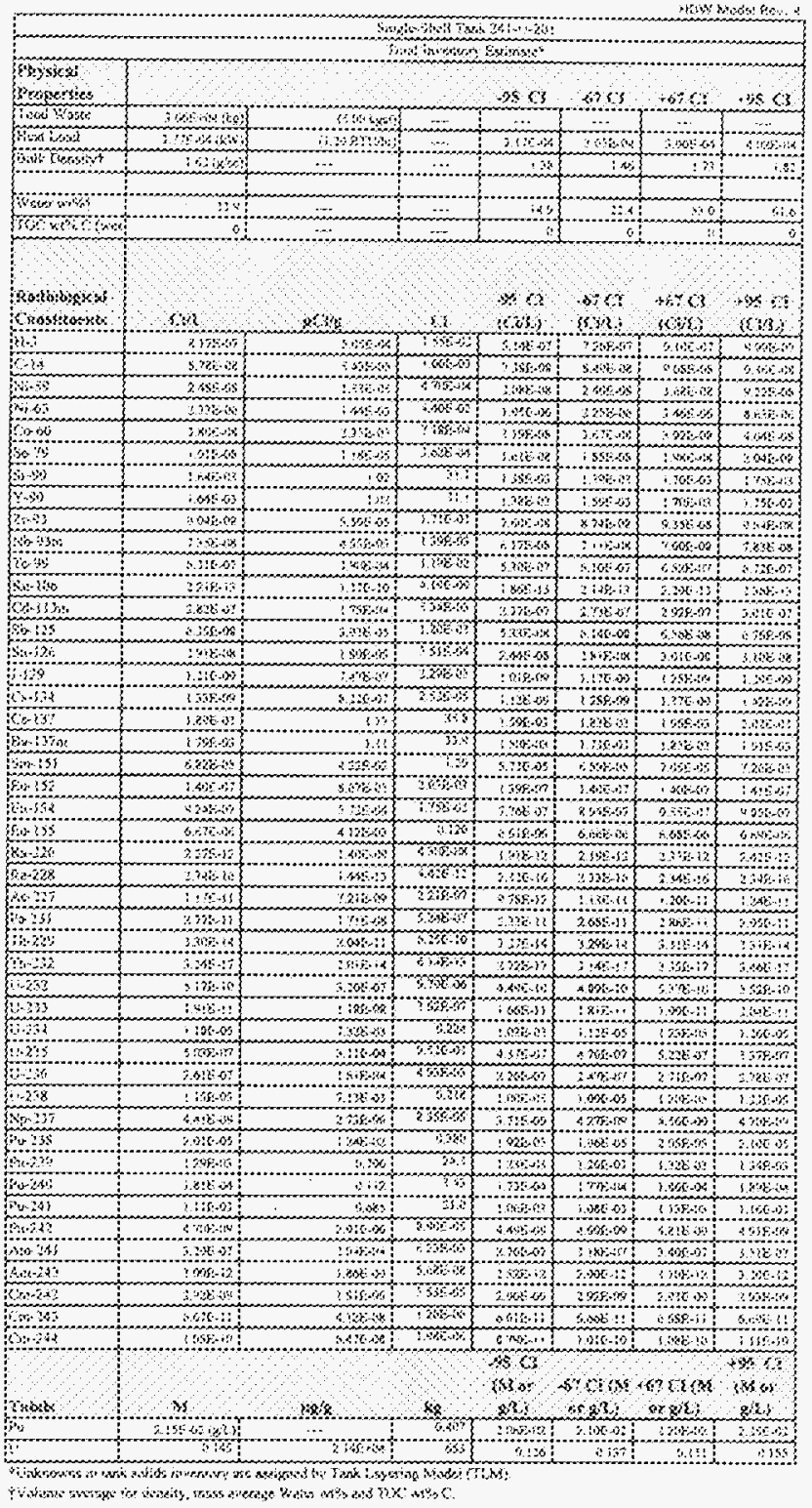




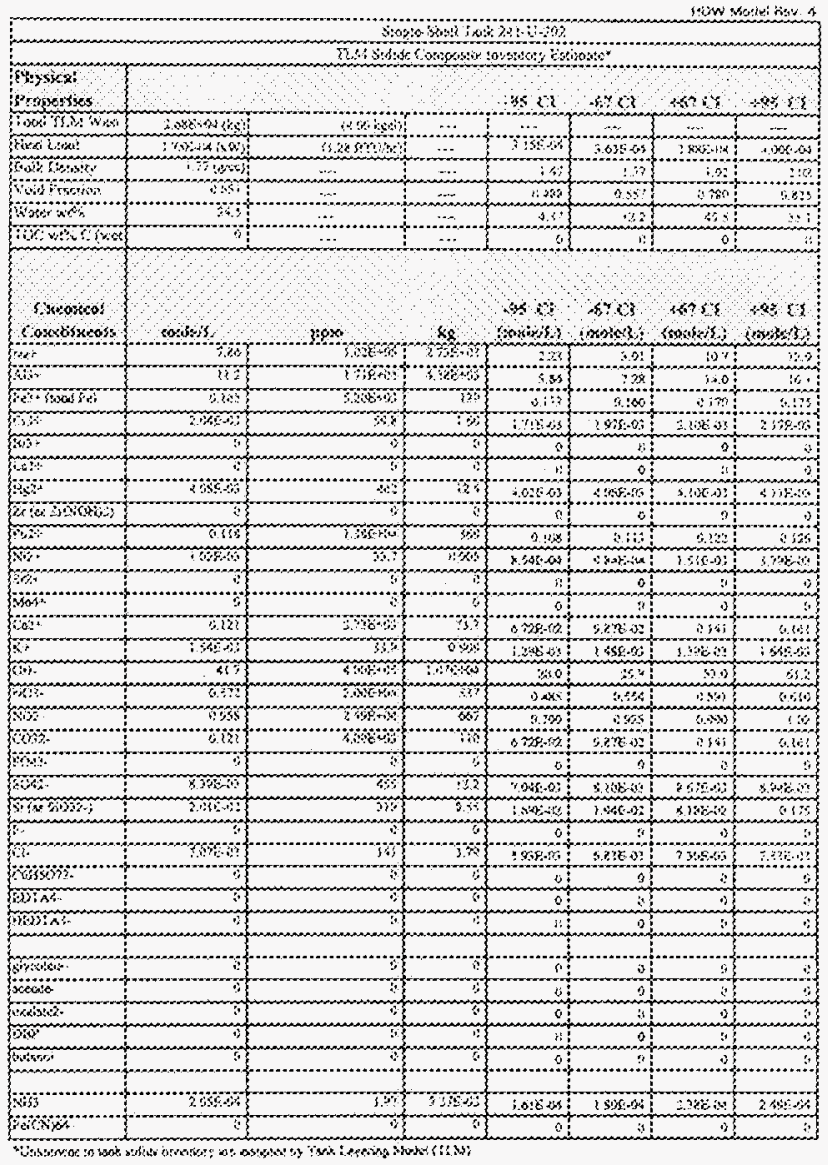




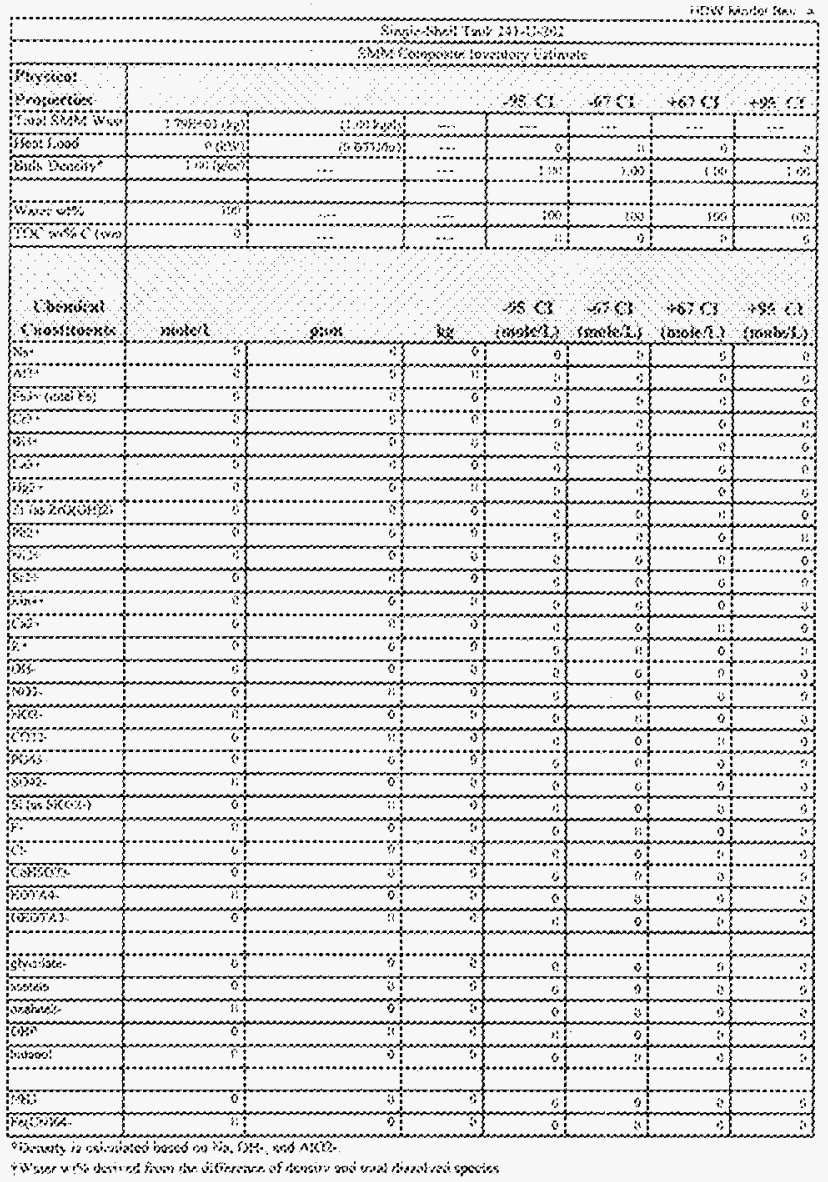




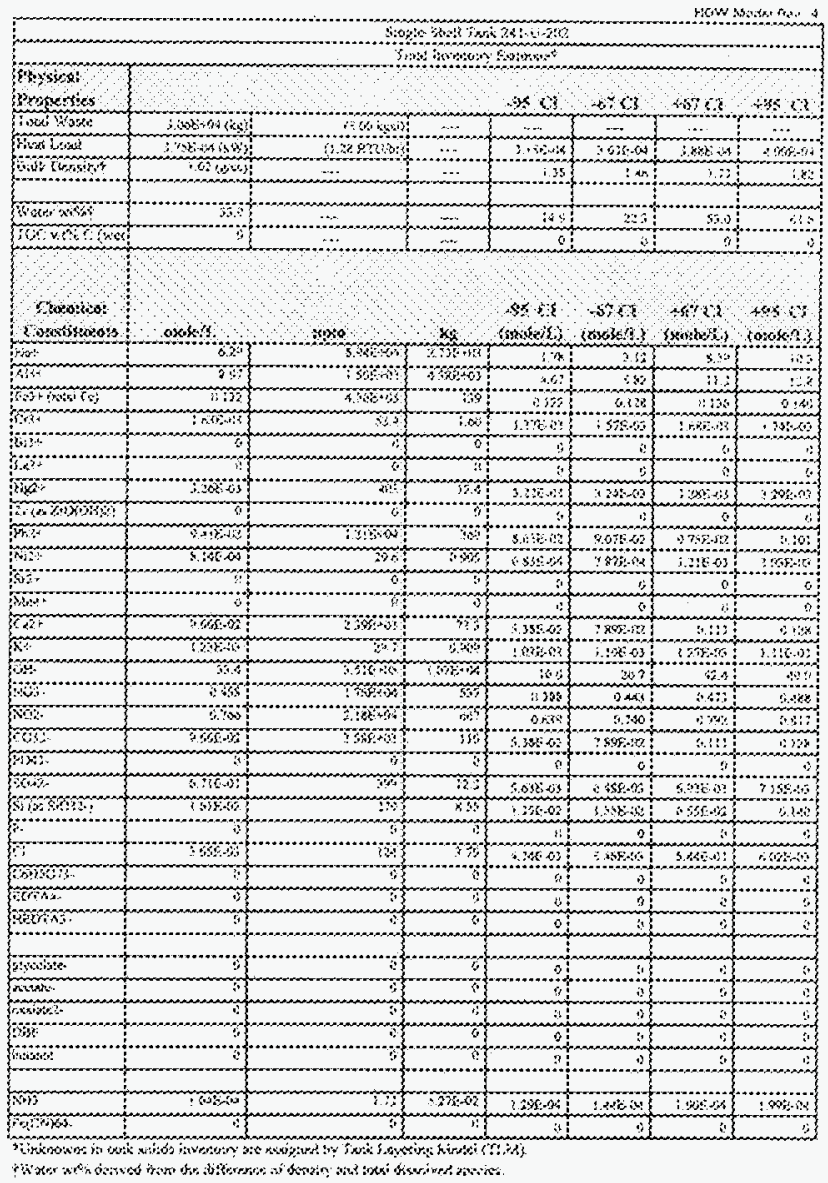




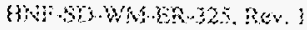

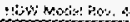

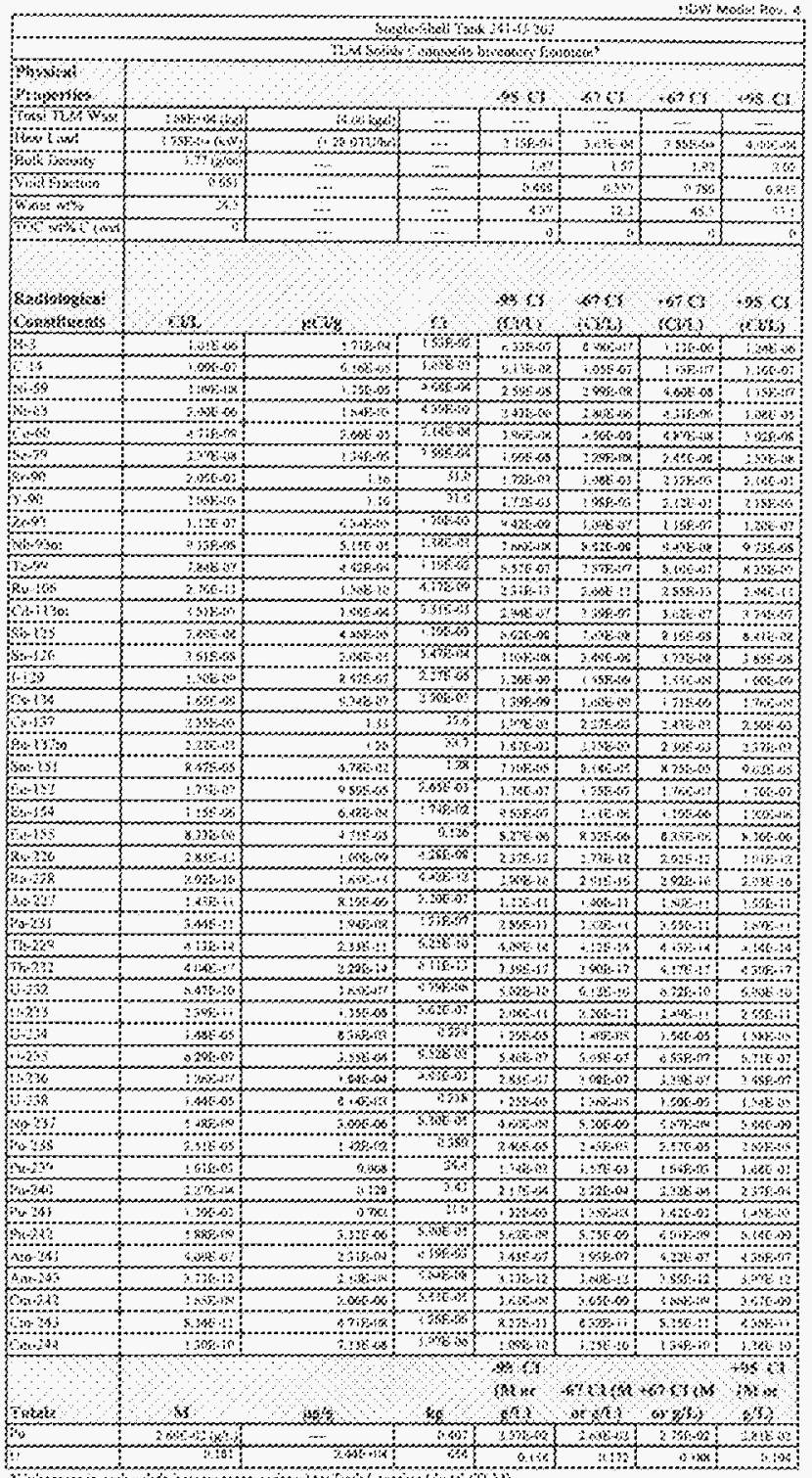

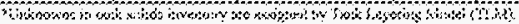




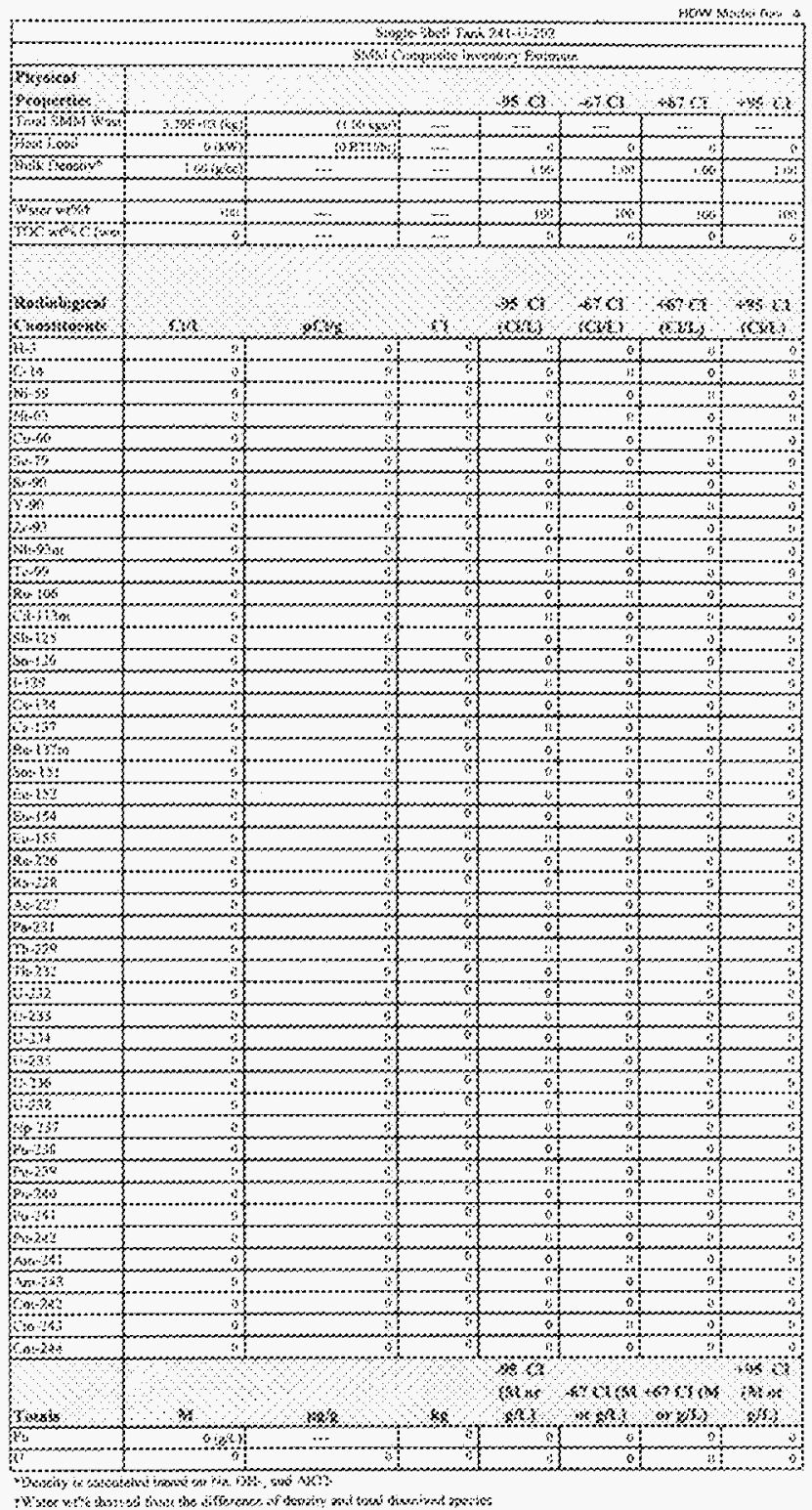




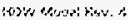

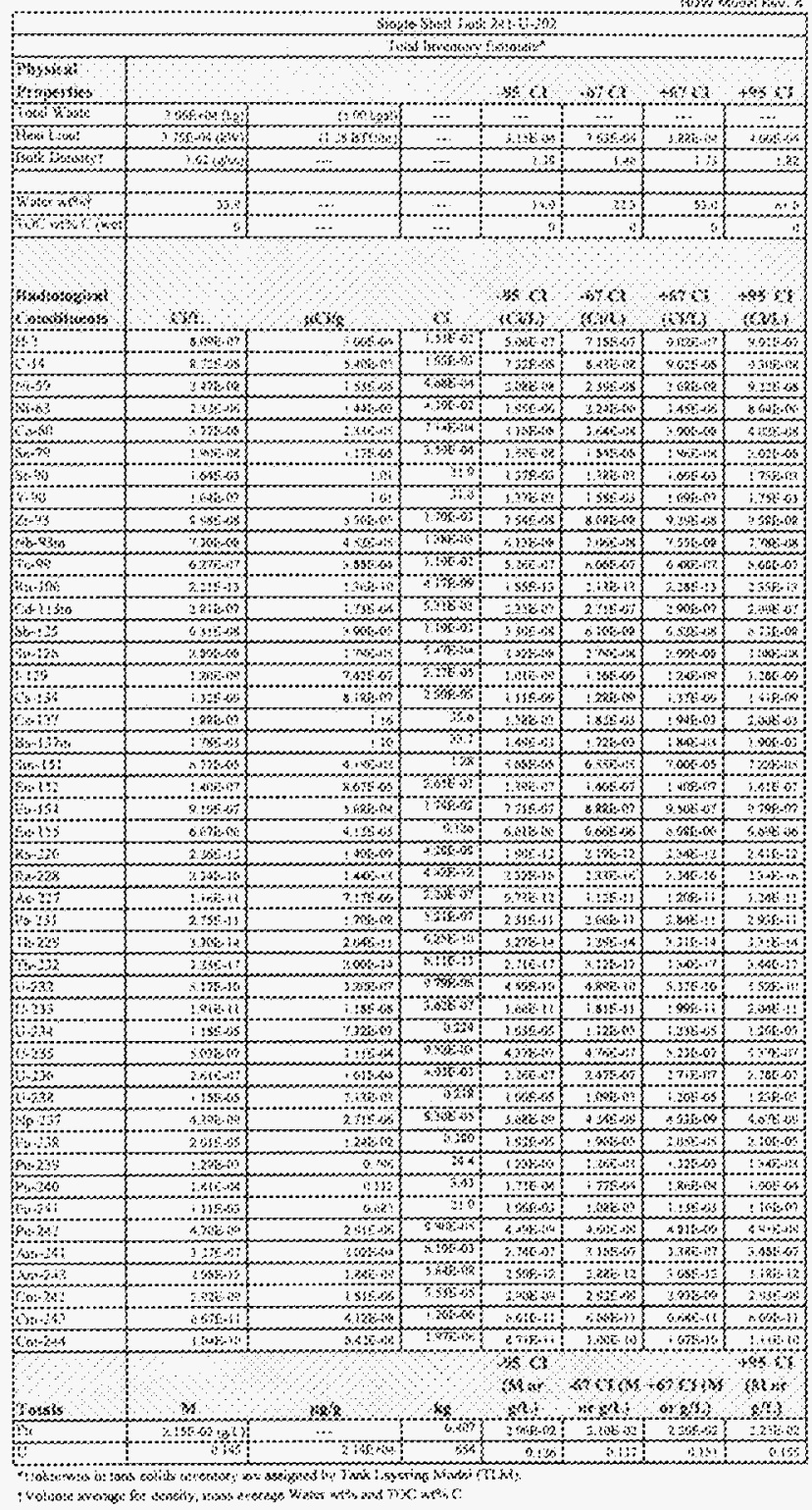




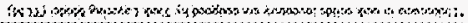

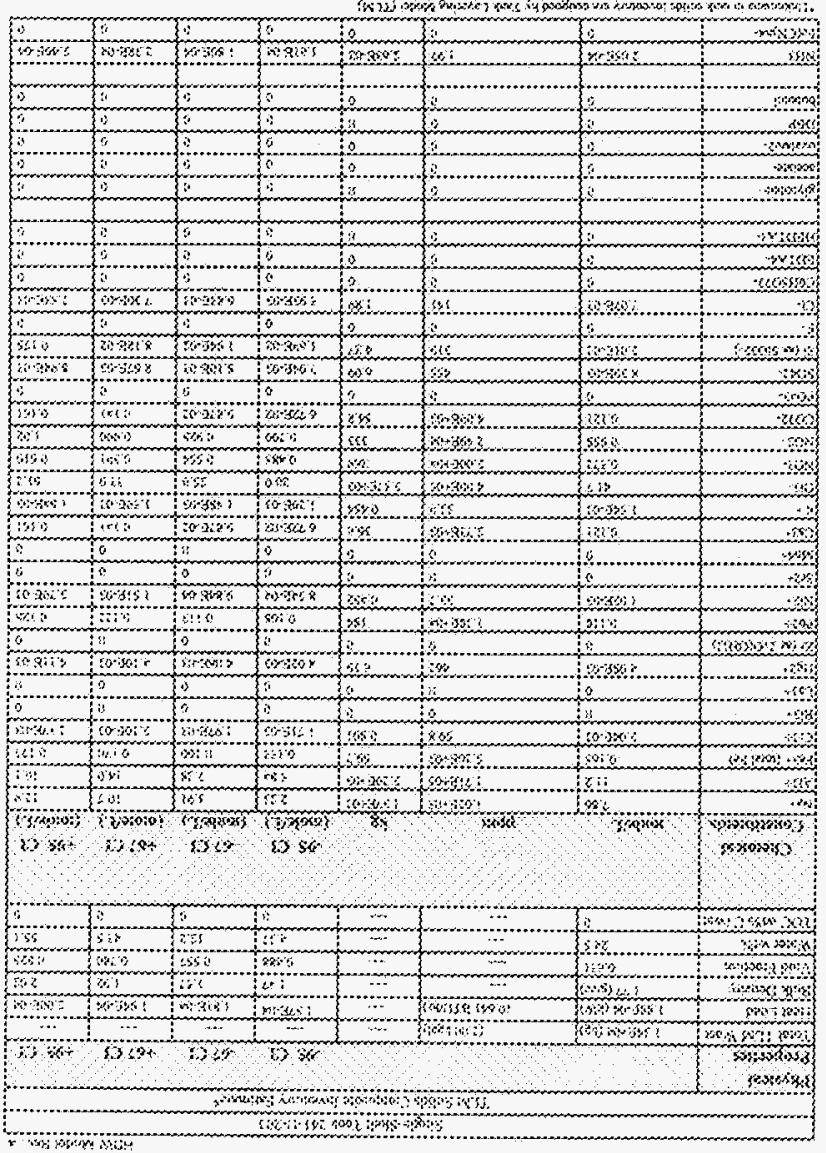




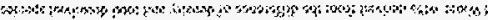

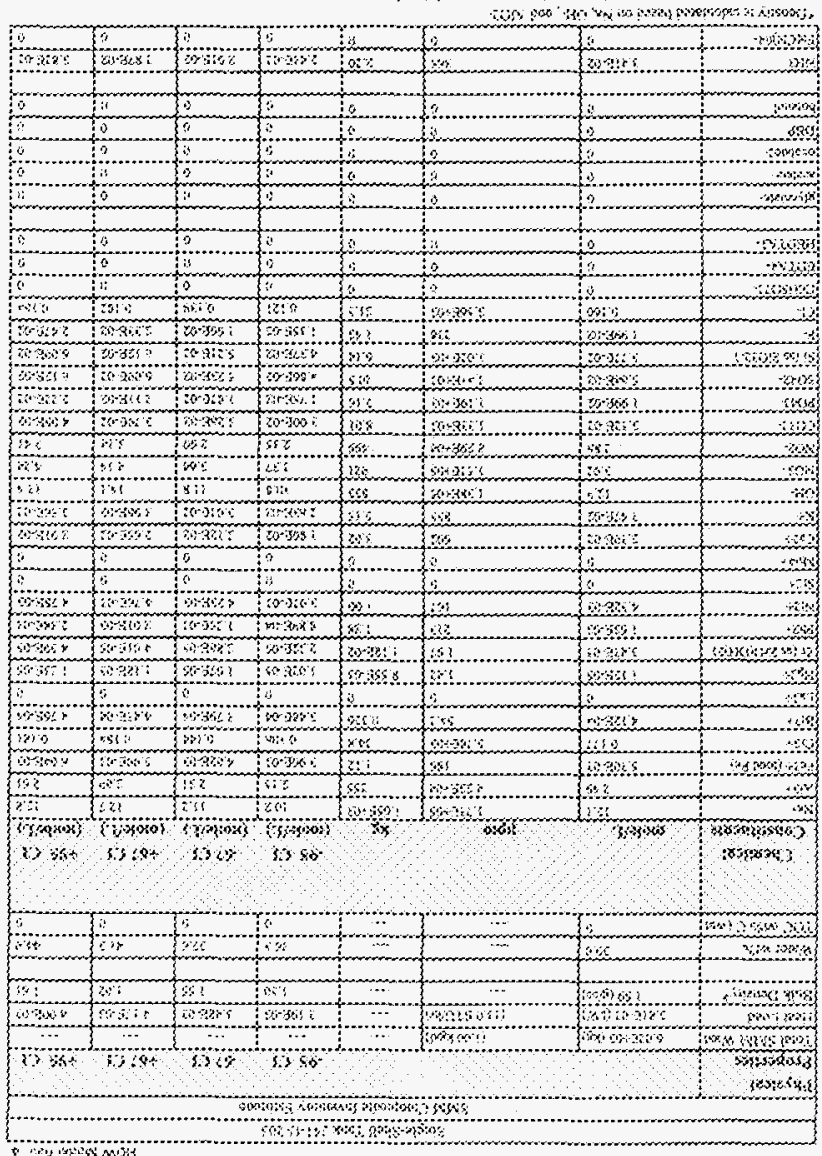




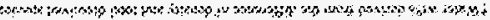

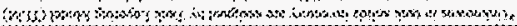

\begin{tabular}{|c|c|c|c|c|c|c|c|}
\hline 5 & 4 & 8 & $\because !$ & $\because$ & : & $a$ & -exins \\
\hline$\omega \mathrm{HL}$ & W? & 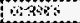 & Touss & wo & Hi & $30 \mathrm{ar}$ & 30 \\
\hline & & & 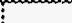 & & & 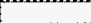 & \\
\hline$\therefore$ & 6 & 8 & 0 & 3 & 5 & i & \\
\hline$\because$ & $i$ & 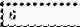 & 8 & $\cdots$ & 8 & $\because$ & $y$ \\
\hline$\therefore$ & $\because$ & 6 & $\because$ & 3 & 3 & 2 & Wotav \\
\hline$i$ & 6 & 17 & 0 & 8 & $\because$ & $\therefore$ & *⿻一𠃋十 \\
\hline$\vdots$ & $\therefore$ & 26 & 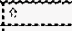 & 4 & 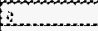 & $i$ & Nonia \\
\hline & & & 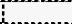 & & & 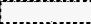 & \\
\hline 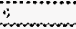 & החמ & 20 & 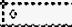 & $\%$ & $\because$ & $i$ & 0,000 \\
\hline 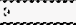 & is & 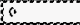 & i: & $: 1$ & 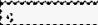 & $\because$ & $T+i, 0,2$ \\
\hline$\therefore$ & 4 & 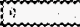 & 0 & 3 & in. & $\because$ & $-s i p a x$ \\
\hline 6515 & bas & Whot: & कos 3 & $s e$ & $\infty 6$ & (6rose & \\
\hline किति & brost & 6ons & $x_{0}$ & tri & $10<$ & atopo & \\
\hline 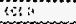 & 30 & Wo: & (i) Ko & $4: 4$ & $x_{1}$ & 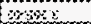 & $x$ \\
\hline 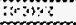 & 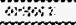 & (1) 201 & $20+4 \times 4:$ & $x$ & 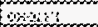 & asts & 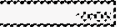 \\
\hline Het & Frotat & Wret & jeorsh & Wh & 6 & 30,800 & 3ax \\
\hline 815 & ist $t$ & Das & noses & 80 & Q6yes & sico & 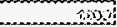 \\
\hline$\therefore$ & b? & ans & 26 & $\mathrm{~K}$ & W.8\% & 3 & 9 \\
\hline$\therefore i$ & $x$ & 58 & $\alpha 5$ & igho: & $x+5$ & Q & \\
\hline $3 \times$ & sis & ite & $\therefore i$ & $x+6 \%$ & onsise & $x$ & \\
\hline 340 & Wot: & 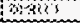 & $50-30: 5$ & $\infty$ & 30 & $0, \infty, \mathrm{i}$ & \\
\hline 613 & $64^{\circ}$ & 17046 & Wht & 50 & toga2 & $55 x 8$ & \\
\hline 8 & 5 & 8 & 4 & & 6 & $\because$ & \\
\hline 4 & 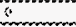 & $1:$ & 6 & 3 & $i$ & 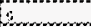 & \\
\hline (5.118 & Wh & (itr) & Nowis: & $x:$ & 8 & $60 x+3$ & \\
\hline Bars & $601 t$ & $03 \mathrm{~B}$ & $50-39:$ & $x \rightarrow$ & 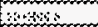 & wose & 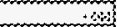 \\
\hline \%कst & का & 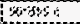 & $\alpha-3,2$ & tit.58\% & ova & xit & Wornosing \\
\hline 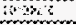 & 30 & itait & 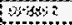 & 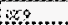 & S6 & 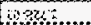 & 3 \\
\hline$\because$ & & $i$ & 5 & $+\cdots$ & 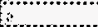 & 8 & 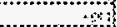 \\
\hline W6! & axpl & $[x+3):]$ & moni & weo & $s \%$ & wats & +24 \\
\hline 8080 & $F_{i n}+96 s^{3}$ & mon? & $20 \cdot \mathrm{W}$, & Sis & (W6) & wo & $\infty$ \\
\hline seis & ait & sestis & mit & $x+\infty$ & 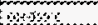 & $\therefore 210$ & Wowatind \\
\hline 31 & 6 & ins & 60 & $040 x$ & 2014 & 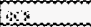 & (1) \\
\hline$\therefore$ & at & as & 26 & sos & 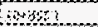 & 8 & $\therefore$ \\
\hline (rowks! & Trotos? & $(1+40$ os & onsosin & $x_{3}$ & 606 & 306 & $x 8$ onsones \\
\hline 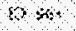 & $m+\alpha$ & $x<0$ & $c \alpha$ & & & & x sonses \\
\hline 8 & is & 2 & 3 & $\cdots$ & & in & 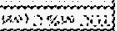 \\
\hline 40 & 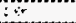 & 28 & (5) & $\cdots$ & $\cdots$ & tis? & $10 \% \operatorname{son} \alpha$ \\
\hline & & & & & & & \\
\hline$\therefore$ & 8 & N! & $\ldots:$ & & & $(*+\infty)$ & 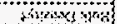 \\
\hline ins? & 659 & ENisesi & mats: & $\cdots$ & 60690006 & (nalowokir & on $7 \times$ \\
\hline & & $\ldots$ & $\cdots$ & $\cdots$ & ans & (x) now $3 \%$ ? & $\sin 20,60$ \\
\hline (1) $\times 4$ & $210^{6}$ & 406 & ns 6 & & & & 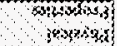 \\
\hline & & & $x^{20003}$ & rostato & & & \\
\hline & & & 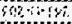 & 40 & & & \\
\hline
\end{tabular}




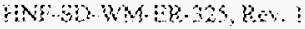

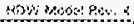

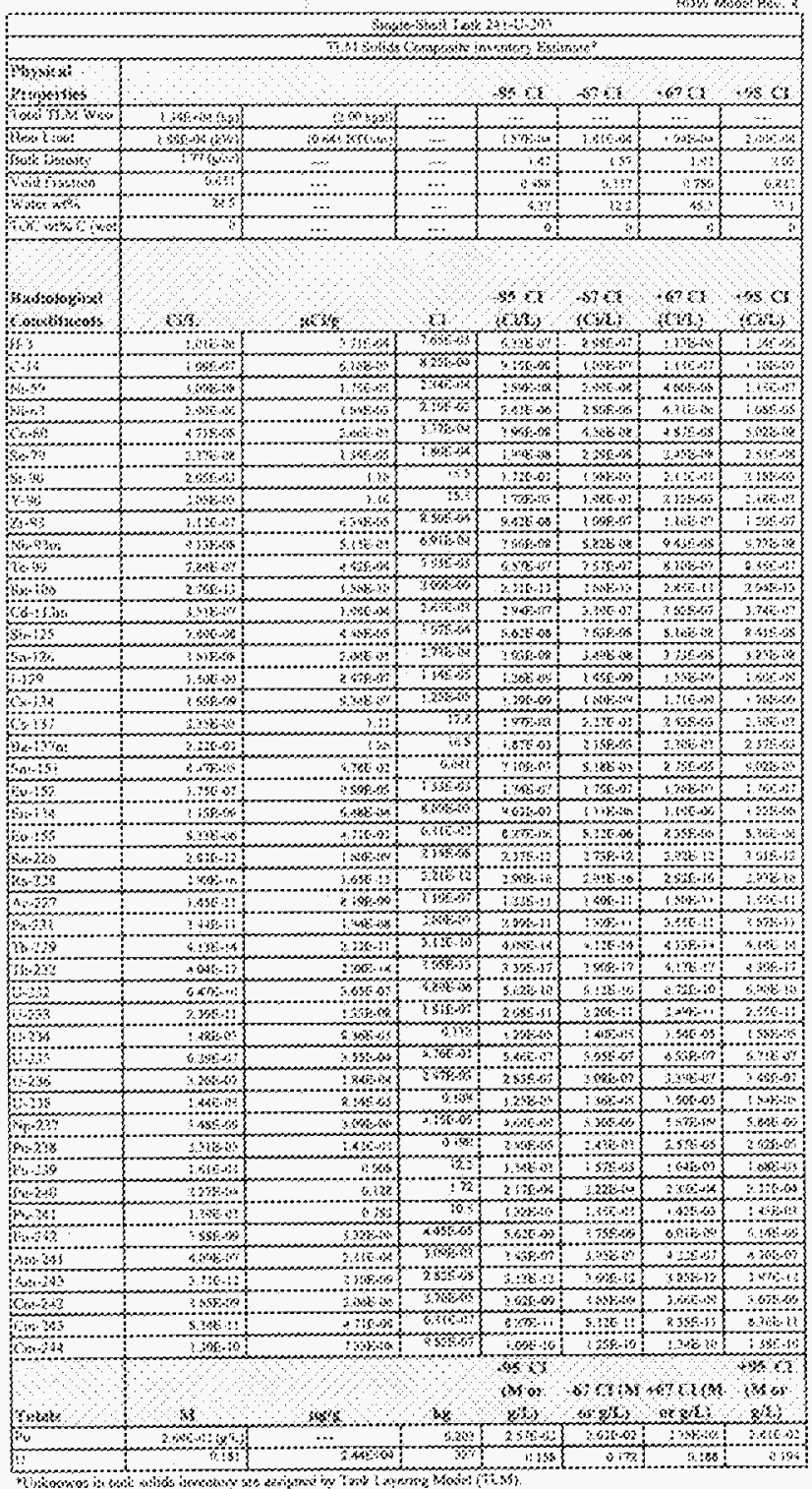


Hew Mopes in: 4



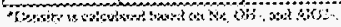

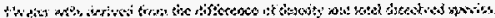




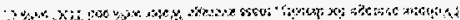

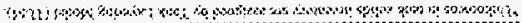

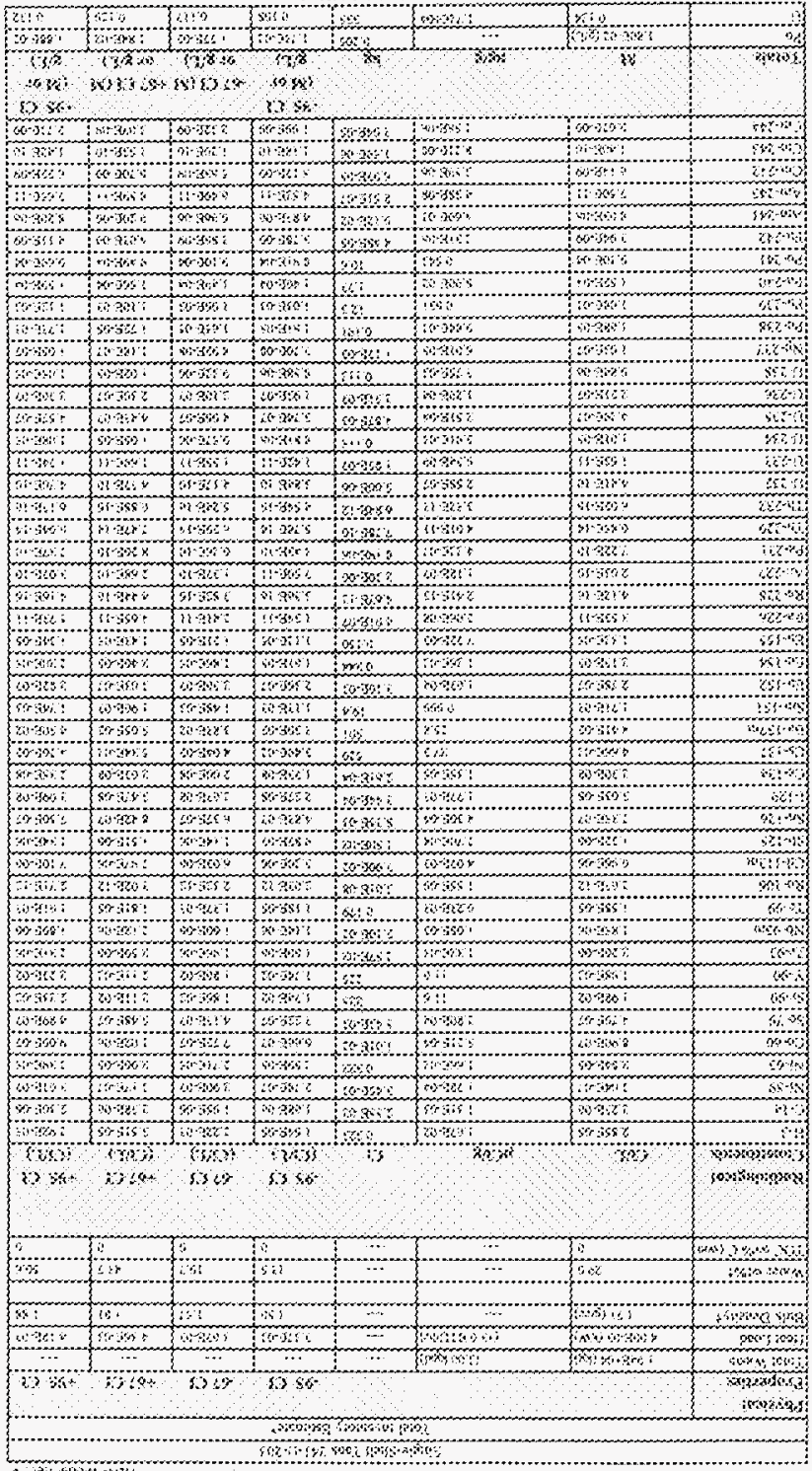




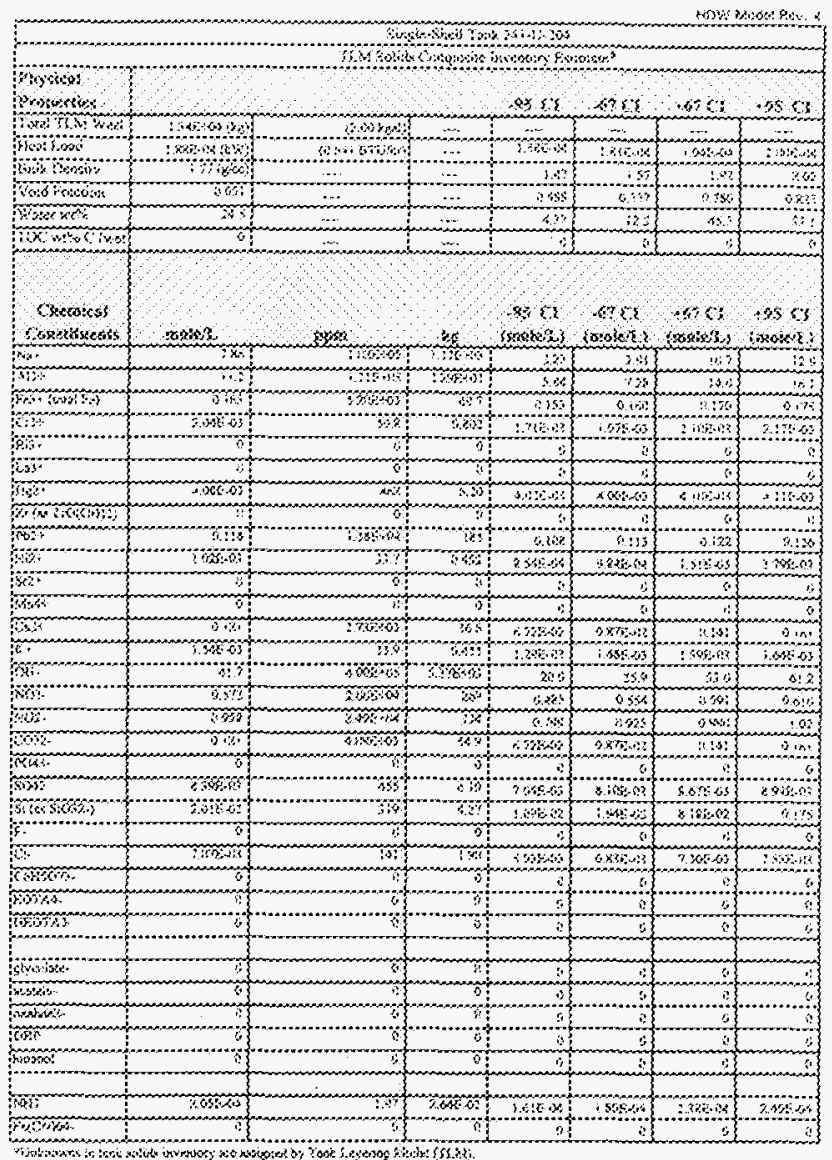




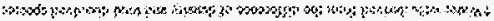

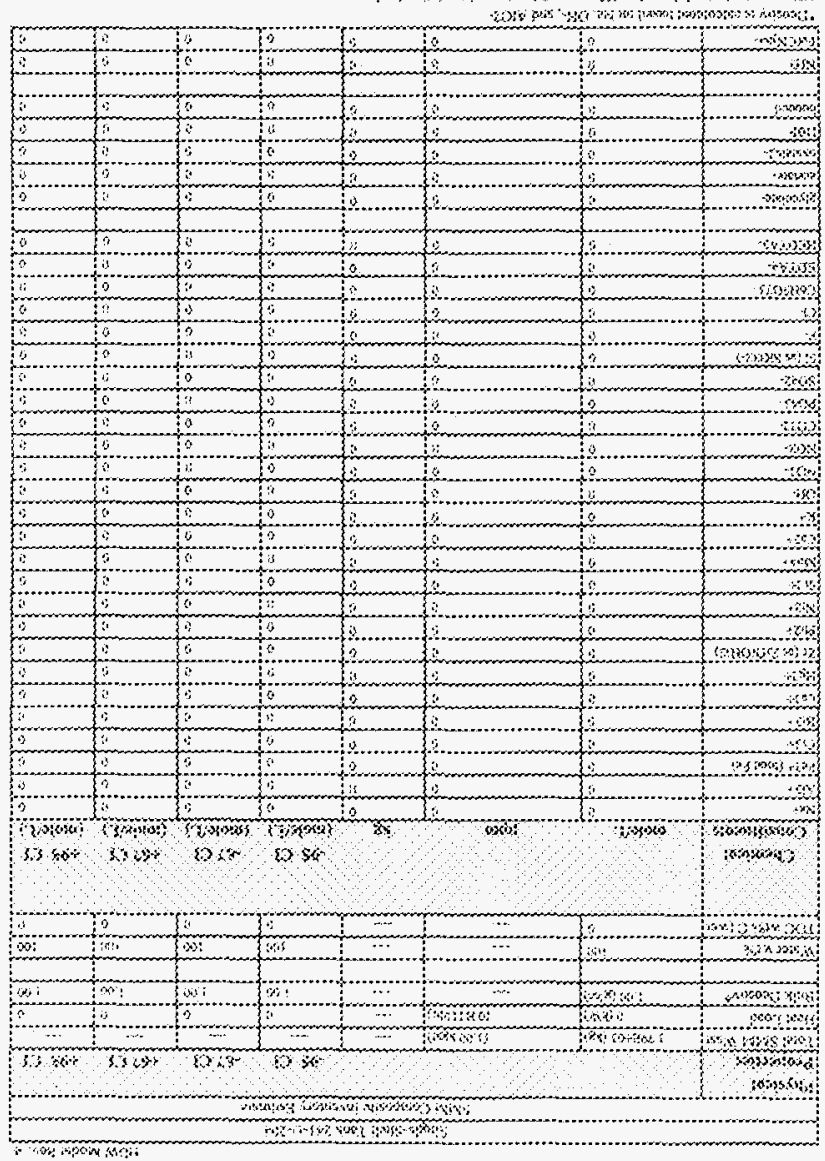




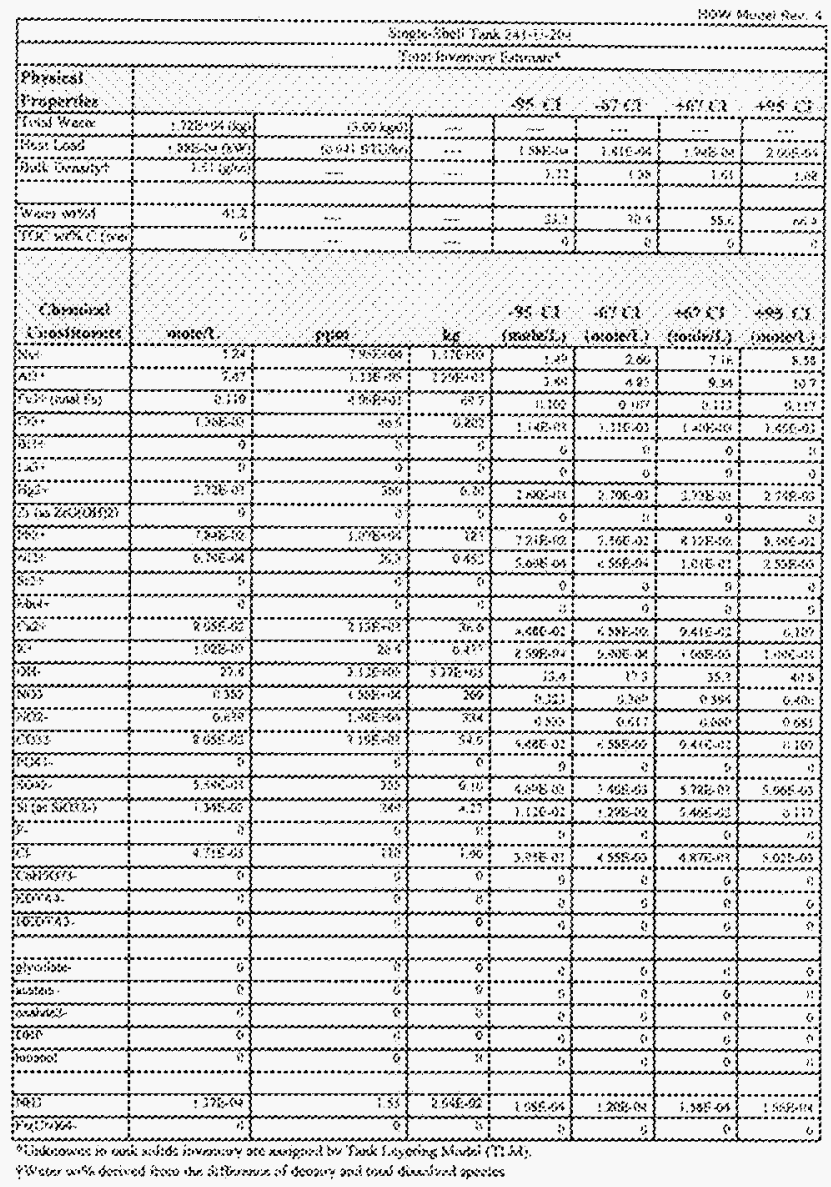


mow sond riat

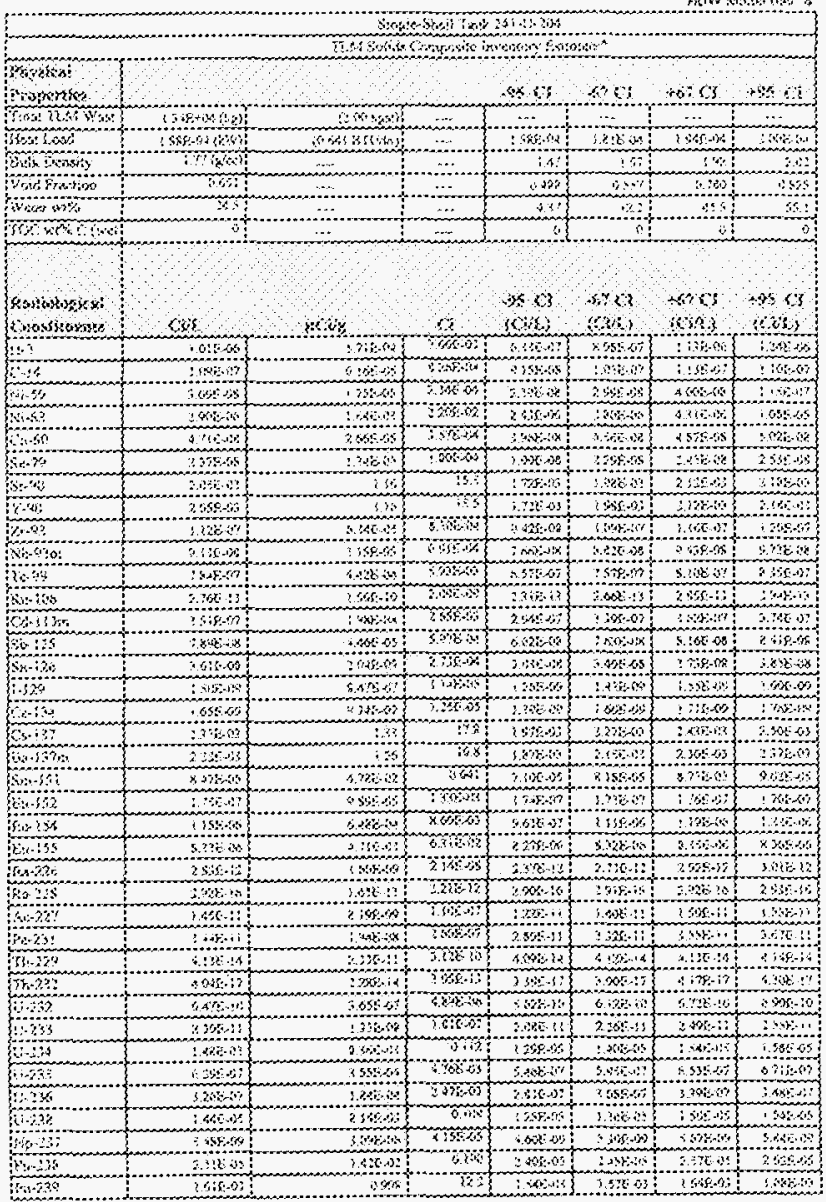




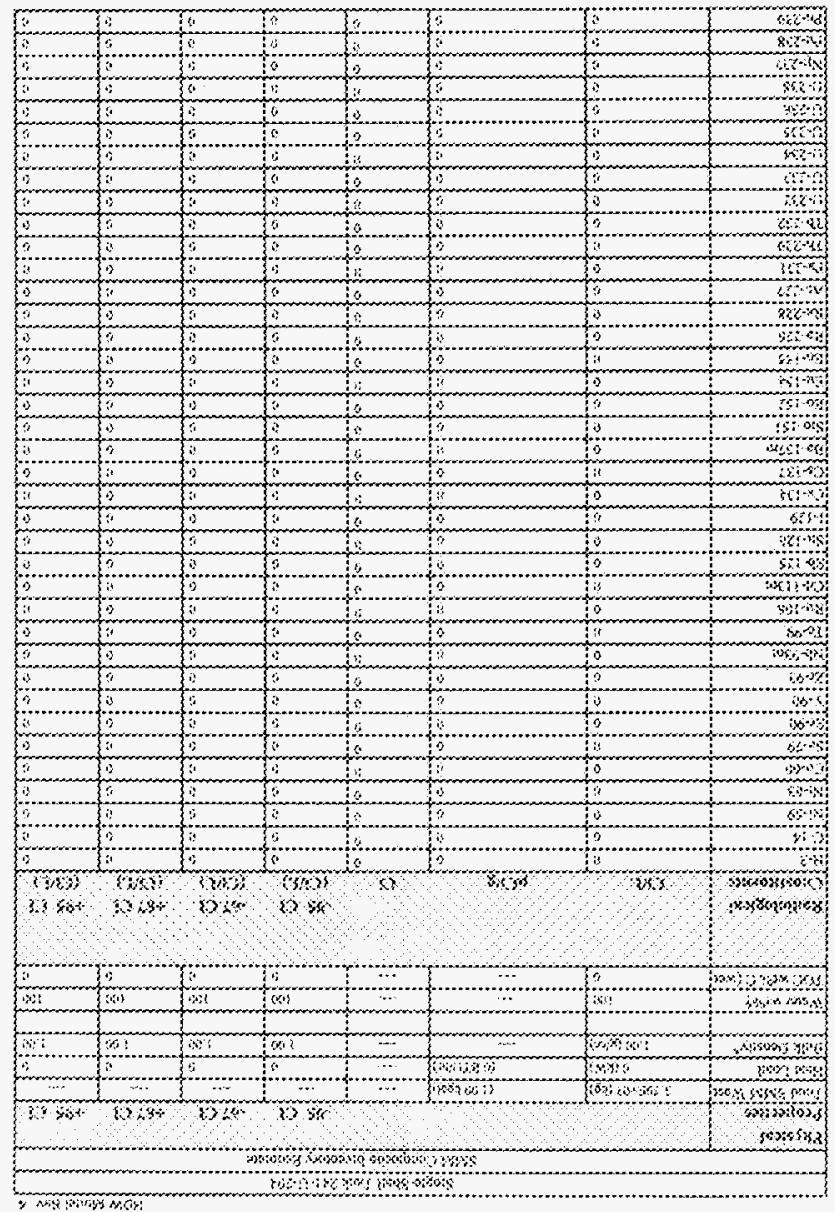




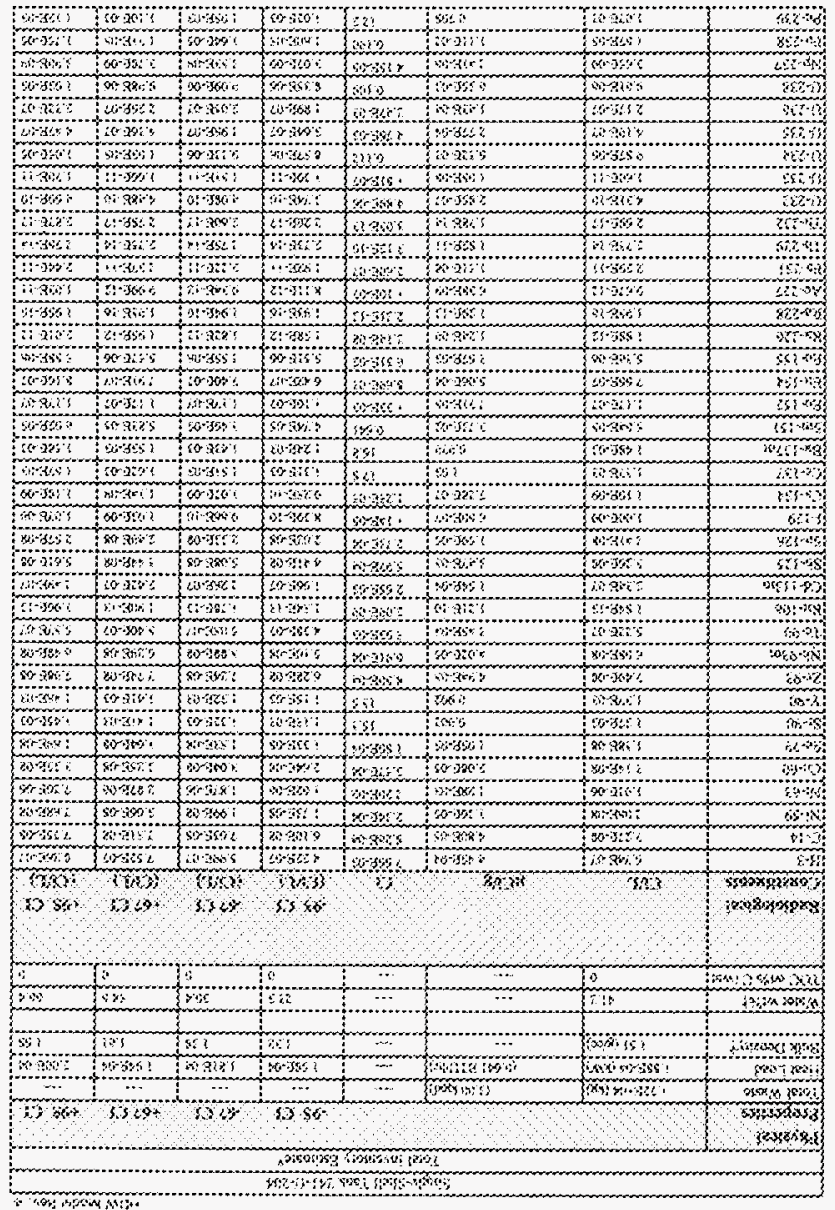


THS PACE INENTIORALU B.F GSAKK 


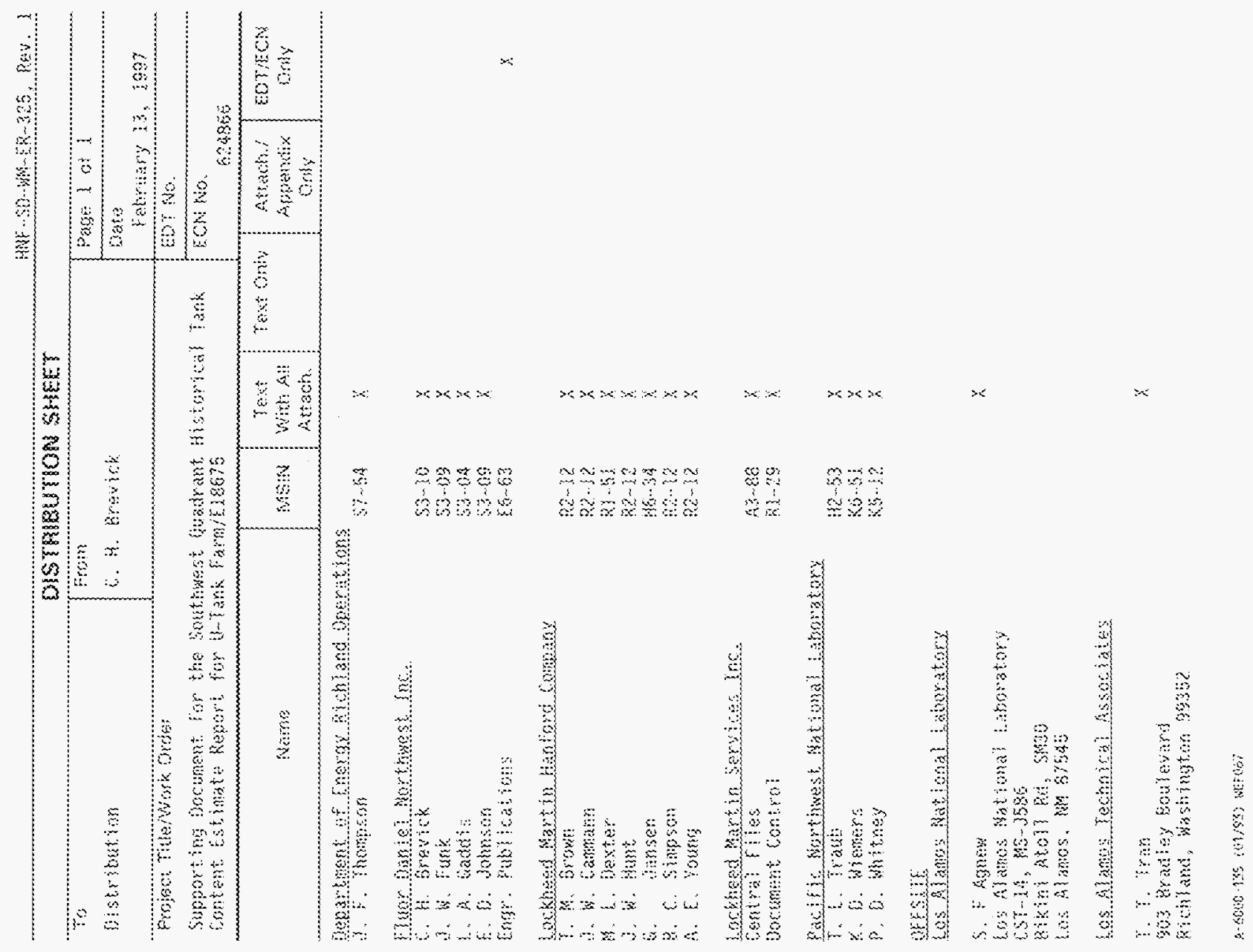




\section{ThS Pë MTEMONALY}

AF BWBS 